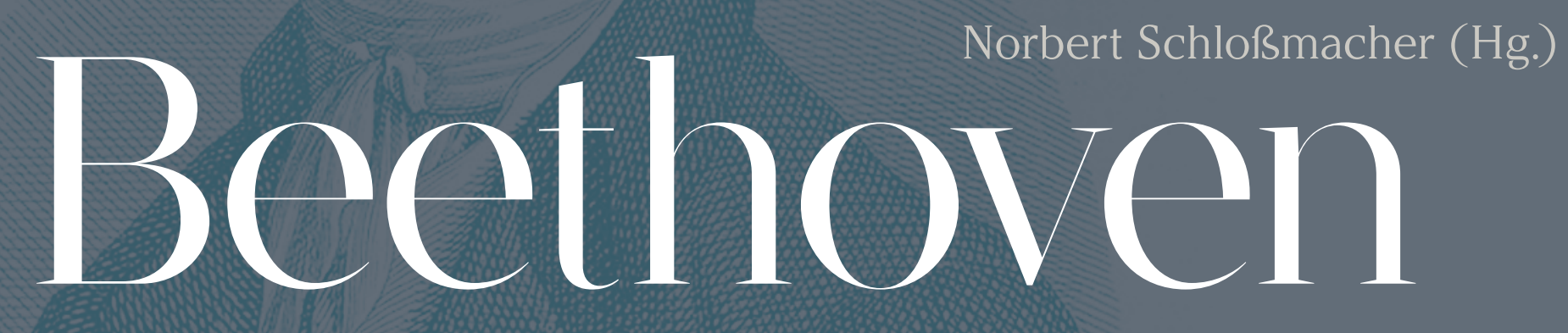

\title{
Die Bonner Jahre
}

an

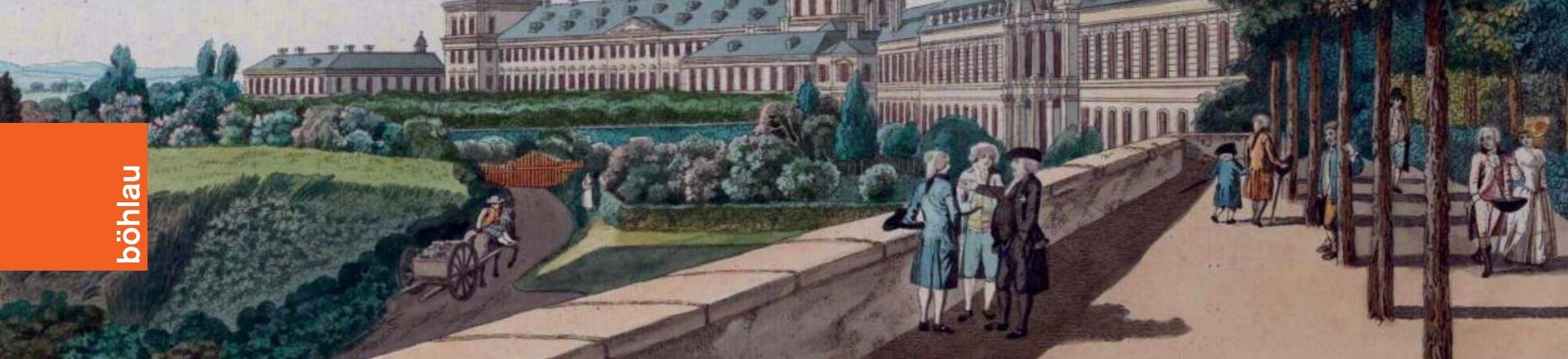




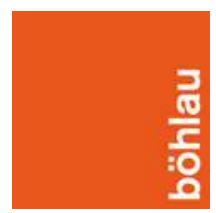

(C) 2020 by Böhlau Verlag GmbH \& Cie. KG, Köln https://doi.org/10.7788/9783412519704 | CC BY-NC 4.0 


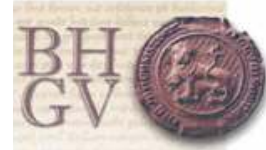

Bonner Geschichtsblätter

Herausgegeben vom Bonner Heimat- und Geschichtsverein und dem Stadtarchiv Bonn

Band 69/70

Bonn 2020 


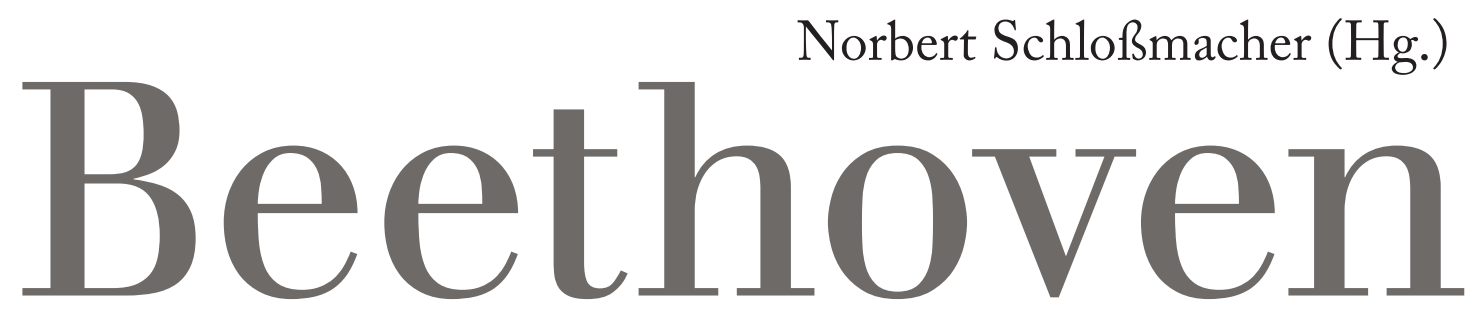

Die Bonner Jahre 
Veröffentlicht mit freundlicher Unterstützung des Stadtbezirks Bonn, des Landschaftsverbandes Rheinland, der Jubiläumsgesellschaft BTHVN und des Stadtarchivs Bonn.

Bibliografische Information der Deutschen Nationalbibliothek:

Die Deutsche Nationalbibliothek verzeichnet diese Publikation in der

Deutschen Nationalbibliografie; detaillierte bibliografische Daten sind im Internet über http://dnb.d-nb.de abrufbar.

(C) 2020 by Böhlau Verlag GmbH \& Cie. KG, Lindenstraße 14, D-50674 Köln

Dieses Material steht unter der Creative-Commons-Lizenz Namensnennung - Nicht kommerziell 4.0 International. Um eine Kopie dieser Lizenz zu sehen, besuchen Sie http://creativecommons.org/licenses/by$\mathrm{nc} / 4.0 /$.

Umschlagabbildungen:

Oben: Der junge Beethoven. Kupferstich nach Zeichnung von C. Stainhauser (akg-images)

Unten: Blick vom Alten Zoll entlang der Bonner Residenz nach Westen. Kupferstich von Lorenz Janscha nach Johann Ziegler, 1792 (Stadtarchiv Bonn)

Redaktion: Dr. Norbert Schloßmacher Einbandgestaltung: Guido Klütsch, Köln Satz: F5 Mediengestaltung, Bonn

Vandenhoeck \& Ruprecht Verlage | www.vandenhoeck-ruprecht-verlage.com

ISBN (Print) 978-3-412-51968-1

ISBN (OA) 978-3-412-51970-4 


\section{Inhalt}

Zur Einführung

\section{Anfänge}

Silke Bettermann

Johann und Maria Magdalena van Beethoven - Eine bürgerliche Ehe im

kurfürstlichen Bonn

Norbert Schloßmacher

Die Taufe Ludwig van Beethovens am 17. Dezember 1770 in der Pfarrkirche

St. Remigius zu Bonn

Gisbert Knopp

Alt-St. Remigius - nicht nur Beethovens Taufkirche.

Wiederentdeckung der einst größten Pfarrkirche Bonns

\section{Voraussetzungen}

Alexander Wolfshohl

"Elementarbuch zur psichologie Ordnung der geschäfte".

Lesestoff und Leserschaft in Bonn zu Beethovens Jugendzeit

Michael Ladenburger

Der Clavierinstrumentenbestand und -instrumentenbau in Bonn als Anregung

für den jungen Beethoven - Auf den Spuren des Instrumentenbauers

Gottlieb Friedrich Riedler

Alexander Wolfshohl

Nichts weniger als Atheisten und Gottesschänder? Oder: Hundert thätige

Männer, der Kern des Volkes? Intellektuelle Gruppierungen in Bonn unter

den letzten Kurfürsten

Elisabeth Reisinger

Persönliches Amusement und politische Agenda - Bedeutungen von Musik

für Kurfürst Maximilian Franz

John Wilson

Das Instrumentalmusik-Repertoire der kurfürstlichen Hofmusik zur Zeit des jungen Beethovens 


\section{Zeitgenossen, Freunde, Wegbegleiter}

Ingrid Bodsch

Beethovens Bonner Jugendfreunde

$277-300$

Barbara Mülhens-Molderings

"Wir Bönner sind doch ganze Kerls!" - Beethoven und die Bonner Musikerfamilie Ries $301-338$

Nicole Kämpken

"ein sehr heller Punkt meines Lebens" - Franz Gerhard Wegeler und

Ludwig van Beethoven

Detlev Arens

Einer, der im Lande blieb - Johann Joseph Eichhoff (1762-1827) als

(Jugend-)Freund Ludwig van Beethovens

Pia Heckes

Beethoven und Graf Waldstein - Der Rittersitz Disteling zu Godesberg und die

Musik zu einem Ritterballett

Helmut Loos

Christian Gottlob Neefe (1748-1798) und seine Bedeutung für Ludwig van Beethoven $389-416$ Joanna Cobb Biermann

Beethoven und Simrock

\section{Weichenstellungen}

Dieter Haberl

Beethovens erste Reise nach Wien 1786/87

Julia Ronge

Beethovens Reise nach Mergentheim 1791 - Nahaufnahme einer bekannten

Unternehmung

Norbert Schloßmacher

Ludwig van Beethoven, Joseph Haydn und (Bad) Godesberg $499-516$

\section{Fortwirken}

Yvonne Leiverkus

Die Rezeption der Nachricht von Beethovens Tod in Bonn $.517-544$

Personenregister 


\section{Zur Einführung}

Ludwig van Beethoven, 1770 in Bonn geboren, 1827 in Wien gestorben, gehört zu den Ikonen der Welt-Kultur. Er gilt als der bekannteste Komponist überhaupt, seine Werke gehören zu den meistgespielten und zwar auf der ganzen Welt.

Deshalb ist es nicht verwunderlich, dass sich nicht bloß Musiker*innen und Musikwissenschaftler*innen für seine Schöpfungen interessieren, seine Musik spielen und erforschen, sondern dass auch Historiker*innen alles daran setzen, um eine möglichst lückenlose Biografie und ein möglichst vollständiges Bild seiner Lebenswelt und seiner Prägungen zeichnen zu können. Den Anfang haben 1838 zwei seiner rheinischen Freunde, Franz Gerhard Wegeler und Ferdinand Ries, mit ihren Biografischen Notizen gemacht, viele andere sind ihnen gefolgt, nicht immer verlässlich und gelegentlich selbstverliebt.

Folglich verfeinerte sich das Bild vom Leben dieses Genies über die Jahrzehnte immer weiter. Und bei jeder Neuerscheinung einer BeethovenBiografie ertappte man sich bei dem - irrigen - Gedanken, dass doch bereits Alles gesagt bzw. aufgeschrieben sei und es eigentlich nicht Neues zu erfahren gebe.

Dass das Jubiläumsjahr, zumal in seiner stolzen Vaterstadt, in besonderer Weise zu einer Beschäftigung mit Ludwig van Beethoven anregt und motiviert, liegt auf der Hand. Der unmittelbare Ansporn war, der Rolle der Heimatstadt für die Formierung des Genies neu auf die Spur zu kommen, dabei die in Bonn herrschenden Verhältnisse und die dort wirkenden maßgeblichen Kräfte, nicht nur aber vor allem in Sachen Musik, noch einmal in den Blick zu nehmen. Dass dabei der kulturaffine kurfürstliche Hof, zumal der musikbegeisterte und musikgebildete, zudem „aufgeklärte" Kurfürst Maximilian Franz für die Entwicklung Beethovens eine ganz zentrale Bedeutung besaßen, überrascht nicht.

Kindheit, Jugend und erste Erwachsenenjahre, ziemlich genau 22 Jahre, verbrachte Ludwig van Beethoven - von einigen wenigen Reisen abgesehen in seiner Geburtsstadt Bonn. Im Herbst 1792 zog es ihn dann nach Wien. Aus dem von seinem Arbeitgeber geförderten befristeten Studienaufenthalt wurde aufgrund der politischen Entwicklung in Europa ein dauerhaftes Bleiben an der Donau, wo Beethoven die folgenden gut 34 Jahre bis zu seinem Tod im Frühjahr 1827 lebte und arbeitet.

Welche Grundlagen für sein außergewöhnliches Können und Schaffen wurden in jenen Bonner Jahren gelegt? Konkret: Was wissen wir über seine Herkunftsfamilie? In welcher gesellschaftlichen, politischen und weltanschaulichen Atmosphäre erblickte er das Licht dieser Welt und wuchs in diese hinein? 
Welche (Aus-)Bildung, welche Sozialisation erfuhr er in der zu seiner Zeit etwa 10.000 Einwohner zählenden kurkölnischen Haupt- und Residenzstadt? Wer waren und wie beeinflussten ihn seine Freunde, Lehrer, Förderer und Weggefährten? Wie also sah seine direkte Lebenswelt aus, wo liegen die Schlüssel zu seinen Erfolgen?

Diese und andere Fragen sind, wie erwähnt, oft gestellt worden. Viele wurden beantwortet, gelegentlich durchaus unterschiedlich, manches scheint abschließend erarbeitet und dargestellt, anderes bleibt ungeklärt, wieder anderes wird kontrovers diskutiert.

Der vorliegende Sammelband verfolgt das Ziel, den Forschungsstand zu Beethovens Bonner Jahren zusammenzufassen, zu aktualisieren und durch völlig neue Fragestellungen zu bereichern. In insgesamt 19 Beiträgen werden zum Teil neue, gelegentlich unerwartete und auch überraschende Akzente gesetzt: Es wird Neuland betreten, bereits Erforschtes kommt auf den Prüfstand, neue Antworten auf alte Fragen werden gesucht und gefunden. Und das Ergebnis ist alles andere als ein „alter Wein in neuen Schläuchen”.

Die Anfänge: Silke Bettermann blickt in die Familiengeschichte Beethovens und arbeitet die privaten Lebensumstände des früh geförderten Musikers mit ihren Höhen und Tiefen heraus. Norbert Schloßmacher erkundet die Geschehnisse um Beethovens Taufe am 17. Dezember 1770, durch deren Registrierung er - aktenkundig und wahrnehmbar - die Bühne dieser Welt betritt. Gisbert Knopp unternimmt es, Beethovens bereits 1806 niedergelegte Tauf- und Pfarrkirche - St. Remigius - erstmals grundlegend, kirchen- wie baugeschichtlich, zu erforschen.

Fünf Aufsätze widmen sich zentralen Voraussetzungen für Beethovens spätere musikalische wie gesellschaftliche Disposition. Alexander Wolfshohl befasst sich mit einem Thema der Bildungsgeschichte und wirft einen ausgiebigen Blick auf das Leseverhalten und auf die Existenz von Bibliotheken in Bonn am Ende des Ancien Régime. Frauen wie Männer in großer Zahl gaben sich offenkundig mit Verve ihrem Lesevergnügen hin; erstmals ausgewertet wurden dabei Bibliothekskataloge, Ausleihverzeichnisse und Subskribentenlisten. Michael Ladenburger beschreibt zum einen die rasante Entwicklung der Tasteninstrumente zur Zeit Beethovens, explizit untersucht er den Bestand an entsprechenden Instrumenten in Bonn und schaut dabei auf deren Besitzer und ihren Einsatz. Zum anderen geht der Autor dem ebenso verschlungenen wie unerforschten Lebensweg des zeitweise auch in Bonn tätigen Klavier- und Orgelbauers Gottlieb Friedrich Riedler nach. Die aufgeklärten Kreise in Bonn, tonangebend am Hof, in den Bildungseinrichtungen und in derStadtgesellschaft, sind das Thema von Alexander Wolfshohl, der auch anhand bislang unberücksichtigter Quellen Freimaurer, Illuminaten und die in Bonn so wichtige Lesegesellschaft präsentiert und zeigt, warum Bonn mit seiner Hohen Schule eine Hochburg der Aufklärung war. Viele der erwähnten Akteure waren Teil des 
unmittelbaren, beruflichen wie persönlichen Umfeld Beethovens. Elisabeth Reisinger schildert aufgrund neuer Funde den enormen Stellenwert von Musik für Beethovens Landesherrn, Kurfürst-Erzbischof Maximilian Franz von Österreich, sowohl hinsichtlich seiner Person wie auch seines Hofes. John Wilson geht detailliert dem breiten Repertoire der kurfürstlichen Hofmusik, der Beethoven bekanntlich selbst angehörte, nach.

Zeitgenossen, Freunde, Wegbegleiter spielten eine wichtige Rolle in Beethovens Bonner Jahren. Ingrid Bodsch nähert sich den Bonner Jugendfreunden, darunter Carl August von Malchus, den Kindern der Familie von Breuning sowie dem Kreis um den Gasthof Zehrgarten am Bonner Marktplatz. Zu den prägenden Protagonisten des musikalischen Bonn gehörten Mitglieder der Familie Ries. Sie steht im Mittelpunkt des mit neuen Forschungsergebnissen aufwartenden Beitrags von Barbara Mülhens-Molderings. Vater Franz Anton Ries war Geigenlehrer Beethovens; bis zu seinem Lebensende zeigte Beethoven wiederholt seine hohe Wertschätzung für den Bonner Violinisten. Mit dem Sohn Ferdinand verband Ludwig eine durchaus innig zu nennende dauerhafte Beziehung. Gleiches gilt für den späteren Arzt und Ehemann der BeethovenFreundin Eleonore von Breuning, Franz Gerhard Wegeler, dessen tiefgegründetes, wenngleich nicht immer ungetrübtes Verhältnis zu Beethoven von Nicole Kämpken nachgezeichnetwird.Zum Kreisum Beethovens Jugendfreunde zählte auch der Hofkoch, Kaufmann, spätere Bonner Bürgermeister und Direktor der Rheinschifffahrtsbehörde Johann Joseph Eichhoff, der von Detlev Arens gewürdigt wird. Pia Heckes bringt eine der frühen Kompositionen Beethovens, die Musik zu einem Ritterballett, mit dem biografisch noch weitgehend unerforschten, schillernden Graf Ferdinand Ernst von Waldstein, einem der wichtigen Förderer des jungen Beethovens, in Verbindung. Auch zu den politischen Ambitionen jenes Graf Waldstein, der Beethoven die vielzitierte Widmung "Mozart's Geist aus Haydens Händen" mit auf den Weg nach Wien gab, wird Neues und Unvorhergesehenes enthüllt. Helmut Loos fasst eigene Forschungen zu Beethovens angeblich wichtigsten Lehrer Christian Gottlob Neefe zusammen und relativiert mit Hilfe eines ausführlichen Blicks auf dessen politisch-gesellschaftlich-weltanschauliche Haltung zumindest teilweise die lange Zeit unwidersprochene enge Lehrer-Schüler-Beziehung. Mit dem ambivalenten und zeitweise von Auseinandersetzungen belasteten Verhältnis zwischen Beethoven und dem erfolgreichen Bonner Musikverleger Nikolaus Simrock hat sich auf der Basis eigener früherer Studien Joanne Cobb Biermann auseinandergesetzt.

Zu den Weichenstellungen für Beethovens Karriere gehörte zweifellos sein erster Aufenthalt in der Musikmetropole Wien (1786/87), der, wie Dieter Haberl zeigt, weit länger dauerte, als lange angenommen, und damit zweifellos einen entsprechend nachhaltigen Einfluss auf sein späteres Schaffen besaß. Die Reise des Bonner Hoforchesters zum Generalkapitel des Deutschen Ordens in 
Mergentheim im Jahre 1791 zählte ebenfalls zu den prägenden Ereignissen in Beethovens Bonner Jahren. Julia Ronge hat die einschlägigen Quellen einer erneuten kritischen Durchsicht unterzogen und zeigt auch hier - nicht nur mit Blick auf den logistischen Aufwand - den großen Wert, den Musik in jenen Kreisen besaß. Beethovens Beziehung zu dem dank der Entdeckung einer Heil- und Mineralquelle seit 1790 zu einer Nebenresidenz mit hohem kulturellen Anspruch aufgestiegenen Ort Godesberg ist das Thema von Norbert Schloßmacher, wobei das in mehrfacher Hinsicht legendäre und wegweisende Treffen zwischen dem 21-jährigen Ludwig van Beethoven und dem 60-jährigen, längst arrivierten Joseph Haydn im Sommer 1792 im Mittelpunkt steht.

Beethovens Fortwirken in seiner Heimatstadt gilt der Beitrag von Yvonne Leiverkus; sie spannt den Bogen vom verspäteten Bekanntwerden von Beethovens Tod und den in Bonn veranstalteten Trauerfeierlichkeiten bis hin zum ersten Beethovenfest und der Enthüllung des Beethoven-Denkmals auf dem Münsterplatz vor prominenten Gästen im Sommer 1845.

Als Herausgeber möchte ich an dieser Stelle den Autorinnen und Autoren für ihre Beiträge und ihr Mitwirken ganz herzlich Dank sagen. Es war ausgesprochen beglückend, dass nahezu alle Einladungen, an diesem Band mitzuarbeiten, gern und bereitwillig angenommen wurden. Die Zusammenarbeit war nicht nur äußerst angenehm, sondern in vieler Hinsicht auch sehr bereichernd. Ihnen allen gebührt allerhöchste Anerkennung. Ralf Kolmsee zeichnet für das Layout verantwortlich. Für die Zurverfügungstellung von Illustrationen sei den entsprechenden Häusern gedankt, an erster Stelle dem Beethoven-Haus Bonn und seinen Mitarbeiter*innen. Dr. Ludwig Krapf war mit Rat und Tat behilflich und stets zur Stelle. Die Resultate so manch intensiver, ebenso freundschaftlicher wie kritischer Erörterung haben unmerklich Eingang in den vorliegenden Band gefunden. Die Jubiläumsgesellschaft BTHVN hat die vorbereitenden Arbeiten großzügig unterstützt. Gleiches gilt für den Stadtbezirk Bonn. Auch der Landschaftsverband Rheinland gehört zu den Förderern. Hierfür sei ebenfalls ein herzliches Dankeschön gesagt.

Der Band, zugleich Jahrgang 68/69 (2019/20) der vom Bonner Heimat- und Geschichtsverein gemeinsam mit dem Bonner Stadtarchiv herausgegebenen Bonner Geschichtsblätter, erscheint zeitnah zur 250. Wiederkehr des Tauftags des Bonner Komponisten, der den Abschluss des Jubiläumsjahres markieren sollte. Doch gestaltete sich das Jahr 2020 in ganz vieler Hinsicht völlig anders als geplant. Ludwig van Beethoven, mehr noch seine Werke, sind hingegen Konstanten: Seine Musik gilt als unsterblich, und sie ist es wohl auch. Und davon lebt jede Beschäftigung und die Auseinandersetzung mit ihm.

Bonn, im August 2020

Norbert Schloßmacher

Herausgeber

10 | Norbert Schloßmacher 


\section{Johann und Maria Magdalena van Beethoven - Eine bürgerliche Ehe im kurfürstlichen Bonn}

Silke Bettermann

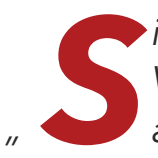

ie führten Beide eine rechtschaffene friedliche Ehe, sie zahlten alle Virteljahr ihren Haußmieth und gelifferte Brod auf den Tag und so auch andere[s]" und "sind dem Haußmann Theodor Fischer niemahl was schuldig geblieben" ${ }^{\prime 2}$. Mit diesen Worten fasst der Bonner Bäckermeister Gottfried Fischer (1780-1864) den Eindruck zusammen, den Johann und Maria Magdalena von Beethoven nach den Erinnerungen seiner älteren Schwester Cäcilie (1762-1845) und anderer Bekannter aus Bonn auf ihre Nachbarn gemacht haben. Fischers Notizen stellen die reichhaltigste Quelle zum Alltagsleben des Paares und seiner Kinder dar und bieten zugleich generell einen interessanten Einblick in die Lebensumstände bürgerlicher Familien im Umkreis des Kurkölner Hofes. Sie werden deshalb als Hauptgrundlage für den im Folgenden unternommenen Versuch einer Annäherung an die Situation der Familie Ludwig van Beethovens dienen, obwohl sie aufgrund ihrer relativ späten Entstehung (etwa zwischen 1837 und 1857) ${ }^{3}$ und der Tatsache, dass sie sich zumeist auf die Erinnerungen älterer Zeitzeugen stützen, eine ganze Reihe von Irrtümern und Unklarheiten enthalten.

Bereits bei der Frage nach dem Geburtsdatum von Beethovens Vater wird die Problematik der in vielen Fällen nach wie vor lückenhaften Quellenlage greifbar. Zwar ist seine Abstammung als Sohn des kurfürstlichen Kapellmeisters Ludwig van Beethoven (1712-1773) und seiner Frau Maria Josepha Ball (um 1714-1775) aufgrund der Archivalien des 18. Jahrhunderts nie in Zweifel gezogen worden, ${ }^{4}$ jedoch konnte - anders als im Fall seiner Geschwister ${ }^{5}$ - bislang für Johann van Beethoven kein Taufeintrag in einem der Kirchenbücher des 18. Jahrhunderts entdeckt werden. ${ }^{6}$ Deshalb wird in der Literatur in der Regel auf der Grundlage eines wohl von Sigismund Graf zu Salm-Reifferscheid (1735-1798) erstellten Berichtes aus dem Jahr 1784, in dem Johann van
Gottfried Fischer (17801864), Aufzeichnungen über die Familie van Beethoven. Reinschrift, 1850er Jahre, S. 17 (Beethoven-Haus Bonn)

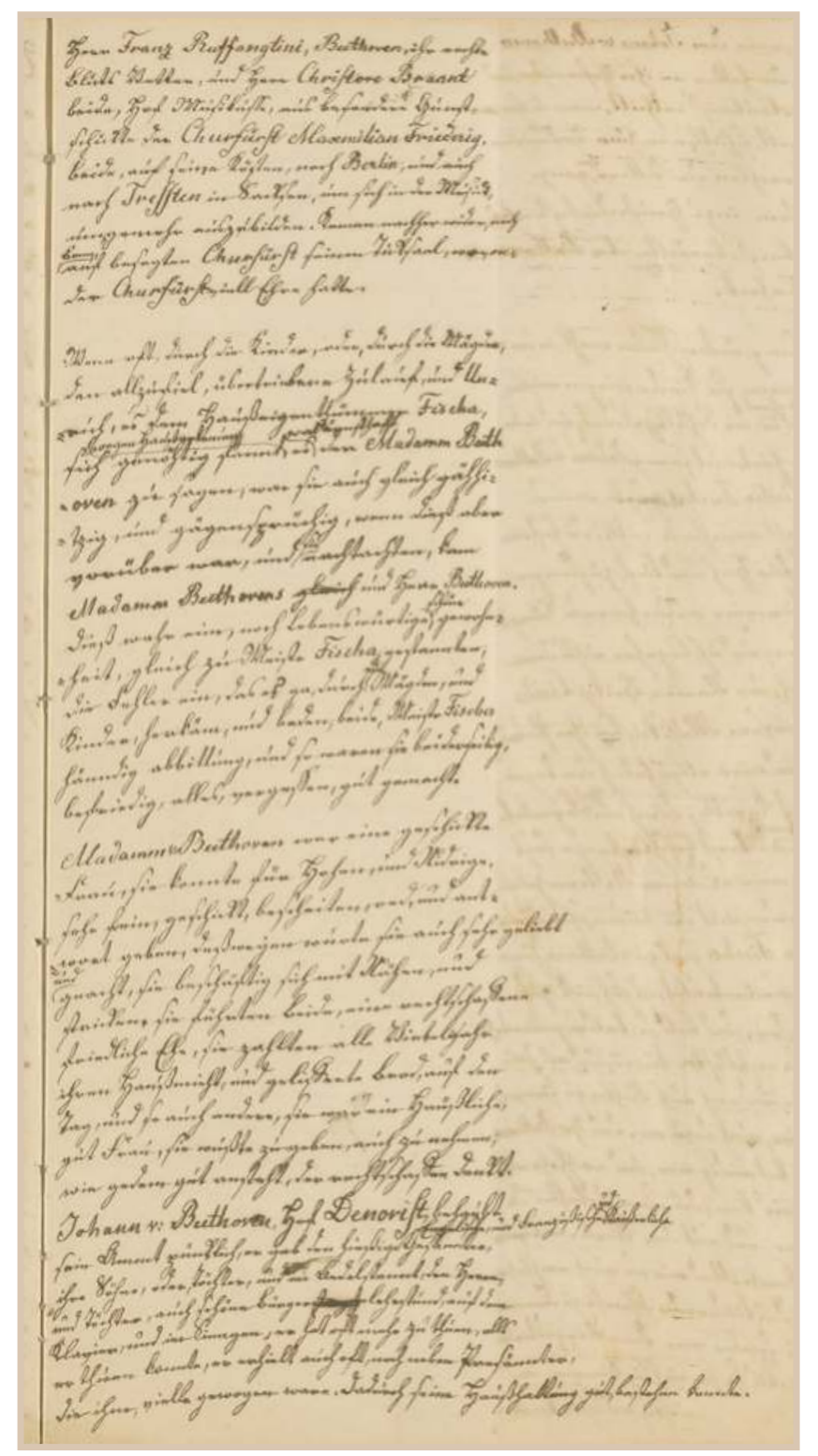


Beethoven als 44-jährig bezeichnet wird, ${ }^{7}$ angenommen, dass er in den Jahren um 1739/40 außerhalb Bonns geboren wurde. ${ }^{8}$ Da jedoch die in diesem Dokument gemachten Altersangaben teilweise unzuverlässig sind (u.a. heißt es dort, Beethovens Mutter sei 32 Jahre alt, während sie im Jahr 1784 de facto bereits ein Alter von 37 bzw. 38 Jahren erreicht hatte), wäre es auch möglich, dass Johann bereits etwas früher zur Welt kam. Darauf deuten zumindest die Aufzeichnungen Gottfried Fischers hin, der angibt, Beethovens Vater sei am 18. Dezember 1792 im Alter von 63 Jahren gestorben. ${ }^{9}$ Zudem betont Fischer mehrfach die enge Freundschaft zwischen Johann van Beethoven und seinem eigenen Vater, dem Bäckermeister Johann Theodor Fischer (1730-1795) ${ }^{10}$. Glaubt man dieser Quelle, so scheinen die beiden Freunde in etwa gleichalt gewesen zu sein, was darauf hin deuten würde, dass Beethovens Vater vielleicht doch früher als 1739 geboren worden wäre.

Zur Kindheit und Jugend Johanns geben neben Fischers Notizen verschiedene, bereits von Alexander Wheelock Thayer ${ }^{11}$ und Ludwig Schiedermair ${ }^{12}$ veröffentlichte und von Joseph Schmidt-Görg $1964^{13}$ zusammengestellte und ergänzte Archivalien nähere Auskunft. Sein Vater, der in seiner Heimatstadt Mecheln eine Ausbildung als Sänger und Organist erhalten hatte, war seit 1733 als Bassist an der kurfürstlichen Kapelle in Bonn tätig und lebte seitdem in Bonn. 1761 wurde er zum Kapellmeister der Hofkapelle ernannt, betrieb aber zugleich auch einen kleinen Weinhandel und gehörte zur Gruppe der wohlhabenden und angesehenen Bürger in der Residenzstadt. Darauf deuten nicht nur verschiedene Äußerungen Gottfried Fischers hin, ${ }^{14}$ in dessen Elternhaus Ludwig van Beethoven d. Ä. dieselbe Wohnung gemietet hatte, die später sein Sohn mit seiner Familie bewohnte, sondern zum Beispiel auch die Tatsache, dass Johann van Beethoven als Junge eine gewisse Zeit lang das Bonner Jesuiten-Gymnasium besuchte. ${ }^{15}$ Parallel zum Schulbesuch wurde er von seinem Vater im Gesang unterrichtet und wirkte bereits vor seinem Stimmbruch bei Aufführungen der Bonner Hofkapelle mit. ${ }^{16}$ Ab 1756 war er dort offizielles Mitglied und wurde als solches auch von 1759 bis zu seinem Tod in den Kurkölnischen Hofkalendern geführt - zunächst bis 1763 als Accessist, das heißt als Nachwuchssänger, dann als einer der Vocalisten und ab 1784 als Tenorist. ${ }^{17}$ Ein Hinweis auf Johanns musikalische Fähigkeiten findet sich in einem Gesuch seines Vaters aus dem Jahr 1764, in dem dieser um ein Gehalt für seinen Sohn bittet. Darin heißt es, dass "Joannes Beethoven bereits 13. jahr lang ... mit seiner singstim den sopran, Conteralt und tenor in jeden vorfallenden nothwendigkeiten auf dem Duc sahl [Doxale] abgesungen, zugleich auch vor die Violin capabel ist" ${ }^{\prime \prime 1}$. Wie dieser Text erkennen lässt, müssen Ausbildung und Berufsbeginn Johann van Beethovens in ganz ähnlicher Weise verlaufen sein wie später im Fall seines eigenen ältesten Sohnes: Er besuchte die Schule, erhielt gleichzeitig Musikunterricht und nahm seine Tätigkeit für den Kurkölner Hof bereits als Kind auf, wobei er über Jahre hinweg unentgeltlich tätig war. 
Erst als Reaktion auf das oben erwähnte Gesuch Ludwig van Beethovens d. Ä. wurden Johann ab 1764 jährlich 100 Reichstaler als Besoldung gewährt, eine Summe, die in den folgenden Jahren um zunächst 25 und später um 50 Reichstaler aufgestockt wurde. ${ }^{19}$ Damit stand ihm 1769 mit einem regelmäßigen Einkommen von insgesamt 125 Reichstalern jährlich etwa doppelt so viel Geld zur Verfügung, wie für die Unterbringung seiner Mutter in einem Kloster benötigt wurde. ${ }^{20} \mathrm{Im}$ Jahr 1784 hatte sich sein Gehalt dann mehr als verdoppelt und belief sich auf 315 Reichstaler. ${ }^{21}$

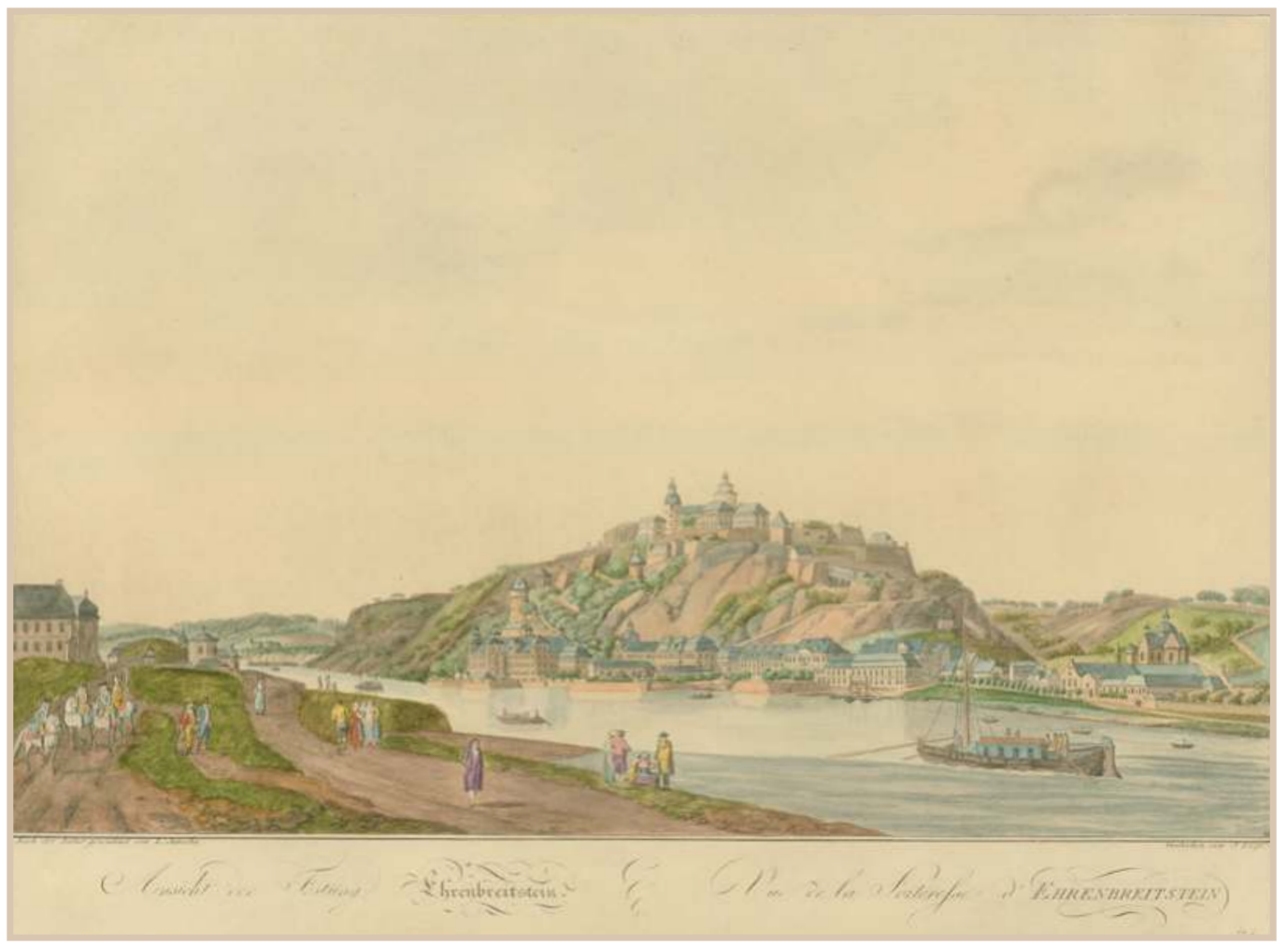

Anders als im Fall ihres Mannes ist der Geburtstag Maria Magdalena Keverichs, der Mutter Ludwig van Beethovens, in Ehrenbreitstein durch den Eintrag ihrer Taufe im Kirchenbuch der dortigen Heilig-Kreuz-Kirche eindeutig belegt. ${ }^{22}$ Sie kam am 19. Dezember 1746 als jüngstes Kind des kurfürstlichen Oberhofkochs und späteren Inspektors der Kurtrierer Küche Johann Heinrich Keverich (1702-1759) ${ }^{23}$ und seiner Frau Anna Clara, geb. Westorff (17071768), ${ }^{24}$ zur Welt. Ihre Eltern gehörten zur angesehenen Schicht der bürgerlichen Hofbediensteten und lebten in weitgehend gesicherten Verhältnissen. Neben den Archivalien, die Rückschlüsse auf die gute wirtschaftliche Situation ihrer Familie erlauben ${ }^{25}$ und die persönliche Bindung ihres Vaters an Kurfürst Johann Philipp von Walderdorff (1701-1768) erkennen lassen, ${ }^{26}$ belegt insbe-
Festung und Ort Ehrenbreitstein von Koblenz aus. Kupferstich von Johann Ziegler nach Lorenz Janscha, 1792 (Beethoven-Haus Bonn) 
sondere ein Konvolut mit Festbeschreibungen, Huldigungs- und Glückwunschadressen das Ansehen ihrer Familie. Dieser Handschrift ist zu entnehmen, dass Maria Magdalena am 1. April 1756 beim Amtsantritt des Kurfürsten auftrat und gemeinsam mit anderen Mädchen aus Ehrenbreitstein ein Gedicht zu seiner Begrüßung vortrug. ${ }^{27}$ Auch die Tatsache, dass ihr älterer Bruder Johann Peter (1734-1807)28 nach seinem Eintritt in den Koblenzer Karmeliterkonvent dort bis zum Prior aufstieg, lässt die Zugehörigkeit der Familie zum gehobenen katholischen Bürgertum erkennen.

Diesem sozialen Umfeld entsprechend, wählte Anna Clara Keverich 1762 als Ehemann für ihre damals 16-jährige Tochter den Kurfürstlich-Trierischen Leibkammerdiener Johann Laym (auch Leym) (1733-1765), einen zu diesem Zeitpunkt knapp 30 Jahre alten Witwer, der die Verantwortung für drei kleine Kinder aus seiner ersten Ehe zu tragen hatte. ${ }^{29}$ Auch er gehörte zum Kreis der geachteten bürgerlichen Hofbediensteten, und die am 30. Januar 1763 mit ihm geschlossene Ehe ${ }^{30}$ bedeutete für Maria Magdalena eine glänzende Partie.

Da jedoch Johann Layms Kinder aus erster Ehe ${ }^{31}$ anscheinend bereits in den beiden ersten Jahren nach der Heirat mit Maria Magdalena Keverich starben, und auch der gemeinsam Sohn des Paares, Johann Peter Anton (25. Oktober - 27. November 1764), nur wenige Wochen alt wurde, ${ }^{32}$ muss das Leben als Ehefrau und Mutter für die junge Frau von Anfang an emotional belastet gewesen sein. So verwundert es nicht, dass sie später wiederholt von den negativen Folgen einer Eheschließung gesprochen haben soll, ${ }^{33}$ wobei sie sich nicht unbedingt allein auf ihr Leben mit Johann van Beethoven bezogen haben muss.

Als - nur gut zweieinhalb Jahre nach der Hochzeit - am 28. Oktober 1765 auch Johann Laym ${ }^{34}$ starb, kehrte die junge Witwe wohl in ihr Elternhaus zurück. ${ }^{35}$ Wahrscheinlich dürfte sich das Zusammenleben mit ihrer Mutter dort jedoch nicht unproblematisch gestaltet haben. Denn Anna Clara Keverich, die nach dem Tod ihres Mannes zunächst durchaus selbstbewusst versucht hatte, dessen Tätigkeit als Admonitor (Verwalter) der Hofküche weiterzuführen, dieses Amt aber 1761 niedergelegt hatte, ${ }^{36}$ wandte sich in ihren letzten Lebensjahren immer stärker einer religiösen und asketischen Lebensführung zu. So wurde sie zwar in Ehrenbreitstein als außerordentlich fromm und tugendhaft verehrt, ${ }^{37}$ man sah in ihrer extremen Art der Selbstkasteiung aber auch Anzeichen für eine nachlassende geistige Gesundheit. ${ }^{38}$

Aus dieser häuslichen Situation heraus erklärt sich vielleicht die Entscheidung ihrer Tochter, trotz ihrer Erfahrungen zwei Jahre nach dem Tod ihres ersten Mannes erneut zu heiraten. Diesmal entschied sie sich für die Ehe mit Johann van Beethoven, den sie möglicherweise durch die Vermittlung ihrer Kusine Anna Margaretha Daubach (1730-1772) oder deren Mann Johann Konrad Rovantini (†1766), der wie Johann als Musiker bei der Kurkölner Hofkapelle angestellt war, kennengelernt hatte. ${ }^{39}$ 


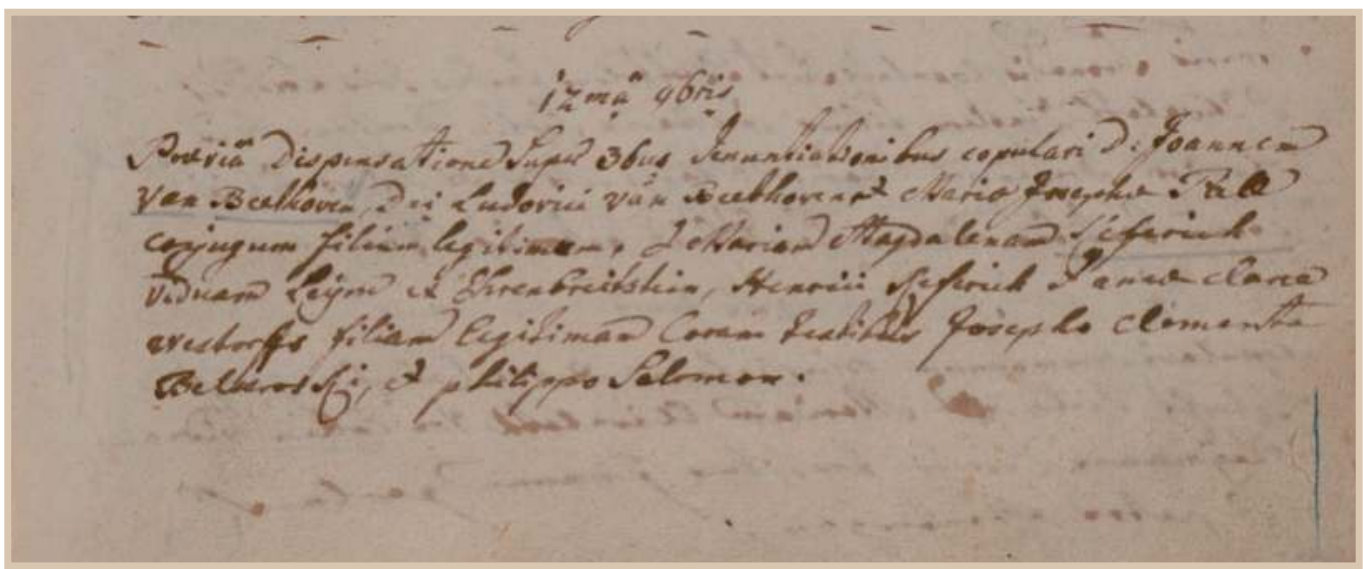

Nach Aussage Gottfried Fischers stieß der Heiratswunsch des Paares beim Vater des Bräutigams auf heftige Ablehnung. ${ }^{40}$ Aber anscheinend sah man die Verbindung auch seitens des Kurtrierer Hofes kritisch. Darauf deutet jedenfalls die Formulierung in einem Protokoll der kurfürstlichen Kammer aus dem Jahr 1768 hin, in der diese Ehe als „übel geraten" bezeichnet wird. ${ }^{41}$ Dennoch feierten Maria Magdalena Keverich und Johann van Beethoven am 12. November 1767 in der Bonner Kirche St. Remigius ihre Hochzeit. ${ }^{42}$ Die Umstände dieser Eheschließung scheinen allerdings (zumindest aus der Sicht Gottfried Fischers) nicht völlig der Normalität entsprochen zu haben. Denn sie fand nicht am Wohnort der Braut, sondern an demjenigen des Bräutigams statt. ${ }^{43}$ Während Fischer vermutete, dass dies durch die Ablehnung Ludwig van Beethovens d. Ä. zu erklären sei, ${ }^{44}$ wäre es aber durchaus auch möglich, dass die im Herbst 1767 schwierige Situation in Ehrenbreitstein für die Wahl Bonns als Ort der Heirat ausschlaggebend war. Denn in diesen Monaten war der dortige Landesherr schwer erkrankt und lag in Fieberdelirien. ${ }^{45} \mathrm{Da}$ Maria Magdalena Keverichs Eltern und ihr erster Ehemann in kurfürstlichen Diensten gestanden hatten und ihr Vater zudem offenbar eine besonders enge Beziehung zu Johann Philipp von Walderdorff besessen hatte, könnte dessen lebensbedrohliche Erkrankung für Angehörige ihrer Gesellschaftsschicht durchaus ein Grund dafür gewesen sein, auf eine Hochzeitsfeier im Residenzort zu verzichten.

Waren damit die Bedingungen, unter denen die Hochzeit Maria Magdalenas und Johann van Beethovens stattfand, vielleicht nicht ideal, so scheint ihre Eheschließung aber dennoch von Familienangehörigen, Bekannten und Freunden akzeptiert worden zu sein. Denn Fischer berichtet von einer Reise des frisch vermählten Paares zu den Verwandten der Braut und erwähnt, dass sich in Bonn zahlreiche Gratulanten einfanden. ${ }^{46}$

Mit ihrer zweiten Heirat war für Maria Magdalena Keverich zwar eine Trennung von ihrer vertrauten Umgebung gegeben, jedoch verblieb sie in denselben sozialen Verhältnissen, in denen sie auch bisher gelebt hatte. Wie in
Heiratseintrag der Eltern Beethovens vom

12. November 1767

im Kirchenbuch der Pfarrei

St. Remigius, Bonn

(Stadtarchiv Bonn) 


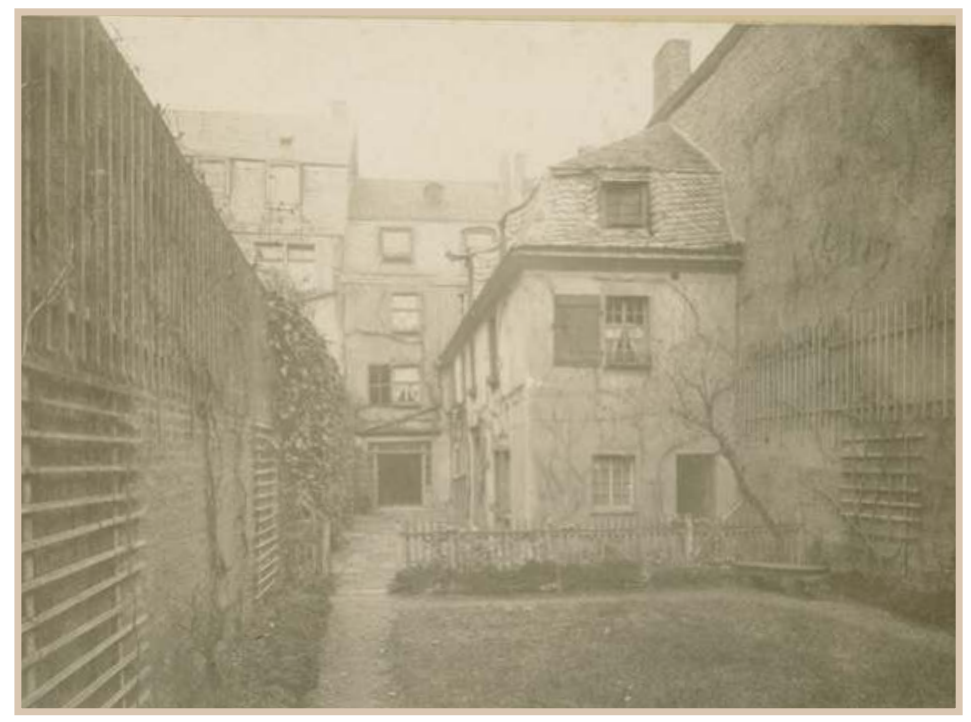

Ehrenbreitstein, so war auch in Bonn das gesellschaftliche und wirtschaftliche Leben ganz vom kurfürstlichen Hof bestimmt, dessen Politik seit dem Tod Kurfürst Clemens Augusts (1700-1761) weitgehend vom Einfluss des ersten Ministers Caspar Anton Freiherr (ab 1782 Graf) von der Heyden, genannt Belderbusch (1722-1784), dominiert wurde. Dieser verfolgte, anders als es in der ersten Jahrhunderthälfte üblich gewesen war, einen restriktiven Sparkurs, was einen Rückgang der wirtschaftlichen Aktivitäten und der Bevölkerungszahl in der Stadt zur Folge hatte. So befand sich Bonn genau zu der Zeit, als Maria Magdalena und Johann van Beethoven heirateten, in einer tiefgreifenden Krise. ${ }^{47}$

Geburtshaus Ludwig van Beethovens, Bonn, Bonngasse 20 (ehemals Nr. 363, später Nr. 515). Fotografie von Gustav Ebbinghaus, 1903 (BeethovenHaus Bonn)
Im Ganzen scheinen Johann und Maria Magdalena van Beethoven ihre Ehe dennoch unter recht guten Vorzeichen begonnen und zunächst in geordneten wirtschaftlichen Verhältnissen gelebt zu haben. ${ }^{48}$ Die Häuser, in denen sie zur Miete wohnten, ${ }^{49}$ lagen in den marktnahen Straßen der Stadt, in denen Händler und Gewerbetreibende sowie zahlreiche für den Hof tätige Angehörige des Bürgertums ansässig waren. Da Johann durch seine Tätigkeit als Sänger in der Hofkapelle über ein zwar nicht üppiges, jedoch gesichertes Einkommen verfügte und zudem ein gesuchter Musik- und Gesangslehrer war, standen ihm ausreichende finanzielle Mittel für den Unterhalt seiner Familie zur Verfügung. ${ }^{50}$ Zudem dürften er und seine Frau wohl auch von ihren Eltern unterstützt worden sein. ${ }^{51}$

Vor allem in den Jahren, in denen das Ehepaar im Haus der Familie Fischer in der Bonner Rheingasse wohnte, das heißt mit zwei kürzeren Unterbrechungen zwischen Herbst 1776 und Anfang 1787, ${ }^{52}$ muss es ihm finanziell gut gegangen sein. Nach den Aufzeichnungen Gottfried Fischers hatte Johann van Beethoven im zweiten Obergeschoss des Hauses eine großzügige, ca. $120 \mathrm{~m}^{2}$ umfassende Wohnung gemietet, deren Raumaufteilung von Fischer so detailliert beschrieben wird, dass ihre Rekonstruktion, jedenfalls in großen Teilen gelang. ${ }^{53}$ Man verfügte über insgesamt sechs Zimmer und eine Küche. Zwei große, zur Rheingasse hin gelegene Räume dienten als Empfangs- oder Repräsentationszimmer. Sie waren durch eine Tür voneinander getrennt, so dass man sie bei Bedarf miteinander verbinden und in einen kleinen Saal verwandeln konnte. Hier stand Johann van Beethovens Klavier, und hier erteilte er Unterricht oder veranstaltete Hauskonzerte. ${ }^{54}$ Zum Hof hin lagen die kleineren Privaträume, darunter ein Speisezimmer und ein Schlafzimmer für die Kinder. Ergänzt wurde der eigentliche Wohnbereich durch einen Kellerraum, einen

16 | Silke Bettermann

(C) 2020 by Böhlau Verlag GmbH \& Cie. KG, Köln

https://doi.org/10.7788/9783412519704 | CC BY-NC 4.0 


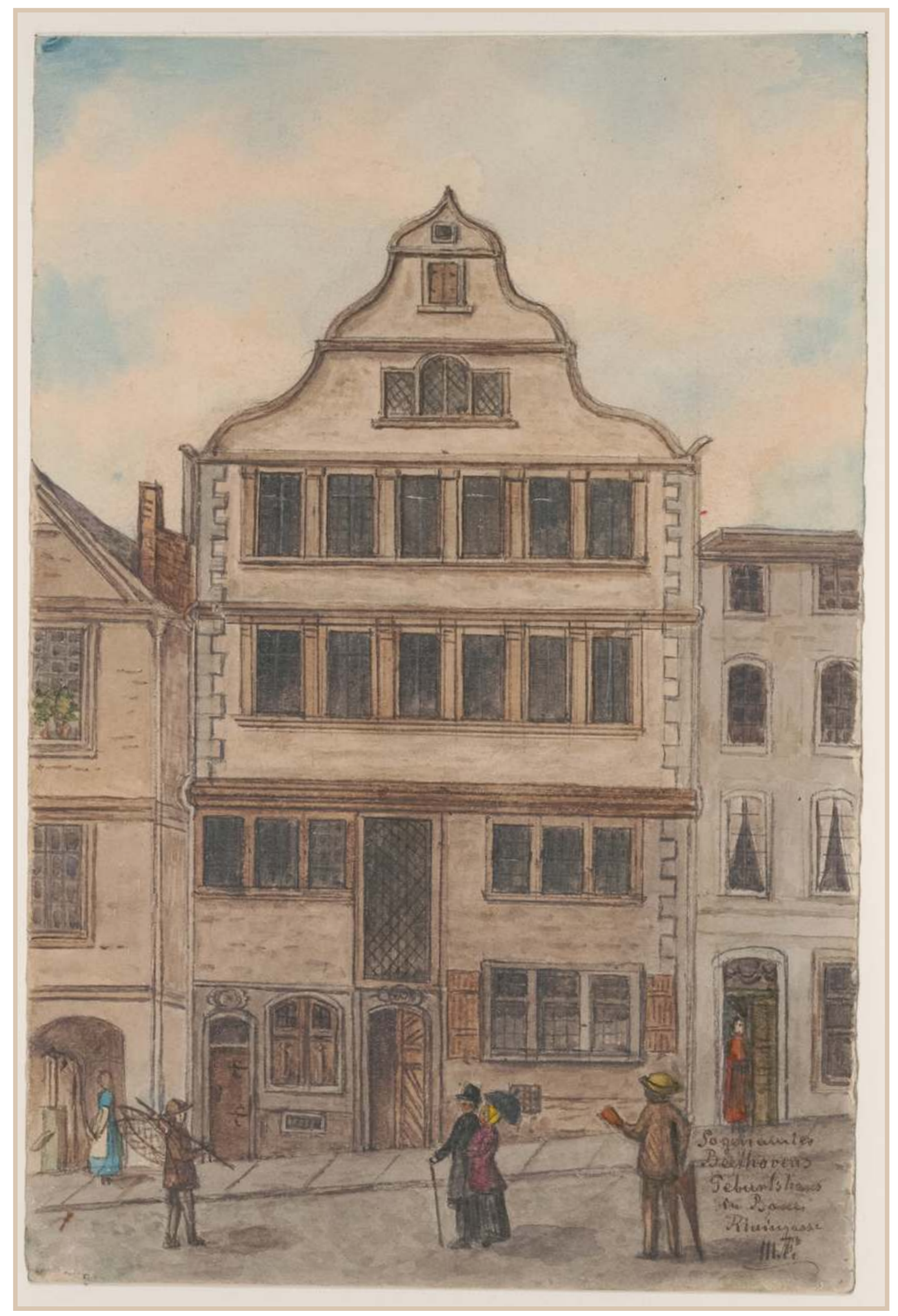

Das Haus der Familie Fischer in Bonn, Rheingasse 7 (ehemals Nr. 966, später Nr. 934). Aquarell von Mathias Frickel, um 1890 (Stadtarchiv Bonn) 


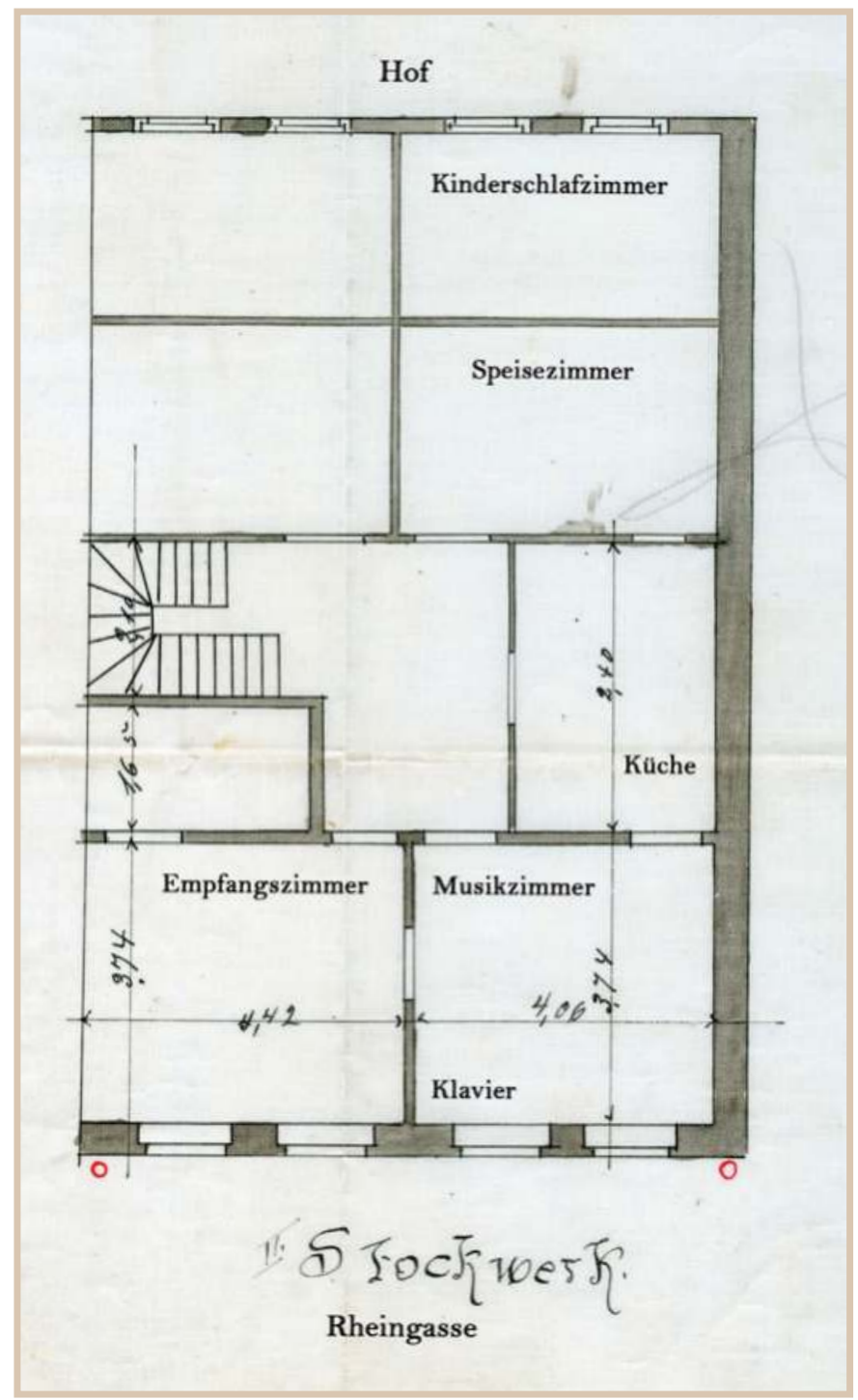

Grundriss der Wohnung der Familie van Beethoven in der 2. Etage des Hauses Rheingasse 7; nach einer Bauzeichnung, 1898 (Stadtarchiv Bonn). Neue Einträge auf der Grundlage der Forschungen von Gerhard Geiß

Koblenzer Dienstmagd. Kupferstich von B. Picart, letztes Drittel 18. Jahrhundert (MittelrheinMuseum Koblenz)

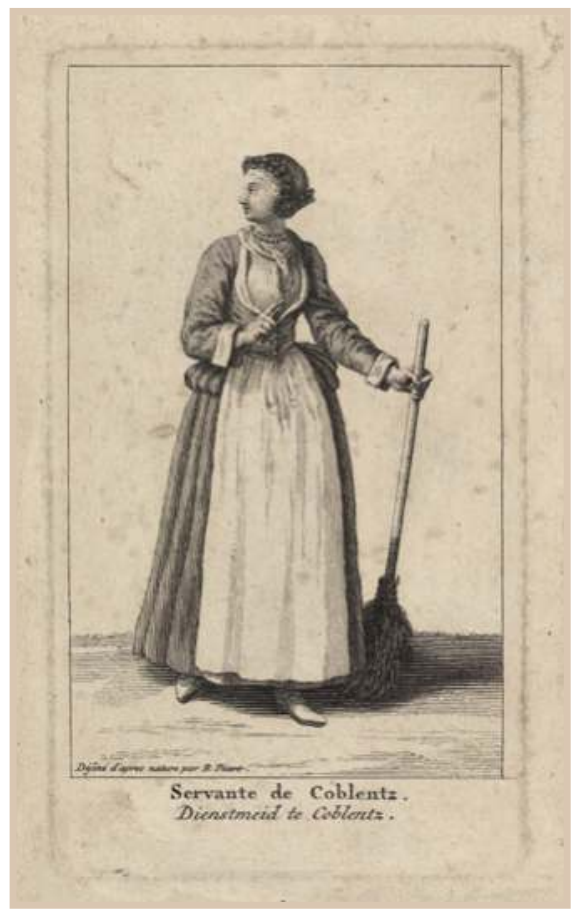

abschließbaren Speicherbereich sowie ein Zimmer für die Mägde im Dachgeschoss des Hauses. - Bei späteren Umbauten wurden unter anderem die Fensterfront zur Rheingasse verändert (vier statt sechs Fenster) und aus den kleinen hofseitigen vier Zimmern entstanden zwei größere.

Wie sich verschiedene Zeitzeugen erinnerten, beschäftigten Maria Magdalena und Johann von Beethoven regelmäßig weibliche Haushaltshilfen, ${ }^{55}$ und zumindest zeitweilig zusätzlich eine "hülfsfrau" ${ }^{\prime \prime 6}$, in deren Händen auch die Versorgung der Kinder in ihrer frühesten Jugend lag. Dies bestätigt die Annahme, dass man über ein doch recht beachtliches Einkommen verfügte ${ }^{57}$ und dass sich das Leben der Familie ganz im Rahmen des in ihrer Gesellschaftsschicht Üblichen gestaltete.

Zwar sind keinerlei Gegenstände erhalten geblieben, die die materielle Lebenskultur Maria Magdalena und Johann van Beethovens belegen könnten, und auch keine bildlichen Darstellungen - wie etwa Portraits des Ehepaars ${ }^{58}$ bekannt, die ihre alläglichen Lebensumstände dokumentieren, dennoch ist es zumindest bis zu einem gewissen Grad möglich, eine Vorstellung von der Einrichtung ihrer Wohnung zu gewinnen. Denn anscheinend waren noch bis weit ins 19. Jahrhundert hinein einige ihrer Möbelstücke in Bonn erhalten. 
Darauf deutet etwa eine Werbeanzeige des Malers Carl Backof (aktiv in der Jahrhundertmitte) im Bonner Wochenblatt hin, die im Jahr 1845 erschien und sich auf eine Serie von 32 Lithografien mit Szenen aus Beethovens Jugend bezog. Dort wird betont, dass das in den verschiedenen Darstellungen gezeigte "Möblement" vom Zeichner "nach dem antiken Nachlaß" gestaltet worden sei..$^{59}$

Diese Bildfolge muss zwar heute als verloren gelten, jedoch ist es denkbar, dass einige der erwähnten Möbelstücke auch auf den Randszenen eines Schmuckblattes wiedergegeben sind, das Backof anlässlich der Errichtung des BeethovenDenkmals auf dem Bonner Münsterplatz gestaltete. Die dort dargestellten Interieurs erwecken den Eindruck einer für das späte 18. Jahrhundert typischen gutbürgerlichen Einrichtung, wie ihn auch die bis zum Jahr 1960 im Beethoven-Haus Bonn ausgestellten historischen Möbelstücke vermittelt haben. ${ }^{60}$ In Bezug auf Dekorations- und Luxusgegenstände erlauben vor allem die Geschenke Rückschlüsse auf den Besitz der Familie, die Johann van Beethoven im Jahr 1773 Caspar von Belderbusch überreichte, um seine Position in der Bonner Hofkapelle zu verbessern. In einer später von ihm erstellten Liste werden eine Standuhr, mehrere kleine Gemälde, sowie eine Sammlung dekorativen ostasiatischen Porzellans und verschiedene Tischaufsätze genannt, ${ }^{61}$ die wohl kaum zu diesem Zweck neu erworben wurden, sondern aus dem Besitz der Familie ge-

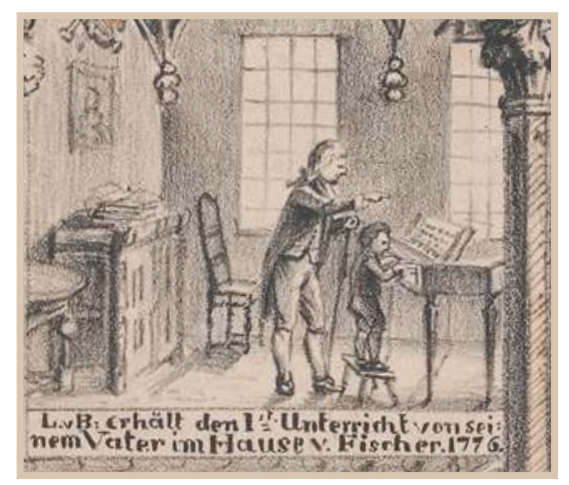
stammt haben dürften. ${ }^{62}$ Sie lassen ebenfalls die gehobenen Lebensumstände erkennen, in denen sich die Eltern Ludwig van Beethovens über lange Zeit befanden. ${ }^{63}$

Wie wohl situiert Johann und Maria Magdalena van Beethoven in den Jahren in der Rheingasse Haus gehalten haben müssen, soll abschließend ein Abschnitt aus den Fischerschen Aufzeichnungen verdeutlichen, der ausführlich über ihre Art, das Weihnachtsfest zu begehen, berichtet: "Herr Johann v: Beethoven lies allgährlich vor Weiyhnahtzeit ein schwehr Schwein schlachten,

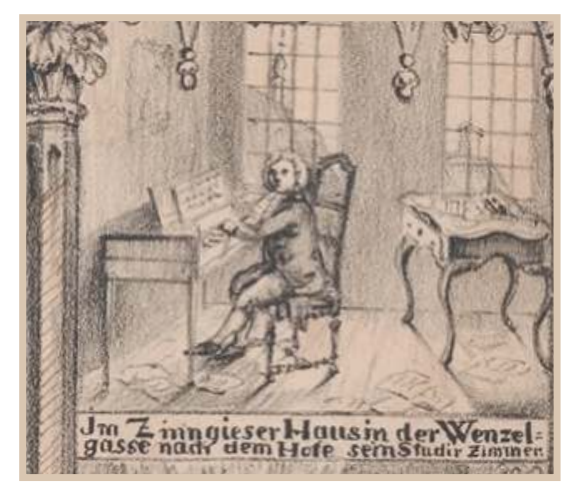

Erinnerungsblatt zur Errichtung des BeethovenDenkmals auf dem Bonner Münsterplatz. Lithografie von Carl Backof, um 1845 (Stadtarchiv Bonn). Gesamtansicht und zwei Ausschnitte 
Schmuckblatt mit dem Haus der Familie Fischer in der Rheingasse. Herausgegeben anlässlich des ersten Beethovenfestes in Bonn 1845. Lithografie von Fr. Michelis (Stadtarchiv Bonn)

dann machte der Hof Backmeister Asbach der Madamm Beethoven die Würsch [Würste]. ... wenn dann die Feyer [d.i. der Weihnachtsgottesdienst, an dem die Hofsänger und -musiker mitwirkten] geänntig, $\mathrm{Hr}$ : v: Beethoven mit den seinige und auch noch andere nach Hauß kamen, dann war der Hof Backmeister Asbach auch mit dabey, dann war nach alten Brauch frische Würsch gebraten, warme Wein, Punsch, Kafe bereit, dann wurte gespeißt und Getrunken und den ankommende Tag hinndurch gefeyert und so beschloßen." ${ }^{64}$

Dieser Text liefert gleichzeitig Hinweise auf die Freude an Geselligkeit, die das Leben im Elternhaus Ludwig van Beethovens über Jahre hinweg prägte. ${ }^{65}$ So feierte man nicht nur das Weihnachtsfest und den Namenstag Maria Magdalenas in größerer Runde ${ }^{66}$, sondern beherbergte auch wiederholt auswärtige Gäste ${ }^{67}$ und bot Musikern, wie Franz Georg Rovantini (1757-1781)68 oder Tobias Friedrich Pfeifer (um 1750-nach 1803)69, Kost und Logis. Mit der Familie des Hausbesitzers lebte man in gut nachbarlicher Gemeinschaft und pflegte den persönlichen Kontakt. ${ }^{70}$ Bedingt durch Johanns Unterrichtstätigkeit und seine zahlreichen professionellen Beziehungen war es zudem durchaus üblich, regelmäßig Musikfreunde zu empfangen und Hauskonzerte zu veranstalten, bei denen auch immer wieder der begabte älteste Sohn der Familie auftrat. ${ }^{71}$ Anscheinend war der Erfolg solcher Veranstaltungen groß, und ihre Zahl nahm bis zur Mitte der 1780er Jahre so sehr zu, dass sich der Vermieter der Wohnung, der im Erdgeschoss des Hauses seine Bäckerei betrieb und damit in einem völlig anderen Tagesrhythmus lebte als die Musikerfamilie, nachhaltig gestört fühlte und Johann van Beethoven trotz ihrer langjährigen Freundschaft um Auszug bat. ${ }^{72}$

Scheinen sich damit die Lebensumstände der Eltern van Beethovens knapp 20 Jahre lang wirklich gut gestaltet zu haben - ungeachtet aller im 18. Jahrhundert üblichen Probleme, die sich zum Beispiel durch die hohe Kindersterblichkeit, die fast jährlich wiederkehrenden Hochwasserkatastrophen oder die regelmäßigen Ausbrüche der Pocken ergaben, - so ist seit 1784 eine rasche Verschlechterung ihrer Lage zu beobachten. Dies erscheint umso erstaunlicher, da sich die Situation im Herbst 1783 noch ganz anders dargestellt hatte. In dieser Zeit hatten sich Maria Magdalena Rovantini (1755-1786), eine Kusine zweiten Grades der Mutter Beethovens, die als Gouvernante in Rotterdam lebte, gemeinsam mit ihrer wohlhabenden Arbeitgeberin und deren Tochter mehrere

20 | Silke Bettermann 
Wochen lang als Gäste in der Rheingasse aufgehalten, ${ }^{73}$ und im Anschluss daran hatte Maria Magdalena mit ihrem knapp 13-jährigen Sohn Ludwig, den sein Vater schon seit Jahren intensiv auf eine Karriere als Musiker vorbereitete ${ }^{74}$ eine Konzertreise in die Niederlande unternommen. ${ }^{75}$ Auf dieser Fahrt trat der Junge unter anderem am Hof des Prinzen Willem V. von Oranien-Nassau (1748-1806) auf, ${ }^{76}$ was nicht nur die praktische und organisatorische Kompetenz seiner Mutter unter Beweis stellt, sondern auch darauf hindeutet, dass ihr die nötigen Mittel zur Deckung der durch eine solche Reise entstehenden Kosten zur Verfügung gestanden haben müssen. Zudem scheint auch die Laufbahn Ludwigs in Bonn gleichzeitig einen finanziell rentablen Verlauf genommen zu haben. Ab Anfang 1784 war er als Organist für den Kurfürsten tätig ${ }^{77}$ und wurde einige Monate später in dieser Funktion fest bei Hof angestellt. ${ }^{78}$

Dennoch kam es im Jahr 1784 innerhalb weniger Monate zu einem geradezu dramatischen finanziellen Abstieg der Familie. Dies könnte mit dem Tod des bis dato in Bonn einflussreichen und bei der Bevölkerung verhassten "Ersten Staatsministers" Caspar Anton von Belderbusch am 2. Januar 1784 in Verbindung stehen, zu dessen Protegés Johann van Beethoven offenbar gehört hatte. Nach den Recherchen Wolf D. Pennings muss sich die Stimmung in Bonn innerhalb weniger Wochen regelrecht aufgeheizt haben ${ }^{79}$ und sich nicht nur gegen den verstorbenen Minister selbst, sondern auch gegen die von ihm geförderten Personen gewandt haben. Infolgedessen erschien Johanns Name auf einer Liste angeblicher Spione und Denunzianten, "welche anjetz dienstloß und um billigen preis $z u$ vermiethen sind" ${ }^{\prime 80}$. Es liegt nahe anzunehmen, dass derartige Schmähschriften zu einer nachhaltigen Rufschädigung der Betroffenen geführt haben und infolgedessen die Nachfrage nach dem privaten Musikunterricht zurückging, den Johann van Beethoven über Jahre hinweg erteilt hatte und der einen beachtlichen Teil seines Einkommens ausgemacht hatte. Indirekt wird diese Vermutung durch die Erinnerungen Franz Gerhard Wegelers (1765-1848) bestätigt, der offenbar nichts von Privatunterricht wusste. Stattdessen schreibt er: "Hier [d.h. in Beethovens Familie] hatte man sich außer dem Gehalt des Vaters, keines Erwerbzweigs zu erfreuen, mithin fand überall Beschränkung statt.." ${ }^{11} \mathrm{Da}$ Wegeler Ludwig van Beethoven erst im Jahr

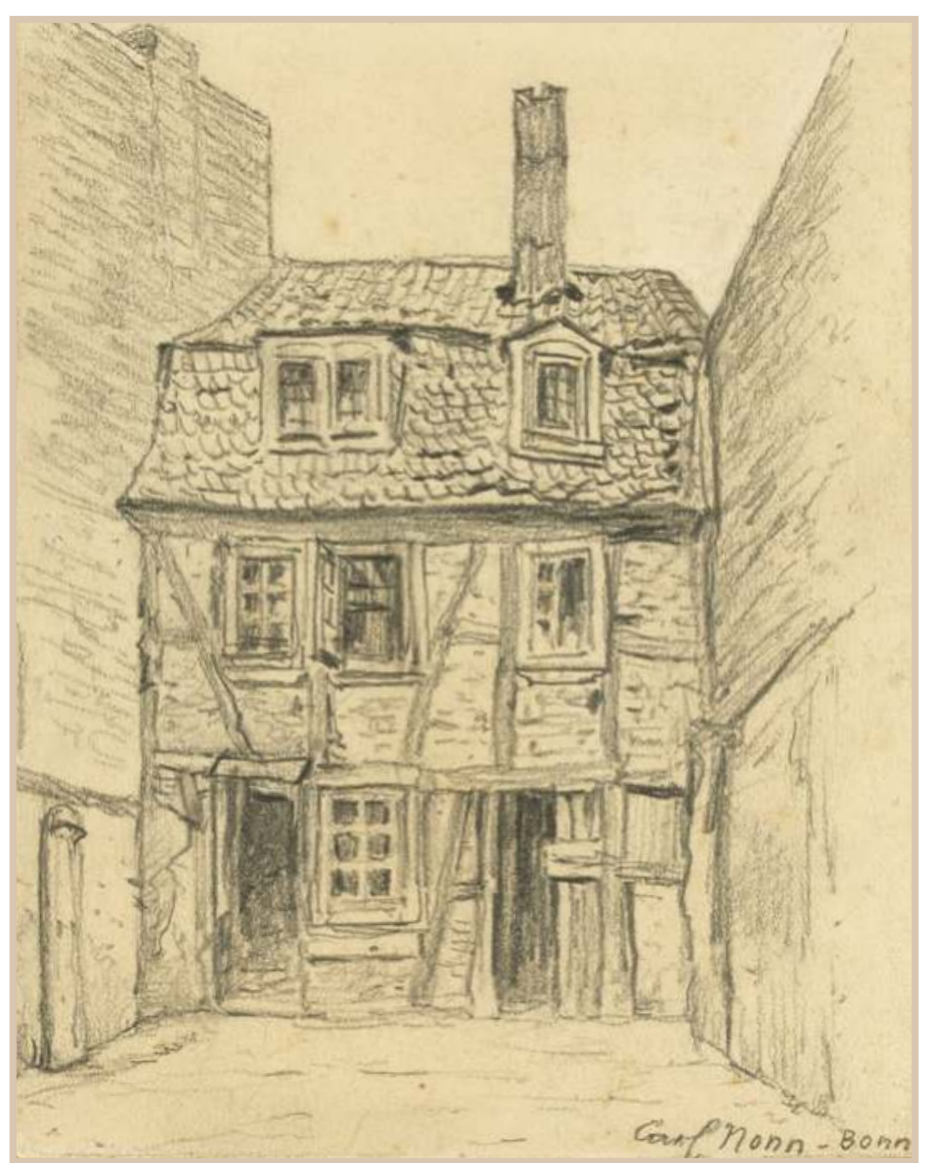

Haus Wenzelgasse 25 (ehemals Nr. 518, später Nr. 476), das letzte Wohnhaus der Familie van Beethoven in Bonn. Bleistiftzeichnung von Carl Nonn, 1928 (BeethovenHaus Bonn) 
1782 kennenlernte und sich seine Erinnerungen auf die Zeit vor seiner eigenen Abreise nach Wien im September 1787 beziehen, ${ }^{82}$ ist es gut möglich, dass der hier vermittelte Eindruck aus der Zeit stammt, als die Familie bereits in Schwierigkeiten geraten war. Auch die Erwähnung Johanns und Ludwigs in dem wohl von Graf zu Salm-Reifferscheid im Frühsommer 1784 erstellten „ProMemoria die Kurfürstliche Hof Musikque betrefend" liefert einen Hinweis auf die angespannte finanzielle Lage. Denn dort werden beide explizit als arm bezeichnet. ${ }^{83}$ Schließlich deutet auch die Tatsachte, dass Johann im folgenden Jahr versuchte, eine Entschädigung für die Geschenke zu erhalten, die er Caspar Anton von Belderbusch mehr als ein Jahrzehnt zuvor gemacht hatte, ${ }^{84}$ auf seine permanent wachsenden Schwierigkeiten hin.

Dementsprechend entschlossen sich die Eltern Beethovens, die Wohnung in der Rheingasse aufzugeben, und übersiedelten nach einer oder zwei Zwischenstationen ${ }^{85}$ in das kleine Hinterhaus Wenzelgasse $25^{86}$. Dort lebte die Familie, bestehend aus dem Elternpaar, den drei halbwüchsigen Söhnen Ludwig (1770-1827), Kaspar Anton Karl (1774-1815), Nikolaus Johann (17761848) und dem knapp einjährigen Töchterchen Maria Margarete Josepha (1786-1787) ab Anfang 1787. Obwohl sich damit die regelmäßigen Ausgaben sicher verringert haben dürften und inzwischen auch Ludwig ein Gehalt als Mitglied der kurfürstlichen Hofkapelle bezog, ${ }^{87}$ scheint sich die Situation jedoch nicht wesentlich verbessert zu haben, was unter Umständen in Zusammenhang mit den Behandlungskosten für die schwere Erkrankung Maria Magdalenas gestanden haben könnte, die an "Schwindsucht"88 litt und am 17. Juli 1787 starb. Bereits wenige Tage später, am 24. Juli, sah sich ihr Mann gezwungen, ein Bittgesuch an Kurfürst Maximilian Franz zu richten, in dem er um die Gewährung eines Vorschusses von 100 Reichstalern ersuchte, $\mathrm{da}$ "er durch die langwierige und anhaltende Krankheit seiner Frau in sehr mißliche Umstände gerathen und bereits genöthigt worden seye, seine Effecten theils zu verkaufen, theils zu versetzen" ${ }^{\prime \prime 9}$. Anscheinend war die wirtschaftliche Bedrängnis der Familie zu diesem Zeitpunkt tatsächlich so groß geworden, dass sich auch Freunde und gute Bekannte, wie Franz Anton Ries (1755-1846), zu einer Unterstützung bemüßigt sahen. ${ }^{90}$

Nach dem Tod seiner Frau verlor Johann van Beethoven offenbar völlig den Halt. Auch wenn die Ereignisse heute im Einzelnen nicht mehr genau nachzuverfolgen sind, ${ }^{91}$ deutet doch alles darauf hin, dass sich sein Abgleiten in Depression und Alkoholismus nicht mehr aufhalten ließ. Für den jungen Ludwig van Beethoven bedeutete dies die Übernahme der Rolle des Familienvorstandes, die sein Verhältnis zu seinen beiden jüngeren Brüdern (die kleine Schwester starb bereits vier Monate nach dem Tod der Mutter) nachhaltig prägen sollte. In den folgenden Jahren arbeitete er neben seiner Tätigkeit als Hoforganist zuweilen zusätzlich als Kopist für die Hofkapelle, ${ }^{92}$ wurde 1789 als Bratschist Mitglied des Ensembles ${ }^{93}$ und hatte dort wohl auch 
Soloauftritte bei Klavierkonzerten. Gleichzeitig musste er nicht nur die Verantwortung für seine Brüder, sondern auch für seinen Vater übernehmen, was sich insbesondere auch darin niederschlug, dass ein Teil der Einkünfte Johanns aus seiner Anstellung bei der kurfürstlichen Kapelle ab Anfang 1790 an Ludwig ausgezahlt wurde. ${ }^{94}$

An dieser Stelle erscheint es angebracht, einen kurzen Blick auf die Geschwister Ludwig van Beethovens zu werfen. Seine Mutter hatte in Bonn insgesamt sieben Kinder zur Welt gebracht, von denen vier bereits in den beiden ersten Lebensjahren starben. ${ }^{95}$ Bis zu seinem vierten Lebensjahr war Ludwig das einzige Kind der Familie, was vielleicht mit ein Grund für die besondere Aufmerksamkeit des Vaters in Bezug auf seine intensive frühe Förderung gewesen sein könnte. Auch der etwa dreieinhalb Jahre jüngere Kaspar Anton Karl erhielt eine musikalische Ausbildung, über die jedoch bislang kaum Einzelheiten bekannt sind. ${ }^{96}$ Über die Jugend des jüngsten der drei überlebenden Brüder, Nikolaus Johann, der zweieinhalb Jahre nach Kaspar Karl geboren wurde, liegen dagegen genauere Informationen vor. Er kam bereits vor dem Tod seiner Mutter als Lehrling in die Bonner Hofapotheke, um dort eine Ausbildung zu absolvieren. ${ }^{97}$ Nachdem im Oktober 1792 der Einmarsch der französischen Revolutionstruppen im Rheinland erfolgt war und Kurfürst Maximilian Franz Bonn verlassen hatte, wurde er als Apotheker 3. Klasse zur Arbeit im Hospital der französischen Armee in Bonn zwangsverpflichtet, ${ }^{98}$ arbeitete dann vorübergehend in der Einhornapotheke in Linz am Rhein ${ }^{99}$ und folgte schließlich im Dezember 1795 seinen beiden Brüdern, die Bonn bereits 1792 und 1794 verlassen hatten, nach Wien. ${ }^{100}$

Zum Abschluss dieses Überblicks über das Leben der Familie Ludwig van Beethovens in Bonn sollen noch einmal ihre Zeitgenossen zu Wort kommen. Gottfried Fischer äußert sich ausführlicher zu Aussehen ${ }^{101}$ und Charakter der Eltern des Komponisten. Über den Vater schreibt er: "Hr: Johann v: Beethoven war ... ein ärnsthafter Mann"102, der sein Amt in der Hofkapelle gewissenhaft ausführte, oft mehr zu tun hatte, als er bewältigen konnte und häufig Geschenke erhielt, da "ihm vielle gewogen ware"103. Von Beethovens Mutter heißt es: "Madamm v: Beethoven war eine geschickte Frau, sie konnte für Hohen und Nidrige sehr fein, geschickt, bescheiten red und antwort geben, deßwegen wurte sie auch sehr geliebt und geacht", und: "sie war eine Haüßliche, gut Frau, sie wußte zu gebe, auch zu nehmen, wie gedem gut ansteht, der rechtschaffen denkt ${ }^{\prime \prime 104}$. Insgesamt war sie es wohl, die die Familie stützte und zusammenhielt. Und obwohl sie von Franz Gerhard Wegeler als sanft und fromm bezeichnet wird ${ }^{105}$, muss Maria Magdalena van Beethoven doch eine den praktischen Anforderungen des Lebens gewachsene Persönlichkeit gewesen sein, die die Fragen der Haushaltsführung selbstbewusst löste ${ }^{106}$ und sich anscheinend auch recht gut gegen die Schwächen ihres Mannes durchsetzen konnte ${ }^{107}$. 
Wie Ludwig van Beethoven selbst das Leben mit seinen Eltern in Bonn in Erinnerung behielt, lässt sich vielleicht am besten den Biographischen Notizen seiner beiden Jugendfreunde Franz Gerhard Wegeler und Ferdinand Ries (1784-1838) entnehmen. Dort schreibt Ries zusammenfassend:

"Beethoven erinnerte sich seiner frühern Jugend und seiner Bonner Freunde mit vieler Freude, obschon es im Grunde bedrängte Zeiten für ihn gewesen waren. Von seiner Mutter besonders sprach er mit Liebe und Gemüthlichkeit, nannte sie öfters eine brave, eine herzensgute Frau. - Von seinem Vater, der am meisten am häuslichen Unglücke schuld war, sprach er wenig und ungern, allein ein hartes Wort, das ein Dritter über ihn fallen ließ, brachte ihn auf." ${ }^{\prime 108}$

GOTTFRIED FISCHER, Reinschrift der Erinnerungen an Beethovens Jugend, um 1857, S. 17, in: Beethoven-Haus Bonn, BH 173,1; zitiert nach MARGOT WETZSTEIN, Familie Beethoven im kurfürstlichen Bonn. Neuauflage nach den Aufzeichnungen des Bonner Bäckermeisters Gottfried Fischer, Bonn 2006, S. 41

Einschub im Entwurf Fischers zu seinen Erinnerungen an die Familie van Beethoven, in: Beethoben-Haus Bonn, BH 173,2, fol. 8v.; zitiert nach MARGOT WETZSTEIN, Das Haus in der Rheingasse. Beethovens Wohnhaus im Kontext der Bonner Geschichte (16601860). Gottfried Fischers Materialsammlung, Bonn 2010, S. 21

Vgl. zur Entstehung der Aufzeichnungen Fischers und zur Quellenlage WETZSTEIN, Familie Beethoven (wie Anm. 1), S. VII-XII

Vgl. FISCHER, Reinschrift (wie Anm. 1), S. 1, zitiert nach WetzSTEIN, Familie Beethoven (wie Anm. 1), S. 7

Maria Bernhardine Ludovica (1734-1735) und Markus Joseph (geboren 25.4.1736); vgl. Joseph SCHMIDT-Görg, Beethoven. Die Geschichte seiner Familie (Veröffentlichungen des Beethoven-Hauses in Bonn, Neue Folge, Reihe 4: Schriften zur Beethoven-Forschung 1), Bonn/München/Duisburg 1964, S. $118 f$.

Vgl. WetzStein, Familie Beethoven (wie Anm. 1), S. 6 Anm. 15, unter Bezugnahme auf Theo MohlberG, Die Familie van Beethoven, in: Mitteilungen der westdeutschen Gesellschaft für Familienkunde 39, 1999, S. 90-93

Vgl. SCHMIDT-GöRG, Beethoven (wie Anm. 5), D 372, mit Abdruck eines Auszugs des Textes.

Vgl. ebd., S. 58, und Knud Breyer, Familie, in: Heinz von Loesch und Claus RaAB (Hgg.), Das Beethoven-Lexikon (Das Beethoven-Handbuch 6), Laaber 2008, S. 231 234, hier 231; zuletzt JuLIA RONGE, I. Bonn - Beruf Musiker, 1770-1792, in: Beethoven. Welt, Bürger, Musik. Ausstellungskatalog, hg. von der Kunst- und Ausstellungshalle der Bundesrepublik Deutschland und dem Beethoven-Haus Bonn, Köln 2019, S. 20f., hier S. 20

Vgl. FISCHER, Reinschrift (wie Anm. 1), S. 68; zitiert bei WetzSTEIN, Familie Beethoven (wie Anm. 1), S. 122

Vgl. FisCHeR, Reinschrift (wie Anm. 1), S. 7f.; zitiert bei WetZSTEIN, Familie Beethoven (wie Anm. 1), S. 22f.

Vgl. Alexander Wheelock Thayer, Ludwig van Beethovens Leben, hg. von HermanN Deiters, bearbeitet und erweitert von Hugo RIEMANN, 5 Bde, hier Bd. 1, Leipzig ${ }^{31917}$, Bd. 1, S. 115-126 


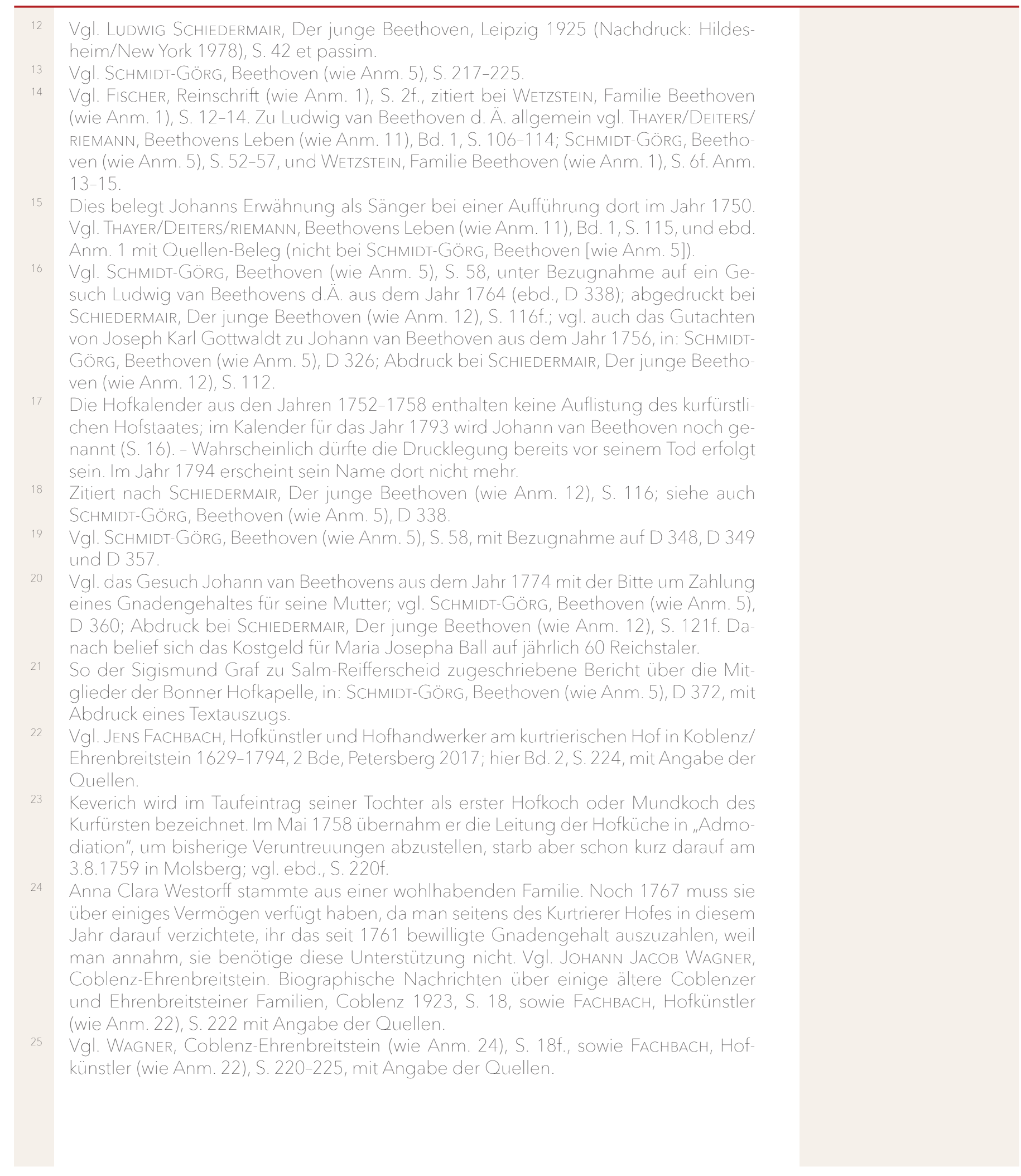

Johann und Maria Magdalena van Beethoven - Eine bürgerliche Ehe im kurfürstlichen Bonn | 25

(C) 2020 by Böhlau Verlag GmbH \& Cie. KG, Köln

https://doi.org/10.7788/9783412519704 | CC BY-NC 4.0 
26 Einen Hinweis auf die Hochschätzung, die der Vater Maria Magdalena Keverichs bei der Familie von Walderdorff genoss, liefert etwa die Tatsache, dass für ihn nach seinem Tod Seelenmessen in der dafür zur Verfügung gestellten Hofkapelle der kurfürstlichen Residenz (Philippsburg) gelesen wurden. Vgl. FACHBACH, Hofkünstler (wie Anm. 22), S. 221, sowie VOLKER LEMKE, Molsberg und Salz - Schicksalsorte für das Leben der Familie Keverich, in: Matthias von deR BANk (Hg.), Das Mutter-Beethoven-Haus in Ehrenbreitstein, Koblenz/Petersberg 2020

27 Vgl. JeNS FACHBACH, „Jo! mit mund, sinn und inner'm Hertzen Jubiliere frohes Trier'sches Landt!" - Eine Episode aus der Kindheit der Maria Magdalena Keverich; in: VON DER BANk, Mutter-Beethoven-Haus (wie Anm. 26). Das insgesamt dreibändige Konvolut befindet sich im Archiv der Familie von Walderdorff in Molsberg. Johann Peter und Maria Magdalena waren die einzigen der insgesamt sechs Kinder Anna Clara Westorffs und Johann Heinrich Keverichs, die das Erwachsenenalter erreichten; vgl. SchMIDT-GÖRG, Beethoven (wie Anm. 5), S. 156.

Layms erste Ehefrau Maria Josepha Ernestine Kelsinger, war gerade erst, am 10.10.1762, gestorben; vgl. WAGNER, Coblenz-Ehrenbreitstein (wie Anm. 24), S. 19.

Vgl. den bereits bei Wegeler zitierten Hochzeitseintrag: FRANZ GEORG WEGELER und FERDINAND RIES, Biographische Notizen über Ludwig van Beethoven, Koblenz 1838, S. 2 .

Johann Philipp (*4.2.1760), Johann Franz Ludwig (*30.9.1762) und Maria Friederike (*27.6.1761). Während die Geburtsdaten der Kinder durch Einträge in den Ehrenbreitsteiner Kirchenbüchern gesichert sind, stützen sich die Angaben zu ihren Tod (1763 für die beiden Söhne und "in frühester Kindheit" für die kleine Tochter) auf einen Text Johann Jacob Wagners, dem anscheinend weitere, aktuell nicht zugängliche Informationen vorlagen. - Eine Aufarbeitung und Veröffentlichung des in Ehrenbreitsein erhaltenen Wagnerschen Nachlasses steht bislang aus. - Vgl. WAGNER, Coblenz-Ehrenbreitstein (wie Anm. 24), S. 19

Vgl. SCHMIDT-GÖRG, Beethoven (wie Anm. 5), S. 233 Anm. 73

In den Aufzeichnungen Gottfried Fischers heißt es u.a.: "Madamm v: Beethoven sagt aber zu Jungfer Cicilia Fischer, wenn sie aber meinen guten Rath annehmen wolle, bleiben sie Ledig, so haben sie, das wahre, ruhiste, schönste, vergnügeste Leben Denn was ist Heyrahten, ein wenig freud, aber nachher, eine Kette, von Leiden..." In FISCHER, Reinschrift (wie Anm. 1), S. 55; zitiert nach WETZSTEIN, Familie Beethoven (wie Anm. 1), S. $98 f$

Vgl. SCHMIDT-GÖrG, Beethoven (wie Anm. 5), S. 233 Anm. 73.

Darauf deutet zumindest die Tatsache hin, dass Layms Nachlass „auf Anstehen seiner Gläubiger" am 7.7.1766 versteigert wurde; vgl. WAGNER, Coblenz-Ehrenbreitstein (wie Anm. 24), S. 19, und ebd. Anm. 3 unter Bezugnahme auf eine Anzeige in der Coblenzer Zeitung

36 Nach ihrem Ausscheiden aus der Hofküche erhielt sie als Gnadengehalt jährlich 3 Klafter Holz, 6 Malter Korn und ein Zumaß Wein. Vgl. FACHBACH, Hofkünstler (wie Anm. 22), S. 222, mit Angabe der Quellen

In ihrem Todeseintrag im Kirchenbuch der Heilig-Kreuz-Kirche heißt es, sie sei "wegen ihrer Frömmigkeit im ganzen Thal bekannt gewesen"; zitiert nach FACHBACH, Hofkünstler (wie Anm. 22), S. 223

38 Vgl. die 1768 erfolgte Eingabe des Ehrenbreitsteiner Vogtes Georg (auch Gereon) Friedrich Jenger (1718-1786) beim Trierer Kurfürsten, in der Anna Clara als schwachsinnig bezeichnet wird; vgl. WAGNER, Coblenz-Ehrenbreitstein (wie Anm. 24), S. 109f., sowie FACHBACH, Hofkünstler (wie Anm. 22), S. 222, mit Angabe der Quellen.

39 Vgl. Wagner, Coblenz-Ehrenbreitstein (wie Anm. 24), S. 46, sowie Wetzstein, Familie Beethoven (wie Anm. 1), S. 33 Anm. 132 


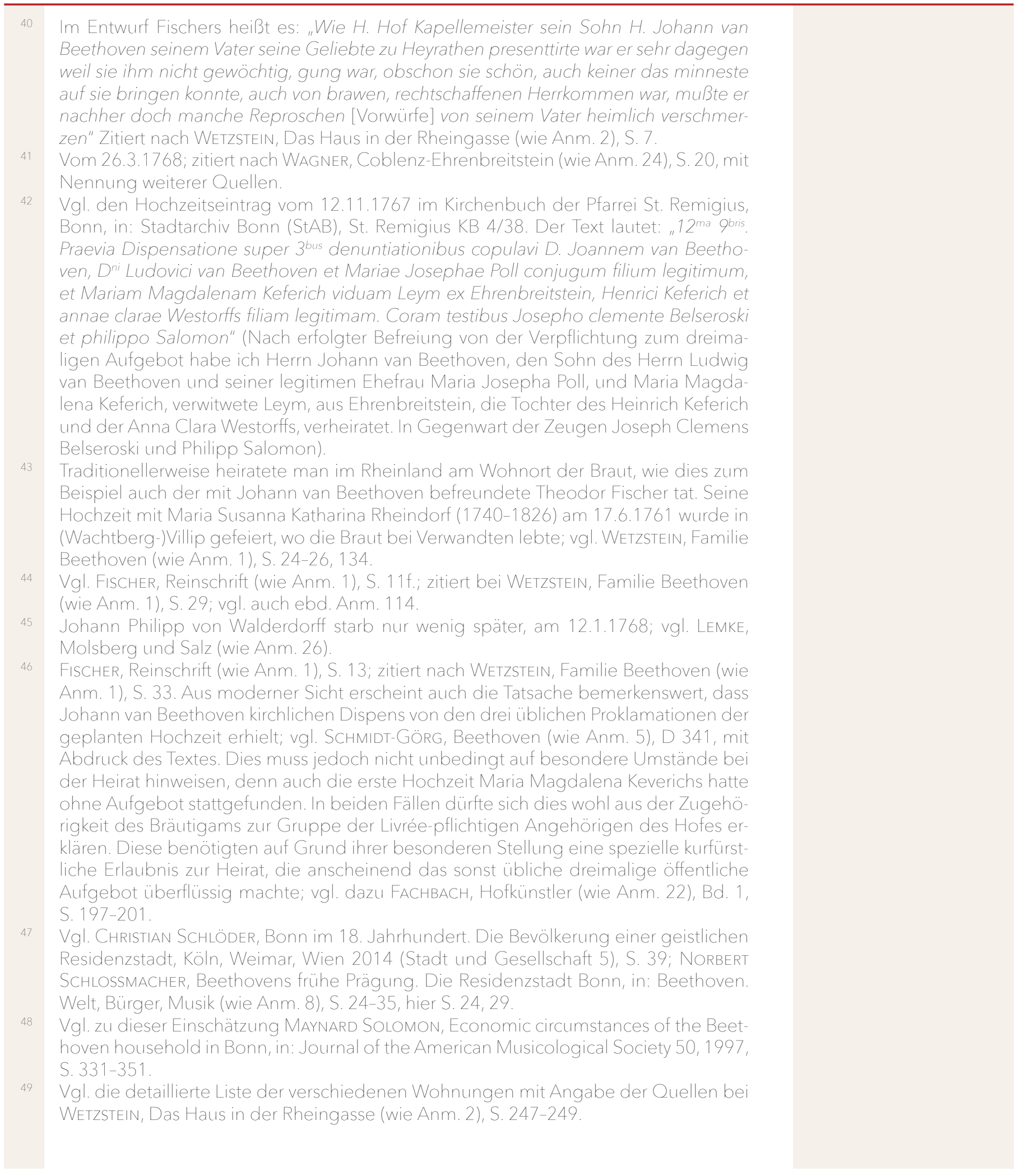

Johann und Maria Magdalena van Beethoven - Eine bürgerliche Ehe im kurfürstlichen Bonn | 27 
Gottfried Fischer schreibt explizit:.... er gab den hießige Engelische und Franzößische und Kaißerliche Gesandterihre Söhne oder Töchter und im Aedelstannt den Herrn und Töchter, auch schöne Bürger lehrstund auf dem Klavier und im Sinngen, er hat oft mehr zu thuen alls er thuen konnte... Dadurch seine Haußhaltung gut bestehen konnte" FISCHER, Reinschrift (wie Anm. 1), S. 17, zitiert nach WETZSTEIN, Familie Beethoven (wie Anm. 1), S. $41 f$.

51 Darauf deutet zumindest die bereits erwähnte Eingabe Georg Friedrich Jengers an den Trierer Kurfürsten Clemens Wenzeslaus (1739-1812) aus dem Jahr 1768 hin, in der es heißt, dass das Vermögen der Anna Clara Westorff "durch eine übel geratene Heirat ihrer einzigen Tochter bis auf 300 Taler verschwunden sei", was eigentlich nur bedeuten kann, dass sie die junge in Bonn lebende Familie finanziell unterstützt hat. Zitiert nach JOHANN JACOB WAGNER, Beethoven und seine Beziehungen zu Ehrenbreitstein, in: Festbuch zum 450. Jubiläum der St. Sebastianus Schützenbruderschaft, Ehrenbreitstein 1970, S. 29

Wetzstein, Das Haus in der Rheingasse (wie Anm. 2), S. $248 f$.

53 Vgl. FisCher, Reinschrift (wie Anm. 1), S. 62, zitiert nach WETZSTEIN, Familie Beethoven (wie Anm. 1), S. 114, und Fischers Einzelnotiz (Beethoven-Haus Bonn, BH 173, 36), zitiert bei WetzSTEIn, Das Haus in der Rheingasse (wie Anm. 2), S. 149. Herrn Gerhard Geiß, Bonn, sei für die Rekonstruktion herzlich gedankt.

Vgl. FISCHER, Reinschrift (wie Anm. 1), S. 62, zitiert nach WeTZSTEIN, Familie Beethoven (wie Anm. 1), S. 113

55 Vgl. FisCher, Entwurf (wie Anm. 2), zitiert bei WeTzSTEIN, Das Haus in der Rheingasse (wie Anm. 2), S. 19, sowie Thayer/Deiters/Riemann, Beethovens Leben (wie Anm. 11), Bd. 1, S. 488

FISCHER, Reinschrift (wie Anm. 1), S. 15, zitiert nach WeTzSTEIN, Familie Beethoven (wie Anm. 1), S. 38

57 Allerdings mussten die Eheleute schon bald auf die Unterstützung durch Maria Magdalenas Mutter verzichten, da diese bereits am 13.9.1768 starb. Und auch das mütterliche Erbe musste man verloren geben, da der Nachlass von Georg Friedrich Jenger veruntreut worden war. Obwohl sie noch 1776 diesbezügliche Anstrengungen unternahmen, scheint es Maria Magdalena und Johann van Beethoven nicht gelungen zu sein, aus Ehrenbreitstein irgendwelche Vermögenswerte zu erhalten: vgl. WAGNER, Coblenz-Ehrenbreitstein (wie Anm. 24), S. 109f., sowie FACHBACH, Hofkünstler (wie Anm. 22), Bd. 2, S. 222

58 An dieser Stelle seien der Vollständigkeit hal ber die beiden Bildnisse erwähnt, die um 1880 von dem Kölner Konsul Walter Jagenberg und dem ebenfalls in Köln ansässigen Restaurator und Maler Melchior Kempen als Portraits der Eltern Beethovens von der Hand Benedikt Beckenkamps (1747-1828) publik gemacht wurden und mit dieser Zuschreibung und Identifikation der Dargestellten Anfang des 20. Jahrhunderts als Postkarten vom Verein Beethoven-Haus Bonn veröffentlicht wurden (Beethoven-Haus Bonn, B 2290 und B 538). Die von Anfang an berechtigterweise in Zweifel gezogene Authentizität der Darstellungen wurde zuletzt von Bettina Mosler überzeugend widerlegt, ebenso wie die behauptete Autorschaft Benedikt Beckenkamps. Vgl. BETTINA Moster, Benedikt Beckenkamp, 1747-1828. Ein rheinischer Maler (Publikationen des Kölnischen Stadtmuseums 4), Köln 2003, S. $245 f$.

59 Zitiert nach WeTZSTEIn, Das Haus in der Rheingasse (wie Anm. 2), S. 114 Anm. 209

60 Es handelte sich um einen Tisch und mehrere Stühle mit hoher Lehne, die sich ehemals im sogenannten "Bonner Zimmer" des Museums befanden und am 9.5.1960 bei einem Brand zerstört wurden. 


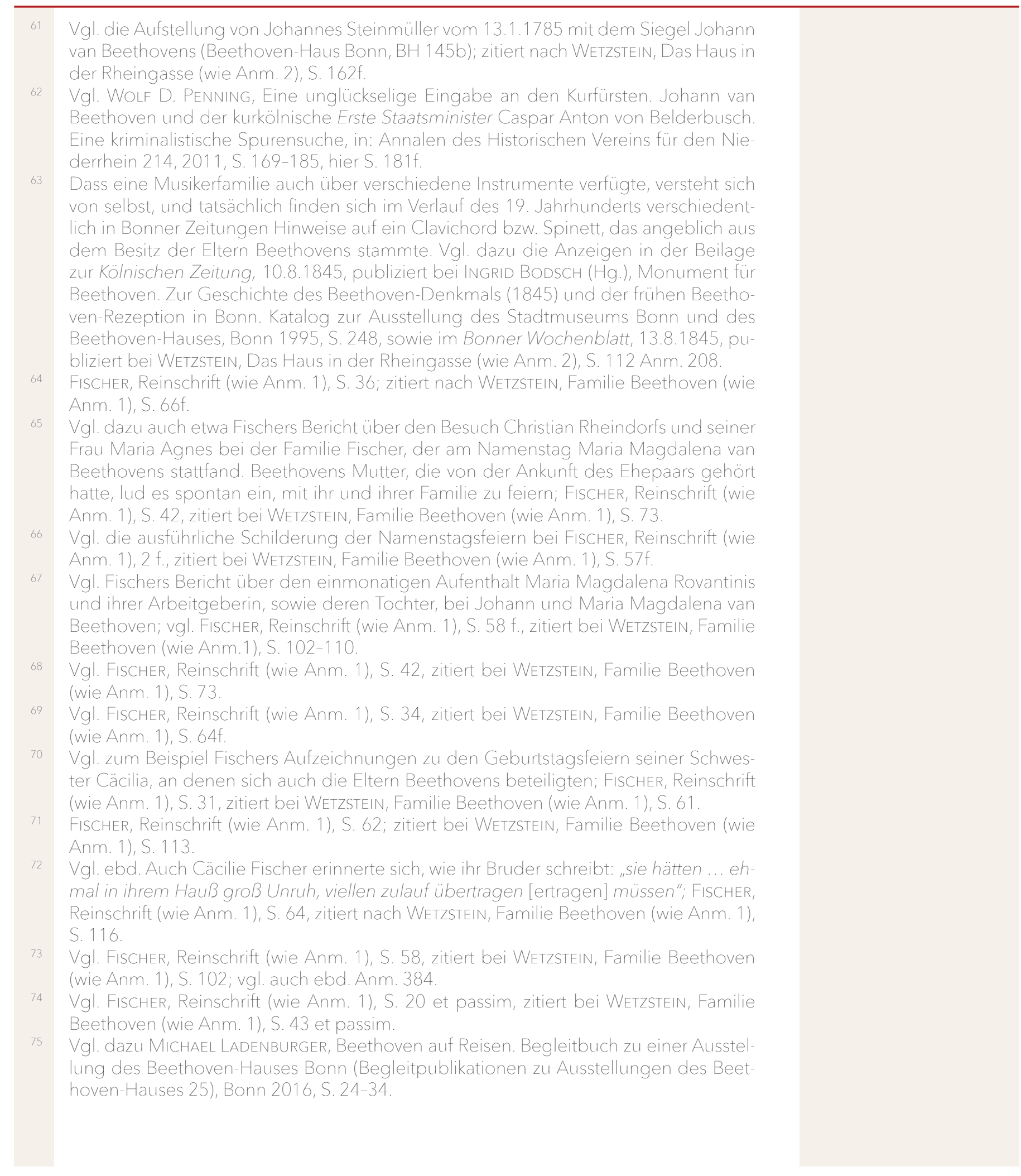

Johann und Maria Magdalena van Beethoven - Eine bürgerliche Ehe im kurfürstlichen Bonn | 29

(C) 2020 by Böhlau Verlag GmbH \& Cie. KG, Köln

https://doi.org/10.7788/9783412519704 | CC BY-NC 4.0 
Diesen Auftritt belegt eine erhaltene Zahlungsanweisung für das Konzert vom 23.11.1783, in: Koninklijk Huisarchief, Den Haag, F 1 "Fiancien” Nr. 60); Vgl. LADENBURGER, Beethoven auf Reisen (wie Anm. 75), S. 30.

Vgl. Christian Gottlob Neefes Schreiben an Assessor Kummer, 20.1.1784 (Beethoven-Haus Bonn, NE 224)

Vgl. die Anweisung des Kurfürsten an die Hofkammer über die Zahlung der Gehälter an die Mitglieder der Hofkapelle, in: Landesarchiv NRW, Abt. Rheinland, Kurköln II, Nr. 471, f. 26r. und v. Übrigens nicht bei SCHMIDT-GÖRG, Beethoven (wie Anm. 5). Vgl. auch RONGE, I. Bonn (wie Anm. 8), S. 21

PENNING, Eine unglückselige Eingabe (wie Anm. 62), S. $171 \mathrm{f}$.

StAB, SN 94/85 (Sammlung Kaufmann), zitiert nach PENNING, Eine unglückselige Eingabe (wie Anm. 62), S. 170 und Anm. 5

WEGELER/RIES, Biographische Notizen (wie Anm. 30), S. 9

S. ebd., S. XIf.

Vgl. SCHMIDT-GÖRG, Beethoven (wie Anm. 5), D 373, mit Abdruck eines Auszugs des Textes.

84 Val. dazu ausführlich und mit Anführung der verschiedenen Quellen WETZSTEIN, Das Haus in der Rheingasse (wie Anm. 2), S. 152-161; vgl. auch PENNING, Eine unglückselige Eingabe (wie Anm. 63), S. 179-182.

Zunächst mietete die Familie Räume in der Rheingasse Nr. 939 und zog entweder direkt von dort aus in die Wenzelgasse, oder tat dies nach einer vorüberkehrenden Rückkehr in das Haus der Familie Fischer; vgl. KNUd BREYER, Elternhaus, in: vON LOESCH/ RAAB, Beethoven-Lexikon (wie Anm. 7), S. 214-217, hier S. 217; WeTZSTEIN, Das Haus in der Rheingasse (wie Anm. 2), S. $248 f$.

86 Das aus Vorder- und Hinterhaus bestehende Gebäudeensemble gehörte dem Zinngießer Peretti und wurde von mehreren Familien bewohnt; vgl. WETZSTEIN, Das Haus in der Rheingasse (wie Anm. 2), S. 249, unter Bezugnahme auf JoSEF DiETz, Topographie der Stadt Bonn vom Mittelalter bis zum Ende der kurfürstlichen Zeit (Bonner Geschichtsblätter16/17), 2 Bde, Bonn 1962/63, hier Bd. 2, S. 694.

$87 \mathrm{Vgl}$. die bereits erwähnte Anweisung des Kurfürsten an die Hofkammer vom 25./27.6.1784 über die Zahlung der Gehälter an die Mitglieder der Hofkapelle, in der Johann van Beethoven mit einem Jahresgehalt von 300 und Ludwig mit einer jährlichen Besoldung von 150 Reichstalern aufgeführt sind (wie Anm. 78); freundlicher Hinweis von Julia Ronge, Beethoven-Haus Bonn, 24.4.2020

Vgl. Beethovens Brief an Joseph von Schaden in Augsburg, Bonn, 15.9.1787 (Beethoven-Haus Bonn, BH 1); ediert bei Sieghard BrandenBuRg (Hg.), Ludwig van Beethoven. Briefwechsel. Gesamtausgabe, 7 Bde, München 1996-1998, hier Bd. 1, Nr. 3.

Kurfürstliche Verfügung zu dem nicht mehr erhaltenen Bittgesuch, zitiert nach SCHIEDERMAIR, Der junge Beethoven (wie Anm. 12), S. 191; vgl. auch SCHMIDT-GÖRG, Beethoven (wie Anm. 5), D 376.

90 Ferdinand Ries erinnerte sich später daran, dass ithn Beethoven einmal bat, seinen Vater zu grüßen und ihm auszurichten, er habe nicht vergessen, wie die Umstände waren, als seine Mutter starb. Wie Ries später erfuhr, hatte sein Vater, „da die Familie sehr bedürftig war, [sie] bei dieser Gelegenheit auf jede Art thätig unterstützt"; WEGELER/ RIES, Biographische Notizen (wie Anm. 30), S. 75.

91 So ist zum Beispiel nicht klar, warum Johann van Beethoven in den Archivalien des Jahres 1790 nicht unter den in der Wenzelgasse Nr. 476 wohnenden Personen genannt wird, obwohl Fischer angibt, er habe 1788 dort gelebt und sei am 18.12.1792 auch dort gestorben; vgl. dazu WetzSTEIN, Das Haus in der Rheingasse (wie Anm. 2), S. 249 Vgl. JOHN D. WILSON, Beethoven als Mitglied einer Hofmusikerfamilie, in: Beethoven. Welt, Bürger, Musik (wie Anm. 8), S. 44-50, hier S. 47-50. 
Von 1790 bis 1794 wird er als in dieser Position in den Kurkölner Hofkalendern geführt. Vgl. SCHMIDT-GÖRG, Beethoven (wie Anm. 5), D 378, D 380 - D 382. Offenbar wurde Johann van Beethoven mit dem kurfürstlichen Dekret vom 20.11.1789 (ebd. D 378), das die Auszahlung der Hälfte seines Gehaltes an seinen ältesten Sohn Beethoven anwies, zugleich vom Dienst in der kurfürstlichen Hofkapelle suspendiert; so THAYER/ Deiters/RIemann, Beethovens Leben (wie Anm. 11), Bd. 1, S. $236 f$.

Der Vollständigkeit halber seien an dieser Stelle die Namen und Lebensdaten aller Kinder, die Maria Magdalena gebar, aufgeführt: Johann Peter Anton Laym (25.10.27.11.1764); Ludwig Maria van Beethoven (getauft 2.4.1769-8.4.1769); Ludwig van Beethoven (getauft 17.12.1770-26.3.1827); Kaspar Anton Karl van Beethoven (getauft 8.4.1774-15.11.1815); Nikolaus Johann van Beethoven (getauft 2.10.177612.1.1848); Anna Maria Franziska van Beethoven (getauft 23.2.1779-27.2.1779); Franz Georg van Beethoven (getauft 17.1.1781-16.8.1782); Maria Margarete Josepha van Beethoven (getauft 5.5.1786-26.11.1787). Daten und Schreibweisen der Vornamen nach SCHMIDT-GÖRG, Beethoven (wie Anm. 5), S. 119, 125, 233. Bei der Angabe des Todesjahres 1788 für Maria Margarete Josepha durch WETZSTEIN, Das Haus in der Rheingasse (wie Anm. 2), S. 249, dürfte es sich um ein Versehen handeln.

Franz Gerhard Wegeler erinnerte sich, dass er später seinen Unterhalt als Klavierlehrer verdient habe, überlieferte jedoch nicht Näheres zu seiner Kindheit und Jugend; vgl. WEGELER/RIES, Biographische Notizen (wie Anm. 30), S. 7; vgl. auch SCHMIDT-GöRG, Beethoven (wie Anm. 5), S. 62 f. Nach Gottfried Fischer, der hier jedoch schlecht informiert zu sein scheint, soll er als junger Mann vorübergehend nach Frankreich gegangen "und in ein Regiment Musicks Chor eingetretten seyn", in: FISCHER, Reinschrift (wie Anm. 1), S. 68, zitiert nach WetzSTEIN, Familie Beethoven (wie Anm. 1), S. 124, sowie ebd., Anm. 457

Vgl. Wetzstein, Familie Beethoven (wie Anm. 1), S. 124 Anm. 457, ohne Nennung von Quellen.

Dekret des Kommandanten der Armée de Sambre et Meuse vom 18.3.1795, zitiert bei ThaYer/Deiters/Riemann, Beethovens Leben (wie Anm. 11), Bd. 1, S. 414; vgl. dazu auch MARION WüHR, Die Apotheken im ehemaligen Oberen Erzstift Köln (Quellen und Studien zur Geschichte der Pharmazie 31), Stuttgart 1985, S. 168

Vgl. WüHR, Apotheken (wie Anm. 99), S. 169, 349. Vgl. auch - mit einem Schwerpunkt auf seiner Tätigkeit in Österreich - ERIKA EIKERMANN, Der Apotheker Johann van Beethoven (1776-18148), in: Bonner Geschichtsblätter 59, 2009, S. 107-140.

Vgl. zur Biographie Kaspar Anton Karls und Nikolaus Johanns allgemein JULIA RONGE, Brüder, in: vON LOESCH/RAAB, Beethoven-Lexikon (wie Anm. 8), S. 155-158.

Die bereits häufig in der Literatur angeführten Abschnitte zum Aussehen der beiden Eltern seien hier nur der Vollständigkeit halber noch einmal zitiert: "Herr Johann van Beethoven seine Stattur. Mittle größe, gelänktes [längliches] Gesicht, breite Stirn, runde Naß, breit in die Schulter, ärnBhafte Augen, was Narfen im Gesicht, ein dünnes Hahrzöppen Frisur.... Madamm van Beethoven ihre Stattur. Zimmliche größe, gelänktes Gesicht, blasse Farb, was gehöffelte Naß [gemeint ist wohl eine stumpfe Nase], Maager, und ärnsthafte Augen." Nach FISCHER, Reinschrift (wie Anm. 1), S. 12, zitiert nach WetZSTEIn, Familie Beethoven (wie Anm. 1), S. 30

FisCher, Reinschrift (wie Anm. 1), S. 29; zitiert nach WetzSTEIN, Familie Beethoven (wie Anm. 1), S. 59

FISCHER, Reinschrift (wie Anm. 1), S. 17; zitiert nach WETZSTEIN, Familie Beethoven (wie Anm. 1), S. 42

FIsCher, Reinschrift (wie Anm. 1), S. 17; zitiert nach WeTZSTEIN, Familie Beethoven (wie Anm. 1), S. 41

Vgl. Wegeler/Ries, Biographische Notizen (wie Anm. 30), S. 8.

Johann und Maria Magdalena van Beethoven - Eine bürgerliche Ehe im kurfürstlichen Bonn | 31 


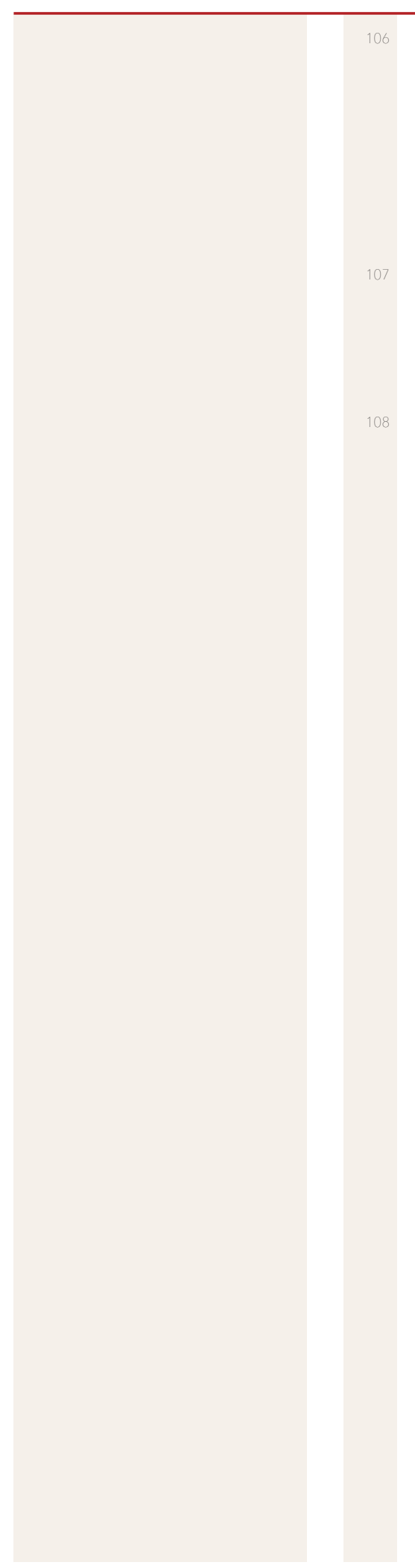

Bezeichnend ist dafür die von Gottfried Fischer anekdotenhaft überlieferte Erinnerung seiner Schwester: "Wenn Hr: Johann v: Beethoven sein Monahtlich Gehalt oder von sein Schularen Gelder erhielt, hat er spaß, wenn er kam und sie im zimmer da saß, da schüttelt er das Geld seine Frau in den Schoß, und sagt, nun Frau haußt damit, dan gab sie ihm für ein Flasch Wein und sagt, mann muß die Männer doch nicht so lehr abzigen laße, denn wär könnte das über sein Herz bringe. sagt er auch ... Ja, Ja, die Frau hat recht, sie hat auch recht, und sie behalt auch ihr recht." In: FISCHER, Reinschrift (wie Anm. 1), S. 28; zitiert nach WETZSTEIN, Familie Beethoven (wie Anm. 1), S. $58 f$.

Vgl. die von Fischer nicht in seine Reinschrift übernommene Notiz: "Madamm van Beethoven sagte ehmal, die nothwendigen Artikel wie Haußmieht, Becker, Schuster, Schneider müsste am ersten zahlt sein, aber Saufschult würt sie nimmer zahlen." In: FISCHER, Entwurf (wie Anm. 2); zitiert nach WETZSTEIN, Das Haus in der Rheingasse (wie Anm. 2), S. 21

Wegeler/RIES, Biographische Notizen (wie Anm. 30), S. 122 


\section{Die Taufe Ludwig van Beethovens am 17. Dezember 1770 in der Pfarrkirche St. Remigius zu Bonn ${ }^{1}$}

- s war gewiss nur eine kleine Schar, die sich am Montag, dem 17. De-

zember 1770, aus der Wohnung im Hinterhaus der Bonngasse 20, ${ }^{2}$ im Herzen der kurfürstlichen Haupt- und Residenzstadt Bonn, auf den Weg zur nur wenige hundert Meter entfernten Pfarrkirche St. Remigius machte, um ein neugeborenes Kind auf den Namen Ludovicus taufen zu lassen. Bei diesem Säugling handelte sich um den Sohn der Eheleute Johann und Maria Magdalena van Beethoven, geborene Keverich, verwitwete Leym. Es war ihr zweites gemeinsames Kind; ein erster Sohn, Ludwig Maria, war am 8. April 1769, wenige Tage nach seiner Geburt gestorben. ${ }^{3}$

Wann der Täufling Ludwig das Licht dieser Welt erblickte, ist nicht überliefert. Weder in privaten Unterlagen noch in späteren biographischen Texten gibt es verwertbare Hinweise auf den Geburtstag. Auch amtlicherseits wurden Geburten seinerzeit noch nicht festgehalten oder gar beurkundet. Dies erfolgte erst mit der Errichtung der Standesämter und der Einführung der Zivilstandsregister in kommunaler Verantwortung; im linksrheinischen Teil des vor dem Untergang stehenden Heiligen Römischen Reichs Deutscher Nation geschah dies unter französischer Verwaltung im Jahre 1798, in anderen Teilen Deutschlands sogar erst in den 1870er Jahren. Zuvor oblag die Aufzeichnung der als maßgeblich betrachteten Eckdaten menschlicher Existenz, nämlich Getauftwerden, Heiraten und Sterben, ausschließlich den Kirchen.

Vereinzelt haben sich entsprechende Notizen bereits aus dem Spätmittelalter erhalten. Im 16. Jahrhundert wurde das Führen von Kirchenbüchern (Tauf-, Heirats- und Sterberegister) durch die jeweiligen Ortsgeistlichen obligatorisch: Zunächst in den Kirchen der Reformation, später dann auch in der Katholischen Kirche, beschlossen auf dem Konzil von Trient in den 1560er Jahren. ${ }^{4}$ Es vergingen allerdings mitunter Jahrzehnte, ehe diese Vorschriften umgesetzt und derartige Verzeichnisse flächendeckend geführt wurden. Für die Pfarrei St. Remigius setzen die Aufzeichnungen über die gespendeten Taufen im Jahr 1614 ein; es handelt sich gleichzeitig um die frühesten Quellen ihrer Art für das Bonner Stadtgebiet.

\section{Die Pfarrkirche St. Remigius}

St. Remigius war eine von vier Bonner Pfarrkirchen. Sie war Mittelpunkt des mit Abstand größten und bevölkerungsreichsten Sprengels ${ }^{5}$ und spielte allein schon von daher eine beherrschende Rolle in der ganz überwiegend katholischen Stadt. Die Anfänge von Kirche und Pfarrei datieren spätestens ins 


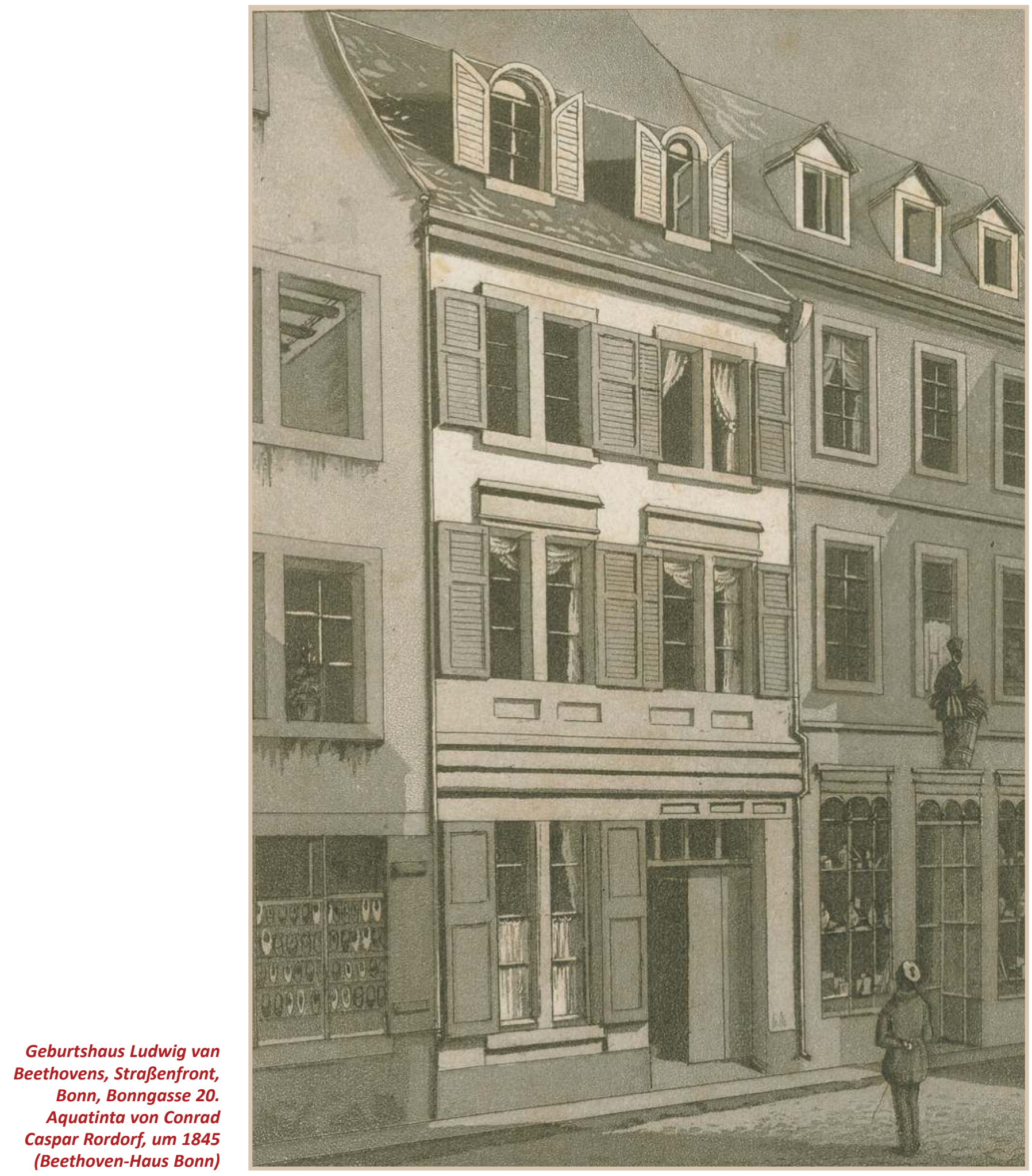

34 | Norbert Schloßmacher

(C) 2020 by Böhlau Verlag GmbH \& Cie. KG, Köln

https://doi.org/10.7788/9783412519704 | CC BY-NC 4.0 
8. Jahrhundert; sowohl die Ersterwähnung im Jahre 795 als auch der archäologische Befund einer kleinen Saalkirche aus dieser Epoche sprechen dafür. ${ }^{6}$ Auf ein möglicherweise noch höheres Alter deutet das Patrozinium hin: Der fränkische Bischof Remigius (um 436-533), als dessen bekannteste und geschichtsträchtigste Tat zweifellos die Taufe des Merowingerkönigs Chlodwig (um 466 - 511) galt und gilt (um 498), zählte - gemeinsam mit dem ebenfalls in Bonn verehrten HI. Martin - zu den beliebtesten Heiligen im Frankenreich. Zahllose Kirchen im französisch- wie im deutschsprachigen Raum wurden nach ihnen benannt.

Endgültig seit Beginn des 14. Jahrhunderts waren Kirche und Pfarrei St. Remigius im Besitz des Bonner Cassiusstifts. Später wurde die Pfarrstelle förmlich in das Stift inkorporiert. So verwaltete jeweils ein Stiftsherr das Pastorat, mit dem in der Regel auch das einflussreiche und repräsentative Amt des Dechanten verbunden war. Noch im 17. Jahrhundert hieß es aufgrund des großen Prestiges der Pfarrstelle, dass sich auf dieses Amt nur "hervorragende Männer ... bewerben können."7 Die Baulast teilte sich das Stift mit der Stadt, da auch sie das Kirchengebäude nutzte. Unter anderem war in der Sakristei zeitweise das städtische Archiv untergebracht, und der Turm wurde von der Stadtwache genutzt. ${ }^{8}$

Die zahlreichen an St. Remigius verorteten Stiftungen, Kongregationen, Bruderschaften und Sodalitäten machten die Pfarrei zu einem Zentrum katho-

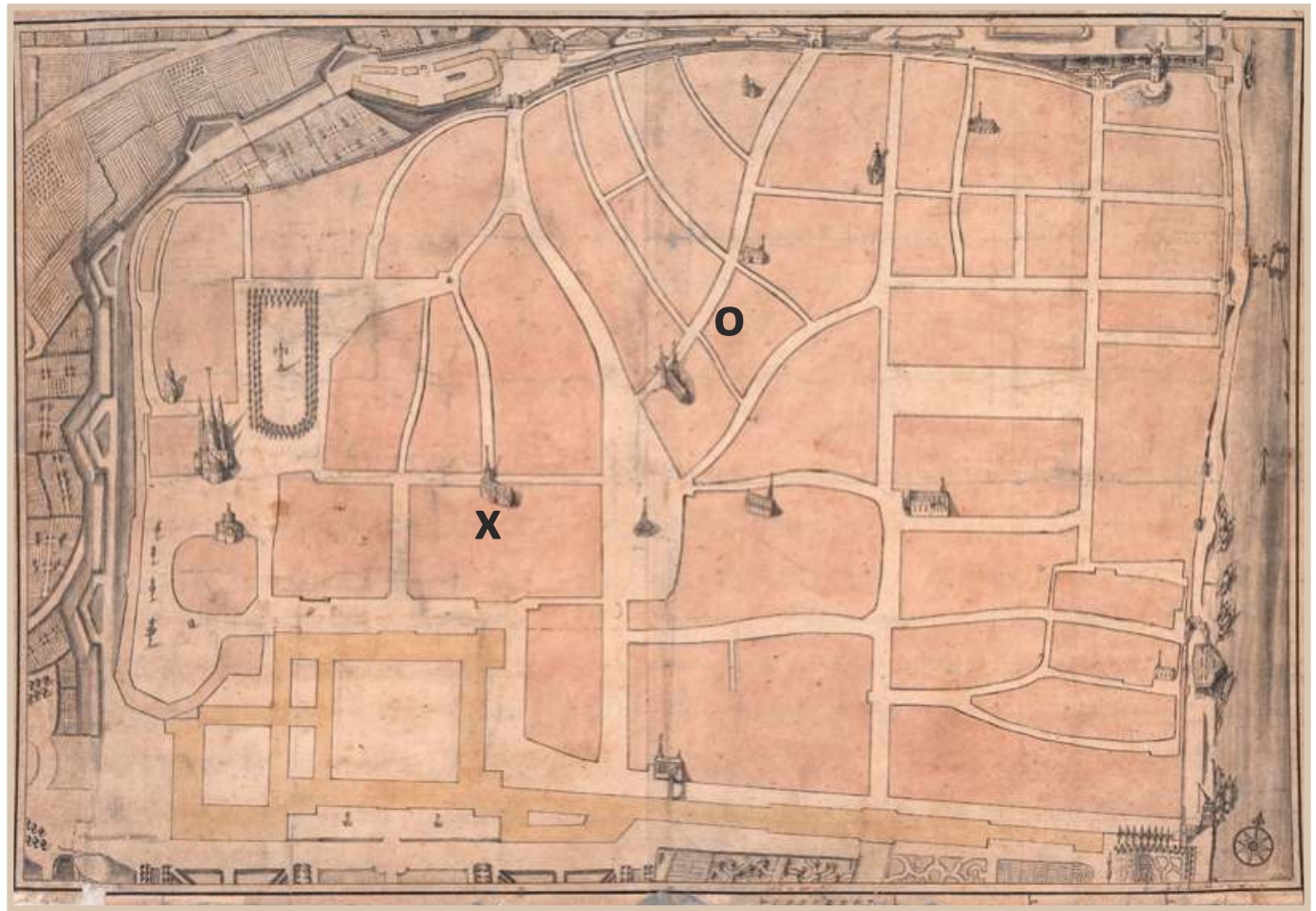

Die Taufe Ludwig van Beethovens am 17. Dezember 1770 in der Pfarrkirche St. Remigius zu Bonn | 35 (C) 2020 by Böhlau Verlag GmbH \& Cie. KG, Köln

https://doi.org/10.7788/9783412519704 | CC BY-NC 4.0
Stadtplan von Bonn von Hermann Sandfort, um 1780. (Stadtarchiv Bonn) Eingezeichnet wurden die Pfarr-, Stifts- und Klosterkirchen.

x Pfarrkirche St. Remigius o Geburtshaus Ludwig van Beethovens 


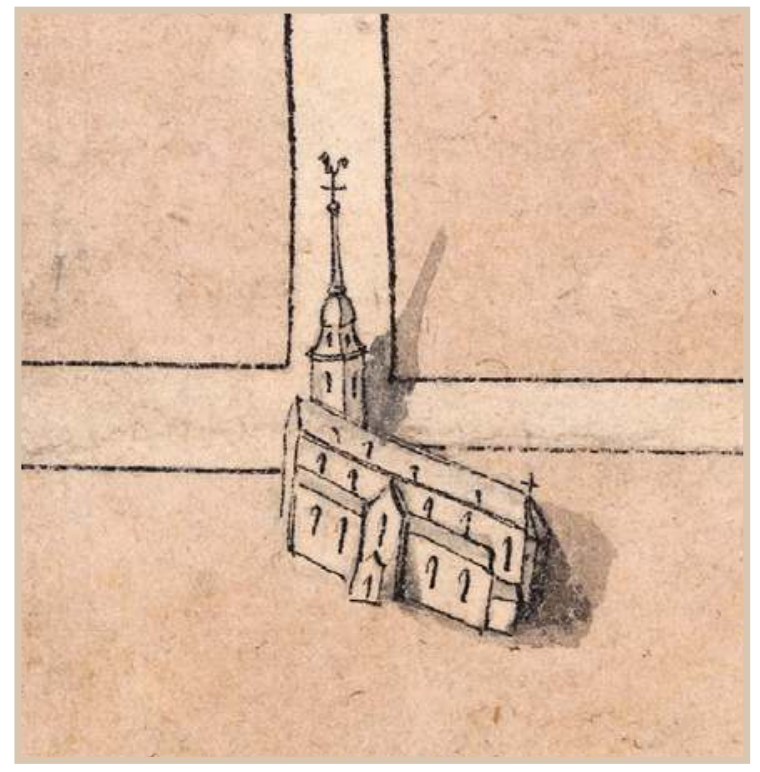

lisch-bürgerlichen Lebens in der Stadt. Innerhalb des Gebietes der Kirchengemeinde bestanden zudem zahlreiche geistliche, das kirchliche Leben der Stadt prägende Einrichtungen und Institutionen, ${ }^{9}$ hier in der Reihenfolge ihrer Entstehung: Neben einigen Beginenkonventen, die im 18. Jahrhundert allerdings nicht mehr bestanden, sind zu nennen die 1258 erstmals erwähnte, im Zweiten Weltkrieg zerstörte Gertrudiskapelle am Rheinufer, in der Brüdergasse das 1274 gegründete Minoritenkloster und an der heutigen Engeltalstraße das wohl erst im 14. Jahrhundert entstandene Kloster Engelthal (Augustinerchorfrauen). Frühneuzeitliche, im Zusammenhang mit der Katholischen Reform (Gegenreformation) von den geistlichen Landesherrn initiierte Gründungen waren Ende des 16. Jahrhunderts der Jesuitenkonvent, der sich im 17. Jahrhundert in der Bonngasse (Namen-Jesu-Kirche) etablierte und auch das Bonner Gymnasium unterhielt, das

Pfarrkirche St. Remigius aus dem Stadtplan von Hermann Sandfort (Ausschnitt). Der Kirchturm befindet sich gegenüber dem Eingang in die Acherstraße (Stadtarchiv Bonn)
1618 installierte Kapuzinerkloster (an der heutigen Kapuzinerstraße), von dem aus die seit 1699 belegte und bis heute gepflegte Wallfahrt nach Kevelaer ihren Anfang nahm, das 1624 eingerichtete Franziskanerkloster (an der heutigen Franziskanerstraße), unter anderem Sitz des hochadligen Michaelsordens und der gleichnamigen Bruderschaft, der 1629 ins Leben gerufene Konvent von Kapuzinerterziarinnen (Kapuzinessen, an der heutigen Ecke Kölnstraße/ Bertha-von-Suttner-Platz) und schließlich das 1664 errichtete Haus der Congrégation de Notre-Dame(Welschnonnen), eine primär derMädchenbildung verpflichtete Gemeinschaft (an der heutigen Welschnonnenstraße). Der Jesuitenkonvent wurde 1773 im Zusammenhang mit der Aufhebung des Ordens durch Papst Clemens XIV. aufgelöst. Die übrigen Häuser wurden 1802 im Zuge der Säkularisation geschlossen. Mit Ausnahme der ehemaligen Jesuitenkirche, heute Bischofskirche der Altkatholiken, und der früheren Minoritenkirche in der Brüdergasse haben sich keine baulichen Spuren dieser zahlreichen Einrichtungen erhalten.

Über die Ausstattung der früheren Hauptpfarrkirche Bonns ist wenig bekannt. Erhalten haben sich der Taufstein (siehe weiter unten) und die Rokoko-Kanzel, die sich heute im Bonner Münster befindet. ${ }^{10}$

Auch die eigentliche Baugeschichte ist aufgrund fehlender Quellen weitgehend unbekannt. Wiederholt kam es zu zum Teil massiven Zerstörungen an der Kirche und zu entsprechenden Wiederauf- und Umbauten. Abgesehen von nur wenigen, zudem detailarmen und teilweise wohl auch stilisierten Darstellungen auf Stadtplänen hat sich keine zuverlässige Abbildung der Remigiuskirche erhalten. Die jüngste und wohl auch authentischste Darstellung findet sich auf dem Stadtplan des Offiziers und späteren Mathematikprofessors an der

36 | Norbert Schloßmacher

(C) 2020 by Böhlau Verlag GmbH \& Cie. KG, Köln

https://doi.org/10.7788/9783412519704 | CC BY-NC 4.0 
Bonner Hochschule Hermann Sandfort. ${ }^{11}$ Sie zeigt ein vergleichsweise langgezogenes, wohl geostetes Langhaus auf einem kreuzförmigen Grundriss, offenbar eine dreischiffige Basilika mit Anbauten. Der Haupteingang befand sich wohl im seitlich, unmittelbar am Eingang zur Acherstraße gelegenen, zu Beginn des 18. Jahrhunderts neu errichteten Turm. Lediglich die markante welsche Turmhaube wird auf einem Kupferstich des Jahres 1777, entstanden im Zusammenhang mit dem verheerenden Brand der Bonner Residenz, wirklichkeitsgetreu abgebildet. ${ }^{12}$

Die Remigiuskirche exisitiert nicht mehr. Ein Brand infolge eines Blitzeinschlags hatte das Gotteshaus am 10. Mai 1800 schwer beschädigt, so dass es nur noch mit Einschränkungen genutzt werden konnte. Und nachdem im Zuge der Säkularisation im Jahre 1802 das in unmittelbarer Nähe der Remigiuskirche befindliche Minoritenkloster an der Brüdergasse geschlossen worden war, ${ }^{13}$ erhob man 1806 die nun funktionslos gewordene frühere Klosterkirche unter Übertragung des althergebrachten Patroziniums zur neuen Pfarrkirche. Der erste Gottesdienst dort fand am 2. März 1806 statt. ${ }^{14}$ Die bisherige Pfarrkirche wurde geschlossen und bald darauf, wohl im Jahre 1807, niedergelegt. ${ }^{15} \mathrm{Zu}$ den wenigen Ausstattungsstücken, die seiner Zeit aus der alten in die neue Remigiuskirche übernommen wurden, gehört der Taufstein. Ein solcher war in der vormaligen Klosterkirche nicht vorhanden, da sie ja nicht über das Taufrecht, das officium primum bzw. das ius baptizandi, verfügt hatte. Bei dem bis heute erhaltenen und genutzten marmornen Taufstein handelt es sich um eine Arbeit im Stil des Rokoko aus der Mitte des 18. Jahrhunderts, mit einem mit eleganten Rocailleformen reich gezierten Holzdeckel, bekrönt von einer den Heiligen Geist symbolisierenden Taube.

\section{Das Taufsakrament}

Auch wenn die in Teilen religionskritische Aufklärung, zumindest ihre Vorboten, bereits an die Tore der kurkölnischen Haupt- und Residenzstadt geklopft und teilweise auch schon Einlass gefunden hatte, so bestimmte die tiefe Verwurzelung sowohl der Obrigkeit wie auch des allergrößten Teils der Bevölkerung in traditionell christlich - hier katholisch - dominierten Wertvorstellungen weiterhin den Alltag. Insbesondere ihre äußeren Vollzüge, ihre Rituale und Abläufe, waren auch noch in der zweiten Hälfte des 18. Jahrhunderts nicht verhandelbar und prägend: Erst mit dem Empfang des Taufsakraments, so der tiefe Glaube, begann das Leben als Christ, allein die Taufe ermöglichte die Teilhabe an Christus und die als alternativlos angesehene Mitgliedschaft in der Kirche, die wiederum der notwendige Schlüssel zur Erlangung des Seelenheils war. Dem Ungetauften öffnete sich keine Himmelstür, nicht einmal ein Platz auf dem Kirchhof war ihm vergönnt. Von daher verwundert es nicht, welche Bedeutung die Taufe, und zwar gerade die Kindertaufe, für die Menschen besaß. Sie war aus kirchlicher wie sozialer Perspektive zwingend 


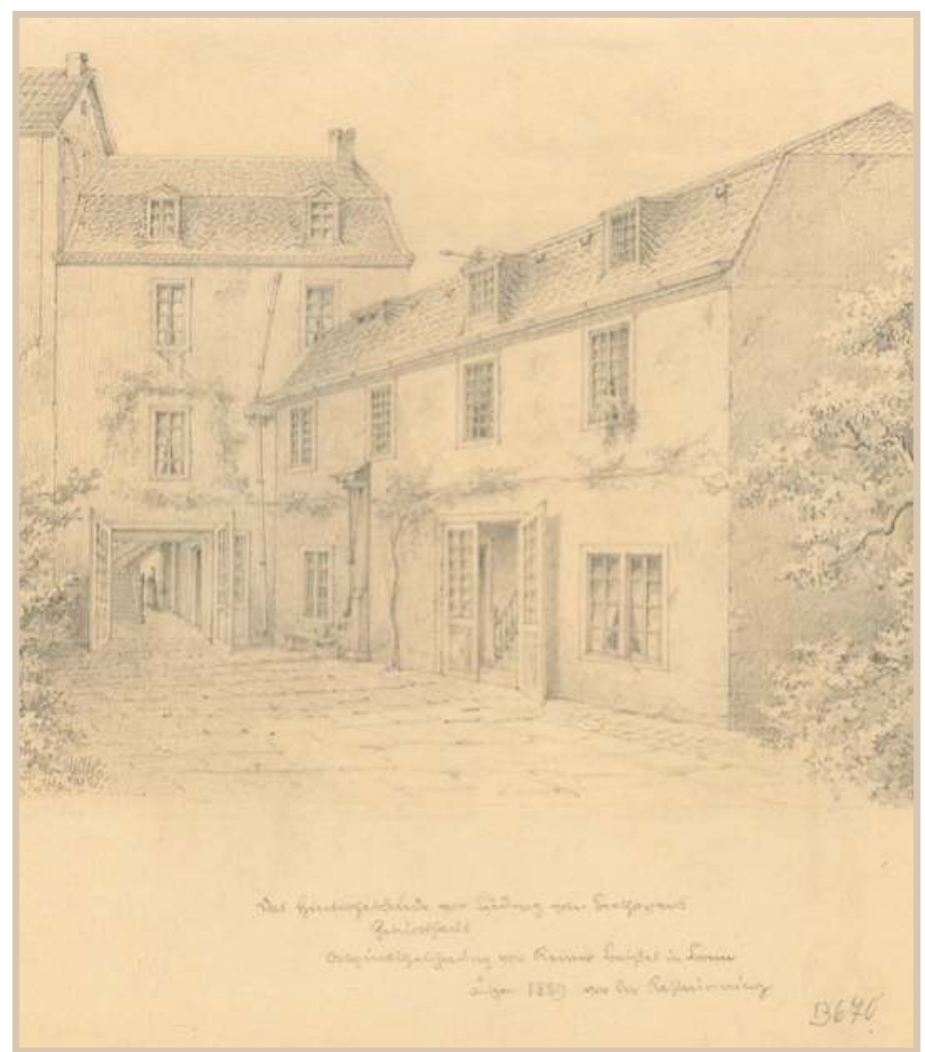

Geburtshaus Beethovens, Hinterhaus Bonngasse 20. Das Dachzimmer oben rechts gilt als das Geburtszimmer. Zeichnung von Reiner Beißel, 1889 (Beethoven-Haus Bonn)

\section{Die Geburt}

und wurde in der Regel schnellstmöglich nach der Geburt vollzogen. ${ }^{16}$ Die Praxis der unbedingten sofortigen Taufe stand dabei durchaus in der Kritik: In der medizinischen Literatur findet sich beispielsweise die Klage, dass aus lauter Sorge um das Seelenheil der Neugeborenen sogar schwache Kinder oft ungeachtet der Witterung zur Taufe getragen werden. So formulierte 1825 der Bonner Kreisphysikus Dr. Andreas Anton Velten (1775-1842):

„Der Gebrauch der Katholiken, ihre Kinder an demselben oder wenigstens am folgenden Tag der Geburt bei jeder Jahreszeit in die Kirche zur Taufe zu tragen, kostet nach meiner Meinung manchem derselben das Leben. ... Er wäre zu wünschen, daß unsere Kirche für diesen Gegenstand eine den Erfahrungen der Ärzte anpassende Veränderung träfe." ${ }^{17}$

Wir wissen zwar so gut wie nichts über die Religiosität, über den Grad der Frömmigkeit im Hause Beethoven; die enge Bindung an die Kirche und damit die zeitnahe Taufe wird jedoch auch in dieser Familie zu keinem Zeitpunkt in Frage gestellt worden sein.

Es ist davon auszugehen, ohne dass hierüber Klarheit besteht, dass Ludwig am Sonntag, dem 16. Dezember 1770, das Licht der Welt erblickt hatte. Es war der dritte Adventssonntag, der mit Blick auf das näher rückende Fest der Geburt Christi und den entsprechenden Eingangsvers (Introitus) des Gottesdienstes Gaudete (Freuet euch) heißt und den allgemeinen Ernst der adventlichen Bußund Fastenzeit unterbricht: ${ }^{18}$ Ludwig van Beethoven, wahrscheinlich ein Sonntagskind, welch schöner Gedanke.

Etwas anderes als Hausgeburten gab es in jener Zeit nicht; meist war die Küche der Ort des Geschehens. - Der bis heute als Geburtszimmer Ludwig van Beethovens identifizierte Raum im Bonner Beethoven-Haus war jedoch zweifellos keine Küche. - Eine ärztliche Unterstützung bei der Geburt war schon aus ökonomischen Gründen eine große Ausnahme, selbst die Hinzuziehung einer Hebamme keine Selbstverständlichkeit. Daher wird - auch aufgrund der Erfahrungen mit dem früh verstorbenen ersten Kind - die Sorge der werdenden Eltern und entsprechend die Erleichterung nach der erfolgreichen Entbindung groß gewesen sein. 


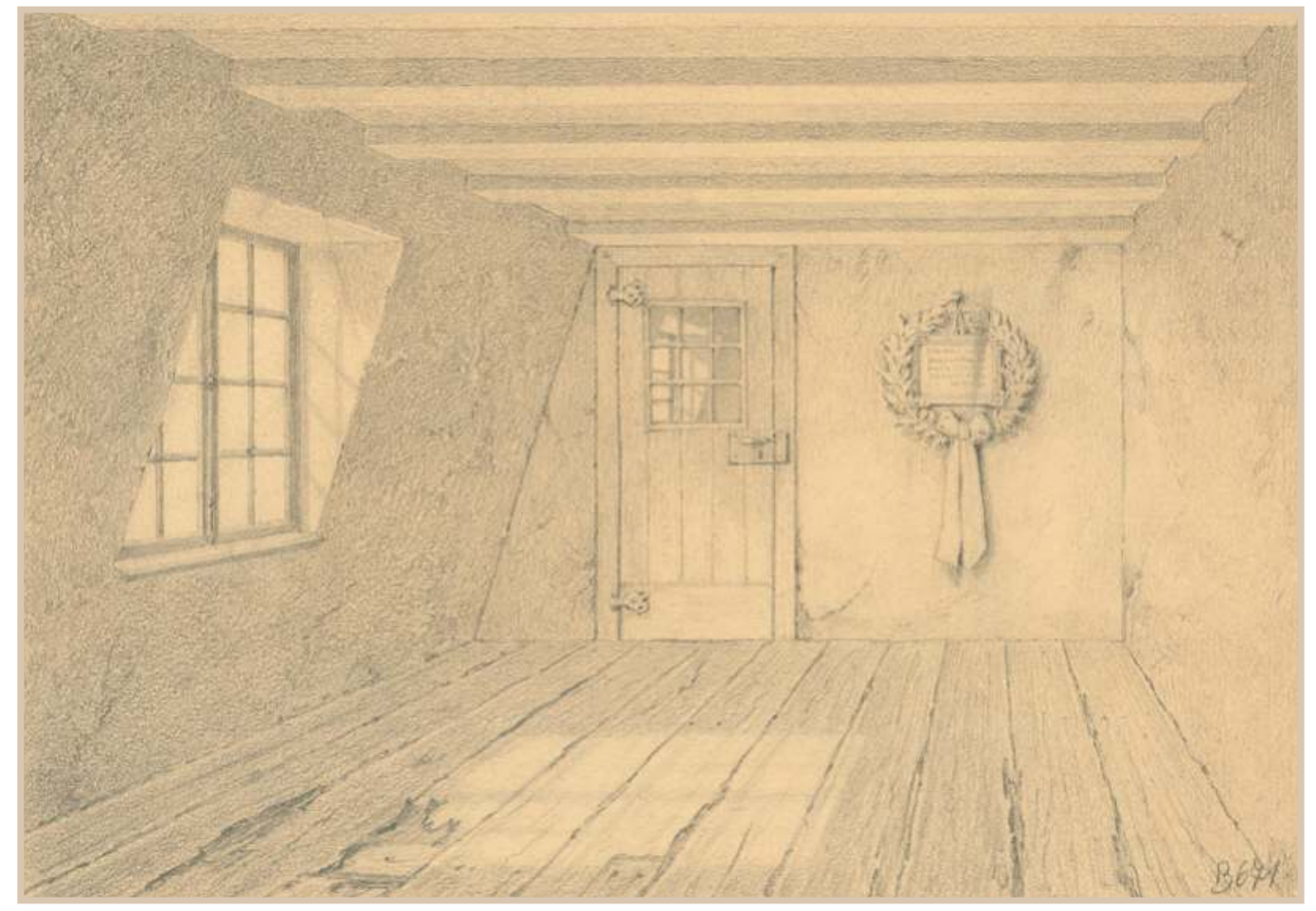

Das Geburtszimmer im Beethoven-Haus Bonn. Zeichnung von Reiner Beißel, 1889 (BeethovenHaus Bonn)

\section{Das Pfarrhaus}

Vielleicht noch an jenem Sonntag, vielleicht auch erst am Morgen des folgenden Tages, hatte sich ein Familienmitglied, vielleicht der Vater, vielleicht auch der Großvater, auf den Weg ins Pfarrhaus gemacht, um - vermutlich im "Ansprach-Zimer" - einen zeitnahen Termin für die Taufe zu erbitten. Dieses Pfarrhaus, Haus zum Ahren genannt, lag in der Remigiusstraße 1 (vor 1870 Nr. 36, 1773 Nr. 111); Bauzeichnungen des Erdgeschosses und der ersten Etage sind überliefert. ${ }^{19}$ Es war erst wenige Jahre zuvor neu errichtet worden. 1766 hatte Kurfürst Maximilian Friedrich von Königsegg-Rothenfels (1708-1784, Landesherr seit 1761) Bürgermeister und Rat der Stadt Bonn aufgefordert, eine Kollekte unter den Pfarrangehörigen zur Finanzierung eines Neubaus durchzuführen. ${ }^{20}$ Auch der "Capellmeister H[err] van Beethoven", gemeint ist der Großvater des Täuflings, wohnhaft "Bonngasse", findet sich in der "Collections Roll zu Auferbawung des newen Pastorat Hausses". ${ }^{21}$ Das Pfarrhaus stand neben dem Eckhaus zur Fürstenstraße, gleich beim Eingang zum seinerzeit größten Kirch- bzw. Friedhof der Stadt, der die Pfarrkirche umgab, und der erst 1787 aufgrund eines kurfürstlichen Erlasses geschlossen wurde. Diesem Kirchhof ist auch die ungewöhnliche Form des Remigiusplatzes geschuldet. Das ehemalige Pfarrhaus, das schon bald nach dem Abriss der alten Remigiuskirche umgewidmet wurde und von dem sich eine Fotografie aus der Zeit um 1900 überliefert hat, wurde 1905 durch einen prächtigen Jugendstil-Neubau ersetzt. ${ }^{22}$ 

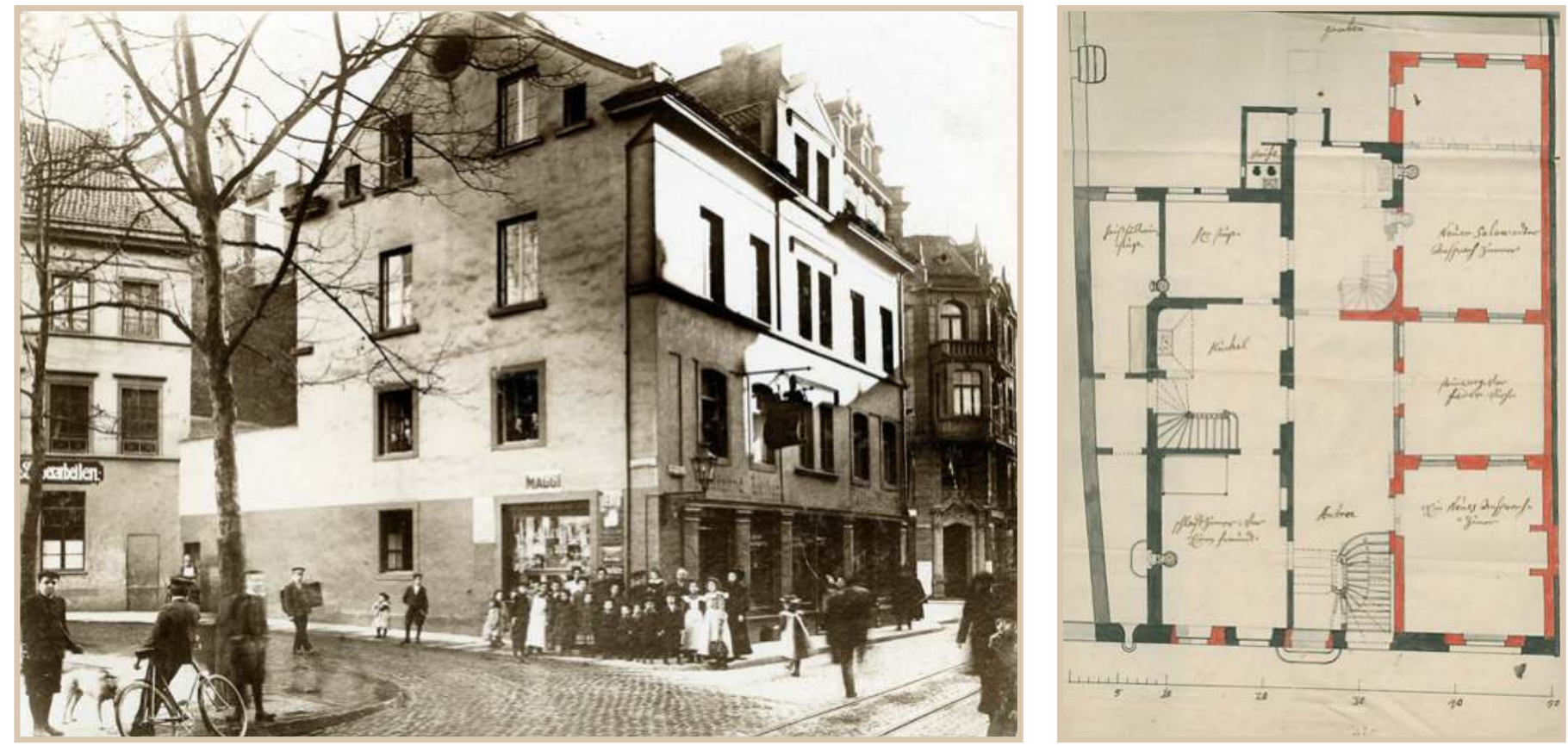

Haus Remigiusstraße 1, kurz vor 1770 als Pfarrhaus von

St. Remigius erbaut, 1905 niedergelegt. Fotografie von Carl Schaaf, um 1900 (Stadtarchiv Bonn)

Bauzeichnung des Erdgeschosses des Ende der 1760 er Jahre erbauten Pfarrhauses von St. Remigius, Remigiusstraße 1. Unten rechts das neue "Ansprach-Zimer" (Stadtarchiv Bonn)

\section{Taufgesellschaft und Familie van Beethoven}

Wann die eingangs erwähnte kleine Schar an diesem Wintertag mit dem Neugeborenen aufbrach, ist nicht bekannt. Abgesehen von dem einen oder anderen frühmorgendlichen Gottesdienst wird die Kirche den ganzen Tag für die Taufspendung zur Verfügung gestanden haben.

Zur Taufgesellschaft gehörten zweifellos der Vater, Johann van Beethoven, sowie die beiden Paten, die Nachbarin Gertrud Baum und Ludwig van Beethoven, der Großvater, möglicherweise auch seine Frau, Ludwigs Großmutter. ${ }^{23}$ Die Kindsmutter war nicht dabei, sie hatte als Wöchnerin das Bett zu hüten. Die Großeltern mütterlicherseits waren bereits verstorben (s. weiter unten). Auswärtige Verwandte hatten die Nachricht von der Geburt des Kindes gewiss noch gar nicht erhalten. Darüber, wer möglicherweise sonst noch zur Begleitung gehörte - Nachbarn, Freunde, Verwandte, Kollegen des Vaters -, lässt sich allenfalls spekulieren.

Werfen wir zunächst einen Blick auf die Familie:24 1733 beginnt die Verbindung zwischen Bonn und der Familie van Beethoven: Im März diesen Jahres engagierte Kurfürst Clemens August (1700-1761, Landesherr seit 1723), den im Januar 1712 im heute belgischen Mechelen geborenen Ludwig (Louis) van Beethoven (d. Ä.) für seine Bonner Hofkapelle. Louis war das zweite von vier Kindern des Mecheler Bäckermeisters Michael van Beethoven (16841749) und dessen Frau Maria Louise Stuyckers (1685-1749), die nach einer Insolvenz 1739 vor ihren Gläubigern flohen, später nach Bonn zogen ${ }^{25}$ und dort auch verstarben. Seit etwa 1733 lebte auch deren älterer Sohn Kornelius

40 | Norbert Schloßmacher

(C) 2020 by Böhlau Verlag GmbH \& Cie. KG, Köln

https://doi.org/10.7788/9783412519704 | CC BY-NC 4.0 
(1708-1764) in Bonn, wo er zweimal heiratete, aber keine Kinder hinterließ. ${ }^{26}$ Sein jüngerer Bruder Ludwig war von früher Kindheit an in Chören und Orchestern tätig gewesen, zuletzt an der LambertusKathedrale in Lüttich. In Bonn war er zunächst als Sänger, seit dem Regierungsantritt von Kurfürst Maximilian Friedrich (1761) als Hofkapellmeister tätig. Im Nebenerwerb betrieb einen Weinhandel.

Bereits wenige Monate nach seinem Umzug nach Bonn, am 7. September 1733, heirateten Ludwig van Beethoven (d. Ä.) und Maria Josepha Poll (um 1714-1775) in St. Remigius in Bonn. ${ }^{27}$ Sie hatten drei Kinder. Das jüngste war der 1739 oder 1740 geborene Johann, der Vater des Täuflings Ludwig, um dessen Herkunft sich manche Gerüchte ranken, insbesondere da

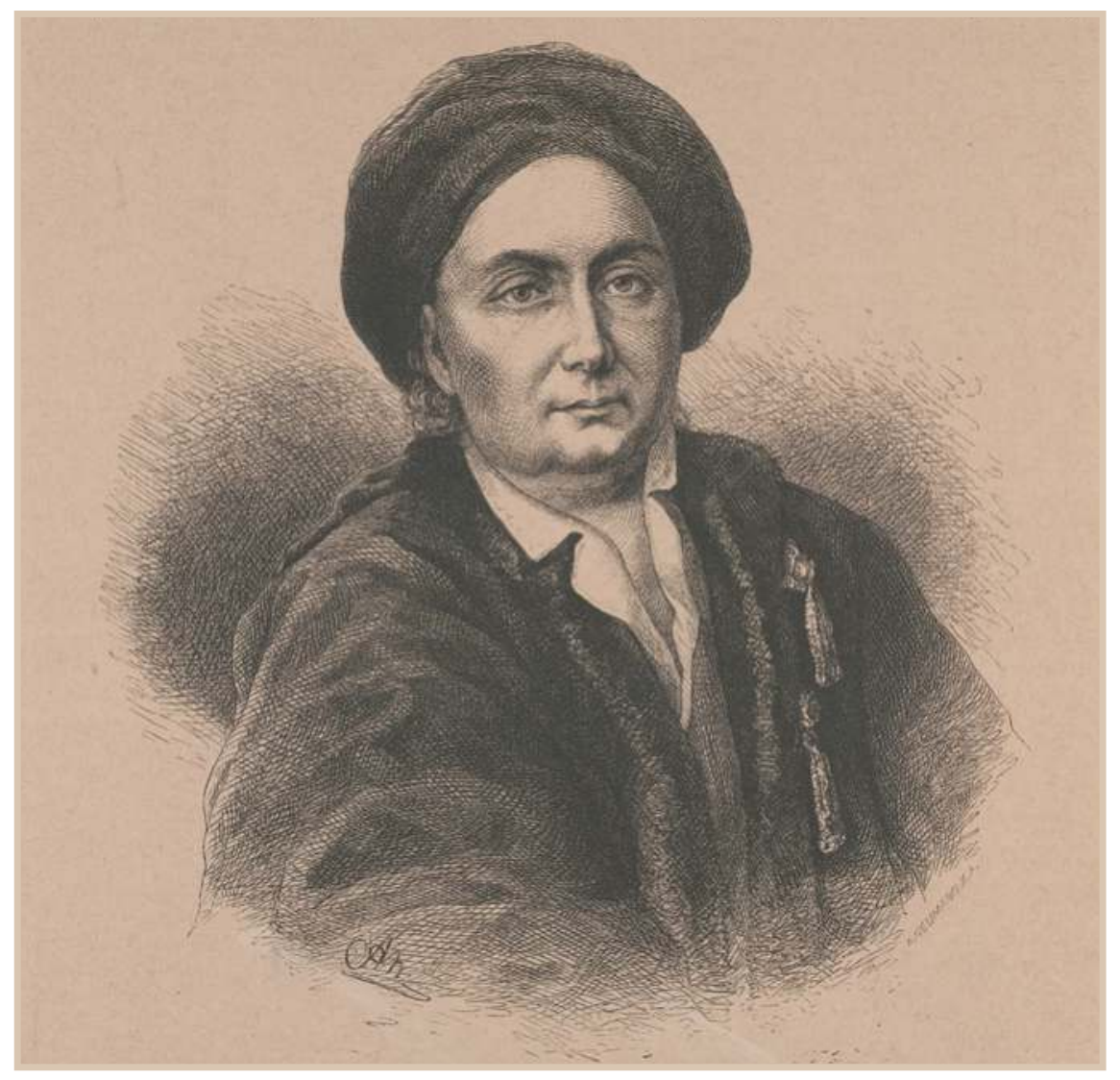
für ihn kein Taufeintrag, weder in

Bonn noch in der Region, gefunden werden konnte. So gibt es - nicht belegbare - Mutmaßungen, dass Johann möglicherweise in der - nicht bekannten Heimat der Mutter zur Welt gekommen ist. ${ }^{28}$

Johann trat in die Fußstapfen seines Vaters und wurde 1756 als Sänger in den kurfürstlichen Dienst aufgenommen. Daneben erteilte er Musikunterricht. Am 12. November 1767 heiratete er in Bonn die am 19. Dezember 1746 getaufte - noch junge - Witwe Maria Magdalena Leym, geborene Keverich. ${ }^{29}$ Sie stammte aus Ehrenbreitstein, seit 1937 ein Stadtteil von Koblenz ${ }^{30}$, und war das sechste und jüngste Kind der Eheleute Anna Clara Westorff (1707-1768) und Johann Heinrich Keverich (1701-1759), ${ }^{31}$ Oberhofkoch im Dienste der Trierer Kurfürsten an deren Residenz in Ehrenbreitstein. Im Januar 1763, gerade 16 Jahre alt geworden, hatte sie den bedeutend älteren kurfürstlichen Kammerherrn Johann Leym geheiratet, der bereits 1765 verstarb.

Wohl über Bonner Verwandte, möglicherweise die Familie des Hofmusikers Rovantini32, hatte die junge Witwe Johann van Beethoven kennengelernt. Gleich nach der Hochzeit bezogen die Eheleute die bescheidene Wohnung in der Bonngasse. Insgesamt sieben Kinder sollten dem Paar zwischen 1769 und 1786 geboren werden, wovon lediglich drei das Erwachsenenalter erreichten:

Ludwig van Beethoven, der Großvater (1712-1773). Holzschnitt nach einem Gemälde von Wilhelm Amelius Radoux (Stadtarchiv Bonn) 
Neben dem Komponisten Ludwig die Brüder Kaspar Anton Karl van Beethoven (1774-1815), ${ }^{33}$ Vater von Ludwigs Neffen Karl (1806-1858), und Nikolaus Johann van Beethoven (1776-1848). ${ }^{34}$ Die Mutter starb am 17. Juli 1787, der Vater am 18. Dezember 1792, wenige Wochen, nachdem der Sohn Ludwig Bonn in Richtung Wien endgültig und auf Dauer verlassen hatte.

\section{Das Umfeld}

Die Umstände, in die Ludwig van Beethoven wenige Tage vor dem Weihnachtsfest des Jahres 1770 hineingeboren wurde, waren solide, aber wohl alles andere als glänzend. Das erste Kind der Eltern war früh verstorben, die Bewerbung des Vaters auf einen offenbar attraktiven Posten in Lüttich gescheitert. ${ }^{35}$ Und auch wenn die wirtschaftliche Situation keinesfalls prekär war, so war die junge Familie nicht auf Rosen gebettet. Immobilienbesitz vermochten sich die van Beethovens jedenfalls nicht anzueignen. Allein die zahlreichen Umzüge innerhalb des Bonner Stadtgebietes - insgesamt sieben Wohnungswechsel in zwei Jahrzehnten lassen sich nachweisen - gelten als Indiz für den allenfalls bescheidenen Wohlstand der Familie. ${ }^{36}$ Das Umfeld in der Bonngasse war überwiegend bürgerlich; die Gegend zählte stets zu den mittleren Wohnquartieren der Stadt. ${ }^{37}$ Lediglich vis-à-vis des späteren Beethoven-Hauses stand der repräsentative Gudenauer Hof, das einzige Adelspalais im Stadtzentrum. In dieser Bonngasse verbrachte Ludwig van Beethoven die ersten Jahre seiner Kindheit, ehe die Familie 1774 zunächst in eine Wohnung am Dreieck, dann 1776 (vor dem 2. Oktober) in die Rheingasse verzog. ${ }^{38}$

In Bonn hatte der Landes- und Stadtherr, Kurfürst und Erzbischof Maximilian Friedrich, genauer gesagt sein die Regierungsgeschäfte führender Minister Caspar Anton von der Heyden genannt Belderbusch (1722-1784), ${ }^{39}$ nach der glamourösen Epoche seines Vorgängers, des Wittelsbachers Clemens August, eine rigorose Sparpolitik eingeleitet. Sie hatte unter anderem zu einer deutlichen Verschlankung des kurfürstlichen Hofes, vor allem zur Reduzierung des Personals, und einem damit verbundenen Rückgang der Wirtschaftskraft wie der Bevölkerungszahl geführt. ${ }^{40}$ Etwa 12.000 Einwohner zählte die Stadt im Jahre 1770, ihr Sozialprofil war äußerst vielschichtig: ${ }^{41}$ Das Spektrum reichte von dem in entsprechenden Stadthöfen lebenden kurkölnischen Adel, dem höheren Klerus und einigen wenigen vermögenden Handelsfamilien, die man der Oberschicht zurechnen kann, über eine äußerst differenzierte Mittelschicht mit den Familien der Beamtenschaft, der - schrumpfenden Zahl an - Hofbediensteten, dem mittleren und niederen Klerus, sowie den Kaufleuten und Handwerkern, bis hin zu einer etwa ein Viertel der Stadtbevölkerung umfassenden Unterschicht, deren wirtschaftliche Existenz nicht dauerhaft gesichert war. Sie lebte - überwiegend auch in topografischer Hinsicht - am Rand der Stadt. ${ }^{42}$ 


\section{Die Taufe}

Vielleicht am späten Vormittag, vielleicht auch erst am Nachmittag jenes 17. Dezember 1770, machte sich die Taufgesellschaft auf den Weg. Man ging die Bonngasse entlang, passierte Kirche und Kolleg der Jesuiten, erreichte die Sternstraße, wandte sich nach links zum Marktplatz, um gleich nach rechts über die Marktbrücke (die keine mehr war) in die Remigiusstraße einzubiegen. Nach wenigen Schritten war das Portal der Remigiuskirche erreicht.

Welcher der an St. Remigius tätigen Priester das Taufsakrament spendete, ist nicht überliefert. Pfarrer an St. Remigius war seiner Zeit Peter Isbach (1739-1782), ein gebürtiger Bonner, dem 1766 in vergleichsweise jungen Jahren diese bedeutende Pfarrei übertragen und der bereits 1767 mit dem Amt des Dechanten betraut worden war. Isbach stammte aus dem Kreis der Kanoniker des Bonner Cassiusstifts ${ }^{43}$ und galt "als Eiferer für die Ehre Gottes und als ausgezeichneter Prediger". ${ }^{44}$ Möglicherweise war es aber auch einer der an St. Remigius tätigen Kapläne, der die liturgische Handlung vornahm.

Die maßgeblichen Elemente der Taufzeremonie sind über die Jahrhunderte hinweg im Kern die gleichen geblieben: Das stellvertretend für den Täufling gesprochene Taufversprechen seitens der Paten, mit der Absage an das Böse und dem Bekenntnis zum Glauben an den dreifaltigen Gott, die Segnung mit geweihtem Öl, das Entzünden der Taufkerze, das symbolische Anlegen des weißen Taufkleids, das „im Kölner Taufritus zu einer Kopfbinde oder zu einem Leinentüchlein (mitra seu linteolum) zusammengeschrumpft" ${ }^{\prime \prime 5}$ war, sowie das Übergießen mit geweihtem Wasser über dem Taufbecken, das, wie erwähnt, in die heutige Remigiuskirche übertragen wurde und bis heute seinen Zweck erfüllt. - Übrigens existieren drei solcher Kopfbinden bzw. Taufhäubchen, die allesamt Beethoven getragen haben soll. ${ }^{46}$

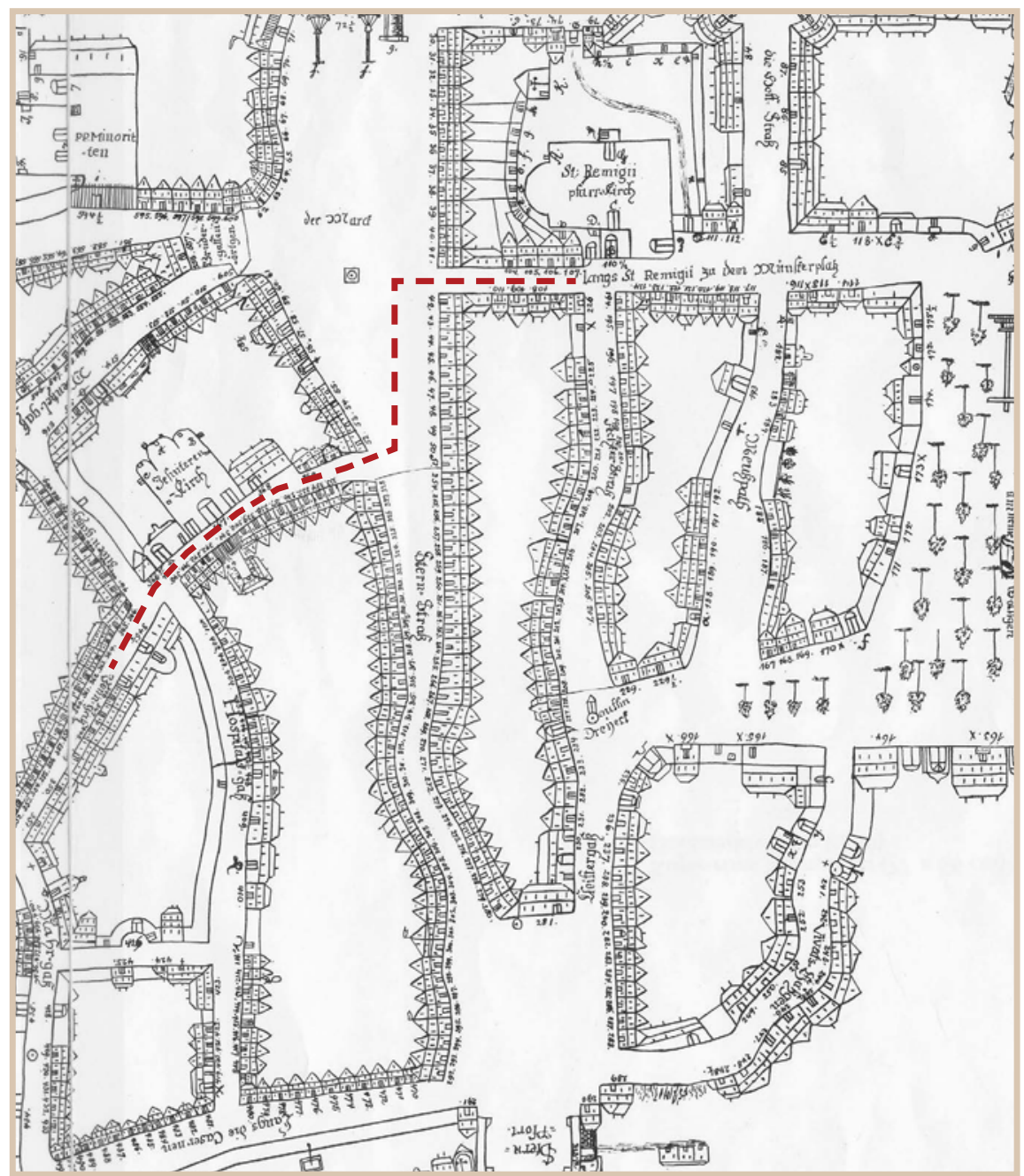

Stadtplan von Bonn von 1773 (Ausschnitt) mit Einzeichnung des Wegs der Taufgesellschaft vom Geburtshaus in der Bonngasse über den Markt zur Remigiuskirche (Kopie: Stadtarchiv Bonn) 


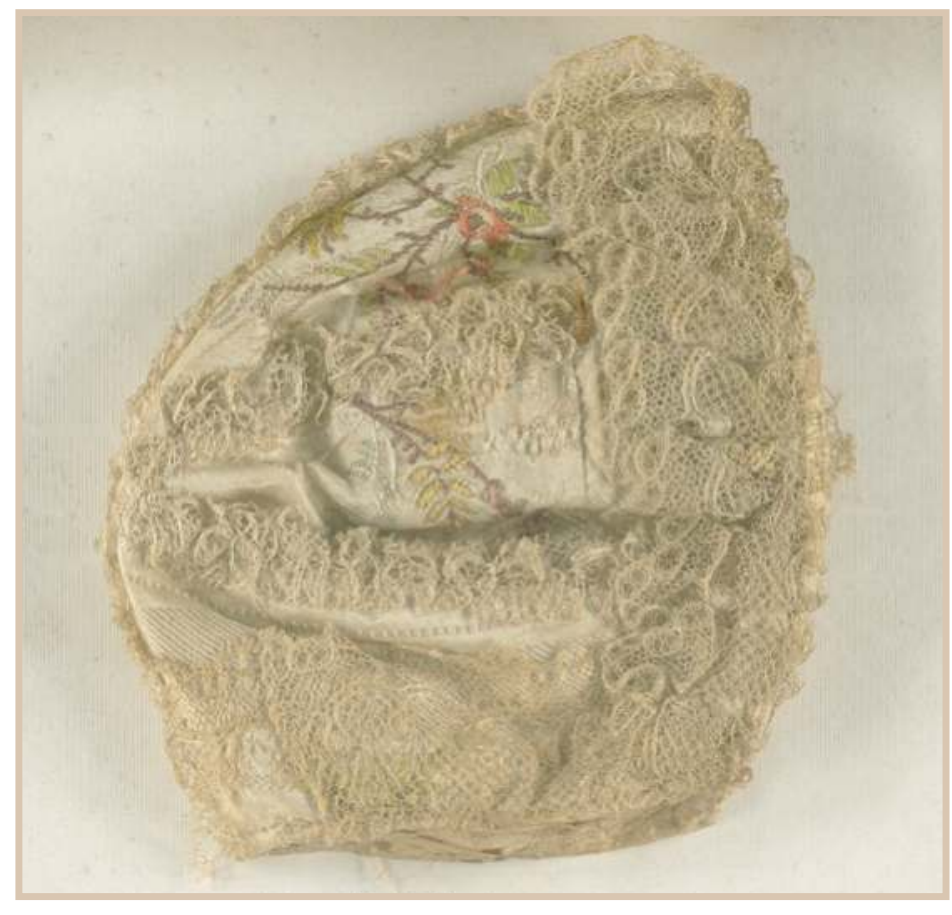

Beim Taufsakrament kam und kommt den Paten eine besondere Rolle zu: Üblicherweise handelt es sich um zwei Personen, nicht zwingend, aber in der Regel eine Frau und ein Mann, deren Aufgabe darin besteht, zum einen, falls notwendig, die erfolgte Taufe zu bezeugen, und zum anderen, Sorge für die christliche Erziehung des ihnen anvertrauten Kindes zu tragen und dabei die Eltern zu unterstützen. Oft stand hinter derWahl der Taufpaten auch die Überlegung, dass diese gegebenenfalls auch in Lebenskrisen intervenierend und mit Rat und Tat helfend eingreifen sollten.

Dem jungen Ludwig standen sein Großvater Ludwig und Gertrud Baum, geborene Müller, als Paten zur Seite. Seinen Großvater, der bereits drei Jahre nach der Geburt seines Enkels verstarb, hat der Komponist stets in hohen Ehren gehalten. Gertrud Baum war die Ehefrau des kurfürstlichen Kellerschreibers

Eines von drei angeblichen Taufhäubchen Beethovens. Es handelt sich um dasjenige Exemplar mit der glaubwürdigsten Provenienz; es stammt aus dem Besitz der Familie Wegeler (Beethoven-Haus Bonn, Sammlung Wegeler) und späteren Kellermeisters Johann Baum. ${ }^{47}$ Sie waren unmittelbare Nachbarn der van Beethovens, gewiss befreundet oder zumindest gut bekannt, und wohnten im Haus Bonngasse 18 (vor 1870 Nr. 516, 1773 Nr. 364). ${ }^{48}$ - Bei dem früh verstorbenen Erstgeborenen Ludwig Maria war ebenfalls eine Nachbarin und Gattin eines Hofbediensteten, Anna Maria Courtin, geborene Lohe, Patin gewesen. Sie war die Frau des Schlossermeisters und Hofschlossers Johann Courtin. ${ }^{49}$

Nach Abschluss des Gottesdienstes machte sich die Taufgesellschaft wieder auf den Weg nach Hause. Ob und wie der Tauftag weiter gestaltet wurde, hat sich wie so Vieles aus der Kindheit des großen Komponisten nicht überliefert. Denkbar, aber nicht gesichert ist, dass die Patin Gertrud Baum zu einer kleinen Feier in ihr Haus eingeladen hatte. ${ }^{50}$ Man stieß auf den Täufling an, ließ ihn hochleben und gab ihm viele gute Wünsche mit auf den Weg, nicht ahnend, welch ein Genie an jenem Montag, dem 17. Dezember 1770, in der Bonner Pfarrkirche St. Remigius das Sakrament der Taufe empfangen hatte.

\section{Der Taufeintrag}

Derweil hatte der Pfarrer für den ordnungsgemäßen Eintrag der Taufe in das entsprechende Kirchenbuch zu sorgen. Nur das Nötigste wurde festgehalten: in der Mitte der Zeile das Datum "1 $17^{\mathrm{ma}} X^{\text {bris" }}$ (septima decima Decembris), darunter der Name des Getauften "Ludovicus"; in der linken Spalte die Eltern "D[ominis] Joannes van Beethoven. et Helena Keverichs conjuges [Eheleute]";

44 | Norbert Schloßmacher

(C) 2020 by Böhlau Verlag GmbH \& Cie. KG, Köln

https://doi.org/10.7788/9783412519704 | CC BY-NC 4.0 


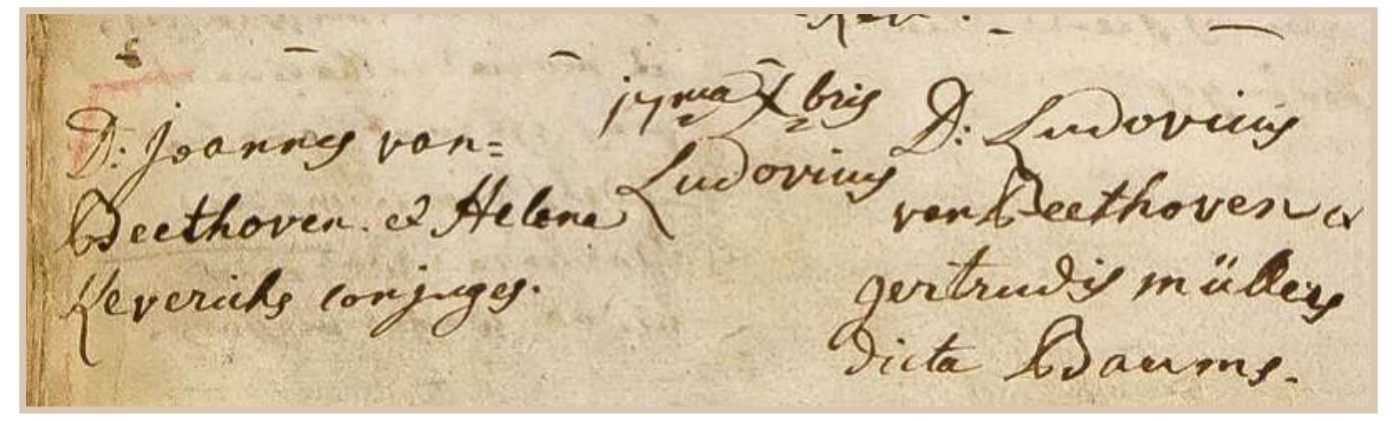

Taufeintrag Ludwig van Beethovens im Kirchenbuch von St. Remigius, links die Namen der Eltern, rechts die Namen der Taufpaten (Ausschnitt) (Stadtarchiv Bonn)

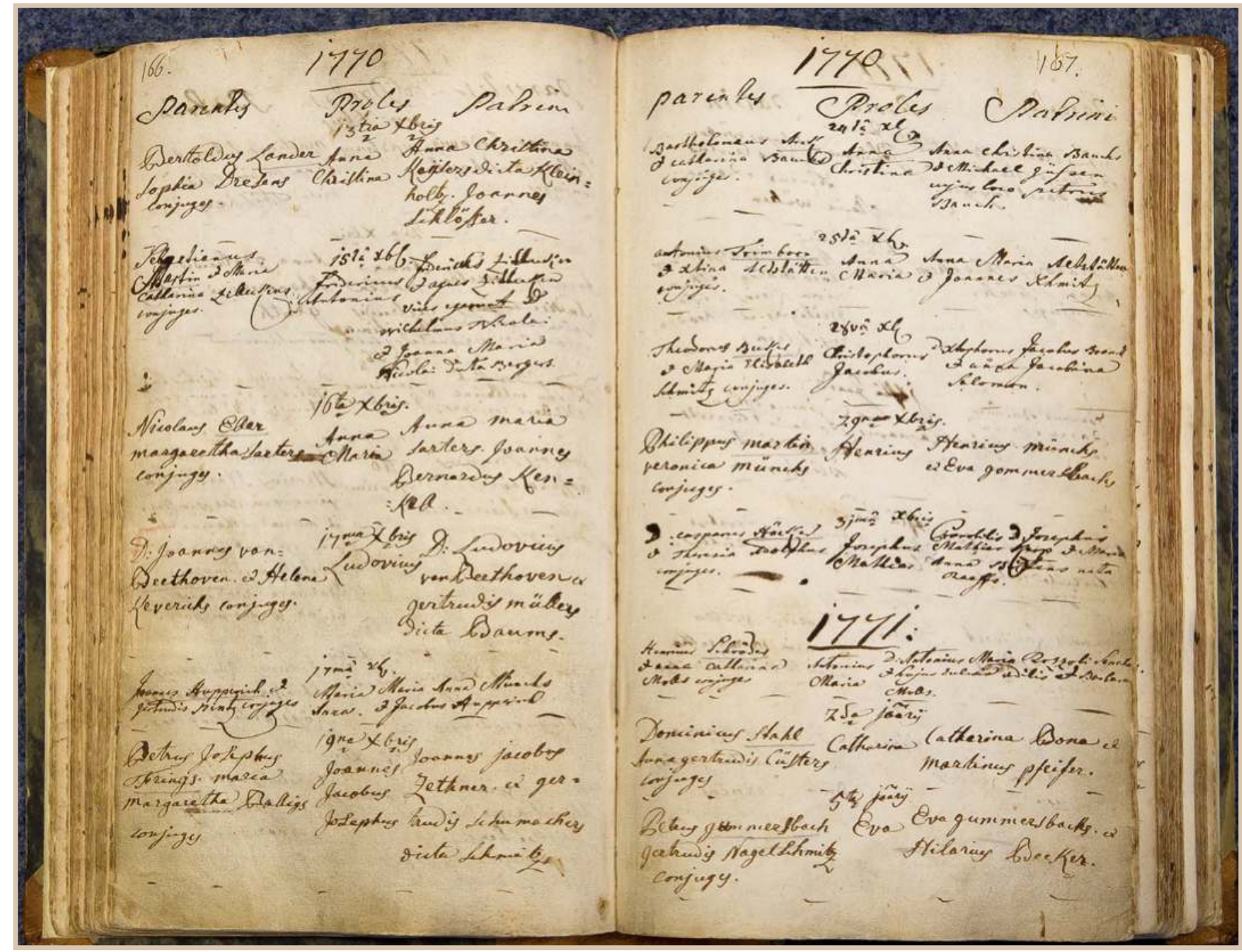

Aufgeschlagene Doppelseite des Taufregisters, linke Seite dritter Eintrag von unten: Der Taufeintrag Ludwig van Beethovens (Stadtarchiv Bonn)

Die Taufe Ludwig van Beethovens am 17. Dezember 1770 in der Pfarrkirche St. Remigius zu Bonn | 45 (c) 2020 by Böhlau Verlag GmbH \& Cie. KG, Köln

https://doi.org/10.7788/9783412519704 | CC BY-NC 4.0 


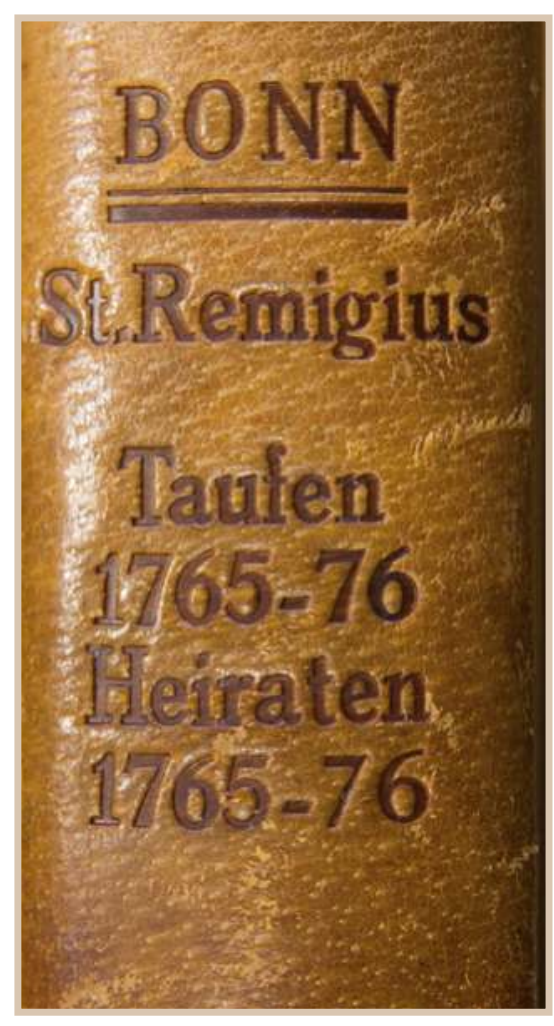

in der rechten die Namen der Paten, zunächst der Großvater "D[ominus] Ludovicus van Beethoven", sodann die Nachbarin "Gertrudis Müllers dicta [genannt] Baums". Mutter wie Taufpatin wurden also mit ihren Mädchennamen vermerkt, der Familienname gleichsam als Zusatz beigefügt. Bemerkenswert in diesem Zusammenhang und nur als Nachlässigkeit des Pfarrers zu erklären ist die Verwendung eines falschen Vornamens der Mutter (Helena), die sowohl bei ihrer Geburt, ihrer Heirat, der Geburt ihrer übrigen Kinder und auch bei ihrem Sterbeeintrag nie anders als Maria Magdalena hieB. ${ }^{51}$

1810 bat Beethoven seinen Freund Franz Gerhard Wegeler (17651848), ihm eine Kopie des Taufeintrags nach Wien schicken zu lassen. Beethoven bewegte sich seinerzeit auf Freiersfüßen, doch die Auserkorene, Therese Malfatti (1792-1851), wies den Antrag zurück. ${ }^{52}$

Auf die Rückseite dieser beglaubigten Abschrift notierte Beethoven eigenhändig: "1772", sowie den Kommentar: "Es scheint der Taufschein nicht richtig, da noch ein Ludwig vor mir, eine Baumgarten war glaube ich meine Pathin". Beethoven war lange Zeit davon überzeugt gewesen, erst 1772 geboren worden zu sein. Dies war sowohl der Unaufmerksamkeit in der Familie als auch einer Verwechslung mit seinem älteren, früh verstorbenen (1769) Bruder gleichen Namens geschuldet. Auch bei dem von seinem Vater bei Ludwigs erstem nachzuweisenden Konzertauftritt - Köln, 26. März 1778 - angegebenen Alter von

Kirchenbuch von St. Remigius, Rückeneinband mit Prägung (Stadtarchiv Bonn) sechs Jahren handelte es sich weniger um einen Schwindel (Stichwort: Wunderkind) als vielmehr um einen Irrtum. ${ }^{53}$

Nach Beethovens Tod wurden zwei weitere Kopien des Taufeintrags angefertigt. Beide stehen in Bezug zu den schon früh einsetzenden Projekten einer Biografie des Komponisten. Den einen (vom 28. Juni 1827) erbat sich Franz Gerhard Wegeler, der von Stephan Breuning mit der Konzeption einer Lebensbeschreibung beauftragt worden war. ${ }^{54}$ Den zweiten (vom 2. Juli 1827) bestellte Tobias Haslinger über Nikolaus Simrock für die Wiener Biografen um Karl Holz und Anton Gräffer..$^{55}$ Beide wortgleichen Abschriften wurden von Oberbürgermeister Johann Martin Joseph Windeck (1765-1839) beglaubigt.

Der ursprüngliche und eigentliche Taufeintrag findet sich auf Seite 166 eines vorgebundenen, paginierten Folianten mit den Einbandmaßen $34 \mathrm{~cm}$ (Höhe) $x$ $21,5 \mathrm{~cm}$ (Breite) x 4,5 cm (Dicke). Neben Vorsatz- und Nachsatzpapier enthält der Band auf den ersten 342 Seiten die Taufeinträge der Pfarre St. Remigius für die Zeit vom 25. Dezember 1765 bis einschließlich 2. April 1776. Nach einigen Leerseiten folgen auf 113 weiteren Seiten, mit neu beginnender Zählung, die Notizen zu den Heiraten des gleichen Zeitraums, vom 17. Oktober 1765 bis 10. März 1776, wobei am Ende (p. 113) eine Heirat vom 18. Februar nachgetragen wurde. Die letzte beschriebene Seite, nachträglich mit der Seitenzahl 114 versehen, enthält schließlich - auf den Kopf gestellt - sechs Taufeinträge für die

46 | Norbert Schloßmacher

(C) 2020 by Böhlau Verlag GmbH \& Cie. KG, Köln

https://doi.org/10.7788/9783412519704 | CC BY-NC 4.0 


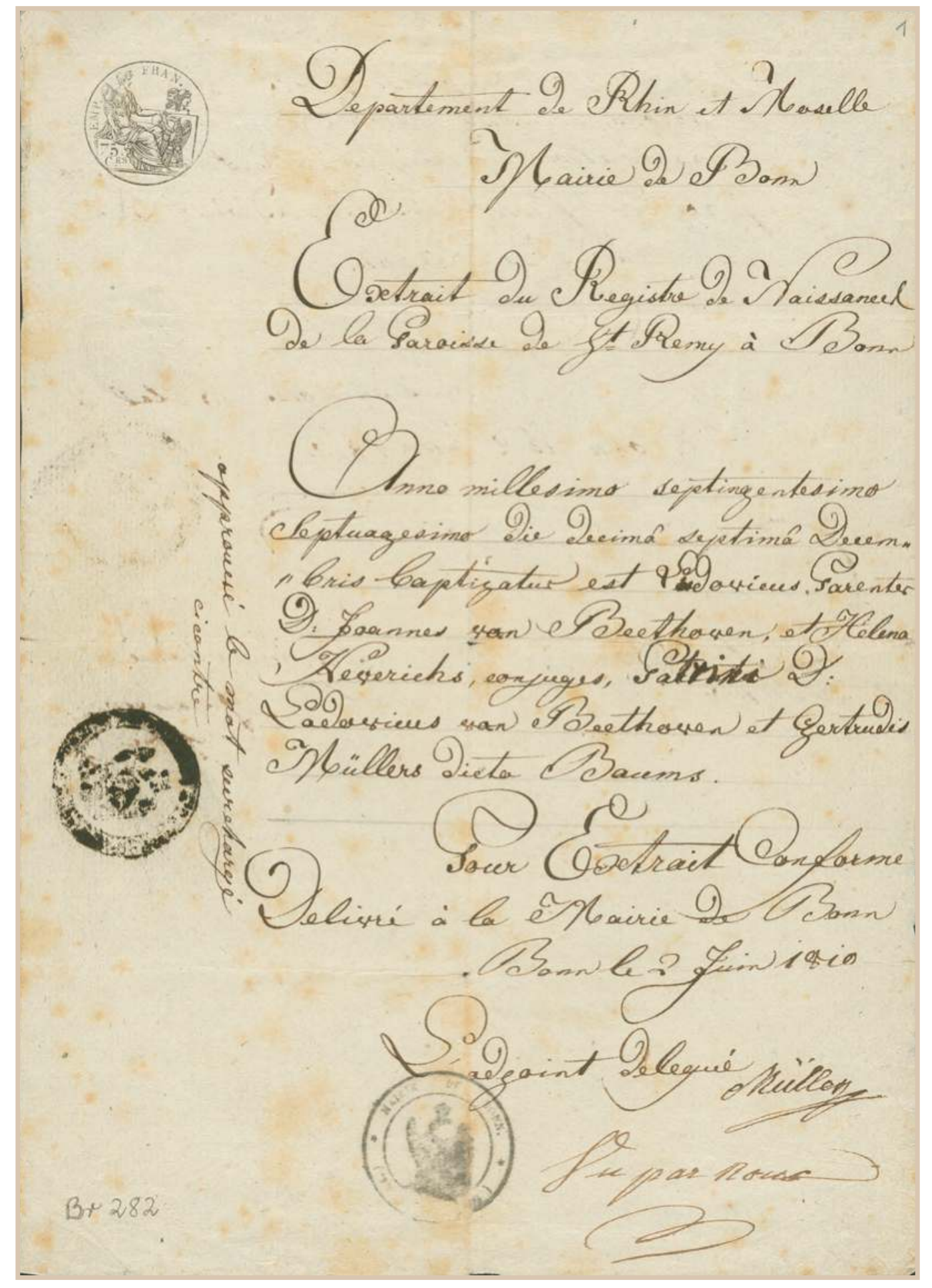

Auszug aus dem Taufregister von St. Remigius, Bonn, 2. Juni 1810

(Beethoven-Haus Bonn, Sammlung H. C. Bodmer) 
Taufeintrag Maria Anna Hupperichs im Kirchenbuch von St. Remigius, 17. Dezember 1770 (Stadtarchiv Bonn)

Zeit zwischen dem 2. und 7. April 1776. Der Band ist zu einem unbekannten Zeitpunkt restauriert worden, der schweinslederne Rücken scheint jüngeren Datums zu sein und trägt den geprägten Titel "BONN / St. Remigius / Taufen / 1765-76 / Heiraten / 1765-76". Er gehört zum Bestand von Stadtarchiv und Stadthistorischer Bibliothek Bonn und trägt die Signatur KB 4/35.

Dieses wie die übrigen Kirchenbücher der damaligen Stadt Bonn wurden 1798 bei Einführung der Standesämter dem Bonner Standesamt übergeben. 1934 kamen sie im Zusammenhang mit der Einrichtung der Beratungsstelle für Familien- und Sippenforschung als Teil der NS-Rassenideologie in den Bestand des Stadtarchivs. ${ }^{56}$

\section{Maria Anna Hupperich}

Betrachtet man das Taufregister genauer, so sieht man unterhalb des Eintrags für Ludovicus van Beethoven eine weitere Notiz vom selben Tag: Ebenfalls an jenem 17. Dezember 1770 wurde Maria Anna Hupperich über den Taufstein von St. Remigius gehalten. Ihre Eltern waren die Eheleute Johannes Hupperich und Gertrud, geborene Bintz. Taufpaten waren Maria Anna Münchs und Jakob Hupperich. Ob Maria Anna in einer gemeinsamen Zeremonie zeitgleich mit Ludwig getauft wurde oder in einem eigenen Gottesdienst zu einem späteren Zeitpunkt an jenem Tag, ist nicht bekannt.

Die Familie der Maria Anna Hupperich lebte mit größter Wahrscheinlichkeit in einem der so genannten Bogenhäuser an der nördlichen Stadtmauer, ${ }^{57}$ das heißt in einem der Armenquartiere der Stadt. Während über ihr Leben weiter nichts bekannt ist, gehört der am gleichen Tag und am gleichen Ort getaufte Ludwig van Beethoven zu den bekanntesten und berühmtesten Menschen überhaupt.

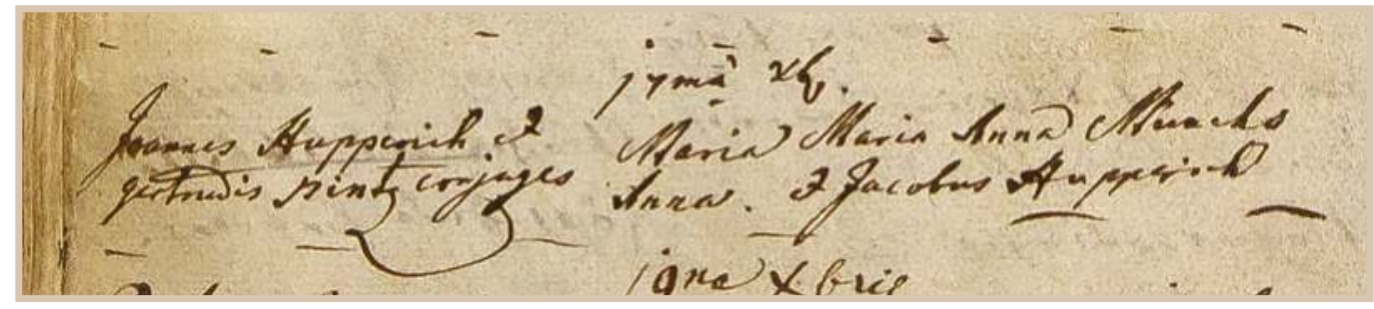

Der Beitrag erschien in einer unwesentlich anderen Fassung als kleine Monographie unter folgendem Titel: NORBERT SCHLOSSMACHER, Der erste Auftritt ... Ludwig van Beethovens Taufe im Kirchenbuch von St. Remigius. Faksimile und Kommentar (Jahresgabe des Vereins Beethoven-Haus 2019), Bonn 2019. Für die Genehmigung des QuasiWiederabdrucks sei dem Beethoven-Haus Bonn Dank gesagt.

Die bis heutige gültige straßenweise Nummerierung der Häuser findet sich erstmals im Adress-Buch der Stadt Bonn und der Gemeinde Poppelsdorf, Bonn 1870. Sie ersetzte die 1793 eingeführte durchgängige Häusernummerierung, nach der das Ge-

48 | Norbert Schloßmacher

(c) 2020 by Böhlau Verlag GmbH \& Cie. KG, Köln

https://doi.org/10.7788/9783412519704 | CC BY-NC 4.0 
burtshaus Beethovens die Nr. 515 trug. Vgl. Josef Dietz, Topographie der Stadt Bonn vom Mittelalter bis zum Ende der kurfürstlichen Zeit, 2 Bde (Bonner Geschichtsblätter 16/17), Bonn 1962/63, hier Bd. 1, S. 242. Eine erste Häusernummerierung findet sich in einem Einwohnerverzeichnis nebst Stadtplan von 1773; hier trägt das spätere Beethoven-Haus die Nummer 363 (s. Abb. auf dem Nachsatz). Eine Kopie dieses Plans in: Stadtarchiv Bonn (StAB), Ba 80; das Einwohnerverzeichnis in: ebd., Ku 34/1.

Die Taufe hatte am 2. April 1769 in der Pfarrkirche St. Remigius stattgefunden. Diese und alle übrigen Angaben zu Taufen, Heiraten und Sterben in Bonn stammen aus den jeweiligen, bei den Kirchengemeinden geführten Kirchenbüchern, die sämtlich zu den Beständen des Bonner Stadtarchivs gehören und im Folgenden nicht eigens nachgewiesen werden

Vgl. Friedemann Merkel, Kirchenbücher, in: Religion in Geschichte und Gegenwart 4, Tübingen 2008, Sp. 1160-1162; Alfred RINNERTHALER, Matrikel, in: Lexikon für Theologie und Kirche 6, Freiburg 1997, Sp. 1476. Im Kölner Raum war es der päpstliche Nuntius Ottavio Mirto Frangipani (1544-1612), der in seinem 1597 publizierten Directorium den Pfarrern ihre „Buchführungspflichten” noch einmal nachdrücklich auferlegte. Vgl. HANSGEORG MOLITOR, Das Erzbistum Köln im Zeitalter der Glaubenskämpfe (1515-1688), (Geschichte des Erzbistums Köln 3), Köln 2008, S. $479 f$.

Die genaue topographische Beschreibung des Sprengels bei GERMAN HUBERT CHRISTIAN MAASSEN, Geschichte der Pfarreien des Dekanates Bonn. I. Theil: Stadt Bonn, Köln 1894, S. 176; vgl. dort auch, soweit nicht anders angemerkt, insgesamt zur Bonner Kirchen- und Pfarrgeschichte. Vgl. auch Josef Herberg (Hg.), Kirchen in Bonn. Geschichte und Kunst der katholischen Pfarreien und Gotteshäuser, Petersberg 2011, zu St. Remigius S. 65-73. Ein Stadtplan mit Kennzeichnung der frühneuzeitlichen Pfarreinteilung als Anlage bei CHRISTIAN SCHLÖDER, Bonn im 18. Jahrhundert. Die Bevölkerung einer geistlichen Residenzstadt (Stadt und Gesellschaft 5), Köln/Weimar/Wien 2014.

Für eine detaillierte Baugeschichte von St. Remigius vgl. den Beitrag von GISBERT KNOPP in diesem Band

Zitiert nach ManfRed Peter KoCH, Die älteste Geschichte der Stadt Bonn aus dem Jahre 1656, verfasst von Adolph Sigismund Burman, Textausgabe - Übersetzung und Kommentar, Bonn 2011, S. 206

Vgl. Josef Niessen, Geschichte der Stadt Bonn, I. Teil, Bonn 1956, S. $139 f ., 198 f$.

Vgl. hierzu Manfred Groten u. a. (Hgg.), Nordrheinisches Klosterbuch. Lexikon der Stifte und Klöster bis 1815, Teil 1, Siegburg 2009, S. 326-448 (die im heutigen Bonner Stadtgebiet gelegenen Häuser).

Für das Folgende vgl., wie erwähnt, den Beitrag von GISBERT KNOPP in diesem Band

Hermann Sandfort (1752-1819), Ingenieur, Offizier, vornehmlich mit Vermessungsaufgaben betraut, zeitweilig Dozent und Professor an der Bonner Hochschule; vgl. MAx BRAUBACH, Die erste Bonner Hochschule. Maxische Akademie und kurfürstliche Universität 1774/77 bis 1798 (Academia Bonnensia 1), Bonn 1966, S. $189 f$

Vgl. hierzu KARL-HeInz StadeR, Der Brand der Bonner Residenz im Jahre 1777 und ihr Wiederaufbau in der zeitgenössischen Abbildung, in: Bonner Geschichtsblätter 28, 1976, S. 76-94.

Vgl. NORBERT SCHLOSSMACHER, „Alles ist wegen Aufhebung der Klöster und Stifter verstört ...". Das Personal der Bonner Stifte und Klöster am Vorabend der Säkularisation, in: Bonner Geschichtsblätter 53/54, 2004, S. 203-268, hier S. 241-244. 
Vgl. Regina Hönerlage und Thomas P. BeCKER, Die Aufzeichnungen der Anna Catharina Rederscheidt (1792-1817), in: Bonner Geschichtsblätter 43/44, 1993/94 (1996), S. 132-162, hier S. 151

Vgl. ebd

16 Vgl. EduARD Hegel, Das Erzbistum Köln zwischen Barock und Aufklärung, Vom Pfälzischen Krieg bis zum Ende der französischen Zeit (1688-1814) (Geschichte des Erzbistums Köln 4), Köln 1979, S. 272.

17 Das Zitat stammt aus einer 1825 verfassten Handschrift mit dem Titel Medizinische Topographie des Kreises Bonn, einer amtlichen Beschreibung des Distrikts aus medizinischer Sicht. Hier zitiert nach der Edition von DIETER KöRSCHNER, Medizinische Topographie des Kreises Bonn von Dr. Anton Velten (Veröffentlichungen des Stadtarchivs Bonn 40), Bonn 1988, S. 181

18 Der Eingangsvers - entnommen dem Brief des Apostels Paulus an die Philipper aus dem Neuen Testament (Phil 4, 4,5) - lautet: "Freut euch im Herrn zu jeder Zeit! Noch einmal sage ich: Freut euch! Denn der Herr ist nahe." reichend empfundene Wiederherstellung des Pfarrhauses nach dem Bombardement von 1689 beschwert; vgl. SchlöDER, Bonn im 18. Jahrhundert (wie Anm. 5), S. 31 Anm. 89. Und 1765 hatte der damalige Pfarrer Caspar Kemling noch einmal nachdrücklich auf die problematische Situation aufmerksam gemacht; vgl. sein Schreiben an den Kurfürsten, in: StAB, Ku 105/3.

22 Für entsprechende Hinweise danke ich den Kolleginnen der Unteren Denkmalbehörde Bonn

23 Wiederholt ist von der Alkoholsucht der Großmutter die Rede, und davon, dass ihr Mann sie in Köln in einem Kloster untergebracht habe. Ob und wann dies geschah, ist unklar; gestorben ist sie jedenfalls in Bonn. Vgl. u. a. JOSEPH SCHMIDT-GÖRG, Beethoven. Die Geschichte seiner Familie (Schriften zur Beethovenforschung 1), München/ Duisburg 1964, S. 83. Breyer nimmt an, dass die Alkoholkrankheit erst nach 1773, dem Sterbejahr ihres Mannes, ausgebrochen sei. Vgl. KNud BREYER, Familie, in: HEInZ vON LOESCH und Claus RAAB (Hgg.), Das Beethoven-Lexikon (Das Beethoven-Handbuch 6), Laaber 2008, S. 231-234, hier S. 231

24 Für das Folgende wurde, wenn nicht eigens angemerkt, Bezug genommen auf SCHMIDT-GÖRG, Beethoven (wie Anm. 23). Vgl. auch die knappe Zusammenfassung BREYER, Familie (wie Anm. 23). Allgemein zur Musikgeschichte in Bonn im 17. und 18. Jahrhundert vgl. Claudia Valder-KneChtges, Die Musikgeschichte, in: Dietrich HÖROLDT (Hg.), Bonn als kurkölnische Haupt- und Residenzstadt (Geschichte der Stadt Bonn 3), Bonn 1989, S. 449-514

Vgl. SCHMIDT-GÖRG, Beethoven (wie Anm. 23), S. $49 f$

Vgl. ebd., S. 51.

Die Datierung anhand des Kirchenbuchs ist eindeutig; der Name der Ehefrau liest sich eher Boll oder Ball. Vgl. hierzu ausführlich JOSEPH SCHMIDT-GÖRG, Beethovens rheinische Vorfahren, in: Dürener Geschichtsblätter 28, 1962, S. 593-605, der den Nachweis führt, dass Maria Josepha zwar zum Zeitpunkt der Heirat ein Pfarrkind von St. Remigius war, aber gleichzeitig nahelegt, dass sie nicht aus Bonn stammte. Vgl. auch THEO MOLBERG, Die Familie van Beethoven, in: Mitteilungen der Westdeutschen Gesellschaft für Familienkunde 39, 1999/2000, S. 90-93. Molberg konnte zwar weitere biographische 
Dokumente ermitteln, ihrer Herkunft ist er jedoch auch nicht näher gekommen.

So auch SCHMIDT-GÖRG, Beethoven (wie Anm. 23), S. 58.

Vgl. ebd. Im Weinort Köwerich an der Mosel, der für sich die Herkunft der Familie Keverich reklamiert, ließen sich keine entsprechenden genealogischen Spuren finden; vgl. ebd., S. 598.

Ihr Geburtshaus, das so genannte Mutter-Beethoven-Haus, ist mittlerweile als Museum eingerichtet worden

Das Grab von Johann Heinrich Keverich, zumindest seine Grabtafel, befindet sich in der katholischen Pfarrkirche St. Adelphus in (Wallmerod-)Salz im Westerwald. Für den Hinweis danke ich Herrn Werner Schui.

So SCHMIDT-GÖRG, Beethoven (wie Anm. 23), S. 59, 85, der namentlich Johann Konrad Rovantini, einen Vetter der Braut, nennt. Zur Familiengeschichte Rovantini vgl. MARGOT WETZSTEIN (Hg.), Familie Beethoven im kurfürstlichen Bonn. Neuauflage nach den Aufzeichnungen des Bonner Bäckermeisters Gottfried Fischer, Bonn 2006, S. 33.

Vgl. JuliA Ronge, Brüder, in: Beethoven-Lexikon (wie Anm. 24), S. 155-158.

Ein ausführliches Lebensbild des als Apotheker in Österreich Tätigen zeichnet ERIKA EIKERMANN, Der Apotheker Johann van Beethoven (1776-1848), in: Bonner Geschichtsblätter 59, 2009, S. 107-140

Vgl. u. a. SCHMIDT-GÖRG, Beethoven (wie Anm. 23), S. 59; neuerdings: JAN CAEYERS, Beethoven. Der einsame Revolutionär, München 2012, S. $42 f$.

Eine Übersicht über die verschiedenen Bonner Wohnplätze der van Beethovens in: MARGOt WetzSTEIN (Hg.), Das Haus in der Rheingasse. Beethovens Wohnhaus im Kontext der Bonner Geschichte (1660-1860). Gottfried Fischers Materialsammlung, genealogische Erschließung von THEO MOLBERG (Veröffentlichungen des Beethoven-Hauses Bonn, Für Kenner und Liebhaber), Bonn 2010, S. 247-249. SCHLÖDER, Bonn im 18. Jahrhundert (wie Anm. 5), S. 64, stellt in diesem Zusammenhang fest, dass "die innerstädtische Mobilität" in jener Zeit in Bonn insgesamt vergleichsweise hoch war.

Folgt man der sozialtopographischen Analyse von SCHLÖDER, Bonn im 18. Jahrhundert (wie Anm. 5), so zählten sämtliche Wohnungen der Familie van Beethoven zu Quartieren mittlerer Kategorien, in der Regel zur dritten von insgesamt sieben; vgl. die entsprechende Karte, in: ebd., Anlage. Vgl. in diesem Zusammenhang auch BusSO VON DER DOLLEN, Das Stadtbild der Residenzstadt Bonn zu Ende der kurfürstlichen Zeit. Ein Versuch der Rekonstruktion mit Hilfe der quantifizierenden Methode, in: Bonner Geschichtsblätter 40, 1990 (1993), S. 361-414.

Vgl. WetzSTEIN, Haus in der Rheingasse (wie Anm. 36), S. 248

Vgl. zu ihm - mit Hinweisen zur älteren Literatur - WOLF D. PENNInG, Kurkölnischer Erster Conferentzminister und Landkomtur des Deutschen Ordens. Der Weg Caspar Antons von Belderbusch an die Macht unter dem Kurfürsten Maximilian Friedrich in den Jahren 1761-1768, in: Annalen des Historischen Vereins für den Niederrhein 220, 2017, S. 171-215. Belderbusch war der eingetragene Pate von Ludwigs jüngerem Bruder Kaspar Anton(!) Karl.

Die beste Zusammenfassung der Stadtgeschichte des 18. Jahrhunderts bietet weiterhin EDITH ENNEN, Die Kurkölnische Haupt- und Residenzstadt in einem Jahrhundert der friedlichen und glanzvollen Entwicklung, in: HöROLDT, Bonn (wie Anm. 24), S. 205349. Genaue Zahlen bei CHRISTIAN SCHLÖDER, Der Einfluss der Residenzfunktion auf die Bevölkerungsentwicklung Bonns im 18. Jahrhundert, in: Bonner Geschichtsblätter 64, 2014, S. 31-46, basierend auf der Studie SCHLÖDER, Bonn im 18. Jahrhundert (wie Anm. 5)

Die Taufe Ludwig van Beethovens am 17. Dezember 1770 in der Pfarrkirche St. Remigius zu Bonn | 51 
Vgl. hierzu auch den Versuch einer Sozialtopographie der Stadt, in: ENNEN, Die Kurkölnische Haupt- und Residenzstadt (wie Anm. 40), hier S. 300-306.

Vgl. hierzu die Studie von Gregor OHM, Zur Sozialpolitik in der Residenzstadt Bonn zur Zeit der Kurfürsten Max Friedrich und Max Franz, in: Bonner Geschichtsblätter 47/48, 1998, S. 179-252, hier insbesondere S. $201 f$

Vgl. Dietrich Höroldt, Das Stift St. Cassius zu Bonn von den Anfängen der Kirche bis zum Jahre 1590 (Bonner Geschichtsblätter 11), Bonn 1957, S. 281.

Vgl. MAASSEN, Geschichte der Pfarreien (wie Anm. 5), S. 197. Zu Isbach vgl. JOSEPH JANSSEN und FrIeDrich WILHELM LOHMANN, Der Weltklerus in den Kölner Erzbistums-Protokollen 1661-1825, 3 Bde, hier Bd. 2, Köln 1935, Sp. 708

HeGel, Das Erzbistum Köln (wie Anm. 16), S. 272.

Vgl. hierzu u. a. Michael Ladenburger, Beethoven und sein Bonner Freundeskreis. Ausgewählte Dokumente aus der Sammlung Wegeler im Beethoven-Haus, Bonn 1998, S. 32

Die Familie Baum ist mehrfach als in der Bonngasse wohnhaft nachgewiesen. Vgl. Dietz, Topographie (wie Anm. 2), passim. Ebd., Bd. 1, S. 233, ist davon die Rede, dass "Kellerschreiber Baum" im Jahre 1771 die an seinem Haus befindliche Pumpe "auf schwere Kosten", also für viel Geld, erwarb. Die Kurkölnischen Hofkalender verzeichnen Johann Baum seit Aufnahme der weltlichen Hofbediensteten 1759 als "Kellerschreiber". 1786 wurde er offenbar zum "Kellermeister" befördert; im Kurkölnischen Hof-Kalender für das Jahr 1787 (S. 35) wird er jedenfalls erstmals in dieser Funktion genannt

Es handelt sich um das spätestens seit dem 19. Jahrhundert Im Mohren genannte Haus, an dessen Fassade eine entsprechende Figur angebracht wurde. Vgl. DiETz, Topographie (wie Anm. 2), Bd. 1, S. 284. (s. Abb. S. 34)

Die Courtins lebten im Haus Bonngasse 24 (vor 1870 Nr. 517, 1773 Nr. 361). Ihr Mitpate war ebenfalls der Großvater Ludwig van Beethoven. Vgl. auch DIETZ, Topographie (wie Anm. 2), Bd. 1, S. 280. Der Hinweis auf das Hofamt Courtins u. a. in: Churfürstlich-Cöllnischer Hof-Calender auf das Jahr 1769, S. 20. Schreibweise dort: Cortin.

Ein Sohn der Patin, der 1771 geborene Cunibert Joseph Baum, erwähnt 1838 einen von seiner Mutter in ihrem Haus ausgerichteten "Taufschmaus". So in einem Beitrag in der Beilage zu Ausgabe 242 der Kölnischen Zeitung 1838, hier zitiert nach WETZSTEIN, Das Haus in der Rheingasse (wie Anm. 34), S. 16 Anm. 16.

51 Lediglich bei der Taufe des jüngsten Kindes Maria Margaretha Josepha (St. Remigius, 5.5.1786) wird als Vorname der Mutter nur Magdalena eingetragen. Das Kind starb übrigens am 26.11.1787. SCHMIDT-GÖRG, Beethoven (wie Anm. 23), S. 62, wagt die Vermutung, dass die im Rheinland sowohl für Helena wir für Magdalena übliche Koseform Lenchen Ursache für diesen Irrtum ist

Vgl. Michael Lorenz, Malfatti von Rohrenbach zu Dezza, Therese, in: Beethoven-Lexikon (wie Anm. 23), S. $476 f$

Vgl. Maynard SOlomon, Beethoven. Biographie, München 1977, S. 18; KNud BreYER, Geburtsdatum, in: Beethoven-Lexikon (wie Anm. 23), S. $280 f$.

Beethoven-Haus Bonn, Sammlung Wegeler, W 206.

Beethoven-Haus Bonn, Sammlung H. C. Bodmer, HCB Br 327.

So im Jahresbericht des Stadtarchivs Bonn 1933/34 (S. 3), in: StAB, N 41/1185. Die Einrichtung der Beratungsstelle für Familien- und Sippenforschung, in: StAB, Pr 42/74. phie (wie Anm. 2), Bd. 1, S. 48. 


\section{Alt-St. Remigius - nicht nur Beethovens Taufkirche. Wiederentdeckung der einst größten Pfarrkirche Bonns}

E ist sicherlich ein Phänomen, dass ausgerechnet die ehemalige Hauptpfarrkirche von Bonn mit dem größten Pfarrsprengel in den schriftlichen Quellen nur spärlichen Niederschlag gefunden hat und auch ihr äußeres Erscheinungsbild nur vage überliefert ist. Dabei lässt schon das Patrozinium des heiligen Remigius auf eine Gründung in merowingischer Zeit schließen eine Ersterwähnung ist schon 795 bezeugt.

Manfred van Rey, der die Bonn betreffenden mittelalterlichen Quellen gesichtet und ausgewertet hat, stellt fest: Über einen Zeitraum von vier Jahrhunderten gibt es für St. Remigius keine Erwähnung!1

Die Pfarrkirche St. Remigius wurde - nach einem Blitzeinschlag - wie auch die benachbarte Martinskirche Anfang des 19. Jahrhunderts abgebrochen und damit offensichtlich auch aus dem Gedächtnis gestrichen, ohne zeichnerische oder archäologische Dokumentation, so dass weder ihr Aussehen und ihre ursprüngliche Größe noch ihre Lage exakt zu ermitteln sind. Das Patronat des HI. Remigius ging auf die ehemalige Minoritenkirche St. Ludwig von Toulouse in der Brüdergasse über, so dass nicht einmal der Patrozinium-Name, sondern nur noch die Platzbezeichnung - heute wieder - an den Heiligen erinnert.

\section{Ersterwähnung}

Die Kirche des hl. Remigius wird urkundlich zuerst in den Hellmann`schen Regesten erwähnt: 795 übertrug(en) Gerbert und/oder („seu”) Reginar "ad ecclesiam sancti Remigii, quae est constructa in vico Bunnense", Eigengut in den "campis Bonnensibus", das an den Besitz von Otbert und von St. Peter grenzte - womit hier wohl die Dietkirche gemeint ist. Die Lage der Kirche wird genauer bestimmt durch eine weitere Erwähnung: Unter Erzbischof Hadebald (819-841) schenkte Alvard "ad ecclesiam, quae est constructa in villa Basilica et ubi praeesse [videtur] Hathabaldus primae sedis Agrippinensium civitatis episcopus, vineam in pago Bonnensi in marca ... Fristorp", das heißt er schenkte der Kirche bzw. den Reliquien des hl. Remigius einen Wingert in Friesdorf. Hier wird die „ecclesia” des hl. Remigius bezeichnet als „constructa in villa Basilica”. Im Jahre 804 wird diese villa basilica erstmals erwähnt, als eine bei der Stiftskirche St. Cassius entstandene Siedlung. Sie war keine Stadt oder Dorf, sondern kultischer Mittelpunkt: Auf engem Raum lagen hier schon in fränkischer Zeit drei Kirchen: die Stiftskirche selbst, unmittelbar davor die zugehörige Tauf- und Pfarrkirche St. Martin und auf dem heutigen Remigiusplatz die Remigiuskirche. 
Innerhalb dieser villa basilica, aber deutlich von ihr abgegrenzt, lag der um 800 erstmals erwähnte vicus Bonnensis, eine Fernhändlersiedlung in Einstraßenform; sie erstreckte sich vom Münster- bis zum Remigiusplatz, möglicherweise über den heutigen Marktplatz hinaus bis zum Rhein.

Abgesehen davon, dass sich vicus Bonnensis und villa Basilica räumlich überschnitten, könnte die Ergänzung "et ubi praeesse [videtur]" Bischof Hadebald mit Dietrich Höroldt dahingehend interpretiert werden, dass St. Remigius eine erzbischöfliche Eigenkirche gewesen sei, als Kirche der curtis Bonna, des erzbischöflichen Hofs. ${ }^{2} 1304$ wird sie dann erstmals als Besitz des Cassiusstiftes bezeichnet. Für das Jahr 1280 ist bezeugt, dass am Kirchhof von St. Remigius mehrere Häuser erbaut wurden, deren Eigentümer jährliche Stiftungen an die Kirche leisteten. ${ }^{3}$

Später übernahm St. Remigius die Aufgabe der Stadtkirche, was auch bedeutete, dass die Pflicht zur baulichen Unterhaltung und den Kosten des Kultus zwischen dem Cassiusstift und der Stadt geteilt war. Die Remigiuskirche trat damit in ein engeres Verhältnis zum Bürgertum, war Ort der Festgottesdienste des Rates und beherbergte bis ins 15. Jahrhundert der größeren Sicherheit wegen, die kirchlicher Besitz genoss, das städtische Archiv. Unter Erzbischof Ruprecht von der Pfalz soll der Bonner Bürger und Glasmacher Wynmar beauftragt worden sein, die in einer Truhe in der Sakristei der Remigiuskirche liegenden Freiheitsbriefe zu entwenden oder zu verbrennen, was allerdings vereitelt werden konnte, und der Täter mit dem Tod bezahlen musste. Auf dem Turm der Stadtkirche befand sich auch die städtische Brandwache ${ }^{4}$.

Ihr Pfarrbezirk umfasste den größten Teil der seit 1244 ummauerten Stadt: Die Pfarrgrenze ging vom Remigiusplatz über die Ach(t)erstraße zum Sterntor, umschloss die Sternstraße, die Bonngasse, Kölnstraße, einen Teil der Maargasse, die Kesselgasse, die Josephstraße, Heisterbacherhofstraße, Hatschiergasse, Commanderie, Windmühle, Engelthal, ging aufwärts am Rhein entlang, umfasste den ganzen südlichen Teil, den Markt, die Wenzelgasse und die dazwischenliegenden Straßen bis zur Residenz.

Nach vier Jahrhunderten des Schweigens der Quellen verdanken wir Caesarius von Heisterbach erstmals wieder eine Nachricht über St. Remigius: Genannt wird in einem Zusammenhang, der für uns nicht relevant ist, ein gewisser "sacerdos Arnoldus ... Bonnae in parochia sancti Remigii".

Eine nächste Erwähnung findet sich für das Jahr 1280, als der Bonner Bürger Lambert von Gielsdorf und seine Ehefrau Mechthild zu ihrem und ihrer Kinder Seelenheil der Kirche des hl. Remigius eine Mark Kölner Pfennige aus ihren neuen Häusern neben dem Kirchhof spendeten. Dabei wirkten nicht nur der Pfarrrektor bzw. Pleban (Leutpriester, Pfarrer), sondern noch zwei weitere Kapläne und ein Glöckner mit. Die Schenker trafen über die Verteilung der jährlichen Spende genaue Anordnungen, aus denen unter anderem hervorgeht, dass der Pleban einen eigenen Scholaren hatte. Die 
Tatsache, dass nicht nur Dekan und Kapitel des Cassiusstifts die Schenkungsurkunde besiegelten, sondern auch die Stadt ihr Siegel einschließlich rückseitigem Sekretsiegel anhängte, bezeugt die herausragende Rolle der Pfarrkirche St. Remigius für die Stadt. Ihr hier erstmals bezeugter umgebender Friedhof war bis zu seiner Aufhebung 1787 die zentrale und größte städtische Begräbnisstätte.

Erst 1281 ist wieder ein Pleban von St. Remigius, Ludolf, namentlich genannt. Mit seinem Confrater Gerhard, Pleban von St. Martin, stellte er sich Reinhard von Westerburg, Propst des Cassiusstifts und Bruder des Erzbischofs Siegfried von Westerburg, zusammen mit drei Kanonikern des Stifts als Bürge für die Zahlung von immerhin 48 Mark zur Verfügung, als der Propst für diesen Betrag die Kurie des verstorbenen Dekans Hermann auf Lebenszeit als Wohnung übernahm.

Die nächsten urkundlichen Erwähnungen von 1290 und 1297 bezeugen nur Besitztümer bzw. Schenkungen bei der Pfarrkirche "ecclesia parrochialis" St. Remigius oder "iuxta ecclesiam Sancti Remigii".

1304 erklärte der Stiftsdekan, Magister Ludolf, dass er künftig die Pfarrkirchen St. Remigius und St. Gangolf, deren Kollation bzw. Präsentation dem Stiftskellner zustehe, nur noch geeigneten Kanonikern, nämlich Priestern, übertragen könne.

Der Liber Valoris, ein Steuerverzeichnis von 1308 zur Ermittlung der Decima des Erzbischofs, weist für St. Remigius Abgaben von 18 Mark, für St. Martin 20 Mark und für St. Gangolf 6 Mark auf.

Die Kirche St. Remigius ist mit der Ersterwähnung im Jahre 795 früher bezeugt als die Martinskirche in unmittelbarer Nähe des Münsters. Ihr großer Pfarrbezirk lässt es als wahrscheinlich erscheinen, dass dieser zunächst aus dem Bereich der Urpfarre Dietkirchen herausgelöst und dann erst der Pfarrbezirk des späteren Münsters abgesteckt worden ist. Eine Filiation der Dietkirche ist nicht belegt. St. Martin und St. Remigius dürften von vornherein als Pfarrkirchen mit allen Rechten ausgestattet gewesen sein. Da die Kirche St. Remigius in unmittelbarer Nähe des erzbischöflichen Hofes - Ersterwähnung 1112 - lag und ihr Pfarrbezirk den größten Teil der Bonner Innenstadt umfasste, spricht vieles dafür, dass es sich bei ihr um die Hofkirche des in den Komplex der späteren Residenz miteinbezogenen erzbischöflichen Hauses handelt.

\section{Kriegerische Auseinandersetzungen, Zerstörungen, Brand und Wiederaufbau}

Die Funktion Bonns als Residenzstadt der Kurfürst-Erzbischöfe von Köln brachte es mit sich, dass sie fortan in alle kriegerischen Auseinandersetzungen miteinbezogen und hier entsprechend durch Bombardierung und Brandschatzung Schäden an der Bausubstanz zu beklagen waren. ${ }^{6} 1584$ wurde Bonn im Kölnischen Krieg durch den Gegner - und Nachfolger - des abgesetzten Erzbischofs Gebhard Truchsess von Waldburg, Herzog Ernst von Bayern, nach 
einmonatiger winterlicher Belagerung eingenommen. Vier Jahre darauf überfiel am Tag vor Heiligabend der Parteigänger Gebhards, Martin Schenk von Nideggen, die Stadt, besetzte sie und ließ sie von seinen Söldnern vollständig plündern. Um seinen Truppen Sold bezahlen zu können, ließ Gebhards Bruder Karl Truchsess im Dezember 1587 aus allen Bonner Kirchen und Häusern silbernes Tafelgeschirr, Kelche und sonstiges Kirchengerät beschlagnahmen, um daraus Notmünzen schneiden zu lassen.

Erst im folgenden Jahr, 1588, konnten spanische und deutsche Truppen nach Belagerung und heftiger Beschießung die Stadt wieder erobern.

Im Dreißigjährigen Krieg hatte Bonn - in seinen Mauern lebten inzwischen etwa 4000 Menschen - wiederholt unter Kriegszügen, Plünderungen, Einfällen und Brandschatzungen zu leiden. Im September 1620 lagen drei Jahre lang niederländische Truppen auf dem Kemper Werth, der so genannten Pfaffenmütze, einer Rheininsel vor der Siegmündung. 1631 waren es die Schweden unter Wolf Heinrich von Baudissin, im nächsten Jahrzehnt hessische und wiederum schwedische Truppen, die plündernd durch das Rheintal zogen.

Die Kirche oder nur der Turm von St. Remigius wurden des Öfteren vom Blitz oder Feuer heimgesucht, deren Ursache auch im Funkenflug nahegelegener Brände liegen konnte. Der Kanoniker am Cassiusstift Adolf Sigismund Burmann berichtet in seiner Historia Universalis, der Geschichte seiner Heimatstadt, dass er selbst miterlebte, wie 1653 der Turm von St. Remigius vom Blitz getroffen abbrannte und dann nochmals 1689 bei dem schweren Bombardement auf die Stadt in Brand geriet. Für den Wiederaufbau 1653 haben die Ratsherren den Schaden bezahlt, mehr oder weniger im eigenen Interesse, da hier die Stadtwache untergebracht war ${ }^{7}$.

Weitere Belagerungen musste Bonn 1673, 1689 und 1703 über sich ergehen lassen. Die schlimmsten Folgen für die Stadt brachte die Belagerung des Jahres 1689. Die von dem kurkölnischen Minister Wilhelm Egon von Fürstenberg, einem Parteigänger Ludwigs XIV., ins Land gerufenen französischen Truppen - etwa 4000 Mann - besetzten Bonn, woraufhin die verbündeten brandenburgischen, kaiserlichen, münsterschen und holländischen Truppen unter dem Befehl von Friedrich III. Preußen - Kurfürst und Herzog von Brandenburg - die Stadt im Sommer 1689 einschlossen. Bei der Beueler Schanze waren 140 schwere Geschütze und 30 Mörser in Stellung gebracht. Am 24. Juli 1689 begann das tagelang andauernde Bombardement auf die Stadt. Die Wirkung war verheerend. An verschiedenen Stellen der Stadt brachen Brände aus, die sich rasch verbreiteten. Bei einem erneuten Beschuss am 6. August wurde der Turm des Münsters getroffen und geriet in Brand, wobei auch das Geläut mit acht Glocken verloren ging. Sämtliche Kirchen und Klöster hatten mehr oder weniger größere Schäden zu beklagen. An St. Remigius waren es wieder die Dächer, der Turm und die Glocken, die stark in Mitleidenschaft gezogen waren. Am 15. Oktober 1689 kapitulierte die Besatzung. Außer den in Stein errichte- 
ten, und dennoch teilweise stark zerstörten oder schwer beschädigten Gebäuden der kurfürstlichen Residenz, wie dem Rathaus und den Kirchen und Klöstern, waren im Grunde genommen alle Bürgerhäuser in den umliegenden Gassen bis zur Kölnstraße verbrannt: Bonn war in Schutt und Asche versunken.

Der Wiederaufbau der Kirchen und Klöster setzte schon bald ein. Für St. Remigius bemängelte die Vertretung der Zwölfter, eine der beiden Körperschaften der städtische Selbstverwaltung, dass das Stiftskapitel von St. Cassius nichts für die Reparatur von Dach und Schiff tue, obwohl es als Kollator dazu verpflichtet sei. Die Bürger hätten sogar gedroht, die Zahlungen des Zehnten einzustellen. 1692 hatte eine "Kollekte und gutmütige Beisteuer" 112 Reichstaler 3 Albus 5 Heller erbracht, die zum Ankauf von Schiefer verwendet wurden. Auch sonst wurden städtische Mittel zur Reparatur von Chor und Gewölben aufgebracht, allerdings mit Protest gegenüber dem Stift, das sich seiner Verpflichtung offenbar nach wie vor entzog9. Aber es ging nicht nur um die Reparatur der Dächer von Schiff und Chor, sondern auch um das leidige Thema: Turm.

\section{Streit um die Kosten für den Aufbau des neuen Turmes}

Von Ende September 1720 datiert eine Art Gutachten, das die beiden Meister, Vitus Bieler aus Düsseldorf und Vitus Leydahler aus Koblenz sowie Bruder Sylvester vom Karmeliterkloster in Pützchen nach eingehender Inaugenscheinnahme im Auftrag des Magistrates erstellt hatten ${ }^{10}$. Darin werden die nötigen Maßnahmen zur Sanierung des Turmes aufgeführt. Offensichtlich handelte es sich insbesondere um statische Schäden: Der Turm war von mehreren vertikalen Rissen durchzogen, die die Vermauerung des Westportals und des darüber befindlichen Fensters sowie das Einziehen von zahlreichen Ankern erforderlich machten. Sie müssten sämtlich eingezogen sein, bevor eine neue "Kuppel", das heißt Gewölbe, aufgesetzt werden könne. Zudem müssten noch zwei Ecken am Turm neu eingedeckt werden.

Ohne nähere Informationen über Sanierungskosten des alten Turms oder Diskussionen und Beschlussfassung für einen eventuellen Neubau findet sich für den 2. Oktober 1720 die Nachricht, dass der "erste Nagel zum neuen Kirchthurm" unter großer Feierlichkeit eingeschlagen worden sei ${ }^{11}$. Eine Nachricht, die überrascht, da sie an keiner anderen Stelle - weder in den Akten noch in der Literatur - auch nur ansatzweise wiederholt wird. Deutet der "Nagel" darauf hin, dass der Turm - nur - in Fachwerkbauweise errichtet wurde?

Die Auswertung des Stadtplans von Hermann Sandfort aus dem Ende des 18. Jahrhunderts hatte bereits vor geraumer Zeit zu der Erkenntnis eines neuen Turmes an der Nord-West Ecke des Kirchengebäudes geführt, die durch die Nachricht vom Oktober 1720 ihre Bestätigung findet.

Vom 9. März 1722 datiert dann ein Schreiben - in lateinischer Sprache - des Pfarrers von St. Remigius, Heribert Bauch, an Kurfürst Joseph Clemens ${ }^{12}$, in 
dem er berichtet, dass der Turm - "laus Deo" - wieder aufgebaut sei und zwar mit Geldern, die der Kurfürst - "serenissimus" - geschenkt hatte. Es bliebe aber dennoch eine ungeheure Summe offen, über deren Zahlung in Bürgerschaft und Rat heftig gestritten würde. Mit Zustimmung des Kurfürsten hatte der Hofrat - "consilium aulicum" - schon längst eine Kollekte unter den Pfarrangehörigen beschlossen und festgelegt, wie viel ein jeder zu zahlen habe. Nach entsprechender Mitteilung waren denn auch viele gehorsam - „paruerunt" - und hatten den Betrag bezahlt. Aber die führenden Kreise - „primares tribunum" -, die so genannten "Herren Zwölften", weigerten sich, weil sie zu dieser Baumaßnahme überhaupt nicht hinzugezogen und gefragt worden seien. Sie baten jetzt darum, die Kollekte solange aufzuheben, bis dem Rat "magistratus" - Rechnung darüber abgelegt worden sei, wie die Finanzierung zustande kommen solle. Sie wandten sich deshalb zur Klärung oder Schlichtung an den Bonner Vize-Satrapen - „Vicesatrapam Bonnensem” - Steinman ${ }^{3}$.

Im Übrigen seien sie im Besitz eines Rechtstitels, wonach sie nichts zum Wiederaufbau des Turmes beitragen müssten, weil er beim letzten Mal auch nicht durch Kollekten, sondern aus allgemeinen Haushaltsmitteln - „ex communi aerario" - bezahlt worden sei. Etwas geschmacklos fügte man dann hinzu: Wenn es an Haushaltmitteln fehle, so könne man ja aus den Einkünften des Leprosenhauses "von der Höhe", auch wenn dies nur ein geringerer Fundus sei, die entsprechenden Mittel nehmen. Die Verwirrung sorgte natürlich auf beiden Seiten für größten Verdruss, insbesondere bei den Gläubigern und Handwerkern, die nun noch länger auf ihre Bezahlung warten mussten. Der Pfarrer erbittet deshalb die Meinung des Kurfürsten in dieser Angelegenheit.

Dieser Brief des Pfarrers an den Kurfürsten ist aber noch in anderer Hinsicht von großem Interesse: Er scheint unsere Annahme zu bestätigen, dass bei der Zerstörung von 1689 der mittelalterliche Turm derart in Mitleidenschaft gezogen und ruiniert war, dementsprechend die Kosten einer Sanierung derart hoch waren, dass man sich entschloss, einen neuen Turm zu errichten. Entsprechend lautet die Bezeichnung des Aktenstücks "Concernit aedificandam turrim Ecclesia S. Remigii de anno 1722". Aber auch die im Text mehrfach benutzte Formulierung "reaedificationem turris" ist in diesem Sinne zu verstehen.

Am 23. August 1756 erfolgte Benediktion und Taufe neuer Glocken durch den Stiftsdechanten in Gegenwart des Obristlandhofmeisters Graf von Hohenzollern und des Grafen von Seinsheim. Drei Monate später, in der zweiten Adventswoche, fand im Münster die Glockenweihe von vier großen Glocken durch Kurfürst Erzbischof Clemens August statt, die Martin Legros, der bekannte Glockengießer aus Malmedy, zusammen mit drei Glocken für St. Gangolf gegossen hatte. ${ }^{14}$ Die zeitliche Nähe lässt einen direkten Zusammenhang, das heißt denselben Glockengießer Martin Legos, auch für die Glocken von St. Remigius als sehr wahrscheinlich erscheinen. 


\section{Das Pfarrhaus}

Ein anderes Problem hielt im Mai 1765 Pfarrer Caspar Kemmerling und alle Beteiligten in Atem: Das Pfarrhaus an der Ecke Remigiusstraße/Remigiusplatz war seit längerem baufällig und drohte, wie das Nachbargebäude, einzustürzen. Ein erhaltener, nicht signierter und datierter Plan zeigt das Erdgeschoss, die eine Hälfte mit den zu erhaltenden Mauern, die andere - für pfarramtliche Zwecke zu nutzende - mit neuen an die vorhandene Außenmauer angelehnten Mauerzügen, insgesamt eine großzügige Raumaufteilung. Die "Pfarrgenossen" mussten - wie immer - durch eine Kollekte und Spenden - "freiwillige beysteür" - einen Teil der Kosten dazu aufbringen. Schon mit Verfügung vom 24. Mai 1766 hatte Kurfürst Maximilian Friedrich Bürgermeister und Rat mit Nachdruck aufgefordert, diese durchzuführen. In der dafür aufgelegten "Collections Roll" findet sich auch der Name des Großvaters von Ludwig van Beethoven in der "Bonngasse”. ${ }^{15}$ Am 5. Januar 1768 beschloss der Magistrat zudem eine Geldaufnahme zu den bedeutenden Kosten der Reparatur der Remigiuskirche ${ }^{16}$.

\section{Weitere Zerstörungen und Blitzeinschlag}

Die kaum notdürftig wiederhergestellte Stadt hatte mit der Belagerung von 1703 im Spanischen Erbfolgekrieg erneut eine Beschießung zu ertragen. Wieder lag eine französische Besatzung in der Stadt und holländische und kaiserliche Truppen standen vor den Toren. Nachdem die Stadt von Hunderten von Kanonen und Mörsern beschossen worden war, erfolgte am 6. Mai 1703 die Übergabe. Ob und inwieweit die Remigiuskirche unmittelbar in Mitleidenschaft gezogen wurde, ist unklar.

Auch bei dem großen Schlossbrand Mitte Januar 1777 blieb die Remigiuskirche nicht verschont. Durch Funkenflug - die Pulverkammer im Schloss war in die Luft geflogen - waren bereits am ersten Brandtag 13 große Brände in der Stadt entstanden. Remigius begann mehrfach zu brennen: Ihre Rettung verdankt sie dem unermüdlichen Fleiß des Dachdeckergesellen Anton Grimm, dem der Stadtrat als Anerkennung jährlich einen Reichstaler am Mietzins des von ihm bewohnten Bogenhauses an der Windmühle nachließ ${ }^{17}$.

Der Chronist Jacob Müller berichtet für Samstag, den 10. Mai 1800, von einem fürchterlichen Gewitter, das nachmittags gegen 5 Uhr einsetzte und den Turm von St. Remigius direkt unter dem Kreuz entzündete. Bis gegen 12 Uhr in der Nacht brannte er einer Kerze gleich, trotz anhaltenden Platzregens, bis auf das unter den Glocken befindliche Gewölbe ab. Die Glocken seien geschmolzen und in Stücken heruntergefallen. Des Weiteren habe die Kirche aber keine Schäden erlitten, ebenso wie die Häuser in der Nachbarschaft. Anderntags, Sonntag den 11. Mai, hat man in der Pfarrkirche wie üblich die Sonntagsmessen gehalten, um nicht den Anschein zu erwecken, „als wenn sie zum Gottesdienst unbrauchbar wäre"18. Einer anderen Quelle zufolge hatte allerdings der 
"Commandant" verlauten lassen, dass die Kirche nicht mehr zum Gottesdienst, wohl aber als Magazin gebraucht werden könne. Entsprechend reagierte die Stadtverwaltung, die ab sofort sämtliche gottesdienstlichen Veranstaltungen in St. Remigius verbot. Als Ausweichquartier sollte die benachbarte frühere Jesuitenkirche dienen ${ }^{19}$.

Im Archiv des Bonner Münsters befindet sich eine kleine von "B .C. Wagner" unterschriebene Notiz: "Bonn 1800 den 10 may schluch das gewieter in sant Remigiuskirch Turm zwischen 5 und 6 Uhr und das Trümmer ist ueber die ganzen Statt geflochen und hat keinen schaden gethan und den 12. Mäy hielt die Bürgerbruderschaft 13 stündlich Gebeth in derfranziskanerkirch zu Danksagung das unß gott die statt bewaret hat." 20 .

Wie Werner Hesse schreibt, hätte man beim ersten Zeichen des Brandes die vom Blitz getroffene Spitze des Turmes mit ein paar derben Axthieben zusammenhauen und den ganzen Ausbruch der Flammen hemmen können. „Lachend stand eine große Menge Volkes auf dem kleinen Kirchhofe und in den engen Straßen in der Nähe der Kirche herum und sah dem Schauspiele zu, wie sich die Flammen immer weiter ausdehnten". Ein städtischer Mitarbeiter habe, nachdem er weder durch Geld, gute Worte oder Drohungen einige Werkleute zu Löscharbeiten in der Spitze des Turms hat bewegen können, sich selbst mit einigen Bürgern hinauf gewagt, wo bereits der alte Dachdecker Esper mit einer alten Handspritze zu Gange war. „... die Menge unten aber habe sich an dem Verderben gelabt" zitiert Hesse aus einem Zeitzeugenbericht. "Aus allen Mitteilungen geht hervor, dass die Bürger sich den Verlust des Turmes nur selbst zuzuschreiben haben"21. Macht sich in dieser Äußerung bereits die Bereitschaft bemerkbar, sich wie bei der Martinskirche, deren Baufälligkeit durch Lösung des Ringankers nachgeholfen wurde, eines weiteren Kirchenbaus zu entledigen? Immerhin konnte durch das Eingreifen „wackerer Bürger" ein Umsichgreifen des Feuers verhindert werden. Aber die Kirche selbst hatte offenbar doch so sehr gelitten, dass ihre Erhaltung unmöglich schien, und der Gottesdienst in die Namen-Jesu-Kirche, die ehemalige Jesuitenkirche, verlegt wurde. Allerdings hat man noch 1802 den ersten Geburtstag "des ersten Konsuls" mit einem musikalischen Hochamt in St. Remigius, zu dem sich die Spitzen der Zivil- und Militärbehörden eingefunden hatten, festlich begangen. ${ }^{22}$

\section{Beginn der Abbrucharbeiten am Turm}

Es wurden zwar noch notdürftige Reparaturen durchgeführt, aber offensichtlich stand der Abbruchbeschluss fest: 1806 wurde dann damit begonnen, das gesamte Gebäude, mit Ausnahme des Turms, dem Erdboden gleichzumachen. Die Steine wurden, wie auch bei anderen Bonner Abbrüchen, beispielsweise von Schloss Herzogsfreude in Röttgen, zum Festungsbau nach Wesel transportiert, ein Teil für den Neubau des Arresthauses in Bonn in der Kesselgasse benutzt. ${ }^{23}$ Der schon 1787 auf kurfürstliche Anweisung vor allem aus hygieni-

60 | Gisbert Knopp 
schen Gründen aufgegebene südlich der Kirche gelegene Kirchhof wurde mit Bäumen bepflanzt. ${ }^{24}$

Der Abriss von St. Remigius scheint mit einem Mysterium verbunden zu sein: Da wird in Bonn 1806 - das genaue Datum ist nicht bekannt - das nach dem Münster größte Gebäude der Stadt abgebrochen und sämtliche Quellen schweigen! Kein Stein, kein Architekturteil - mit Ausnahme der weiter unten beschriebenen Spolien aus dem Arresthaus -, kein Relief, nichts hat sich erhalten! Es hat sich auch kein offizieller oder inoffizieller Bericht, keine Ansichtszeichnung, kein Grundriss, keine Bauaufnahme oder dergleichen überliefert; auch das Stadtarchiv und die kirchlichen Archive schweigen. ${ }^{25}$ Der Abbruch des großen Kirchengebäudes, der sich über einen längeren Zeitraum hingezogen haben muss, findet nirgendwo schriftlichen Niederschlag. Man kann sich also überhaupt kein Bild von der Pfarrkirche St. Remigius machen. Aber es tun sich noch weitere Fragen auf: Was ist mit der Einrichtung, dem Inventar, den sieben Altären, den Gemälden und Figuren, den Vasa Sacra, den Gerätschaften, Paramenten, Fahnen etc. oder dem Pfarrarchiv geschehen? Nichts von alledem, nicht der kleinste Hinweis, hat sich bis heute erhalten. Ausnahmen bilden lediglich der große Hochaltar mit dem Gemälde der Taufe Chlodwigs von Johann Spilberg und der Taufstein aus Lahnmarmor, die beide in die ehemalige Minoriten-, jetzige Pfarrkirche St. Remigius verbracht werden und die Kanzel, die im Münster, mittlerweile ebenfalls zur Pfarrkirche umgewidmet, Aufstellung findet.

\section{Neues Domizil für die Stadtwache}

Der Abbruch des Turms der alten Kirche, der der Stadtwache diente, und die Räumung des Platzes scheint sich noch einige Jahre, wenigstens bis 1809 hingezogen zu haben. All denen, die an einer Verschönerung ihrer Vaterstadt interessiert waren, musste er deshalb ein Dorn im Auge sein. Aber das größte Hindernis war, ein anderes Lokal für die Turmwächter zu finden. Alles, was man bislang besichtigt hatte, schied aus irgendeinem Grunde aus. Und dann war da auf einmal eine ganz neue Idee: "Das Projekt besteht in einem Observatorium oben den Gemeindehause" - gemeint ist das barocke Rathaus am Markt - "welches sich nach Art wie jenes ober dem Koblenzerthore, daselbst erheben, für jenes prächtige Gebäude eine neue Zierde, und für die ganze Stadt ein neuer Nutzen und eine neue Annehmlichkeit seyn soll." Dieses kühne Projekt, für das schon die Pläne und eine exakte Kostenberechnung vorlagen, sollte allein durch Subskription der Bürgerschaft finanziert werden ${ }^{26}$. Die Begeisterung für dieses Bauprojekt scheint schon bald verklungen zu sein. Bereits wenige Monate später heißt es, dass ein „Wachtthurm" nicht zur Architektur des Hauses passe, es vielmehr verunstalte und auch zu viel koste. ${ }^{27}$

Schließlich kam man zu dem naheliegenden Beschluss, das „Observatorium” für die Nachtwächter auf den nördlichen Turm der nahegelegenen Namen- 
Jesu-Kirche, und zwar ganz oben in die Galerie unter der Kuppel, zu verlagern. Hierfür war lediglich ein neuer Zugang von der Straße her erforderlich. Vermutlich wechselte auch die alte Brandglocke den Ort. In ihrer in gotischer Minuskel abgefassten Umschrift beschränkt sie sich, was völlig ungewöhnlich ist, lediglich auf den Um- bzw. Neuguss mit Datum:

$$
\text { .renovata . anno . domini . m. ccccc. xxx . v . }
$$

(Erneuert im Jahre des Herrn 1535)

Darunter ein hängender Lilienfries. Die Umschrift verweist auf den Neuguss einer älteren Glocke, übernimmt aber nicht, wie üblich, deren Inschrift. Als Glockengießer vermutet Jörg Poettgen den bislang bis 1536 belegten Johann von Collen. ${ }^{28}$ Es grenzt schon an ein Wunder, dass diese Glocke überhaupt die zerstörerischen Zeiten überdauert und unbeschädigt erhalten ist: Schon von den Schäden von 1689 heißt es, dass auch die Glocken zerstört wurden. Vom Blitzeinschlag im Mai 1800 wird berichtet, dass die Glocken geschmolzen und in Stücken heruntergefallen seien. Nach der Sanierung der Türme der NamenJesu-Kirche 2012 wurde die alte Glocke - sie dürfte die älteste Glocke Bonns sein - in das Geläut dreier neuer Glocken klanglich integriert.

\section{Neugestaltung des Kirchplatzes}

Der Platz, an dem die Kirche gestanden hat, sollte geebnet, gesäubert, mit Sand bedeckt und mit Akazienbäumen bepflanzt, die umgebenden Mauern mit davor gepflanztem Gesträuch "belebt" werden. Eine "Römische Ara, von

Remigiusplatz nach der Neugestaltung mit der vermeintlichen Ara Ubiorum. Detail aus: Plan D`Aligment de la Ville de Bonn, 11. September 1812, Geometer M. Herter (Landesarchiv NRW)

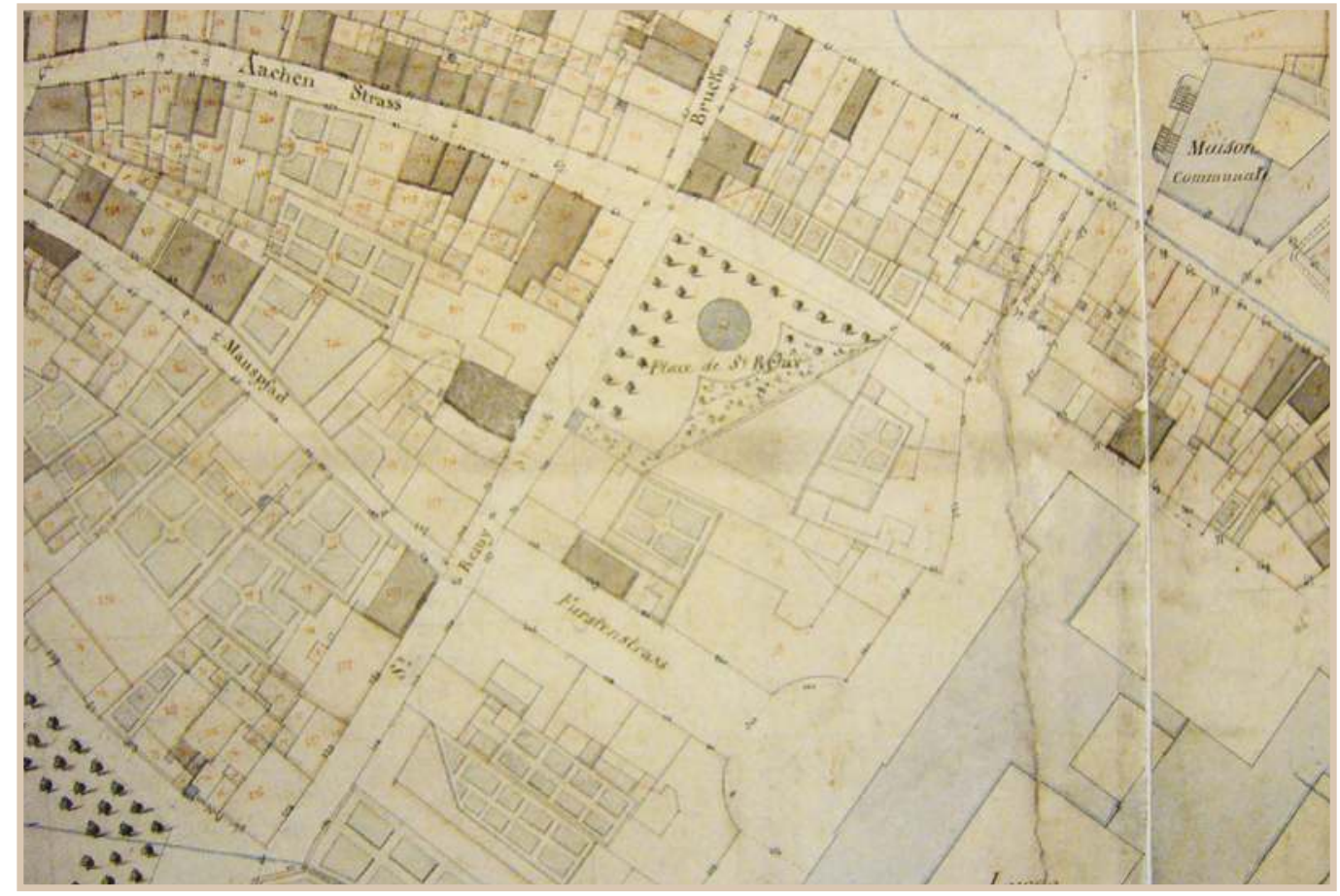

62 | Gisbert Knopp 

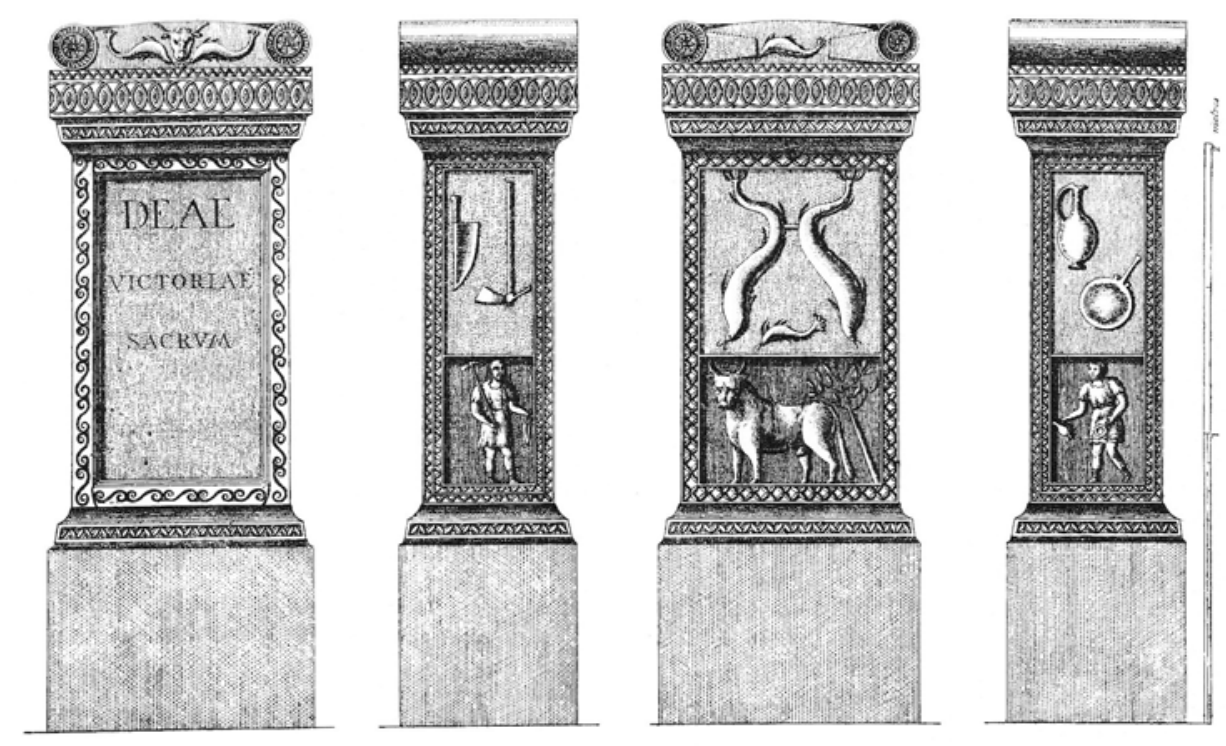

einem geschätzten Kenner des Alterthums verehrt", soll auf eine besondere Erhöhung und auf felsenartig gemauerte Steine gesetzt, von italienischen Pappeln umgeben, dem Platz und der ganzen Stadt eine neue Zierde sein ${ }^{29}$. Der Altar ist tatsächlich - wohl im November 1807 - auf dem Remigiusplatz aufgestellt worden. In seiner Rede zum 5. Jahrestag der Krönung Napoleons am 3. Dezember 1809 erwähnt Bürgermeister Graf von Belderbusch die Stiftung eines römischen Sieges-Altares durch einen der Munizipalräte ${ }^{30}$. Stifter war der in Bonn geborene Kanonikus Franz Pick, der neben einer großen Sammlung von Kunstschätzen auch den im 16. Jahrhundert bei dem römischen Flottenkastell Alteburg, nahe Köln, ausgegrabenen, in die erste Hälfte des 3. Jahrhunderts zu datierenden Altar der Siegesgöttin Victoria - die Ara Ubiorum - erworben und dann der Stadt Bonn mit der Auflage des Standortes geschenkt hat. ${ }^{31}$ Der Altar befindet sich heute im LVR-Landesmuseum Bonn. Um das Andenken an die Pfarrkirche St. Remigius nun gänzlich auszulöschen, wurde der Platz konsequenterweise in Römerpatz umbenannt.

\section{Das innerkirchliche Leben der Pfarrkirche - ein Schlaglicht}

Einen kleinen Einblick in das innerkirchliche Leben der Pfarrei, soweit es mit finanziellem Aufwand verbunden war, vermitteln die Rechnungen des Kirchmeisters von St. Remigius für die Jahre 1636 bis $1645^{32}$. Kirchmeister ist zu dieser Zeit der Apotheker Heinrich Steinhausen, der das Haus an der Ecke Markt/Bischofsgasse bewohnte. Während des Dreißigjährigen Krieges habe Bonn, obwohl Schweden, Kaiserliche und Hessen in der Umgebung hausten, dank der Vorsorge des Kurfürsten Ferdinand in den letzten zehn Jahren wenig
Der Bonner Victoria-Altar, aufgestellt und veröffentlicht anlässlich des 5. Jahrestages der Krönung Napoleons 1809 auf dem Remigiusplatz an der Stelle der ehemaligen Pfarrkirche St. Remigius. Lithografie nach einer Zeichnung von R. J. de Gerolt (Repro aus: Rheinisches Landesmuseum Bonn. 150 Jahre Sammlungen 1820-1970) 
gelitten. Nach seiner Schilderung war der Hochchor mit dem Hochaltar durch ein Gitter abgeschlossen. Von der Decke hing ein kupferner Leuchter oder Krone. Am Festtag des hl. Remigius wurde im Chor ein Bild, wohl ein Gemälde, des Heiligen auf zwei Schragen aufgestellt. Außer dem Hochaltar gab es noch sechs weitere Altäre im Kirchenraum. Erwähnt wird der Annen-Altar, der Antonius-Altar, der Katharinen-Altar. Ein Muttergottes-Altar befand sich in "Vnser L. frauwen Choergen". In der Sakristei, die hier "Gehrkammer" genannt wird, wird das bewegliche Inventar aufbewahrt. 1638 beschaffte die Kirche auf "Befehl der Stadt" eine neue Fahne aus rotem Seidendamast: auf der einen Seite das Bild der Auferstehung Christi, auf der anderen Bildnisse der hll. Cassius und Florentius und in der Mitte das des Kirchenpatrons des hl. Remigius. Im selben Jahr fertigte der Kölner Gold- und Silberschmied Alexander von Orsbach für die Kirche ein prächtiges Silberkreuz an, das 99 1/2 Reichstaler 11 Albus oder 323 Gulden kostete. Allein das Silber wog $33 / 4$ Pfund, die Teile aus Kupfer waren vergoldet, das Kruzifix ganz aus Silber. Zu den Kosten hatte die Stadt 50 Reichstaler aus einer testamentarischen Verfügung beigesteuert. Die Kirche besaß auch eine Orgel; der Organist war festangestellt und bekam ein Jahresgehalt von 18 Talern oder 39 Gulden. Er konnte, was sicherlich ganz nützlich war, auch die Orgel reparieren. Unter dem Steinboden der Kirche befanden sich zahlreiche Grabstellen, die an die Familien Verstorbener verkauft worden waren. Die Gräber lagen in der ganzen Kirche verstreut, die Nähe zum Chor oder am Marien-Chörchen war natürlich auch mit höheren Kosten verbunden. Die Kirchenstühle wurden gegen eine bestimmte Summe - 6 Albus je Stuhl - vergeben. Die Kirchenfenster müssen, laut Bericht, in schlechtem Zustand gewesen sein. 1639 und 1640 sollen die Chorfenster von Meister Laurens Glaeßmecher für 58 Gulden repariert worden sein. Im Glockenturm hingen drei Glocken, die kleinste wird hier "Mittagsglocke" genannt. Sie erhielten nacheinander neue Riemen zur Befestigung der Klöppel, neue Hanfseile und wurden mehrmals mit Seife gewaschen. Das Kirchendach wurde 1640 an mehreren Stellen repariert.

Um die Kirche herum lag der Kirchhof, der vor Ostern gründlich gereinigt wurde. 1640 stand hier bereits die Skulptur "Christus am Ölberg". Den Kirchhof umgab eine Mauer mit zwei Zugängen: einer nach der Remigiusstraße und der andere zur Bischofsgasse. Sie waren mit Gitterrosten versehen, um das Vieh fernzuhalten. In der Nähe der Kirche lag auch das "Offermanns"-(Küster-) Haus, das 1636, "weil solches gantz verfallen" auf Anweisung der Stadt grundlegend repariert wurde.

Am Fest Maria Lichtmess - "Mariae lehtmissen fest" - des Jahres 1637 erstrahlte die Kirche in besonders hellem Lichterglanz: Alle Altäre, der gesamte Chor und der große Chorleuchter waren mit Kerzen besteckt. Anschließend an das Hochamt erhielten alle von den Geistlichen bis zu den Chorjungen Kerzengeschenke. 
Am "Osterabend", das heißt am Karsamstag, wurde gegen Mittag in der Kirche eine "Simmel Spend" (Semmel-Spende) verteilt, auch hier wieder vom Pastor bis zum Totengräber und den Chorjungen, der Rest für die Armen. Sie waren aus zwei Malter Weizen gebacken, Spenden eines Deutschherren und sieben Bauern aus Kessenich und Poppelsdorf. Am Osterfest stand die 12 Pfund schwere Osterkerze neben dem Altar, außerdem waren alle Altäre reich mit Kerzen versehen. Der Kirchmeister hielt natürlich auch den erhöhten Kommunionweinverbrauch an Ostern in seinen Rechnungen fest: 1643 betrug er 7 Quart 1 Pint. Am Osterdienstag erhielten die Chorsänger eine Weinspende von 4 Quart "Bleichart”, einem hellroten Ahrwein.

Während des ganzen Maimonats wurde nachts durch den Offermann, Quirin Stark, geläutet. Man gedachte durch das Läuten der geweihten Glocken die Dämonen (Hexen) zu vertreiben. - Durch Verordnung des Kurfürsten Maximilian Heinrich vom 29. Februar 1668 war das Mailäuten regelrecht angeordnet, am 26. Januar 1780 dann aber bei 25 Goldgulden unter Strafe gestellt worden. ${ }^{33}$

Am Pfingstdienstag erhielten der Pastor, die "Vice Capellani", Schulmeister, Chorsänger und Kirchmeister nach der Vesper in der Sakristei 4 Quart Bleichart geschenkt.

An Fronleichnam - "H. Sacramentztag" - zog eine Prozession mit größtem Gepränge und Feierlichkeit durch die Stadt. Wie zu Pfingsten erhielten die gleichen Personen wieder die entsprechende Weinspende. 1644 nahmen zum ersten Mal "Engel" daran teil, „ausgezierte Engel ... bürgers Kinder". Sie erhielten zur Belohnung Zuckerkonfekt. Am zweiten Sonntag nach Fronleichnam war "allemal ... Kirchweyung St. Remigii". Das Gotteshaus wurde mit "grünem Mey" geschmückt.

Das Fest des Kirchenpatrons - 1. Oktober - wurde natürlich mit besonderem Glanz begangen. Neben dem Bild des Heiligen wurde eine Kerze von 18 Pfund im Chor aufgestellt. Das Geld hierfür war durch Sammeln im "Kirspel" (Kirchspiel) aufgebracht worden. Nach alter Tradition nahmen an der Prozession auch die Minoriten aus dem nahegelegenen Kloster teil. Auch sie erhielten eine entsprechende Weinspende, ebenso wie die Pfeifer auf dem Turm und die Turmwächter. Die Chorknaben und Jungen erhielten, wie üblich, "Gobbelger" oder "Göbbelchen", die vom Bäcker Johann Hagen in der Sternstraße gebacken worden waren. Wie am Osterabend wurde auch an Heiligabend in der Kirche die "Simmel-Spendt" auf die gleiche Weise und an den gleichen Personenkreis verteilt. Spender der zwei Malter Weizen für ihre Herstellung war Johann Otto Waldbott, Herr zu Gudenau.

Ein namentliches Sterberegister für die angegebenen zehn Jahre bietet das Läuteverzeichnis: Für jedes Geläute beim Begräbnis erhielt die Kirche 12 Albus oder 1/2 Gulden. Eine besonders große Zahl von Sterbefällen, nämlich 104, weist das Jahr 1636 auf. Zu diesem Zeitpunkt wütete in Bonn die Pest. ${ }^{34}$ 


\title{
Das Inventar der Kirche um die Mitte des 17. Jahrhunderts Liber Pastoralis 1646
}

Eine aufschlussreiche Quelle, an der vielleicht auch die Bedeutung von St. Remigius im kirchlichen Leben Bonns gemessen werden kann, ist sicherlich sein "Kirchenschatz". ${ }^{35}$ Es handelt sich um ein 1646 angelegtes Buch, in dem der jeweilige Pfarrer minutiös das gesamte Kircheninventar aufführt. Das Deckblatt ist sehr schön handschriftlich beschrieben und gegliedert:

\author{
„LIBER \\ PASTORALIS \\ Continnens ea, quae spectans ad \\ Parochialem ecclesiam s. Remigii \\ Apud Bonnenses, et Pastoribus ibidem scire expediunt, ac \\ promovere incumbunt. \\ In gratiam successorum suorum \\ congestus et scriptus \\ Lamberto Putz, Juliaceni ex Frotzem \\ ss. Theol. Licent. dicta scientiae \\ Pastore, et ad ss. Martyres \\ Cassium, Florentium soc. \\ Canonico indigno. \\ Anno post natum Christum \\ 1.6.4.6. \\ Deus propitius esto mihi peccatori . Luc 18 \\ S. Remigi ora pro nobis"
}

Man hat den Eindruck, dass der aus dem Jülicher Land, näherhin aus (Vettweiß-)Froitzheim stammende Pfarrer Lambert Putz den Titel mit einem gewissen (Besitzer-)Stolz gestaltet hat.

Die längere Vorrede verrät schon eine gewisse Bildung des Pfarrers: Sie beginnt direkt mit einem Zitat in Hexametern. Der Pfarrer soll darauf bedacht sein, alles zu inventarisieren, sauber und ordentlich zu halten und den Schatz auch noch zu vermehren. Auf den nächsten 14 Seiten wird nun das gesamte Inventar aufgeführt, beginnend mit der großen Monstranz und dem großen Ziborium. Sie sind beide - wie es Vorschrift ist - silbervergoldet. An der Monstranz hängen zwei vergoldete Münzen. Es folgen ein kleineres Ziborium mit einer Pyxis für die Krankensalbung und eine silberne Büchse für die heiligen Öle. Als nächstes wird das bereits in den Kirchenrechnungen erwähnte große silberne Kreuz im Wert von 100 Reichstalern aufgeführt. Dann sechs silbervergoldete Kelche, ein Weihrauchfass, eine Silberschale mit dem Bildnis des hl. Remigius, dazu noch zwei Kelche zur Kommunionausteilung. Schließlich noch drei Stiftungen: ein silbernes Schiffchen mit Löffelchen zum Weihrauchfass, 
eine goldene Münze mit dem Bildnis Papst Ignaz XIII. und eine silberne Dose für die heiligen Öle.

Für 1663 dann die Eintragung von Pastor Josef Bücken der Stiftung des Adolf Wolff Baron von Metternich, einer Monstranz und einer vergoldeten Dose für Hostien.

Unter "N[ota] B[ene]" berichtet Pastor Ferdinand Elckens 1693 von dem Diebstahl der großen Monstranz und des Ziboriums und den Bemühungen um deren Neuanschaffung. Aus einem Vermächtnis erhält er drei Pfund Silber, und auch die Kosten für den Goldschmied werden testamentarisch verfügt. Somit konnten eine neue Monstranz und auch das Ziborium in Auftrag gegeben werden. Der Pastor ließ aber, auch aus Geschenken, noch eine kleine Monstranz für den täglichen Gebrauch und eine silberne Schale anfertigen.

Wegen der Gefahr erneuter Belagerung und Bombardierung ließ der Pfarrer dann die Pretiosen in Kisten verpacken und an Ort und Stelle im Bereich der Kirche vergraben. Als das - bei der Belagerung 1689 - auch nicht mehr sicher genug erschien, wurden sie nach Köln, wo die Gefahr geringer erachtet wurde, zu den Karmelitern gebracht. Der Pfarrer selbst brachte eine Albe, eine Kasel und ein kleines Kreuz in der Sakristei in Sicherheit.

Die Liste des Inventars wird weitergeführt mit "Kupfernen und zinnenen Werck". Darunter werden aufgeführt: sieben schöne kupferne Weihwasserkessel, kleinere und größere kupferne Leuchter, sechs zinnene Schüsselchen mit entsprechenden Ampullen, eine kupferne Lampe vor dem Allerheiligsten und ein größeres kupfernes Licht von der Bruderschaft.

In der Reihe der "ecclesiae libri" werden insbesondere die Kölner Missale, eines in Samt gebunden mit Silber-Schließen, aufgeführt, zwei Römische Missale, zwei Agenden der Kölner Kirche, Vesperbücher, alte und neue Psalteria und Gesangbücher für die Prozessionen.

Sodann werden aufgeführt: Pluviale (Chormäntel) und Kaseln (Messgewänder). An Chormänteln besaß die Kirche drei: Der kostbarste aus weißem Seidendamast mit rotem Aufschlag, auf dem schildförmigen Rückenstück ein mit Gold umbordetes Marienbild; der zweite war von rotem Damast, der dritte von schwarzem wollenen Tuch. An Kaseln führt das Inventar insgesamt 19 Stück auf, in den verschiedensten Farben und kostbarsten Stoffen, im Rückenteil meist mit einem Kreuz belegt, mehr oder weniger reich bestickt. In den folgenden Jahren kamen noch weitere Stiftungen an Kaseln und Dalmatiken hinzu. Insgesamt ein reicher Schatz an Paramenten.

Als nächstes wird alles das genannt, was mit dem Kelch für das Messopfer in Zusammenhang steht: Vela (Tücher zur Verhüllung des Kelches), entsprechend den Messgewändern aufwändig verziert, Corporalia, Purificatoria etc. Besonderen Wert legte man offenbar auf sogenannte Antependien, als Vorhang oder Vorsatztafel vor die steinerne Mensa, den Altarunterbau, angebracht, entsprechend den jeweiligen Festen mehr oder weniger kunstvoll 
gestaltet. Das Inventar weist Antependien für sieben Altäre auf: Für den Hauptaltar - "in Sommo Altari" - hält man sechs Stück vor, die sich in Machund Stoffart sowie Farbe unterscheiden. Das erste: "ein Antependium vom Silbernstuck mit seiden gulden fransen, und aufgesetzter schöner Kanten". Die ebenfalls sechs Antependien für den Marien-Altar sind nicht weniger kostbar, davon ist ein schwarzes im Eigentum der Bäckerbruderschaft - "fraternitatis pistorum". Aufgeführt sind weiter die Antependien für den Anna-Altar, den Katharina-Altar, den Antonius-Altar, den Dreikönigen-Altar - SS.Trium Regum - und den Heilig-Kreuz- oder Leonardus-Altar. Es fällt auf, dass bei der Reihung der sieben Altäre keiner dem hl. Remigius, dem Kirchenpatron, geweiht ist.

Als letztes wird im Inventarverzeichnis aufgeführt "Underscheidliche allerlei gezeughs zierathen", worunter unter anderem ein Kreuz, vergoldete oder wächserne Engelsbilder, „zwei paar gezierte Heiligthums Häupter mit ihren Zubehör", mehrere auf Kupfer gemalte vergoldete Täfelchen, zwei "Chorkäpger" für die Staue des hl. Remigius, drei Stück - zwei blaue, ein buntes - für die Statue der hl. Anna, samt zugehörigen Kronen und Kränzen, für die Statue der Jungfrau eine schöne Perlenkrone und Kränze; schließlich drei kleine Glöckchen, drei rote Antependien für den Tabernakel, und schließlich eine große Fahne und zwei kleinere.

\section{Kircheninventar von 1737}

90 Jahre später, im März 1737, legte Pfarrer Herbert Bauch erneut ein Inventar der Kirche an, mit 64 Positionen nicht so umfänglich wie das vorige. ${ }^{36} \mathrm{Am}$ Anfang werden die beiden Monstranzen, die große und die kleinere, aufgeführt, die inzwischen mit angehängten Kostbarkeiten reich geschmückt sind. Es folgen ein großes und ein kleines Ziborium, acht Kelche mit Patene und Löffelchen, zwei silbervergoldete Becher, mehrere silberne Leuchter, ein silbernes Weihrauchfass mit Schiffchen, kupferne und zinnene Gegenstände und Behältnisse und dann mehr als 30 liturgische Paramente, angefangen von vier Kapellen, der Rest sind dann mehr oder weniger aufwändig, mit Gold- und Silberstickereien auf kostbaren Stoffen gearbeitete Kaseln für alle Feste und Anlässe in allen liturgischen Farben.

\section{Verbindung des Hofes zu St. Remigius}

Die Verbindung des Hofes der Wittelsbacher zur früheren Hofkirche - die Nachfolge hatte jetzt die direkt am Galerieflügel der Residenz und mit dieser durch eine Brücke miteinander verbundene Kirche des Klosters der Franziskaner Observanten übernommen - zeigt sich an entsprechenden Bestattungen im Kirchenraum. Für Clemens August ist dies genauer überliefert: Der in seiner Zeit üblichen Mehrfachbestattung entsprechend wurde, wie bei seinen Vorgängern, beim Tod des Clemens August 1761 das Herz zur Muttergottes 
nach Altötting - dem quasi Hausheiligtum der Wittelsbacher - gebracht, während seine Eingeweide in der Pfarrkirche St. Remigius in Bonn, Gehirn, Augen und Zunge aber in einem kleinen Sepulcrum vor dem Papst Clemens geweihten Altar in der Clemenskapelle der Bonner Kapuzinerkirche beigesetzt wurden. ${ }^{37}$

Einmal jährlich begab sich Joseph Clemens in seiner Funktion als Erzbischof von der Hofkapelle aus zu den beiden Pfarrkirchen St. Remigius und St. Martin zur Taufwasserweihe. Während seines Exils in Frankreich (1702-1715) sollte jeweils am Fest des hl. Joseph in St. Remigius eine von der Josephsbruderschaft organisierte Prozession stattfinden. Als ihr Schirmherr wollte er für den Fall seiner Anwesenheit auch ihr Bruderschaftsgewand tragen. Verschiedene Prozessionen von der Hofkapelle nach St. Remigius sind zudem für diese Jahre für die Woche nach Fronleichnam sowie den Karsamstag überliefert. ${ }^{38}$ Sie belegen die zentrale Rolle der Pfarrkirche St. Remigius innerhalb des Gefüges der Residenz.

\title{
Liste der Pfarrer von St. Remigius
}

Die Pfarrer von St. Remigius wurden aus dem Kreis der Kanoniker des CassiusStiftes, dem das Kollationsrecht zustand, ausgesucht und in das Amt hauptamtlich eingesetzt: ${ }^{39}$

\author{
1559-1579 Albertin Radius \\ 1591 Schwenck \\ 1585-1592 Laurentius Fabritius \\ 1592-1623 Johann Wilich \\ 1623-1641 Johann Jordaneus \\ 1641-1647 Lambert Putz \\ 1647-1662 Ferdinand Strobelius \\ 1662-1691 Johann Buecken \\ $1691-1716$ Ferdinand Elckens ${ }^{40}$ \\ 1716-1740 Herbert Bauch \\ 1741-1753 Franz Rudolf Hoynck \\ 1754-1766 Caspar Kemmerling \\ 1766-1776 Peter Isbach \\ 1777-1797 Cornelius Metternich \\ 1798-1806 Johann Heinrich Joseph Klöckner
}

\section{Gerettete Ausstattungsstücke}

Vor dem Abbruch der Kirche ließ der damalige Pfarrer Klöckner einige der kostbaren Ausstattungsstücke, wie den barocken Hochaltar und den marmornen Taufbrunnen in die ehemalige Minoritenkirche, jetzige Pfarrkirche St. Remigius, die Kommunionbank in die Namen-Jesu-Kirche und die Kanzel in 
Barocker Hochaltar mit dem Gemälde der Taufe des Frankenkönigs Chlodwig durch Bischof Remigius. 1806 aus der abzubrechenden Kirche St. Remigius in die zur Pfarrkirche umgewidmeten ehemaligen Minoritenkirche überführt (Foto: LVR-Amt für Denkmalpflege)

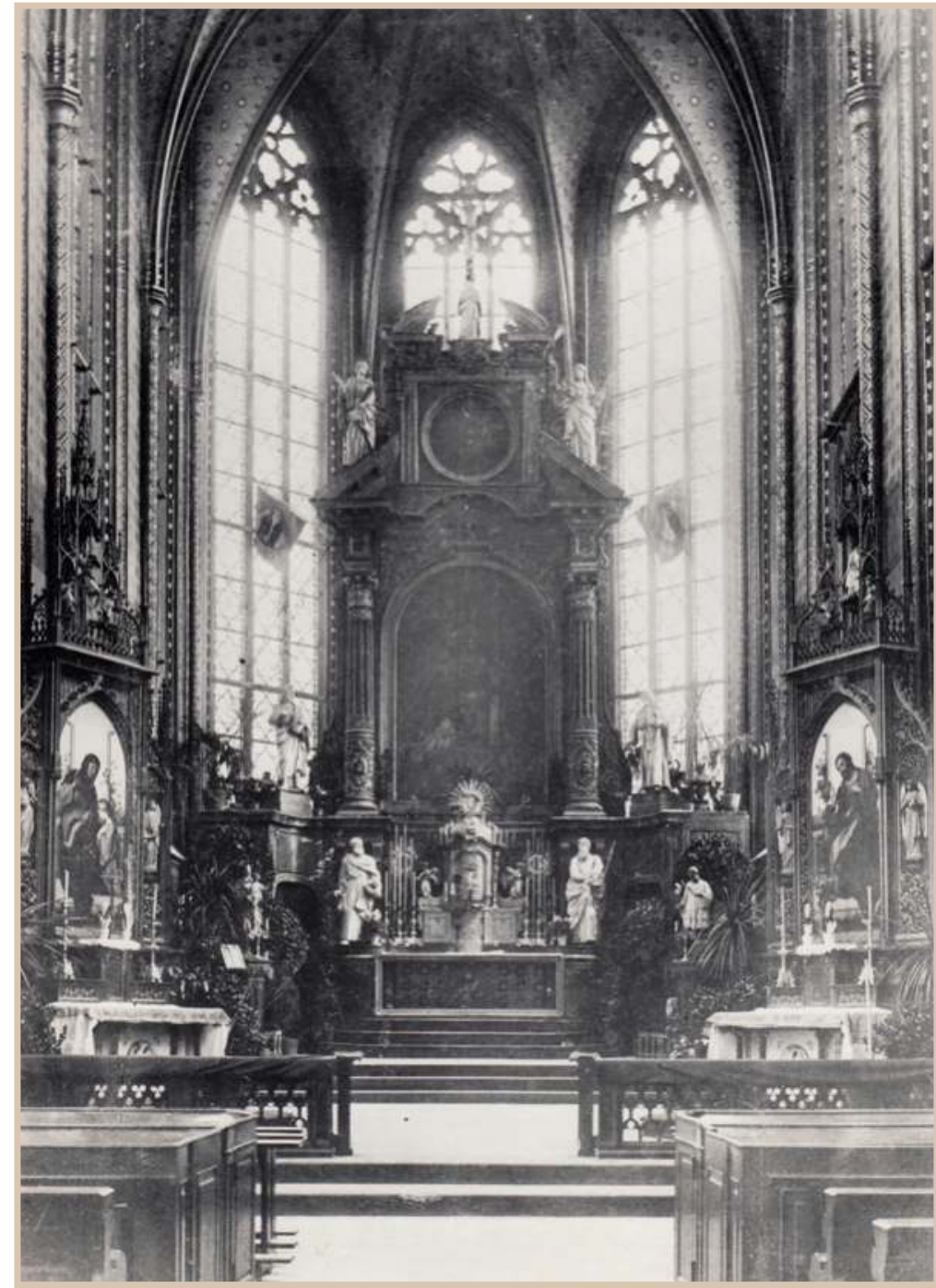

das Münster übertragen. Es hat den Anschein, als wenn diese Ausstattungsstücke gezielt ausgesucht wurden, weil sie an dem neuen Ort mit der neuen Bestimmung als Pfarrkirche bislang fehlten.

Bei der Brand katastrophe von 1689 war die Einrichtung in der Minoritenkirche größtenteils vernichtet worden. Ein neuer Hochaltar wurdevon dem Laienbruder Dorotheus Fucks gefertigt und 1702 konsekriert. Die Wiederherstellung der übrigen Ausstattung erfolgte erst ein halbes Jahrhundert später, ab 1738. Zu ihr gehörte die prachtvolle Kanzel, ursprünglich wohl farbig gefasst. Im Typus folgte sie den aufwändigen Kanzeln der Predigerkirchen der Jesuiten und Minoriten in Köln. Zur Neuausstattung zählte insbesondere die Orgel, ein bedeutendes Werk des Kölner Orgelbauers Ludwig König. Sie ist im Zweiten Weltkrieg durch Feuer zerstört worden. Einzig erhalten hat sich der Spieltisch, der als Leihgabe im Beethoven-Haus in Bonn ausgestellt ist. Auf diesem Instrument hatte auch derjunge Ludwig van Beethoven gespielt. Als letztes erfolgte 1759 die Aufstellung eines neuen marmornen Antonius-Altars in der nördlichen Seitenkapelle. In einer Expositionsnische wurde die silberne Figur des hl. Antonius vom Vorgängeraltar - ein Geschenk des Kurfürsten Maximilian Heinrich von 1661 - eingestellt. ${ }^{41}$

Aus der alten St. Remigiuskirche gelangten vor dem Abbruch außer dem Hauptaltar aber noch andere Altäre in die Minoritenkirche, so der Anna- und Josephs-Altar, ferner zwei Chorbänke. Eine plastische Gruppe "Christus am Oelberg" wurde im Kreuzgang aufgestellt, wo sich bereits andere Gemälde aus der alten Kirche befanden. ${ }^{42}$ Erläuternd hierzu die Angaben in den zeitgenössischen Aufzeichnungen der Anna Catharina Rederscheidt, wonach "alle Heiligen Bilder" aus Alt-St. Remigius in die neue Pfarrkirche übertragen worden sein sollen. ${ }^{43} \mathrm{Im}$ Clemenschen Inventar von 1905 werden noch einige Gemälde und Skulpturen genannt ${ }^{44}$. Von Rederscheidt erfahren wir aber auch über den Verbleib so manch anderer Inventarstücke aus den aufgelösten Klöstern.

70 | Gisbert Knopp 
Am 2. März 1806 hat schließlich in der neuen Pfarrkirche St. Remigius der erste Gottesdienst stattgefunden.

\section{Der Hochaltar}

Der prachtvolle große Hochaltar - er wurde am 30. Januar 1806 aufgestellt ${ }^{45}$ passte von der Größe und den Proportionen sehr gut an seinen neuen Standort. Er war eine Stiftung des Kurfürst-Erzbischofs Maximilian Heinrich zur Erinnerung an seine in der Hauptpfarrkirche St. Remigius am 8. Oktober 1651 durch Kardinal Fabio Chigi, den päpstlichen Nuntius in Köln, Mediator des Vatikan bei den Friedensverhandlungen in Münster und späteren Papst Alexander VII., vollzogenen Bischofsweihe - die erste Konsekration eines Kölner Erzbischofs seit 100 Jahren.

Der großmächtige, von den Figuren Johannes des Täufers und Johannes des Evangelisten, der hll. Lucia und Adelheid ${ }^{46}$, Petrus und Paulus flankierte ädikulaähnliche Altaraufsatz zeigte zwischen kannelierten Säulen und abschließendem Sprenggiebel ein Gemälde mit der Darstellung der Taufe des Frankenkönigs Chlodwig durch Remigius, den Bischof von Reims. Es war dies ein Hauptwerk des deutsch-niederländischen Malers Johann Spilberg (1619-1690), entstanden wohl unmittelbar nach seiner Berufung von Amsterdam als Hofmaler an den Hof Herzog Wolfgang Wilhelms in Düsseldorf. Fast vier Jahrzehnte bis zu seinem Tod am 10. August 1690 war Spilberg am Düsseldorfer Hof, insbesondere als Porträtist, tätig.

Die Darstellung des nicht mehr erhaltenen Gemäldes ${ }^{47}$ ist in einer Lithografie des 19. Jahrhunderts exakt überliefert: In einem säulenumstandenen gewölbten Raum ist die mit reicher Personenstaffage und Assistenzfiguren umgebene Szene deutlich in den Vordergrund gerückt: Remigius in aufwändigem bischöflichem Ornat, weißbärtig, mit der Linken das Pluviale zurückschlagend, tauft den vor ihm knienden Chlodwig. Der hermelingefütterte, mit Lilien bestickte Krönungsmantel, ebenso wie die auf einem verzierten Kissen abgelegten Insignien,
Taufe des Frankenkönigs Chlodwig durch Bischof Remigius. Kreidelithografie des 19. Jahrhunderts nach dem Hochaltargemälde von Johann Spilberg (1655)

(Foto: LVR-Amt für

Denkmalpflege, St. Sturm)

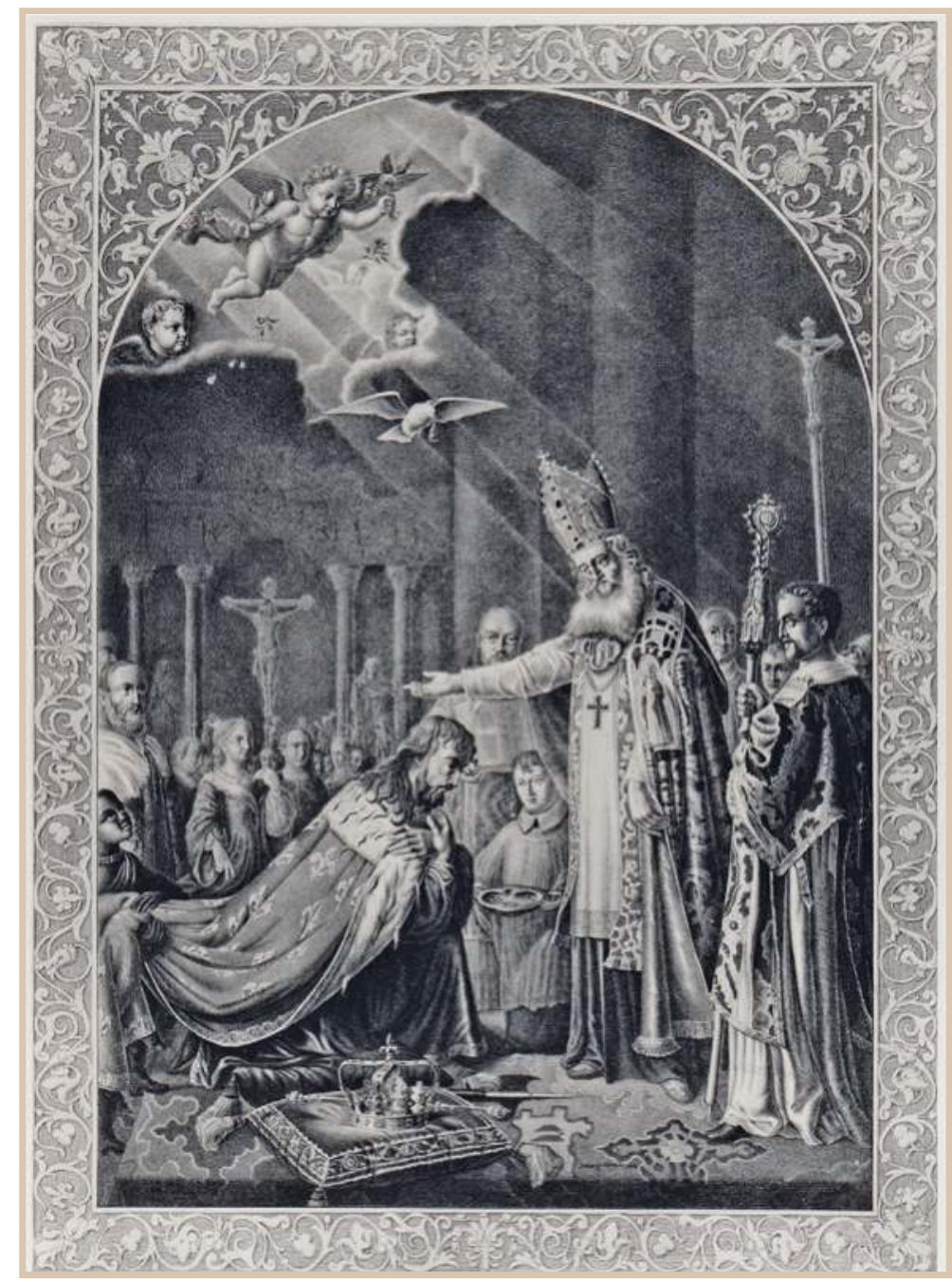




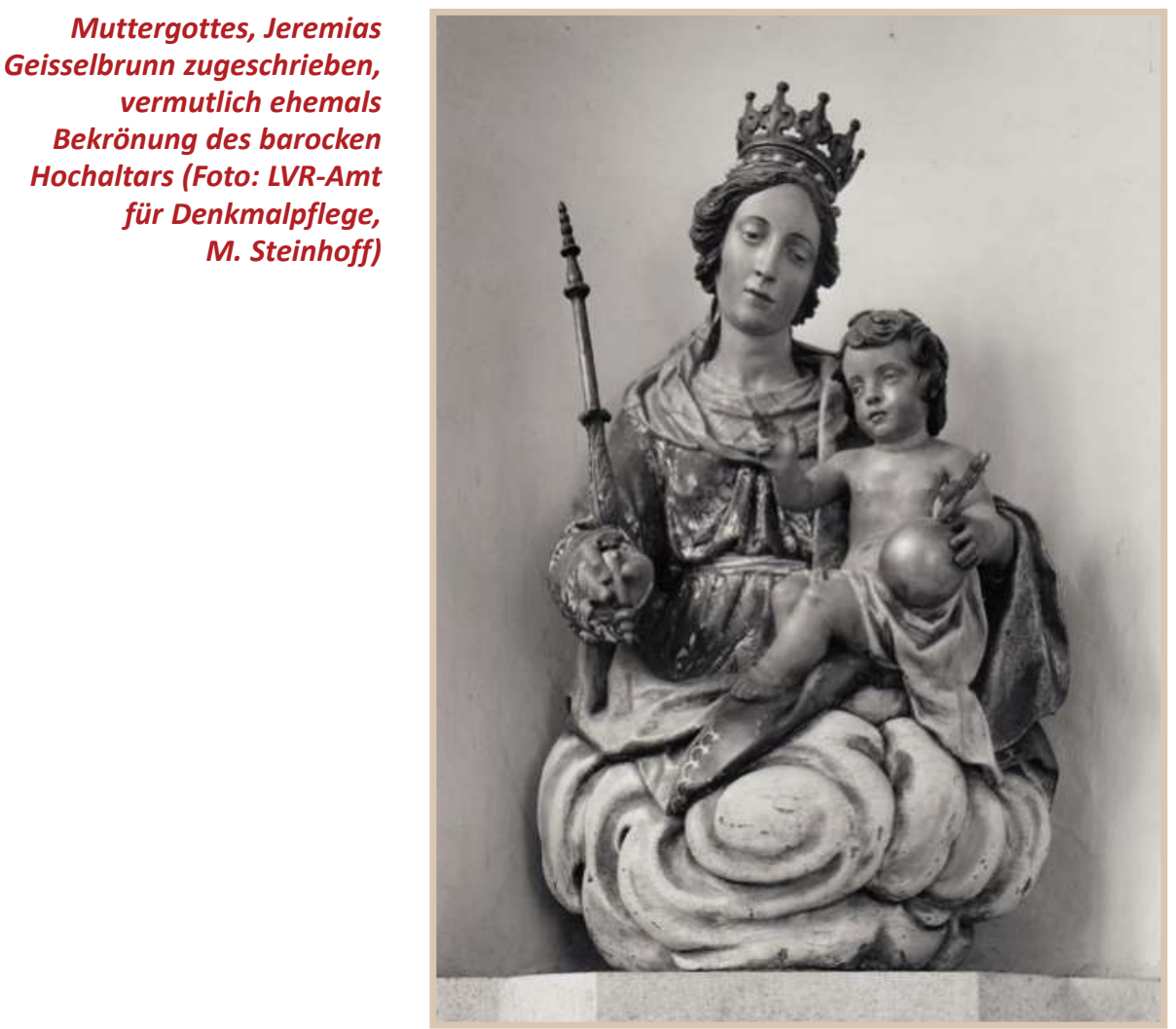

Krone, Zepter und Hellebarde, weisen ihn als König aus. Die ganze Szene ist in Dunkel gehüllt, lediglich durch die aus einer Engelsglorie herabschwebende Taube mit dem Salbgefäß in dem linken oberen Bildteil erhellt.

Neueren stilkritischen Untersuchungen zufolge könnte es sich bei dem Hauptaltar mit seinem umfangreichen Figurenprogramm um ein bedeutendes Werk des Bildhauers Jeremias Geisselbrunn handeln, der in Köln wegen seiner herausragenden Arbeiten, unter anderem in der Jesuitenkirche Maria Himmelfahrt und am Engelbert-Schrein bekannt ist. Von daher liegt auch die Annahme nahe, dass das in der heutigen Remigiuskirche erhal-

tene Andachtsbild der Himmelskönigin als Muttergottes auf den Wolken ehemals, wie nachweislich auf dem Hochaltar der Kölner Jesuitenkirche, ursprünglich den krönenden Abschluss des Altares bildete und zwar statt der später dort befindlichen Schmerzensmutter unter dem hohen Kreuz. Entsprechend ist 1973 ein Abguss der Bonner Madonna dem rekonstruierten Hochaltar der ehemaligen Jesuitenkirche St. Mariae Himmelfahrt in Köln eingefügt worden. ${ }^{48}$

Für die Neuausstattung der jetzigen Pfarrkirche mit den Altargemälden der Spätnazaener wurde 1899 der Barockaltar entfernt und in Einzelteilen im Kreuzgang gelagert. Lediglich das Spilbergsche Gemälde fand einen neuen Platz im Obergaden des südlichen Mittelschiffs an der Stelle, wo sich ursprünglich die erste (Schwalbennest-)Orgel befand. Bei dem Brand im Zweiten Weltkrieg soll es sehr stark beschädigt und schließlich als nicht restaurierbar eingestuft worden sein. ${ }^{49}$ Die in Bonn verbliebenen Bildwerke der Heiligen Petrus, Paulus und Lucia scheinen dem Zweiten Weltkrieg zum Opfer gefallen zu sein.

Während des Ersten Weltkriegs, im Oktober 1916, wurden die architektonischen Reste des barocken Hochaltars zusammen mit dem kostbaren marmornen Antoniusaltar an die Abteikirche auf dem Michaelsberg in Siegburg verkauft und dort auch aufgestellt. Die Zerstörung der Abteikirche im Zweiten

72 | Gisbert Knopp 
Weltkrieg haben die beiden Altäre, wenn auch beschädigt, überstanden; sie wurden aber im Zuge des Wiederaufbaus aus dem Kirchenraum entfernt. ${ }^{50}$

\section{Der marmorne Taufstein}

In der Kirche eines Bettelordens gehört aus naheliegenden Gründen ein Taufstein nicht zum Inventar. Es war daher nur folgerichtig, dass dieser aus der alten Pfarrkirche in die zur Pfarrkirche umgewidmeten Minoriten-Kirche transloziert wurde. Der Taufstein fügte sich der übrigen barocken Ausstattung sehr gut ein. Seine Form ist ungewöhnlich, ebenso wie die reichhaltige Schnitzerei des Deckels. Auf einem am unteren Rand profilierten schmalen Sockel sitzt der ovale Taufbrunnen. Sockel und Becken sind aus heimischem Lahnmarmor gearbeitet.

Als Lahnmarmor werden polierbare Kalksteine des Mitteldevons aus dem Südosten des Rheinischen Schiefergebirges zusammengefasst. Der Abbau dieses international nachgefragten Natursteins reicht bis ins 16 . Jahrhundert zurück. Im Rheinland findet er sich unter anderem an der Balthasar-NeumannTreppe in Schloss Augustusburg in Brühl und an der Heiligen Stiege auf dem Kreuzberg in Bonn.

Dem marmornen Brunnenbecken angepasst ist der gebauchte, kunstvoll geschwungene Deckel. Er wurde, was nicht auf den ersten Blick zu erkennen ist, aus Holz gearbeitet, entsprechend dem Marmor patiniert und an den geschnitzten Verzierungen leicht vergoldet. Geschmückt ist er durch vier sich verjüngende Bänder, die mit floralen Elementen belegt sind. Dazwischen befinden sich am oberen und unteren Rand für das Rokoko typische, sehr kunstvoll und detailreich gearbeitete muschelförmige Rocaillen, die auch eine Datierung des gesamten Taufbrunnens um 1740 erlauben. Bekrönt wird der Deckel durch eine Darstellung des HI. Geistes, symbolisierend in Form einer Taube. Sie hat die Flügel ausgebreitet und den Kopf zum Taufwasser geneigt. An ihrem Corpus ist ein Ring mit der Befestigung zur Anhebung des Deckels. Es hat ganz den Anschein, als sei das

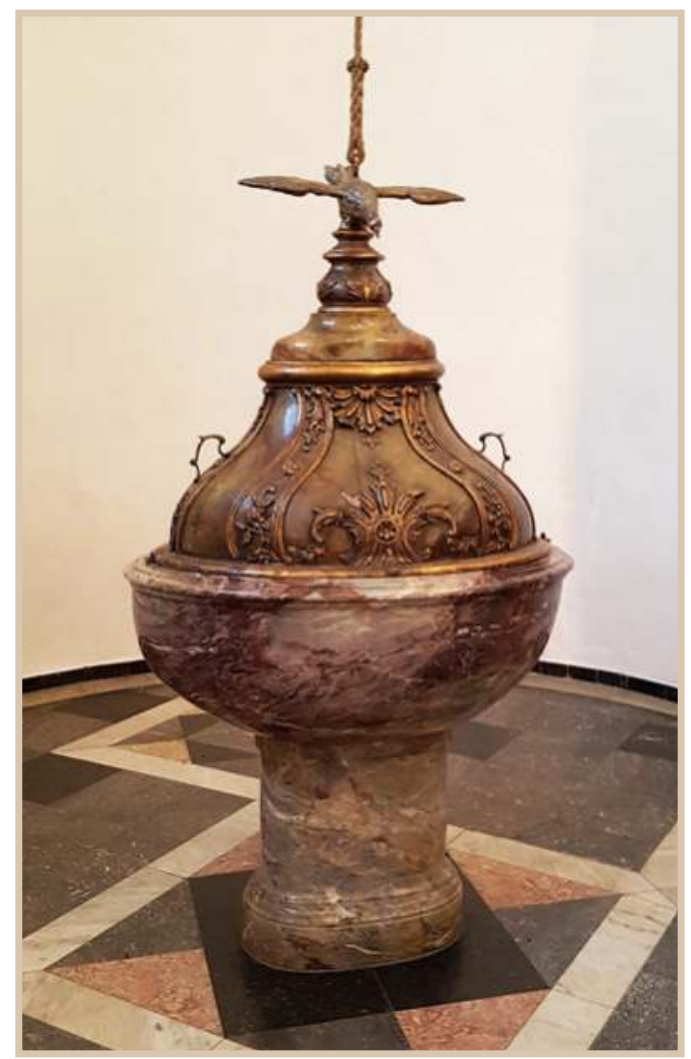

Marmorner Taufbrunnen mit Rocaillendekoration am Deckel. 1806 vor dem Abbruch der alten Remigiuskirche in die frühere Minoritenkirche übertragen (Foto: Gisbert Knopp) 
Holzkunstwerk eine "rheinische” Arbeit, ein Künstler ist allerdings nicht zu ermitteln.

Der lebhaft gemusterte Lahnmarmor hat eine Vielzahl von Farbtönen von gelblichen bis tief dunkelroten. Aber weder der Steinmetz noch die genaue Provenienz des Steins sind bekannt. ${ }^{51}$ Ein von der Form und vom Stil vergleichbarer marmorner Taufstein befindet sich in der Basilika von Ottobeuren.

Die Form der Kuppa, des eigentlichen Beckens, ist schlicht. Höhe 0,90 m, größter Durchmesser 1,00 m, kleinster Durchmesser 0,70 cm.

Mit der ovalen Form weicht unser Taufstein von der üblichen - aus frühchristlichen Baptisterien übernommenen - oktogonalen ab. Die Abmessungen des Taufsteins werden von der Funktion bestimmt: Der Täufling wird über das Becken gehalten und sein Kopf mit dem Taufwasser übergossen.

Das Besondere dieses Taufsteins, was ihn als musikgeschichtliches und kulturelles Zeugnis international interessant macht, ist: Am 17. Dezember 1770 wurde Ludwig van Beethoven in der alten St.-Remigius-Kirche an diesem Taufbecken durch Übergießen mit Taufwasser getauft. ${ }^{52}$ - Für die Beethoven-Verehrung hat sich dieser Taufstein deshalb als eine Art Reliquie entwickelt.

Im März 1933 wurde aus Anlass des 40-jährigen Priesterjubiläums von Pfarrer Lambert Reinermann eine Taufkapelle geschaffen, wobei die Wand hinter dem Emmaus-Altar abgebrochen und der unter Kurfürst Ferdinand 1620 in Ziegeln angebaute kleine halbrunde Nebenchor für diese Funktion geöffnet und "würdig gestaltetet" wurde. Der Taufstein, der „ein Glanzstück der Kapelle" bilden sollte, kam in der Mitte des um eine Stufe abgesenkten Marmorbodens zu stehen. Ein neues Fenster, das der Bonner Glasmaler Jörres nach Entwürfen des Gewerbeoberlehrers Pape anfertigte, ergänzte das Raumbild. Bei der Gelegenheit wurde auch der, wie man meinte, aus „italienischem Marmor" bestehende Taufstein "gründlich erneuert". ${ }^{33}$ Was damit gemeint war, lässt sich bei heutiger Inaugenscheinnahme nur noch ungenau feststellen: der Holzdeckel, der nach Clemen "vergoldet" war ${ }^{54}$, ist heute gelb-bräunlich "marmorierend" überstrichen, nur in den geschnitzten Teilen leicht vergoldet. An allen Seiten zeigen sich zum Teil verkittete, lange Vertikalrisse - die Ansätze der in Einzelteilen gefertigten Stücke. Der große Distanzring zum Knauf ist erneuert und auch ohne Schnitzereien. Die möglicherweise erneuerte Taube darüber erscheint versilbert; ihr rechter Flügel weist eine Bruchstelle auf. Am unteren Becken sind verschiedene mit rotem Marmorersatz verkittete Ausbrüche zu erkennen, vor allem aber ein sich über die ganze Höhe diagonal hinziehender Riss, der nach derselben Methode behandelt wurde.

Bei genauer Betrachtung des Taufsteins am jetzigen Aufstellungsort kommt mir immer mehr der Gedanke, dass hier die Proportionen nicht stimmen: Vermutlich stand der Taufstein nämlich auf einer - ovalen - 10 bis $15 \mathrm{~cm}$ hohen Plinthe oder auf einer ringsum geführten Stufe, beides aus dunklem Lahn- 
marmor. Sie dürfte in der Eile, als man den Taufstein herausbrach, zerbrochen in Alt-St. Remigius verblieben sein.

\section{Die Kanzel}

Die barocke Kanzel, die nicht in die Minoritenkirche gebracht wurde, fand in der ebenfalls zur Pfarrkirche - mit dem übernommenen Patrozinium St. Martin - umgewidmeten ehemaligen Stiftskirche St. Cassius inmitten der Barockaltäre eine neue wunderbare Bleibe. Zuvor dürfte es in der Stiftskirche keine Kanzel gegeben haben.

Drei Pilaster, die sich aus Voluten entwickeln, unterteilen den elegant geschwungenen Kanzelkorb. Auf den Voluten sind die vier Evangelistensymbole und das auf einem Buch stehende Lamm mit dem Kreuz als Hinweis auf die Apokalypse dargestellt. Die Unterseite des Schalldeckels zeigt die Taube als Symbol des HI. Geistes. Auf dem oberen Rand sitzen Moses mit den Gesetzestafeln und David mit der Leier: Sie deuten den Ort der Verkündigung der Gebote und des gesungenen Lobes Gottes an. Nebensitzende Putten zeigen auf die von Voluten getragene Bekrönung: das Auge Gottes in dreieckigem von einem Strahlenkranz umgebenen Nimbus. In ihren fein gearbeiteten Ornamenten und Figuren stimmt die Kanzel

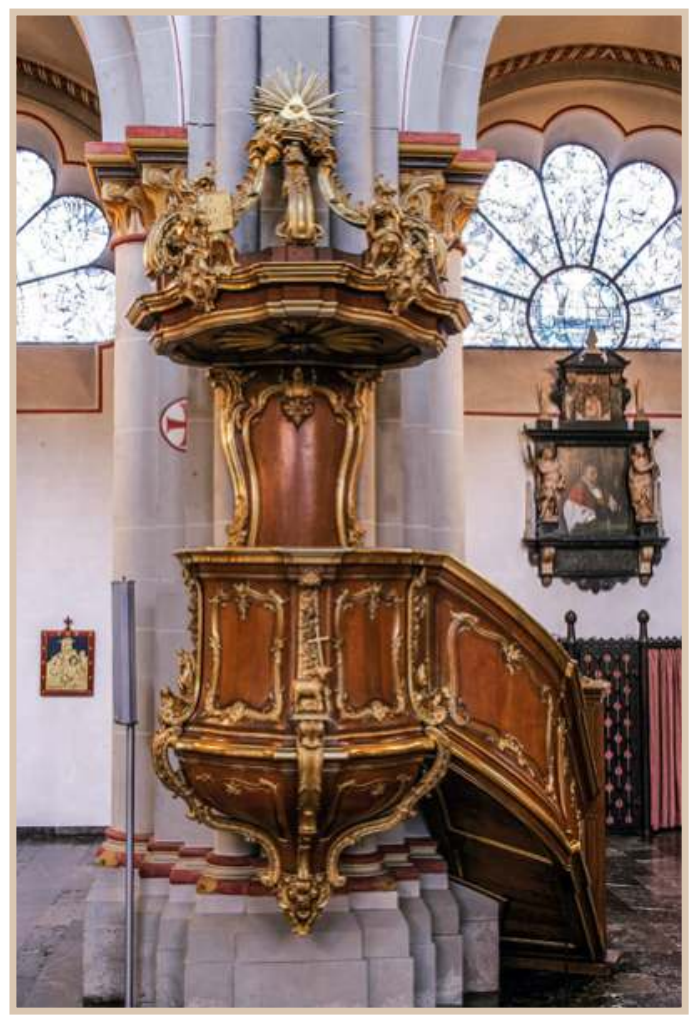
zeitlich mit dem Taufstein überein, wobei auch hier eine Werkstatt oder ein Künstler nicht zu ermitteln sind.

1966 wurde die Kanzel umfassend restauriert, spätere Farbschichten entfernt, die fehlenden Teile nachgeschnitzt und in den Ornament- und figürlichen Teilen neuvergoldet.

\section{Grabsteine}

Wie die meisten mittelalterlichen Kirchen diente auch das Innere von St. Remigius als Begräbnisstätte. Nur eine einzige Grabplatte wurde offensichtlich beim Abbruch aus der Kirche sorgfältig aus dem Boden gelöst, auf den Alten Friedhof verbracht und dort an der nördlichen Friedhofsmauer aufgestellt. Sie ist heute verschollen. Dabei handelte es sich um die Grabplatte des 1685 ver-
Barocke Kanzel im Bonner Münster, aus der Pfarrkirche St. Remigius vor deren Abbruch 1806 übertragen (Foto: Nobert Bach) 
storbenen Maximilian Heinrich von Burman, Sohn des kurfürstlichen Geheimrats und Kanzlers Peter von Burman, 1674 Dechant von St. Simeon in Trier und St. Georg in Köln sowie Trierer Generalvikar und Offizial, schließlich Trierer Titularbischof. Die Familiengrabstätte befand sich der Inschrift zufolge vor dem Marien-Altar. ${ }^{55}$

\section{Das vermeintliche Aussehen von St. Remigius - Bildquellen, Ansichten}

Das Aussehen des Kirchengebäudes von St. Remigius über die Jahrhunderte hinweg gibt nach wie vor Rätsel auf, was auch an den ungenügenden Bildquellen liegen mag. Auch German Hubert Maaßen, der Verfasser der Bonner Dekanatsgeschichte, kann schon 1894 kein Bild mehr von der abgebrochenen Kirche geben, hält lediglich fest, dass das Kirchengebäude in den Wechselfällen vielfache Erneuerungen und viele Veränderungen erfahren habe, und dass die Abbildung im Merian-Stich sicherlich nicht das älteste Bauwerk widergibt. ${ }^{56}$

Die Archäologen haben bei ihrer Grabung 1934 Reste von Grundmauern einer kleinen Saalkirche des 8. Jahrhunderts und von zwei späteren Bauten freigelegt. Als früheste Anlage ergab sich nach ihrem Bericht ein geosteter Rechteckbau von 4,50 m lichter Breite und unbestimmter Länge, mit $50 \mathrm{~cm}$ breiten Tuffmauern in Lehmverband, 2,00 bis 2,20 $\mathrm{m}$ unter dem heutigen

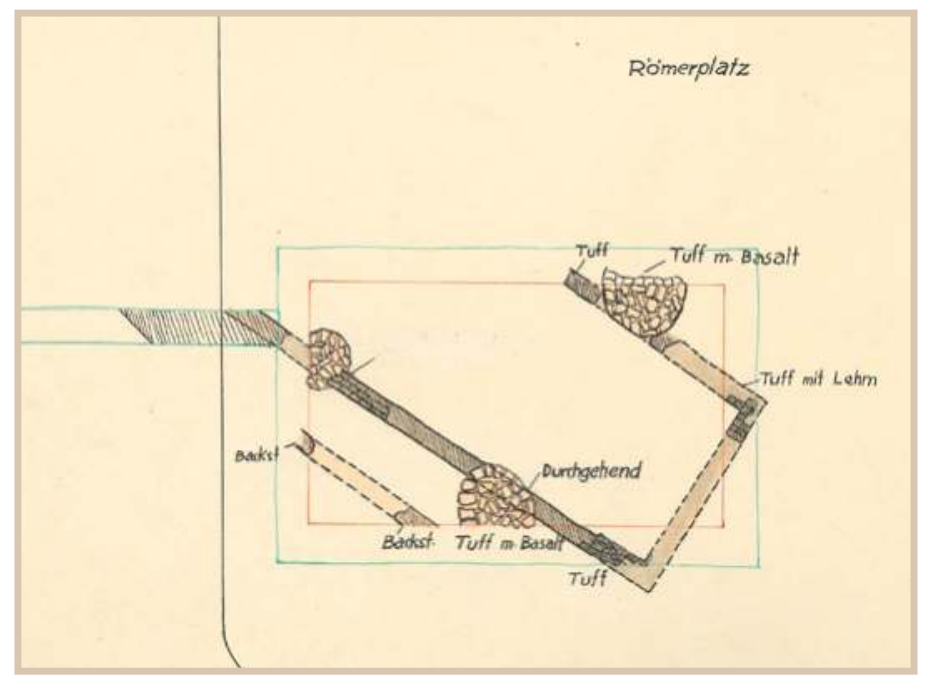
Straßenniveau, teils nur in der untersten Steinlage, teils bis zu 1,20 m Höhe erhalten. Nördlich daneben wurde eine jüngere gleichgerichtete Mauer von $60 \mathrm{~cm}$ Breite aus Basalt, Tuff, Ziegelbruch in Trassmörtel 0,50 bis 1,80 m unter der heutigen Oberfläche festgestellt. Zu einer noch jüngeren Anlage gehören drei runde Pfeilerfundamente von 2,00 m Durchmesser aus geschichteten Basalt- und Tufflagen in Trassmörtel. Ein Pfeiler liegt auf der untersten Lage des ältesten Baus; die beiden anderen Pfeiler haben dessen Mauern durchbrochen. Die Oberkanten der drei Pfeiler lagen 0,80, 0,20, 1,70, die Unterkanten 2,00 m unter der heutigen Oberfläche. Die Ausschachtung reichte bis 2,20 m Tiefe im Lehmboden. Das Gelände, beson-

Grabungsplan (1934) Josef Heinen (LVR-Landesmuseum Bonn/LVR-Amt für Bodendenkmalpflege im Rheinland) ders die Südwesthälfte, war mit späteren Sargbestattungen belegt. ${ }^{57}$

Bei dem doch relativ tief gegründeten Pfeilerbau, von dem sich hier Reste fanden, wird es sich zweifelsfrei - auch dem Steinmaterial nach zu urteilen - um den romanischen Bau des 11./12. Jahrhunderts handeln. St. Remigius war mittlerweile die Pfarrkirche Bonns mit dem größten, umfangreichsten Pfarrsprengel geworden.

76 | Gisbert Knopp 
Die Grabung von 1968 durch Walter Sölter auf dem Remigiusplatz ist in ihrem Ergebnis nur schwer zu deuten und vor allem nicht mit der früheren Grabung in Verbindung zu bringen ${ }^{58}$. Wie erwähnt wurde beim Abbruch von St. Remigius ein Teil des Steinmaterials beim Bau des Arresthauses in der Kesselgasse verwandt. In den Fundamenten des Gebäudes fanden sich beim Abbruch 2011 einige für die Baugeschichte aufschlussreiche Spolien, so unter anderem der Teil eines Kreuzrippengewölbes, ein Gesimsteil oder auch ein Teil des Kreuzrippengewölbes sowie das Bruchstück eines Blendmaßwerks. Von diesen Teilen lässt der Schnitt des Kreuzrippengewölbes mit dem im Rheinland nicht unüblichen so genannten Birnstabprofil - Kölner Dom, Chorerdgeschoss; Altenberger Dom, nördlicher Vierungsbogen; ehemalige Minoritenkirche in Bonn beide Seitenschiffe - eine exakte Datierung um 1275 zu. Was bedeutet

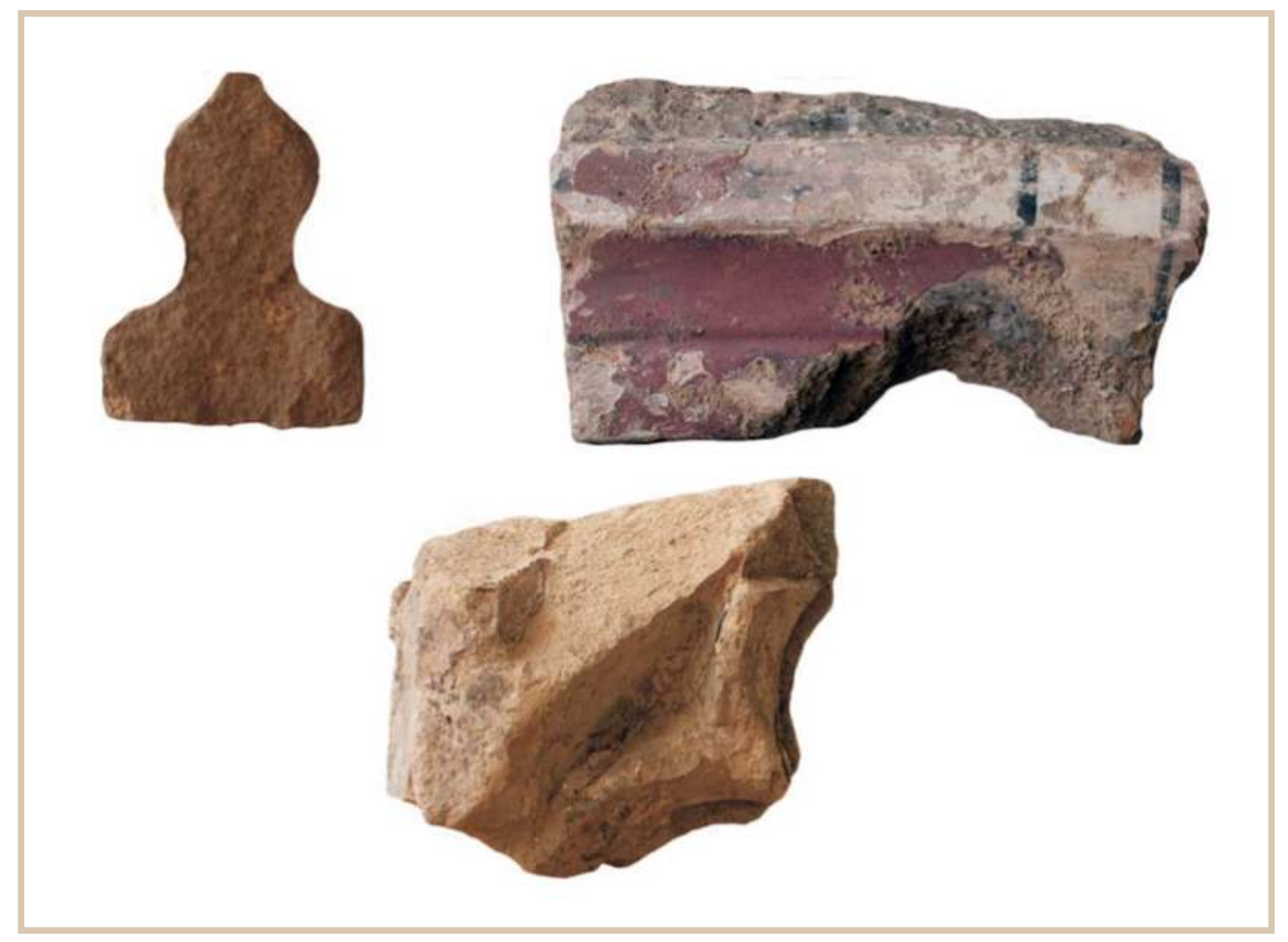

dies für St. Remigius? Mit Sicherheit, dass der Bau - in der Nachfolge des romanischen Kirchleins - insgesamt der Zeit der Hochgotik, also der zweiten Hälfte des 13. Jahrhunderts angehört. Der romanische Turm dürfte bei diesem gotischen Neubau als fester Bestandteil geblieben sein.

Für die Folgezeit geben Darstellungen auf Stichen, Karten, Plänen und Gemälden eine, wenn auch nur ungenügende, Vorstellung vom äußeren Aussehen von St. Remigius.
Gotische Spolien aus St. Remigius, 2011 ergraben aus den Fundamenten des Arresthauses in der Kesselgasse (Fotos: ABS Gesellschaft für Archäologische Baugrund-Sanierung, Köln) 


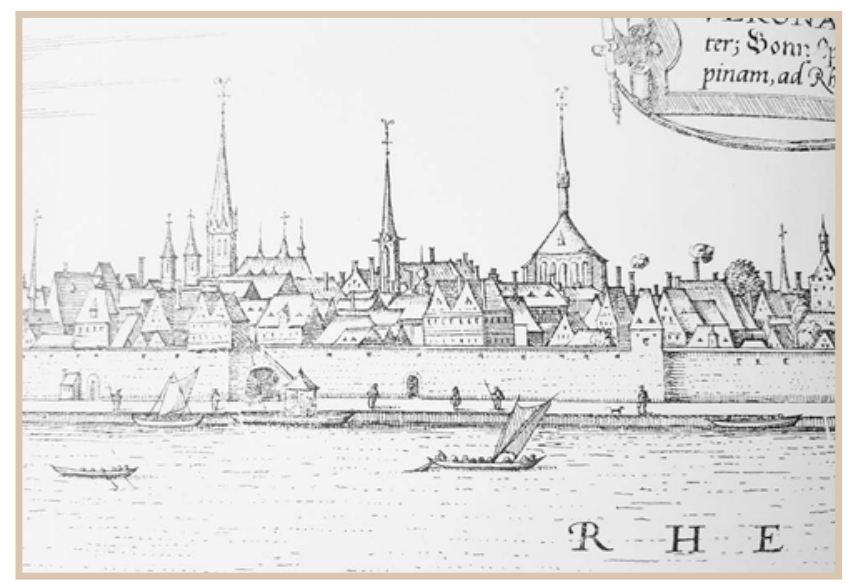

1. Dem Kupferstich einer Rheinansicht von Franz Hogenberg. In einer Kartusche bezeichnet „VERONA, nunc BONNA, Communiter; Bonn Oppidum supra Coloniam Agrippinam, ad Rheni flumen, illusstre 1575".

Zu sehen ist zwischen den Türmen des Münsters (seitenverkehrt) und der Minoritenkirche in der Brüdergasse die Remigiuskirche, ein schlanker hoher Turm mit Hauptschiff und nördlichem Seitenschiff.

2. Die Vogelschau auf Bonn von Petrus Pannensmit, datiert, Neuss 3. Februar 1588. Sie ist bezeichnet als „Warhaftige Abconterfeytung der Churfürstlichenn Stat Bonn, mit ihren kirchen, Clöstern, Pfortzen, Thürmen, graben, Straessen und Gassen, wilch den

Ausschnitt aus der Rheinansicht Verona, nunc Bonna ..., der ersten Gesamtansicht von Bonn.

Kupferstich von Franz Hogenberg, 1575 (Stadtarchiv Bonn)

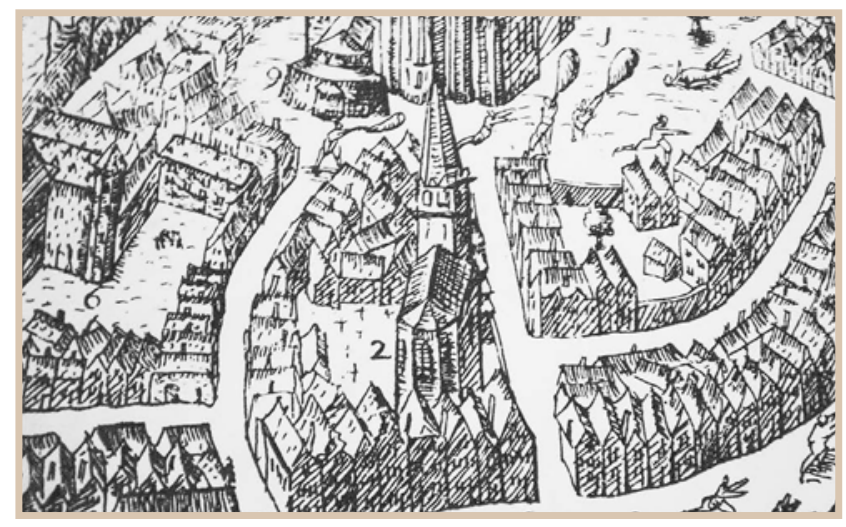

23. Decembris Anno 1587 durch Martin Schenk eingenommen". (Es folgt die Widmung an Francesco Voss).

St. Remigius ist mit Nr. 2 gekennzeichnet und liegt mit dem Friedhof in OstWest-Richtung auf dem Remigiusplatz direkt hinter der Häuserzeile des Marktplatzes. Wenn es sich wirklich um eine "naturgetreue" Abbildung des Stadtbildes handelt, dann sieht man in St. Remigius eindeutig einen einheitlich-gotischen Bau, einschiffig, mit polygonalem Chor. Der hohe, mit Dreiecksgiebeln verzierte Turm könnte noch vom romanischen Vorgängerbau stammen. In der zeitlichen Einordung des Kirchengebäudes käme, wie bei der Minoritenkirche, die zweite Hälfte des 13. Jahrhunderts in Frage.

3. Eine weitere Vogelschau aus demselben Jahr 1588 von Gerardus Stempel zeigt Bonn und die ganze Umgebung während der Belagerung mit den einzelnen Truppenteilen. Das ist wohl auch der wichtigere Bildinhalt, während die Topografie der kleinen Stadt doch eher vernachlässigt wurde. St. Remigius ist als kleiner romanischer Bau dargestellt, einschiffig

Wahrhafftige Abconterfeytung der Churfürstlichenn Stat Bonn... Ausschnitt aus dem Stadtplan von Bonn. Kupferstich von Petrus Pannensmit, 1588 (Stadtarchiv Bonn) mit mittlerem Querhaus und vorgesetztem Westturm.

4. Die vorige Darstellung dürfte möglicherweise die Vorlage für die Darstellung von St. Remigius in dem bekannten Kupferstich von Matthäus Merian von 1646 gewesen sein. Sie zeigt, wie im Stempel-Stich, das kleine romanische Kirchengebäude, einschiffig mit zweijochigem Querhaus und vorgesetztem Westturm, der in den beiden Untergeschossen die Breite des Schiffs aufweist. Hier ist auch mit dem großen Portal der Hauptzugang zur Kirche deutlich gemacht. Der Ansatz des Turmhelms ist durch Dreiecksgiebel verunklärt.

78 | Gisbert Knopp

(C) 2020 by Böhlau Verlag GmbH \& Cie. KG, Köln

https://doi.org/10.7788/9783412519704 | CC BY-NC 4.0 


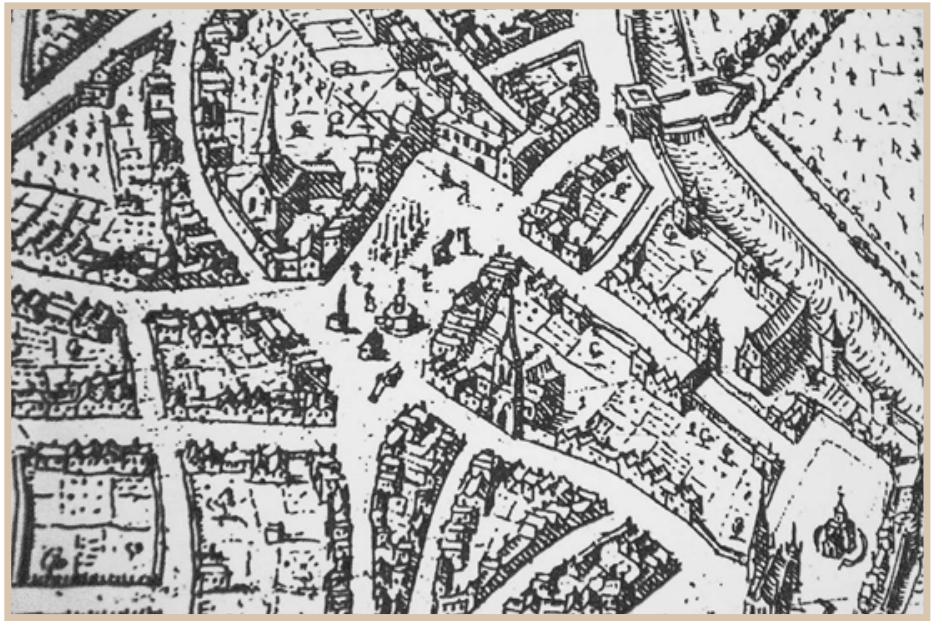

Ausschnitt aus dem Plan Bonn und Umgebung aus der Vogelschau anlässlich der Belagerung von 1588. Kupferstich von Gerardus Stempel (Stadtarchiv Bonn)

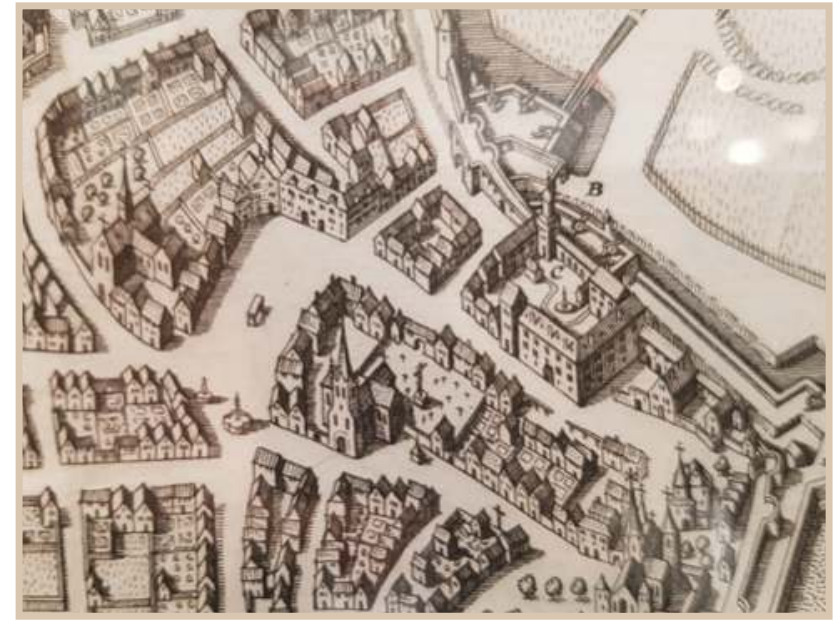

Ausschnitt aus dem Vogelschauplan der Stadt Bonn. Kupferstich von Matthäus Merian, 1646 (Stadtarchiv Bonn)
Obwohl diese Darstellung, gerade in letzter Zeit, als wirklichkeitsgetreues Abbild für das Äußere von St. Remigius angesehen wird, kommt es für eine realistische Betrachtung des Kirchengebäudes nicht in Frage. Abgesehen davon, dass bei Merians Stadtansichten in den Einzelbauten keine Detailgenauigkeit verfolgt wird, gibt es für St. Remigius andere Gründe, die ein derartiges kleines, mittelalterlich anmutendes Kirchengebäude ausschlieBen: Bereits im Kircheninventar von 1646 - dem Jahr der Entstehung des Kupferstichs - werden sieben Altäre genannt, die in der Kirche in Benutzung sind. 1651 wird für die Kirche ein großer Barockalter gestiftet, der später, vor dem Abbruch von St. Remigius in der ehemaligen Minoritenkirche aufgestellt wird. Da er hier bis ins Gewölbe reichte, ist eine Höhe von etwa 12 m anzunehmen. Er hätte sicherlich die Dimensionen dieses kleinen romanischen Kirchenraums gesprengt.

5. Eine Überraschung bietet in der Hinsicht ein Gemälde des Niederländers Abraham Storck von $1674 .{ }^{59}$ Es zeigt das Rheinufer, perspektivisch stark verkürzt, mit dem schlossartigen Zollhaus und dem "Neuen Turm", rechts davon, stark ans Ufer gerückt, die Minoritenkirche und links, ganz ohne Zweifel, die Westfront von St. Remigius: den stattlichen quadratischen Turm zwischen beiden Seitenschiffen. Der Turm weist über zwei Rundbogenfenstern die umlaufende Galerie für die städtische Feuerwache auf. Über der Galerie die auf anderen Abbildungen gelegentlich zart angedeuteten Dreiecksgiebel, hier sogar mit Uhr,
Das Bonner Rheinufer von Süden.

Ölgemälde von

Abraham Storck, 1679

(StadtMuseum Bonn) 
Das Bonner Rheinufer von Süden. Ölgemälde von Abraham Storck, 1679 (Ausschnitt) (StadtMuseum Bonn)

links: Grundriss Bonn von Leo Scheufele, um 1674 (Ausschnitt) (aus: SATZINGER, Das kurfürstliche Schloss in Bonn)

rechts: Situationsplan Bonn von Antonio Riva, 1713 (Ausschnitt) (aus: SATZINGER, Das kurfürstliche Schloss in Bonn)

Stadtplan zum Register der Stadt Bonn von 1773 (Ausschnitt) (Kopie Stadtarchiv Bonn) und dahinter die Turmhaube als Faltdach ausgebildet, wie wir es vom Münster her kennen vor der Zerstörung 1689.

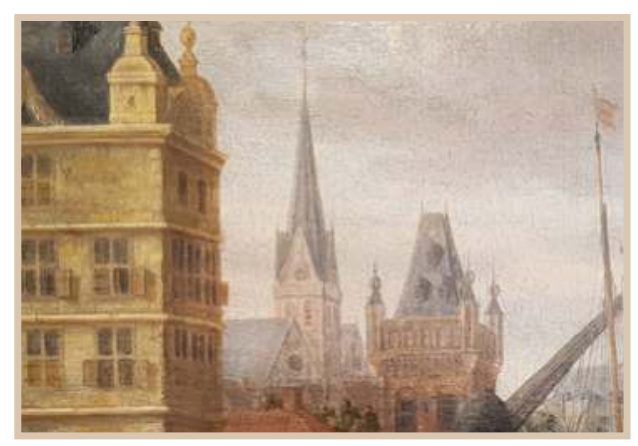

Insgesamt eine realistische Darstellung mit hoher Wahrscheinlichkeit, wohl die letzte Darstellung für die Zeit vor der Zerstörung von 1689.

6. Ein "Geometrischer Grundriß der Residenz Vestung Bonn von Leo Scheufele", um 1674, zeigt für St. Remigius einen dreischiffigen Grundriss mit polygonalem Chor und einem Anbau an der Nordseite.
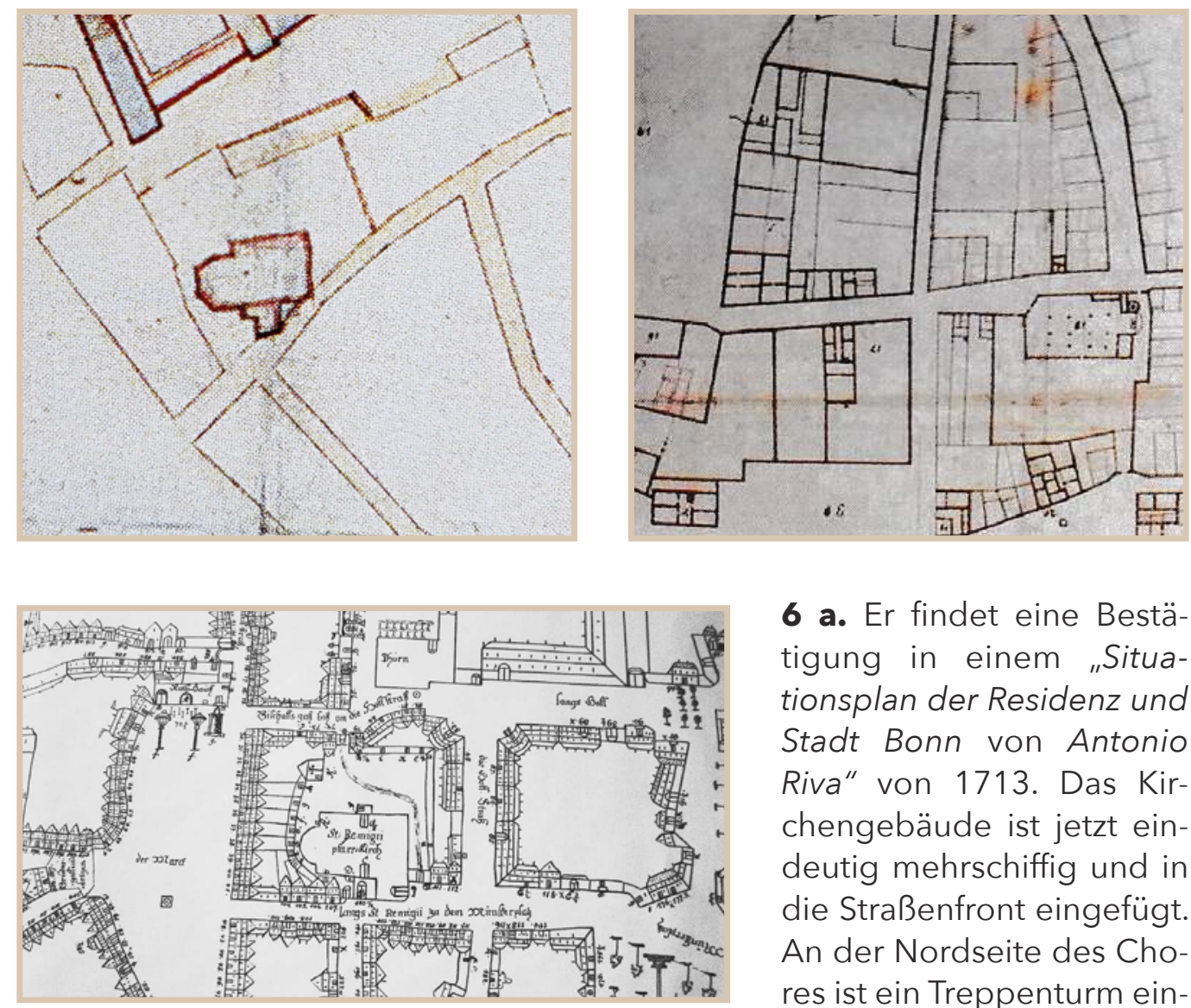

6 a. Er findet eine Bestätigung in einem "Situationsplan der Residenz und Stadt Bonn von Antonio Riva" von 1713. Das Kirchengebäude ist jetzt eindeutig mehrschiffig und in die Straßenfront eingefügt. An der Nordseite des Chores ist ein Treppenturm eingestellt.

6 b. Auch der Stadtplan zum Register der Stadt Bonn von 1773 zeigt einen breiten, wohl mehrschiffigen Kirchenraum, allerdings mitrundem Chorabschluss und südlichem Eingang. An der Nord-West Ecke ist bereits der Grundriss des - neuen - Turmes (s. u.) mit Zugang von Westen ausgewiesen.

80 | Gisbert Knopp

(c) 2020 by Böhlau Verlag GmbH \& Cie. KG, Köln

https://doi.org/10.7788/9783412519704 | CC BY-NC 4.0 
7. Etwas Licht in das Dunkel bringt ein Plan wohl aus den 1770 er oder 1780er Jahren. Er zeigt das ummauerte und mit den Stadttoren markierte Stadtgebiet; eingezeichnet sind, was erstaunen mag, nur die Kirchen, insgesamt dreizehn (s. S. 35). Die einzelnen Bauten sind, obwohl sehr klein, detailgenau dargestellt. Sie verraten eine geübte Hand und genaue Ortskenntnis. Planverfasser ist, laut

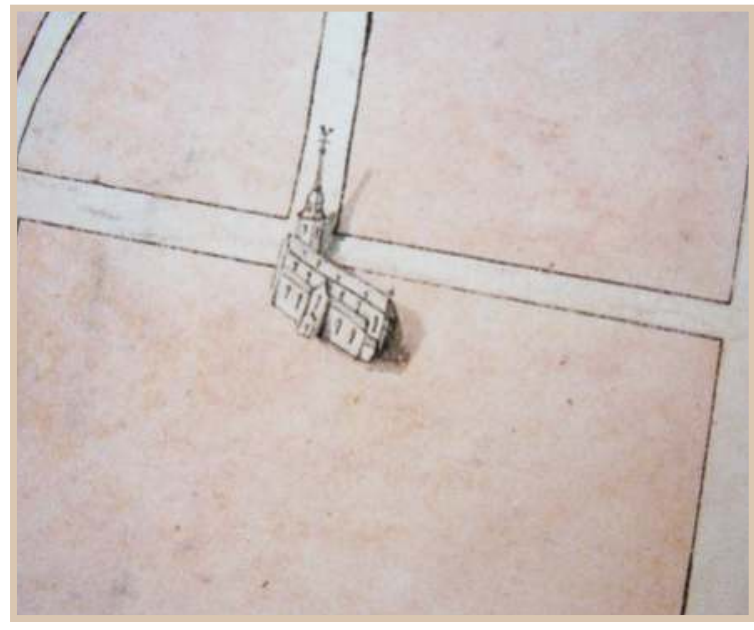

Bezeichnung am unteren rechten Rand, Hermann Sandfort (1752-1819). Von ihm stammt auch ein kürzlich in Wien in der Österreichischen Nationalbibliothek aufgefundener großformatiger Plan der Bonner Residenz mit Teilen der Gartenanlagen aus dem Jahr 1775. Sandfort ist für diese Zeit belegt als Mathematiklehrer, dann Professor der 1773 gegründeten Akademie und späteren Universität, aber auch als Landvermesser und entwerfender Architekt ${ }^{60}$. In welcher, möglicherweise städtischer, Funktion er unseren Plan erstellte, ist ebensowenig zu ermitteln wie der Anlass zu seiner Erstellung.

Die Remigiuskirche in OstWest-Richtung eingezeichnet als fünfjochige, dreischiffige Basilika mit übergiebeltem Querhaus, polygonalem Chor und hohem Turm am nördlichen Seitenschiff. Und gerade dieser Turm liefert den Schlüssel zu neuen Erkenntnissen: Er ist nämlich nicht mehr Teil der Westfront, sondern seitlich an der Nordseite angelehnt und mit barocker welscher Haube bekrönt. Nach den vielen Bränden und Teilzerstörungen des mittelalterlichen Westturms, zuletzt 1689, verwundert es nicht, wenn der Turm in einfacher schlichter

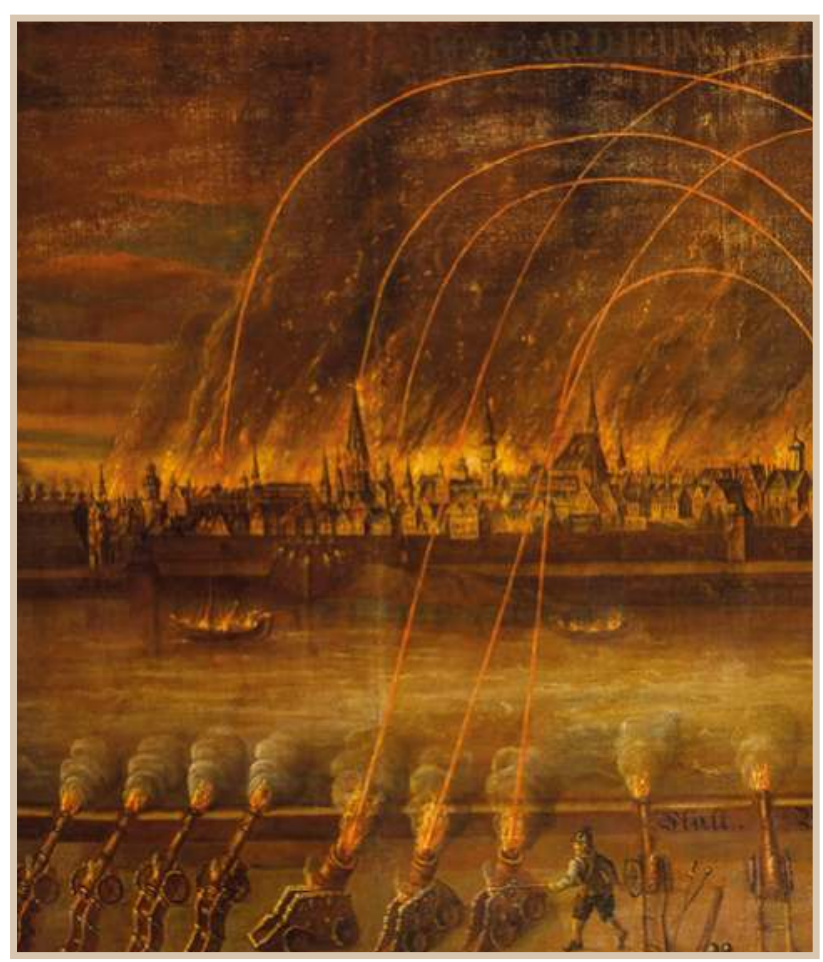

Alt-St. Remigius - nicht nur Beethovens Taufkirche | 81 (c) 2020 by Böhlau Verlag GmbH \& Cie. KG, Köln https://doi.org/10.7788/9783412519704 | CC BY-NC 4.0
Plan der Stadt Bonn. Gezeichnet von Hermann Sandfort, um 1780 (Ausschnitt) (Stadtarchiv Bonn)

Die Bombardierung Bonns. Gemälde eines unbekannten Malers, um 1700 (Ausschnitt) (StadtMuseum Bonn) 
Stadtansicht Bonns. Detail aus dem Gemälde des Stadtpatrone-Altar im Bonner Münster, 1704 (Foto: Nobert Bach)

Stadtprospekt von Bonn. Kupferstich von Johann Georg Ringlin nach Friedrich Bernhard Werner, nach 1700. St. Remigius mit Nr. 14 bezeichnet (Ausschnitt) (Stadtarchiv Bonn)

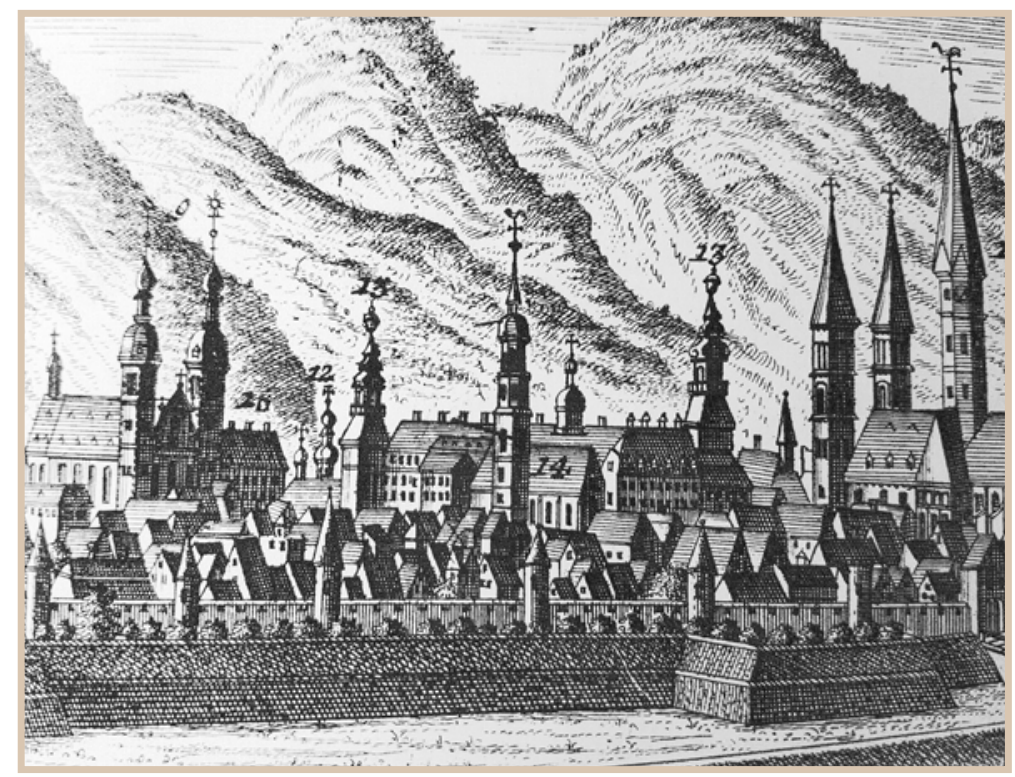
Beueler Schanze aus. ${ }^{61}$ Turm.

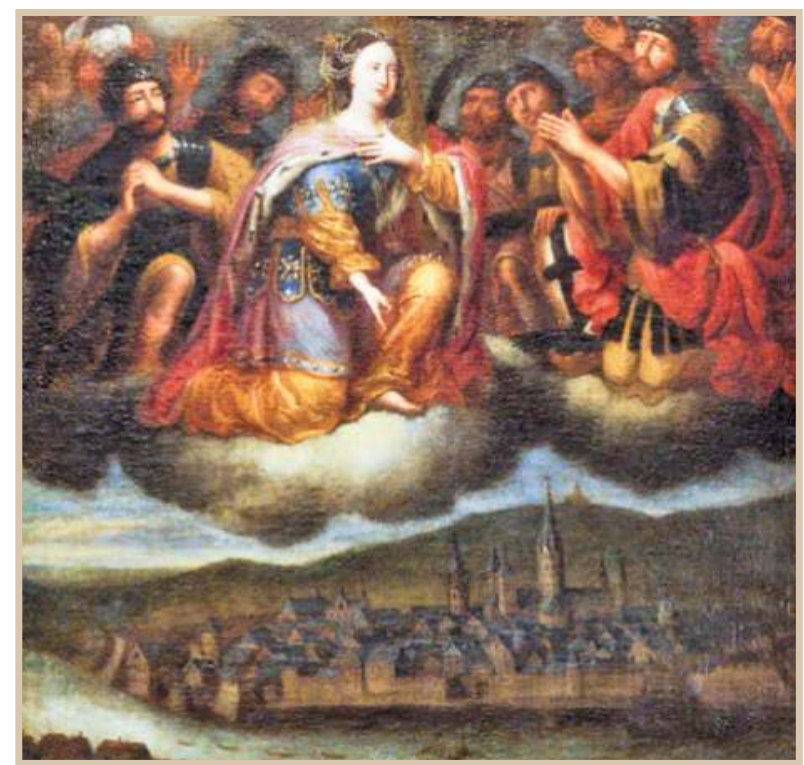

Bauweise - möglicherweise nur als Treppenturm - eiligst hochgezogen wurde, um den Glocken und der städtischen Brandwache eine neue Bleibe zu geben. Dabei ist der mittelalterliche Turm bis auf die Höhe des Kirchendachs heruntergezont, denDachflächen angeglichen, um die weitere Nutzung als Kirchenraum und Eingang sicherzustellen. Die Errichtung des neuen Turms erfolgte nach dem erwähnten Hinweis offiziell ab Oktober 1720, möglicherweise aber schon früher.

7 a. Der Turm in seiner barocken Vielfalt ist bereits in dem mit größter Akribie gemalten Stadtprospekt im Gemälde "Die Bombardierung Bonns 1689" zwischen dem Münster und der Minoritenkirche deutlich sichtbar. Das einige Jahre später fertiggestellte Bild zeigt die Bombardierung Bonns von der

7 b. Auch die Stadtansicht im Gemälde des Stadtpatrone-Altars im Bonner Münster - gestiftet 1701, fertiggestellt 1704 - zeigt bereits den neuen barocken

8. Eine Bestätigung für den seitlichen Turmneubau findet sich auf dem Stadtprospekt von Werner und Ringlin, entstanden bald nach 1700 (als Nr. 14 gekennzeichnet): ein sehr schlanker, wenigstens sechsgeschossiger Turm. Das obere Geschoss ist oktogonal, zurückversetzt mit Galerie, darüber eine offene Laterne und als Bekrönung eine Welsche Haube und der unvermeidliche Hahn.

8 a. Das oberste Geschoss mit Turmhaube und langgezogener Bekrönung ist auch auf einer der Radierungen von Jacob Rousseau vom Schlossbrand 1777 über den Arkaden des Nordflügels vom Innenhof der Residenz zu erkennen.

82 | Gisbert Knopp 


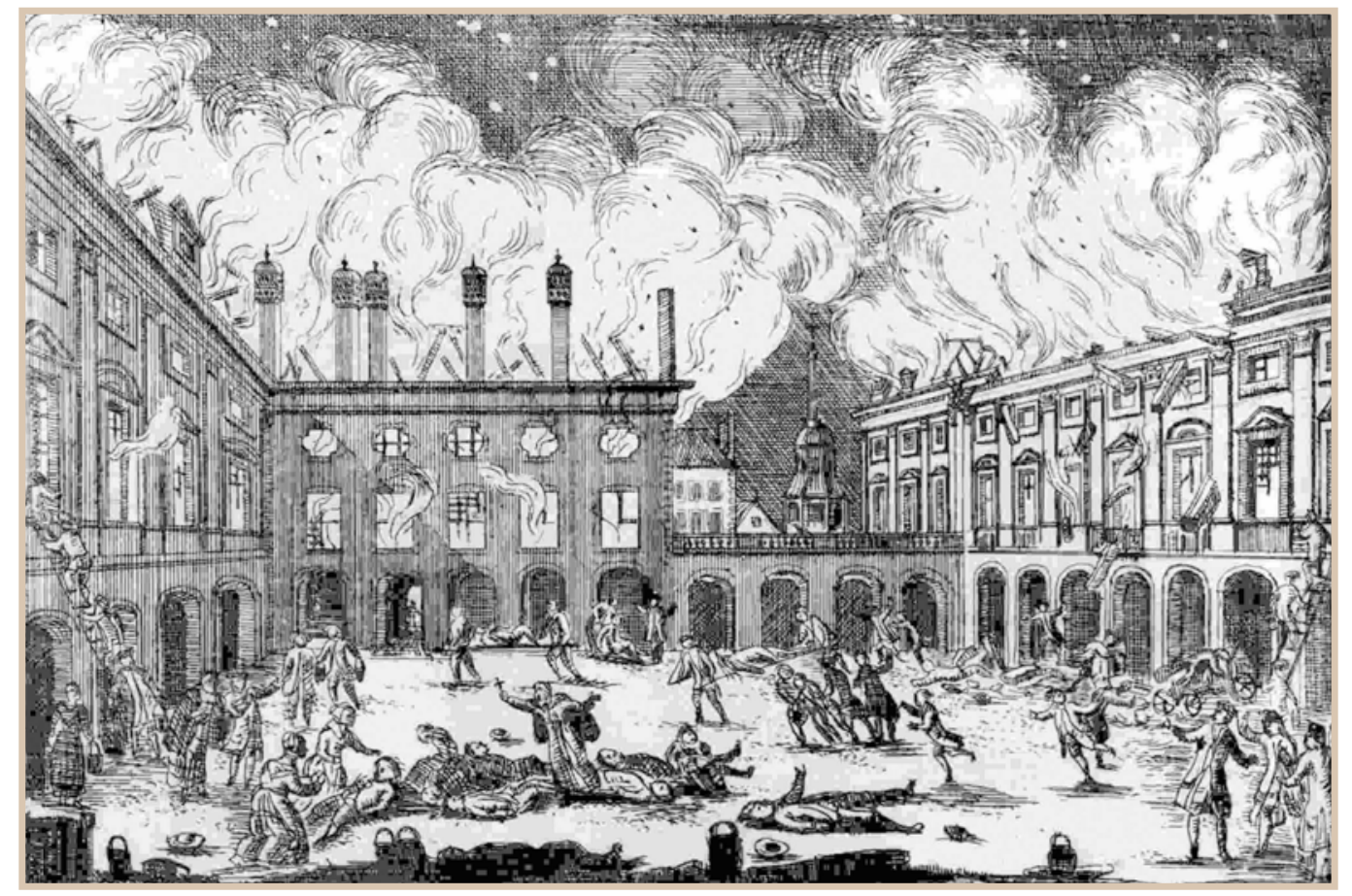

Brand der Residenz, 1777. Blick in den Hof über die Arkaden des nördlichen Flügels auf die barocke Haube des Turms von St. Remigius. Zeitgenössische Radierung von Jacob Rousseau (Stadtarchiv Bonn)

9. Aus der Zeit kurz vor dem Abbruch der Kirche stammt ein mit Grund Riss der Stadt Bonn bezeichneter Plan, datiert um 1800. Er zeigt - in einer etwas schematischen Darstellung - die mit den barocken Bastionen und der mittelalterlichen Mauer umwehrte Stadt. Die einzelnen Straßenzüge sind mit ihrer Zeilenbebauung dargestellt, ebenso sämtliche Kirchen und Klöster. Von daher ergibt sich auch eine genauere Datierung nach der Neuumschreibung der Pfarreien des Bonner Stadtgebietes von 1803: die vormalige Stiftskirche St. Cassius und Florentius trägt bereits den Titel "Haupt Pfar Kirche", das Mino-

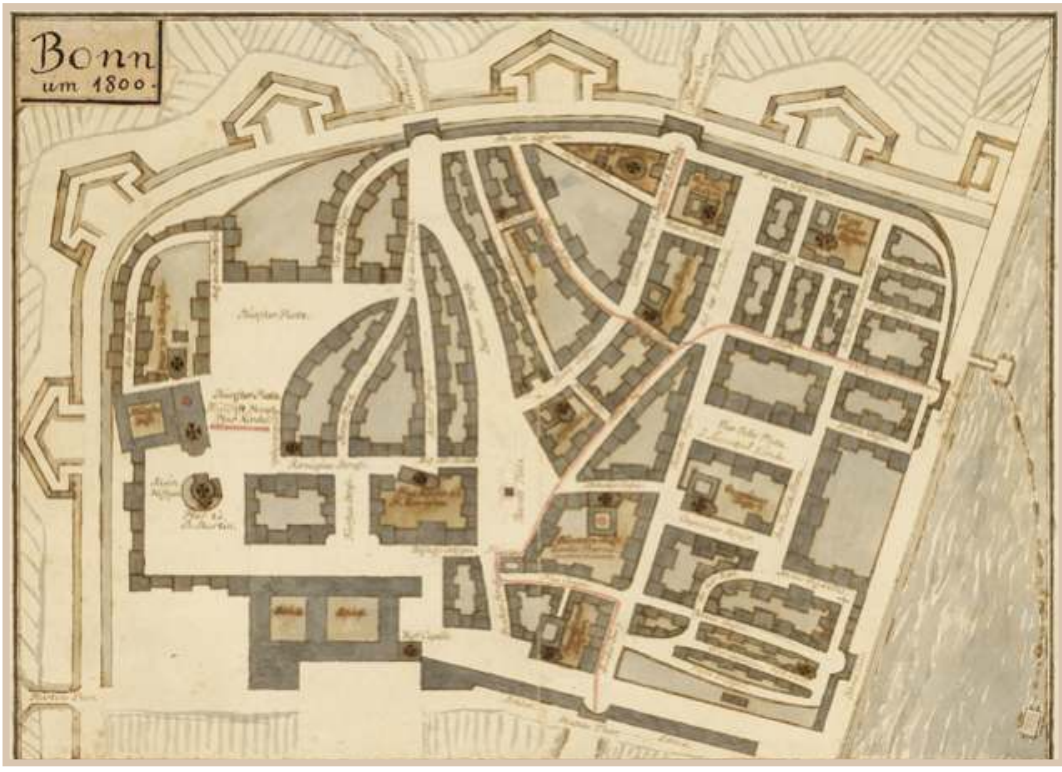
ritenkloster "Zweite Pfarrei". Auch St.

Remigius ist noch als "Pfar Kirche zu St. Remigius" bezeichnet und im Grundriss in Ost-West-Richtung als dreischiffiger Bau mit polygonalem Chor deutlich erkennbar. Vom Grundriss her scheint sie sogar größer als die Minoritenkirche Bonn um 1800. Grundriss. Anonyme Tuschezeichnung (Stadtarchiv Bonn) gewesen zu sein. 


\section{Resümee}

Bei der Gesamtschau der überlieferten Darstellungen auf (Stadt-)Plänen, Stichen und Gemälden ist Sandforts Plan nicht nur die jüngste, sondern vielleicht auch die realistischste Darstellung, denn man verfolgte mit ihr den Zweck, eine bestimmte Vorstellung von der Lage, vom Aussehen und von der Größe der dargestellten Kirchen zu bekommen. Danach handelte es sich bei unserer St.-Remigius-Kirche um eine dreischiffige Basilika mit Querhaus. Das Kirchenschiff ist wenigstens fünfjochig mit anschließendem polygonalem Chorhaupt. Rechnet man pro Joch ca. 5 m Breite, ergibt sich eine Gesamtlänge von mehr als 25 Metern, in der Größe also vergleichbar mit der ehemaligen Minoriten - jetzigen St. Remigius-Kirche in der Brüdergasse. Damit ist auch die Frage, ob es sich um einen einheitlichen gotischen Neubau, oder um einen in späterer Zeit erweiterten, vor allem erhöhten romanischen Bau handelt, eindeutig beantwortet. Die in den Fundamenten des Arresthauses aufgefundenen Spolien sichern den Beweis eines gotischen Kirchenbaus aus der Zeit um 1275. Die Zahl der Altäre und die Höhe des barocken Hochaltares - etwa 12 Meter - geben hier die Vorgaben für die Ausmaße des Baus. Lediglich der aus romanischer Zeit stammende Turm wurde in den Neubau integriert.

Besonders aufschlussreich ist das Gemälde des Niederländers Abraham Storck von 1674 mit der Darstellung der westlichen Turmfront und den beiden Seitenschiffen von St. Remigius. Es vermittelt bereits in diesem Teil eine Vorstellung von der Größe des imposanten dreischiffigen Gesamtbauwerks.

Es spricht Vieles dafür, dass nach der Zerstörung von 1689 ein neuer eleganter barocker Turm für die Brandwache seitlich an der Nord-West-Ecke errichtet wurde. Er ist auf zahlreichen Abbildungen deutlich erkennbar. Die zweigeschossigen Reste des alten romanischen Turms wurden, was nahelag, in das Kirchenschiff miteinbezogen. Für einen Solitär spricht aber auch, dass - nach dem sich über mehrere Jahre hinziehenden Abbruch des Kirchengebäudes ab 1806 - der Turm, weil für die Stadtwache von Nöten, als einziges Bauteil stehengeblieben war. Das hätte mit dem romanischen, in das Mittelschiff und das Gebäude eingebundenen Turm nicht geschehen können.

St. Remigius dürfte, durch die ständigen Zerstörungen und Plünderungen bedingt, in der Barockzeit, also seit der zweiten Hälfte des 17. Jahrhunderts, sukzessive eine Neuausstattung erfahren haben, dabei äußerst qualitätsvoll, wovon die überkommenen Teile, wie der große Hochaltar, die Kanzel und der Taufstein ein lebhaftes Zeugnis geben. Es waren dies in den meisten Fällen Stiftungen des Kurfürsten, des Adels oder reicher Bürger. Das Inventar von 1646, das auf 14 Seiten den ganzen "Kirchenschatz" verzeichnet, zeugt nicht gerade von einer armen, aber auch nicht von einer luxuriös ausgestatteten Pfarrkirche. Reliquienschreine oder dergleichen finden sich hier nicht. Auf die wenigen kostbaren Zimelien hat man ein besonderes Auge geworfen, sie wurden bei drohender Gefahr an Ort und Stelle vergraben oder, was einigerma- 
Ben verwundert, nach Köln in Sicherheit gebracht. Paramente scheinen in ausreichender Zahl für die entsprechenden Anlässe und Feste vorhanden gewesen zu sein. Was verwundert, ist, dass zwar von den verschiedenen, mehr oder weniger kostbaren Antependien, aber an keiner Stelle des Inventars von wertvollen Altarretabeln oder Gemälden die Rede ist. Das kommt wohl erst mit der barocken Neuausstattung.

Die Rechnungsbücher des Kirchenmeisters der Jahre 1636 bis 1645 geben ein etwas anschaulicheres Bild vom Kircheninneren, der Ausstattung, vor allem aber von einem regen Gemeindeleben. Der Hochchor mit dem Hauptaltar war mit einem Gitter versehen, eine große Leuchterkrone hing von der Decke herab. Am Festtag des hl. Remigius wurde ein großes Gemälde des Pfarrpatrons hier aufgestellt. Außer dem Hochaltar gab es noch sechs weitere Altäre im Kirchenraum. Die Kirche besaß auch eine Orgel. Neben dem Küster war der Organist fest angestellt. Einnahmen erzielte man vor allem durch die Überlassung von Grabstätten in der Kirche und außerhalb sowie der Vergabe von Kirchenstühlen und dem Begräbnis-Läuten.

Die Taufkirche Beethovens, die auch stets die Pfarrkirche der Familie Beethoven war, hat doch mehr Spuren hinterlassen als erwartet. Aus den zahlreichen historischen Quellen ergibt sich mosaikartig - vor dem geistigen Auge ein eindeutiges Bild vom Aussehen des Kirchengebäudes vor seinem Abbruch im Jahre 1806.

Hierzu und zu Folgenden MANFRED van REy, Studien zur Geschichte von Bonn im Frühund Hochmittelalter. Stifte, Klöster und Pfarreien (Veröffentlichungen des Stadtarchivs Bonn 73), Bonn 2019; dort die weiteren Belege zur mittelalterlichen Geschichte von St. Remigius

Vgl. Dietrich HÖroldt, Das Stift St. Cassius zu Bonn von den Anfängen der Kirche bis zum Jahre 1580 (Bonner Geschichtsblätter 11), Bonn 1956, S. 43, 342

Vgl. Josef NiESSEN, Geschichte der Stadt Bonn 1, Bonn 1956, S. 128

Vgl. ebd., S.139f., $198 f$

In: Distinctio III 8

Vgl. hierzu und zum Folgenden EDITH ENNEN, Die kurkölnische Residenz Bonn und ihr Umland in einem Jahrhundert der Kriege, in: DIETRICH HÖROLDT (Hg.), Bonn als kurkölnische Haupt- und Residenzstadt 1597-1794 (Geschichte der Stadt Bonn 3), Bonn 1989, S. 15-203.

Vgl. Manfred Peter Koch, Die älteste Geschichte der Stadt Bonn aus dem Jahre 1665 verfasst von Adolf Sigismund Burman, Bonn 2011, S. 119, 207

So der seinerzeitige Guardian des Bonner Minoritenklosters: ANTON WISSINGH, Beschreibung der bedauernswerten Stadt Bonn und des Minoritenklosters, in: Stifts- und Münsterarchiv, Find-Nr. 19. - Vgl. auch NORBERT FLÖRKEN, Die Belagerung und Zerstörung Bonns 1689, Köln 2015, S. $113 f$.

Vgl. ENnEN, Residenz (wie Anm. 6), hier S. $179 f$.

Stadtarchiv Bonn (StAB), Ku 105/1.

Alt-St. Remigius - nicht nur Beethovens Taufkirche | 85 
Vgl. [VELTEN], Beiträge zur Geschichte der sämmtlichen früheren und jetzigen Kirchen und Klöster der Stadt Bonn und nächsten Umgebung. Gesammelt und herausgegeben von Einem Bonner, Bonn 1861, S. 95.

12 Historisches Archiv des Erzbistums Köln, Christianitäten, Dekanat Bonn, St. Remigius Nr. 2. - Für unermüdliche Übersetzungshilfe bin ich in besonderer Weise Prof. Dr. Toni Diederich, Bonn, zu Dank verpflichtet.

13 Wohl eine Art Schiedsmann, eine Amtsbezeichnung, die bislang nicht geklärt werden konnte.

14 Vgl. hierzu Gisbert Knopp, Die Glocken des Martin Legros für das Bonner Münster die Stiftskirche St. Cassius und Florentius -, die Pfarrkirche St. Gangolf und die Schlosskirche, in: Bonner Geschichtsblätter 57/58, 2008, S. 99-146.

15 StAB, Ku 105/3 (Zeichnung), sowie Ku 105/4. Vgl. hierzu auch NORBERT SChLosSMACHER, Der erste Auftritt ... Ludwig van Beethovens Taufe im Kirchenbuch von St. Remigius. Faksimile und Kommentar (Jahresgabe des Vereins Beethoven-Haus 2019), Bonn 2019, sowie sein Beitrag in diesem Band.

Vgl. [VELtEN], Beiträge (wie Anm. 11), S. 95

Vgl. EDITH ENNEN, Die kurkölnische Haupt- und Residenzstadt in einem Jahrhundert der friedlichen und glanzvollen Entwicklung, in: HöroLDT, Bonn (wie Anm. 6), S. 205349, hier S. 240

StAB, SN 10/3: Chronik des Jacob Müller (Diarium), 10.5.1800; ebd. SN 10/9: Lamberz’sche Chronik, Bd. 1

StAB, SN 19/4: Chronik des Jacob Müller (Fata Bonnensia), 10.5.1800.

Stifts- und Münsterarchiv, Find-Nr. 117: loser Zettel ohne Überlieferungszusammenhang als Ausschnitt erhalten; freundliche Auskunft von Frau Regina Schürholt.

WeRnER HESSE, Geschichte der Stadt Bonn während der französischen Herrschaft (1792-1815), Bonn 1879, S. 202ff.

Vgl. ebd., S. $213 f$ StAB, SN 10/9: Lamberz'sche Chronik, Bd. 1, 29.6.1807.

So German Hubert Christian MaAssen, Geschichte der Pfarreien des Dekanates Bonn. 1. Theil: Stadt Bonn, Köln 1894, S. 179.

Bedauerlicherweise wurden zahlreiche städtische Akten zur Remigiuskirche durch einen Wasserschaden in der unmittelbaren Nachkriegszeit zerstört.

Vgl. Wochenblatt des Bönnischen Bezirks, 19.11.1808. Dort auch das Zitat.

Vgl. ebd., 29.4.1809

Vgl. Helga Giersiepen, Die Inschriften der Stadt Bonn, Wiesbaden 2000, Nr. 65, S. 68. Wochenblatt des Bönnischen Bezirks, 29.4.1809.

Ebd., 9.12.1809, zitiert nach NORBERT FLÖRKEN, Die französischen Jahre in Bonn 17941814, Bonn 2016, S. 614-616, 839, mit Abb.

Vgl. HeSSE, Geschichte (wie Anm. 21), S. 237.

Vgl. Josef Dietz, Aus den Rechnungen des Kirchmeisters von St. Remigius (16361645), in: Bonner Geschichtsblätter 1, 1937, S. 365-383.

Vgl. ebd., S. 368.

Vgl. ebd., S. 368.

Stifts- und Münsterarchiv, St. Remigius Nr. 1. - Frau Regina Schürholt sei für die Archivalienrecherche sehr herzlich gedankt. 
StAB, Ku 105/11

37 Vgl. Gisbert Knopp, Der Tod des Kölner Kurfürst-Erzbischofs Clemens August - Letzte Reise, Obduktionsberichte, Trauerfeierlichkeiten und Begräbnis im Kölner Dom, in: Bonner Geschichtsblätter 68, 2018, S. 71-110, hier S. 89

Vgl. VANESSA KROHN, Pietas Bavarica am Rhein. Die kirchliche Bau- und Ausstattungstätigkeit im Erzbistum Köln unter Joseph Clemens und Clemens August von Bayern (Tholos Kunsthistorische Studien 10.1), Münster 2019, S. 119

Ein entsprechendes Verzeichnis bei MAASSEN, Geschichte (wie Anm. 24), S. 195-198. Eine Liste der Kanoniker des Cassiusstifts bei HÖROLDT, Das Stift St. Cassius (wie Anm. 2), S. 227-282

Ferdinand Elckens, geboren in Heppendorf am 6.8.1691, starb 1716 als Pfarrer von St. Remigius und wurde dort vor dem Barbara-Altar beigesetzt, den er selbst kurz zuvor hatte errichten lassen. Vgl. KARL CORSTEN, Studien zur Pfarrgeschichte von St. Jakob in Köln, in: Annalen des Historischen Vereins für den Niederrhein 158, 1956, S. 5-86, hier S. 23.

Vgl. GISBERT Knopp, Die Altargemälde der Spätnazaener in der Kirche St. Remigius in Bonn (Arbeitsheft der rheinischen Denkmalpflege 56), Worms 2000, S. 15

Möglicherweise handelt es sich um die Figurengruppe, die in den Kirchenrechnungen erwähnt wird und seit 1640 auf dem Kirchhof der alten St. Remigius-Kirche stand. Vgl. MAASSEN, Geschichte (wie Anm. 24), S. 179

Anna Catharina Rederscheidt war eine Bäckerstochter aus der Stockenstraße. Getauft wurde sie am 15.1.1750 in St. Remigius. Ihre "Aufzeichnungen" über die Franzosenzeit befinden sich im Bestand des Landesarchivs Nordrhein-Westfalen. Sie sind ediert und erläutert: Regina HönerLAge und ThOMAS P. BECKER, Die Aufzeichnungen der Anna Catharina Rederscheidt (1792-1817), in: Bonner Geschichtsblätter 43/44, 1993/94 (1996), S. 132-162, hier S. 150f.; freundlicher Hinweis von Norbert Schloßmacher.

Vgl. Paul Clemen, Die Kunstdenkmäler der Stadt und des Kreises Bonn (Die Kunstdenkmäler der Rheinprovinz 5,3), Düsseldorf 1905, S. 139

Vgl. KNopp, Altargemälde (wie Anm. 41), S. 1.5

Die Figur der hl. Lucia von Syrakus ist sicher eine Reverenz an den Konsekrator. - Eine bildliche Darstellung der hl. Adelheid in diesem Zusammenhang verwundert zunächst, doch wird sie im Zusammenhang stehen mit der im benachbarten Vilich bzw. Pützchen verehrten Heiligen, deren Kult in jener Zeit eine Wiederbelebung erfuhr.

Das Gemälde mit der Taufe Chlodwigs, mit Sicherheit eine Auftragsarbeit, fällt aus dem Rahmen der bisher bekannten, meist Porträt-Gemälde; es wird auch in keinem neueren Werkverzeichnis aufgeführt. Das verwundert, da es in dem Standardwerk von Friedrich Schaarschmidt, dem Konservator der Kunstsammlung der Düsseldorfer Akademie unter den herausragenden Werken Spilbergs, den Porträts Herzog Wolfgang Wilhelms und seiner Nachfolger, ausdrücklich erwähnt wird: „... ein Altarblatt für die Remigiuskirche in Bonn die Bekehrung Chlodwigs nach der Schlacht bei Zülpich und dessen Taufe durch den heiligen Remigius darstellend" erwähnt wird: FRIEDRICH SCHAARSCHMIDT, Zur Geschichte der Düsseldorfer Kunst insbesondere im XIX. Jahrhundert, Düsseldorf 1902, S. 9. - Die wohl früheste Erwähnung findet sich im Rheinischen Antiquarius III. 14, 1864, S. 3: "Auch das Altarbild von Spielberg, den hl. Remigius darstellend... wurde in die neue St. Remigiuskirche gebracht". - In THIEME-BECKER, Allgemeines Lexikon der Bildenden Künstler 31, 1937, S. 378, wird das Bild zusammen mit einer Kreuzigung Christi in St. Andreas in Düsseldorf, sowie Arbeiten für das Jagdschloss des Prinzen Philipp Wilhelm in Benrath erwähnt.

Alt-St. Remigius - nicht nur Beethovens Taufkirche | 87 (c) 2020 by Böhlau Verlag GmbH \& Cie. KG, Köln https://doi.org/10.7788/9783412519704 | CC BY-NC 4.0 
Vgl. Hans Peter Hilger, Zum Werk des Kölner Barock-Bildhauers Jeremias Geißelbrunn, in: Beiträge zur Rheinischen Kunstgeschichte und Denkmalpflege (Die Kunstdenkmäler des Rheinlandes, Beiheft 20), Düsseldorf 1974, S. $180 f$.

49 Das Gemälde, immerhin 2,70 × 4,00 m groß, hat die Zerstörung der Kirche offensichtlich doch überstanden: Auf einem Foto vom 15.8.1950 ist es an besagter Stelle im Obergaden zu sehen. Erst im April 1958 wurde es abgenommen und dabei "erheblich beschädigt": Rahmen zerbrochen, zwei lange Risse; die Leinwand war durch den Brand mürbe geworden. Es wurde zunächst im Kreuzgang "abgelegt", um eine weitere Unterbringung zu klären (Aktenvermerk des Konservators Hans Kisky über Ortstermine am 23.4. und 30.4 1958: Alt-Akten Rheinisches Amt für Denkmalpflege, Abtei Brauweiler). Nach Auskunft des Pfarrers an den Verfasser wurde es dann 1962 als "nicht restaurierungsfähig" entsorgt.

Vgl. Knopp, Altargemälde (wie Anm. 41), S. 15-18

WILLI WABEL, Form Farbe Glanz - Lahnmarmor im Barock (Beiträge zur Geschichte Nassaus und des Landes Hessen 8), Wiesbaden 2015, S. 251. Von den 32 von Wabel untersuchten Taufsteinen aus Lahnmarmor ist der Bonner der Einzige mit ovalem Grundriss

Über die Taufe Beethovens val. SCHLossmaCHER, Der erste Auftritt (wie Anm. 15), sowie sein Beitrag in diesem Band.

Deutsche Reichszeitung, 13.3.1933.

Clemen, Kunstdenkmäler (wie Anm. 44), S. 138.

Vgl. GieRsiePEN, Inschriften (wie Anm. 28), S. 210f. Die hier erwähnte, auf Geheiß Erzbischof Ferdinands an das nördliche Seitenschiff angefügte Seitenapsis ist verwechselt mit der in der Minoritenkirche. Giersiepen bezieht sich hier fälschlich auf ENNEN, Haupt- und Residenzstadt (wie Anm. 17), S. 43

MAASSEN, Geschichte (wie Anm. 24), S. 178.

Bericht WIELAND/HEINEN, in: Bonner Jahrbücher 139, 1934, S. 210

Freundliche Auskunft: Christoph Keller, LVR-Amt für Bodendenkmalpflege im Rheinland. Ihm verdanke ich auch die Übersendung des Heinen-Plans.

Abraham Storck, geb. 1644 in Amsterdam, gest. 1708 ebd. Bekannt als Marinemaler. Er schuf vornehmlich Hafen-, See- und Küstenstücke mit reicher Figurenstaffage. Bekannt sind Veduten holländischer Häfen, aber auch Ansichten deutscher und italienischer Städte, wie etwa Düsseldorf, Mainz und Köln. Unklar ist, ob er persönlich an Ort und Stelle war - vielleicht auf einer Reise entlang des Rheins nach Italien -, oder nach Stichvorlagen arbeitete.

Vgl. ERIC HARTMANN und MARC JUMPERS, Zwischen Bestandsaufnahme und idealisierendem Schaustück. Ein unbekannter Plan der Bonner Residenz aus dem Jahre 1775, in: INSITU 5, 2013, S. 199-216. Ausführlicher zu Sandfort: MAX BRAUBACH, Die erste Bonner Hochschule. Maxische Akademie und kurfürstliche Universität 1774/77 bis 1798 (Academia Bonnensia 1), Bonn 1966, S. 189f. Demnach muss der Stadtplan vor 1792 angefertigt worden sein, da Sandfort ab dann als Offizier in den Reichstruppen gegen Napoleon diente

${ }_{61}$ Die Bombardierung Bonns 1689. Bonn als Festungsstadt. Begleitbuch zur Ausstellung "Die Bombardierung Bonns im Jahre 1689. Ein Gemälde kehrt zurück", hg. von INGRID BODSCH, bearb. von SigRID LANGE, Bonn 2014. 


\section{„Elementarbuch ztrr psichologie \\ Ordnung der geschäfte"}

\section{Lesestoff und Leserschaft in Bonn \\ zu Beethovens Jugendzeit}

\section{Gegenstandsbestimmung}

Die geistesgeschichtliche, soziale und politische Wirkung von Büchern ist unbestreitbar. Das wird in der Frühmoderne besonders greifbar. Im 17. Jahrhundert war die Aufklärung eine Sache der Gelehrten, eines europaweit vernetzten, aber überschaubaren Kreises. Im 18. Jahrhundert änderte sich das. Mit dem Bevölkerungswachstum wuchs der Bedarf des absolutistischen Staates an Verwaltungskräften, das heißt, der Bedarf an Menschen mit buchmäßiger Bildung. Dadurch entstand eine breite gesellschaftliche Schicht von zunehmender Bedeutung: die der Gebildeten. Es waren Leserinnen und Leser, Autoren und Autorinnen aus dieser nicht mehr durch Geburtsstand oder Beruf bestimmten gesellschaftlichen Gruppe, die die Ziele der Aufklärung fortentwickelten, verbreiteten und Denk- und Handlungsanstöße gaben. Das wäre ohne Printmedien nicht gelungen. Im letzten Drittel des 18. Jahrhunderts stieg die Buchproduktion rasant an, und es entfaltete sich das Zeitschriften- und Zeitungswesen. Lesebedürfnis und Lektüreangebot steigerten sich gegenseitig. ${ }^{1}$ Das machte vor den Toren Bonns nicht Halt. Die Stadt war zwar keine Metropole, aber sie war Residenz, also ein Ort politischen Handelns. Die Hofmusik war von anerkanntem Niveau, unter den Musikern gab es weitgereiste Künstler von europäischem Rang. Und Bonn beherbergte eine Hohe Schule, erst Akademie, dann Universität, die ein Flaggschiff der katholischen Spätaufklärung wurde. Das bedeutet: In Bonn gab es im letzten Drittel des 18. Jahrhunderts wache, gebildete Menschen, die mit neuen Ideen in Berührung kamen, darauf reagierten und sich zum Teil für eine Änderung bestehender Verhältnisse aktiv einsetzten. Was diese Menschen an Büchern und Zeitschriften lesen konnten, wo sie es konnten und was sie gelesen haben, dem soll hier nachgespürt werden.

\section{Bibliotheken und Bücher in Bonn}

Von Bonner Buchbeständen gegen Ende der kurfürstlichen Zeit wissen wir. In einigen Fällen sind Inventare überliefert, in anderen Fällen gibt es Hinweise auf das Vorhandensein eines Bestandes, dessen jeweilige Ausrichtung sich erschließen oder begründet vermuten lässt. 


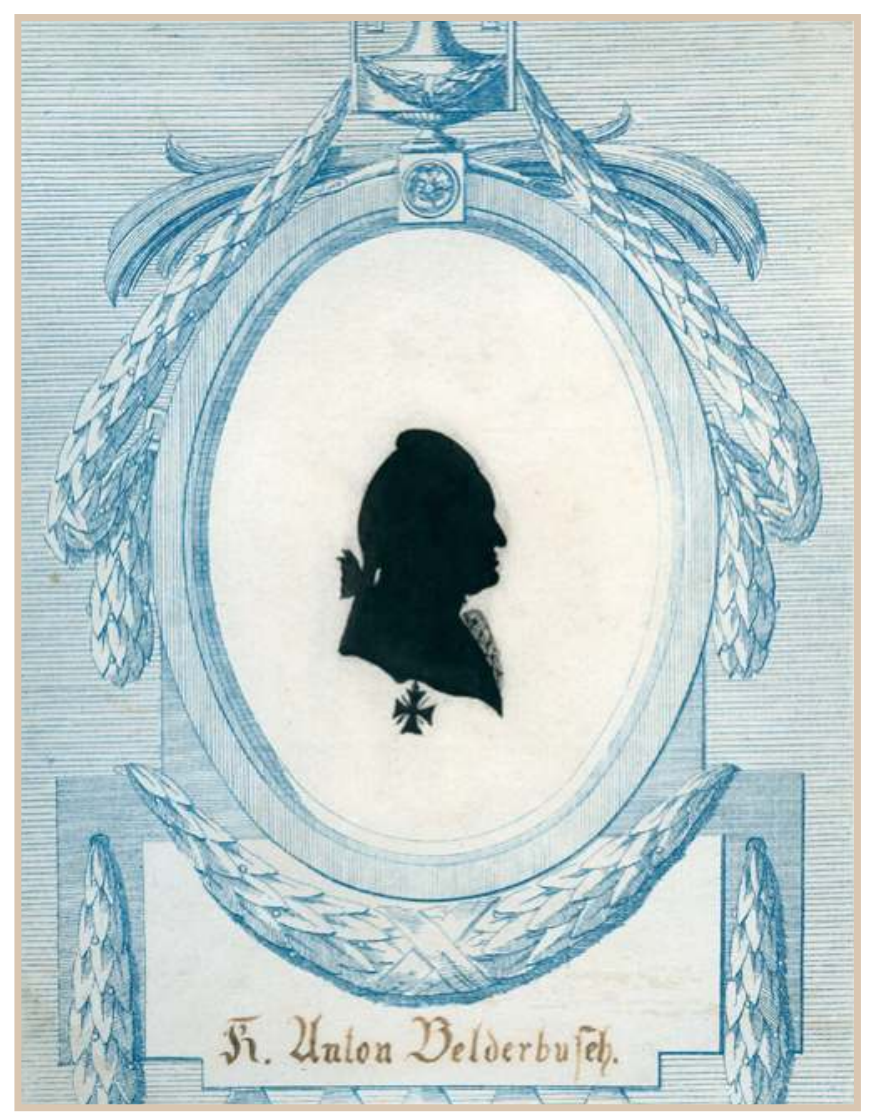

\subsection{Die Bibliothek der Grafen Belderbusch}

Über eine eigene Bibliothek verfügte Caspar Anton von Belderbusch, der Erste Staats- und Geheime Konferenzminister (1722-1784). Als im Frühjahr 1779 sein von ihm geförderter Neffe Karl Leopold von Belderbusch (1749-1826) über das eigene Machtstreben stolperte und auf den Gesandtenposten in Paris abgeschoben wurde, nahm er Bücher mit, deren Abgang im belderbuschschen Hauptkatalog notiert wurde. ${ }^{2}$ Das lässt auf sorgfältig-fachkundige Betreuung und größeren Umfang der Bibliothek schließen. Ihr Standort war der Belderbuscher Hof, das Stadtpalais am Rheinufer, der spätere, im Zweiten Weltkrieg zerstörte Boeselager-Hof. ${ }^{3}$ Der Minister hat die Bibliothek als Bestandteil eines zukünftigen Familienfideikommisses angesehen, das heißt, er hat sie als bedeutenden Wert geschätzt. Einerseits mag sie für ihn ein Moment adliger Selbstdarstellung gewesen sein, andererseits wird sie ihm, seiner Lebensgefährtin Äbtissin Caroline von Satzenhofen (17341785) und seiner Familie als Bildungsspeicher, Informationsquelle und zur Unterhaltung gedient haben. Und das sollte erhalten bleiben. Für einen

Caspar Anton Freiherr von der Heyden, seit 1782

Reichsgraf von Belderbusch OT (1722-1784). Zeitgenössischer Schattenriss (Stadtarchiv Bonn) größeren Leserkreis zugänglich kann dieser Buchbestand nicht gewesen sein. Das wäre ungewöhnlich und hätte sicher schriftlichen Niederschlag gefunden. Der aber fehlt. Die eine oder andere Ausleihe im gesellschaftlichen Umkreis schließt das nicht aus.

Mitbewohner des Belderbuscher Hofs waren seit etwa 1780 der jüngere Neffe Anton Graf von Belderbusch (1758-1820), kurfürstlicher Kammerherr und Erbhofmeister, auch k.k. Kämmerer, der spätere Maire bzw. Oberbürgermeister der Stadt und preußische Landrat, und dessen erste Ehefrau Anna Maria Freiin Wambolt von Umstadt (*1764). Anton von Belderbusch gehörte zum Bekanntenkreis der Familie Beethoven; von Besuchen bei der Musikerfamilie berichtet Bäckermeister Fischer. ${ }^{4}$ Musikalische Berührungen mögen die Verbindung vertieft haben. Nicht unwahrscheinlich, dass man sich über literarische Neuerscheinungen austauschte.

\subsection{Die Bibliothek des Freiherrn Forstmeister von Gelnhausen}

Zehn Jahre nach dem Tod des Ministers Belderbusch wird in Bonn eine andere nicht-öffentliche Bibliothek inventarisiert; und dies Inventarium ist erhalten: "Verzeichniß Sämtlicher auf der Biblioteck Sr. Excellenz des Herrn

90 | Alexander Wolfshohl

(c) 2020 by Böhlau Verlag GmbH \& Cie. KG, Köln

https://doi.org/10.7788/9783412519704 | CC BY-NC 4.0 
Landkomthurn Freiherrn von Forstmeister sich befindlichen Bücher den $17 t$ Mai 1794". Der genannte Besitzer ist Karl Franz Friedrich Hastard Anton Freiherr Forstmeister von Gelnhausen OT, Komtur zu Muffendorf, 1792 Landkomtur zu Koblenz, kurkölnischer Kammerherr, Geheimer Kriegsrat, Generalleutnant und Obriststmarschall, auch des Hohen Deutschen Ordens Geheimer Staats- und Konferenzminister (1731-1814). ${ }^{5}$ In seinem Haus in der Bonngasse in Bonn ${ }^{6}$ muss es einen Bibliotheksraum gegeben haben, denn das Verzeichnis führt die vorhandenen Titel nach dem Ort ihrer Aufstellung an: "Im Schranck/Lit.A. in Nro: I, Im Schranck/Lit. B. in Nro: 2." bis hin zu "Im Schranck/Lit. L." Eine Systematik mag anfangs angedacht gewesen sein, ist aber nicht streng durchgeführt worden. Autoren und einzelne Werke tauchen mehrfach in verschiedenen Schränken auf. Hier ist das Einsortieren wohl nach numerus currens der Anschaffung erfolgt. Die Titel werden im gesamten Inventar nur in Kurzform angegeben, dazu die Bandzahl und das Format. Autorennamen fehlen häufig, Erscheinungsort und -jahr stets. Von daher ist eine Identifizierung der bezeichneten Werke nicht immer sicher möglich.

Das erste Buch in $A$ ist die Bibel, vorhanden in zwei Ausgaben. Dann folgen geschichtliche Werke; diese auch "Im Schranck/Lit. B./ in Nro: 2.", etwa eine Histoire d'allemagne in 10, eine Histoire romaine in 16 Bänden, eine Histoire du bas Empire in 24, ein Abrégé de L.H. ecclesiastique von 3 Bänden, wohl eine Kurzfassung der Kirchengeschichte des Abbé Fleury (1620-1723), eines entschiedenen Episkopalisten und Gallikanisten. Weitere Geschichtswerke über die europäischen Staaten und einzelne Dynastien werden bereichert von einer Histoire de L'Asie in 15 Bänden und einer vierbändigen Histoire chinoise. Bei einem belesenen Deutschordensritter nicht verwunderlich ist die Histoire de L'ordre Teutonique in 8, eine Histoire de Malthe in 7 Bänden und die Devoirs des ch. de Malthe, womit die 1762 in Paris erschienenen Instructions sur les principaux devoirs du chevalier de Malte von François-Aimé Pouget gemeint sein dürften.

"Im Schranck C/Lit. C./in Nro 3."folgen Naturgeschichte, Historisch-Politisches, dazu Wörterbücher und andere Nachschlagewerke. Die Memoirenliteratur des 18. Jahrhunderts ist vertreten; darunter in mehrere Sprachen übersetzte, immer wieder aufgelegte Titel wie die Memoires du Duc de Villars des Diplomaten und Marschalls von Frankreich Claude-Louis-Hector du Villars (16531734), die Memoires de Bonneval des Claude Alexandre Comte de Bonneval (1675-1747), der als Militär schließlich im osmanischen Reich Karriere machte und zum Islam konvertierte, und die Memoires du Comte de St Germain, das heißt, die angeblichen Erinnerungen jenes Abenteurers, Alchemisten und Freimaurers (ca. 1710-1784), der zwischen 1745 bis 1780 als schillernde Gestalt die höfische Welt Europas beschäftigte. Mehrfach sind die Werke und Korrespondenz Friedrichs II. von Preußen vorhanden, insgesamt 29 Bände. La Science militaire, sechsbändig, ein Kriegs Lexikon, einbändig, ein dreibändiges 
Dictionaire militaire und ein L'Exercice de L'Infanterie, wiederum einbändig, gehören ins berufliche Feld Forstmeisters als Kriegsrat und Generalleutnant.

"Im Schranck/Lit D." finden wir eine Encyclopedie, wobei die Bandzahl von 35 darauf schließen lässt, dass es sich wieder um die 1751-1780 Paris erschienene Encyclopédie von Diderot und d'Alembert handelt, "das bedeutendste Buch der französischen Aufklärung"7. Vor allem aber sind in dieser Abteilung Reiseberichte vertreten, also jene Gattung, die im 18. Jahrhundert "eine fast explosionsartige Entwicklung" genommen hatte und „zu einer Lieblingslektüre der Zeit" geworden war. ${ }^{8}$ Darunter sind die Memoires de Benyowsky, das sind die Voyages Et Mémoires De Maurice-Auguste, Comte De Benyowsky, Magnat des Royaumes D'Hongrie et De Pologne etc. etc.: Contenant ses Opérations militaires en Pologne, son exil au Kamchatka, son Evasion et son Voyage à travers l'Océan pacifique, au Japon à Formose, à Canton en Chine et les détails de I'Etablissement qu'il fut Chargé parle Ministère François de formerà Madagascar, zuerst 1791 in Paris erschienen, womit ein terminus post quem für die Anschaffung des Buchs gegeben ist. Daneben enthält $D$ etliche echte und fiktive Briefausgaben, etwa die Briefe der Madame de Maintenon (1635-1719), aber auch Lettres juives, wahrscheinlich Jean-Baptiste Marquis d'Argens' (1703-1771) Lettres juives ou Correspondance philosophique, historique et critique entre un Juif voyageur à Paris et ses correspondans en divers endroit, ein 1736 erschienener Briefroman, der religiöse Toleranz einforderte, während die Lettres de Lenclos zu einem anderen Genre von Briefroman gehören, denn es wird sich um Claude Prosper Jolyot de Crebillons (1707-1777) Lettres de Ninon de l'Enclos au Marquis de Sevigné (1750) handeln, deren zeitgenössische deutsche Übersetzung dann den bezeichnenden Untertitel trägt: Ein Roman der Liebe und damit zeigt, dass das Werk zur sentimentalen Literatur gehört. Offensichtlich ist die bibliothekarische Einordnung des Buchs nur vom Titel her erfolgt.

E enthält u.a. die Metamorphoses d'ovide, La Lusiade des Luis de Camões (1524-1580), sodann die französischen Klassiker des 17. Jahrhunderts: Pierre Corneille (1606-1684), Jean Baptiste Racine (1639-1699), Jean de La Fontaine (1621-1695), Jean Baptiste Molière (1622-1673), Nicolas Boileau-Despréaux (1636-1711), wobei die drei Letztgenannten das Moralisierend-Satirische verbindet. Die Gesellschaftskritiker des 18. Jahrhunderts sind vertreten, etwa durch Jean Jacques Rousseau (1712-1778) und François Marie Arouet de Voltaire (1694-1778), in Ausgaben von 17 bzw. 55 Bänden. An Bühnenautoren findet sich neben Pierre-Augustin Caron de Beaumarchais (1732-1799) unter anderem der kaiserliche Hofdichter Pietro Metastasio (1698-1782), zwölfbändig, dessen Schauspiele vielen Komponisten als Textgrundlage dienten. Philosophische Titel fehlen nicht, so die Réflexions philosophiques p[ar] Holland, die Égarements de La Raison und die Oeuvres de Thomas in 4 Bänden, womit der Aquinate gemeint sein dürfte. Als angewandte, zukunftweisende Philosophie

92 | Alexander Wolfshohl 
lassen sich die Essais Sur le Commerce einstufen, unter welchem Titel vielleicht ein Klassiker der Nationalökonomie geführt wird: Richard Cantillon (16851734) Essai sur la nature du commerce en général, die englische Originalausgabe 1755 erschienen, hier in französischer Übersetzung.

Unter $F$ findet sich Politisches, etwa von Jacques Necker, dem zeitweiligen französischen Finanzminister, De l'administration des finances de La France (1784) oder von Jean-Pierre-Louis de Luchet Essai sur la secte des Illuminés (1789). In das Gewand eines Briefromans ist ein pädagogisches Werk der Madame de Genlis (1746-1830) eingekleidet, das 1782 erschienen ist: Adèle et Théodore, ou lettres sur l'éducation, contenant tous les principes relatifs aux trois différens plans d'éducation des Princes, des jeunes Personnes et de Hommes.

Mit den Bezeichnungen La Bastille und van der Noot könnten zwei revolutionäre Schriften erfasst sein: La Bastille dévoilée (1789-90) ${ }^{9}$ und Hendrik van der Noot Manifeste des Brabançons contre l'empereur (1789). Im Übrigen sind von $F$ und $G$ an zunehmend auch fiktionale, dichterische Titel aus den knappen Angaben ermittelbar, wenn auch andere Textsorten vorkommen. Gehobene Unterhaltungsliteratur, zum Teil sittlich-belehrend, herrscht vor. Alle Ausgaben dieser Gruppe sind fremdsprachlich, fast ausschließlich in Französisch, ab und an ist ein lateinisches, italienisches oder englisches Werk darunter. Selbst Horace Walpole The Castle of Otranto von 1764, das Schlüsselwerk der Gothic Novel, ist nur in französischer Übersetzung, wohl Amsterdam 1767, vorhanden.

Abteilung $H$ bietet dasselbe Bild. La Fontaine ist noch einmal mit 10 Bänden vertreten, die französische Literatur des 18. Jahrhunderts mit vielen Titeln, erotisch, galant, satirisch. Erneut sind Werke von Rousseau und Voltaire hier eingestellt. Dazu fügen sich als gleichfalls von der Zensur verfolgte Schriftsteller Charles-Louis de Montesquieu (1688-1755) und Nicolas Fromaget (17001759). Kritisieren Montesquieus fiktive Lettres persanes (1721) die politischen, kulturellen, sozialen und wirtschaftlichen Verhältnisse Frankreichs durch die Sicht angeblich persischer Reisender, so stellt Fromaget im Cousin de Mahomet (1742) in der Maske eines reisenden Libertins den Sultanshof in Konstantinopel dar und führt damit subversiv die moralischen Verhältnisse des französischen Hofs und der Gesellschaft vor. Allen vier Autoren gemeinsam ist der aufklärerische Blick auf das, was angestrebt werden muss. Dass sich in diesem Schrank in Forstmeisters Bibliothek auch philosophische Werke finden, nimmt nicht wunder, unter ihnen die morale de Confucius, wohl La morale de Confucius, philosophe de la Chine, Amsterdam 1688. Von Torquato Tasso (1544-1595) sind Gerusalemme liberata und Orlando furioso in der Originalsprache da. Englische Werke informieren über Captain Cooks Leben und Reisen; Edward Gibbon (1737-1794) fehlt nicht, der europaweit beachtete, wirkungsmächtige kirchenkritische Historiograph, mit The History of the Decline and Fall of the Roman Empire, offenbar in der nach 1788 erschienenen zwölfbändigen neuen 
Ausgabe. Von den vielbeachteten englischen Dichtern seien nur zwei genannt: Henry Fielding (1707-1757) mit The History of Tom Jones, a foundling (1749), und Laurence Sterne (1713-1768), der für die deutsche Literatur mit seiner freigeistigen Haltung und dem erzählerischen Prinzip der Digression vorbildhaft geworden ist: Tristram Shandy (1759-1767), Yorick (1768) und Letters (1775) stehen in Forstmeisters Bibliothek in der Originalsprache zur Verfügung.

Drei Sachtitel sind als letzte in "Schranck $H^{\prime \prime}$ inventarisiert: Bruchausen Institution. Physice. Anton Bruchausen (1735-1815), Ex-Jesuit, Professor an der kurfürstlichen Universität Münster, hat mit seinen zweibändigen Institutiones physicae (1783-85) eine grundlegende Einführung in die Physik vorgelegt, die Goethe noch in seiner Farbenlehre erwähnen wird. Bruchausens Anweisung zur Verbesserung des Ackerbaues und der Landwirthschaft Münsterlandes / für die Landschulen und den Landmanne des Hochstiftes Münster, 2 Teile 1790, wurde auf Befehl des Kurfürsten Max Franz in 500 Exemplaren auf Landeskosten an die Lehrer im Hochstift geschickt. Bruchausens mindestens einmalige Anwesenheit in Bonn ist durch einen Besuch in der Lesegesellschaft belegt, der sogenannten Lese, einem aufklärerischen Nukleus der Stadt, worauf noch einzugehen ist. Der Autor und der Leser Forstmeister können sich gekannt und im Gespräch ausgetauscht haben. Das zweite Sachbuch sind die principes des armes, worunter eine Waffenkunde zu denken ist, und schließlich folgt ein Titel, von dem wir erfahren, dass er nicht im Schrank steht: "Teutschordens Buch haben Sr Excellenz".

Mit $J$ beginnt überwiegend das Deutschsprachige, ohne dass eine klare Klassifikation erkennbar wäre, wenn man von der Sprache absieht. Das bleibt bis einschließlich des letzten Schrankes $K$ so. - Eine kleine repräsentative Auswahl möge die inhaltliche und thematische Breite und Ausrichtung des vorhandenen Buchbestands zeigen. Antike Schriftsteller stehen hier noch einmal, eindeutig als übersetzt auszumachen, so Plinius 2dus Naturgeschichte, Diodors Bibl. Geschichte oder Ciceros Briefe. Die neue Heloise, Rousseaus Liebesroman, der gegen ständisch-verkrustetes Denken Position bezieht, ist auch auf Deutsch da. Von den originär deutschen Dichtungen, die das Inventar enthält, sind etliche bemerkenswert, heute zwar oft nur noch Fachleuten bekannt, doch in ihrer Zeit gelesen und bedeutsam. Ewald von Kleist (17151759), der preußische Offizier und patriotische Lyriker, ist ebenso mit einer Ausgabe seiner sämtlichen Werke vorhanden wie der Rationalist, didaktische Lyriker und Dramatiker Johann Friedrich Freiherr von Cronegk (1731-1758). In Leßings Schriften dürften außer dichterischen auch die weithin wirkenden theoretischen Texte des großen Aufklärers Gotthold Ephraim Lessing (1729-1781) zu finden sein. Johann Carl August Musäus (1735-1787) steht hier, der ironische bzw. satirische Moralist, und Johann Carl Wezel (1747-1819), der mit Belphegor oder Die wahrscheinlichste Geschichte unter der Sonne (1776), "eine scharfe Auseinandersetzung mit dem Leibnizschen Optimismus" in 
Romangewand veröffentlicht hat. ${ }^{10}$ Von Friedrich Gottlieb Klopstock (17241803) gehört auch Die deutsche Gelehrtenrepublik (1774) zum Bestand, in der, ständisch übergreifend, die Vereinigung aller gebildeten Deutschen vom Leistungsgedanken her gedacht wird; ähnlich Ardinghello von Wilhelm Heinse (1746-1771): Dieser „erste deutsche Künstlerroman, entwirft das utopische Modell einer elitären Demokratie"11. Johann Timotheus Hermes (1738-1821) ist mit seinen Romanen vertreten, in denen er normative Moral, Rollenbilder und feudalistische Verhältnisse skeptisch hinterfragt. Ebenso Sophie von La Roche (1731-1807) mit Romanen, in denen sie Frauen in den Mittelpunkt stellt, aktive Züge der Heldinnen unterstreicht und Handlungen schildert, "die auf soziale Verhältnisse einwirken"12. Christoph Martin Wieland (1733-1813), der sicherlich bedeutendste Prosadichter der Aufklärung in Deutschland, der Wegbereiter Shakespeares auf der deutschen Bühne, Herausgeber und Autor des Teutschen Merkur, stilbildend, die gesellschaftlichen Verhältnisse und weltanschaulichen Fragen seiner Zeit erfassend, vielfältig und differenziert dazu Stellung nehmend, ist in einer Reihe von Einzelausgaben zu finden. Forstmeister muss ihn geschätzt haben. Auch das Lesevergnügen mag eine Rolle gespielt haben, ebenso wie bei den Skizzen von August Gottlieb Meißner (1753-1807), einem aufklärerischen Belletristen, der, Lessing und Wieland folgend, sich „bemühte, die Bildungs- und Erziehungsabsicht der Aufklärung in populären Literaturformen zu vermitteln"13. Dass Christian Gottlob Neefe (1748-1798), Hoforganist und bis 1784 Musikdirektor des Hofschauspiels, mit seinen Dilettanterien (1785) hier nicht fehlt, kann nicht verwundern. Mit Johann Aloys Blumauer (1755-1798), dem Wiener Zensor, Herausgeber des Wiener Musenalmanach, Satiriker, Verfechter der josephinischen Reformen und entschiedenem Gegner des Ultramontanismus, ist der literarische Sturm und Drang vertreten.

Alle genannten Werke können wir heute noch lesen und uns ein differenzierteres Bild erarbeiten, als es diese Übersichtsskizze geben kann, aber es wird eine unbeantwortbare Frage bleiben, was Forstmeisters 46 Bände Comedien Bücher und Operette enthielten. Waren es gesellschaftskritische Texte im jokosen Genre und einaktige kleine Opern, die in den adligen Häusern in Bonn aufgeführt werden konnten und wurden?

Etliche der deutschsprachigen Titel in den Schränken J bis $L$ müssen zum Informationsapparat des kurkölnischen und Deutschordens-Ministers Forstmeister, des im politischen Feld Tätigen, gehört haben. In Auswahl seien genannt: Geschichte von Hume, Die Engländer in Indien, Cabot englische Kolonien in Nordamerika, Burken Englische Pflanzungen (gemeint ist: Edmund Burke, Jahrbücher der neuern Geschichte der Englischen Pflanzungen in Nordamerika: Seit dem Jahre 1755 bis auf itzige Zeiten, Zur Forts. der Geschichte der Englischen Kolonien in Nordamerika, erschienen 1775/76), Rüßels Geschichte von Amerika (also: William Russel, Geschichte von Amerika, in deut- 
scher Übersetzung 1780). Zu außenpolitischen Fragen gehören etwa auch Feldzüge Friedrich des 2ten Königs von Preußen oder Theilung Von Pohlen. Der in kaiserlichem Sinne publizistisch tätige Reichshofrat Freiherr Friedrich Carl von Moser ${ }^{14}$ ist mehrfach vertreten, so mit Was ist gut Kaißerlich (der vollständige Titel lautet: Was ist: gut kayserlich? und: nicht gut kayserlich, 1766). Zum Innenpolitischen und Lokalen zählen beispielsweise: Illuminaten-Orden, wohl die nach Auflösung des Illuminatenordens 1788 erschienene Darstellung Der ächte Illuminat oder die wahren, unverbesserten Rituale der Illuminaten; wie auch: Astronomisches Jahrbuch, Statistick, Brandspritzen Unterricht oder Ferro Gebrauch der Kalten Bäder. Der später geadelte Pascal Joseph Ferro, ein aus Bonn stammender Wiener Mediziner, verdient um die Einführung der Pockenschutzimpfung, hatte 1780 mit der Hydrotherapie als Kaltwasserbehandlung in der Donau begonnen. Der Titelformulierung nach muss Forstmeister die erste Auflage von 1781 besessen haben. Auf die unter Kurfürst Max Franz regen Wiener Beziehungen und das Vorbild der kaiserlichen Reformen dürfte auch verweisen: Briefe über den Zustand der Schulen zu Wien, gemeint ist sicherlich: Freymüthige Briefe an Herrn Grafen von V. über den gegenwärtigen Zustand der Universität und der Schulen zu Wien (1775), anonym veröffentlicht von Johann Tobias Sattler, Johann Michael Afsprung und Johann Friedrich Mieg. Die Ansichten vom Niederrhein, 2 Bände, sind keine illustrierte Prachtausgabe, sondern die politisch akzentuierte Darstellung einer Reise, die der revolutionär denkende Georg Forster (1754-1794) mit dem jungen Alexander von Humboldt 1790 nach England unternommen hat, wobei sie der Rückweg nach Paris führte; Teil 1 und 2 davon sind 1791 erschienen. Aktuelle Fragen berührten sicher die Eröfnung der Schelde, das ist: Simon Nicolas Henri Linguet, Die Eröfnung der Schiffahrt auf der Schelde: Erörterung der ihrentwegen zwischen Ihrer kaiserl. königlichen Majestät und den vereinigten Niederlande entstandenen Streitfrage (1784) oder Kur Kölnische appel. Privilegien, womit gemeint sein dürfte: Rechtliche Prüfung der kurkölnischen Appellationsprivilegien, und der dabei erforderlichen Feierlichkeiten in Rücksicht der bei dem kaiserlichen Reichskammergerichte anhängigen Appellationsprocesse (1785). Auch kirchenpolitische Auseinandersetzungen der Zeit haben ihren Niederschlag in der Bibliothek gefunden, so der sogenannte Nuntiaturstreit, in dem vier deutsche Metropoliten, darunter Köln, ermutigt durch Joseph II., ihre Unabhängigkeit von Rom zu behaupten versuchten, worüber auf dem Emser Kongress 1786 beraten wurde. Zu den Vorgängen nahm der Ex-Jesuit Franz-Xaver von Feller (1735-1802) Stellung, ein scharfer Gegner der josephinischen Reformen. Mit dem Emser Congreß im Bibliotheksverzeichnis wird Fellers Coup-D'oeil oder Blick auf den Emser Congreß mit Voraussetzung des wahren Zustands etc. und dessen Anhänge (1788) notiert sein. Militärische Werke sind vorhanden wie Von Löhneißen HoffKriegs u. Reitschuh/15, Kriegs Wißenschafft oder Der Vollkomne Officier. Einige 
Bücher behandeln die Kaiserkrönung: Kaißer Krönung, Krönungs Listen und Krönungs actus, worunter sich auch das Krönungsdiarium Leopold II. (1791) befinden mag, denn Forstmeister hat als Mitglied des kurkölnischen Hofstaats an der Krönung teilgenommen und drei Exemplare subskribiert. ${ }^{16}$ Familiär und persönlich ist wohl die Anschaffung weiterer Titel begründet, darunter etwa: Deutsches Adels Lexicon, Wappen der Bergischen Ritterschaft und Rechtsfragen ehelicher Güter, denn die beiden Erstgenannten enthalten Angaben zu Forstmeisters Geschlecht bzw. seine Ahnentafel, und der Letztgenannte befasst sich mit Rechtsfragen, die ihn beschäftigt haben müssen, als der Konkurs der Familie drohte und sein Neffe schließlich 1780 die reichsunmittelbare Herrschaft verkaufen musste. ${ }^{17}$

Außer den Schränken mit ihrem skizzierten Inhalt hat es in Forstmeisters Bibliothek zwei als Verschlag bezeichnete Aufbewahrungsorte gegeben: "Im Verschlag Nro 1 sind beigepackt" illustrierte Bücher, Kupferstiche und Zeichnungen, zum Teil in Folioformat, darunter "4 Portraits als Kaißerin Eleonora, Franz der 2te, Max Frid. und Flittner". Mit dem vertraulich-saloppen Max Frid. dürfte Kurfürst Max Friedrich gemeint sein, mit Flittner die junge Schauspielerin Friederike Flittner(1760-1815), Stieftochter des Hoftheater-Prinzipals Gustav Friedrich Wilhelm Großmann (1746-1796) und "Stern der Gesellschaft"18. "Im Verschlag Nro 2 sind beigepackt": "die Figuren zur romanischen Historie - 10 Bänd. 4ㅇ", offenbar ein illustriertes Werk in Quartformat.

Vom Bibliotheksbestand her auf den Leser Forstmeister zu schließen, ist methodisch gewagt. Ohne weitere Quellen lässt sich nicht sagen, was ihn zur Anschaffung bewogen und was die Lektüre in ihm angestoßen oder ausgelöst hat. Aber die bibliographische und literarhistorische Erschließung der vorhandenen Titel ermöglicht doch einige Aussagen: Forstmeisters buchmäßige Bildung fußt offenbar, wie es einem Angehörigen seines Standes und seiner Schicht entspricht, im traditionellen antiken Kanon. Die Fülle dichterischer Texte, vor allem seiner Zeit, zeigt ihn als literarisch sehr interessiert. Die Vielzahl fremdsprachiger Titel insgesamt deutet auf gelebte Mehrsprachigkeit, was bei einem adligen Kavalier und politischen Beamten seines Ranges im Ancien Régime nicht verwundert. Auffallend häufig vertreten sind Autorinnen und Autoren von aufklärerischer, kritischer Haltung und humanisierendem Anspruch. Die Fülle ihrer Schriften, fiktional wie nicht-fiktional, lässt den Schluss zu, dass deren Lektüre ihn besonders beschäftigt hat, dass er mit den vertretenen Grundpositionen übereinstimmte. Der kaiserliche Gesandte Graf Franz Georg von Metternich (1746-1818) und Freiherr Franz Wilhelm Spiegel zum Diesenberg (1752-1815) ${ }^{19}$, der Hofkammerpräsident, seit 1786 Kurator der Universität und Präsident der Landschulkommission, haben Forstmeister aller-

Kurfürst-Erzbischof Maximilian Friedrich von Königsegg-Rotenfels (1708-1784). Zeitgenössischer Schattenriss (Archiv Haus Melschede der Freiherrn von Wrede) 
Karl Franz Friedrich Hastard Anton Freiherr Forstmeister von Gelnhausen OT (1734-

1815). Zeitgenössischer

Schattenriss (Archiv Haus Melschede der Freiherrn von Wrede)

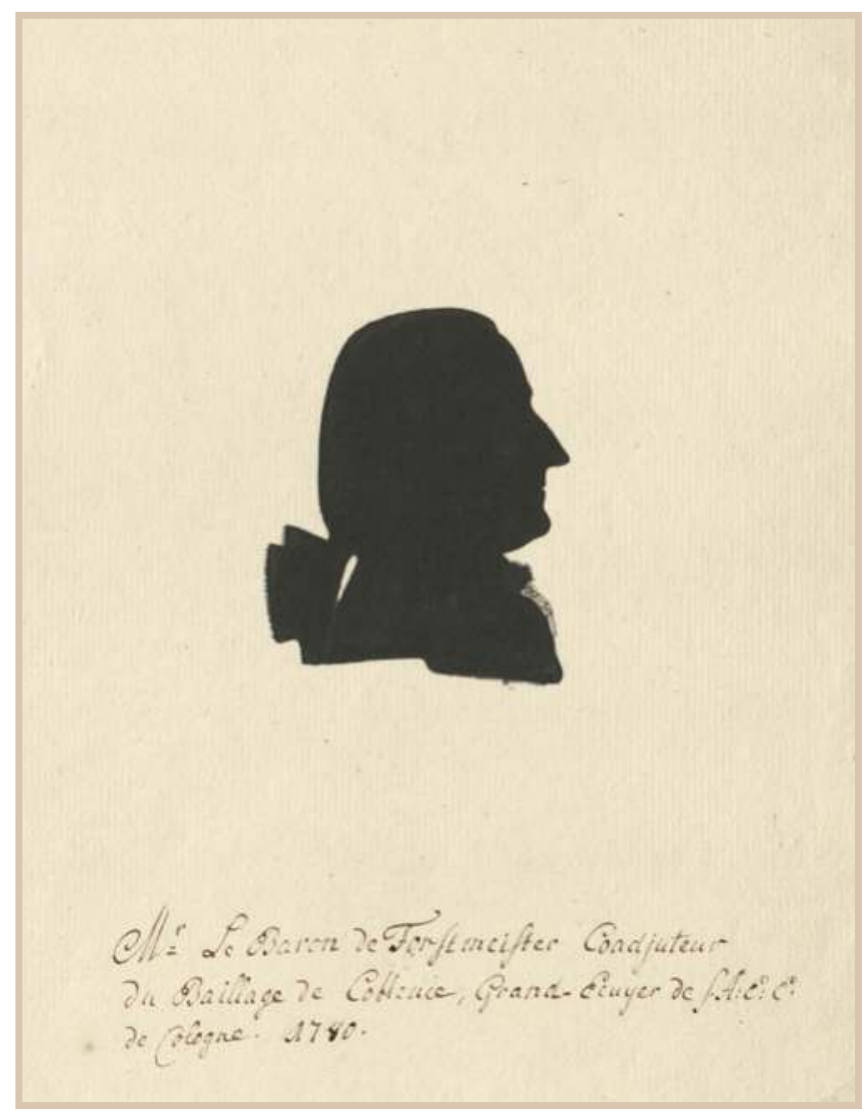

dings als politisch unfähig hingestellt, weswegen ihn Kurfürst Max Franz auch auf ein Nebengleis als Deutschordens-Minister geschoben habe. Forstmeister war, so Spiegel, „kaum imstande, einen Brief fehlerfrei zu schreiben, ein schwacher Mann, der allen gefallen wollte". ${ }^{20}$ Von daher läge es nahe zu bezweifeln, dass er als Minister die Reformen seines Dienstherrn aufgeschlossen und zukunftszugewandt begleitet hat. ${ }^{21}$ Aber in der Hofgesellschaft, speziell in Bonn, muss er als aufgeklärter Kopf wahrgenommen worden sein. Am 16. Februar 1788 nimmt die Vollversammlung der Lese auf ihrer dritten Sitzung nach der Gründungsversammlung Forstmeister, der schon der früheren Bonner Freimaurerloge angehört hatte, als Mitglied auf.

\subsection{Das Ausleihverzeichnis des Freiherrn Forstmeister von Gelnhausen}

Forstmeisters Buchanschaffungen, doch wohl über die städtischen Buchhandlungen getätigt, werden nicht verborgen geblieben sein, und die Lektüre wird zu weiterführenden Gesprächen darüber geführt haben. Darauf lässt eine gattungsmäßig eher unbedeutende Quelle schließen: Forstmeisters Verzeichnis der ausgelehnten Bücher. ${ }^{22}$ Begonnen vor Juli 1789 und fortgeführt bis September 1793, ${ }^{23}$ enthält es in Abbreviatur Angaben zu ausgeliehenen Werken, einschließlich der Bandanzahl, und die Namen der Entleihenden. Die Eintragungen erfolgten durch verschiedene Hände, meist in deutscher Kurrentschrift, zum Teil auch in lateinischer Kursive. Vornamen der Entleihenden fehlen bis auf einen Fall. Adlige Titel sind beigegeben, vereinzelt auch nachgetragen. Einige Titelformulierungen sind gesellschaftlich versiert, andere zeigen eine gewisse Unsicherheit. Hier und da ist einem Entleihernamen ein erläuternder Zusatz beigefügt, den Nachnamen bürgerlicher Ausleiher meist ein $H$ vorangestellt, aber offenbar nicht konsequent jedesmal bei einund demselben Entleiher. Bei einigen fehlt ein $\mathrm{H}$ oder eine nähere Bestimmung. Falls Forstmeister selber Eintragungen vorgenommen hat, kann das sowohl an gesellschaftlichem Abstand wie an besonderer Nähe zum Entleiher liegen.

Nicht alle Namen lassen sich eindeutig bestimmten Personen zuordnen, wiederholt kommen mehrere Individuen in Frage, bei etlichen haben die Rechercheversuche zu gar nichts geführt. Aber die deutbaren Namen lassen gesellschaftliche Offenheit des Bibliotheksbesitzers über den eigenen Stand hinaus erkennen. Die Spanne reicht vom Hochadel 
bis zu jüdischen Hoflieferanten und beschränkt sich nicht auf Männer. Das sei anhand einer Auswahl skizziert; die gesamte Liste ist im Anhang beigegeben. Fürstin Hohen Zoller und Fürstin Hohenlohe gehören dem Hochadel an; drei Hohenlohes waren in den 1780er und 1790er Jahren Kölner Domherren, vermutlich Verwandtschaft der Fürstin; ein Hohenzoller war bis 1767 Erster Geheimer Konferenzminister und Obristhofmeister Max Friedrichs. Zur adligen Hofgesellschaft zählen auch Gräfin Belderbusch oder Comtesse Metternich, die Erstgenannte kann nur Anna Maria Freiin Wambolt von Umstadt, sein, die oben genannte damalige Ehefrau des Erbhofmeisters Anton von Belderbusch; bei der zweiten ist wohl nicht an die Frau des ebenfalls oben genannten kaiserlichen Gesandten Graf von Metternich zu denken, der zunächst in Koblenz und ab 1791 in Brüssel residierte, sondern an Antonette[!] Gräfin Wolff-Metternich geborene von Asseburg (1744-1827), Ehefrau bzw. Witwe des Hofkammerund Oberappellationsgerichtspräsidenten Johann Ignaz Graf Wolff-Metternich (1740-1790). Beider Tochter Felicitas (1767-1797) leiht ebenfalls aus. Frau v. Schorlemmer ist wohl die Gattin des kurfürstlichen Kammerherrn Friedrich Wilhelm Freiherr von Schorlemmer. Beide Herren, Wolff-Metternich und Schorlemmer, waren Lese-Mitglieder. Die Damen von Bornheim können im damaligen Bonn nur zur Familie der Freiherrn von Waldbott-Bassenheim zu Bornheim gehören. Clemens August von Waldbott-Bassenheim (1731-1792) war Adliger Hofrat, Amtmann zu Brühl und kurkölnischer Landkommissarius; sein Sohn Franz Karl (1760-1804) war kurfürstlicher Kämmerer, Hofrat und zunächst Domherr in Münster; dessen Bruder Max Friedrich (*1764), Kämmerer und kurkölnischer Hauptmann, wurde 1788 in die Lese aufgenommen. Frau v. Heathcote muss Antoinette geborene Wolter sein, die Ehefrau des in Bonn seit 1781 akkreditierten englischen Diplomaten Rudolph Heathcote, identisch mit der an anderer Stelle als Englische Gesandtin bezeichneten Entleiherin. Erbdroste zu Münster ist vermutlich Adolf Heidenreich Droste zu Vischering (1769-1826), wenn nicht noch dessen 1790 gestorbener Vater, beide Regierungsbeamte des Bistums Münster; die Entleihe macht längere Anwesenheit in Bonn wahrscheinlich. Vielleicht gehört auch der eifrige Ausleiher H. Mittelmeyer zu den westfälischen Amtsträgern und ist gleichzusetzen mit dem Geistlichen Rat Anton Ferdinand Mittelmeyer, bis 1786 Assessor des Akademierats und erzbischöflichem Generalkommissar im Herzogtum Westfalen. ${ }^{24}$ Zum Bonner Hofstaat im engeren Sinne gehören beispielsweise Graf Salm, entweder der Obristhofmeister Sigismund Altgraf von SalmReifferscheid-Dyck (1735-1798), Intendant der Hofmusik, oder dessen Sohn Franz (1770-1831), kurkölnischer Erbmarschall,, ${ }^{25}$ und $B$ [aron] Waldenfels, d.h. Johann Christian Freiherr von Waldenfels (1742-1796), als Staats- und Konferenzminister Leiter der Kurfürstlichen geheimen Staatskanzlei; Sigismund Graf Salm und Waldenfels waren beide ebenfalls in der Lese. Ein weiterer Vertreter der höchsten Chargen ist der Obristjägermeister Clemens August 


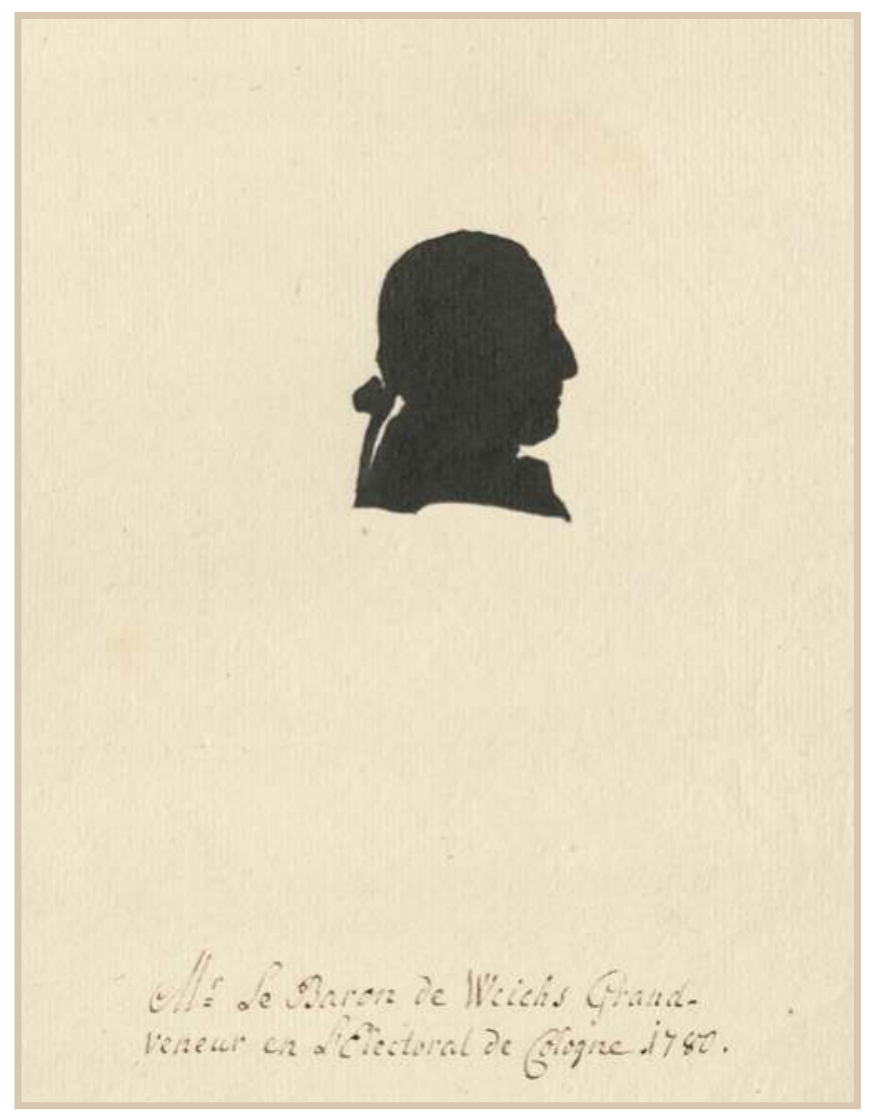

von Weichs zu Rösberg (1730-1809), aus erster Ehe ein Schwager Forstmeisters. Der Domherr von Weichs kann nur sein Bruder Franz Salentin von Weichs, Domherr zu Paderborn und Osnabrück, sein, kein Mitglied des Hofstaats, aber der Hofgesellschaft. Im Hofstaat ist eine Reihe weiterer Entleiher zu suchen. Bourscheidt tritt ohne weitere Charakterisierung auf. In den späten Hofkalendern taucht ein Futterknecht Anton Bourscheid auf, also ein Untergebener Forstmeisters, der wohl 1790 zum Futterschreiber aufsteigt. Sollte er gemeint sein? Oder beruht die reine Nachnamensnennung auf besonderer Vertrautheit zu einem Gleichrangigen? Dann könnte der Entleiher zur Familie der Freiherrn von Bourscheidt zählen, die in verschiedenen Funktionen zu finden ist. Max Freiherrvon Bourscheid zu Burgbroel etwa war bis 1789 kurfürstlicher Kammerknabe, das heißt, seine Ausbildung gehörte zu den dienstlichen Obliegenheiten Forstmeisters. Vorausgesetzt ein Angehöriger der freiherrlichen Familie ist gemeint, so käme vielleicht auch Kammerherr Ferdinand von Bourscheidt (17661816) in Betracht, "ein Mann der feinsten Bildung", oder Karl Joseph Maria von Bourscheidt (1761-

Clemens August von Weichs zu Rösberg, Obristjägermeister (1730-1809).

Zeitgenössischer Schattenriss (Archiv Haus Melschede der Freiherrn von Wrede)
1820), wie Forstmeister Deutschordensritter, Leutnant in k.k. Diensten, auch er in der Lese. ${ }^{26} \mathrm{H}$. Heckel könnte, falls ebenso Titelkürzung vorliegt, der Geheime und Kabinettssekretär Franz Leopold Edler von Heckel sein, ein Lese-Gründungsmitglied. H. Frings kann den Hofkaplan Gerard Frings meinen, Präzeptor der kurfürstlichen Edelknaben und damit Forstmeisters Untergebener; während der epithetonlose Hegel am ehesten Simon Hegel ist, als kurfürstlicher Hoflaquai gleichfalls dem Obriststallmeister unterstellt. In der Lese zu finden ist auf jeden Fall H. Steiger (seit Dezember 1788), der Hofschauspieler Anton Steiger (1756-1809), der von 1779 bis 1784 in Großmanns Truppe war und seit 1789 Regisseur am Nationaltheater in Bonn ist. Bei dessen Wiedereröffnung 1789 deklamierte er eine von Neefe verfasste Rede, musikalisch begleitet durch eine Chorkomposition von Joseph Reicha. Rößer ist vielleicht der kurfürstliche Leibchirurg Hofrat Dr. Maximilian Justin Anton Röser, auch ein LeseMitglied, wenn es nicht einer jener Röser ist, die im Dienst des Deutschen Ordens mehrfach auftreten. Wer mit H. v. Breuning gemeint ist, muss offenbleiben. Infrage kommen der Kanonikus und Geistliche Rat Johann Lorenz von Breuning (1738-1796), der Onkel der Beethoven-Freunde, vielleicht auch schon einer seiner jungen Neffen, ferner sein Bruder Georg Joseph von

100 | Alexander Wolfshohl

(c) 2020 by Böhlau Verlag GmbH \& Cie. KG, Köln

https://doi.org/10.7788/9783412519704 | CC BY-NC 4.0 
Breuning (1730-1797), Geheimer Hof- und Regierungsrat, seit 1791 Deutschordenskanzler, oder dessen Sohn Franz Jakob (1763-1827), ebenfalls Hof- und Regierungsrat des Deutschen Ordens. Sie alle gehörten derselben gesellschaftlichen Gruppe an, und die Älteren waren wie Forstmeister in der kurfürstlichen Zeit in der Lese. ${ }^{27} \mathrm{H}$. Schmitz ist, wenn wir uns im selben sozialen Feld umsehen, möglicherweise wieder ein Kapitular des Münsterstifts und Lese-Gründungsmitglied, und zwar der Kanonikus Joseph Schmitz, der bis Ende 1786 Sekretär des Freiherrn von und zu Gymnich war, Forstmeisters Ministerkollegen in der Staatskonferenz.

Ein weiterer Staatsdiener ist gewiss Velten, und zwar wohl Anton Joseph Velten, Oekonomiekommissionskanzlist. 1790 gehört er (wie andere, ranghöhere Entleiher und Forstmeister selbst) dem kurfürstlichen Hofstaat an, der zu Wahl und Krönung Leopolds II. in Frankfurt angereist ist. ${ }^{28} \mathrm{H}$. Windeck dürfte meines Erachtens im damaligen Bonn am ehesten mit dem Hofratsprokurator Carl Windeck zu identifizieren sein, Lese-Mitglied seit 1790. In H. Zartmann lässt sich der Regiments-Chirurgus und Kammerdiener Christoph Zartmann sehen, ebenfalls Lese-Mitglied; er entleiht Dr. Marx Beobachtungen, das heißt, die deutsche Ausgabe von Marx Jakob Marx Observationes medicae, 3 Teile, 1784-1787. Zartmann verkauft 1785 sein Haus in der Stockenstraße an den Handelsmann Ernst Eschbaum. ${ }^{29}$ Ist dies der Eschbaum der Entleiherliste? Nichts spricht dagegen, denn es finden sich darin mehrere Kaufleute, und zwar aus den Familien der Hofjuden. Ein bemerkenswertes Zeichen gelebter Toleranz, rund drei Generationen vor der rechtlichen Gleichstellung dieser Bevölkerungsgruppe in Europa, und zugleich ein Indiz für Bildungs- und Assimilierungsstreben in jüdischen Familien, zumindest in denen der jüdischen Elite. Wir finden: Sussmann Kauffmann (1732-1817), Moyses Kauffmann (17681847), Salomon Kauffmann (1772-1832), Jud Kauffmanns Tochter, womit Goldina Kauffmann (1771-1843), verheiratete Gompertz, gemeint sein wird, das heißt, Vater Kauffmann und drei seiner Kinder, ferner Lion Marx (17561834), ein jüngerer Bruder des Verfassers der genannten Observationes medicae. Vor allem Kauffmanns belieferten den Hof. Aus einer positiv verlaufenden wirtschaftlichen Beziehung mag sich eine nähere Beziehung zu Forstmeister entwickelt haben.

Dass Militärs bei Forstmeister Bücher ausliehen, hat sich gewiss auch aus beruflichem Kontakt ergeben. So finden sich etwa Grabler, vermutlich der Fähnrich Sigismund Grabler, und Willich wahrscheinlich Justus Martin Willich, kurfürstlicher Truchsess, Rittmeister und Oberbereiter, Lese-Mitglied; auch er 1790 mit zur Krönung in Frankfurt. Mit v. Stieler können wir ein Glied dieser Offiziersfamilie fassen, am ehesten wohl General-Major Ferdinand von Stieler, Kommandant von Bonn, als Kriegsrat gleichsam Forstmeisters Kollege; während H. v. Lohausen jener Clemens Franz Joseph Freiherr von Calkum genannt Lohausen sein wird, kurfürstlicher Kämmerer und Obristleutnant, der gleich 
Augusta Clementine Freifrau von Weichs, geb. von

Steinen zu Scherffen (1742-

1822). Zeitgenössischer

Schattenriss (Archiv Haus

Melschede der Freiherrn von

Wrede)

Forstmeister Lese-Mitglied und Vertreter des Ritterstands beim kurkölnischen Landtag war.

Dem Deutschen Orden gehören als Ritter mehrere Entleiher an. Während Karl von Bourscheidt, wie dargelegt, allenfalls vermutungsweise infrage kommt, kann H. v. Andlau sicher nur Johann Baptist Freiherr von Andlau sein, Patenkind der Erzherzogin Marie Christine. Mit seinem Besuch in der Lese am 6. Juli 1789 wird er in Bonn fassbar; am 1. August 1789 wird er schon in die Lese aufgenommen. Andlau ist damals noch Novize. Er mietet sich im Haus des Kaufmanns Eschbaum ein. ${ }^{30} 1790$ schlägt Hochmeister Max Franz den Novizen Andlau in Frankfurt in St. Bartholomäus zum Ritter, drei Tage nach der Krönung Leopolds II., in Gegenwart der kaiserlichen Familie, vieler Fürsten und von rund 2.400 Gästen. Forstmeister ist in die Zeremonie eingebunden. ${ }^{31}$ Als Deutschordensritter lassen sich noch zwei Herren ausmachen, nämlich Haubtmann v. Wiedenbrück als Ferdinand Freiherr von Wiedenbrück OT, kurfürstlicher Kämmerer, Obristwachtmeister, und B. de Wolzogen, dies wird der evangelische Ordensritter Karl Freiherr von Wolzogen OT (1737/38-1792), Komtur in der Ballei Sachsen, kurfürstlicher Kämmerer, Obristlieutenant, sein. Im Dienst des Ordens stehen H. Rentmstr. Meder, das heißt, Johann Leopold Meder (1721-1797), Rentmeister der Kommende Muffendorf, und junger Meder, dessen Sohn Johann Franz Meder, der Nachfolger seines Vaters als Rentmeister ebendort und spätere Maire von Godesberg. ${ }^{32}$ Und mit Hr Vogt zu Elsen kann nur Johann Laurenz Oeppen, Ballei-Rat der Ballei Koblenz, gemeint sein.

Nicht nur an den oben genannten Obristjägermeister von Weichs, Forstmeisters Schwager, sind Entleihungen im Familienkreis gegangen. Frau von Forstmeister (auch: Frau von Forstmeisterin) ist sicher Karolina von Forstmeister, geborene von Steinen zu Scherffen, Witwe des 1787 in Bonn gestorbenen Neffen Karl von Forstmeister; sie wohnt zwei Häuser weiter in der Bonngasse. Und B[aron] v. Steinen, Baronne von Steinen und Fräul[ein] v. Steinen gehören zweifelsohne zu dieser Familie, die zugleich mit den Weichs versippt war. Die zweite Ehefrau des Obristjägermeisters ist Augusta Clementine, geborene Freiin von Steinen zu Scherffen. Vielleicht zählt Frau von Geldern ebenfalls dazu, denn Friderike[!] von Steinen, eine Schwester der Augusta Clementine von Weichs und der verwitweten Freiin Karolina von Forstmeister, war mit einem Grafen von Geldern verheiratet. 
Dem Hof stand auch das Ehepaar Bowater nahe, John Bowater of Woolwich, Esquire, und Frances Bowater, englische Abenteurer, denen es doch gelang, einen gewissen Platz in Bonn zu gewinnen. 1790 wird Bowater in die Lese aufgenommen, "ein Englischer Gentleman am hiesigen Hofe", und der Umgang der Eheleute mit Forstmeister muss so gewesen sein, dass sie dessen Bibliothek häufig frequentieren und Bücher ausleihen konnten. ${ }^{33}$

Etliche Entleiher sind, wie gesagt, noch nicht zu bestimmen, zum Beispiel $H$. Jacquemin. Gehört er zur lothringischen Familie von Jacquemin? Ist er Mitglied des Hofstaats von Erzherzogin Marie Christine und Albrecht von SachsenTeschen, dem 1789 aus Brüssel geflüchteten Statthalterpaar, das längere Zeit in Schloss Clemensruhe lebt? Jacquemin entleiht über 40 Bände auf einmal, was auf mehr als einen Leser schließen lässt. Steht er mit Andlau in näherer Verbindung? Nicht auszuschließen, denn 1798 heiratet eine Sophie de Jacquemin einen Gerard Carl Friedrich von Andlau. ${ }^{34}$ Gar kein Bestimmungsansatz hat sich etwa ergeben für $\mathrm{H}$. Hofmeister und Peter, obwohl diese beiden zu den häufigen Nutzern der Bibliothek gehören.

Insgesamt haben die Versuche, die Titel in Forstmeisters Bibliothek zu konkretisieren und die Ausleihenden zu identifizieren, trotz mancher Unsicherheit Greifbares erbracht, was Folgerungen zulässt: Die Ideen der Aufklärung müssen Forstmeister interessiert haben; und Forstmeister hat nicht nur in chevaleresker Geste an Gleichgestellte ausgeliehen, sondern seine Bibliothek über die Grenzen von Stand und gesellschaftlicher Sphäre hinaus lese- und bildungsinteressierten Menschen geöffnet. Das heißt, er hat aufklärerische Idealvorstellungen und Ziele ein Stück weit in die eigene Lebensführung integriert, nämlich Wissen zu verbreiten und Toleranz zu leben. Ein kleines Detail aus dem alltäglichen Leben macht das ebenfalls deutlich: Karoline Großmann, die Bonner Theaterprinzipalin, ist 1784 schwer erkrankt. Ihr Ehemann kann sich nicht um sie kümmern, weil er mit einem Teil der Truppe in Frankfurt am Theater arbeitet. Madame Fiala, einer der Stars der damaligen Hofbühne, seit Anfang des Jahres wieder in Bonn, hält Großmann brieflich auf dem Laufenden. Am 2. März 1784 schreibt sie:

"Die arme Frau hat so lange ich hier bin keinen Schlaf, und keinen Apetit zum Eßen, und seit meinem Brief an Sie, hat sie das Bett nicht Verlassen. Fritzgen war beim Obriststallmeister, da dieser sie fragte: was ihre Mutter mache, War ihre Antwort mit Thränen, daß sie noch sehr schlecht wäre. Da sagte er, er wolle ihr den juden Doktor schicken."

Hofrat Professor Dr. Kauhlen hatte als bisher behandelnder Arzt keinen Erfolg erzielt. Forstmeister schickte in der Tat den "Judendoktor" Dr. Moyses Abraham Wolff, der die richtige Diagnose stellte und Kauhlen scharf tadelte. Kauhlen fügte sich für die weitere Behandlung Wolffs Anweisungen. ${ }^{35}$ 
Gustav Friedrich Wilhelm

Großmann (1746-1796),

Theaterprinzipal (aus:

JOHANN GOTTLIEB

BÄRSTECHER, Taschenbuch

für Schauspieler und

Schauspielliebhaber,

Offenbach 1779 -

Münchener Digitalisierungszentrum)

\subsection{Andere adlige Privatbibliotheken}

Bibliotheken in adliger Partikularhand wie bei Belderbuschs oder Forstmeister wird es zu Ende der Kurfürstenzeit in Bonn noch mehrere gegeben haben, allein schon als Teil ständischer Repräsentation. Dass in den Häusern der führenden Familien Bücher vorhanden waren, dass man gegebenenfalls untereinander Lektüre austauschte, können wir annehmen. ${ }^{36}$ Gräfin Belderbusch, die, wie erwähnt, bei Forstmeister auslieh, konnte über die hauseigene Bibliothek verfügen. Grafen und Gräfinnen Hatzfeld und Salm sowie Graf NesselrodeReichenstein, der Hofratspräsident, und seine Frau werden zu den Buchbesitzern gehört haben. Auch vom Freiherrn von Waldenfels, dem Staatsminister, und seiner Gattin ist das anzunehmen. Ein Graf Salm und Baron Waldenfels zählen, wie erwähnt, zu Forstmeisters Entleihern. Im Palais der Grafen Wolff-Metternich war um 1740 ein Bibliotheksraum vorhanden, unter anderem zivilrechtliche Literatur enthaltend. Ein Inventar von 1790 nennt einen Bücherschrank, aber keine Titel. ${ }^{37}$ Einen solchen gab es 1795 auch noch im Gudenauer Hof der Familie von der Vorst-Lombeck-Gudenau, über seinen Inhalt wissen wir indessen gleichfalls nichts. ${ }^{38}$ Der schon erwähnte Hofkammerpräsident und Universitätskurator Freiherr Spiegel zum Diesenberg hat Bücher besessen. Wir erfahren davon in einem nicht abgeschickten Entlassungsge-

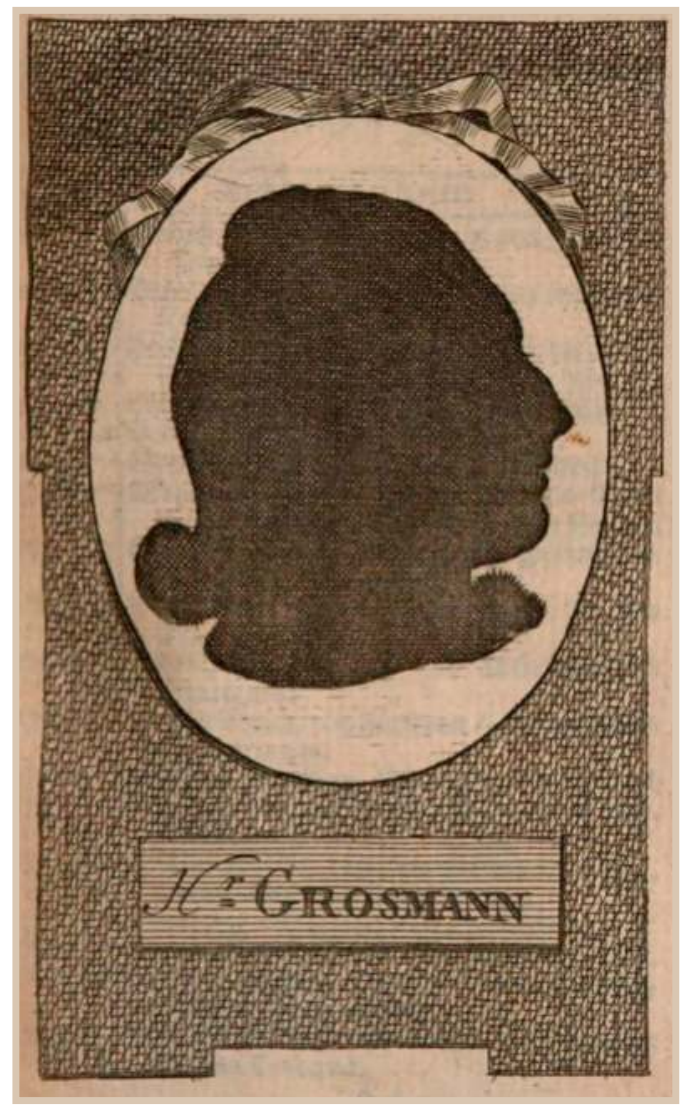
such an den Kurfürsten, in dem Spiegel die infolge seiner Amtstätigkeit entstandenen finanziellen Belastungen auflistet. Darin heißt es:

"Das Flüchten hat mir viel gekostet. Meine Weine, Leinwand, Porzellan und Silberzeug nebst Betten hatte ich mit ganz unglaublichen Frachtkosten von Bonn nach Dorsten und von dort bis hierher [Schloss Canstein] mit 3 fr. Laubtaler $p$. Zentner bringen lassen. Meine Bibliothek, die ich mit den Effekten des Grafen von Westphalen [des kaiserlichen Gesandten am Niederrhein] geflüchtet hatte, kostete mir, weil sie bis nach Brünn ging, beinahe 1000 Gulden. Alle diese Stücke müßte ich wieder zurückbringen lassen und dann doch erleben, daß mein Gehalt mit meinen Präbendeneinkünften nicht hinreichend sein würde, mich zu unterhalten. ${ }^{.39}$

\subsection{Die Bibliothek der Theaterprinzipale Gustav Friedrich} Wilhelm und Karoline Großmann

Am 5. November 1787 wurde in Köln die "Großmannische Bibliothek", bestehend aus "vielen auserlesenen und neuen recht wohl conditionirten meistens zum Theater und sonstig zur schönen und angenehmen Lektüre gehörigen Büchern", versteigert. ${ }^{40}$ Das war der sequestrierte Buchbestand des frühe- 
ren Bonner Theaterprinzipals Gustav Friedrich Wilhelm Großmann, bekannt wegen seines sozialen Engagements als aufklärerischer Dramatiker, und seiner Frau, der Prinzipalin Karoline Großmann. Von 943 Nummern des Katalogs betreffen 47 "Opern und Musikalien", unter den übrigen 896 aber finden sich Hunderte von Schauspielen, vielfach mehrere in einem Lot zusammengefasst. Das Repertoire der großmannschen Truppe ließe sich daraus erschließen, selbst wenn es keine anderen Quellen dafür gäbe. ${ }^{41}$ Das Gros der Texte stammt aus den 70er- und 80er-Jahren des 18. Jahrhunderts. Den Erscheinungsjahren zufolge, soweit angegeben, sind nur wenige nach der Verabschiedung Großmanns aus Bonn 1784 erworben. Autorennamen fehlen vielfach, die Katalogaufnahme ist offensichtlich dem gedruckten Titel gefolgt und hat die Verfasser als bekannt vorausgesetzt. Heute überwiegend vergessen, zeigt die Überprüfung, dass es damals führende Theaterdichter waren. Der GroßmannKatalog erweist sich als ein Kompendium des Hoch-Aktuellen, VielfachDiskutierten wie auch des Populären.

Ein Textkorpus wie dieser muss für einen Theaterunternehmer in der damaligenZeitvon großerwirtschaftlicher Bedeutung, vielleicht eine Überlebensfrage gewesen sein. So wird der Bestand vielfach genutzt, aber auch gehütet worden sein. Bei einigen Exemplaren hat der Auktionator auf den Zustand hingewiesen: "Seraphine ein Familien Gemälde in 5 A., Frank. 1784. NB. dieses ist mit Dinten durchstrichen” (Lot 434, 5), "Der lustige Tag oder Figaro's Hochzeit, Lusts. in 5 A, Kehl 1785. ächte und beste Auflage, NB. etwas beschmüzt und mit Bleyfeder durchstrichen" (584) und "Göz von Berlichingen, mit der eisernen Hand, Schs. 1773. schlecht conditionirt" (Lot 781). Alle drei Stücke sind in Bonn offenbarnichtgegeben worden. Im „Verzeichnis deraufgeführten Theaterstücke” überwiegen Lustspiele, doch auch bei diesen ist eine sozialkritische Tendenz unübersehbar. ${ }^{42}$ Lessing, mit dem Großmann in freundschaftlicher Beziehung stand, ist im Korpus ebenso vertreten wie Schiller, den er selbst "beinahe mehr gefördert hat, als Dalberg". ${ }^{43} 1784$ wird in Bonn Kabale und Liebe, Schillers bittere Abrechnung mit dem feudalen Ständestaat, aufgeführt. Die Verschwörung des Fiesco zu Genua ${ }^{44}$, das aufwühlende Stück um die Verführbarkeit des politisch Handelnden, hat hier am 20. Juli 1783 die Uraufführung erlebt - der Mannheimer Intendant Freiherr von Dalberg hatte es abgelehnt. Die theatralische Literatur in Großmanns Bibliothek weist ihn als gebildeten, wachen, aufgeklärten und aufklärerischen Kopf aus. Zum selben Ergebnis führt die Durchsicht der nicht-theatralischen Titel. Nicht verwunderlich, dass Autoren auftauchen, die auch Forstmeister führt, angefangen von Diodor und Cicero, über Torquato Tasso, Jean de La Fontaine, Voltaire, Laurence Sterne, über Ewald von Kleist, den Freiherrn von Cronegk, Johann Carl Wezel, Sophie von La Roche, August Gottlieb Meißner und andere. Insgesamt aber ist der Bestand, selbst bei Übereinstimmungen mit Forstmeisters Büchern, anders akzentuiert; es finden sich mehr Texte von Autoren, die außer Klopstock und 
Wieland für die Entwicklung der dichterischen Sprache, besonders die Entfaltung der deutschen Gefühls- und Ausdruckssprache, Wesentliches geleistet haben. Gottlieb Wilhelm Rabener (1714-1771), Christian Fürchtegott Gellert (1715-1769), Johann Wilhelm Ludwig Gleim (1719-1803), Karl Wilhelm Ramler (1725-1798), Christian Felix Weiße (1726-1804), Salomon Gessner (17301788), Gottfried August Bürger (1747-1794) sind hier zu nennen, ebenso wie die jüngeren Vertreter des Sturm und Drang: Friedrich Maximilian Klinger (1752-1831), Matthias Claudius (1740-1779) und Johann Wolfgang Goethe (1749-1832) ${ }^{45}$. Auch Edmund von Harold (1737-1808) gehört mit seiner Übertragung des Ossian hierher, Großmann besitzt sie ebenso wie die englische Originalausgabe.

Großmanns Aufmerksamkeit für den intellektuellen Diskurs der Zeit wird deutlich unter anderem durch Friedrich Heinrich Jacobis Über die Lehre des Spinoza in Briefen an den Herrn Moses Mendelssohn (1785) und Thomas Wizenmanns Die Resultate der Jakobischen und Mendelssohnschen Philosophie, kritisch untersucht(1786), zwei Schriften aus dem sogenannten Pantheismusstreit, oder an kirchenkritischen Büchern wie Gaudenzio Valottis Wichtiges Promemoria an die weltlichen Regenten, welche der Römischen Glaubenslehre zugethan sind (1782), einem antikurialen Werk, wie auch an Franz Rudolph von Grossings Allgemeines Toleranz- und Religionssystem für alle Staaten und Völker der Welt (1784). Großmann war Illuminat. Dass er die illuminatischen Ziele von Persönlichkeitsbildung und Humanisierung der Gesellschaft angestrebt hat, macht seine Theaterarbeit wahrscheinlich. Und der Erwerb der genannten Bücher weist genauso darauf hin wie jene von Wilhelm Willer Die Sittenlehre in Denk-Sprüchen der Deutschen, ein Versuch (1781) oder von Johann Jacob Dusch Moralische Briefe zur Bildung des Herzens (1781; Erstausgabe 1756). Den erziehenden Familienvater sehen wir gewiss in Sophie von La Roches Pomona für Deutschlands Töchter (1783) oder Auszüge aus guten Büchern für die Töchter, deutsch und französisch, 3 Theil, Berl. 1788 sowie Ein Rechenbuch in gutem Manuskript und Band [o.J.] und Jakob Friedrich Feddersens Das Leben Jesu für Kinder (1778)46. Wie bei Rousseau wird Jesus hier als Tugendlehrer und "Muster des Guten" dargestellt. Dass der Auktionskatalog die Bonner Illuminatenzeitschrift Beiträge zur Ausbreitung nützlicher Kenntnisse enthält, ohne Jahresangabe, d.h. vermutlich alles Erschienene, rundet das Bild ab.

In Köln ist Großmanns Bibliothek versteigert worden, aber ist sie zuvor in Bonn gewesen?

Großmann selber kann mit kurfürstlicher Genehmigung parallel zum Bonner Engagement andernorts gastieren; ab 1783 spielt er zeitgleich in Frankfurt am Main und Mainz. Die Leitung der Hofbühne liegt in den Händen seiner Frau Karoline. Bonn bleibt der Wohnsitz der Familie. Allein schon der Umfang der Bibliothek macht es unwahrscheinlich, dass sie zur Gänze mit auf Gastspielreisen genommen wurde. Möglicherweise ist das Gros der Bücher, abgesehen von 
benötigten Spieltexten, sogar nach Karoline Großmanns Tod (29. März 1784) in Bonn oder der Region deponiert gewesen. Bei einem Brand des Frankfurter Theaters am 11. April 1785 ist Großmann betroffen. "Der Direktor hat Alles eingebüßt - nichts als sein und seiner 6 Kinder Leben davon gebracht", schreibt Goethes Mutter am 14. Mai 1785 an Fritz von Stein. Andere Quellen ergeben, es sind "Möbel und sonstige Haushaltungsgegenstände vernichtet, auch eine Anzah/ Werthsachen und etwa 1000 Gulden Geld". ${ }^{47}$ Vom Verlust an Büchern ist nicht die Rede.

Wenn wir davon ausgehen, dass der Buchbestand sich zwischen 1778 und 1784 zumindest größtenteils in Bonn befunden hat, so dürften die theatralischen Texte als konstantes Kapital doch eher nur einem kleinen, beruflich bestimmten Kreis zugänglich gewesen sein, während die übrigen durchaus im Freundes- und Bekanntenkreis ausgeliehen worden sein können, gerade auch, wenn sie aktuelle Themen betrafen. Absichern lässt sich diese doppelte Vermutung nicht, aber es spricht nichts dagegen, vielmehr spricht Großmanns aufklärerische Haltung dafür.

Zwei der großmannschen Bücher fügen sich so in das kulturelle Geschehen in der Residenz, dass wir sie als ein Echo von Gesprächen und anspruchsvoller, dilettantischer Übung ansehen können. Es sind: Johann Christian Hendel. Schattenrisse edeler Teutscher. Aus dem Tagebuch eines physiognomischen Reisenden. Bd. 1. Nebst 28 Schattenrissen. Halle/Saale: Hendel 1783, und: Adam Friedrich Geisler. Schattenrisse edler deutscher Frauenzimmer oder offenherzige und unpartheyische Nachrichten von jetzt lebenden - berühmten - schönen und biedern Damen. 1. Heft Halle/Saale: Hendel 1784. Beide sind nicht nur ein Reflex der "Silhouettierwut" der Zeit ${ }^{48}$, sondern gehören in die Auseinandersetzung um Johann Caspar Lavaters Physiognomische Fragmente

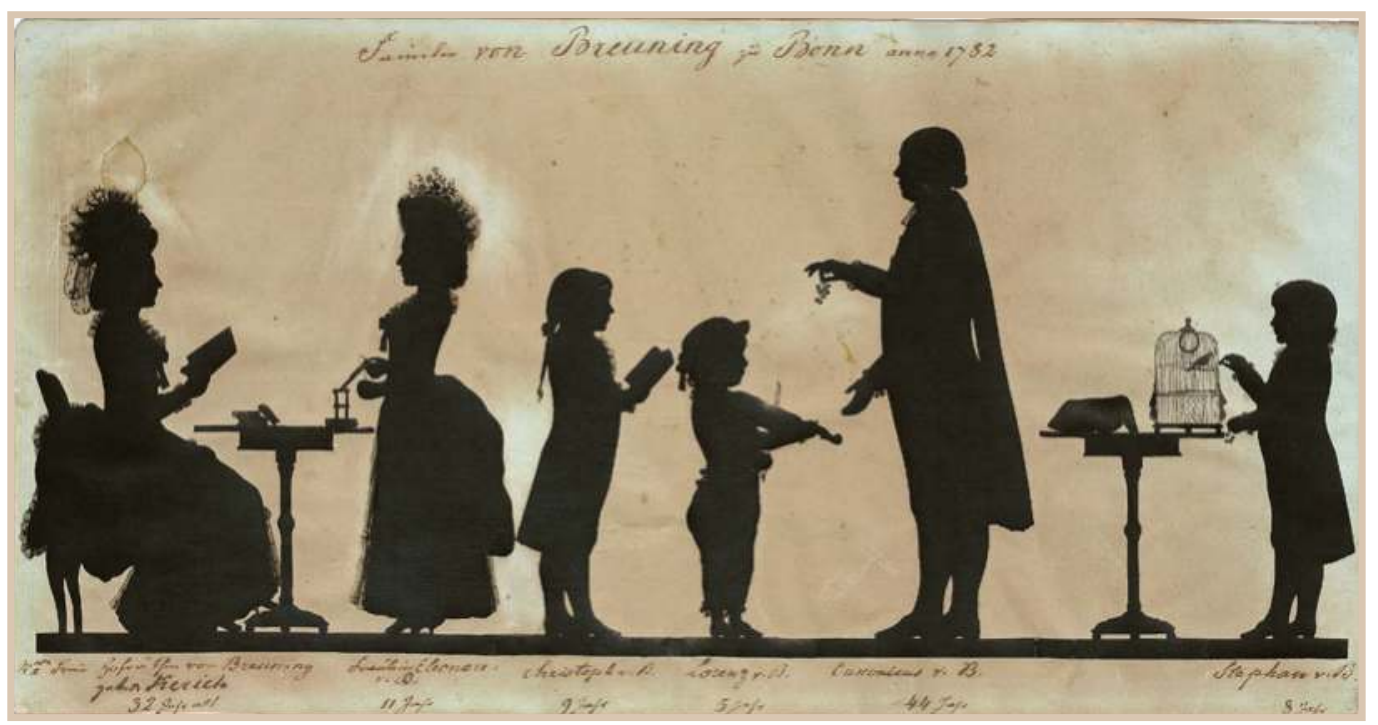

Familie von Breuning. Schattenriss 1782 Von links: Frau Helene von Breuning (1750-1838),

Eleonore (1771-1841), Christoph (1773-1841), Lorenz (1777-1798), Kanonikus Lorenz von Breuning (1738-1796), Stephan (1774-1827) (Beethoven-Haus Bonn, Leihgabe Karl-Oswald von Nell) 


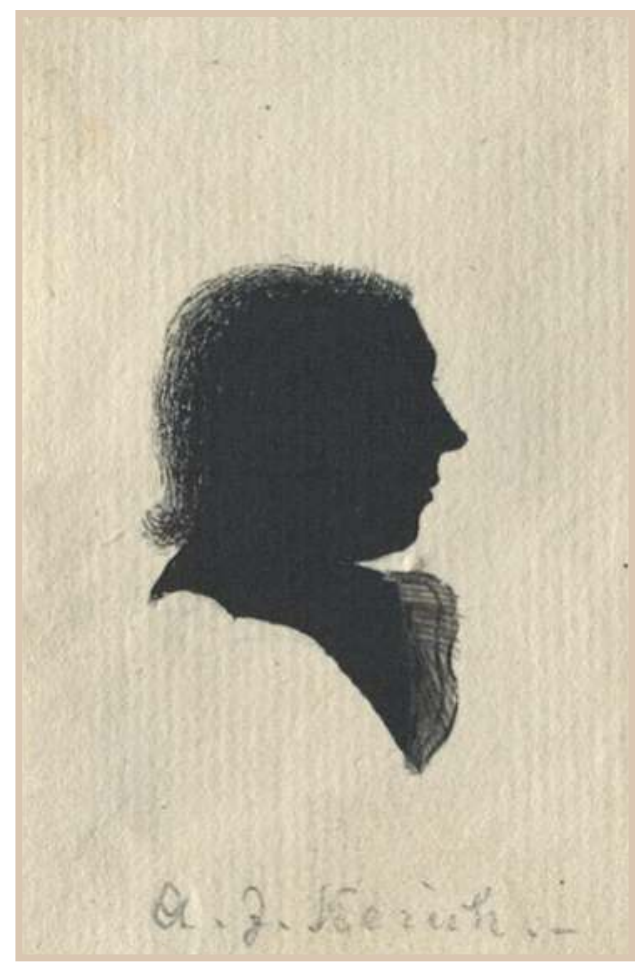

zur Beförderung der Menschenkenntniß und Menschenliebe. Gott schuf den Menschen sich zu Bilde! Mit vielen Kupfern. Bd. 1-4. Leipzig und Winterthur: Weidmanns Erben und Reich und Heinrich Steiner und Compagnie 1775-1778, ein Werk, das 1785 in der Hofbuchdruckerei angeboten wurde und sich auch im Katalog der Hofbibliothek findet. ${ }^{49}$

In Bonn wurde silhouettiert. Gruppenbilder der Familie von Breuning (1782), ein Schattenriss Beethovens (1786), ein wohl etwas jüngerer seines Freundes Christoph von Breuning (17731841 ) sind ebenso bekannt wie die kleinen Profilbildnisse in den Stammbüchern von Beethoven (1792) und Babette Koch (zwischen 1790 und 1802). Einen Schattenriss von Eleonore von Breuning (1771-1841) besitzt Beethoven noch 1826, ${ }^{50}$ und auch vom Onkel mütterlicherseits der Breuning-Geschwister, Joseph Abraham Kerich (1751-1821), ist ein solcher überliefert.

Eine ganze Sammlung von getuschten Silhouetten hat sich im Archiv Haus Melschede der Freiherrn von Wrede erhalten, vermutlich von Engelbert Freiherrn von Wrede (1742-1808) herrührend. Die Schattenbilder bilden Kurfürst Max Friedrich ab sowie eine Reihe von Persönlichkeiten der Hofgesellschaft in Bonn und in Münster wie auch des Reichskammergerichts in Wetzlar. ${ }^{51}$

Joseph Abraham Kerich (1751-1821), Kanoniker und Stiftsscholar. Zeitgenössischer Schattenriss (Beethoven-Haus Bonn, Dauerleihgabe der JuliusWegelerschen-Familienstiftung)
Zwischen Wetzlar und Bonn gab es Verbindungen, bedingt durch die dortige Ausbildung im Staatsdienst tätiger Juristen, zum Teil vertieft durch Mitgliedschaft in Freimaurer- und Illuminatenlogen. ${ }^{52}$ Forstmeisters Silhouette ist darunter. Von Großmann selber, von Joseph Reicha, vom Minister Belderbusch sind Schattenrisse an anderer Stelle erhalten. Vielleicht ist auch bei den Bildnissen von Kurfürst Max Friedrich und Friederike Flittner im "Verschlag Nro 1" der forstmeisterschen Bibliothek an Schattenrisse zu denken. Silhouettieren war im letzten Drittel des 18. Jahrhunderts eine Form gesellschaftlicher Unterhaltung der aufgeklärten Eliten. Im Adel wie im Bürgertum übte man sich in der Fertigkeit, solch kleine Profilbildnisse herzustellen. Silhouetten wurden europaweit weitergereicht und ausgetauscht, auf Charakterzüge der Dargestellten hin befragt und die Befunde diskutiert. Die Annahme, dass "sich im Anblick des menschlichen Umrisses Wesentliches über die Seele sagen ließe" ${ }^{\prime \prime 3}$, wurde fraglos vorausgesetzt, fand aber auch scharfe Ablehnung, als die Modeerscheinung "groteske Ausmaße"54 erreichte. 1786 zum Beispiel setzt "Hoforganist Neefe" eine Belohnung für die Wiederbeschaffung einer Schnupftabaksdose aus, die einen Deckel "mit drei emaillierten Schattenrissen" hatte. ${ }^{55}$ Von Neefe stammt vielleicht auch ein mit $n$ markierter Aufsatz in der Bonner Illuminatenzeitschrift Beiträge zur Ausbreitung nützlicher Kenntnisse, in zwei Teilen am 28. Juni und 5. Juli 1784 erschienen: „Etwas über und aus Lavaters physiognomischen Fragmenten", und schon am 10. Mai hatte der Herausgeber ein spöttisches

108 | Alexander Wolfshohl

(C) 2020 by Böhlau Verlag GmbH \& Cie. KG, Köln

https://doi.org/10.7788/9783412519704 | CC BY-NC 4.0 


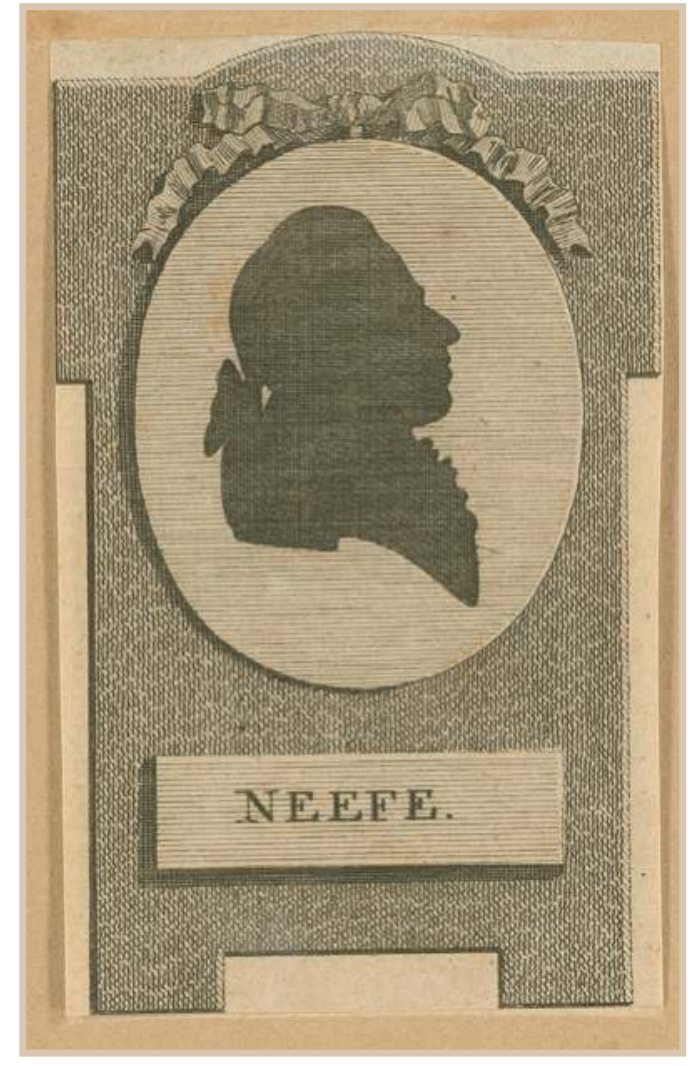

Epigramm "Frage an Lavatern nebst dessen Antwort" eingerückt. ${ }^{56}$ An Bonn ist die Mode also nicht vorübergegangen, und man darf annehmen, dass im Kreis der Silhouettierenden ebenso über die Aussagekraft der Schattenbilder und deren Deutungsmöglichkeiten diskutiert wurde wie etwa in Frankfurt, in Göttingen oder Weimar. ${ }^{57}$

\subsection{Weiterer Buchbesitz im Kreis} und Umkreis der Bonner Aufklärer Beethovens lebenslanger Freund Franz Gerhard Wegeler (1765-1848) gibt in den Biographische(n) Notizen eine kleine Skizze des gesellschaftlichen Lebens in einem kultivierten Haus: Bei Familie von Breuning "herrschte, bei allem jugendlichen Muthwillen, ein ungezwungener, gebildeter Ton. Christoph von Breuning versuchte sich früh in

kleinen Gedichten, was bei Stephan von Breuning viel später, aber nicht ohne Glück geschah. Hausfreunde zeichneten sich durch gesellige Unterhaltung aus, welche das Nützliche mit dem Angenehmen verband." ${ }^{158}$

Ein Zeugnis dieses Kreises sind die überlieferten Silhouetten. Als Gegenstand für Gespräche boten sie sich ebenso an wie Bücher, die man gerade las. Bei Familie von Breuning hat bekanntlich Wegeler den fünf Jahre jüngeren Beethoven eingeführt, und Beethoven hat hier ein zweites - förderliches und bildendes - Zuhause gefunden. Neben der verwitweten Hofrätin Helene von Breuning, geborene Kerich (1750-1838), ihren vier mit Beethoven befreundeten Kindern, Eleonore, Christoph, Stephan (1774-1827) und Lorenz, genannt Lenz (1777-1798), gehören dazu ihre schon erwähnten Verwandten, ihr Schwager Johann Lorenz von Breuning (1738-1796) und ihr Bruder Joseph Abraham Kerich, der Hausherr, beide Canonici am Münsterstift. Breuning hat die Lese mitbegründet, Kerich wird 1791 aufgenommen. Als die Münsterschule 1785 zu einer zukunftsweisenden Musterschule umgeformt werden soll, reist Breuning nach Mergentheim, um sich dort "von der Vorzüglichkeit der neuen Lehrart zu überzeugen"59. Zuständig für Schulfragen ist Kerich in seiner Funktion als Stiftsscholaster. Aufgeschlossenheit gegenüber neuen geistigen Strömungen können wir also bei beiden voraussetzen. Den aufgeschlossenen
Christian Gottlob Neefe (1748-1798), Hoforganist und Musikdirektor der Hofkapelle. Zeitgenössischer Schattenriss (BeethovenHaus Bonn) 


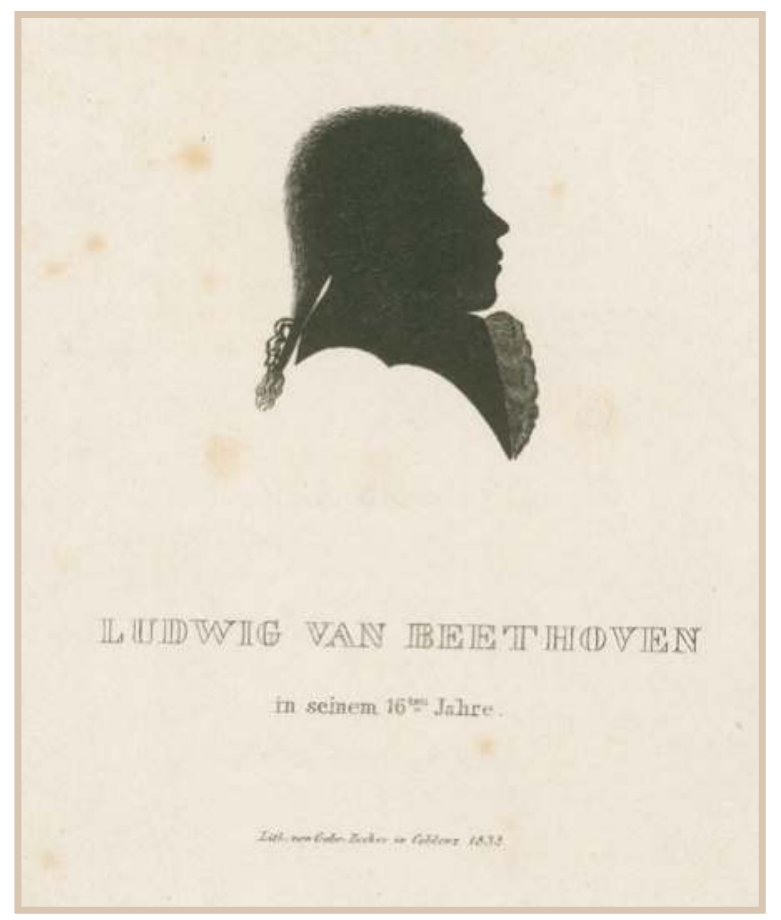

Gesprächskreis können wir uns erweitert denken durch die Familie des gleichfalls schon genannten Georg Joseph von Breuning; er wohnt gleichsam um die Ecke in dem seinem Bruder Johann Lorenz gehörenden Haus Auf dem Kleinhöfchen (heute: Martinsplatz).

Hofkammerrat und Akademierat Johann Gottfried von Mastiaux (1726-1790), der bekannte Musikliebhaber, hat auf seinem Anwesen ein Gartengebäude, in dem die berühmten Konzerte stattfanden. Hier wird vermutlich seine bedeutende Musikalienbibliothek untergebracht gewesen sein, und vermutlich wohl noch mehr an Büchern, auch wenn das nur auszugsweise überlieferte Inventar darüber nichts Konkretes sagt. ${ }^{60}$ Von den fünf sorgfältig (aus)gebildeten Kindern finden wir drei in der Lese, die gleichnamigen Zwillinge Caspar Anton (17661828) und Caspar Anton Joseph (1766-1815) sowie Max Joseph (1768-1815). Die Mitgliedschaft deutet auf aktive Beteiligung am intellektuellen Geschehen hin, auf Auseinandersetzung mit politischen Ideen. Der ältere der Zwillinge ist 21-jährig, noch Kanoniker am Münsterstift,

Ludwig van Beethoven (1770-1827). Lithografie der Gebrüder Becker, nach einem zeitgenössischen Schattenriss, wohl von Joseph Neesen (Beethoven-Haus Bonn) unter den Lese-Gründern und 1790 Direktor der Gesellschaft. Als entschiedener Vertreter der Aufklärung geht er im publizistischen Kampf gegen das Kölner Domkapitel so weit, dass er eine Zeitlang nach Süddeutschland ausweichen muss; er hat dort seit 1788 eine Domherrnpräbende in Augsburg. ${ }^{61}$ Seine Schwester Amalie von Mastiaux (1770-1851), Beethovens Klavierschülerin, verfolgt alle neuen literarischen Erscheinungen "mit Lebendigkeit". 62 Sie wird nach dem Einmarsch der Armée de Sambre-et-Meuse auf Seiten der Cisrhenanen stehen. ${ }^{63}$ Bücher in größerer Anzahl kann es auch im Haus der mit den Mastiaux verwandten Familie Peltzer gegeben haben. Johann Jakob Tillmann (von) Peltzer (1738-1798), Hof-, Regierungs- und Oberappellationsgerichtsrat, auch er Gründungsmitglied der Lese, "schaffte alle damaligen Novitäten an: Hagedorn, Gellert, Rabener u.s.w... ${ }^{64}$ Friedrich von Hagedorn (1708-1771) gehört zwar noch dem literarischen Rokoko an, ist aber von der Haltung her schon der Aufklärung zuzurechnen, ebenso wie Rabener und Gellert, denen wir in Großmanns Bibliothek bereits begegnet sind. Die Lektüre von Johann Gottfried Herder (1744-1803) und Joachim Heinrich Campe (1746-1818), also von zwei Autoren mit Tendenz zum Sturm und Drang, ist für das peltzersche Haus gleichfalls überliefert. Sie gehören zum Lesestoff, vielleicht auch zum Besitz von Peltzers lebenslangem Freund und Hausgenossen Hofkammerrat Peter Joseph Boosfeld (1750-1819), dessen „Belesenheit in deutscher und französischer Literatur" bezeugt ist. Herder-Lektüre kann in Bonn damals kein Einzelfall gewesen sein; in der Bibliothek der Lese ist er mit

110 | Alexander Wolfshohl

(c) 2020 by Böhlau Verlag GmbH \& Cie. KG, Köln

https://doi.org/10.7788/9783412519704 | CC BY-NC 4.0 
mehreren Werken vertreten, und Eleonore von Breuning gibt Beethoven am 1. November 1792 zum Abschied nach Wien auf einem Stammbuchblatt einen Spruch von Herder mit auf den Weg.

Es sind überwiegend nur historische Quellensplitter, die auf die Existenz privater Bibliotheken im Kreis und Umkreis der Aufklärer hinweisen, aber es gibt deren noch mehr als die genannten. Meist hören wir davon, wenn die Bibliothek den Besitzer wechselt respektive aufgelöst wird. Am Sonntag, dem 31. August 1817, annonciert Notar Peter Joseph Eilender (1767-1831), Beethovens Jugendfreund aus dem Zehrgarten-Kreis, im Bonner Wochenblatt, dass ab dem 1. September die Hinterlassenschaft der Frau Witwe Koch, geborene Klemmer, in ihrem Sterbehaus in der Hundsgasse versteigert werde, darunter "eine kleine Sammlung guterBücher". Es handelt sich bei der Verstorbenen um Anna Maria Koch (1749-1817), die frühere Wirtin des Gasthauses Zehrgarten am Markt, Mutter von Babette Koch, der späteren zweiten Ehefrau des Grafen Anton von Belderbusch. Witwe Koch hat im Zehrgarten zusätzlich eine Buchhandlung betrieben, sie hat unter anderem die Lese mit Neuerscheinungen beliefert und ist verlegerisch tätig gewesen, so etwa mit Eulogius Schneiders Elegie an den sterbenden Kaiser Joseph II. Den 26. Februar 1790.65 In den Stammbuchblättern für Beethoven hat sie sich mit Versen aus Schillers Don Carlos und einer warmherzigen Widmung eingetragen. Am 7. September 1817 annonciert Eilender dann: „Das gedruckte Bücherverzeichniß wird am Montag im Sterbehause ausgetheilt." Der Aufruf der Bücher wird für Donnerstag, den 11. September, angesetzt. Welche Titel zur Auktion kommen sollten, muss offenbleiben, die Liste scheint nicht erhalten. Nur vermuten lässt sich, dass bei Witwe Koch in der "kleine(n) Sammlung guter Bücher" Titel aus der ZehrgartenZeit vorhanden waren. ${ }^{66}$

Der Autor Wilhelm Joseph Heinen berichtet im Begleiter auf Reisen durch Deutschland (1808) unter anderem von der Bibliothek des Bonner Notars Johann Heinrich Falkenstein (1743-1809). Im Kern wird Falkensteins Bücherei in die kurfürstliche Zeit zurückreichen, zumindest enthielt sie "viele Manuscripte" seines 1795 gestorbenen Schwagers, des Zöllners und Poeten Johann Merckenich, Lese-Mitglied seit 1788.67 In Heinens Reiseführer erfährt der Leser auch von den Kunst-und Naturaliensammlungen des langjährigen Hausfreundes der Witwe Koch, Johann Heinrich Crevelt (1751-1818). Für das Bonner kulturelle Leben ist dieser Arzt und Gelehrte zwischen 1780 und 1815 überaus bedeutsam geworden. Den Illuminaten stand er nahe, die Lese hat er mitbegründet, siebenmal war er deren gewählter Direktor, und er hat sich zu Anfang des 19. Jahrhunderts um die Bildersammlung der Gesellschaft verdient gemacht. ${ }^{68}$ Aus seinem "Naturalien-Cabinette, worin vieles noch angerühmt zu werden verdiente, führe ich meine Leser in die Bibliothek des bemeldeten Herrn Doctor Crevelt. Diese besteht aus ungefähr 14-1500 Bänden und enthält einige sowohl wegen typographischer Schönheit, als innerm Gehalte wichtigen Werke." 
Heinen gibt einige naturwissenschaftliche Werke als Beispiele an, darunter die "Histoire naturelle des singes et des Makis" (1799-1800) von Jean Baptiste Audebert (1759-1800), „ein Prachtwerk mit colorirten Kupfern, in fol.". An literarischen Titeln nennt er "Wielands Werke, Prachtausgabe in 4to. Gessners Schriften in 4to, mit von ihm selbst geätzten Kupfern." Crevelt hat vielleicht auch bibliophil gesammelt. "Der Alcoran, ein arabisches Manuscript" mag so in den Bestand gekommen sein. ${ }^{69}$ Nach Crevelts Tod ging die Sammlung in verschiedene Hände. Dem ersten Jahrbuch der Preußischen Rhein=Universität (1821) ist zu entnehmen, woher die Bestände der im Aufbau befindlichen neuen Universitätsbibliothek, der heutigen ULB, stammen; darunter als "sehr dankenswerthe Beiträge ... eine ... Auswahl aus der Büchersammlung des verstorbenen Doktors C $r$ e $v$ e I t zu Bonn, naturhistorische Werke und Reisebeschreibungen". ${ }^{70}$ Das erhaltene Akzessionsjournal weist die Titel genauestens aus. ${ }^{71}$

Gleichfalls in die preußische Universitätsbibliothek gelangt ist der BuchNachlass von Professor Joseph Claude Rougemont(1756-1818), dem Illuminaten und Lese-Mitbegründer, 3400 Bücher und 4000 Dissertationen, zwei Drittel davon medizinische und ein Drittel naturwissenschaftliche Werke, darunter "ein Probedruck der französischen Urversion seines Werkes Abhandlung von der Hundswuth, mit zahlreichen Anmerkungen von seiner Feder". ${ }^{72}$ Rougemonts Schüler Wegeler hat diese dann ins Deutsche übertragen. Bei Rougemonts Büchersammlung handelt sich um eine Spezialbibliothek, die schon in der kurfürstlichen Zeit aufgebaut wurde. Seinen Studenten dürfte sie nicht verschlossen gewesen und weiterführende, auch über das vorrangig Medizinische hinausgehende Gedanken werden dadurch angestoßen worden sein.

Bücherbesitz bei den Professoren der Hohen Schule ist üblicherweise zu erwarten und lässt sich für einige der aufgeklärtesten Köpfe nachweisen: den Exegeten Thaddaeus Anton Dereser OCD (1757-1827), den Juristen Philipp Hedderich OFMConv (1744-1808) und den Pädagogen Bonifaz Anton Oberthür (1749-1804)..$^{73}$

Vom revolutionären Straßburg aus, wohin er ohne Abschied abgereist war, bedankte sich Dereser am 8. Januar 1792 bei Spiegel für das ihm zugesandte nachträgliche Entlassungsdekret. Nach Grußzeile und Unterschrift fügte er an: "Wie ich Ihnen bei meiner Abreise sagte, habe ich etliche mir unentbehrliche Bücher mitgenommen. Nämlich 1. Darthe Vet. Test., 2. Hetzels Bibel, noch unvollständig, 3. Reallexikon 1. B., 4. Castelli Lexikon Syriacum, 5. Predigten für christliche Moral. Für diese habe ich in meiner Bücherzelle sehr viele andere zurückgelassen, die die Universität entschädigen. ${ }^{174}$

Hedderich war beim Einmarsch der Franzosen auf die rechte Rheinseite ausgewichen und hatte seine Bibliothek zurückgelassen. Jahrelang sorgte er sich um deren Bestand und die Aushändigung als Privatbesitz. 1805 Professor in Düsseldorf geworden, hat er, inzwischen wieder im Besitz von "fast 1000 Wer- 
ken und 2000 Dissertationen und Deduktionen", diese gegen eine Leibrente der dortigen Bibliothek (der heutigen Universitäts- und Landesbibliothek) übereignet; laut Braubach sind die Bücher noch vorhanden. ${ }^{75}$

Professor Oberthür (1749-1804) hatte in seiner Bonner Zeit eine Dienstwohnung im ehemaligen Jesuitenkolleg in der Bonngasse, schräg gegenüber dem Hauptgebäude der Hohen Schule. Sie umfasste Schlafzimmer, Empfangszimmer und Arbeitszimmer, und dort wird sich seine Büchersammlung befunden haben, über die er seinem Bruder brieflich nach Würzburg berichtete. Bei ihm, der für die Reform des Schulwesens im Kurfürstentum berufen worden war, können wir pädagogische Neuerscheinungen vermuten, wie er als vielfältig interessierter Aufklärer Novitäten überhaupt erworben haben mag, denn in Messezeiten gab er viel Geld für Buchanschaffungen aus. ${ }^{76}$

Als im Januar 1788 der Gymnasialprofessor Dr. Vitus Jäger (*1752) gestorben war, annoncierte Oberthür im Bönnischen Intelligenzblatt: "Unter den Büchern des dahier verstorbenen Herrn Prof. Jäger finden sich verschiedene Fragmente; vermuthlich hat er also Bücher an Freunde ausgeliehen. Diese sowohl als auch jene, welche allenfalls an der Verlassenschaft etwas zu fordern haben, werden ersucht, das ein oder andere innerhalb 3 Wochen beim Herrn Geistl. Rath Oberthür anzugeben, damit der Status berichtigt werden könne."${ }^{177}$ Offenbar ist die Anzeige ergebnislos gewesen, sie musste wiederholt eingerückt werden.

Eulogius Schneider (1756-1794), der deutschlandweit bekannte vehemente Aufklärer und Autor, wurde 1789 Professor der schönen Wissenschaften an der Hohen Schule. Er hat schon vor seiner Bonner Zeit über Bücher verfügt und in den Berufungsverhandlungen geäußert, sein Gehalt müsse so bemessen sein, dass es Neuanschaffungen erlaube. ${ }^{78}$

Der älteren Generation zugehörig und kein Aufklärer in der Frontlinie war der Kanoniker und Professor des Völker- und Staatsrechts Joseph Vitalian Lomberg (1739-1805). In Mülheim am Rhein (heute Köln-Mülheim), einem mehrkonfessionellen Gemeinwesen im Herzogtum Berg, gab es die Tradition der jährlichen sogenannten Kontroverspredigten. Am Fronleichnamstag 1780 hatte der Sonntagsprediger Pater Simplicianus Haan OESA die These vertreten: „Kein Protestantkann selig werden". Protestantischerseits wurde Beschwerde eingelegt und die gedruckte Predigt von Staats wegen vorläufig konfisziert. Über ein grundsätzliches Verbot der Kontroverspredigten wurde offenbar nachgedacht. Ordensleute aus Köln bestellten ein Gutachten bei Lomberg, worin dieser dann darlegte, die gehaltene Kontroverspredigt entspräche katholischen Grundpositionen. Die Konfiszierung wurde aufgehoben, Lombergs Gutachten anonym veröffentlicht. Es entstand ein heftiger, publizistisch begleiteter Streit, in den sich Johann Peter Eichhoff (1755-1825) als Herausgeber der Materialien zur geist- und weltlichen Statistick des niederrheinischen und westphälischen Kreises mit beißender Schärfe einmischte. ${ }^{79} \mathrm{Er}$ 


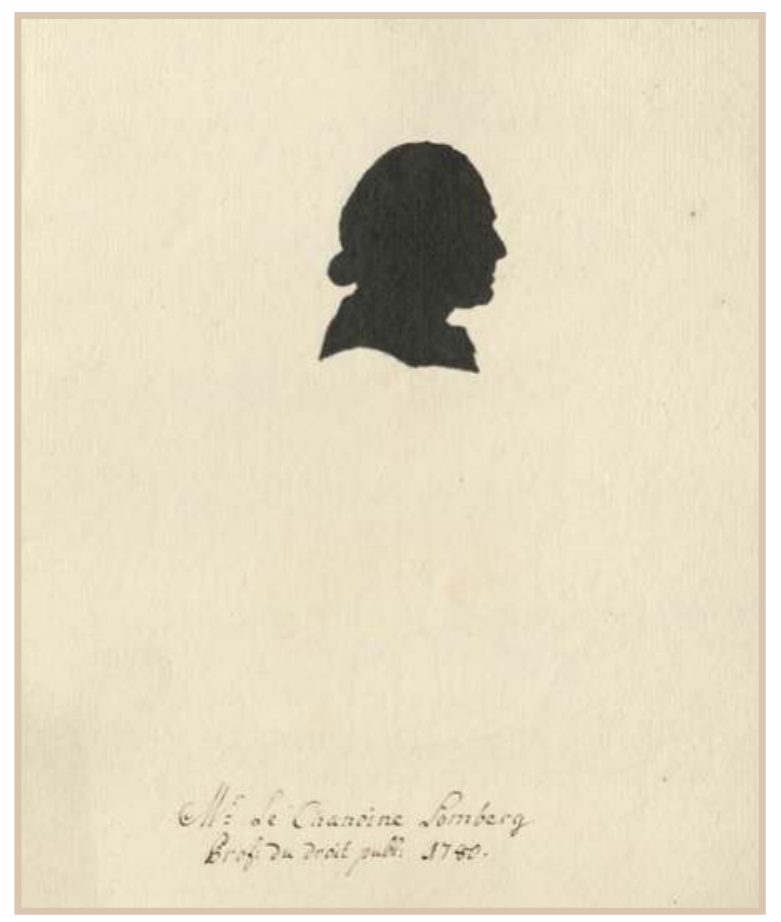

entlarvte Lomberg als Autor, druckte Gegenargumente $a b$, nahm bewertend Stellung und fügte abschließend hinzu: "Die Mönche konnten sich nirgend helfen, und so war der Dienst, welchen Herr Professor Lomberg denselben leistete, von größtem Belange. Das nun erkannten die Herren auch, da sie ihrem Wohlthäter nicht nur einen sogenannten Affiliationsbrief zuschickten, sondern denselben auch zugleich mit einem ansehnlichen Geschenk aus ihrer Bibliothek zu Köln regalirten. ${ }^{80}$ Die insgesamt ergiebige Quelle zeigt unter anderem, dass Lomberg Bücher besessen hat - sicher nicht nur die geschenkten Werke, sondern zuvor schon welche, denn das Geschenk wird zielführend ausgewählt worden sein -, und sie ist ein Beispiel für Konfrontationen, wie sie im Kreis der Bonner Intellektuellen bis hin zu erbitterter Gegnerschaft ausgetragen werden konnten.

Ein Wissensspeicher, der der Professorenschaft insgesamt zur Verfügung stand, muss die Akademie-Bibliothek gewesen sein. In ihr dürfte die Jesuiten-Bibliothek aufgegangen sein. Nach Auflösung des Ordens 1773 und

Prof. Dr. Joseph Vitalian Lomberg (1739-1805), Kanoniker und Jurist. Zeitgenössischer Schattenriss (Archiv Haus Melschede der Freiherrn von Wrede) Übernahme der Lehre durch die staatliche Hand mag sie im Kolleggebäude in der Bonngasse geblieben sein, in dem auch weiterhin Professoren wohnten. Offenbar hat sie die Zeitläufte überdauert, denn nach (Wieder-)Gründung der Universität durch König Friedrich Wilhelm III. taucht sie in den Akten der Universitätsbibliothek auf, zumindest das, was von ihr noch vorhanden war. Das genannte Akzessionsjournal verzeichnet "V. Catalogus librorum quorundam, e bibliotheca Academiae quondam Bonnnesis, residuorum. ${ }^{181}$ Theologische Literatur, mit zahlreichen Titeln aus dem 17. Jahrhundert, bildet einen Schwerpunkt des Bestandes, darunter eindeutig Jesuitisches. Auch das Alphabetum Tibetanum, Missionum apostolicarum commodo editum, Romae 1759, gehört dazu - in Tibet missionierten die Jesuiten seit der ersten Hälfte des 17. Jahrhunderts. Mit der Errichtung der kurfürstlichen Hohen Schule könnte der Besitz an Werken von Johann Amos Comenius (1592-1670), Christian Wolff (1679-1754) und Johann Christoph Gottsched (1700-1766) zusammenhängen. Eindeutig ablesbar ist die Tendenzwende an Schriften der Bonner Aufklärer. Es finden sich Hedderich, Ginetti, Rougemont, Eulogius Schneider, Scheidler, auch Andreas Spitz OSB (1747-1811), Anselm Becker OSB (1756-1843), Johann Ludwig (v.) Werner (1759-1829), Johann Anton Zulehner (1764-1795), Reiner Stupp (1767-1825), Johannes Neeb (1767-1843). Oberthürs Entwurf zur Verbesserung der Erziehungs- und Lehranstalten, für die Erzstift-KöInischen Stadt- und Landschulen auf Veranstaltung[!] der Kurfürstl. Max. Akademie. Bonn 1784, gemeinsam mit Karl von Belderbusch erarbeitet,

114 | Alexander Wolfshohl

(c) 2020 by Böhlau Verlag GmbH \& Cie. KG, Köln

https://doi.org/10.7788/9783412519704 | CC BY-NC 4.0 
oder Ferdinand Hanfs Elementar-Mathematik für die Kurkölnischen Gimnasien. 1ter Th. Arithmetik. Bonn 1791, zeigen wie etliche Dissertationen, Defensionsthesen und Vorlesungsverzeichnisse die neue Richtung. Wissenschaftliche Positionen, Forschungsergebnisse und Lehre der aufgeklärten kurfürstlichen Akademie und Universität spiegeln sich im Buchbestand.

Johann Joseph Eichhoff (1762-1827) war ein Bruder von Johann Peter Eichhoff (1755-1825), ein selbstbewusst-engagierter Illuminat und LeseGründer, Jugendfreund Beethovens, später Maire von Bonn und Generaldirektor des Rheinschifffahrts-Oktrois. ${ }^{82}$ Nach seinem Tod verfügten die Söhne eine Nachlass-Auktion seiner großen Sammlung. Dabei sind auch Bücher zum Aufruf gekommen. Einige ersteigerte der aus jüdischer Gelehrtenfamilie stammende Kaufmann Nathan Horwitz Schlesinger: „Haushaltungskunst' von Suckow, ,Gedichte' von Pfeiffer, La Contenance de Scipio Africanus, Friedrichs hinterlassene Werke, Oeuvres des Montesquieu, Jacobi's Briefe, Archenholtz ,England und Italien'.83 Mit Johann Joseph Pfeiffer (1771-1808), einem Bonner Juristen, der unter anderem in Jena studiert hatte, späterem Generalsekretär der Mairie, war ein örtlicher Schriftsteller vertreten; die anderen Autoren lassen erneut auf Herkunft aus einer Aufklärungsbibliothek schließen, die sich zur Auseinandersetzung mit der europaweiten geistigen Bewegung anbot. ${ }^{84}$ Schlesinger ersteigerte die Bücher 1828 als 59-Jähriger. Das sagt nichts über ihn als Leser in seiner Jugend aus, allenfalls über das Interesse des älteren Mannes. Einen Hinweis darauf, ob Aufklärungsliteratur die Familien der Judengasse erreicht hat, gibt der Kauf nicht. Die Kaufleute Herz Salomon Oppenheim (1752-1832), Vater des Bankiers, und Meyer Heymann Gunzenhausen (17441817) besaßen Bücher, doch offenbar nur Hebraica. Über 100 bzw. 50 gingen in die jeweilige Nachlassauktion. Dasselbe gilt für die Versteigerung nach dem Tod von Dr. Moyses Abraham Wolff, dem bereits erwähnten früheren Leibarzt von Clemens August; wieder wechselten einige Hebraica den Besitzer. Im Nachlass von Simon Baruch (1755-1823), dem Sohn des großen Finanziers Baruch Simon, waren hebräische und deutsche Bücher; Titel sind nicht genannt, und die späte Erwähnung sagt abermals nichts über einen Bestand zur kurfürstlichen Zeit. Dass aber die Literatur der Epoche vor den Toren der Judengasse nicht Halt machte, zeigt Forstmeisters Ausleihverzeichnis, und es wird auch noch an anderen Indizien zu sehen sein. ${ }^{85}$

\subsection{Die Handbibliothek des Erzherzogs und jungen Kurfürsten Max Franz}

Als Max Franz 1784 die Nachfolge Max Friedrichs antrat, brachte er aus Wien eine Bibliothek mit. "Das Verzeichnis der Bücher welche S. Kurf. Durchl. Max. Franz Erzherzog zu Oesterreich nach Bonn mitgebracht und ferner hieselbst neu angekauft haben" hat sich erhalten. ${ }^{86}$ Auf 120 Seiten, 110 davon beschrieben, finden sich zunächst Sachliteratur, die den Großteil ausmacht, und Poesie, insgesamt ohne weitere Kategorisierung alphabetisch geordnet. Es folgen 
Kurfürst-Erzbischof Maximilian Friedrich (17081784) und Kurfürst-Erzbischof Maximilian Franz, Hoch- und Deutschmeister OT (1756-1801). Kupferstich aus: Kurfürstlich-Kölnischer Hofkalender auf das Jahr 1781 (Beethoven-Haus Bonn)

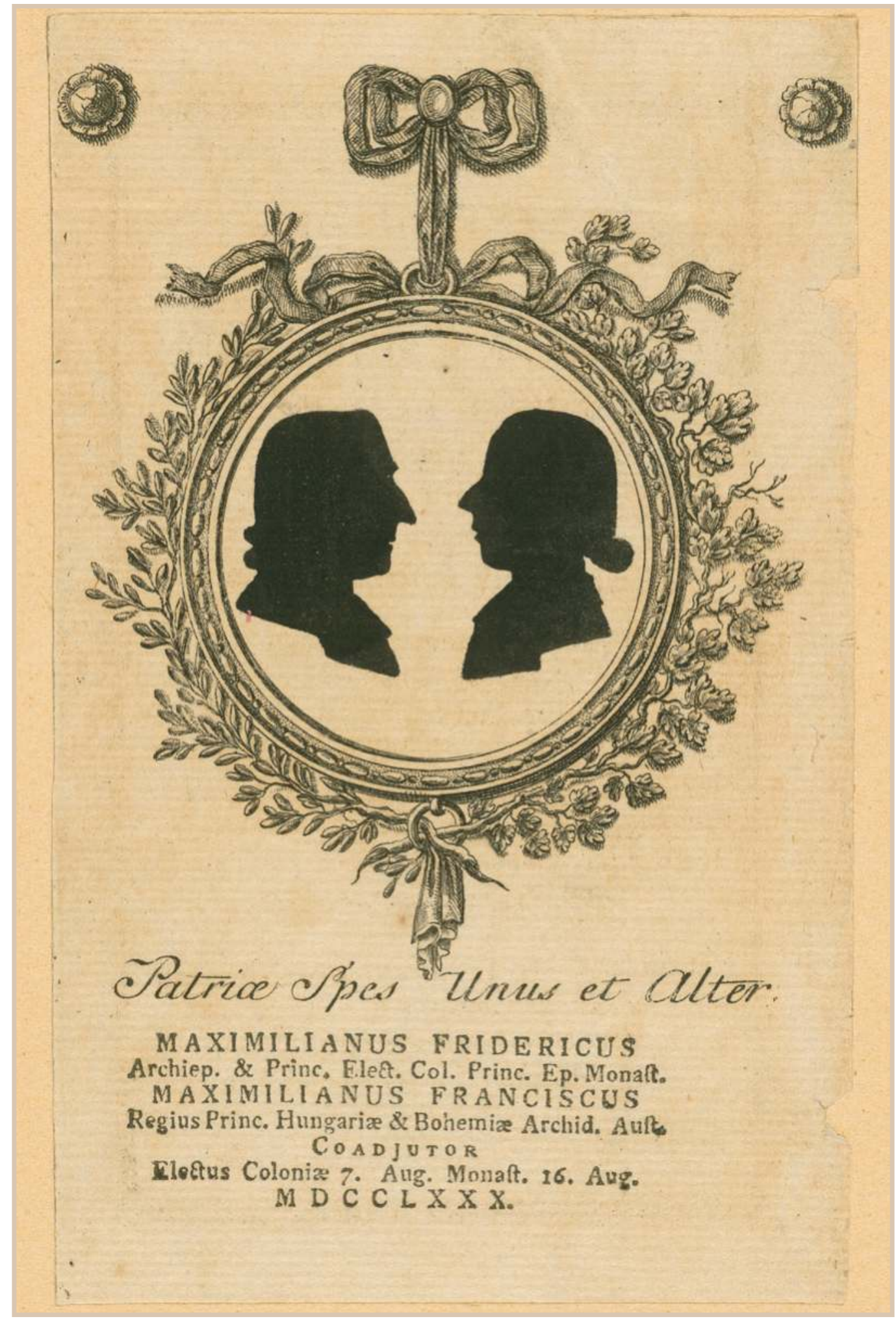

116 | Alexander Wolfshohl

(c) 2020 by Böhlau Verlag GmbH \& Cie. KG, Köln

https://doi.org/10.7788/9783412519704 | CC BY-NC 4.0 
Gebeth- und Gesang-Bücher sowie Kantate. Alles zusammen rund 700 Titel, auch mehrbändige; 63 Titel Ungebundene Bücher kommen am Ende des Verzeichnisses noch hinzu. Dramatische Texte sind eigens aufgelistet: Deutsche Theater-Stücke, einschließlich Theaterliteratur 83 Titel, Französische TheaterStücke, 47 Titel, und Italiänische Theater-Stücke, 35 Titel. Karten und Pläne sind in verschiedenen Gruppen erfasst; gefolgt von Kupferstichen, also künstlerisch eingestuften Blättern.

Wann dieses Inventarium in Bonn angelegt worden ist, wird nicht erklärt, doch ist kein von 1786 bis 1794 erschienenes Buch mehr verzeichnet. Darauf wird zurückzukommen sein. Vom Bestand her scheint ein Einblick in den Bildungsweg des jungen Erzherzogs möglich. Das buchmäßige Rüstzeug, das Max Franz nach Bonn mitgebracht hat, und die Arbeitsthemen, die ihm in den ersten Bonner Jahren wichtig waren, werden hier greifbar.

Derim Inventarium erfasste Bestand zeigt, abgesehen von denTheaterstücken, kaum Fiktionales. Young ist da, mit den europaweit gelesenen Nachtgedanken, Blumauer und Cronegk, denen wir bei Forstmeister auch begegnet sind, ersterer mit einer Ausgabe seiner Schriften, ebenso Wieland und (unter den Theaterstücken) Goethe mit Erwin und Elmire. Entschieden aber herrscht Sachliteratur vor. Militärisches verweist vielleicht auf die ursprünglich für Max Franz vorgesehene soldatische Karriere; Löhneisens Neue Hof- Kriegs und Reit-Schul (1729), wovon Forstmeister ein Exemplar derselben Ausgabe besaß, fehlt nicht. Titel und Karten zu Preußen verstehen sich aus den erst wenige Jahre und Jahrzehnte zurückliegenden Kriegen. Historische und juristische Literatur ist mit Grundlagenwerken und Einzeluntersuchungen, beispielsweise über landesfürstliche Rechtspositionen, vertreten; Samuel Freiherr von Pufendorf (1632-1694) liegt mit 2 Werken vor, Johann Stephan Püttner (17251807) mit 17, Burkhard Gottholf Struve (1671-1738) mit 6 Titeln; von Hedderich gibt es 4 und vom Münsteraner Professor Clemens Becker (1724-1790) eines: De regimini Episcoporum per tria prima Saecula (1784). Staats- und Kameralwissenschaft ist ein Schwerpunkt, unter anderem mit elf Werken von Johann Heinrich Gottlob von Justi (1720-1771), "dessen bleibende wissenschaftliche Bedeutung im Bereich der Staats- und Kameralwissenschaften liegt ${ }^{487}$. Seine Abhandlung von den Manufaktur- und Fabriken-Reglements (1762) ist ebenso vorhanden wie seine Grundsätze der Policey-Wissenschaft (1759), wohl eine frühere Ausgabe von Die Grundfeste zu der Macht und Glückseligkeit der Staaten oder ausführliche Vorstellung der gesamten Policey-Wissenschaft (1760/61), worin die heutige "Verwaltungslehre ihren vollgültigen Vorläufer" hat. Weitere seinerzeit diskutierte Kameralisten in der Sammlung sind etwa: Joseph von Sonnenfels (1732/33-1817) - später Widmungsträger von Beethovens Klaviersonate Nr. 15 op. 28 - mit fünf Titeln, darunter die Grundsätze der Polizey-Handlung und Finanzwissenschaft (1770-76), Johann Wilhelm von der Lith (1709-1775) mit Abhandlung von den Steuren[!] (1766) und Jacques 
Necker (1732-1804) mit De L'administration des Finances de la France (1784) und "Des Herrn von Necker Versuch über den Kornhandel und über die Gesetze diesen Gegenstand betreffend: Aus dem Französischen übersetzt" (1777) oder Charles Etienne Pesselier (1712-1763) Gedanken eines Bürgers von den Bedürfnissen, Rechten, und Pflichten der wahren Armen, aus dem französischen des Herrn Pesselier; übersetzt (1769). Der Buchbestand lässt hier auf einen aufmerksamen, auf die Verbesserung der Staatsfinanzen und auf das Wohl der Bevölkerung bedachten Leser schließen. Verständlicherweise gehören physiokratische Autoren zur Lektüre, so Jean François de Melon (1675-1738) mit Kleine Schriften über die Handlung und Manufacturen; übersetzt (1756); und zu demselben Fachbereich gehören zum Beispiel Herzogthum Krain. Unterricht im Ackerbau hieselbst (1776), das Chemnitzer Mineral und Bergwerks Lexicon (1743) und, wie bei Forstmeister, Bruchausens Institutiones. Agrarreform und Melioration werden nicht ausgespart; das zeigen Werke wie: Böhmische Domainen-Verwandlung in Bauern-Güter (1777) und Henri Louis Duhamel de Monceau (1700-1782) Von der Fällung der Wälder und gehöriger Anwendung des gefällten Holzes mit Kupfertafeln (1766-67).

Medizinische Vorsorgegedanken belegt die Pest-Ordnung von Johann Wilhelm Managetta Ritter von Lerchenau (1588-1666), zuerst 1679 postum erschienen und noch im 18. Jahrhundert als gültig angesehen. Sie liegt vor in einer Ausgabe Wien 1727. Auch die Kaiserlich-königliche Instruction für die Feld-Chyrurgen (1779) oder, erneut wie in Forstmeisters Bibliothek, Ferro Vom Gebrauche der kalten Bäder (1781) zeugen davon.

Theologisches und Philosophisches gehört zur Ausbildung eines geistlichen Fürsten. Von breitem Interesse zeugt, dass von David Hume (1711-1776) Einzeltitel und eine französischsprachige Gesamtausgabe Ses oeuvres (17601764) angeschafft wurden. Des Hallenser Aufklärers Christian Freiherrn von Wolff (1679-1754) Gedanken von den Kräften des Menschenverstandes (1754) weist in dieselbe Richtung wie die zahlreichen Titel zu Pädagogik und Schule, so: Preußen. Landschul-Reglement für die Katolischen[!] in Schlesien und Glatz (1765), Mainz. Einrichtung der Trivial- und Real-Schulen (1773), Mainz. Verfassung der verbesserten hohen Schule daselbst (1784), Was sind Trivialschulen?(Wien 1776),Kaiserlich-KöniglichePrüfung derHauptnormalschulLehrlinge, um künftig die Soldaten-Kinder zu unterrichten (1780), Methodenbuch für Lehrer der deutschen Schulen in den K.K. Erblanden (1775) oder Ferdinand Kindermann (1740-1801, seit 1777: Ritter von Schulstein) Von dem Einfluße der niedern Schulen auf das gemeinsame Leben (1776).

2.8 Die kurfürstliche Hofbibliothek in den letzten Jahrzehnten des 18. Jahrhunderts

Max Franz hat, wie gesagt, die mitgebrachte Bibliothek nur anfangs erweitert. 1785 ist das Inventar offenbar aus gegebenem Anlass erstellt worden: Der 
Kurfürst ließ im Herbst diesen Jahres seinen Buchbestand der vorhandenen Hofbibliothek inkorporieren und diese "besonders zum Nutzen und Gebrauch der Beamten und studierenden Jugend" öffnen. ${ }^{88}$ Früher ein Bestandteil fürstlicher Repräsentation und außer dem Kurfürsten wohl nur den höchsten Hofchargen und Spitzen der Regierungsbehörden zugänglich, sollte sie eine Bildungseinrichtung zum Vorteil von Staat und Gesellschaft werden.

Versammelt waren dort nun die Bibliotheken von Clemens August, Max Friedrich und Max Franz, sodann die von Max Friedrich 1781 erworbene medizinische Fachbücherei des Kölner Professors Johann Georg Menn (1729/30-1781)89 und Bücher aus Klosterbibliotheken. Um Neuerwerbungen kümmerte sich Max Franz weiterhin. Ihm zur Seite stand Spiegel zum Diesenberg, der in der Doppelfunktion als Hofkammerpräsident und Universitätskurator die Modernisierung des Bestandes entscheidend vorantrieb. Anforderungswünsche der Professoren wurden eingeholt und geprüft, das Ziel war, „einen höheren Grad von Gemeinnützigkeit" 90 zu erreichen. Leiter der Bibliothek war bis 1792 der Hofkammerrat und spätere Universitätssyndikus Reiner Josef Esser (1747-1834), das älteste durch Ballotage aufgenommene Mitglied der neugegründeten Lese. Esser, ein tüchtiger und umsichtiger Verwaltungsjurist ${ }^{91}$, organisierte 1794 die Flüchtung der Bibliothek und der Archive ins Rechtsrheinische und weiter bis nach Hamburg. Der junge Hof- und Regierungsrat Joseph Wurzer (1770-1860), seit 1. April 1794 auch Lese-Mitglied, brachte sie dort sicher unter. ${ }^{92}$ Von einem Restbestand, der nicht mehr hatte gerettet werden können, holte die französische Verwaltung die wertvollsten Stücke nach Paris, das Übrige wurde nach vergeblichen Auktionsversuchen in Bonn zur Veräußerung nach Köln geschafft. ${ }^{93}$ Max Franz starb 1801, das Alte Reich endete 1806, und die rechtsrheinischen Gebiete des früheren Kurfürstentums gelangten an die Rheinbundstaaten. Zu deren Gunsten, vor allem des Großherzogtums Hessen, wurden 1808 die in Hamburg lagernden Bibliotheksbestände durch den ehemaligen Unterbibliothekar Bendfeld versteigert. Ein durchschossenes Exemplar des präzisen Auktionskatalogs mit Angaben der Ersteigerer und erzielter Preise hat Bendfeld dann an den in hessischen Dienst übernommenen Esser geschickt. Esser gab den Katalog 1822 an die neue Bonner Universitätsbibliothek

\author{
Reiner Josef Esser, \\ Hofkammerrat (1747-1834). \\ Ölgemälde nach 1826 \\ (Beethoven-Haus Bonn)
}


weiter, wo er erhalten ist. So sind wir über Umfang und Inhalt informiert, der Bestand umfasste 14.776 Nummern, zum Teil mehrbändige Ausgaben in einem Lot, doch häufiger auch bei diesen für jeden Band eine Nummer. ${ }^{94}$ Von der Klassifizierung her scheint eine barocke Bibliothek vorzuliegen, vergleichbar der irgendeiner beliebigen geistlichen Bildungsinstitution von Rang. Die Sytematik umfasst: Historia universalis / Historia ecclesiastica / Historia profana / Geographica, Cosmographia et Topographia / Archaeologia et Symbolica / Philologia, Auctores classici / Philologia, Lexica / Philologia, Poesis / Rhetorica, Symbolica et Epigraphica / Philologia, Linguistica / Philologia, Critica / Historia literaria et bibliographia / Philosophia / Mathesis / Kunstwerke / Medica et chirurgica / Jus canonicum et civile / Staatsrecht / Theologia.

Inhaltlich und thematisch ist die Genese ablesbar. Mehr als ein Fünftel der Nummern umfasst die Theologie. Auch Vorlieben früherer Büchersammler mag man entdecken: Zum Beispiel tritt bei den Amusements de la Campagne, ou Récreations historiques, avec quelques Anecdotes secrets et galantes, Paris 1742, oder 60 Amusements de la Campagne, Paris 1734, unwillkürlich Clemens August als Leser vor Augen. ${ }^{95}$ Die Durchsicht der Titel ergibt jedoch ein differenzierteres Bild. So ist die Dichtung der Aufklärung vorhanden und noch breiter aufgestellt als in den schon erwähnten anderen Bonner Buchbeständen. Wieder finden sich Rabener, Gellert, Klopstock, Ramler, Christian Felix Weiße, Gessner, Wieland, des Weiteren etwa auch Friedrich Ludwig von Kanitz (16541699), der an der Wende zur Aufklärung stand und den später noch Goethe bewunderte, dann Johann Christoph Gottsched (1700-1766), bedeutsam für die Entwicklung von Schauspiel und Bühne, Albrecht von Haller (1708-1777), der berühmte Göttinger Naturwissenschaftler und Literat, Johann Adolf Schlegel (1721-1793), der mit lehrhaften Verserzählungen hervorgetreten ist, oder Moritz August von Thümmel (1738-1817), Romancier in der Nachfolge Laurence Sternes. Auch Herder fehlt nicht. Werke zur Kriegskunst sind da, vielleicht angesichts der Revolutionswirren und eines mit Frankreich drohenden Krieges noch vermehrt. Vor allem aber ist das, was Max Franz' Bibliothek an modernen Akzenten aufwies, nach 1785 beibehalten und in der Hofbibliothek verstärkt worden. In der Abteilung Philosophie finden sich die Werke Kants und solche der Auseinandersetzung damit, der Bereich Staats- und Reichsrecht wurde vermehrt um Titel über Völkerrecht und Naturrecht. Das Hamburger Politische Journal, eine jener Zeitungen, die man im intellektuellen Deutschland las, ist bei der Auktion mit den Jahrgängen 1786 bis 1792 vorhanden.

Staatswissenschaft, Polizeiwesen - einschließlich Wasserpolizei -, Kameralistik, Finanzlehre und Fabrikwissenschaft sind angewachsen und erweitert um Rechnungswesen und Buchhaltung. Stilistik und Briefsteller fehlen nicht. Die an der Universität lehrenden Professoren Peter Wilhelm de Ginetti (1735-1804) ${ }^{96}$, Rougemont und Wegeler, seit 1789 Ordinarius für Gerichtsmedizin und Geburtshilfe, mögen den Erwerb aktueller Literatur angeregt haben, beispiels- 
weise hat die Auseinandersetzung um die Pockenschutzimpfung ihren Niederschlag im Bestand gefunden. Ganz auf Verbesserung der Lebensverhältnisse im medizinischen Bereich zielend - wie auch darüber hinaus - sind praktische Anleitungen für den Hausvater, die Hausmutter und die Gesundheitserziehung der Kinder. Auf Steigerung der Erträge des Landes und damit auf Wohlfahrt der Bevölkerung ausgerichtet, ist die Botanik erweitert um Ökonomische Botanik, um Werke zur Forstwirtschaft (mit Holzsaat), zu Ackerbau und Grasbau, Weinbau und Gartenbau, zur Düngungslehre, zu Schaf- und Bienenzucht. Montanistik, einschließlich Mineralogie, Metallurgie, Bergbaukunde und Hüttenwesen, tritt hinzu. Lichtenbergs Magazin für das Neueste aus der Physik und Naturgeschichte fehlt nicht, bricht aber 1792 mit dem dritten Heft von Band 8 ab; „der 8te Band ungebunden", heißt es im Katalog. ${ }^{97}$ Der Bucherwerb korrespondierte mit der Ausrichtung der neuen Universität, an der ab 1788 auch Kameralistik und Statistik, ab 1790 Mineralogie und ab 1793 Chemie gelehrt wurden. Abhandlungen aus der Naturlehre, der Mechanik und der Haushaltungskunde, bis hin zu Unterricht von den neuen Küchen- und anderen Eisengesundheits-Geschirren, Wien [o.J.], zielen ebenfalls auf praxisbezogene Belehrung. Auch Grundlagenwerke zu Technologie, Architektur und Baukunde fehlen da nicht.

Eindrucksvoll zeigen die um Schule und Pädagogik kreisenden Schriften, wie in diesem Bereich gearbeitet werden sollte und wurde. Vorhanden sind beispielsweise J. A. Hasslingers Anzeige von Menschenbildung. Wien 1788, Landschulbibliothek oder Handbuch für Schullehrer auf dem Lande. 4 Bände. Berlin 1780-90, J. H. Campe allgemeine Revision des gesamten Schul- und Erziehungswesens, 16 Theile. Hamb. [1]785-92, Anleitung zum Unterrichte der Taubstummen des Abbé de l'Epée zu Paris, mit einer grossen Kupfertafel, 1 Theil. Wien. [1]786, Gedanken über die vollständige Vorbereitung fähiger Jünglinge zu wichtigen Absichten der Wohlfahrt des Staates. [0.O.] [1]776. Die letztgenannte Titelformulierung benennt das eigentliche Ziel der Reformen des Kurfürsten und Spiegels. Unterstützt wurden beide von überzeugten Aufklärern unter den Professoren und den Amtsträgern in Regierung und Verwaltung.

Aus fürstlichen Handbibliotheken und Klosterbibliotheken erwachsen, war die kurfürstliche Hofbibliothek eine Bildungseinrichtung geworden, die vor allem wissenschaftlichem Interesse zur Verfügung stand. Hofkammerrat Esser hatte vor ihrer Etablierung als Hochschulbibliothek eine Verordnung über die Nutzungsmodalitäten erarbeitet. Modifiziert galt sie bis 1794. Im Vorwort zum Auktionskatalog schreibt Benfeld 1808: „Zur Geschichte dieser Bibliothek gehört, dass sie den Studierenden auf der Universität zu Bonn täglich offen stand, von 4 Uhr Nachmittags bis Abends sieben, wo sie alle Bequemlichkeiten hatten."

Gegenüber Bildungsreisenden von auswärts war man aufgeschlossen, zeigte die Universitätseinrichtungen und die Bibliothek, einige Besucher nahmen das Neue wahr und hielten es fest. 1787 kam Abbate Bertòla (1753-1798) nach Bonn. Literarhistorisch gilt er heute als Prototyp der Romantiker. Gefühle, die 
die durchquerten Landschaften auslösten, interessierten ihn vorrangig. So erfahren Leserin und Leser kaum Fakten über die Realien besuchter Orte. Über Bonn macht er ein paar karge, wenig aussagekräftige Angaben, geht aber an einer Stelle darüber hinaus: "seit einiger Zeit werden auch die nützlichern Wissenschaften hier gelehrt." Das muss ihm bemerkenswert erschienen sein. ${ }^{98}$ Wilhelm von Humboldt hat Bonn 1788 besucht und Begegnungen und Eindrücke ausführlich im Reisetagebuch festgehalten, zum Teil mit etwas herber Kritik. Über die Bibliothek schreibt er:

"Im Ganzen ist sie geordnet, aber in den kleinen Abtheilungen der Fächer fehlt alle Ordnung. Sie ist auch weder zahlreich, noch in irgendeinem Fach vollständig. Nur die Sammlung von Bibelausgaben zeichnet sie aus. ... Nur jetzt sucht der Cammer-Präsident von Spiegel, der Curator der Universität ist, philosophische und kameralistische anzuschaffen. So sah ich doch Tetens ${ }^{99}$, Mendelssohn und Kant u.s.f. Ins Haus bekommt kein Student ein Buch. Allein es ist auf der Bibliothek ein grosses Zimmer mit Pulten, wo 40 bis 50 Platz haben. Jeder hat da sein Pult, sein Licht, seine Schreibmaterialien auf kurfürstliche Kosten und bekommt jedes Buch. Diess[!] Zimmer steht Abends von 5-7 offen, nur freilich in den Ferien nicht." 100

Ausführlich schildert der Koblenzer Geistliche und Pädagoge Joseph Gregor Lang (1755-1834) in seinem Reisebericht 1789 die Reformen im Kurstaat, die er als josephinisch einstuft; positiv bewertet er die universitäre Arbeit, nennt Namen - alle sind es Lese-Mitglieder - und erwähnt zweimal, dass Max Franz die Bibliothek „durch seinen grossmüthigen Beitrag ansehnlich vermehret" habe, sowie: „Der Zutritt ist frei, und wird von den Bönner[!] Minervensöhnen fleissig besuchet."101

Was eine solche Studiermöglichkeit - ein beleuchteter Arbeitsplatz in einem geheizten Raum und kostenloser Schreibbedarf - am Ende des 18. Jahrhunderts für junge Menschen aus bescheidenen Verhältnissen bedeutet hat, können wir heute kaum noch ermessen. Das war Nachwuchsförderung, die, unabhängig von Stand und Herkommen, den Besten und Fleißigen zum Wohle aller zugutekommen sollte. Fast selbstbewusst wurde im jährlichen Vorlesungsverzeichnis, veröffentlicht im Bönnische(n) Intelligenzblatt, darauf hingewiesen. Ab 1787 heißt es dort: „Die Kurfürstliche Bibliothek steht täglich mehrere Stunden offen, und es ist nicht nur jedem Kandidaten der freie Zutritt erlaubt, sondern er trift[!] auch die bequemste Einrichtung zum Lesen an."102

\subsection{Lesekabinette und Lesegesellschaften}

Periodika waren in der Hofbibliothek nur wenige zu finden, und gerade Zeitschriften und Zeitungen hatten sich, wie gesagt, in der zweiten Hälfte des 18. Jahrhunderts außerordentlich weiterentwickelt. "Annalen”, "Beiträge”, "Correspondenzen”, "Intelligenzblätter", "Magazine” kamen in großer Zahl heraus, um Fachleuten und interessierten, gebildeten Laien Informationen zu 
liefern und Diskussionsforen zu bieten. Lesekabinette, Lesezirkel und Lesegesellschaften ermöglichten vielfach die Lektüre von mehr Blättern, als sie sich ein einzelner Abonnent leisten konnte; und dadurch vergrößerte sich die Leserschaft erheblich. In Bonn gab es ein Lesekabinett am Markt, begründet von Johann Peter Eichhoff, Rat und Deputierten des Grafen von BentheimSteinfurt beim kurkölnischen Landtag, dem schon erwähnten überaus engagierten Publizisten, Illuminaten, Mitbegründer und ersten Direktor der Lese. Seit Anfang 1785 war er in kurfürstlichem Auftrag Herausgeber und Redakteur des Bönnischen Intelligenzblatt(es). Als Eichhoff dann bis Ende 1786 als Registrator und Archivar des Deutschen Ordens nach Maastricht ging, ${ }^{103}$ übernahm sein Schwager Professor Dr. med. Johann Bernhard Constantin von Schönebeck (1760-1835), der schon die illuminatischen Beiträge zur Ausbreitung nützlicher Kenntnisse herausgegeben hatte, die Leitung des Intelligenzblatt(es) und des Lesekabinetts. ${ }^{104} \mathrm{Er}$ informierte darüber in einer Anzeige im Intelligenzblatt:

"Ich mache hiermit dem gelehrten Publikum bekant, daß ich das von dem Hrn. Archivar Eichhof errichtete, von den vortreflichsten Männern noch immer besuchte Lesekabinet hieselbst auf dem Markt, worin man die besten periodischen Schriften sowohl, als gelehrte und politische Zeitungen und Bücher lesen kan, ununterbrochen fortsetze ..."105

Wo das Kabinett seinen Sitz hatte, wissen wir nicht, erfahren aber aus der Annonce, dass es täglich von 9 bis 12 und von 15 bis 20 Uhr geöffnet sei und dass der jährliche Beitrag 6 Taler betrage (wobei auch monatliches Abo möglich war). Die Höhe des Jahresbeitrags schränkte den Kreis längerfristiger Mitglieder auf Wohlhabende ein. Zum Vergleich drei Professorengehälter: Elias Peter Joseph van der Schüren OFMConv (1750-1829) bezog an der Akademie 1777 jährlich 50 und an der Universität 1790100 Reichstaler, er hatte freilich durch die Ordenszugehörigkeit für Kost, Logis und Kleidung nichts aufzubringen. Das gilt auch für den 1786 berufenen Achatius Apel OFM, der 1790 ein Jahresgehalt von 154 Reichstaler erhielt. Franz Gerhard Wegeler bekam als Ordinarius im Dezember 1789 ein Einstiegsgehalt von 300 Reichstalern pro anno. Und mit der von Kurfürst Max Franz am 25. Juni 1784 verfügten neuen Besoldungsordnung für die Hofmusik erhielten der Tenorist Johann van Beethoven 200 Reichstaler und der Hoforganist Ludwig van Beethoven 100 Reichstaler Jahresgehalt. ${ }^{106}$

Am 5. Dezember 1786 inserierte Schönebeck, er gebe seinen Büchervorrat und seine Correspondenzen an die Witwe Anna Maria Koch, geborene Klemmer, ab, die eine Buchhandlung eröffne. Unklar bleibt, ob das Lesekabinett nun im Gasthaus der Witwe Koch, dem Zehrgarten, weitergeführt wurde oder ob der Bestand als Leihbibliothek genutzt werden konnte. Über die Modalitäten der zugesicherten "genaueste(n) und prompteste(n) Bedienung" durch Witwe Koch erfährt der Leser nichts. ${ }^{107}$ 
Vielleicht entstand durch Schönebecks Ausscheiden eine Lücke, denn der oben genannte Professor Dr. theol. Bonifaz Anton Oberthür, Illuminat, Geistlicher Rat, Direktor des Gymnasiums und Leiter der Lehrerausbildung, schrieb am 3. April 1786 an seinen Bruder nach Würzburg: "Ich habe hier eine Privatlesegesellschaft eingeführt, wo man die artigsten Journale liest. ${ }^{\prime 108}$ Der Illuminaten-Orden hatte sich 1785 auf politischen Druck hin aufgelöst, das heißt, auch die Bonner Loge, die Minervalkirche Stagira, war erloschen. Denkbar, dass die Etablierung der "Privatlesegesellschaft" auch damit in Zusammenhang steht.

Im Jahr darauf, am 1. Dezember 1787, gründeten 35 aufgeklärte Bonner eine förmliche Lesegesellschaft, keine Geheimbundloge mehr, sondern eine öffentlich auftretende Vereinigung unter dem Protektorat des Kurfürsten, der „alles, was zur Beförderung dieses als ein zur Geisteskultur nützlichen Instituts beyzutragen geneigt" war. ${ }^{109}$ Übereinstimmende Wertvorstellungen und Ideale verbanden die Mitglieder. Abkehr von Standesschranken, Gleichwertigkeit aller, sowohl in Diskussionen als auch bei Abstimmungen über anstehende Fragen, machten die Gesellschaft zu einer Demokratie in nuce.

Persönlichkeitsentwicklung, Förderung von Bildung, Humanisierung der Gesellschaft waren Leitziele. Am Beginn der Arbeit standen die Erarbeitung einer Satzung und der Aufbau einer Bibliothek. Erhoben wurde ein Halbjahresbeitrag von zwei Reichstalern; zudem verpflichtete sich jedes Mitglied, eine abonnierte Zeitschrift oder monetären Ausgleich dafür beizusteuern. Die Liste der bei der Gründungsversammlung zugesagten Periodika ist nicht erhalten; aber eines der Abonnements ist erschließbar: der Bezug der Gothaischen gelehrten Zeitung. In der zweiten Sitzung am 2. Januar 1788 trugen verschiedene Mitglieder noch weitere Journale bei. Das Protokoll verzeichnet: Gespräche im Reiche der Todten von Neuwied, Annalen von Linguet, Meusels historische Litteratur, Forsters und Lichtenbergs Magazin, das Jesuiten Journal, die ökonomische Wochenschrift von Neuwied, die neue deutsche Chronik von Schubart, G.W. Boehmers Magazin für das Kirchenrecht, die Kirchen- und Gelehrten-geschichte, göttingische Fortsetzung von Büschings wöchentlichen Nachrichten, das geographisch-statistisch[e] Wochenblatt von Fabri und Hammerdörfer, das Brezinger Journal, die allg. Deutsche Bibliothek von Nicolai, das Jahrbuch der Menschheit, Lichtenbergs Magazin über das Neueste aus der Physik und Naturgeschichte, der deutsche Merkur, Meiners und Spittlers historisch[es] Magazin, das deutsche Musäum, Fr[ank]f[ur]t[e]r Ristretto, die Leidener Zeitung, Fr[ank]f[ur]t[e]r Oberpostamtszeitung, die erlanger Zeitung, das leipziger Intelligenzblatt, den Nouvelliste politique, das brittish Register, den Köln[ischen] Staatsboth, die Göttinger gelehrten Anzeigen. ${ }^{110}$ Fast ausnahmslos lassen sich die Zeitschriften ermitteln; deutlich wird das Bestreben der LeseMitglieder, sich wissenschaftlich, literarisch-kritisch und politisch aktuell und breit informieren zu können. Die Frage, ob die abonnierten Zeitschriften poli- 
tisch hinreichend orientierten, beschäftigte die Generalversammlung immer wieder. Zusätzliche Periodika sollten das gewährleisten; so wurden bestellt: Moniteur, Gazette nationale fransaise, Deutsche Staatslitteratur, Deutsches Magazin (des Freiherrn von Eggers) und Hamburger Zeitung. Das war der geläufige Kurztitel für Staats- und Gelehrte Zeitung des Hamburgischen unpartheyischen Correspondenten, Ende des 18. Jahrhunderts das meistgelesene Blatt in Europa, eine Tageszeitung mit einer Auflage von damals 30.000 Exemplaren. 4.000 davon gingen sofort in den Hafen auf abgehende Schiffe. Die Zeitung hatte als erste eine Redaktion mit Berufsjournalisten, arbeitete mit Korrespondenten vor Ort und konnte dank der außergewöhnlich freizügigen reichsstädtischen Zensur manches berichten, was andernorts unmöglich war. ${ }^{111}$ Am 15. Januar 1788 erbot sich Professor Rougemont, die Göttinger gelehrten Anzeigen beizusteuern.

Die Buchanschaffungen der ersten Zeit waren Nachschlagewerke, ergänzt um wissenschaftliche, auch populärwissenschaftliche Literatur. Noch die Rubriken des ersten Inventarverzeichnisses der Lese von 1814 spiegeln die Ausrichtung der Frühzeit (und sie enthalten zahlreiche der bis 1794 erworbenen Titel): ${ }^{112}$ I. Dictionnaires, Lexicons, Wörterbücher (31 Titel); II. Bücher von Anzeigen und Recensionen (15); III. Zeitschriften (72); IV. Gelegenheitsschriften (14); V. Reisebeschreibungen u. Geographie (27); VI. Geschichte, Statistik und Politik (65); VII. Nekrologen und Biographien (9); VIII. Gottesgelehrtheit und Moral (5); IX. Rechtsgelehrtheit (37); X. Arztneigelehrtheit (8); XI. Kammeralwissenschaften (5); XII. Naturhistorie, Mathematik u. Physik (17); XIII. Philosophie (12); XIV. Erziehungswissenschaften (4); XV. Schöne Künste und Wissenschaften (24). - Dichtung ist in der XV. Abteilung enthalten, aber nur durch wenige Autoren vertreten, und zwar mit Werken von Marivaux, Voltaire, Wieland, Herder, Goethe und Schiller sowie einigen Einzeltiteln. Es ist die Bibliothek einer Lesegesellschaft als Bildungseinrichtung par excellence.

Im Frühjahr 1788 mietete sich die Lese in der zweiten Etage des Rathauses ein; der Kurfürst schenkte Mobiliar. Ein Diener wurde für Öffnungsstunden, Beleuchtung und Heizung engagiert. Im Lesekabinett konnten die - nur männlichen - Mitglieder lesen und sich über das Gelesene austauschen. Ausleihen konnten sie nicht. Die Bibliothek war eine reine Präsenzbibliothek. Wiederholt wurde überlegt, davon abzugehen, und am 1. August 1790 wurde ein entsprechender Antrag in der Generalversammlung nach ausführlicher Debatte verworfen, denn, so die Argumentation des geschäftsführenden Ausschusses, "durch das Ausleihen der Bücher würde das Institut zu einer Leihbibliothek herabgewürdigt." ${ }^{\prime 113}$ Die Lektüre des Einzelnen vor Ort sollte verknüpft bleiben mit dem Gespräch untereinander und den gemeinsame Bestrebungen, nach außen zu wirken, die Aufklärung voranzutreiben. Den 1790 verabschiedeten "Gesetze(n) der Lesegesellschaft in Bonn" wurde ein Satz des Illuminatengründers Adam Weishaupt vorangestellt: „Die Geselligkeit der Glieder ist die Seele einer jeden 
Gesellschaft". ${ }^{114}$ Geselligkeit meinte damals Begegnungsfähigkeit, Soziabilität im Sinne des Vermögens, auf die Gemeinschaft zuzugehen, sich auf sie einzustellen, und die Bereitschaft, sich darin fortzuentwickeln. Das sollte auch das Emblem deutlich machen, das sich die Generalversammlung am 23. September 1790 für ein Petschaft auswählte. Es war ein umschwirrter Bienenkorb, d.h. ein freimaurerisches Bildzeichen protestantischer Herkunft, mit der Devise "et sibi et aliis", also: tätig sein sowohl für sich als auch für die andern. ${ }^{115}$

Soweit ich sehe, wurde nur einmal eine Ausnahme von der

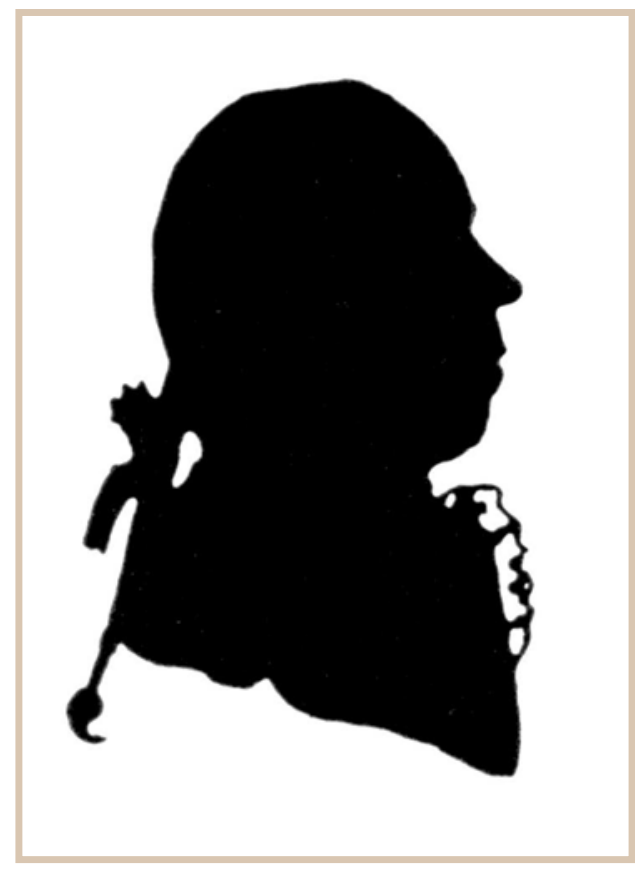
Nichtausleihe gemacht. Am 1. Februar 1793 beschloss die Generalversammlung als eine "Besondere Begünstigung für Herrn Musick Director Reicha während seiner Krankheit", Bücher aus der Bibliothek zu entleihen. Reicha (1752-1795), seit 1785 in Bonn und Gründungsmitglied der Gesellschaft, konnte sich damals nur noch an Krücken bewegen. ${ }^{116}$ In der Sitzung vom 1. August beantragte Neefe eine vergleichbare Erlaubnis: "Herr HofOrganist Neefe erklärte weilen ihm die Stiege zu den Lesezimmern zu hoch seye, er von der Gesellschafft austretten wolle, es seye denn daß man ihm vergönnen werde einige Journale von Zeit zu Zeit zu Hauße zu erhalten." Darüber wird ballotiert - mit dem Ergebnis: "Das Gesuch des Herrn HofOrganisten Neefe, einige Journal nach Haus zu bekommen wird nicht verstattet." Dem Protokoll der Sitzung vom 2. November 1793 ist zu entnehmen, dass Neefe noch einen Vorstoß gemacht hat, die Mehrheit aber unverrückbar am Grundsatz festhielt: "H[errn] Neefe betreffende Frage, ob derselbe gleich H[errn] Reicha Journalen sich Nach Hauß kommen laßen dörfte? R[esolviert] wurde durch Ballotement Verworfen. "117

Joseph Reicha (1752-1795),

Direktor der Instrumentalmusik.

Silhouette von Joseph Widnmann, vor 1785 (aUs: ERICH OTTO DEUTSCH, Mozart und seine Welt in zeitgenössischen Bildern, Kassel 1961)
Die Beschränkung auf eine Präsenzbibliothek bedeutete, wie angesprochen, kein Abschließen nach außen, sie gewährleistete vielmehrständige Verfügbarkeit der Bücher und Bindung der Mitglieder an den Ort gemeinschaftlicher Tätigkeit. Lektüre sollte sinnhaft weiterwirken; eine Zeitschrift mit Beiträgen aus der Lese, ein Volkskalender, ein Lesebuch für die Landschulen waren in Planung, einzelne Buchveröffentlichungen von Mitgliedern zeugen davon. ${ }^{118}$ Wir können davon ausgehen, dass sich Gespräche über Gelesenes, auch erregte Diskussionen außerhalb der Lese fortgesetzt haben, sei es an der Hohen Schule, sei es im Zehrgarten, wo Professoren mit Studenten oder Angehörige des Hofes sich trafen, oder in den Familien. Selbst das Ghetto der Judengasse wurde, wie angedeutet, erreicht. Juden und Protestanten konnten in Bonn uneingeschränkt studieren und taten das auch. Salomon Anschel z.B., herausragend begabt, wurdevom Kurfürsten und von Spiegel gefördertund späterfürs Auswärtsstudium finanziell unterstützt von der Lese. Und Lese-Mitglied Dr. Wolff Jakob Wolff, der schon erwähnte Arzt, aufgenommen 1790, kam aus einer Hofjudenfamilie.

126 | Alexander Wolfshohl

(c) 2020 by Böhlau Verlag GmbH \& Cie. KG, Köln

https://doi.org/10.7788/9783412519704 | CC BY-NC 4.0 
Ideen, Ziele, Visionen blieben nicht im Lesekabinett und in der Hofbibliothek, genauso wenig wie in der Hohen Schule, sondern haben ihre Wirkung gehabt, besonders für das Weltbild der jungen Generation. ${ }^{119}$

\subsection{Buchverbreitung mit und ohne Subskriptionen}

Umfassende Informationen über Neuerscheinungen erhielt man im 18. Jahrhundert durch Rezensionsjournale, "die wichtigsten Organe der nationalen und internationalen Wissenschaftskommunikation und der Verbreitung wissenschaftlicher Information in interessierte Kreise der Öffentlichkeit." ${ }^{120}$ Entsprechende Zeitschriften waren in Bonn greifbar; in der Lese zum Beispiel, wie erwähnt, Nicolais Allgemeine deutsche Bibliothek, das auflagenstarke und im deutschen Sprachraum weitbeachtete Blatt. Der Lese wurden von Verlegern und Buchhändlern auch unmittelbar Angebote gemacht, so von Johann Ludwig Gehra aus Neuwied, einem ehemaligen Illuminaten, der nicht versäumte, der Gesellschaft einen Besuch abzustatten. Einen breiteren Käuferkreis erreichten Inserate im wöchentlich erscheinenden Bönnische(n) Intelligenzblatt, sei es dass auf eine überregionale Buchauktion hingewiesen wurde oder dass die örtlichen Buchhandlungen das Eintreffen von Büchern ankündigten und erhältliche Titel nannten. Auch zur Subskription von Neuerscheinungen wurde aufgerufen, so für die "durchaus kritisch gefeilte" neue Ausgabe von Christian Daniel Schubarts sämtlichen Gedichten. Beim Herausgeber des Blattes konnte man unterzeichnen und erhielt die Zusage: "Die Liste der Subskribenten wird dem Werke vorgedrukt." ${ }^{\prime 21}$

Zwar hat, wenn ich richtig sehe, niemand aus Bonn Schubart vorbestellt, aber eine Reihe von städtischen Buchbesitzern finden wir in den Subskriptionslisten von vier anderen Druckwerken. Zu schon bekannten Namen kommen hier andere, von denen wir zum Teil freilich nur wissen, dass sie eben eines der subskribierten Werke erworben haben. Die Titel sind: Christian Gottlob Neefes Dilettanterien, 1785 ohne Ort- und Verlagsangabe erschienen, Johann Bernhard Constantin von Schönebecks Niederrheinische Monatsschrift, Bonn 1787, Eulogius Schneiders Gedichte, Frankfurt/ Main 1790, und das von Johann Philipp Schulin herausgegebene Vollständig(e) Diarium der Römisch-Königlichen Wahl und Kaiserlichen Krönung Ihro nunmehr allerglorwürdigst regierenden Kaiserlichen Majestät Leopold des Zweiten, Frankfurt/Main 1791.122 Wenn auch unter den Vorbestellern schon erwähnte Leserinnen und Leser sind, so erscheinen doch auch neue Namen; der Kreis der Lektürefreunde zeigt sich größer als bisher.

Neefes kleines Buch, eher "Miszellaneen" zu nennen, enthält Prosaskizzen mit moralischer Tendenz, Lieder in der Art Gellerts, literarisch durchaus versiert, und Gelegenheitsgedichte unter-
Eulogius Schneider (17561794), Franziskaner, Prof. an der Hohen Schule in Bonn, seit 1793 öffentlicher Ankläger in Straßburg, 1794 in Paris guillotiniert. Kupferstich von Christian Wilhelm Ketterlinus nach Philipp Gottfried Lohbauer, 1790 (Stadtarchiv Bonn)

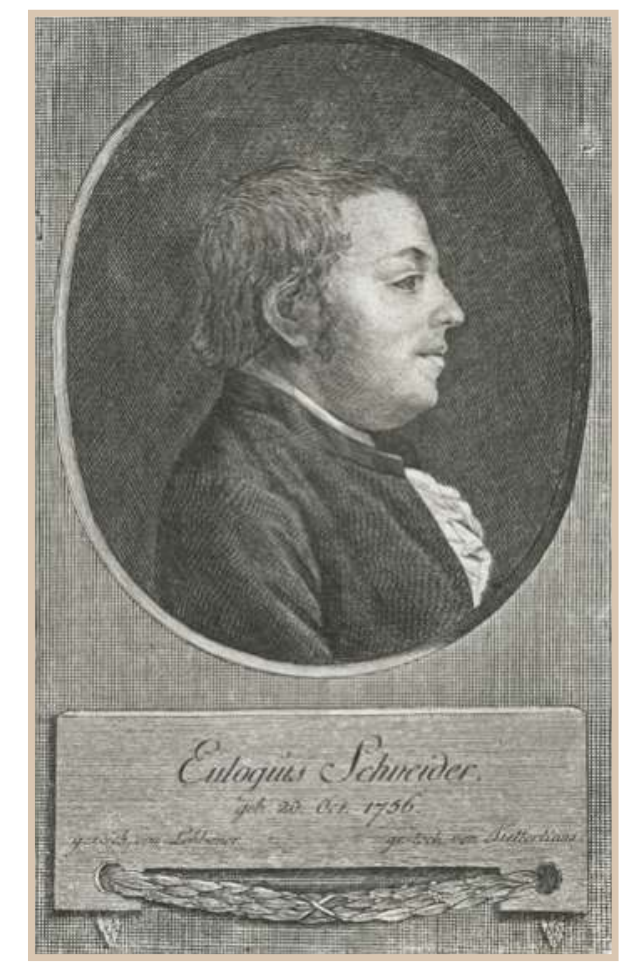


Susanna Maria Neefe (1751-1821). Fotografie eines zeitgenössischen Schattenrisses (BeethovenHaus Bonn)

Johann Ludwig Dörfeld (1744-1829), englischer Gesandtschaftssekretär. Zeitgenössischer Schattenriss (Beethoven-Haus Bonn)

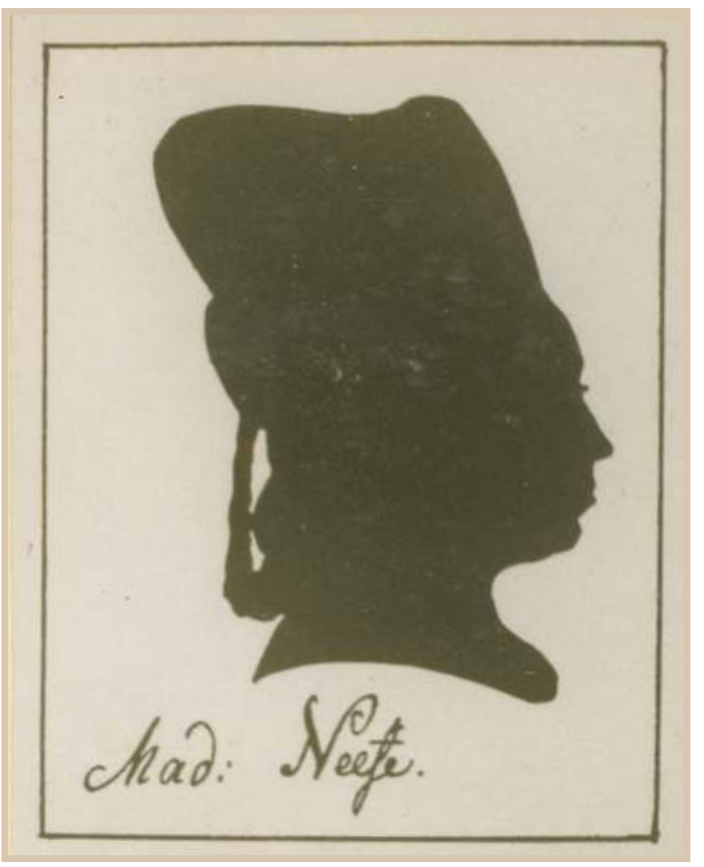

schiedlicher Art und Anlässe. An Kurfürst Max Franz, Gräfin WolffMetternich zur Gracht, Reichsfreiin von Schall, Reichsfreiin von Landsberg, geborene Reichsgräfin von Wolff-Metternich zur Gracht, Kurfürst-Erzbischof Friedrich Karl von Mainz richten sich Widmungsgedichte, teilweise panegyrische Verse. Wenn auch von höfischer Logik geprägt, betonen sie indirekt doch auch Nähe des dichterischen Ichs zur angesprochenen Person. Auch Susanna Maria Neefe, der Ehefrau, und der Freundin Katharina d'Antoine, Frau des Hauptmanns d'Antoine, der in den illuminatischen Beiträge( $n)$ eine längere Abhandlung über Kirchenmusik veröffentlicht hat, sind Verse zugeeignet. Der Kreis der Subskribenten umfasst überwiegend Angehörige von Hofstaat und Hofgesellschaft, darunter Neefes Illuminaten-Logenbrüder, und spiegelt sicherlich die bildungsmäßige Elite der Residenz zumindest teilweise. Ausleiher aus Forstmeisters Bibliothek sind zu finden, darunter Frau von Heathcote, Gattin des englischen Gesandten, die gleich vier Exemplare nimmt, oder Gräfin Metternich, deren Ehemann und Töchter ebenfalls subskribieren. Forstmeister selber hat vorbestellt - das Exemplar in seiner Bibliothek wurde schon erwähnt -, "Kammerherr von Wolzogen" desgleichen, und "Kandidat Eschbaum" wird der in Forstmeisters Entleiherliste zu findende Eschbaum sein, damals Student der Hohen Schule. "Fräulein von Cressener" ist Henriette Cressener, die Tochter des vormaligen englischen Gesandten George Cressener. Nach dem Tod ihres Vaters (17. Januar 1785) ist sie in 
Bonn geblieben und wohnt im Englischen Hof, einem Gasthof gegenüber der Residenz. Max Franz schätzt sie; 1790 reist "Mademoiselle de Cressener" mit zur Kaiserkrönung nach Frankfurt, sie gehört zu den „unter Churköllnischer Protection stehenden Fremden"123. Johann Ludwig Dörfeld, der englische Gesandtschaftssekretär, und dessen Ehefrau haben je ein Exemplar geordert. Dörfeld gehört zu Beethovens Freundes- und näherem Bekanntenkreis, ebenso wie Vorbesteller Crevelt, die Brüder Eichhoff, Witwe Koch, die ZehrgartenWirtin, auch deren Bruder Jakob Klemmer, Max von Mastiaux und Baron Karl Ludwig von Keverberg, Neffe des gleichfalls subskribierenden Propstes von Weichs und des Obristjägermeisters von Weichs, dem wir bei Forstmeister als Entleiher begegnet sind. An Musikerkollegen finden wir Ries und Simrock, die beide je drei Exemplare bestellen, während die Brüder Heller jeder eines für sich wollen. In musikliebenden und -pflegenden Häusern und Familien war der Gedichtband also vorhanden. Selbst wenn sich Beethoven wohl kein Exemplar von Neefes Dilettanterien hat leisten können, als Lesestoff werden sie ihm zugänglich gewesen sein - wie überhaupt davon auszugehen ist, dass damals jedes einzelne Buchexemplar einen größeren Leserkreis erreichte als heute.

Schönebecks Monatsschrift, möglicherweise als eine Art Folgejournal der von ihm bis Ende 1785 herausgegebenen illuminatischen Beiträge gedacht, erschien 1786 in sechs Heften, das heißt, nur ein Jahr lang. Der Sammelband, für den subskribiert wurde, macht insgesamt die vorurteilsfreie, fortschrittliche Haltung deutlich. Richtungweisend sind Aufsätze wie "Allgemeine Grundsätze über die Erziehung" oder "Soll ein Frauenzimmer von jedem ernsthaften Studium abgehalten werden?" An Subskribenten sind neben mehreren Ungenannten 95 namentlich aufgeführt, darunter 29 Bonner, denen Johann Peter Eichhoff zuzurechnen ist, der damals beruflich in Maastricht weilte. 13 von ihnen zählen zur aufklärerischen Führungsgruppe der Stadt, sie gehören später zu den Mitgliedern der Lese.

Professor Eulogius Schneider hat in Bonn im Mai 1789 seine Vorlesungen aufgenommen. In den Beginn seiner Lehrtätigkeit fällt das Datum, an dem Beethoven mit zwei Freunden, Anton Reicha und Karl Ferdinand Kügelgen, an der Hohen Schule eingeschrieben wird: 14. Mai 1789. Und sie waren nicht die einzigen, die an diesem Tag immatrikuliert wurden. Wollten die jungen Leute die akademische Attraktion selber erleben? Ich sehe keine andere Erklärung für die zeitlich ungewöhnliche Einschreibung mitten im Schul- und Studienjahr. ${ }^{124}$ Schneider muss in der Tat faszinierend gewirkt haben. Darauf lassen die hoch-emotionalisierten Turbulenzen, Widerstand und Verteidigung, die er bald auslöste, schließen. Die Subskribentenliste, die seinen 1790 erschienenen Gedichten vorangestellt ist, führt der Kurfürst selbst an. ${ }^{125}$ Hofgesellschaft und Hofstaat sind vertreten. Die Schauspielerinnen Christine und Dorothea Keilholz bestellen je ein Exemplar; der einen von ihnen ist ein Preisgedicht im Band gewidmet. Die drei Freunde Kügelgen, Beethoven und Reicha, die Letzt- 

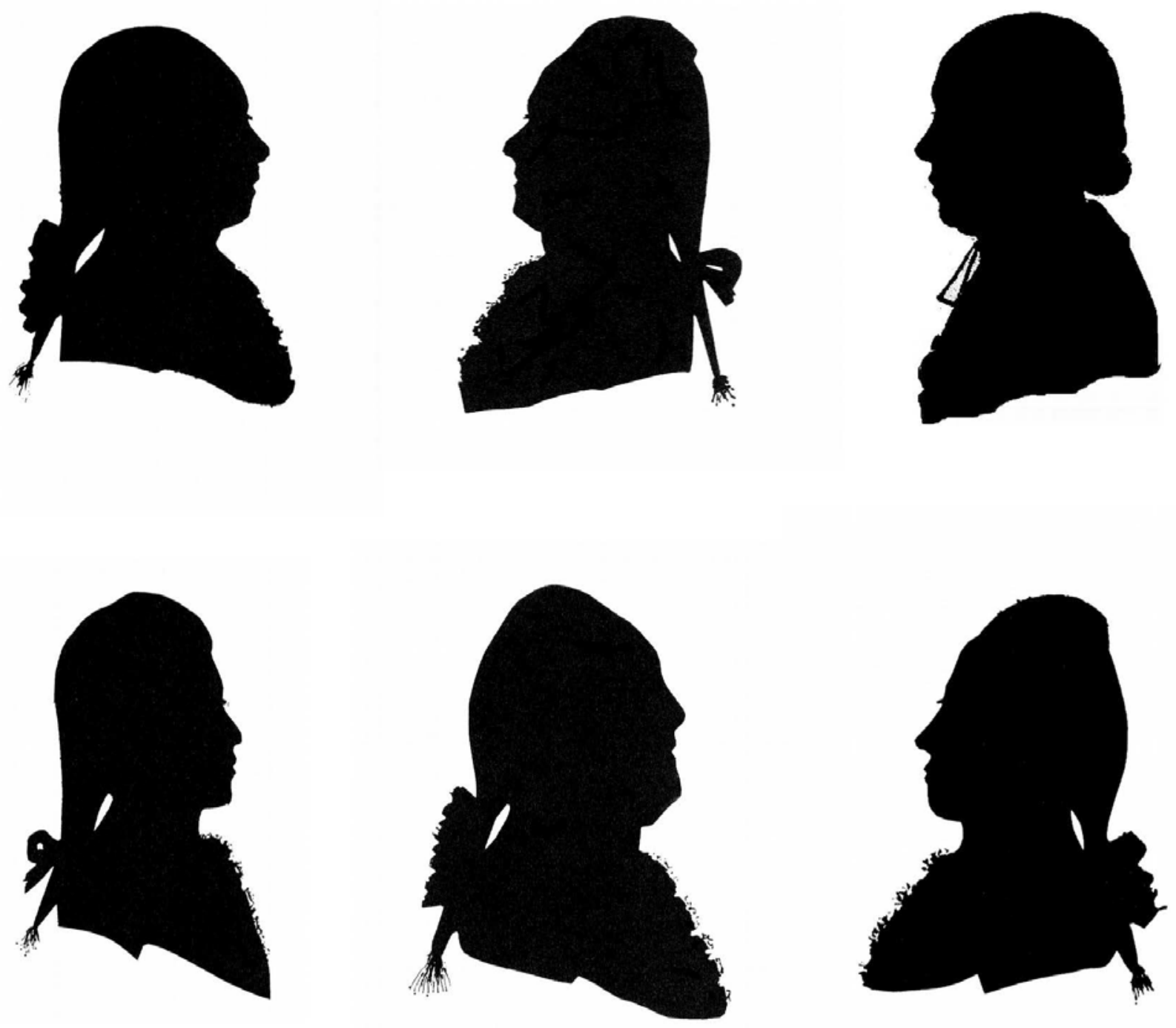

Stephan von Breuning, Christoph vpn Breuning, Kanonikus Lorenz von Breuning (obere Reihe von links nach rechts) Karl Ferdinand Kügelgen, Karl-Wilhelm Freiherr von Keverberg, Johann Joseph Eichhoff (untere Reihe von links nach rechts) (Zeitgenössische Schattenrisse, Beethoven-Haus Bonn) 
genannten als Hofmusiker ausgewiesen, haben sich eingetragen, und 43 ihrer Kommilitonen. Einer der Breuning-Brüder ist darunter, Christoph oder Stephan, dann ihr Freund Matthias Koch aus dem Zehrgarten, aber auch dessen Schwester, die wohl umschwärmte Babette Koch (1771-1807), die spätere Gräfin Belderbusch, oben schon wegen der Silhouetten in ihrem Stammbuch erwähnt. Mit Joseph Löw Sussmann (1765-1844) ist unter der Subskribenten der Erstauflage auch wieder ein Angehöriger einer der Hofjudenfamilien dabei, ein Schwager des erwähnten Buchbesitzers Nathan Horwitz Schlesinger. ${ }^{126}$ Groß ist die Zahl der Lese-Mitglieder unter den Abonnenten, sicher eine Spiegelung der Position, die Schneider, der sehr bald nach seiner Ankunft in Bonn schon aufgenommen worden war, in der Lese hatte. Die Protokolle zeigen, dass seine radikalen Ansichten lebhafte Debatten entfachten; entsprechend enthalten die Gedichte Zündstoff. Seine galanten Poeme eckten an, weil man sie von einem Priester nicht erwartete. In Huldigungsversen und Heldenlob nimmt er die Haltung eines Weltdeuters ein und stellt sich durch seinen Lobpreis letztlich über diejenigen, denen seine Dichtung gilt. Er geißelt die katholische Kirche und vertritt konsequent das Ziel der Befreiung von herkömmlichen Fesseln. ${ }^{127}$ Selbst in der lyrischen Schilderung seiner Reise an den neuen Wirkungsort Bonn schlägt er zu: "So kamen einst gepurpurte Spionen, / Und hochgeweihte Straßenräuber,/ Thuiskons Erbe auszuplündern,/ Vom Vatikan gesandt.// Da sogen sie des Deutschen Mark./ Und gaben Ablaß ihm dafür,/ Und Aeser, die er fassen sollte/ Mit Perlen und Rubinen." ${ }^{128}$ Der aktuelle Bezug dessen, was hier als historisierender Blick getarnt ist, wurde sehr wohl verstanden, gerade auch in Köln, wo der päpstliche Nuntius Pacca und die Domherrn residierten und man das geschmückte "Aas' vieler Heiliger hoch verehrte. Immer wieder wird deutlich, wo Schneider politisch steht: "Dem Fanatismus Hohn zu sprechen,/ Der Dummheit Zepter zu zerbrechen,/ Zu kämpfen für der Menschheit Recht, / Ha! Das vermag kein Fürstenknecht./ Dazu gehören freie Seelen, / Die lieber Tod, als Heuchelei,/ Und Armuth vor der Knechtschaft wählen./ Und wisse, daß von solchen Seelen/ Die meine nicht die letzte sei!" 129 Oder im Gedicht "Auf die Zerstörung der Bastille": ... "Gefallen ist des Despotismus Kette, / Beglücktes Volk! Von Deiner Hand:/ Des Fürsten Thron ward dir zur Freiheitsstätte, / Das Königreich zum Vaterland./ Kein Federzug, kein: Di es ist u n s er Wi / l e,/ Entscheidet mehr des Bürgers Loos./ Dort lieget sie im Schutte, die Bastille,/ Ein freier Mann ist der Franzos!"130 Die Verbreitung von Schneiders Gedichten muss weit über den Kreis der Subskribenten hinausgegangen sein. Schon bald war 1790 eine zweite Auflage nötig. Der aufklärerische Reiseschriftsteller Aloys Wilhelm Schreiber (17611841) berichtet 1795 vom Geschäftsgang eines Freundes in Bonn "nach dem entlegenern Theile der Stadt ..., wo die niedrigste Volksklasse Tagelöhner und Lastträger, wohnen. In einem dunklen Stübchen fand er dort drei oder vier rüstige Sansculotten in Lumpen um einen alten Tisch gelagert, 
und vor ihnen Schneiders Gedichte aufgeschlagen. Der Eine las vor, und die übrigen horchten mit offenem Mund. Lest ihr auch dergleichen Bücher? fragte mein Freund. Warum nicht?, erwiderte einer von ihnen. Wir haben uns den Taler, den das Buch kostet, vom Munde abgespart, aber das reut uns nicht, Der sagt, wie ihm ums Herz ist und deckt seinen Brüdern das Spiel auf." ${ }^{\prime \prime 1}$

Die vierte der oben genannten Subskriptionslisten (Anhang 5), die zum Krönungsdiarium Leopolds II., enthält deutlich weniger Namen aus Bonn. Fast alle haben sie zur Suite des Kurfürsten bei der Krönung gehört und erscheinen in ihrer Funktion dann auch im Diarium, unter ihnen Lese-Mitglieder. Etlichen sind wir als Buchbesitzer schon begegnet. Die Lese selbst hat ebenfalls vorbestellt.

\section{Buchbesitz und Buchkenntnis bei Beethoven?}

Beethoven wuchs in einer hochmusikalischen und literaturreichen Atmosphäre auf. Im Elternhaus begegnete er Besuchern wie den Theaterprinzipalen Großmann, den Brüdern Eichhoff oder Anton von Belderbusch. In der Hofmusik und am Theater hatte er Kontakt zu Kollegen wie dem väterlichen Franz Ries, Nikolaus Simrock und Christian Gottlob Neefe. Der Umgang mit musikliebenden und -ausübenden Häusern wie Hatzfeld, Wolff-Metternich, Mastiaux, Gruben oder Wurzer und die Freundschaft zu Breunings wird Lektüre-Anregungen geboten haben, wie sie auch der Zehrgarten-Kreis gegeben haben muss. Texte von Gellert, Klopstock, Wieland, Pfeffel, Schubart, Claudius, Herder, Klamer Schmidt, Hölty, Goethe, Anton von Halem und Sophie Mereau hat Beethoven schon in Bonn gekannt. Schneiders Gedichte hat er, wie gesagt, erworben; die Kantate auf den Tod Josephs II. des Schneider-Schülers Severin Anton Averdonk (1768-1817) hat er 1790 vertont (WoO 87), und Schillers Ode An die Freude hatte er bei seiner Abreise nach Wien im Gepäck, um sie in Musik zu setzen. Das sind Spuren von Literaturkennntnis, die wir uns umfangund detailreicher denken sollten.

Beethoven war ein besessener Leser. Von rund 800 Titeln ist nachweisbar, dass er sie gekannt hat. Kompositionen und Kompositionspläne, Exzerpte von Textstellen, Anstreichungen und Notate in Büchern, Erwähnungen in Briefen und Gesprächen usw. zeugen davon; die Bücher in seinem Nachlass verweisen auf die Breite seiner Interessen. ${ }^{132}$

Die Bibliothèque nationale de France in Paris bewahrt die Originalpartitur von Beethovens Menuett in As-dur für zwei Violinen, Viola und Violoncello WoO 209, bisher datiert: vermutlich Bonn Anfang 1790. Auf dem ersten Blatt finden sich oben Notizen seiner Hand "Elementarbuch zur Psichologie Ordnung der geschäfte". ${ }^{133}$ Was mag dahinter stehen?

Beethoven wird, wie dargelegt, 1789 im laufenden Schul- und Studienjahr immatrikuliert. Das akademische Jahr begann im November und endete im September. Die Namen aller Schüler und Studenten wurden in das Matrikelbuch der Hohen Schule eingetragen, bei fortlaufendem Besuch weitere Jahres- 
angaben ergänzt. Aus dem Matrikelbuch waren jährlich sogenannte Auszugslisten mit den aktuellen Schüler- und Studentennamen zu erstellen und dem Kurfürsten vorzulegen. Offizielle Neuimmatrikulationen wurden, wie die Daten ausweisen, nicht zu Beginn des Novembers, sondern erst am Ende eines Kalenderjahrs oder am Anfang des nächsten vorgenommen. Die Listen wurden später ausgefertigt; sie sind undatiert, doch Begleitschreiben oder die Angabe individueller Einschreibungsdaten lassen meist auf den Ausfertigungszeitraum schließen.

Für Beethovens Besuch der Hohen Schule ergibt sich aus den Akten Folgendes: Die Immatrikulation für das Schul- und Studienjahr 1788/89 fand am 18. Dezember 1788 statt. Am 19. und 22. Dezember kamen zwei Nachzügler hinzu, und am 22. März, 20. April, 29. April und 6. Mai 1789 je ein Seiteneinsteiger. Am 14. Mai 1789 erfolgte dann die Einschreibung von zwölf jungen Leuten, darunter, wie gesagt, Beethoven, Reicha, Kügelgen. Selbst wenn Beethoven schon vor der offiziellen Aufnahme die eine oder andere Veranstaltung besucht haben sollte, so wird das allenfalls zwischen dem 6. Mai und 14. Mai gewesen sein, und der Beginn seines Besuchs der Hohen Schule ist mit Mai 1789 anzusetzen. Am 23. Mai endete die erste Opernsaison nach Wiedereröffnung des Nationaltheaters.

Für Beethoven und seine beiden Freunde nennt das Matrikelbuch als Studienzeitnur 89, ein weiteres Jahristnichtnachgetragen. Die Neu-Immatrikulation zum Schul- und Studienjahr 1789/90 wurde am 3. Dezember 1789 vorgenommen. Die Auszugsliste für diesen Jahrgang, erstellt im Sommer 1790, führt keinen der drei Freunde mehr auf, das heißt, sie waren nicht mehr eingeschrieben. ${ }^{134}$ Beethovens offizieller Besuch der hohen Schule dürfte auf 1789 beschränkt gewesen sein - wobei die am 13. Oktober beginnende Wintersaison 1789/90 am Theater sicherlich Probenarbeit bedeutet hat, die regelmäßiger Unterrichtsteilnahme entgegenstand. Dazu aber musste sich jeder Studierende bei der Einschreibung dem Syndikus Esser gegenüber per Handschlag verpflichten. ${ }^{135}$

Immatrikuliert war Beethoven in der Philosophischen Fakultät, was angesichts seiner Vorbildung nur den Eintritt in den fachstudienvorbereitenden zweijährigen Cursus bedeuten kann. ${ }^{136}$ Die traditionellen Cursus-Fächer waren im ersten Jahr Logik und Metaphysik, im zweiten Mathematik und Physik. Bereits bei der Errichtung der Akademie war an eine fachliche Erweiterung gedacht worden, u.a. um Psychologie. ${ }^{137}$ Bei der schon erwähnten Modernisierung der Lehre unter Max Franz und Spiegel kam dann dieses Fach hinzu. Die erste Ankündigung enthält das Vorlesungsverzeichnis für 1786/87: "Hr. D. Abel im Wint[ter] Psychologie, im Somm[er] Tugendlehre u[m] $10 \mathrm{U}$ [hr] Vorm[ittags] u. 3 U[hr] Nachm[ittags]. ${ }^{138}$ Gemeint ist Achatius Apel OFM, seit 1786 Professor für Elementarmathematik, Psychologie und Tugendlehre. Apel las, wie sein Kollege Elias van der Schüren, der auch den Cursus betreute, nach Feder. 
Der Göttinger Ordinarius Johann Georg Heinrich Feder (1740-1821) war ein führender Kopf der psychologischen Richtung der zeitgenössischen Philosophie. Psychologie mit ihrem Blick in das Innere des Menschen verstand er als Basiswissenschaft der Logik, der Metaphysik und der Sittenlehre. Sein entsprechendes Grundlagenwerk erfuhr mehrere Raubdrucke, was für dessen Popularität spricht. ${ }^{139}$

Feders Freund und Mitarbeiter Christoph Meiners, gleichfalls ein Göttinger Ordinarius, war aufgrund einer Abhandlung, in der er die These vertrat, dass alle Philosophie in der Psychologie gründen müsse, 1772 zunächst zum außerordentlichen Professor ernannt und 1775 zum ordentlichen Lehrstuhlinhaber aufgerückt. Von Meiners sind zwei spätaufklärerische Elementarbücher über die Psychologie erschienen. ${ }^{140}$

Werke beider Autoren waren in Bonn greifbar, Feder und Meiners in der Hofbibliothek. Im Auktionskatalog habe ich gefunden: "I.G.H. Feders und Chr. Meiners philosophische Bibliothek, 1-4r Band, Götting. [1]788-91", "I.G.H. Feders über das moralische Gefühl. Kopenh. [1]792" und "C. Meiners Dessen Anweisungen für Jünglinge zum eigenen Arbeiten. Hannov. [1]791". ${ }^{141}$ Die Lese-Bibliothek hatte laut Inventarverzeichnis von 1814 vier Titel von Meiners, in acht Bänden. Zwar ist keines der Psychologie-Lehrbücher darunter, aber alle verzeichneten Werke sind Veröffentlichungen vor der Gründung oder aus der Frühphase der Lese (1775, 1781-82, 1788-90, 1792). Ferner war ein Jahrgang des von Meiners und Ludwig Timotheus von Spittler herausgegebenen Göttingische(n) historische(n) Magazin, Hannover 1787, vorhanden. Das allein ließe den begründeten Schluss zu, dass Feder und Meiners im intellektuellen Bonn zur Zeit der kurfürstlichen Universität keine Unbekannten gewesen sind. Doch es gibt weitere Indizien dafür: Der Universitätskurator Spiegel zum Diesenberg hatte während seines Studiums in Göttingen bei Feder gehört und vor allem bei Feder und Meiners verkehrt; und Wilhelm von Humboldt erwähnt in seinem Reisetagebuch, Caspar Anton von Mastiaux sei "sehr von Feder eingenommen". ${ }^{142}$

Bei seinem Besuch der Hofbibliothek war Humboldt, wie gesagt, aufgefallen, dass Tetens vorhanden war. Das kann nur der Kieler Ordinarius Johann Nikolaus Tetens (1736-1807) sein, ein weiterer bahnbrechender Psychologielehrer der Zeit. ${ }^{143}$ Mit Philosophische Versuche über die menschliche Natur und ihre Entwicklung, 2 Bände, Leipzig: Weidmann 1777, schlug er den Weg in die moderne Entwicklungspsychologie ein. Auch Tetens konnte man also in Bonn lesen.

Die neue Lehre wurde fest etabliert, sie war Gegenstand bei den halbjährlichen Prüfungen, denen sich die Cursus-Teilnehmer (genauso wie die Gymnasiasten) stellen mussten. Wer sich dabei besonders auszeichnete, durfte als Privileg unter dem Vorsitz des betreffenden Professors in der Aula gedruckte Thesen öffentlich verteidigen. Der im Zusammenhang mit der Flüchtung der 
Hofbibliothek erwähnte Joseph Wurzer berichtet: "Mir selbst ist diese Ehre auch zuteil geworden, indem ich im Sommer 1787 unter Vorsitz des Professors Apel Thesen aus der Psychologie und der Mathematik öffentlich in der Aula verteidigt habe."144

Wie den Vorlesungsverzeichnissen zu entnehmen ist, las während Beethovens Studienzeit an der Hohen Schule im Sommer 1789 Elias van der Schüren "den Kandidaten des ersten Jahrs Logik und Metaphysik über Feder" und Achatius Apel offenbar den Kandidaten des zweiten Cursus-Jahres "Moralphilosophie nach Feders Handbuch". Ferner hatte er "sich erboten täglich 2 Stunden den unteren Schulen [d.h. den fünf Gymnasialklassen] die Seelenlehre zu erklä-
Ludwig van Beethoven, Menuett in As-dur für zwei Violinen, Viola und Violoncello WoO 209. Autographe Partitur, Bonn, Herbst 1789 (Bibliothèque Nationale de France, Paris)

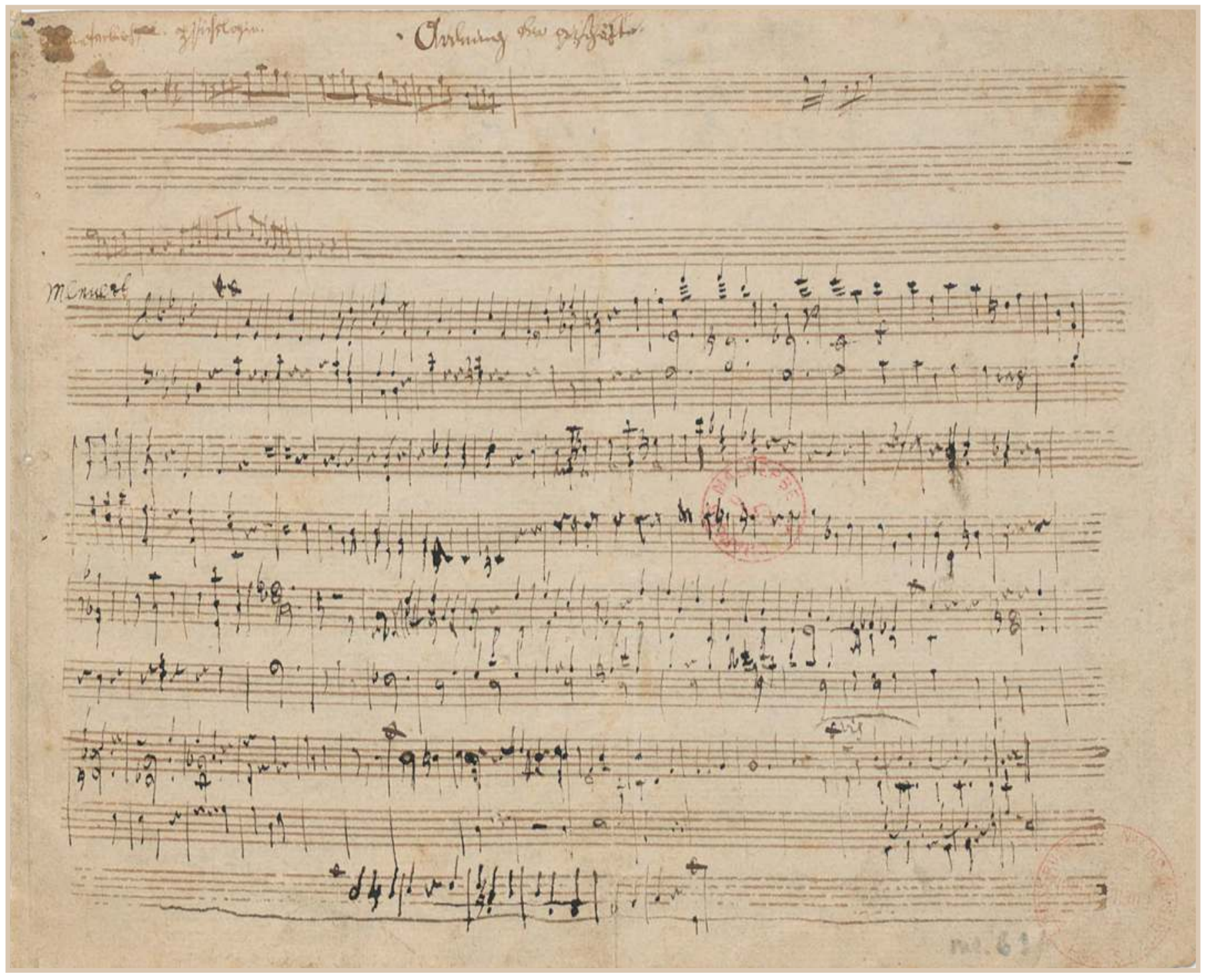


ren." ${ }^{145}$ In dem ab November 1789 folgenden Schul- und Studienjahr lautete die Ankündigung ähnlich: „Herr Dr. van der Schüren liest den Kandidaten des ersten Jahrs Logik und Physik über Feder vor des Morgens von 8-9, und Nachmittags von 2-3" und "Herr Dr. Apel hält von 9-10 in der Moralphilosophie nach Feders Handbuch Vorlesungen. Auf Verlangen wird er auch in der Psychologie, und praktischen Philosophie Privatvorlesungen geben. Ferner hat er sich erboten täglich 2 Stunden den untern Schulen die Seelenlehre zu erklären.” Des Weiteren wird angeboten: „Dr. Scheidler hält von 9-10. Vormittags öffentliche Vorlesungen über die Staatswirthschaft nach seinem eigenen herausgegebenen Lehrplane. Privatvorlesungen hält er im Winter über die Polizeyund Handlungswissenschaft ....". ${ }^{146}$ Ferdinand August Scheidler war 1787 auf den neuen Lehrstuhl für Staatswirtschaft und Statistik berufen worden; unter anderem las er über die sogenannten Kammergeschäfte, das heißt, über Verwaltungseinrichtung und Geschäftsführung, und führte praktische Übungen dazu durch. ${ }^{147}$

Mit der spätaufklärerischen, das heißt, der neuen Psychologie und mit der Betriebslehre kann Beethoven in seiner Studienzeit an der Hohen Schule also in Berührung gekommen sein. In der einen oder anderen Lehrveranstaltung mag es Literaturhinweise gegeben haben, vielleicht zur Vorbereitung, vielleicht zu vertiefender Lektüre. Solche Hinweise könnte Beethoven gehört haben, sei es als Teilnehmer einer Vorlesung oder Übung selbst oder als Information durch einen Professor oder Kommilitonen. Denkbar, dass ihm während der Arbeit am Menuett in As-dur zwei Werke einfielen, die zu lesen er nicht vergessen wollte, so dass er, nicht in exakter Titelformulierung, sondern schlagwortartig, an den Rand schrieb: "Elementarbuch zur psichologie Ordnung der geschäfte". ${ }^{148}$

Vgl. Marlies Prüsener und Herbert Göpfert, Lesegesellschaften, in: Ernst L. HausWEDELL und Christian VOIGT (Hgg.), Buchkunst und Literatur in Deutschland 1750 bis 1850, 1, Texte, Hamburg 1977, S. 285-303

In Paris hat Karl Leopold den mitgenommenen Bestand ausgebaut. Zu der nach seinem Tod 1826 durchgeführten Auktion ist ein Katalog mit 1383 Nummern, vielfach mehrbändiger Werke, erschienen; davon ist ein annotiertes Exemplar (mit erzielten Preisen) an die hiesigen Erben gegangen, das sich im Stadtarchiv Bonn erhalten hat (StAB, I g 1109). Mehr als die Hälfte des Bestands bilden Werke zur Geschichte und deren Nebenfächern. Theologie, Jura, Philosophie und Pädagogik sind vertreten, u.a. durch Hobbes, Descartes, Adam Smith und Kant. Naturgeschichte und Physik sind vorhanden, ebenso Statistik und Finanzlehre; Botanik, Agrikultur mit Meliorationslehre, Medizin, Mathematik, Militärkunde, Architektur und Astronomie desgleichen. Die schöne Literatur wird von der Antike dominiert. Mittelalterliches Bildungsgut, etwa Dante und Sebastian Brant, fehlen nicht. An neuzeitlicheren französischen Dichtern finden sich Corneille, Molière, Racine und Voltaire; die kleine Sparte deutscher Texte enthält Barthold Hinrich Brockes, den bedeutenden Frühaufklärer, Lessing, Herder

136 | Alexander Wolfshohl 
und Wieland. Die große Encyclopédie ou dictionnaire raisonné des sciences des arts et des métiers fehlt ebensowenig wie zahlreiche Wörterbücher und Grammatiken. Mit elf Nummern ist die Gruppe der Musikalien klein, enthält aber „305. Fidelio, drame lyrique, mis en musique par Van Beethoven. Paris, in-fol. br." (S. 26). Erschienen 1826 bei Farrenc, dürfte der Fidelio eine der letzten Erwerbungen Belderbuschs gewesen sein. Es ist ein reizvoller, wenngleich spekulativer Gedanke, in dieser Bibliothek einen Widerschein dessen zu sehen, was in Bonn im Haus des Ministers vorhanden war, angelegt von ihm und von seinem Neffen vorangetrieben.

Hierzu Cornelia Kirschbaum, Wohnbauten des Hofadels in der kurkölnischen Residenzstadt Bonn im 17. und 18. Jahrhundert (Tholos. Kunsthistorische Studien 10.2), Münster 2019; zur Bibliothek S. 108f. In dem beigegebenen Inventar des Belderbuscher Hofs von 1797 heißt es: "ein großes[!] Saal, worin sich die Bibliotheque befindet" (ebd., S. 322). - Seit 1772 im Besitz der Familie, wird das Haus ab 1779 vom Minister bis zu seinem Tod 1784 genutzt. Zur Buchentnahme durch Karl Leopold von Belderbusch siehe Wolf D. PenNIng, Caspar Anton von Belderbusch, seine Neffen und ihr Bonner Stadtpalais, Zur Geschichte des Belderbuscher (Boeselager) Hofs, in: Bonner Geschichtsblätter 57/58, 2008, S. 147-184, dort S. 172.

Vgl. Margot WetzSTEIn (Hg.), Familie Beethoven im kurfürstlichen Bonn, Neuauflage nach den Aufzeichnungen des Bonner Bäckermeisters Gottfried Fischer. Übertragen, kommentiert, illustriert..., Bonn 2006, S. 127

Zu Forstmeister vgl. Klaus Oldenhage, Kurfürst Erzherzog Maximilian Franz als Hoch- und Deutschmeister (1780-1801) (Quellen und Studien zur Geschichte des deutschen Ordens 34), Bad Godesberg 1969, S. 76f.; UDO ARNOLD, C. G. DE DIJN, M. VAN DER EYCKEN U.a., Ritter und Priester. Acht Jahrhunderte Deutscher Orden in Nordwesteuropa [Katalog], Turnhout 1992, S. 166; OLAF KRISZIO und ANDREA SEMROCH, Karl Friedrich Franz Hatard[!] Anton von Forstmeister zu Gelnhausen, in: Der Deutsche Orden im Bonner Raum [Katalog], hg. v. Projektbereich Ostdeutsche Landesgeschichte der Universität Bonn, Bonn 22000, S. 38. - Prof. Dr. Dr. Udo Arnold, dessen Arbeiten ich den ersten Hinweis auf die Bibliothek Forstmeisters entnommen habe, sei für Auskunft und bereitwillige Weichenstellung herzlich gedankt. - Mein herzlicher Dank gilt auch Mag. Bernhard Huber, Deutschordenszentralarchiv (DOZA) in Wien, der sich die Mühe gemacht hat, die dort vorhandenen diesbezüglichen beiden Aktenfaszikel (DOZA, Abt. Ri 120, Nr. 462/2) zu fotografieren und mir die Aufnahmen zuzuschicken. - Das Bibliotheksverzeichnis ist ein geheftetes Papierfaszikel, unpaginiert; die anfängliche Bezeichnung der Blätter endet mit Blatt 6. Es nennt mehr als 500 Titel. Manche sind mehrfach vorhanden, andere nicht greifbar, weil nur summarisch erfasst. - Ein kurzer Überblick über den Bestand auch bei MAGDA FISCHER, Zur Geschichte der Deutschordensbibliothek in Altshausen. Die Bücherschätze im Schloß von Altshausen am Ende des 18. Jahrhunderts, in: Zeitschrift für Württembergische Landesgeschichte 47, 1988, S. 235-268; hier S. 257f. Fischer gibt als Datum für die Erstellung des Inventars den 27.3.1794 an; die Lesung ist hingegen eindeutig: "27. Maii 1794”.

1773: Nr. 351 in der Bonngasse; das spätere Haus Simrock.

So die Einschätzung des Deutschen Historischen Museums, Berlin (https://www. deutsches-museum. de/bibliothek/unsere-schaetze/enzyklopaedien/diderot-encyclopedie/; Zugriff 26.12.2019).

SVen Aage Jørgensen, Klaus Bohnen und Per Øhrgard, Aufklärung, Sturm und Drang, frühe Klassik: 1740-1789 (Geschichte der deutschen Literatur 6), München 1990, S. $194 f$.

9 Der Titel war auch in der Bibliothek der Bonner Lesegesellschaft vorhanden, über die noch zu handeln sein wird. 
JøRGENSEN/BOHnen/Øhrgard, Aufklärung (wie Anm. 8), S. 186

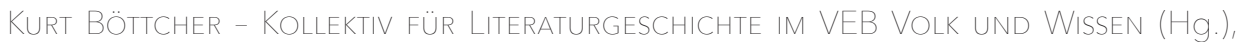
Aufklärung. Erläuterungen zur deutschen Literatur, Berlin 1971, S. 736

Ebd., S. 638.

Walter Weber, Meißner, August Gottlieb, in: NDB 16, 1990, S. 694

GÜNTER ChRIST, Moser, Friedrich Carl Freiherr von, in: NDB 18, 1997, S. 178-181.

Eine der zwischen 1561 und dem Ende des 18. Jahrhunderts erschienenen Ausgaben resp. Bearbeitungen dieses Grundlagenwerkes vielleicht: GEORG ENGELHARD VON LÖHNEISEN, Neu-eröffnete Hof- Kriegs- und Reit-Schul, Das ist: Gründlicher Bericht della Cavalleria, oder von allen, was zur Reuterey gehörig und einem Cavalier davon zu wissen gebühret: nach den ersten Titul dieses überaus rar-wordenen Buches, Welches aber anjetzo in einen gantz andern Stand gesetzet, verneuert... Alles mit schönen und kostbaren Kupfferstichen illustriret ... zu sonderbahrer Plaisir und GemüthesErgötzung, vor die Augen gestellet Von Valentin Trichter, bey des Heil. Röm. Reichs freyen Stadt Nürnberg bestallten Bereuter, Nürnberg 1729.

Vollständiges Diarium der Römisch-Königlichen Wahl und Kaiserlichen Krönung Ihro nunmehr allerglorwürdigst regierenden Kaiserlichen Majestät Leopold des Zweiten, Frankfurt 1791. - Zu weiteren von Bonnern subskribierten Exemplaren des Diariums siehe weiter unten.

JohANn Wilhelm Franz FreyHerR VON KROHNE, Allgemeines Teutsches Adels-Lexicon 1, Lübeck 1774; 2, Hamburg 1776; hier 1, Sp. 301f. - H. J. VETTER, Authentische Sammlung der bei der Bergischen Ritterschaft vorhandenen und aufgeschworenen Adlichen Wappen und Stammtafeln nebst Bemerkung der Auffschwörungs-Zeit und vollständigem Register, Köln 1791, S. 25f. - Zum Konkurs siehe JürgEN ACKERMANN, Reichsdebitverwaltung für die Freiherren Forstmeister von Gelnhausen, in: Zeitschrift des Vereins für Hessische Geschichte und Landeskunde 109, 2004, S. 95-113. (Online-Version: http://www.vhghessen.de/inhalt/zhg/ZHG 109/06_Ackermann_Reichsdebitverwaltung.pdf, Zugriff 1.10.2019).

18 Die schon in Bonn zum Ensemble gehörende Friederike Flittner, Tochter Karoline Großmanns aus erster Ehe, war die später berühmte Schauspielerin Friederike Bethmann-Unzelmann. Zitat nach Ludwig SCHIEDERMAIR, Der junge Beethoven, Leipzig 1925, S. 51. - Zu den Bildnissen siehe weiter unten

Der Beiname der Familie von Spiegel erscheint in den Quellen als Desenberg und Diesenberg. Die Deutsche Biographie, das Landesarchiv NRW, das Stadtarchiv Bonn u.a. haben sich für die Variante Desenberg entschieden; Franz Wilhelm von Spiegel selbst hat stets mit Diesenberg unterschrieben. Dem ist hier (wie auch bei Max Braubach) gefolgt. - Zu Spiegel vgl. ALEXANDER WOLFSHOHL, Nichts weniger als Atheisten und Gottesschänder? Oder: Hundert thätige Männer, in diesem Band.

MAX BRAUBACH, Die Lebenschronik des Freiherrn Franz Wilhelm von Spiegel zum Diesenberg, zugleich ein Beitrag zur Geschichte der Aufklärung in Rheinland-Westfalen (Veröffentlichungen der Historischen Kommission des Provinzialinstituts für Westfälische Landes- u. Volkskunde XIX [Westfälische Briefwechsel und Denkwürdigkeiten 4]), Münster 1952, S. 196.

21 Zu Forstmeisters Stellung am Hof vgl. Oldenhage, Kurfürst (wie Anm. 5), S. 76f. Über Forstmeisters Einschätzung durch den Erzherzog-Koadjutor Max Franz siehe ALBERT SCHULTE, Ein englischer Gesandter am Rhein. George Cressener als Bevollmächtigter an den Höfen der geistlichen Kurfürsten und beim Niederrheinisch-Westfälischen Kreis 1763-1781 (Veröffentlichungen des Stadtarchivs Bonn 7), Bonn 1971, S. 83. Forstmeister wird (wie einer der Kölner Domherren Hohenlohe) in Wien am 24.6.1801 
zu den Zeugen gehören, in deren Anwesenheit Max Franz sein Testament unterzeichnet; vgl. MAX BraUBACH, Maria Theresias jüngster Sohn Max Franz. Letzter Kurfürst von Köln und Fürstbischof von Münster, Wien und München 1961, S. 471

Unter derselben Signatur wie das Bücherverzeichnis: Wien, DOZA, Abt. Ri 120, Nr. 462/2; ein eigenständig geheftetes, unpaginiertes Papierfaszikel. Bei Rückgabe wurde der Entleihername durchgestrichen; in einzelnen Fällen so kräftig, dass er ohne weitere Hilfsmittel nicht zu entziffern ist.

Das Auftreten des Entleihers H. v. Andlau in Bonn ist zeitlich fassbar (siehe weiter unten) und gibt damit einen ungefähren Anhaltspunkt für den Beginn der Liste; der letzte Eintrag, auf einem eingeklebten Zettel, ist datiert: 7.11.1793.

So in kurkölnischen Hofkalendern am Ende der Max-Friedrich-Zeit und noch in: Neues genealogiches Reichs- und Staatshandbuch auf das Jahr 1790, Teil 2, TL. 2, Frankfurt 1790, S. 69 (urn:nbn:de:bvb:12-bsb10428420-9).

Sigismund Altgraf von Salm war verheiratet mit Eleonore Maria von Waldburg-Zeil (1735-1804), deren Mutter eine Königsegg-Rothenfels war. Der Sohn Franz Altgraf von Salm (1772-1831) ehelichte Franziska zu Hohenlohe-Bartenstein (1770-1812).

Zur Schwierigkeit der Identifizierung siehe Anhang 1. - Das Zitat zu Ferdinand von Bourscheidt aus GotTLIEB HOESTERMANN, Aus der Lebensbeschreibung des Heinrich Gottlieb Hoestermann [Ms. in Privatbesitz]; hier nach MAX BRAUBACH, Die erste Bonner Hochschule. Maxische Akademie und kurfürstliche Universität 1774/7 bis 1798 (Academica Bonnensia 1), Bonn 1966, S. 335. - Zu Karl Joseph Maria von Bourscheidt siehe MAX BRAUBACH, Eine Jugendfreundin Beethovens, Babette Koch-Belderbusch und ihr Kreis, Bonn 1948, S. 98, sowie Oldenhage, Kurfürst (wie Anm. 5), S. 67 und Anm. 167.

Georg Joseph von Breuning war Mitglied der Lese von 1788 bis 1793, sein Sohn Franz Jakob von 1792 bis 1794 .

Zu Veltens Sohn Friedrich Marian Velten (1759-1784), dem Gymnasialprofessor und Illuminaten, siehe WOLFSHOHL, Nichts weniger als Atheisten (wie Anm. 19).

Vgl. Josef DIETZ, Topographie der Stadt Bonn vom Mittelalter bis zum Ende der kurfürstlichen Zeit, 2 Bde (Bonner Geschichtsblätter 16/17), Bonn 1962/63, hier Bd. 2, S. 660.

Es sind die Räume, die Kapellmeister Joseph Reicha, der wegen seiner Gichterkrankung keine Treppen mehr steigen kann, gerade aufgegeben hat: Zwei Stockwerke mit je einem großen bemalten Saal, zwei tapezierten Zimmern und einem kleinen Raum; zur Raumaufteilung vgl. ebd.

Vgl. Oldenhage, Kurfürst (wie Anm. 5), S. $54 f$

Vgl. HEINRICH NeU, Eine Quelle zur Geschichte des Bonner Landes am Vorabend seiner Annexion durch Frankreich, in: Bonner Geschichtsblätter 21, 1967, S. 153-159.

Bowaters bewohnen ein Haus des Grafen von Holnstein mit Hausmeister, Koch, fünf Dienern, fünf Mägden, Mobilien, Pferden und Wagen. Seit 1782 schulden sie die Miete, so dass Graf Holnstein prozessieren muss. 1791 verkauft er das Haus, der Käufer soll alle Gerichtskosten übernehmen; vgl. DiETz, Topographie (wie Anm. 29), S. 51 6f. Die Vornamen und Namensergänzung der Bowaters nach KIRSCHBAUM, Wohnbauten (wie Anm. 3), S. 402

Einzelne Familienglieder der Familie Jacquemin (auch Schakmin) standen seit dem 18. Jahrhundert in kaiserlichen bzw. Österreichischen Diensten. Heinrich Ludwig Freiherrvon Jacquemin (1713-1792) und Carl Graf von Jacquemin waren kaiserliche Kavalleriegeneräle. - Zur Verbindung Jacquemin und Andlau siehe etwa MARTIN WELLMER, Andlaw-Birseck, Konrad Karl Friedrich Freiherr von und zu, in: NDB 1, 1953, S. 272. 
Vgl. Elisabeth Mentzel, Madame Fiala. Aus dem Leben einer Schauspielerin des 18. Jahrhunderts, in: Deutsche Thalia, Jahrbuch für das gesamte Bühnenwesen 1, 1902, S. 1-35, Zitat S. 15. "Fritzchen" ist Friederike Flittner; der "Judendoktor" kann nur Dr. Moyses Abraham Wolff gewesen sein, Clemens Augusts ehemaliger Leibarzt, denn die zeitweise in Wolffs Praxis mitarbeitenden verwandten Ärzte lebten damals nicht in Bonn, Dr. Simon Meyer Cassel seit 1781 in Köln und Dr. Wolff Jacob Wolff noch bis 1787 in Marburg. - Für Forstmeisters Mitmenschlichkeit zeugt auch seine Fürsorge gegenüber Bonner Hofbediensteten nach seiner Flucht vor den Franzosen; vgl. NEU, Quelle (wie Anm. 32)

Gräfin Belderbusch, die über eine eigene Bibliothek verfügte, lieh, wie erwähnt, auch bei Forstmeister aus, siehe weiter unten.

Kirschbaum, Wohnbauten (wie Anm. 3), S. 134, 136, 143. - MoniKa Gussone und HANS-WERnER LANGBRANDTNER, Bibliothek, in: GUDRUN GERSMANN und HANS-WERnER LANGBRANDTNER (Hgg.), Adlige Lebenswelten im Rheinland. Kommentierte Quellen der Frühen Neuzeit, Köln/Weimar/Wien 2009, S. 59-68, hier S. 61

Vgl. Kirschbaum, Wohnbauten (wie Anm. 3), S. 181

Zitiert nach BRAUBACH, Lebenschronik (wie Anm. 20), S. $234 \mathrm{f}$.

Ein Exemplar des Versteigerungskatalogs (Köln 1787) ist in der Universitäts- und Stadtbibliothek Köln erhalten (Signatur: Kat 53). Zu Großmann vgl. GÜNTHER HANSEN, Großmann, Gustav Friedrich Wilhelm, in: NDB 7, 1966, S. 156f.; JOSEPH KÜRSCHNER, Großmann, Gustav Friedrich Wilhelm, in: ADB 9, 1879, S. 752-756.

Was in Bonn gespielt wurde, ist zusammengestellt bei DORIS und ARNOLD E. MAURER, Dokumente zur Bonner Theatergeschichte 1778-1784: Hoftheater unter Gustav Friedrich Wilhelm Großmann und Karoline Großmann (Veröffentlichungen des Stadtarchivs Bonn 47), Bonn 1990, hier S. 273-295: Verzeichnis der aufgeführten Theaterstücke.

Vgl. ebd.; dort auch die Einschätzung: „Gegeben wurde, ganz im Sinne des Hofs, und obschon man sich ,Hoftheater' nannte, bürgerliches Aufklärungstheater, untermischt mit Unterhaltungsstücken." Ebd., S. 300.

43 Wilhelm Pfeiffer-Belli, Theater und Schauspielkunst, in: Heinrich Voelcker, Die Stadt Goethes, Frankfurt am Main im XVIII. Jahrhundert (ND der Ausgabe 1932), Frankfurt 1982, S. 273-288, hier S. 278f. Ähnlich auch Elisabeth MentzeL, Schillers Jugenddramen zum ersten Male auf der Frankfurter Bühne, in: Archiv für Frankfurts Geschichte und Kunst, 3. Folge, 4, 1893, S. 64-160, hierzu S. 86.

Vgl. Peter Mertz, Die Uraufführung des "Fiesko" war in Bonn, in: Maske und Kothurn. Vierteljahrsschrift für Theaterwissenschaft 10, 1964, S. 484-487.

Vom Werther ist nicht nur eine Ausgabe von 1774 vorhanden, vielleicht die Erstausgabe, sondern auch die Dramatisierung von Willer Werther. Ein bürgerliches Trauerspiel (1778). - Zu Beginn des Dramas nennt die Figur des Werther (in Akt 1,2) drei Bücher aus ihrem Besitz "Sternheim", "Yorick" und "Homer"; die beiden ersten enthält auch der Versteigerungskatalog der großmannschen Bibliothek. Sternes Yorick ist vielleicht oft gelesen worden; das Exemplar ist "schlecht conditionirt" (Nr. 1049).

Vgl. Christine Reents und Christoph Melchior, Die Geschichte der Kinder- und Schulbibel. Evangelisch - katholisch - jüdisch (Arbeiten zur Religionspädagogik 48), Göttingen 2011, S. 195.

47 Katharina Elisabeth Goethe, Die Briefe der Frau Rath Goethe, gesammelt und hg. von Albert Koester, Leipzig 1968, S. 201f. (Brief 114); Mentzel, Jugenddramen (wie Anm. 43), S. $117 f$ 


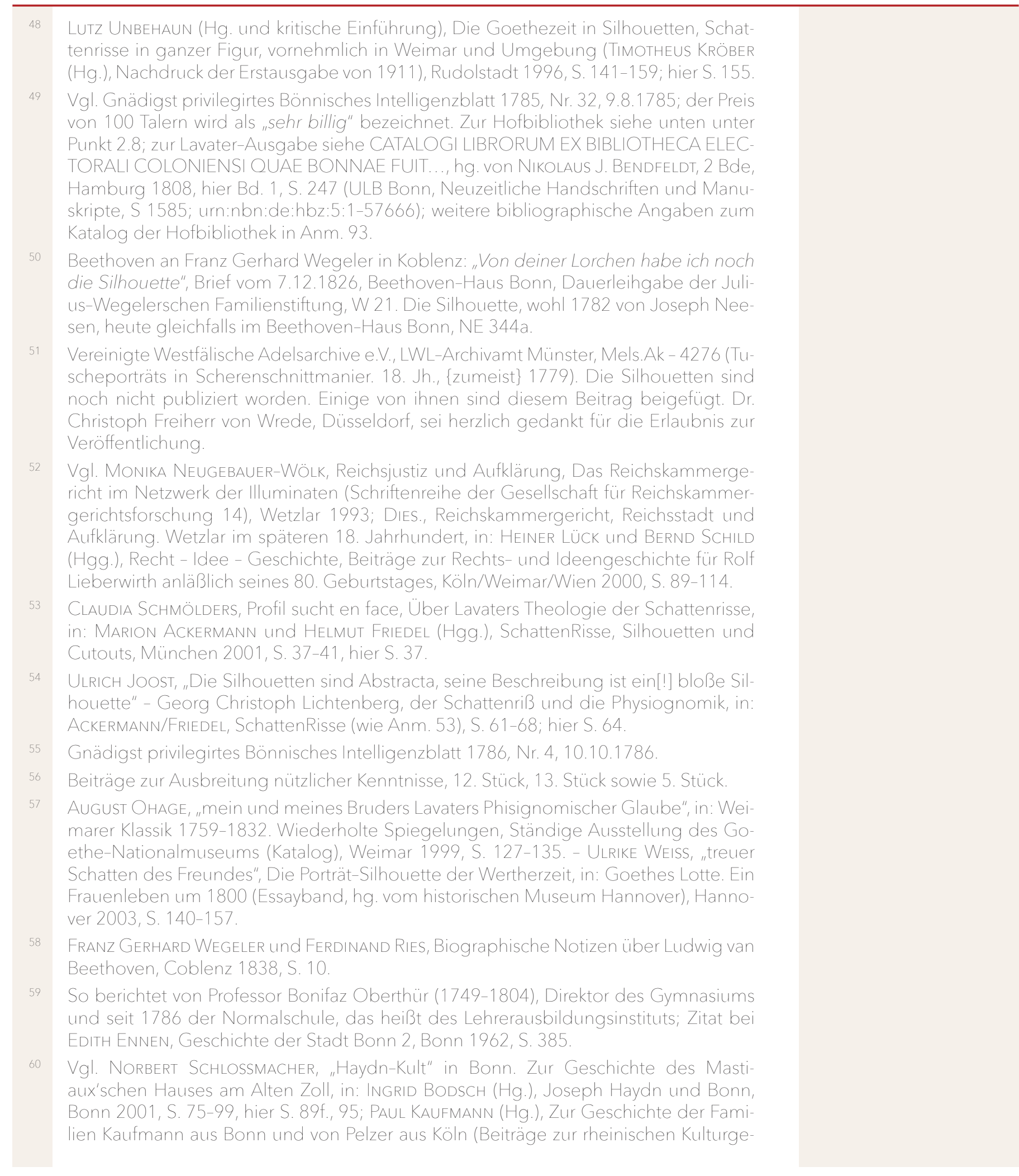

„Elementarbuch zur psichologie - Ordnung der geschäfte" | 141 
schichte), Bonn 1897, S. 75; DeRS., Aus den Tagen des Kölner Kurstaats. Nachträge zur Kaufmann- von Pelzerschen Familiengeschichte, Bonn 1904, S. 48f. - Das Haus wird 1790 nach Mastiauxs Tod vom Kurfürsten erworben; Kanonikus Max Joseph von Mastiaux besaß seit 1789 ein Haus Am Hof. - Mit der Schreibung des Nachnamens Peltzer folge ich der eigenhändigen Unterschrift Joh. Jakob Tillmann Peltzers.

Vgl. AlEXANDER WOLFSHOHL, Lesepaten für Beethoven? Zur Bedeutung der Bonner Lesegesellschaft von 1787, in: BERNHARD R. ApPEL und JuLIA RONGE (Hgg.), Beethoven liest (Schriften zur Beethoven-Forschung 28), Bonn 2016, S. 307f.; DERS., "Lichtstrahlen der Aufklärung". Die Bonner Lese-Gesellschaft - Geistiger Nährboden für Beethoven und seine Zeitgenossen (Begleitpublikation zu einer Sonderausstellung im Beethoven-Haus Bonn), Bonn 2018, S. 13

In einer Schmähschrift über die "Freiheitsschwärmer" von 1798 wird sie aufgeführt; siehe KaUfmanN, Geschichte (wie Anm. 60), S. 9 KaUfMAnN, Aus den Tagen (wie Anm. 60), S. 58.

Zum Buchbesitz im peltzerschen Haus siehe Kaufmann, Geschichte (wie Anm. 60), S. 9, 21, 110; Zitat S. 9, das Folgezitat S. 110.

Auf Schneider wird weiter unten noch einzugehen sein.

Bonner Wochenblatt, 31.8.1817

WiLHELM JOSEPH HEINEN, Der Begleiter auf Reisen durch Deutschland: frei nach dem Französischen bearbeitet, mit einer Vorrede und Zusätzen, die Aachen, Bonn, Coblenz und Cöln betreffen, vermehrt, 1-2, Köln 1808; hier 1, S. 149. - Max Braubach sagt von Falkenstein, er sei Besitzer "einer reichen Bibliothek" gewesen, gibt dafür aber keine Quelle an; vgl. BRAUBACH, Jugendfreundin (wie Anm. 26), S. 112.- Merckenichs waren Nachbarn der Familie Beethoven in der Rheingasse, sie wohnten zwei Häuser neben Fischer; vgl. WetzSTEIn, Familie Beethoven (wie Anm. 4), S. 117, 120, sowie Dietz, Topographie (wie Anm. 29), S. 535, 537. Merckenich führt am 21.7.1790 Professor Ferdinand Franz Wallraf aus Köln als Gast in die Lese ein. Vgl. Gästebuch der Lese- und Erholungsgesellschaft Bonn, StAB, SN 109 (Depositum Lese)/194.

Vgl. WOLFSHOHL, "Lichtstrahlen” (wie Anm. 61), S. 22f; DERS., Lesepaten (wie Anm. 61), S. 304

Vgl. HeInEN, Begleiter (wie Anm. 67), S. $145 f$.

C. F. HEINRICH, Die Bibliothek, in: Jahrbuch der Preußischen Rhein-Universität 1, Bonn 1819-1821, S. 40-45, hier S. 44f.; das bezogene Exemplar des Jahrbuchs gehörte zum Altbestand der Lese- und Erholungsgesellschaft Bonn von 1787, der mit der Bildersammlung im Januar 2018 vom Beethoven-Haus Bonn erworben wurde. - Zur Übernahme von Büchern Crevelts auch WILHELM ERMANN, Geschichte der Bonner Universitätsbibliothek (1818-1901) (Sammlung bibliothekswissenschaftlicher Arbeiten 37/38), Halle 1919, S. 34: Im Januar 1819 wurden für 1000 Taler 675 Werke erworben.

Universitäts- und Landesbibliothek Bonn (ULB), Neuzeitliche Handschriften und Manuskripte, Verzeichniß der sämtlichen Bücher..., welche seit Oct. 1818 bis zu Ende des Jahres 1819 zur Königlichen Universitätsbibliothek in Bonn ... gekommen sind, S 2907 (urn:nbn:de:hbz:5:1-58920). - Birgit Schaper (Leitung der Abteilung Handschriften der ULB Bonn) sei für mancherlei Recherchehilfe herzlich gedankt.

72 Die Schenkung erfolgte 1867 durch Rougemonts Schwiegersohn. 1354 Werke in 2406 Bänden wurden von der Universitätsbibliothek übernommen, der Rest anderen Bibliotheken angeboten (https://www.ulb.uni-bonn.de/de/sammlungen/historischebibliotheken/rougemont-claude-joseph; dort auch das Zitat; Zugriff 23.11.2019).

142 | Alexander Wolfshohl

(C) 2020 by Böhlau Verlag GmbH \& Cie. KG, Köln

https://doi.org/10.7788/9783412519704 | CC BY-NC 4.0 
Hedderich hat "mit Oberthür, Dereser und anderen ... Bonn zu einer Hochburg der Aufklärung und kurienfeindlicher Tendenzen" gemacht; so August FranzEN, Hedderich, Philipp, in: NDB 8, 1969, S. $186 f$.

MAX BraUbaCH, Neue Funde und Beiträge zur Kulturgeschichte Kurkölns im ausgehenden 18. Jahrhundert, in: Annalen des Historischen Vereins für den Niederrhein 172, 1970, S. 155-215, hier S. 188. - StAB, SN 160 - 485 (Nachlass Spiegel).

Braubach, Hochschule (wie Anm. 26), S. 129-131, Zitat S. 131; Ders., Neue Funde (wie Anm. 74), S. 197

Die Erwähnungen von Büchersammlung und Bucherwerb im Briefwechsel Oberthürs mit seinem Bruder hier nach MAX BRAUBACH, Der Bonner Professor Oberthür und die Aufklärung in Kurköln, in: Annalen des Historischen Vereins für den Niederrhein 126, 1935, S. 108-157, hier S. 117 und Anm. 41.

Gnädigst privilegirtes Bönnisches Intelligenzblatt 1788, Nr. 3, 15.1.1788.

Eulogius SchneIder, Gedichte, Frankfurt 1790, S. 45 (Gelegenheitsgedicht an Professor Augustinus Schelle in Salzburg, der Schneider Bücher geschickt hatte). Zur Berufungsverhandlung vgl. BRAUBACH, Hochschule (wie Anm. 26), S. 206.

Zu Eichhoff siehe CHRISTIAN SCHLÖDER, Johann Peter Eichhoff, in: Internetportal Rheinische Geschichte (http://www.rheinische-geschichte.lvr.de/Persoenlichkeiten/johannpeter-eichhoff-/DE-2086/lido/57c69f644b4e52.18322639; Zugriff 19.1.2020)

JOHANN PETER EICHHOFF, Materialien zur geist- und weltlichen Statistick des niederrheinischen und westphälischen Kreises und der angrenzenden Länder nebst Nachrichten zum Behuf ihrer ältern Geschichte 1, Erlangen 1781, S. 95-162, S. 214-228; Zitat S. 222. - Ein Affiliationsbrief bekundet die geistliche Gemeinschaft zwischen einem Orden und einem Wohltäter, in die sich der Wohltäter durch Wohlwollen und Guttaten selber eingebracht hat; der Orden nimmt den Wohltäter dafür in seine fürbittenden Gebete auf. ULB, Neuzeitliche Handschriften und Manuskripte, S 2907 (wie Anm. 71). - Von der Forschung ist diese Bibliothek offenbar bisher übersehen worden. Mit der Hofbibliothek kann sie nicht identisch gewesen sein, weil deren Bestände aus Bonn fortgeschafft und zerstreut wurden, worauf unter 2.8 eingegangen wird.

Zu Eichhoff siehe ChrISTIAN SCHLÖDER, Johann Joseph Eichhoff, in: Internetportal Rheinische Geschichte (http://www.rheinische-geschichte.Ivr.de/Persoenlichkeiten/ johann-joseph-eichhoff-/DE-2086/lido/57c69f159a1 fa0.40276060; Zugriff 5.4.2020).

Zu Nathan Horwitz Schlesinger siehe KLAUS H. SCHULTE, Bonner Juden und ihre Nachkommen. Eine familien- und sozialgeschichtliche Dokumentation (Veröffentlichungen des Stadtarchivs Bonn 16), Bonn 1976, S. 514 Anm. 20

Mit Friedrichs hinterlassene Werke dürfte die 15-bändige Nachlassausgabe Friedrich II. von Preußen (Kempten 1788/89) versteigert worden sein. Die Haushaltungskunst von Suckow, einem Leipziger Ordinarius für Physik und Mathematik, ist eine Bearbeitung von J. G. von Eckhardts Experimentalökonomie über das mineralische, vegetabilische und animalische Reich, oder Anleitung zur Haushaltungskunst (Leipzig 1782). Johann Wilhelm von Archenholtz war ein weitbeachteter spätaufklärerischer Publizist; England und Italien erschien 1785

Zu Buchbesitz und Bucherwerb bei Hertz Salomon Oppenheim siehe SCHULTE, Bonner Juden (wie Anm. 83), S. 402, 403 Anm. 6, bei Meyer Heymann Gunzenhausen ebd., S. 288 Anm. 4, bei Moyses Abraham Wolff ebd., S. 532, bei Simon Baruch ebd., S. 111,587

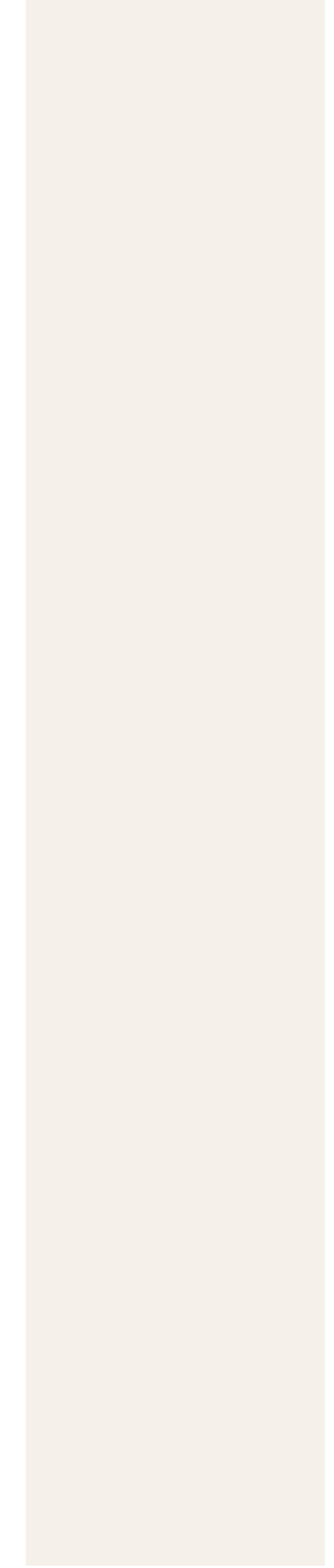

„Elementarbuch zur psichologie - Ordnung der geschäfte“ | 143 
87 Dies wie auch das Folgezitat nach NIKOLA RosSBACH, Einführung zu Justis "Schauplatz der Künste und Handwerke" (1762) in der Digitalen Bibliothek der Herzog-August-Bibliothek Wolfenbüttel (http://diglib.hab.de/edoc/ed000115/start.htm; Zugriff 9.1.2020)

88 Max Braubach, Die "Kurfürstliche Bibliothek" in Bonn, in: Bonner Mitteilungen 12 (Sonderheft der Universitäts-Bibliothek), 1933, S. 12-18; Zitat aus der erwähnten Verordnung, die Syndikus Esser erarbeitet und Max Franz verbessert hatte, ebd., S. 13.

Zum Buchbestand 1784 siehe „Inventar und Taxation des Schlosses zu Bonn .... und .... der Bibliothek ... nach dem Tod Maximilian Friedrichs" und "Katalog sämtlicher zum Nachlass von Josef Clemens und Maximilian Friedrich gehörender Bücher" (Landesarchiv NRW, Abt. Rheinland, Kurköln II Nr. 341, sowie ebd., Nr. 379). Erhalten ist auch der "Katalog der Bibliothek des Kölner Mediziners Johann Georg Menn" in der ULB, Neuzeitliche Handschriften und Manuskripte, S 834 (urn:nbn:de:hbz:5:1-37236). BRAUBACH, "Kurfürstliche Bibliothek” (wie Anm. 88), S. 16.

Esser hat später von Arnsberg aus noch manche kurkölnischen Belange geregelt. In preußischer Zeit war er Regierungsrat und seit 1826 Träger des Roten Adlerordens 3. Klasse; von ihm stammt unter anderem eine Denkschrift zur bürgerlichen Integrierung der jüdischen Bevölkerungsgruppe (1820), vgl. WOLFSHOHL, "Lichtstrahlen” (wie Anm. 61), S. 17

Vgl. IRENe H. Lauterbach (Hg.), Drei Generationen Wurzer im 18. und 19. Jahrhundert. Die Autobiographien von Joseph und Ferdinand Alexander Wurzer, Frankfurt u.a. 2015, S. 233, $238 f$.

Vgl. Max Braubach, Das Ende der kurkölnischen Universität Bonn, in: Historisches Jahrbuch 45, 1925, S. 271-292, hier S. 288.

CATALOGI (wie Anm. 49). Bd. 1 enthält die historische, philosophische und philologische Klasse, Bd. 2 die medizinische, juristische und theologische Klasse. Infolge des hastigen Einpackens in Bonn gibt es freilich, wie Bendfeld schon im Vorwort erwähnt, Irrläufer in den Klassen. - Etliche der Ersteigerer sind Agenten, andere haben wohl zum Eigenbesitz erworben, so Mendelssohn (wohl Abraham und Leah Mendelssohn, die Eltern Felix und Fanny Mendelssohns) oder die Stadtbibliothek und die Commerzbibliothek in Hamburg (in deren beider Beständen sich also heute noch ehemals Bonner Bücher befinden können).

Ebd. 1, S. 183, 274

Auch Ginetti war Illuminat; vgl. zu ihm WOLFSHOHL, Nichts weniger als Atheisten (wie Anm. 19).

97 Vielleicht ist es ein Widerschein des ersten Koalitionskrieges, dass die Einzelhefte nicht mehr gebunden sind? - CATALOGI (wie Anm. 49), 1, S. 277

Ein Teilabdruck von Bertòlas Reisebericht erschien zuerst 1790 in einem italienischen Journal, die vollständige deutsche Übersetzung: AureLIO BerTólA DE GIORGI, Malerische Rhein-Reise von Speyer bis Düsseldorf. Aus dem Italienischen, Mannheim 1796, hier S. 232. - Zu Bertòla siehe Michèle StÄUBLE-LIPMAN-WuLF, Aurelio de' Giorgi Bertola, in: Historisches Lexikon der Schweiz HLS, Version vom 19.11.2013 (https://hls-dhsdss.ch/de/articles/024166/2013-11-19/; Zugriff 13.1.2019); JÖRG-ULRICH FECHNER, Erfahrene und erfundene Landschaft, Aurelio de' Giorgi Bertòlas Deutschlandbild und die Begründung der Rheinromantik, Opladen 1974.

99 Johann Nikolaus Tetens (1736-1807), aufklärerischer Professor der Philosophie und Mathematik in Kiel. Zu ihm siehe Hugo Liepmann, Tetens, Johann Nicolaus, in: ADB 37, 1894, S. 588-590 


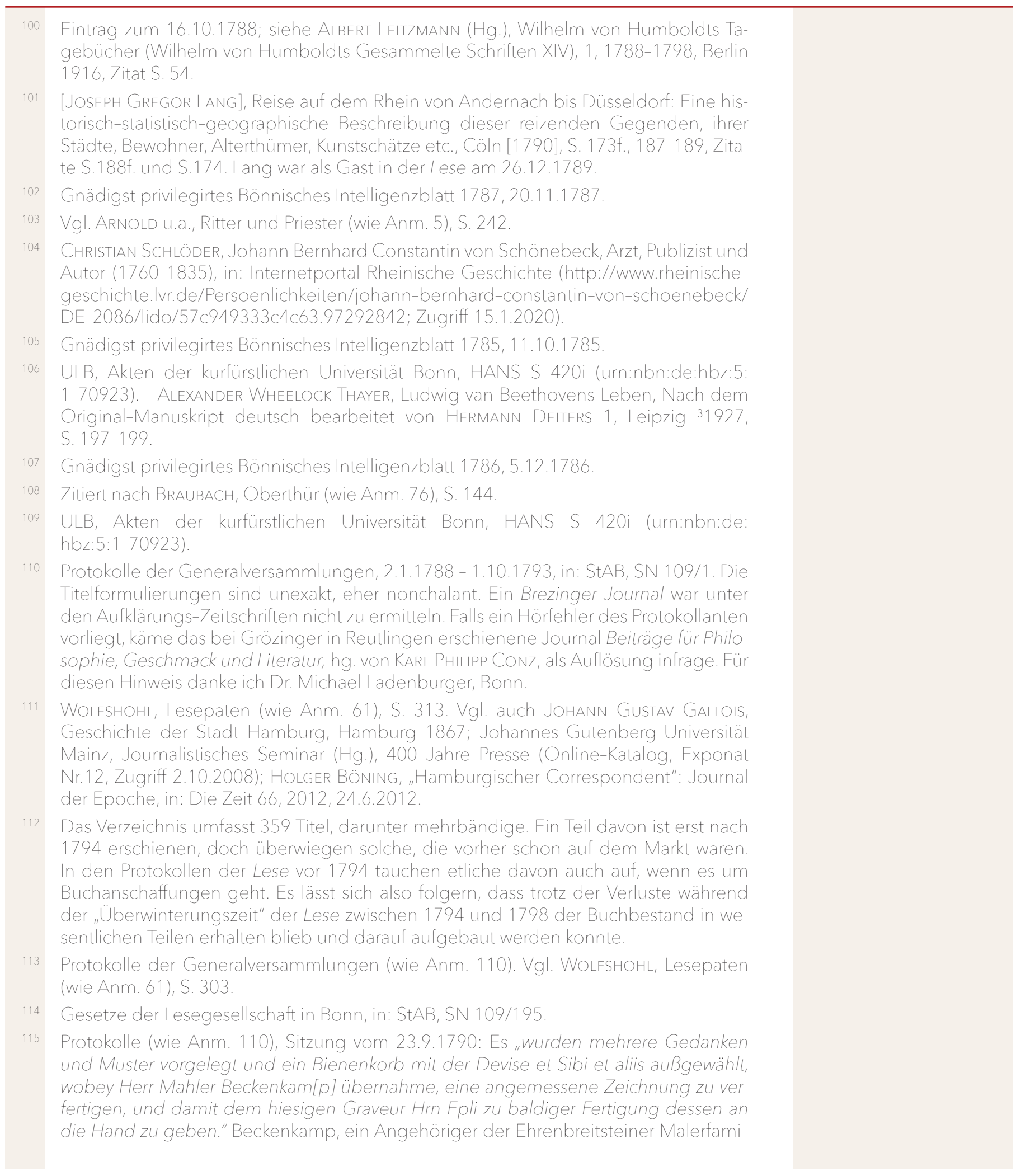

"Elementarbuch zur psichologie - Ordnung der geschäfte" | 145 
lie, Theatermaler und Schauspieler, seit 1789 Lese-Mitglied, Ehemann der Hofsängerin Veronika, geborene Cremer, gehörte zum Freundeskreis der Familie Beethoven.

Vgl. Günter Grünsteudel, Die Mitglieder der Wallersteiner Hofkapelle in Kurzporträts, 3. Folge: Josef Reicha, in: Rosetti-Forum 3, 2002, S. 73-76.

Protokolle der Generalversammlungen 2.11.1793 - 1.6.1806, StAB, SN 109/2

Vgl. WOLFSHOHL, Lesepaten (wie Anm. 61), u.a. S. 301.

Vgl. DERS., "Lichtstrahlen" (wie Anm. 61), S. 15-17. FISCHER, Deutschordensbibliothek (wie Anm. 5), S. 256, gibt irrtümlich an, in der Lese sei die Aufnahme von Juden verboten gewesen; ARNOLD, Der Deutsche Orden (wie Anm. 5), S. 38, hat das übernommen. Die Lese hatte sich vielmehr geradezu programmatisch für Toleranz erklärt und handelte auch so; Frauen allerdings waren ausgeschlossen.

Rolf StOCKMAnN, Portal Rezensionszeitschriften der deutschen Aufklärung (https:// www.sub.uni-goettingen.de/projekte-forschung/projektdetails/projekt/portal-rezensionszeitschriften/; Zugriff 20.1.2020). Gnädigst privilegirtes Bönnisches Intelligenzblatt 1, 1785, 16.8.1785

Auszugslisten der Besteller aus Bonn bzw. mit Bezug zu Bonner Familien sind als Anhang 5 beigegeben.

Als solche bekommt sie ein reichsstädtischerseits organisiertes Quartier: Töngesgasse / G.N.35. / bei Herrn Diehl; vgl. Rückerinnerung der Anwesenheit aller höchsten und hohen Fremden während der Wahl- und Krönungszeit Leopold des II., Frankfurt 1790, S. 58. Vgl. AleXANDER WOLFSHOHL, "Ihre wahre freundin wittib Koch - Ir warer Freund Waldstein". Freunde, Helfer, Weggefährten Beethovens in Bonn und darüber hinaus, in: THOMAS LeiBNITZ ( $H g$.), Beethoven, Menschenwelt und Götterfunken (Begleitbuch zur Ausstellung der Österreichischen Nationalbibliothek), Wien 2020, S. 17-27; hier S. 21 Siehe den Auszug aus der Liste in Anhang 4.

Offen sagt er: "Lebe wohl Theologie!/ Lange hast du mich gequälet,/ Weibermärchen mir erzählet,/ Und gedacht, ich glaubte sie." Wiederholt brandmarkt er unaufgeklärtes, unchristliches Verhalten der Geistlichkeit, so im Gedicht "Der böse Priester": "Der Pfaff, der Menschen lächelnd kränkt, / Am rauchenden Altar/Auf Brudermord mit Wollust denkt/ Ist - Satan im Talar.", Eulogius SCHneIder, Gedichte, Frankfurt 1790, S. 177 bzw. S. 40

Ebd., S. 223. Mit dem Hinweis auf Thuiscon, den fiktiven Ahnherrn der Deutschen, weist Schneider sich als Kenner der sog. Bardendichtung aus

Ebd., S. $232 f$

Ebd., S. 247.

[ALOYS WILHELM SCHNEIDER], Streifereyen durch einige Gegenden Deutschlands, Leipzig 1795, S. 267ff; hier nach: ElisABETH CHARLOTTE ZeIM, Die rheinische Literatur der Aufklärung (Köln und Bonn) (Germanistische Texte und Studien 14) (ND der Ausgabe Jena 1932), S. 102 Anm.1

Einige der nachgelassenen Bücher mögen, ohne dass das nachzuweisen wäre, noch aus Bonn stammen.- Zu Beethoven als Leser vgl. AppeL/RONGE, Beethoven liest (wie Anm. 61). Das Beethoven-Haus Bonn versucht seit einigen Jahren, „alle Werke zu ermitteln, die der Komponist las, studierte, kopierte, exzerpierte, vertonte, besaß, entlieh, verlieh, verschenkte, sich zum Kauf notierte oder mit denen er in Gesprächen konfrontiert wurde, die Ausgaben und Auflagen zu identifizieren sowie Parallelexemplare zu erwerben" (https://www.beethoven.de/de/bibliothek\#beethovens-bibliothek; Zugriff 20.12.2019) 


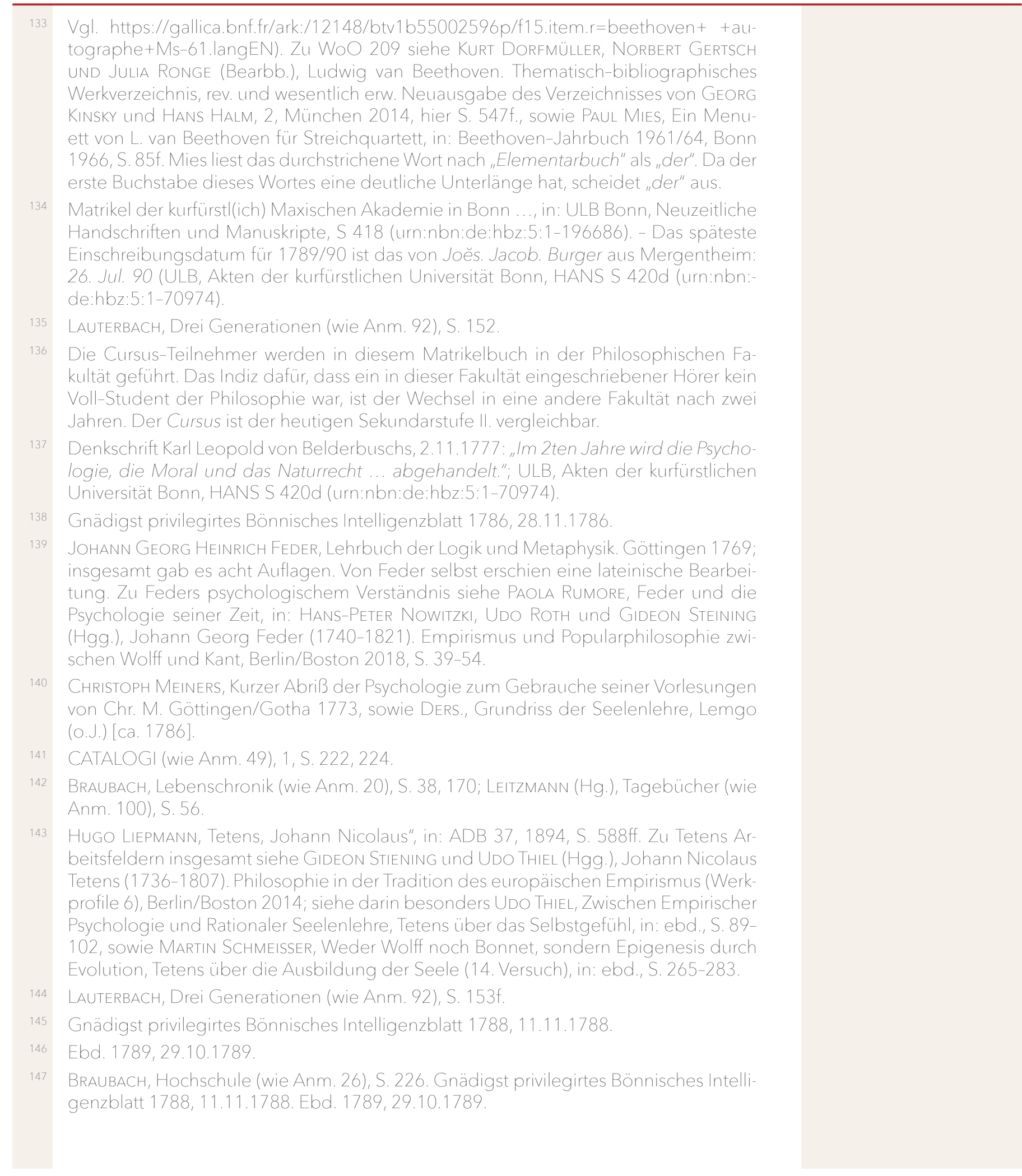

"Elementarbuch zur psichologie - Ordnung der geschäfte“ | 147 
148 Eine Anfrage aus dem Beethoven-Archiv Bonn unter Hinweis auf WoO 209, ob es in der Bibliothek der Lese ein Elementarbuch zur Psychologie gegeben habe oder die Randnotizen in Zusammenhang mit Beethovens Studienzeit stehen könnten, war Anlass für die Suche nach Psychologie und Kameralistik in Lehre und Buchbestand in Bonn zu Beethovens Jugendzeit. - Im internen fachlichen Austausch wurde dann vorgeschlagen, das "Elementarbuch Psichologie" zu identifizieren mit: S. C. Harttrodt, Elementa psychologiae empiricae, Bremen: Foerster 1778. Indessen handelt es sich hierbei, wie ein zeitgenössischer Rezensent darlegt, um eine kleine Unterrichtsmitschrift, die sich Harttrodt, ohne eigene Teilnahme, ausgeliehen und unautorisiert herausgeben hat. Friedrich August Carus (1770-1807), ein Vertreter der neuen psychologischen Richtung, hat sie als "nach alter Eintheilung" eingestuft, und der Rezensent bescheinigt Harttrodt, er habe nicht das Mindeste von der Sache verstanden; vgl. Friedrich August CARUS, Nachgelassene Werke, hg. von Ferdinand Gotthelf Hand, Theil 3, Geschichte der Psychologie, Leipzig 1808, S. 681; ULB Bonn, B 1078 (3); und Auserlesene Bibliothek der neuesten deutschen Litteratur, 15. Bd., Lemgo 1779, S. 122-126 (https://digital.slub-dresden.de/werkansicht/dlf/80265/1/0/). Für eine Empfehlung im fortschrittlichen Bonn spricht das nicht 


\section{ANHANG 1}

(WIEN, DOZA, Ri 120, Nr. 462/2)

"Verzeichnis der ausgelehnten Bücher"

[der Bibliothek des Karl Franz Friedrich Hastard Anton Freiherr Forstmeister von Gelnhausen OT] ${ }^{1}$

\section{$\mathbf{S}[$ eine] Ex[zellenz]}

A H. v. Andlau

B Gräfin Belderbusch, Comtesse de Blankenheim,

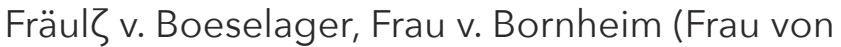
Bornheim), Fräul v. Bornheim, Bourscheidt, Madame Bowater (Mad. Bowatre, Madame Bowather, Mad. Bowather), (H.) Bowather (Mr. Bowather, Mons. Bowather, Monsieur Bowather), H. v. Breuning, Frau Brigaß...

D H. Fähndrich v. Delwich, H. Erbdroste zu Münster

E Eschbaum

F H. Frings, Frau v. Forstmeister (Frau von Forstmeisterin)

G Frau v. Geldern, Grabler (H. Grabler), H. Graf (H. Graff), Fräulein v. Guttenberg

H Frau v. Heathcote, Englische gesandtin ${ }^{2},(\mathrm{H}$. Heckel, Hegel, H. Hofmeister (H. Hoffmeister), Fürstin Hohenlohe, Fürstin Hohen Zoller, H. Hünten

J H. Jacquemin

K Kauffmann, H. J. ${ }^{3}$ Kaufmann, Jud Kaufmann, Moyses Kaufmann, Salomon Kaufmann, Sussmann Kauffmann, Jud Kauffmanns Tochter, Mr. le Conseiller Kerp, Kircher (Kircher pr. R.), Vicarius Kirchrath (Vic. Kirchrath)

L Laufer(Lauffer), La Comtesse de Lichtenstein, H. v. Lohausen

M Lion Marx, H. Rentmstr. Meder (H. Rent $\zeta$ Meder), (H.) Ju: Meder (Jungen Meder, junger Meder), Comtesse Metternich, Feli v. Metternich, (H.) Mittelmeyer (Mittelmeyer)

P Peter

R Rößer

S St. Vanne, Comte de Salm (Graf Salm), [...] v. Senden, Fähnrich Schmidt, H. Schmitz, Frau v.

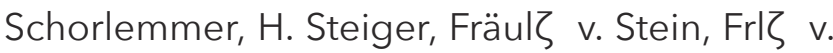
Steinen, v. Steinen, B. de Steinen, Baronne de Steinen, Mad. de Steinen [...], H. oberstlieut. v. ${ }^{4}$ Stieler

T de Tripps

V H. Velten, H. Vogt zu Elsen, Vola, Secretaire des Postes Imperial (Imperiale)

W B. Waldenfels, H. Obristjägermeister (H. Oberjägermeister) [v. Weichs], H. Domherr v. Weichs, H. Haubtmann v. Wiedenbrück, H. Willich, H. Windeck, H. Hofrath v. Wolter, B. ${ }^{5}$ de Wolzogen

\section{Z H. Zartmann}

Zwei umfangreichere Sendungen sind ohne Nennung eines Entleihernamens nach "Kamberg" abgegangen; eine davon datiert: "d. 2. März 1790”. Die Bücher sind jeweils als zurückgekommen wieder ausgetragen worden.

Die Namen der Entleiher sind, soweit lesbar, buchstabengetreu aus dem Verzeichnis ausgezogen und alphabetisch angeordnet. Nur bei Forstmeister ist vom Alphabet abgewichen und "S. Ex." an die Spitze gestellt. Eintragsvarianten sind in runden Klammern beigegeben. Ein eingeklammertes "H" vor einem Namen bedeutet, dass sich bei diesem Entleiher das Prädikat "Herr" nur aus Unterführungszeichen ergibt.

Vermutlich identisch mit der wenige Einträge zuvor genannten Entleiherin.

"J." nachträglich eingefügt

"v." nachträglich eingefügt.

"B." nachträglich eingefügt 
(BONN, Universitäts- und Landesbibliothek)

Christian Gottlob Neefe. $\rightarrow \mathrm{L}$

Dilettanterien. 1785.

"Verzeichniß der Subscribenten."

Herr Hofrath Altstädten

Herr Hauptmann D'Antoin, 3 Exemplare $\rightarrow \mathrm{L}$

Herr Hofkommissarius Bachem

Sr. Exzellenz Herr Hofrathspräsident, Graf von

Belderbusch

Herr Bitter zu Bonn

Herr Hofkammerrath Breuer $\rightarrow \mathrm{L}$

Herr von Burscheid [falls Carl von Bourscheidt OT

$\rightarrow \mathrm{L} \rightarrow$ Schn

Herr D. Crefeld, Professor der Botanik $\rightarrow \mathrm{L}$

Fräulein von Cressener, 2 Exemplare

Herr Hauptmann Defournai $\rightarrow \mathrm{L} \rightarrow$ Schn

Herr Registrator Dericks

Madam Dörfeldt [geb. Struve]

Herr Sekretair Dörfeldt $\rightarrow \mathrm{L}$

Herr Kanonikus Dreesen ${ }^{2} \rightarrow \mathrm{L} \rightarrow$ Schn

Herr Rath Eichhof $\rightarrow \mathrm{L} \rightarrow$ Schn

Herr Mundkoch Eichhof, 2 Exemplare $\rightarrow \mathrm{L} \rightarrow$ Schn

Herr Kandidat Eschbaum

Fräulein Therese Feusser $\rightarrow$ Schn

Herr Hofkappellan Forlivesi $\rightarrow$ L

Sr. Exzellenz Freiherr von Forstmeister, Sr. kurf.

Durchl. zu Köln Obriststallmeister $\rightarrow \mathrm{L} \rightarrow$ Schn

Herr Hofkapellan u. Pagenpräzeptor Frings $\rightarrow \mathrm{L}$

Herr Hofrath von Gerold, 5 Exemplare $\rightarrow \mathrm{L}$

Herr Hofkammerrath Gunsberg

Herr Hofratssekretair Guisez [durch die Heirat sei-

ner Schwester Maria G. Schwager von Joh. Peter

Eichhoff]

Sr. Exzellenz Freiherr von Gymnich, Sr. kurf. Durchl. zu Köln erster Minister, 6 Exemplare

Frau von Heatcoth, 4 Exemplare
Herr von Heckel, Sr. kurf. Durchl. zu Köln geheimer Kabinetssekretair $\rightarrow \mathrm{L}$

Herr Hofsänger [Ferdinand] Heller $\rightarrow$ Schn

Herr Hofviolinist [Gaudenz] Heller $\rightarrow \mathrm{L}$

Herr Hoftapezierer Henri

Herr Hofkammerrath Höcker

Herr Hofrat Kauhlen, 3 Exemplare $\rightarrow \mathrm{L} \rightarrow$ Schn

Herr Kaufmann [möglicherweise Kauhlens

Schwager Matthias Jos. Kaufmann, seit 1776

Schöffenbürgermeister $\rightarrow \mathrm{L} \rightarrow$ Schn; vielleicht

aber auch ein Mitglied der gleichnamigen

Hofjudenfamilie]

Herr geistl. Rath u. Pagenhofmeister Kaiff $\rightarrow$ Schn

Herr Jakob Kemp

Herr von Keverberg zu Aldengoor

Herr Kandidat Kints

Herr Jakob Kemp $\rightarrow \mathrm{L}$

Madam Koch [Tochter u. Sohn: $\rightarrow$ Schn]

Herr Hofkammerrath Löltgen [Garnisonspfarrer

Löltgen: $\rightarrow \mathrm{L} \rightarrow$ Schn]

Herr von Lohausen, kurf. Kammerpage $\rightarrow \mathrm{L}$

Herr Kanonikus u. Prof. Lomberg

Herr Max von Mastiaux $\rightarrow$ L [Amalie v. Mastiaux: $\rightarrow$ Schn]

Sr. Exzellenz Herr Kammerpräsident Graf von

Metternich $\rightarrow \mathrm{L}$

Ihro Exzellenz Frau Gräfin von Metternich

Herr Max Graf von Metternich $\rightarrow \mathrm{L}$

Komtesse Felicitas von Metternich

Komtesse Antonetta von Metternich ${ }^{3}$

Herr Meyer, Dechant des Stifts Münster in Bonn

Herr Hofkammerrath Müller $\rightarrow \mathrm{L}(?)^{4}$

Herr Neesen, kurf.-pfalzbairischer Rath $\rightarrow \mathrm{L}$

Herr Direktor Oberthür $\rightarrow \mathrm{L} \rightarrow$ Schn

Herr Hofrath Pelzer $\rightarrow \mathrm{L} \rightarrow$ Schn

Herr Hofmusikus Ries, 3 Exemplare $\rightarrow \mathrm{L}$

Herr Baron von Rolshausen $\rightarrow \mathrm{L} \rightarrow$ Schn

Herr Artillerieleutnant Sandfort, Lehrer der

Mathematik $\rightarrow \mathrm{L} \rightarrow$ Schn

Herr Hofrath von Schall, 5 Exemplare $\rightarrow \mathrm{L} \rightarrow$ Schn 
Herr Hauptmann von Schall $\rightarrow \mathrm{L} \rightarrow$ Schn

Herr Schevastes

Herr Herr Stabsfourier Schmidt

Herr Kanonikus Schmitz $\rightarrow \mathrm{L} \rightarrow$ Schn

Herr D. von Schönebeck, Lehrer der

Naturgeschichte zu Bonn [verschwägert mit den

Brüdern Eichhoff]

Herr Hofmusikus Simrock, 3 Exemplare $\rightarrow \mathrm{L}$

Herr Ferdinand Stark

Herr Starz

Herr General von Stieler $\rightarrow$ Schn

Herr Hofkammerrath Tossetti, 2 Exemplare

Herr Obristlieutenant u. Kammerherr von Trotti

Herr Probst von Weichs $\rightarrow \mathrm{L} \rightarrow \mathrm{Schn}$

Herr Stallmeister Willich $\rightarrow \mathrm{L} \rightarrow$ Schn

Herr von Wolzogen, Kammer- und Teutschherr

Herr Professor Zeyhen, 10 Ex. $\rightarrow \mathrm{L}$

Herr Best, Arzt zu Köln [i.e. Crevelts Schwager,
Professor der Medizin an der Universität zu Köln] Herr Direktor Großmann zu Frankfurt, 5 Exemplare Frau Räthin Göthe ebendaselbst [i.e. Frankfurt am Main $]^{5}$

Fräulein Therese von Gymnich, Stiftsdame zu Neuß Fräulein Johanna von Gymnich, Stiftsdame zu Neuß, 2 Exemplare Herr Romberg, kurf. köln. u. fürstbischöfl. Hofmusikus zu Münster Herr Schauspieler Schmidt zu Frnkf. am M. [Vorgänger Neefes als Präfekt der Illuminatenloge Stagira]

Herr Joh. Jacob Willemer zu Frankfurt am Main, 4 Exemplare

Herr Amtmann Windeck zu Bornheim ${ }^{6}$

Herr von Wrede, Domküster zu Münster u.

Domkapitular zu Hildesheim

Die Subskribentenliste folgt im Original dem Nachnamenalphabet. Die Bonner Vorbesteller sind hier ausgezogen, einige Nicht-Bonner angehängt, wenn ein Bezug zu Bonner Persönlichkeiten eindeutig ist. Die Illuminaten (unterstrichen) und die späteren Lese-Mitglieder $(\rightarrow L)$ sind eigens markiert; angemerkt ist auch eine spätere Subskription: der Gedichte von Eulogius Schneider (Anhang 4) ( $\rightarrow$ Schn).

Paul Dreesen (1757-1832), Kanoniker am Münsterstift in Bonn und an St. Aposteln in Köln, war ein aktives und offenbar geschätztes Gründungsmitglied der Lese, 1788 der dritte gewählte Direktor der Gesellschaft und anschließend deren Sekretär, d.h. Schriftührer. 1804 war er Kantonal- bzw. Oberpfarrer in (Godesberg-)Marienforst, ab 1805 in gleicher Funktion in (Bonn-)Lessenich.

Aufgrund der Angabe "Kammerpräsident" und der Vornamen der hier genannten gräflichen Familie Metternich kann es sich nur um Johann Ignaz Graf Wolff-Metternich zur Gracht, seine Frau Antonette geb. von der Asseburg und deren Kinder handeln. In der Subskribentenliste ist als Wohnorthinweis "daselbst" angegeben. Die unmittelbar voraufgehenden beiden Besteller wohnen aber in Frankfurt. Der dritte Besteller vor Wolff-Metternich ist der o. 9. "Max von Mastiaux zu Bonn". Offenbar bezieht sich das „daselbst” hierauf, und es liegt ein Flüchtigkeitsfehler, evtl. des Setzers, vor

Angesichts fehlender Vornamen ist die Lese-Mitgliedschaft nicht gesichert.

In Großmanns Frankfurter Theater-Zeit entwickelte sich eine freundschaftliche Beziehung zwischen ihm und Catharina Elisabeth Goethe. Da nun einerseits Frau Rat mit Willemer befreundet war, andererseits der Kontakt zwischen Neefe und Großmann nach dem Abschied des Prinzipals aus Bonn nicht abgebrochen war, sind die entsprechenden Frankfurter Vorbestellungen leicht erklärbar

Verwandt mit Carl Windeck, Procurator, Lese-Mitglied, 1790 Subskribent von Schneiders Gedichten (2 Ex.). 
(BONN, Universitäts- und Landesbibliothek)

Johann Bernhard Constantin von Schönebeck (Hg.),

Niederrheinische Monatsschrift. Erster Band.

Bonn 1787: Gedruckt für den Herausgeber in der Kurfürstl. Hofbuchdruckerei.

Verzeichniß der Subscribenten ${ }^{1}$

[In Bonn:]

Herr Hofrath und Criminalreferendar Altstädten ${ }^{2}$

Herr Geheimrath von Breuning ${ }^{3} \rightarrow \mathrm{L}$

Herr Jaques[!] Bürger

Herr Crevelt, Doctor der Arzneykunst $\rightarrow \mathrm{L}$

Herr Daniels, Prof. der Rechte $\rightarrow \mathrm{L}$

Herr de la Roque, Candidat der Rechte

Herr Canonicus Dreesen $\rightarrow \mathrm{L}$

Herr Registrator Dierickx

Herr Joh. Joseph Eichhof!! $\rightarrow L$

Herr Hofrath und Polizeykommissar von Gerold $\rightarrow \mathrm{L}$

Herr Hofkammerrath von Gunsberg

Herr Prof. Hauser $\rightarrow \mathrm{L}$

Herr geistlicher Rath und Prof. Hedderich $\rightarrow \mathrm{L}$

Herr Kaltenauer, K.K. Postmeister in Bonn, 8 Exemplare

Freyherr von Keverberg, 8 Exemplare

Herr Karl Theodor Klein, aus Rheinbach, Candidat

Herr Obristkämmerer, Freyherr von Lombeck

Herr von Mastiaux, Scheffen des Kurfürstl. hohen Gerichts zu Bonn ${ }^{4}$

Herr Friedrich Memering, Candidat der Rechte

Herr Zollnachgänger Merkenich $\rightarrow \mathrm{L}$

Herr Müller, Candidat der Rechte

Herr Candidat Pulte

Freyherr von Reichersberg der jüngere

Freyherr von Schall, Kurfürstl. Köln. Hauptmann und Kammerherr $\rightarrow \mathrm{L}$

Herr Prof. Schallmeyer $\rightarrow \mathrm{L}$

Herr Späner, Candidat der Rechte

Herr Canonicus Wrede $\rightarrow \mathrm{L}$

Herr Hofkammerrath Wrede

Herr Professor Zeyen 
[Auswärtige Subskribenten mit Bezug zu Bonn, u.a.:]

Herr Best, Doctor und Professor der Arzneykunst in Köln ${ }^{5}$

Herr Hofkammerrath und Oberkellner Borlatti zu Lechenich

Fräulein von Deuren, Canonissin in Villich

Herr Rath und Archivar Eichhof in Mastricht[! $]^{6} \rightarrow \mathrm{L}$

Herr Hofrath du Mont in Köln ${ }^{7}$

Freyherr von Hüpsch in Köln

Herr Prediger Schöneberg in Obercassel

Herr Canonicus und Prof. Wallraf in Köln?

Nach S. 197; Nachtrag S. 294. - Die späteren Lese-Mitglieder sind markiert.

Hofrat Bertram Maria Altstädten (*1744), der als Dichter unter dem Pseudonym Apollinar veröffentlichte, befreundet mit Ferdinand Franz Wallraf (1748-1824) in Köln.

Georg Joseph von Breuning (1730-1797), Deutschordens-Staats- und Konferenzrat, älterer Bruder des Kanonikers Johann Lorenz von Breuning.

Johann Gottfried von Mastiaux (1726-1790), Wirkl. Hofkammerrat, Amtmann und Akademierat, Vater der Brüder Caspar Anton, Caspar Anton Joseph und Max Joseph von Mastiaux, alle drei Lese-Mitglieder; Caspar Anton, wie im Beitrag erwähnt, Gründungsmitglied und späterer Direktor der Lese

Freund und Schwager Dr. Johann Heinrich Crevelts.

Johann Peter Eichhoff war von Juni 1785 bis Dezember 1786 mit der Neuordnung des Archivs der Ballei Altenbiesen des Deutschen Ordens beauftragt

Du Mont gehörte zum Netzwerk um Wallraf, Altstädten, Schönebeck, Johann Peter Eichhoff u.a.

Der Gelehrte und Sammler Jean Guillaume Adolphe Fiacre Honvlez, genannt Baron von Hüpsch (1730-1805), mit dem Johann Peter Eichhoff in seiner Kölner Zeit zusammengearbeitet hatte

Franz Wallraf (1748-1824), Gelehrter und Kunstsammler in Köln. 
(BONN, Universitäts- und Landesbibliothek)

Eulogius Schneider.

Gedichte. Mit einem Porträt des Verfassers.

Frankfurt: in Commission der Andräischen Buchhandlung 1790.

(Seite XV)

Subscribenten=Verzeichnis.

Se kurfürstl. Durchlaucht, mein gnädigster Landesherr, der Kurfürst von Köln.

Se königl. Hoheit der Herzog Albrecht von Sachsen-Teschen, 5 Exempl.

(Seite XVI)

Bacherach. Hr. Holthof, Kelln.

(Seite XVII)

Bonn. Hr Aleff, Stud. - Hr Amecke, Stud. - Hr Angelbis. - Hr Anschel, Stud. - Hr Arnds, Hofr. - Hr Averdonk, Canon. in Ehrenstein. - Herr Bacciochi - Hr Simon Baruch. - Hr Basch, Bürgerm. - Hr Becker, Prof. - Hr de Berghes, Refer. - Hrvon Bersword, kurköln. geh. Rath. - Hrvan Bethoven, Hofmus. - Hr Engelb. Biegeleben. - Hr von Blum, Rath. - Hr Boosfeld, Hofkammerr. - Hr von Braumann, Stud. - Hr von Breuning, kurk. geh. Rath. - Hr von Breuning, geistl. Rath. - Hr von Breuning, Stud. - Hr Caramé, Stud. - Hr Christ, Stud. - Frau von Coels - Hr Corneli, Stud. - Hr Corty, Stud. - Hr Cramer von Clauspruch, geistl. geh. Staatsref. - Hr von Cramer, Kanzleidir. - Hr Cremer, Stud. - Hr Crevelt, Doct. - Hr von d'Aix. - Hr Daniels, Hofr. und Prof. - Hr Dardenne, Hofschausp. - Hr Deckher, Stud. - Hr Defournay, Major. - Hr Dreesen, Can. - Hr Ebhard, Hofr. - Hr Eichhof, gräfl. Bentheimischer Rath. - Hr Eichhof. - Hr Esser, Hofkammerr. - Fräulein von Feuser. - Hr Fickermann, Stud. - Freih. von Forstmeister, kurk. Obriststallm. - Hr Freusberg, Landdechant und Past. zu St. Martin. - Hr Geisler, Adjut. - Hr Graf, Stud. - Hr von Gruben, Stud. - Hr Baron von Goudenau, kurk. Obristhofmarschall. - Frau Gräfinn von Hatzfeld - Hr Heller, Hofmus. - Hr Heuser, Stud. - Hr Hirschmann.

- $\mathrm{Hr}$ Ho-

[Seite XVIII]

henschurz. - Hr Homberg, Past. in Dietkirchen. - Hr Hupp, Maler. - Dem. Marianne Joassin. - Hr Isaak, Hofk. - Hr Jungen, Stud. - Hr Kaipf, Knabenhofm. - Hr Kalt, Hofkam. - Hr Kaufmann, Hofk. - Hr Kauhlen, Hofrath und Prof. - Dem. Christine Keilholz - Dem. Dorothee Keilholz, Hofschauspielerinnen. - Hr Abbé Kettels, Hofmeister bei den Freih. von Warsberg. - Hr Klein, Stud. - Dem. Babet Koch. - Hr Koch, Stud. - Hr Kolter, Stud. - Hr Kracht, Stud. - Hr Krummans, Stud. - Hr Kruse, Stud. - Hr Kügelgen, Stud. - Hr Lachaussé, Stud. - Freifr. von Leroth, des Damenstifts zu Dietkirchen Coadj. - Hr Löltgen, Garnis. Past. - Freih. von Lombeck. - Freih. von Lützelrode. - Hr Lux, Hofschausp. - Hr Martin, Stud. - Fräul. v. Mastiaux. - Hr Memering, Stud. - Hr Merkenich, Rheinzölln. - Hr Mertens, Licent. - Hr Graf von Metternich. - Hr Meunier, Vic. - Hr Müller, Hofk. ${ }^{2}$ - Hr Nachtsheim, Stud. - Hr Neefe, Hofmus. - Hr Graf von Nesselrode-Reichenstein, kurk. Reg. Präsid. - Hr Nettekoven, Oberkellner. - Hr Nüdel, Stud. - Hr Oberthür, geistl. Rath und Direct. 
- Hr Pelzer, geh. Rat - Herr Pfau, Hofmus. - Hr Pfeifer, Stud. - Hr Pick, Stud. - Hr Reicha, Musikdir. - Hr. Reicha, Hofmus. - Hr Reumont, Stud. - Hr Riegel, Lehrer am Münsterstift ${ }^{3}$ - Freih. von Rolshausen, Kammerh. und Hofrat - Hr Roth, Weltgeistl. - Hr Rougemont, Prof. - Hr D. Sandfort, Lieuten. - Hr Schäfer, Stud. - Freih. v. Schall,

[Seite XIX]

kurk. Hauptmann. - Freih. von Schall, geh. Rath. - Hr Scheben, Prof. - Herr Scheidler, Hofk. und Prof. - Hr Schmitz, Can. - Hr Schmitz, Stud. - Hr Schnitzler, Hofkapl. - Hr Schugt, Stud. - Hr v. Seida, Stud. - Hr Simrock, Hofmus. - Hr Graf von Spee, kurk. Obristkuchenm. - Freih. von Spiegel zum Diesenberg, Kammerpräs. - Hr Stachelscheidt, Stud. - Hr Stahl, Hofk. und Baumeist. - Hr Steiger, Hofschauspield. - Hr von Stieler, kurk. Generalmaj. - Hr Jos. Löw Sussmann. ${ }^{4}$ - Hr von Tautphäus, geh. Secr. - Hr Thaddäus, Prof. - Hr Theile, kurf. Kammerd. - Hr Thönessen, Stud. - Hr Töring, Stud. - Hr Urbach, Stud. - Hr Vohs, Hofschausp. - Hr Wacker, Stallm. - Freih. von / Waldenfels, kurk. Staatsminister. - Freih. v. Waldenfels, Domherr zu Trier und Würzburg. - Hr Graf von Waldstein, kurk. geh. Staatsrath. - Freih. von Warsberg, Domh. zu Trier und Worms. - Hr Weber, Stud. - Freih. v. Weichs, Probst. - Hr Weis, Stud. - Freih. v. Wenge, Kammerh. - Hr Werner, Hofrath und Prof. - Hr Wessel, Stud. - Freih. von Widenbruck, Major - Hr Willig, Stallm. - Hr Windeck, Proc. 2 Exempl. - Hr Worms, Stud. - Hr von Wreden, Can. - Hr Wulf, Proc.

(Seite XXIII)

Leipzig. ... Mad. Höpp, geb. Mainone.

$\cdots$

Insel Malaga. Hr Karl Mainone.

Mergentheim. ... Frau Kanzlerinn von Tautphäus.

$\cdots$

Norf. Fräul. Therese Cramer von Clauspruch.

Die Namen der Subskribenten sind im Original nach den Wohn- resp. Bestellorten geordnet. Die Schreibweise folgt der Vorlage. Außer den Bonnern sind noch Besteller von andernorts genannt, wenn sie familiäre Beziehungen zu Bonn hatten. Die Namen der Lesemitglieder sind blau, die der Studierenden rot.

Lese-Mitgliedschaft wegen fehlenden Vornamens nicht gesichert.

Lese-Migliedschaft 1791

Joseph Löw Sussmann genannt Wetzlar (1765-1844), Tuchhändler, Großvater von Dr. Robert Wetzlar (1847-1912), dem Stifter des Robert-Wetzlar-Berufskollegs (Bonn), und Großonkel von Moses Hess (1812-1875). Seine Schwester Zippora Wetzlar (1764-1824) war in erster Ehe mit Heymann Loeb Gunzenhausen verheiratet, dem Neffen von Meyer Heymann Gunzenhausen (1735-1817), in zweiter Ehe mit Nathan Horwitz Schlesinger (1769-1834); siehe die Erwähnungen im Beitrag. 
(Beethoven-Haus Bonn, Bibliothek)

[Johann Philipp Schulin.]

Vollständiges Diarium der Römisch-Königlichen Wahl und Kaiserlichen Krönung Ihro nunmehr allerglorwürdigst regierenden Kaiserlichen Majestät Leopold des Zweiten.

Frankfurt am Main: Jäger 1791.

Allerhöchst-, Höchst- Hohe und Hochzuverehrende Herren Subscribenten und Pränumeranten auf das Wahl- und Krönungs-Diarium Sr. Kaiserl. Majestät Leopold II. ${ }^{1}$

Hohe und Hochzuverehrende Herren Subscribenten und Pränumeranten nach alphabetischer Ordnung. Expl.

\begin{tabular}{|c|c|}
\hline 1 & Monsieur le Baron d'Aix. ${ }^{2}$ \\
\hline 1 & $\begin{array}{l}\text { Se. Excellenz, Herr Graf von Belderbusch Kaiserl. } \\
\text { Kammerherr und Churköllnischer Landhofmeister. }\end{array}$ \\
\hline 15 & Herr Secretair Boutmy in Bonn. ${ }^{4}$ \\
\hline 3 & $\begin{array}{l}\text { Se. Excellenz, Herr Carl Franz Friedrich, Freiherr von } \\
\text { Forstmeister zu Gelnhausen, des hohen deutschen } \\
\text { Ordens Ritter, Coadjutor der Balley Coblenz, } \\
\text { Kommenthur zu Muffendorf, Churcöllnischer gehei- } \\
\text { mer Conferenzminister, Kriegsrath und } \\
\text { Generallieutenannt, auch des hohen deutschen } \\
\text { Ordens Staats- und Conferenzminister. }\end{array}$ \\
\hline 1 & $\begin{array}{l}\text { Se. Excellenz, Herr Reichsfreiherr von Gymnich. } \\
\text { Kaiserl. Generalmajor Churmainzischer geheimer Rath } \\
\text { und Gouverneur der Stadt Mainz }{ }^{5}\end{array}$ \\
\hline 1 & Herr Hofapotheker Hittorf in Bonn. \\
\hline 1 & $\begin{array}{l}\text { Herr Hörster, Churcöllnischer Hof- und } \\
\text { Regierungsrath. }\end{array}$ \\
\hline 1 & Die Lesegesellschaft in Bonn. \\
\hline 1 & Herr Hofr. und Kammerherr v. Metternich in Cölln. \\
\hline
\end{tabular}
Expl.

\begin{tabular}{|c|c|}
\hline 1 & Hr. Pelzer, Churköllnischer Hof- und Regierungsrath. \\
\hline 1 & Hr. Landcommandeur, Freihr. von Roll. \\
\hline 4 & $\begin{array}{l}\text { Se. Excellenz Hr. Graf v. Romanzow, Kämmerer Sr. } \\
\text { Majestät der Kaiserin von Rußland und bevollmächtig- } \\
\text { ter Minister an den Rheinischen, Schwäbischen, } \\
\text { Fränkischen und Westphälischen Kreißen. }\end{array}$ \\
\hline 1 & $\begin{array}{l}\text { Hr. Ferdinand August Freihr. Spiegel zum Diesenberg, } \\
\text { Domherr zu Münster und Osnabrück. }\end{array}$ \\
\hline 1 & $\begin{array}{l}\text { Hr. Friedrich Ernst Freihr. Spiegel zum Diesenberg } \\
\text { und Canstein, des deutschen Ordens Kommandeur } \\
\text { und Churköllnischer Geh. Rath. }\end{array}$ \\
\hline 1 & $\begin{array}{l}\text { Hr. Franz Wilhelm, Freiherr Spiegel zum Diesenberg } \\
\text { und Canstein, Churcöllnischer Kammerpräsident und } \\
\text { Curator der Universität zu Bonn. }{ }^{6}\end{array}$ \\
\hline 1 & Hr. Vogel, Churköllnischer Hofkammerrath. \\
\hline 1 & $\begin{array}{l}\text { Hr. Freihr. von Westerholt, Oberstallmeister von } \\
\text { Churkölln. }\end{array}$ \\
\hline 1 & $\begin{array}{l}\text { Hr. Freihr. von Wrede, Domscholaster zu Hildesheim } \\
\text { und Domkantor zu Münster.7 }\end{array}$ \\
\hline
\end{tabular}

Das Subskribentenverzeichnis ist alphabetisch angelegt; die Namen der Vorbesteller aus Bonn bzw. Hofstaat und Hofgesellschaft sind, soweit mir erkennbar, hier ausgezogen; die Namen der Lese-Mitglieder in blau.

Franz Josef Freiherr d'Aix, kurf. Kämmerer und Oberst-Lieutenant.

Lese-Mitglied 1792

Vermutlich zur Suite des Statthalterpaares der Österreichischen Niederlande gehörend, evtl. Etienne Philipp Joseph Boutmy de Katzmann (1739-1817), der 1809 als Gesandter nach St. Petersburg ging

Clemens August Ferdinand von und zu Gymnich war zudem kurkölnischer Kammerherr und Amtmann zu Liedberg. Außer den drei zum Hofstaat und zur Hofgesellschaft Kurkölns gehörenden Freiherrn Spiegel zum Diesenberg subskribiert noch ein weiterer Spiegel ein Exemplar: „Hr. Clemens Freihr. Spiegel zum Diesenberg und Canstein, Domscholaster in Preussisch-Minden und Domherr zu Paderborn."

Zu Engelbert Anton Freiherrn von Wrede zu Melschede (1742-1808) vgl. die Ausführungen zur Silhouettensammlung in diesem Beitrag

156 | Alexander Wolfshohl 


\section{Der Clavierinstrumentenbestand und -instrumenten- bau in Bonn als Anregung für den jungen Beethoven - Auf den Spuren des Instrumentenbauers Gottlieb Friedrich Riedler}

ede Beschäftigung mit diesem Thema, das hier im Wesentlichen auf Saiteninstrumente eingeschränkt wird und den Orgelbau nur in einem Fall einbezieht ${ }^{1}$, beruht auf Christian Gottlob Neefes Bericht über das Bonner Musikleben im Magazin der Musik von $1783^{2}$ sowie einer Ergänzung vier Jahre später ${ }^{3}$. Die Folgen von Beethovens früher Begegnung mit Spitzenerzeugnissen des Cembalo- wie Hammerklavierbaus lassen sich in Carl Ludwig Junkers Bericht in der damals wichtigsten süddeutschen Musikzeitschrift über das Auftreten der Bonner Hofkapelle in Mergentheim 1791 nachlesen. Junker berichtete dabei erstmals über Beethovens Art, das Klavier zu spielen, und seine Ansprüche an das Instrument. ${ }^{4} 2001$ veröffentlichte NorbertSchloßmacher wichtiges Quellenmaterial zum Bonner Hofkammerrat Johann Gottfried von Mastiaux, der sich an die Spitze der beachtlichen Bonner Hausmusikszene gesetzt hatte. ${ }^{5}$ Leider ist die Quellenlage darüber hinaus äußerst dürftig, verdient es aber, hier einmal zusammengefasst, erschlossen und um einige neue Dokumente ergänzt zu werden. Ein besonderes Augenmerk sei Gottlieb Friedrich Riedler/Riedlen geschenkt, dem wohl einzigen Klavier- und Cembalobauer in Bonn zur Zeit des jungen Beethoven. - Seine weitgehend im Dunkeln liegende Biographie wird am Ende dieses Artikels abgehandelt.

Im Folgenden soll erläutert und anschaulich gemacht werden, wie anregend der Bonner Instrumentenbestand für den jungen Beethoven war und um welche Instrumententypen es sich im Einzelnen handelte. Gleich vorweg sei die Einschränkung gemacht, dass keines dieser Instrumente erhalten bzw. identifiziert ist. Es gibt aber vergleichbare Instrumente, anhand derer wir uns eine Vorstellung machen können.

Das letzte Viertel des 18. Jahrhunderts brachte eine Hochblüte instrumentenbaulicher Versuche und Weiterentwicklungen. Am bekanntesten ist wohl die von Anton Weidinger in Wien erfundene Ventiltrompete, die dann zuerst von Joseph Haydn prominent eingesetzt wurde: Vier Tage vor der Uraufführung von Beethovens 1. Sinfonie erklang an gleicher Stelle im Wiener Hofburgtheater erstmals Haydns Trompetenkonzert Hob VIle:1.

Besonders rasant, ausdauernd und experimentierfreudig war die Entwicklung auf dem Gebiet der Tasteninstrumente. Die Liste der Sonderformen, wie sie etwa Ernst Ludwig Gerbers Altes Tonkünstlerlexikon ${ }^{6}$ mitteilt, ist lang. In Jacob Adlungs Anleitung zur musikalischen Gelahrtheit, in zweiter, von Neefes Lehrer 


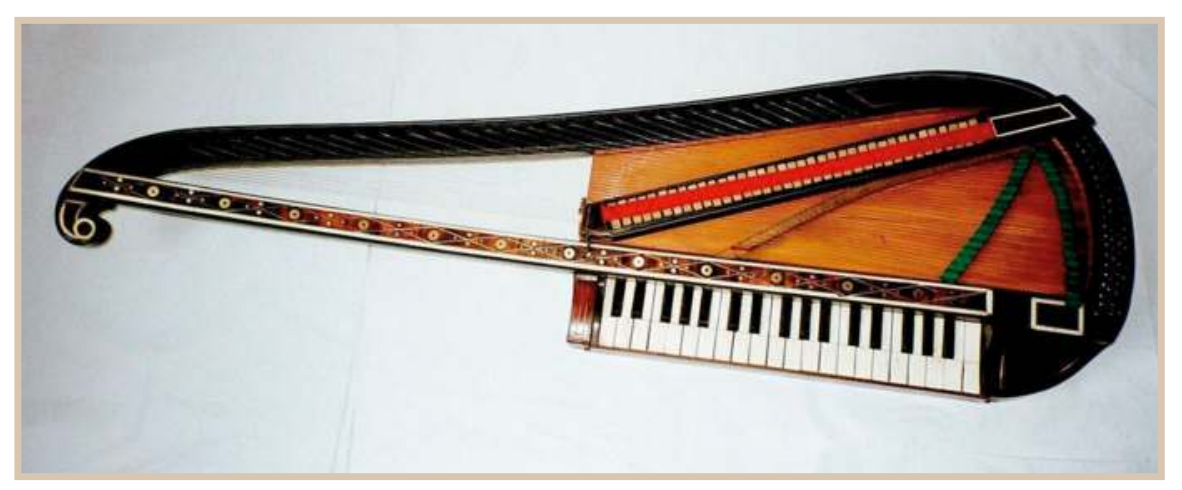

Johann Adam Hiller besorgter Auflage im selben Jahr wie Neefes Bericht erschienen, nimmt deren Beschreibung nicht weniger als 34 Seiten ein. ${ }^{7}$ Daniel Gottlob Türk nennt in seiner 1789 erschienenen Klavierschule ${ }^{8}$, die auch Beethovens Aufmerksamkeit auf sich zog, nicht weniger als 18 Sonderformen von Hammerklavieren?, zu denen wenige Jahre

Orphika mit drei Oktaven Tonumfang, wie in Beethovens Stücken WoO 51 benötigt. Unsigniert. Vermutlich Wien frühes 19. Jahrhundert (Musikinstrumentenmuseum der Universität Leipzig) später noch weitere hinzukamen, darunter die Orphica. Lorenz von Breuning bereicherte - sicherlich im Zusammenwirken mit Beethoven - den Bonner Instrumentenbestand um eine absolute Novität, als er 1798 bei seiner Rückkehr vom Wiener Studienaufenthalt das erst drei Jahre zuvor von Carl Leopold Röllig ${ }^{10}$ erfundene und vom Wiener Klavierbauer Joseph Dohnal in dessen Auftrag gebaute tragbare Hammerklavier (mit einem Tonumfang von maximal drei Oktaven) als Geschenk an seine Schwester Eleonore samt zwei von Beethoven eigens für sie und dieses Instrument komponierte Stücke in C-Dur und F-Dur WoO $51^{11}$ mitbrachte. Das Instrument trug dem damals weitverbreiteten Wunsch Rechnung, in allen Lebenslagen und an jedem Ort musizieren zu können, wie es etwa auch in Stockflöten oder Stockklarinetten zum Ausdruck kommt - Holzblasinstrumente, die auf dem Weg zum Musizieren im Grünen zunächst als Spazierstock dienen konnten.

Freilich konnten sich viele Sonderformen nicht dauerhaft etablieren, für viele hat sich nicht ein einziges Instrument bis auf unsere Tage erhalten. Für unser Verständnis des damals so reichen Musiklebens und des Klangideals, das Beethoven für seine Klaviermusik vorschwebte, ist jedenfalls die grundsätzliche Erkenntnis wichtig, dass eine Monokultur wie etwa der seit 1884 weitgehend unverändert gebaute Flügel von Steinway \& Sons damals undenkbar war. Der Parameter Klang wird heute leider oftmals sträflich unterschätzt. Hammerklaviere erfuhren, so im Falle des produktivsten Produzenten von allen, Thomas Broadwood in London, der Beethoven 1817 ein Instrument schenkte, ungefähr zweimal im Jahr einen "Modellwechsel" mit zumindest kleineren Weiterentwicklungen. Mit dem Aufstieg des Hammerklaviers zu einem ausgereiften und zunehmend individuellen Instrument, das dessen Erbauer zudem klanglich und hinsichtlich der Ausstattung des Möbels in gewissem Umfang an den Kundenwünschen ausrichteten, begann auch der Abstieg des Cembalos und des Clavichords, die aber noch Jahrzehnte weiter gebaut bzw. genutzt wurden. ${ }^{12}$ Die Zeit des Übergangs war experimentell, spannend und für den jungen Beethoven prägend, wie seine Äußerungen zu Hammerklavieren und seine klanglich in bis dahin nicht gekannter Weise ausdifferenzierten

158 | Michael Ladenburger

(C) 2020 by Böhlau Verlag GmbH \& Cie. KG, Köln

https://doi.org/10.7788/9783412519704 | CC BY-NC 4.0 
Kompositionen aus seiner Wiener Zeit zeigen. Im frühen 19. Jahrhundert kam es immer öfter vor, dass sich Kunden bei der Bestellung ihres Hammerflügels den Ton ihrem persönlichen Klangideal entsprechend auswählten. Beethoven suchte in seiner Wiener Zeit immer wieder Klaviere für Bekannte aus, etwa für die Frankfurter Pianistin Dorothea Krug, die sich für ihr Instrument aus der Werkstatt Streicher 1810 den Ton "etwas runder und bedeckter" wünschte. ${ }^{13}$ Anton Georg Graf Apponyi hatte im Folgejahr sogar noch umfangreichere Wünsche, die sich auch auf die Anzahl der Pedale, die möbelmäßige Ausstattung des Gehäuses und den Anschlag bezogen. ${ }^{14}$ Noch

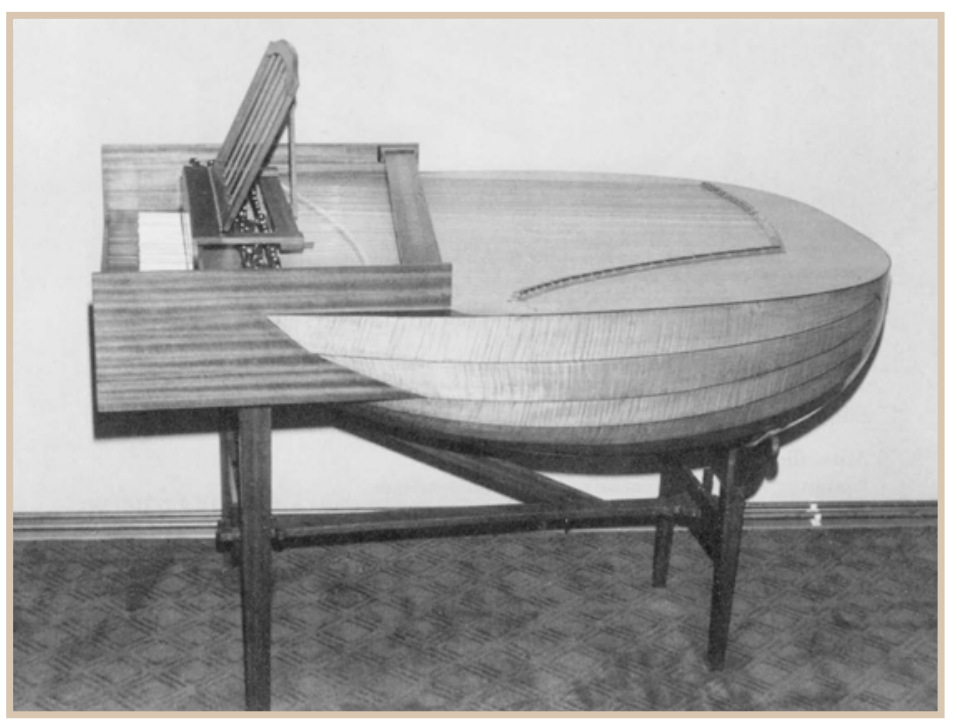
die ein Jahrhundert später erschienene instruktive Ausgabe von Beethovens Klaviersonaten von Hans von Bülow spricht bezeichnenderweise von Klangfarben von Orchesterinstrumenten (wie Flöte u.a.), denen der Pianist nachspüren sollte. Wie wir sehen werden, war dies Pianisten im letzten Drittel des ausgehenden 18. Jahrhunderts ohne Abstriche auch auf Tasteninstrumenten möglich.

Instrumentenbauer ließen sich oftmals in Residenzstädten nieder, waren aber in der Regel keine Angestellten bei Hof, sondern freiberuflich und mit Bürgerrecht tätig. In Bonn ist in den Hofkalendern beim Personal der Bonner Hofkapelle lediglich ein Saitenmacher (für Streichinstrumente) verzeichnet. Klavierbauer gab es damals ungleich mehr als heute, allerdings haben wir mit der einen bereits erwähnten vorübergehenden Ausnahme - Riedler - keine Kenntnis von Bonner Klavierbauern in dieser Zeit. In den Wiener Jahren Beethovens waren es dort mehr als 150. Heute werden in Wien bezeichnenderweise keine Klaviere mehr produziert, dafür gibt es aber Restauratoren für Hammerklaviere.

\section{Ein „Spathsches Clavier" für den Bonner Hof}

Bonn war schon Mitte des 18. Jahrhunderts mit einem interessanten neuartigen Instrument versorgt worden. Der ersten, 1758 erschienenen Auflage von Adlungs Anleitung zur musikalischen Gelahrtheit kann man entnehmen:

„Von Franz Jacob Spath, einem Instrumentmacher aus Regenspurg, wurde 1751 dem Kürfürsten zu Bonn ein Clavier vorgestellt mit 30 Veränderungen, welcher ihn reichlich beschenkte. Nach der Erzehlung der frankfurter Zeitung 1752. im 4ten Stück waren unter solchen Veränderungen forte, piano, pianissime, ein Echo, Harfe, Laute ${ }^{15}$, Pandaleon, und ordentliche Flaute Travers befindlich." 16

Lauten-Clavicymbel von Johann Christoph Fleischer (Hamburg, um 1718, Nachbau von Rudolf Richter, Ludwigsburg 1980) (aus: 300 Jahre Johann Sebastian Bach. Eine Ausstellung der Internationalen Bachakademie in der Staatsgalerie Stuttgart. Katalog, hg. von ULRICH PRINZ unter Mitarbeit von KONRAD KÜSTER, Tutzing 1985) 
Schematische Darstellung einer Cembalo-Kiel-Mechanik, einer Tangentenmechanik eines Klavichords und eines Tangentenflügels sowie einer Hammerflügelmechanik (aUs: JESINE HAASE Und DIETER KRICKEBERG, Tasteninstrumente des Museums, Berlin 1981, S. 59, 95)

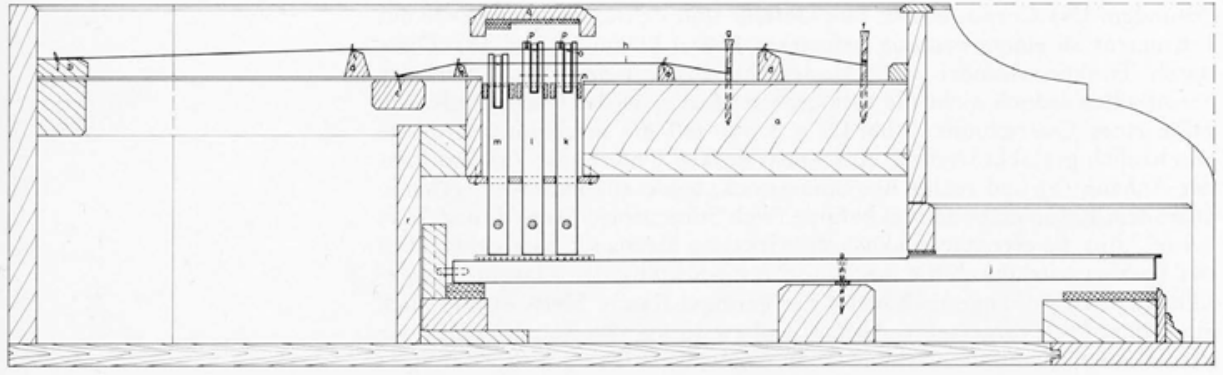

Modell einer Kielklavier-Mechanik am Beispiel des Cembalos von Johann Christoph Fleischer (Schnitt)

a - Stimmstock, b - Achtfuß-Anhang, $c$ - Vierfuß-Anhang, $d$ - Achtfuß-Stege, e - Vierfuß-Stege, $f$ - Achtfuß-Wirbel, g - Vierfuß-Wirbel, h - Achtfuß-Saite, i - Vierfuß-Saite, j - Taste, k - Achtfuß-Springer (nsp[inett] “), I - AchtfußSpringer ( ste, $\mathrm{r}$ - Damm

Die Springer werden auch als „Docken“ bezeichnet.

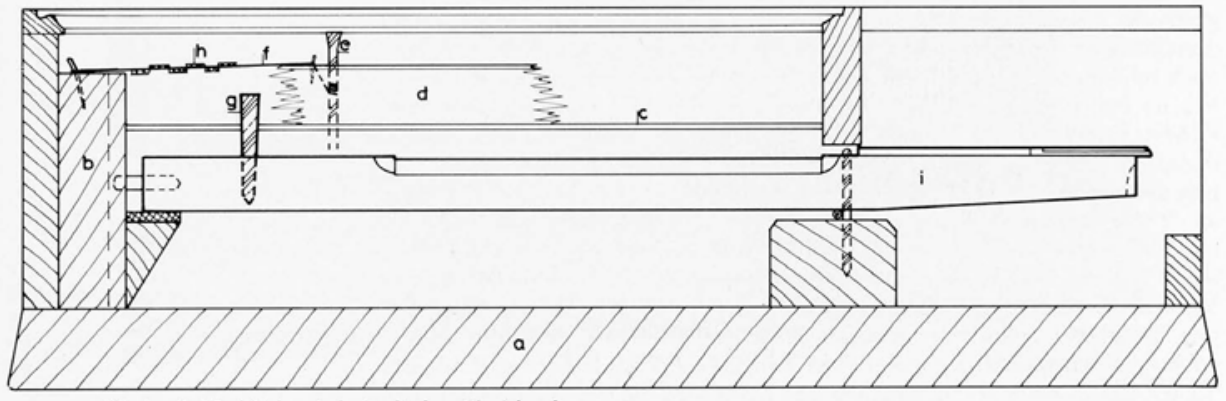

Mechanik-Modell des niederländischen Clavichords

$\mathrm{a}$ - Unterboden, b - Anhang, c - Resonanzboden, $\mathrm{d}$ - Steg, e - Wirbel, $\mathrm{f}$ - Saite, $\mathrm{g}$ - Tangente, $\mathrm{h}$ - Flechtdämpfung, $\mathrm{i}-$ Tastenhebel

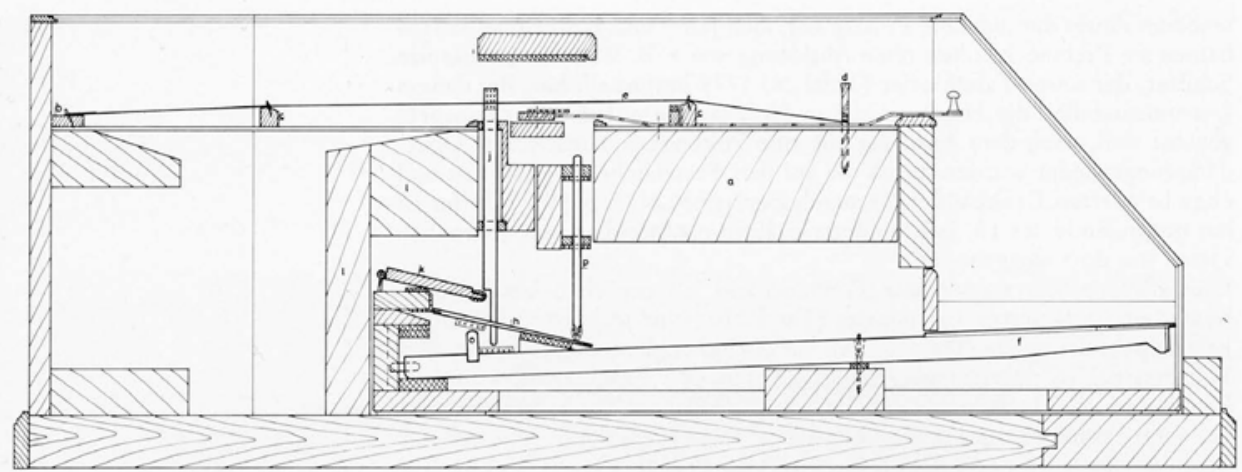

Mechanik-Modell des Tangentenflügels von Späth \& Schmahl

a - Stimmstock, b - Anhang, c - Stege, d - Wirbel, e - Saite, f - Tastenhebel, h - Treiber, j - Dämpfung,

$\mathrm{k}$ - Dämpfungsaufhebung, 1 - Damm, o - starrer Stößer, $\mathrm{p}$ - Tangente

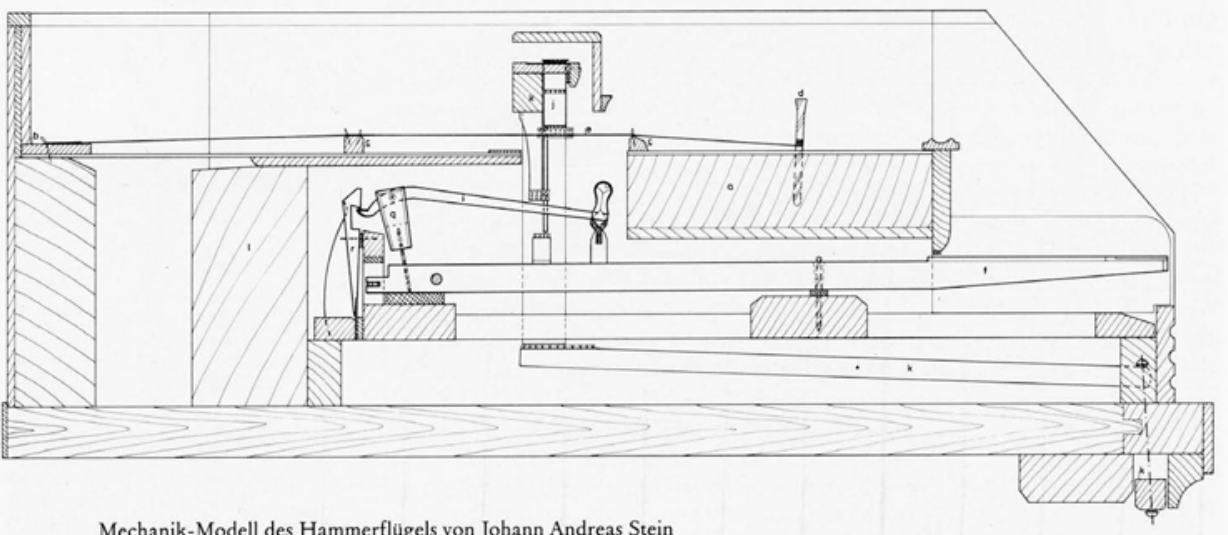

a - Stimmstock, b - Anhang, c - Stege, d - Wirbel, e - Saite, f - Tastenhebel, i - Hammer, j - Dämpfung,

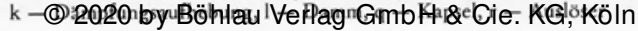

https://doi.org/10.7788/9783412519704 | CC BY-NC 4.0 
In diesem Zusammenhang berichtete Freiherr Friedrich Karl Karg von Bebenburg (1709-1773) an Kurfürst Clemens August (1700-1761), dessen Stimme er seit 1743 beim Immerwährenden Reichstag in Regensburg führte, am 13. September 1751 nach Bonn: "Dasjenige Clavecin, welches Euer Churfürstl: Durchl. während dero lezteren Anwesenheit in München dem hiesigen Clavier- und Orgelmacher Spath zu verfertigen anbefohlen haben, ist nunmehr in vollkommenen Stand."17 "Der Künstler" habe ihm eine allerdings nicht ausreichende Beschreibung übergeben, versichere, dass das Instrument des Kurfürsten "huldreichstes Vergnügen finden" werde und bitte darum, "das gewiß Rare Werk" selbst dem Kurfürsten präsentieren zu dürfen und "alle dabei befindliche Veränderungen genauer zeigen, und jemanden wegen tractirung dieses Instruments recht informiren zu können". Karg von Bebenburg fragt, wann und wo ein solches Treffen zustande kommen könnte. Der Kurfürst antwortete am 27. September aus Schloss Clemenswerth, das Instrument solle schnellstmöglich nach Bonn gebracht und dort einer von ihm benannten Person erläutert werden. Die erwähnte Beschreibung liegt nicht mehr bei. Sie wurde sicherlich dem Pianisten, soweit es sich um einen Hofmusiker handelte, also am ehesten Gilles van den Eeden (1708-1782) übergeben, der als erster Orgellehrer des jungen Beethoven gilt. Das "in der That sehr rare Clavecin" wurde noch im Oktober von Karg von Bebenburg auf den Weg nach Bonn gebracht ${ }^{18}$ und wohl (inklusive Douceur) aus der Privatschatulle des Kurfürsten bezahlt.

Es handelte sich vielleicht schon um ein Clavecin d'amour oder eine Vorstufe dazu, ein Klavier, das - später mit Tangentenmechanik - als Kombinationsinstrument mit Cembalo angeboten wurde. Es war ein von Spath erfundener Zwischenschritt von den Kielen der Cembali bzw. den durch eine denkbar einfache Mechanik gesteuerten Metall-Tangenten des Clavichords zu den Hämmern der Fortepiani: ein Holzstäbchen, die sogenannte Tangente, wird von unten mittels einer bereits aufwändigen Mechanik gegen die Saite geschleudert. Die Erwähnung des Pandaleon deutet aber auf eine einfache Mechanik mit (unbelederten) Hämmern, die der "ordentlichen Flöte" auf ein zusätzliches Orgelregister (eher denn auf ein den Flötenton lediglich imitierendes Saiten-Register) hin. Ferner scheint das Instrument einen Harfen- und Lautenzug, einen (doppelten) Moderator für den piano- bzw. pianissimo-Effekt sowie eine Verschiebung (una corda) und eine Dämpferaufhebung besessen zu haben.

Spath selbst ging in Beethovens Geburtsjahr mit folgender Annonce an die Öffentlichkeit:

"Regensburg.

Um die Bekanntmachung des folgenden Aufsatzes sind wir von da aus gebeten worden. Wir wünschten, und der Leser wird es auch wünschen, daß sich der Verfasser etwas deutlicher auszudrücken gewußt hätte. 
Da es allerdings verdienet, einem geehrten Publico diejenige neuerfundene Tangirung ohne Hämmerund Kiele bekanntzumachen, welche Endesgesetzter bey dem sogenannten Clavecin d'Amour hervorgebracht hat; so wird solches hiermit bewerkstelliget, und versichern wir dadurch nicht allein dieses an sich schon sehr beliebte Instrument nach seiner innerlichen Vortrefflichkeit, Werth und Dauer gar sehr vergrößerten, sondern auch einen geschickten Spieler durch die so verschiedene Trückung theils delicat und zärtlich, theils aber auch penetrant, doch silberhafft ausfallende Töne das vollkommenste Vergnügen und Bewunderung zugehet, wobey noch dieses aus einem Manual mit 8 bis 10 Veränderungen bestehende schöne Instrument vor allen Clavecins und Pantaleons in Betracht des so zärtlichen Tractement um so mehr angenehm sey müsse, als dabey eine gar geringe Unterhaltung des Stimmens erforderlich, folglich der Spieler mit vielen Reize das Glänzende in seiner Gewalt hat. Der Preiß ist 30 bis 40 Ducaten.

Jedoch aber das musikalische Vergnügen vermittelst mehrerer Abwechslung [auf] einen noch höhern Grad der Vollkommenheit zu bringen, verfertiget Endes bemerkter dergleichen Clavecins d'Amour auch mit zwey über einander liegenden Manualen (oder Clavieren), wo nehmlich bey dem untern der beliebte Flügel [Cembalo], bei dem obern aber das sogenannte Clavecin d'Amour, nebst einer ganz natürlichen Flauto traversiere [Tangentenflügel mit einem Orgelregister] auf das schönste angebracht sind. Kenner und welche ihr Vergnügen darinnen suchen, sich auf dergleichen Instrumenten ganz allein zu divertiren, finden bey dieser Invention ihr vollkommene Satisfaction um so mehr, als sie dabey 50 der schönsten Veränderungen vor sich haben, Endes gefertigter aber hoffet auch hierinnen denjenigen Beyfall zu finden, der ihn schon mehrmalen angetrieben hat, auf immer größere Vollkommenheiten seiner so beliebt= als weit und breit verführten Instrumente Bedacht zu nehmen und sich durch jedesmalige prompte Bedienung einem geehrten Publico beliebt zu machen.

Franz Jacob Spath.

Bürger, Orgel und Instrumentmacher

in Regensburg." 19

Beethoven wird 1791 mit der hier beschriebenen Weiterentwicklung des Spathschen Tangentenflügels Bekanntschaft machen.

Welchen Weg das Spathsche Instrument nach dem Tod des Kurfürsten ging, ist nicht zu belegen. Der riesige Nachlass von Clemens August, der selbst Viola da Gamba, Zither (Psalterium) und Cembalo spielte und sich - anders als sein Nachfolger Max Friedrich - mit Musikinstrumenten regelrecht umgeben hatte, wurde bis hin zu den minderen Dingen verzeichnet, da er versteigert werden sollte. Beträchtliche Teile fanden auch in mehreren Auktionen neue Besitzer, aber detailliert-exakte Beschreibungen der Stücke geben die Inventare nicht. Das Inventar "Abgängige Meublen deren Schlößeren Augustusburg Falcken- 
lust zeit dem Jahr 1761" gibt immerhin Hinweise: "Im Schlafzimmer. Nr. 7. Das Clavecin ist dem Leib Medico Wolff vermuthlich extradiret worden."20 Ein weiteres "Clavecin" und ein "Clavir sambt Fuß [Untergestell] und Pult" wurden nach Bonn transportiert, letzteres "vermuthlich verkauft". ${ }^{21}$ Für Schloss Falkenlust ist ein "schwartz Lacquirtes Clavecin sambt Fuß" als abgängig verzeichnet. ${ }^{22}$ Ferner war vorhanden ein „eingelegter Tisch mit verguldeten meßin [Messingbeschlägen] garnirt, worinnen ein Clavier sich befindet, und mit einem BlaßBalch [Blasbalg], der selbst aufgezogen werden kann, versehen ist, hat gekauft gnädige Frau Abtißin von Satzenhoven von Vylich." 23 Es wird sich also um ein Clavierinstrument mit einem zusätzlichen, auf dem Unterboden befestigten Orgelregister gehandelt haben.

Für unser Thema wären diese Angaben eher peripher, wären nicht noch viele weitere Instrumente, darunter auch Harfen und Streichinstrumente inklusive Clemens Augusts eigener Viola da Gamba ebenfalls veräußert worden und zumindest zum Teil noch zur Zeit des jungen Beethoven in dessen Umkreis in Gebrauch gewesen. ${ }^{24}$ Hier seien nur einige wenige einschlägige Instrumente und ihre künftigen Besitzer erwähnt: ein großes und ein kleines Psalterium, also eine Vorform des Hackbretts und der Zither, aus dem sich später das Cembalo und Klavichord entwickelte, „so sich bei der Freyfrau von Daes [wohl die Gattin oder Mutter des kurkölnischen Kämmerers Baron François-Joseph d'Aix], und Ihro geschenkt seyn soll"25, sowie ein Clavier und ein "leyer-Clavier" [wohl eine Leier, also ein gezupftes Saiteninstrument, hier mittels einer Klaviatur zu spielen] gehört haben, das "Herr Euguelman" bzw. „Euguelmar", der Betreiber des Gasthauses Englischer Hof ${ }^{26}$ Friedrich Eigelmayer, und der mit dem Verkauf des Nachlasses befasste Hofkammerrat Johann Baptist Broggia, der einen Steinwurf von Beethovens Geburtshaus wohnte ${ }^{27}$, für 24 Reichstaler 30 Stüber bzw. 2 Reichstaler 30 Stüber erwarben. Im Musikzimmer des Bonner Residenzschlosses war neben einem „blauen Clavier, und Ein der gleichen schwartzes, welche reparirt werden müßen" auch ein "Clavichordium, so der Frantz Toussy [der Cellist der Hofkapelle Franz Tussy] ihm von $\mathrm{S}^{r}$ Churfürstl. D[urch]l[auch]t geschenkt zu seyn angeben, gleichwohlen in der MusicsKammer befindlich ist." ${ }^{\prime 28}$

Mit dem jungen Beethoven in direkter Verbindung steht aber der Verkauf eines (wohl zweimanualigen) Cembalos. In einem weiteren Inventar des Nachlasses von Kurfürst Clemens August, das im Februar 1765 angelegt wurde, sind zwei Cembali verzeichnet und erfreulicherweise zumindest die Gehäuse näher beschrieben: "N. 621 Ein großes Instrument in Form eines steets stücks [Sterzstücks], worauf die Jagd gemahlet, durchaus gefürnist, mit grün angestrichenem, und zum theil verguldetem Fuß sambt dazugehörigen Pulput [Pult], mit 2 verguldeten Leuchter. 300 Rtlr N. 622 Ein dito in Form eines sterts stücks, worauf der grund schwartz, und Blumen gemahlet, mit zugehörigen Fuß, sambt Pulput und Leuchter 200 Rt/r". ${ }^{29}$ Sterzstück bezieht sich auf die 
Form, die einem Fleischstück vom Ende eines Kuh- oder Schweineschwanzes ähnelt. Der Begriff Sterz wurde auch für die geschwungenen Griffe eines Pflugs verwendet. Ruckers etwa setzte der Produktionsnummer auf den Klaviaturrahmen seiner Cembali in Flügelform ein "St" für Staartstuck vor. Es bezeichnet also die große Bauform im Gegensatz zum Virginal, der kleinen Bauform, bei dem die Saiten quer zur Klaviatur verlaufen und dessen Gehäuseform in etwa dem Klavichord bzw. Tafelklavier entspricht. Da Jagd und Musik die großen Leidenschaften des Kurfürsten waren, verwundert die Bemalung des erstgenannten Instrumentes keineswegs. Bemalt wurden damals meist der Gehäuserahmen, die Innenseite des Deckels oder auch der Resonanzboden im Inneren des Instrumentes. Das letztere Instrument hat nun am 15. Mai 1765 Hofrat Emanuel Joseph von Breuning für 153 Reichstaler erworben. ${ }^{30}$ Beethoven, der ab 1782 bei den Breunings ein- und ausging, hat es kennengelernt und darauf vielleicht auch dessen Tochter Eleonore unterrichtet. Es dürfte im Hause Breuning später noch ein zweites Instrument gegeben haben. Einziger Beleg dafür ist das vermutlich auch in dieser Hinsicht getreue Portrait von Eleonore von Breuning, ein repräsentatives, großformatiges Ölgemälde, das sie an einem Hammerklavier oder Klavichord zeigt. ${ }^{31}$ Es dürfte aus der Mitte der 1780er Jahre stammen (Vgl. S. 344).

\section{Die Bonner Hausmusikszene und ihre Interpret(inn)en}

Neben der kurfürstlichen Hofmusik und teilweise mit ihr verzahnt, wies Bonn damals auch eine gehobene und offenbar gut vernetzte hausmusikalische Szene auf. Neefe erwähnt 1783 in seinem Artikel im Magazin der Musik unter den Pianisten die Gräfinnen Belderbusch und Hatzfeld, Frau Hofrätin von Belzer sowie Hauptmann von Schall und Hauptmann d'Antoine. Die Gräfin Belderbusch gehörte übrigens wie Frau von Belzer, Frau von Lützerod und Neefe zu den Subskribenten von Gottlieb Christian Fügers Charakteristischen Klavierstücken, im Eigenverlag 1784 in Tübingen erschienen und später von Neefe rezensiert. ${ }^{32}$ Die Stücke mit Titeln wie Ausgelassenheit, Lebhaftigkeit, Fröhlichkeit, Heiterkeit, Freude und Frohlocken, Schwermuth und Gemütsunruhe weisen auf Beethovens in den 1790er Jahren entstandenes Klavierstück Lustig - traurig C-Dur/c-Moll WoO 54 und den La Malinconia-Satz im Streichquartett B-Dur op. 18 Nr. 6 voraus.

Bei den Subskribentinnen handelt es sich wohl um Anna Maria, geb. von Wambolt, die seit 1781 mit der Erb-Hofmeister und späteren Maire Anton Maria Carl von Belderbusch (1758-1820) verheiratet war. Sie und/oder ihre ältere Schwester Maria Augusta Franziska waren Ende der 1760er Jahre Gesangsschülerinnen von Beethovens Vater. Belderbusch heiratete in zweiter Ehe 1802 Beethovens Jugendfreundin Babette Koch. Anna Maria war also die angeheiratete Nichte des mächtigsten Mannes des Kurstaates, Minister Kaspar Anton von Belderbusch, dessen Erbe ihr dadurch sehr vermögend gewordener 
Mann war. Mit "Hofrätin Belzer" ist wohl Theresia Barbara angesprochen, die Gattin von Jakob Tillmann Peltzer (1738-1798), Onkel der in der Folge erwähnten Geschwister Mastiaux. Peltzer erhielt 1777 die durch den Tod von Emanuel Joseph von Breuning erledigte Hofratsstelle. Er gehörte 1787 zu den Gründungsmitgliedern der Lesegesellschaft, war also Franz Anton Ries, Nikolaus Simrock und Neefe verbunden. Mit "Frau von Lützerod" wird vielleicht die Gattin von Johann Friedrich Freiherr von Lützerath (in den Quellen auch: Lützerode bzw. Lützelrod) gemeint sein. ${ }^{33}$ Hauptmann Schall war Clemens August von Schall zu Bell (1758-1814), der wie sein sich auch als Komponist betätigender Kollege Ferdinand d'Antoine (1746-1793), der mehrfach von Neefe zu Kompositionen angeregt wurde, Mitglied der in Bonn von 1781 bis 1785 bestehenden Loge des Illuminatenordens war, zu dem auch Beethovens Geigenlehrer und Mentor Franz Anton Ries, Nikolaus Simrock und Neefe gehörten. ${ }^{34}$ Die Subskribenten dürften also von letzterem auf die Neuerscheinung aufmerksam gemacht worden sein.

Neefe legte vier Jahre später in derselben Zeitschrift einen neuerlichen Bericht vor, der neben den bereits bekannten auch einige neue Namen unter den Bonner Pianistinnen und Pianisten bietet:

„Bonn, vom 8ten April, 1787 ... Unsre Residenzstadt wird jetzt immer anziehender für Musikliebhaber durch den gnädigsten Vorschub unsres theuersten Churfürsten. Er hat eine große Sammlung von den schönsten Musikalien, und verwendet täglich noch viel auf die Vermehrung derselben. Durch ihn haben wir Gelegenheit, öfters gute Virtuosen auf mancherley Instrumenten zu hören. Gute Sänger kommen selten. Die Musikliebhaberey nimmt unter den Einwohnern sehr zu. Das Clavier wird vorzüglich geliebt; wir haben hi[e]r mehrere steinische Hammerclaviere aus Augsburg [Hammerflügel von Johann Andreas Stein, dem damals führenden Klavierbauer], und andern denen entsprechende Instrumente. Unter den Liebhaberinnen, die ihre schönen Hände mit diesem Instrumente beschäftigen, nenne ich Ihnen die Gräfinnen: Hatzfeld, Belderbusch, Felise Metternich, Frau von Waldenfels, Fräulein v. Weichs, Frau v. Cramer, Frau geheime Räthinn Belzer, Fräulein v. Gruben, Fräulein v. Mastiaux etc. Der junge Hr. Baron v. Gudenau spielt auch brav Clavier, und außer dem jungen Bethoven verdienen noch die Kinder des Capellmeisters ${ }^{35}$ wegen ihres vorzüglichen und so früh entwickelten Talents bemerkt zu werden. Des Hrn. v. Mastiaux Hrn. Söhne spielen sämtlich fertig Clavier, wie sie schon aus ältern Briefen von mir wissen."36

Die Mozart-Verehrerin Gräfin Maria Anna Hortensia von Hatzfeld, Tochter des Grafen Johann Karl von Zierotin aus Wien und seiner Frau, einer geborenen Gräfin von Königsegg-Erps, Nichte des Kurfürsten Maximilian Friedrich, Frau des kurfürstlichen Geheimrats, Hauptmanns der Leibgarde und Generalleutnants Clemens August Johann Nepomuk Graf Hatzfeld (dessen Bruder, der Eichstätter Domherr August Clemens Ludwig Maria, ein Freund Mozarts war), 
CHRISTIAN Gottlob NEEFE, Dilettanterien, [Bonn] 1785 (Archiv des Rhein-SiegKreises)

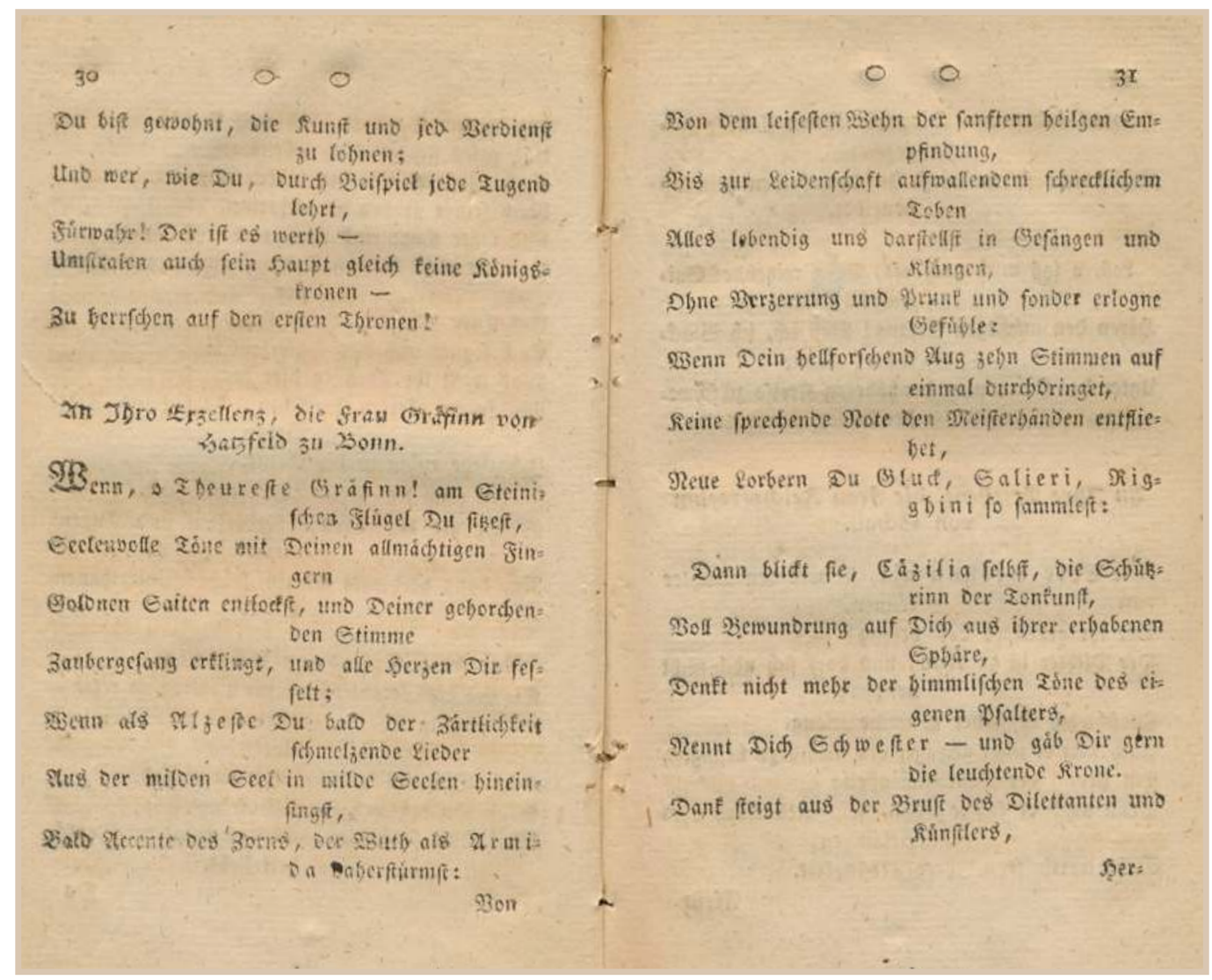

würdigte Neefe mit einem Gedicht in seiner Anthologie Dilettanterien, das wie folgt beginnt:

„Wenn, o Theuerste Gräfinn!, am Steinischen Flügel Du sitzest, Seelenvolle Töne mit Deinen allmächtigen Fingern, Goldnen Saiten entlockst, und Deiner gehorchenden Stimme Zaubergesang erklingt, und alle Herzen Dir fesselt". ${ }^{37}$

Beethoven widmete ihr seine in Bonn entstandenen, 1791 im Druck erschienenen 24 Variationen für Klavier über die Ariette "Venni amore" von Vinzenzo Righini WoO 65, Neefe zwei Jahre später seine bei Simrock erschienenen Variationen über den Priestermarsch aus Mozarts Zauberflöte ${ }^{38}$. Beethovens Wahl der Widmungsträgerin ist nicht - wie sonst so oft - eine späte, vom Werk eigentlich unabhängige Entscheidung, vielmehr, offenbar auf bester Information beruhend, zielsicher getroffen worden: 1782 hatte Maria Anna Hortensia in Wien bei einer Privataufführung im Palais Auersperg die Titelpartie von Righinis Armida gesungen. Ihre ältere Schwester Franziska war seit 1767 mit Maximilian Karl Heinrich Joseph Graf Thurn und Taxis verheiratet und mit dem Klavierbauer Stein persönlich bekannt. Sie machte am 11. Dezember 1788 in Augsburg einen Eintrag in Nannette Steins Stammbuch. ${ }^{39}$ 
Felise Metternich ist Felicitas von WolffMetternich zur Gracht, eine Schülerin Neefes und Widmungsträgerin seines Liedes Klementin. Ihre Mutter Antonie, die spätestens seit 1781 mit Beethovens Vater Johann in persönlichem Kontakt stand, wurde ebenfalls von Neefe bedacht, nicht nur mit einem eigenen Werk, sondern sie wurde auch zur Widmungsträgerin von Beethovens erstem gedruckten Werk auserkoren, den 1782 erschienenen Neun Variationen über einen Marsch von Ernst Christoph Dressler für Klavier WoO 63, womit ihr die Förderung des jungen Komponisten ans Herz gelegt werden sollte. Neefe vermittelte wahrscheinlich die Drucklegung wie auch die Widmung. Vater bzw. Gatte war der Präsident der Hofkammer Johann Ignaz Graf Wolff-Metternich zur Gracht, auf den später im Zusammenhang mit dem Orgelbau in der Schlosskirche nochmals zurückgekommen wird. Im Metternichschen Hof am Vierecksplatz stand laut einem 1790 aufgestellten MobilienVerzeichnis ein Hammerflügel ("Mahag[o]ni Clavicin") und dort und an den weiteren Wohnsitzen mehrere Clavichorde. ${ }^{40}$

Das Netzwerk war auch sonst eng geflochten. Beim Obristjägermeister Clemens August Freiherr von Weichs zu Rösberg, dessen Tochter Caroline (1773-1845) hier wohl angesprochen ist, stand ein Cousin Beethovens aus Ehrenbreitstein in Diensten. Sie heiratete später Friedrich Wilhelm Graf von Bocholtz, während Felicitas von WolffMetternich den Bund der Ehe mit Hermann Werner Freiherr von BocholtzAsseburg einging. Man ist geneigt, bei dem in Zusammenarbeit mit Ferdinand Graf Waldstein entstandenen Ritterballet WoO 1, das ein Kriegs- und ein Jagdlied umfasst und im März 1791 vom Bonner Adel aufgeführt wurde, an bewusste Anspielungen auf Graf Hatzfeld und Freiherr von Weichs zu denken.

Frau von Cramer war die aus einer angesehenen Kölner Juristenfamilie entstammende Josepha Maria Ursula (1751-nach1795), die Schwester von Johann Arnold Heinrich Joseph Cramer von Clauspruch, kurkölnischer präsentierter Assessor beim Reichskammergericht in Wetzlar ${ }^{41}$, seit 1781 verheiratet mit Heinrich Ludwig Karl von Gebler. Zur Familie gehörten mit Friedrich Joseph Anton und Peter Josef Xaver Johannes Nepomuk Cramer v. Clauspruch weitere Mitglieder des Hofes bzw. der Kölner Kurie. Der kurkölnische Geheime Rat

BeEthoven, Neun Variationen über einen Marsch von Ernst Christoph Dressler für Klavier WoO 63, Originalausgabe, Götz, Mannheim 1782 (Beethoven-Haus Bonn) 
und Staatssekretär Constantin von Gruben war Direktor des kurfürstlichen Akademierates. Seine Tochter Walburga war Geigenschülerin von Beethovens Verwandtem Franz Rovantini († 1781) gewesen. Gruben veranstaltete Hauskonzerte, an denen sich nach den Erinnerungen des Bäckermeisters Fischer ${ }^{42}$ neben Rovantini, der um 1780 bei den Beethovens in der Rheingasse wohnte, auch Vater und Sohn Beethoven beteiligten. Der junge Baron von Gudenau dürfte einer der drei Söhne des kurfürstlichen Kämmerers, Geheimen Rats, Oberappellationsgerichts-Präsidenten und Staatsministers Clemens August von der Vorst Freiherr zu Lombeck-Gudenau, Burggraf von Drachenfels († 1817) gewesen sein. ${ }^{43}$

Zu der im Umfeld der Illuminaten in Bonn vom 12. April 1784 bis 4. April 1785 in 52 Heften erschienenen Wochenzeitschrift Beiträge zur Ausbreitung nützlicher Kenntnisse hat Neefe zahlreiche Artikel beigesteuert, gleich der erste "Ueber das Karackteristische oder ueber die Sprache der Instrumentalmusik"144 enthält zwar umfangreiche musikästhetische Erörterungen, es wird mehrfach auf die Bedeutung Joseph Haydns hingewiesen und kurze Erwähnungen von musizierenden Bonner Damen gemacht, doch sucht man Angaben zu Instrumenten oder Instrumentenbauern vergebens. ${ }^{45}$

Am besten informiert sind wir über den für unser Thema besonders wichtigen Hofkammerrat Reichsritter Johann Gottfried von Mastiaux zu Neuenhofen (1726-1790). Er betrieb im vorletzten Dezennium des 18. Jahrhunderts hochstehende Hausmusikpflege, in die auch seine fünf Kinder, ab 1764 im ZweiJahres-Rhythmus geboren, voll einbezogen waren. Während der Vater Horn, Klarinette und Flöte spielte, waren die Söhne Streicher (Kaspar Anton spielte zusätzlich auch Klavier) und das jüngste Kind, die ein halbes Jahr vor ihrem späteren Klavierlehrer Beethoven geborene Amalia, Pianistin. ${ }^{46}$ Sie war eine Freundin von Eleonore von Breuning und Babette Koch, denen auch Beethoven sehr nahestand. In dieser Besetzung war problemlos ein Großteil der Musikliteratur aufführbar, die ja damals überwiegend aus Kammermusikwerken oder Orchesterwerken in kammermusikalischen Übertragungen bestand. In Mastiaux' Haus gab es im Winter jede Woche ein jedermann zugängliches Konzert. Max Franz war öfters zu Gast und daher über Amalias Begabung gut im Bilde. Ferdinand Goebel, der Sohn von Mastiaux' engem Freund und Kollegen, dem gleichfalls musikbegeisterten kurfürstlichen Kellner (Rentmeister), Hofrat und Bürgermeister von Rheinberg, Franz Goebel (1722-1808), er hatte den Vornamen seines Onkels Dr. Ferdinand Dejean erhalten, von dem später noch die Rede sein wird, ging während seines Bonner Jura-Studiums (1786/87 und 1788/89) im Hause Mastiaux ein und aus und beteiligte sich an der dortigen Hausmusik auf Horn, Geige und Bratsche sowie Gesang. Er gehörte zum Kreis um Babette Koch, was durch einen Briefwechsel und Einträge der drei Goebel-Kinder in Babettes Stammbuch dokumentiert ist. Er war also gewiss auch Beethoven persönlich bekannt. Sein Hauptinstrument war die Geige. Sein 
Vater soll mehrere Klaviere besessen haben. ${ }^{47}$ Ferdinand musste seinen Eltern, die sich Sorgen um seinen Studienfortschritt machten, regelmäßig berichten. ${ }^{48}$ Er beruhigte sie mit der Bemerkung, auch der Kurfürst hätte gegen das Musizieren nichts einzuwenden, „im gegentheil so lang es nit übertrieben wird hat er so was gern, besonders Music". ${ }^{49}$ Dank dieser Quelle wissen wir, dass ein Kreis von jungen Leuten im Sommer jeweils donnerstags bei schönem Wetter manchmal schon um 4 Uhr, meistens aber um 5 Uhr morgens in die "Baumschul" (das damals bewirtschaftete "Lusthäuschen", das heute als kurfürstliches Gärtnerhäuschen bezeichnet wird) ging, um vier Stunden Musik zu machen. Kurfürst Max Franz kam teilweise 3 bis 4 Mal pro Tag dorthin. Einmal sprach der sichtlich vergnügt zu einem Menuett tanzende Max Franz Amalia an:

"nur schade, daß es so viele mühe kostet einen Flügel mit zu bringen, sonst müßten wir ihre Kunst izst auch hören. Als wir darauf ein lustiges Rondo machten fing er an zu springen, und wollte absolut nit haben, daß der Fr[äulein] Mastiaux aufstehen sollte als er mit sie sprach." ${ }^{\prime 50}$

Die Baumschul war auch bei Beethoven ein beliebter Ort, wie wir aus der Bemerkung Franz Gerhard Wegelers in seinem Brief an Beethoven vom 28. Dezember 1825 schließen können: "die Steine von Bonn, Creuzberg, Godesburg, die Baumschul etc etc haben für dich Haken, an welche du manche Idee froh anknüpfen kannst" ${ }^{\prime \prime 1}$. Bei den Mastiauxschen Hauskonzerten war gelegentlich neben dem Kurfürsten, der sich dort so wohl fühlte, dass er das Haus nach Mastiaux' Tod erwarb, auch musikalische Prominenz zu Gast. Johann Peter Salomon, ehemals Mentor des ganz jungen Franz Anton Ries, war dort anlässlich eines Heimatbesuchs im November 1779 sogar täglich präsent gewesen. Ein Hauskonzert mit seiner Beteiligung wurde mit einer Sinfonie von Haydn beschlossen. Da Mastiaux in Briefkontakt mit Joseph Haydn gestanden haben soll, könnte die Verbindung Salomon - Haydn eventuell auch von Mastiaux mitvorbereitet worden sein. Die beiden frühen Haydn-Biographen Georg August Griesinger und Albert Christoph Dies ${ }^{52}$ berichten nichts Originäres zur Vorgeschichte von dessen London-Aufenthalt. ${ }^{53}$

Nur ein gutes halbes Jahr nach Franz Anton Ries' Rückkehr von einem halbjährigen Sonderurlaub in Wien, der Vorbild für Beethovens ersten WienAufenthalt 1787 gewesen sein dürfte, wird Ries erwähnt: „Der junge Mirman"54 habe bei ihm "ein Concert erbärmlich gekratzt und schier keinen einzigen Ton rein" gespielt, woraufhin man seine Tochter Amalia "ein Concert aufm Clavier spielen" lassen habe. "darauf spielte mein Anton [sein 1766 geborener Sohn] ein Duetto mit H[errn] Ries auf der Violine: und zwar so schön, daß sich alles verwunderte. Mirman legte hierauf seine Violine in den Kasten, und wollte den ganzen abend keine note mehr spielen. Von der stunde an nimmt er Lection bey $H[e r r n]$ Ries, welcher ihm auf seine Fragen, geantwortet daß er gegen meinen Anton nichts wisse, und auch schwerlich selben erreichen werde", da er durch schlechte Lehrer falsche Angewohnheiten habe, schreibt Mastiaux. ${ }^{55}$ 


\section{Die Instrumentensammlung Mastiaux}

Neben einer beeindruckenden Musikaliensammlung, die unter anderem nicht weniger als 80 Sinfonien von Joseph Haydn und 50 Klavierkonzerte verschiedener Meister umfasst haben soll, dürfte auf den jungen Beethoven vor allem Mastiaux' Sammlung historischer Instrumente Eindruck hinterlassen und Anregung gegeben haben. Neefe listet im Magazin der Musik von 1783 auf:

„Ein Flügel von Andreas Rückers, dem ältern, de Ao. 1646.

Ein grosser Flügel, von Joh. Rückers, de Ao. 1659.

Ein Flügel, von Johann Cauchet, de Ao. 1659.

Ein Flügel von eben diesem Meister de Ao. 1661.

Ein grosser Flügel, von Joh. Peter Cauchet, de Ao. 1664.

Ein Clavichord, von Friderici.

Ein grosses piramidenförmiges Hammerclavier, von Mechanicus Riedeln,

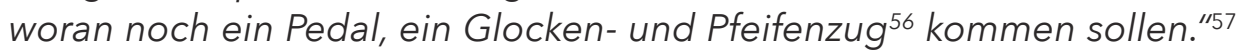

Hinzu kommen Streichinstrumente mit klangvollen Namen wie die zwischen 1662 und 1693 datierten Cremoneser Geigen (und eine Bratsche) von Girolamo (Hieronymus), Antonio und Nicolo Amati, Antonio Stradivari, Andrea Guarneri sowie des damals besten Geigenbauers im deutschsprachigen Raum, Jacob Stainer in Absam/Tirol, letztere, „wenn sie nicht ächt sein sollte, doch den wenigen ächten, die Stainer gemacht, doch nichts nachgiebt." ${ }^{\prime 58}$ Stainer baute Instrumente von 1644 bis um 1680. Hinzu kommt eine 1670 in Rom von einem "Nicola **" erbaute Geige. Mit Schreiben vom 3. Mai 1783 bot Mastiaux Franz Goebel das Instrument zum Tausch an. Seine Beschreibung ist insofern sehr aufschlussreich, als Mastiaux den Charakter des Instrumentes zu vermitteln sucht: "[sie scheine ihm] eine uralte Romanische Violin zu seyn in der Tiefe viel starker als die ihrige, voll von Ton, und recht gut für in Sinfonien, dan der Ton ist durchdringend, wenn sie recht angegriffen wird" ${ }^{59}$. Zugleich unterschied er sie von einer speziell für Kammermusik geeigneten Geige, die Goebel zu ihm zur Reparatur durch einen Aachener Geigenmacher geschickt hatte. Diese sei "besonders scho[e]n und für Solo, auch Trio und Quartetten", sie sei nun "schöner und heller als vorher", auch durch Löcher im Steg. Es dürften keine schweren Saiten aufgezogen werden.

Neefes Auflistung ist noch nicht einmal komplett. Mastiaux, dessen Hauptinstrument das Horn war, berichtete Goebel am 12. Juli 1784: „Kunsthorn mit allen Tönen habe ich neue auf dem Wege." Es handelte sich also um Instrumente mit Inventionsbögen, die das Spiel in anderen Tonarten als F ermöglichten.

Die hohe Qualität von Mastiaux' Instrumentensammlung geht auch aus dem Brief an Goebel vom 26. Februar 1780 hervor. Er habe eine sehr teure Violine von einem "vortrefflichen Violinisten" erworben, er selber habe aber "noch wenigsten 4 bis 6 andere, die noch weit besser seien". 
392

bamuen genstbigt warb, als ifs bas 2 tutfpeyen uิberfiel.

Unter ber פonenge feinet gefammleten פDuficalien,

balt er folgenbe für oie betrádtlidffen:

80 Einfonien, von Jofeph కaiben,

30 Cuatuor, unb

40 Crio, von ebenbemfelbent. Unb t̂́bet

so Clavierconcerte, von, ben beffen Alutoten.

Unter bet zableteiden Gamutumg feiner Jiffint:

mente, seiduen fí auts:

¿Ein Slůgel, von 2tnoreas shúctcrs, bent attern, de Ao. 1646 .

Ein grofier Slâgel, von Job. Rúaters, de Ao. 1659.

Ein Slúgel, von Jobann Couchet, de Ao. 1659.

Ein Slügel yon eben biefem \$Reifter, de A0.s66r.

Ein grofier Stuggel, vou Job. Peter Coudet, de Ao. 1664.

Ein Clavidorb, vou Sriberici.

Ein grofies piramibenfórmiges bammerclavier,

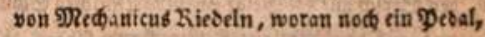
ein Gloden , unb Yुfeifenjug fommen follen.

Ein Contrabâ, you Paut 2flet [ihe 1726 .

Ein Dioloncell, you cben biefem פReifter 1739.
Eine \&dote 2fltviola, von ben Gebriberu 2tuton bieron. 2(mati, Eremona 1662.

Eine åd)te đeige, yon 2(nton 2(mati , Eremona 1673.

Eine \&dte Geige, you tricol. 2(mati, Sobne bed fieren. Itmati, Eremona 1682.

Zine ådbte Geige, von 21nton Gradivari, Eret mona 1670.

Line von 2tnor. Evarnieri, Eremona 1693.

Eine von LTicola * * 9ioma 1670 .

Inater mebrern eine yon Jacob Gtainer, Die, weun fie aud nidt dibt feyn follte, teu romig didten, bie Etainer gemadt, bod niфts nadgiebt.

In bem Saufe bes Şerrn Şoffatmmerrath) 20Ite ftsoten, tanu man juweilen sin red! guteb Quartett bostut.

Şert Şauptmann Dantcine, ein teiben fhaftliळet Derebrer unb Senuer ber Zonfanft ; fpielt Eeige unb etwas Elavier. Die Sunft bes Sab̨es bat er aub SNarpurg, Sirnberger unb פitepel crlernt. Seinen

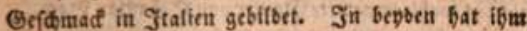
and bas ?efen ber yुartituren, von clasiffen Coms poutiften treffic genáżt. Eomponitt bat er:

a) Il mogdo al rovefcio, o fia, le donse cho consmandano. Opera buffa.

2365

Bei den aufgelisteten „Flügeln" sind Cembali aus den Werkstätten der führenden, von Hans Ruckers begründeten flämischen Cembalobauer-Dynastie in Antwerpen angesprochen, und zwar von der zweiten und dritten Generation, nämlich Andreas Ruckers I. (1579-ca. 1651/53) und Andreas Ruckers II. (16071654 oder 1655). Johannes Couchet (1615-1655) war der Neffe von Johannes Ruckers (1578-1642), dem älteren Bruder von Andreas I. Er arbeitete in der Werkstatt seines Onkels Johannes mit, der keine Söhne hatte. Johann Couchets vier Söhne wiederum wurden allesamt Cembalobauer, darunter auch Petrus Johannes. Die von Neefe angegebenen Baujahre der Instrumente lassen sich nicht immer mit den Lebensdaten ihrer Erbauer in Übereinstimmung bringen. (Weil auch Instrumente von Couchet betroffen sind, ist dies nicht unbedingt ein Hinweis auf Fälschungen, die es auch auf diesem Gebiet gab. Der aus der Nähe von Lüttich stammende, in Paris tätige durchaus renommierte Cembalobauer Pascal Taskin baute im 18. Jahrhundert Ruckers-Instrumente um, gelegentlich aber auch komplett neue zweimanualige Instrumente, die er als Umbauten mit Erweiterung des Tonumfangs [ravalément] von RuckersInstrumenten ausgab, da für sie ein weit höherer Preis zu erzielen war. ${ }^{60}$ ) 


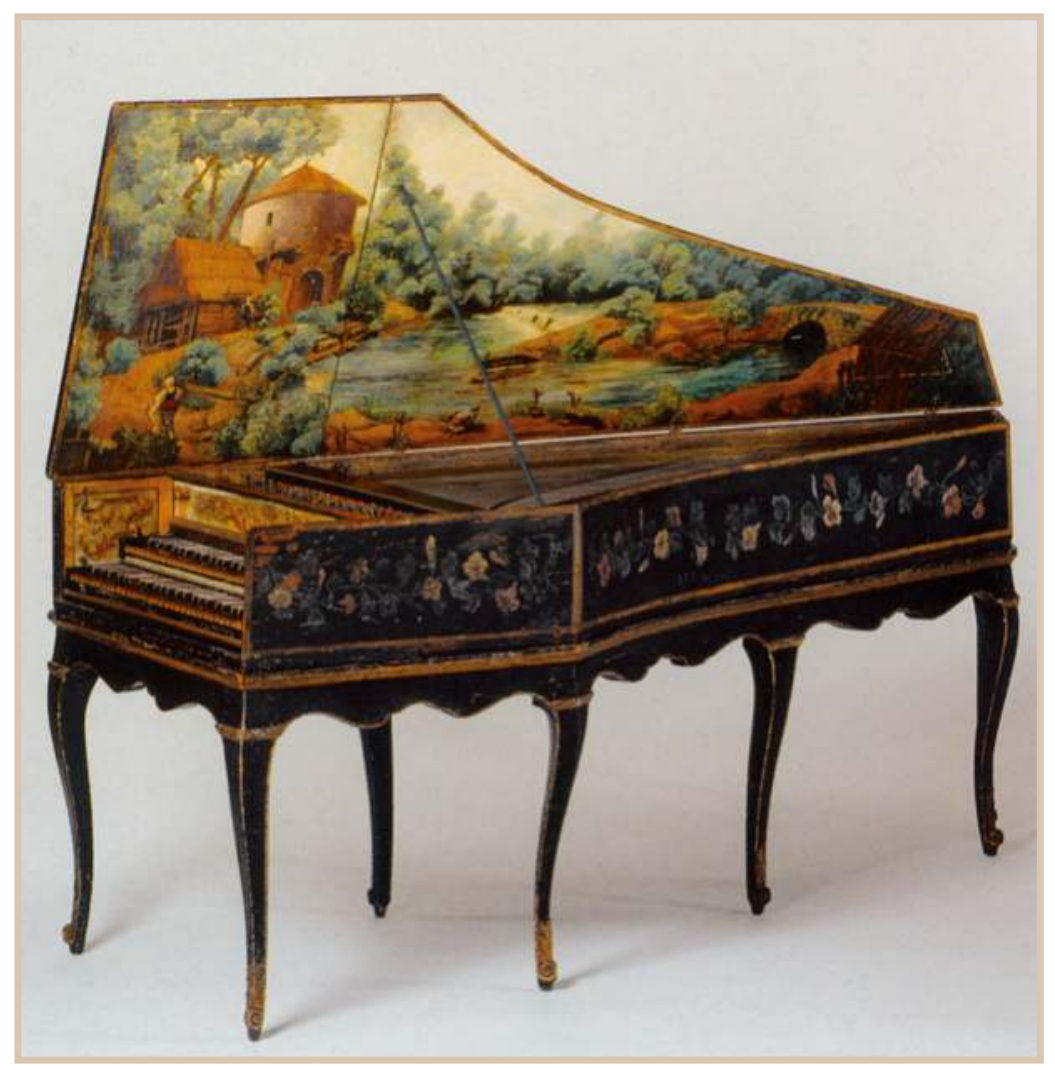

"Große Flügel" meinen zweimanualige Instrumente. Ob diese schon zweimanualig erbaut oder wie so oft erst im 18. Jahrhundert erweitert wurden, wissen wir natürlich nicht, auch nicht ob bei den Instrumenten später der Tastenumfang vergrößert wurde. Jedenfalls wies die Sammlung Mastiaux eine ganze Reihe hochkarätiger Cembali auf, die zum Besten gehören, was der Instrumentenbau insgesamt je zustande gebracht hat.

Grant O'Brien verzeichnet in seinem Ruckers-Werkkatalog zwei Instrumente von 1646 (Antwerpen, Vleeshuis Museum 76.4, 1646a AR und Paris, Musée de la musique, Cité de la Musique, E 979.2.1., 1646b AR), kann aber für die anderen keine Vergleichsinstrumente aus demselben Baujahr nachweisen. ${ }^{61}$

Da Mastiaux' Instrumente nicht erhalten bzw. identifiziert und deren Vorbesitzer nicht bekannt sind, lässt sich über die Ausstattung der Gehäuse nichts

Andreas Ruckers I., Cembalo, Antwerpen 1628 (Sammlung Beurmann, Museum für Kunst und Gewerbe Hamburg). Die Gehäusefassung entspricht ungefähr jener des von

Hofrat Breuning aus dem Nachlass von Kurfürst Clemens August erworbenen Instruments sagen. Vielleicht boten sie dem jungen Beethoven auch kunsthistorische Entdeckungen. Um 1612 wurden Ruckers-Cembali von Peter Paul Rubens, der seine Werkstatt in nächster Nähe zu Ruckers hatte, und Jan Breughel bemalt. Die Beziehungen der führenden Antwerpener Cembalobauer und Maler waren damals eng, sie gehörten derselben St. Lukas-Gilde an. Anna, Tochter von Andreas I. Ruckers, heiratete den bekanntesten Stillleben-MalerAntwerpens, Johann Davidszoon de Heem, ihre Mutter war mit Jacob Jordaens, dem führenden Antwerpener Maler nach Rubens' Tod († 1640), verwandt.62

Das Clavichord stammte aus der Werkstatt der Geraer Orgel-und Klavierbauer Christian Ernst und Gottfried Christian Friederici (1709-1780 bzw. 1714-1777), einer der innovativsten deutschen Werkstätten des 18. Jahrhunderts, deren Instrumente von Carl Philipp Emanuel Bach favorisiert wurden. Christian Ernst hatte bei zwei der bedeutendsten mitteldeutschen Orgelbauer - Gottfried Silbermann, der auch an der Weiterentwicklung des Hammerklaviers maßgeblich beteiligt war, und Heinrich Gottfried Trost - das Orgelbauer-Handwerk erlernt, wandte sich aber bald schon auch dem Klavierbau zu. Bereits 1745 entstanden seine ersten aufrechtstehenden Klaviere mit Stoßzungenmechanik (die Hämmer im Diskant mit Elfenbein verstärkt), die er "Pyramide" nannte. Clavicytherien, i.e. aufrechtstehende Cembali, gab es schon ab dem letzten

172 | Michael Ladenburger

(c) 2020 by Böhlau Verlag GmbH \& Cie. KG, Köln

https://doi.org/10.7788/9783412519704 | CC BY-NC 4.0 
Drittel des 15. Jahrhunderts. ${ }^{63}$ Sie blieben aber die Ausnahme. Carl Philipp Emanuel Bach, Leopold Mozart und Goethes Vater waren Friedericis prominenteste Kunden. Er begründete damit eine Bauform, die besonders im 1. Drittel des 19. Jahrhunderts in Blüte stand.

Das Clavichord spielte für den jungen Beethoven eine zentrale Rolle. Es war sicherlich sein Hauptinstrument. Die Möglichkeit eines Tastenvibratos ("Bebung”) - die Tangente wird durch Reduktion und Steigerung des Tastendrucks geringfügig bewegt wie das ein Streicher mit dem Finger auf der Saite tut - war in Zeiten der Empfindsamkeit und einer blühenden Hausmusikpflege hochgeschätzt. ${ }^{64}$ Es gab sogar Versuche, diesen Effekt auf dem Cembalo möglich zu

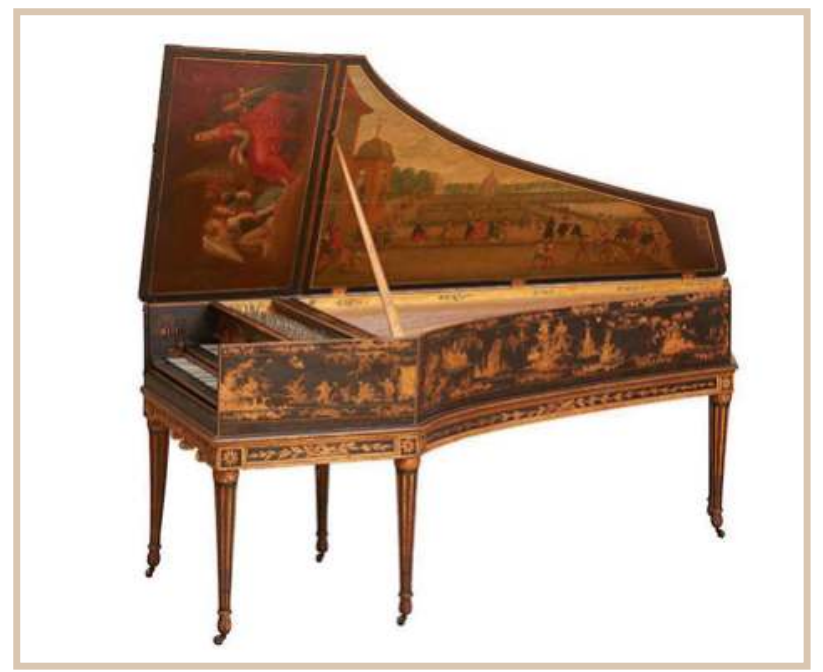
machen. Nicht zufällig wurde das Clavichord damals meist mit dem quasi umfassenden Begriff "Clavier" bezeichnet. Beethoven spielte auf den Bebungs-Effekt, den kein anderes Tasteninstrument ermöglicht, noch in seinen zwischen 1808 und 1821 komponierten Sonaten für Klavier und Violoncello op. 69 bzw. für Klavier solo opp. 106 und 110 an, obwohl die Mechanik der damals gebräuchlichen (und allein schon wegen des Tonumfangs unverzichtbaren) Hammerklaviere nur eine sehr vage Annäherung erlaubte. Die parallele Nutzung von Clavichord, Cembalo und frühem Hammerklavier (sowie Orgel) generell, nicht zuletzt aber durch den jungen Beethoven, und die schrittweise Ablösung des Cembalos findet ihren unüberhörbaren Niederschlag in dessen frühester Klaviermusik. So erlangt die Klaviersonate WoO 47 Nr. 2 (1783) gespielt auf einem möglicherweise in Italien gefertigten anonymen Hammerflügel Wiener Bauart von ca. 1785-90 von Olga Pashchenko65, die wie Beethoven Cembalistin, Organistin und Fortepianistin ist und geschult in der historisch informierten Aufführungspraxis, dank stilistisch passender Artikulation, Arpeggierung etc. eine bislang ungekannte Blüte. Die Musik lebt. Ihre Rhetorik überwältigt, die kompositorische Substanz (üblicherweise beurteilt nach Kriterien des 19. und 20. Jahrhunderts) verliert ihre vermeintlich zentrale Bedeutung. Erstere kommt auf einem zeitgenössischen Instrument (womit hier die Jahre von ca. 1770 bis ca. 1800 angesprochen sind) wegen des andersartigen Klangbildes - vergleichsweise dünne Saiten und der bei diesem Instrument sehr dünne Resonanzboden bewirken einen schlanken und außergewöhnlich obertonreichen Klang - ganz anders zum Tragen als auf einem Hammerflügel des 1. Drittels des 19. Jahrhunderts oder gar einem modernen Instrument. Ferner wird einem deutlich vor Augen geführt, wie eng Instrumentarium und Spieltechnik zusammengehören und weshalb moderne Instrumente - nicht zuletzt auch wegen der Unkenntnis der Interpreten in Hinblick auf historische Fingersätze und Artikulationen - für die Interpretation solcher auf

„Andreas Ruckers Antverpiae 1636" signiertes, aber 1787 von Pascal Taskin erbautes Instrument (Sammlung Beurmann, Museum für Kunst und Gewerbe Hamburg) 


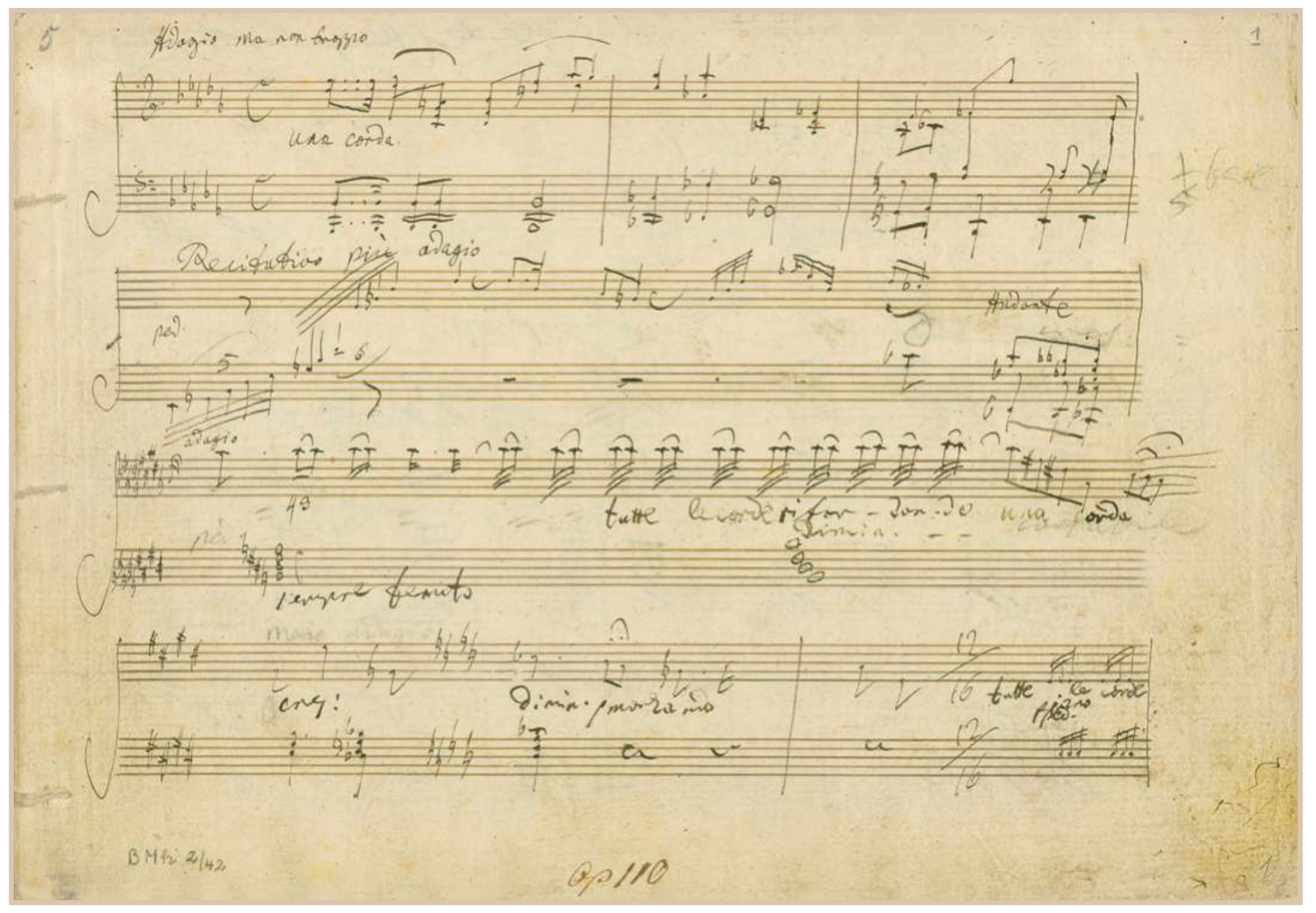

Fingersatz $43 \mathrm{im}$ Autograph von Beethovens Klaviersonate As-Dur op. 110, 3.

Satz, 5. Notenzeile

(Beethoven-Haus Bonn, Sammlung H. C. Bodmer)
Rhetorik ausgerichteter und von klanglicher Variabilität lebender Werke gänzlich ungeeignet sind. Das auf solche Weise und auf einem Instrument der Entstehungszeit gespielte Werk tritt dann und nur dann den Beweis an, dass der 12-jährige Beethoven nicht lediglich eine frühe, gefällige Kostprobe seines Talentes vorlegte, sondern schon hier in der Einheit von Komponist und Interpret die Grenzen des Zeitstils zu weiten suchte.

\section{Musikinstrumentenhandel in Bonn}

Neefe handelte mit Friederici-Instrumenten. Ob verwandtschaftliche Beziehungen dabei eine Rolle gespielt haben, ist nicht zu klären. ${ }^{66}$ Er verfügte über Beziehungen in die Region. Friederici war im $40 \mathrm{~km}$ westlich von Neefes Geburtsort Chemnitz gelegenen Meerane zur Welt gekommen. Neefes Frau Susanna Maria Zinck wurde 1751 in Warza bei Gotha geboren. Sie war ebenso wie die 1761 in Gotha geborene Christina Sophia Henriette Hartmann Schauspielerin und Sängerin in der Seylerschen Schauspieler-Gesellschaft, deren

174 | Michael Ladenburger

(C) 2020 by Böhlau Verlag GmbH \& Cie. KG, Köln https://doi.org/10.7788/9783412519704 | CC BY-NC 4.0 
musikalischer Leiter Neefe von 1776 bis 1779 war. (Da man den bereits erwähnten Marsch von Ernst Christoph Dressler, über den Beethoven sein erstes gedrucktes Werk schrieb, bisher nicht nachweisen kann, ist es denkbar, dass Neefe nicht nur Druck und Widmung organisierte, sondern Beethoven auch das Thema vorgab. Dressler, Sänger und Geiger, wirkte von 1764 bis 1767 am Hof in Gotha und mag daher mit Neefes späterer Frau und Friederici bekannt gewesen sein. ${ }^{67}$ ) Christina Sophia Henriette Hartmann wurde 1779 Mitglied der Bonner Hofschauspielergesellschaft unter ihrem Schwager Großmann und heiratete 1780 Neefes Kollegen Christoph Brandt, den besten Geiger der Hofkapelle nach Franz Anton Ries. Sie stand dann von 1789 bis 1793 auf der Bühne des Bonner Nationaltheaters, war damals also Kollegin des jungen Beethoven. Ihre 1792 geborene Tochter Caroline wurde 1817 die Frau Carl Maria von Webers, mit dem Beethoven im Oktober 1823 in Baden zusammenkam und ihm wegen seiner überwältigenden Herzlichkeit und Zuvorkommenheit einen denkwürdigen Tag bescherte. Möglicherweise spielten da Bonner Reminiszenzen eine Rolle.

Neefe musizierte beim Dienst in der Oper auf einem Cembalo. Laut Inventar des Residenzschlosses von 1784 stand im "Komoedien Hauß auf dem Theatro Ein Clavier in Form eines Sterzstück".68

Auch Nikolaus Simrock handelte - vermutlich seit ca. 1790 - mit Instrumenten und weiterem Zubehör, jedenfalls trat er ab diesem Zeitpunkt mit Inseraten auf diesem Gebiet in Erscheinung. Er tat dies also erst, nachdem der eine Zeitlang in Bonn arbeitende Riedler die Stadt bereits wieder verlassen hatte, aber vor dem Weggang von Beethoven - in bester Geschäftslage am Markt Nr. $173^{69}$ (heute: Markt 35, seit etlichen Jahren Löwen-Apotheke). Im Bönnischen Intelligenzblatt vom 13. und 27. Juli 1790 - der Zeitpunkt ist möglicherweise bewusst gewählt, weil Bonn vor der Anfang Oktober erfolgten Krönung Kaiser Leopolds II. in Frankfurt ${ }^{70}$ stärker frequentiert war - schaltet der Hofmusikus Simrock ein Inserat, mit dem er bewirbt,

"folgende Waaren in der besten Qualität und gegen die billigsten Preise immer vorräthig zu haben". Darunter zählen "Stimmsteller, Stimmgabeln, Stimmhammer, Drathrollen für Claviere [Saiten], Alte und neue musicalische Instrumente, verschiedene Sorten von Clavieren etc.".

Am 24. Mai 1791 annonciert er "die mehrsten Sorten musikalischer Instrumenten". Simrock war 1775 nach Bonn gekommen, um als Waldhornist in der Hofkapelle zu dienen, ab 1784 bekam er eine Sonderdotation für das Besorgen von Musikalien für den Hof. Er stammte aus Mainz, das in seinen Jugendjahren ein Zentrum der Tafelklavier-Produktion war. ${ }^{71}$ Natürlich gab es bei Instrumenten auch Privatverkäufe, wie ein Inserat im Intelligenzblatt vom 1. November 1785 belegt: "Ein schönes, wohl conditionirtes Clavier steht zu verkaufen. Nähere Nachricht ist in hiesiger kurfl. HofBuchdruckerei zu haben." Vermutlich handelte es sich um ein Clavichord. Direkt anschließend bot Simrock zwei Klavierkonzerte 
von Leopold Anton Kozeluch an. Der Instrumentenhandel war für ihn ein logischer nächster Zwischenschritt, ehe er 1793 vom Musikalienhändler zum Musikverleger aufstieg. In seinem Verlagskatalog von 1824 weist er im Vorwort darauf hin, dass er unter anderem ein umfassendes Sortiment an Instrumenten biete, darunter „Pianofortes, Flügel, aufrechtstehende und tafelförmige, von den besten Meistern in Wien, London und andernwärts verfertigt". Er handelte damals mit Flügeln von zwei führenden Klavierbauern: Nannette Streicher in Wien und Thomas Broadwood in London. Zu ersterer hatte Beethoven enge persönliche Beziehungen, für letztere nutzte er alte Bonner Verbindungen. Von seinem langjährigen Weggefährten Franz Anton Ries (1755-1846) war ein Sohn, Joseph Franz (1791-1861), seit 1819 Klavierbauer in Wien, der andere, Peter Joseph (1791-1882), von seinem älteren Bruder Ferdinand vermittelt seit 1822 beim produktivsten Klavierbauer der Zeit, Broadwood in London, für die Abwicklung von Bestellungen aus dem Ausland zuständig.

\section{Gottlieb Friedrich Riedlers „Pyramide”}

Neefes Bericht von 1783 enthält auch als einziger substanzielle Angaben zum "Mechanicus Riedlen". Das in der Sammlung Mastiaux befindliche pyramidenförmige Instrument hat eine besondere Entstehungsgeschichte mit möglicherweise offenem Ausgang. Mastiaux berichtete Franz Goebel in kurzen Abständen und ausführlich über das Projekt, das er als seine "Caprice" bezeichnet.

Im Briefwechsel Mastiaux - Goebel ${ }^{72}$ ist aus pragmatischen Gründen meist von Streichinstrumenten die Rede. Mastiaux organisierte für Goebel die Reparatur von dessen Streichinstrumenten durch einen Aachener Geigenmacher. Dieser kam immer wieder nach Bonn - und blieb einmal acht Tage vor Ort -, um größere Reparaturen an Streichinstrumenten vorzunehmen und Bögen mit neuem Bezug (Pferdehaaren) zu versehen. Nur einmal erwähnt Mastiaux ein Tasteninstrument, wenn er Goebel rät, das seine zu verkaufen und auch eine Pyramide (von Riedler) zu erwerben. Der erhaltene Briefwechsel erstreckt sich über den Zeitraum Dezember 1778 bis April 1790, wobei die Jahre 1781, 1788 und 1789 komplett fehlen und nur die Jahre 1782 und 1783 durch eine hohe Frequenz sehr gut dokumentiert sind. Das sind allerdings die beiden ersten Jahre, in denen Riedler in Bonn tätig war. Auch wenn sein Name (wie übrigens auch der des Aachener Geigenmachers) nirgends genannt wird, ist aufgrund von Neefes Bericht klar, dass es sich beim Erbauer des Tasteninstrumentes um Riedler gehandelt haben muss. Dieses Instrument wird erfreulicherweise von Mastiaux recht ausführlich geschildert. Es belegt, dass Kombinationsinstrumente zur Zeit des jungen Beethoven hoch im Kurs standen, man mit Leidenschaft ans Werk ging und Mastiaux das Risiko des Experiments keineswegs scheute, sondern sich regelrecht in dieses hineinstürzte. Wie die Geschichte ausging, ist nicht überliefert. Aus 1784 sind nur zwei Briefe auf uns gekommen, aus den beiden Folgejahren nur jeweils einer. 
Mastiaux erwähnte das Kombinationsinstrument in Pyramidenform mit Glocken und Flöten erstmals in seinem Schreiben an Goebel vom 22. November 1782. Spätestens da muss also Riedler in Bonn sesshaft gewesen sein. "ich lasse mir ein Clavier von Glocken machen”. Die Glocken würden gegossen und mit Stimmstahl gestimmt. Er bittet um alle in Rheinberg verfügbaren 13 "Stimmstähle", die Goebels Schwager, der Chirurg Dr. Ferdinand Dejean, mitbringen solle.

Ferdinand Dejean, am 9. Oktober 1731 in Bonn als Sohn des kurfürstlichen Mundschenks Anton Dejean geboren, war unter anderem als Schiffsarzt extrem weit gereist und als Stadtchirurg des Malaria-geplagten Batavia (Hauptquartier der Niederländischen Ostindien-Kompagnie und Hauptstadt von Niederländisch-Indien, heute Jakarta/Indonesien) bereits in jungen Jahren zu einem großen Vermögen gekommen. Er ging in die Musikgeschichte ein, weil er im Dezember 1777 - aus Bonn kommend - in Mannheim persönlich etliche Werke für Flöte bei Wolfgang Amadeus Mozart bestellte (KV 285, 285b, 313 und 314). Im Mai 1787 besuchte Dejean, der 1784 zu seiner Schwester nach Rheinberg gezogen war, sein Patenkind Ferdinand Goebel in Bonn und kam auch mit Mastiaux zusammen. Er zeigte sich in einem Brief an seinen Schwager vom in Bonn herrschenden Geist der Aufklärung, der ihn selbst in besonderem Maße bewegte, begeistert:

"Obschon ich meine Vatter stadt stiller, trauriger als gewöhnlich antraff, so mus ich doch auch zugleich gestehen, das[s] das, was sie im fröhlichen scheint verlohren zu haben, reichlich sich im soliden und mehr aufgeklärthen Geistesumständen ersezt mit vorkömt. ... Unter vielen Lands Kinder welche ich für dero jahren sehr aufgeklärth finde, ist vorzüglich der älteste Herr von Mastiaux schest[?]en [schätzen?] zu halten, unglaublich und unaussprechlich seyn deßen Verdienste. Auch Zeigen [= zeichnen] sich in eben dießem Fach beßonders aus die Liebe, artige, sehr geschickte und gelehrte Fraulein Von Mastiaux; glücklich, ja tausend mahl glücklich der Vatter einer solcher Famille". ${ }^{73}$

Bei den Angesprochenen handelt es sich also wohl um den damals 22-jährigen Max und seine 17-jährige Schwester Amalia.

Dejean besorgte, nachdem Mastiaux am 29. November bzw. 6. Dezember 1782 den Eingang der Stimmstähle bestätigt und die Bestellung aufgegeben hatte, schließlich 18 Pfund "ungearbeitetes [unbearbeitetes] unvermischtes japanisches rothes Kupfer und 6 Pfund Malaka Zinn", also Zinn aus Malakka (im Süden Malaysias an der gleichnamigen Wasserstraße gelegen), das in der nötigen Qualität weder in Bonn, noch Köln und Frankfurt/Main aufzutreiben gewesen war. Es kam schließlich aus Amsterdam, wo Dejean 1768 vorübergehend gelebt hatte. Am 3. Dezember lässt Mastiaux Goebel wissen, dass es einen Gießer gebe. Der scheint allerdings hinsichtlich solcherart Glocken über keine Erfahrung verfügt zu haben: „dieses muß ich selbst, und der Mechanicus wel- 
cher das Clavier macht, und die Klocken auf der Drechselbank stimmt, am besten wissen." Am 17. Dezember bestätigte Mastiaux, dass das Kupfer und Zinn aus Amsterdam eingetroffen seien.

"es giebt ein en Piramide aufrechtstehendes Hammer Clavier das saiten spiel soll eben fertig, und stärker seyn als dero großer Flügel; es soll sich leichter spielen [lassen] als dero kleines Hammerstück. In den Clavier Kasten kömmt ein tiefes Pedal, und ein gantzes Register Klocken; den Fuß machet ein S[c]h[r]ank aus, worin ein Register Flöten kömmt. die säiten machen auch nebst dem hellen Ton einer Fagotte, und einer Laute nach. Die Invention ist neu, welchen ein Mechanicus so von Berlin und Petersburg hiehin bringt. Alles läuft zu ihm dieses Clavier zu sehen und zu hören, ich bekomme es in 2 Tagen namlich das saiten spiel erst nach Haus, und demnächst giebt er sich ans Klockengießen. Ich hoffe alles wird gut reussiren. Völlig wird es aber in 2 Monathen noch nicht fertig. ich harre raptim".

Am 20. Dezember 1782 vermeldete er schließlich:

"gestern habe ich das saiten spiel, einer Hammerstück [also ein Klavier mit einer Hammermechanik statt einer Tangentenmechanik oder gar Kielen], erhalten. Wenn Ew.HWohlgeb: gelegentlich hoffen das ihrige [Klavier] wieder los zu werden riethe ich darzu, und statt dessen sich dieser eines anzuschaffen. Dan [= denn] auch ohne die Klocken und pfeiffen ist es schon eine ganz andere arth; und von einem ganz neu erfundenen Mechanism[u]s; und von ganz andern Ton. Und erfodert nur die halbsche Raumplatz in einem Zimmer dan es steht aufrecht wir ein Hohes und schmales Sriban [= Schreibsekretär]. Ich riethe hierauf bedacht zu seyn, und wenn die Klöckelger gut gerathen kann man deren auch allzeit drein machen."

Auf letztere musste er allerdings bis zum 31. Januar 1783 warten.

"Heut habe ich die erste probe von 2 klöckelger das hohe $E$, und das A erhalten. Zukünftige Woche erhalte ich deren mehr. Alsdan geht es ans stimmen." Wenn Mastiaux einen Mechanikus in Berlin und St. Petersburg erwähnt, so dürfte damit der Hofrat Carl Ludwig Bauer (um 1730-1798) in Berlin angesprochen sein, derFlötenuhren (ein mechanisches Musikinstrument mitOrgelpfeifen) an König Friedrich II. für Schloss Sanssouci (1769) und an Zarin Katharina II. in St. Petersburg (1784) lieferte. ${ }^{74}$ Der hatte um 1776 ein Crescendo genanntes Hammerklavier in Pyramidenform erfunden, $3 \mathrm{~m}$ hoch, $1 \mathrm{~m}$ breit, $1 / 2 \mathrm{~m}$ tief, mit Metallsaiten, 5 Oktaven und 3 Pedalzügen, die den nahtlosen Übergang vom pp zum ff ermöglichten. Es bot 8 Veränderungen und eine Transponiervorrichtung mittels Verschiebung der Klaviatur. Besonders bemerkenswert ist der Zusatz: "man rühmte ihm ein ausgezeichnetes Stimmunghalten nach". ${ }^{75}$ Bauers Royal crescendo, ein Tafelklavier mit Orgelregister ähnlich den Clavecins royales, stammt bereits aus dem Jahr 1768, hatte 4 1/2 Oktaven, 6 Pedale (Veränderungen) und 1 Flötenregister. ${ }^{76}$ 
Wie Neefes nachfolgende Beschreibung unter 6) nahelegt, scheint Riedler hieran angeknüpft zu haben. Es liegt also nahe zu vermuten, dass Riedler auf Wanderschaft gegangen war und entweder zeitweise bei Bauer gearbeitet oder zumindest dessen Instrumente gekannt hat.

Was das Glockenregister anlangt, bezog sich Riedler möglicherweise zusätzlich auf Carillons, die der Holländer Amries Weltman in Paris in Cembali und Hammerklaviere einbaute, nach dem Design von Du Moutier (1758). Glockenspiele gab es auch in Orgeln, zum Beispiel in der berühmten Orgel von Joseph Gabler im Kloster Weingarten (1737-1750). Riedlers Instrument hatte ferner einen Fagott- und Lautenzug.

Später bat Mastiaux Goebel, ihm einen „blechenen Leuchter für aufs Clavier nach den ihrigen"77 anfertigen zu lassen, nach dessen Muster er anschließend in Bonn einen zweiten machen lassen könne.

\section{Zum Repertoire der Hausmusik}

Exkurs: Übrigens sind wir durch den Briefwechsel auch über das hausmusikalische Repertoire in Ansätzen unterrichtet. Mastiaux versorgte Goebel mit Notenmaterial, das heißt er ließ bei Interesse in Bonn Abschriften erstellen (möglicherweise auch bei Beethovens Kapellkollegen Johann Baptist Paraquin). Konkret genannt sind: im ersten Brief (vom 8. Dezember 1778) "6 Trios von Schröter, diese sind überaus schön" sowie "Concerte von Reichard". Aufgrund des Datums handelt es sich wohl um Cembalokonzerte von Johann Friedrich Reichardt, vermutlich das 1773 bei Hartknoch in Riga erschienene B-Dur- bzw. das g-Moll-Konzert oder - wegen Verlag und Besetzung noch wahrscheinlicher - das 1777 bei Schwickert in Leipzig erschienene Konzert in g-Moll (mit 2 Flöten im Orchester). ${ }^{78}$ Eher nicht in Frage kommen Cellokonzerte von Joseph Reicha, damals Cellist der mit der Bonner Hofkapelle in Verbindung stehenden Oettingen-Wallersteinschen Hofkapelle. Er wurde selbst in seiner Zeit als Bonner Konzertdirektor in den Hofakten manchmal als Reichard geführt. Mastiaux erwähnt ferner „etliche schöne Claviersachen [für] M[admoise]lle" (Schreiben vom 5. Februar 1779), angesprochen ist wohl Goebels Tochter Lise (geb. 1764) oder Marianne (geb. 1769), "3tens ich hatte mir schon die Sonate für 2 Claviere hier aus Simrocks Verlag ${ }^{79}$ in ein Buch abschreiben lassen. Sie hätten die Sonaten für 4 Hände auch behalten sollen" (vielleicht eine Abschrift der erst 1783 bei Andre in Offenbach erschienenen vierhändigen Sonate mit Violine und Violoncello aus op. VII von Johann Georg Lang), er schickt "bald neue Trio für Klavier Violin und Bass von Vanhall" (beides im Schreiben vom 18. Oktober 1782), ein weiteres Klaviertrio von Johann Baptist Vanhal (Schreiben vom 23. Dezember 1783), "schöne neue aber schwere Sonaten, mit einer beschwerlichen Violine, aber ohne Bass" (Schreiben vom 30. Dezember 1783), Quartette für Klavier, Flöte, Violine und Viola von Johann Georg Lang (wohl sein bei Andre in Offenbach und in 
Koblenz im Selbstverlag erschienenes op. $11{ }^{80}$ (Schreiben vom 26. Februar 1784). Von Lang verlegte Boßler in Speyer im selben Jahr drei Klaviertrios. Der ebenfalls aus Böhmen stammende, seit 1780 in Wien tätige Vanhal, der als erster freischaffender Komponist gilt, war ein viel gespielter Komponist. Lang war als Konzertmeister des Trierer Kurfürsten, der in Ehrenbreitstein residierte, in mehrfacher Hinsicht „naheliegend”. Er war für seine Klavierkonzerte geschätzt. Der bereits 1699 geborene Christoph Gottfried Schroeter fällt altersmäßig fast etwas aus dem Rahmen. Simrock annoncierte als Musikalienhändler sechs Klaviertrios opp. 8 und 9 (wohl die 1787 bei Schott in Mainz erschienenen Ausgaben). Schroeter ist insofern zusätzlich erwähnenswert, als 1763 im 3. Band von Lorenz Christoph Mizlers Musikalischer Bibliothek eine Abhandlung aus seiner Feder über das "neue" Hammerklavier erschien. Mizler war Schüler Johann Sebastian Bachs gewesen.

Kommen wir zu Neefes Bericht von 1783 zurück. Nach der Schilderung des 12-jährigen Hoffnungsträgers Ludwig van Beethoven fährt er über Riedler fort: "Noch muß ich eines geschickten Mechanicus Riedlen erwähnen, den wir ohnlängst erst hieher bekommen. Er heißt Gottlieb Friederich Riedlen, zu Tutlingen im Würtembergischen 1749 gebohren. Er verfertigt alle Gattungen von Clavierinstrumenten, als

Bekielte Flügel, nach der gewöhnlichen Art.

Flügel mit stählernen Federn, anstatt der Rabenfedern, und nach einer noch unbekannten Einrichtung.

Besonders gute Instrumente mit neuerfundnen Hämmern, von denen sich der Spieler alle Zufriedenheit erwarten darf.

Instrumente nach einer neuen Erfindung mit Federn und Hämmern zugleich. Instrumente mit Darmsaiten, auf denen man die Wirkung von 2 Violinen, Viole, Violoncell, Contrabaß und Flöte hervor bringen kann und zwar mit aller Gemächlichkeit.

Hat er ein Mittel erfunden, die meisten Clavierinstrumente unverstimmbar zu machen, obwohl die Witterung sehr auf die Saiten wirkt.

Ein Instrument, auf welchem alles, was der Spieler spielt, in währendem Spielen durch einen besondern Mechanismus in Noten abgedruckt wird.

Beyläufig gedenk ich noch seiner Geschicklichkeit, in der Verfertigung verschiedner physicalischer Instrumente, und in der Wissenschaft von der Electricität." ${ }^{\prime \prime 1}$

Neefe nennt hier eine ganze Reihe von Instrumententypen, von denen aber nur eines "gewöhnlich" ist. Die anderen sind eben erst erfundene Klavierinstrumente.

Unter 1) sind normale einmanualige Cembali angesprochen.

2) meint Cembali mit Kielen, die aus Stahl statt wie üblich aus Vogelfedern gefertigt sind. Sie ergeben dementsprechend einen härteren, präsenteren Klang. Das andersartige Material ist natürlich nicht nur vorteilhaft, sondern 
auch mit Nachteilen verbunden, weshalb sich diese Modifikation nicht durchgesetzt hat, zumal die Cembaloproduktion ohnehin stark im Abnehmen begriffen war.

3) Um welche Abwandlung der Prell- oder Stoßzungenmechanik oder der Hammerköpfe es sich handelt, lässt sich aus der knappen Beschreibung nicht ableiten. Es ist die Zeit des Übergangs von unbelederten Hammerköpfen (also aus blankem Holz, diesbezüglich ähnlich den Tangenten, wie sie der in den 1760 er Jahren aufgekommene Tangentenflügel aufwies) zu belederten. ${ }^{82}$ Es geht also um den Klangeffekt, den der Einsatz des Moderators - durch den ein Filzstreifen zwischen Tangente (resp. Hammer) und Saite geschoben wird beim frühen Tangenten- resp. Hammerflügel ermöglicht.

4) Neefe spricht hier ein Kombinationsinstrument Cembalo - Hammerflügel an, wie es sich der aus Wallonien stammende, seit 1760 in London ansässige Jean-Joseph (auch John Joseph) Merlin 1774 patentieren ließ.83 Kombinationsinstrumente wurden damals auch in Italien und Spanien gebaut. ${ }^{84} \mathrm{Sie}$ waren im Grundsatz keine Novität. Claviorgana, die Spinett und Orgel (bzw. beide ergänzend zusätzlich ein Regal [Zungenstimme]) kombinieren, gab es schon seit der Mitte des 15. Jahrhunderts. Im Claviorganum von Joshua Pock (Innsbruck 1591, heute: DomQuartier Salzburg) sind alle drei Instrumente vereinigt. Alle drei Instrumente waren jedes für sich längst etabliert. Neu bei der Kombination Cembalo/Hammerklavier ist, dass das letztere eben erst erfunden worden war und das erstere später ablöste. Mindestens ein Exemplar eines Vis-à-vis-Kombinationsinstruments, von Jean Marius gebaut, gab es bereits $1716 .{ }^{85}$

Die Kombinationsinstrumente des 18. Jahrhunderts sorgten für eine fließende Ablösung des Cembalos durch das Hammerklavier. Man wusste die Vorzüge eines absolut ausgereiften Cembalos noch länger zu schätzen, lechzte gleichzeitig aber nach den neuen klanglichen und spieltechnischen Möglichkeiten des Hammerklaviers. So neigte sich mit dem stilistischen Wandel in der Musik der 2. Hälfte des 18. Jahrhunderts, mit der die Optimierung des Hammerklaviers untrennbar einherging, die Waage zunehmend und schließlich endgültig zugunsten des Hammerklaviers, das man damals nicht grundlos Fortepiano nannte. Selbst bei der Orgel wurden damals Versuche unternommen, über den Anschlag ansatzweise eine größere dynamische Flexibilität zu ermöglichen $^{86}$, also lange vor der Erfindung des Registerschwellers der romantischen Orgel der Mitte des 19. Jahrhunderts.

Kombinationsinstrumente Cembalo - Hammerklavier hatte wenige Jahre zuvor auch der bereits erwähnte, in Bonn sehr geschätzte Augsburger Klavierund Orgelbauer Johann Andreas Stein (1728-1792) gefertigt. ${ }^{87}$ Er baute sie ab 1769 als sogenanntes Poli-Tono-Clavichordium, später als Vis-à-vis-Instrumente. Letztere sind auf zwei Spieler ausgerichtet. Auf einer Seite gibt es drei Klaviaturen, zwei für Cembalo (8' oberes Manual; 16', 2x 8' - einer mit Lauten- 
Claviorganum von Joshua Pock, Innsbruck 1591 (aus: ALFONS HUBER [Hg.], Das österreichische Cembalo. $600 \mathrm{Jahr}$ Cembalobau in Österreich, Tutzing 2001)

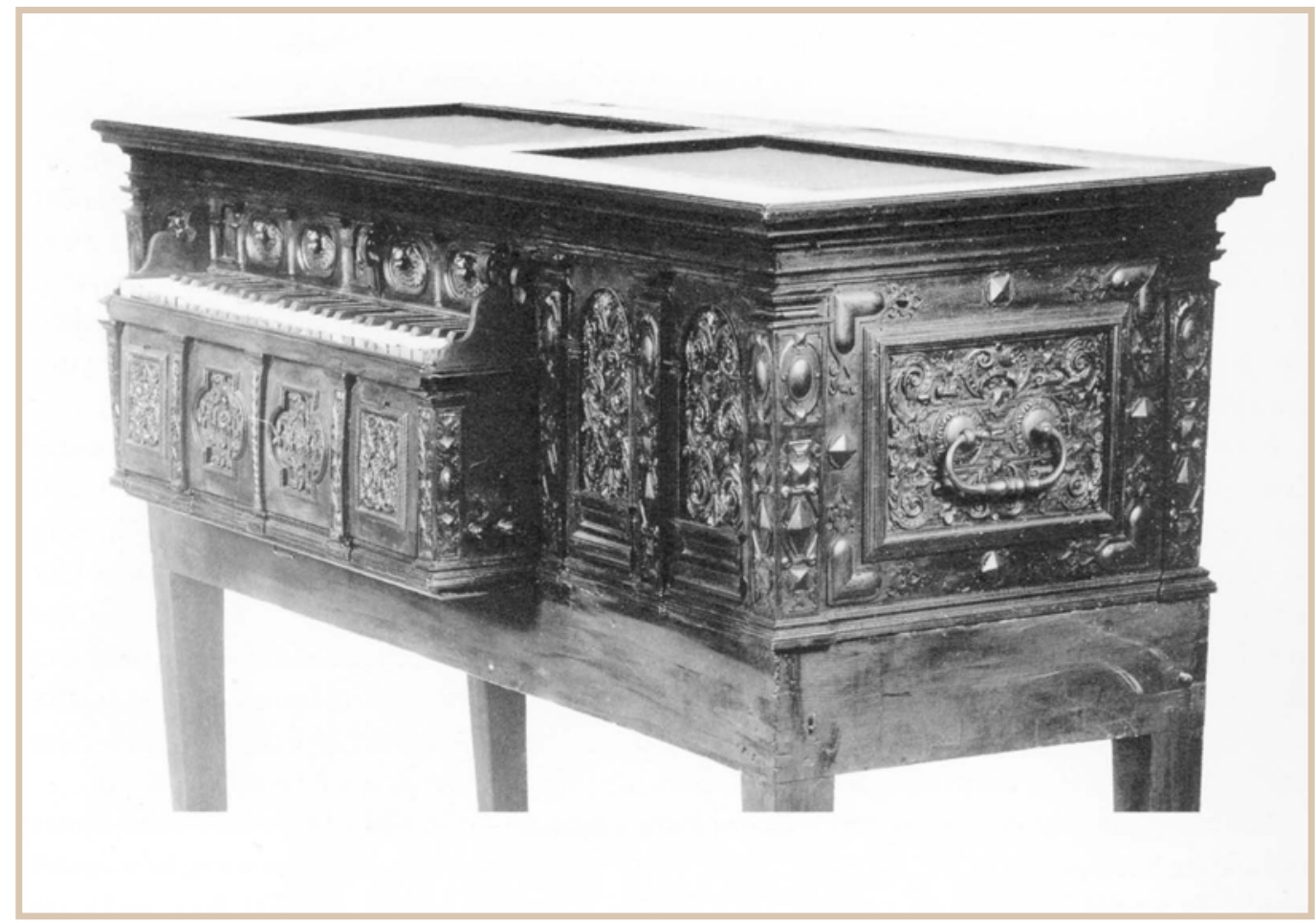

zug - und repetierender 4'/8' mittleres Manual), auf dem untersten Manual können alle vier Cembaloregister und das Hammerklavier kombiniert werden. Auf der gegenüberliegenden Seite gibt es eine Klaviatur für das Hammerklavier. Die Mechanik für das Hammerklavier, das also von beiden Seiten gespielt werden kann, ist auf der Unterseite des Instruments durch eine aus dem Orgelbau entlehnte, hier sternförmig verlaufende Draht-Abstrakten-Mechanik miteinander verbunden. Zwei dieser Instrumente haben sich erhalten: in der Academia filarmonica/Museo di Castelvecchio in Verona (1777) und im Conservatorio di Musica S. Pietro a Majella, Neapel (1783). ${ }^{88}$ Dieses Kombinationsinstrument belegt zugleich den Übergang vom einen zum anderen Instrumententyp - im Großen wie im Kleinen. Die Hammerköpfe, die auf die Saiten treffen, sind noch unbeledert, also aus blankem Holz. In der Folge ist der Klang zwischen beiden Teilinstrumenten sich ähnlicher, etwa was das Obertonspektrum anlangt, als wenn die Hämmer beledert wären, wie es bald darauf ausnahmslos üblich wurde. Freilich ist das Cembalo an seinem brillanteren, silbernen Klang heraushörbar.

Im Jahr von Beethovens Weggang nach Wien, 1792, ließ sich James Davis in London seine diesbezügliche Erfindung patentieren. ${ }^{89}$ Matthäus Müller in Wien baute später ebenfalls Vis-à-vis-Instrumente, allerdings nur als Hammerklaviere. Solche Instrumente ermöglichten die heute weitgehend vergessene Kunst des gemeinsamen Improvisierens.

182 | Michael Ladenburger

(C) 2020 by Böhlau Verlag GmbH \& Cie. KG, Köln

https://doi.org/10.7788/9783412519704 | CC BY-NC 4.0 
4 und 7) Ein Neefes Beschreibung entsprechendes Instrument, das Cembalo und Hammerflügel vereinigt, hat sich in der Musikinstrumentensammlung des Deutschen Museums, München erhalten. ${ }^{90}$ Es handelt sich um ein Cembalo mit Hammerflügel-Register und Notenschreibeinrichtung von Jean-Joseph (auch John Joseph) Merlin, London 1780 (Datierung auf dem Vorsatzbrett); das Hammerklavier bzw. Cembalo ist mit Zügen zu- bzw. abschaltbar.

Das Patent, das die Kombination beider Instrumententypen, nicht aber die Notenschreibvorrichtung betrifft, hat sich in den National Archives ${ }^{91}$ erhalten. Riedler bezog sich also dop-

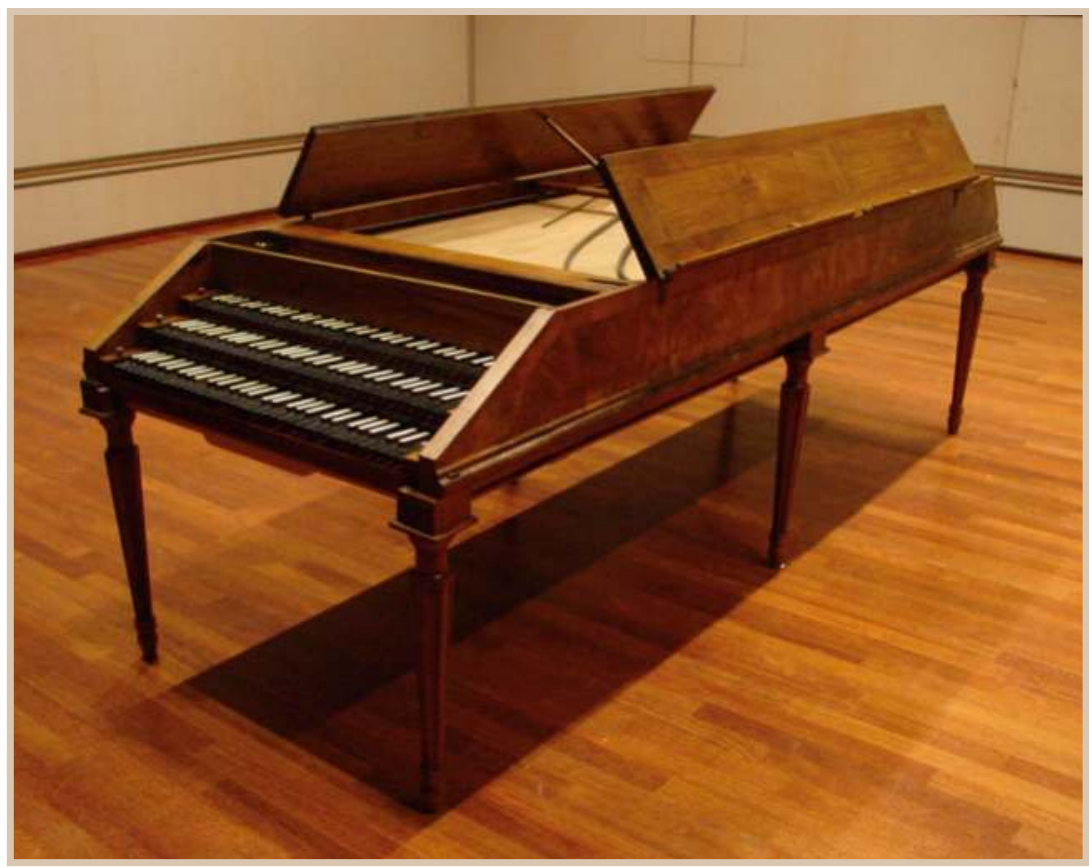
pelt auf ein solches Instrument, denn unter 7) beschreibt Neefe ein Instrument mit Notenschreibeinrichtung. Oberhalb der Saiten wird mittels eines Uhrwerks eine Notenpapier-Rolle vorbeigezogen, die fast über die ganze Saitenlänge reicht. Jeder Taste zugeord-

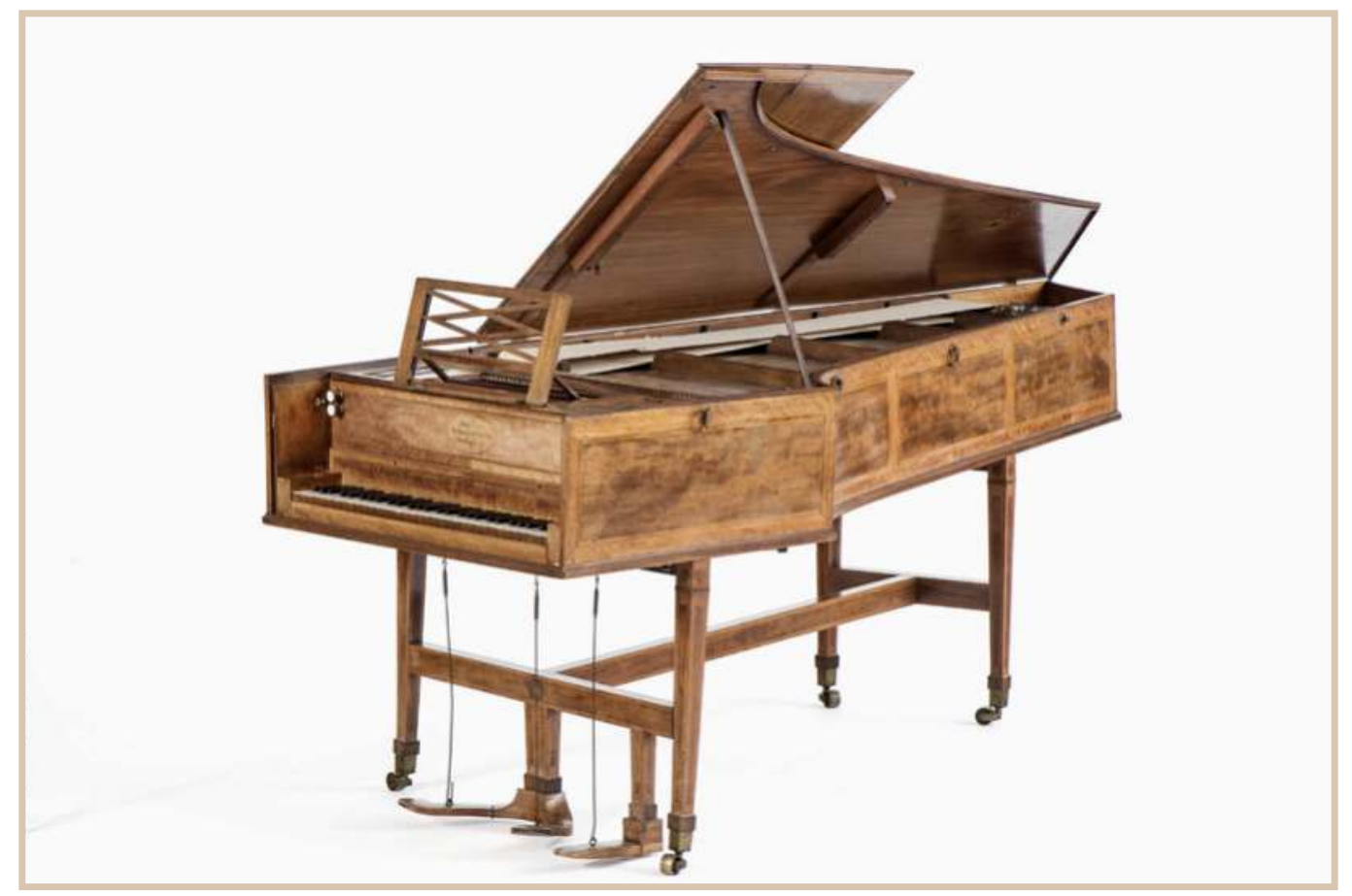

Johann Andreas Stein, Vis-àvis-Kombinationsinstrument Cembalo/Hammerflügel (1777), Verona, Academia filarmonica/Museo di Castelvecchio (Foto: Michael Latcham)

Jean-Joseph (auch John Joseph) Merlin, Cembalo mit Hammerflügel-Register und Notenschreibeinrichtung, London 1780 (Deutsches Museum München)

Der Clavierinstrumentenbestand und -instrumentenbau in Bonn als Anregung für den jungen Beethoven | 183 (C) 2020 by Böhlau Verlag GmbH \& Cie. KG, Köln

https://doi.org/10.7788/9783412519704 | CC BY-NC 4.0 


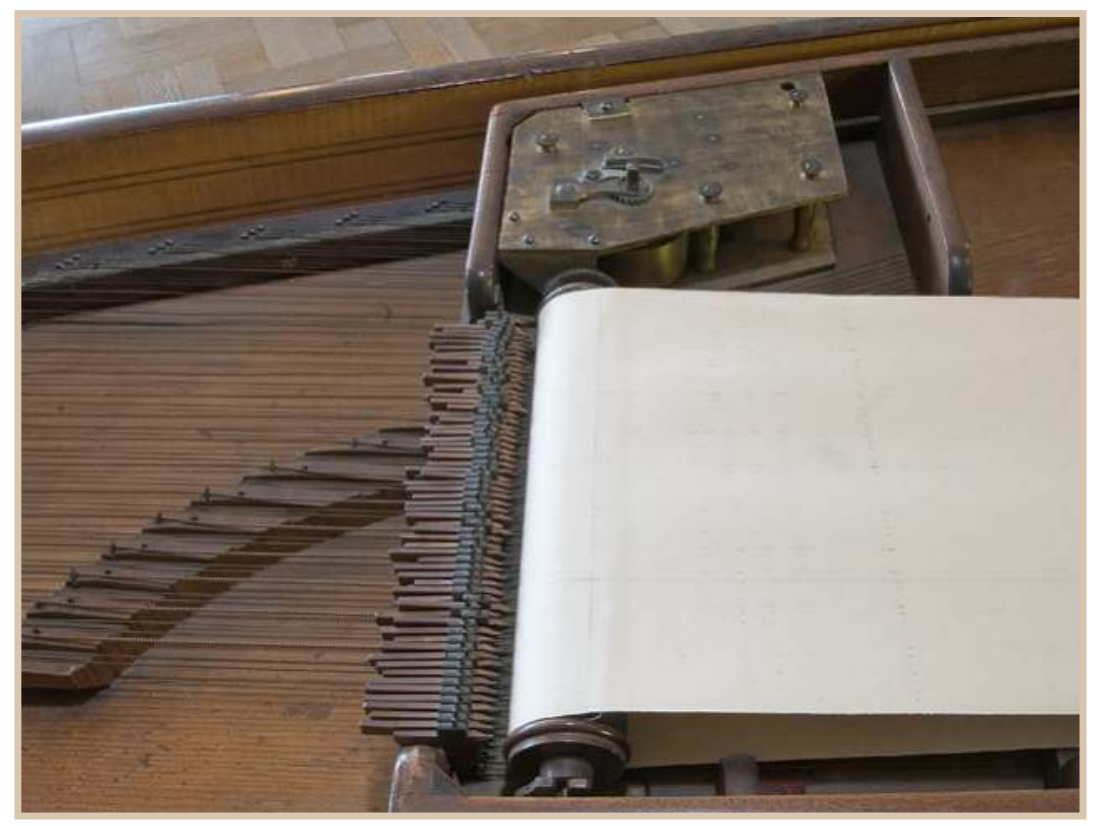

nete Bleistifte zeichnen das Gespielte im hinteren Bereich des Instrumentes ca. $30 \mathrm{~cm}$ vor der Anhangleiste auf. ${ }^{92}$ In einer Zeit, in der das Fantasieren Hochkonjunktur hatte und Ausweis der Meisterschaft eines Musikers war, nahm auch der Wunsch zu, solche Momente spontaner, und dementsprechend vergänglicher Inspiration der Nachwelt zu erhalten. So postulierte der Musikästhetiker Johann Georg Sulzer "Fantasier-Maschinen”: „Es wäre demnach eine wichtige Sache, wenn man ein Mittel hätte, die Fantasien groBer Meister aufzuschreiben.. ${ }^{193}$ Eine einschlägige Erfindung wurde vor 1746 von einem Mr. Creed in London gemacht. ${ }^{94}$ Im Jahr 1752 reichte

Notenschreibeeinrichtung an Merlins Cembalo mit Hammerflügel-Register (Deutsches Museum München)
Johann Friedrich Unger bei der Königlichen Akademie der Wissenschaften in Berlin seinen „Entwurf einer Maschine wodurch alles was auf dem Clavier gespielt wird, sich von selber in Noten setzt", ein, der zwar erst 1774 gedruckt, aber bereits 1753 von Johann Hohlfeld technisch umgesetzt wurde. ${ }^{95} \mathrm{Ob}$ Riedler Ungers/Hohlfelds Maschine oder die spätere Erfindung von Merlin kannte oder nicht, entziehtsich unserer Kenntnis. Sollte Riedler aufWanderschaft, wie bereits vermutet, in Berlin Station gemacht haben, so läge das nahe.

Beethoven selbst hat sich in seinen Wiener Jahren als gefeierter Improvisator mit diesem Thema intensiv befasst, auch im Sinne der Selbstreflexion. 1807/08 machte er sich auf Skizzenblättern Notizen über das Fantasieren: "Man fantasirt eigentlich nur, wenn man gar nicht acht giebt, was man spielt, so würde man auch am besten, wahrsten fantasiren öffentlich - sich ungezwungen überlassen, eben was einem einfällt". ${ }^{96}$ Umso attraktiver wäre es gewesen, einen solchen einzigartigen Moment festzuhalten, was bei Beethoven nur in der Chorfantasie op. 80 und der Klavierfantasie op. 77, in Ansätzen am Beginn des 1. Satzes des 5. Klavierkonzertes op. 73 und in der Introduktion zu den Variationen über das Lied "Ich bin der Schneider Kakadu" für Klaviertrio op. 121a in gedruckte Notentexte einging.

5) Das Magazin der Musik, wie andere Musikzeitschriften der Zeit, gelegentlich aber sogar nicht der Musik gewidmete Periodika wie der Teutsche Merkur ${ }^{97}$, sind voll von Berichten über neue Erfindungen auf dem Sektor des Instrumentenbaus. Zumindest Neefe wird die Zeitschrift vorgelegen haben, in dem zum Beispiel im selben Jahrgang ein Bericht über neuartige Instrumente und ihre Erbauer erschien ${ }^{98}$, darunter ein Bogenklavier. Es handelte sich um ein

184 | Michael Ladenburger

(C) 2020 by Böhlau Verlag GmbH \& Cie. KG, Köln

https://doi.org/10.7788/9783412519704 | CC BY-NC 4.0 
Instrument mit Darmsaiten, die mittels eines mit dem Tastenmechanismus verbundenen Bogens gestrichen wurden. So wollte der Erbauer, Johann Carl Greiner in Wetzlar (dem Sitz des Reichskammergerichts, natürlich mit Verbindungen nach Bonn), dem "sehnlichen Wunsch" der Pianisten entsprechen, auch solche Klangmöglichkeiten zur Verfügung zu haben. ${ }^{99}$ Auf der Basis des Bogenklaviers entstand dann sein so genanntes Bogenhammerklavier, ein zweimanualiges Kombinationsinstrument aus Streichinstrument mit Darmsaiten - eine Weiterentwicklung des Bogenklaviers, auf dem sogar eine Bebung möglich gewesen sein soll - sowie Hammerklavier mit Stahlsaiten und oberschlägiger Mechanik. ${ }^{100}$ Bei der Bewerbung von neuerfundenen Instrumententypen wurde jeweils ins Zentrum gestellt, wie viele "Veränderungen" des Klanges sie zu bieten haben, je mehr desto besser. Streichklaviere waren keine wirklich neuen Erfindungen, in der Vergangenheit aber Einzelanfertigungen geblieben. Schon Leonardo da Vinci machte sich Gedanken zu einem solchen Instrument. Aber im 18. Jahrhundert galten deren Möglichkeiten als besonderes Attraktivum und gerieten ins Blickfeld einiger experimentierender Instrumentenmacher wie Johann Hohlfeld in Berlin.

\section{Gottfried Friedrich Riedler - ein gescheiterter Experimentator?}

In der Ausgabe vom 16. Juli $1788^{101}$ der bei Heinrich Philipp Boßler, Beethovens wichtigstem Verleger der Jahre 1783-1784, in Speyer erschienenen Musikalischen Real-Zeitung, damals das bedeutendste, auf Korrespondentenbasis funktionierende, einschlägige Organ im süddeutschen Raum, gab es eine anonyme Nachfrage speziell nach dem in Neefes Bericht unter 7) geführten Instrument. "Anfrage. In dem Cramerschen Magazine Febr. und März 1783 steht S. 396. unter den mechanischen Arbeiten des Hrn. Gottl. Friedr. Riedlen zu Bonn 7 tens, ein Instrument, auf welchem alles, was der Spieler spielt, in währendem Spielen durch einen besondern Mechanismus in Noten abgedrukt wird.' Hierüber erbittet sich ein Freund der Tonkunst 1. Bestättigung dieser Nachricht 2. Biographische Nachricht des Erfinders, wie und wenn er auf solche Erfindung gekommen sey? 3. Den Preiß eines solchen Instruments und 4. Wenn es zu seiner äusern Form etwas besonders haben sollte, eine kleine Zeichnung von demselben. Diese Nachricht kann entweder an den Rath Bossler in Speier oder an die Expedition der musikal. Realzeitung daselbst, eingesandt werden."

Eine Antwort der Redaktion findet sich in der Ausgabe vom 12. November 1788:

"Hr. Riedlen hat sich zwar zu so einem Instrument anheischig gemacht, und deshalben die Anzeige im Cramerschen Magazin veranlaßt, hat es aber so lange er in Bonn war, nicht verfertigt und ist nun schon beinahe $3 \mathrm{Jahr}$ von dort weg, ohne daß jemand dessen Aufenthalt bekannt wäre." ${ }^{102}$

Über die Gründe später mehr. 
Riedlers Lebenslauf liegt nahezu komplett im Dunkeln. Gottlieb Friedrich Riedlen, wie er bisher, Neefe folgend, in der Beethoven-Literatur genannt wurde, hieß korrekt Riedler. Laut Neefes Bericht ist er 1749 in Tuttlingen geboren. Gemäß Johann Jacob Mosers Genealogischen Nachrichten von seiner eigenen, auch vilen anderen angesehenen Würtembergischen, theils auch fremden Familien ${ }^{103}$ ist er bereits 1747 im nahegelegenen zum Tuttlinger Amt gehörenden Aldingen zur Welt gekommen und zwar als siebtes Kind der Sibylla Juliana Esenwein (geb. 1720) und des Johann Heinrich Riedlen, dem dort und im benachbarten Talheim/Baar von 1739 bis 1765 wirkenden Pfarrer. Sibylla war die Tochter von Riedlers Amtsvorgänger Georg Daniel Esenwein. ${ }^{104}$ Mosers in zwei Punkten unzuverlässige Angaben halfen immerhin, der Person auf die Spur zu kommen. Tatsächlich, das heißt nach Ausweis des entsprechenden Kirchenbuchs, wurde "Gottlieb Friderich Riedler" am 19. Mai 1749 getauft. ${ }^{105}$ Im Aldinger Konfirmandenregister wird seine 1763 durch seinen Vater erfolgte Konfirmation unter dem Namen "Gottlieb Friederich Riedler" verzeichnet. ${ }^{106}$ In diesem Jahr wurde übrigens die Orgel der dortigen Kirche einer Reparatur unterzogen, möglicherweise eine Anregung für den jungen Riedler, sich dem Instrumentenbau zu widmen. ${ }^{107}$

Sein Vater, Johann Heinrich Riedler, war am 24. Mai 1705 als Sohn eines gleichnamigen Meisterschneiders in Tübingen getauft worden. Ob er mit dem Tübinger Schreiner Andreas Riedlen verwandt war, ist nicht zu klären. ${ }^{108}$ Es wäre insofern von Interesse, als das Schreinerhandwerk ja meist die handwerkliche Grundlage für Klavier- und Orgelbauer war. Johann Heinrich Riedler starb am 8. November 1767 in Talheim. ${ }^{109}$ Seine spätere Ehefrau war am 13. August 1720 in Aldingen getauft worden, wo am 18. November 1738 auch die Eheschließung stattfand. Sie starb am 25. Januar 1780 in Stuttgart, wohin sie nach dem Tod ihres Mannes wohl zu einem ihrer Kinder gezogen war. ${ }^{110}$ Ihre Tochter Juliana Charlotte starb 1770 in Stuttgart, die Tochter Friederike Luise überlebte ihre Mutter ebenda. Auch Gottlieb Friedrich könnte sich 1780 dort aufgehalten haben (siehe S. 196).

$\mathrm{Zu}$ Riedlers Werdegang vor seiner Bonner Zeit liegen derzeit keinerlei Informationen vor. Vermutlich lernte er das Schreiner-, Klavier- und/oder Orgelbauerhandwerk in seiner näheren Heimat. Anschließend könnte er wie erwähnt auf Wanderschaft gegangen sein und sich zumindest vorübergehend in Berlin aufgehalten haben. Da Neefe seine "Geschicklichkeit, in der Verfertigung verschiedner physicalischer Instrumente, und in der Wissenschaft von der Electricität" lobt, käme auch Augsburg in Frage. Dort waren Georg Friedrich Brander, Johann Christoph Thenn, Johann Andreas Erdmann und Jakob Langenbucher auf diesem Gebiet tätig. ${ }^{111}$ Augsburg hätte nahegelegen, war doch ebendort zugleich der Wirkungsort des Klavier- und Orgelbauers Johann Andreas Stein. Auch mit dem umherziehenden Schausteller („Elektrisierer") Martin Berschitz könnte er in Berührung gekommen sein. Sämtliche 
diesbezüglichen Nachforschungen blieben ergebnislos. Hingegen dürfte Riedler in Kontakt mit dem schwäbischen Geistlichen und ambitionierten Physiker Gottlieb Christoph Bohnenberger (1732-1807), damals Pfarrer in Simmozheim bei Calw, gekommen sein, der im Oktober 1781 in Stuttgart einen „Künstler" besuchte, welcher Elektrisiermaschinen fertigte. ${ }^{112}$

Riedler war, wie wir gesehen haben, spätestens im Herbst 1782 in Bonn sesshaft und in direktem Kontakt mit Mastiaux und Neefe. Vermutlich war das Brückenglied zu Neefe, der im Vorjahr zum Hoforganisten ernannt worden war, das Projekt einer neuen Orgel für die neue Bonner Schlosskirche. Bedarf gab es seit dem Schlossbrand von 1777. Vielleicht war dies sogar neben dem Interesse des Kurfürsten an physikalischen und elektrischen Instrumenten ein wesentlicher Grund gewesen, weshalb Riedler nach Bonn kam. Einen leichten Stand dürfte er insgesamt nicht gehabt haben. Als Protestant konnte er das Bürgerrecht nicht erwerben - vielleicht hätte er es aus Kostengründen auch gar nicht haben wollen - und die einschlägigen ortsansässigen Handwerker werden sorgsam darauf geachtet haben, dass er ihnen nicht das Wasser abgrub. Insofern ist der (erschließbare) Auftrag für die Schlosskirchen-Orgel durchaus erstaunlich, gab es doch mit Peter Kemper in Poppelsdorf einen ortsansässigen Orgelbauer, der sich ebenfalls um den Auftrag beworben hatte.

\section{Gab es eine Riedler-Orgel von 1784?}

Entscheidende, das heißt unmittelbare Quellen fehlen uns auch bezüglich dieses Projektes. Der bisherige Kenntnisstand lautete:

„Kurz nach Fertigstellung der Schloßkirche baute der Bonner Orgelbauer G. F. Riedler eine kleine Orgel, die wahrscheinlich auf der heute nicht mehr existierenden oberen Mittelempore aufgestellt wurde. Diese Mittelempore im zweiten Stockwerk diente wohl als Musikempore, sie wurde nach dem Zweiten Weltkrieg nicht wieder eingebaut.

Über Größe und Disposition kann nur spekuliert werden, einiges spricht dafür, daß sie gut zehn Register auf einem Manual hatte und ein süddeutschitalienisch beeinflusstes Instrument gewesen ist.

Auf diesem Instrument haben sowohl Neefe als auch der junge Beethoven gespielt. Die Riedler-Orgel wurde 1822 an das Evangelische Lehrerseminar in Moers verkauft und dort aufgestellt. Nach 1870 befand sie sich in sehr schlechtem Zustand und wurde 1876 durch ein neues Instrument ersetzt." ${ }^{\prime 113}$ Neefe erwähnt die Orgel in seinen Lebenserinnerungen:

"Biss 1784 gieng ich meinen gewöhnlichen Pfad; ich spielte die Hof-Orgel, (welche sehr klein, und nur ein Nothelfer ist, bis zur Erbauung einer neuen). Ein vortreffliches Werk ist mit der ganzen Kapelle bei dem großen Schlossbrand verunglückt." ${ }^{\prime 114}$

Neefe kam erst zwei Jahre nach der Feuersbrunst nach Bonn. Über das Provisorium haben wir keine konkrete Kenntnis. Wie aus dem verwendeten Prä- 
sens hervorgeht, bestand es jedenfalls zum Zeitpunkt der Abfassung seiner Memoiren (1789) noch fort. Er hat vermutlich öfter die Orgel der FranziskanerKirche aus der Werkstatt der führenden mittelrheinischen Orgelbauer-Dynastie Stumm gespielt. ${ }^{115}$ Die direkt neben dem Schloss gelegene FranziskanerKirche diente ebenfalls als Hofkirche.

Kurfürst Maximilian Friedrich hatte eine neue Orgel für die Schlosskirche in Auftrag gegeben, doch ist über die näheren Umstände nichts bekannt. Sein Nachfolger Max Franz, der das Amt am 27. April 1784 antrat, ließ den Fall neu aufrollen. Dessen Bruder, Kaiser Joseph II., hatte im Vorjahr in Wien die so genannte Josephinischen Reformen verfügt, die zu einer massiven Reduzierung der aus seiner Sicht überhandgenommenen figuralen Kirchenmusik führte. ${ }^{116}$ Aus der Sicht von Max Franz sollte die Orgel vor allem dem Continuo-Spiel dienen. Ohnehin war die Orgelsolo-Literatur in diesen Jahren und diesen Breiten nicht auf große Instrumente ausgerichtet. Wahrscheinlich wurde in der kirchenmusikalischen Praxis in dieser Übergangszeit überwiegend improvisiert und der gregorianische Choral - damals im Rheinland in Pfundnoten gesungen - auf der Orgel, mit Vorund Zwischenspielen durchsetzt, Ton für Ton akkordisch (in Dur und Moll, nicht mehr in den Kirchentonarten) begleitet. ${ }^{117}$

Die Hofkammer wurde mit einer gründlichen Prüfung beauftragt. Deren Ergebnis ist dokumentiert. ${ }^{118}$ Es handelt sich um eine Stellungnahme des kurfürstlichen Bau- und Jagdschreibers Hofkammerrat Andreas Isaac an den Präsidenten der Hofkammer Johann Ignaz Graf Wolff-Metternich zur Gracht. Sie wurde sämtlichen Hofkammerräten zur Kenntnis gebracht, zu denen auch Mastiaux gehörte.

"Dienstag, d 20"n Julius 1784

Da in gefolg des von Eur Churfürst/ ${ }^{n}$ Durchlaucht auf die un[ter]th[äni]gste Vorstellung des Orgelmachers Riedlen ertheilten g[nädi]gst[e]n apostillaris der Hofkammerrath Isaac in betreff einer großen neuen Hoforgel gehorsamst angebogene Relation erstattet, und Höchstderoselben anwesende Hofkammer Praesident und Räthe selbiger beipflichten; so sehen bemeldte Hofkammer-Praesident und Räthe hierunter der g[nädi]gst[e]n Entschließung entgegen. Pro Extractu Pro[toco]lli Cameralis."

"Relatio.

Als in gefolg des mir g[nädi]gst gethanen Auftrags, den Orgelmacher N Riedlen zu mir vorgeladen, und demselben zu erkennen gegeben, daß ihre Kurfürstl. D[urc]hl[auch]t Max Franz Unser g[nädig[st[e]r Herr g[nädi]gst nicht gemeint [geneigt] wären, mit der in Arbeit seyenden neuen Orgel von 30. Registern /: weil diese, allem Vermuthen nach, für eine so kleine Hofkapell alzu groß und lächerlich ausfallen dörfte :/ weiter fortfahren, sondern statt deren eine kleine von etwa 4. bis 6. Registern verfertigen zu laßen, als worüber er den genauesten Preis vorläufig abzugeben hätte, erwiederte dersel- 


\section{Celatio.}

(a) :

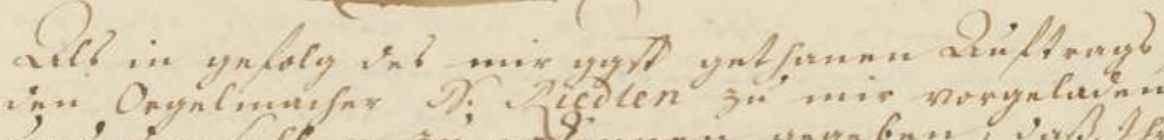

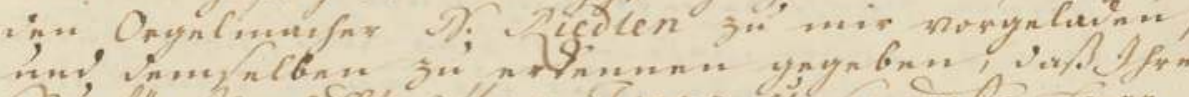

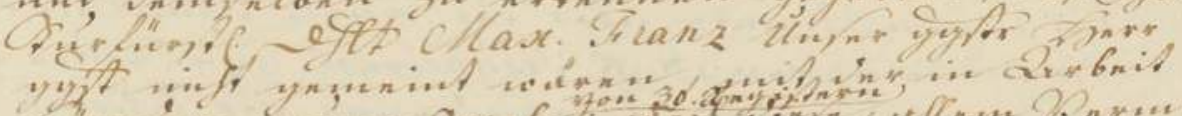

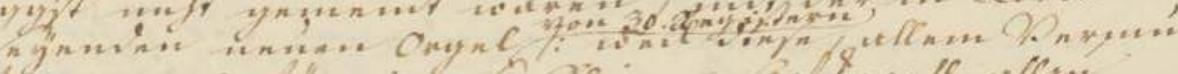

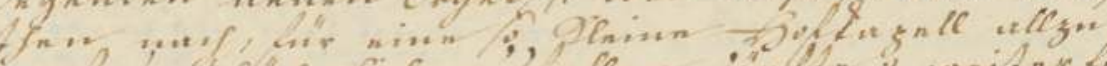

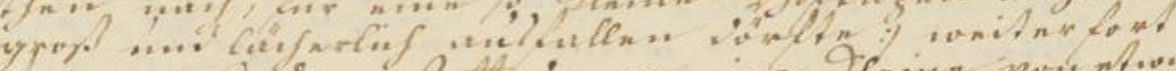

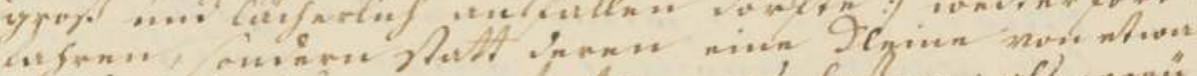

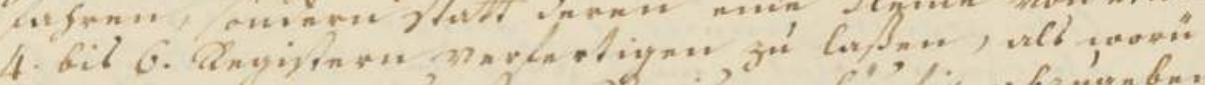

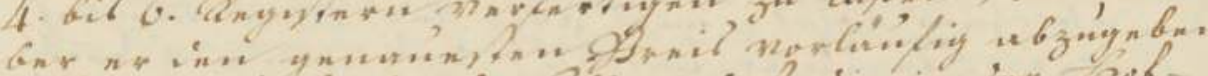

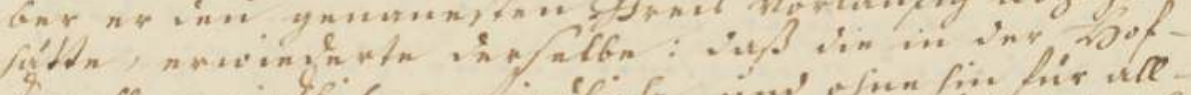

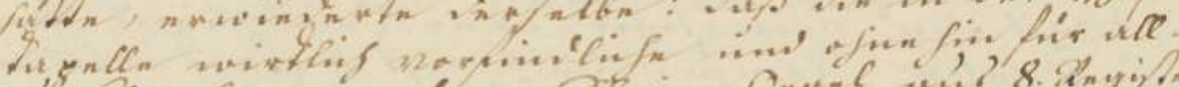

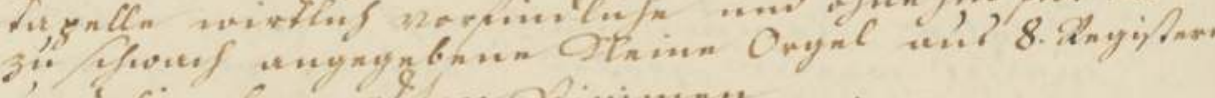

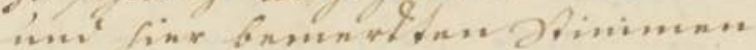

$$
\begin{aligned}
& \text { 1. Princional ?. S...l. } \\
& \text { 3. ynus, \&. Si,j? }
\end{aligned}
$$

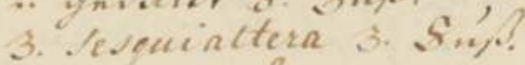

$$
\begin{aligned}
& \therefore \text { a.e bir.s. }
\end{aligned}
$$$$
\text { 4. cotar. 4. Sil.? }
$$

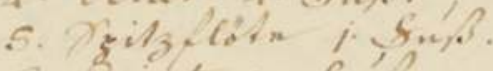

G. Guint ar. S.e.s.

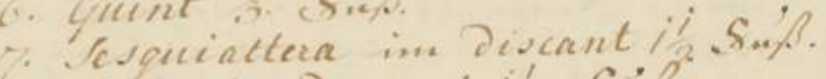

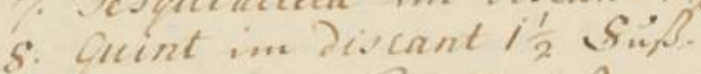

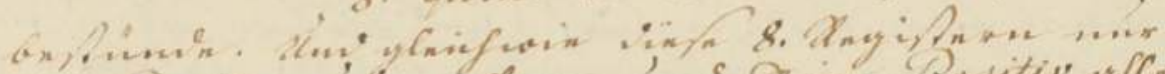

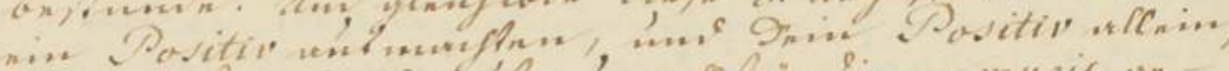

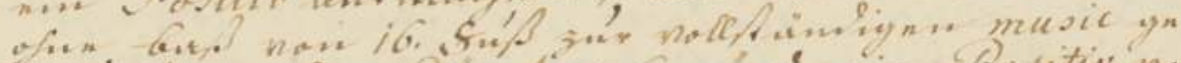

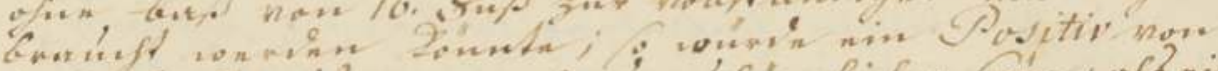

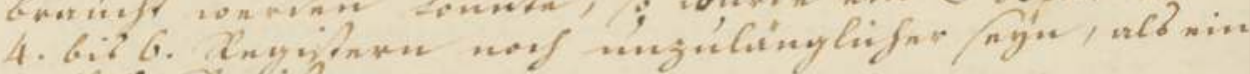
noir \&. Anvilons

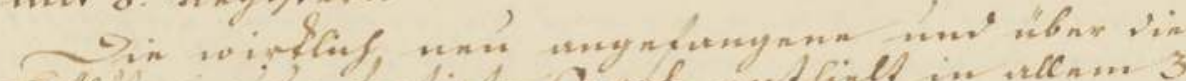

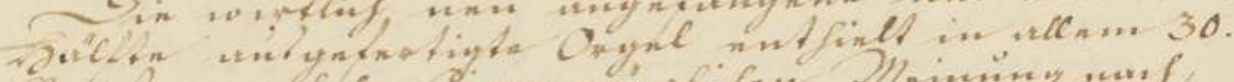

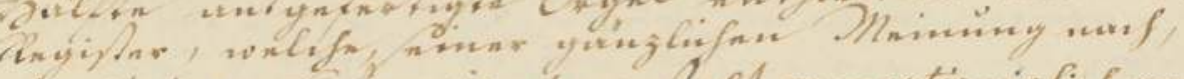

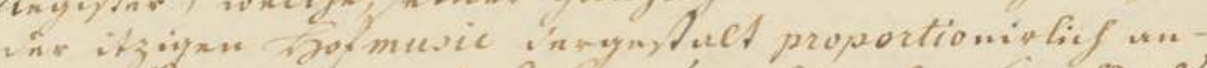

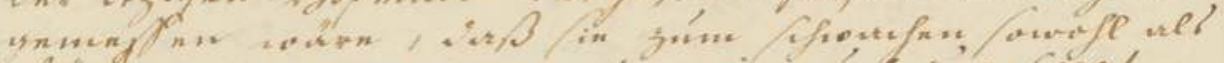

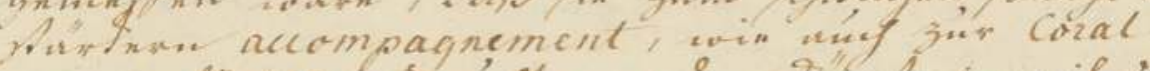

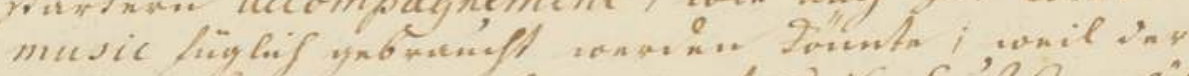

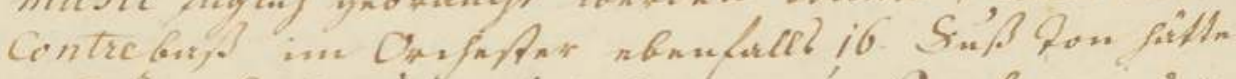

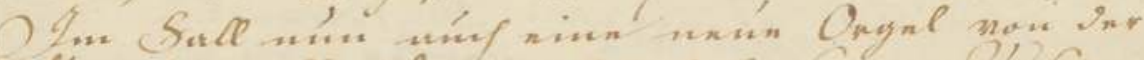

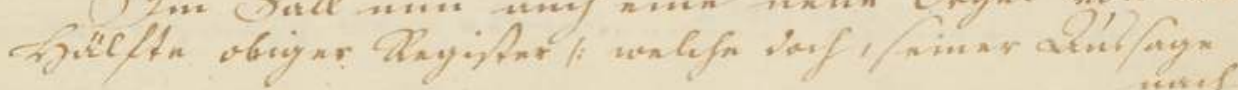

Stellungnahme Hofkammerrat Andreas Isaac, 20. Juli 1784

(Landesarchiv NRW) 
be: daß die in der Hofkapelle wirklich vorfindliche und ohne hin für allzu schwach angegebene kleine Orgel aus 8. Registern und hier bemerkten Stimmen

Principal 2. Fuß.

gedackt 8. Fuß.

Sesquialtera 3. Fuß. im Baß

Octav. 4. Fuß.

Spitzflöte 1. Fuß.

Quint 3. Fuß.

Sesquialtera im discant 1 1/2 Fuß.

Quint im discant 1 1/2 Fuß.

bestünde. Und gleichwie diese 8. Registern nur ein Positiv ausmachten, und kein Positiv allein, ohne Baß von 16. Fuß zur vollständigen music gebraucht werden könnte; so würde ein Positiv von 4. bis 6. Registern noch unzulänglicher seyn, als ein mit 8. Registern.

Die wirklich, neu angefangene und über die Hälfte ausgefertigte Orgel enthielt in allem 30. Register, welche seiner gänzlichen Meinung nach, der itzigen Hofmusic dergestalt proportionirlich angemessen wäre, daß sie zum schwachen sowohl als stärkern accompagnement, wie auch zur Coralmusic füglich gebraucht werden könnte, weil der Contrebaß im Orchester ebenfalls 16 Fuß Ton hätte.

Im Fall nun auch eine neue Orgel von der Hälfte obiger Register /: welche doch seiner Aussage nach unter 3000. Rthlr nicht gemacht werden konnte:/ g[nädi]gst beliebt und angeschafft werden wollte; so wäre diese auf eine Art zwar hinlänglich; man könnte aber die music damit nur in einem einzigen Fall secundiren, und wäre ohne die nothwendige Veränderung der Schwäche und Stärke, die in der music allzeit abzuwechseln pflegt, eben so wenig wie das wirklich befindliche positiv brauchbar, mithin nur in einer Kirche zum Coral, nicht aber zur music tauglich. Er verhoffte daher unthgst, daß, wo die bereits zur Halbscheid verfertigte neue Orgel seiner unzielsetzlichen Meinung nach nicht so stark, als vermuthet werden wollte, sondern zur music nur blos hinlänglich und nichts überflüßiges enthielte, aus bereits angeführten Gründen dem billigen Antrag gemäß zu 4000. Rthlr verfertiget, und seiner Zeit aufgestellt mögte.

Um nun völlig vergewissert zu seyn, in wie weit das des besagten Riedlen gegründet seyn möge, habe mich demnach bei hiesigem Franziskaner-Bruder und Organisten Willibald Koch, welcher bekannter Dingen hierinn viele Wissenschaft besitzt, auch dergleichen Arbeit an unterschiedlichen Ort- und Plätzen öfters mitbearbeiten, einrichten und aufsetzen geholfen, desfalls genau erkundiget, und ihm die vom Riedlen völlig gemachte Eintheilung [Disposition (und Aufriss?)] vorgezeigt, worauf derselbe sich dann geäußert hat, daß seines Ermessens die angefangene Orgel von 30. Registern für hiesig-vollständige music gar nicht zu stark, und die specificirte Registern, wobei /: außer der im 
Pedal angeführten Possaune von 32. Fuß, welche füglich was geringer eingerichtet werden könnte :/ keines überflüßig, um deswillen sehr wohl angebracht wären, weil diese niemal zusammen, sondern für forte und piano gebraucht würden.

Mit denen in Klöstern zum blosen Coral, auch allenfalls geringen und doch stark ausgebenden Orgeln hätte es hingegen die Bewandniß, weil darinn unterschiedliche Zungenwerker, als Trompet, Claron Krumhorn, vox humana und dergleichen stark durchdringende Registern der Ursachen sich befänden, damit die Geistlichen im Chor hiedurch im Singen mehr unterstützt, und nicht allzeit mit vollständiger Stimme anzuhalten genöthigt wären. Wo nun dergleichen Registern in der neuen Orgel keine, sondern nur bloß einhellige labial oder lieblich klingende Stimmen sich vorfänden, so wäre diese auch der music ganz angemessen.

Daß aber der Organist so weit, wie dermal noch angegeben werden will, von der Orgel entfernt sitzen und schlagen soll, wollte vom bes[agte]m Bruder deswegen nicht gebilliget werden, weil dadurch öfters, besonders im Winter und feuchter Witterung unter andern Vorfällen sich auch zutragen dörfte, daß die allzu lang geleitete Dräte sich verfangen, und die Claves bei dem Anschlag den behörigen Ton nicht gleich von sich geben würden.

Der zuletzt angesetzte Preis von 4000. Rthlr schien demselben auch in etwa stark übertrieben zu seyn, zumal, wenn g[nädi]gst erwogen werden wollte, daß die groß- und prächtige Orgel bei den P.P. Franziskanern zu Bruel, welche in 53. Registern, 3. Klavier und 6. Blasbälgen bestünde, mit Kasten und all übrigem Zubehör, die Vergoldung allein ausgenommen, nur 3000. Rthlr, die schöne Orgel zu Dusseldorf von 54. Registern 3. Klavier und 6. Blasbälgen 3500. Rthlr und die hiesige Franziskaner-Orgel von 32. Registern 2. Klavier und 3. Blasbälgen 2000. Rthlr gekostet hätten.

Bei solch' der Sachen wahren liegenheit will es von Eur Kurfürst ${ }^{n}$ D[urc]hI[auch]t g[nädig]gst[e]r Entschließung abhangen, ob die wirklich angefangene Orgel von 30. Registern mit ihren dazu bestimmten Tönen /: worauf bereits mit Materialien und baaren Gelte über 1000. Rthlr bezahlt worden sind :/ nach vorher näher zu bestimmendem accord völlig verfertigt, oder aber mit derselben einsweiliger Zurücksetzung die dermalig-befindliche kleine Orgel bis aufs anderweitig-g[nädi]gst[e]r Verordnung zum weitern Gebrauch beibehalten werden solle.

S[alvo].M[eliore] And[reas] Isaac"

"Die Hofkammer schickt ein Relation des Hofkammer Rathen Isaac in Betreff einer großen neuen Hoff Orgel, pflichtet selbiger bey, und sehnt hierunter der gnädigsten Entschließung gehorsamst entgegen."

"Kurfürst[lich]e Hofkammer hat zu trachten eine schickliche, dem Ort angemeßene Orgel verfertigen zu laßen; 10 bis 12 Register sind erklecklich, mehrere überflüßig, der Instrumental Musick schädlich, und machen so ungereimten Effect als die bei die Franziskaner in Bruel und Bonn; wie das bereits verfertigte 
zu benutzen wäre, und um welchen Preis selbe vollendet werden könnte; hierüber hat Hofkammer das nötige besorgen zu laßen.

Bonn den $14^{\text {tn }}$ August 1784

C. A. Schulten m[anu] $\mathrm{p}$ [ropria]"

Aufgrund der schlechten Quellenlage muss offenbleiben, ob es eine RiedlerOrgel im strengen Sinn überhaupt gegeben hat. Es hat den Anschein, als habe Kurfürst Max Franz - er konnte gelegentlich in Rechtsfragen recht "unkonventionell" vorgehen - den Orgelneubau gestoppt und dann das Projekt zumindest massiv reduziert. Seine Argumente werden der überteuerte Preis, die üppige Disposition mit zu vielen und zu dominanten Zungenstimmen, die zu erwartenden Probleme mit komplizierten und langen Trakturwegen bei einem vermutlich freistehend geplanten Spieltisch gewesen sein. Riedlers Buhlen mit einer angeblichen Erleichterung beim Singen für die Geistlichen und den Chor scheint er - nicht ganz unverständlich - als nicht überzeugend empfunden zu haben. Bezüglich "Coral", also dem gregorianischen Choral, und "music", also der orchesterbegleiteten figuralen Kirchenmusik, hatte der Kurfürst, was die Erfordernisse an die Orgel anlangt, offenbar andere Auffassungen oder aber er scheute die Höhe der Ausgaben.

Wir kennen weder die ursprüngliche noch die modifizierte Auftragsvergabe und nur einige wenige damit verbundene Zahlungen. In den Landrentmeisterei-Rechnungsbüchern wird der erwähnte Vorschuss/Anzahlung/ Materialbereitstellung von über 1000 Reichstalern für den Orgelneubau an Riedler nur mit einer einzigen Zahlung von 50 Reichtalern, die eine Abschlagszahlung war, Mitte Oktober 1783 verzeichnet: „Dem Mechanico N: Riedlen auf die Neue Hoforgel in Abschlag den $16^{\text {ten }} 8$ bris 1783"119. Ob der - abgesehen von den vermutlich intern verrechneten, heute nicht mehr nachvollziehbaren Materialbereitstellungen - vermutlich gröBere Teil der Kosten aus der Privatschatulle des Kurfürsten (gemäß einer früheren, jetzt aber obsoleten Zusage von Maximilian Friedrich) oder einer anderen Quelle bestritten wurden, ist nicht bekannt. Riedlers Name findet sich ansonsten in den LandrentmeistereiRechnungsbüchern für 1784 und 1785 nur unter "aller-

Inventar des Bonner Residenzschlosses, 1784 (Ausschnitt) (Landesarchiv NRW) hand Arbeitslohn". Für den 1. April 1785 ist folgende Ausgabe für mehrere Klavierstimmungen verzeichnet: "Riedeler wegen gestim[m]ten Clavier 14 Conv 5 rt 16 2/3 alb [Summe] 23 Rthl 2 Alb", während für den 14. August 1784 unter den Ausgaben für die Hofkapelle vermerkt ist: "Kilian wegen gelehnten Clavier 1 Rth 64 Alb 8 Hllr". Im Landmeisterei-Rechnungsbuch des Folgejahres ist unter dem 12. August 1785 verzeichnet: "Riedel wegen gestimmten Clavier 4 Cron. 69 1/3 Alb [Summe] 8 Rthl 29 Alb 4 Hllr". Danach findet sich Riedler nicht mehr. ${ }^{120}$ Offenbar wurden die Ausgaben für den Orgel-

192 | Michael Ladenburger

(C) 2020 by Böhlau Verlag GmbH \& Cie. KG, Köln

https://doi.org/10.7788/9783412519704 | CC BY-NC 4.0 
bau im Wesentlichen nicht aus der Hofkasse bestritten. Zahlungen aus der Regierungszeit von Max Franz sind nicht nachzuweisen.

Für die Annahme, dass es einen Einschnitt in das Orgelbau-Projekt gab, spricht auch die bereits von Hübner veröffentlichte Eingabe des Poppelsdorfer Orgelbauers Peter Kemper bezüglich einer umzuarbeitenden oder neuen Orgel in der Schlosskirche. Er beschreibt das vorhandene Instrument eindeutig als Orgelpositiv. Das trifft auch auf das Provisorium zu. Laut dem aus Anlass des Regierungswechsels 1784 erstellten Inventar des Bonner Residenzschlosses handelte es sich um „Eine kleine Orgel, so ehedem zu Poppelsdorff gestanden, mit einer Sitz Banck." 121 Kemper bietet mehrere Optionen an - von einer Zerlegung, Reinigung, Stimmung und Überarbeitung der Blasbälge des vorhandenen Instruments für lediglich 35 Reichstaler, über ein neues Positiv auf Prinzipal 4'-Basis mit sieben Registern für 500 Reichstaler bis hin zu einem Neubau eines Positivs mit acht Registern auf Prinzipal 8'-Basis und mit einem Zungenregister für 1000 Reichstaler - jeweils unter Verwendung eines vorhandenen Gehäuses. ${ }^{122} \mathrm{Ob}$ sein Befund einer zu kleinen Windlade und daraus folgend zu unruhigem Wind objektiv war oder mehr dem eigenen Geschäftssinn, das heißt dem Wunsch, einen finanziell lukrativeren Neubau errichten zu dürfen, entsprang, ist schwer zu sagen. Jedenfalls ist bei seinen Vorschlägen von maximal 8 Registern die Rede - kaum vorstellbar, hätte die Vorgänger-Orgel 10-12 oder gar 30 Register umfasst. Er spricht von einem "Manual, wozu der Kasten bei hofe schon vorrätig, nach folgendem, dem Plaz und der Musik mehr angemessenen Plan, verfertigt würde". Das kann man durchaus auch so interpretieren, dass er nicht das bestehende Gehäuse, sondern ein vermutlich von Riedler gefertigtes, aber nicht mehr zum Einbau gekommenes, sondern bei Hof gelagertes, aus den erwähnten über 1000 Reichstalern finanziertes Gehäuse verwenden, aber an einem anderen für die instrumental begleitete Kirchenmusik günstigeren Platz aufstellen wollte. Die Eingabe dürfte vermutlich zwischen 1785 und 1792 oder 1794 gemacht worden sein. Kemper nennt das Jahr

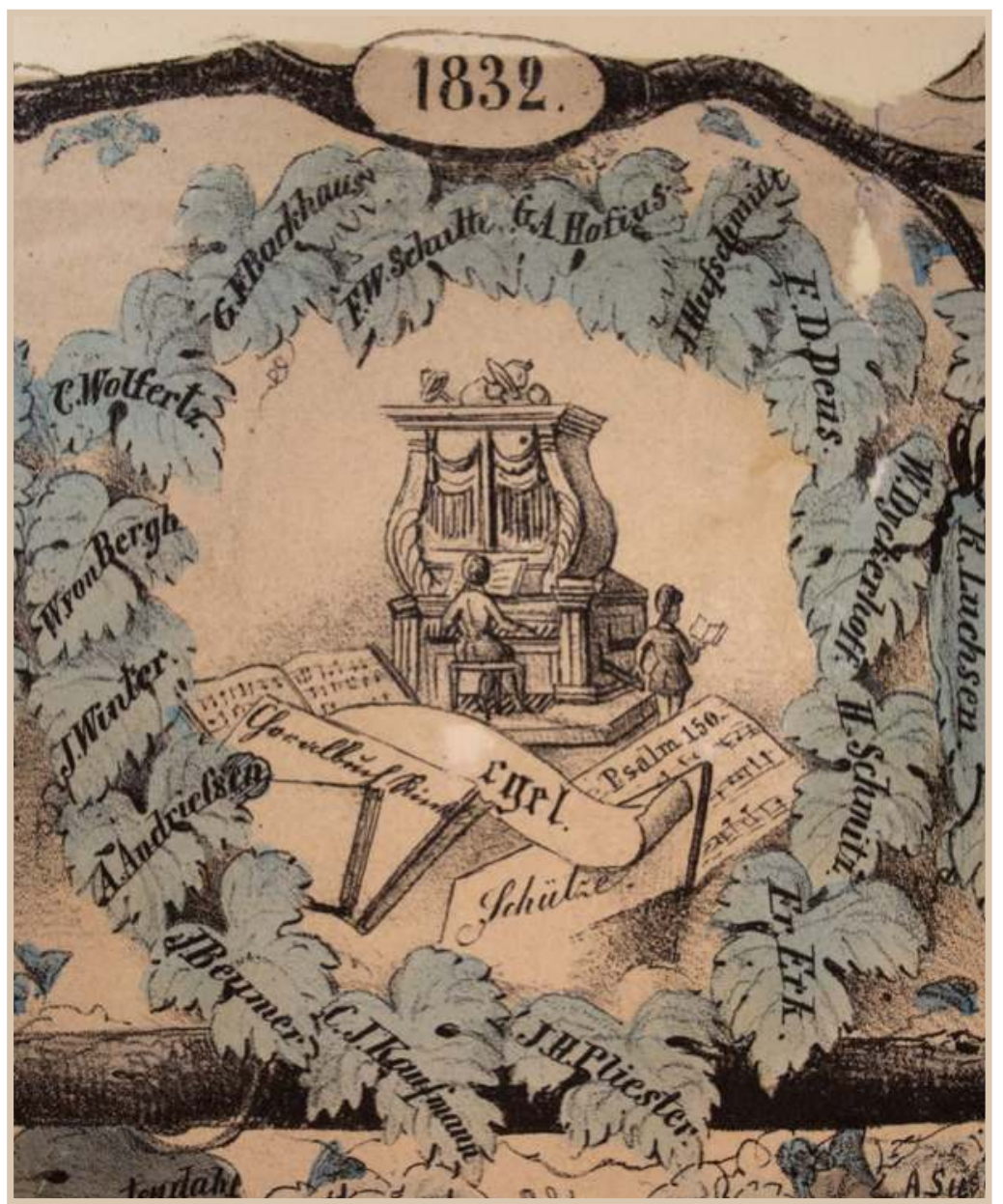

„Abgespeckte“ Riedler-Orgel aus der Bonner Schlosskapelle?, auf: Gedenkblatt zum 25-Jahr-Jubiläum des Moerser Seminars. Kolorierte Lithografie, 1846

(Ausschnitt) (Grafschafter Museums- und Geschichtsverein, Grafschafter Museum im Moerser Schloss) 


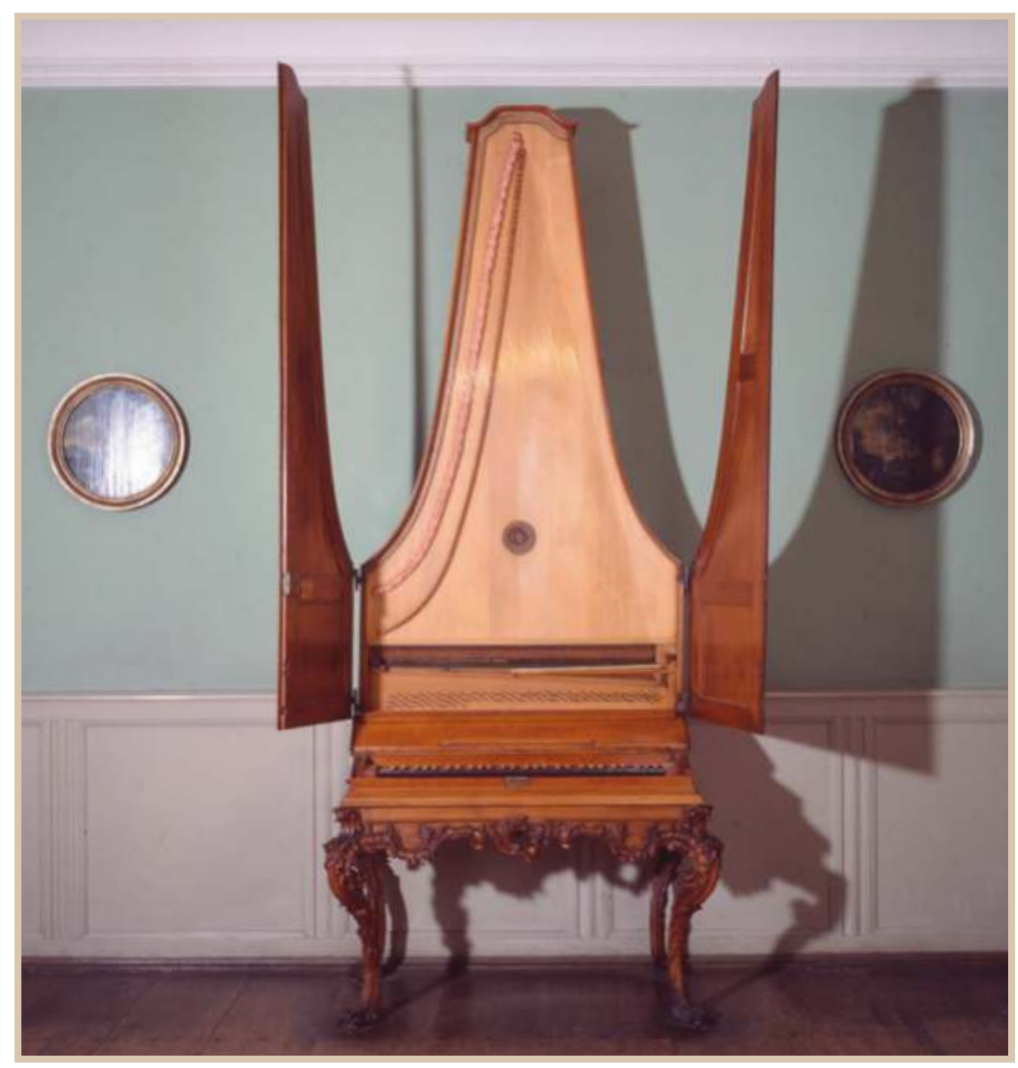

1784 als in der Vergangenheit liegend. Da der Kurfürst wegen der französischen Invasionstruppen sich im Dezember 1792 nach Münster zurückziehen musste und erst im April 1794 und nur für ein halbes Jahr nach Bonn zurückkehrte und sicherlich andere Sorgen als aufwändige Zukunftsgestaltung hatte, ist es angesichts des Umstandes, dass Kemper schließlich doch noch, allerdings nur mit der Minimallösung zum Zug kam, wahrscheinlich, dass dieser erst im Frühjahr 1794 an den Hof herantrat. Jedenfalls versetzte er die vorhandene Orgel im Juli 1794 innerhalb der Hofkapelle für bescheidene 12 Reichstaler. ${ }^{123}$ Drei Monate später war das Kurfürstentum de facto Vergangenheit. Der Kurfürst hätte eine größere Lösung wohl erst bei seiner ja beabsichtigten dauerhaften Rückkehr erwogen. Der Standort der Orgel vor und nach der Versetzung ist nicht mit Sicherheit zu bestimmen. Beethovens Jugendfreund Franz Gerhard

Pyramidenflügel von Christian Ernst Friederici (Freies Deutsches Hochstift / Frankfurter GoetheMuseum)
Wegeler ${ }^{124}$ schreibt - allerdings im Rückblick von drei Jahrzehnten nach seinem Wegzug aus Bonn -, die Orgel sei in der Schlosskapelle nicht sichtbar aufgestellt gewesen. Sie dürfte also wohl im rechts über der Apsis gelegenen, durch drei Fenster mit dem Kirchenraum verbundenen Doxale, wo bei Aufführungen auch das Orchester platziert war ${ }^{125}$, aufgestellt gewesen und 1794 in den Kirchenraum versetzt worden sein, als klar wurde, dass mit figuraler Kirchenmusik für längere Zeit nicht mehr zu rechnen war. Die Bauamtsrechnungen der Jahre 1781/82 weisen umfangreiche Zahlungen für Schreiner-, "Virnisier"- und Schlosserarbeiten im "Neuen Doxsaal" nach. ${ }^{126}$ Die Schlosskapelle wurde nach der französischen Invasion noch drei Jahre für zwei Gottesdienste pro Woche und dann wieder ab 1806 durch das katholische Lyzeum und die evangelische Gemeinde genutzt. ${ }^{127}$ Die von Riedler ursprünglich geplante Orgel mit 30 Registern hätte sowieso nirgendwo anders als im Kirchenraum aufgestellt werden können.

Das von Riedler eher überarbeitete als komplett neu erbaute Positiv mit ca. acht Registern wurde schließlich, wie bereits erwähnt, 1822/23 in das evangelische Lehrerseminar in Moers umgesetzt, wo es bis 1876 seinen Dienst tat. ${ }^{128}$

Sollte die Orgeldarstellung auf einem großen Gedenkblatt zum 25-JahrJubiläum des Moerser Seminars ${ }^{129}$ (im Jahresring 1832, also 10 Jahre nach der

194 | Michael Ladenburger

(c) 2020 by Böhlau Verlag GmbH \& Cie. KG, Köln

https://doi.org/10.7788/9783412519704 | CC BY-NC 4.0 
Aufstellung der Orgel) tatsächlich ein sicherlich stilisiertes, aber einigermaßen getreues Abbild der "abgespeckten" Riedler-Orgel - allerdings erst in der Zusammenstellung von Kemper unter Verwendung des zuvor nicht genutzten Gehäuses von Riedler - darstellen, so ähnelte das Instrument durchaus einem aufrechtstehenden Flügel (hier in Lyra-Form), wie ihn Riedler für Mastiaux gebaut haben dürfte. Da Neefe als (zu dieser Zeit allerdings nicht unumstrittener) Hoforganist zumindest am Rande in das Orgelbau-Projekt einbezogen gewesen sein dürfte, ja nebenbei mit Friederici-Instrumenten handelte, wird eine stilistische Anspielung auf dessen Pyramiden bei ihm auf Wohlwollen gestoßen sein. Die von Neefe erwähnte Beteiligung des Kapelldirektors Cajetano Mattioli ist genauso wenig dokumentiert wie jene Andrea Luchesis 1794. Mattioli war von April 1783 bis April 1784 abwesend und wurde im Juni 1784 von Max Franz entlassen. - Aber: All das muss ohne neue Quellenfunde Spekulation bleiben.

Resumee: Die massive Beschneidung des Orgelbau-Projekts dürfte Riedler in beträchtliche wirtschaftliche Schwierigkeiten gebracht haben. Über die Folgen berichtete das Bönnische Intelligenzblatt vom 11. Oktober 1785:

\section{„EdictalLadung}

Da der Mechanicus R. Riedlen sein WohnOrt dahier verlassen hat; von dessen dermaligem Aufenthalt man zur Zeit keine Nachricht hat; und dann bei hiesigem Kurfüstl. hohen weltlichen Gericht sich verschiedene Gläubiger gegen ihn gemeldet, auch Einige ins besondere sich um die Verabfolgung der ihm anvertrauten Effecten angestanden haben; daher vor allem die in Rechten erforderliche EdictalLadung erkant worden ist; als wird Allen und Jeden so an besagtem Riedlen etwan noch eine Schuldforderung oder Ansprache an dessen zurückgelassenen Effecten haben mögen, zu derselben Beibringung und Justificirung eine peremtorische Frist von 6 Wochen unter Strafe des ewigen Stillschweigens hiermit anberaumt, wie nicht weniger Er Riedlen, um sich in nämlicher Frist con - vel dissitento vernehmen zu lassen, hierdurch abgeladen. Welchem Vorgangen, oder bei dessen Entstehung in der Sache ferner rechtlichen Ordnung nach verfahren werden sol. Signatum Bonn, den 15ten September 1785 Ad Mandatum F. L. L. Rasche G[erichts]sch[rei]b[e]r"

Da sich Riedler nicht meldete, brachte das Blatt am 24. Januar 1786 folgende Meldung:

\section{"Versteigerung.}

Bonn. Es wird hiermit bekannt gemacht, daß am Montag, den 6. Februar, laufenden Jahres, Nachmittags 2 Uhr, in d. Polls Behausung in der Bonngasse dahier, die von dem Mechanicus Riedlen daselbst zurückgelassene Sachen, bestehend in einige Hausmobilien, von Tischen, Kommoden, Bettstätte etc. sodann in allerhand Schreinergezeug, Fournier-Holz, einer Drehebank etc. auch in verschiedenen musicalischen Instrumenten, als eine Basgeige 
[Violoncello oder Kontrabass], Laute, und einigen Clavieren, worunter sich ein aufrechtstehender Flügel befindet, an den Meistbietenden gegen baare Zahlung versteigert werden sollen."

Das Pollsche Haus wird die Nummer 354 des Stadtplans von 1773 gewesen sein. ${ }^{130}$ Das heutige Beethoven-Haus hatte damals die Hausnummer 363. Die Gebäude waren also nur wenige Meter entfernt (acht Häuser lagen dazwischen) auf derselben Straßenseite gelegen, Riedlers Quartier ungefähr im Bereich des heutigen Bertha-von-Suttner-Platzes. Die Familie Beethoven wohnte in Riedlers Bonner Zeit allerdings bereits in der Rhein- bzw. Wenzelgasse.

\section{Derfeigerung.}

Bonn. Es wito biemit befannt gemant, Dap ain Frontag, Den 6. Fetruar, laus fenden Sabrs, Rademittags 2 ubr, in 0. polls zebaufung in Der Bonngafie Dabier, Die von bem Insedanicus Diteden dafelofit burúcfgelaffens Eaden, beftebeno in einigen Sausmobitien, von Sifकen, Rommoden.

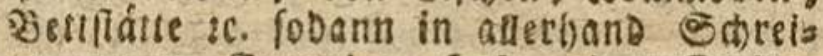
nergeseug, fourniers solh, einer Drebes bart sc. aud in verfobiebenen multcalifwen Inftuanenten, als einet sosogeige, raute, und einigen (Slatieren, morunter fid) ein aufredoffebender Flugel befinvet, an Den aneiffietenben gegen banre alblung vers freigert merben follen.

Riedler logierte und arbeitete also im "Musikerviertel". In der Bonngasse wohnten damals mehrere Hofmusiker. Nikolaus Simrock hat - allerdings erst einige Jahre nach Riedlers und Beethovens Bonner Zeit - seine Notenkopisterei (später seinen Verlag) genau gegenüber im Haus Bonngasse 351 eingerichtet.

Riedler dürfte also vermutlich auf der Flucht vor ungeduldig gewordenen Auftraggebern und Gläubigern Bonn bei Nacht und Nebel verlassen haben und untergetaucht sein. Vielleicht wurde er mit nicht leicht zu behebenden Reklamationen konfrontiert. Seine Spur verliert sich. Dementsprechend ist sein Sterbedatum, wie zu erwarten, weder in Oberkassel (wo die Bonner Protestanten ihre Gemeinde hatten) noch in Aldingen verzeichnet. ${ }^{131}$

Riedler scheint es allerdings nicht nur in Bonn

Inserat, in: Bönnisches Intelligenzblatt, 24. Januar 1786 (Universitäts- und Landesbibliothek Bonn) so ergangen zu sein. Oliver Hochadel zitiert einen Brief, der sich auf Stuttgart und einen chronologisch unmittelbar vor Bonn liegenden Vorfall bezieht:

"Mitunter macht sich der umherziehende Mechanikus auch aus dem Staub und lässt geprellte Handwerker zurück. Ein gewisser Riedler (?), der sich für einige Zeit in Stuttgart aufhält, gibt vor, 'er verreyse auf 4 Wochen, kam aber nicht mehr, und was er an allerley elektrischen und anderem Apparat in seinem Quartier zurückgelassen hatte, wurde subhastirt, reichte aber nicht hin, seine Schulden zu bezahlen." "132

Es ist durchaus möglich, ja sogar wahrscheinlich, dass Riedler wie viele andere Instrumentenbauer, die experimentierfreudig waren, seine Erfindungen nicht zur Serienreife oder -fertigung bringen konnte, aus handwerklichen Gründen oder weil ihm das Geld ausging. Die Meldung im Magazin der Musik hatte also wohl eher den Charakter einer Subskription. Für den jungen Beethoven entscheidend war aber weniger das Ergebnis als das Bemühen an sich, das Clavier und speziell das Pianoforte stetig weiterzuentwickeln im Sinne

196 | Michael Ladenburger

(C) 2020 by Böhlau Verlag GmbH \& Cie. KG, Köln

https://doi.org/10.7788/9783412519704 | CC BY-NC 4.0 
einer größeren Klangvielfalt. Es ist nicht vorstellbar, dass sich Beethoven und Riedler nicht mehrfach begegnet wären, fiel doch die Zeit des Orgelbaus in die Amtszeit des zweiten Hoforganisten, zu dem Beethoven im Februar 1784 ernannt worden war. Vermutlich nahm Beethovens spätere Fachsimpelei mit führenden Wiener Klavierbauern wie Nannette und Andreas Streicher, Matthäus Andreas Stein, Conrad Graf und Wilhelm Leschen (Löschen) hier ihren Ausgangspunkt.

Welche Auswirkungen Beethovens frühe Berührung mit hervorragenden Hammerklavieren in Bonn nach sich zog, zeigt der erste ausführliche Bericht über sein Klavierspiel, der 1791 in der führenden süddeutschen Musikzeitschrift erschien. Auch wenn er oft zitiert wurde, kann er hier nicht fehlen.

"Noch hörte ich einen der größten Spieler auf dem Klavier, den lieben guten Bethofen; von welchem in der speierischen Blumenlese vom Jahr 1783. Sachen erschienen, die er schon im 11. Jahr gesezt hat. Zwar ließ er sich nicht im öffentlichen Konzert hören; weil vielleicht das Instrument seinen Wünschen nicht entsprach; es war ein spathischer Flügel, und er ist in Bonn gewohnt, nur auf einem Steinischen zu spielen. Indessen, was mir unendlich lieber war, hörte ich ihn phantasiren, ja ich wurde sogar selbst aufgefordert, ihm ein Thema zu Veränderungen aufzugeben. Man kann die Virtuosengröße dieses lieben, leisegestimmten Mannes, wie ich glaube, sicher berechnen, nach dem beinahe unerschöpflichen Reichthum seiner Ideen, nach der ganz eigenen Manier des Ausdruks seines Spiels, und nach der Fertigkeit, mit welcher er spielt. Ich wüßte also nicht, was ihm zur Größe des Künstlers noch fehlen sollte. Ich habe Voglern [Abbé Georg Joseph Vogler ${ }^{133}$ ] auf dem Fortepiano (von seinem Orgelspiel urtheile ich nicht, weil ich ihn nie auf der Orgel hörte) gehört, oft gehört, und Stundenlang gehört, und immer seine auserordentliche Fertigkeit bewundert, aber Bethofen ist ausser der Fertigkeit sprechender, bedeutender, ausdrucksvoller, kurz, mehr für das Herz: also ein so guter Adagio- als Allegrospieler. Selbst die sämmtlichen vortreflichen Spieler dieser Kapelle sind seine Bewunderer, und ganz Ohr wenn er spielt. Nur er ist der Bescheidene, ohne alle Ansprüche. Indes gestand er doch, daß er auf seinen Reisen, die ihn sein Kurfürst machen ließ, bei den bekanntesten guten Klavierspielern selten das gefunden habe, was er zu erwarten sich berechtigt geglaubt hätte: Sein Spiel unterscheidet sich auch so sehr von der gewöhnlichen Art das Klavier zu behandeln, daß es scheint, als habe er sich einen ganz eigenen Weg bahnen wollen, um zu dem Ziel der Vollendung zu kommen, an welchem er jezt steht. Hätte [= Wäre] ich dem dringenden Wunsche meines Freundes Bethofen, den auch Hr. Winneberger unterstützte, gefolgt, und wäre noch einen Tag in Mergentheim geblieben, ich glaube, Herr Bethofen hätte mir Stundenlang vorgespielt, und in der Gesellschaft dieser beiden großen Künstler, hätte sich der Tag für mich in einen Tag der süssesten Wonne verwandelt."134 
Entscheidend an diesem Bericht ist für unser Thema, dass Beethoven von Bonn her verwöhnt war und zur Demonstration seiner pianistischen Kunst Instrumente von Johann Andreas Stein bedurfte, die er dem vorhandenen Instrument des eingangs bereits erwähnten Franz Jakob Spath, bei dem es sich um einen Tangentenflügel gehandelt haben dürfte, vorzog - nicht im Sinne des relativen Bevorzugens, sondern einer conditio sine qua non für einen öffentlichen Auftritt in herausgehobenem Rahmen. Die in Bonn beheimateten Hammerflügel von Johann Andreas Stein können nicht älter als zehn Jahre gewesen sein, denn Stein baute den modernen und Maßstab gewordenen Bautyp erst seit 1780 und ein Kunde in Bonn wird in seinem bis 1777 geführten Notizbuch nicht erwähnt. ${ }^{135}$

Kehren wir noch einmal zum Bonner Klavierrepertoire zurück: In NeefeDrucken findet man meist Terrassendynamik, nur in wenigen Werken in größerer Zahl auch crescendi, einmal scemando, gleichbedeutend mit decrescendo. ${ }^{136}$ Es gibt aber auch Werke ganz ohne dynamische Angaben, zum Beispiel die Veränderungen über "Kunz fand einst einen armen Mann", 1774 bei Schwickert in Leipzig erschienen. ${ }^{137}$ Die im Vorjahr ebenda erschienenen 12 Klavier-Sonaten hat er, wie er im Vorwort schildert, für die doch überwiegende Zahl der "Liebhaber des Klavichords, welche zu ihrem eigenen Vergnügen nichts mehr, als ein Solo interessiren" geschrieben, während doch ansonsten meist Sonaten mit Violine (teils ad libitum) dominierten. Das Clavichord war, wie man auch seinen Dilettanterien von 1785 entnehmen kann, eindeutig sein Lieblingsinstrument.

„Allein die wahre Art das Klavier zu spielen, so wie die guten Kompositionen für dieses (sehr in Mode gekommene) Instrument sind noch so selten, als ehedem. Die wahre Spielart besteht nicht blos in Fertigkeit, sondern auch in Expreßion, deren das Klavier (besonders das Klavichord) so fähig ist. Wenn die Herren und Damen eine Edelmannische Sinfonie auf ihren Hämmerklavieren abtrommeln können, dann denken sie Wunder gethan zu haben, und sie finden immer Zuhörer, die weniger verstehen, und ihnen doch mit einer Kennermiene ein gravitätisches Bravo zunicken”. ... „Die [Carl Philipp Emanuel] Bachischen Adagios erfordern eine genaue Bekanntschaft mit den Modificationen, deren das Klavichord fähig ist, wollen tief aus der Seele vorgetragen seyn." ${ }^{\prime 138}$

Späterhatte sich dann auch bei ihm dieWaage zugunsten des Hammerklaviers geneigt, wie man an der reichen dynamischen Auszeichnung seiner Variationen über "Das Frühstück schmeckt viel besser hier" (1793) und anderer Werke ablesen kann. Wenn in Ausgaben keine dynamischen Angaben zu finden sind, heißt dies natürlich nicht, dass ein Pianist, dem ein Hammerklavier zur Verfügung stand, die neuen Möglichkeiten nicht eigenständig genutzt hätte. Verleger haben noch lange Zeit auf den Titelblättern bewusst "für Klavier oder Orgel" angegeben ${ }^{139}$, um eine möglichst breite Käuferschicht anzusprechen. 


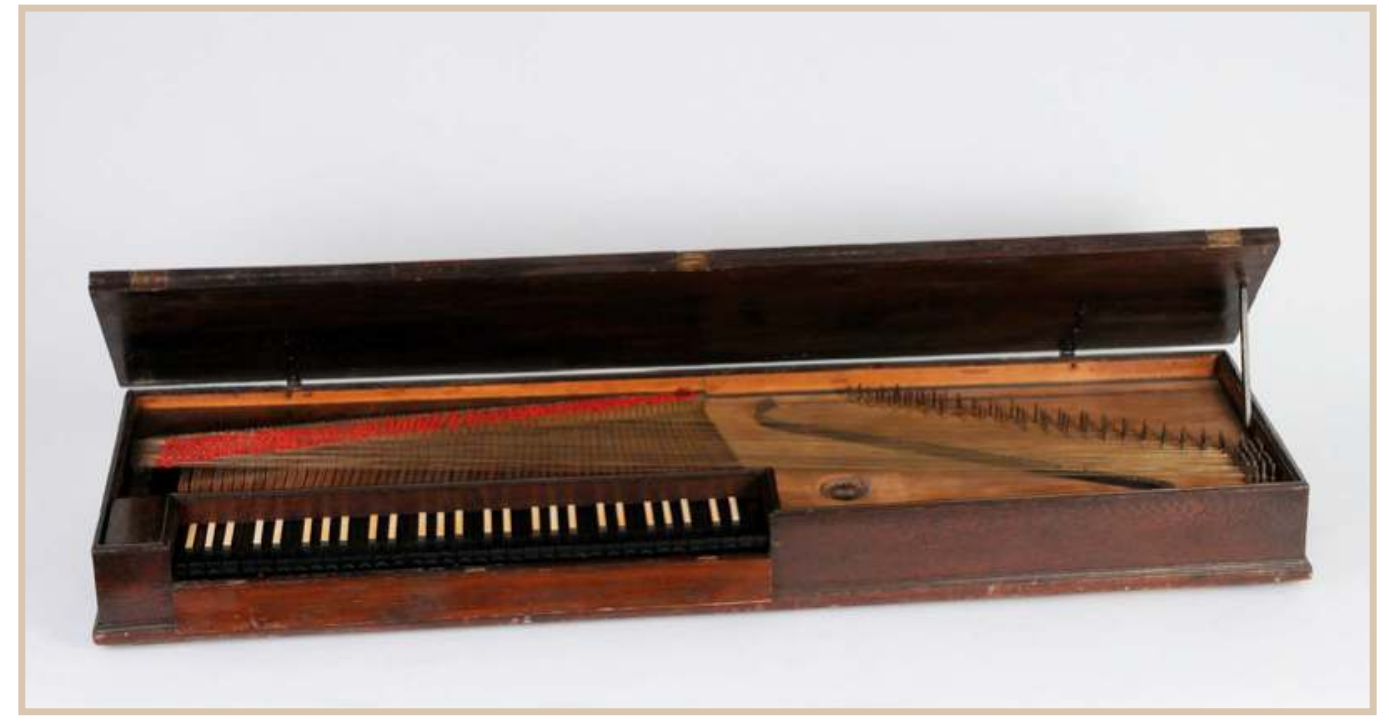

Christian Ernst Friederici, Bundfreies Clavichord, Gera 1765 (Musikinstrumentenmuseum der Universität Leipzig)

Mit Beethoven als Speerspitze entstand nun aber Klaviermusik, die nur noch auf dem modernsten Typ des Hammerklaviers adäquat zum Klingen gebracht werden konnte. Außer an den bereits genannten Kriterien kann man das unter anderem am geforderten größeren Tonumfang festmachen, der zu Beethovens Lebzeiten von 5 auf 6 1/2 Oktaven anstieg, ebenso an klanglichen Vorschriften wie die bei Beethoven allerdings erst 1816, also erst sehr spät notierte Anweisung „una corda”, die eine Ausdünnung des Klanges bewirkt, da nur eine (auf einem Wiener Instrument in der Regel zwei) statt drei Saiten angeschlagen wird, eine Klangmodifikation die ihm aber bereits 1802 besonders wichtig war. ${ }^{140}$

Ganz am Rande sei noch erwähnt, dass ein bundfreies Reiseclavichord ${ }^{141}$, 1786 erbaut von dem nach Kopenhagen übersiedelten, aus Deutschland stammenden Otto Joachim Tieffenbrunn, wiederholt als aus Beethovens Besitz bezeichnet wurde. Für diese Zuschreibung gibt es allerdings keinerlei Beleg, ebenso wenig wie für die These, Beethoven habe das Instrument 1787 bzw. 1792 auf seinen beiden Reisen nach Wien im Gepäck gehabt. ${ }^{142}$ Sehr wahrscheinlich besaß die Familie Beethoven ein normales Clavichord, über das wir aber keine Informationen haben.

Die in Bonn vorhandenen modernen Hammerklaviere haben schon in Beethovens Frühwerk Spuren hinterlassen. Die Kurfürst Maximilian Friedrich gewidmeten drei Klaviersonaten WoO 47, 1783 als zweites Werk von Beethoven im Druck erschienen, und das chronologisch erste Klavierkonzert Es-Dur WoO 4, 1784 komponiert, enthalten dynamische Angaben und zwar nicht nur im Sinne von Terrassendynamik forte bzw. piano, sondern auch schon ein crescendo sowie zahlreiche $\mathrm{fp}$ (fortepiano). Das noch in Bonn begonnene und hier wohl in einer ersten Fassung uraufgeführte 2. Klavierkonzert op. 19 bietet 


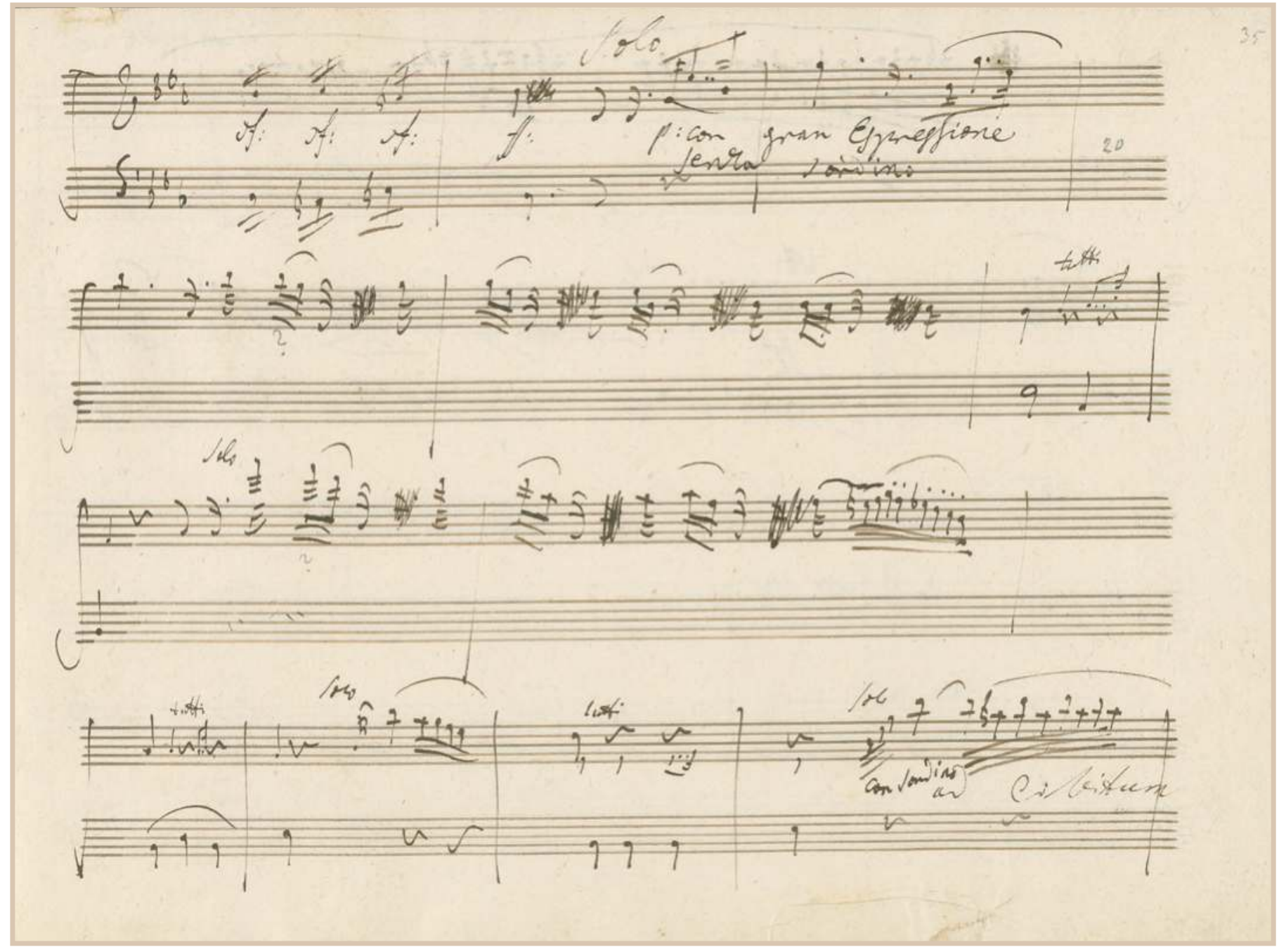

Beethoven, 2. Klavierkonzert op. 19, Solostimme, Autograph (Beethoven-Haus Bonn, Sammlung H. C. Bodmer) in seiner endgültigen Version von 1801 im 2. Satz revolutionäre Klangeffekte durch Dämpferaufhebung über mehrere Takte und Harmoniewechsel hinweg, was ein dem Sfumato in der Malerei vergleichbares Ergebnis zeitigt. Ob diese auch schon in der Frühfassung enthalten waren, lässt sich nicht sagen, da Beethoven den Solopart erst für die Drucklegung endgültig fixierte, während er bis dahin als Solist eher improvisierend vorging, es jedenfalls nicht nötig hatte, einen vollständig ausgearbeiteten Solopart auf dem Notenpult liegen zu haben, wie wir noch aus einem Bericht von Ignaz Ritter von Seyfried wissen, der Beethoven 1803 bei der Uraufführung des 3. Klavierkonzerts op. 37 umblätterte und ins Schleudern kam, da er viele leere Blätter und ansonsten vermutlich überwiegend nur eine Leitstimme in den Noten vorfand.

Auf welchem Instrument Beethoven konzertierte, als er im November 1783 im Buitenhof (dem heutigen niederländischen Parlamentsgebäude) in s'Gra-

200 | Michael Ladenburger

(C) 2020 by Böhlau Verlag GmbH \& Cie. KG, Köln

https://doi.org/10.7788/9783412519704 | CC BY-NC 4.0 
venhage (Den Haag) vor dem Statthalter der Niederlande Willem V. Batavus von Nassau-Oranien, von Streichern begleitet, spielte und fürstlich entlohnt wurde, ist noch nicht geklärt. Da Beethoven wohl bei dieser Gelegenheit bewusst wurde, dass er ein eigenes Klavierkonzert komponieren sollte - eine Absicht, die er im Jahr darauf umsetzte -, wäre es natürlich reizvoll zu wissen, ob bei diesen Überlegungen auch das Instrument eine Rolle spielte. Willem V. besaß und spielte ein Hackbrett, 1769 von Antonio Battaglia in Mailand erbaut. ${ }^{143}$ Es gehört klanglich in den Rahmen der hier besprochenen instrumentenbaulichen Versuche im Übergang von Cembalo/Clavichord zum Hammerklavier, ist allerdings kein Tasteninstrument, sondern wird wie das von Pantaleon Hebenstreit Anfang des 18. Jahrhunderts erfundene und von Gottfried Silbermann gebaute Pantalon/Pantaleon mit Holzschlägeln, die auf einer Seite mit Leder überzogen waren, gespielt. Es handelt sich mithin um eine Vorform des Hammerklaviers.

Wie wir gesehen haben, konnte Beethoven aus Bonn nicht nur das zu Recht oft beschworene aufgeklärte Gedankengut, das sein Weltbild prägte, mit nach Wien nehmen, sondern auf musikalischem Gebiet auch ein besonderes Sensorium für Klangvielfalt, das sich noch in einigen seiner in Bonn, dann aber in einzigartiger Weise in seinen in Wien entstandenen Klavierwerken widerspiegelte. Dies geschah interessanterweise nicht in seinen ersten Wiener Jahren, sondern schlug sich in den gedruckten Notentexten parallel zur fortlaufenden Entwicklung und Verbreitung der Hammerklaviere schwerpunktmäBig erst ab 1801 nieder.

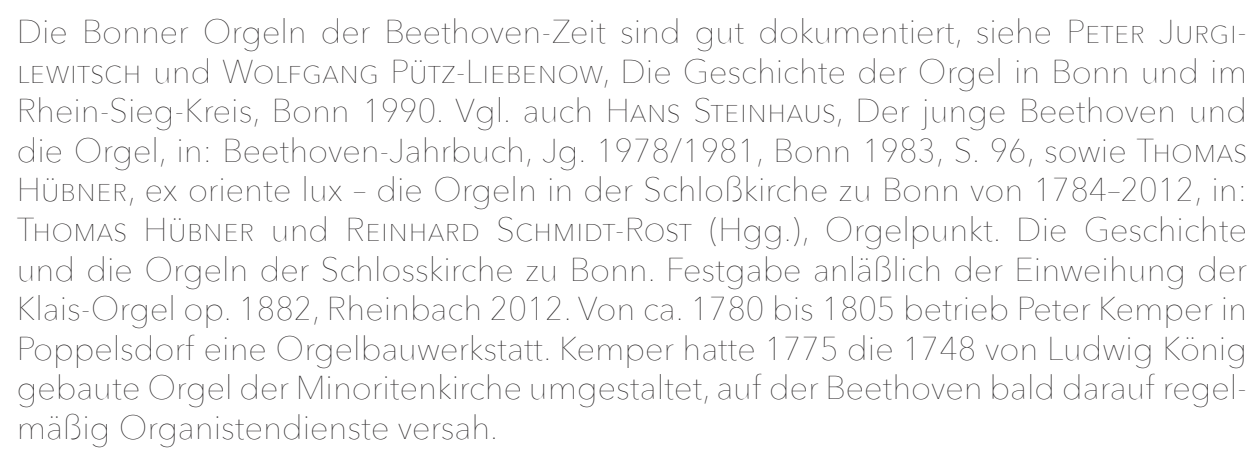

[Christian GOtTlob NeEFE], Nachricht von der churfürstlich-cöllnischen Hofcapelle zu Bonn und andern Tonkünstlern daselbst. den 30sten März 1783, in: CARL FrIEDRICH Cramer (Hg.), Magazin der Musik, Hamburg 1, 1783, S. 377-396. Der Bericht über Bonn ist zusammen mit den anderen im Februar/März d.J. im Magazin der Musik erschienenen wiederabgedruckt in: CHRISTIAN AUGUST VON BERTRAM (Hg.), Litteratur- und Theater-Zeitung, Nr. XXXIV, Berlin, 23.8.1783. Neefes Bericht zu Riedler wird hier auf S. 544 gekürzt wiedergegeben. Freundlicher Hinweis von Stefanie Kuban.

Bonn, vom 8ten April, 1787 [vermutlich Christian GOTtlob NeEFE], in: Cramer, Magazin (wie Anm. 2), Hamburg 2, 1787, S. $1385 f$.

Der Clavierinstrumentenbestand und -instrumentenbau in Bonn als Anregung für den jungen Beethoven | 201 (c) 2020 by Böhlau Verlag GmbH \& Cie. KG, Köln

https://doi.org/10.7788/9783412519704 | CC BY-NC 4.0 
Vgl. hierzu auch den Beitrag von JULIA RONGE in diesem Band.

NORBERT SCHLOSSMACHER, "Haydn-Kult" in Bonn. Zur Geschichte des Mastiaux'schen Hauses am Alten Zoll, in: INGRID BODSCH (Hg.), Joseph Haydn und Bonn, Bonn 2001, S. 74-99

ERNST LUDWIG GERBER, Historisch-Biographisches Lexicon der Tonkünstler welches Nachrichten von dem Leben und Werken musikalischer Schriftsteller, berühmter Componisten, Sänger, Meister auf Instrumenten, Dilettanten, Orgel- und Instrumentenmacher, enthält, Leipzig 1790

JACOB AdLung, Anleitung zur musikalischen Gelahrtheit, Dresden/Lepzig 21783, S. 660-693.

8 Daniel GotTlob Türk, Klavierschule, oder Anweisung zum Klavierspielen für Lehrer und Lernende, 1789, S. 2f. 1802 erschien wiederum im Eigenverlag eine neue vermehrte und verbesserte Ausgabe, die ebenfalls in Leipzig und Halle vertrieben wurde.

Über die Hammerklaviere der Zeit und ihre Sonderformen hat Michael Latcham eine Vielzahl höchst informativer Publikationen verfasst, auf die hier ebenso zurückgegriffen werden konnte wie dankenswerterweise auf zahlreiche freundschaftlich-fachkundige Hinweise des Autors. Den älteren Erkenntnisstand in Bezug auf Beethovens Instrumentarium der Bonner und frühen Wiener Zeit referiert TILMAN SKOWRANECK, The Keyboard Instruments of the young Beethoven, in: SCOTT BURNHAM und MICHAEL P. STEINBERG (Hgg.), Beethoven and his world, Princeton 2000, S. 151-192. Eine spezielle Sonderform ist das 1780 von Joseph Gundacker Graf Thürheim erfundene sechsmanualige Pianoforte pour la parfait Harmonie (einzig erhaltenes Exemplar: Johann Jakob Könneke zugeschrieben, von Andreas Rebele signiert, Wien 1796, Wien, Kunsthistorisches Museum, Sammlung Alter Musikinstrumente, Inv. Nr. 610), bei dem nicht die ansonsten hier im Zentrum stehenden klanglichen oder anschlagstechnischen Qualitäten im Fokus standen, sondern bei dem höchst aufwändig (32 statt 12 Tasten pro Oktave) das Problem der ungleichschwebenden Stimmung (Reinterz-Stimmung) zu lösen getrachtet wurde. Für nähere Angaben siehe ANNA SCHIRLBAUER, Das Elternhaus der Barbara Ployer und das Pianoforte "harmonie parfait" im Spiegel der Korrespondenz Ployer - Thürheim (www.anna-schirlbauer.com/publikationen, eingesehen am 31.12.2019). Die Erfindung ist allerdings nicht gänzlich neu, sondern hat einen Vorläufer im Clavemusicum Omnitonium Modulis Diatonicis, Cromaticis, et Enarmoniis von Vito Trasuntino von 1606 (Bologna, Museo Civico Medievale, Inv. Nr. 1766).

1801 erfand Röllig auch ein „musikalisches Geigenbogen-Instrument mit einer Klaviatur" und schon zuvor die Xänorphica, ein Streichinstrument, das man mittels einer Klaviatur spielte. Vgl. CURT SACHS, Real-Lexikon der Musikinstrumente zugleich ein Polyglossar für das ganze Instrumentengebiet, Berlin 1913, S. $285 f ., 360$ und 424.

Autograph Beethoven-Haus Bonn, Dauerleihgabe der Julius-Wegelerschen-Familienstiftung, W 2. Vgl. auch den Brief Franz Gerhard Wegelers an Anton Schindler, 23.12.1827, in: Staatsbibliothek zu Berlin - Preußischer Kulturbesitz, Mus.ms.autogr. Beethoven 38,28

12 Vgl. Christian Ahrens, Quellen zur Verwendung von Fortepiano und Clavichord in Deutschland bis 1850, in: Christian Ahrens und GreGor KLINKE (Hgg.), Von Mozart bis Chopin. Das Fortepiano 1770-1850. Tagungsbericht Herne 2007, München/Salzburg 2010, S. 165-177 
Zitiert nach Uta Goebl-Streicher, JutTa Streicher und Michael Ladenburger (Hgg.), "Diesem Menschen hätte ich mein ganzes Leben widmen mögen". Beethoven und die Wiener Klavierbauer Nannette und Andreas Streicher, Bonn 1999, S. 126. Darin auch Beethovens sehr persönlich gefärbtes Urteil über Mechanik und Anschlag eines Hammerflügels, den er 1796 für ein Konzert in Preßburg geliehen bekam; ebd., S. 186-189. Vgl. ebd., S. 133-136.

15 Neben dem obligaten Lautenzug bei Cembali und Spinetten gab es neben "Streichinstrumenten" mit Klaviatur bereits im frühen 18. Jahrhundert auch "Zupfinstrumente" mit Klaviatur wie das Lauten-Clavicymbel von Johann Christoph Fleischer (Hamburg, um 1718), das die reiche Lautenliteratur spieltechnisch für Clavicynisten erschließen sollte, ohne wesentliche Veränderungen beim Klang in Kauf nehmen zu müssen. Ein solches Instrument wurde 1980 nach einer zeitgenössischen Beschreibung von Rudolf Richter nachgebaut; beschrieben und abgebildet in: ULRICH PRINZ unter Mitarbeit von KONRAD KüSTER (Hgg.), 300 Jahre Johann Sebastian Bach. Eine Ausstellung der Internationalen Bachakademie in der Staatsgalerie Stuttgart. Katalog, Tutzing 1985, S. $364 f$.

Erfurt 1758, S. 576f. Die Frankfurter Quelle kann nicht identifiziert werden, beruht möglicherweise auf einem Irrtum. Diese Angabe fehlt in der 2. Auflage von 1783

Landesarchiv Nordrhein-Westfalen, Abt. Rheinland (LAV NRW R), Kurköln VI, Nr. 708. Für hilfreiche Auskünfte zu einschlägigen Archivbeständen sei Martin Früh gedankt. Ebd., Schreiben vom 14.10.1751.

In: Musikalische Nachrichten und Anmerkungen 18, Leipzig 1770, S. 142

LAV NRW R, Kurköln II, Nr. 246, f. 1 v.

Ebd., f. $3 \mathrm{v}$ und $14 \mathrm{v}$.

Ebd., f. 58v. In einem im Juni 1772 erstellten Inventar (ebd., Kurköln II, Nr. 252) fehlen demgemäß diese Instrumente, f. 44 ist für das zweite "Garde des Robes Zimmer" ein gläserner Schrank verzeichnet, "worin Musique" aufbewahrt worden war, "die Musique ist aber verkauft". Für die damalige Zeit mit ihrem Hunger nach neuester Musik ist dies ein normaler Vorgang. Ein Teil des Musikalienbestandes (die weniger der Mode unterworfene Kirchenmusik sowie Opern) waren allerdings am 5.4.1766 Beethovens Großvater als Kapellmeister übergeben und von diesem quittiert worden (ebd., Kurköln II, Nr. 330). Von 37 "Musicalien Bücher[n]" konnten am 30.4.1766 nur wenige verkauft werden (ebd., Kurköln II, Nr. 271, Positionen 894-930)

Ebd., Kurköln II, Nr. 275, f. 99. Sie bezahlte dafür den stattlichen Preis von 71 Reichstaler. Maria Johanna Caroline Josepha Antonia von Satzenhoven (1728-1785), war seit 1762 Äbtissin des adeligen Damenstifts Vilich und Lebensgefährtin von Staatsminister Caspar Anton von Belderbusch.

Zu den Käufern gehörten nicht zuletzt Mitglieder des Hofstaates bzw. Hofbedienstete. Kaplan Abbé Clemens Dobbeler kaufte eine Geige. Er war ein begeisterter Geiger, der nie ohne sein Instrument reiste und Beethovens Originalität früh im 1790/91 komponierten Trio Es-Dur WoO 38 entdeckte; vgl. LuDWIG SCHIEDERMAIR, Der junge Beethoven, Bonn 1925, S. 222f. An weiteren Käufern aus dem Umfeld Beethovens seien hier nur die Namen Graf Hatzfeld, Kügelgen, Graf Salm und von Weichs genannt.

LAV NRW R, Kurköln II, Nr. 265, f. 173r. Sie wohnte im Himmeroder Hof in der Wenzelgasse Nr. 543, Beethoven wohnte in seinen letzten Bonner Jahren schräg vis-à-vis in Nr. 518 
In diesem Gebäude (1773 die Nrn. 83 und 84: Hoffstr./Fürstenstr. 2) gab es im 1. Stock einen Redoutensaal. In den 1790er Jahren lebte dort auch Beethovens Mentor Franz Anton Ries. Vgl. hierzu ausführlich den Beitrag von BARBARA Mülhens-MolderIngs in diesem Band.

27 Cöllenstr. Nr. 370. Ihm gehörte auch das Haus Bonngasse Nr. 351, das 1803 über mehrere Zwischenbesitzer an Nikolaus Simrock verkauft wurde. Broggia erwarb aus dem Nachlass Clemens Augusts auch eine Viola da Gamba (LAV NRW R, Kurköln II, Nr. 275, f. 103v). Sämtliche Ortsangaben gehen auf Alexander Wolfshohl zurück.

(C) 2020 by Böhlau Verlag GmbH \& Cie. KG, Köln https://doi.org/10.7788/9783412519704 | CC BY-NC 4.0 Nr. 277, f. 47v. beiliegenden Umschlag). Nicole Kämpken. für herzlich gedankt sei

Cramer, Magazin (wie Anm. 2), 26.7.1787, S. $1385 f$ nisse, Bonn, 21.3.1785 18. Jahrhundert, Tutzing 2001, S. 128f., 159 Wolff-Metternich (S. 160) und Belderbusch (S. 166f). um cum Taxa ... in dem Sommer Apartement hiesiger Residentz", in: ebd., Kurköln II,

Ebd., f. 135v. Das andere Instrument konnte zumindest in diesem Zuge nicht verkauft werden. Der wichtigste Unterschied zwischen beiden dürfte ohnehin die Fassung des Gehäuses gewesen sein. Breuning erwarb am 14.4.1766 für 13 Reichstaler noch einen Spiegel mit vergoldetem Rahmen. Beethovens Großvater oder Vater sind als Käufer mit einem Betrag von 29 Rtl. 55 Stüber aufgeführt (ebd., Kurköln II, Nr. 279, auf einem

Beethoven-Haus Bonn, Leihgabe Karl-Oswald von Nell 1. Abgebildet im Beitrag von

In: Cramer, Magazin (wie Anm. 2), 2. Hälfte 1783, S. 1364-1367 (Subskriptionsaufruf, datiert 23.8.1783) und 24.4.1787, S. 1308-1310 (Rezension). Vgl. BERNHARD R. ApPEL, Charakterstück, in: Die Musik in Geschichte und Gegenwart, Teil 1, Bd. 2 (21995), Sp. 636-642. Gottlieb Christian war der Bruder des berühmten Malers Heinrich Füger, der 1783 zum Vizedirektor der Wiener Akademie berufen wurde.

Die Identifizierung der Subskribentinnen verdanke ich Alexander Wolfshohl, dem da-

Vgl. hierzu den Beitrag von ALEXANDER WOLFSHOHL in diesem Band

Andrea Luchesi. Er war mit (Josepha) Antonetta d'Antoine verheiratet. Sie hatten eine Tochter und vier Söhne, von denen der nach dem Kurfürsten benannte Maximilian Friederich (*11.12.1775), und M. Jakob Ferdinand (*18.12.1777) musikalisch besonders begabt waren. Vgl. auch CLAUDIA VALDER-KNECHTGES, Andrea Luchesi, ein Italiener im Umkreis des jungen Beethoven. Zur Auffindung von sechs Violinsonaten des letzten Bonner Hofkapellmeisters, in: Bonner Geschichtsblätter 40, 1990, S. 29-56.

Christan Gottlob Neefe, Dilettanterien, [Bonn] 1785, S. 30f. Neefe widmet dem "Fräulein Hannchen" auch eine Eloge, in: Beiträge zur Ausbreitung nützlicher Kennt-

Die Ausgabe war erst der siebte von Simrock verlegte Musikdruck.

UtA GOeBl-Streicher (Hg.), Das Stammbuch der Nannette Stein (1787-1793). Streiflichter auf Kultur und Gesellschaft in Augsburg und Süddeutschland im ausgehenden

Vgl. Michael Ladenburger, Neue Dokumente zu zwei Kopisten am Bonner kurfürstliche Hof und ihrer Zusammenarbeit mit Beethovens Vater, in: Bonner Beethoven-Studien 9, Bonn 2011, S. 160ff. Dort auch Informationen zum Musikrepertoire im Hause

So in: Churfürstlich-cöllnischer Hof-Kalender auf das Jahr 1782, S. 37 


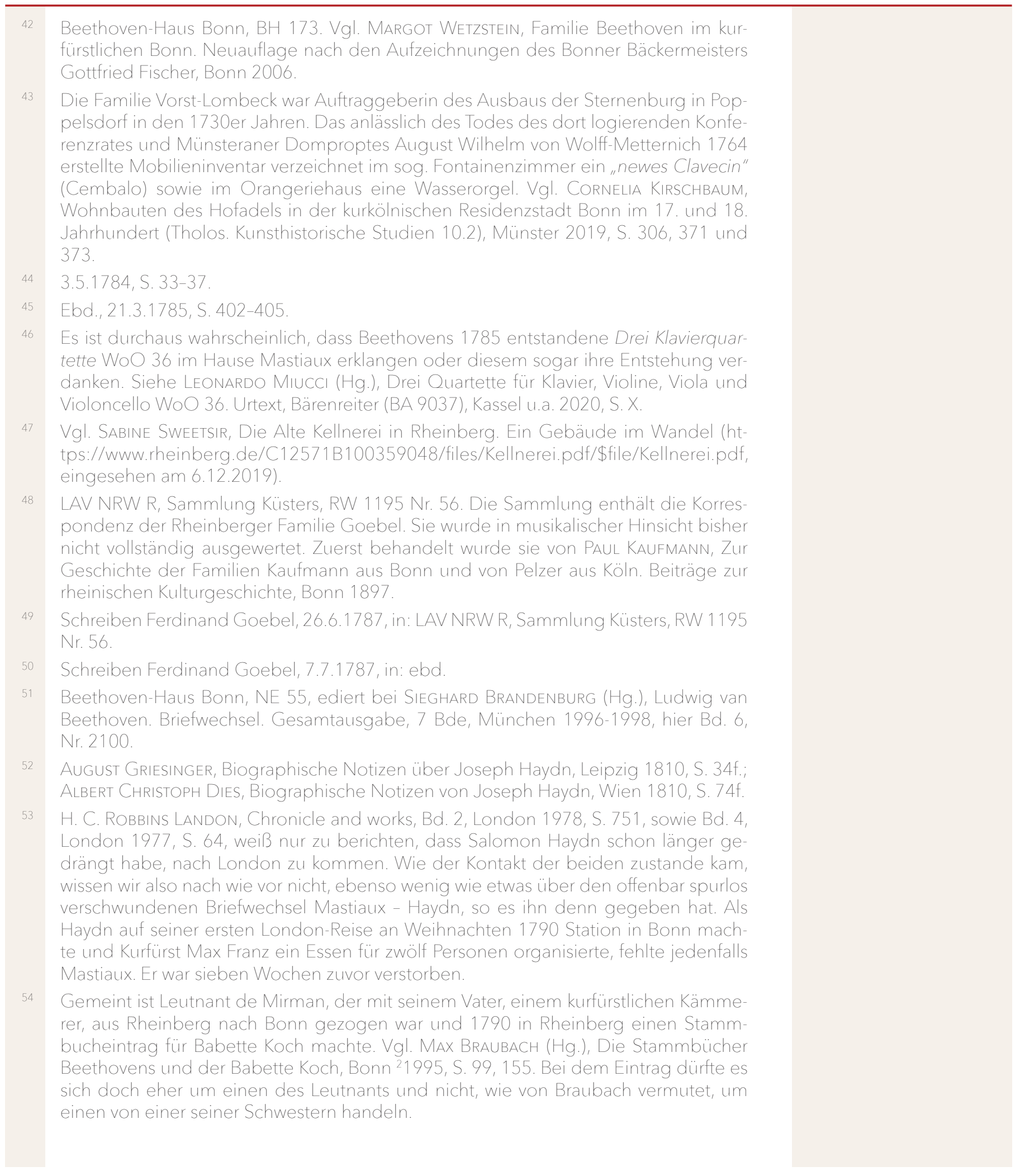

Der Clavierinstrumentenbestand und -instrumentenbau in Bonn als Anregung für den jungen Beethoven | 205 
Mastiaux an Franz Goebel, 17.11.1780, in: LAV NRW R, Sammlung Küsters, RW 1195 Nr. 52.

56 Das Pedal kann sich eventuell auf ein „normales” Klavierpedal zur Klangveränderung, eher aber auf die Erzeugung des Windes für den Pfeifenzug oder auf das Bespielen des Orgelregisters bezogen haben, wie es später etwa Klinckerfuß in Stuttgart baute. Ein Kombinationsinstrument Hammerklavier/Orgel kündigte zu dieser Zeit in Koblenz Peter Senft an: Anzeige im Gnädigst privilegierten Koblenzer Intelligenz-Blatt, 14.4.1783, sowie Peter Carl Bauer, der drei unterschiedliche Kombinationsinstrumente anbot, von denen eines "mit einer blasenden Flautraverse" versehen war. Die Annoncen sind zitiert bei RUDOLF EWERHART, Die Orgel- und Claviermacher Senft in Koblenz und Augsburg, Tutzing 2011, S. 151-153. Ein Glockenspielklavier wurde 1793 bei der Bonner Erstaufführung von Mozarts Zauberflöte eingesetzt. Neefe musste den Glockenspiel-Part adaptieren, da zunächst nur ein Instrument mit geringerem Tonumfang zur Verfügung stand, ehe dann ein größeres gefunden werden konnte (das damals verwendete Stimmenmaterial aus der kurfürstlichen Sammlung heute: Modena, Biblioteca Estense Universitaria, Mus.787, f. 271a).

In: Cramer, Magazin (wie Anm. 2), S. 392.

Ebd., S. 393

LAV NRW R, Sammlung Küsters, RW 1195 Nr. 52. Dort auch die folgenden Zitate.

Zum Beispiel Holyrood Palace, Edinburgh. Ein (mit täuschender Absicht) „Anderias Ruckers Antverpiae 1636" signiertes, 1787 erbautes Instrument von Taskin befindet sich in der Sammlung Beurmann, Museum für Kunst und Gewerbe Hamburg, Vgl. Andreas Beurmann, Historische Tasteninstrumente. Cembali Spinette Virginale Clavichorde, München etc. 2000, S. 114-123. Taskin baute seit 1768 ein "peau de buffle”Register. Die Kiele sind mit weichem Büffelleder überzogen. Dies ergibt einen Klang, der eher einem Streich- denn einem Zupfinstrument entspricht - einer von den vielen Versuchen, dem Cembalo andere Klangfarben und zumindest geringfügige dynamische Variabilitätsmöglichkeiten zu erschließen.

${ }_{61}$ GRANT O'BRIEN, Ruckers. A harpsichord and virginal building tradition, Cambridge etc. 1990. Ein auf 1669 datiertes und signiertes Cembalo von Petrus Johannes Couchet befindet sich im Rijksmuseum Amsterdam.

Ebd., S. 9, 12, 146, 157

Das älteste erhaltene, um 1470/80 erbaute Cembalo (London, Royal College of Music) hat diese Bauform.

Es ist kein Zufall und für unsere Zeit bezeichnend, dass nach sechs Dekaden zunehmend historisch informierter Aufführungspraxis diese "Werkzeuge der Empfindsamkeit" fröhliche Urständ feiern im vibrato-befähigten Synthesizer "Osmose" der Firma Expressive E, siehe: Die Macht der Maschinen. Des Dudels Kern, in: Die Zeit, 3.1.2020, S. 33.

Zu hören im Konzertraum des Beethoven-Hauses Bonn.

Für entsprechende Recherchen im Stadtarchiv Gera sei Ute Schlicke gedankt.

Dressler wurde am 13.8.1732 im thüringischen Greußen geboren. Seine Mutter hieß Catharina Elisabeth, geborene Renner. Taufpaten waren mit Tobias Christoph Reuschel, Johann Ernst Schuchardt und Magdalena Sophie Sachs Ortsansässige. Siehe: Kirchenbuch Greußen, Landeskirchenarchiv Eisenach, K 18/18-3, S. 962. Freundlicher Hinweis von Ute Kaufmann, Landeskirchenarchiv Eisenach. 


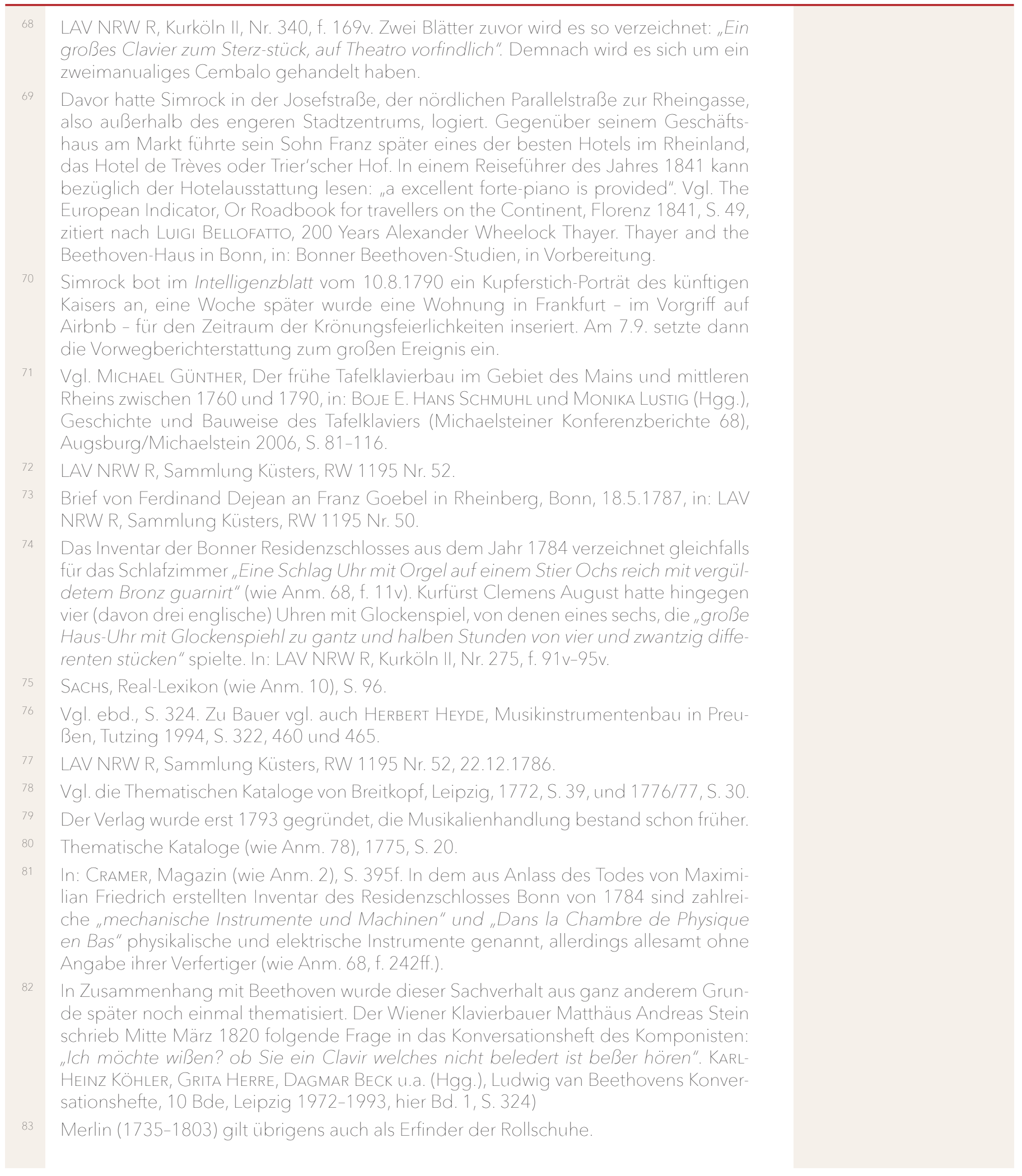

Der Clavierinstrumentenbestand und -instrumentenbau in Bonn als Anregung für den jungen Beethoven | 207 (C) 2020 by Böhlau Verlag GmbH \& Cie. KG, Köln

https://doi.org/10.7788/9783412519704 | CC BY-NC 4.0 
Einen umfassenden Überblick über alle Formen von Kombinationsinstrumenten Cembalo - Klavier bietet MICHAEL LATCHAM, The combination of the piano and the harpsichord throughout the eigtheenth century, in: THOMAS STEINER (Hg.), Instruments à claviers - expressivité et flexibilité sonore. Keyboard Instruments - Flexibility and Expression. Tagungsbericht Lausanne 2002, Bern etc. 2004, S. 113-152, bzw. DERS.., String length in pianos and harpsichords, in: AHRENS, Quellen (wie Anm. 12), S. $76 f$.

Ein Vis-à-vis-Cembalo aus der Zeit um 1700 ist dargestellt auf einer anonymen Tuschfederzeichnung in der Bibliothéque Nationale, Paris. Eine Abbildung bringt MICHAEL LATCHAM, The notebook of Johann Andreas Stein: facsimile - transcription - translation, Wilhelmshaven 2014, Bd. II, S. 434

"Nach der Erfindung Schröters [in Nordhausen] kann man bei einerlei Registern [i.e. unveränderter Registrierung] auf der Orgel die angenehmste der Hauptveränderungen, nämlich das Sanfte und Starke, oder das forte und piano, ohne Umstände und dadurch hervor bringen, daß die Windlade so eingerichtet wird, daß der Wind in sie auf sieben verschiedenen Wegen hinein geführt wird. Die Ladenventile werden nach sieben verschiedenen Wind graden hinaufgedrükkt; und man höret bloß die schwächsten Stimmen, wenn man die Tasten schwach niederdrükkt; hingegen alle gezogne Stimmen, so bald man die Tastatur stark drükkt." Johann SAmuel Halle, Die Kunst des Orgelbaus, Eigenverlag, Brandenburg 1779, S. 179. Es ist wörtlich zitiert in Justin Heinrich Knechts Vollständiger Orgelschule für Anfänger und Geübtere, 2. Abteilung, Breitkopf, Leipzig 1796, S. 30, die sich in Beethovens Nachlass befand. Eine solche Orgel hat sich in Beethoven weiterem Wirkungsfeld in Eckenhagen/Bergisches Land erhalten und zwar von Johann Christian Kleine, allerdings erst 1794/95 erbaut, also kurz nach Beethovens Umzug nach Wien. Kleine baute eine "Koppel Forte - Piano" ein. Drückt man die Taste nur ca. den halben Tastengang, so sprechen nur die Register des 1. Manuals (Positiv) an, drückt man die Taste komplett, so schalten sich die Register der 2. Manuals (Hauptwerk) dazu. Für den Hinweis auf das Instrument und mich mit ihm an Ort und Stelle bekannt gemacht zu haben sei Johannes Geffert herzlich gedankt. Siehe auch HUbERT FASEN und WALTER FRIEHS, Archivfunde waren großer Glücksfall, in: Barockorgel Eckenhagen. Abschluss der Restaurierung 2008, Eckenhagen 2008, S. 18. Diese zwar selten eingebaute Vorrichtung hat sich erstaunlich lange gehalten und kam noch in der Weil-Orgel der evangelischen Kirche Rheinbrohl (erbaut 1869) zum Einsatz. Freundliche Mitteilung von Hans-Wolfgang Theobald. Der dynamischen Abstufung vom pp zum ff (durch die Veränderung des Tastendrucks) unter Einbezug der Bebung hatte schon Johann Andreas Steins Erfindung (1772) eines von ihm Melodica genannten Orgelregisters als Sonderform der Vox humana gedient, das u.a. auf einem Cembalo oder Hammerflügel platziert oder auch in eine Orgel eingebaut werden konnte. Von der Melodica hat sich allerdings kein Exemplar erhalten, wenn sie denn tatsächlich gebaut worden sein sollte. Siehe: JOHANN ANDREAS STEIN, Beschreibung eines neuerfundenen Clavierinstrumentes, Melodica genannt, in: Neue Bibliothek der schönen Wissenschaften und der freyen Künste XIII/1, Leipzig 1772, S. 106-116.

87 Ein weiteres erhaltenes Kombinationsinstrument baute 1786 der in Paris ansässige, aus Deutschland stammende Joachim Swanen, Paris, Musée des arts et metiérs, Inv. Nr. 6615, siehe LATCHAM, combination (wie Anm. 84), S. $146 f$.

88 Auf dem Veroneser Instrument haben Andreas Staier und Christine Schornsheim eine faszinierende CD eingespielt: Harmonia mundi France HMC 901941, vgl. LATCHAM, notebook (wie Anm. 85), Bd. II, S. 432-434. 


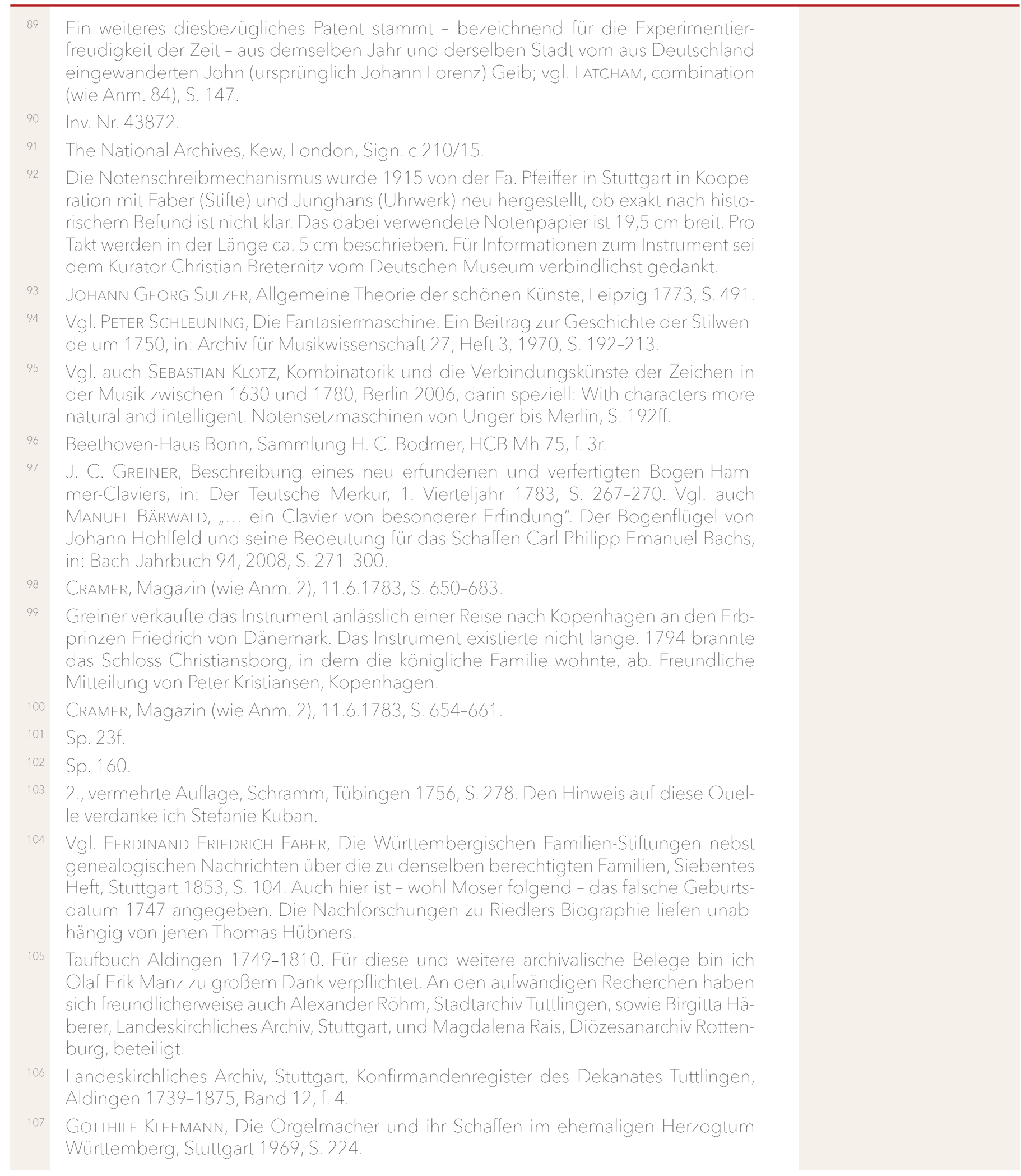

Der Clavierinstrumentenbestand und -instrumentenbau in Bonn als Anregung für den jungen Beethoven | 209 
108 Freundliche Mitteilung von Udo Rauch, Stadtarchiv Tübingen. Ein Tübingen-Bezug existierte. Der Urgroßvater mütterlicherseits hatte ebenfalls in Tübingen gelebt.

Totenregister Talheim 1705-1808, Bd. 6, S. 126.

Sterberegister Stiftskirche Stuttgart, f. 176.

Vgl. Oliver Hochadel, Öffentliche Wissenschaft. Elektrizität in der deutschen Aufklärung, Göttingen 2003.

vgl. ebd., S. 237.

HÜBnER, ex oriente lux (wie Anm. 1), S. $133 \mathrm{ff}$.

Walther Engelhardt (Hg.), Christian Gottlob Neefens Lebenslauf von ihm selbst beschrieben. Nebst beigefügtem Karackter 1789 (Beiträge zur rheinischen Musikgeschichte 21), Köln 1957, S. 21.

Wohl von Johann Philipp und Johann Heinrich Stumm in Sulzbach, 27 Register, 2 Manuale und Pedal

Vgl. OTто BIBA, Die Wiener Kirchenmusik um 1783, in: Beiträge zur Musikgeschichte des 18. Jahrhunderts (Jahrbuch für österreichische Kulturgeschichte II/1), 1971, S. 7-79. Im Inventar des Bonner Residenzschlosses von 1784 wird unter dem im Doxale aufbewahrten Notenmaterial innerhalb der figuralen Kirchenmusik an "L'Orgue obligé", also Werke mit konzertierender Orgel, lediglich eine Messe und eine Salve regina von Joseph Haydn (vermutlich Hob XXII Nr. 4 oder 7 sowie Hob XXIIIb Nr. 2) und eine Messe (die allerdings als fehlend) eines nicht näher bezeichneten Schmidt verzeichnet, wie Anm. 68, f. 247v, 249r und 253v

117 So im sogenannten Engeltaler Orgelbuch (vor 1794) und Siegburger Orgelbuch (um 1800) dokumentiert, Beethoven-Haus Bonn, Sammlung Familie Veith, Leihgabe Veith 1 bzw. ohne Signatur, vgl. auch Silke BetTermann und Michael LADENBURGER (Hgg.), Die Königin der Instrumente, Bonn 2000, S. 149-151.

LAV NRW R, Kurköln II, Nr. 480, f. 11-18

LAV NRW R KurköIn IV, Nr. 4397, Bauamtsrechnungen 1783/1784, S. 16 Nr. 55, unter den Zahlungen "An Künstler" (im Gegensatz zu jenen an Meister und Handwerker) verzeichnet.

Da Riedler nicht Mitglied des Hofstaates war, findet er sich auch nicht in der Auflistung der Ausgaben für die Trauerfeier für Kurfürst Maximilian Friedrich, wo Hunderte von Personen, darunter zahlreiche Hofmusiker mit Reise- und Kleiderkosten verzeichnet sind; LAV NRW R, Kurköln II, Nr. 360.

LAV NRW R, Kurköln II, Nr. 340, f. 168r, sowie Nr. 328, f. 83v. (zwei Überlieferungen)

Ebd., Nr. 457 f. 42f. (und Beleg 256). Die Übertragung bei HüBNER, ex oriente lux (wie Anm. 1), S. 181f. enthält vier sinnentstellende Transkriptionsfehler: statt "neu gestimmt" muss es "rein gestimmt", bei der zweiten Disposition muss es Principal 8 Fuß statt 4 Fuß, statt "die schon vorrätigen Tasten" muss es "den schon vorrätigen Kasten [Gehäuse]" heißen. Der geforderte Preis ist nicht 3000, sondern 1000 Reichstaler.

LAV NRW R, Kurköln IV, Nr. 4406, Bauamtsrechnungen 1.1 --30.9.1794, f. 11 v. ." Ilaufende Nr.] 256 Orgelmacher Kempen wegen Versetzen der Hof Orgel in der HofKapel im Julio 12 Rth".

Franz Gerhard Wegeler und Ferdinand Ries, Biographische Notizen über Ludwig van Beethoven, Koblenz 1838, S. 12. Wegeler bezog sich sehr wahrscheinlich auf den Zustand 1784-1794, da er sich 1794 vor den Franzosen in Sicherheit gebracht hatte und erst 1796 von Wien nach Bonn zurückkehrte und in der späten französischen und der preußischen Zeit in Koblenz lebte. 


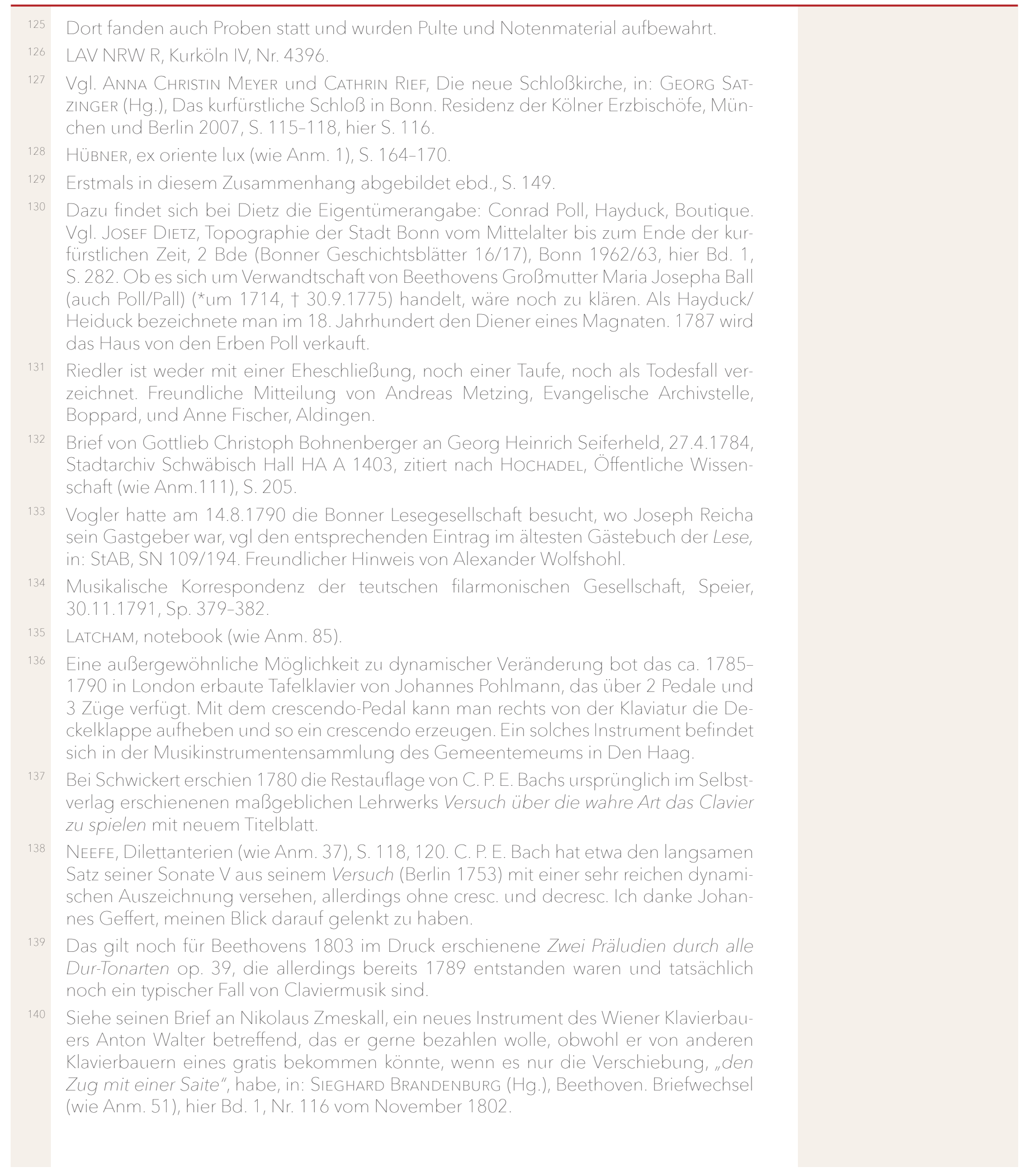

Der Clavierinstrumentenbestand und -instrumentenbau in Bonn als Anregung für den jungen Beethoven | 211 


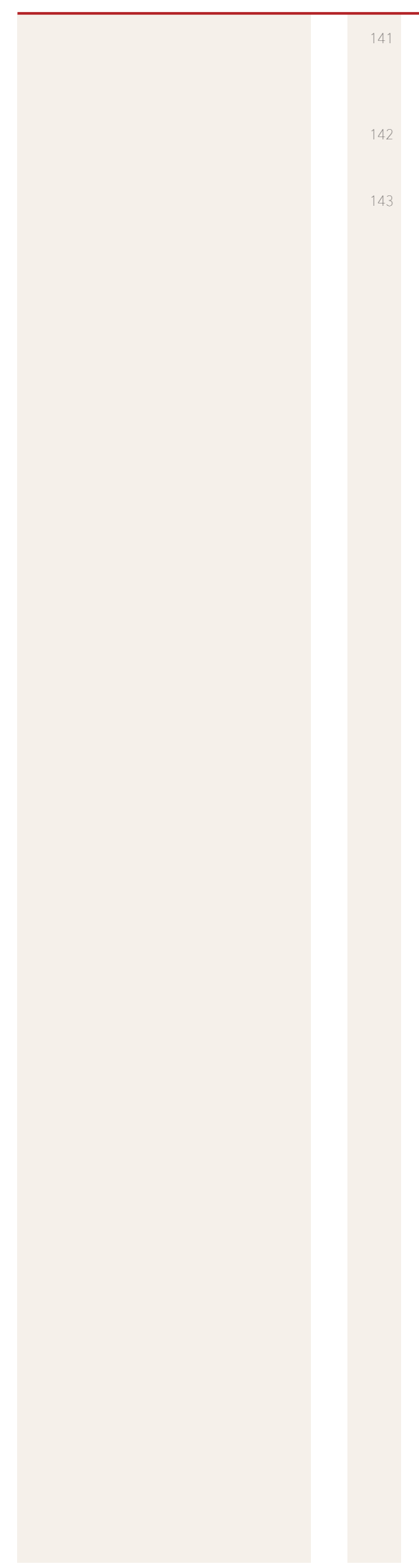

Paris, Musée de la musique, Cité de la Musique, E.264. Bundfrei bedeutet, dass zu jeder Taste eigene Saiten existieren, im Gegensatz zu gebundenen, bei denen zwei bis vier Tasten auf eine Saite bzw. Saitenpaar zugreifen.

Vgl. etwa SIEGBERT RAMPE, Beethovens Klaviere und seine Klavierimprovisation, Klangwelt und Aufführungspraxis, München und Salzburg 2015, S. 14

43 Heute Rijksmuseum Amsterdam, https://www.rijksmuseum.n//en/search/objects?p $=30 \& p s=12 \& \mathrm{f}$. objectTypes. sort=musical + instrument\&st $=$ Objects \& $i i=2 \# /$ BK NM-11430-20,350 


\section{Nichts weniger als Atheisten und Gottesschänder? Oder: Hundert thätige Männer, der Kern des Volkes?}

Intellektuelle Gruppierungen in Bonn unter den letzten Kurfürsten

Onn war bis 1794 Residenz, das heißt, offizieller Sitz eines Kurfürst-Erz-

bischofs. Hier saßen und arbeiteten die Zentralinstitutionen seines Territoriums: der Hofrat als oberste Regierungs-, Justiz-, Polizei- und Lehensbehörde, die Hofkammer als staatliche Finanzverwaltung, der Kriegsrat, die Kurfürstliche Staatskonferenz als beratendes Regierungsorgan mit der Geheimen Kanzlei, und hier arbeitete die Zentralbehörde für kirchliche Angelegenheiten, der sogenannte Geistliche Staat. Da die Kurfürsten Max Friedrich und Max Franz zugleich Fürstbischöfe von Münster waren, waren auch Vertreter entsprechender dortiger Behörden in Bonn, und für Max Franz als Hochmeister kamen solche des Deutschen Ordens hinzu. Personell getragen wurden diese Institutionen vom Hofadel und von Beamtenfamilien. An ihrer Spitze aber stand der Fürst, auf ihn waren sie ausgerichtet, er verkörperte die oberste Entscheidungsinstanz, wie er auch den Staat und die ständische Gesellschaftsordnung repräsentierte. Geschäftsgang wie Hofzeremoniell machten das immer wieder deutlich. Selbst der jährlich in Bonn zusammenkommende Landtag als Ständevertretung des rheinischen Landesteils akzentuierte nichts wesentlich anderes; ebenso nicht die ausländischen Gesandtschaften am Ort.

In Bonn hat es intellektuelles Leben gegeben. Hier lebten Menschen, die wissenschaftlich oder künstlerisch ausgebildet waren, die das politisch-soziale Geschehen beobachten und dazu Stellung nehmen konnten und die durch ihre berufliche Tätigkeit auch herausgefordert wurden, das zu tun. ${ }^{1}$ Im letzten Drittel des 18. Jahrhunderts sind sie im Kreis des Hofes, der Beamtenschaft, der Hohen Schule und der führenden Kaufmannsfamilien zu suchen. Dort gab es entsprechende Vorbildung, Zugriff auf Lektüre und Gesprächsformen, die die Information und Auseinandersetzung über epochale Fragen ermöglichten. Nicht zwingend muss dabei eine fortschrittliche Haltung eingenommen worden sein. Der einzelne Intellektuelle kann „als Kritiker bestehender Sinndefizite oder als Hüter bestehender Sinnpotentiale" Position bezogen haben, er kann sich in Passivität und Marginalität zurückgezogen, sich gegen Veränderungen gestemmt oder aber aktiv darauf hingearbeitet haben. ${ }^{2}$

An der Staatsspitze stand 1770 Kurfürst Max Friedrich (1708-1784), Jesuitenzögling, Dr. phil., 1756 Priesterweihe und Wahl zum Domdechanten in Köln, 1761 Erzbischof und Kurfürst von Köln, 1762 Fürstbischof von Münster, ein Grandseigneur des Ancien Regime, doch „ein Mann von Kenntnissen, von Verstand und Scharfsinn" ${ }^{3}$ und offenbar nicht ohne Reformwillen. Hochbe- 
Ehemaliges Jesuitengymnasium und spätere Akademie, die Hohe Schule in der Bonngasse, vis-à-vis der Namen-Jesu-Kirche. Aquarell über Bleistift von Mathias Frickel, 1894 (Stadtarchiv Bonn)

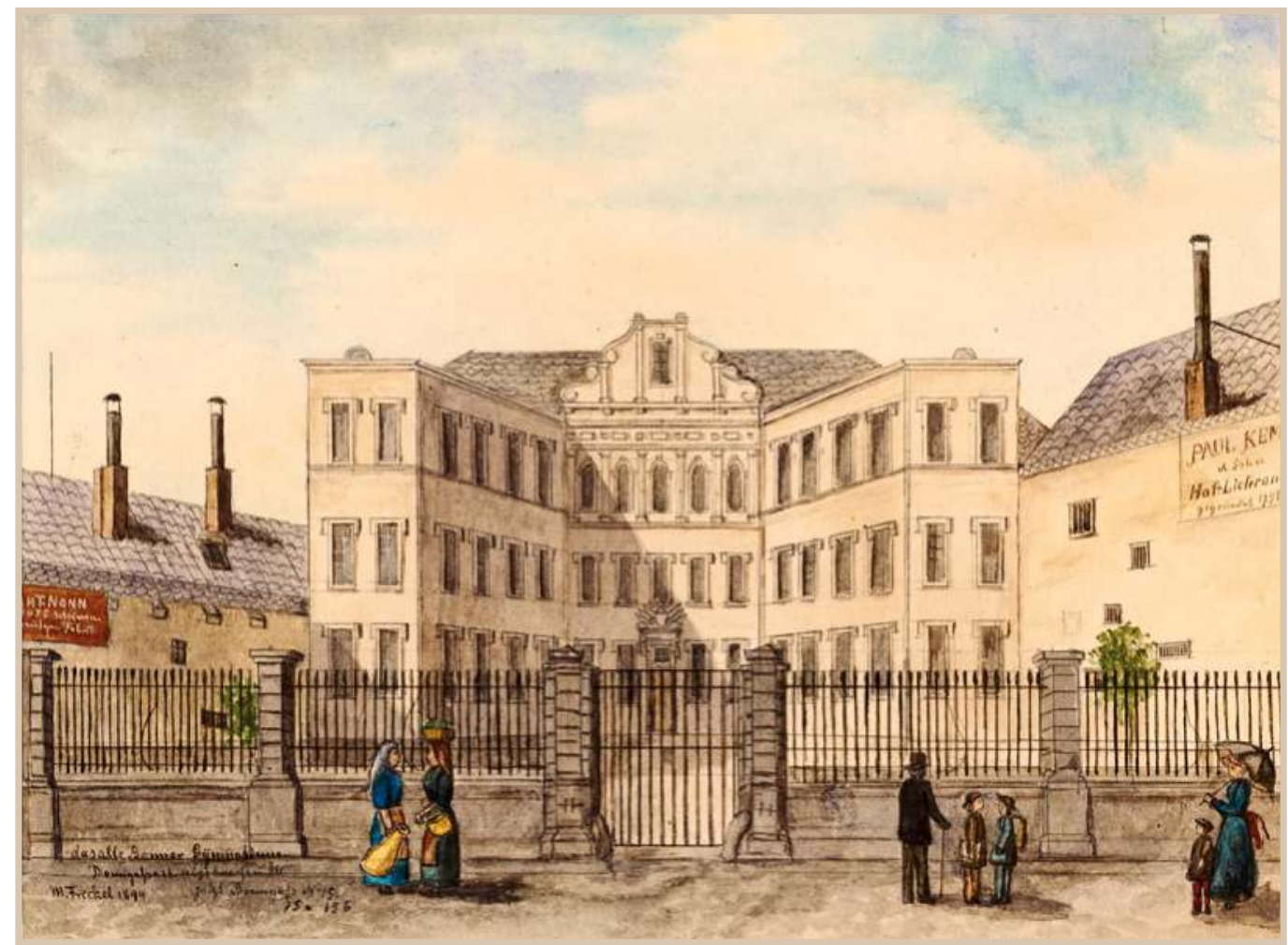

deutsam war die Wahl seines Ersten Staats- und Geheimen Konferenzministers, des Freiherrn Caspar Anton von der Heyden, genannt Belderbusch (17221784, seit 1782 Reichsgraf von Belderbusch), auch er Jesuitenzögling, studierter Jurist, 1741 Lizentiat der Rechte in Löwen, seit 1749 im Deutschen Orden, 1766 Landkomtur von Aldenbiesen. ${ }^{4}$ Von wem die den Staat und die Kirche betreffenden Entscheidungen des Kurfürsten nun ausgingen, ist unerheblich, wichtig vielmehr, dass der Weg zum aufgeklärten Absolutismus eingeschlagen wurde. ${ }^{5}$

Deutlich sind die Schritte kirchlichen Aufklärungshandelns, etwa die Reduzierung der Feiertage von 37 auf 18, das Zurückdrängen barocker Volksfrömmigkeitsformen, das Verbot „übernachtender Prozessionen und Bittfahrten”6. 1769 nahm Kurköln am Koblenzer Kongress „zur Aufstellung von Beschwerden und Ansprüchen gegenüber der römischen Kurie" teil. ${ }^{7}$ Staatlichem Souveränitätsdenken war das alles verpflichtet, es sollte aber auch der allgemeinen Wohlfahrt dienen, ebenso wie das 1774 in Bonn eingerichtete Armen- bzw. Arbeitshaus und die 1778 etablierte Brandversicherungsgesellschaft. Nach der Aufhebung des Jesuitenordens 1773 erfolgte der Ausbau des bisherigen Bonner Jesuiten-Gymnasiums zu einer Akademie mit dem Ziel der Erhebung zur Universität. Fortschrittliche Professoren wurden berufen, worauf noch einzugehen ist. 1778 folgte die Unterstellung des gesamten erz-

214 | Alexander Wolfshohl

(C) 2020 by Böhlau Verlag GmbH \& Cie. KG, Köln

https://doi.org/10.7788/9783412519704 | CC BY-NC 4.0 
stiftischen Schulwesens unter den 1777 eingerichteten Bonner Akademierat, ausgehend von dem Gedanken, dass Volksbildung ein Baustein zum Glück des gemeinen Mannes sei. ${ }^{8} 1778$ wurde das Hoftheater unter Minister Belderbusch als Intendanten zu einem Nationaltheater ausgebaut. Als Direktor wurde Gustav Friedrich Wilhelm Großmann (1743-1796) berufen, studierter Jurist, ehemaliger Legationssekretär, dann aber nach beruflichem Wechsel ein dezidiert aufklärerischer Schriftsteller und Theaterleiter. Sozialkritische Ansätze zeichnen seine eigenen Stücke aus. Wie es im Berufungsdekret heißt, sollte am Bonner Theater "die deutsche Schauspielkunst zu einer Sittenschule für das deutsche Volk" erhoben werden. 1782 brachte er Schillers Die Räuber auf die Bühne; 1783 inszenierte er in Bonn die Uraufführung von Schillers Die Verschwörung des Fiesko zu Genua. Ein republikanisches Trauerspiel. Schon 1779 hatte er den Musiker und Komponisten Christian Gottlob Neefe (17481798) nach Bonn gezogen, und Neefe, ein reformierter Protestant, erhielt 1781 das Anwartschaftsdekret und 1782 das Amt des Hoforganisten - eines katholischen Erzbischofs!

Der Reformwille der Staatsspitze manifestierte sich also markant. Zu fragen bleibt, ob deren aufklärerisch bestimmte Zielvorstellungen nur von einigen leitenden Amtsträgern umgesetzt wurden oder ob sie in den Institutionen mitgetragen wurden und in Hof- und Stadtgesellschaft breiteren Rückhalt fanden. Zwar lässt sich für viele der in diesem Zusammenhang interessanten Persönlichkeiten nicht mehr klären, wie sie zu neuen Gedanken gestanden, wie sie auf Veränderungen im jahrhundertealten politischen Überbau reagiert haben. Umrisse und partielle Einblicke aber lassen sich gewinnen, vor allem weil es in Bonn im letzten Viertel des 18. Jahrhunderts aufklärerische, reformorientierte Gesellschaften gab.

\section{Freimaurerloge der Strikten Observanz}

Seit Juni 1776 ist in Bonn eine erste Freimaurerloge fassbar. Quellenmaterial mit eindeutiger Provenienz ist nicht erhalten; konkrete Nachweise maurerischer Arbeit fehlen, aber die Namen der Mitglieder sind bekannt. An der Spitze stand Franz Wilhelm Freiherr von Spiegel zum Diesenberg und Canstein (17521815). In Bonn als Page erzogen, erhielt er den gymnasialen Fachunterricht am Jesuiten-Gym-

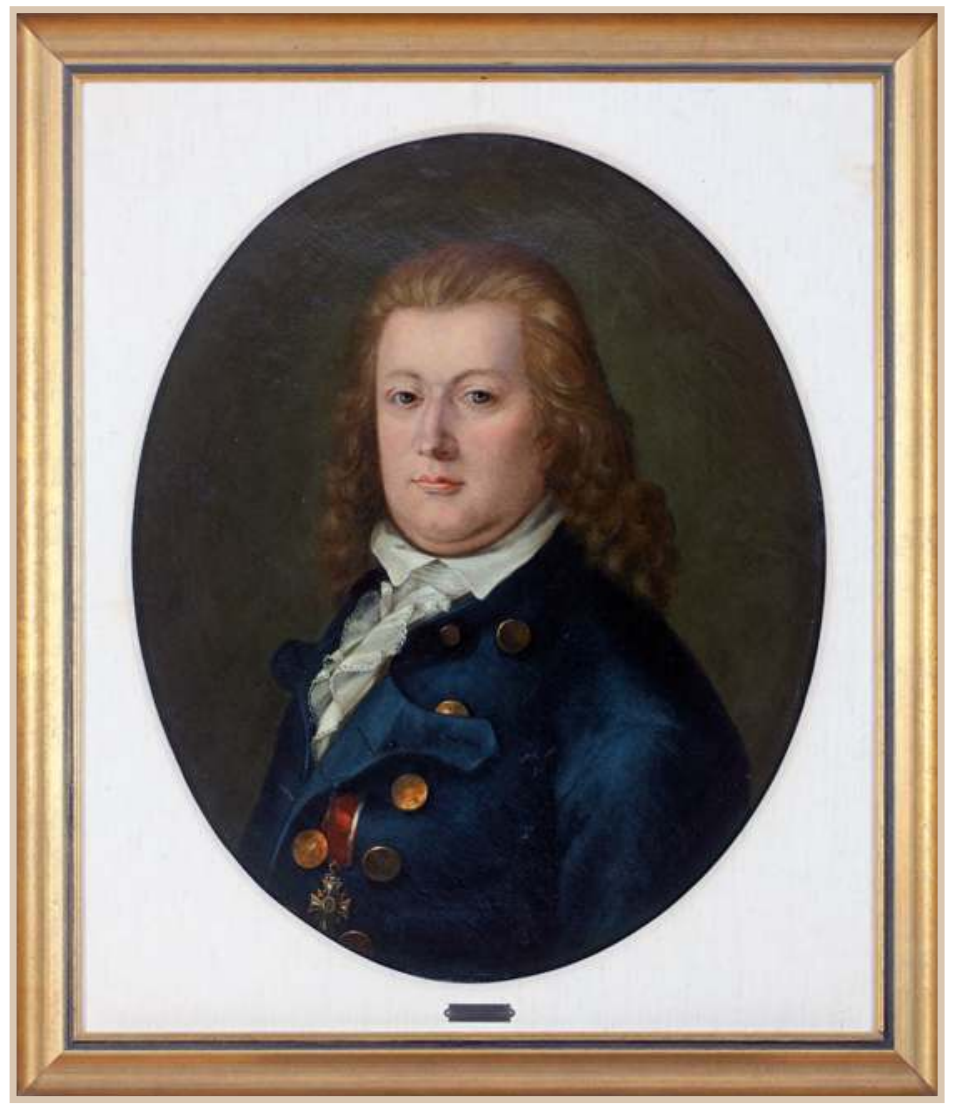

Freiherr Franz Wilhelm von Spiegel zum Diesenberg und Canstein (1752-1815), Kurkölnischer Hofkammerpräsident, Kurator der kurfürstlichen Universität. Ölgemälde von Clemens August Joseph Philippart, um 1790. Geschenk von Dr. Joh. Heinrich Crevelt an die Lese (Beethoven-Haus Bonn) 
nasium, wurde Kammerknabe des Kurfürsten und studierte dann Philosophie und Jura in Löwen und im aufgeklärten Göttingen. Dort wurde er 1773 in eine Loge der Strikten Observanz ,Augusta zu den drei Flammen' aufgenommen. „Die Strikte Observanz war eine streng hierarchische Organisation, die mit ihrer ritterlich-aristokratischen Prägung die ursprüngliche Ethik der englischen freemasons, die Gleichheit der maurerischen Brüder, aufgegeben hatte."10 Man war bestrebt, möglichst hochrangige Standesvertreter zu gewinnen, um über sie humanitäre Veränderungen auf den Weg zu bringen. Spiegel zum Diesenberg bekam im Oktober 1775 anlässlich seiner Rückkehr von Göttingen den Auftrag, am Niederrhein neue Logen zu errichten. In Bonn, das heißt, im Umkreis des Kurfürsten, gelang ihm das. Die von ihm gewonnenen Mitglieder aus Hofstaat und Hofgesellschaft spiegeln das Prinzip ständischer Orientierung der Strikten Observanz ausnahmslos wider. Alle sind von Adel, darunter drei Verwandte Max Friedrichs, der der Loge offenbar wohlwollend gegenüberstand. Die Loge bildeten: ${ }^{11}$

- Freiherr Franz Wilhelm von Spiegel zum Diesenberg und Canstein (17521815), Kurfürstlicher Kämmerer

- Freiherr Friedrich Karl von Forstmeister zu Gelnhausen OT (1731-1814), Kurfürstlicher Kämmerer und Obriststallmeister, Adliger Geheimer Rat und Kriegsrat, General-Wachtmeister, Komtur zu Muffendorf und Koadjutor der Ballei Koblenz ${ }^{12}$

- Freiherr Clemens August von Kleist (1720-1797), Kurkölnischer Wirklicher Geheimer Rat, Adliger Geheimer Kriegsrat, General-Lieutenant und ViceGouverneur von Bonn; Obrister eines Infanterie-Regiments

- Freiherr Karl Otto von und zu Gymnich (1715-1785), Exzellenz, Kurkölnischer Adliger Geheimer Konferenzrat, Präsident des Hofrats

- Freiherr Joseph von Leerodt (1733-1790), Adliger Geheimer Rat ${ }^{13}$

- Fürst Joseph von Hohenlohe-Bartenstein (1740-1817), Domherr in Köln und Straßburg

- Graf Ernst von Königsegg-Rothenfels (1754-1819), Domherr in Köln

- Graf Meinrad von Königsegg-Aulendorf (1737-1803), Domherr in Köln und Straßburg

- Graf Maximilian von Thurn und Taxis (1745-1825), Kaiserlicher Kammerherr ${ }^{14}$

- Prinz Emanuel von Salm-Salm (1742-1806), Malteserritter, spanischer General a.D.

Spiegel wurde Meister vom Stuhl, ging aber im Herbst 1776 zur theologischen Ausbildung nach Rom, und ohne ihn als treibende Kraft hatte die maurerische Arbeit offensichtlich keinen Bestand. Die Spur der Loge verliert sich; spätestens 1780 wird sie aufgehört haben zu existieren. Aber das Festhalten an freimaurerischen Wertvorstellungen ist zumindest für einige der Bonner Logenbrüder anzunehmen. Forstmeister war schon 1767 Mitglied der Düsseldorfer Loge La Parfaite Amitié gewesen, 1778 gehörte er zu den Gründern der 
Münsteraner Loge der Strikten Observanz, zu deren interimistischem Meister vom Stuhl Taxis eingesetzt wurde. ${ }^{15}$ Die beiden Königsegg aber sowie Salm-Salm und Leerodt (mit seinen Söhnen) sind in der Kölner Loge Le Secret de trois Rois wiederzufinden. Diese war zwar auch aristokratisch geprägt, gehörte aber nicht der Strikten Observanz an, sondern setzte sich nach längerer Auseinandersetzung entschieden davon ab. ${ }^{16}$

\section{Illuminaten in Bonn: Minervalkirche Stagira}

Aufklärerische Ideen haben in Bonn um 1780 noch Menschen über den Kreis der Hofgesellschaft hinaus bewegt. Selbst wenn ihr Verständnis von Aufklärung unterschiedlich gewesen sein dürfte, fanden sie sich doch zu gemeinsamem Tun zusammen: 1781 bildete sich eine weitere Loge, eine sogenannte Minervalkirche des lluminatenordens, mit Namen Stagira. Der Illuminatenorden, 1776 von Adam Weishaupt (1748-1830), Professor für Kirchenrecht an der Universität Ingolstadt, gegründet, war eine Geheimgesellschaft, die sich als Eliteorganisation der Aufklärergesellschaft verstand. ${ }^{17}$ Bis zur Selbstauflösung nach dem Verbot durch den bayrischen Kurfürsten 1785 zählte er wohl um die 2000-2500 Mitglieder, darunter bedeutende und einflussreiche Persönlichkeiten. ${ }^{18}$ Seit 1780 hatte der bekannte Freimaurer Adolph Freiherr Knigge (1742-1796) die Organisationsstruktur des Ordens ausgebaut und ihn mit dem Freimaurertum zu verknüpfen gesucht. ${ }^{19}$ Gegliedert in drei Klassen, sollte die mittlere Klasse von den drei (ursprünglichen) Maurergraden gebildet werden, so dass niemand im illuminatischen System hätte aufsteigen können, der nicht gleichzeitig Freimaurer war. Knigge konnte zahlreiche Freimaurer zum Eintritt bewegen, sicher auch, weil die angestrebten Ziele konvergierten. Persönlichkeitsentwicklung, Humanisierung der Gesellschaft, Herrschaft von Moral und Recht bis hin zu einem "ersehnte(n) Reich von Freiheit und Vernunft ${ }^{\prime \prime 2}$ strebten die Illuminaten an. Dass sich der Wert eines Menschen durch dessen inneren Adel bestimme, war Grundsatz der Illuminaten wie der unter Knigges Beteiligung reformierten Freimaurerei.

Die Namen von 28 Bonner Illuminaten sind bekannt bzw. identifiziert; zumindest zeitweilig waren sie Mitglieder der Minervalkirche Stagira. ${ }^{21}$ Auffallend ist die soziale Mischung. Das entsprach illuminatischem Programm, lässt aber auch erkennen, dass sich Vertreter verschiedener Stände und Berufsgruppen in den reformerischen Zielen wiedergefunden und deshalb vereinigt haben. Adel ist nur zu knapp einem Fünftel vertreten. Freiherr von Spiegel, der frühere Meister vom Stuhl der Freimaurerloge, wurde Illuminat, doch war er seit 1779

Bildnis eines Deutschordensritters. Stuckrelief in Originalrahmen, Ende 18. Jh. Vergleichsporträts ermöglichen die Identifizierung als Karl Franz Friedrich Hastard Anton Freiherr Forstmeister von Gelnhausen OT (1731-1814), Landkomtur zu Koblenz, kurkölnischer Kammerherr (Rosgartenmuseum Konstanz) 
Landdrost des kurkölnischen Herzogtums Westfalen mit Amtssitz in Arnsberg, also nur wenig in Bonn. Im Januar 1784 rief ihn Kurfürst Max Friedrich nach dem Tode Belderbuschs in die Residenz, aber im Sommer war Spiegel schon wieder in Arnsberg. ${ }^{22}$ Für illuminatische Logenarbeit vor Ort kann nicht viel Raum geblieben sein. Lothar Franz Michael Freiherr von und zu Erthal (17171805) findet sich gleichfalls unter den Bonner Illuminaten. Er war ein Bruder des Erzbischofs von Mainz und des Bischofs von Würzburg und Bamberg, die beide seit Ende der 1770er Jahre Reformer im Schul- und Fürsorgewesen waren. Wie lange und in welcher Funktion sich Erthal in Bonn aufhielt, ist quellenmäßig derzeit nicht zu sagen.

Aber auch Angehörige von Hof- und Staatsorganen mit mehr Präsenz am Regierungssitz sind vertreten. Die gleichnamigen Brüder Clemens August von Schall, kurfürstliche Kammerherren, politisch und sozial aufgeschlossen, wach und engagiert, begegnen von nun an immer wieder. Der ältere (17481814), Offizier, Musikliebhaber und -kenner, ist wohl in Bonn Illuminat geworden, während der jüngere (1758-1814), wie Freiherr von Spiegel als Page erzogen und kurfürstlicher Kammerknabe, nach dem Jura-Studium als Praktikant am Reichskammergericht in Wetzlar 1782 in die Freimaurerloge Joseph zu den drei Helmen und in den Illuminatenorden aufgenommen wurde. 1783 kehrte er nach Bonn zurück, war zunächst Adliger Hofrat und wurde dann unter Max Franz 1792 Hofmarschall. Er blieb enger Berater und Vertrauter des Fürsten bis zuletzt. Bernhard Franz Joseph von Gerold (17471828), auch Jurist, Wirklicher Gelehrter Hofrat, wurde gleichfalls 1783 Mitglied der Bonner Minervalkirche. Ferdinand d'Antoine (1746-1793)23, Hauptmann in kurkölnischen Diensten, war wie der ältere Schall nicht nur Militär, sondern auch Musikliebhaber und -kenner. Zudem ist er als Komponist hervorgetreten, was ihn mit der Gruppe der Musiker in engere Verbindung gebracht hat.

Insgesamt sind sieben Hofmusiker und Schauspieler in der Minervalkirche fassbar, also ein Viertel der bekannten Mitglieder dieser Loge, darunter besonders aktive. Ob die innere Beweglichkeit, die der Beruf erforderte, die Weltläufigkeit, die er vielfach mit sich brachte, sie zu weltanschaulicher Offenheit geführt hat? Hervorzuheben sind: Neefe, der schon 1774 Freimauerlieder vertonte und wohl von Knigge als Illuminat gewonnen worden war, ab 1783 Präfekt der Bonner Illuminatenloge, und Großmann, beide schon erwähnt, sowie die Hofmusiker Franz Anton Ries (1755-1846) und Nikolaus Simrock (1751-1832), deren gesellschaftspolitische Haltung hier wohl zum ersten Mal greifbar ist. Ries wird als Violinlehrer und hilfreicher väterlicher Freund für den jungen Beethoven bedeutsam, Simrock später einer von dessen Verlegern. Ständig vor Ort waren auch die Hofmusiker nicht, bedingt durch die Begleitung des Kurfürsten auf Reisen, unter anderem nach Westfalen, was bisweilen monatelange Abwesenheit mit sich brachte. 
Ein weiteres Brüderpaar findet sich in der Loge: Eichhoff. ${ }^{24}$ Der jüngere, Johann Joseph (1755-1825), war damals noch kurfürstlicher Mundkoch.25 Ausgebildet auf Kosten Max Friedrichs in Paris, verheiratet mit der Hofsängerin Eva Grau, verließ er später den Hofdienst, wechselte schließlich in die Verwaltung, wurde 1811 Generaldirektor im Rheinschifffahrts-Oktroi in Köln und als Sachverständiger für die Rheinschifffahrt zum Wiener Kongresses geladen, auf dem er dann eine wirtschaftsliberale Position vertrat. ${ }^{26}$ Der ältere der Brüder Eichhoff, Johann Peter (1762-1827), mit Schulbildung am JesuitenGymnasium, war als Gräflich Bentheimischer Rat Vertreter des Grafen beim Kölnischen Landtag und darüber hinaus „einer der entschiedensten publizistischen Vorkämpfer der rheinischen Aufklärung". ${ }^{27}$ In den 1770 er Jahren hat er zunächst in Köln und nach 1780 in Bonn entsprechende Zeitschriften ediert, unter anderem zeigen sie ihn als Verfechter religiöser Toleranz und volkswirtschaftlich interessiert, wach und aufgeschlossen. Von 1785 an gab er im Auftrag des Kurfürsten das Bönnische Intelligenzblatt heraus, später auch die Gazette de Bonn, in der 1789 die beiden derfranzösischen Nationalversammlung vorliegenden Entwürfe der Erklärung Menschen- und Bürgerrechte abgedruckt werden - erstmals im deutschen Sprachraum, und das vor der Abstim-
Dr. theol. Dr. iur. utr. Philipp Franz Anton Hedderich OFMConv (1743-1808), Prof. für das geistliche Recht und für das besondere Erzstiftkölnische Staatsrecht an der Hohen Schule in Bonn. Anonymer Punktierstich um 1780 (Stadtarchiv Bonn) mung darüber!

Hoch ist der Anteil an Mitgliedern geistlichen Standes bzw. geistlicher Herkunft: Insgesamt werden es 11 von 28 sein. Acht dieser Kleriker gehörten zugleich zu den akademischen Lehrern, die mit insgesamt 13 fast die Hälfte der fassbaren Logenmitglieder ausmachten. ${ }^{28}$ Der seinerzeit bekannteste unter ihnen war sicher Philipp Anton Hedderich (1743-1808), Dr. theol. Dr. iur. utr., nach Erhebung der Akademie zur Universität 1786 zweimaliger Rektor. Hedderich wurde schon 1774 berufen, Minoritenpater, Febronianer und Episkopalist, Ordinarius für Kanonisches Recht und für das Erzstiftische Staatsrecht. Auf seine Arbeit gingen Positionen und Beschlüsse des Emser Kongresses von 1786 zurück, der sich gegen päpstliche Eingriffe in den deutschen Erzbistümern richtete. ${ }^{29}$ Sein Wirken erregte weithin Aufsehen; die französischen Enzyklopädisten exzerpierten ihn. Von seinem Lehrstuhl aus wurde Bonn eine Keimzelle des Reformkatholizismus. In einem Rigorosum beispielsweise vertrat er als Prüfer die Ansicht, dass auch eine katholisch geschlossene Ehe auflösbar sei. ${ }^{30} 1779$ forderte das Domkapitel seine Bestrafung, weil er die These von landesherrlichen Vorrechten in kirchlichen Dingen vertreten hatte,

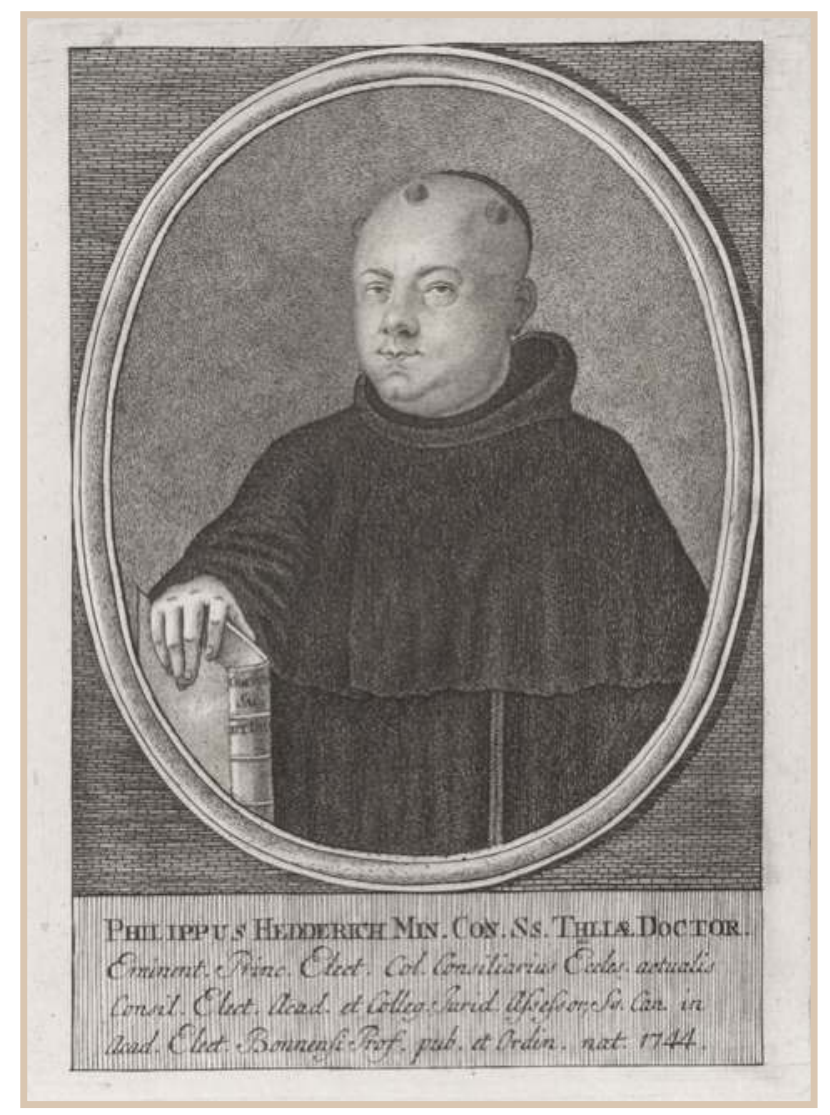


Dr. phil. Thaddaeus Anton Dereser OCD (1756-1818), Prof. für die HI. Schrift und die orientalischen Sprachen an der Hohen Schule in Bonn. Kupferstich von Johann Weinreis um 1790 (Stadtarchiv Bonn)

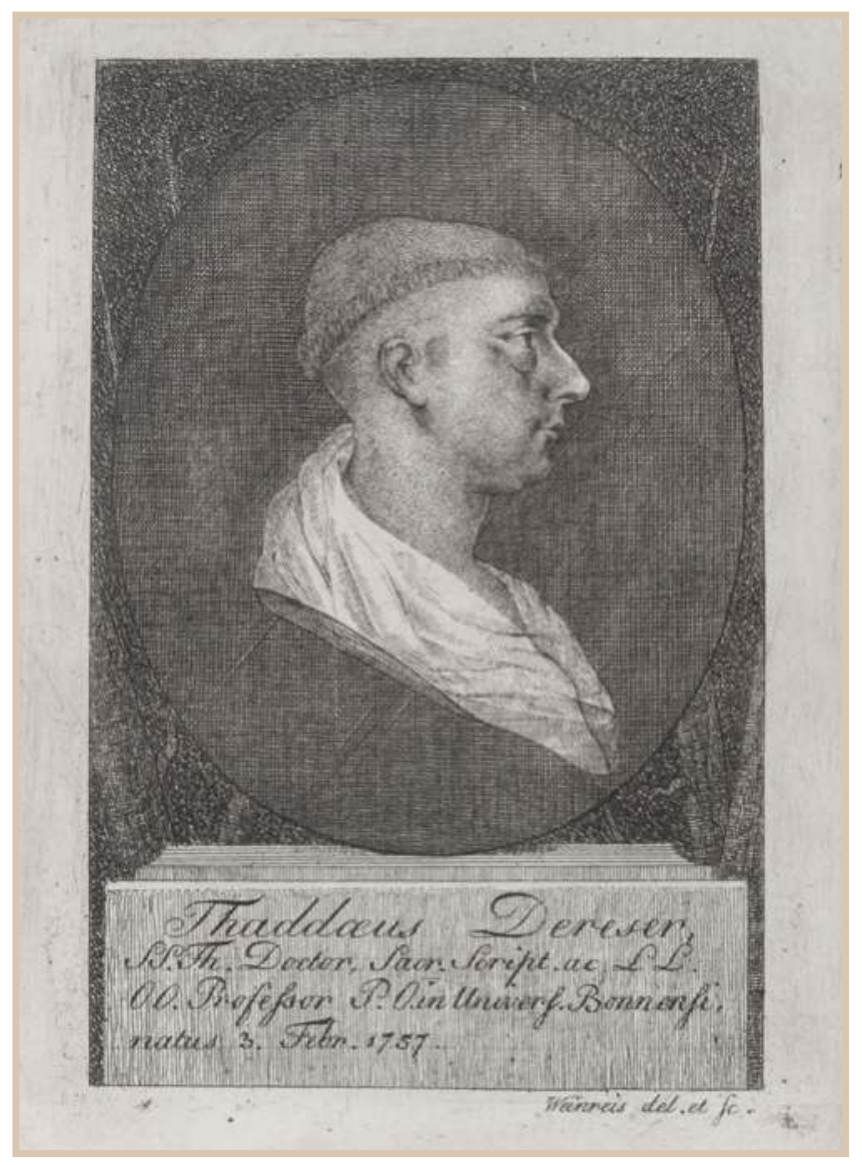

1783 machte der Papst seine Approbation der Akademie als Universität von der Entfernung Hedderichs aus dem Amt abhängig. Als einen zweiten Luther bezeichneten ihn seine Gegner, Papst Pius VI. nannte ihn "infensissimus Sedis Apostolicus hostis". ${ }^{31}$ Da Max Friedrich wie auch später Max Franz an ihm festhielten, wurde die Bonner Universität allein mit kaiserlicher Bestätigung eröffnet. Den bedeutsamen Posten des erzbischöflichen Zensors hatte Hedderich seit 1782 inne.

Aus dem Kreis von Hedderichs Hörern kamen auch nachmalige Kollegen. Elias Peter Joseph van der Schüren (1750-1829), gleichfalls OFMConv, hörte Hedderich schon in dessen Trierer Zeit 1771-1774. In Bonn studierte er dann Theologie und Philosophie. 1777 wurde er Professor für Metaphysik, Moral und Naturrecht, 1783 für Logik, Metaphysik und praktische Philosophie; das heißt, er betreute auch den Cursus, die einem Fachstudium vorgeschalteten beiden Jahre, vergleichbar der heutigen Sekundarstufe II. Daneben gab er Privatkollegs. Für den Sommer 1790 bot van der Schüren eine Privatvorlesung über die kantische Philosophie an; seine Kant-Studien und -Vermittlung hat er selber in seinem Abschiedsgesuch vom 26. Februar 1792 als bedeutend hervorgehoben. ${ }^{32}$ Als van der Schüren hinsichtlich der Naturrechtslehre Ende der 1780er Jahre dem protestantischen Göttinger Professor Feder folgte, der Freimaurer und Illuminat war, warf das Domkapitel ihm „Irrlehren" vor. ${ }^{33}$ 1790/91 war er Rektor, 1792 legte er die Professur nieder und ging wie zwei seiner Kollegen ins revolutionäre Straßburg, verließ den geistlichen Stand und heiratete.

Ähnlich umstritten war Thaddaeus Anton Dereser, Karmelitermönch (1757-1827), Dr. phil.; 1783 erhielt er den Ruf auf den Lehrstuhl für Exegetik des Neuen Testaments und für Griechisch (und nach 1786 für die HI. Schrift und orientalische Sprachen). Beachtet und angegriffen wurde Deresers Bibelexegese nach protestantischem Vorbild, so erklärte er den Untergang von Sodom und Gomorrha als Wirken von Naturkräften. Ende 1791 schied er aus dem Amt und ging nach Straßburg.

Überregionales Aufsehen erregte auch Andreas Spitz, Benediktiner (1745-1811), Ordinarius für Kirchen- und theologische Geschichte Deutschlands, desgleichen 1783 berufen. Ebenfalls strikter Febronianer, bestritt er das Prinzip der Unfehlbarkeit des Papstes. 1790 drängte Papst Pius VI. bei Kurfürst Max Franz auf seine Entfernung - vergeblich. ${ }^{34}$ 
Desgleichen angefeindet wurde der Benediktiner Sebastian Scheben (1750-1792), seit 1783 Professor für Pastoraltheologie. Er holte die kurfürstliche Erlaubnis ein, Vorlesungen in der Muttersprache halten zu dürfen. Seine Gegner warfen ihm vor, er habe gesagt, "daß ein Priester auch ohne bischöfliche Approbation gültig absolvieren könne." ${ }^{\prime 35}$

Unter den Nicht-Klerikern in der Illuminatenloge seien zwei Mediziner herausgestellt, auch sie seit 1783 Lehrstuhlinhaber: Dr. med. Peter Wilhelm Joseph de Ginetti (1735-1804) wurde auf dem Jesuitengymnasium in Münstereifel erzogen, legte mit 15 Jahren die ersten Gelübde ab, ging diesen Weg aber später um einer Eheschließung willen nicht weiter. Er war Professor primarius für Medizin in Köln, bezeichnet als "doctor expertissimus". Ginetti vertrat das Prinzip der Notwendigkeit des anatomischen Unterrichts an Leichen, was in katholischen Kreisen immer noch umstritten war.

Für die Ausbildung und wohl auch weltanschauliche Formung seiner Studenten wichtiger dürfte sein Kollege Dr. med. Joseph Claudius Rougemont (1756-1818) gewesen sein, Professor und Leibwundarzt des Kurfürsten. In Paris geschult, las er in Bonn über Anatomie und Chirurgie, über Ophthalmologie und venerische Erkrankungen sowie privatim über Geburtshilfe. Hofrat Bertram Maria Altstädten (*1744), ein Literaturfreund, der auch unter dem Pseudonym Apollinar veröffentlichte, rühmte ihn bei der Feier der Universitätserhebung 1786 und wieder beim Jubiläum 1791: "Sein reiner, offener Charakter, seine absichtslose, menschenfreundliche Hülfsbegierde bezeichnen in ihm den Weisen", heißt es da. " Die Arbeiten und das spätere humanitäre Wirken seiner Schüler, besonders von Salomon Anschel (1771-1814) und Franz Gerhard Wegeler (1765-1848), Beethovens lebenslangem Freund, lassen sich auch als Resultat von Rougemonts Einsatz sehen. ${ }^{37}$

Befreundet war Rougemont in der Loge mit Dr. phil. Dr. iur. utr. Gottfried Daniels (1754-1827), Hof- und Regierungsrat und seit 1783 Professor für Pandekten und die juristische Praxis. "Sein edelmüthiges Bestreben, der bürgerlichen Gesellschaft geschäfts-fähige Männer zu ziehen, siehet sich mit dem fruchtbarsten Erfolge belohnt, und die vielen gründlichen Jünglinge ... zeugen von dem Segen seines vortreflichen Unterrichtes", heißt es bei Altstädten über Daniels Tätigkeit. ${ }^{38}$

Dr. med. Peter Wilhelm Joseph de Ginetti (17351804), Prof. in Köln, seit 1783 Lehrstuhlinhaber für Physiologie in Bonn.

Kupferstich von Johann

Weinreis, um 1790

(Stadtarchiv Bonn) 


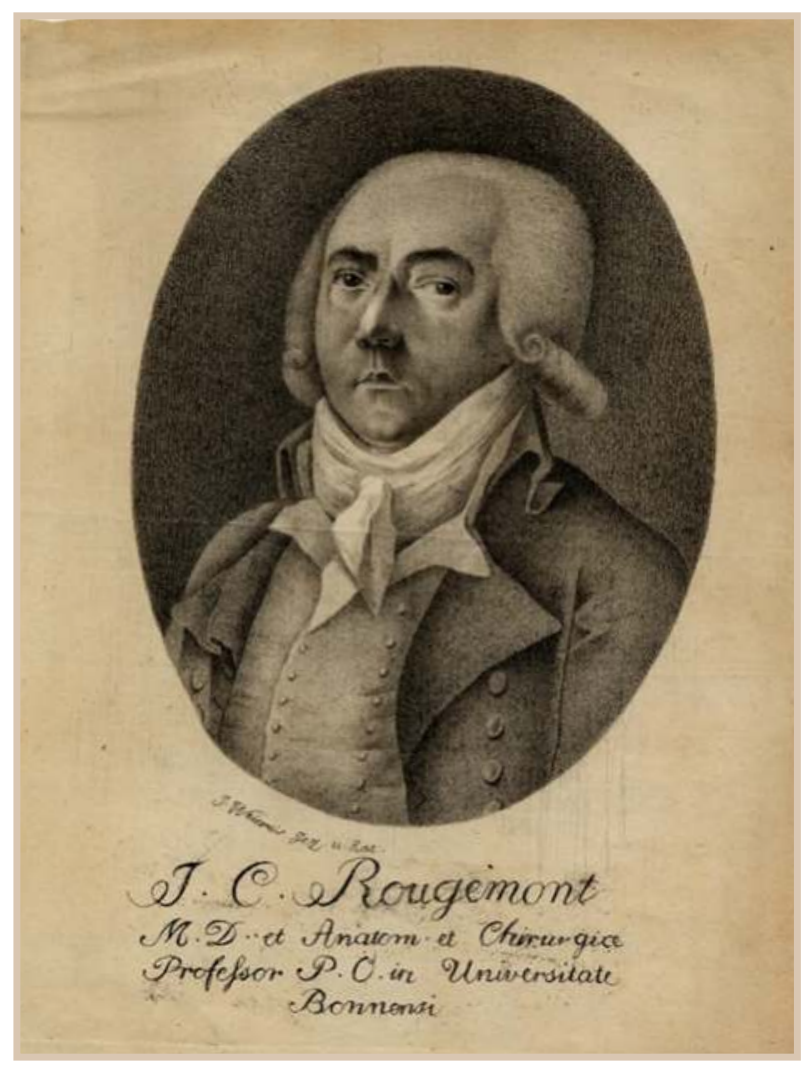

Die weltanschauliche Position der genannten Illuminaten ist in Umrissen durchaus erschließbar, ebenso die Zielsetzung der Arbeit in der Minervalkirche. Vor allem macht eine auf größere Breitenwirkung hin angelegte Zeitschrift dies deutlich, nämlich die Beiträge zur Ausbreitung nützlicher Kenntnisse (erschienen Bonn: Nr. 1,1784 - Nr. 52,1785), ein wöchentlich erscheinendes Organ allgemeinbildenden Anspruchs, das man als Sprachrohr der Illuminaten bezeichnen kann.

„Etwas für diejenige, die zur Bildung angehender Menschen etwas beitragen können: über die Lektüre" ist ein zweiteiliger Aufsatz betitelt; und schon zu Beginn wird hier die aufklärerische Position deutlich, die der ganzen Zeitschrift eignet: „denn es ist außer allem Zweifel, daß die Lektüre guter, zwekmäßiger Schriften, den Verstand aufkläre - die schlafende Fähigkeiten aufwecke - den Geschmack für das wahrhaft schöne befördere, und verfeinere -; und überhaupt den Menschen mit solchen Kenntnissen bereichere, die deßelben würdig und ihm unentberlich sind, um ein nützliches Mitglied der Gesellschaft zu werden - und diejenige Glückseligkeit geniessen zu können, wozu ihm der Schöpfer Grund-Anlage und Fähigkeit gegeben". ${ }^{39}$

Unter anderen Johann Peter Eichhoff, Neefe, Gerold, Schall d.Ä. veröffentli-

Dr. med. Joseph Claudius Rougemont (1756-1818), Prof. für Anatomie und Chirurgie an der Hohen Schule in Bonn. Radierung von Johann Weinreis, um 1790 (Yale University, USA, Harvey Cushing/John Hay Whitney Medical Library. Historical Library) chen hier. Neben Spezialabhandlungen, etwa über politische oder musikalische Fragen, trat Allgemein-Belehrendes. Auch Gedichte wurden publiziert. Sprachgewandtheit war ein akademisches Erziehungsziel der Zeit, und das Beherrschen literarischer Formen gehörte zur kulturellen Übung der Gebildeten. Ein Hoffnungsträger der Logenbrüder gerade in diesem Bereich war offensichtlich Johann Friedrich Marian Velten, geboren 1759, der schon mit 19 Jahren als Gymnasialprofessor Deutsch, Latein und Schönschreibekunst lehrte. Er legte seinem Unterricht Johann Christoph Gottscheds Kern der Deutschen Sprachkunst, aus der ausführlichen Sprachkunst Herrn Professor Gottscheds, zum Gebrauche der Jugend von ihm selbst ins Kurze gezogen zugrunde. ${ }^{40}$ Velten unterrichtete täglich "Brief- und Erzählungsstyl" und "alle Gattungen in Prose und gebundener Rede". ${ }^{41}$ Auf Praxisbezug und literarische Bildung wurde also Wert gelegt. Aus Gesundheitsgründen schied Velten früh aus dem Lehrbetrieb aus, wurde als Kanzlist an die Hofkammer versetzt und starb im Oktober 1784, 25-jährig, an der Schwindsucht. Die Wertschätzung, die der junge Mann erfuhr, lässt sich noch greifen. 1783 wurde die Schaubühne nach der Rückkehr des Kurfürsten aus Westfalen mit einem Prolog von Velten eröffnet, den Demoiselle Großmann deklamierte. ${ }^{42}$ Im selben Jahr, am 26. August

222 | Alexander Wolfshohl

(c) 2020 by Böhlau Verlag GmbH \& Cie. KG, Köln

https://doi.org/10.7788/9783412519704 | CC BY-NC 4.0 
1783, sandte Neefe Veltens Ode an die Weisheit an einen Illuminatenbruder in Frankfurt am Main. ${ }^{43}$ Und 1785 gab Peter Joseph Eichhoff in einem Sammelbändchen heraus, was von Veltens "hinterlassenen Handschriften aufzufinden war". ${ }^{44}$ Der Illuminat druckte in der Dezemberausgabe 1788 eine Ode von Apollinar-Altstädten ab: "An Herrn von Schönebeck", das heißt, an den Schwager der Eichhoff-Brüder Dr. med. Bernhard Constantin von Schönebeck (17601835), den Herausgeber der Beiträge. Hierin heißt es: "O Freund! da wandeln wir einst brüderlich / Mit unserm VE LTEN Hand in Hand / Der wie ein schöner Morgenstern in schöner Lichtgestalt / An unserm Horizont erschien, und früh verschwand". 45 Velten muss eine leuchtende Spur im Gedächtnis seiner aufklärerischen Freunde hinterlassen haben. Die 1787 gegründete Lesegesellschaft, auf die noch einzugehen ist, erhielt 1809 als Geschenk sein postumes IdealPorträt, gemalt von Johann Weinreis (1759-1826). Es zeigt einen jungen Mann, hinsichtlich Frisur und Kleidung nicht vom Ende des Ancien Régime, sondern frisiert und gekleidet nach der Mode des beginnenden 19. Jahrhunderts. In der linken Armbeuge hält er eine Mütze und einen Lorbeerkranz. Dergestalt ist Velten aus seiner Lebenszeit in die spätere Gegenwart des Malers gerückt, das Porträt aktualisiert ihn gleichsam und stellt ihn durch das antikisierende Kranz-Symbol zugleich in einen überzeitlichen Zusammenhang. Die Lese nahm das Bildnis dankbar in ihre Sammlung auf, weil sie, wie im Protokoll vermerkt ist, damit "das Portrait eines sehr geschickten Mannes und Mitbürgers erhält, der zu früh von seinem Leben abgerufen, und dadurch dem ganzen gelehrten Publicum entrißen wurde, sein geist solle in unserer gesellschaft wieder aufleben, und sein Andenken geheiligt sein." 46

Trotz allen Engagements zeigten sich Spannungen in der Loge, und die Mitglieder hatten den Eindruck, nicht voranzukommen. Der ältere der beiden Brüder Schall hat die Gruppe wenige Monate vor ihrer Auflösung als „ein kleines im politischen sinn ohnbedeutendes hauflein" bezeichnet, "wo wir noch keinen eintzigen Großen, und wichtigen Mann des Hofes in unserer Mitte zehlen, wo wir noch gar nicht wissen, noch wissen können, wie der Kurfürst, oder das Ministerium über uns dencken mag, wo wir eher vermuthen müßen, daß wir bei der mindesten offenbahrung gedruckt, und verfolgt würden werden, wo uns der noch sehr dumme und in diesen stucken sehr Aberglaubische pöbel verketzern und uns für nichts weniger als für Atheisten, und Gottesschänder ausposaunen würde". ${ }^{47}$

Johann Friedrich Marian Velten (1759-1784), Gymnasialprofessor für Deutsch, Latein und Schönschreibekunst an der Hohen Schule in Bonn, ab 1781 Hofkammeraccessist, Literat. Postumes IdealPorträt von Johann Weinreis, 1809. Geschenk des Malers an die Lese (Beethoven-Haus Bonn) 


\section{Ein neuer Tempelorden? \\ Eine Gesellschaft von Literaturfreunden, ein Lesekabinett und die Litte- rarische Gesellschaft von 1787}

Graf Belderbusch, der Staats- und Konferenzminister, starb im Januar, Kurfürst Max Friedrich im April 1784, die Bonner Freimaurerloge existierte nicht mehr und die Illuminatenloge näherte sich ihrer Auflösung. Das hätte das Ende innovativer Bestrebungen in der Residenzstadt bedeuten können. Doch der eingeschlagene Kurs wurde fortgesetzt. Zuvorderst lag das am neuen Landesherrn, Erzherzog Max Franz von Österreich (1756-1801), der, wie erwähnt, zugleich Fürstbischof von Münster und seit 1780 schon Hoch- und Deutschmeister des Deutschen Ordens war. Max Franz, ein Anhänger der Reformpolitik seines Bruders Kaiser Joseph II., arbeitete zunächst mit dem amtierenden Akademieratspräsidenten, dem Grafen Karl von Belderbusch zusammen, einem Neffen des Ministers. Gleich 1784 wurde Bonifaz Anton Oberthür (1745-1831) aus Würzburg berufen: als Professor für Katechetik, Direktor des Gymnasiums und der Landschulkommission, das heißt, der zentralen Schulbehörde. Seine Aufgabe sollte sein, das Schulwesen neu zu organisieren und zu verbessern. Oberthür kam als Illuminat. ${ }^{48}$

An die Spitze der neu gebildeten Staatskanzlei berief der Kurfürst im Juni 1784 aus Wetzlar einen der Assessoren am Reichskammergericht, den Freiherrn Johann Christian Joseph von Waldenfels (1742-1796). Waldenfels war Freimaurer und Illuminat. ${ }^{49}$ Zunächst Wirklicher Geheimer Staats- und Konferenzrat wurde er 1786 zum Staats- und Konferenzminister befördert; er sollte die Reformabsichten des Kurfürsten in Regierungsarbeit und Justiz verwirklichen helfen. ${ }^{50}$ Für die Bereiche Finanzen, Bau und Bildung holte sich Max Franz den als Freimaurer und Illuminaten wiederholt erwähnten Landdrosten Spiegel zum Diesenberg nach Bonn. Spiegels Tätigkeit in Westfalen muss ihn dem Kurfürsten empfohlen haben; er wurde Extra-Konferenzial-Regierungsrat, Hofkammerpräsident, Oberkommissar des Hofbauamts, Kurator der Universität, Präsident der Landschulkommission - mithin: Finanz- und Kultusminister in einer Person. Die politischen Ziele, über die sich Spiegel bis zum Ende des Kurstaats mit seinem Fürsten auseinandersetzt, sind konstant eminent aufklärerisch; dazu gehören die Aufhebung der Klöster und Stifte, um ihre Einkünfte wohltätigen Zwecken nutzbar zu machen, und die Verbesserung schulischer Bildung. Die Einführung sogenannter Industrieschulen, in denen „praktische Arbeit wie Stricken, Nähen, Spinnen und Gartenbau" gelehrt wurde, hatte Spiegel schon in Westfalen begonnen. ${ }^{51}$ In Bonn sorgte er für die Erweiterung des akademischen Fächerangebots um Psychologie, Kameral- und Finanzwissenschaft mit Statistik und Buchführung, Land- und Forstwirtschaft sowie Mineralogie und Chemie. ${ }^{52}$

Garanten dafür, dass die Richtung der Hohen Schule beibehalten wurde, waren zunächst die von Max Friedrich und Belderbusch berufenen und weiter- 
hin in Bonn wirkenden Lehrkräfte. Die Personalpolitik Spiegels und des Kurfürsten vergrößerte den Kreis der engagierten, fortschrittlichen Persönlichkeiten; es blieb nicht bei der Berufung Oberthürs. Die Dissertationen und Defensionsthesen, die in Bonn entstanden, zeigen, dass das geistige Klima seinen stark aufklärerischen Akzent behielt. ${ }^{53}$ Unterschiedliche Positionen und Kontroversen der Dozenten sind belegt, publizistische Geschütze von außerhalb zeigen die Heftigkeit der akademischen und zugleich weltanschaulichen Auseinandersetzung. Auch wenn die Hohe Schule keine Vereinigung war, deren Mitglieder bewusst in gemeinsamer Aktivität Veränderungen in Gesellschaft und Staat anstrebten, ist sie doch zu den intellektuellen Gruppierungen im damaligen Bonn zu zählen.

1785 existierten die Freimaurer- und die Illuminatenloge, wie gesagt, nicht mehr, aber die früheren Mitglieder vor Ort waren beruflich oder gesellschaftlich miteinander weiterhin in Kontakt.

Dass sie ihre Wert- und Leitvorstellungen aufgegeben haben, ist nicht anzunehmen, vor allem bei den eminent auf Weltverbesserung durch Erziehung ausgerichteten ehemaligen Illuminaten nicht. Gerade die Professoren unterihnen dürften in den Bildungszielen der Staatsspitze die Erziehungsziele des Ordens zumindest teilweise wiedererkannt haben. Vermutlich im Zusammenhang mit der aufgelösten Minervalkirche könnte es zu sehen sein, dass Oberthür eine private Lesegesellschaft inaugurierte und Johann Peter Eichhoff ein Lesekabinett gründete. Dies mag der Hintergrund dessen sein, dass die wachsame Öffentlichkeit in der kleinen Stadt im August 1786 von einem "neuen Tempelorden" munkelte. ${ }^{54}$

Dass es unter den reformorientierten Intellektuellen in der überschaubaren Residenzstadt mancherlei Berührungen gab, sei es professionell, sei es privat, liegt auf der Hand. Die Mitglieder der privaten Lesegesellschaft und die Besucher des Lesekabinetts müssen nicht nur ehemalige Illuminaten gewesen sein, vielmehr ist anzunehmen, dass der Kreis sich erweitert hat. Quellenmäßig lässt sich das zwar nicht im einzelnen fassen, ist aber doch zu erschließen: Am 1. Dezember 1787 gründeten 35 Bonner eine Litterarische Gesellschaft, die heute noch existierende Lese- und Erholungsgesellschaft, kurz Lese genannt. ${ }^{55}$ Am 3. April 1788 eröffnete sie ein neues Gesellschaftslokal im Bonner Rathaus mit einem kleinen Festakt. Gründungsmitglied Dr. jur. Clemens August Schücking (1759-1790) trug dabei eine selbstverfasste Ode vor. ${ }^{56}$ Deren erste Strophe lautet:

Erzherzog Maximilian Franz von Österreich (1756-1801), Kurfürst-Erzbischof von Köln OT, Hoch- und Deutschmeister, Protektor der Litterarischen Gesellschaft in Bonn, der sogenannten Lese. Zeitgenössischer unbezeichneter Schattenriss in Kupferstich-Zierrahmen (Deutschordenszentralarchiv Wien) 
„Erfreut betreten wir den schönen Ort,

Der zum Genusse weiser Fröhlichkeit

Und zur Veredlung der Gesellschaft uns

Nun, Freunde! Künftighin versammeln soll.

So freun sich Menschen die zum fernen Zweck

Erst in der Stille muthig fortgewürkt, **

Nachdem ihr Werk Beifall und Kraft gewann,

Nun Hand in Hand dem Ziele näher gehn!

Schnell hob das Institut sein Haupt empor,

Ein Fürst, der Menschen Glück, verlieh ihm Schuz[!],

Der Edlen viele nahmen Theil daran!"

Johann Peter Eichhoff edierte die Ode und kommentierte sie: "** Die Gesellschaft fing unter wenigen Lektürefreunden an, welche erst Journale unter sich circulieren liessen, aber, weil sich dabei manche Unbequemlichkeit äusserte, in der Folge ein paar Zimmer mietheten, wo die Journale hingelegt und die Freunde einander finden und unterhalten konten[!]. H[e]raus[g]e]b[r]." Schücking wie Eichhoff deuten hier, knapp resümierend, auf eine längere Entwicklung vor der konstitutiven Sitzung vom 1. Dezember 1787 hin. Eines der Gründungsmitglieder, Dr. Johann Heinrich Crevelt (1751-1818), der zum Lehrkörper der kurfürstlichen Akademie gehört und in den Beiträgen zur Ausbreitung nützlicher Kenntnisse, dem erwähnten Illuminaten-Organ, veröffentlicht hatte, schrieb 1808 als damaliger Direktor der Lese über deren Entstehung: "1787. Dreizehn Personen, Freunde der Wissenschaften und Literatur vereinigen sich, entwerfen den Plan zu einer Literair-Gesellschaft und sind die ersten Stifter. Aus ähnlichem Antriebe gesellen sich mehrere Männer zu ihnen, und zu Ende des Jahres ist ihre Anzahl schon auf 39 gestiegen." ${ }^{\prime 57}$ Abgesehen davon, dass Crevelt die Zahl der Gründungsmitglieder um vier erhöht, was sich bei Einsicht in die Protokolle eindeutig als kleiner Irrtum erweist, kann der Hergang zutreffend erinnert sein; er stimmt zu dem, was Schücking und Eichhoff mitteilen. Carl Moritz Kneisel, langjähriger späterer Sekretär der Lese, hat 1837 in seiner zur 50-Jahr-Feier erschienenen Geschichte der Gesellschaft die Zahl 39 schon auf 35 korrigiert. Im Übrigen aber hat er den sukzessiven Verlauf der Entstehung verkürzt. Dass sich, wie Crevelt sagt, 13 Personen vereinigten, fasste Kneisel als Umschreibung der Gründungssitzung auf und musste dann das Anwachsen auf 35 in die vier Dezemberwochen bis zur ersten Generalversammlung am 2. Januar 1788 packen. Er hat auch versucht, diese 13 namhaft zu machen, und glaubte, sie im Ergebnisprotokoll zur ersten Januarsitzung zu finden. Dies Protokoll enthält jedoch in einem Anhang nur die Namen der 35 Gründungsmitglieder, und zwar bis auf einen ohne irgendeine zusätzliche Kennzeichnung. Allerdings hat der Protokollant im Verlauf der Niederschrift nicht alle 35 auf einer Seite notieren können, sondern musste nach 13 Namen auf der nächsten Seite fortfahren. Kneisel sah nun in den 13 Erstgenannten die von Crevelt 


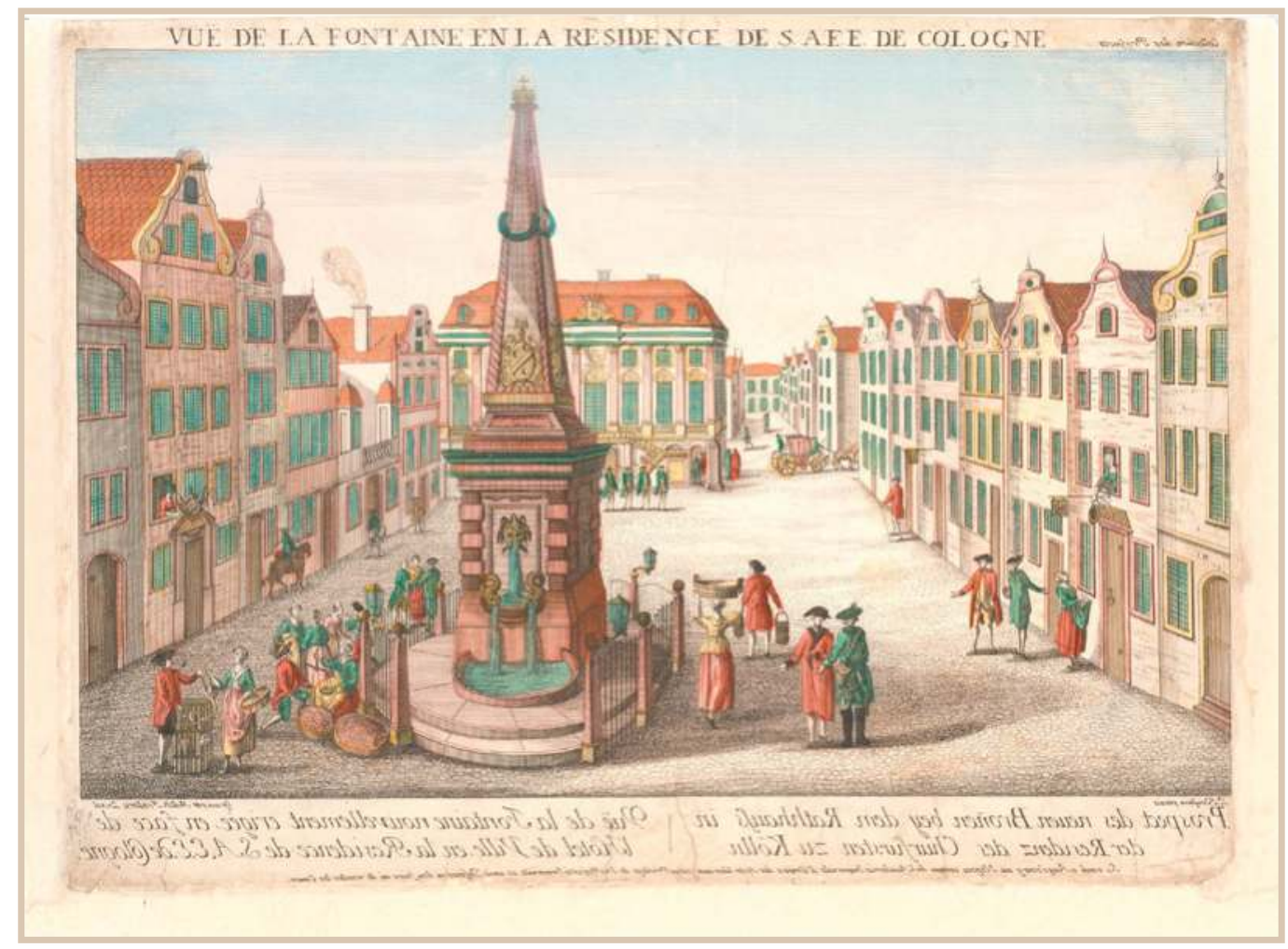

erwähnten "ersten Stifter" und hob sie in seiner Festschrift auch so aus der Gruppe der 35 Gründungsmitglieder heraus. ${ }^{58}$ Seither sind ihm mehrere Veröffentlichungen über die Lese - bis heute - gefolgt. Meines Erachtens zu Unrecht.

Der erste auf der Namensliste ist "Frh Von Schall der ältere Kurfürstlicher Kammerherr, und Hauptmann des Von Kleistischen Infanterie Regiments." Schall wird in der Folgezeile herausgehoben durch eine Art Ehrentitel "Erster Beförderer des Instituts". Erläutert wird das nicht. Es ist der zitierte Illuminat Schall, von dem die resignierende Einschätzung der Bonner Minervalkirche stammt. Der erste Direktor der Lese aber ist Johann Peter Eichhoff. Beide Männer werden mithin für die Formierung und Ausrichtung der neuen Gesellschaft wichtig gewesen sein, und das wohl im illuminatischen Sinne. Überprüft man die Liste der 35 Gründungsmitglieder auf ehemalige llluminaten, so zeigt sich, dass insgesamt 13 frühere Minervalen dabei waren - nur sind sie nicht en bloc auf der ersten Seite notiert. Aber, dass es 13 Illuminaten sind, legt den Schluss nahe, dass Crevelt sie mit den "Stiftern" gemeint hat und dass sie die Promotoren der Neugründung waren.

Von Zielen und Organisationsformen des aufgelösten Ordens wich man mit der Gründung der Lesegesellschaft insoweit nicht ab, als dessen unterste Stufe, die der Minervalklassen, angesetzt war „als eine gelehrte und Lesege-
Der Bonner Marktplatz mit dem Rathaus im Hintergrund. Im zweiten Obergeschoss war von 1788 bis 1794 und von 1802 bis 1818 das Domizil der Lese. Kupferstich (gespiegelt) von Balthasar Friedrich Leizel nach einer Vorlage von Franz Rousseau, nach 1777 (Stadtarchiv Bonn) 
sellschaft, die ihren Adepten Literatur und Theorie der Aufkärung nahebringen sollte. ${ }^{\prime 59}$ Die in den Bonner Logen-Akten erhaltenen Allgemeine Ordens Statuten zeigen das überdeutlich: „XVI. Damit alle Mitglieder Von einem geiste beseelt werden, und so viel möglich nur einen Willen haben, so werden ihnen Bücher Vorgeschrieben, die sie lesen müßen, und wornach sie sich bilden können. Aus den monathlichen, wenigstens halben Bogen langen Arbeiten, u. aus den Vorleßungen bey Versammlungen, werden Obere und Mitbrüder gelegenheit haben, Ihren Vortrag, Ihren Fleis und den wachsthum ihrer Kentniße zu beurtheilen." ${ }^{0}$ Zwang zu bestimmter Lektüre gab es in der neuen Gesellschaft nicht, aber der Aufbau einer Bibliothek, die der Bildung des einzelnen wie der Gemeinschaft dienen und Wirkung nach außen ermöglichen sollte, war vorrangiges Ziel. ${ }^{61}$ Anders als bei den Illuminaten aber wurden Mitglieder nicht geworben und nicht erst nach deren gründlicher Selbsterforschung über ihre Aufnahme entschieden. Vielmehr kamen Vorschläge über Neuaufnahmen aus der Gesellschaft selbst, und es wurde in den Generalversammlungen per Ballotage, das heißt, Abstimmung mit schwarzen und weißen Kugeln, darüber entschieden. Nicht jeder Vorschlag hatte Erfolg. Über die Abstimmungsergebnisse sollte nach außen Verschwiegenheit gewahrt bleiben. Im Übrigen aber war die Lese keine geheime Loge mehr, sondern arbeitete öffentlich unter dem Protektorat des Kurfürsten, der den Freimaurern und Illuminaten bekanntermaßen skeptisch gegenüberstand. Stand und Beruf allein schon der Gründungsmitglieder zeigen die Nähe zum Hof. Es mag an der Abkehr von allem Geheimgesellschaftlichen und an der kurfürstlichen Schirmherrschaft gelegen haben, dass die Mitgliederzahl rasch anstieg. Ende 1788 waren von den identifizierbaren ehemaligen Bonner Illuminaten, soweit sie noch in der Residenz lebten, bis auf vier alle in der Lese. ${ }^{62}$ Das waren 20 von 85 Mitgliedern; dazu kam noch, wie erwähnt, Schücking aus Münster, der schon bei der Gründung dabei war. Als am 2. Dezember 1789 das Porträt des Kurfürsten in dessen Anwesenheit im Gesellschaftslokal aufgestellt wurde, trug der junge Domherr Caspar Anton von Mastiaux (1766-1828), Lese-Gründungsmitglied und 1790 gewählter Direktor, eine programmatische Rede vor. Darin heißt es: "Lange genug hat unser Vaterland unter dem Joche der Unwissenheit geseufzet. Lange genug war Ubien gefesselt am Gängelbande des Vorurtheils: und noch immer sind sie nicht alle zerstiebt die Schatten der Finsternisse, die über unserem Horizonte schweben. Noch ist ein beträchtlicher Theil der Volkserziehung in den Händen des Eigennutzes, und der Stupidität. Noch hat das Erzstift keine Volksschriften hervorgebracht, die diesen Namen verdienen. ... Freunde! der Arbeiten sind noch viele, das urbar zu machende Feld ist unermeßlich. ... Zählt unsere Vereinigung nicht hundert thätige Männer, den Kern des Volkes, aus jedem Stand, aus jeder Klasse, verbunden zu einem gemeinschaftlichen Zwecke? Männer, die in jedem Winkel des Staates das heilige Feuer der Aufklärung anzufachen, zu nähren, 
zu unterhalten im Stande sind; die jede Lücke bemerken, und jedem Heilmittel ihre Aufmerksamkeit, ihre Kraft widmen? Sichert die Vereinigung des bürgerlichen Ansehens nicht jedes Mitglied vor dem rächenden Verfolgungsgeiste des Vorurtheils, der sich sonst dem einzelnen Wahrheitsforscher wüthend entgegenstemmt...? Gab nicht Maximilian unserm Bunde seinen Beifall? Verlieh er nicht Schutz? War sein Lächeln nicht Befehl, daß wir fortwirken sollen? Und können wir von Ihm nicht auch künftig alles erwarten, wenn gemeines Wohl, wenn Arbeitslust und Glückseligkeit durch uns auf seine Unterthanen übergehen soll?"63

Die ideelle Herkunft verbarg die Lese nicht. Der erste Paragraph der Gesetze der Lesegesellschaft in Bonn lautete von Anfang an: "Jeder Litteraturfreund, und Lectür freund, kan darinn aufgenommen werden. Rang komt gar nicht in Anschlag."64 Die Abkehr von ständischem Denken, wie erwähnt, ein freimaurerischer Grundsatz, hatte dezidiert auch im Illuminatenorden gegolten. Dessen Gründer Adam Weishaupt war als Autor in der Bibliothek vertreten - er findet sich noch $1814 \mathrm{im}$ ersten erhaltenen Bibliotheksverzeichnis. Als die revidierte Fassung der Gesetze, auf die sich dann jedes Mitglied durch Unterschrift verpflichten musste, 1790 kodifiziert wurde, stellte man ein Zitat voran: "Die Geselligkeit der Glieder ist die Seele einer jeden Gesellschaft. Adam Weißhaupt." 65 Und die Erinnerung an den jung verstorbenen Illuminatenbruder Velten wurde, wie geschildert, wachgehalten, sei es als Personifizierung einer verklärten Vergangenheit und weltanschaulichen Herkunft der Lese, sei es als Projektionsfläche des Angestrebten, bis sie schließlich in einem Ideal-Porträt Konkretisierung fand.

\section{Beethoven - Illuminatenzögling? Lese-Aspirant?}

Beethoven war kein Illuminat. „Bewahrt hat ihn mit Sicherheit sein angeblich jugendliches Alter vor der offiziellen Aufnahme in den Illuminatenbund. Bei korrekter Angabe seines Geburtsjahrs wäre er Neefes intensivem Werben kaum entgangen. Zum Glück nahm man an, er sei ein oder zwei Jahre jünger", schreibt Hans-Josef Irmen 1999 in seinem Aufsatz Neefe als Freimaurer und Illuminat, 66 und schildert dann die indoktrinative Erziehungsvorstellung der Illuminaten. Trotz fehlender Mitgliedschaft Beethovens im Orden geht Irmen aber von bedeutendem persönlichen Einfluss Neefes auf Beethoven aus. Auch wenn das nicht communis opinio der heutigen Forschung ist, weder im positiven noch im negativen Sinne, ${ }^{67}$ so ist doch sicher, dass Beethoven im Umkreis von Illuminaten sozialisiert worden ist. Und das dürfte nicht ohne Wirkung für Leitgedanken und Weltbild, Wertekanon und Selbstverständnis geblieben sein.

Auch Mitglied der Lese war Beethoven nicht. Sein Alter kann kein Hinderungsgrund gewesen sein, denn ein Mindestalter für die Aufnahme nennen die Statuten nicht - auch wenn das nahezu unentwegt in der Literatur behauptet 
wird. Caspar Anton von Mastiaux war bei der Gründung 21 Jahre alt; Maximilian Freiherr von Weichs zu Wenne, Kurfürstlicher Kammerknabe und gleichfalls Gründungsmitglied, war 20. Studenten aber waren von der Mitgliedschaft ausgeschlossen. Vom Mai 1789 bis gegen Jahresende besuchte Beethoven offiziell die Hohe Schule, ${ }^{68}$ in diesem Zeitraum war ein Beitritt also nicht möglich. Im Übrigen freilich hätte er bis zur Abreise nach Wien aufgenommen werden können. Dass niemand in der Lese ihn vorschlug, mag an seinen finanziellen Verhältnissen gelegen haben. Den Jahresbeitrag zu leisten, dürfte ihn überfordert haben.

Durchreisende Fremde konnten zu einer Visite in die Lese eingeführt werden, Bonner Bürgern war ein einmaliger Schnupperbesuch eingeräumt. Das Gästebuch gibt Auskunft über fremde oder städtische Besucher und die sie einführenden Mitglieder. Ludwig van Beethoven findet sich hier nicht.

Fehlt also eine Verbindung Beethovens zur Lese auf der formellen Seite, so war er doch vielfach von Lese-Mitgliedern umgeben. Allein 15 seiner HofmusikerKollegen zählen dazu, zum Teil sehr aktive, darunter auch solche mit illuminatischer Vergangenheit. Schon unter den Gründern waren 1787 Christian Gottlob Neefe, Franz Anton Ries, Joseph Reicha, Nikolaus Simrock. 1788 folgten Sebastian Pfau, Joseph Welsch und Georg Libisch, 1789 dann Maximilian Willmann, Friedrich Müller und Thomas Pokorny, 1790 schließlich Gaudenz Heller, Andreas Bamberger, Andreas Perner, Joseph Lux und Johann Baptist Paraquin. Auch Hofschauspieler Anton Steiger war seit 1788 in der Gesellschaft, und seit 1789 der Theatermaler Johann Peter Beckenkamp, Ehemann der Hofsängerin Veronika Beckenkamp, geb. Krämer. Bei Familie von Breuning, die Beethoven gleichsam eine zweite Heimstatt geboten hat, in den musikausübenden Häusern der Grafen Belderbusch und Wolff-Metternich oder von Mastiaux, von Gruben und Wurzer traf er ebenfalls auf Lese-Mitglieder.

Darüberhinaus hatte Beethoven Freunde im sogenannten Zehrgarten-Kreis, jenem informellen Zirkel, der in den Jahren um 1790 im Gasthaus Zum Zehrgarten am Markt verkehrte. Max Braubach hat in mehreren Veröffentlichungen die Teilnehmer zu bestimmen versucht; insgesamt nennt er 25 männliche Namen als erweisbar, ergänzt um einige nur vermutungsweise genannte, und einige junge Frauen. Etliche sind hier schon erwähnt, es waren führende intellektuelle Köpfe der Residenz darunter. Zum Zehrgarten-Kreis zu zählen sind Christoph von Breuning, Stephan von Breuning, Martin Degenhart, Peter Joseph Eilender, Bartholomäus Fischenich, Karl Ludwig Freiherr von Keverberg, Matthias Koch, Gerhard Kügelgen, Karl Ferdinand Kügelgen, Jakob Richter, Heinrich von Struve ${ }^{69}$. Alle weiteren, 15 an der Zahl, waren Lese-Mitglieder, seit 1787 Johann Heinrich Crevelt, Johann Ludwig Dörfeld, Johann Joseph Eichhoff, Romuald Anton Jochmaring, Johann Jakob Tillmann Peltzer, Wenzel Hermann Polzer, Carl Josef Wreden, seit 1788 Thaddaeus Anton Dereser, Franz Leopold von Heckel, Ferdinand Graf von Waldstein, 1790 Engelbert Floret, 
Franz Gerhard Wegeler, 1791 Ferdinand Freiherr von Bourscheidt, Jakob Klemmer und 1792 Carl August Malchus. ${ }^{70}$

Freundschaft und Geselligkeit hatten unter den Aufklärern einen hohen Stellenwert, sie wurden als über den privaten Bereich hinausgehende soziale Erscheinungen von öffentlicher Bedeutung angesehen. So bildeten "sich nicht selten im Umkreis der ... Lesegellschaften lockere Vereinigungen, die auf Sympathie und Interessenskonvergenz der Mitglieder beruhten.." Al Als Beethoven Bonn Ende 1792 zur zweiten Ausbildungsreise nach Wien verließ, gaben ihm die Freunde aus dem Zehrgarten-Kreis Stammbuchblätter mit, die heute, als Büchlein gebunden, in der Österreichischen Nationalbibliothek in Wien aufbewahrt werden. ${ }^{72}$ Literatur-Zitate, die den Stammbuch-Eintragungen beigegeben sind, erlauben Rückschlüsse auf das, was den Kreis beschäftigte. Es ist die aufklärerische Gedankenwelt. Bei deren Vermittlung dürfte der Einfluss der bedeutenden älteren Persönlichkeiten, die dem Zirkel angehörten, die Illuminaten gewesen oder aktuell Lese-Mitglieder waren, gerade auf die jüngeren Teilnehmer nicht gering gewesen sein. Anregung, Austausch, weiterführende Diskussionen von langer Nachwirkung muss es gegeben haben. Der oben genannnte Bartholomäus Fischenich (1768-1831), Dr. jur. utr., schon mit 24 Jahren Professor für Natur- und Völkerrecht an der kurfürstlichen Universität, Wirklicher Hofrat und später preußischer Staatsrat, hat in der Rückschau gesagt, der Zehrgarten-Kreis sei der "Mittelpunkt alles geistigen und geselligen Vergnügens in Bonn" gewesen. ${ }^{73}$

\section{Bezüge über Bonn hinaus}

Die skizzierten intellektuellen Gruppierungen waren, wie angesprochen, nicht lokal isoliert. Freimaurerlogen jeder Richtung pflegten ihr weithin ausgespanntes Beziehungsgeflecht schon um der Durchsetzung ihrer humanitären Vorstellungen willen. Dass die Bonner Gründung der Strikten Observanz durch Spiegel zum Diesenberg in Göttinger Auftrag erfolgte, gehört in diesen Zusammenhang. Und nach der Auflösung der Loge haben einzelne ihrer Mitglieder, wie gesagt, in anderen Logen weitergewirkt. Bei den Illuminaten als dezidierter Geheimgesellschaft sollten die einzelnen Grade keinen Überblick über den gesamten Orden haben, sondern idealiter nur die Leitung der nächsthöheren Ebene kennen. Für die Minervalkirche Stagira war das die Provinzialinspektion, die zunächst in München, später in Neuwied saß, wohin persönliche Beziehungen bestanden. Sie überdauerten auch die Auflösung des Ordens. In der Praxis konnte die partielle Geheimhaltung ohnehin nicht völlig gewahrt werden. So unternahm Freiherr Knigge als Mitglied der obers-

Dr. Bartholomäus Fischenich (1768-1831). Prof. für Natur-, Völker und peinliches Recht an der Hohen Schule in Bonn. Miniatur eines unbekannten Malers (aus: MAX BRAUBACH, Die erste Bonner Hochschule, Bonn 1966) 
ten Ordensleitung Werbe- und Organisationsreisen. Im Juni 1782 visitierte er die Loge in Neuwied. Ein damaliger Besuch in Bonn ist erschließbar, was Kontakte über die hierarchische Stufung hinweg mit sich brachte. Die Lese war nicht Glied eines größeren Systems fester Ordnung, aber sie war mit der gebildeten Welt vielfältig verflochten. Das zeigen Spuren in den Protokollen der Generalversammlungen und vor allem das Gästebuch der Gesellschaft.

Insgesamt gab es in der Bonner intellektuellen Elite mannigfache überörtliche Verbindungen, sei es vom Studium in Paris, Wien oder Göttingen her, wo nicht nur Spiegel zum Diesenberg gewesen war, sei es durch berufliche Kontakte, etwa nach Wetzlar zum Reichskammergericht, nach Mergentheim als Sitz der Deutschordenszentrale oder von der Hohen Schule aus zu anderen Universitäten, wie auch durch verwandtschaftliche und freundschaftliche Beziehungen. Die Linien laufen über die Reichsgrenzen hinweg, ein europaweites Netzwerk scheint auf.

Man mag gegen die hier vorgelegte historische Skizze einwenden, sie zeichne ein zu positives Bild. Gewiss, was ein jedes einzelne Mitglied der Bonner aufklärerischen Gesellschaften bewogen hat, in die Logen oder in die Lese einzutreten, mag unterschiedlich gewesen sein. Mancherlei kann dabei mitgespielt haben. Standesbewusstes Clubdenken bei einzelnen Freimaurern der Strikten Observanz? Mystifizierungsfreude bei den Illuminaten? Karrierehoffnung bei Lese-Mitgliedern, da der Kurfürst der Protektor war? Das alles ist nicht auszuschließen, aber gerade dass bestimmte Namen immer wieder auftreten, dass es gewissermaßen Durchgänge von einer Gesellschaft zur nächsten gab, zeigt, dass für etliche der Intellektuellen andere Motive wichtiger gewesen sein müssen. ${ }^{74}$ Selbstzeugnisse, illuminatische Papiere, Akten und Schrifttum der Hohen Schule, die Briefwechsel Crevelts, Oberthürs, Spiegel zum Diesenbergs, Fischenichs, die Akten der Lese oder Bonner Bibliotheksinventare ${ }^{75}$ erweisen eindrücklich und detailliert, dass es in Bonn im letzten Drittel des 18. Jahrhunderts Menschen gab, für die "Glückseligkeit" nicht nur ein aus der Antike stammendes Schlagwort der Zeit, sondern eine Zielvorstellung war, auf die sie in gemeinsamer Anstrengung hinarbeiten wollten. Einen Widerschein ihres tiefempfundenen Humanitätsanspruchs kann man in Beethovens Brief an den Bonner Jugendfreund Heinrich von Struve sehen, dem er am 17. September 1795 von Wien aus nach Russland schreibt:

"du bist also jezt in dem kalten Lande, wo die Menschheit noch so sehr unter ihrer Würde behandelt wird, ich weiß gewiß, daß dir da manches begegnen wird, was wider deine Denkungs-Art, dein Herz, und überhaupt wider dein ganzes Gefühl ist. wann wird auch der Zeitpunkt kommen wo es nur Menschen geben wird, wir werden wohl diesen glücklichen Zeitpunkt nur an einigen Orten heran nahen sehen, aber allgemein - das werden wir nicht sehen da werden wohl noch Jahrhunderte vorübergehen. ${ }^{176}$ 
Bernhard Havermann geht von 900 bis 1000 Personen, also knapp 10\% der rund 10.233 Bonner Einwohner aus; vgl. BERNHARD HAVERMANN, Freimaurer, Illuminaten und Lesegesellschaften im kurfürstlichen Bonn (1776-1794) (Diplomarbeit an der Universität der Bundeswehr), München [1993], S. 17f. Vgl. in diesem Zusammenhang auch ChristiAn SCHLÖDER, Bonn im 18. Jahrhundert. Die Bevölkerung einer geistlichen Residenzstadt (Stadt und Gesellschaft 5), Köln, Weimar, Wien 2014.

Zur Begriffsgeschichte und zur sozialen Bedeutung des Intellektuellen siehe EDWARD W. SAID, Götter, die keine sind. Der Ort des Intellektuellen (Aus dem Englischen von Peter Geble), Frankfurt/Main und Wien 1998. Zur Kurzinformation siehe Brockhaus Enzyklopädie, 24 Bde, hier Bd. 10, Mannheim 1989, S.555f., Zitat S. 556.

So beurteilt ihn der durchaus kritische Freiherr Franz Wilhelm von Spiegel zum Diesenberg und Canstein später in seiner Chronik meines Lebens; MAX BRAUBACH, Die Lebenschronik des Freiherrn Franz Wilhelm von Spiegel zum Diesenberg. Zugleich ein Beitrag zur Geschichte der Aufklärung in Rheinland-Westfalen (Veröffentlichungen der Historischen Kommission des Provinzialinstituts für Westfälische Landes- und Volkskunde XIX [Westfälische Briefwechsel und Denkwürdigkeiten 4]), Münster 1952, S. 156

Zu Belderbusch vgl. WOLF D. PENNING, Kurkölnischer Erster Conferenzminister und Landkomtur des Deutschen Ordens. Der Weg Caspar Anton von Belderbuschs an die Macht unter dem Kurfürsten Maximilian Friedrich in den Jahren 1761-1781, in: Annalen des Historischen Vereins für den Niederrhein 220, 2017, S. 171-215; von demselben Autor auch weitere einschlägige Studien, insbesondere in den Annalen des Historischen Vereins für den Niederrhein sowie in den Bonner Geschichtsblättern.

Ein Indiz für die Einstellung Max Friedrichs mag auch darin zu sehen sein, dass er anders als seine erzbischöflichen Vorgänger, keinen Jesuiten mehr zum Beichtvater nahm. Nach dem Tod Clemens Augusts 1761 blieb zwar der bisherige Beichtiger noch zwei Jahre auf seinem Posten, danach aber war die Stelle (ausweislich der Hofkalender) bis 1766 unbesetzt, und ab 1767 verknüpft mit dem Hofpredigeramt. Zunächst wurde P. Lucianus Pesch berufen, dann P. Paulinus, beide aus dem Kapuzinerorden.

ALBERT GERHARDS, Die liturgische Entwicklung zwischen 1600 u. 1800, in: FrANK GüNTER ZEHNDER (Hg.), Religiosität und Frömmigkeit im Rheinland des 18. Jahrhunderts (Der Riss im Himmel, Clemens August und seine Epoche 5), Köln 2000, S. 19-36, hier S. 30-32; AloIs DöRING, Wallfahrtsleben im 18. Jahrhundert. Von der mittelalterlichen Fernpilgerreise zur barocken Nahwallfahrt, in: ebd., S. 37-58, hier S. $55 f$

MAX BRAUBACH, Kurköln. Gestalten und Ereignisse aus zwei Jahrhunderten rheinischer Geschichte, Münster 1949, S. 351. Vgl. auch DeRS., Die erste Bonner Hochschule. Maxische Akademie und kurfürstliche Universität 1774/77 bis 1798 (Academica Bonnensia 1), Bonn 1966, S. 24.

Braubach, Hochschule (wie Anm. 7), S. 27; vgl. auch Günter Cronau, Veränderungen des religiösen Lebens, in: INGRID REISSLAND (Hg.), Vom Kurkölnischen Krummstab über den Hessischen Löwen zum Preußischen Adler. Die Säkularisation und ihre Folgen im Herzogtum Westfalen 1803-2003 (Katalog), Arnsberg 2003, S. 77-85, hier S. 79.

Zitiert nach EDITH ENNEN und DIETRICH HÖROLDT, VOm Römerkastell zur Bundeshauptstadt. Kleine Geschichte der Stadt Bonn, Bonn 41985, S. 155.

Monika Neugebauer-Wölk, Reichsjustiz und Aufklärung, Das Reichskammergericht im Netzwerk der Illuminaten (Schriftenreihe der Gesellschaft für Reichskammergerichtsforschung 14), Wetzlar 1993, S. 19

Nichts weniger als Atheisten und Gottesschänder? 
JOSEPH HANSEN (Hg.), Quellen zur Geschichte des Rheinlandes im Zeitalter der französischen Revolution 1780-1801, Erster Band 1780-1791 (Publikationen der Gesellschaft für Rheinische Geschichtskunde 12) (Nachdruck der Ausgabe Bonn 1931, hg. von StePHAN LAUX), Düsseldorf 2003, S. 64-66. Vgl. auch Jürgen GUTMANN, Seit 1775 Freimaurerei in Bonn, Bonn ${ }^{32000, ~ S . ~ 13-17 . ~ D e r ~ J o h a n n i s l o g e ~ " F r i e d r i c h ~ W i l h e l m ~ z u m ~}$ eisernen Kreuz", Bonn, sei vielmals gedankt für die Überlassung dieses im Selbstverlag erschienen Bandes.

Vgl. zu ihm den Beitrag von Alexander Wolfshohl "Elementarbuch psichologie Ordnung der geschäfte". Lesestoff und Leserschaft in Bonn zu Beethovens Jugendzeit, in diesem Band. - Freiherr von Spiegel, der zunächst ab 1771 noch als Kammerknabe mit einem Stipendium des Kurfürsten studiert hatte, wurde 1773 Kämmerer mit einem Gehalt, das ihm half, das auswärtige Studium fortzusetzen. Obriststallmeister Freiherr Forstmeister von Gelnhausen, seit 1771 von Amts wegen für die Ausbildung der Edel- und Kammerknaben verantwortlich, hatte sich für ihn verwendet. Vgl. BRAUBACH, Lebenschronik (wie Anm. 3), S. 163f., 166, 169.

Zu Leerodt siehe auch MARTIN OTTO BRAUn, An den Wurzeln der Tugend. Rheinischer Adel und Freimaurerei 1765-1815 (Modern Academic Publishing 2015), S.137

Graf Maximilian von Thurn und Taxis war (wohl seit 1769) mit Gräfin Franziska von Zierotin (1745-1831) verheiratet, einer Großnichte des Kurfürsten und damals ersten Dame am Bonner Hof.

15 Vgl. Elmar WiLdt, Die Loge zu Münster, ihr Umfeld und ihre Mitglieder um 1780, in: Westfälische Zeitschrift 143, 1993, S. 71-142.

Vgl. Hansen, Quellen (wie Anm. 11), S. 64-67.

Weishaupt, Jesuitenzögling am Gymnasium in Ingolstadt, hatte im Verlauf seiner Studien eine scharfe Kehrtwendung gegen die Societas Jesu vollzogen. Als Kirchenrechtler wurde er mit dem Lehrstuhl betraut, den 90 Jahre lang die Jesuiten innegehabt hatten. 1775 las Weishaupt nicht nur Kanonisches Recht, sondern auch Praktische Philosophie nach dem Göttinger Ordinarius Johann Georg Heinrich Feder; zu Feder vgl. Anm. 12. - 1777 wurde Weishaupt in die Münchener Freimaurerloge aufgenommen. Zu Weishaupt siehe DanIEL JACOBY, Weishaupt, Adam, in: ADB 41, 1896, S. 539550. - Minervalklasse wurde die unterste Stufe in der Ordenshierarchie nach Minerva, der Göttin der Weisheit, genannt, Minervalkirche daher die einzelne Loge; der Name Stagira wurde nach dem griechischen Geburtsort des Aristoteles gewählt. sche Hochschulschriften 18), München 1991. Eine kurze Übersicht über die Entwicklung des Ordens ebd., S.7f.

Siehe hierzu ausführlich: PETER KAEDING, Adolph von Knigge, Begegnungen mit einem freien Herrn, Berlin 1991. Zur Verbindung der Illuminaten mit dem Freimaurertum auch NeugebaUer-WöLk, Reichsjustiz (wie Anm. 10), S. 16-46.

Neugebauer-Wölk, Reichsjustiz (wie Anm. 10), S. 27.

Siehe Anhang 1. Die Namen sind entnommen aus Hansen, Quellen (wie Anm. 11), S. 43-45; Alfred BeCKER, Christian Gottlob Neefe und die Bonner Illuminaten (Bonner Beiträge zur Bibliotheks- und Bücherkunde 21; Veröffentlichungen aus den Beständen der Universitätsbibliothek Bonn 3), Bonn 1969; sowie SchüTtLer, Mitglieder (wie Anm. 18), S. 199, und dessen Fortführung: https://projekte.uni-erfurt.de/illuminaten/ Mitglieder_des_Illuminatenordens.

22 Vgl. Braubach, Lebenschronik (wie Anm. 4), S. 196, $203 f$.

Die Schreibweise des Nachnamens folgt der von d'Antoine selbst gewählten Form. 


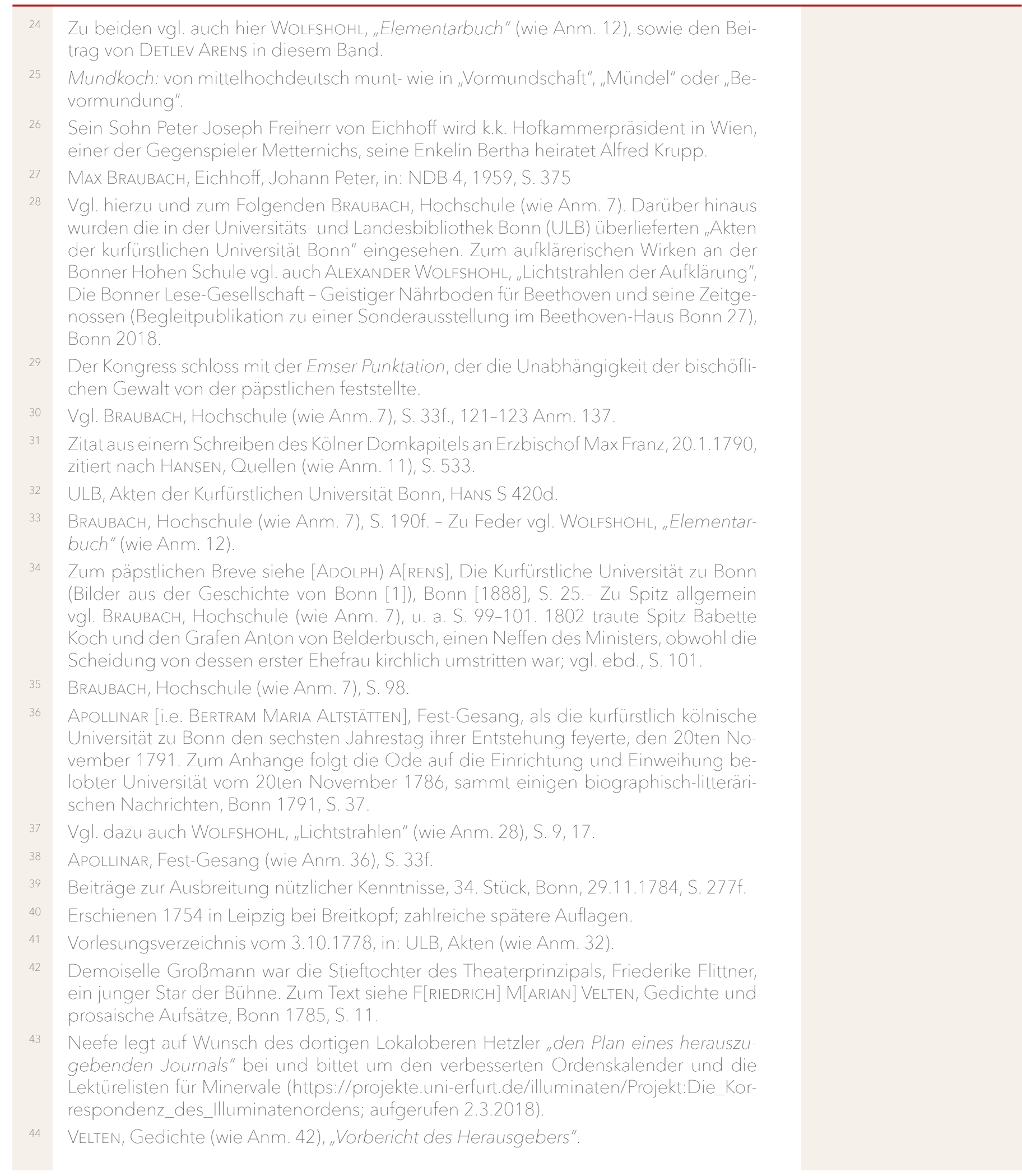

Nichts weniger als Atheisten und Gottesschänder? | 235 (c) 2020 by Böhlau Verlag GmbH \& Cie. KG, Köln https://doi.org/10.7788/9783412519704 | CC BY-NC 4.0 
45 Der Illuminat. Eine Monatsschrift, hg. von D. J. H. FABER, in Gesellschaft einiger aufgeklärter Männer und Freunde der Aufklärung, December 1788, Frankfurt am Main, S. 13.

Protokolle der Generalversammlungen, 6.7.1806 - 3.12.1825, Sitzung vom 3. Sept. 1809, in: Stadtarchiv Bonn (StAB), SN 109 (Depositum Lese)/3. - Als die Lesegesellschaft 1813 ihr 25-jähriges Bestehen feierte, wurde beim Festakt u. a. Velten rezitiert; vgl. C[ARL] M[ORITZ] KNEISEL, Geschichtliche Nachrichten von der Lese- und Erholungsgesellschaft in Bonn, Bonn 1837, S. $9 f$

BECKER, Neefe (wie Anm. 21), S. 61

Vgl. Schüttler, Mitglieder (wie Anm. 18), S. 112, sowie Neugebauer-WöLk, Reichsjustiz (wie Anm. 10), u.a. S. 15, 17, 32-34

49 Ebd., S. 160

Zu Waldenfels in Bonn siehe MAX BRAUBACH, Der kurkölnische Minister Waldenfels, in: Annalen des historischen Vereins für den Niederrhein 118, 1931, S. 144-151. CRONAU, Veränderungen (wie Anm. 8), S. 79.

Zur Modernisierung der akademischen Lehre siehe etwa die Schriftstücke Spiegels und des Kurfürsten, in: ULB, Akten (wie Anm. 32), Hans S 420b.

Bei BrAUBACH, Hochschule (wie Anm. 7) findet sich eine Auflistung der akademischen Schriften. - Zu den Defensionsthesen vgl. auch WOLFSHOHL, "Elementarbuch" (wie Anm. 12).

HANSEN, Quellen (wie Anm. 11), S. 61f. - Die Freimaurer der Strikten Observanz hatten das Maurertum als geheimes Fortleben des mittelalterlichen Ritterordens der Tempelherren aufgefasst. Unklare Kenntnis davon mag in Bonn zu der Bezeichnung "neue(r) Tempelorden" geführt haben.

Vgl. AlEXANDER WOLFSHOHL, Lesepaten für Beethoven? Zur Bedeutung der Bonner Lesegesellschaft von 1787, in: BERNHATd R. ApPEL und Julia RONGE (Hgg.), Beethoven liest (Schriften zur Beethoven-Forschung 28), Bonn 2016, S. 289-322; zur Liste der Gründungsmitglieder siehe S. 296-298.

Die Ode veröffentlichte Eichhoff als Herausgeber des Bönnischen(n) Intelligenzblatt(s) in einer der wöchentlichen Beilagen dazu: Bönnisches Wochenblatt, XXII. Stück, Dienstag, den 27. May, 1788. - Schücking war zunächst in Münster Sekretär des Grafen Nesselrode-Reichenstein. Dort wurde er 1783 als Freimaurer in die erwähnte Loge Friedrich zu den drei Balken aufgenommen; zugleich war er Illuminat. Nach Bonn kam er wohl 1785, als Nesselrode Hofratspräsident wurde. Zu Schücking vgl. http://www. westfaelische-geschichte.de/per4795 und https://projekte.uni-erfurt.de/illuminaten/ Clemens_August_Schücking; Zugriff 6.3.2020. Nesselrode wurde 1788 Lese-Mitglied. Gesetze der Lesegesellschaft in Bonn, Zweite Auflage, nach der ersten von 1789 abgedruckt, nebst den später gemachten Abänderungen und einer historischen Uebersicht dessen was bei der Gesellschaft von ihrem Entstehen bis itzt merkwürdiges vorgefallen, Bonn 1808, S. [III]; StAB, SN 109/28.

KNEISEL, Geschichtliche Nachrichten (wie Anm. 46), S. 2, und im Anhang Namen-Verzeichnis, S. 1

59 Neugebauer-WöLk, Reichsjustiz (wie Anm. 10), S. 27

ULB, Neuzeitliche Handschriften und Manuskripte, S 444, II, 2, S 833; abgedruckt bei BECKER, Neefe (wie Anm. 21), S. 43-50, allerdings nicht ohne Lesefehler.

${ }_{61} \mathrm{Vgl}$. WOLFSHOHL, "Elementarbuch" (wie Am. 12).

62 Siehe Anhang 2. 


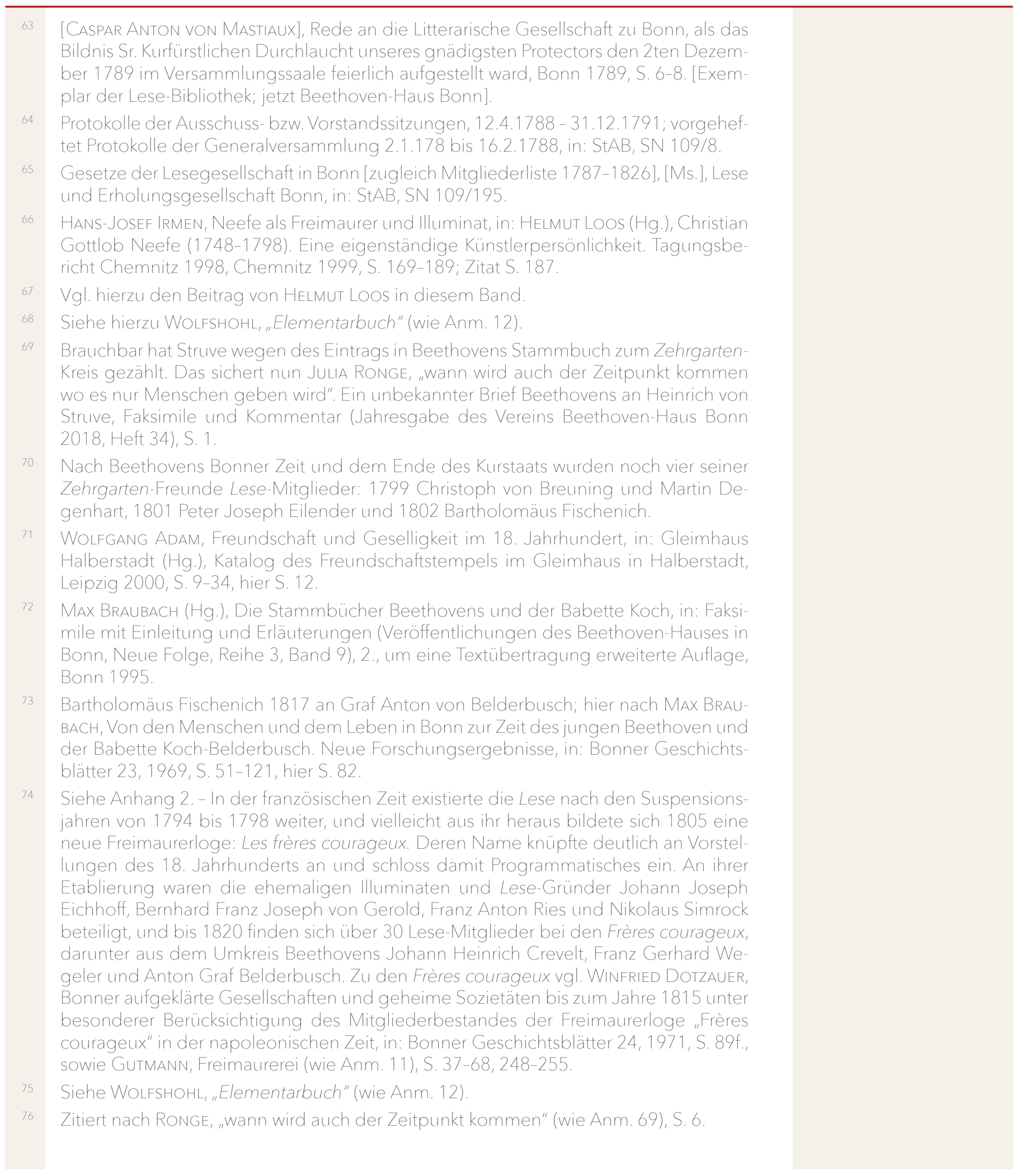

Nichts weniger als Atheisten und Gottesschänder? | 237 (c) 2020 by Böhlau Verlag GmbH \& Cie. KG, Köln https://doi.org/10.7788/9783412519704 | CC BY-NC 4.0 


\section{Illuminaten in Bonn - Minervalkirche Stagira}

Die Amts- und Rangbezeichnungen der in der folgenden Liste aufgeführten Illuminaten sind aus den Hofkalendern gezogen und gelten, wenn nicht anders angegeben, nur für den Zeitraum vor Auflösung der Bonner Minervalkirche und des Ordens 1785.

Zunächst sind die Schauspieler und Musiker zusammengestellt; die Hofmusiker unter ihnen gehörten durch ihre Anstellung zum Hofstaat. Dannfolgen weitere Persönlichkeiten aus Hofstaat und Hofgesellschaft. Anschließend sind Professoren der Hohen Schule genannt; diejenigen mit einem Ratstitel zählten ebenfalls zur Hofgesellschaft. Hoch ist der Anteil von Geistlichen unter diesen Professoren: acht von dreizehn. Zur Geistlichkeit gehören auch die anschließend Aufgeführten: der Sekretär Kanonikus Schmitz und der Politiker Freiherr von Spiegel zum Diesenberg. Die in der Liste zuletzt Erwähnten, Freiherr von Waldenfels und Dr. Schücking, waren zwar Illuminaten, doch ist bei ihnen eine Mitwirkung in der Minervalkirche Stagira überaus fraglich. Sie kamen erst in der Auflösungszeit der Loge nach Bonn und sind quellenmäBig illuminatisch hier nicht greifbar.

Joseph Schmidt (1753-1787, Schauspieler, seit 1778 in Großmanns Truppe; erster Lokaloberer bzw. Präfekt der Minervalkirche Stagira)

Christian Gottlob Neefe (1748-1798, Musiker und Komponist; nach Schmidts Weggang von Bonn 1783 zweiter Lokaloberer der Minervalkirche; seit 1781 Hofmusiker)

Friedrich Wilhelm Gustav Großmann (1743-1820, Jurist, Schauspieler, Theaterprinzipal)

Nikolaus Simrock (1751-1832, Hofmusiker und Musikalienhändler)

Franz Anton Ries (1755-1846, Hofmusiker)

Franz Tussy (*1750, Sprachmeister, Musiker; vermutlich 1791 Hofschauspieler; vielleicht ein Sohn des des Hofmusikers Franz Tussy)

Lothar Franz Michael Freiherr von und zu Erthal (1717-1805, K.k. u. Kurmainzischer Wirklicher Geheimer Rat; Oberstkämmerer $\left.{ }^{1}\right)$

Clemens August Freiherr von Schall zu Bell d. Ält. (1748-1814, Kurkölnischer Kämmerer, Kurkölnischer Hauptmann)

Clemens August Freiherr von Schall zu Bell d. Jüng. (1758-1814, Jurist, Kurköln. Kämmerer, Reichskammergerichtspraktikant in Wetzlar, seit 1782 in Bonn)

Bernhard Franz Josef von Gerold² (1747-1828, Jurist, Wirklicher Gelehrter Hofrat)

Ferdinand d'Antoine (1746-1793, Kurkölnischer Wirklicher Capitain, Komponist)

Johann Peter Eichhoff (1755-1825; Journalist, ab 1781 Gräflich Bentheimischer Rat und Deputierter des Grafen von Bentheim-Steinfurt beim kurkölnischen Landtag)

Johann Josef Eichhoff (1762-1827, Kurfürstlicher Mundkoch)

Amtsbezeichnungen nach den Kurmainzer Hofkalendern von 1780 und 1781, frühere derzeit nicht zu ermitteln. Die Schreibweise des Familiennamens folgt Gerolds eigener Unterschrift. Für den nachfolgend genannten d'Antoine gilt das ebenfalls.

238 | Alexander Wolfshohl

(c) 2020 by Böhlau Verlag GmbH \& Cie. KG, Köln

https://doi.org/10.7788/9783412519704 | CC BY-NC 4.0 
Prof. Dr. phil. Heinrich Gottfried Wilhelm Daniels (1745-1827, 1780 Hofgerichtskommissarius, 1783 Lehrstuhl für die Pandekten und die juristische Praxis an der Hohen Schule)

Prof. Dr. med. Peter Wilhelm Joseph de Ginetti (1735-1804, seit 1783 Lehrstuhl für Physiologie und Botanik, Wirklicher Geheimrat)

Prof. Dr. med. Franz Wilhelm Kauhlen (1750-1793, seit 1776 Lehrstuhl für Medizin, 1777 Kurfürstlicher Titular-Hofrat, 1782 auch Garnisonsmedicus)

Prof. Dr. med. Joseph Claudius Rougemont (1756-1818, Lehrstuhl für Anatomie u. Hebammenkunst)

Prof. Johann Friedrich Marian Velten (1759-1784, 1777-1781 Gymnasiallehrer für Deutsch, Latein und Schönschreibekunst, dann Hofkammerkanzlist)

Prof. Dr. theol. Dr. jur. utr. Philipp Franz Anton Hedderich OFMConv (1744-1808, 1774 an die Hohe Schule berufen, Lehramt für das geistliche Recht $u$. für das besondere

Erzstiftkölnische Staatsrecht, 1779 Kurfürstlicher Geistlicher Rat, ab 1782 Bücherzensor)

Prof. Dr. [iur. can.?] Elias Peter Joseph van der Schüren OFMConv (1750-1829, 1777 Lehrstuhl für Metaphysik, Moral und Naturrecht, 1783 für Logik, Metaphysik und praktische Philosophie)

Prof. Dr. [theol.?] Anselm Becker OSB (1756-1843, 1783 Lehrstuhl für Polemik)

Prof. Dr. jur. utr. Franz Heinrich Cramer OSB (1740-1796), 1783 Lehrstuhl für Diplomatik und Reichsgeschichte)

Prof Dr. [theol.?] Sebastian Scheben OSB (1750-1792, 1783 Lehrstuhl für Pastoraltheologie)

Prof. Dr. theol. Anton Andreas Spitz OSB (1745-1811, 1783 Lehrstuhl für Kirchengeschichte und die theologische Geschichte Deutschlands)

Prof. Dr. phil. Thaddaeus Anton Dereser OCD (1757-1827, 1783 Lehrstuhl für Exegetik des Neuen Testaments und für Griechisch)

Prof. Dr. theol. Bonifaz Anton Oberthür (1749-1804,1784 Lehrstuhl für Katechetik, Direktor des Gymnasiums und Präses des Professoralhauses)

Joseph Schmitz (1736-1810, Kanonikus des Münsterstifts, zeitweise Sekretär des Ministers Freiherrn Karl Otto von und zu Gymnich ${ }^{3}$ )

Franz Wilhelm Freiherr von Spiegel zum Diesenberg und Canstein (1752-1815, Kurfürstlicher Adliger Geheimrat, Landdrost von Westfalen, Präsident der Landstände des Herzogtums Westfalen)

Johann Christian Freiherr von Waldenfels (1742-1796, Assessor des Bayerischen Reichskreises am Reichskammergericht in Wetzlar, Juni 1784 Berufung als Kurkölnischer Staats- und Konferenzrat, Juni 1786 Beförderung zum Staats- und Konferenzminister)

Dr. jur. Clemens August Schücking (1759-1790; wohl erst 1785 nach Bonn gekommen als Sekretär des neuen Hofratspräsidenten Grafen von Nesselrode-Reichenstein)

Gymnich war Mitglied der Bonner Freimaurerloge der Strikten Observanz. 
ANHANG 2

\begin{tabular}{|c|c|c|c|}
\hline \multicolumn{4}{|c|}{ Aufklärerische Gesellschaften in Bonn } \\
\hline $\begin{array}{l}\text { Freimaurerloge } \\
(1776-\text { ca. 1779) }\end{array}$ & $\begin{array}{c}\text { Minervalkirche Stagira } \\
(1781-1785)\end{array}$ & \multicolumn{2}{|l|}{$\begin{array}{l}\text { Litterarische Gesellschaft } \\
\text { (sog. Lese; seit 1787) }\end{array}$} \\
\hline Frhr. von Spiegel $\mapsto$ & Frhr. von Spiegel $\mapsto$ & Frhr. von Spiegel & $(1787)$ \\
\hline Frhr. von Forstmeister $\mapsto \mapsto$ & & Frhr. von Forstmeister & $(1788)$ \\
\hline Frhr. von und zu Gymnich & d'Antoine $\mapsto$ & d'Antoine & $(1788)$ \\
\hline Fürst von Hohenlohe & Becker $\mapsto$ & Becker & $(1788)$ \\
\hline Frhr. von Kleist & Cramer & & \\
\hline Graf von Königsegg (I) & Daniels & & \\
\hline Graf von Königsegg (II) & Dereser $\mapsto$ & Dereser & $(1788)$ \\
\hline Frhr. von Leerodt & Johann Peter Eichhoff $\mapsto$ & Johann Peter Eichhoff & $(1787)$ \\
\hline Prinz von Salm-Salm & Johann Joseph Eichhoff $\mapsto$ & Johann Joseph Eichhoff & $(1787)$ \\
\hline \multirow[t]{17}{*}{ Graf von Thurn und Taxis } & von Gerold $\mapsto$ & von Gerold & $(1787)$ \\
\hline & de Ginetti & & \\
\hline & Hedderich $\mapsto$ & Hedderich & $(1788)$ \\
\hline & Kauhlen $\mapsto$ & Kauhlen & $(1788)$ \\
\hline & Neefe $\mapsto$ & Neefe & $(1787)$ \\
\hline & Oberthür $\mapsto$ & Oberthür & $(1787)$ \\
\hline & Ries $\mapsto$ & Ries & $(1787)$ \\
\hline & Rougemont $\mapsto$ & Rougemont & $(1787)$ \\
\hline & Frhr. von Schall d. Ält. $\mapsto$ & Frhr. von Schall d.Ält. & $(1787)$ \\
\hline & Frhr. von Schall d.Jüng. $\mapsto$ & Frhr. von Schall d.Jüng. & $(1788)$ \\
\hline & Scheben $\mapsto$ & Scheben & $(1788)$ \\
\hline & Schmitz $\mapsto$ & Schmitz & $(1787)$ \\
\hline & van der Schüren $\mapsto$ & van der Schüren & $(1787)$ \\
\hline & Simrock $\mapsto$ & Simrock & (1787) \\
\hline & Spitz & & \\
\hline & Tussy & & \\
\hline & $\begin{array}{l}\text { Die Minervalkirchen-Mitglieder Frhr. } \\
\text { von und zu Erthal, Großmann und } \\
\text { Schmidt waren } 1787 \text { nicht mehr in } \\
\text { Bonn, Velten war } 1784 \text { gestorben. }\end{array}$ & $\begin{array}{l}\text { Ende } 1788 \text { umfasste die Lese } 85 \\
\text { Mitglieder; hier sind nur die } 20 \\
\text { genannt, die zuvor einer der Bonner } \\
\text { Logen angehört hatten. }\end{array}$ & \\
\hline
\end{tabular}




\section{Persönliches Amusement und politische Agenda Bedeutungen von Musik für Kurfürst Maximilian Franz}

I... beyderseitige Rheinufer prangten mit einigen Tausenden von Freude taumelnden Unterthanen, die mit fliegenden Fahnen und klingendem Spiel, auch beständigem Lauffeuer aus ihrem Schießgewehr ein unabläßliches Jubelgeschrey machten, so das schier erstaunte anstossende Gebirge mit einem freudigen Wiederhall in die Nachbarschaft aussprengte. Der von einer so außerordentlichen Last stolze Rheinfluß schien vorsätzlich mit langsamen Fluthen das in vollem Siegeszug ankommende Schiffsheer hinunterrollen zu wollen, um desto länger das Vergnügen zu haben, den erhabenen Liebling des vielgeliebten Maxen tragen zu mögen."

Im Oktober 1780, zwei Monate nach seiner Wahl zum Koadjutor und damit designierten Nachfolger des amtierenden Kölner Kurfürsten Maximilian Friedrich (Regierungszeit 1761-1784), besuchte Maximilian Franz von Habs-
Elisabeth Reisinger

Ankunft des frisch gewählten Koadjutors Maximilian Franz zu Schiff auf dem Rhein in der kurkölnischen Residenzstadt am 3. Oktober 1780. Ölgemälde von

Franz Rousseau

(Beethoven-Haus Bonn)

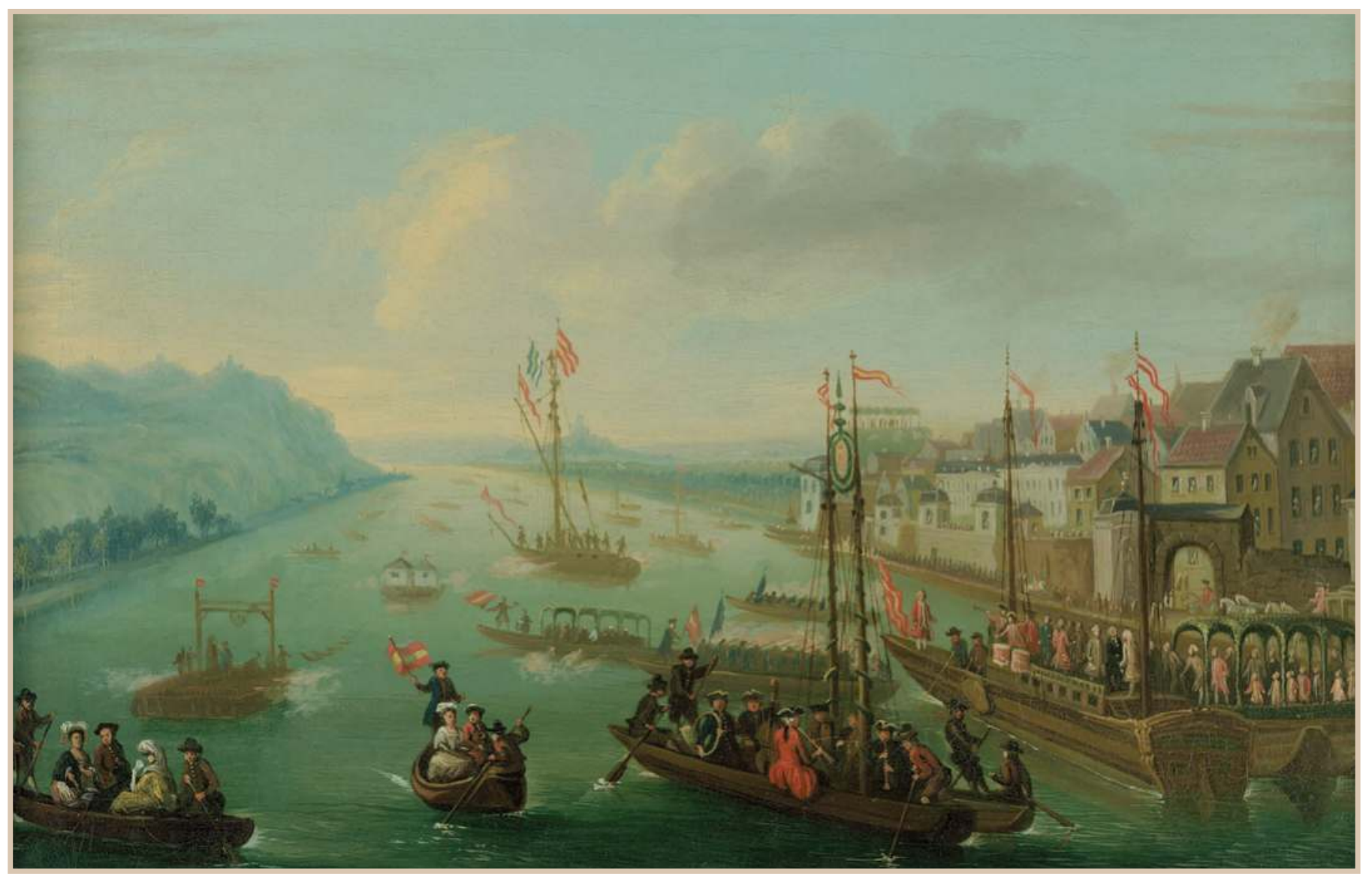

Persönliches Amusement und politische Agenda - Bedeutungen von Musik für Kurfürst Maximilian Franz | 241 


\section{Empfang des Koadjutors \\ Maximilian Franz durch \\ Kurfürst Maximilian \\ Friedrich im Ehrenhof des \\ Residenzschlosses. \\ Ölgemälde von \\ Franz Rousseau \\ (Beethoven-Haus Bonn)}

burg-Lothringen (1756-1801) Bonn zum ersten Mal. Bei dieser Gelegenheit lernte er die musikalische Landschaft seiner künftigen Residenz kennen, die der weithin für seine musikalischen Kompetenzen und Aktivitäten bekannte Erzherzog wohl durchaus interessiert zur Kenntnis nahm. Es wurden Bälle und Konzerte veranstaltet, sowie mehrere Opern aufgeführt. Mit dem Engagement der Großmannschen Theatertruppe hatte Maximilian Friedrich 1778 erstmals einen regelmäßigen, für Publikum zugänglichen Theater- und Opernbetrieb in Bonn etabliert. ${ }^{2}$ Institutionalisierten Konzertbetrieb gab es zwar keinen, Vokalund Instrumentalmusik wurde dagegen vielfältig in Bonns aristokratischen und bürgerlichen Häusern gepflegt. ${ }^{3}$ Angehörige des Hofes kamen zudem in den Genuss einer reichen Musikpflege an der Hofkirche, für die Hofkapellmeister Andrea Luchesi (1741-1801) verantwortlich zeichnete und für die unter Maximilian Friedrich ein umfangreiches Notendepot angelegt wurde. ${ }^{4}$ Auch diesen Aufgabenbereich der Hofmusik lernte Maximilian Franz während seines Besuchs 1780 kennen: Am 12. Oktober wurde mit einem Festhochamt, wohl angemessen musikalisch umrahmt, der gemeinsame Namenstag von amtie-

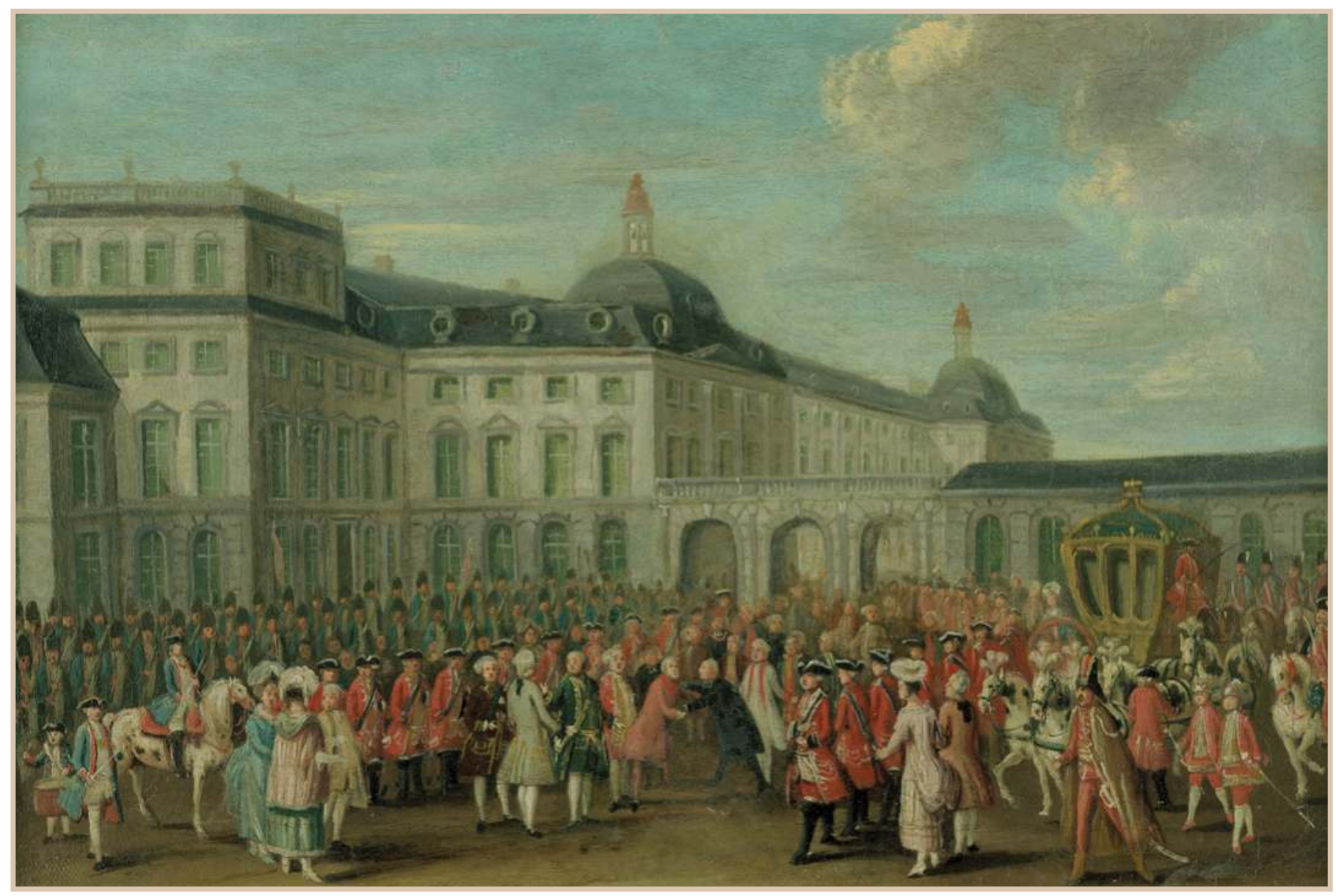

242 | Elisabeth Reisinger

(c) 2020 by Böhlau Verlag GmbH \& Cie. KG, Köln

https://doi.org/10.7788/9783412519704 | CC BY-NC 4.0 
rendem und künftigem Kurfürsten gefeiert, wobei außerdem die neu errichtete Hofkirche erstmals benutzt wurde. ${ }^{5}$

Beethoven, der Zeit seines Lebens nie offiziell aus Hofdiensten entlassen wurde, war von 1782 bis 1792, also zehn Jahre, in der Bonner Hofmusik tätig - der Großteil dieser Zeit ist deckungsgleich mit jenen Jahren (1784-1794), in denen Maximilian Franz in Bonn residierte. In dieser relativ kurzen Zeitspanne, bis der kurfürstliche Hof in Bonn aufgrund der heranrückenden französischen Truppen aufgelöst werden musste und der Kurfürst die Stadt endgültig verließ, sind entscheidende Entwicklungen im Musikleben am und um den Hof zu beobachten, die Beethoven in erster Reihe miterlebte.

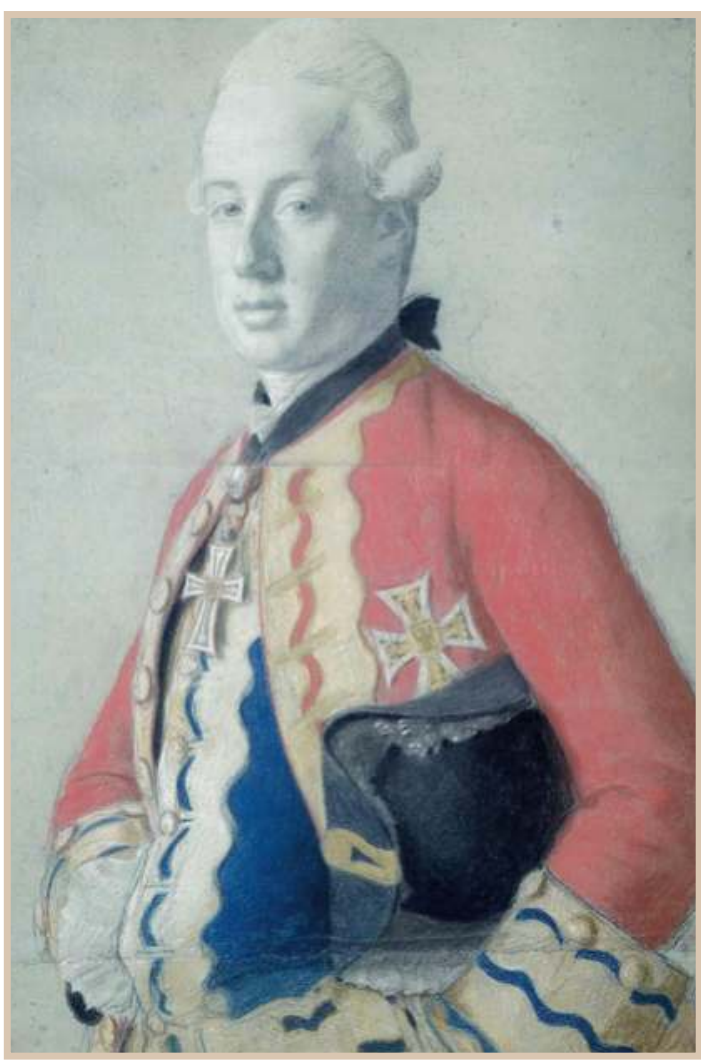

Die folgenden Ausführungen nehmen vor allem die Perspektive von Kurfürst Maximilian Franz ein, sowohl als "privater" Musikliebhaber als auch politischer Machthaber. Dabei folgt der Beitrag einer chronologischen Struktur, in der bestimmte Jahre, die auch in Beethovens Vita als Orientierungspunkte gelten können, für Tiefenbohrungen zu jeweils bestimmten Aspekten herangezogen werden. Dies soll veranschaulichen, wie eng die musikalische Laufbahn des jungen Hofmusikers mit den soziokulturellen Rahmenbedingungen am Bonner Hof verwoben war. Zugleich offenbart sich in den gewählten Zeitpunkten die Brisanz, die das Geistes- und Kulturleben in der kurkölnischen Residenzstadt gleichermaßen gerafft in einer Zeitspanne von lediglich zehn Jahren erfuhr.

\section{4 - Der Kurfürst, seine Musiker und seine Musik}

Nach dem Tod Maximilian Friedrichs im April 1784 brach Maximilian Franz unverzüglich nach Bonn auf. Vergingen bis zur feierlichen Inthronisierung noch mehr als drei Monate - die Bischofsweihe im Bonner Münster fand sogar erst im Mai 1785 statt -, wurde eine Evaluierung der Hofadministration unmittelbar nach seiner Ankunft in Gang gesetzt. Der neue Herrscher hatte konkrete Vorstellungen für seinen Machtbereich, vor allem war ihm daran gelegen, bereits vorhandenes Potential im Rahmen der zur Verfügung stehenden öko-
Erzherzog Maximilian Franz (1756-1801). Pastellzeichnung von Jean-Etienne Liotard, 1778 (Amsterdam Rijksmuseum) 
nomischen Mittel effizient auszuschöpfen. Auch der Bereich der Hofmusik wurde diesbezüglich nicht ausgespart: Sämtliche Mitglieder wurden einer Überprüfung ihrer geleisteten Dienste, Fähigkeiten und Gehaltseinstufung unterzogen. ${ }^{6}$ Während dies für manche in Gehaltskürzungen resultierte (tatsächliche Entlassungen gab es hingegen nicht), muss das Ergebnis für Beethoven zufriedenstellend gewesen sein: sein Posten als Hilfsorganist, den er seit zwei Jahren unbezahlt versehen hatte, wurde künftig mit einer Entlohnung versehen. ${ }^{7}$ Er war ab nun festes und vor allem bezahltes Mitglied der kurfürstlichen Hofkapelle.

Doch nicht nur auf administrativer Ebene hatte der neue Kurfürst konkrete Vorstellungen, die er im Laufe der kommenden Jahre schrittweise umsetzte, sondern ebenso von der Rolle der Musik an seinem Hof. Zunächst bedeutete Musik für ihn persönliches Amusement. Von Kindheit an hatte Maximilian selbst musiziert. Am Wiener Hof von Hofmusikern in Gesang sowie an Tastenund Streichinstrumenten ausgebildet, widmete er sich auch im Erwachsenenalter der aktiven Musikpflege, sei es noch in Wien womöglich begleitet von seinen Kammermusikern, ${ }^{8}$ beim Singen aus Opernpartituren mit seinem Bruder, ${ }^{9}$ seine Schwester auf dem „Bassettl" begleitend, ${ }^{10}$ oder auch als Kurfürst mit Familienmitgliedern und Angehörigen der Bonner Oberschicht. ${ }^{11}$ Bekannt und wiederholt zitiert ist in diesem Kontext Neefes Beschreibung der kurfürstlichen Musikliebe in einer Rede zur Wiedereröffnung des Bonner Hoftheaters 1789:

„Der Kurfürst ist nicht blos ein Freund der Bühne und der Tonkunst, wie die Meistens seines gleichen; sondern er verdient unter den Kennern seinen Platz. Er weiß Stücken, Schauspieler, musikalische Kompositionen und praktische Tonkünstler mit Einsicht und Geschmack zu beurtheilen. Er besitzt selbst einen ansehnlichen Vorrath (den er immer noch vermehrt) der neuesten und besten Opernpartituren, die er sehr fertig ließt und womit er sich zuweilen Nachmittags nach besorgten Regierungsgeschäften im Kabinet amusirt. Die Arien singt er dann selbst; das Klavier, ein Violoncell, zwei Violinen und eine Viola begleiten ihn. Mehrstimmige Gesänge vertheilt er unter die Accompagnateurs, die singen können."12

Maximilian Franz musizierte also nicht nur mit anderen Adeligen, sondern häufiger noch - regelmäßig nachmittags zur Entspannung - mit ausgewählten Hofmusikern. Der von Neefe hier erwähnten Gruppe, Maximilians Bonner Kammermusik, gehörten neben Neefe selbst (Klavier) Beethoven (Viola, Klavier), Franz Anton Ries (Violine) und Bernhard Romberg (Violoncello) an. ${ }^{13}$ Ein Dokument aus dem Nachlass des Kurfürsten im Haus-, Hof- und Staatsarchiv Wien nennt als weitere Kammermusiker außerdem Andreas Romberg (Violine), Sebastian Pfau (Flöte), sowie den Sänger Luigi Simonetti. ${ }^{14}$ Diese Musiker, die allesamt aus der persönlichen Schatulle des Kurfürsten entlohnt wurden, darf man sich also an Maximilians Seite beim Musizieren abseits der Regierungs- 
geschäfte vorstellen. Sie repräsentierten eine exquisite Auswahl auf ihren jeweiligen Instrumenten. Franz Anton Ries, Sohn von Johann und Vater von Ferdinand (beide ebenfalls Hofmusiker), zählte zu den besten Violinisten der Hofmusik. ${ }^{15}$ Sein Eintritt erfolgte 1779/8016, vermutlich spielte er also bereits für Maximilian, als dieser Bonn als Koadjutor besuchte. Sebastian Pfau wurde, nachdem er Mitglied des Kölner Domchors gewesen war, um 1781/82 als Flötist in der Bonner Hofmusik angestellt. ${ }^{17}$ Die Cousins Andreas und Bernhard Romberg waren eigentlich in der Dommusik in Münster engagiert. Maximilian, der ebenfalls das Amt des Fürstbischofs von Münster bekleidete, dort regelmäBig residierte und daher auch mit der Musik des Doms wohlvertraut war, hatte die beiden 1790 nach Bonn rekrutiert. ${ }^{18}$ Sie gehörten jener jüngeren Generation von Bonner Hofmusikern an, von denen einige später bemerkenswerte Karrieren außerhalb Bonns absolvieren sollten. ${ }^{19}$

Ein bemerkenswerter Fall ist der Tenor Luigi Simonetti, einer der Neuzugänge in der Hofmusik unter Maximilian Franz. Der Forschung ist er vor allem bekannt durch den oft zitierten Bericht Carl Ludwig Junkers über das Gastspiel der Bonner Hofmusik in Mergentheim ${ }^{20}$ sowie durch seinen Briefwechsel mit Constanze Mozart. ${ }^{21}$ Dass er im Auftrag des Kurfürsten mit Constanze über den Erwerb von Handschriften verhandelte, zeigt, dass er durchaus das besondere Vertrauen Maximilians genossen haben dürfte. In Bonn trat er, abgesehen von seinem Engagement in der Kammermusik, wo er vermutlich sowohl für den Kurfürsten als auch mit diesem im Duett sang, in den am Hof regelmäßig stattfindenden Konzerten auf. ${ }^{22}$ Bemerkenswerterweise sang er jedoch weder an der Hofkirche noch am Theater.

Der bereits mehrfach erwähnte Neefe war eine vielschichtige Figur des Bonner Musiklebens. 1779 war er als eine Art musikalischer Leiter zur Theatertruppe Großmanns gestoßen, die das Hoftheater bespielte. Ab 1781 folgte er Gilles van Eden als Organist an der Hofkirche nach und trat damit in die Hofmusik ein. Dieser Posten diente ihm schließlich nach der Entlassung der Großmannschen Truppe 1784 als Absicherung. Er blieb in Bonn, und auch wenn das Urteil über ihn im Pro Memoria von $1784^{23}$ alles andere als positiv ausfiel, sollten sich ihm bald weitere Tätigkeitsfelder eröffnen - eben als Teil der kurfürstlichen Kammermusik sowie ab 1789 erneut in einer zentralen Funktion am Hoftheater. ${ }^{24}$ Außerdem war er offenbar in die musikalische Weiterbildung des Kurfürsten eingebunden, denn 1787 berichtet er in einem Brief an seinen Freund, den vormals in Bonn tätigen Theaterdirektor Großmann: "Kürzlich hat mir der Kurfürst die Gnade erzeigt, mich zu seinem Lehrmeister in der musikal[ischen] Harmonie zu erwälen." 25

Eine Neueinführung unter Maximilian Franz scheint die möglicherweise einer persönlichen Neigung ${ }^{26}$ folgende Einrichtung eines festen HarmonieEnsembles gewesen zu sein. Dieses genoss hochstehenden Rang. ${ }^{27}$ In diesem Zusammenhang ist von Interesse, dass von Beethovens Bläseroktett op. 103, 
das erst 1830 im Druck erschien, eine Bonner Frühfassung existiert ${ }^{28}$, die möglicherweise für seine von Publikum und Landesherrn so geschätzten Kollegen geschrieben worden war, nämlich dem Kern der Bläser der Bonner Hofmusik (Oboe: Georg Liebisch und Joseph Welsch, Klarinette: Michael Meuser und Joseph Pachmeyer, Fagott: Theodor Zilecken und Georg Welsch, Horn: Andreas Bamberger und Nikolaus Simrock). ${ }^{29}$ Nach der Reduktion der Hofmusikkapelle in Bonn 1794 zählten die Mitglieder der Harmoniemusik zu den letzten mit Besoldung am Hof verbliebenen Musikern. ${ }^{30}$ Liebisch, der Bonn 1794 verlassen hatte und nach Wien gegangen war, erfuhr womöglich noch weitere Protektion durch seinen vormaligen Dienstherren: In Max Franzens Nachlass hat sich der rudimentärer Entwurf eines Briefs vom Ende des Jahres 1794 erhalten, in dem sich der Kurfürst mit eindringlichen Worten an Graf Johann Wenzel Ugarte, einst Teil von seiner Wiener Entourage und nun Hofmusikgraf am Kaiserhof, wendet:

"An den K.K. Kammerherrn u. Hof Musik Director Graf Ugarte in Wien

Mergenth. d. 20. dec. 1794

Lieber Graf Ugarte!

Aus Meinem Wohnsiz in Meinem Kollnischen Lande durch den französischen Einfall vertrieben, und des grösten theils meiner Einkünfte beraubt sehe Ich Mich gezwungen, den grösten theil meines Hofstaat und ins besonderen der Hof Musick zu entlassen. Der Hoboist Liebisch, der sich so wohl durch sein stilles und ruhiges Betragen, als seinen Fleiß jederzeit vor allen ausgezeichnet, verdienet, daß Ich ihm allerdings dieses nachstehende Zeugniß gebe, damit er in seinem Vaterland ein besseres Fortkommen haben könne." ${ }^{\prime \prime}$

In Wien war Liebisch zunächst am Freihaus-Theater angestellt, ab 1801 am Theater an der Wien, sowie ab 1802 in Diensten des Grafen Franz Esterházy in Ungarn. ${ }^{32}$

In der oben zitierten Rede erwähnt Neefe einen weiteren zentralen Aspekt, in dem sich das Musikinteresse des Kurfürsten manifestierte: dessen Notensammlung. Diese bildete eine wesentliche Grundlage für die genannten Ensembles sowie das Musikleben am Hof ab 1784 allgemein, stand sie doch den Hofmusikern zur Verwendung offen. Die Sammlung umfasste dabei bei weitem nicht nur Opern, sondern Musik aus allen Genres mit einem Schwerpunkt auf Instrumentalmusik. Die heute noch erhaltenen Teile ${ }^{33}$ sowie mehr noch ein überliefertes Inventar ermöglichen einen tiefen Einblick in musikalische Interessen und Agenden des Erzherzogs und Kurfürsten. ${ }^{34}$

Von der ursprünglich mehr als 3500 Einheiten umfassenden Sammlung Maximilians (Kompositionen von über 270 Komponistlnnen) dürfte heute noch etwa ein Drittel erhalten sein. Während also die Überlieferung der Noten große Lücken aufweist, erhalten wir aus einem noch existenten Katalog detailliert Auskunft über den einstigen Inhalt der Sammlung. ${ }^{35}$ Ein Schwerpunkt (ca. 90\%) lag auf Instrumentalmusik, insbesondere kammermusikalischen 
Gattungen. Dies spiegelt die oben beschriebene Musikpflege in kleineren Ensembles am Hof wieder. Eindeutige Präferenzen hinsichtlich der Komponisten sind nur in Ausnahmefällen festzustellen, wie etwa bei den Quartetten, wo vor allem Werke von Komponisten wie Johann Baptist Vanhal, Anton und Carl Stamitz, Carlos d'Ordoñez oder Luigi Boccherini aufscheinen. Von keinem besaß Maximilian allerdings so viele Kammermusikwerke wie von Giuseppe Maria Cambini (ca. 150 Quartette, 12 Quintette, 36 Trios) und Joseph Haydn (über 70 Trios, ca. 60 Quartette, 8 Quintette). Von beiden listet der Katalog außerdem noch zahlreiche Symphonien auf (von Cambini ca. 30, von Haydn ca. 80) - damit waren diese beiden Komponisten mit Abstand am stärksten in der Sammlung vertreten.

Die Überstellung der Noten von Wien nach Bonn bedeutete am kurfürstlichen Hof vor allem im Bereich der Instrumentalmusik, und hier besonders der Kammermusik, eine beträchtliche Repertoireerweiterung. In etwa 2000 Stücke umfasste die Sammlung bereits 1784, und sie wurde in Bonn nach den Vorlieben des Kurfürsten stetig erweitert, „privat” finanziert aus der kurfürstlichen Schatulle. ${ }^{36}$ Dass Neuerwerbungen dabei immer am Puls des Musikmarkts und die Sammlung stets „up to date" waren, ist in erster Linie auf den eigentlich als Hornist am Hof angestellten Nikolaus Simrock zurückzuführen. Für seine Nebenbeschäftigung als Notenkopist erhielt er mit Maximilians Regierungsantritt eine Art Monopol für die Anschaffung und das Vervielfältigen neuer Noten, die vor allem Eingang in die kurfürstliche Sammlung fanden. ${ }^{37}$

\section{6-1789 - Machtpolitische Agenden in Theater und Kirche}

1778 war von Maximilian Friedrich ein festes Hoftheater mit deutschsprachigem Schwerpunkt installiert worden. ${ }^{38} 1784$ wurde nach dessen Tod im April der Spielbetrieb umgehend eingestellt. Dies bedeutete jedoch einen tieferen Einschnitt als den üblichen Verzicht auf Theateraufführungen während der Trauerzeit. Großmanns Kompanie, die das Privileg am Hoftheater innegehabt hatte, war entlassen worden. In den folgenden Spielzeiten gastierten von November 1784 bis Frühjahr 1785 die Böhmsche Theatertruppe sowie im Februar 1786 das französische Hoftheater des Kurfürsten von HessenKassel in Bonn. ${ }^{39}$ Danach fand für drei Jahre praktisch kein Theaterbetrieb statt. Dies lag jedoch nicht daran, dass der neue Kurfürst kein Interesse an einem Hoftheater hegte, im Gegenteil: Die Thematik wurde eingehend diskutiert, und es wurde intensiv an einem neuen Konzept für das künftige kurfürstliche Theater gearbeitet. In Maximilian Franzens Nachlass haben sich mehrere Entwürfe dazu erhalten, in denen nicht nur die Notwendigkeit eines festen Hoftheaters thematisiert wird, sondern ebenso die Vorteile einer "NationalSchaubühne", vor allem auf moralischer Ebene. ${ }^{40}$ Derartige Überlegungen spielten im Übergang vom exklusiven, repräsentativen Hoftheater zum kommerziell geführten und einem größeren Publikum zugänglichen Theaterbe- 


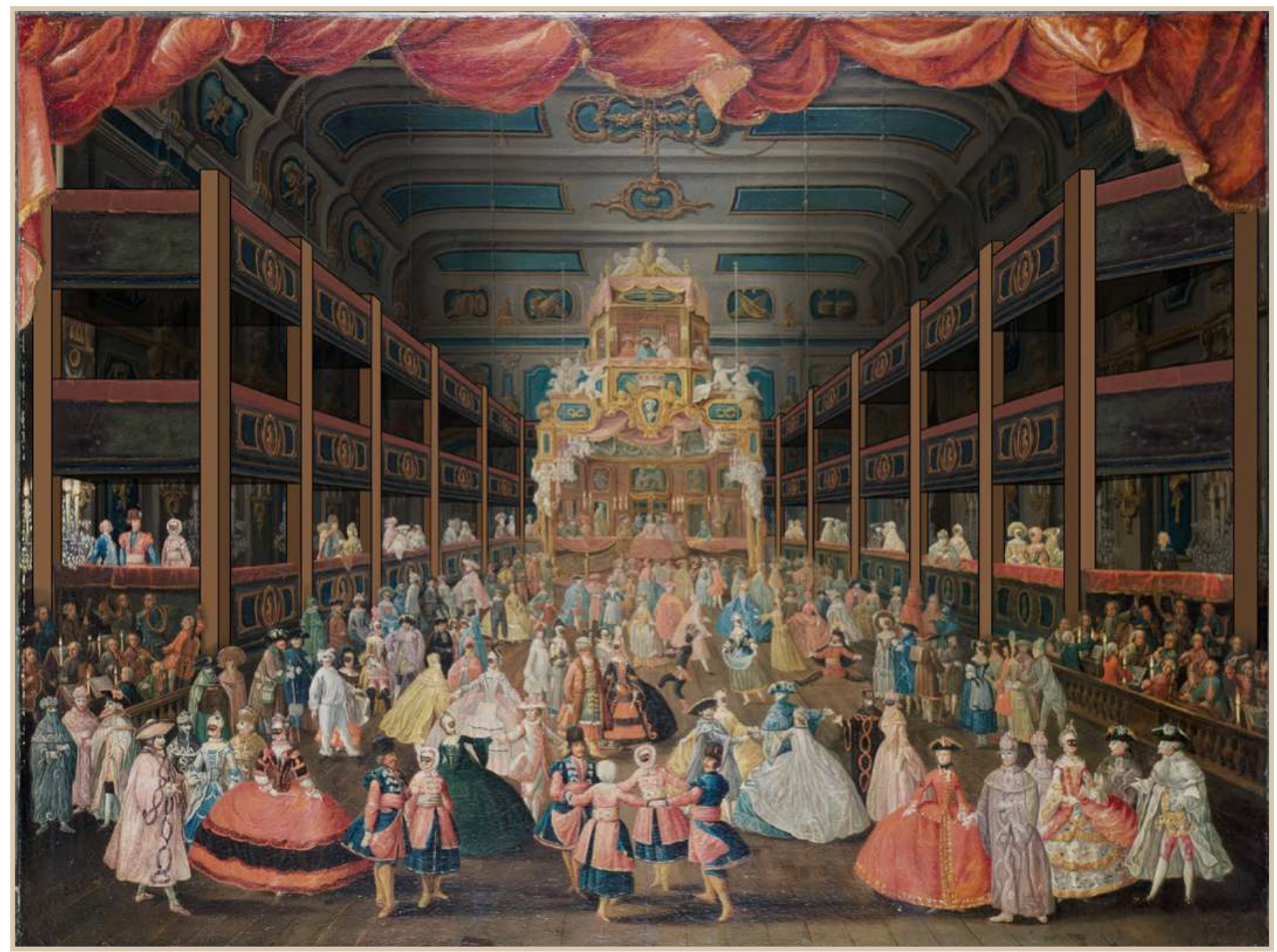

Digitale Rekonstruktion des Bonner Hoftheaters nach der Renovierung 1788, mit hinzugefügten Logen (auf der Basis des Bönnischen Ballstücks von Franz Rousseau, Öl auf Leinwand, um 1754. Blick ins Publikum

[Stadtmuseum Bonn]) (C) Alyssa A. Abraham Aus der Zeit von Maximilian Franz sind keine Darstellungen des Theaters erhalten. trieb europaweit eine Rolle. Das Ausspielen dieser moralischen und patriotischen Karten diente allerdings ebenso oft zumindest teilweise der Rechtfertigung der Aufrechterhaltung eines Theaterbetriebs während wirtschaftlich schwieriger Zeiten. ${ }^{41}$ In den Bonner Konzepten taucht weiter durchgehend die Forderung nach der Vereinigung von Hofmusik und Theater auf, sowie nach einem Repertoire, das sowohl Sprech- als auch Musiktheater mit einem einzigen Ensemble bedienen könnte. Es ging darum, den kulturellen Bedürfnissen des Hofes aber ebenso zunehmend eines zahlenden, sozial differenzierteren Publikums möglichst effizient und kostengünstig nachzukommen. Ein Theater, das sowohl Sprechtheater als auch Oper anbot, war dabei nicht wegzudenken.

Als zwar an den Hof angegliederter, jedoch im Großen und Ganzen autonom geführter Impresa-Betrieb erfüllte das „in der Kurfürstl. Residenzstadt

248 | Elisabeth Reisinger

(C) 2020 by Böhlau Verlag GmbH \& Cie. KG, Köln

https://doi.org/10.7788/9783412519704 | CC BY-NC 4.0 
Bonn zu errichtende National-Theater"42 nun allerdings andere Zwecke als ein auf die Repräsentation der Herrschenden ausgerichtetes Hoftheater. Durch den Wegfall seiner Exklusivität und durch den Zugang breiterer Bevölkerungsschichten erlangte das Theater durchaus eine neue Form der innenpolitischen Bedeutung. Der Kurfürst konnte sich als ökonomisch handelnder "Diener des Volkes" positionieren, der in allgemein verständlicher Volkssprache gleichzeitig für die theatrale Unterhaltung sowie die moralische Erbauung seiner Untertanen Sorge trug. ${ }^{43}$ Diese Entwicklung war in Bonn bereits von Maximilian Friedrich eingeleitet worden; schon er wohnte außerdem, wie dann auch Maximilian Franz, dem Bühnengeschehen eher aus einer kleinen Seitenals aus der prunkvollen Mittelloge bei. ${ }^{44}$

Inwiefern der Landesherr - sowohl Maximilian Friedrich als auch Maximilian Franz - direkten Einfluss auf den Spielplan nahm, ist auf Basis der bekannten Quellen schwierig zu beurteilen. Da aber aus den Verträgen zur Neueinrichtung 1789 die Eigenständigkeit der Theaterdirektoren hinsichtlich des Neuerwerbs von Aufführungsmaterial hervorgeht (wenngleich es ihnen ebenso frei stand, sich aus der Sammlung des Kurfürsten zu bedienen), ist wohl davon auszugehen, dass weniger das konkrete Alltagsgeschäft als mehr die allgemeine Ausrichtung vom Herrscher bestimmt wurde. ${ }^{45}$ Zur Realisierung des Repertoires auf der Bühne wurden neue musikalische Kräfte am Hof engagiert. Quellen wie die jährlich erscheinenden Hofkalender listen ab etwa 1789 neue Streicher, Bläser und VokalistInnen auf. ${ }^{46}$ Mit der Aufnahme des Spielbetriebs am 3. Jänner 1789 erhielt auch Beethoven zusätzlich zu seinen Tätigkeitsfeldern in Kirche und Kammer eine weitere Aufgabe: als Bratschist im Hoftheater. Das nun vergrößerte Orchester kam auch in der Hofkirche zum Einsatz. Aus dem fast lückenlos (heute in Modena) erhaltenen kirchenmusikalischen Aufführungsmaterial ist abzulesen, dass unter Maximilian Franz die im Gottesdienst spielende Besetzung nach und nach um zusätzliche Bläser (Klarinetten, Flöten und Hörner), zusätzliche Violin-Pulte sowie Ripieno-Stimmen bei den Vokalistlnnen erweitert wurde. Zwar wurden die Anlässe, zu denen figurale Kirchenmusik vorgesehen war, in der Quantität reduziert, die Qualität der musikalischen Ausgestaltung, wenn denn nun Solistlnnen, Chor und Orchester verlangt waren, scheint aber keineswegs Einbußen erfahren zu haben, eher im Gegenteil. Maximilian Franz war immerhin Kurfürst, Landesherr und Erzbischof von Köln, Fürstbisch of von Münster sowie Hochmeister des Deutschen Ordens. Die Vereinigung dieser Ämter in einer Person dürfte auch Ende des 18. Jahrhunderts noch einen gewissen Repräsentationshabitus erfordert haben. Festliche Hochämter, sowohl regulär im Jahreskreis als auch zu besonderen Anlässen, erfuhren eine reiche musikalische Ausgestaltung. Die Ritterschläge des Deutschen Ordens, die nun mehrfach in der Hofkirche stattfanden, waren etwa hochrepräsentative Veranstaltungen, bei denen die Hofmusik in ihrer ganzen Stärke, inklusive Trompeten und Pauken, zum Einsatz kam. ${ }^{47}$ Solche 
Musik diente (nun durchaus im Unterschied zum Theater) "Repräsentation" in ihrer ursprünglichen Bedeutung: als Vergegenwärtigung von Macht.

Die musikalische Bedienung dieser Repräsentationsbedürfnisse erfolgte aus dem umfangreichen Bestand an Kirchenmusik, den Maximilian Franz von seinem Vorgänger übernommen hatte und der während seiner zehnjährigen Regierungszeit noch einmal um fast die gleiche Menge aufgestockt wurde. ${ }^{48}$ Zugleich wurden die Notenbestände aus der Zeit Maximilian Friedrichs und zum Teil noch Clemens Augusts weiter verwendet. Mehr noch: Mit dem musikalischen Material wurde durchaus dynamisch umgegangen - so wurde es etwa an die gewünschte Besetzung angepasst oder nach offenbar ästhetischen Vorstellungen bearbeitet, indem häufig neue "Füllstimmen" an jenen Stellen einer Komposition hinzugefügt wurden, an denen eigentlich eine kleinere Besetzung vorgesehen war. All dies fiel in den Verantwortungsbereich von Kapellmeister Luchesi, der wohl auch Neuanschaffungen sowie das letztlich im Gottesdienst gespielte Repertoire auswählte. Der Einfluss des Kurfürsten ist hier - ähnlich wie beim Theater - auf einer eher indirekten Ebene zu sehen, indem er durch seine politischen Entscheidungen die Rahmenbedingungen vorgab, wie etwa die Abschaffung von Prozessionen, Vorgaben zurAusgestaltung der Gottesdienste, liturgische Abläufe an Feiertagen oder die Einführung des deutschen Gemeindegesangs.

Kirchenlieder in Volkssprache waren ab 1786 an der Bonner Hofkirche zu hören. ${ }^{49}$ Diese Gesänge ersetzten jedoch keine andere Form musikalischer Gottesdienstgestaltung, sondern wurden zusätzlich zu figuraliter und choraliter musizierten Gottesdiensten eingeführt. ${ }^{50}$ Das Decorum eines so hohen geistlichen Würdenträgers musste schließlich gewahrt bleiben - und so heißt sogar noch in den politisch und ökonomisch schwierigen 1790er Jahren in einem Entwurf für die künftige Hofhaltung des Kurfürsten und Erzbischofs:

„Die Würde eines Erzbischofs mit jener eines Kurf[ür]st[en] verpaart erfordert, daß man eine besondere Sorge für die Kirchlichen Functionen, und deren Anstand trage. Es würde dem publicum höchstauffallend seyn, ein Erzbischöfliches pontifical-amt mit bloß deutsch. Gesängen zu hören." ${ }^{151}$

In den erhaltenen Gesangbüchern der Hofkirche sind zwei Liedzyklen abgedruckt: die Singmesse Hier liegt vor Deiner Majestät aus dem sogenannten Landshuter Gesangsbuch von Franz Seraph Kohlbrenner, ${ }^{52}$ das auch etwa in Salzburg Verbreitung gefunden hatte, sowie der von Joseph II. 1783 für die habsburgischen Länder vorgeschriebene Normalmessgesang mit der Messliedreihe Wir werfen uns darnieder. ${ }^{53}$ Hinter der Einführung solcher Lieder standen durchaus politische Motive, das zeigen sowohl das Salzburger als auch das Wiener Beispiel. Einfachheit, Verständlichkeit und Lehrhaftigkeit des Gottesdienstes sollten eine Fokussierung auf die Grundlagen von Glauben und Moral sowie die Beteiligung der Bevölkerung im Gottesdienst befördern - dies wurde zumindest gegenüber dem Volk propagiert, etwa im bekannten Hirtenbrief des 
Salzburger Fürsterzbischofs Hieronymus Colloredo von $1783 .{ }^{54}$ Dies brachte nun neue Funktionen von Musik in die Kirche, die durchaus vergleichbar waren mit den Diskussionen rund um die Ausrichtung der Theater. Nützlichkeit und Menschenbildung, die auch durch Pädagogisierung von Kirchenmusik in für das Volk verständlicher Sprache erreicht werden sollten, wurden nun als Aufgaben zur Rechtfertigung geistlicher Herrschaft postuliert. ${ }^{55}$ Dies ist einerseits im Kontext systemerhaltender Reformstrategien von Seiten der katholischen Kirche in durchaus brisanten Zeiten zu sehen sowie andererseits als Mittel zur Legitimierung von Herrschaft, die zunehmend nicht mehr in erster Linie über Gottesgnadentum gerechtfertigt wurde, sondern über Nutzen und Leistung.

\section{0-1792 - „daß ein Fremder, der die Music liebt, nie ohne musicalische Nahrung von Bonn wieder abreisen wird"}

1790 und 1792 besuchte Joseph Haydn die kurkölnische Residenzstadt, allerdings keineswegs als "ein Fremder", denn er genoss hier bereits erhebliches Ansehen. Bereits 1783 berichtete Neefe in einer Beschreibung des Bonner
Doppelseite aus dem Inventar der persönlichen Notensammlung Maximilians mit Quartetten von Joseph Haydn (Gallerie Estensi, Biblioteca Estense Universitaria, Modena)

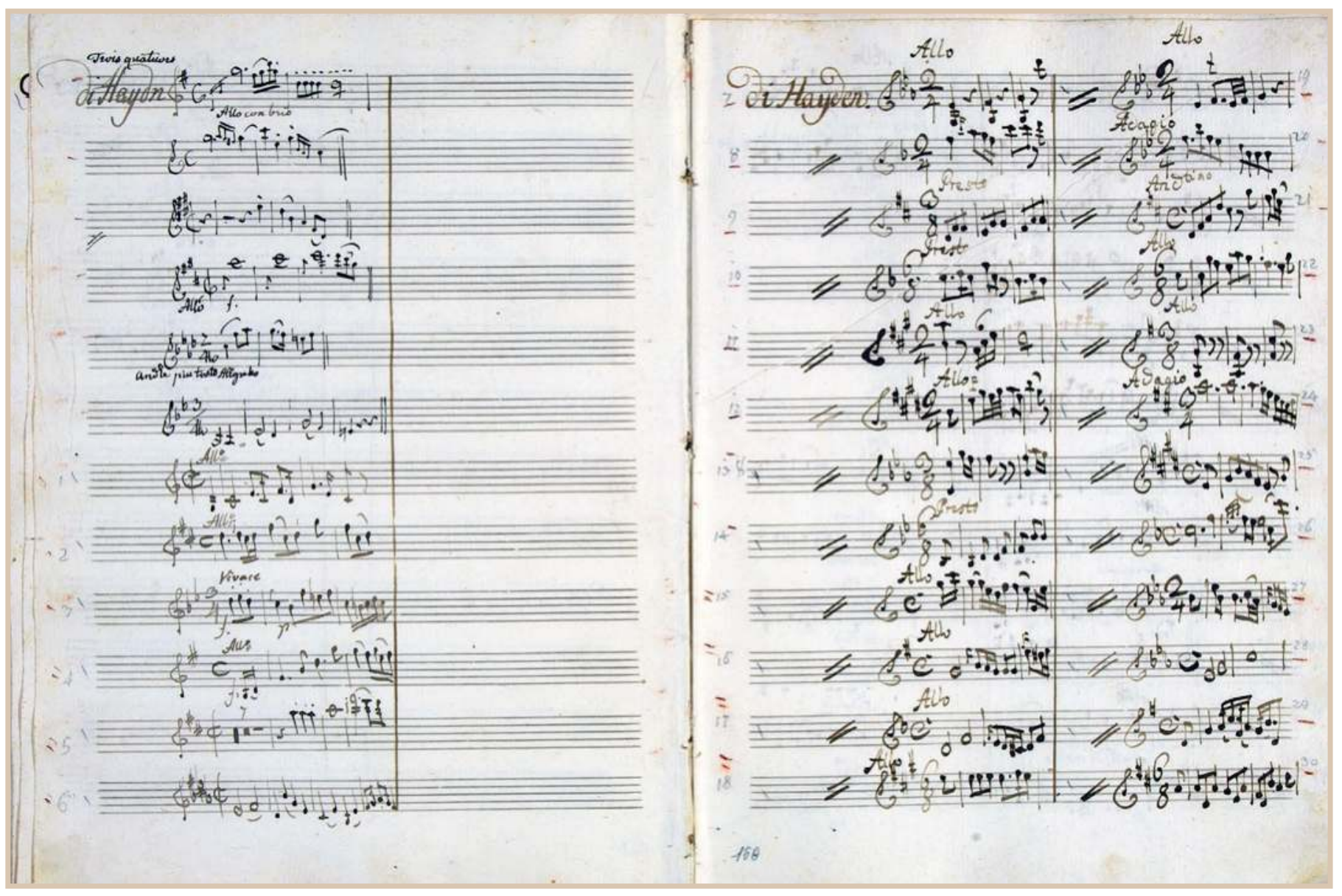


Musiklebens in Friedrich Cramers Magazin der Musik über die Bewunderung und Pflege Haydnscher Musik bei Gottfried von Mastiaux, einem der wichtigsten Häuser ${ }^{57}$ im Bonner Musikleben außerhalb der kurfürstlichen Schlossmauern:

"Herr Hofkammerrath von Mastiaux, ein Mann der kein Vergnügen kennt und wünscht, als das Vergnügen der Music; sie ist seine liebste, seine tägliche Gesellschafterinn. Er besitzt Talente und Einsichten in diese Kunst; die erstern hat er auch auf seine Kinder, deren er fünfe, 4 Söhne und eine Tochter besitzt, fortgepflanzt, und um ihnen die letztern zu gewähren spart er keine Kosten. ... Es ist in der Tat für einen fühlenden Mann kein geringes Vergnügen, einen Vater mitten unter seinen Kindern sitzen zu sehen, und ihn mit selbigen ein Quintett ausführen zu hören. Er ist der einzige, der schon seit geraumer Zeit den Winter hindurch wöchentlich ein Concert bey sich giebt, woran jeder Musicliebhaber, er sey fremd oder einheimisch, Antheil nehmen kann. Er besitzt einen grossen Vorrath an guten Musicalien, und so viel Instrumente, daß er ein vollständiges Orchester damit etablieren kann. Jeder Musiker ist sein Freund, ist ihm willkommen. Von Joseph Haiden ist er ein Anbeter und wechselt mit ihm Briefe." 58

Als Maximilian Franz, dem zumeist fälschlicherweise eine Vorliebe für Mozart zugeschrieben wird, 591784 in Bonn ankam, fügte er sich hier also mit seinem eigenen Interesse an Haydn hervorragend ein. ${ }^{60}$ Wie bereits angedeutet, war Haydn der meist vertretene Komponist in Maximilians Sammlung. Wenngleich diese Präferenz für Haydn sowie das offenbare Interesse, Haydns neueste Veröffentlichungen möglichst schnell zu erwerben (Symphonien und Quartette etwa finden sich in der Eintragungsschicht ab 1784 sogar in Kompositionsreihenfolge $\left.{ }^{61}\right)$, manifest und auffallend ist, ist ein direkter Kontakt Maximilians mit Haydn zwar nicht überliefert, allerdings wohl durchaus wahrscheinlich. Immerhin hätte Maximilian Haydn bereits in Wien persönlich kennenlernen können. Besonders 1777 hätte es dazu reichlich Gelegenheit gegeben: Im Juli jenen Jahres spielte die Esterházysche Kapelle unter Haydns Leitung im Schönbrunner Schlosstheater und bei der kaiserlichen Tafel. ${ }^{62}$ Natürlich waren diesem Besuch Haydns in Wien zahlreiche weitere vorangegangen und gefolgt. Dazu passt, dass Maximilian einen Großteil seiner Haydn-Abschriften bereits vor 1784 für seine Sammlung erworben hatte.

Im Dezember 1790 erreichte Haydn auf seinem Weg nach England Bonn. Eine Begegnung mit der dynamischen Kirchenmusikpflege an der Hofkirche unter Luchesis Ägide bildete den ersten Einblick in das Musikleben vor Ort. Haydns Biograph Albert Christoph Dies berichtet, dass Haydn am Tag nach seiner Ankunft von Johann Peter Salomon, selbst aus Bonn stammend, zum Hochamt in die Hofkirche geleitet wurde, bei dem - offenbar zur Überraschung Haydns - eine seiner eigenen Messen aufgeführt wurde. ${ }^{63}$ Womöglich war es Beethoven, der die Orgel spielte. Mit Sicherheit schüttelten sich Haydn und Beethoven die Hände, als Haydn nach der Messe vom Kurfürsten auf das 
Oratorium gerufen wurde, um die Hofmusiker zu treffen, sowie am darauffolgenden Abend bei dem von Maximilian organisierten Diner, zu dem letzterer seine besten Musiker geschickt hatte. ${ }^{64}$ Wohl erfuhr Haydn bei diesen Gelegenheiten von den kompositorischen Ambitionen des jungen Organisten und ermunterte diesen vielleicht, ihm beim nächsten Treffen eigene Werke vorzulegen.

Diese Chance ergriff Beethoven, als Haydn bei seiner Rückreise von England im Juli 1792 erneut in Bonn Station machte. Franz Gerhard Wegeler berichtet, dass das kurfürstliche Orchester ein Frühstück für Haydn ausgerichtet und Beethoven diesem dabei eine Kantate vorgelegt habe. ${ }^{65}$ Wie schon von Julia Ronge $^{66}$ festgestellt, handelte es sich dabei wohl entweder um Auf den Tod Josephs des Zweiten WoO 87 oder Auf die Erhebung Leopolds des Zweiten zur Kaiserwürde WoO 88, die beide um 1790 entstanden waren. ${ }^{67}$ Die Komposition der ersteren dürfte ein Auftrag der Bonner Lesegesellschaft gewesen sein aus Anlass einer (letztlich nicht stattgefundenen) Trauerfeier nach dem Tod Josephs II., des Kurfürsten Bruder. ${ }^{68}$

Die Lesegesellschaft war 1787 gegründet worden und setzte sich zunächst vor allem aus ehemaligen Mitgliedern der 1785 aufgelösten Minervalkirche Stagira der Bonner Illuminaten zusammen, zu deren Mitgliedern eine ganze Reihe von Hofmusikern wie Neefe, Franz Anton Ries und Simrock gehörten. ${ }^{69}$ Auch zahlreiche Mitglieder der Bonner Oberschicht und der hohen Hofbeamten waren hier zu finden wie Freiherr Franz Wilhelm von Spiegel zum Diesenberg, ab 1786 Präsident der Hofkammer, sowie Caspar Anton von Mastiaux (Sohn des bereits als Haydn-Liebhaber erwähnten Gottfried von Mastiaux). Der Kurfürst selbst trat der Lesegesellschaft nicht bei, war jedoch ein häufiger Gast, stellte sie unter sein Protektorat und ließ zudem auf seine Kosten ein neues Gebäude für die Gesellschaft einrichten. ${ }^{70}$

1788 trat Graf Ferdinand Waldstein der Lesegesellschaft bei, kurz nachdem er nach Bonn gekommen war. Den Spross einer böhmischen Adelsfamilie, in den hochadeligen Kreisen Wiens erzogen, ausgebildet und vernetzt, hatten seine Karrierebestrebungen im Deutschen Orden nach Bonn und zum amtierenden Hochmeister, Maximilian Franz, geführt. Waldstein übernahm verschiedene, durchaus zentrale und einflussreiche Funktionen im Orden und scheint zu einem engen Vertrauten Maximilians geworden zu sein. ${ }^{71}$ Wegeler geht sogar soweit, ihn als „Liebling und beständige[n] Gefährte[n] des jungen Kurfürsten" zu bezeichnen. ${ }^{72}$ Nicht nur politische Ambitionen oder der familiäre Hintergrund im Hochadel der habsburgischen Länder verbanden den Grafen mit dem Kurfürsten, sondern auch das Interesse an Musik. Waldstein spielte Klavier - womöglich partizipierte er gar bei kammermusikalischen Zusammenkünften um Maximilian Franz. ${ }^{73}$ Ebenso wie der Kurfürst begann er wohlwollendes Interesse an der Karriere Beethovens zu hegen. Man kann annehmen, dass er und andere Förderer Beethovens federführend waren in 
der Vergabe des oben erwähnten Kompositionsauftrags für die Trauerfeier 1790 an den jungen Hofmusiker (und nicht etwa an andere, erfahrenere Bonner Komponisten). Auch die Entstehung von Beethovens zweiter Bonner Kantate aus Anlass der Kaiserkrönung eines weiteren Bruders von Maximilian Franz (Leopold II.) könnte mit der Lesegesellschaft oder sogar dem Kurfürsten selbst in Zusammenhang stehen. ${ }^{74}$

In der Lesegesellschaft begegneten sich standesübergreifend Künstler, Intellektuelle, Adlige. Dies bettet sich in Tendenzen des 18. Jahrhunderts ein, in denen zunehmend freiwillig eingegangene Bindungen, in Freundeskreisen und Sozietäten, alte durch Stand und Beruf determinierte Bindungsmuster überlagerten. ${ }^{75}$ Haydn lernte also auch diesen Sektor des Bonner Sozial- und Kulturlebens kennen - nicht nur als Hintergrund für die ihm präsentierten Kompositionen Beethovens, sondern ebenso ganz direkt: Am ersten Weihnachtstag des Jahres 1790, dem Tag seiner Ankunft in Bonn, begleitete er den Hofmusiker Franz Anton Ries in die Lesegesellschaft und trug sich in deren Gästebuch ein. ${ }^{76}$

Haydns weitere Geschäftswege in Bonn führten ihn zu Nikolaus Simrock. ${ }^{77}$ Simrock spielte eine wichtige Rolle für die Erweiterung der kurfürstlichen Musiksammlung und möglicherweise gelang es ihm auch aufgrund dieser Geschäftsbeziehung, seinen Dienstherrn mit den aktuellsten Veröffentlichungen Haydns zu versorgen. Simrock sorgte mit seinem blühenden Geschäft außerdem für reichlich Repertoire für die um 1786 im Akademiensaal des Schlosses installierten Hofkonzerte - in Bonn erstmals regelmäßig stattfindende Orchesterkonzerte, bei denen vor allem aktuelle Instrumentalmusik erklang und in deren Publikum nahezu immer auch der Kurfürst selbst anzutreffen war. ${ }^{78}$

Haydn hatte bei seinen Aufenthalten in Bonn einen durchaus aufschlussreichen Einblick in die musikalische Landschaft der Stadt nach sechs bzw. acht Jahren unter der Regierung Maximilian Franzens erhalten, und er war gewiss nicht "Ohne musicalische Nahrung von Bonn wieder" 79 abgereist. Einzig das Hoftheater hatte er nicht in Aktion erlebt, da seine Besuche in spielfreie Zeiten (Weihnachtszeit und Sommer) gefallen waren. Die Vernetzung mit den hiesigen Musikern, die offenbar vom Kurfürsten angeregt und gewünscht worden war, hatte aber konkrete Folgen: Wenige Monate nachdem Haydn im Juli ein zweites Mal in der kurkölnischen Hauptstadt Station gemacht hatte, folgte ihm Beethoven im November 1792 unter Fortzahlung seines Hofmusiker-Gehalts sowie einer jährlichen Sonderzahlung zu einer weiteren Studienreise nach Wien. ${ }^{80}$

In den 1790er Jahren begannen die Kriegswirren ihre Schatten in die kurkölnische Residenzstadt vorauszuwerfen. Maximilian Franz war gezwungen, sich Gedanken zu machen über die Zukunft seines Landes, seines Hofes und nicht zuletzt seiner eigenen Person. Die letzte Zeit bis zur schließlichen Aufgabe Bonns nach dem Einfall französischer Truppen im Rheinland im Herbst 1794 
war geprägt von Plänen zur Umstrukturierung der Hofhaltung und Sparmaßnahmen bis hin zu durchaus konkreten Entwürfen zur Wiedereinrichtung einer kurfürstlichen Residenz in Münster, wo Maximilian Franz bereits eine Grundlage für ein „Exil” zur Verfügung hatte. Im Bereich der Hofmusik wurden diese Entwicklungen zunächst um 1793 manifest, als entschieden wurde, den Hoftheaterbetrieb mit Ostern 1794 gänzlich einzustellen und das Theater in den nächsten Spielzeiten wieder an externe Wandertruppen zu vergeben. Damit ging einher, dass auch die Verträge mit einer Reihe von Sängerlnnen und Orchestermusikern nicht über diesen Zeitpunkt hinaus verlängert wurden. ${ }^{81}$ Die Hofmusik wurde nach und nach reduziert, einige der jüngeren Musiker hatten Bonn schon zuvor im Bestreben nach weiteren Karriereoptionen verlassen. ${ }^{82}$ Für die musikalische Versorgung am Hof war schließlich ein auf das nötigste verkleinerte Vokalensemble mit rudimentärer Instrumentalbegleitung für den Kirchendienst sowie die Kammer- und Harmoniemusik des Kurfürsten vorgesehen.

Der Kurfürst verstand diese Neuausrichtung allerdings weniger als leidige Notwendigkeit, bedingt durch die desaströse politisch-ökonomische Situation, sondern eher als Chance für eine grundlegende Reform. Der Historiker Max Braubach zitiert in diesem Zusammenhang einen Brief des Kurfürsten an den kurmainzischen Kanzler im Februar 1793, in dem Maximilian zudem an ein vorbildhaftes kollektives Handeln zumindest der drei geistlichen Kurfürsten appelliert:

"Ich habe keine Nepoten oder Familie, der ich aushelfen müßte, keine Mätressen oder Bastarde, denen ich Schätze sammeln wollte. Ich liebe Ordnung und das Geld nicht zur Unzeit zu verschwenden, damit es einem daran im Notfalle nicht gebreche. Wenn man unter den drei geistlichen Kurfürsten einig würde, keine so teure als unnütze Leibgarden, keine so kostspielige Hofkapellen-Musik, auch etwas weniger adelige Hofchargen ... so würde es wohl für den Hofdienst und Ansehen genug sein." ${ }^{183}$

In diesem Sinne müssen wohl auch Maximilian Franzens Handlungen und Entscheidungen in den letzten Tagen des Bonner Hofes und seiner Hofmusik bzw. die Pläne und Ideen für die etwaige Wiedereinrichtung einer kurfürstlichen Hofhaltung gelesen werden. Der Musik kamen darin Funktionen vor allem in der Abdeckung des Kirchendienstes durch ein reduziertes Ensemble an Vokalisten, einem Regens Chori und einem Organisten, sowie in der Bedienung des Kurfürsten durch kleinere Ensembles zu. Ein großes Orchester scheint nicht mehr vorgesehen gewesen zu sein; Theater und Oper wurden 1793 auch personell vom Hof abgekoppelt. Maximilians persönliches Interesse an Musik und der Vergrößerung seiner Notensammlung (weiterhin aus eigenen finanziellen Mitteln) blieb jedoch bis zu seinem Tod 1801 ungebrochen. 
Die Rücksicht auf den ehemaligen Wohlstand und Ansehen des Erzstifts Köln in denen erstern Zeiten: dessen Abnahmen in Mittlern, und dessen Befestigung in jetzigen Zeiten bey Gelegenheit der durch die weise Vorsorge eines vielgeliebten Max Friedrich beförderten und auf des theuersten Erzherzogs Max Franz königl. Hoheit, in: J[OHANN] P\{ HILIPP] N[ERIUS] M[ARIA] V[OGEL] (Hg.), Kurfürstlich-kölnischer Hofkalender für das Jahr 1781, Bonn [1780], S. 28.

Vgl. Elisabeth Reisinger, Juliane Riepe und John D. WiLson, in Zusammenarbeit mit BIRGIT LODES, The Operatic Library of Elector Maximilian Franz: Reconstruction, Catalogue, Contexts (Schriften zur Beethoven-Forschung 30; Musik am Bonner kurfürstlichen Hof 2), Bonn 2018, S. 47-104

Vgl. etwa Christian Gottlob Neefes anonym veröffentlichte Beschreibung des musikalischen Bonn 1783: Nachricht von der churfürstlich-cöllnischen Hofcapelle zu Bonn und andern Tonkünstlern daselbst, in: FrIedRICH Cramer ( $\mathrm{Hg}$.), Magazin der Musik 1783, S. 377-396

Diese Sammlung ist dokumentiert durch ein "Inventarium hiesig Kurfürstlichen Residentz-Schloßes, d[e]d[it] Bonn den 8ten May 1784", in: Landesarchiv Nordrhein-Westfalen, Abt. Rheinland (LAV NRW R), Kurköln II, Nr. 340; vgl. dazu REISINGER/RIEPE/ WILSON, The Operatic Library (wie Anm. 2), S. 231, 235-240 und 461, sowie AdOLF SANDBERGER, Die Inventare der Bonner Hofmusik, in: Ausgewählte Aufsätze zur Musikgeschichte 1, München 1924, S. 109-134, hier S. 114-128; zum heute in der Biblioteca Estense Universitaria in Modena erhaltenen Bonner Kirchenmusikbestand vgl. BIRGIT Lodes, ElisABeth Reisinger und John D. Wilson, Zwischen Wien, Bonn und Modena. Erzherzog Maximilian Franz und die kurkölnischen Musiksammlungen, in: Studien zur Musikwissenschaft (Druck in Vorbereitung), sowie die Website und Datenbank des Forschungsprojekts "The Music Library of Elector Maximilian Franz": https://musikwissenschaft.univie.ac.at/maxfranz (eingesehen am 11.01.2020).

Die Rücksicht (wie Anm. 1), S. 39. Die unter Kurfürst Joseph Clemens errichtete Hofkirche war 1777 einem Brand zum Opfer gefallen und wurde durch einen weitaus bescheideneren Neubau ersetzt.

Das entsprechende Dokument "Unterthänigstes Pro Memoria die Kurfürstliche Hof Musique betrefend", in: LAV NRW R, Kurköln II, Nr. 471, f. 11 v-12r, wurde bereits von Thayer in Übertragung publiziert; AleXANDER WHEELOCK THAYER, Ludwig van Beethoven's Leben, hg. von HERMANn DeITERS, bearbeitet und erweitert von HUgO RIEMANN, Bd. 1, Leipzig 31917, S. 189-199

In der Aufstellung "Jährliche Besoldungen der Hofkapelle und Musik S[eine]r Kurf[ürst] I[ichen] D[urc]h[lauh]t welche aus der Land Rentmeisterey a 1a Juli 1784 zu zahlen sind" ist für Beethoven erstmals ein jährliches Gehalt von 150 fl[orin] [Gulden] vorgesehen, in: LAV NRW R, Kurköln II, Nr. 471, f. 26r-v (Übertragung in THAYER/DEITERS/ RIEMANN [wie Anm. 6], S. 197-199). Diese Summe wurde offenbar vom Gehalt des eigentlichen Organisten, Christian Gottlob Neefe, abgezogen

81776 waren Maximilian von seiner Mutter Maria Theresia zwei Violinisten als persönliche Kammermusiker zugewiesen worden: Haus-, Hof und Staatsarchiv Wien (HHStA), Obersthofmeisteramt, Prot. 38 (1775/76), f. 241r/v.

9 Darüber berichtet etwa JOHANN FRIEDRICH REICHARDT in: Bruchstücke aus Reichardts Autobiographie, in: Allgemeine musikalische Zeitung 15, 1813, Nr. 41, vom 13.10.1813, Sp. 665-674, hier: Sp. 665 


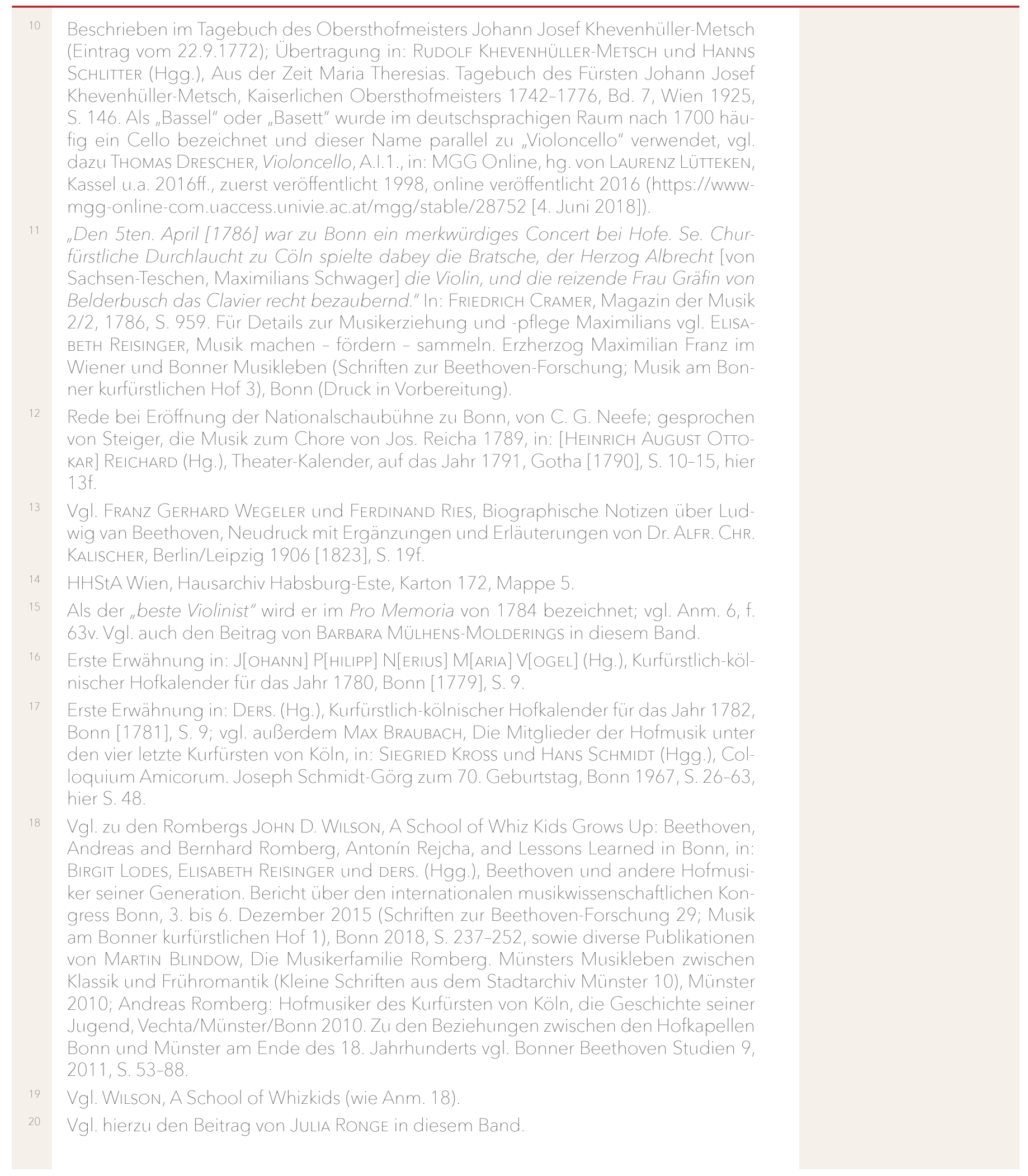


Mozart. Briefe und Aufzeichnungen. Gesamtausgabe, hg. von der Internationalen Stiftung Mozarteum Kassel, 2005, Bd. 4, Brief 1206: Constanze Mozart (Wien) an Luigi Simonetti (Bonn), 28.12.1791, S. 177f. Es handelte sich dabei um Abschriften von La clemenza di Tito und Die Zauberflöte; letztere wurde schließlich tatsächlich vom Kurfürsten erworben, vgl. REISINGER/RIEPE/WILSON, The Operatic Library (wie Anm. 2), S. 317-331, sowie ReISINGER, Musik machen (wie Anm. 11).

Wie etwa auch in Mergentheim; vgl. Anm. 20. Vgl. außerdem JOHN D. WILSON, From the Chapel to the Theatre to the Akademiensaal: Beethoven's Musical Apprenticeship at the Bonn Electoral Court, 1784-1792, in: Beethoven Studies 4, S. 1-23, hier S. 17 (im Druck).

"Christian Neffe der Organist ... könnte dieser wohl abgedanckt werden, weilen nicht besonders auf der Orgel versirt, ist übrigens ein frembder, von gar keinen Meritten, und Calvinischer Religion." Vgl. Anm. 6, f. 63v

Zu Neefes Tätigkeiten in Bonn, insbesondere am Hoftheater vgl. IRMGARD LEUX, Christian Gottlob Neefe (1748-1798) (Veröffentlichungen des Fürstlichen Institutes für musikwissenschaftliche Forschung zu Bückeburg, 5/2), Leipzig 1925; HeLMUT LoOs (Hg.), Christian Gottlob Neefe (1748-1798). Eine eigenständige Künstlerpersönlichkeit. Tagungsbericht Chemnitz 1998, Chemnitz 1999; IAN WOODFIELD, Christian Gottlob Neefe and the Bonn National Theatre, with New Light on the Beethoven Family, in: Music and Letters 93, 2012, S. 289-315; REISINGER/RIEPE/WILSON, The Operatic Library (wie Anm. 2), S. 71, S. 143-147, 160f. Vgl. auch den Beitrag von Helmut Loos in diesem Band

Schreiben Neefes an Großmann, 11.3.1787 (Beethoven-Haus Bonn, BH 197)

Angeblich hatte Maximilian bereits in Wien ein eigenes Ensemble dieser Art unterhalten, zu dem allerdings leider bis auf eine Erwähnung durch Johann Friedrich Reichardt (Bruchstücke [wie Anm. 9], Sp. 666) nichts weiter überliefert ist.

Vgl. beispielsweisen den enthusiastischen Bericht über den Auftritt der Bonner "Harmonie" beim Generalkapitel des Deutschen Ordens in Mergentheim im Herbst 1791; abgedruckt im Beitrag von JULIA RONGE in diesem Band.

Vgl. Kurt Dorfmüller, Norbert Gertsch und Julia Ronge, Ludwig van Beethoven. Thematisch-bibliographisches Werkverzeichnis, Bd. 1, München 2014, S. 649-651. HHStA Wien, Hausarchiv Habsburg-Este, Karton 172, Mappe 5; aus diesem Akt geht außerdem hervor, dass die Harmonie aus der persönlichen Schatulle des Kurfürsten bezahlt wurde.

ARMin RAAB, Beethoven und die Harmoniemusik, in: Christoph-Hellmut Mahling, Kristina Pfarr und Karl Böhmer (Hgg.), Zur Harmoniemusik und ihrer Geschichte (Schloss-Engers-Colloquia zur Kammermusik 2), Mainz 1999, S. 113-124, hier S. 119. Dies bestätigen erhaltene Besoldungslisten, etwa in HHStA Wien, Hausarchiv Habsburg-Este, Karton 172, Vgl. f. 11 r.

HHStA Wien, Hausarchiv Habsburg-Este, Karton 155, f. 31 r-v.

Vgl. TheOdore AlBRECHT, Franz Stadler, Stephan Fichtner und die anderen Oboisten am Theater an der Wien während Beethovens "heroischer" Periode, in: Journal der Gesellschaft der Freunde der Wiener Oboe 18, Juni 2003, S. 3-12, hier S. 7.

33 Aufgrund von Erbwegen heute in der Biblioteca Estense Universitaria im norditalienischen Modena aufbewahrt, vgl. dazu Lodes/Reisinger/WILSON, Zwischen Wien, Bonn und Modena (wie Anm. 4). 


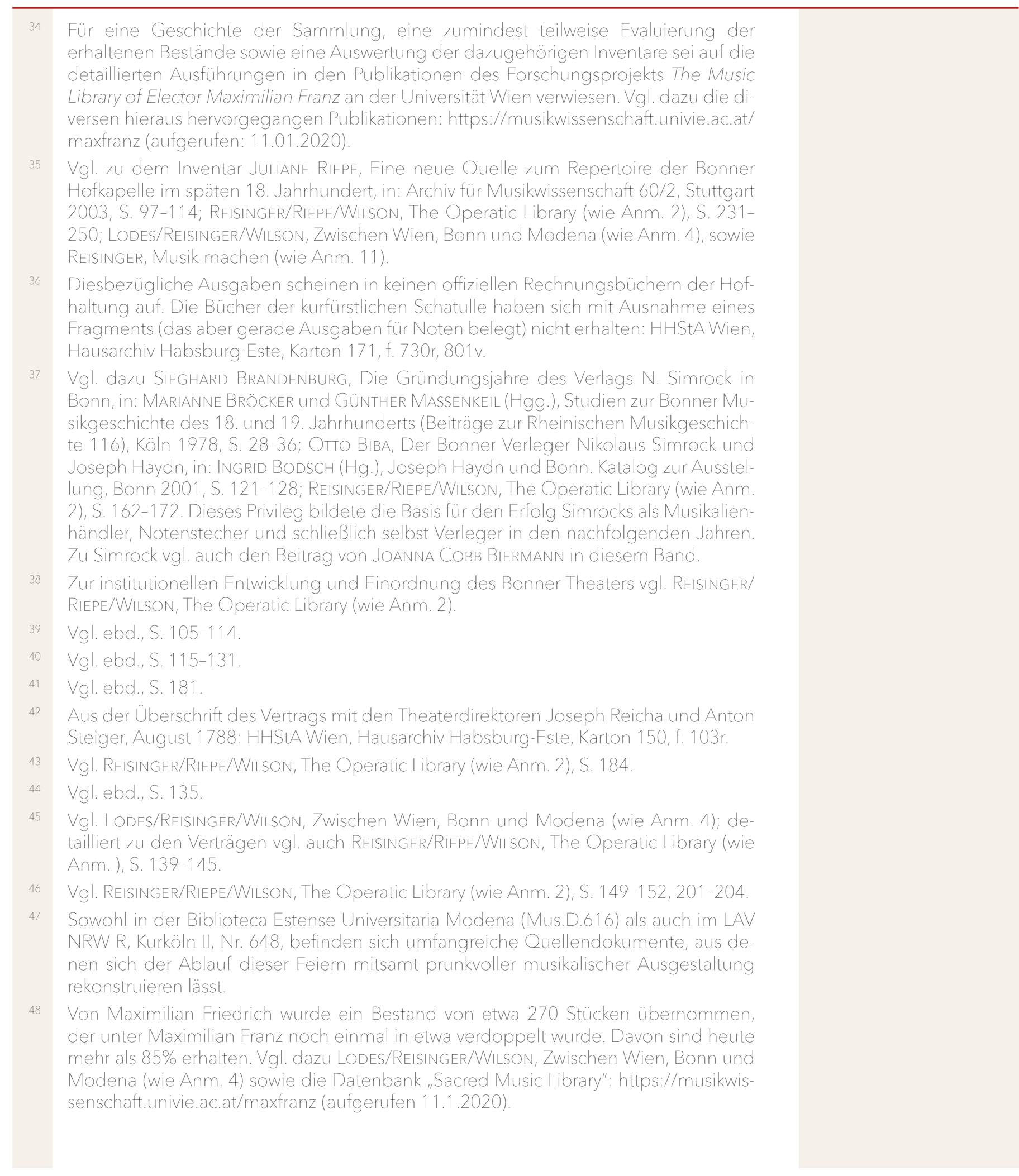


49 Erstmals im Hofkalender erwähnt für das Jahr 1786 für die Andachten während der Fronleichnamsoktav; vgl. J[OHANN] P[HILIPP] N[ERIUS] M[ARIA]V[OGEL] [Hg.], KurköInischer Hofkalender für das Jahr 1787, Bonn 1786, unpaginiert. Im Frankfurter Staats-Ristretto vom 24.4.1786 wird von der Einführung deutscher Gesänge in Bonn berichtet: „Zu Bonn sind am vorigen Sonntag, Montag und Dienstag die neuen deutschen Gesänge für die Hofkapelle bei der Abendandacht gesungen worden, wobey ein unglaublicher Zufluß des Volkes war." Zitiert nach WOLfGang MATTHäUs, Beiträge zur Musikgeschichte Bonns 1772-1791, in: Bonner Geschichtsblätter 21, 1967, S. 136-152, hier S. 139

Im Hofkalender für 1792 etwa ist am Sonntag in der Fronleichnamsoktav vermerkt: "Um 10 Uhr ist die deutsche Segenmeß, und um 11 U. das hohe Amt wie gewöhnlich." Vgl. J[OHANN] P[HILIPP] N[ERIUS] M[ARIA] V[OGEL] [Hg.], Kurköllnischer Hofkalender für das Jahr 1793, Bonn 1792, unpaginiert LAV NRW R, Kurköln II, Nr. 637, f. 3 r.

Gesänge und Gebethe während der heiligen Messe in der kurfürstlichen Hofkapelle zu Bonn, 1794 (Stadtarchiv und Stadthistorische Bibliothek Bonn, I k 95).

Andacht in der Fronleichnams Octave zum Gebrauche des öffentlichen Gottesdienstes in der kurfürstlichen Hofkapelle in Bonn, undatiert (ebd., I k 84).

Abgedruckt in PETER HERSCHE, Der aufgeklärte Reformkatholizismus in Österreich, (Quellen zur neueren Geschichte 33), Frankfurt a. M. 1976, S. 74-79. Colloredo in Salzburg kann in vielerlei Aspekten als ein Maximilian Franz vergleichbares Beispiel eines geistlichen Herrschers jener Zeit gelten

Vgl. Werner Freitag, Symbolische Kommunikation und Amtscharisma, in: GerHARD Ammerer u.a. (Hgg.), Höfe und Residenzen geistlicher Fürsten. Strukturen, Regionen und Salzburgs Beispiel in Mittelalter und Neuzeit. Ergebnisse der internationalen und interdisziplinären Tagung in der Salzburger Residenz, 19.-22. Februar 2009 (Residenzforschung 24), Ostfildern 2010, S. 72. NeEFE, Nachricht (wie Anm. 3), S. 395

Vgl. hierzu Norbert Schlossmacher, "Haydn-Kult" in Bonn. Zur Geschichte des Mastiauxschen Hauses am Alten Zoll, in: BodsCH, Haydn (wie Anm. 37), S. 74-100.

NeEFE, Nachricht (wie Anm. 3), S. 388-393. Die erwähnten Briefe sind laut Bartha verloren bzw. wurden noch nicht entdeckt, vgl. DÉnES BARTHA (Hg.), Joseph Haydn. Gesammelte Briefe und Aufzeichnungen, Kassel u.a. 1965, S. 24

Zur tatsächlichen Beziehung Maximilians zu Mozart vgl. ElisABETH ReIsinger, The Prince and the Prodigies. On the Relations of Archduke Maximilian Franz with Mozart, Beethoven, and Haydn, in: Acta Musicologica 91/1, 2019, S. 48-70, hier S. 50-58.

Zu Maximilian und Haydn vgl. ebd., S. $66 f$.

Dank an John D. Wilson für diesen Hinweis.

62 Georg Feder, Haydn, (Franz) Joseph, in: Ludwig FInscher (Hg.), Die Musik in Geschichte und Gegenwart, 2., neubearbeitete Ausgabe, Personenteil 8, Kassel, Stuttgart u.a. 2002, Sp. 901-1094, hier Sp. 920.

63 Vgl. Biographische Nachrichten von Joseph Haydn, nach mündlichen Erzählungen desselben entworfen und herausgegeben von ALBERT CHRISTOPH DIES, mit Anmerkungen und einem Nachwort neu herausgegeben von HORST SEEGER, Berlin 1810, S. 80-82. Vgl. ebd

65 Vgl. Wegeler/Ries, Biographische Notizen (wie Anm. 13), S. 20. 


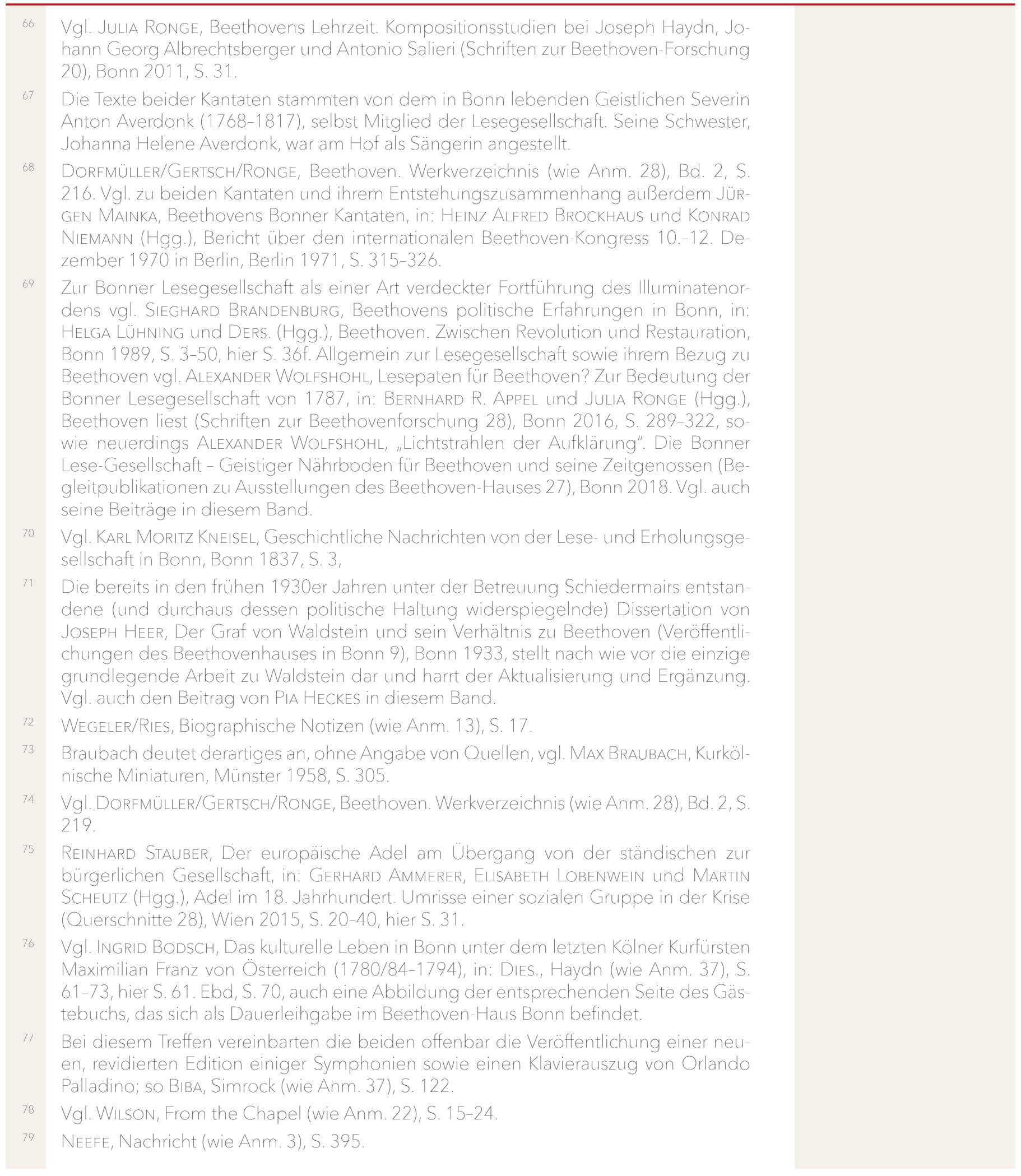




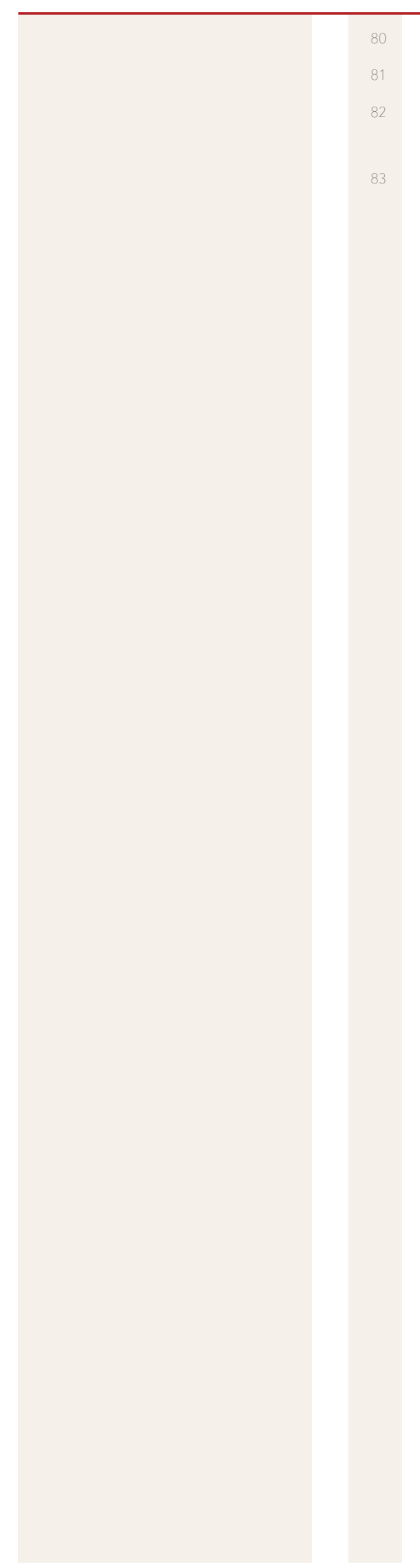

Vgl. zu diesen Studien Ronge, Beethovens Lehrzeit (wie Anm. 66).

Vgl. Reisinger/RIEPE/WiLson, The Operatic Library (wie Anm. 2), S. 173-179

Vgl. etwa zu den Karrieren Anton Reichas und der Romberg-Cousins: WiLson, A School of Whizkids (wie Anm. 18)

Zitiert nach Max BrAUBACH, Maria Theresias jüngster Sohn Max Franz. Letzter Kurfürst von Köln und Fürstbischof von Münster, Wien und München 1961, S. 106; die Quelle selbst wird leider weder hier noch in der ersten Fassung des Bandes (DERS., Max Franz von Österreich. Letzter Kurfürst von Köln und Fürstbischof von Münster. Versuch einer Biographie auf Grund ungedruckter Quellen, Münster 1925) angegeben. 


\section{Das Instrumentalmusik-Repertoire der kurfürstlichen Hofmusik zur Zeit des jungen Beethovens}

V on den vielen prägenden Eindrücken, die Beethoven während seiner ersten 22 Lebensjahre in Bonn sammeln konnte, ist erst kürzlich einer der überraschenderen Art zu Tage getreten: Als zweiter Hoforganist ab dem Jahre 1784, als Bratschist im Hoforchester ab 1789 und als Pianist in der Kammermusik schon lange vor 1790 tätig, lernte der junge Hofmusiker ein musikalisches Repertoire kennen, das für seine Zeit eine erstaunliche Breite, Vielfältigkeit und vor allem auch Aktualität besaß.

Der letzte Kurfürst Kölns, Maximilian Franz, war zu seinen Lebzeiten als passionierter Musiksammler durchaus bekannt. ${ }^{1}$ Die neuesten Quellenstudien der überlieferten Manuskripte und Drucke der Biblioteca Estense Universitaria lassen jedoch erstmals den tatsächlichen Umfang seiner Sammlung erkennen. ${ }^{2}$ Während die Bestände von Opern und geistlicher Musik bereits ausführlich beschrieben wurden, ${ }^{3}$ steht im Bereich der Instrumentalmusik eine vollständige Auswertung der Quellenlage noch aus. Mithilfe eines zeitgenössischen, unglaublich detaillierten Inventars im Ausmaß von 642 Seiten und einer Analyse der handschriftlichen Schichten (im Zeitraum von 1784 bis 1794 waren kontinuierlich neue Werke katalogisiert worden), ist es möglich, einen Überblick über den ursprünglichen Umfang dieser Sammlung von instrumentaler Musik und ihrer zeitlichen Entwicklung zu geben. ${ }^{4}$ Durch das Zusammenfügen der Hinweise, welche sowohl die Manuskripte selbst als auch die Archivquellen geben, ist es erstmals möglich, die Entwicklung der Bonner Hofkonzerte - oder "Akademien" - zu Beethovens Jugendzeit darzustellen. ${ }^{5}$

\section{Die einmalige Musikbibliothek eines „tiefe[n] Kenners”}

Ein anonymer Bonner Musiker, mit großer Wahrscheinlichkeit Christian Gottlob Neefe, wollte seinem neuen Vorgesetzten nicht bloß schmeicheln, als er Maximilian Franz im August 1784 als "tiefe[n] Kenner" bezeichnete und seine Förderung des Bonner Musiklebens lobte, welche sich „immer mehr und mehr ausbreitet" und durch welche "der Geschmack sich täglich mehr verfeinert." ${ }^{\prime 6}$ Im April hatte der neuangekommene Kurfürst eine Musikbibliothek mit sich gebracht, die in etwa 2350 Werke jeder signifikanten Gattung enthielt: rund 380 Sinfonien, 460 Trios, 900 Quartette, 100 Konzerte und Kassationen, 330 andere kammermusikalische Werke, 26 Ballette und ca. 150 sowohl gröBer als auch kleiner angelegte Vokalwerke. ${ }^{7}$ Während seiner Zeit in Bonn sammelte Max Franz weiterhin mit großem, beinahe manischem Eifer neue Werke, bis seine Bibliothek schließlich einen Umfang von 3500 Einheiten erreichte - die geistliche Musik, welche separat davon in der Schlosskapelle 
aufbewahrt wurde, nicht mitgezählt. Dies ließ sie mit den größten Musikbibliotheken dieser Zeit in Konkurrenz treten. Die Musiksammlung der Herzogin Anna Amalia in Weimar, eine der bedeutendsten ihrer Zeit, umfasste im Vergleich dazu zum Zeitpunkt ihres Todes im Jahr 1807 einen Umfang von 3000 Werken. $^{8}$ Eine weitere zeitgenössische und ebenso bedeutsame Sammlung einer anderen Anna Amalia, der Prinzessin von Preußen, war sogar noch umfangreicher: Bei ihrem Tod im Jahr 1787 umfasste sie in etwa 600 Bände, die mehr als 3800 Werke beinhalteten. ${ }^{9}$ Die Musikbestände der kaiserlichen Hofbibliothek in Wien, der sogenannten Kaisersammlung, sind schwieriger zu schätzen, doch die derzeitige Anzahl von 3200 Signaturen wurde vermutlich bis weit in das 19. Jahrhundert hinein nicht erreicht. Sie repräsentiert damit 150 Jahre Sammlungsgeschichte, die sich über mehrere Generationen habsburgischer Herrscher zurückverfolgen lässt. ${ }^{10}$ Dies verdeutlicht, dass Maximilian Franz' Musikbibliothek nicht nur zu den größten des späten 18. Jahrhunderts zu zählen ist, sondern auch zu jenen, die am schnellsten aufgebaut wurden.

Doch Maximilians Sammlung unterschied sich in einem wichtigen Aspekt von ihren weitaus berühmteren Konkurrenten. Normalerweise erfüllten diese Musiksammlungen mit ihren mit Goldprägung versehenen Ledereinbänden, die Geschmack und Gelehrtheit ihrer Eigentümer verdeutlichen sollten, eine entscheidende Repräsentationsfunktion. Der Erzherzog und Kurfürst war jedoch mehr an Werken interessiert, die er als versierter Bratschist und guter Pianist und Sänger selbst spielen konnte bzw. an Stücken, die von den ihm zur Verfügung stehenden Musikern aufgeführt werden konnten. ${ }^{11}$ Partituren und Stimmen ließ er, wie heute noch ersichtlich ist, daher nur selten binden (ausgenommen kirchenmusikalische Werke). Diese praktische Veranlagung Maximilians war gepaart mit einem beinah pedantischen Hang zur methodischen Vervollständigung: Noch während seiner Zeit in Wien, wo ihm unter anderem zwei ausgezeichnete Violinisten zur Verfügung standen, ${ }^{12}$ erstellte Maximilian ein umfassendes Kompendium an Streichduos, -trios und -quartetten aus seiner Heimatstadt Wien, sowie aus London, Paris und dem süddeutschen Raum. So erwarb er beispielsweise jedes käuflich zu erwerbende quatuor concertant des Komponisten Giuseppe Maria Cambini, das 139 Werke umfasste. ${ }^{13}$ Doch es ist beinahe jeder bedeutende Komponist des frühen Streichquartetts mit Stücken in erstaunlich großer Anzahl vertreten: Johann Baptist Vanhal (42), Anton und Carl Stamitz (36 und 27), Karl von Ordonez (18) und selbstverständlich Joseph Haydn (33). Nicht weniger beeindruckend war seine Sammlung von kammermusikalischen Kompositionen Luigi Boccherinis: Die 42 Quartette (alle bis op. 32), 30 Quintette, 12 Sextette und 35 Trios in Maximilians Bibliothek repräsentieren de facto Boccherinis gesamten Katalog an Kammermusik, die vor 1784 im Druck erschien. ${ }^{14}$ Ähnliches gilt für seine Anschaffungen von reinen Streichersinfonien vor 1784. 
Auch in Bonn unterhielt Maximilian ein kleines kammermusikalisches Ensemble ${ }^{15}$ und verfolgte weiterhin die Entwicklungen der jeweiligen Gattungen. Da ihm aber nun eine ganze Hofkapelle zur Verfügung stand, verschob sich der Schwerpunkt der neuerworbenen Werke. Seine Bemühungen verwendete er nun darauf, Stücke bestimmter Gattungen zu beschaffen, die die Stärken seines neuen Ensembles am besten demonstrierten - im besonderen deutsche Opern, Sinfonien und Klaviermusik. Vor allem der Bereich der Klaviermusik, der sowohl Sonaten als auch Konzerte umfasst, erfuhr nach 1784 einen besonderen Anstieg. ${ }^{16}$ Dementsprechend füllten sich die leeren Inventarseiten seiner Musikbibliothek, die offenbar von Franz Anton Ries betreut wurde. Der Kurfürst stieß mit seiner Sammelbegeisterung auf einen Gleichgesinnten unter seinen Hofmusikern. Anfang Dezember 1784 wurde dem Hofhornisten und aufstrebenden Musikalienhändler Nikolaus Simrock ein jährliches Gehalt von 40 Reichstalern als eine Art "Finderlohn" gewährt, gemeinsam mit dem Privileg, die erstandenen Werke auch als Kopiervorlage für die Vervielfältigung und den Verkauf nutzen zu dürfen. Sobald Simrock neue Werke beschafft hatte, fanden diese nicht nur Eingang in den Bestand des Kurfürsten, ${ }^{17}$ sondern pries er diese auch üblicherweise in der lokalen Zeitung (Bönnisches Intelligenzblatt) zum allgemeinen Verkauf an. Oft wurden Opernpartituren vor Ort für Tasteninstrumente neu arrangiert und ins Deutsche übersetzt (oder mit gerade erst vorgenommenen Verbesserungen bereits bestehender Übersetzungen ausgestattet) - die zwei letzteren Tätigkeiten wurden von Christian Gottlob Neefe übernommen. Um 1790 war Bonn durch Simrocks geschickten Sammlungseifer, den unstillbaren Wunsch nach neuen Werken seitens des Kurfürsten, das große Engagement Neefes und anderer Hofmusiker sowie schließlich durch die hohe Qualität der Werke von Komponisten, die möglicherweise sogar im direkten Kontakt mit Simrock standen, zur Drehscheibe für die Weiterverbreitung von Musik an andere Theater geworden. Zu Simrocks Klienten gehörten deutsche Theatertruppen aus Mainz, Mannheim, Hamburg und sogar Berlin. ${ }^{18}$

Einige der Hinweise, die sowohl im Inventar als auch in den überlieferten Manuskripten zu finden sind, deuten darauf hin, dass der Kurfürst die Bestände seiner Bibliothek nicht nur für sein eigenes Amüsement nutzte, sondern diese auch für Aufführungen frei zugänglich machte und sie sogar an einzelne Hofmusiker verlieh. Eine handschriftliche Notiz in Tinte unter der Liste der geistlichen Musik, "Die KirchenMusik ist dem Capellmeister übergeben", spiegelt die Tatsache wider, dass Maximilian nach seiner Ankunft in Bonn seine einigermaßen bescheidene Kirchenmusik-Sammlung an Andrea Luchesi für die Nutzung in der Schlosskapelle zur Verfügung stellte. In den Auflistungen der Opern finden sich Bleistiftnotizen wie "Reicha" oder " $R$ " am Rand bestimmter Titel, die zeigen, dass Joseph Reicha, der Musikdirektor des Theaters ab dem Jahr 1789, einige Partituren ausgeliehen hat. Nicht jede dieser Opern 


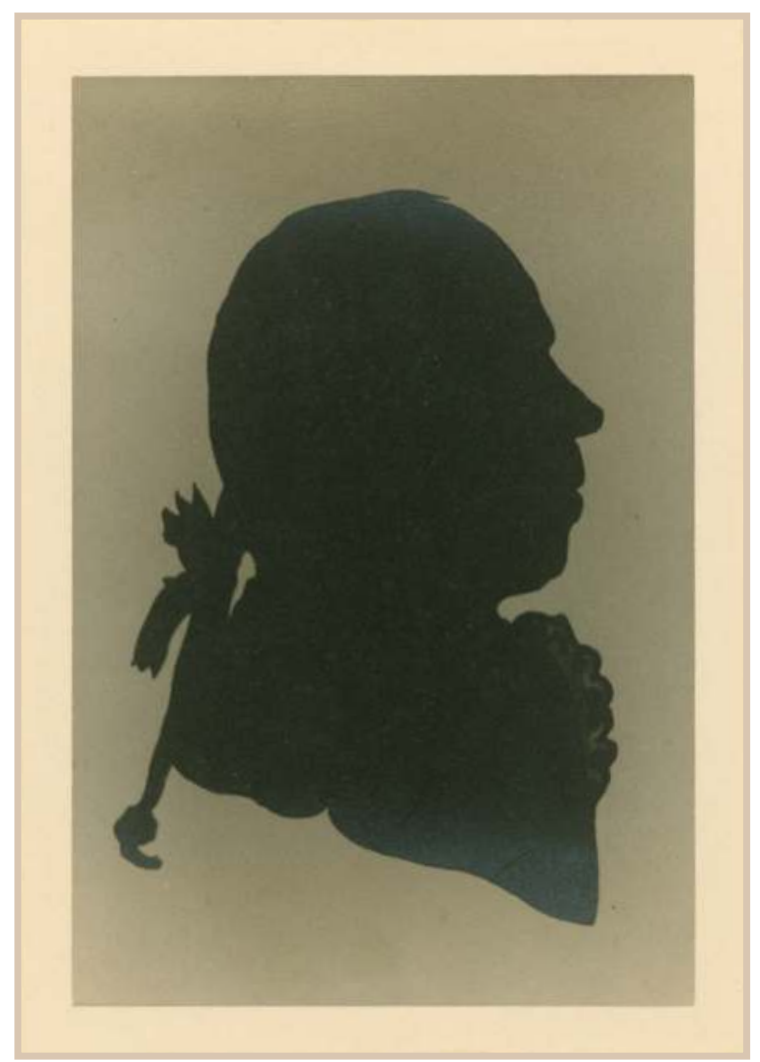

schaffte es allerdings in den Spielplan, was ein Hinweis darauf sein könnte, dass das Ausleihen auch zur Vorprüfung der Aufführungstauglichkeit gedient hat. ${ }^{19}$ Letztlich borgte sich nicht nur Luchesi, sondern auch der junge Beethoven Bestände aus dem Bereich der Instrumentalmusik aus, was zwei kleine Blätter belegen, die in die Inventarliste eingefügt wurden. ${ }^{20}$

Die beinahe unvergleichliche Größe und Vollständigkeit, sowie der Fokus auf das neueste Repertoire und die Zugänglichkeit der Musikbibliothek Maximilians, geben einen deutlichen Aufschluss darüber, wie der Kurfürst die Hofkapelle zu entwickeln gedachte. Es gibt daher allen Grund zurAnnahme, dass sich der musikalische Geschmack tatsächlich „täglich mehr verfeinert[e].” Diese Vorzüge hielten sich jedoch mit Maximilians besonderem Sinn für Sparsamkeit und einer instinktiven Abneigung gegen extravagante Selbstverherrlichung, die sehr oft ein entscheidender Bestandteil der (musikalischen) Repräsentation des 18. Jahrhunderts war, die Waage. Ersterer hatte zur Folge, dass das Theater mehr als vier Jahre geschlossen blieb und viele Hofmusiker ihre Anstellung verloren oder nur ein reduziertes Gehalt bezogen. ${ }^{21}$ Letztere schien die Kreativität vieler sonst so produktiver Komponisten am

Joseph Reicha (1752-1795). Silhouette (Beethoven-Haus

Bonn)
Hof, darunter auch des jungen Beethoven, so sehr eingeschränkt zu haben, dass sie über einige Jahre hinweg kein neues Werk komponierten. ${ }^{22}$ Es wäre allerdings ein Fehler, Maximilian Franz erste Jahre in Bonn nur als Zeit der strengen Sparmaßnahmen und Kürzungen im Kulturbereich zu sehen. Generell zeigen sich bei genauerer Betrachtung der Herrschaftszeit des Kurfürsten von Beginn an entscheidende Veränderungen und Entwicklungen in allen drei Bereichen des kürfürstlichen Hofes - Kirche, Theater und Akademiesaal -, in denen die Musiker tätig waren. Jeder dieser drei Bereiche wurde maßgeblichen Reformen unterzogen, die - früher als bisher angenommen wurde schließlich in einem wiederbelebten Musikleben am Hof resultierten.

\section{Die Etablierung eines „grosse[n] öffentliche[n] Concert[s]" in Bonn}

Von den unterschiedlichen Aufführungsbereichen des kurfürstlichen Hofes, in denen der junge Beethoven tätig war, zählen zu den bisher am wenigsten erforschten, jedoch bedeutendsten seiner späten Jugendjahre, die Hofkonzerte im Großen Akademiesaal. Obwohl diese Konzerte hin und wieder in der Sekundärliteratur Erwähnung finden, haben Autoren bisher ihre Wichtigkeit unterschätzt, oder sie in manchen Fällen sogar - entgegen der Quellenlage auf eine wesentlich längere Tradition zurückgeführt. Es gibt tatsächlich mehre-

266 | John D. Wilson

(C) 2020 by Böhlau Verlag GmbH \& Cie. KG, Köln

https://doi.org/10.7788/9783412519704 | CC BY-NC 4.0 
re Gründe zur Annahme, dass Konzerte vor 1784 eher eine Seltenheit im Musiklebens des Hofes darstellten, doch bis 1792 eine immer bedeutsamere Rolle einnahmen. Mit großer Wahrscheinlichkeit wurden auch einige Beethovens früher Kompositionen in diesem Rahmen erstmals zur Aufführung gebracht.

Der Große Akademiesaal, der sich direkt über dem Hoftheater befand, dürfte mit Sicherheit schon seit der Erbauung des Westflügels des Schlosses in den frühen 1750ern existiert haben. Belege zu Konzerten dort sind jedoch bis zur Regierungszeit von Maximilian Franz nur dünn gesät. Das einzig dokumentierte Konzert unter seinem Vorgänger fand während der zweiwöchigen Festivitäten statt, die Maximilians Wahl zum Koadjutor 1780 begleiteten. ${ }^{23}$ Weder ist ein Programm zu diesem Ereignis überliefert, noch weiß man mit Sicherheit, aus welchem Bestand die Musikalien kamen. Wie bereits andernorts diskutiert, wurde die wesentlich kleinere Instrumentalmusik-Sammlung des Hofes in der Zeit der Regentschaft Maximilian Friedrichs in der Schlosskapelle aufbewahrt und war in erster Linie für den Gebrauch während des Hochamtes gedacht. ${ }^{24}$ Weitere Instrumentalmusik-Bestände, die in der Folge im Akademiesaal oder dem Theater aufbewahrt wurden, hat damals offenbar nicht gegeben. Dies allein wäre noch keine ausreichende Begründung der Annahme, dass Konzerte am Hof nur selten stattgefunden hätten, aber ein häufig übersehener Kommentar in Cramers Musikmagazin von 1783, der allgemein Neefe zugeschrieben wird, gibt der Vermutung Recht:

"Gnug, daß man hieraus schon abnehmen kann, daß ein Fremder, der Music liebt, nie ohne musicalische Nahrung von Bonn wieder abreisen wird. Zu wünschen wäre nur noch, daß unter dem Schuze Sr. Churfürstl. Gnaden, ein grosses öffentliches Concert hier errichtet würde. Dadurch würde diese Residenz eine Zierde mehr bekommen, und die gute Sache der Musik mehr befördert werden." 25

Neefes Wunsch ging innerhalb des ersten Jahres nach Maximilian Franz Amtsantritt zwar in Erfüllung, doch war dies zunächst ein Pyrrhussieg, denn eine der vielen negativen Auswirkungen der Amtsübernahme war, dass sein Gehalt im Juli 1784 halbiert wurde. ${ }^{26} \mathrm{Im}$ November fragte er vergeblich bei Hof um die Wiederauszahlung seines vollen Lohns an, indem er sich als Klavierbegleiter "im künftigen Hofkonzert" 27 empfahl. Zwar sind Dokumente, die das Entstehen dieser Konzerte belegen würden, in den überlieferten Hofakten bisher noch nicht entdeckt worden, aber diesbezügliche Überlegungen hinsichtlich einer möglichen Konzerttätigkeit waren offenbar ein entscheidender Faktor in der Anstellung Joseph Reichas 1785, welcher bis dahin als Kapellmeister der Oettingen-Wallersteins tätig gewesen war - ein Hof, der für seine besondere Instrumentalmusik-Pflege bekannt war. ${ }^{28}$ Erstmals wird er im Hofkalender von 1786 als „Koncert-Direktor" erwähnt - im Gegensatz zu seinem Vorgänger Gaetano Mattioli, der ab 1777 als „Instrumentalmusik-Direktor” 
gedient hatte. Noch aussagekräftiger ist Reichas Ansuchen um eine Anstellung im Juni 1785, in der sein Titel als "Concert-Meister" angeführt, aber schließlich durchgestrichen und zu "Concert-Directeur" umbenannt wurde. ${ }^{29}$

1786 scheinen aber dann Konzerte bereits regelmäßig stattgefunden zu haben, bei welchen neben den Hofmusikern auch Künstler von außerhalb musizierten. In einem Brief an Großmann vom 1. Februar schreibt Neefe von einer Vereinbarung mit einer gastierenden, französischen Komödien-Truppe aus Hessen-Kassel: "Sie haben freien Eintritt in unser Konzert $u$. wir in ihre Komödie. [Marie Wilhelmine] Rousselois hat schon in unsrem Konzert gesungen; heute singt einer, dessen Namen ich nicht weiß. Der Kurfürst kommt nie in das Schauspiel, wohl aber jedesmal ins Konzert." 30 Dass diese Akademien für die Musiker die Möglichkeit boten, sich unter den Adel zu mischen, wird an späterer Stelle deutlich, an der Neefe mit beißender Ironie feststellt, dass "Die Franzosen $u$. besonders die Rousselois weiß sich ganz anders mit der hiesigen Noblesse im Konzert zu benehmen, als unsre blöden teutschen Weiber und Mädgens." ${ }^{11}$ Hin und wieder traten auch Adelige auf die Bühne und sogar der Kurfürst selbst wird gelegentlich auf seiner Viola gespielt haben. Anton Reichas lebhafte Erinnerungen, die er im hohen Alter diktierte, enthalten unter anderem den jungen Beethoven, der mit so einer Intensität ein Mozart-Konzert gespielt habe, dass dabei die Klaviersaiten rissen, Reichas Improvisation einer Flöten-Kadenz in einer Sinfonie und diese überraschende Anekdote:

„Es gab eine Gräfin, die des Öfteren bei den Konzerten hier zu singen pflegte, die sogar vom Fürsten selbst mitgestaltet wurden, der die Viola bei sinfonischen Werken spielte. Diese Gräfin, die eine außerordentlich feine Stimme hatte, sang mit so einem Gefühl, dass sie alle in Begeisterung versetzte, die ihr zuhörten. Einmal sang sie die sechste Szene in der Tonart d-Moll aus Mozarts ,Idomeneo' [=Electras Rache-Arie ,Tutte nel cor vi sento' aus dem ersten Akt], die einen so großen Eindruck auf Beethoven und mich selbst hinterließ, dass wir nichts anderes mehr tun konnten, als über mehrere Wochen hinweg Tag und Nacht davon zu träumen. Es hat mich so sehr beeindruckt, dass ich es nie vergessen habe." 32

Die Programme der Konzerte wurden offenbar nicht veröffentlicht bzw. nicht im Bönnischen Intelligenzblatt abgedruckt, was Alexander Wheelock Thayer, der weder Neefes Korrespondenzen noch Reichas Autobiographie kannte, zu dem Schluss führte, dass die Akademien nicht regelmäßig stattgefunden hätten. ${ }^{33}$ Die einzige Ausnahme ist eine Erwähnung, die zeigt, dass es für die örtlichen Würdenträger und die ausländischen Gäste ein geregeltes Verfahren im Kartenerwerb gab. Im Zuge der bevorstehenden Einweihung der neuen Universität am 19. November 1786 kündigte das Intelligenzblatt im Vorblick auf die damit einhergehenden dreitägigen Festivitäten an:

"Abends um halb 6 Uhr wird auf dem grossen Akademiensaal ein grosses musikalisches Concert gehalten, wobey nebst dem hohen Adel und sämmt- 
lichen Kurfürstl. Räthen mit ihren Ehefrauen, auch erwachsenen Söhnen und Töchtern, die Geistlichkeit, die Offiziere, die Glieder der Universität, fort alle Fremde von Distinction erscheinen können...die gewöhnlichen Billete für den Hofstaat und Fremden bey dem Kurfürstl. Hof-Fourier Ali, für die Akademisten aber bey dem Universitäts-Syndikus, Hofkammerrath Esser, in ihren Behausungen zu bekommen sind." ${ }^{34}$

Aus dieser Formulierung wird nicht ganz deutlich, ob Universitätsangehörige regelmäßigen Zugang zu den Hofkonzerten hatten, oder dieser nur auf diesen besonderen Anlass beschränkt war. In jedem Fall scheint die nur in dieser Quelle so genau beschriebene Zusammensetzung des Publikums auf den ersten Blick nicht genau mit der des "grossen[n] öffentliche[n] Concert[s]" übereinzustimmen, wie Neefe es sich 1783 vorgestellt hat. Ebenso wird dieser Anspruch dem öffentlichen Zugang zum Theater nicht gerecht, der von Maximilian Friedrich im Jahr 1779 initiiert und 1789 unter Steiger und Reicha als kommerzielles Unternehmen für den Kartenverkauf wieder aufgenommen wurde. Auf der anderen Seite handelt es sich dabei auch nicht um den exklusiven, aristokratischen Kreis an Zuhörern, dem Beethoven später in Wien begegnete und vor dem seine Sinfonien und Konzerte häufig zum ersten Mal aufgeführt wurden, bevor sie überhaupt in größeren, öffentlichen Akademien gegeben wurden. ${ }^{35}$ Bei dem Publikum der Hofkonzerte handelte es sich vielmehr um eine Mischung aus Adeligen, Hofbeamten, Gästen, reisenden Musikern und möglicherweise auch den führenden Intellektuellen der Stadt.

Bislang sind noch keine genaueren Informationen zum Vorschein gekommen, die uns Auskunft darüber geben könnten, ob diese Konzerte regelmäßig stattfanden, ob sie das ganze Jahr über oder nur saisonal abgehalten wurden. Urteilt man hingegen nach der Größe der Sammlung und der in der Biblioteca Estense Universitaria überlieferten Bonner Orchesterstimmen für Sinfonien, so scheinen sie die Anzahl an Konzerten, die zur gleichen Zeit in Wien stattgefunden haben, bei weitem in den Schatten zu stellen. ${ }^{36}$ Neben den 330 Sinfonien, die Maximilian bereits 1784 besaß, machte er sich auch ein großer Teil des Orchesternotenmaterial der Schlosskapelle zu eigen, nachdem dessen Verwendung im Gottesdienst eingeschränkt worden war. Noch vor den Neuanschaffungen, die mit Simrocks Hilfe getätigt wurden, dürfte der Kurfürst

Anton Reicha (1770-1836). Zeitgenössische Lithografie von A. Frey (BeethovenHaus Bonn) 
seine Bibliothek auf einen Bestand mit über 650 Orchesterwerken ausgeweitet haben. Wie auch bei anderen Höfen üblich, wurden die extern angekauften Stimmensätze mit vor Ort angefertigten Kopien der Violin- und Bassstimmen ergänzt und gelegentlich wurde vom Bass ein eigener Fagottpart abgeleitet, wenn dieser in der originalen Besetzung fehlte. Diese Stimmen scheinen jedoch nicht en masse für jede vorhandene Sinfonie kopiert worden zu sein; dies geschah erst allmählich, als diese Werke für eine Aufführung vorbereitet oder in Betracht gezogen wurden. Die Existenz dieser lokal angefertigten Stimmen und eine Untersuchung ihrer Papierarten geben möglicherweise einen Hinweis darauf, welche Werke in den Akademien gehört wurden und in etwa wann; auch handschriftliche Interpretationshinweise wären hierfür hilfreich.

Ein vollständiges Bild wird sich erst nach der ausführlichen Auseinandersetzung mit diesen Quellen ergeben können, doch erste Untersuchungen zeigen, dass es eine starke Präferenz für Werke gab, die sowohl ganz neu als auch länger und anspruchsvoller waren. Beispielsweise wurden Haydns ambitionierte neuere Sinfonien wie Nr. 74-81 und auch die größer angelegten unter seinen früheren Werken (wie die Trauersinfonie Nr. 44 und die Sinfonie in H-Dur Nr. 46) sehr wahrscheinlich aufgeführt oder geprobt, während seine kürzeren Sinfonien aus früheren Zeiten und kleine neue Werke wie die acht Nokturnen (Hob. Il/25-32) unberührt blieben. Von Mozart, dessen Sinfonien überraschenderweise nur spärlich in Maximilians Sammlung vertreten sind, zeigen die meisten der überlieferten Werke Aufführungsspuren, darunter die Sinfonien KV 200, KV 297 (Pariser Sinfonie) und KV 551 (Jupiter Sinfonie) sowie auch die Sinfoniefassung der Posthorn-Serenade KV 320. Zu den weiteren Sinfonien der 1780 er und frühen 1790 er Jahre, die offenbar aufgeführt wurden, zählen einige von Ignaz Pleyel, Adalbert Gyrowetz, Joseph Martin Kraus, Johann F. X. Sterkel und Franz Anton Hoffmeister (einschließlich seiner programmatischen Pastoralsinfonie La Primavera von 1793). Die um Jahrzehnte älteren Sinfonien von Johann Christian Bach, Leopold Hoffmann und Karl von Ordonez scheinen indessen im Regal liegen geblieben zu sein. Während dies zwar auf eine Vorliebe für das Neue und Schwierige hinweist, dürften die Konzerte jedoch auch Sondierungsräume für ältere Musik gewesen sein. Ein Hinweis darauf fand sich erst kürzlich in einer Quelle, in der man es auf den ersten Blick nicht vermuten würde: Beethovens frühe Skizzen. Ein Blatt des Fischhof-Manuskripts diente ursprünglich als erste Seite einer ersten Violinstimme zu Johann Sebastian Bachs Kantate Der Herr denket an uns, BWV 196, die von einem Kopisten Simrocks geschrieben wurde. ${ }^{37}$ Dass eine 60 Jahre alte Kantate, die für protestantische Gottesdienste gedacht war, in Bonn kopiert und wahrscheinlich sogar dort aufgeführt wurde, wirft einige Fragen auf, zumal dieser fragmentarische Teil der Stimme nicht nur die kurze Sinfonia (hier als "Ouvertüre" bezeichnet), sondern auch den darauf folgenden vierstimmigen Choral ent- 


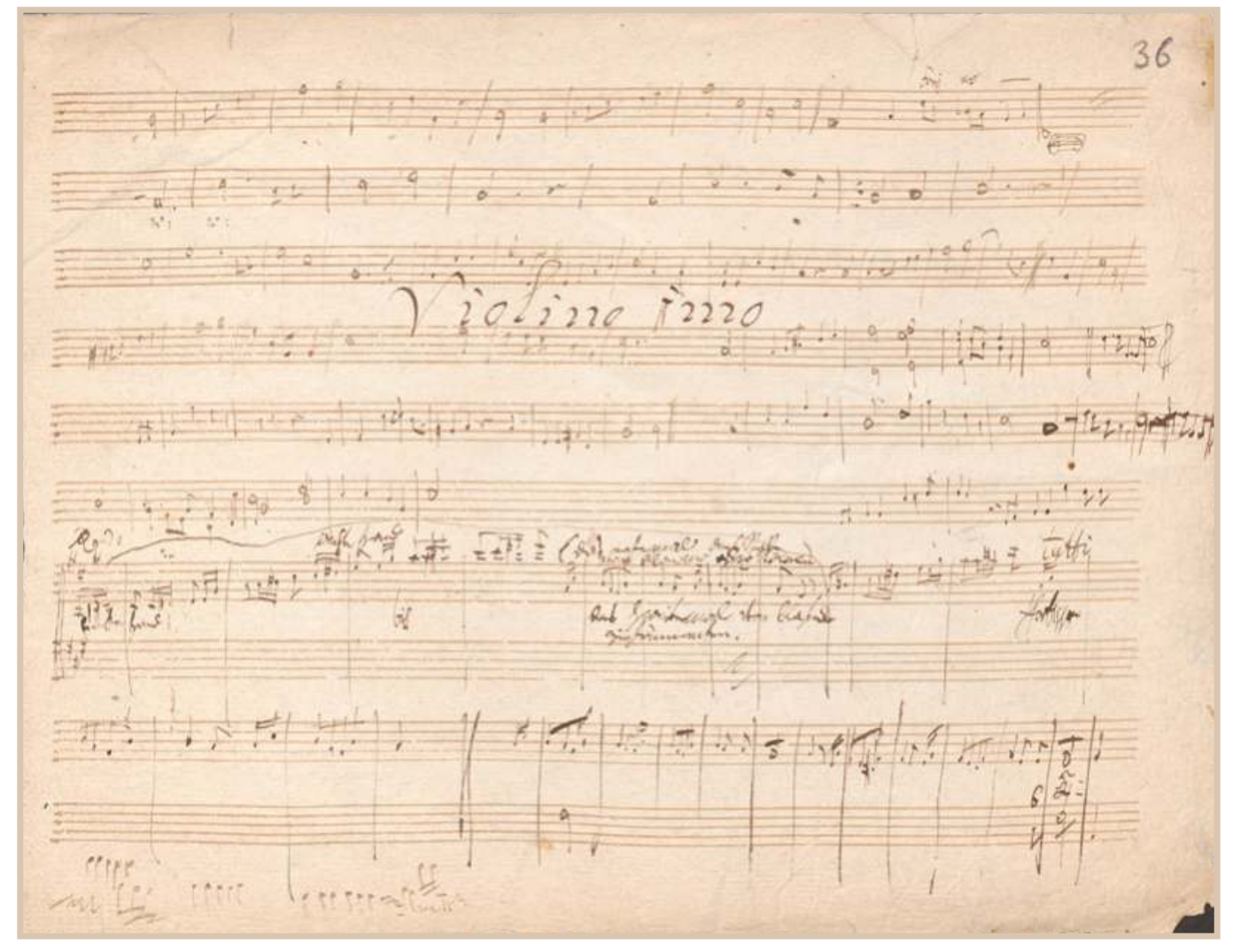

hält, was darauf hindeutet, dass er ursprünglich zu einem Stimmensatz des gesamten Werks gehörte. ${ }^{38}$ Wäre eine Aufführung in der Kapelle oder in einem anderen liturgischen Kontext nicht in Frage gekommen, so scheint eine Darbietung während der Hofkonzerte zwar denkbar, wenn auch unkonventionell.

Kurz vor dem 30. März 1787 (Palmsonntag) war eine Akademie auch der Rahmen, in welchem Haydns Die sieben letzten Worte unseres Erlösers am Kreuze, Hob. XX/1a, erstmals in Bonn zu hören war. ${ }^{39}$ Das Besondere an dieser Aufführung war, dass die Wiener Premiere, die erste außerhalb Spaniens, nur vier Tage zuvor stattgefunden hatte. ${ }^{40}$ In der Modena-Abschrift (Mus.D.167), neben den Abschriften in Oettingen-Wallerstein, Regensburg und Berlin eine der frühesten, ist in jeder der einzelnen Stimmen der lateinischen Text über den Noten in einer anderen Hand zu lesen. Scheinbar wurde dieser während der Proben hinzugefügt. ${ }^{41}$

Neben Sinfonien und anderen Orchesterwerken wurden in den Akademien auch Konzerte, einzelne Arien und größere Ensembles aus Opern gegeben, die im Hoftheater sonst nicht aufgeführt wurden. Für Lokalkomponisten boten diese Teile des Programmes die seltene Möglichkeit, ihre eigenen Werke vorzustellen. Andreas Romberg schrieb während seines Aufenthalts in Bonn, oder kurz vor seiner Ankunft im Herbst 1790, zwei Violinkonzerte - Nr. 6 und 7 - und
Beethoven: Skizzen auf wiederverwendeter Violinstimme (Staatsbibliothek zu Berlin) 


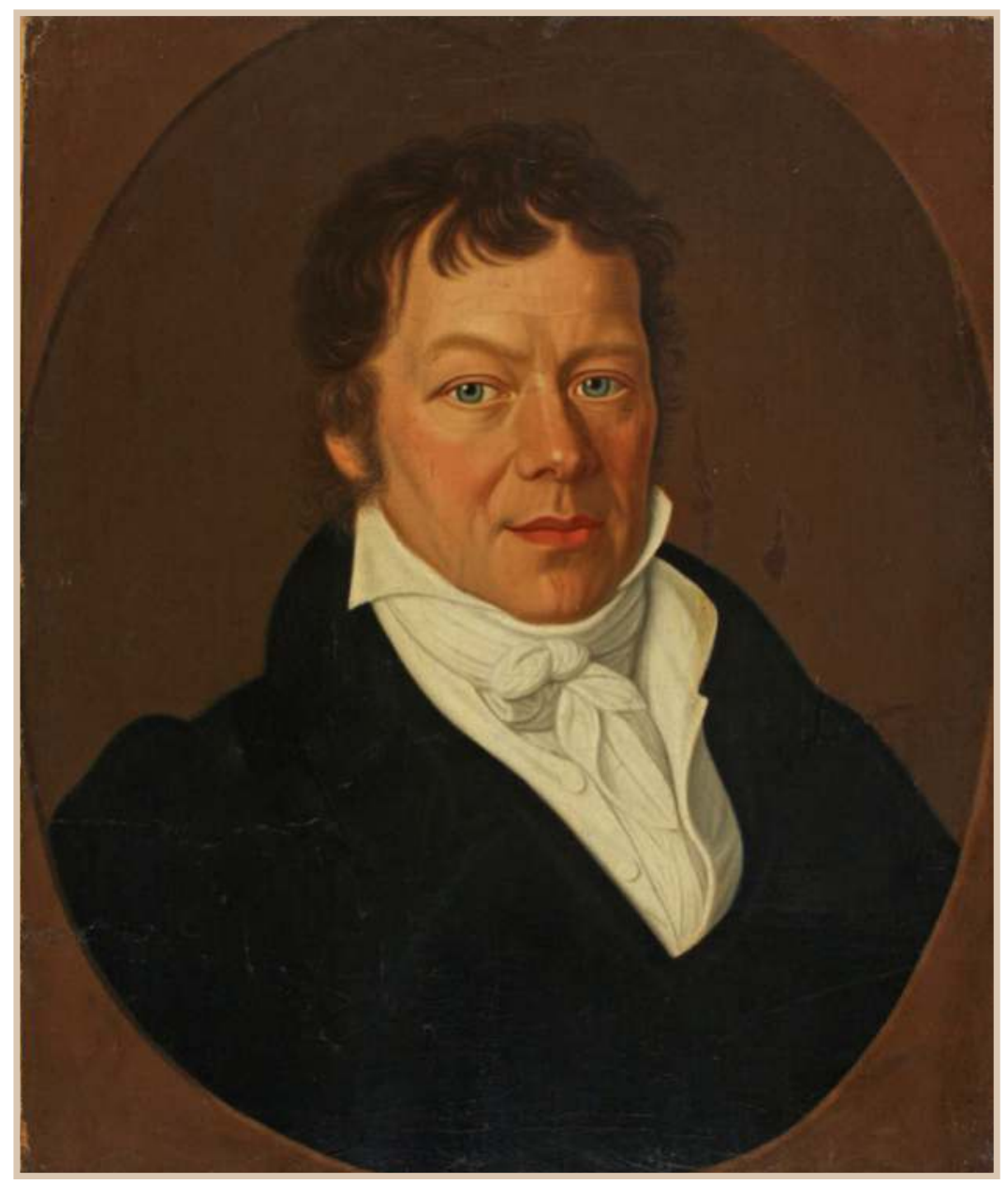

vervollständigte Nr. 8 im Jahr 1792. ${ }^{42}$ Die überlieferten Stimmen zu Nr. 7 und 8 sind auf der gleichen Papierart notiert, die bei vielen Bonner Musikalien aus 1790/91 Verwendung fand, was vermuten lässt, dass sie womöglich für eine Aufführung bei Hofe herauskopiert wurden. Ebenfalls aus dem Jahr 1792 stammt eine Sinfonia concertante für Violine und Violoncello. ${ }^{43}$ Bei zwei weiteren Werken, einer Konzert-Arie für Sopran (Con questo ferro indegno) vom August 1790 und einer Sinfonie in D-Dur von 1792, ist unklar, ob diese jemals in Bonn aufgeführt wurden, da keine Stimmen erhalten sind, jedoch entsprechen sie der Besetzung des Hoforchesters und dem ungewöhnlichen Stimmumfang der führenden Hofsopranistin Magdalena Willmann. ${ }^{44}$

Anton Reicha berichtet ebenfalls in seiner Autobiographie darüber, einige Werke für die Hofkonzerte komponiert zu haben, darunter eine Sinfonie und diverse "Scènes italiennes."45 Einige dieser Werke aus seiner Bonner Zeit haben tatsächlich überlebt und wurden

Andreas Romberg (17671821). Zeitgenössisches Gemälde (Stiftung Historische Museen

Hamburg, Museum für Hamburgische Geschichte) erst kürzlich in Reichas Nachlass in der Bibliothèque nationale de France wiederentdeckt. ${ }^{46}$

Beethovens frühe Konzerte und Orchesterwerke könnten ebenso für diese Akademien intendiert gewesen sein. Diese haben leider alle nur fragmentarisch überlebt oder sind verloren gegangen. Die einzige Quelle für sein Klavierkonzert in Es-Dur WoO 4 ist ein professionell kopierter Klavierauszug, ${ }^{47}$ der - trotz Beethovens Titelblattaufschrift "agè [sic] de douze ans" - auf Papier notiert wurde, das zwischen 1787 und 1790 in Bonn verwendet wurde und daher nicht auf die Zeit seiner Konzertreise nach Den Haag (Frühjahr 1784), sondern erst später in diesem Jahrzehnt, als keine derartigen Konzertreisen bekannt sind, zu datieren ist. ${ }^{48}$ Die früheste Fassung seines Klavierkonzertes in B-Dur Op. 19 und seines Oboenkonzertes WoO 206 sind beide verschollen. Zwei unvollständige Partituren, die beide so scheinen, als dürften sie einmal komplett gewesen sein, zählen eventuell auch zu den Werken, die in den Akademien gespielt worden sind: das Violinkonzert WoO 5 und die Romance

272 | John D. Wilson

(C) 2020 by Böhlau Verlag GmbH \& Cie. KG, Köln

https://doi.org/10.7788/9783412519704 | CC BY-NC 4.0 


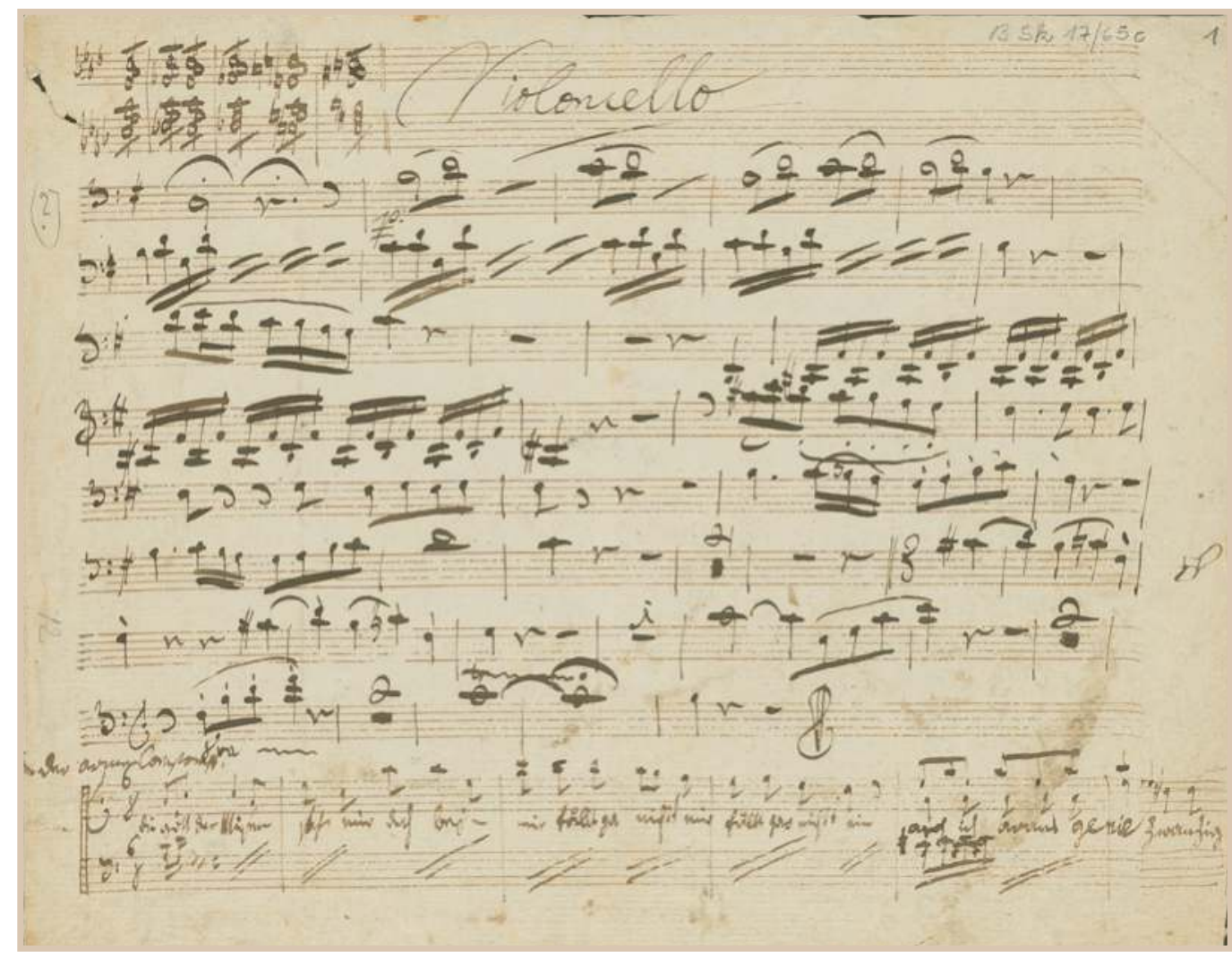

cantabile für Querflöte, Fagott, Klavier und Orchester WoO 207. Ersteres ist beachtenswerter Weise auf demselben Papier wie Rombergs Violinkonzert Nr. 6 mit achtzeiliger Rastrierung notiert, das sonst nirgends unter den Bonner Manuskripten zu finden ist, was darauf hindeutet, dass Beethoven Romberg auf dem Leib komponierte. Letzteres, ein langsamer Satz in e-Moll, gehörte möglicherweise einmal zu einem Konzert in G-Dur; ein fragmentarischer Celloteil eines schnellen Satzes in dieser Tonart von Beethovens Hand ist noch vorhanden. ${ }^{49}$ Schließlich scheinen rückblickend noch drei für Bonn komponierte Konzertarien, zwei für Bass WoO 89 und 90 und eine für Sopran WoO 92, für die Akademie-Konzerte mit Joseph Lux und Magdalena Willmann zwischen 1790 und 1792 gedacht gewesen zu sein. ${ }^{50}$

Schlussendlich können die Bonner Hofkonzerte als eine Art "Werkstatt für neue Musik" betrachtet werden, in der nicht nur die neuesten Werke aus ganz Europa, sondern auch Stücke junger, begabter Lokalkomponisten von einem ausgezeichneten Orchester zum ersten Mal einem musikalisch gebildeten Publikum präsentiert wurden. Bedenkt man, dass dies in Beethovens Wiener Jahren nur selten der Fall war, so wird verständlich, warum der Komponist dort sowohl mit dem Orchester als auch dem Publikum so häufig unzufrieden war. Aus seiner Sicht hatten wohl beide einen gewissen Nachholbedarf.
Beethoven: Cellostimme eines unbekannten Orchesterwerkes (Beethoven-Haus Bonn, Sammlung H. C. Bodmer) 
Vgl. hierzu den Beitrag von ELISABETH REISINGER in diesem Band.

Dieser Zweck war Bestandteil zweier FWF-Forschungsprojekte, die zwischen 2013 und 2019 vom jetzigen Autor gemeinsam mit Elisabeth Reisinger und Birgit Lodes durchgeführt wurden: "The Music Library of Elector Maximilian Franz".

Vgl. Elisabeth Reisinger, Juliane Riepe und John D. Wilson, in Zusammenarbeit mit BIRGIT LODES, The Operatic Library of Elector Maximilian Franz: Reconstruction, Catalogue, Contexts (Schriften zur Beethoven-Forschung 30; Musik am Bonner kurfürstlichen Hof 2), Bonn 2018. Zwei künftig erscheinende Bände vom Projektteam widmen sich der Kirchenmusiksammlung. Siehe auch die online-Quellendatenbank: https:// musikwissenschaft.univie.ac.at/maxfranz; Zugriff: 20.4.2020.

4 Das Inventar befindet sich heute in der Biblioteca Estense Universitaria zu Modena unter der Signatur "Catalogo Generale 53 I-II" (neue Signatur 40.4.10). Einen Überblick des Inventars liefert JULIANE RIEPE, Eine neue Quelle zum Repertoire der Bonner Hofkapelle im späten 18. Jahrhundert, in: Archiv für Musikwissenschaft 60/2, 2003, S. 97-114. Zu den Inventar-Kopisten und ihrer zeitlichen Anordnung siehe REISINGER/ RIEPE/WILSON, The Operatic Library (wie Anm. 3), S. 231-250.

Zu diesen Entwicklungen im Detail vgl. JOHN D. WILSON, From the Chapel to the Theatre to the Akademiensaal: Beethoven's Musical Apprenticeship at the Bonn Electoral Court, 1784-1792, in: DAVID Wyn JONES und KeITH CHAPIn (Hg.), Beethoven Studies 4, Cambridge 2020, S. 1-23

Beiträge zur Ausbreitung nützlicher Kenntnisse, 20.8.1784, S. 161-167, hier 161.

Diese quantitative Analyse basiert auf Aufzählungen Elisabeth Reisingers, vgl. DiES., Musik machen - fördern - sammeln. Erzherzog Maximilian Franz im Wiener und Bonner Musikleben. (Musik am Bonner kurfürstlichen Hof 3) Bonn, im Druck, Anhang E.

Vgl. RICHARD MüNNICH, Aus der Musikaliensammlung der Weimarer Landesbibliothek, in: Hermann Blumenthal (Hg.), Aus der Geschichte der Landesbibliothek zu Weimar und ihrer Sammlungen, Jena 1941, S. 168-184.

Vgl. Eva Renate Blechschmidt, Die Amalien-Bibliothek. Musikbibliothek der Prinzessin Anna Amalia von Preußen (1723-1787), Berlin 1965.

Vgl. JOHn A. RiCE, Empress Marie Therese and Music at the Viennese Court. 17921807, Cambridge 2003.

Vgl. hierzu den Beitrag von ElISABETH ReISIngER in diesem Band.

Vgl. DorotheA Link, Mozart's Appointment to the Viennese Court, in: Dies. (Hg.), Words about Mozart. Essays in Honour of Stanley Sadie, Woodbridge 2005, S. 153178, hier S. 161

Vgl. Dieter Lutz Trimpert, Die Quatuors Concertants von Giuseppe Cambini, Tutzing 1967, S. 243-306.

Vgl. YVES GÉRARD, Thematic, Bibliographical and Critical Catalogue of the Works of Luigi Boccherini, London 1969.

Vgl. hierzu den Beitrag von ELISABETH REISINGER in diesem Band.

REISINGER, Musik machen (wie Anm. 7), Anhang E.

Vgl. Reisinger/Riepe/Wilson, The Operatic Library (wie Anm. 3), S. 162-172. Zu Simrock vgl. auch den Beitrag von JOANNA COBB BIERMANN in diesem Band.

18 Eine Übersicht der erhaltenen Opernpartituren aus Simrocks Kopistenbetrieb samt ihren Provenienzen und ihrem heutigen Fundort befindet sich bei REISINGER/RIEPE/ WILSON, The Operatic Library (wie Anm. 3), S. 373-380. 


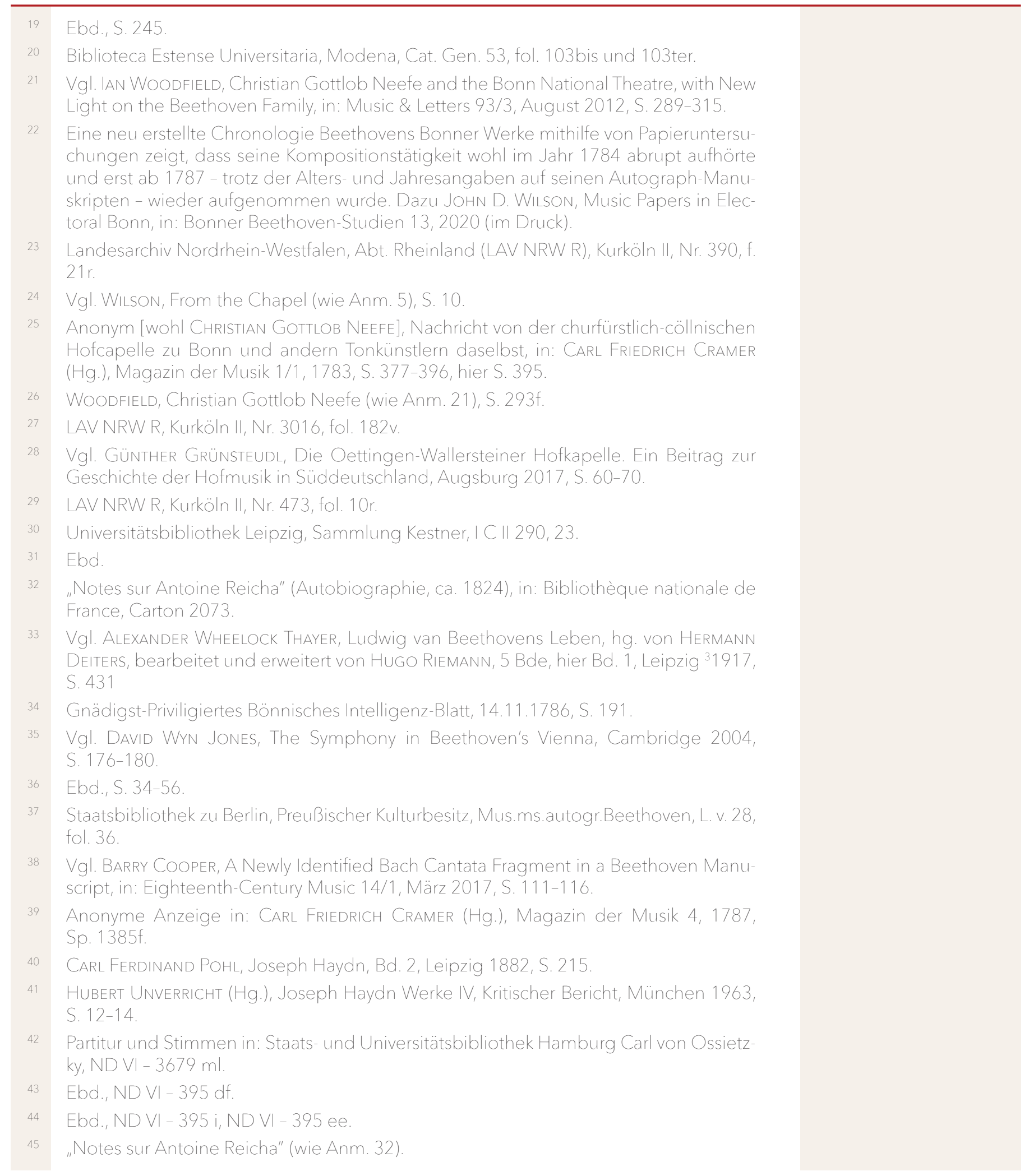

Das Instrumentalmusik-Repertoire der kurfürstlichen Hofmusik zur Zeit des jungen Beethovens | 275

(C) 2020 by Böhlau Verlag GmbH \& Cie. KG, Köln

https://doi.org/10.7788/9783412519704 | CC BY-NC 4.0 


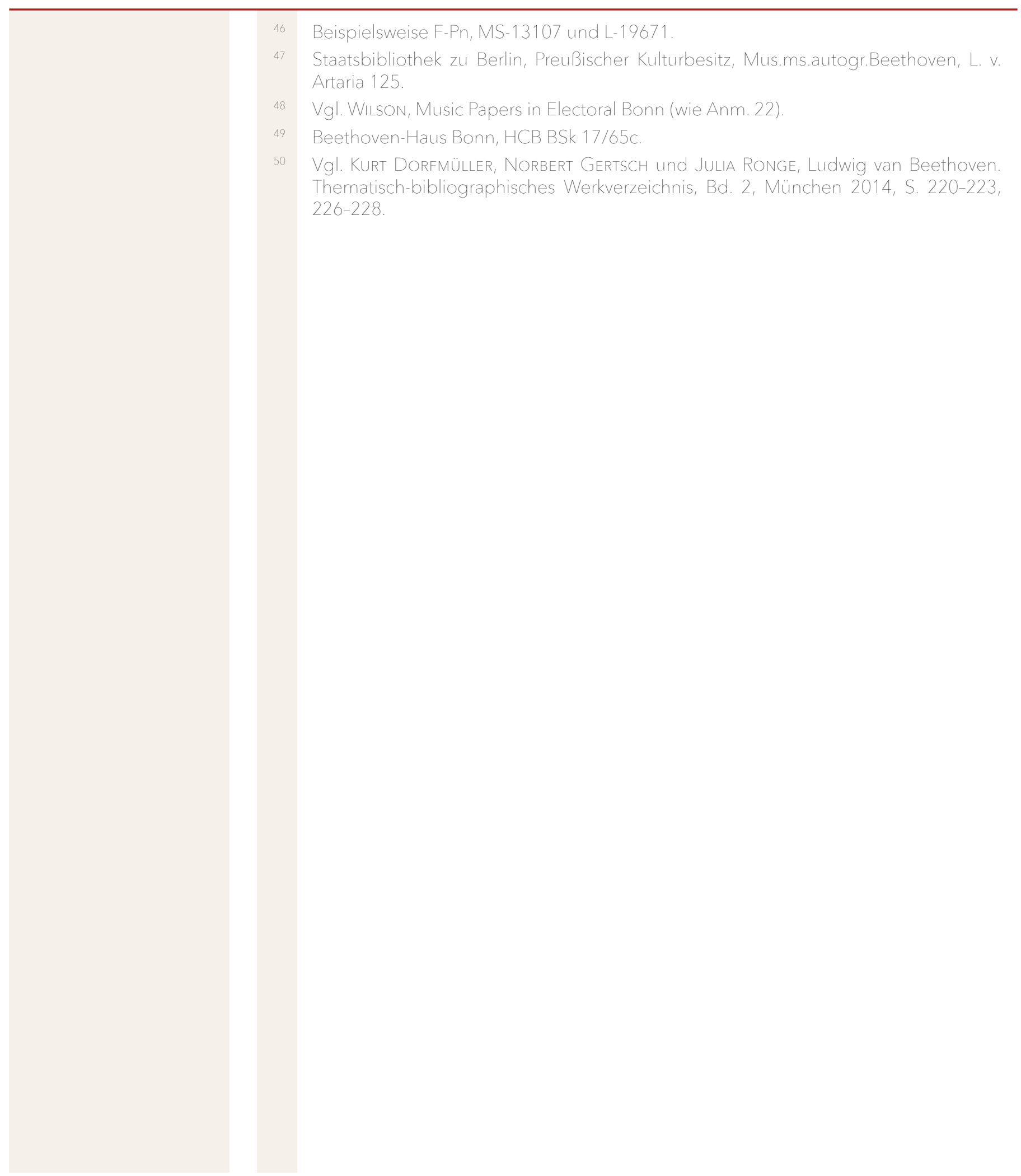

276 | John D. Wilson

(C) 2020 by Böhlau Verlag GmbH \& Cie. KG, Köln https://doi.org/10.7788/9783412519704 | CC BY-NC 4.0 
"Und doch würde dich keiner so in deine Jugendjahre zurückgeführt, dich an

Ingrid Bodsch hundert lustiger und trauriger Gestalten haben erinnern können, als ich ..."1

\section{Beethovens Bonner Jugendfreunde}

\section{Fräulein Westerhold, Jeannette Hohnrath}

Es ist der älteste, engste ${ }^{2}$ und einer der wenigen Beethoven bis zum Lebensende verbunden gebliebene Freund aus den Bonner Jugendjahren, der sich Beethoven in einem Brief vom 1. Februar 1827, wenige Wochen vor dessen Tod, als Erinnerungsstütze empfiehlt, sofern dieser seinen Blick zurück in seine Jugend schweifen lassen möchte. Interessanterweise nennt Franz Gerhard Wegeler (1765-1848), fünf Jahre älter als Beethoven und seit 1802 verheiratet mit der gemeinsamen Jugendfreundin Eleonore von Breuning (1771-1841), in seinem Brief nur zwei Personen namentlich, zwei Frauen, an die (nicht nur) Beethoven ehedem schwärmerische Gedanken verschwendet hatte. Wegeler stützte sich dabei vor allem auf seine Frau Eleonore, die er offensichtlich nicht zur Reihe der - unerfüllt gebliebenen - Jugendlieben Beethovens zählte. Insbesondere sie hülfe nämlich seinem Gedächtnis „besonders ... durch Erzählungen von Fräul[ein] Westerhold, Jeannette Hohnrath, und wie die et ceteras alle geheißen haben, treu nach ...."3 Obwohl Beethoven an den beiden hübschen jungen Damen aus adeligem Haus, die bei ihren BonnAufenthalten im Haus der Familie von Breuning lebende und sicher mit der gleichaltrigen Eleonore von Breuning befreundete Kölnerin Johanna (Jeannette) von Honrath ${ }^{4}$ sowie Maria Anna Wilhelmine von und zu WesterholtGysenberg ${ }^{5}$, offenbar ehedem erhebliches Interesse gezeigt hat, das nicht nur in seiner Umgebung auffiel, sondern auch durch persönliche Widmungen von Beethoven an Jeannette ${ }^{6}$ und Wilhelmine ${ }^{7}$ belegt ist, und er sich Jeannettes offenbar sofort erinnerte, als er 1823 in den Zeitungen eine Notiz über die militärische Karriere ihres Mannes las $^{8}$ standen sie mit Beethoven schon in keiner Verbindung mehr, als dieser Bonn Anfang November 1792 für immer verlassen hat.

So vertraut der Ton auch ist, mit dem Wegeler seinen Freund an die Bonner Jugendjahre erinnert, so verweist das im gleichen Brief zum Ausdruck gebrachte Bedauern über das vorherige "hartnäckige Stillschweigen" - Wegeler schrieb Beethoven nach Erhalt einer von Beethoven veranlassten Notensendung durch den Musikverlag Schott - des zu diesem Zeitpunkt allerdings schon todkranken Beethovens auf Wegelers "letzte Briefe" an ihn, dass das Bewahren alter Freundschaften bei Beethovens Freunden eine gewisse Leidensfähigkeit, 
Das von Breuning'sche Haus am Münsterplatz, ein Kanonikerhaus aus dem 18. Jahrhundert. Kolorierte Zeichnung von Mathias Frickel, 1896 (Dauerleihgabe des Stadtarchivs Bonn im Beethoven-Haus Bonn) jedenfalls eine große und geduldige Zuneigung voraussetzte. Immerhin, Beethoven war sich dieses Umstands schon in jungen Jahren bewusst, auch seiner "unverzeihlichen Nachläßigkeit" im Beantworten von Briefen seiner liebsten Freunde, und leistete dafür regelmäßig Abbitte unter Beteuerung seiner Freundschaft. ${ }^{10}$

Auch von den aus der Bonner Jugendzeit Beethovens stammenden Freundschaften waren nur wenige von längerer Dauer.

\section{Das Stammbuch}

Überdauert hat die Zuneigung zu Wegelers Frau Eleonore, 1792 bei Beethovens Abschied aus Bonn 21 Jahre alt, die wegen des langen Zögerns ihrer Mutter in die Einwilligung zur Eheschließung mit Wegeler - diese erfolgte am 28. März 1802 in (Bad) Neuenahr - weitere zehn Jahre als unverheiratete Frau im

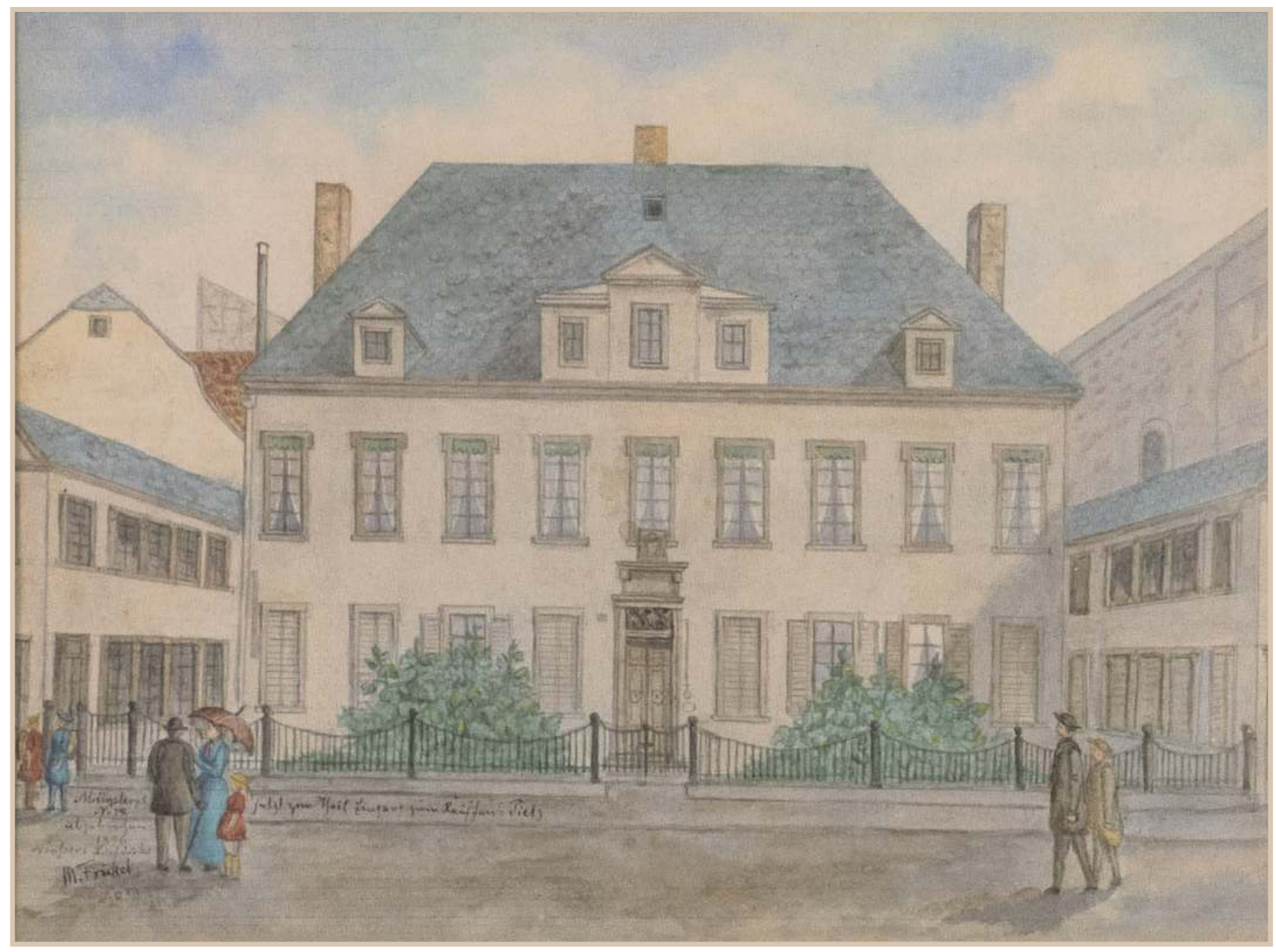

278 | Ingrid Bodsch

(c) 2020 by Böhlau Verlag GmbH \& Cie. KG, Köln

https://doi.org/10.7788/9783412519704 | CC BY-NC 4.0 
mütterlichen Hause lebte, gehörte zu den Personen, die sich bei Beethoven in den letzten Tagen vor seiner Abreise nach Wien am 2. November 1792 mit Widmungen und Illustrationen verabschiedeten. Diese Beethoven an seinem letzten Bonner Abend wahrscheinlich "lose" übergebenen ${ }^{11}$ und bis zu seinem Tod von ihm vermutlich in einer Kassette aufbewahrten Freundschaftsbekundungen wurden erst viele Jahrzehnte nach Beethovens Tod bei ihrem Erwerb durch die heutige Wiener Nationalbibliothek zusammengebunden und zum so genannten Beethoven-Stammbuch. ${ }^{12}$ Als solches gehört das "schmale, unscheinbare Büchlein" nur aufgrund seines ehemaligen Besitzers zu den "erlesensten Kostbarkeiten" der an Schätzen reichen Bibliothek. Denn die "vergilbten Papierblättchen" trügen, so im Beethoven-Jubiläumsjahr 1927 die Einschätzung des damaligen Vorstands der Handschriften-

und Papyrussammlung der Österreichischen Nationalbibliothek, „schriftliche Eintragungen einfacher, größtenteils ganz oder fast ganz unbekannter Menschen, Männer und Frauen.."13 Wenn auch in dieser Verallgemeinerung nicht ganz richtig, so stimmt natürlich, dass die meisten heute tatsächlich unbekannt wären, würde das Interesse an Ihnen nicht über die Person Beethovens wachgehalten oder erst so richtig initiiert. Für Beethoven jedenfalls waren die Stammbuchblätter eine ihm liebe Erinnerung an die guten Dinge in seiner Jugend, insbesondere an die seitdem nie mehr wiedergesehene Eleonore Wegeler, von der Beethoven neben ihrem Widmungsblatt, datiert 1. November 1792, offenbar auch die heute im Bonner Beethoven-Haus aufbewahrte Silhouette auf Goldgrund besaß, die das junge "Lorchen" von Breuning im Alter von 12 Jahren zeigt, ${ }^{14}$ zu einem Zeitpunkt also, als nur wenig später der ein halbes Jahr ältere Beethoven über seine mit Wegeler - nach dessen Aussage 1782 geschlossene Freundschaft ${ }^{15}$ - zum ersten Mal als Klavierlehrer zweier ihrer Kinder, Eleonore und Lorenz (1777-1798), Eingang in das am Münsterplatz in Bonn gelegene Haus von Helene von Breuning, geborene Kerich (1750-1838), Witwe des beim Bonner Schlossbrand 1777 ums Leben gekommenen kurfürstlichen Hofrats Emanuel Joseph von Breuning (1741-1777) gefunden hat.

Eleonore von Breuning, spätere Frau Wegeler (1771-1841). Schattenriss, wohl 1782 (BeethovenHaus Bonn) 


\section{Der Zehrgarten}

Zweifellos gehörte in Beethovens letzten Bonner Jahren der vertraute Zugang zur Familie von Breuning und seine Aufenthalte im Zehrgarten, dem insbesondere bei der geistigen Elite Bonns beliebten Gasthaus der Witwe Anna Maria Koch, geborene Klemmer (1749-1817)16, mit angeschlossener Buchhandlung, zu den angenehmen und prägenden Erlebnissen seines Lebens. Die Kochs waren nicht von Adel wie die mit ihnen befreundeten von Breunings, aber Michael Koch (1736/37-1783), der verstorbene Ehemann der WirtshausBesitzerin, seit 1767 als Kellerdiener, seit 1776 als Hof-Botellier und WeingartenAufseher in kurfürstlichen Diensten nachgewiesen, gehörte wie ihr im Haus lebender und als Bereiter im kurfürstlichen Reitstall beschäftigter jüngerer Bruder Jakob Klemmer (*1760)17, und viele der übrigen Gäste, inklusive der Professoren, zum kurkölnischen Hof. Michael Koch war seit 1777 der Besitzer des Hauses Zum Zehrgarten, mit Lizenz zum Weinausschank, und seine die Liegenschaft 1783 erbende Frau offenbar die geborene Unternehmerin.

Angesichts der Tatsache, dass auffällig viele Mitglieder der 1787 gegründeten Bonner Lesegesellschaft - neben der Universität ein weiterer "Leuchtturm der Aufklärung" in Bonn - seit 1784 zu den regelmäßigen Gästen des Zehrgartens gehörten, sah sich Max Braubach sogar zur Aussage verführt, dass „vielleicht stärker noch als die Universität" auf die Bildung der Lesegesellschaft „jener Freundeskreis aus dem Zehrgarten eingewirkt hat". Schon von den 13 Gründungsmitgliedern der Lese gehörten Crevelt, Eichhoff, Heckel, Polzer und Dörfeld zum Stammpublikum des Zehrgartens. ${ }^{18}$

Natürlich verkehrten im Hause der Witwe Koch auch Adelige, die nur wegen des kurkölnischen Hofes bzw. wegen des Kurfürsten und gleichzeitig Hochmeister des Deutschen Ordens zeitweilig in Bonn weilten, wie als vornehmster unter ihnen und seit 1788 ebenfalls Mitglied der Lesegesellschaft der aus altösterreichischem Uradel stammende Ferdinand Graf Waldstein, dessen Empfehlungen Beethoven in Wien viele Türen geöffnet haben dürften. Während Graf Waldstein, obwohl nur sieben Jahre älter als Beethoven eher die Rolle als wichtigsten der frühen Förderer Beethovens zukommt, aber wohl kaum als Jugendfreund bezeichnet werden kann, gilt das bei einigen anderen Tischgenossen im Zehrgarten umso mehr, nicht aber bei dem schon mit 24 Jahren im Herbst 1792 nach seiner Rückkehr von der Universität Jena zum Professor an die Kurfürstliche Universität Bonn berufenen Juristen Bartholomäus Fischenich (1768-1831). ${ }^{19}$ Die einzige bekannte Quelle, in der sich Fischenich zu Beethoven äußert, verrät lediglich seine besondere Wertschätzung für das kompositorische Können und die geistige Haltung des um zwei Jahre jüngeren Bonner Hofmusikers. ${ }^{20}$ Da Fischenich nur wenige Wochen vor der Abreise Beethovens wieder nach Bonn gekommen ist, beschränkten sich die persönlichen Begegnungen vermutlich auf wenige gemeinsame Aufenthalte im Zehrgarten der Witwe Koch, den Fischenich aus Anlass des Todes von Anna 
Maria Koch († 1817) in einem Kondolenzbrief an seinen Freund Anton Graf Belderbusch, dem schon lange verwitweten Schwiegersohn der ehemaligen Wirtin, als das Haus bezeichnet, in dem er "einen schönen Theil (seines) Lebens und manche frohe Stunde zugebracht, es war einst der Mittelpunkt alles geistigen und geselligen Vergnügens in Bonn. Nun ist es ausgestorben, und wir blicken mit Wehmuth auf die verlassene Stätte hin.."21 Von Wegeler erfahren wir darüber hinaus nur, auch im Hinblick auf Fischenich, dass seit den späten 1780er Jahren vom Zehrgarten auch eine besondere Anziehungskraft in Gestalt von Barbara ${ }^{22}$ (Babette) Koch (1771-1807) „nachherige Gräfinn Belderbusch", der ältesten Tochter der ZehrgartenWirtin, ausgegangen ist. „Babette Koch ..., eine vertraute Freundinn der E. von Breuning, eine Dame, welche von allen Personen weiblichen Geschlechts," so schwärmte Wegeler noch 1838 und im Angesicht seiner noch lebenden Frau Eleonore, der erwähnten "vertrauten Freundinn", "die ich in einem ziemlich bewegten Leben, bis zum hohen Alter hinaus, kennen lernte, dem Ideal eines vollkommenen Frauenzimmers am nächsten stand. ... Nicht nur jüngere Künstler, wie Beethoven, die beiden Romberg, Reicha, die Zwillingsbrüder Kügelgen u.s.w. umgaben sie, sondern geistreiche Männer von jedem Stand und Alter, wie D. Crevels als Hausgenosse, der früh verstorbene Professor Velten, der nachherige Staatsrath Fischenich, der Professor, nachherige Domcapitular Thaddäus Dereser, der nachherige Bischof Wrede, die Privat-Secretaire des Kurfürsten Heckel und Floret, der Privat-Secetair des Oesterreichischen Gesandten, Malchus, der nachherige Holländische Staatsrath von Keverberg, der Hofrath von Bourscheidt, der hier erwähnte Christoph von Breuning und viele Andere." 23

\section{Abschied von Bonn}

Von den von Wegeler hier als Verehrer von Babette Koch, der auch "in den höchsten Kreisen ... Sympathie und Bewunderung", selbst seitens des Kurfürsten Maximilian Franz entgegengebracht wurde, ${ }^{24}$ aufgezählten jüngeren und älteren Herren, sind auch drei - Christoph von Breuning (1773-1841), Johann Heinrich Crevelt (1751-1818), Carl August Malchus (1770-1840) -, die sich mit Widmungsblättern ihrem nach Wien reisenden Freund Beethoven

Babette - eigentlich Barbara - Koch (17711806). Tochter des Zehrgarten-Gastwirtpaars, später verheiratete Gräfin Belderbusch. Fotografie eines verschollenen Gemäldes (Stadtarchiv Bonn) 
empfahlen. Ob alle drei "am Abend seines Abschieds", wie die "wittib Koch" als Beethovens "wahre Freundin" unter ihrer ein Schiller-Zitat aus Don Carlos aufgreifenden Widmung, datiert 1. November 1792, vermerkte, ${ }^{25}$ im Zehrgarten mit Beethoven zusammensaßen und ihm alles Gute wünschten, ist leider unbekannt. Vom gleichen Datum sind noch die Einträge von zwei Hausgenossen der klugen und tatkräftigen Wirtin, Johann Heinrich Crevelt und Frau Kochs jüngerer Bruder Jakob Klemmer, dessen Spuren sich nach 1794 verlieren, als er von Kurfürst Maximilian Franz mit Schulhengsten aus dem kurfürstlichen Reitstall und als Reitlehrer zu Maximilian Franz' Bruder Ferdinand nach Mailand geschickt wird, sowie von Peter Joseph Eilender (1767-1831) und den Geschwistern Eleonore und Christoph von Breuning. Unbekannt ist auch, wer sich aus dem Kreis der übrigen elf, die Beethoven mit Freundschaftsbekundungen beschenkten, eingefunden hatte, deren Widmungsblätter vom 24. Oktober (Carl August Malchus, Babettes jüngere Schwester Marianne Koch sowie ihr Bruder Matthias Koch und Johann Jakob Richter), 25. Oktober (Johann Joseph Eichhoff), 29. Oktober (Ferdinand Graf Waldstein) und vom 31. Oktober (Johann Martin Degenhart und Heinrich Struve) datieren. ${ }^{26}$

Eine rauschende Feier wird es aber selbst bei Anwesenheit aller14 Freunde nicht gewesen sein angesichts der frühen Abfahrt Beethovens am nächsten Morgen und der unsicheren Zustände, die bekanntlich sowohl den Reisenden wie auch die in Bonn verbleibenden Freundinnen und Freunde erwarteten. Denn obwohl die Einträge auf den Stammbuchblättern keine Silbe darüber verlauten lassen, so war die Lage in Bonn im Herbst 1792 - es war das Jahr des ersten Koalitionskriegs gegen Frankreich - äußerst gespannt, nachdem eine französische Revolutionsarmee unter General Custine als Reaktion auf den Einmarsch der Koalitionstruppen in Frankreich ihrerseits auf deutsches Gebiet vorgestoßen war und am 21. Oktober 1792 Mainz eingenommen hatte, die Residenz des Mainzer Kurfürsten, gleichzeitig Reichskanzler des Reichs. Die kurkölnische Residenzstadt Bonn hätte sich ebenso kampflos ergeben müssen wie Mainz. "Alles”, so schrieb am 23. Oktober 1792 der seit dem Sommer in Bonn am Münsterplatz residierende kaiserliche Gesandte Westphalen, „packt und flüchtet, was und wie es kann. ${ }^{27}$ Erst Ende Oktober beruhigte sich die Lage durch die Ankunft hessischer und preußischer Truppen in Koblenz, doch schon wenige Wochen später sah sich der Kölner Kurfürst Maximilian Franz aufgrund nunmehr aus dem Westen drohender Gefahr - die Franzosen hatten die alte Kaiserstadt Aachen besetzt - zum Verlassen Bonns in Richtung Münster genötigt. Seine noch in Bonn verlebte Regierungszeit blieb überschaubar, sie umfasste nach seiner Rückkehr nach Bonn im Frühjahr 1793 bis zur endgültigen Flucht im Herbst 1794 kaum mehr als 1 1/2 Jahre. Beethovens Karriere in Bonn wäre, hätte er nicht noch die Gunst der Stunde nutzen und mit einem kurfürstlichen Stipendium im Herbst 1792 nach Wien reisen können, zwei Jahre später auf jeden Fall und ganz gewiss ohne Stipendium und Lohnfortzahlung 
beendet gewesen. Und kaum hätten sich Mitte der 1790er-Jahre neben Beethovens Brüdern auch einige seiner engsten Bonner Freunde für mehr oder weniger lange Zeit in Wien niedergelassen, wenn sie sich durch die Einnahme Bonns durch die Franzosen und die daraus resultierenden sehr unsicheren Lebensverhältnisse in der Stadt nicht dazu veranlasst gefühlt hätten.

\section{Degenhart, Eichhoff, Eilender, Koch}

Degenhart (1768-1800), den Braubach zusammen mit Matthias Koch zu den engsten Jugendfreunden Beethovens zählt, gehörte nicht dazu. Er stellte sich ebenso wie der vier Jahre jüngere Peter Joseph Eilender - beide hatten zuletzt an der kurfürstlichen Universität Jura studiert - „im Gefolge Eichhoffs ... nach Einzug der Franzosen für die französische Verwaltung zur Verfügung". ${ }^{28}$ Weder von Eilender, der in enger Verbindung zur Familie Koch und Graf Belderbusch blieb - als Notar unterschrieb er sowohl die Scheidung Belderbuschs von seiner, Belderbusch schon lange abhanden gekommenen ersten Frau, und war Trauzeuge von Belderbuschs Heirat mit Babette Koch am 9. Oktober 1802 -, noch von Degenhart gibt es Zeugnisse späterer Kontakte zu Beethoven. Eichhoff hingegen, der als einziger in seiner Abschiedswidmung von 1792 Beethovens Rückkehr nach Bonn "zu unserm trauten Kreis" beschwor, feierte 1814/15, als er beim Wiener Kongress als Sachverständiger die Angelegenheiten der Rheinschifffahrt vertrat, ein spätes Wiedersehen mit Beethoven, und wurde von dem "guten Jungen", ${ }^{29}$ wie er nach Bonn berichtete, freundlich aufgenommen und als Kurier für Mitbringsel an Wegeler und Crevelt benutzt. Dass zwischen 1792 und 1815 keine Briefe gewechselt wurden, scheint weder Beethoven noch Eichhoff die Freude am einmaligen Wiedersehen verdorben zu haben. Mit dem nach Braubach anderem engsten Bonner Jugendfreund Beethovens, dem bei Abreise Beethovens nach Wien 19 Jahre alten Matthias Koch, hat es ein rascheres und jugendfrischeres Wiedersehen gegeben. Matthias, der seinen Onkel Jakob Klemmer beim Pferdetransport nach Mailand begleitet hat, blieb auf der Rückkehr mindestens ein Jahr in Wien, bevor er 1797 nach Bonn zurückkehrte, heiratete und schon 1805 in Offenbach starb, wo er als Bibliothekar im Dienst des Fürsten von Isenstein-Birstein stand. Matthias Koch, der im Widmungsblatt an Beethoven von 1792 nebst seinem Zitat aus einer Ode von Klopstock das Zitat seiner Mutter aus Schillers Don Carlos fortsetzte, hatte wohl viel vom Charakter seiner Schwester Babette, denn Stephan von Breuning (1774-1827) bezeichnete ihn im Nachruf nicht nur als echtes Künstler-Talent, sondern auch mit "reinem Sinn für alles Gute, Schöne und Große". ${ }^{0} \mathrm{Am}$ 12. Januar 1796 schrieb Stephan von Breuning seiner Mutter, dass er und sein Bruder Christoph bei der Ankunft in Wien am 26. Dezember 1795 in Wegelers Zimmer zu ihrer Freude auch Matthias Koch angetroffen hätten, der aus Mailand angereist war. ${ }^{31}$ Das aus alten Zehrgarten-Zeiten wiederbelebte freundschaftliche Verhältnis der jungen Bonner in Wien hielt sicher bis zur 
Der Bonner Marktplatz mit der sogenannten Fontäne und dem Rathaus im Hintergrund. Radierung von Franz Rousseau nach Charles Dupuis, um 1790. Rechts das Gasthaus

Zum Zehrgarten (Stadtarchiv Bonn)
Rückreise von Matthias Koch 1797 an, denn im Herbst 1796 drückte Stephan von Breuning nebst herzlichen Grüßen an Babette Koch, ihre Mutter und Heinrich Crevelt gegenüber dem schon zuvor nach Bonn zurückgekehrten Wegeler die Hoffnung aus, dass sein junger Bruder Lorenz und Beethoven Matthias Koch überreden könnten, den Winter über noch in Wien zu bleiben. ${ }^{32}$ Wiedergesehen haben sich nach Matthias Kochs Abreise 1797 er und Beethoven nicht, und es hat sich auch kein briefliches Zeugnis erhalten, dass Beethoven und Matthias Koch bis zu dessen frühen Tod 1805 noch einmal Kontakt zueinander gesucht hätten. Völlig im Dunkeln bleibt ja selbst, ob Beethoven seinen Gönner Graf Waldstein je in Wien wiedergesehen hat. Vergessen hat er ihn natürlich nicht. Auch mit Crevelt, dem allseits geliebten treuen Hausgenossen der Familie Koch, der dieser in zärtlicher Liebe und Fürsorge bis zu seinem eigenen Tode anhing, hat Beethoven keine Korrespondenz unterhalten, aber auch ihn, dem er sicher bei jedem Besuch im Zehrgarten begegnet ist, hat er nicht vergessen. Ihn bestimmte er zum Empfänger des der Bonner Lesegesellschaft 1815 von Eichhoff aus Wien überbrachten Porträtstiches, dass "als Andenken alter Freundschaft" an Crevelt fallen sollte, sobald die Lese als Ersatz das versprochene Ölgemälde in Besitz nähme. ${ }^{33}$

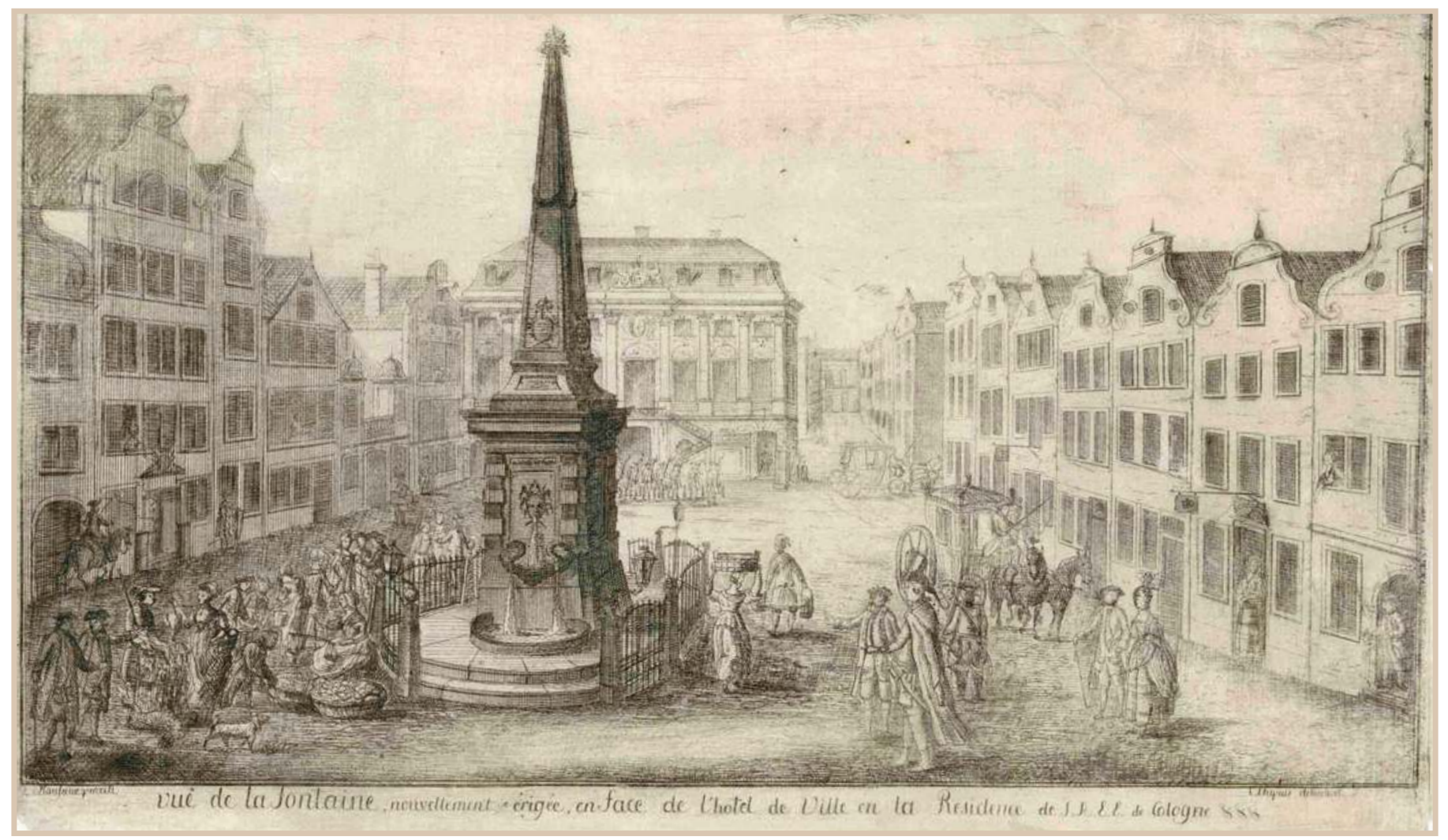

284 | Ingrid Bodsch

(c) 2020 by Böhlau Verlag GmbH \& Cie. KG, Köln

https://doi.org/10.7788/9783412519704 | CC BY-NC 4.0 


\section{Johann Jakob Richter}

Gar keine Kontakte nach der Abreise Beethovens aus Bonn finden sich im Falle des erst spät identifizierten Bonner Freundes Johann Jakob Richter, der sich auf dem Stammbuchblatt für Beethoven kurz und knapp, und ganz im Sinne der Aufklärung verewigt hat: "Prüfe und wähle, dein ewig treuer Richter". Der zuvor an einem Koblenzer Gymnasium wirkende junge Theologe, 1790 wie Beethoven Subskribent der Gedichte des Bonner Professors Eulogius Schneider, wurde auf Empfehlung Schneiders und des Bonner Ministers und gleichzeitig Universitätskurators Spiegel Ende 1790 als Hofmeister der Söhne von Clemens August Freiherr (seit 1792 Reichsgraf) von Westphalen zu Fürstenberg (1754-1818) eingestellt. Mit ihm, seit 1792 kaiserlicher Gesandter in Bonn, bezog er wie auch Westphalens Sekretär Malchus vermutlich im August das vom Kanonikus Radermacher angemietete Palais am Münsterplatz. ${ }^{34}$ Möglichweise dort, bei den von der Hofrätin von Breuning erzwungenen Klavierstunden für die 1792 sieben und acht Jahre alten Söhne Westphalens, werden sich Richter und Beethoven zum ersten Mal gesehen haben, ${ }^{35}$ um dann in den wenigen Wochen bis zu Beethovens Abreise ihre letztlich kurzlebige Freundschaft in geselliger Runde im Zehrgarten zu vertiefen.

\section{Carl August Malchus}

So kurz und prosaisch die Widmung von Richter an Beethoven gehalten ist, so glutvoll ist die des Beethoven nahezu gleichaltrigen, aus Mannheim gebürtigen Carl August Malchus (1770-1840), der wie Richter zur Zeit ihres Aufenthalts in Bonn im Hause des Grafen von Westphalen wohnte. Die Freundschaft zwischen den jungen Männern muss in kürzester Zeit aufgeblüht sein, denn der später vor allem als ebenso renommierter wie angefeindeter Finanzpolitiker an verschiedenen Höfen bekannt gewordene Malchus kam nämlich erst im Laufe des Jahres 1792 als Legationssekretär des kaiserlichen Gesandten - Malchus' Arbeitgeber Clemens August Freiherr von Westphalen zu Fürstenberg war im Juli 1791 zum „kaiserl. Königl. Bevollmächtigten Minister bei den Kurhöfen zu Coblenz und Bonn und bei dem westphälischem Kreis ernannt (worden), welchen Posten derselbe im Januar 1792 angetreten"36 - nach Bonn. Da Westphalen, wie schon erwähnt, seinen zeitweiligen Wohnsitz im späteren Palais Fürstenberg nahm, dem heutigen Standort der Bonner Hauptpost am Münsterplatz, waren es zum Breuningschen Wohnhaus nur ein paar Schritte, und da wir von Wegeler wissen, dass der junge Beethoven auf nachdrückliche Aufforderung von Helene von Breuning auch dort Klavierstunden gegeben hat bzw. geben musste, könnten sich Beethoven und Malchus sowohl dort wie im Zehrgarten zum ersten Mal begegnet sein. Innerhalb weniger Monate entstand zwischen Malchus, der im Jahr seiner Ankunft in Bonn auch schon Mitglied der Lese wurde, und Beethoven eine enge Freundschaft, die den später geadelten und eher als kühl bezeichneten Malchus am 24. Oktober 1792 zu einer empha- 


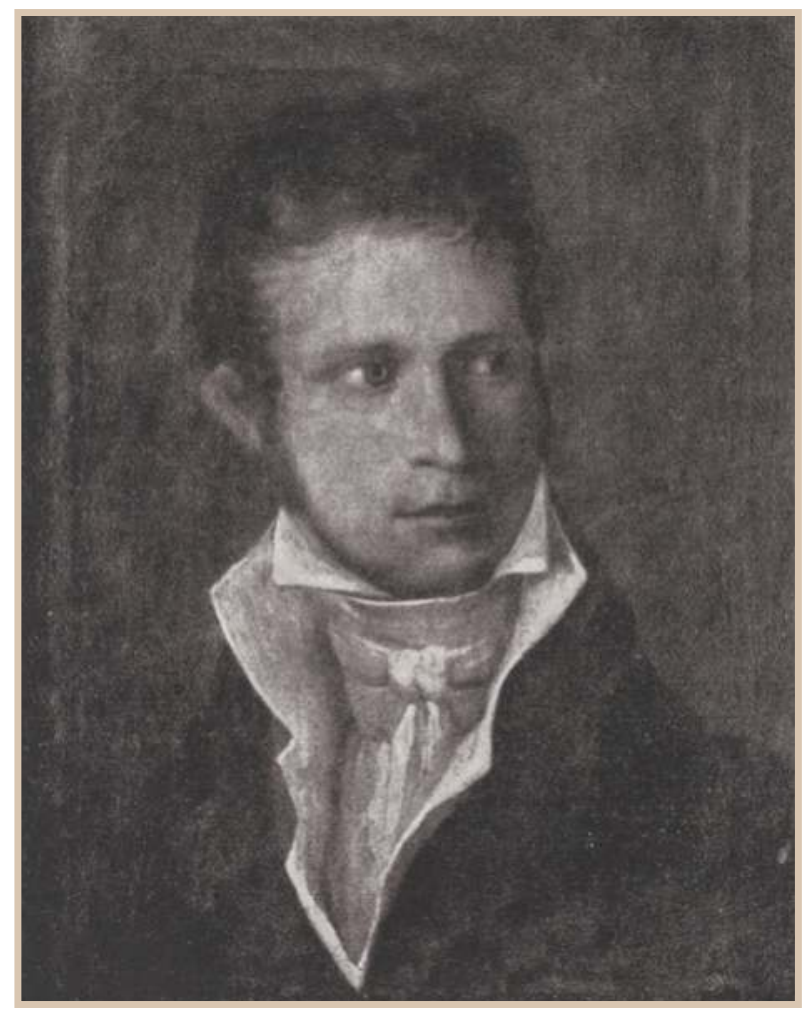

tischen Freundschaftsbekundung im Widmungsblatt für Beethoven am 24. Oktober 1792 hingerissen hat: „Der Himmel mein Inniggeliebter knüpfe mit unauflöslichem Band unsere Herzen - und nur der Tod kann es trennen. - Reich mir deine Hand mein Trauter, und so zum Lebensziel. Dein Malchus." ${ }^{\prime 37}$

Die beiden jungen Männer, die schon in jungen Jahren große Anerkennung ihrer jeweiligen Fähigkeiten gefunden haben, verband auch die Herkunft aus ähnlichen Verhältnissen, die allerdings bei Malchus deutlich wohlhabendere gewesen sind, wie er im Gegensatz zu Beethoven auch über eine sehr gediegene Gymnasialund Hochschulausbildung verfügte, die ihm sein Landesherr, Herzog Karl August von Pfalz-Zweibrücken, gleichzeitig Dienstherr seines Vaters, mit einem Stipendium ermöglicht hatte. ${ }^{38}$

Unabhängig davon, dass Malchus während seines Aufenthalts in Bonn bis zur Flucht des Kurfürsten im Herbst 1794 häufiger mit Missionen, unter anderem zur kaiserlichen Armee, beordert wurde, erstaunt, dass der eben noch den ewigen Freundschaftsbund beschwörende Malchus den Kontakt zu Beethoven offenbar

Carl August Freiherr von Malchus (1770-1840).

Privatsekretär des Grafen Clemens August von

Westphalen zu Fürstenberg, später Minister in den

Königreichen Westphalen und Württemberg.

Foto nach einem

unbekannten Ölgemälde (aus: STEPHAN LEY,

Beethovens Leben in authentischen Bildern und Texten) nach dessen Abreise aus Bonn völlig abbrechen ließ, fast nach dem Motto "Aus den Augen, aus dem Sinn". Drei Briefe, die Beethoven ihm aus seinem ersten Wiener Jahr geschrieben hat, blieben offenbar ohne Antwort, ebenso wie zwei Briefe Beethovens an Babette Koch, die ihn allerdings auch ohne Freundschaftsbekundung nach Wien hatte reisen lassen. War es später Beethoven, der Freunde und Bekannte auf Antwort warten und verzweifeln ließ, so zeigt er sich in seinem Brief vom 2. November 1793 an Eleonore von Breuning als Betroffener, der mit dem hartnäckigen Schweigen derjenigen, denen er sich in enger Freundschaft verbunden fühlte, hadert: „sollten sie die B[abette] Koch sehen, so bitte ich sie ihr zu sagen, daß es nicht schön sey von ihr mir gar nicht einmal zu schreiben. ich habe doch 2-mal geschrieben, an Malchus schrieb ich 3-mal und - keine Antwort, sagen sie ihr, daß, wenn sie nicht wolle schreiben, sie wenigstens Malchus dazu antreiben solle. "39 Der letzte Hinweis zeigt, dass Beethoven um die Macht der Babette Koch auf die sie umschwärmenden Männer wusste. Babette Koch scheinen die "süssen Accorde ${ }^{\prime 40}$ des herausragenden Klavierspielers wohl nicht ins Herz getroffen zu haben. Jedenfalls ist es kaum glaubhaft, selbst wenn man möglicherweise verloren gegangene Korrespondenz nie außer Acht lassen sollte, dass, wie oft suggeriert, ausgerechnet Malchus, seit Anfang des Jahrs 1808 Staatsrat im neugegründeten Königreich Westphalen, sich dafür eingesetzt hätte, um

286 | Ingrid Bodsch

(c) 2020 by Böhlau Verlag GmbH \& Cie. KG, Köln

https://doi.org/10.7788/9783412519704 | CC BY-NC 4.0 
Beethoven 1809 als Hofkapellmeister an den Hof des Napoleon-Bruders Jerome nach Kassel zu ziehen. Belegt ist hingegen die Anhänglichkeit von Malchus an die Familie Koch und seine Verbundenheit mit anderen Mitgliedern des ehemaligen Zehrgartenkreises. Als er sich nach dem Zusammenbruch der französischen Herrschaft und damit auch des Königreichs Westphalen mit seinem König 1813 in Aachen aufhält, kann er auf die alte Freundschaft mit Bartholomäus Fischenich zählen, dem er nicht vergaß, seine Grüße für die noch lebende Witwe Koch und den alten Dr. Crevelt mitzugeben. Babette Gräfin Belderbusch, geborene Koch, war damals schon lange tot. Ob Beethoven noch einmal ein Wort über Malchus verloren hat, ist unbekannt, doch dass er Abweisungen schlecht verkraftet hat, zeigt sein etwas hämischer Kommentar zu den ihm bekanntgewordenen und erst 1802 erfolgreichen Bemühungen des Grafen Belderbusch, Babette Koch zu heiraten. Den freundlichen Grüßen an die "gute Frau Hofräthinn", der er Wegeler auch auszurichten bittet, dass er immer "noch zuweilen ein raptus han", fügte er hinzu: "was Koch's angeht, so wundere ich mich gar nicht über deren Veränderung, das glück ist kugelrund und fällt daher natürlich nicht immer auf das edelste ...." ${ }^{\prime \prime 1}$ Diese Einschätzung hat kein einziger seiner alten Bonner Freunde geteilt, schon gar nicht Wegeler, für den Babette auch charakterlich nach wie vor das Idealbild einer Frau darstellte.

\section{Heinrich Struve}

Ein weiterer Freund aus Bonner Jugendtagen, der Beethoven ein besonders schön gestaltetes Widmungsblatt mit einem ganz im Sinne der Aufklärung formulierten Wahlspruch mit nach Wien mitgegeben hat, war der aus Regensburg gebürtige Heinrich Struve (1772-1851), Sohn des russischen Agenten und späteren Gesandten in Regensburg Anton Sebastian Struve, und nachweislich seines Widmungseintrags für Beethoven mindestens seit Herbst 1792 selbst "in Russisch Kaiserl. Diensten". ${ }^{42}$

Struve kam vermutlich Anfang 1789 wegen seiner allerdings nur wenige Monate später verstorbenen Schwester Susanne Maria, verwitwete Kaufmann, nach Bonn, die 1782 in Regensburg in zweiter Ehe Johann Ludwig Dörfeld (1744-1829) geheiratet hatte, ${ }^{43}$ damals seit 1781 Sekretär des englischen Gesandten Ralph Heathcotte in Bonn, Tischgenosse im Zehrgarten und seit 1787 Mitglied der Lese. Auf einen möglichen späteren Kontakt zu Beethoven gab es lange nur den Hinweis von Lorenz von Breuning an seine Schwester Eleonore, dass Struve ihn und Beethoven im Frühjahr 1795 in Wien besuchen wolle. 2012 tauchte plötzlich auf einer Auktion ein Brief von Beethoven an Struve auf, der just aus dem Jahr 1795 stammt und von Beethoven im Herbst geschrieben wurde. Beethoven antwortet auf eine nicht überlieferte Nachricht Struves an ihn, tröstet ihn über den Tod der Mutter, berichtet über eigene Reisepläne und nimmt Bezug auf die Tätigkeit Struves, den er als Diplomat in 
Franz Gerhard Wegeler (1765-1848). Mediziner, Ehemann von Eleonore von Breuning. Zeitgenössischer Schattenriss (BeethovenHaus Bonn)

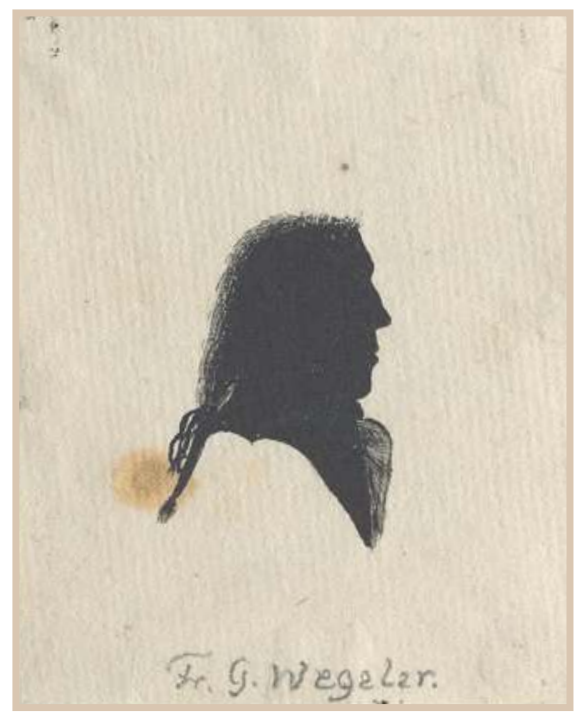

Russland weiß, dem "kalten Lande wo die Menschheit noch so sehr unter ihrer Würde behandelt wird" und bittet ihn, "mir ja immer zu schreiben, so oft du kannst, laß deine Freundschaft für mich sich nicht durch Entfernung vermindern." ${ }^{44}$

\section{Eleonore Wegeler, geborene von Breuning}

Eine der wenigen Personen aus Beethovens Bonner Jugendzeit, die, wie schon erwähnt, Beethoven ein Stammbuchblatt mitgaben ${ }^{45}$ und, obwohl kein Wiedersehen stattfand, bis zu Beethovens Tod mit ihm in anteilnehmender Verbindung stand, ist Eleonore Wegeler, geborene von Breuning (1771-1841). Das „Fräulein Lorchen" hat nicht nur seit 1782, als Beethoven als ihr und ihres jüngsten Bruders Lorenz Klavierlehrer in ihr und ihrer Familie Leben trat, Freundschaftsbekundungen und kleine Geschenke zu festlichen Anlässen mit ihm ausgetauscht. Sie war - noch in der Bonner Zeit Beethovens - die Empfängerin eines seiner ersten erhaltenen Briefe ${ }^{46}$ und Widmungsträgerin zweier seiner Jugendkompositionen. An sie adressiert Beethoven auch seinen am Jahrestag des Abschieds aus Bonn geschriebenen Brief, in dem er, sein damaliges Verhalten als "verabscheuenswerth" geißelnd, sich reuevoll über einen vor seiner Abreise "fatalen Zwist" mit Eleonore äußert und dem Brief als Zeichen seiner "Hochachtung und Freundschaft gegen sie und eines immerwährenden Andenkens an ihr Hauß" die zweite ihr gewidmete Komposition als Druck beifügte. ${ }^{47}$ Das gleiche Schreiben - es ist jenes, in dem Beethoven, häufig zitiert, Eleonore auch um die Anfertigung einer "von HaasenHaaren gestrickte(n) weste" für ihn bittet - ließ aber Eleonore wissen, dass sie keineswegs die erste der Bonner Freundinnen und Freunde war, der Beethoven aus Wien geschrieben hat. Denn Beethoven bittet sie eindringlich, bei Babette Koch und Malchus darauf zu dringen, dass diese ihm auf seine Briefe antworten. Direkten Briefverkehr gab es danach zwischen Eleonore von Breuning und Beethoven kaum noch, die Verbindung wurde vor allem über Eleonores Brüder und ihren späteren Ehemann Wegeler aufrechterhalten. Ob Eleonore Beethoven auf seinen Brief geantwortet hat, ist unbekannt, dass sie ihrer Freundin Babette Koch und Malchus Vorhaltungen machte, eher unwahrscheinlich. Von ihren drei Brüdern hatte sich nur der ihr im Alter nächste Bruder Christoph im Herbst 1792 von Beethoven mit einem Abschiedsvers verabschiedet. ${ }^{48} \mathrm{Er}$ traf wie seine jüngeren Brüder Stephan und Lorenz Beethoven Mitte der 1790er-Jahre in Wien wieder, wo der junge Jurist allerdings nur ein halbes Jahr geblieben ist, bevor er wieder ins Rheinland zurückkehrte. Danach brach der persönliche Kontakt zwischen Beethoven und Christoph von Breuning wohl ab, obwohl Beethoven Wegeler im Juni 1801 wissen ließ, das er vorhabe, "Stoffel nächstens [zu] schreiben". 49 


\section{Franz Gerhard von Wegeler}

Eleonores späterer Mann Franz Gerhard Wegeler hat Beethoven weder eine Widmung auf einem Stammbuchblatt nach Wien mitgegeben, noch hat ihm Beethoven jemals eine Komposition gewidmet. Trotzdem hielt diese Bonner Jugendfreundschaft Beethovens ganzes Leben lang. Das trotz oft jahrelanger Unterbrechungen im Briefwechsel bis zum Tode Beethovens bestehende Nahverhältnis zwischen dem Komponisten und dem Mediziner Wegeler hat sicher auch etwas damit zu tun, dass der alte Bonner Freund, wie später der Kurländer Carl Friedrich Amenda (1771-1836), zu dem Beethoven in kaum mehr als einem Jahr persönlicher Zusammenkünfte - Amenda lebte vom Frühjahr 1798 bis zum Sommer 1799 in Wien - eine danach nur noch über Briefe gelebte innige Zuneigung entwickelte, zu den "fernen Geliebten" zählte, ${ }^{50}$ deren Freundschaft also nicht der Dauerbelastung zu großer räumlicher Nähe und zu häufigen persönlichen Zusammenseins ausgesetzt war, wenngleich im Falle Amendas möglicherweise ein brieflich formulierter und nicht sofort uneingeschränkt zustimmend beantworteter allumfassender Besitzanspruch von Beethoven die Korrespondenz über viele Jahre fast verstummen ließ.51

Die etwa 11/2 Jahre, in denen Wegeler, der im Herbst 1794 nach der Übernahme Bonns durch die Franzosen nach Wien ausgewichen war, ${ }^{52}$ die alte Freundschaft zu Beethoven in regelmäßigen persönlichen Begegnungen auffrischen und vertiefen konnte, bevor er Ende Mai 1796 mit dem zusammen mit seinem Bruder Stephan am 26. Dezember 1795 nach Wien gekommenen Freund und späteren Schwager Christoph von Breuning wieder nach Bonn zurückkehrte ${ }^{53}$, waren nicht immer harmonisch verlaufen. ${ }^{54}$

\section{Stephan von Breuning}

War Wegeler also der über die meiste Zeit ihres Erwachsenenlebens weit entfernt lebende Bonner Jugendfreund, war sein seit 1801 dauerhaft in Wien lebender Schwager Stephan von Breuning der über die längste Zeit ihres Lebens in unmittelbarer Nähe von Beethoven lebende Jugendfreund. Im Gegensatz zu den "fernen Geliebten" lebte er jahrzehntelang in einem auch räumlichen Naheverhältnis zu Beethoven, einem heiklen, fragilen Beieinander. Ungeschönt und doch mit einem gewissen Verständnis für Beethoven schildert Breuning seinem Freund Wegeler, „welchen unbeschreiblichen und ich möchte sagen schrecklichen Einfluß seine Abnahme des Gehörs auf ihn gemacht hat. - Denken Sie sich das Gefühl, unglücklich zu seyn, bey seinem heftigen Charakter, hierbey Verschloßenheit, Mißtrauen oft gegen seine besten Freunde, in vielen Dingen Unentschloßenheit." ${ }^{\prime 55}$ Der Versuch in einer gemeinsamen groBen Wohnung zu leben, scheiterte an Beethovens Unzuverlässigkeit, die er sich nicht eingestehen wollte. Stattdessen zog er bei Ferdinand Ries, der als Bonner Freund, aber nicht als Bonner Jugendfreund gelten kann, da er bei Beethovens Abreise aus Bonn erst acht Jahre alt gewesen ist, über Breuning her, um diesen 
in einem weiteren Brief an Ries sogar einen "Geist der Kleinlichkeit" zuzuschreiben, den er, Beethoven, "von Kindheit an verachtet habe." In Wallung geraten fährt er fort, dass Stephan von Breuning nie mehr in seinem Herzen "den Platz behaupten" wird, "den er hatte", denn, "wer seinem Freunde eine so niedrige Denkungsart beimessen kann, und sich ebenfalls eine solche niedrige Handlungsart wider denselben erlauben, der ist nicht werth der Freundschaft von mir. ${ }^{\prime \prime 56}$

Zwar folgte nur wenige Monate später Beethovens Abbitte beim "treuen, guten, edlen" Stephan, verbunden mit dem Geschenk einer wertvollen Porträtminiatur, und der Bitte, dass "hinter diesem Gemälde auf ewig verborgen" sein müsse, "was eine Zeitlang zwischen unß vorgegangen "57. Beethoven, der auch sein durch andere Menschen befördertes Misstrauen als Ursache sieht - schon 1793 hat er Eleonore von Breuning, bei der er sich ebenfalls für einen offenbar sehr heftigen Zornesausbruch entschuldigte, vor der Gefahr des "Zuflüstern" gewarnt, ${ }^{58}$ das ihn in schlechten Meinungen bestärke -, beließ es nicht beim Geschenk der Miniatur, sondern widmete dem längst wieder versöhnten Freund 1806 sein Violinkonzert op. 61. Mit sicherlich großem Anteil seitens Stephan von Breunings, der auch Wegeler und seine Schwester auf dem Laufenden hielt und um Verständnis bat, wenn Beethoven weder schrieb noch sich für ihm von den Freunden erwiesene Gefälligkeiten bedankte, hielt diese Phase des Einvernehmens bis etwa 1815, als ein unbekannter Vorfall offenbar für Breuning das Fass zum Überlaufen brachte, und er für viele Jahre jede Beziehung zu Beethoven abgebrochen hat. „Erst 1825, als der von Krankheit gezeichnete Komponist ins Schwarzspanierhaus übersiedelt war, suchte von Breuning die Begegnung, um seine bewährte Güte und Fürsorglichkeit zu zeigen",59 die Beethoven auch in häufigen Kontakt mit Stephan von Breunings jungem Sohn Gerhard brachte.

\section{Lorenz von Breuning}

Stephan von Breuning, der Beethoven im Hause seiner Mutter in Bonn zum ersten Mal als Kind von acht Jahren begegnet ist, entsprach auch der Bitte, nach Beethovens Tod die Vormundschaft für dessen Neffen und Alleinerben Karl zu übernehmen, ein Liebesdienst von kurzer Dauer, da Stephan von Breuning, gestorben am 4. Juni 1827, Beethoven nur um wenige Wochen überlebte. Zu diesem Zeitpunkt war das jüngste Breuning-Kind, Lorenz, schon 29 Jahre tot. Der frühe Tod des jungen Mediziners war nicht nur für seine Familie, sondern auch für Beethoven ein einschneidendes Erlebnis, denn, wie erwähnt, schreibt er in den Jahren nach 1800 zweimal, dass von dem ihm zwei oder drei liebsten Menschen auf der Welt einer schon gestorben sei. Interessant ist dabei, dass Lorenz von Breuning keinesfalls die gleichen Gefühle für Beethoven hegte - viel offensichtlicher ist sein Kummer bei der Abreise von Wegeler aus Wien -, da er offenbar ein dauerhaftes freundschaftliches Aus- 
kommen mit Beethoven an einem Ort für ausgeschlossen hielt. In Wien hatte er während seiner Studienjahre oftmals die Gelegenheit, den Umgang Beethovens mit alten und neuen Freunden zu beobachten, unter anderem mit den Vettern Andreas und Bernhard Romberg, alten Kollegen Beethovens aus der Hofkapelle, die seit Herbst 1796 in Wien waren und die Lorenz bei ihren Konzertplänen, auch finanziell, unterstützte. Ihren Dank und ihre Zuneigung zu dem jungen Bonner drücken die ihm zugeeigneten Widmungsblätter von Andreas und Bernhard Romberg aus. ${ }^{60}$ Mit Beethoven war es für die Rombergs nicht so gut gelaufen. Zwar beteiligte er sich an ihrer Akademie, die zur Erleichterung von Lorenz von Breuning auch zu einem großen Einnahmeerfolg wurde, aber zuvor, noch vor dem Konzertaufenthalt Beethovens in Preßburg (Bratislava) war es - nach einer Mitteilung von Lorenz' Bruder Stephan an Wegeler und Christoph von Breuning vom 23. November 1796 - zu einem Eklat beim Fürsten Lichnowski gekommen, als Bernhard Romberg ein ihm vorgelegtes neues Stück nicht spielen konnte und über die Komposition, nicht wissend, dass sie von Beethoven war, zu schimpfen anfing. Eine private Einladung bei seinem Bruder Lorenz allerdings hätte ihm mit dem Spiel von Beethoven und den Rombergs "einen der schönsten Abende in Wien" geschenkt. ${ }^{61}$ Sein Stoßseufzer "Gott weiss, wann wir wieder einmal alle so versammelt seyn werden, wie in Wien" barg leider eine Vorahnung, da der erst im Herbst 1797 nach Bonn zurückgekehrte Lorenz von Breuning dort am 10. April 1798 noch vor Erreichen seines 21. Geburtstages gestorben ist. Am 5. Januar 1797 berichtete Lorenz von Breuning aus Wien Wegeler noch ganz munter über die erfolgreiche Akademie der Rombergs zum Jahresende 1796, in der auch Beethoven nach seiner Rückkehr von einem Konzert in Preßburg (Bratislava) am 23. November 1796 gespielt hatte, um ernüchtert festzustellen: "Bethhofen ist wieder hier. Er hat in der rombergischen Akademie gespielt. Dieser Mensch ist noch immer der Alte, und ich bin froh, daß er, und die Romberge noch so mit einander auskommen. Einmal zwar war er beinahe brouillirt mit ihnen; ich war aber damals der mediateur, und erreichte meinen Zweck so ziemlich. Überhaupt hält er jetz äusserst viel auf mich, und ich denke, (da ich nun einmal sicher bin, daß ich nicht Freund mit ihm sein kann) daß ich ihn nun, wenigstens gewissermassen, und so viel, als ich brauche, um manchmal angenehm mich zu unterhalten, und manchmal Andern einen Dienst zu thun, festhalten werde."62

Als Lorenz von Breuning im Herbst 1797 Wien verließ, nahm er auch ein ihm gewidmetes Stammbuchblatt von Beethoven mit sich. Unter ein Zitat aus Schillers Don Carlos mit drei Zeilen aus der Ansprache des Marquis Posa an Elisabeth, deren erste zwei schon Matthias Koch, von Braubach als einer der engsten Freunde von Beethoven in seiner Bonner Jugendzeit bezeichnet, in seinem Stammbuchblatt zu Beethovens Abreise 1792 verwendet hat - "Die Wahrheit ist vorhanden für den Weisen, / die Schönheit für ein fühlend Herz. I 
sie beyde gehören für einander." - setzte Beethoven mit der Datierung „Wien 1797 am 1. Oktober" die Worte: "lieber guter Breuning, nie werde ich sowohl die Zeit, die ich schon in Bonn ..., als wie auch hier zubrachte, vergessen, erhalte mit dir mir deine Freundschaft, so wie du mich auch immer gleich finden wirst. dein wahrer Freund L. v. Beethven." 63

Es ist müßig zu fragen, ob Beethoven mit Lorenz von Breuning, wäre dieser Zeit seines Lebens in Wien geblieben wie sein Bruder Stephan, "nie in ein Mißverhältniß gekommen" wäre, wie er 1804 gegenüber Ries bei den ihm liebsten Menschen beteuerte. ${ }^{64}$ Ebenso wissen wir nicht, ob Lorenz von Breuning, der offensichtlich weniger von Beethoven hinzunehmen bereit war als sein Bruder Stephan oder Wegeler, sein Verhalten angepasst oder sich aus der Nähe Beethovens zurückgezogen hätte.

Als Fazit lässt sich festhalten, dass auch Freunde mit Beethoven umso besser auskamen, je weiter die räumliche Entfernung und wie groß ihre Nachsicht über manchmal jahrelanges briefliches Schweigen war, dass die alten Bonner Jugendfreundinnen und Jugendfreunde bei Beethoven einen besonderen Stellenwert hatten, der - nimmt man Beethovens Aussage gegenüber Carl Amenda ernst, dass er wie einer der Freunde wäre, „wie sie mein Vaterländischer Boden hervorzubringen pflegt"65 - über die meist damit zusammenhängende Erinnerung an gemeinsam schön verbrachte Stunden in der Jugend hinausgeht, dass Beethoven seine rabiaten Ausfälle gegenüber seinen Jugendfreunden (bis zum nächsten Vorfall) durch Abbitten zu heilen bzw. auf ihr Verständnis hoffte und dass er - wie im Falle von Carl August Malchus und Babette Koch bei ihm besonders am Herzen liegenden Personen, die sich ihm entziehen, zuerst werbend auftritt und dann mit Unmut reagiert. Und fest steht auch, dass ihn drei Bonner Jugendfreunde bis zum Ende seines Lebens in treuer Teilnahme begleiteten - weitgehend aus der fernen Heimat: Eleonore und ihr Mann Franz Gerhard Wegeler, und in Wien, auf dem deutlich komplizierteren Posten, Eleonores Bruder und Wegelers Schwager Stephan von Breuning.

Und damit schließt sich auch der Kreis: Die Mitglieder der gleichen Familie, die ihn als Jugendlichen in ihr Haus, ihre Gesellschaft und in ihr Herz aufgenommen hatten, waren Beethoven, dessen eigener Familiengründungsversuch, ob mit Ehefrau oder den an Kindesstatt angenommenen Neffen, fast tragisch scheiterte, leibhaftig oder im Gedenken bis zu seiner Todesstunde ganz nah. 
Brief vom 1.2.1827 von Franz Gerhard Wegeler aus Koblenz an Ludwig van Beethoven in Wien, vgl. Sieghard Brandenburg, Ludwig van Beethoven. Briefwechsel Gesamtausgabe, 7 Bde, München 1996-1998, hier Bd. 6, Nr. 2235.

Wegeler war sicher einer der drei Freunde, die nach Beethovens eigener Aussage seine "ganze Liebe besaßen", in: Brief Beethovens an Wegeler, Wien 29.6.[1801], vgl. ebd., hier Bd. 1, Nr. 65. Das heißt aber nicht, dass sie immer in Gunst standen. So schrieb am 5.1.1797 Lorenz von Breuning an Wegeler, der gerade erst vor etwa sieben Monaten aus Wien nach Bonn zurückgekehrt war, dass er, Wegeler, - warum auch immer - aktuell bei Beethoven "gar nicht in der Gnade stünde" und Wegeler Beethoven bald schreiben solle, "damit [er] wieder in Ehren komme". Der junge Lorenz von Breuning, den Beethoven neben Wegeler und Amenda zu seinen liebsten Freunden zählte, stand Beethoven, den er seit seinen Kindertagen kannte, nicht vorbehaltlos gegenüber, und hatte für Beethovens gelegentlichen raptus, um einen Ausdruck von Lorenz' Mutter Helene von Breuning zu gebrauchen, weniger Verständnis. Jedenfalls glaubte er "nicht Freund mit ihm [Beethoven] sein zu können". Vgl. FrIEDERIKE GrIGAT, Die Sammlung Wegeler im Beethoven-Haus Bonn. Kritischer Katalog, Bonn 2008, E7. Vgl. Anm. 1 .

Die bei Franz Gerhard Wegeler und Ferdinand Ries, Biographische Notizen über Ludwig van Beethoven, Koblenz 1838, S. 42f., als "schöne, lebhafte Blondine, von gefälliger Bildung und freundlicher Gesinnung, welche viel Freude an der Musik und eine angenehme Stimme hatte", beschriebene Kölnerin Johanna von Honrath (17701823), getauft am 10.8.1770 in St. Aposteln, heiratete im Herbst 1795 den aus Wiener Neustadt gebürtigen Carl von Greth (1754-1827), der in den frühen 1790er-Jahren mit dem kaiserlichen Infanterie-Regiment Nr. 40 nach Köln kam, wo er mit der Familie Honrath bekannt wurde. Er durchlief eine erfolgreiche militärische Karriere; zu Jahresanfang 1823 wurde Feldmarschall-Lieutenant Carl von Greth, Inhaber des Infanterie-Regiments Nr. 23, zum Festungskommandant in Temesvar ernannt, wo seine Frau Johanna am 25.11.1823 an einer Hepatitis gestorben ist. Vgl. KLAUS MARTIN KOPITZ, Beethovens Jugendliebe Johanna von Honrath (1770-1823). Ein Beitrag zu ihrer Biographie, in: Bonner Beethoven-Studien 9, Bonn 2011, S. 155-158.

Maria Anna Wilhelmine von und zu Westerholt-Gysenberg (1774-1852) setzte Wegeler in seinen Biographischen Notizen (wie Anm. 4), S. 43, ebenfalls ein Denkmal: "Darauf [auf Johanna von Honrath] folgte die liebevollste Zuneigung zu einer schönen und artigen Fräulein v. W., von welcher Werther-Liebe Bernhard Romberg mir vor drei Jahren Anecdoten erzählte." Wilhelmine, die am 24.4.1792 den Baron Friedrich Clemens von Elverfeldt genannt Beverförde-Werries heiratete, war das dritte von vier Kindern von Wilhelmine Friederike Franziska Anna Freiin von und zu Westerholt und Gysenberg (1757-1820), reiche Erbtochter des Hauses Westerholt, aus ihrer mit 12 Jahren(!) am 6.10.1769 geschlossenen Ehe mit Ludolf Friedrich Adolf von Boenen zu Berge (1747-1828), unter anderem Mitglied des Geheimen Rats des Erzstifts Köln und Mitglied der Ritterschaft Kurkölns wie des Hochstifts Münster, der mit der Eheschließung Namen, Herrschaft und Besitz seiner jungen Ehefrau übernommen hatte, und am 6.8.1790 in den Reichsgrafenstand erhoben wurde. Die meist auf Schloss Berge residierende Familie, die in Münster mit dem Westerholtschen Hof einen weiteren Wohnsitz besaß, war literarisch interessiert und musikalisch. Der Hausherr blies selbst das Fagott und "hatte aus seinen Bedienten eine Hauskapelle gebildet." Bei den gelegentlichen Aufenthalten der Familie am kurfürstlichen Hof in Bonn kam es zur Bekanntschaft mit Beethoven, der für die Familie ein Trio für Flöte, Fagott und Klavier WoO 37 - das Autograph gehört zum Bestand der Staatsbibliothek zu Berlin - geschrieben und als Klavierlehrer die hübsche und auch am Klavier hoch begabte 
Tochter unterrichtet hat. Vgl. ELMAR WILDT, Die Loge zu Münster, ihr Umfeld und ihre Mitglieder um 1780, in: Westfälische Zeitschrift 143, 1993, S. 71 ff., hier S. 114-116. Die Entstehungszeit des Trios wird wegen Beethovens eigenhändiger Notiz auf dem Autograph um 1785/86 angenommen: "Trio concertant a cl[a]vicembalo, flauto, fagotto composto da Ludovico van Beethoven organista d: S: S: Electeur d[e] cologne." Hinzugefügt hat Beethoven noch seine Altersangabe, wobei ihm mit "age 41" ein kurioser Zahlendreher passierte, weshallb die Angabe, die natürlich „age 14" heißen sollte, wieder durchgestrichen wurde.

Wie sehr Beethoven als junger Mann die nach Wegeler gleichzeitig auch von seinem späteren Schwager Stephan von Breuning angeschmachtete "lebhafte Blondine" mochte, bezeugt auch ein von der Staatsbibliothek Berlin 1942 angekauftes Stammbuchblatt von seiner Hand (vgl. GRITA HERRE, Ein frühes Stammbuchblatt Beethovens, in: Bonner Beethoven-Studien 5, Bonn 2006, S. 115-117), das, entstanden zwischen September 1787 und Oktober 1792, nicht nur eines der frühesten Schriftzeugnisse Beethovens darstellt, sondern mit dem gewählten Zitat - der Vierzeiler endet mit "Und ach! Versteh sein stummes Sehnen." - aus dem Gedicht von Gottfried August Bürger Die beiden Liebenden auch die Hoffnungen von "Ludwig van Beethoven Hofmusikus in Bonn" - so seine Unterschrift - auf Johanna beschreibt, der er sich "zu immer größerer Freundschaft" empfiehlt. Vgl. Kopltz, Johanna von Honrath (wie Anm. 4), S. $155 f$

Von der Hand Beethovens existierte bis zum Brandverlust 1960 im Bestand des Beethoven-Hauses Bonn ein 1927 von der Familie Westerholt ans Beethovenhaus gegebenes, wohl in der zweiten Hälfte der 1780er-Jahre entstandenes kunstvoll zum Briefchen gefaltetes Widmungsblatt Beethovens, von ihm auf der Außenseite eigenhändig adressiert: "a Madame / La Baronesse de Westerholt / Chanoinesse etc. / par son / treshble / Lv. Beethoven" (Vgl. https://katalog.beethoven. de/cgi-bin/biblio/hans_de.pl?t_idn=11, aufgerufen 21.7.2020). Auf der Innenseite des dekorativen Blättchens befand sich ein auf "rosa Seide gedrucktes Gedicht", dessen Textanfang "Rien n'est stable dans cette vie" fast symbolhaft für die unerfüllte Liebe Beethovens steht, so die Berichte von Beethovens aus Münster stammenden Hofmusikerkollegen Romberg von der "Werther-Liebe" stimmen, wobei Beethoven zum Glück nicht dem literarischen Vorbild gefolgt ist und sich nach Einsicht in die Vergeblichkeit seiner Hoffnungen erschossen hat.

8 Dass Beethoven auch nach über 30 Jahren von alten Bonner Freunden nicht an "Jeannette Hohnrath", die er nach dem Zeugnis von Wegeler bei den Breunings in Bonn kennengelernt hat, wo sie laut Wegeler "oft einige Wochen ... zubrachte", erinnert werden musste, zeigt sein entsprechender Eintrag in einem seiner Konversationshefte. Dort schrieb er nämlich eine in den Wiener Tageszeitungen im Februar 1823 veröffentlichte Notiz ab, dass Carl von Greth zum Festungskommandanten von Temesvar ernannt worden sei und vermerkte dazu: "Jeanette Hohenrath". Vgl. KopITz, Beethovens Johanna von Honrath (wie Anm. 5), S. 155.

Vgl. Beethovens Brief an Wegelervom 29.6.[1801], in dem Beethoven auch seine viel zitierte Liebe zum alten "Vaterland und die schöne Gegend, in der [er] das Licht der Welt erblickte" und zum "Vater Rhein" kundtut (wie Anm. 2). Dass Beethoven hierin tatsächlich keinen guten Ruf hatte, ist auch aus einem Brief Amendas an Andreas Streicher vom 15.1.1806 zu entnehmen, in dem Amenda schreibt, dass ihn Streicher vor der Vernachlässigung durch Beethoven gewarnt hätte. Vgl. auch Anm. 51

10 Wegeler dankt er im Brief vom 29.6.1801 (wie Anm. 2), dass er trotzdem "immer der treue gute biedere Freund" geblieben sei, Amenda beschwört er kurz darauf (vor Juli 1801), nicht zu "zweifeln, daß ich seiner je vergessen könnte - weil ich nicht schreibe 
oder geschrieben - als wenn sich das Andenken der Menschen sich nur so gegeneinander erhalten könnte". Vgl. BRANDENBURG, Beethoven Gesamtausgabe (wie Anm. 1), hier Bd. 1, Nr. 66. Im gleichen Brief bittet Beethoven Amenda, ihm immer seine Liebe, seine Freundschaft zu erhalten, da Amenda "gewiß unter den zwei Menschen, die meine ganze Liebe besaßen, und wovon der eine noch lebt", er "der Dritte" sei. All gemein, so auch BrandenburG, Beethoven Gesamtausgabe (wie Anm. 1), hier Bd. 1, Nr. 66 Anm. 2, wird bis in die neueste Literatur (vgl. auch MATTHIAS HENKE, Beethoven - Akkord der Welt, München 2020, S. 78ff.) vermutet, dass es sich bei den zwei namentlich nicht Genannten um Beethovens Bonner Freunde Wegeler und den jüngsten Breuning-Sohn Lorenz (Tauftag 25.9.1777-10.4.1798) handelt, ehemals in Bonn zusammen mit seiner Schwester Eleonore der jüngste Klavierschüler Beethovens, der nach Abschluss seines 1794 in Wien begonnenen Medizinstudiums in Wien 1797 nach Bonn zurückgekehrt war und dort ein halbes Jahr später am 10.4.1798 gestorben ist. Auf die ihm liebsten Freunde kam Beethoven fast im gleichen Wortlaut drei Jahre später in seinem Brief an Ferdinand Ries vom 24.7.1804 zu sprechen, ein Brief, der mit einer Rechtfertigung seiner Freundschaftsaufkündigung zu Stephan von Breuning beginnt sowie einer Entschuldigung seiner unbeherrschten Zornausbrüche - "werde ich aber auch einmal gereizt zu einer Zeit, wo ich empfänglicher für den Zorn bin, so platze ich stärker aus, als jeder Andere." -, um danach das Hohelied der wahren Freundschaft zu singen: "Ich habe nur zwei Freunde auf der Welt gefunden, mit denen ich auch nie in ein Mißverhältniß gekommen, aber welche Menschen! Der eine ist todt, der andere lebt noch. Obschon wir fast sechs Jahre hindurch keiner von dem andern etwas wissen, so weiß ich doch, daß in seinem Herzen ich die erste Stelle, wo wie er in dem meinigen einnimmt." Vgl. Brandenburg, Beethoven Gesamtausgabe (wie Anm. 1), hier Bd. 1, Nr. 185. Dass es sich bei dem toten Freund um Lorenz von Breuning handelt, wird allgemein angenommen, ob mit dem lebenden aber Amenda, wie BRANDENBURG, Beethoven Gesamtausgabe (wie Anm. 1), hier Bd. 1, Nr. 186 Anm. 5, annimmt, und nicht doch eher der Bonner Freund Wegeler gemeint ist, muss offenbleiben, denn der briefliche Kontakt war zu beiden nach 1801 lange unterbrochen.

Vgl. MaX BraubaCH, Die Stammbücher Beethovens und der Babette Koch, Bonn 1970, S. XIff. Nach Braubach kann das wechselhafte Schicksal der Widmungsblätter nach Beethovens Tod durchaus auch zum Verlust einiger Blätter geführt haben, weshalb es mehr Einträge als nur die von den 14 uns heute bekannten Personen gegeben haben könnte.

Vgl. Hans Gerstinger, Ludwig van Beethovens Stammbuch. Nach dem Original im Besitze der Nationalbibliothek zu Wien und mit Genehmigung der Generaldirektion herausgegeben, Bielefeld/Leipzig 1927, S. $5 f f$.

Am 7.12.1826 schrieb Beethoven an Wegeler: "Von deiner Lorchen habe ich noch die Silhouette, woraus zu ersehen, wie mir alles Gute und Liebe aus meiner Jugend noch theuer ist." Vgl. zum Brief, der sich immer noch im Wegelerschen Familienbesitz resp. der Julius-Wegelerschen-Familienstiftung befindet GRIGAT, Sammlung Wegeler (wie Anm. 2), D16. Selbstverständlich ist dieser Brief auch - unter dem falschen Datum 7.10.1826 - abgedruckt in WEgELER/RIES, Biographische Notizen (wie Anm. 4), S. 49ff. Die vermutlich von Joseph Neesen, Bonn, 1782 angefertigte Silhouette wurde vom Beethoven-Haus Bonn erst 2015 käuflich erworben. Die beim Ankauf recherchierte Provenienz des hübschen Bildchens, die als Erstverkäufer Karl van Beethoven nachweist, belegt eindeutig Karls Onkel und Erblasser Ludwig van Beethoven als langjährigen Besitzer des Miniaturporträts. 
Wegelers Zeugnis, dass er schon 1782 „mit dem 12jährigen Jüngling ... bekannt” wurde und mit ihm abgesehen von seinem Wienaufenthalt vom September 1787 bis zum Oktober 1789 zum Abschluss seines Medizinstudiums bis Beethovens Abreise nach Wien Anfang November 1792 in Bonn "in der innigsten Verbindung" gelebt habe (so WEGELER/RIES, Biographische Notizen [wie Anm. 4], S. XIf.), wurde hinsichtlich des frühen Datums 1782 gelegentlich angezweifelt. Vgl. WIEBKE RoLofF, Wegeler, Franz Gerhard, in: Heinz von Loesch und Claus RaAB (Hgg.), Das Beethoven-Lexikon, Laber 2008, S. 836f, hier S. 836.

16 Anna Maria Koch, seit 1783 verwitwet, führte das Haus Zum Zehrgarten an der Westseite des Bonner Markts mit "Weinhantierung" bis zum Verkauf des Hauses 1802 als "Gasthalterin, Kostgeberin, Zimmervermieterin" unter Einschluss eines Porzellanhandels und einer Buchhandlung als Witwe weiter, wobei sie die bei ihr vorrätige Literatur regelmäßig seit 1786 im Bönnischen Intelligenzblatt annoncierte.

17 Vgl. Braubach, Stammbücher (wie Anm. 11), S. 147

18 Vgl. Max Braubach, Von den Menschen und dem Leben in Bonn zur Zeit des jungen Beethoven und der Babette Koch-Belderbusch, in: Bonner Geschichtsblätter 23, Bonn 1969, S. 51-121, hier S. 107. Hinsichtlich der nicht eindeutigen Zahl der Gründungsmitglieder vgl. den Beitrag von ALEXANDER WOLFSHOHL, Nichts weniger als Alteisen, in diesem Band.

19 In mehreren Briefen, von denen aufgrund der Kriegswirren im Rheinland wohl nur der letzte seine Adressaten erreichte, schilderte Fischenich seinen engen Jenaer Freunden Charlotte und Friedrich Schiller die Umstände seiner Antrittsvorlesung und den Genuss an der Lehre, wie wir aus dem Antwortbrief von Friedrich von Schiller vom 11.2.1793 wissen, in dem sich sein ihn "ewig liebender Freund" Schiller trotzdem besorgt äußert: "Der Krieg in Ihrer Nachbarschaft macht mir bange für Ihre Ruhe und noch mehr für Ihre Gesundheit." Zitiert nach: https://web.archive.org/web/20160304192401/http:// www.wissen-im-netz.info/literatur/schiller/briefe/1793/179302111.htm; aufgerufen am 21.7.2020

Ohne Beethovens Namen zu nennen legte Fischenich am 26.1.1793 einem Brief an Charlotte von Schiller mit der Bitte um ihr Urteil "eine Composition der Feuerfarbe bei" (nach dem erst im August 1792 erschienen Gedicht von Sophie Mereau), die von "einem hiesigen jungen Mann" stamme, "dessen musikalische Talente allgemein angerühmt werden, und den nun der Kurfürst nach Wien zu Haidn geschickt hat. Er wird auch Schillers Freude und zwar jede Strophe bearbeiten. Ich erwarte etwas vollkommenes, denn so viel ich ihn kenne, ist er ganz für das Große und Erhabene." Vgl., auch zur Replik Charlottes von Schiller vom 11.2.1793, dass ihr die Komposition gefalle und sie sich freue, wenn der Künstler auch die Freude komponierte, KLAUS MARTIN KOPITZ und Rainer Cadenbach unter Mitarbeit von Oliver Korbe und Nancy Tanneberger (Hgg.), Beethoven aus der Sicht seiner Zeitgenossen in Tagebüchern, Briefen, Gedichten und Erinnerungen, München 2009, Bd. 1, S. $272 f$.

Brief vom 23.6.1817, zitiert nach BRAUBACH, Von den Menschen (wie Anm. 18), S. 82.

Ihren Vornamen fand Barbara Koch seit jeher "so häßlich", dass sie 1805, schon längst Gräfin Belderbusch, eine Freundin darum bat, ihrem erwarteten Patenkind, so es ein Mädchen würde, auf keinen Fall den Namen Barbara zu geben, vgl. Brief vom 6.8.1805, abgedruckt bei BRAUBACH, Von den Menschen (wie Anm. 18), S. 60f. Braubach, ebd., S. 63, vermutet deshalb, "daß die Form Babette wohl als eine Art Verschönerung später von ihr oder ihren Freunden gewählt worden ist", während „im Familienkreise noch lang das deutsche Wort und zwar in der verniedlichenden Koseform" verwendet wurde, und der im Hause lebende vertraute Freund der Familie Koch und Gründungsmitglied der Bonner Lesegesellschaft, der Arzt Johann Heinrich Crevelt (1751-1818) 
von ihr noch 1802 in seiner Korrespondenz mit seinem Freund Freiherr Franz Wilhelm von Spiegel (1752-1815), dem letzten kurkölnischen Minister, liebevoll als "Bärbchen” sprach.

WEGELER/RIES, Biographische Notizen (wie oben Anm. 4 ), S. 58f. Nach den umfassenden Recherchen Braubachs, wobei er weniger die relativ kurze Zeit, die Beethoven als Tischgenosse im Zehrgarten verbrachte, sondern vor allem das Umfeld von Babette Koch und Ihrer Familie über viele Jahre im Blick hatte, gibt es für einige der von Wegeler genannten Personen kein anderes Zeugnis als das seinige, dass sie - wie die Hofmusiker Romberg und Reicha - zum Kreis der Zehrgartengesellschaft gehört haben, wohingegen Wegeler andere, deren Zugehörigkeit andernorts eindeutig belegt ist, nicht erwähnt. Vgl. BraUBACH, Von den Menschen (wie Anm. 18), S. $82 f$

Aus einem Brief von Johann Heinrich Crevelt vom 23.11.1790 geht hervor, dass Kurfürst Maximilian Franz den Hofkammerrat Vogel angewiesen hat, für die Schwestern Koch, Babette und Marianne, zwei Billets für einen Ball zu reservieren, mit der Begründung, dass die zwei jungen Mädchen, damals 19 bzw. 18 Jahre alt, „wirklich die wohlerzogensten aus dem Bürgerstande in Bonn" wären. Vgl. BraubaCH, Von den Menschen (wie Anm. 18), S. 63f., sowie Anm. 34

Vgl. Braubach, Stammbücher (wie Anm. 11), S. 7

Zu allen aufgeführten Personen vgl. die alphabetisch sortierten Kurzviten bei BRAUBACH, Stammbücher (wie Anm. 11), S. 134 ff.

Zitiert nach MAX BRAUBACH, Beethovens Abschied von Bonn, Vorträge G 166, Geisteswissenschaften, Rheinisch-Westfälische Akademie der Wissenschaften, Köln/Opladen 1970, S. $7 f$.

Braubach, Stammbücher (wie Anm. 11), S. 144

Zitiert nach ebd., S. 143

Ebd., S. 149

Vgl. Grigat, Sammlung Wegeler (wie Anm. 2), Nr. E2.

Vgl. ebd., Nr. E7.

Zitiert nach BRAUBACH, Stammbücher (wie Anm. 11), S. 141

Vgl. Braubach, Von den Menschen (wie Anm. 18), S. 55 Anm. 15.

Zu den ausführlichen Recherchen und Erkenntnissen über den zuvor nicht identifizierten Richter, dessen Geburtsort, Geburts- und Sterbejahr auch für Braubach nicht zu erhellen waren, dafür anderes umso mehr, vgl. ebd., S. 54ff.

CARL August Malchus, Selbstbiographie, in: Zeitgenossen. Ein biographisches Magazin für die Geschichte unserer Zeit, Erster Band, Dritte Abteilung, Leipzig 1828, S. 161-176, hier S. 163

Vgl. Braubach, Stammbücher (wie Anm. 11), S. 5 bzw. S. 153-155.

Vgl. die Kurzbiographie von PETER KLIMm, Karl August Malchus. Ein Diener vieler Herren, in: DeRs., Grenzgänger. Pfälzisch-französische Lebensläufe, Mannheim 2011, S. 101-113.

Brief an Eleonore von Breuning, 2.11.1793, vgl. BRANDENBURG, Beethoven Gesamtausgabe (wie Anm. 1), hier Bd. 1, Nr. 11

Über die Konzerte Beethovens 1796 in Prag berichtete der mit Beethoven in Wien verkehrende und vielseitig gebildete k.k. Hofsekretär Johann Daniel Ribini (1760-1820) der an der Karriere Beethovens sehr interessierten Mozartschülerin Anna von Paszthory: "Beethoven spielt mit viel Beyfall in Prag, hat auch in den Herzen einiger dortigen Damen süsse Accorde getroffen, und denkt mit seiner Kunst u. seinem Rufe 
nach Berlin zu ziehen." Vgl. Anna SCHIRLBAUER, "Vor 3 oder 4 Tagen begegnete mir Beethoven..." Beethoven, Keglevich, Zmeskall, "Adelaide” und Pressburg 1796 in unbekannten Briefen von Johann Daniel Ribini, Wien 2019, S. 10. Abgerufen als pdf von der Seite der Autorin: https://www.anna-schirlbauer.com/aktuell/, 21.7.2020

Brief Beethovens vom 29.6.[1801] an Wegeler (wie Anm. 2)

Vgl. BraubaCH, Stammbücher (wie Anm. 11), S. 23. Der Eintrag lautet: "Bestimmung des Menschen./ Wahrheit erkennen, Schönheit lieben, Gutes wollen, das Beste thun./ Bonn den 30ten October 1792./ Denk, auch ferne, zuweilen Deines/ wahren aufrichtigen Freundes/Heinr. Struve aus Regensbrg./ in Russisch Kaiserl. Diensten // Nach der Blüthe der Jugend erndte im reifern Alter die Früchte der Weisheit ein."

Zum genauen Heiratsdatum vgl. Regensburgisches Diarium, Oder: Wöchentliche Frag $=$ und Anzeige=Nachrichten, unter: Hiesige Begebenheiten. "In der Evangelischen Gemeinde Getrauet: Den 14. Febr. [1782] Tit. Herr Johann Ludwig Dörfeld, Sekretair bey der Königl. Großbrittanischen Gesandtschaft am Churfürstl. Köllnischen Hofe, mit Tit. Frau Susanna Maria Kaufmännin, verwittibten Frau Legationssekretairin...

Vgl. hierzu JuLIA RONGE, „wann wird auch der Zeitpunkt kommen wo es nur Menschen geben wird". Ein unbekannter Brief Beethovens an Heinrich von Struve. Faksimile und Kommentar (Jahresgabe des Beethoven-Hauses Bonn 2018), Bonn 2018

Vgl. BraubaCH, Stammbücher (wie Anm. 11), S. 25, wo Eleonore, unterschrieben mit "Ihre wahre Freundinn Eleonore Breuning" ein dreizeiliges Zitat aus dem 4. Teil der gerade aktuell, 1792, erschienenen Zerstreute(n) Blätter(n) von Herder einfügte: „... Freundschaft mit dem Guten/wachset wie der Abendschatten,/bis des Lebens Sonne sinkt."

Brief von Beethoven an die möglicherweise gerade bei ihrem Onkel in Kerpen weilende Eleonore von Breuning [Bonn, Sommer 1792], vgl. BRANDENBURG, Beethoven Gesamtausgabe (wie Anm. 1), hier Bd. 1, Nr. 4

Brief vom 2.11.1793, vgl. ebd., Nr. 11

Vgl. Braubach, Die Stammbuchblätter (wie Anm. 11), S. 27 bzw. S. $134 f$.

Vgl. Brandenburg, Beethoven Gesamtausgabe (wie Anm. 1), hier Bd. 1, Nr. 65

Vgl. HENKE, Beethoven (wie Anm. 10), S. 76

In einem Brief vom 1.7.[1801] formulierte der vorher seine zunehmende Schwerhörigkeit schildernde Beethoven seinen "Anspruch" auf Amenda, der im Falle der Unheilbarkeit des Gehörleidens "alles Verlassen" und zu ihm kommen müsse, um sein Begleiter bei Konzertreisen zu sein, „seine sorgen sein übel tragen" helfe und "hernach ewig" bei ihm bleiben solle. Vgl. BRANDENBURG, Beethoven Gesamtausgabe (wie Anm. 1), hier Bd. 1, Nr. 67. HENKE, Beethoven (wie Anm. 10), S. 75f., jedenfalls äußert die Vermutung, dass die nach diesem Brief für viele Jahre weitgehend versiegende Korrespondenz ihre Ursache in Amendas Zurückschrecken vor diesem Ansinnen gehabt haben könnte. Andererseits zeugen nachfolgende Briefe von Amenda an Andreas Streicher nicht nur von der anhaltenden "zärtlichen Freundschaft" Amendas zu Beethoven, sondern auch von mindestens einem Versuch (1804), Beethoven über Streicher einen nicht überlieferten Brief zukommen zu lassen. In einem Schreiben vom 15.1.1806 an Andreas Streicher betonte Amenda, dass er Beethoven sein "ganzes Leben (hätte) widmen mögen" und er "sehr unglücklich [wäre] auch gar nichts von ihm zu hören". Amenda kannte zu diesem Zeitpunkt keine Adresse von Beethoven und bat Streicher dringend darum, mit der Entschuldigung, ihn mit Beethoven so zu belagern: "Verzeihen Sie, dass ich Ihnen wegen meiner Liebe zu Beethoven so oft beschwerlich falle, wie soll ichs aber machen? Sie haben mirs zwar schon vorhergesagt, daß er mich vernachlässigen würde. - Ja, er thuts, es schmerzt mich - und dennoch werde ich 
mein Lebelang nicht aufhören ihn zu lieben." Vgl. zu den Briefen vom 5.8.1804 bzw. 15.1.1806 Kopitz/CADENBACH, Beethoven (wie Anm. 20), S. 6ff.

Nach Wegelers Selbstzeugnis musste er "im Oktober 1794 [nach Wien] auswandern”, nachdem er, damals Rektor der kurfürstlichen Universität in Bonn, im Moniteur als "ein wütender Feind der Republik geächtet wurde", und er deshalb um seinen Kopf fürchtete. Vgl. Wegeler/RIES, Biographische Notizen (wie Anm. 4), Vorrede, S. XII.

Die Abreise seines Bruders und Wegelers in der Nacht vom 30. auf den 31. Mai 1796 bekümmerte insbesondere Lorenz von Breuning, der seit Herbst 1794 in Wien Medizin studierte, unter anderem beim Chirurgen Johann Nepomuk Hunczovky (17521798), eines ehemaligen Wiener Lehrers von Wegeler und diesem seitdem in enger Freundschaft verbunden, in die nun auch der junge "Lenz" genannte Lorenz einbezogen war. Ohnehin in trauriger Stimmung über den ihm von seiner Schwester Eleonore mitgeteilten Tod des den Breuning-Kindern nach dem frühen Tod ihres Vaters nahestehenden Onkels Johann Lorenz von Breuning (1738-1796) habe er, wie er seiner Schwester am 31.5.1796 schrieb, sich zuvor "halb berauscht", um den Abschied auszuhalten, wobei er vor allem um Wegeler trauerte, seinen einzigen Freund, den er nie mehr wiederzusehen fürchtete: "Mit ihm geht die Hälfte meiner Empfindung, meiner Gefühle und meiner guten Einfälle verloren: denn er hat den Schlüssel dazu." Zum Brief vgl. GRIGAT, Sammlung Wegeler (wie Anm. 2), Nr. E3.

In der Freundschaft zwischen ihm und Wegeler sah Beethoven "kleine Mißhelligkeiten", die er durchaus eingesteht, eher die Freundschaft fördernd als ihr - wie sonst häufig - abträglich: "(und haben nicht eben diese unsere Freundschaft mehr befestigt?)", vgl. Brief vom 29.6.[1801] (wie Anm. 2).

Wien, 13.10.1804, vgl. Grigat, Sammlung Wegeler (wie Anm. 2), Nr. E9.

Baden, 24. 7.1804, vgl. Brandendurg, Beethoven Gesamtausgabe (wie Anm. 1), hier Bd. 1, Nr. 185

Wien, Anfang November 1804, vgl. ebd., Nr. 197. Bei dem Porträt Beethovens handelt es sich um die Miniatur auf Elfenbein von Christian Horneman, die sich heute in der Sammlung des Beethoven-Hauses in Bonn befindet; vgl. die Abb. S. 315

2. 11.1793, vgl. Brandendurg, Beethoven Gesamtausgabe (wie Anm. 1), hier Bd. 1, Nr.11.

Vgl. HENKE, Beethoven (wie Anm. 10), S. 81

Die beiden Widmungsblätter, heute im Bestand des Beethoven-Hauses Bonn, rühmen (Bernhard Romberg) die Freundschaft mit einem Klopstock-Zitat, das die Schönheit der Natur besingt, die aber von der Gewissheit um eine Freundschaft noch übertroffen werde bzw. (Andreas Romberg) verweisen, dass jemand, der "im Sturm der Leiden einen Freund findet, ... nicht ganz vom Schicksal verlassen (ist)." Unterschrieben sind die Widmungsblätter mit "Dein wahrer Freund Brenhard[!] Romberg" bzw. "Dein Dich aufrichtig liebender Freund Andreas Romberg" Vgl. GRIGAT, Sammlung Wegeler (wie Anm. 2), Nr. A16 und A17.

Vgl. ebd., Nr. E5

Vgl. ebd., Nr. E7. HenkE, Beethoven (wie Anm. 10), S. 78, stellt sich dazu die Frage, ob das etwa "doppeltes Spiel" von Lorenz von Breuning gewesen wäre, aber dann müsste man ja davon ausgehen, dass der junge Breuning bei Beethoven einen anderen Eindruck erwecken wollte, wovon - denkt man an seine Vermittlerrolle - nicht auszugehen ist. 


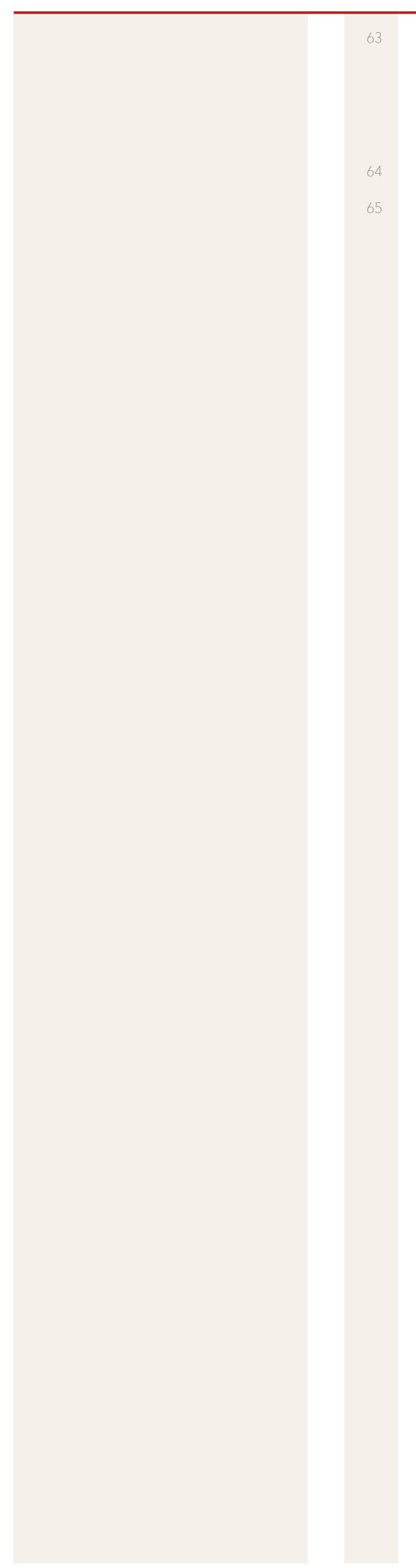

Ludwig van Beethoven, Stammbuchblatt für Lorenz von Breuning, Wien, 1. Oktober 1797, in: Michael LADENBURger (Hg.), Beethoven und sein Bonner Freundeskreis. Ausgewählte Dokumente aus der Sammlung Wegeler im Beethoven-Haus, Bonn 1998, S. 27.

Vgl. Anm. 10

Brief vom 1.7.[1801 ], vgl. BRANDENBURG, Beethoven Gesamtausgabe (wie Anm. 1), hier Bd.1, Nr. 67. 


\section{„Wir Bönner sind doch ganze Kerls!“- \\ Beethoven und die Bonner Musikerfamilie Ries}

$\mathbf{N}$ eben den Beethovens gab es in Bonn eine weitere alteingesessene Familie, deren Mitglieder Einfluss auf die Entwicklung und Gestaltung des Musiklebens in der Stadt und darüber hinaus genommen haben, zuerst am kurfürstlichen Hof, danach während der rund 20 Jahre dauernden Zugehörigkeit zu Frankreich und der sich daran anschließenden Jahre der Integration der Rheinlande in den preußischen Staat. Es handelt sich um die Familie Ries, deren berühmtestes Mitglied der Komponist und Klaviervirtuose Ferdinand Ries (1784-1838) war.

Die Mitglieder der Familien Beethoven und Ries gingen altersmäßig im Gleichschritt, jedoch jeweils um ca. 15 Jahre versetzt. Wie bei den Beethovens war es der Großvater Johann Ries, eine halbe Generation jünger als Ludwig van Beethoven der Ältere (1712-1773), der 1747 mit 24 Jahren den Weg von Bensheim an der Weinstraße an den Hof des prachtliebenden Kurfürsten Clemens August (1723-1761) fand.

\section{Von Bensheim an den kurfürstlichen Hof nach Bonn}

Nachdem er im Mai 1747 mit einem Gehalt von 192 Reichstalern als Hoftrompeter angestellt worden war, heiratete er im Jahr darauf die sechs Jahre ältere Johanna Elisabeth Beyer. Aus der Ehe gingen vier Kinder hervor, Anna Maria (*1751), Bernard (*1752, er starb früh), Adelheid (*1753) und Franz Anton (*1755). Im März 1754 wurde Johann Ries offiziell als Hofmusikus bei den Violinisten angestellt, und als solcher taucht sein Name bis in das Jahr 1787 in den Hofkalendern auf. Jahrelang fungierte er als erster Geiger der Hofkapelle. ${ }^{1}$ Betrieb Ludwig van Beethoven sen., der seit 1762 Maitre de la Chapelle und damit nicht nur Kollege, sondern jetzt auch Vorgesetzter von Johann Ries war, neben dem vielfältigen und umfassenden Dienst in der Hofkapelle noch einen Weinhandel, so ist von Johann Ries eine Nebenbeschäftigung nicht bekannt. Seit Mitte der 1750er Jahre trat er auch als Komponist kirchlicher Werke hervor ${ }^{2}$, von denen sich einige erhalten haben. Seine wichtigste Komposition ist eine Missa Sancti Huberti für Soli, Chor, zwei Hörner, zwei Trompeten, Streicher und Generalbass, die er 1756 für seinen jagdliebenden Dienstherrn Clemens August komponiert hat. ${ }^{3}$ Nach dessen Tod 1761 sollen Johann Ries Werke vom Kapellmeister Beethoven vor der
Barbara

Mülhens-Molderings

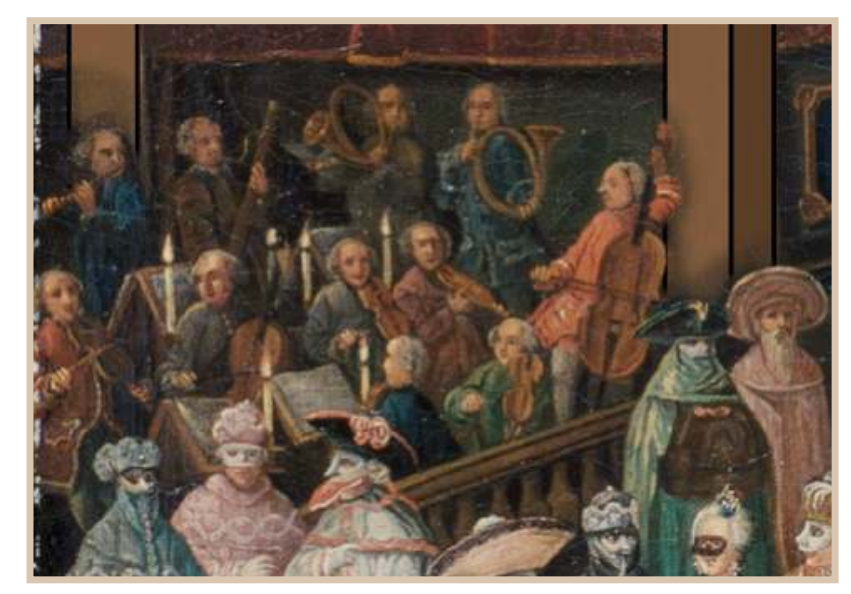

„Wir Bönner sind doch ganze Kerls!“ - Beethoven und die Bonner Musikerfamilie Ries | 301

Musikerempore mit Geigern, darunter möglicherweise Johann Ries (1723-1787). Detail aus: Franz Rousseau, Bönnsches Ballstück, 1754 (Stadtmuseum Bonn) 
Versteigerung des kurfürstlichen Nachlasses gerettet worden sein. ${ }^{4}$ Sie befinden sich heute in der Biblioteca Estense zu Modena. Dass Johann Ries auch über die Grenzen Bonns hinaus ein gewisses Ansehen genoss, beweist ein Eintrag in dem 1792 erschienenen Lexicon der Tonkünstler von Ernst Ludwig Gerber. Es heißt dort: „Ries (Johann), Kammermusikus und Violinist zu Bonn; ums Jahr 1780, hat durch mehrere Kompositionen seine guten Einsichten in die musikalische Setzkunst verrathen. Schade, daß diesen würdigen Mann geheimer Gram und übertriebenes Studieren in der Komposition im Jahre 1782 in das Hospital nach Cölln gebracht hat, wegen einer Kopfkrankheit." ${ }^{\prime 5}$

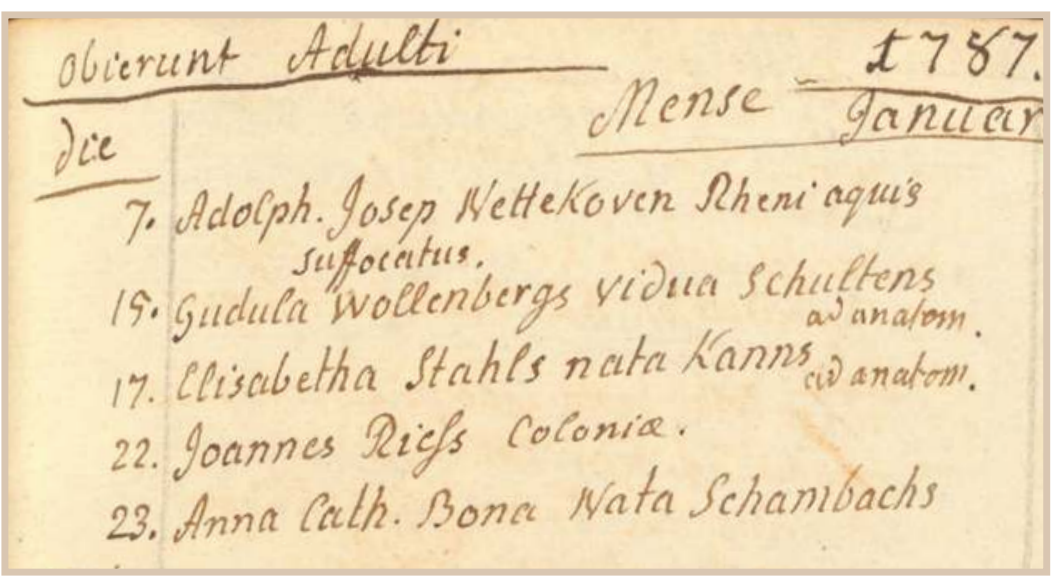

Welcher Natur diese "Kopfkrankeit" war, ist bislang nicht bekannt. Dem vielzitierten Unterthänigsten Pro-Memoria die Kurfürstliche Hof Musique betrefend ${ }^{6}$ von 1784 zufolge erhielt Johann Ries seinerzeit ein Gnadengehalt von 150 Reichstalern und war auf Befehl des Kurfürsten bei den Kölnern Alexianern, einer katholischen Ordensgemeinschaft für Laienbrüder, die in der Krankenpflege tätig war, untergebracht worden. Er starb am 22. Januar 1787 mit 63 Jahren in Köln. ${ }^{7}$

Im Dezember 1773, als Beethovens
Sterbeeintrag Johann Ries im Kirchenbuch von St. Remigius (Stadtarchiv Bonn)
Großvater starb, lebte die Ries-Familie den Angaben von Franz Anton Ries zufolge in der Bonngasse, vis-à-vis des "Beethoven-Hauses", des Geburtshauses des großen Komponisten. ${ }^{8}$ Die Bonngasse würde man heute als bessere Wohngegend bezeichnen. In dieser Straße lagen im ersten Abschnitt vom Markt kommend die Jesuitenkirche und das Gymnasium, das vom Kurfürst Maximilian Friedrich von Königsegg-Rothenfels 1777 in die Maxische Akademie, 1786 von seinem Nachfolger Kurfürst Max Franz in eine Universität umgewandelt worden war. Der Abschnitt der Bonngasse, in der die Beethovens und die Ries wohnten, begann mit der Nr. 345 1/2, dem stattlichen Gudenauer Hof. Großvater Beethoven, Familie Ries und der Hofbäcker Anckenbrand wohnten in einem Komplex von drei gleichen Häusern mit den Nummern 346 bis 348. Die Vermieterin der Ries-Familie war "Wittib Fuchs im Hinter-H(aus) wohnend". Vermutlich wohnte Familie Ries im Vorderhaus mit direktem Zugang und Sicht auf die Bonngasse. War man in der Hofkapelle schon auf Grund der gegenseitigen Patenschaften generell über die Familienverhältnisse der Kollegen informiert, so wird Familie Ries ohne Zweifel davon unterrichtet gewesen sein, dass im Dezember 1770 gegenüber bei Beethovens ein kleiner Junge namens Ludwig geboren worden war. Zum Riesschen Haushalt gehörten damals die beiden Töchter Anna Maria und Adelheid sowie der jüngere Bruder Franz

302 | Barbara Mülhens-Molderings

(c) 2020 by Böhlau Verlag GmbH \& Cie. KG, Köln

https://doi.org/10.7788/9783412519704 | CC BY-NC 4.0 
Anton, die wie der Vater alle drei mittelbar oder unmittelbar mit der Bonner Hofmusik zu tun hatten.

Anna Maria Ries war seit ihrem 11. Lebensjahr in der Hofkapelle als Sängerin tätig. ${ }^{10}$ Am 26. Juli 1774 heiratete sie den Violinisten Ferdinand Drewer, einen gebürtigen Bonner und Mitglied der Hofkapelle seit 1756. ${ }^{11}$ Anna Maria Ries, 19 Jahre älter als der junge Beethoven, wurde 1784 bei der Abfassung des bereits zitierten Pro-Memoria vom Intendanten als die beste Sopranistin bei Hofe bezeichnet. ${ }^{12}$ Mit 400 Florin erhielt sie von allen Sängerinnen die höchste Besoldung; unter den Sängern kam ihr nur Ferdinand Heller gleich, während Beethovens Vater Johann lediglich 300 Florin verdiente. ${ }^{13}$ In der Familie Ries wird tradiert, dass sie unter "Mozarts Leitung die Constanze in der Oper Belmont und Constanze gesungen"14 habe. Diese Oper war in Bonn so beliebt, dass sie von der Wiedereröffnung des Bonner Hoftheaters 1789 bis zu seiner Schließung 1794 fünf Mal aufgeführt worden ist. ${ }^{15}$ Ludwig van Beethoven muss also ihr und ihrem Mann in seiner Bonner Zeit bei allen musikalischen Aufführungen am kurfürstlichen Hof, in der Kirche und im Theater begegnet sein, hat er doch die Jahre 1789 bis 1792 als Bratschist und Orchestermitglied in Bonn gewirkt. ${ }^{16}$

Wie neueste Forschungen ergeben haben, ${ }^{17}$ richteten Hoforchester, Sänger und Schauspieler in den fünf Bonner Spielzeiten von 1789 bis 1793 mehr als 40 Neuproduktionen von Opern ein. Eine erstaunliche Leistung, wenn man bedenkt, dass dies neben den umfassenden Aufgaben des normalen Orchesterdienstes zu erledigen war. Der junge Beethoven war, zumindest zwischen 1789 und Ende 1792, Teil dieser außerordentlich vielfältigen und umfangreichen musikalischen Obliegenheiten.

Anna Maria Ries und Ferdinand Drewer erhielten im Mai 1775 vom Hof die "Erlaubnis auff vier Monate" zu verreisen, und zwar ab Juni bei Vorauszahlung ihres laufenden Gehaltes. ${ }^{18}$ Aus den Akten geht nicht hervor, wohin die musikalische Studienreise gehen sollte. Mit großer Wahrscheinlichkeit war das Ziel aber Wien, die damalige "Hauptstadt" der Musik, in die wenige Jahre später auch Franz Anton Ries, Anna Marias jüngerer Bruder, übersiedeln sollte. 1784 taucht der Name Ferdinand Drewer ein weiteres Mal auf: Beim Amtsantritt des neuen Kurfürsten Max Franz in Bonn wurden Überlegungen zur Kostensenkung beim Orchester angestellt. Ein Vorschlag lautete, sich vom Leiter der Hofkapelle, Cajetan Mattioli, zu trennen und die Leitung der Hofmusik Ferdinand Drewer zu übertragen. ${ }^{19}$ Tatsächlich sollte Mattioli kurze Zeit später Bonn verlassen, doch scheint Ferdinand Drewer die Position des Leiters der Hofkapelle nur vorübergehend ausgeübt zu haben, denn schon im Jahr darauf kam der böhmische Cellist und Komponist Joseph Reicha nach Bonn und wurde zuerst zum Konzertmeister und wenig später auch zum Konzertdirektor ernannt. ${ }^{20}$ Zur selben Zeit erteilte Anna Maria Ries-Drewers jüngerer Bruder Franz Anton, der als der "beste Violinist (vor Solo)"21 der Hofkapelle galt, dem jungen Ludwig van Beethoven Unterricht im Geigenspiel. 


\section{Franz Anton Ries - „Beethovens erster Beschützer" 22}

Franz Anton Ries galt schon früh als Wunderkind auf der Violine. Den ersten Unterricht erhielt er von seinem Vater, den er bereits mit elf Jahren beim Dienst in der Hofkapelle gelegentlich vertrat. Später wurde er von dem berühmten Geiger Johann Peter Salomon (1745-1815) unterrichtet, der selbst dem kurfürstlichen Hoforchester schon mit 13 Jahren beigetreten war und mit Johann Ries am gleichen Pult saß. ${ }^{23}$ Seit 1774 hatte Franz Anton eine feste Anstellung in der Hofkapelle. Um sich auf den höchsten Stand der Musikausübung zu bringen, reichte er nach dem Vorbild seiner Schwester und seines Schwagers drei Jahre zuvor ein Gesuch auf Beurlaubung ein, um nach Wien zu reisen und dort seine musikalischen Fähigkeiten zu vervollkommnen. Dem Gesuch wurde am 13. April 1778 mit der Maßgabe stattgegeben, dass er auf eigene Kosten nach Wien reise, zugleich aber sein Gehalt für sechs Monate vorausgezahlt bekomme. Da sein Abreisedatum nicht belegt ist, ist unklar, wie lange er sich in Wien aufgehalten hat. Dort spielte er sehr erfolgreich in der Kapelle des Grafen Palffy. Bei der Rückreise nahm auch er die damals übliche Reiseroute über Regensburg nach Bonn. So ist für den 11. Februar 1780 nachgewiesen: „per ord. Postwagen nach Nürnberg, um 1/2 9 Uhr, Vormittags, ... Hr. Ries, Musicus von Wien". 24

Gleich nach seiner Rückkehr aus Wien reichte Franz Anton Ries am Bonner Hofe ein Gesuch auf Erhöhung des bisherigen Gehaltes auf 500 Gulden ein, mit der selbstbewussten Bemerkung, dies sei „nicht die Hälfte dessen, was er anderswo verdienen" könne. ${ }^{25}$ Alexander Wheelock Thayer hat im Zusammenhang mit der schriftlichen Gewährung dieser Gehaltserhöhung auf ein interessantes Detail hingewiesen. Es fand sich bei diesem Dokument nämlich ein Papierstreifen, auf dem die kurfürstliche Verwaltung das Einkommen der gesamten Familie Ries addiert hatte, das heißt den jeweiligen Verdienst von Johann Ries, der Tochter Anna Maria, ihres Ehemanns Ferdinand Drewer sowie des Sohnes Franz Anton Ries. ${ }^{26}$ Die Summe belief sich im Jahr 1780 auf knapp 650 Reichstaler. Interessant ist in diesem Zusammenhang weniger die Höhe des Familieneinkommens, sondern die Tatsache, dass die Rechnung für die Gesamtheit der Familie aufgestellt wurde. Diese wurde am Hofe offenbar als Einheit angesehen. Möglicherweise lebte die gesamte Familie 1780 - mit Ausnahme der seit 1777 verheirateten Tochter Adelheid - noch zusammen in einem einzigen Haushalt, eben im Haus Bonngasse 347.

Melanie Unseld hat unlängst das Phänomen der "Musikerfamilie" um 1800 am Beispiel der böhmischen Familie Dussek detailliert untersucht. Als Musterbeispiel einer solch weitverzweigten Musikerfamilie, deren „Mitglieder sich nicht nur vereinzelt mit Musik beschäftigten, ... sondern die (zum Teil über Generationen hinweg) in Musikberufen tätig waren", kann auch die Bonner Familie Ries gelten. 
„Das Erwerbsfeld solcher Familien war dabei die Musik in der Vielfalt der mit ihr notwendigerweise verbundenen, arbeitsteiligen Handlungsbereiche: Noten kopieren, drucken, verlegen, vertreiben, Instrumental- und Gesangsausbildung, Musik einstudieren und üben, Instrumentenbau, solistisches Auftreten und Ensemblespiel, Ensembleleitung, Komposition, Arrangement, Bearbeitung u.v.m. ... Da die Familie als ökonomische Einheit betrachtet wurde, zeichnete jedes einzelne Mitglied der Familie für die ökonomische Stabilität mitverantwortlich. Daher war nicht individueller Erfolg (etwa als Instrumentalistln oder Sängerln) oberstes Ziel, sondern Erfolg im Sinne ökonomischer Sicherheit für die ganze Familie. Der Hausvater und dessen Ehefrau standen dem Haus vor und lenkten entsprechend auch die berufliche Profilierung der Familie insgesamt und der einzelnen Mitglieder. Instrumentenwahl etwa war damit nicht primär individueller Begabung oder gar Vorliebe, sondern strategischer Entscheidung innerhalb einer gesamtfamiliären Struktur sowie - etwa bei Hofmusiker-Familien - der Struktur der Hofkapelle geschuldet."27

Unseld wies in diesem Zusammenhang auch auf das schon erwähnte ProMemoria hin, in dem die Familienverhältnisse der Bonner Hofmusiker eingehend dargestellt werden. Im Eintrag zur Familie Ries wird neben dem - erkrankten - Johann Ries auch seine Frau, ihr Geburtsort (Hadamar) und ihr Alter vermerkt, es wird auf die älteste Tochter Anna Maria Ries, deren Mann Ferdinand Drewer und den Sohn Franz Anton, die als Mitglieder der Hofkapelle jeweils auch einen eigenen Eintrag erhielten, verwiesen. Über Adelheid Ries heißt es lapidar: "die zweite Tochter ist Wirthin". Diese kurze Notiz suggeriert dem Leser, dass sie offenbar keine Beziehung zu musikalischen Tätigkeiten hatte. Schaut man hier jedoch etwas genauer hin, so stößt man dabei auf einige bemerkenswerte Tatsachen, die am Ende auch wieder zur Musik hinführen.

Adelheid Ries (1753-1794) hat vermutlich wie ihre Geschwister eine musikalische Erziehung im Hause der Eltern genossen, doch lagen ihre Stärken möglicherweise auf einem anderen Gebiet. Jedenfalls heiratete sie 1777 „Fridericus Josephus Eygelmayer", den Sohn des langjährigen "Knabentafeldeckers N. Eygelmayr" am Hof des Bonner Kurfürsten. ${ }^{28} 1766$ scheint der Vater
Franz Anton Ries (17551846). Ölgemälde von Amelius Radoux, 1785 (Privatbesitz)

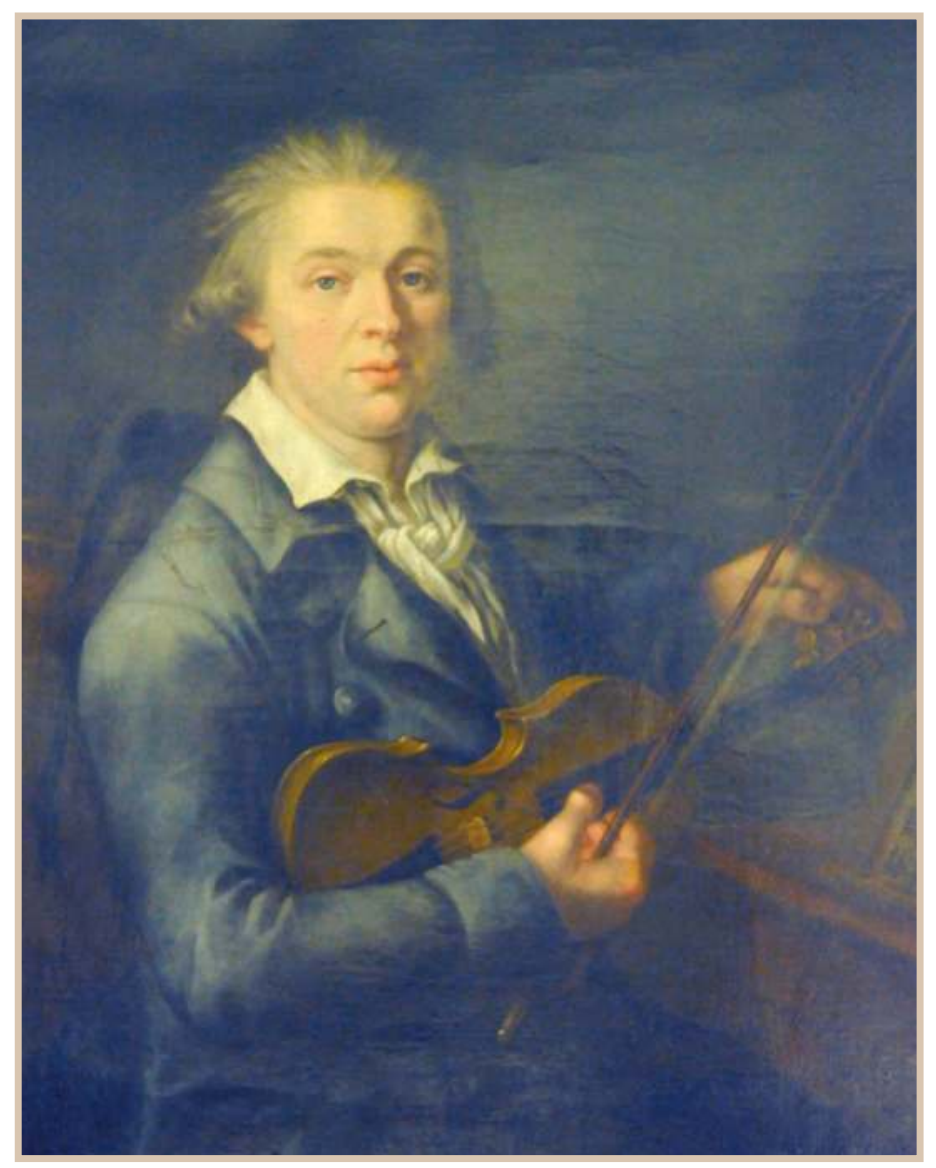


Eigelmayer gestorben zu sein, da 1767 sein Sohn Friedrich Joseph an seiner Stelle im Hofkalender genannt wird. Im gleichen Jahr wird seine Mutter in städtischen Dokumenten als "Witwe" bezeichnet. ${ }^{29}$ Mutter und Sohn erwarben 1767 ein großes Haus, das ganz nahe "bei Hof auf der sog. Fürstenstraße bei dem kurfürstlichen Residenzschloss" lag und das sie zu einem Hotel mit Restaurant namens Englischer Hof oder Cour d'Angleterre umbauten und in den folgenden Jahren sukzessive erweiterten. Der Englische Hof befand sich in Bonns bester Lage. Sein Eingang lag genau gegenüber einem der beiden zur Stadt gelegenen Schlosseingänge. Das Gebäude zog sich um die gesamte Ecke herum (heute Am Hof/Fürstenstraße) und hatte einen rückwärtigen Ausgang auf den Kirchhof von St. Remigius. 1788 heißt es in einem Hofbericht: „Eigelmayr baute den ,Redoutensaal' im Hof von England, mit der vom Hofe ihm gegebenen Versicherung, dass da u. nirgends anders die Redoute sollte gehalten werden." ${ }^{30}$ Dieser Redoutensaal muss mit einer Länge von ungefähr 21 Metern, einer Breite von 11 Metern und einer Höhe von 7,5 Metern eine beträchtliche Größe gehabt haben. Neben einer Bühne für das Orchester bot er Platz für ca. 260 bis 280 Konzertbesucherlnnen. Hier fanden bis 1834 zahlreiche Konzerte, Bälle und Festlichkeiten statt. ${ }^{31}$ Mit ihrer Heirat im Jahr 1777 wurde Adelheid Ries Mitglied einer Hofbediensteten-Familie, die in einer anderen Domäne als der Musik tätig war. Wenn allerdings wenige Jahre später im Englischen Hof ein Redoutensaal eingerichtet wird, stellt sich natürlich die

Blick aus der heutigen Fürstenstraße auf das brennende Residenzschloss, 1777, links der Cour d'Angleterre. Radierung von Franz Rousseau (Stadtarchiv Bonn)

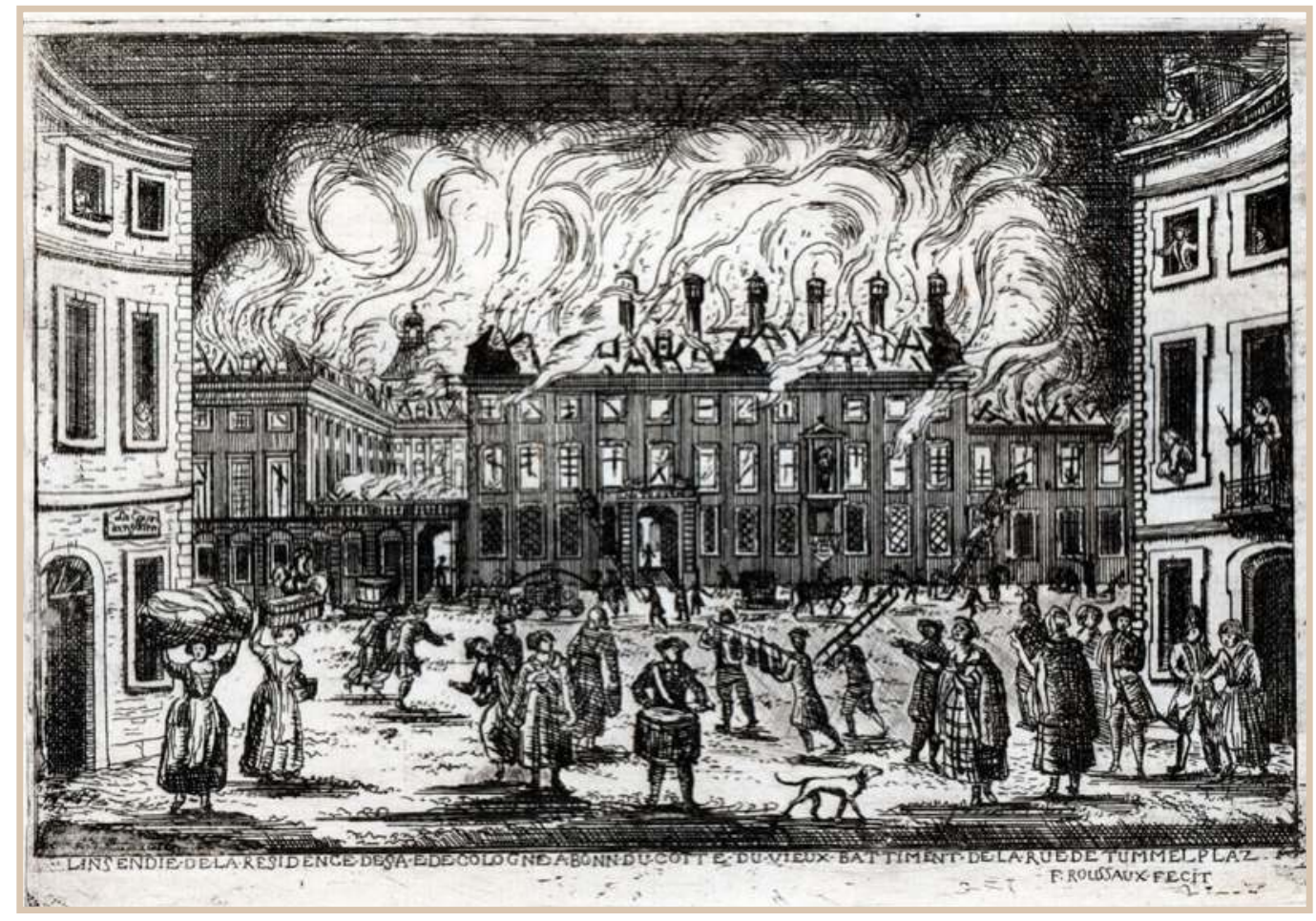

306 | Barbara Mülhens-Molderings

(C) 2020 by Böhlau Verlag GmbH \& Cie. KG, Köln

https://doi.org/10.7788/9783412519704 | CC BY-NC 4.0 
Frage, ob dabei nicht der Einfluss der Ries-Tochter und ihrer Familie - drei wichtigen Mitgliedern des Hoforchesters - maßgebend gewesen ist. 1787 mietete die neu gegründete Lesegesellschaft, vermutlich auf Vermittlung von Franz Anton Ries, dem Bruder der "Wirthin", die ersten "Gesellschafts-Zimmer bei Madame Eygelmeyer für 40 Rtl." ${ }^{22}$ pro Jahr. Als der Kurfürst der Lese bald danach Zimmer im zweiten Stock des Rathauses zur Verfügung stellte, wurde der Mietvertrag mit dem Englischen Hof wieder aufgelöst. ${ }^{33}$

Franz Anton Ries, der bereits in Wien mit den Ideen der Aufklärung in Kontakt gekommen war, trat 1781 dem Illuminatenorden Minervalkirche Stagira in Bonn bei. Zwar wurde dieser schon 1785 verboten, doch entstand an seiner Stelle im Dezember 1787 die Bonner Lesegesellschaft, zu deren Gründungsmitgliedern neben Neefe, Simrock und dem Direktor der Hofkapelle, Joseph Reicha, auch Franz Anton Ries gehörte. Sie alle waren den Ideen der Aufklärung verbunden und setzten sich insbesondere für pädagogische Reformideen ein. Der Kurfürst Maximilian Franz wurde zum Protektor der Lesegesellschaft, die zum Zentrum des damaligen Geisteslebens der Stadt wurde. Die Mehrzahl ihrer Mitglieder stand in enger Beziehung zum Hof, zur Geistlichkeit und zur Universität. ${ }^{34}$ Dass die avancierten aufklärerischen Ideen am kurfürstlichen Hofe und besonders unter den Musikerkollegen des jungen Beethoven auf diesen abgefärbt haben, steht außer Zweifel. ${ }^{35}$ In den beiden Jahren vor Gründung der Lesegesellschaft trat Franz Anton Ries erstmals in eine engere Beziehung zu dem 15 Jahre jüngeren Beethoven, indem er ihm zusammen mit Stephan von Breuning $\left({ }^{*} 1774\right)$ in dessen Elternhaus am Münsterplatz Geigenunterricht erteilte. Franz Gerhard Wegeler, der damals schon im Breuningschen Hause verkehrte, wurde Zeuge einer ihm unvergesslichen Szene:

"Als Beethoven einst im Breuning'schen Hause phantasirte, (wobei ihm häufig aufgegeben ward, den Charakter irgend einer bekannten Person zu schildern,) drang man dem Vater Ries eine Violine auf, um ihn zu begleiten. Nach einigem Zögern gab dieser nach und so mag wohl damals zum erstenmal von zwei Künstlern zugleich phantasirt worden sein; ein schönes, höchst anziehendes Spiel, wodurch später Ries mit seinem Sohne Ferdinand einigemal in öffentlichen Concerten den Zuhörern ein überraschendes Vergnügen machte." ${ }^{\prime 36}$

Franz Anton Ries hatte inzwischen am 27. Dezember 1783 Anna Horst, die Tochter des verstorbenen Hofglasers Goswin Horst, geheiratet. ${ }^{37}$ Am 28. November 1784 wurde als ihr erstes Kind der Sohn Ferdinand geboren. Der Taufeintrag im Kirchenbuch von St. Remigius lautet auf den 29. November. Einen Tag später erschien eine Anzeige seiner Geburt im Bonner Intelligenzblatt. Wo genau Ferdinand Ries 1784 in Bonn zur Welt gekommen ist, konnte bisher nicht geklärt werden. Allerdings spricht Einiges dafür, dass das junge Paar damals im Haus Sternstraße 39 (alte Nr. 196, im Stadtplan von 1773: Nr. 273) 


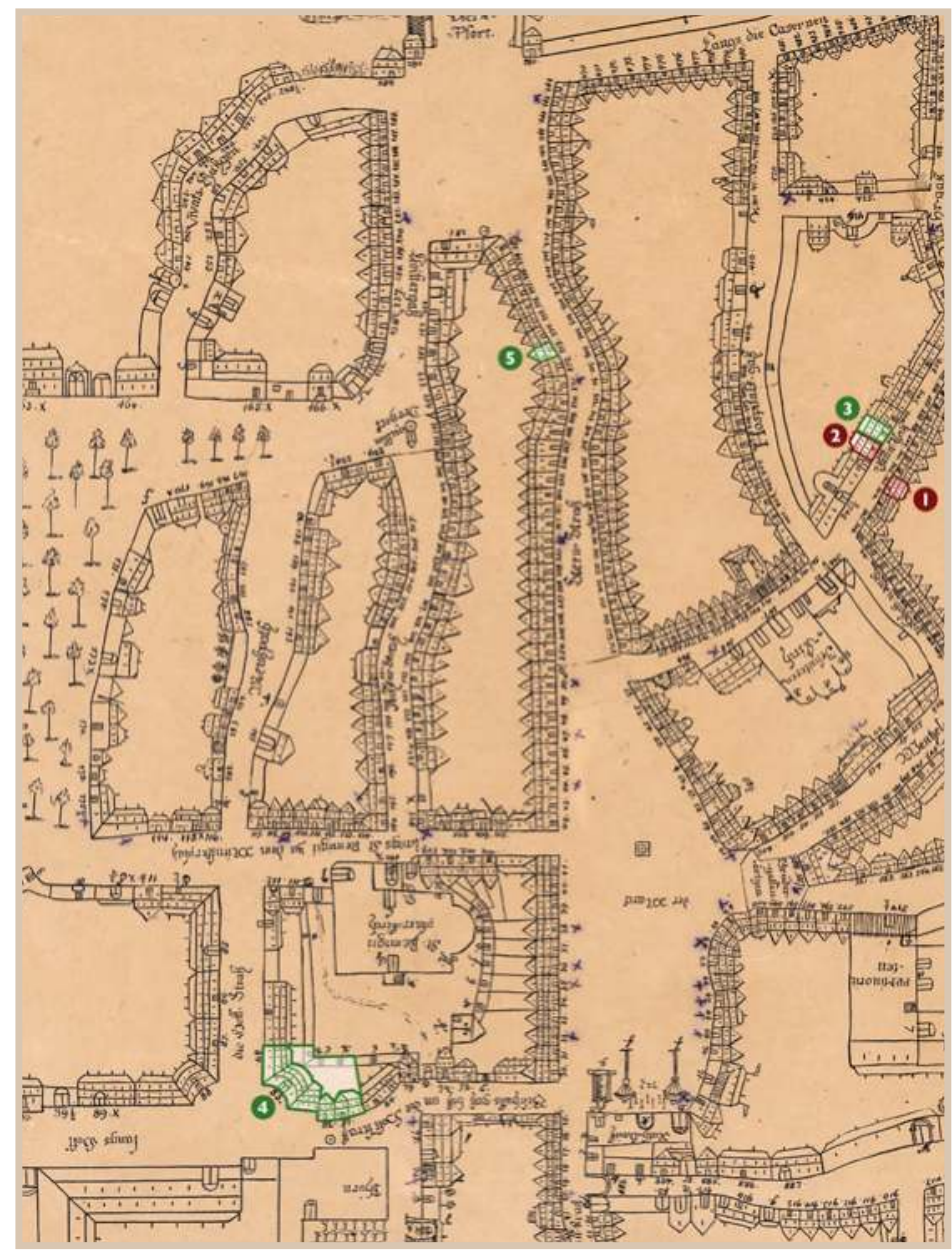

mit dem Beinamen Zum kleinen roten Löwen lebte, das Anna Horst geerbt oder erworben hatte. 1786 muss ihr dieses Haus jedenfalls noch gehört haben, da in einem Dokument zum Verkauf des Nebenhauses angegeben wird, dass nebenan "Hofmusikus Ries" wohnt. ${ }^{38}$ 1790 war das Haus in der Sternstraße schon in den Besitz des Nachbarn übergegangen, und die inzwischen bedeutend gewachsene Familie Ries - das sechste Kind war unterwegs - wohnte zur Miete im Englischen Hof, der Franz Antons Schwester gehörte. ${ }^{39}$

Unmittelbar nach Beethovens Rückkehr von seiner ersten Wien-Reise starb seine Mutter am 17. Juli 1787. Tief erschüttert wurde Beethoven selbst ernsthaft krank, nicht nur physisch, sondern auch seelisch - er selbst sprach von "melankolie, welche für mich fast ein eben so großes übel, als meine krankheit selbst ist". ${ }^{40}$ Franz Anton Ries, der seinem Schüler sehr nahe stand, versuchte als väterlicher Freund in jeder Weise zu helfen, woran sich Beethoven noch nach Jahren dankbar erinnerte. So sagte er zu Franz Antons Sohn Ferdinand, als dieser ihm bei seiner Ankunft in Wien ein Empfehlungsschreiben des Vaters überreichte: „... ich kann Ihrem Vater jetzt nicht

Stadtplan von 1773 (Ausschnitt): 1) BeethovenHaus (Bonngasse), 2) Wohnhaus Großvater Beethoven (Bonngasse), 3) Wohnhaus Familie Johann und Johanna Elisabeth Ries (Bonngasse), 4) Cour d'Angleterre (Fürstenstraße/Am Hof), 5) Wohnhaus Familie Franz Anton und Anna Ries (Sternstraße) (Kopie: Stadtarchiv Bonn) antworten; aber schreiben Sie ihm, ich hätte nicht vergessen, wie meine Mutter starb; damit wird er schon zufrieden sein." 41 Als langjähriger Kollege von Beethovens Vaters wusste Franz Anton Ries um dessen Alkoholprobleme und die sich daraus ergebenden finanziellen Engpässe und familiären Spannungen. 1790 wurde die Situation so schwierig, dass die kurfürstliche Verwaltung dem jungen Beethoven die Hälfte des väterlichen Gehaltes übertrug und er damit faktisch zum Familienoberhaupt wurde. ${ }^{42}$ Möglicherweise hatte Ries auch hier die Hand im Spiel, da er inzwischen als Konzertmeister und Direktor der Hofoper der direkte Vorgesetzte von Beethoven war und für seinen Schützling sorgen konnte. Ende 1792, kurz nachdem Beethoven zum zweiten Mal nach Wien aufgebrochen war, starb auch sein Vater. Die beiden jüngeren Brüder Ludwigs blieben vorerst allein in Bonn zurück. Franz Anton Ries kümmerte sich um sie und nahm 1793/1794 für den in Wien weilenden Beethoven die ihm zustehenden Gehälter in Empfang, ${ }^{43}$ die für die Erziehung seiner Brüder bestimmt waren.

308 | Barbara Mülhens-Molderings

(C) 2020 by Böhlau Verlag GmbH \& Cie. KG, Köln

https://doi.org/10.7788/9783412519704 | CC BY-NC 4.0 
Aber nicht nur familiäre, sondern auch fachliche Förderung ließ Ries dem jungen Kollegen angedeihen. Davon zeugt nach über 200 Jahren noch ein Streifen Papier mit der Handschrift Franz Anton Ries, den John Wilson jüngst im Inventar der Musiksammlung des Kurfürsten entdeckt hat und der belegt, dass sich Beethoven über Ries die Noten zum Studium aus der kurfürstlichen Musiksammlung besorgte. ${ }^{44}$

Anfang September 1791 reiste ein großer Teil des Hoforchesters nach Mergentheim zum Sitz des Hochmeisters des Deutschen Ritterordens, ein Amt, das Kurfürst Maximilian Franz damals inne hatte. Bei einem Zwischenaufenthalt in Aschaffenburg besuchten Franz Anton Ries, der inzwischen Musikdirektor anstelle des erkrankten Joseph Reicha war, gemeinsam mit Beethoven, Simrock und den beiden Rombergs den bekannten Komponisten Abbé Sterkel, bei dem Beethoven die Kollegen mit einer bisher nicht bekannten, dem Sterkelschen Spiel angepassten Spiel-Manier beeindruckte. ${ }^{45}$ Die Auftritte der Bonner Hofkapelle in Mergentheim sind durch den Bericht des Geistlichen Carl Ludwig Juncker vergleichsweise gut beschrieben. ${ }^{46}$ "Das Orchester war vortreflich besezt; besonders gut wurde das Piano und Forte, und das Crescendo in obacht genommen. Hr. Ries, dieser vortrefliche Partiturleser, dieser große Spieler vom Blatt weg, dirigierte mit der Violin. Er ist ein Mann, der an der Seite eines Cannabichs [ehemaliger Kapellmeister in Mannheim] steht, und durch seinen kräftigen, sichern Bogenstrich allen Geist und Leben giebt." Da er auch die Gelegenheit hatte, bei einer Probe zuhören zu dürfen, erfuhr er aus erster Hand von der großen Zufriedenheit des Kurfürsten mit seinen geschätzten Hofkapellisten: "Gleich beim Anfang der Probe wurde der Direktor, Hr. Ries zu seinem Fürsten abgerufen, als er wiederkam, hatte er die Säcke voll Geld. ,Meine Herren, sprach er, der Kurfürst macht ihnen an seinem heutigen Namenstage ein Geschenk von 1000 Th/r."

Franz Anton Ries, der Direktor der Hofkapelle, war inzwischen in Godesberg auch zum Bauherren geworden. 1790 hatte Kurfürst Maximilian Franz den Plan gefasst, Godesberg in einen mondänen Badeort zu verwandeln und verschenkte zu diesem Zweck mehrere Grundstücke zur Errichtung von Logierhäusern für die künftigen Badegäste. ${ }^{47}$ Franz Anton Ries, neben einer Baugesellschaft und dem Kurfürsten selbst der einzige private Bauherr dieser Logierhäuser, konnte sein Haus als erster fertig stellen und erhielt die dafür vom Kurfürsten ausgesetzte Prämie von 1000 Talern. Das Gebäude ist heute noch erhalten und befindet sich in Bad Godesberg, Kurfürstenallee 2-3.

Beethovens zweite Wien-Reise Anfang November 1792 war eine „offensichtlich von Bonn aus gut vorbereitete Einführung in die musikliebenden aristokratischen Zirkel Wiens". ${ }^{48}$ Reiseliteratur gehörte damals in den deutschen Städten und Fürstentümern zu der am meisten gelesenen literarischen Gattung und
Theater und Logierhäuser in Godesberg. Markiert ist das Franz Anton Ries gehörende Gebäude. Kupferstich von Johann Ziegler nach Lorenz Janscha, 1792 (Ausschnitt) (Stadtarchiv Bonn)

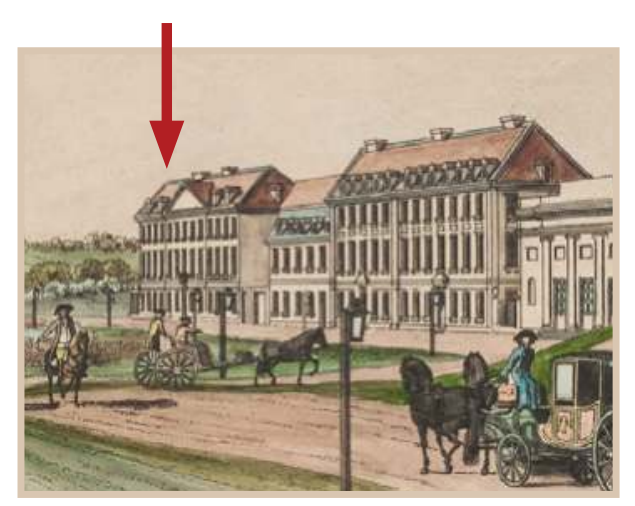

„Wir Bönner sind doch ganze Kerls!“ - Beethoven und die Bonner Musikerfamilie Ries | 309 
Kloster Marienforst von Südwesten. Kupferstich von Johann Ziegler nach Lorenz Janscha, 1792 (Stadtarchiv Bonn) wurde daher auch in der Bibliothek der Bonner Lesegesellschaft ausgiebig gesammelt. ${ }^{49}$ Zwar hatte Beethoven als Nichtmitglied keinen direkten Zugriff auf diese Bibliothek, doch konnten ihm die befreundeten Kollegen, insbesondere Ries, Drewer und Simrock alle notwendigen Details zu der geplanten Reise beschaffen.

Am kurfürstlichen Hof war man ursprünglich davon ausgegangen, dass Beethovens Wien-Aufenthalt nur ein vorübergehender sei und er anschlieBend wieder nach Bonn zurückkehren würde. Dies war jedoch mit der endgültigen Besetzung des Rheinlandes 1794, der Flucht des Kurfürsten und der Auflösung des Hoforchesters nicht mehr möglich. Nachdem die Rheinlande in das französische Empire integriert worden waren, bestand überdies die Gefahr, von den Franzosen zum Wehrdienst eingezogen zu werden. Da der Kurfürst davon ausging, dass er zumindest seinen Münsteraner Bischofssitz behalten würde, plante er, die Besetzung der Hofkapelle drastisch zu reduzieren und die Bonner Musiker an seinen Hof nach Münster zu holen. Die meisten von ihnen wurden „abgedankt” oder, wie Anna Maria Ries-Drewer, in Pension geschickt. Beethoven war davon erst einmal nicht betroffen, er "bleibt ohne Gehalt in Wien bis er einberufen wird". Franz Anton Ries und Ferdinand Drewer waren unter denjenigen, die ihren Status als "Hofmusici" behielten. ${ }^{50}$ Doch der Vormarsch der französischen Revolutionsarmee machte alle Hoffnungen und Pläne sowohl des Kurfürsten als auch seiner Hofmusiker auf eine ruhige und geregelte Zukunft zunichte. Bonn und Godesberg hatten über Nacht allen Glanz verloren. „Die Tanz- und Spielsääle stehen verlassen und verwüstet, die Wohnungen für Badegäste wurden zu Casernen der Soldaten und die englischen Anlagen nicht mehr unterhalten. Seit 1794 mit der Ankunft der Franzosen hat alle Sorge dafür aufgehört", beschrieb ein Rhein-Reisender den Zustand Bonns und Godesbergs unter der Besatzung der französischen Armee. ${ }^{51}$ Im fernen Wien war sich Beethoven der Gefahren, die seinen Bonner Kollegen drohte, durchaus bewusst. So fragte er im August 1794 brieflich bei Nikolaus Simrock nach: "Sie müssen doch auch jetzt in Angst leben? - Was macht der gute Ries?"52 
Das Ende des kurfürstlichen Hofstaates und der Einmarsch der Franzosen änderten schlagartig das Leben der Bonner Bürger, insbesondere jener, die wirtschaftlich zu einem großen Teil vom Hofe abhingen. Denn von einem Tag auf den anderen wurden weder Gehälter noch Pensionszahlungen geleistet. ${ }^{53}$ Darüber hinaus waren Einquartierungen, Requisitionen, Kontributionen und massive Geldentwertung an der Tagesordnung. Franz Anton Ries verlor seine Stellung als Direktor der Hofmusik und musste sehen, wie er seine wachsende Familie ernährte: Er gab Musikunterricht und nahm bei der französischen Verwaltung die Stelle eines Steuereinnehmers an. Daneben wurde er zeitweilig von den französischen Besatzungsbehörden zum Dienst als Stadtrat verpflichtet. 1803 übersiedelte die Familie Ries mit ihren elf Kindern in das ehemalige Klostergut Marienforst bei Godesberg, das Franz Anton Ries als Pächter und "Ökonom" bewirtschaftete. Er konnte 1807 Teile des Klostergeländes käuflich erwerben, veräußerte diese jedoch zwei Jahre später schon wieder.

Das Musikleben in Bonn war in den ersten Jahren der französischen Besatzung fast gänzlich zum Erliegen gekommen. 1807 wurde Ries zum "Musiksmeister" am neu gegründeten Bonner Lyzeum ernannt. Als sich das Leben ab 1808 langsam wieder zu normalisieren begann, organisierte er sogenannte Winterkonzerte, die unter seiner Leitung von einer Konzertgesellschaft betrieben wurden und für eine Neubelebung des Bonner Musiklebens sorgten. ${ }^{54}$

Franz Anton Ries blieb Beethoven sein Leben lang in bester Erinnerung. So schrieb er im Februar 1825 an dessen Sohn Ferdinand: "Grüßen Sie Ihren alten Vater herzlich von mir. Ich bin äußerst erfreut über sein Glück." Diese Bemerkung bezog sich offenbar darauf, dass Franz Anton Ries auch noch im fortgeschrittenen Alter in der Lage war, sich ganz der Musik zu widmen. Auch nach Beethovens Tod muss seine Person noch oft Thema in der Familie Ries gewesen sein. Dies war besonders der Fall, als Franz Gerhard Wegeler und Ferdinand Ries 1837 intensiv damit begannen, Erinnerungen und Materialien für eine Biographie Beethovens zusammen zu tragen, die im Jahr darauf unter dem Titel Biographische Notizen über Ludwig van Beethoven erscheinen sollte. Dabei waren die Erinnerungen von Franz Anton Ries an die Jugendjahre Beethovens von unersetzlicher Bedeutung. So schreibt Wegeler ausdrücklich, dass er bei der Abfassung seines Parts der Biographischen Notizen stellenweise "die Hülfe des Vaters Ries in Anspruch" genommen hatte. ${ }^{56}$ Wie hoch die beiden Autoren die Bedeutung von Franz Anton Ries im Leben Beethovens einschätzten, kommt in der
Widmung an Franz Anton Ries, aus: WEGELER/RIES, Biographische Notizen (Stadtarchiv Bonn)

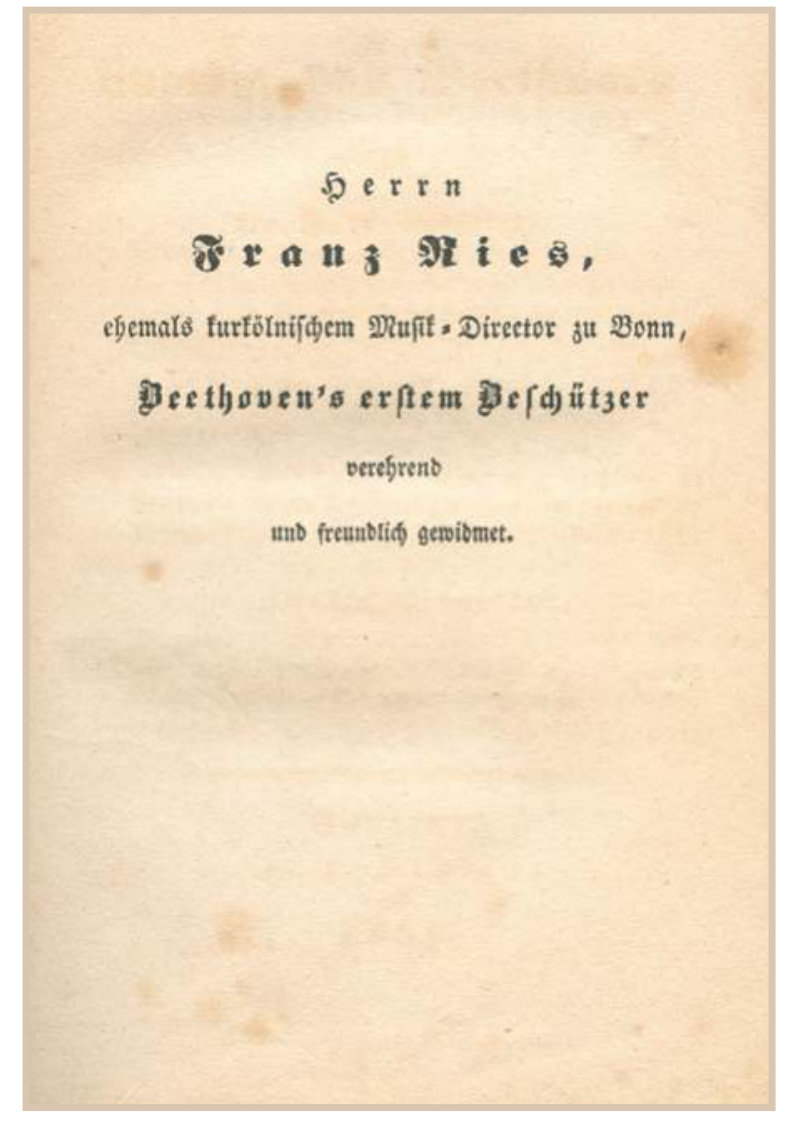


Dedikation des Buches zum Ausdruck. Es ist „Herrn Franz Ries, ehemals kurkölnischem Musik-Director zu Bonn, Beethoven's erstem Beschützer verehrend und freundlich gewidmet". Fast 90-jährig, als ältester noch lebender Freund und Lehrer Beethovens, wurde Franz Anton Ries 1845 als Ehrengast beim ersten Beethovenfest unter Beifall in den Festsaal getragen. ${ }^{57}$ Am Vorabend hatte ihm die Bonner Universität in Anerkennung seiner herausragenden Bedeutung für das Bonner Musikleben die Ehrendoktorwürde verliehen. Im gleichen Jahr wurde er von Friedrich Wilhelm IV. für seine musikalischen Verdienste mit dem preußischen Roten Adlerorden III. Klasse ausgezeichnet. Franz Anton Ries starb am 1. November 1846. Er fand seine letzte Ruhe in einem von der Stadt Bonn gewährten Ehrengrab auf dem Alten Friedhof. ${ }^{58}$ Im Gedenken an ihn gab die Stadt Bonn 1869 einer Straße in der Nähe des Hofgartens den Namen Riesstraße. ${ }^{59}$

\section{FERDINAND RIES (1784-1838) - Schüler, Freund und Biograph Beethovens}

Das berühmteste Mitglied der Musikerfamilie Ries war der am 28. November 1784 geborene Ferdinand. ${ }^{60}$ Als Schüler und Freund Beethovens hat er sich im ersten Drittel des 19. Jahrhunderts nicht nur als Klaviervirtuose, sondern auch als Komponist in Deutschland, Russland, England und Frankreich einen Namen gemacht. Sein Ruhm war so groß, dass Franz Gerhard Wegeler 1838, kurz nach Ferdinands Tod, im Vorwort der Biographischen Notizen über Ludwig van Beethoven schrieb: „Was die Kunst an Ries verloren, weiß Europa; er gehört zu den Wenigen, die ihrem Rufe durch gediegene Werke eine Geltung verschafft haben, welche nicht mit der Gegenwart verschwindet." 61 - Seine Musik wird in jüngster Zeit zunehmend wiederentdeckt, so dass kaum mehr ein Monat vergeht, in dem nicht eine Sinfonie, ein Oratorium oder eines seiner kammermusikalischen Werke in einem europäischen Konzertsaal erklingt.

Franz Anton Ries, der die große musikalische Begabung seines Sohnes früh erkannte, erzog ihn - man möchte fast sagen - nach dem Vorbild seines Geigenschülers und jungen Freundes Ludwig van Beethoven. Ferdinand erhielt nach eigenem Bekunden vom Vater den ersten "sehr gründlichen Unterricht im Clavierspiele und in der Musik überhaupt". 62 Mit sieben Jahren lernte er zusätzlich das Cellospiel von dem berühmten Bernhard Romberg, einem Kollegen des Vaters in der Hofkapelle. Schon im Alter von neun Jahren komponierte er zum Geburtstag seines Vaters sein erstes Werk, ein Menuett. Mit elf Jahren spielte er in Vertretung des Organisten Neefe, wie zuvor schon der junge Beethoven, die Orgel in der Messe, und zwar zwei Mal wöchentlich. ${ }^{63}$ Sein musikalisches Talent war so vielversprechend, dass ihm bereits eine Stellung in der Hofkapelle zugesichert worden war. Da diese sich aber beim Einmarsch der napoleonischen Armee ins Rheinland auflöste, blieb ihm eine Ausbildung und Anstellung in einer der besten Hofkapellen in den damaligen deutschen Landen verwehrt. 
Franz Anton Ries hielt es für unabdingbar, dass sein Sohn seine Ausbildung auswärts weiter fortsetzte und schickte ihn im Jahr 1801 nach München, wo das Hoforchester unter der Leitung des renommierten Konzertmeisters Carl Cannabich tätig war. Da es seinem Sohn nicht gelang, dort Fuß zu fassen, schrieb Franz Anton im Frühjahr 1801 einen Brief an Beethoven in Wien, um zu erfragen, ob die Aussichten für seinen Sohn dort besser seien. Dieser Brief ist nicht erhalten, aber er muss Beethoven wohl an seine eigene Situation im gleichen Alter erinnert haben. Er ersparte sich die direkte Antwort und ließ den gemeinsamen Freund Wegeler in einem Brief vom 29. Juni 1801 folgende Antwort ausrichten: "Wegen Rieß, den mir herzlich grüße, will ich dir näher schreiben, ...". Seiner Meinung nach sei für dessen Sohn Paris der bessere Ort und nicht Wien. Denn „Vien ist überschüttet mit Leuten, und selbst dem Bessern Verdienst fällt es dadurch hart, sich zu halten." 64 Das war in gewisser Weise eine leise Warnung vor der schwierigen Situation, auf die ein sehr junger Musiker in dieser Stadt treffen würde. Beethoven mag bei seiner Antwort auch ein offenbar im Sommer 1800 erlassenes Dekret vor Augen gestanden haben, durch das alle ausländischen Künstler ohne eigenes Vermögen aufgefordert wurden, sofort Wien zu verlassen, da sie den einheimischen Künstlern die Verdienstchancen nähmen. ${ }^{65}$ In Wien zählte man damals um die 6000 Amateurpianisten und etwa 300 professionelle Klavierlehrer. ${ }^{66}$ Diesen Schwierigkeiten zum Trotz erbot sich Beethoven dennoch, nach einer Möglichkeit für den Sohn seines Freundes zu suchen. „... bis den Herbst oder bis zum Winter werde ich sehen, was ich für ihn thun kann, weil dann alles wieder in die Stadt eilt - ..."67

Die widrigen Umstände in München müssen Ferdinand Ries bewogen haben, dem dortigen Aufenthalt ein baldiges Ende zu bereiten. Da er nur sehr wenig Geld besaß, brach er wohl "auf Schusters Rappen" nach Wien auf. Für den genauen Zeitpunkt seiner dortigen Ankunft ist bisher kein Dokument gefunden worden. Vermutlich ist er im Winter 1801 dort eingetroffen und hat sich sofort zu Beethoven begeben, der ihn "gleich freundlich und herzlich"68 aufnahm. Aufgrund seiner großen gesundheitlichen Probleme, die Beethoven Wegeler in seinem Brief mitgeteilt hatte und die sich in den folgenden Monaten nicht bessern, sondern eher noch verschlimmern sollten, sah er sich vermutlich nicht in der Lage, dem jungen Landsmann sofort Klavierunterricht zu erteilen. Stattdessen scheint er ihm im Frühjahr 1802 erst einmal eine Stelle als Pianist beim Grafen Browne, zu dem er beste Beziehungen unterhielt, verschafft zu haben. Graf Browne beabsichtigte im Frühjahr 1802 in die Stadt Baden abzureisen und sich dort eine Weile aufzuhalten. Dies kündigte er in einer Annonce in der Wiener Zeitung vom 27. Februar 1802 an. Dahin sollte ihn Ferdinand Ries den Plänen Beethovens zufolge als "Hauspianist" begleiten. Kurz vor Reiseantritt

\section{L a d r i ch t.}

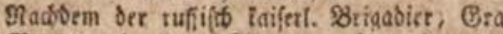
v. Sorewre, in wernig Sagen doa fier abjurrifen geternfet, fo wiro Jeverman, der auf itgenb cia

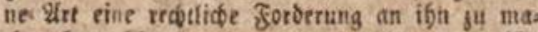
den bat, biemit erimnert, fids vom 24 . $\mathrm{D}$. SH. binaen 8 sagen, bas ift bis 2 SRary. 1802 , beo Dem Srn Grufen in ber finigerfitaffe im Saron Qidtenfteinf(hen Saufe Pr. 1084 im 4ten Erod gu melcen, um der Driaung nad befriediget git

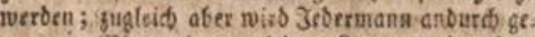

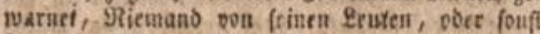
Jemant in feinem Temen Geto ju Teiben, ober

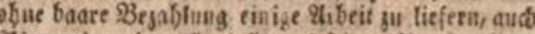
Riemanben, ter allenfalts auf (rinen Stamen. Gero

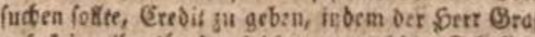
auf leine Itrt fúr oergleiden contrabirte Edulben baftet.

„Wir Bönner sind doch ganze Kerls!“ - Beethoven und die Bonner Musikerfamilie Ries | 313

Annonce von Graf Browne in der Wiener Zeitung, 27. Februar 1802

(Österreichische Nationalbibliothek) 
erhielt Ries noch einen Brief von Beethoven, der sich auf seine Reisevorbereitungen bezog und dem ein Brief an Graf Browne beigelegt war.

"- hier der Brief an gr. Browne, es steht drin, daß er ihnen die 50 \# [Dukaten] voraus geben muß, weil sie sich equipieren müßen, dies ist eine Nothwendigkeit, die ihn nicht beleidigen kann, dann, nachdem das geschehen söllen Sie künftige Woche schon am Montag mit ihm nach Baden gehn - Vorwürfe muß ich Ihnen denn doch machen, daß sie sich nicht schon lange an mich gewendet, bin ich nicht Ihr wahrer Freund, warum verbargen Sie mir Ihre Noth, keiner meiner Freunde darf darben, so lange ich etwas hab, ich hätte ihnen schon eine kleine Summe geschickt, wenn ich nicht auf Browne hoffte, geschieht das nicht, so wenden sie sich gleich an ihren Freund Beethoven"69. In seiner Annonce in der Wiener Zeitung hatte Graf Browne ebenso angegeben, dass mögliche Schulden seinerseits nur bis zum 2. März bezahlt würden und er selbst gedachte, "in wenig Tagen von hier abzureisen". Spätestens am 15. März 1802 wird Graf Browne also nach Baden abgereist sein. Im Sommer dieses Jahres scheint Ries häufiger zwischen Baden, Wien und Heiligenstadt, wohin Beethoven sich für den Sommer aufs Land zurückgezogen hatte, gependeltzu sein. Möglicherweise hat Ries nach der Beendigung seines Engagements beim Grafen Browne im Herbst 1802 eine kurze Reise zu seinen Eltern nach Bonn unternommen und ist am Ende des Jahres über München nach Wien zurückgekehrt, wo er Ende März 1803, kurz vor Beethovens Akademie vom 5. April im Theater an der Wien wieder eintraf. ${ }^{70}$

In den Biographischen Notizen berichtet er über seine Arbeit bei Beethoven: „Beethoven fand gleich in den ersten Tagen, daß er mich brauchen könne "71. Von diesem Zeitpunkt an wurde er für ihn als Kopist und Sekretär, als Unterhändler in geschäftlichen Dingen mit Verlagen und Vermietern und in Anerkennung seiner pianistischen Fähigkeiten schließlich auch als Interpret seiner Werke tätig. Das Verhältnis zwischen Beethoven und dem 14 Jahre jüngeren Ries scheint familiär gewesen zu sein, auch wenn man sich nicht duzte. Dieses Privileg genossen nur äußerst enge Freunde. Als Lehrer war Beethoven für Ries eine Respektsperson, als älterer Freund der Familie aber zugleich auch ein "väterlicher Freund". ${ }^{72}$ "Beethoven erinnerte sich seiner frühern Jugend und seiner Bonner Freunde mit vieler Freude, obschon es im Grunde bedrängte Zeiten für ihn gewesen waren", berichtete Ries über die Jahre, die er bei Beethoven in Wien verbracht hatte. ${ }^{73}$ Der markante Bonner Dialekt, den Beethoven sprach, galt in Wien als unfein, wenn nicht sogar als provinziell. Der junge Ferdinand sprach die gleiche Sprache wie er - das mag für ihn wie ein Stück wiedergewonnene rheinische Heimat gewesen sein. Man darf vermuten, dass Ries und Beethoven unter sich im heimatlichen Bönnsch gesprochen haben. Bekanntermaßen soll Beethoven 1812 bei Peter Joseph Lennés Besuch in Wien begeistert zu ihm gesagt haben: "Dich verstehe ich, Du sprichst Bönnsch!" ${ }^{\prime 14}$ Auf dieses Bönnsch brauchte Beethoven in Wien im 
Grunde nie ganz zu verzichten. Denn dort war seit ca. 1800 eine kleine Gemeinde Bonner Freunde und Musiker stets präsent. Seit der Mitte 1801 lebte dort sein Jugendfreund Stephan von Breuning. Nachdem Ferdinand Ries Wien wieder verlassen hatte, war sein jüngerer Bruder Joseph Franz 1814 nach Wien gezogen, um dort als Klavierbauer tätig zu werden. ${ }^{75}$ Als Mitglied der Ries-Familie und der Bonner Gemeinde in Wien hat sich Beethoven des Öfteren an ihn gewandt, damit er seine Klaviere stimme. ${ }^{76}$ In diesem Zusammenhang taucht er noch 1824 in den Konversationsheften auf, gemeinsam mit Franz Drewer, einem weiteren Bonner Musiker in Wien. Er war ein Sohn von Anna Maria Ries und Ferdinand Drewer, somit ein Vetter der Ries-Brüder, und hatte sich in Wien als Musiker und Kapellmeister niedergelassen. 1809 war er als "Musickmeister bey Sr Durchlaucht Fürsten von Kinsky" tätig. ${ }^{77}$

Ferdinand Ries, der wahrscheinlich die meisten der bis dahin veröffentlichten Werke von Beethoven bei seiner Ankunft in Wien schon kannte, war voller Bewunderung für seinen Lehrerund seine unkonventionelle Lebensweise. Gleichzeitig respektierte er dessen Launen und Schrullen, vor allem, nachdem die zunehmende Schwerhörigkeit offenbar geworden war. Beethoven gab Ries zwar nur Klavierunterricht, sorgte aber auch für seine fundierte theoretische Weiterbildung, indem er den damals berühmtesten Theoretiker Johann Georg Albrechtsberger dazu drängte, Ries trotz seines Ruhestandes noch als Schüler aufzunehmen. Der konnte sich jedoch nur 28 Stunden leisten, und musste danach den "Contrapunkt" wieder aus Büchern studieren. Wie seinen Berichten zu entnehmen ist, waren trotzdem fachliche Diskussionen zwischen Beethoven und seinem wissbegierigen Schüler oft auf der Tagesordnung, vor allem auf den regelmäBigen sommerlichen Spaziergängen und nach erteilten Lektionen. ${ }^{78}$

Im Sommer 1803 stellte Beethoven ernsthafte Überlegungen an, Wien zu verlassen und nach Paris umzusiedeln. Da er inzwischen festgestellt hatte, dass Ries ihm in vieler Hinsicht nützlich sein könnte, schlug dieser ihm vor, ihn "als Schüler und Cassier mitzunehmen". Diese Idee scheint Beethoven sehr gefallen zu haben:

„Einst machte er ernstlich den Plan zu einer gemeinschaftlichen großen Reise, wo ich alle Concerte einrichten, und seine Clavier-Concerte sowohl als andere Compositionen spielen sollte. Er selbst wollte dirigieren und nur

Ludwig van Beethoven. Miniatur - Aquarell und Deckfarben - von Christian Hornemann, 1802 (Beethoven-Haus Bonn, Sammlung H. C. Bodmer) 
phantasiren. Letzteres war freilich das Außerordentlichste, was man hören konnte, besonders wenn er gut gelaunt oder gereizt war. Alle Künstler, die ich je phantasiren hörte, erreichten bei weitem nicht die Höhe, auf welcher Beethoven in diesem Zweige der Ausübung stand." ${ }^{\text {779 }}$

Ries berichtete über diese Reisepläne auch in einem Brief vom 22. Oktober 1803 an den Verlegerfreund Simrock in Bonn. In demselben Brief teilt er ihm mit, dass Beethoven die 3. Sinfonie, die Simrock gerne erworben hätte, nicht verkaufen wolle.

"Es ist nach seiner eigenen Äußerung das größte Werk, welches er bisher schrieb. Beethoven spielte sie mir neulich und ich glaube Himmel und Erde muß unter einem zittern bei ihrer Aufführung. Er hat viel Lust, selbe Bonaparte zu dezidieren, wenn nicht, weil Lobkowitz sie auf ein halbes Jahr haben und 400 Gulden geben will, so wird sie Bonaparte genannt."80

Dazu kam es dann jedoch nicht, denn Beethoven strich 1804 voller Wut die Dedikation an Napoleon, als Ries ihm die Nachricht brachte, dass dieser sich in Paris selbst zum Kaiser gekrönt hatte. Und so wurden auch die Umzugspläne erst einmal verworfen. Diese Sinfonie, deren Entstehung Ferdinand Ries ganz nah verfolgen konnte und deren Uraufführung er im Wiener Palais des Fürsten Lobkowitz am 9. Juni 1804 miterlebte, hat ihn so tief beeindruckt, dass er sie zum Anlass eines eigenen Werkes nahm und die Sinfonie für ein Klavierquartett bearbeitete. - Dieses ist zur Zeit eines der international meistgespielten Stücke von Ferdinand Ries.

Als Schüler Beethovens fand er Eingang in die elitären Musikzirkel des Wiener Adels und führte dort oft Beethovens Werke auf, häufig auch in Gegenwart seines Lehrers. Nachdem dieser seine damals neueste Komposition, das 3. Klavierkonzert, selbst erst ein einziges Mal öffentlich gespielt hatte, forderte er Ries auf, selbiges im Augarten-Konzert im Juli 1804 aufzuführen.

„B. hatte mir sein schönes Concert in C moll (Opus 37) noch als Manuscript gegeben, um damit zum ersten Male öffentlich als sein Schüler aufzutreten; auch bin ich der Einzige, der zu Beethoven's Lebzeiten je als solcher auftrat. Außer mir erkannte er nur noch den Erzherzog Rudolph als Schüler an. ... Beethoven selbst dirigierte und drehte nur um und vielleicht wurde nie ein Concert schöner begleitet. Wir hielten zwei große Proben. Ich hatte Beethoven gebeten, mir eine Cadenz zu komponieren, welches er abschlug und mich anwies, selbst eine zu machen, er wolle sie corrigiren. Beethoven war mit meiner Composition sehr zufrieden und änderte wenig; nur war eine äußerst brillante und sehr schwierige Passage darin, die ihm zwar gefiel, zugleich aber zu gewagt erschien, weshalb er mir auftrug, eine andere zu setzen. Acht Tage vor der Aufführung wollte er die Cadenz wieder hören. Ich spielte sie und verfehlte die Passage; er hieß mich noch einmal, und zwar etwas unwillig, sie ändern. Ich that es, allein die neue befriedigte mich nicht; ich studirte also die andere auch tüchtig, ohne ihrer jedoch ganz sicher wer- 
den zu können. - Bei der Cadenz im öffentlichen Concerte setzte sich Beethoven ruhig hin. Ich konnte es nicht über mich gewinnen, die leichtere zu wählen; als ich nun die schwerere keck anfing, machte Beethoven einen gewaltigen Ruck mit dem Stuhle; sie gelang indessen ganz und Beethoven war so erfreut, daß er laut: bravo! schrie. Dies electrisirte das ganze Publikum und gab mir gleich eine Stellung unter den Künstlern. Nachher, als er mir seine Zufriedenheit darüber äußerte, sagte er zugleich: ,Eigensinnig sind Sie aber doch! - Hätten Sie die Passage verfehlt, so würde ich Ihnen nie eine Lection mehr gegeben haben.' ... Die Clavierstimme des $\mathrm{C}$ moll Concerts hat nie vollständig in der Partitur gestanden: Beethoven hatte sie eigens für mich in einzelnen Blättern niedergeschrieben." ${ }^{11}$

Da Bonn inzwischen Teil Frankreichs geworden und Ferdinand Ries ein Bonner Bürger war, erhielt er Ende 1805 in Wien die Einberufung zum Kriegsdienst. Für den jungen Mann gab es keinen Ausweg, er musste der Aufforderung folgen. Hätte er sich ihr entzogen, hätte das den Ruin seiner Familie in Bonn bedeuten können. So reiste er in weitem Bogen über Prag, Dresden und Leipzig nach Koblenz zur Musterung und zwar zu Fuß! Die Route war überfüllt mit Menschen, die vor der anrückenden französischen Armee flohen, und in den Postkutschen gab es für einen unbemittelten jungen Musiker keinen Platz. Nachdem er aus gesundheitlichen Gründen vom Kriegsdienst befreit worden war, kehrte er ins Elternhaus nach Marienforst zurück. Um seinen Lebensunterhalt zu verdienen, gab er in Bonn Klavierunterricht. Eine seiner Schülerinnen war Eleonore von Breuning, Beethovens Jugendfreundin, die 1802 Franz Gerhard Wegeler geheiratet hatte. Auch die Kinder von Nikolaus Simrock, Dora und Peter Joseph, gehörten zu seinen Schülern. ${ }^{82}$

Beethovens Kompositionen fanden damals mehr und mehr Eingang in die Notenhandlungen und das musikalische Repertoire im Rheinland. Dennoch war es wahrscheinlich Ferdinand Ries, der Beethovens Werke als erster in einem öffentlichen Konzert im Rheinland aufgeführt hat. ${ }^{83}$ Ries gab dieses denkwürdige Konzert in Köln in den ersten Tagen des Jahres 1806, kaum dass er ins Rheinland zurückgekehrt war. Am Tag des Konzertes wurde im Beobachter im Ruhrdepartement das Programm bekannt gegeben:

"Concert. / Heute den 17. Januar um 6 Uhr präcis wird Herr Ferdinand Ries, / Schüler von Beethoven in dem Monheimischen Saale auf der Ehrenstraße, / ein Concert auf dem Piano Forte zu geben die Ehre haben ... Erster Theil. / 1. Neue große Symphonie von Beethoven. / 2. Neues großes Clavier-Concert von Beethoven, mit Begleitung des ganzen Orchesters, gespielt von Hrn. Ferd. Ries. / (3. Duo aus der Camilla, gesungen von Liebhabern.) / 4. Variations von Beethoven, nach einem Thema seines Ballett aus Prometheus, gespielt / von Hrn. Ferd. Ries, der diese Variationen mit seinen eignen Phantasien beschließt. I (Im zweiten Teil: Symphonie von Haydn, Quartett aus Camilla, Phantasie von Ries Vater und Sohn.)"184 
Zwei Tage später folgte in derselben Zeitung eine Rezension:

"Zahlreicher und glänzender war seit vielen Jahren kein Conzert als das angekündigte des Hrn. Ries. ... Hr. Ferd. Ries entsprach vollkommen der ldee, die man sich von ihm, dem Schüler des Hrn. Beethoven gemacht hatte. Sein Spiel war entzückend, und von jedem Kenner wurde die Leichtfertigkeit bewundert, womit er die so schwere Composition seines großen Meisters ausführte." ${ }^{\prime \prime 5}$

Dem Konzert scheint auch der berühmte Kölner Professor, Kanonikus und Kunstsammler Franz Ferdinand Wallraf (1748-1824) beigewohnt zu haben, denn in seinen nachgelassenen Papieren findet sich die Skizze zu einer Konzertbesprechung. ${ }^{86}$ Neben seinen Auftritten als Klaviervirtuose widmete sich Ries in Marienforst zugleich der Komposition eigener Werke. Noch ganz erfüllt von den Erinnerungen an seinen Aufenthalt in Wien schrieb er dort 1806 sein erstes publiziertes Werk Deux Sonates pour le Piano-Forte, die er Beethoven widmete. Die Noten erschienen in Bonn bei Nikolaus Simrock. Im selben Jahr wurde er Mitglied der Bonner Freimaurerloge Les frères courageux, der auch sein Vater und Nikolaus Simrock angehörten.

Auch in Bonn war inzwischen zunehmend in das Bewusstsein getreten, dass die Stadt der Geburtsort mehrerer hochrangiger und international anerkannter Musiker war. In Anerkennung dieser Tatsache machte der Bonner Kanonikus Franz Pick, ${ }^{87}$ ein bekannter Altertumssammler, 1808 eine Eingabe an den damaligen Bürgermeister, den Maire Belderbusch, die altehrwürdige Martinskirche vor der Apsis des Bonner Münsters in ein "Pantheon" zu verwandeln, auf dass „in diesen Hallen die Namen Beethoven, Ries und Salomon etc. widerhallten, im Auslande gepriesen, von uns kaum geehrt." 88

Zu diesem Zeitpunkt war Ferdinand schon nach Paris gereist und schaute sich in der musikalischen Welt der selbst erklärten Hauptstadt Europas um. Leider war ihm dort kein großes Glück beschieden, weder konnte er Schüler gewinnen, noch gelang ihm der Verkauf von eigenen Kompositionen. In Paris herrschte ein anderer Musikgeschmack als in Wien: viel Opernmusik, wenig Klaviermusik. Als er von dort an seine Wiener Freunde schrieb, dass „der Geschmack an Musik daselbst nur ein schlechter sei und man Beethovens Werke dort wenig kenne und spiele", erregte er damit ungewollt Beethovens Zorn, dem diese Mittteilung zu Ohren gekommen war. ${ }^{89}$ Allerdings entsprach diese Feststellung, wie man heute weiß, der damaligen Situation. ${ }^{90}$

In Paris wohnte Ries bei Jean André Saur (1754-1828), einem ehemaligen kurkölnischen Zollbeamten, ${ }^{91}$ der 1804 zum Senator und 1808 zum Comte de I'Empire ernannt worden war. Vater Ries kannte inn mit Sicherheit aus den gemeinsamen Zeiten am kurfürstlichen Hof. Saur wohnte in der Rue de Provence, einer Straße in dem damals sehr angesagten Viertel um die Chaussée d'Antin. In der Nähe lagen viele Theater, auch das Konservatorium. Simrocks Bruder Henri betrieb nicht unweit seinen Notenhandel, wohin sich 
Ferdinand gewiss oft begeben hat. Saur muss in seinem Haus häufig musikalische Soireen veranstaltet haben, zu denen sich junge Künstler bei ihm einfanden. Zu ihnen gehörte auch Adolph Müller, der Sohn des Bremer Musikschriftstellers Wilhelm Christian Müller, dem Ries 1830 den schon erwähnten autobiographischen Brief geschrieben hat. ${ }^{92} \mathrm{Er}$ berichtete nach Hause von seiner Bekanntschaft und dem gemeinsamen Musizieren mit "dem einzigen und talentvollen Schüler und Freund von Beethoven", und "Wir machen dort ... ganz vorzügliche Musik, und haben eine unerschöpfliche Quelle an Beethoven's Schüler Ries. ${ }^{\prime 93}$ Auch wenn ihm in Paris kein öffentlicher oder pekuniärer Erfolg beschieden war, war es künstlerisch eine sehr fruchtbare Zeit, in der Ries ungefähr 25 neue Werke schuf.

Als er in Paris sah, dass er sich dort wohl kaum musikalisch durchsetzen konnte, beschloss er im August 1808, nach Wien zurückzukehren. Allerdings war sein zweiter Aufenthalt in der Stadt nicht von langer Dauer. Österreich erklärte Frankreich am 9. April 1809 den Krieg, mit der Folge, dass es jetzt die Österreicher waren, die Ries zum Kriegsdienst einzogen. Seinen eigenen Angaben zufolge, war er schon mit anderen zur Ausbildung in die Kaserne geschickt worden, doch erfolgte der Angriff der Franzosen so schnell, dass alle derartigen Kriegsvorbereitungen nicht mehr sinnvoll schienen und die Rekruten nach Hause geschickt wurden. ${ }^{94}$ Im Mai wurde Wien bombardiert und eingenommen, so dass Ries nichts anderes tun konnte, als sich erneut nach Hause zu seiner Familie zu begeben.

Nach seiner Rückkehr nach Bonn begann er erneut, wie schon zwei Jahre zuvor, vorwiegend mit Beethovenschen Werken im Rheinland zu konzertieren. Allerdings erwiesen sich die Aufführungsmöglichkeiten unter den Bedingungen der französischen Besatzung als sehr begrenzt. Zudem strebte er nach den Begegnungen mit dem Wiener und Pariser Musikleben danach, auch auf internationaler Ebene Ruhm als Klaviervirtuose und Komponist zu erwerben. Da er von Kollegen gehört hatte, dass die russischen Adeligen Musiker außerordentlich gut bezahlten, und er annahm, dass sich die napoleonischen Expansionsbestrebungen nicht bis nach Russland erstrecken würden, traf er im Winter

$$
\text { I } n \& \& i s \& n \text {. }
$$

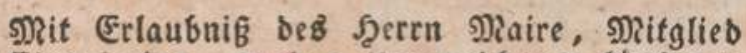
ber (E)brenlegion, werben Unterzei f) uete funftigen Samftag ben 15 ten December ein grofies Eoncert auker Dem Abounement ju geben Die Ebre baben, naci) folgendem Programme;

Duvertuire von Sies.

$$
\text { Erfer Ibeil: }
$$

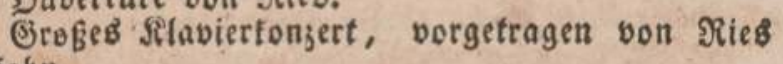
Solnt.

Quartett für 4 Singftimmen, obne Segleitung, bon Ric8.

3 weiter geil:

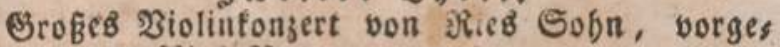
tragen bon Pieg 2 ater.

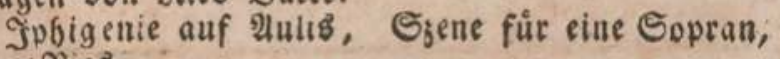
DoIl SRiez.

Santafie von গies.

Der. Eingangepreis ift 30 Stbr bie झerfon. Der 2nfang punttlid) 6 ubr. Willets fino an Der

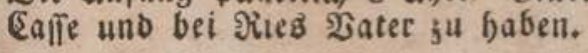

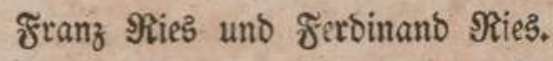
1810 die Vorbereitungen für eine Konzerttournee nach Skandinavien und Russland. Am 15. Dezember gab er gemeinsam mit seinem Vater als Solisten in Bonn ein "Abschiedskonzert", bei dem nur seine eigenen Werke aufgeführt

Konzertanzeige, Bonner Wochenblatt, 8. Dezember 1810 (Stadtarchiv Bonn) 
wurden: eine Ouvertüre, das große Klavierkonzert op. $115^{95}$ und das Konzert für Violine und Orchester op. 24, das er speziell für seinen Vater geschrieben hatte. ${ }^{96}$ Wahrscheinlich hat dieses Konzert im familieneigenen Redoutensaal des Englischen Hofes stattgefunden.

Ende Dezember 1810 brach er zu einer etwas mehr als zwei Jahre dauernden Konzerttournee nach Skandinavien und Russland auf. ${ }^{97}$ Auf dem Wege dorthin machte er Station in Marburg, Kassel, Hamburg und Kopenhagen, wo er jeweils mehrere Wochen oder gar Monate verbrachte, um in jeder dieser Städte private und öffentliche Konzerte zu geben. Über Finnland erreichte er im August 1811 St. Petersburg, wo er seinen Freund und Cello-Lehrer aus Bonn Bernhard Romberg wieder traf. Die beiden beschlossen, die Tournee gemeinsam fortzusetzen, die sie quer durch Russland nach Dorpat, Riga, Witebsk und Kiew führte. Ihren Plan, auch in Odessa, Kazan und Moskau zu konzertieren, mussten sie aufgeben, als die napoleonischen Truppen im September 1812 in Moskau einmarschierten. Damit war die französische Armee bereits zum vierten Mal der Entwicklung von Ries musikalischer Karriere in die Quere gekommen. Die beiden Musiker brachen notgedrungen ihre Tournee ab und kehrten nach St. Petersburg zurück. Da Ries davon überzeugt war, dass Napoleon es nicht wagen würde, auch England anzugreifen, fasste er den Entschluss, über Stockholm und Göteborg nach London zu reisen und in der dortigen, die Musiker von ganz Europa faszinierenden Musikwelt sein Glück zu versuchen. Seine größten Erfolge auf der Tournee durch Skandinavien und Russland feierte Ries in Stockholm, wo er gemeinsam mit dem Königlichen Hoforchester zwei große öffentliche Konzerte gab, in denen er vor allem neue, während der Reise komponierte Werke aufführte wie die Schwedischen Lieder mit Variationen für Klavier und Orchester op. 52, das Große Klavierkonzert mit einem russischen Rondo in e-Moll op. 42 und das in St. Petersburg geschriebene Klavierkonzert mit großem Orchester in cis-Moll op. 55. Die Mitglieder der Königlichen Schwedischen Akademie für Musik waren von seinem Klavierspiel und seinen Kompositionen so begeistert, dass sie ihn in einem Eilverfahren zum Ehrenmitglied der ausländischen Abteilung der Akademie ernannten. Es war für Ries eine Ehrung ganz besonderer Art, war es doch der Stuhl von Johann Georg Albrechtsberger, seinem und Beethovens Wiener Kompositionslehrer, auf den er berufen wurde. Neben seinen eigenen Werken spielte Ries in diesen Konzerten auch Werke von Beethoven, unter anderem das Klavierkonzert in c-Moll, op. 3798, mit dem er im Sommer 1804 erstmals öffentlich als Schüler Beethovens in Wien aufgetreten war. Nach sechs äußerst erfolgreichen Wochen in Stockholm machte er sich Anfang April 1813 auf den Weg nach London. Es war das Ende einer langen Tournee, die trotz aller Reisestrapazen so inspirierend war, dass er in jeder Stadt, in der er konzertierte, auch neue Kompositionen schuf. Mit diesen Werken hatte sich Ries eine eigene kompositorische Handschrift erarbeitet, die ihn sowohl von seinem Lehrer Beethoven 
als auch von den anderen Komponisten seiner Generation unterschied, so dass er voller Selbstvertrauen die Eroberung der Londoner Musikwelt ins Auge fassen konnte.

\section{London 1813-1824 - \\ Beethovens Mann in London}

Als Ries im April 1813 in London eintraf, war gerade unter besonderer Mitwirkung von Johann Peter Salomon, dem früheren Geigenlehrer seines Vaters Franz Anton, die Philharmonic Society gegründet worden. Unter seiner Leitung war kurz zuvor, am 8. März, das erste Konzert der neuen Gesellschaft gegeben worden. Auf dem Programm stand eine Sinfonie von Beethoven. ${ }^{99}$

Vermutlich hat Ferdinand Ries den alten Freund der Familie gleich nach seiner Ankunft in London aufgesucht, sie wurden im Laufe der nächsten zwei Jahre so eng miteinander vertraut, dass Salomon ihn zu seinem Testamentsvollstrecker einsetzte. Als Ries zum ers-

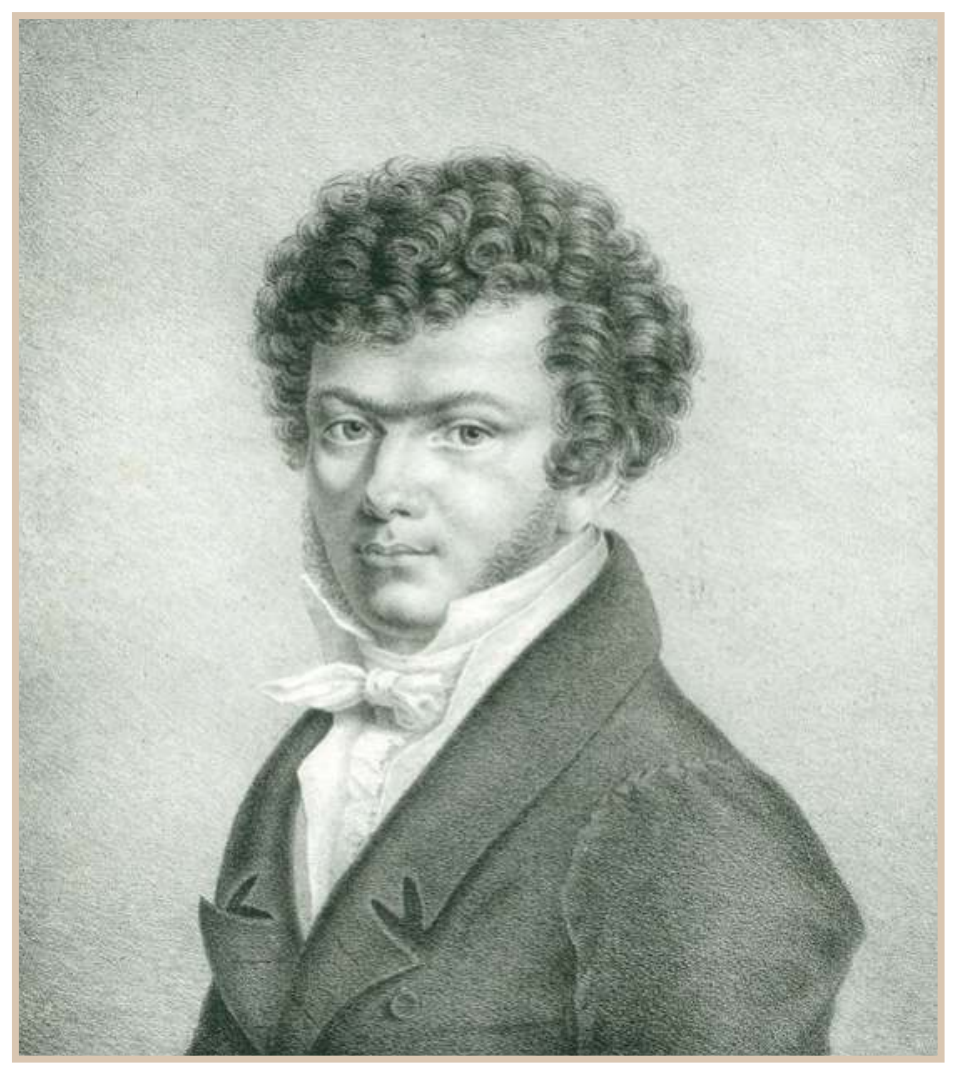
ten Mal am 14. Februar 1814 in der Philharmonic

Society auftrat, tat er das mit der Uraufführung einer neuen, im Auftrag der Gesellschaft geschriebenen Sinfonie. ${ }^{100}$ Aller Wahrscheinlichkeit nach handelte es sich dabei um die 5. Sinfonie op. 112. Der Erfolg seines virtuosen Klavierspiels und der Aufführungen seiner eigenen Werke war so durchschlagend, dass Ries sehr rasch in London Fuß fasste. 1815 wurde er Mitglied der London Philharmonic Society und noch im selben Jahr zu einem ihrer Direktoren ernannt. Die Gesellschaft bestellte bei ihm in den folgenden Jahren drei Sinfonien, eine Ouvertüre und eine Scena für Tenor und Pianoforte. In den elf Jahren, die Ries in London weilte, erlebten neun seiner Werke in der Philharmonic Society ihre Uraufführung. ${ }^{101}$ Er wurde bald zu einem regelrechten "Star" der Londoner Musikwelt, was schon allein daran abzulesen ist, dass er von 1815 an in jeder der vom Frühjahr bis zum Sommer dauernden Spielzeit der Philharmonic Society jeweils drei bis viermal als Komponist, Klaviervirtuose und Dirigent in den Argyll Rooms, dem Konzertsaal der Gesellschaft, aufgetreten ist. „Ries und Kalkbrenner haben, nach Cramer, wol den grössten Namen als Klavierlehrer und Componisten für das Pianoforte und Virtuosen auf diesem Instrumente," berichtete der Korrespondent der Allgemeinen musikalischen Zeitung 1818 aus London. "Ries vervollkommnet sein Spiel immer mehr, und wirklich, bis zum Erstaunen." ${ }^{102}$ Ries komponierte in seiner Londoner Zeit ca.

Ferdinand Ries (1784-1838). Lithografie von Leo Lehmann, 1811

(Privatbesitz) 
siebzig Werke, darunter fünf Sinfonien, zwei Ouvertüren, zwei Klavierkonzerte, ein Oktett, zwei Sextette, zwei Quintette und vier Quartette. Der Kreis seiner Schüler wuchs beständig. Im Juli 1814 hatte er die junge wohlhabende Londonerin Harriet Mangeon geheiratet und verkehrte mit ihr in einem großen Bekanntenkreis von angesehenen Musikern, Künstlern und Schauspielern.

Dass Beethovens Werke während Ries Londoner Jahre in keiner Spielzeit auf den Programmzetteln der London Philharmonic Society gefehlt haben, hat seinen Grund nicht zuletzt in Ries Engagement für die Musik seines berühmten Lehrers im Direktorium der Gesellschaft. Dieses fand seinen Höhepunkt 1817, als er Beethoven im Namen der Society den Auftrag für gleich zwei neue Orchesterwerke übermitteln konnte. Fertig wurde nur eines - es war die 9. Sinfonie. In dem berühmten Brief vom 9. Juni 1817, in dem er Beethoven die Einladung der Gesellschaft nach London und deren Kompositionsauftrag aussprach, teilte er ihm am Ende mit, auf wie großen Zuspruch er bei den Londoner Musikfreunden hoffen konnte: "Gestern Abends war unser letztes Concert, und Ihre schöne Sinfonie in A wurde mit außerordentlichem Beifall gegeben. Es macht einem furchtsam, uns Sinfonieschreibern nur zu denken, wenn man ein solches Werk sieht und hört." ${ }^{103}$

Wie in den alten Wiener Zeiten fungierte Ries seit 1815 auch in London als geschäftlicher Vermittler und Unterhändler Beethovens mit den dortigen Verlegern und korrigierte nach seinen Angaben die Fehler, die sich in die Druckvorlagen und Kopiaturen eingeschlichen hatten. ${ }^{104}$ Wie unersetzlich seine Tätigkeit in London für Beethoven war, lässt sich einem Brief entnehmen, den er 1825, ein Jahr nach der Rückkehr von Ries ins Rheinland an den Berliner Verleger Schlesinger gesandt hat. Er bot diesem zwei neue Violinquartette an und schrieb dazu: "Dieser Antrag dürfte Ihnen besonders deßwegen nicht unwillkommen seyn, weil Sie die Quartetten auch nach Paris und London schicken können. Seit mein Freund Ries nicht mehr in London ist, schicke ich selbst nichts mehr hin, da die Correspondenz und Besorgung mir zuviel Zeit raubt." ${ }^{105}$ Auch wenn vor allem im Riesschen Frühwerk Reminiszenzen an Beethoven zu hören sind - wie hätte dies angesichts seiner großen Nähe zu ihm auch anders sein können -, tritt seit den auf der Skandinavien- und Russland-Tournee komponierten Werken mehr und mehr ein eigener Stil, ein eigener "Klang" in seiner Musik hervor, der bereits von den Zeitgenossen als "romantisch" charakterisiert wurde. ${ }^{106}$ Sein eigener Kompositionsstil setzt sich von demjenigen Beethovens mehr und mehr ab. Ries antizipierte vieles von dem, was man gemeinhin für Neuerungen der Klavierkomponisten der Frühromantik hält. "Schuberts eindringliche harmonische Sprache, Mendelssohns expressive, süße Melodik, Chopins brillante Figuration - alle diese Merkmale" findet man bereits in seinen Werken. ${ }^{107}$ Ries Kompositionen mögen nicht die Tiefe und das Pathos von Beethovens Werken haben, dennoch hat er hinreißende Werke geschaffen, die späte Kritiker - überwältigt von Beethovens Musik -, als Folge 
der Kanonbildung im 19. Jahrhundert lange Zeit nicht als eigenständige Schöpfungen anerkennen wollten oder konnten. Vor allem seine Kammermusikwerke mit ihren überraschenden Modulationen und vielfältigen musikalischen Verzweigungen bereiten oft nicht nur einen wunderbaren Hörgenuss, sondern ebenso ein großes intellektuelles Vergnügen.

Beethoven selbst kannte die Riesschen Kompositionen und scheute sich nicht, ihm brieflich für seine Werke Anerkennung zu zollen. "Komponieren Sie fleißig, Mein liebes Erzherzöglein Rudolph und ich spielen ebenfalls von Ihnen, und er sagt, daß der gewesene Schüler dem Meister Ehre macht," schreibt er Ries 1819. ${ }^{108}$ In einem Brief von 1822, in dem er ihm mitteilt, dass er immer noch den Gedanken hegt, nach London zu kommen, kündigt er an: "Sie werden an mir den gerechten schäzer meines lieben, riesen' Schülers nunmehrigen großen Meisters finden". ${ }^{109}$

Die neue Sinfonie, die Beethoven für die Philharmonic Society schreiben wollte, war immer wieder Gegenstand von Briefen zwischen Wien und London, aber die Fertigstellung ließ auf sich warten. Auch Beethovens London-Reise kam schließlich nicht zustande. 1823 wandte sich Beethoven wieder einmal an Ries und kündigte auch eine Dedikation an: „Da Sie, wie es scheint, eine Dedication von mir bald wünschen, wie gern willfahre ich Ihnen, lieber als dem größten groBen Herrn entre nous. Der Teufel weiß, wo man nicht in ihre Hände gerathen kann. Auf der neuen Sinfonie (die 9te mit Chören) erhalten Sie die Dedication an Sie; - ich hoffe, endlich, die Ihrige an mich zu erhalten." ${ }^{\prime 10}$ Ries selbst hatte seinem Freund und Lehrer zwei Werke gewidmet: 1806 sein op. 1, von dem oben schon die Rede war, und die 1814 in London entstandene Sinfonie Nr. 2 c-Moll op. 80, die 1818 bei Simrock erschienen war. ${ }^{111}$ Beethoven zog es am Ende vor, die 9. Sinfonie dem preußischen König Friedrich Wilhelm III. zu widmen, offenbar in der Hoffnung, den Rothen Adlerorden $2^{\text {ter }}$ Klasse sowie ein größeres geldwertes Geschenk zu erhalten. ${ }^{112}$

1823 beauftragte Beethoven Ries erneut mit Verkaufsverhandlungen zur Herausgabe neuer Werke bei Londoner Verlegern, mit dem Vorsatz, diesmal eines der Werke der jungen Frau seines Freundes zu dedizieren. Offenbar hatte man ihm berichtet, dass Harriet Ries als Londoner Schönheit galt. Mehrere Briefe, in denen er seine Reise nach London ankündigt, enden stets mit den nachdrücklichen Grüßen an Ferdinands Frau. So auch in zwei Briefen von 1822, in denen es heißt: "Nun leben Sie recht wohl, küssen Sie Ihre schöne Frau, bis ich diese feierliche Handlung in Person selbst begehen kann" und "Gott mit Ihnen. Alles Schöne an Ihre Frau, bis ich selbst da bin. Geben Sie Acht; Sie glauben mich alt, ich bin ein junger Alter. - Wie immer Der Ihrige". ${ }^{113}$ Doch auch bei der Widmung an Harriet Ries blieb es am Ende nur beim Vorsatz. Zwar hatte Beethoven sie in einem Brief vom 16. Juli 1823 schon angekündigt. „Die Dedication an Ihre Frau konnte ich nicht selbst machen, da ich ihren Namen nicht weiß. Machen Sie also selbe im Namen Ihres und Ihrer Frau Freundes; 


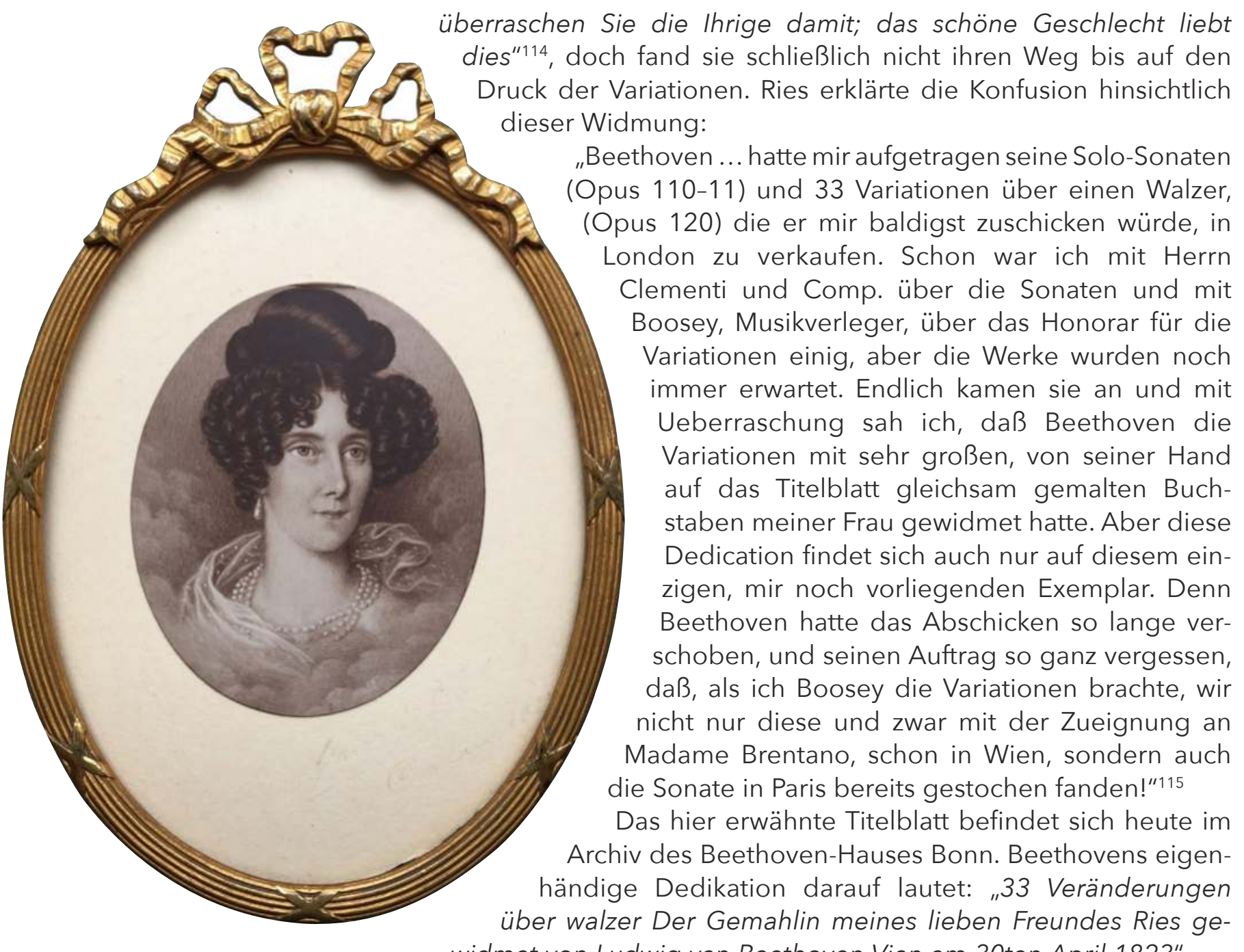

widmet von Ludwig van Beethoven Vien am 30ten April 1823".

In den frühen 1820er Jahren begann Ries darüber nachzudenken, Eng-

Harriet Ries, geb. Mangeon (1796-1863) (Privatbesitz) land zu verlassen und an den Rhein zurückzukehren. Sein Konzert- und Vortragsstil, das Nebeneinander von zarten gefühlvollen Passagen und dem Ausdruck "romantischer Wildheit" hatte das Londoner Publikum tief beeindruckt, wie dem Artikel "Memoir of Ferdinand Ries" in der führenden englischen Musikzeitschrift Harmonicon vom März 1824 zu entnehmen ist.

"Mr. Ries is justly celebrated as one of the finest piano-performers of the present day", heißt es da. "His hand is powerful, and his execution is certain, - often surprising. But his playing is most distinguished from that of all others by its romantic wildness. By means of strong contrasts of loud and soft, and a liberal use of the open pedals, together with much novelty and great boldness in his modulations, he produces an effect upon those who enter into his style, which can only be compared to that 


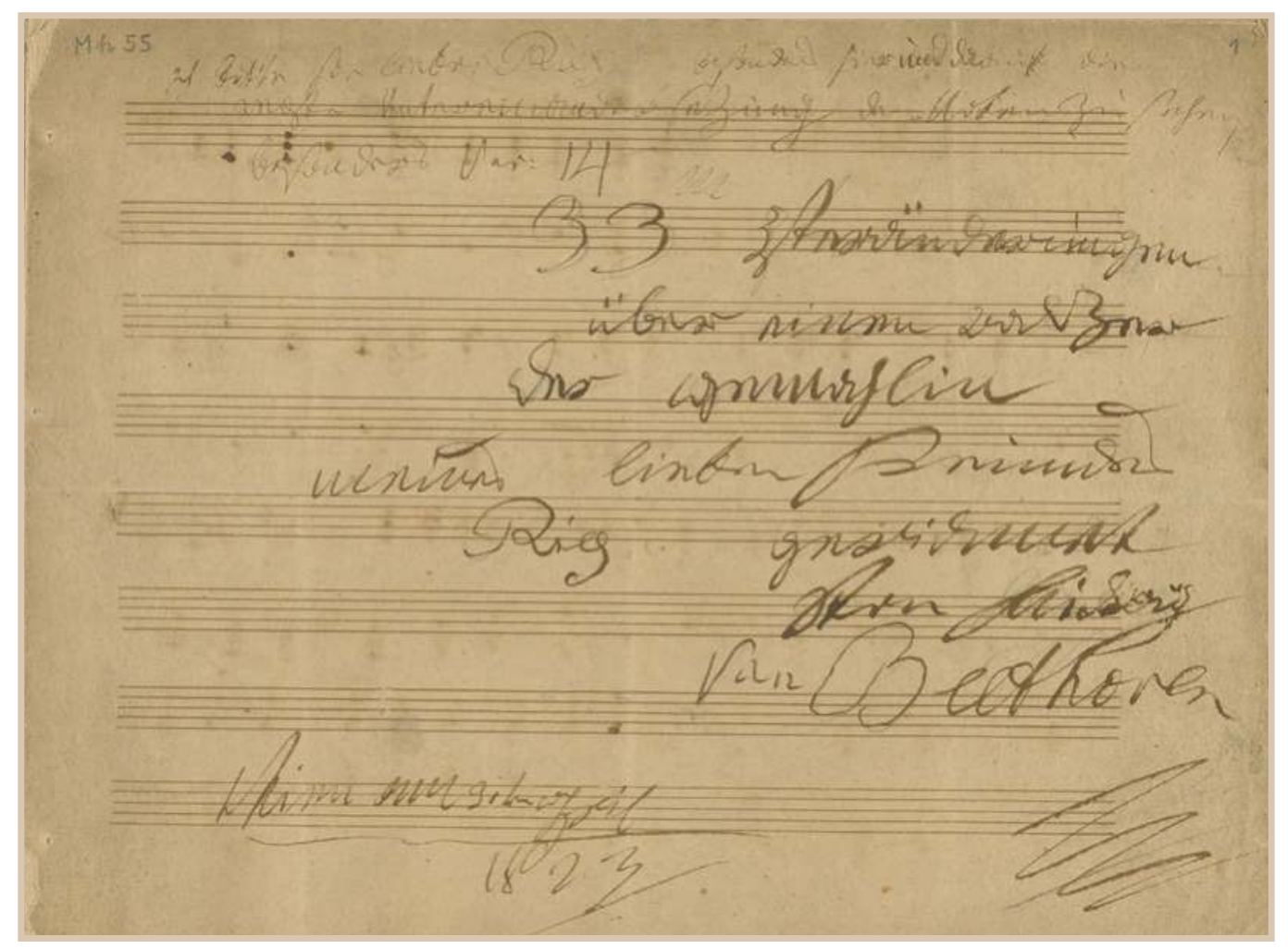

Titelseite der Diabelli-Variationen mit eigenhändiger Widmung von Beethoven (Beethoven-Haus Bonn, Sammlung H. C. Bodmer)

arising from the most unexpected combinations and transitions of the Aeolian harp. It is purely German, and shows him to be, - as we once before remarked, - a true-born native of that country to which, according to Richter, belongs the 'Empire of the air"'.116

\section{Rückkehr ins Rheinland}

Nachdem er am 3. Mai 1824 in den Argyll Rooms ein "Abschieds-Concert von England" gegeben hatte - es handelte sich um das eigens für diesen Zweck komponierte Klavierkonzert a-Moll op. 132 -, traf Ries Mitte Juli mit seiner Familie in Godesberg ein, wo er das so genannte Ries-Haus, das vom Vater erbaute ehemalige Logierhaus neben der Redoute, erwarb. Die Allgemeine Musikalische Zeitung versäumte es nicht, über die Rückkehr des inzwischen international gefeierten Komponisten in seine Heimatstadt zu berichten. So schloss der Artikel über das siebte Niederrheinische Musikfest in Köln von 1824 mit der Nachricht:

"Der bekannte Componist und Klavierspieler Ferdinand Ries ist am 14ten Julius mit seiner liebenswürdigen Familie aus London in Godesberg (einem Kurorte bey Bonn) angekommen, um hinfort in der Nähe seiner und seines Lehrers Beethoven und seines Freundes Salomon Geburtsstadt, Bonn, und bey seinem Vater und den Seinigen der Kunst zu leben. Wir dürfen hoffen, 
daß seine Verbindungen mit den hiesigen Kunstverständigen einen fördernden Einfluß unserer Stadt und Gegend haben werden und heißen ihn freundlich willkommen auf vaterländischem Boden." ${ }^{117}$

Dies hatte man wohl auch in Aachen gelesen, wo 1825 das Niederrheinische Musikfest erstmalig gastieren sollte. Schon Mitte Dezember 1824 trug das Aachener Komitee Ries die Leitung dieses Musikfestes an. Seine enge Beziehung zu Beethoven führte dazu, dass ihm das Komitee vorschlug, Beethoven neuestes Werk, die 9. Sinfonie op. 128 aufs Programm zu setzen. ${ }^{118}$ Die Ankündigung der Sinfonie als vom "Manuscript" gespielt lässt darauf schließen, dass die Aachener Aufführung noch vor dem Druck der Noten stattgefunden hat. Somit erlebte die 9. Sinfonie nach Wien und London ihre erste Aufführung im preußischen Deutschland 1825 in Aachen unter der Direktion von Ferdinand Ries.

Zuerst von Godesberg, später von Frankfurt am Main aus prägte Ferdinand Ries eine ganze Phase der Niederrheinischen Musikfeste, "dieser über das Rheinland hinaus wichtigen musikalischen Großveranstaltungen"119, und dies nicht ohne den Werken seines Freundes Beethoven einen wichtigen Platz einzuräumen. Von den insgesamt acht Musikfesten, die er zwischen 1825 und 1837 leitete, verging kaum eines, bei dem nicht eine Komposition von Beethoven erklungen wäre. Wenn Beethovens Musik in diesen Jahren im Rheinland eine außerordentlich starke Verbreitung gefunden hat, so ist dies in erster Linie Ferdinand Ries zu verdanken. ${ }^{120}$

Doch waren es nicht nur musikalische Angelegenheiten, die Ries und seinen Freund und Lehrer Beethoven in den verbleibenden drei Jahren vor dessen Tod miteinander verbanden. Im Dezember 1825 hatte Ferdinand Ries über seinen in Wien lebenden jüngeren Bruder, den Klavierbauer Joseph Franz, Beethoven sein Porträt mit der Widmung "meinem Freunde und Lehrer" zukommen lassen. ${ }^{121}$ Dem Bericht des Bruders zufolge "sey Beethoven ganz außer sich vor Freuden gewesen, er hätte es gar nicht aus der Hand legen wollen, und endlich, nachdem er es lange angesehen hat, ausgerufen: ,das ist doch noch der alte Junge, er hat mir viel Freude gemacht, wir Bönner sind doch ganze Kerls" ${ }^{\prime \prime 22}$. Ries wusste um Beethovens enge Verbundenheit mit der malerischen Gegend um Bonn und Godesberg, "in der [er] das Licht der Welt erblickte hatte"123. Deshalb lud er ihn ein und legte ihm ans Herz, bei ihm und damit in einer der schönsten Gegenden am Rhein eine Zeitlang zu leben. ${ }^{124}$ Vermutlich waren es seine Wiener Verpflichtungen und die Unannehmlichkeiten der damaligen Reisebedingungen, die den gesundheitlich bereits sehr geschwächten Freund davon abhielten, der Einladung ins Rheinland zu folgen. Schon früher hatte Beethoven mit dem Gedanken gespielt, einige Zeit bei Wegeler zu verbringen, der seit 1807 mit seiner Frau Eleonore und der Familie in Koblenz - der Heimat von Beethovens Mutter - lebte. 1825 antwortete Beethoven auf Ries' Vorschlag und schrieb: "Ich nehme den innigsten Antheil 


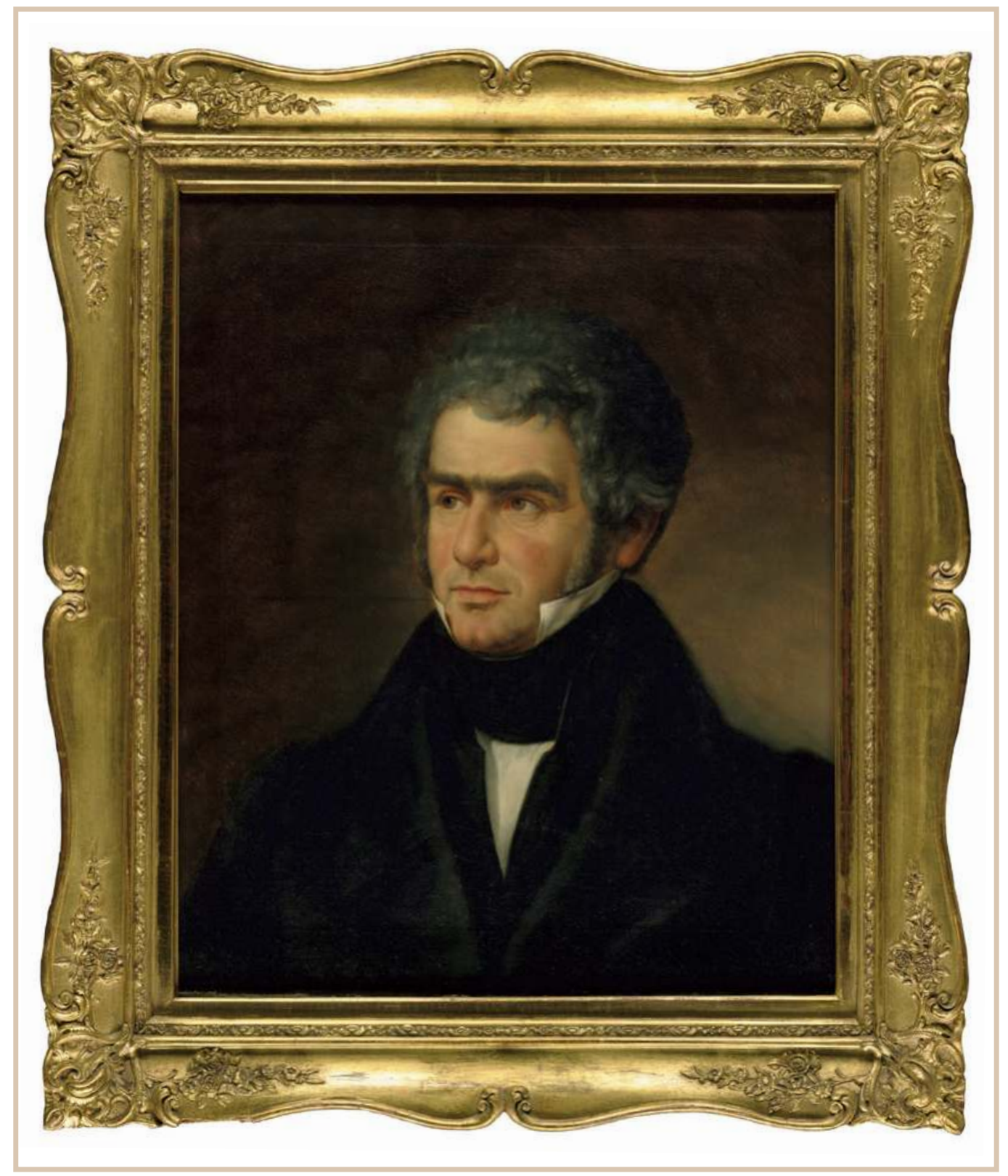

Ferdinand Ries (1784-1838). Ölgemälde, 1820er Jahre (Beethoven-Haus Bonn)

an Ihrem Besitzthum in Godesberg; kein Mensch kann eine neidischere Freude darüber haben, dessen höchste Wünsche ein solcher Besitz erfüllen würde."125 Auch drei Jahrzehnte in Wien hatten nicht bewirken können, dass er aufhörte, sich als Rheinländer zu fühlen.

In den drei Jahren von 1824 bis 1827, in denen Ries in Godesberg wohnte, komponierte er vorwiegend kammermusikalische Werke, darunter nicht weniger als fünf Streichquartette. Die romantische Landschaft in unmittelbarer Nachbarschaft des Siebengebirges, die für Jahrzehnte die erste Adresse der 
begüterten englischen Touristen auf ihrer Grand Tour in den Süden Europas sein sollte, inspirierte Ries zu seinem 8. Konzert für Klavier und Orchester, dem er den Beinamen Gruß an den Rhein gab. Aber letztlich erwies sich Godesberg trotz seiner pittoresken Schönheit als ein zu beschaulicher Ort, nicht nur für den ambitionierten Musiker, der Ries nach wie vor war, sondern ebenso für seine Frau Harriet, die als geborene Londonerin das Großstadtleben vermisste.1827 kehrte Ferdinand Ries daher Godesberg den Rücken und ließ sich mit seiner Familie in der großen Handelsstadt Frankfurt am Main nieder.

Dort erwarben er und seine Frau in der Hochstraße ein stattliches Haus, in dem sie auch einen Musiksaal einrichteten, der zum Treffpunkt von Musikern und Musikliebhabern von nah und fern wurde. Das geistige Klima dieser Stadt bescherte Ries neue Impulse. Hier machte er sich mit der Komposition der Räuberbraut zum ersten Mal auch einen Namen als deutscher Opernkomponist. Am 15. Oktober 1828 wurde sie in Frankfurt uraufgeführt und erlebte anschlieBend in vielen deutschen Städten zahlreiche Inszenierungen, deren Höhepunkt die Aufführung an der Königlichen Oper in Berlin im Beisein des Königs und des gesamten Hofstaates war. ${ }^{126}$

1831 begann für das Ehepaar Ries eine fünfjährige Lebensphase, die durch eine Abfolge von Gasttourneen quer durch Europa bestimmt war. 1832/33 unternahm er gemeinsam mit seiner Frau eine lange musikalische Bildungsreise nach Italien, die sie nach Mailand, Florenz, Rom, Neapel und Venedig führte. Im Laufe dieser Reise komponierte er sein letztes Klavierkonzert in g-moll op. 177 und sein letztes Streichquartett in f-moll WoO 48. 1836 war das Ziel Paris, wo sich unter dem „Bürgerkönig" Louis-Philippe ein außerordentlich aktiver bürgerlicher Musikbetrieb entwickelt hatte. Ries' größter musikalischer Erfolg war dort sein Werk Große Fest-Ouvertüre und Siegesmarsch op. 172, das 1834 in einem Konzert des Konservatoriums-Orchesters zum ersten Mal gespielt und anschlieBend noch über hundert Mal in Pariser Konzerten aufgeführt wurde. ${ }^{127} \mathrm{Ihr}$ rasanter finaler Festmarsch machte Ries in der Stadt geradezu populär. Im November nutzte die Konzertvereinigung Athénée musicale seinen Aufenthalt in der Stadt, um die Fest-Ouvertüre in seiner Gegenwart aufzuführen. ${ }^{128}$ Wo immer Ries in Paris auftrat, wurde er im Unterschied zu seinem ersten Aufenthalt in der Stadt ca. drei Jahrzehnte zuvor als international berühmter Pianist und Komponist glänzend empfangen. Giacomo Meyerbeer gab ihm zu Ehren ein großes Künstler-Diner, an dem fast die gesamte Pariser Musiker-Prominenz teilnahm. ${ }^{129}$

\section{Das Bonner Beethoven-Denkmal und die Biographischen Notizen über Ludwig van Beethoven}

Am 17. Dezember 1835, zum 65. Geburtstag Beethovens, wurde in Ries Heimatstadt unter dem Vorsitz von August Wilhelm von Schlegel der Bonner Verein für Beethovens Monument gegründet. Ein Spendenaufruf des Vereins erschien am 8. April 1836 in der von Robert Schumann herausgegebenen 
Neuen Zeitschrift für Musik. Um das Andenken an seinen verehrten Lehrer und Freund wach zu halten, scharte Ries in Frankfurt sofort ein "Comité aus 10 der ersten Kaufleute" um sich und organisierte ein Gedächtniskonzert, dessen Erlös ganz dem geplanten Beethoven-Denkmal in Bonn zugedacht war. ${ }^{130}$ Unterstützt von 90 Musikliebhabern im Orchester und Chor von Frankfurt fand das Konzert, in dem nur Werke von Beethoven erklangen und das der Rezensent der Neuen Zeitschrift für Musik geradezu als ein „Musikfest im Kleinen” bezeichnete, am 1. Juni 1836 im Hotel Weidenbusch statt. ${ }^{131}$ In seinem Mittelpunkt stand das von Ries gespielte 3. Klavierkonzert in c-moll, mit dem er 1804 zum ersten Mal als Schüler Beethovens in Wien aufgetreten war. ${ }^{132}$ Am 12. Juni bedankte sich August Wilhelm von Schlegel für den Erhalt von

„500 Thr. 14. ... Wir sind alle hocherfreut und Ihnen unendlich dankbar. Sie haben zugleich einen Beweis Ihres Patriotismus, Ihrer liebevollen Anhänglichkeit an den verewigten Beethoven und Ihrer eignen Meisterschaft abgelegt: denn nur einem berühmten Künstler desselben Faches konnte es in diesem Maaße gelingen. Wie entscheidend Ihr persönliches Ansehen für den Erfolg gewirkt, lässt sich schon an dem Ertrage anderer zu demselben Zwecke veranstalteter Concerte in ebenfalls bedeutenden Städten, mit dem Ihrigen verglichen, ermessen." 133

Schon früh waren Ries' Reminiszenzen an die Zeit, die er mit Beethoven verbracht hatte, auf großes Interesse gestoßen, wie der folgende Lexikon-Eintrag von 1833 deutlich macht.

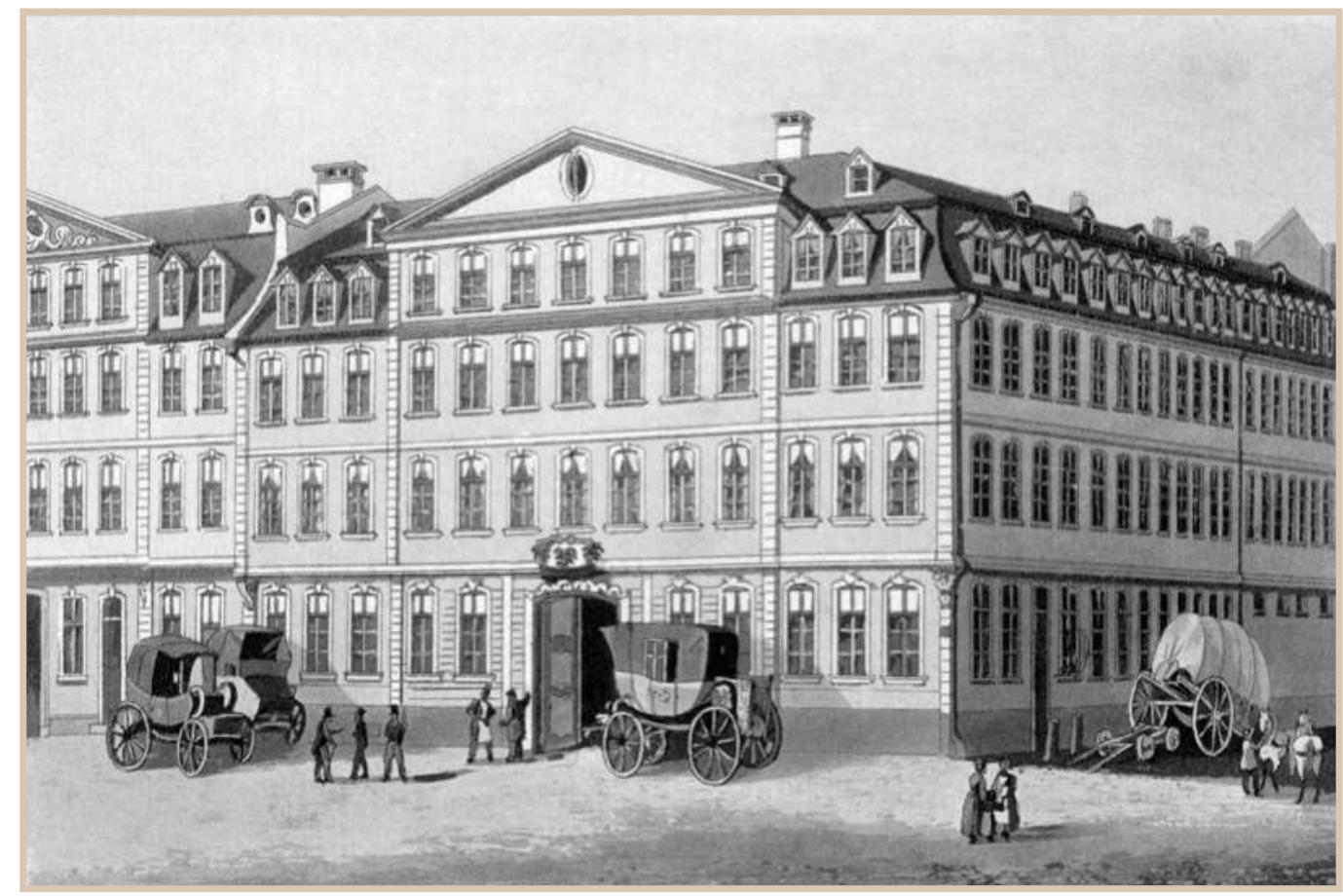

Hotel Weidenbusch, Frankfurt/Main. Lithografie von Frédéric Martens nach Friedrich Joseph Ehemant, 1836 (wikicommons) 
"Sehr anziehend sind die Berichte, welche R. über sein nahes Verhältnis zu Beethoven zu geben vermag, zumal da sein Zusammenleben mit diesem Meister nicht nur in die Zeit fällt, wo derselbe sich auf den höchsten Gipfel der Schöpfungskraft schwang, sondern auch in jene Zeit, wo Beethoven das Unglück hatte, sein Gehör zu verlieren. Je weniger in den Lebensbeschreibungen Beethoven's oder in dessen Nachlaß sich etwas Genügendes über die psychische Wirkung dieses Unglücks auf den großen Mann findet und wir überhaupt mit genauern Nachrichten über sein Wesen, die Art und Weise seines Componierens nur sehr spärlich versehen sind, desto mehr ist es zu wünschen, daß R. Memoiren über diese denkwürdige Zeit herausgeben möchte."134

Nachdem langgehegte Pläne zu einer Beethoven-Biographie von Franz Gerhard Wegeler in Zusammenarbeit mit Anton Schindler gescheitert waren, überzeugte Wegeler 1837 seinen Freund Ries, gemeinsam mit ihm alles das aufzuschreiben, was sie zur Biographie Beethovens erinnerten und sich durch schriftliche, insbesondere briefliche Quellen belegen ließ. Beide Autoren gehörten zu den ältesten Freunden des Komponisten und sahen es als ihre Pflicht an, die im Umlauf befindlichen Irrtümer und falschen Ansichten über Beethoven zu berichtigen. So wurde Beethoven zum großen Thema von Ries' letztem Lebensjahr. Mit Wegeler begann ein intensiver Austausch von Gedanken, Briefen und Dokumenten zur Abfassung der Biographischen Notizen über Ludwig van Beethoven. Die von Ries verfasste Zweite Abtheilung des Buches ist ein äußerst lebendiges Portrait der Person Ludwig van Beethovens, so wie er ihn als Jugendlicher in Wien, aber auch später von London und Godesberg aus erlebt hat. Aus der umfänglichen überlieferten Korrespondenz zwischen den beiden darf man schließen, dass Ries so gut wie alle Briefe des Freundes aufgehoben hat. Auf diesen Schatz stützte er sich bei der Abfassung seiner Erinnerungen und brachte daraus umfassende Zitate ein, gleichzeitig Belege seiner Erinnerungen als auch lebendige Zeugnisse von Beethovens eigener Hand. Wenn es in einer der jüngst erschienenen BeethovenBiographien heißt, dass „diese beiden wichtigen Informanten ... die einmalige Gelegenheit [versäumten], auch das Subjektivere, Emotionale in ihre Lebensbeschreibung einzubeziehen"135, so ist diese Behauptung zumindest für den von Ferdinand Ries formulierten Teil kaum nachzuvollziehen, wird darin doch gerade die menschliche Seite Beethovens besonders deutlich. Er schildert ihn eben nicht, wie es in der Literatur des 19. Jahrhunderts zunehmend zur Mode wurde, als „Titan”, als „Übermenschen”, als „Heroen”, sondern als Zeitgenossen, der bessere und schlechtere Eigenschaften besaß. Aber immer schimmert in Ries Bericht über seine damaligen Erlebnisse eine unwandelbare Verehrung, große Bewunderung und dankbare Treue zu seinem Lehrer und Freund durch. Beethoven rückt hier dem Leser so nahe wie in keiner anderen biographischen Schrift über ihn. 
Im Sommer 1837, während Ries zur Kur in Wiesbaden weilte, beschäftigte er sich neben den Biographischen Notizen auch intensiv mit der Musik Beethovens. "Meine Zeit dort habe ich ganz gut verbracht", schrieb er im Oktober an seinen Bruder Joseph,

„Weil ich für Schlesinger in Paris übernohmen habe, aus den Beethovenschen Klavierwerken 12 Violin Quartetten und 8 Violin Quintetten zu arrangieren die Arbeit selbst ist mir recht interessant und sehr angenehme Erinnerungen damit verknüpft, so daß ich schon 9 Quartetten und 2 Quintetten fertig habe. Ich bin mehreremal auf sehr kitzeliche, kritische Punkte gestoßen, jedoch viele davon werden sich sehr schön machen. Die Quintetten sind aus seinen Klavier Trios op. 70 - das hat viel Überlegung gekostet, auch sind sie schwer, aber gewiß machen sie sich gut."

Gleichzeitig berichtete er, dass

„Wegeler ... bald auf 8 Tage zu mir kommen [wird], um ein Werk über Beethovens Jugend und die Zeit, wo ich mit ihm lebte, mehreres Interessantes enthält, herauszugeben - der Ertrag geht zu Beethovens Monument, wozu ich schon tüchtig beygetragen habe." ${ }^{\prime 136}$

Die Arbeit von Wegeler und Ries an den Biographischen Notizen ging im Dezember 1837 in die finale Phase. Allein glücklichen Umständen ist es zu verdanken, dass Ries am 28. Dezember noch brieflich zu wichtigen Punkten seines Manuskripts Stellung nehmen konnte. Keine zwei Wochen später, am 12. Januar erhielt Wegeler die Nachricht, dass sein Freund plötzlich schwer erkrankt sei. Schon einen Tag später, am 13. Januar 1838, starb Ferdinand Ries mit 53 Jahren in Frankfurt am Main an Typhus. ${ }^{137}$ Zum Gedenken an ihn erklang eine Woche später im Konzertsaal der London Philharmonic Society der Trauermarsch aus Beethovens Eroica. ${ }^{138}$ Die Zeitschrift The Musical World gedachte seiner mit einer ausführlichen Würdigung seiner Musik und seines langjährigen Wirkens in London. ${ }^{139}$

Die Herausgabe der Biographischen Notizen lag nun allein in den Händen von Franz Gerhard Wegeler. Das Buch erschien im Mai 1838 im Koblenzer Verlag Karl Baedeker. Es sollte zu einem literarischen Denkmal für Ludwig von Beethoven werden, das in viele Sprachen übersetzt, zur Keimzelle jeder weiteren Beschäftigung mit dem Leben des Komponisten wurde. ${ }^{140}$

Bei der feierlichen Eröffnung des ersten Beethovenfests in Bonn 1845 waren Franz Gerhard Wegeler und Franz Anton Ries als die ältesten noch lebenden Freunde Beethovens zugegen. Ferdinand Ries war bereits seit sieben Jahren tot, doch war er nicht vergessen, wie dem Bericht des Korrespondenten der Illustrated London News über die Bonner Feierlichkeiten zu entnehmen ist. Er versäumte nicht, daran zu erinnern: "Beethoven never had but two pupils - the Archduke Rodolph (sic!), and Ferdinand Ries."141 
Vgl. Memoir of Ferdinand Ries, in: The Harmonicon XV, 1824, S. 33. In der Forschung wird allgemein davon ausgegangen, dass dieses Memoir auf Ries Mitteilungen an den Herausgeber der Zeitschrift Harmonicon William Ayrton beruht.

Vgl. INGE FORST, Stationen Bonner Musikgeschichte VI: Die Musikerfamilie Ries, in: Bonner Musikkalender 38, 1989, S. 32-35. Von Ries sind zwei Offertorien, vier Marianische Antiphonen, ein Stabat Mater und eine Missa Sancti Huberti aus dem Jahr 1756 erhalten

Vgl. Dies. (Hg.), Johann Ries (1723-1784), Missa Sancti Huberti für Soli, vierstimmig gemischten Chor, Orchester und Orgel, Partitur, Sankt Augustin 1989

Vgl. Adolf SANDBERger, Die Inventare der Bonner Hofkapelle, in: DeRS., Ausgewählte Aufsätze zur Musikgeschichte, 2 Bde, München 1924, hier Bd. 2, S. 109-130, hier S. $112 \mathrm{ff}$

ERNST LUDWIG GERBER, Historisch-Biographisches Lexicon der Tonkünstler, welches Nachrichten von dem Leben und Werken musikalischer Schriftsteller, berühmter Componisten, Sänger, Meister auf Instrumenten, Dilettanten, Orgel- und Instrumentenmacher, enthält, Leipzig 1790-1792, Zweiter Theil, Leipzig 1792, Sp. 291

Vgl. Alexander Wheelock Thayer, Ludwig van Beethovens Leben. Neu bearbeitet und ergänzt von HeRMANn Deiters, Bd. 1, Berlin 21901, S. 177

"1787/obierunt Adulti/ Mense Januario/ die. 22. Joannes Riess/ Colonia. In: Stadtarchiv Bonn (StAB), KB 4/17, S. 37

Franz Anton Ries machte 1838 gegenüber der Kölnischen Zeitung die folgende Angabe: "Beethoven, der Capellmeister, wohnte in der Bonngasse in dem an das jetztige Posthaus anstoßenden Hause Nr. 386, und starb daselbst. Da meine Eltern mit mir gerade nebenan Nr. 387 wohnten, so darf ich auf volle Glaubwürdigkeit Anspruch machen." Zitiert nach THAYER, Beethovens Leben (wie Anm. 6), Anhang VIII, S. $452 f$

Josef Dietz, Topographie der Stadt Bonn, 2 Bde (Bonner Geschichtsblätter 16/17), Bonn 1962, hier Bd. 1, S. 281

10 Vgl. Max Braubach, Die Mitglieder der Hofmusik unter den vier letzten Kurfürsten von Köln, in: Siegfried Kross und Hans SChmidt (Hgg.), Colloquium Amicorum. Joseph Schmidt-Görg zum 70. Geburtstag, Bonn 1967, S. 36. In den Hof-Kalendern erscheint sie von 1765 bis 1794

Nach THAYER, Beethovens Leben (wie Anm. 6), S. 30, erfolgte am 1.3.1756 seine Anstellung als Violinist auf Bittgesuch seines Vaters Laurent Treves (Drewer), eines kurfürstlichen Schützen

Ebd., S. 175.

Ebd., S. $183 f$

Stammbaum der Familie Ries, Privatbesitz.

Vgl. ElisABETH Reisinger, Sozialisation - Interaktion - Netzwerk, in: BIRGIT LOdES, ElisABETH REISINGER und JOHN D. WILSON (Hgg.), Musik am Bonner kurfürstlichen Hof, Band 1 Beethoven und andere Hofmusiker seiner Generation. Bericht über den internationalen musikwissenschaftlichen Kongress Bonn, 3. bis 6. Dezember 2015 (Schriften zur Beethoven-Forschung 29; Musik am kurfürstlichen Hof 1), S. 179-198, hier S. 193 Anm. 42.

Vgl. THAYER, Beethovens Leben (wie Anm. 6), S. $238 f$

Vgl. JOHN D. WILSON, Das Bonner Opernleben zur Zeit des jungen Beethoven (Begleitpublikationen zu Ausstellungen des Beethoven-Hauses 24), Bonn 2015, S. 15

Vgl. ebd., S. $181 \mathrm{f}$ 


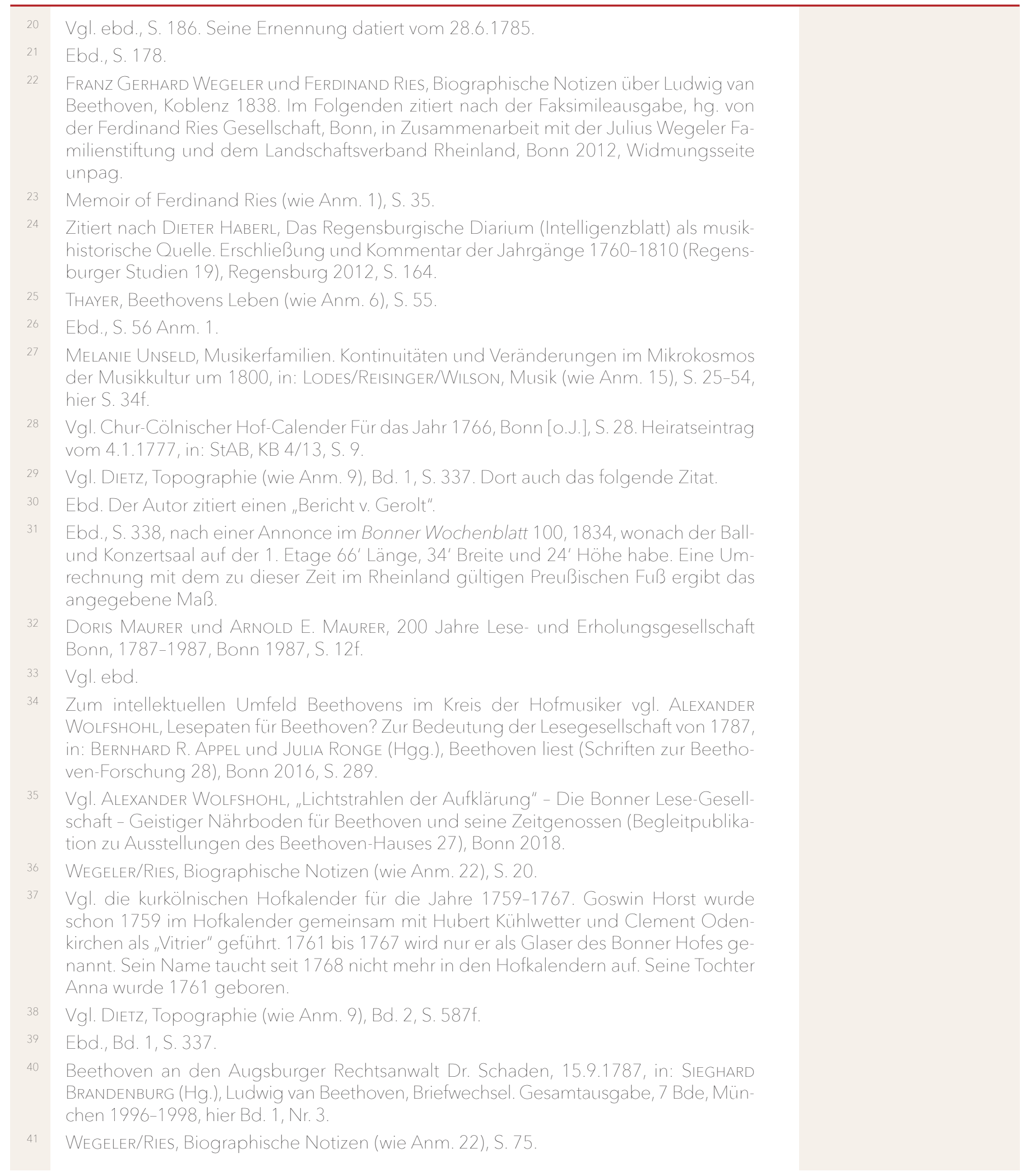

„Wir Bönner sind doch ganze Kerls!“ - Beethoven und die Bonner Musikerfamilie Ries | 333 
Vgl. THAYER, Beethovens Leben (wie Anm. 6), S. 268 Anm. 1.

Vgl. ebd

Vgl. JOHn D. Wilson, Opernleben (wie Anm. 17), S. 10.

45 Michael ladenburger, Beethoven auf Reisen, Bonn 2016, S. 66. Vgl. hierzu und zum Folgenden auch den Beitrag von JULIA RONGE in diesem Band

46 Der Geistliche Carl Ludwig Juncker berichtete hierüber ausführlich: Noch etwas vom Kurköllnischen Orchester, in: Musikalische Korrespondenz der teutschen Filarmonischen Gesellschaft 47, 23.11.1791, Sp. 373-376, und 48, 30.11.1791, Sp. 379-382. Dort auch die folgenden Zitate.

47 Vgl. zum Gesamtzusammenhang NORbert SCHLOSSMACHER, „.... prickelnd, wie Champagner. Zur Geschichte des Bad Godesberger Wassers, in: Godesberger Heimatblätter 41, 2003, S. 54-88. Zur Baugeschichte des „kurfürstlichen” Godesberg vgl. WILFRIED Hansmann, Die Bau- und Kunstgeschichte, in: Dietrich Höroldt (Hg.), Bonn als kurkölnische Haupt- und Residenzstadt (Geschichte der Stadt Bonn 3), Bonn 1989, S. 351-448, hier S. 441-448. Bereits in einem zeitgenössischen Reisebericht heißt es über "die hiesigen Hotels garnis": "Sechs derer, nämlich zum Kaiser, Erzherzog, zum Herzog von York, Prinz von Coburg, zum Prinz von Oranien und das Rissische \{Ries, B. M.-M.\} Haus stehen mit dem Redoutenhause ... in gleicher Linie." Briefe eines Reisenden an seinen Freund ueber den Aufenthalt beim Godesberger Gesundheitsbrunnen, Godesberg 1793, S. 19 (ND 1978, Verein für Heimatpflege und Heimatgeschichte Bad Godesberg).

LADENBURGER, Reisen (wie Anm. 45), S. 74.

Vgl. ebd., S. 9

Nach dem "Münsterschen Hofstaatsentwurf" von Kurfürst Maximilian Franz, undatiert, zitiert nach THAYER, Beethovens Leben (wie Anm. 6), S. 319

51 FrIedRICH Albert KLeBE, Reise auf dem Rhein durch die deutschen Staaten..., 2 Bde, Frankfurt/Main 1801/02, zitiert nach NORBERT SCHLOSSMACHER, Die Redoute in Bad Godesberg - Schauplatz einer denkwürdigen Begegnung zwischen Joseph Haydn und Ludwig van Beethoven im Sommer 1792, in: INGRID BODSCH (Hg.), Joseph Haydn und Bonn. Katalog zur Ausstellung, Bonn 2001, S. 101-113, hier S. 110.

BRANDENBURG, Beethoven. Briefwechsel (wie Anm. 40), Nr. 17

Vgl. TheOdOR Anton Henseler, Das musikalische Bonn im 19. Jahrhundert (Bonner Geschichtsblätter 13), Bonn 1959, S. $18 f$.

54 Vgl. ebd., S. 28-30

55 CECIL HILL, Ferdinand Ries. Briefe und Dokumente (Veröffentlichungen des Stadtarchivs Bonn 27), Bonn 1982, Nr. 128. Ries hatte vermutlich darüber berichtet, dass er jede Woche eine kleine Musikpartie organisierte, woran der Vater immer teilnahm und dass es diesem gut gehe.

WEGELER/RIES, Biographische Notizen (wie Anm. 22), S. XIV.

Vgl. Henseler, Bonn (wie Anm. 53), S.198.

Statt des korrekten Vornamens Franz Anton wurde auf die Grabplatte irrtümlich der Vorname Franz Xaverius eingraviert. Laut Taufeintrag im Kirchenbuch von St. Remigius vom 10.11.1755 lauten seine Vornamen Antonius Franciscus. Vgl. StAB, KB 4/11.

Vgl. Ansgar KleIn (Bearb.), Bonner Straßennamen. Herkunft und Bedeutung (Veröffentlichungen des Stadtarchivs Bonn 70), Bonn 22012, S. 281

Vgl. Ludwig UeBerfeldT, Ferdinand Ries' Jugendentwicklung, Bonn 1915, S. 2.

Wegeler/RIES, Biographische Notizen (wie Anm. 22), S. V-VI. 


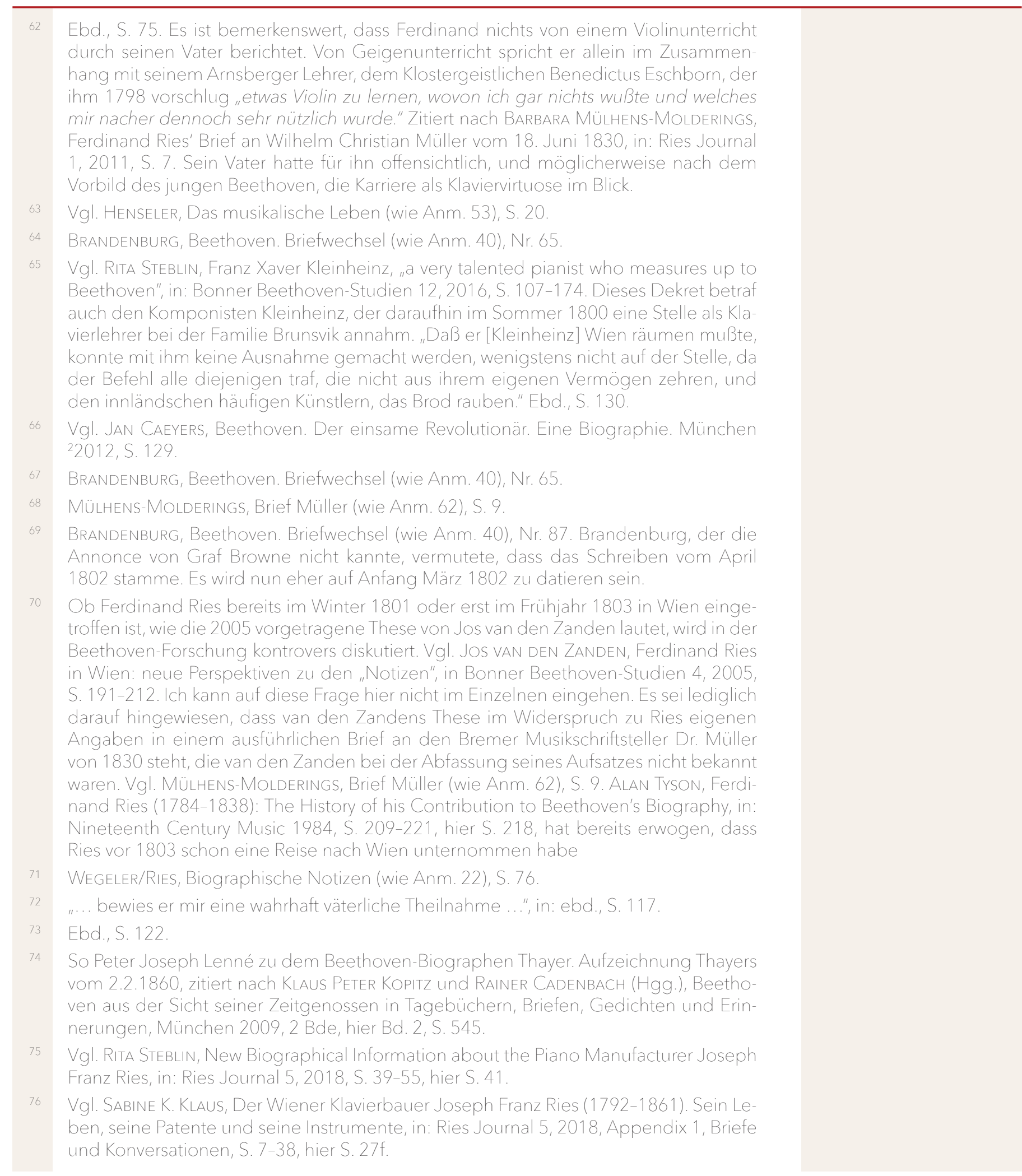

„Wir Bönner sind doch ganze Kerls!“ - Beethoven und die Bonner Musikerfamilie Ries | 335

(C) 2020 by Böhlau Verlag GmbH \& Cie. KG, Köln

https://doi.org/10.7788/9783412519704 | CC BY-NC 4.0 
Freundliche Mitteilung von Rita Steblin vom 7.7.2019. Rita Steblin hat im Herbst 2018 begonnen, teilweise unterstützt von der Autorin, die Aktivitäten der Kinder des Ehepaars Ries-Drewer zu erforschen.

Vgl. Wegeler/RIES, Biographische Notizen (wie Anm. 22), S. 87

Ebd., S. 100.

Vgl. HILL, Briefe (wie Anm. 55), Nr. 14. Zu Beethoven und seinen Paris-Plänen vgl. PHILIPP LEIBBRANDT, "daß um sein Glück zu machen, Paris besser als wien sey”. Beethoven, Paris und das Tripelkonzert op. 56, in: Die Tonkunst 12, 2018, S. 41-48,

Wegeler/RIES, Biographische Notizen (wie Anm. 22), S. $113 f$. Bericht über das Konzert in: Allgemeine musikalische Zeitung (AMZ) VI, 1804, Sp.776. 
eigenes handschriftliches Werkverzeichnis bis 1830 in: MüLhENS-MOLDERINGS, Brief Müller (wie Anm. 62), S. 9f.

Vgl. AMZ 1818, 2, S. 674.

In: HILL, Briefe (wie Anm. 55), Nr. 60

Beethoven bittet Ries um Korrekturen seiner nach London zum Verkauf geschickten Werke, z. B. im Jahr 1819, vgl. BRANDENBURG, Beethoven. Briefwechsel (wie Anm. 40), hier Bd. 4, Nr. 1294 und 1295 vom 8.3. und 19.3.1819.

Ebd., Bd. 6, Nr. 2015 vom 19.7.1825

Memoir of Ferdinand Ries (wie Anm. 1), S. 35.

Susan Kagan, Ferdinand Ries. Piano Sonatas und Sonatinas 2, Booklet zur CD 2009, S. $5 f$.

BRANDENBURG, Beethoven. Briefwechsel (wie Anm. 40), hier Bd. 4, Nr. 1302 vom 25.5.1819. Ebd., Bd. 4, Nr. 1479 vom 6.7.1822.

Wegeler/RIES, Biographische Notizen (wie Anm. 22), S. 155

Ob Beethoven letztere erhalten hat oder ob sie in der bekannten Unordnung seiner Manuskripte untergegangen war, ist nicht bekannt. In jedem Fall hatte Ries die Sendung des Drucks im August 1819 bei Simrock in Bonn in Auftrag gegeben. Vgl. Brandenburg, Beethoven, Briefwechsel (wie Anm. 40), hier Bd. 4, Nr. 1479, Anm. 3

Vgl. König Friedrich Wilhelm von Preußen an Beethoven vom 25.11.1826 und Beethoven an Wegeler vom 10.12.1826, in: BRANDENBURG, Beethoven. Briefwechsel (wie Anm. 40), hier Bd. 6, Nr. 2231 und 2236

Wegeler/Ries, Biographische Notizen (wie Anm. 22), S. 153, 155.

Brandenburg, Beethoven. Briefwechsel (wie Anm. 40), hier Bd. 5, Nr. 1703

Wegeler/Ries, Biographische Notizen (wie Anm. 22), S. 123

Memoir of Ferdinand Ries (wie Anm. 1), S. 35.

AMZ XXVI, 1824, Sp. 602

Vgl. ReInHOld Sietz, Die Niederrheinischen Musikfeste in Aachen in der ersten Hälfte des 19. Jahrhunderts, in: Zeitschrift des Aachener Geschichtsvereins 72, 1960, S. 109-164, hier S. 115

KLAus W. NiemÖLler, Eine musikalische Freundschaft. Sibylle Mertens-Schaaffhausen und Ferdinand Ries, Dirigent der Niederrheinischen Musikfeste, in: Ries Journal 2 , 2012, S. 3-27.

BRÜMMER, Beethoven (wie Anm. 83), S. 59

Franz Gerhard Wegeler an Beethoven, 28.12.1825, in: BRANDENBURG, Beethoven, Briefwechsel (wie Anm. 40), hier Bd. 6, Nr. 2100.

Ferdinand Ries an Peter Joseph Ries, 1.2.1826, in: HILL, Briefe (wie Anm. 55), Bd. 6, Nr. 157

WeGELER/RIES, Biographische Notizen (wie Anm. 22), S. 22

Ebd., S. 163

Brandendurg, Beethoven. Briefwechsel (wie Anm. 40), hier Bd. 6, Nr. 1935 vom 11.2.1825.

Vgl. Ferdinand Ries an seinen Bruder Joseph, 23.2.1831, in: HILL, Briefe (wie Anm. 55),

Bd. 5, Nr. 322

Vgl. Ferdinand Ries an Dr. Schuster, 30.12.1836, in: ebd., Nr. 471

Vgl. Revue et Gazette musicale de Paris 51,1836, S. $445 f$ 


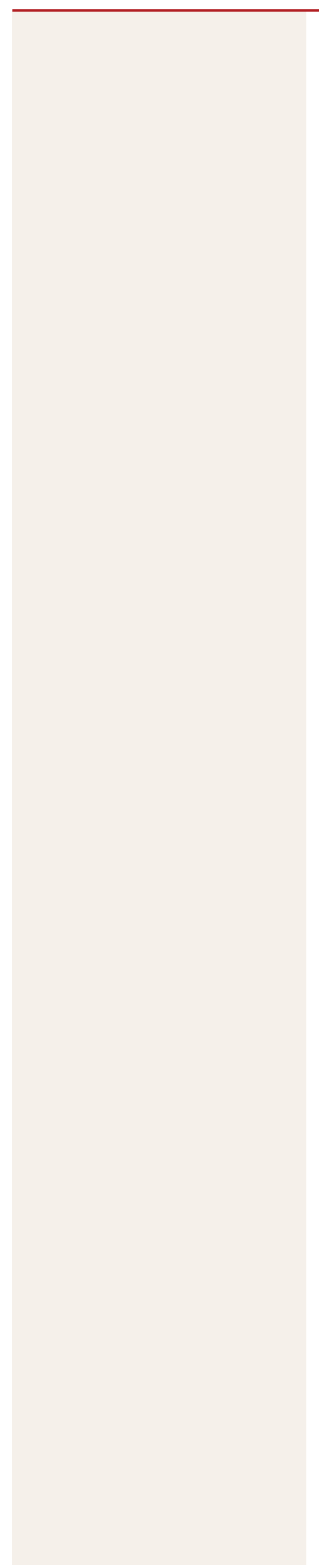

Vgl. Ferdinand Ries an Dr. Schuster, 30.12.1836, in: HILL, Briefe (wie Anm. 55), Nr. 471.

130 Vgl. Ferdinand und Harriet Ries an Joseph Ries, 5.5.1836, in: ebd., Nr. 454.

131 Das Konzert war ursprünglich für den 30.5.1836 geplant. Vgl. Hill, Briefe (wie Anm. 56) Brief 454. Tatsächlich fand es erst am 1.6.1836 im Hotel Weidenbusch statt. Vgl. INGRID FuCHS, Die Briefe von Ferdinand Ries im Archiv der Gesellschaft der Musikfreunde in Wien, in: Ries Journal 6, 2020 (im Druck). Der große Speisesaal des Hotels diente der Frankfurter Museumsgesellschaft von 1832 bis 1860 als Konzertsaal und bot Platz für über 1000 Personen. Hier traten alle berühmten Künstler bei ihren Gastspielen in Frankfurt auf.

Vgl. HILL, Briefe (wie Anm. 55), Nr. 453.

Ebd., Brief 459.

Conversations-Lexicon der neuesten Zeit und Literatur [F.A. Brockhaus] 3, Leipzig 1833, S. 772

135 CAEYERS, Beethoven (wie Anm. 71), S. 183.

136 Ferdinand Ries an Joseph Ries, 21.10.1837, in: HILL, Briefe (wie Anm. 55), Nr. 499. Laut Hill wurden die in dem Brief genannten Notenmanuskripte bis 1982 nicht gefunden. Stammbaum der Familie Ries, Privatbesitz.

The Musical World, 26.1.1838, XCVIII - New Series IV, S. 57. - Ries war bis zu seinem Tod Mitglied der London Philharmonic Society.

139 Ebd., S. 53.

140 Vgl. Michael Ladenburger, Vorwort in Wegeler/Ries, Biographische Notizen (wie Anm. 22), unpaginiert.

141 Illustrated London News, 23. 8.1845, S. $116 f$. 


\section{"ein sehr heller Punkt meines Lebens"- Franz Gerhard Wegeler und Ludwig van Beethoven}

$\mathbf{M}$ it diesen Worten beschrieb Wegeler (2. August 1765 - 7. Mai 1848) Ende Dezember 1825 Beethoven die Bedeutung, die ihre Beziehung für ihn hatte:

"Mir wenigstens ist die Bekanntschaft und die enge, durch deine gute Mutter gesegnete, Jugendfreundschaft mit dir ein sehr heller Punkt meines Lebens, auf den ich mit Vergnügen hinblicke und der mich vorzüglich auf Reisen beschäftigt. Nun sehe ich an dir wie an einen Heros hinauf, und bin stolz darauf sagen zu können: ich war nicht ohne Einwürkung auf seine Entwicklung, mir vertraute er seine Wünsche und Träume, und wenn er später so häufig miskannt ward, ich wußte wohl, was er wollte. Gottlob, daß ich mit meiner Frau, und nun später mit meinen Kindern von dir sprechen darf; war doch das Haus meiner Schwiegermutter mehr dein Wohnhaus als das deinige, besonders nachdem du die edle Mutter verloren hattest." 1

Hier klingt bereits an, was sich bei genauerer Durchsicht des Briefwechsels bestätigt: Die Briefe Beethovens an seinen Bonner Jugendfreund gehören zu den intimsten überhaupt. Die wenigen (erhaltenen) Briefe sind durchweg inhaltsreich und markieren wichtige Punkte in Beethovens Leben. Den mit "Dein uralter Freund Wglr." unterzeichneten Brief nahm Joseph Franz Ries von Bonn mit nach Wien. Ries arbeitete in Wien als Klavierbauer und war anlässlich des 70. Geburtstags seines Vaters Franz Anton Ries, einst Beethovens Geigenlehrer und Kollege in der Bonner Hofkapelle, nach Godesberg gereist. Auch Wegelers Frau Eleonore, geborene von Breuning, fügte einen Brief bei, in dem sie von ihren beiden Kindern berichtete. Beide versuchen, Beethoven eine Reise in die Heimat schmackhaft zu machen und laden ihn nach Koblenz ein, wo Wegeler als Medizinalbeamter in preußischen Diensten stand. Aus Eleonores Schreiben wissen wir auch, wodurch ihr Mann sich Ausgleich zur Arbeit verschaffte:

„Er hatt ein großes Vergnügen die Thema's ihrer Variationen zu Spielen, die Alten stehn oben an doch übt er manchmal mit unglaublicher Geduld ein neues ein - Ihr Opferlied steht an der Spize - nie kömpt er in's Wohnzimmer ohne an's Clavier zu gehen - schon daraus lieber Beethoven! können sie sehn, in welch immerdauerndem Andenken sie bei uns leben - sagen sie uns doch einmal daß dies einigen Werth für sie hatt, $u$. daß auch wir nicht ganz von ihnen vergeßen sind - "2.

Auf diese Bestätigung mussten die Wegelers allerdings über ein Jahr warten, sie fiel dann aber umso herzlicher aus. Am 7. Dezember 1826 diktierte Beethoven bereits bettlägerig seinem Neffen Karl: 
Franz Gerhard Wegeler (1765-1848).

Ölgemälde von Johann

Heinrich Richter,

Koblenz, 1839

(Beethoven-Haus Bonn)

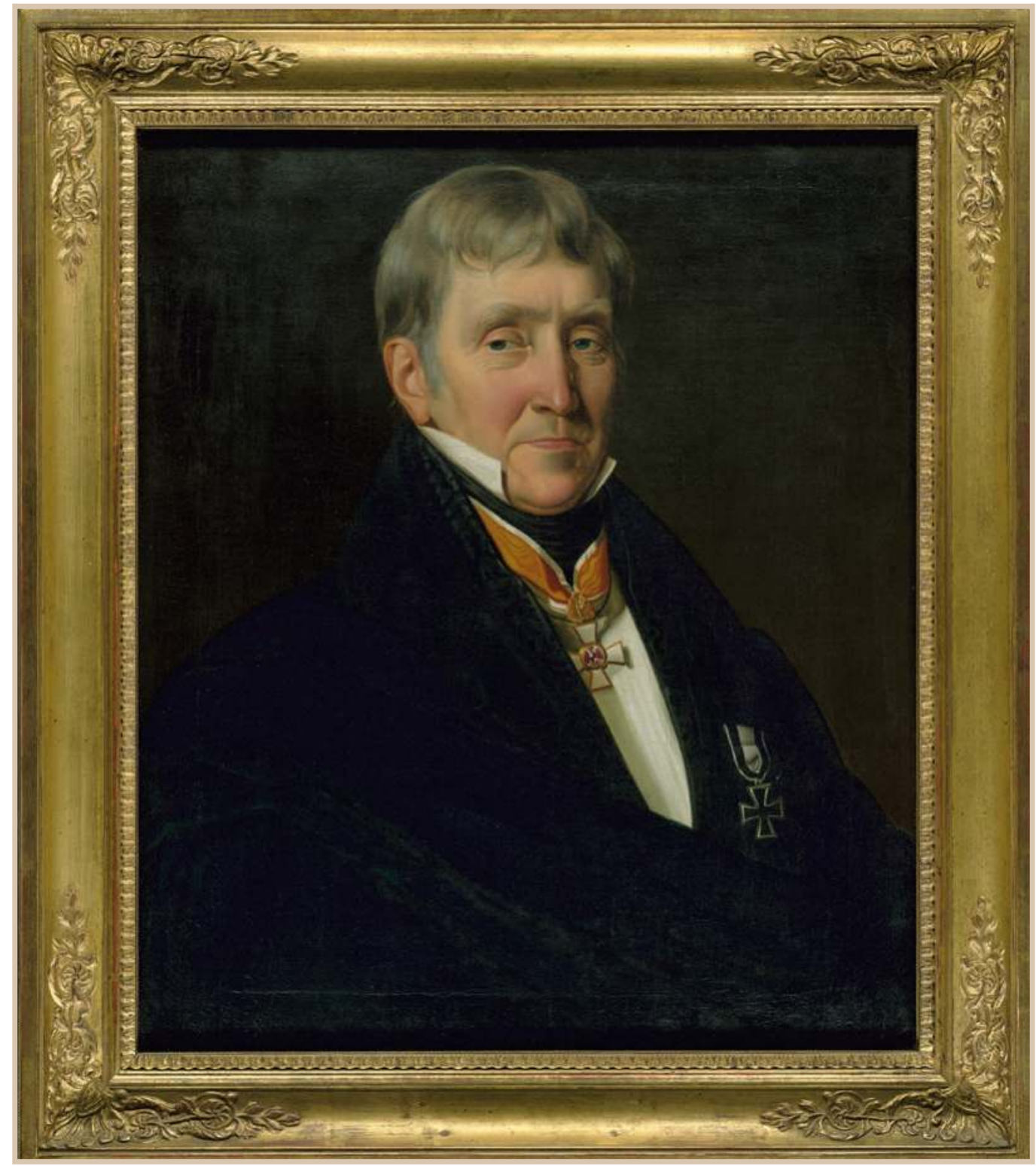

„Welches Vergnügen mir dein, u. deiner Lorchen Brief verursachte, vermag ich nicht auszudrücken. Freylich hätte pfeilschnell eine Antwort darauf erfolgen sollen; ich bin aber im Schreiben überhaupt etwas nachlässig, weil ich denke, daß die bessern Menschen mich ohnehin kennen. Im Kopf mache ich öfter die Antwort, doch wenn ich sie niederschreiben will, werfe ich meistens die Feder weg, weil ich nicht so zu schreiben im Stande bin, wie ich fühle. Ich erinnere mich aller Liebe, die du mir stets bewiesen hast; ... Kam man von einander, so lag dieß im Kreislauf der Dinge; jeder mußte den Zweck seiner Bestimmung verfolgen, u. zu erreichen suchen. Allein die 
ewig unerschütterlichen, festen Grundsätze des Guten hielten uns dennoch immer fest zusammen verbunden. ${ }^{.3}$

Hier stellt Beethoven also in aller Deutlichkeit die gemeinsamen Grundlagen heraus und unterzeichnet: "Wie immer dein treuer, dich ehrender wahrer Freund Beethoven" [Unterschrift eigenhändig]. Er ließ Wegeler über den Schott-Verlag die Lieder op. 121b, op. 122, op. 128 und die Bagatellen op. 126 zukommen. Außerdem kündigte er auch sein Porträt an: die Lithografie von

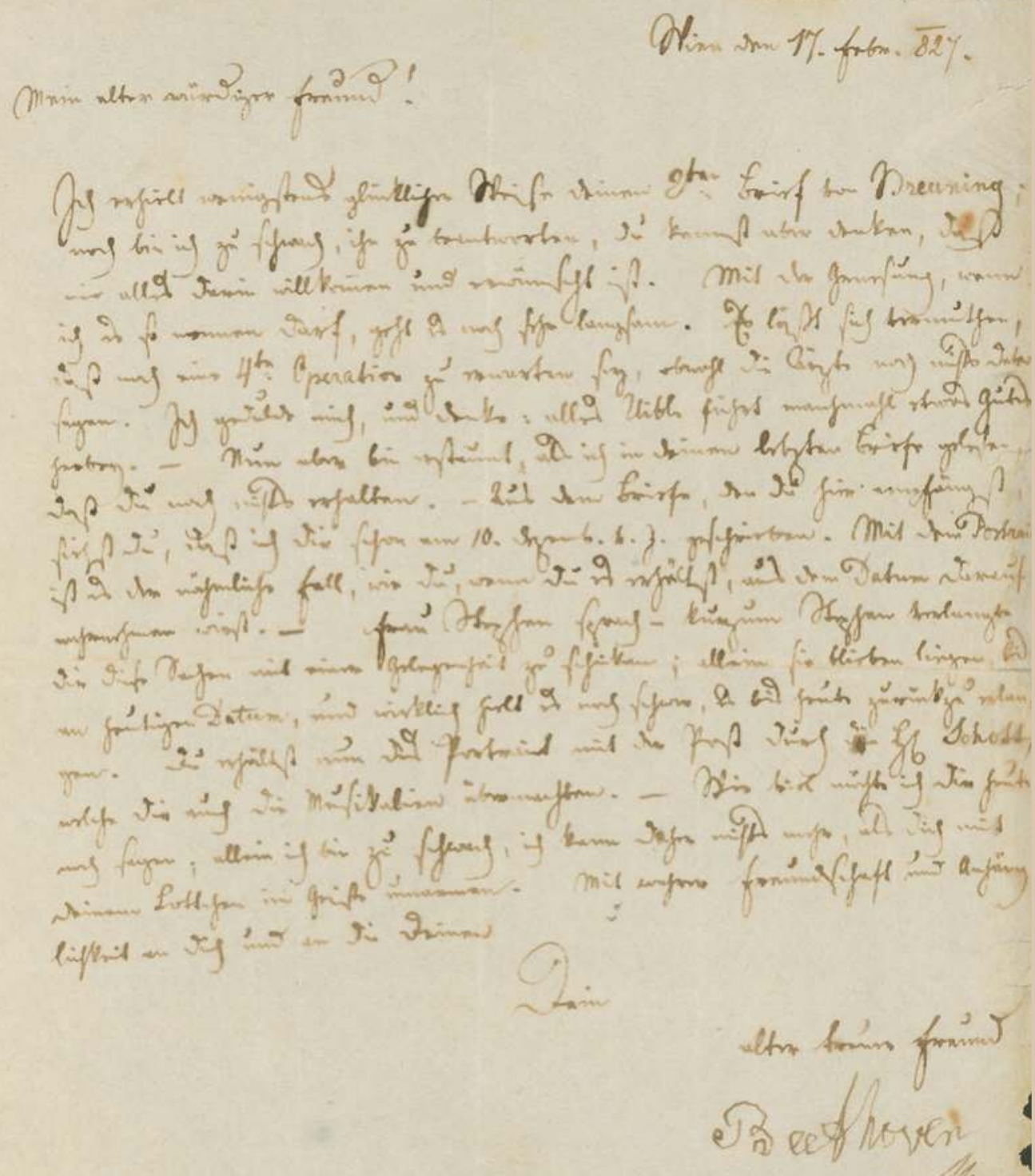

Beethoven an Franz Gerhard Wegeler in Koblenz, Wien, 17. Februar 1827 (Beethoven-Haus Bonn, Dauerleihgabe der Julius-Wegelerschen Familienstiftung) 
Friedrich Dürck nach Joseph Karl Stielers Ölgemälde. Der Brief blieb jedoch liegen und wurde erst zusammen mit dem letzten Brief, fünf Wochen vor Beethovens Tod, am 17. Februar 1827, verschickt. Die Wegelers hatten allerdings in der Zwischenzeit die Noten schon erhalten und bedankten sich Anfang Februar. ${ }^{4}$ Franz Gerhard entwirft einen Plan für die Zeit nach Beethovens Genesung. Er wolle sich mit ihm in Karlsbad treffen, dort drei gemeinsame Wochen verbringen und dann durch Süddeutschland mit Beethoven in die Heimat reisen. Dass diese Idee reines Wunschdenken war, dürfte dem Arzt Wegeler klar gewesen sein. Aber er versuchte sozusagen mit allen Mitteln, Beethoven zu trösten und zu ermuntern. Den letzten Brief an seinen „alten würdigen Freund" diktierte der bereits todgeweihte Beethoven seinem Adlatus Schindler, den Brief ziert eine seiner letzten Unterschriften. ${ }^{5}$ Beide Briefe und das Porträt erhielt Wegeler erst nach Beethovens Tod, gewissermaßen also als allerletzten Gruß. Die Lithografie trägt eine eigenhändige Widmung, die die besonders enge Beziehung der Beiden deutlich macht: "Seinem vieljährigen, geehrten, geliebten Freunde F. v. Wegelervon [gedruckt:] Louis van Beethoven. "6

Elf Jahre nach Beethovens Tod veröffentlichten Wegeler und Ferdinand Ries, der zeitweise Beethovens Sekretär und Schüler gewesen war, gemeinsam die Biographischen Notizen über Ludwig van Beethoven. Mit einer Vielzahl persönlicher Erinnerungen, originärer Informationen und den an sie gerichteten Briefen Beethovens ist diese Publikation bis heute eine der wichtigsten Quellen zu Beethovens Leben. In der Vorrede schrieb Wegeler: „Geboren in Bonn 1765 wurde ich 1782 mit dem 12jährigen Jüngling, der jedoch schon Autor war, bekannt, und lebte ununterbrochen in der innigsten Verbindung mit ihm bis September 1787, wo ich zur Beendigung meiner ärztlichen Studien die Wiener Schulen und Anstalten besuchte." ${ }^{\prime 7}$ Beethoven half damals als Organist der Hofkapelle aus, seinen ersten Auftritt als klavierspielendes Wunderkind hatte er bereits vier Jahre zuvor absolviert. 1782 war auch sein erstes gedrucktes Werk erschienen, die Dressler-Variationen WoO 63. Gerhard von Breuning berichtete später, dass Wegeler, der "liebenswürdige strebsame arme Student" ${ }^{\prime \prime}$, Beethoven bei der Familie Breuning eingeführt habe. Wegeler sei bereits im Hause von Gerhards Großmutter eingebürgert gewesen, vielleicht war er als Betreuer oder Nachhilfelehrer der vier Kinder Eleonore (seine spätere Ehefrau), Christoph, Stephan und Lorenz, genannt Lenz, tätig. Die Witwe Helene von Breuning habe nämlich einen Klavierlehrer für Eleonore und Lenz gesucht und so wurde der junge Beethoven genau wie Wegeler bald zum häufigen Gast im Breuningschen Haus am Münsterplatz. Das geistige Klima, die von Bildung und Kultur und natürlich viel Musik gesättigte Atmosphäre und sicher auch die herzliche Zuneigung Helenes in diesem "zweiten Zuhause” prägten beide Heranwachsende - Wegeler wie Beethoven - in gar nicht hoch genug einzuschätzender Weise. „Beethoven wurde bald als Kind des Hauses behandelt; er brachte nicht nur den größten Theil des Tages, sondern selbst 


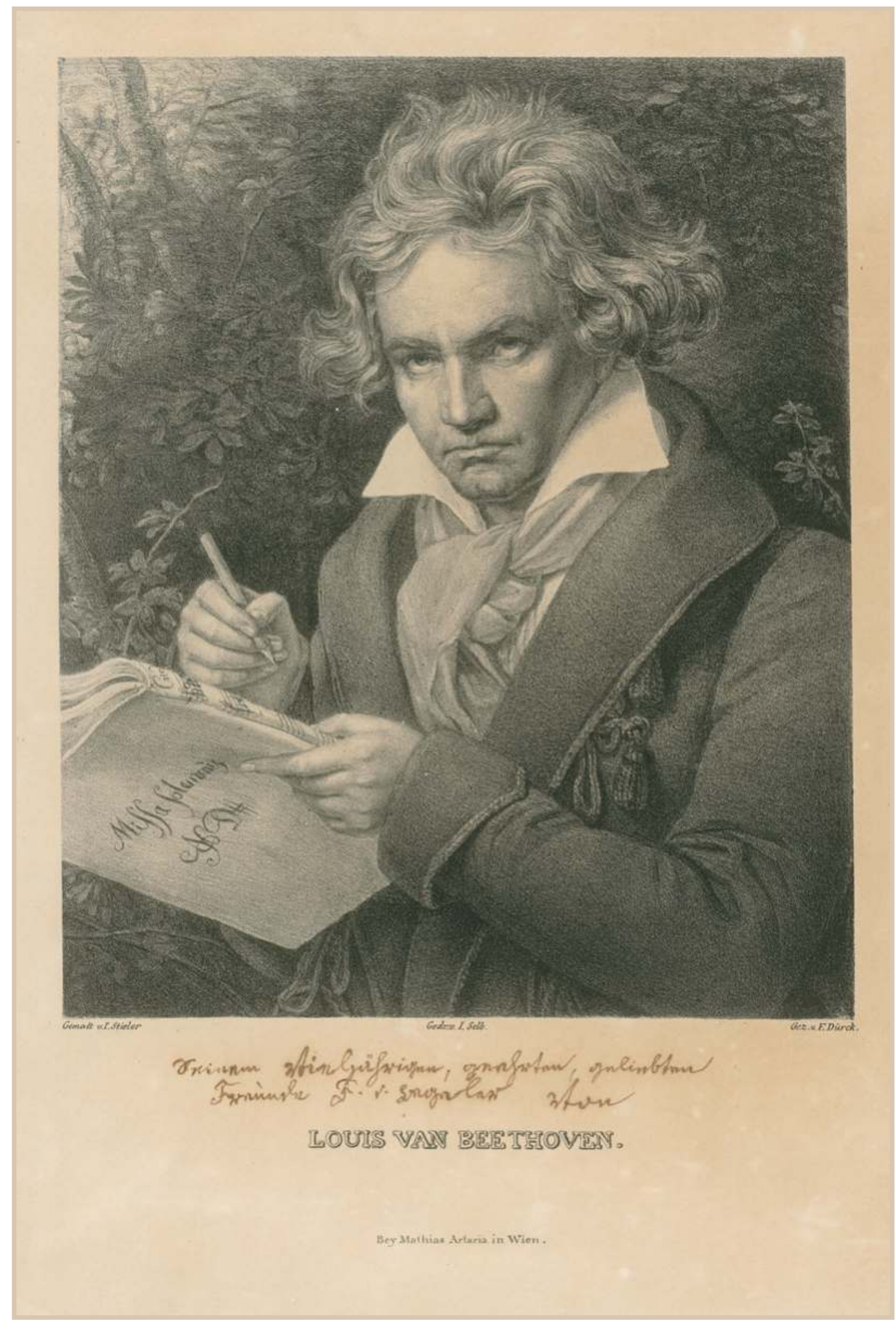

Ludwig van Beethoven. Lithografie von Friedrich Dürck nach dem Gemälde von Joseph Stieler aus dem Jahr 1820, Wien, 1826 (Beethoven-Haus Bonn, Dauerleihgabe der Julius-Wegelerschen Familienstiftung) 
Helene von Breuning (17511838). Anonyme Portraitminiatur im Porzellanrahmen mit Blumendekor, Ende 18./Anfang 19. Jahrhundert (Beethoven-Haus Bonn)

Eleonore von Breuning (1771-1841) am Klavier. Anonymes Gemälde, Bonn, um 1785 (Beethoven-Haus Bonn, Leihgabe Karl-Oswald von Nell) manche Nacht dort zu. Hier fühlte er sich frei, hier bewegte er sich mit Leichtigkeit. Alles wirkte zusammen, um ihn heiter zu stimmen und seinen Geist zu entwickeln. Fünf Jahre älter als Beethoven, war ich fähig, dieses zu beobachten und zu beurtheilen." ${ }^{\prime 9}$

Wie schon angeklungen ist, war Wegeler Mediziner und konnte als solcher später mit Weitsicht und Beharrlichkeit die Gesundheitsfürsorge im Rheinland entscheidend verbessern. Gerade auch als ärztlicher Ratgeber hatte er sicherlich eine besondere Bedeutung für den Zeit seines Lebens von Gesundheitsproblemen geplagten Komponisten. Zu seinem 50-jährigen Doktorjubiläum am 1. September 1839 wurde denn auch in der Festrede seine Empathie und Einfühlsamkeit besonders hervorgehoben, es heißt dort über ihn: "der Arzt und Mensch stets Hand in Hand"10.

Wegeler begann 1783 sein Medizinstudium an der im Gebäude des ehemaligen Jesuitengymnasiums in der Bonngasse von Kurfürst Max Friedrich neu gegründeten so genannten Maxischen Akademie. Unter dem neuen Kurfürsten Max Franz wurde die Akademie 1786 in den Status einer "Voll-Universität" erhoben. Im Rahmen des feierlichen Festakts wurde aus jeder Fakultät eine Arbeit öffentlich vorgestellt. Wegelers Lehrer Hofrat Franz Wilhelm Kauhlen wählte dessen Arbeit über die Atmung und den Gebrauch der Lungen zur öffentlichen Disputation aus. So wurde der Kurfürst auf Wegelers besonderes Talent aufmerksam und schickte ihn zur weiteren ärztlichen Ausbildung in seine

344 | Nicole Kämpken

(c) 2020 by Böhlau Verlag GmbH \& Cie. KG, Köln

https://doi.org/10.7788/9783412519704 | CC BY-NC 4.0 
Heimatstadt Wien. Die an der durch Kaiser Joseph II. 1785 gegründeten Medicinisch-chirurgischen Akademie lehrenden Ärzte waren durchweg herausragende Kapazitäten, das ein Jahr zuvor eröffnete Allgemeine Krankenhaus ein wirkliches Forschungszentrum. Hier gibt es eine deutliche Parallele zu Beethoven, sandte der Kurfürst den jungen Komponisten doch ebenfalls in die Stadt, die nicht nur Zentrum der Medizin, sondern eben auch der Musik war. Im Gegensatz zu Beethoven, dessen Aufenthalt bekanntlich wegen seiner schwer erkrankten Mutter nur ein kurzer bleiben konnte, blieb Wegeler zwei Jahre in Wien. Max Franz hatte bei seinem Regierungsantritt den medizinischen Lehrkörper der Bonner Universität erweitert und seinem Leibarzt Martin von Ney eine Professur in Geburtshilfe erteilt. Als von Ney 1789 seine Stellung wieder aufgab, um zurück nach Wien zu gehen, erinnerte der Kurfürst sich vermutlich an Wegeler und berief ihn als Nachfolger nach Bonn. So wäre die sehr kurze Zeitspanne zwischen Promotion in Wien am 1. September und Anstellungsdekret als Lehrer für Geburtshilfe in Bonn, datiert auf den 11. September 1789, zu erklären. ${ }^{11}$ Wegeler hatte in Wien bei Spezialisten auf diesem Gebiet wie Joseph Jakob von Plenck, dessen Buch Anfangsgründe der Geburtshilfe ein Standardwerk war, und dem Obergeburtshelfer der neu errichteten Gebäranstalt, Simon Zeller, lernen können. Es ist davon auszugehen, dass er auch in den Genuss von Anschauungsunterricht an den berühmten, noch heute im Josephinum zu bestaunenden Wachsmodellen kommen konnte. Joseph II. hatte diese naturgetreuen Wachspräparate des gesamten menschlichen Körpers, insgesamt 1192 Stück, nach einem Florentiner Vorbild anfertigen lassen. Als die Sammlung, die mit 102 Objekten auch die weltweit größte geburtshilfliche Kollektion umfasst, dann öffentlich zugänglich gemacht wurde, dürfte das eine wirkliche Sensation gewesen sein.

Zurück in Bonn oblag Wegeler auch der Unterricht der Hebammen sowie "nach Maasgab seiner Fähigkeit" die Rechtsmedizin und Chirurgie ${ }^{12}$. Die Geburtshilfe durchzog Wegelers medizinische Arbeit Zeit seines Lebens. 1800 veröffentlichte er das bis 1819 in vier Auflagen erschienene Buch für die Hebammen als Lehr- und Nachschlagewerk für die Praxis in einer einfachen und verständlichen Sprache. Er gibt auch methodisch-didaktische Hinweise für die Lehrenden („Die Erfahrung hat mich manche kleine Kunstgriffe gelehrt, mich dem Fassungsvermögen der Frauen anzupassen, und den ihnen so steilen und rauen Weg zu ebnen, und zu verkürzen." $\left.{ }^{13}\right)$. Folgenden Anforderungen müsse eine Schülerin genügen: Sie sollte lesen können und einen guten Verstand besitzen, kleine, geschmeidige Hände mit langen Fingern mit Gefühl haben und zu deren Erhaltung möglichst keine grobe Handarbeit erledigen. Wegeler war im aktuellen Ärztestreit über die Vorteile von natürlichen und Zangengeburten ein klarer Verfechter der natürlichen Geburt (die Geburtszange durften ohnehin nur Ärzte anlegen). Eine große Errungenschaft und die häufigste Maßnahme bei Komplikationen war die Wendung des Kindes, die 
Wegeler ausführlich beschreibt. Durch Drehen des Kindes in eine günstigere Geburtsposition konnten viele ohne Instrumenteneinsatz gerettet werden. Die Hebamme „vergesse nie, daß eine natürliche Geburt durch die Kräfte der Gebärenden geendigt wird, daß sie demnach das Kind nicht zu holen, sondern nur zu empfangen hat; daß ihre Hülfe nur darin bestehen darf, die Geburt, als eine ganz natürliche Verrichtung zu erleichtern, die nöthigen Schmerzen zu lindern, die Frau zu belehren, die möglichen Gefahren von ihr und dem Kinde abzuhalten, und die Geburt so zu leiten, daß solche mit der größten Sicherheit und Beruhigung der Frau und ihrer nächsten Umgebungen vor sich gehe." Wegeler leitete die Hebammenschule in Bonn und seit 1807 in Koblenz und etablierte später - als Regierungs- und Medizinalrat in preußischen Diensten, Leiter der staatlichen Gesundheitsfürsorge - eine qualifizierte Hebammenausbildung mit staatlicher Prüfung und Abschlusszertifikat. Ein hoher Verdienst in einer Zeit, in der nicht nur viele Neugeborene, sondern auch deren Mütter unter der Geburt starben. In beiden Familien, bei Beethovens und Wegelers, starben mehrere Säuglinge.

Dass Beethoven und Wegeler auch politisch ähnlich dachten, belegt die für ihn um 1790/91 erstellte Klavierbearbeitung von Christian Friedrich Daniel Schubarts kritischem und rasch sehr populärem Kaplied von 1787. Es ist ein scharfer Protest gegen Herzog Carl Eugen von Württemberg, der ein Söldnerheer an Holland verkaufte, das an das Kap geschickt wurde und beginnt mit den Versen: "Auf, auf! ihr Brüder und seid stark / Der Abschiedstag ist da! / Schwer liegt er auf der Seele, schwer! / Wir sollen über Land und Meer / Ins heiße Afrika." Beethoven fügte Fingersätze für Wegeler hinzu, wie dieser auf dem Blatt notierte: "Für mich Von Beethoven geschrieben und bezeichnet. Wglr." Auf der Rückseite befindet sich die Sonatine F-Dur WoO $50^{14}$.

1793 wurde Wegeler vom Universitätssenat zum Rektor gewählt, nachdem Joseph Claude Rougemont das Amt abgelehnt hatte. Rougemont war der ehemalige Leibarzt des Kurfürsten Max Friedrich und unterrichtete Anatomie und Chirurgie. ${ }^{15}$ Später übersetzte Wegeler drei medizinische Schriften Rougemonts aus dem Französischen. Als 1794 der Einmarsch der Franzosen in Bonn bevorstand, wies der Kurfürst aus Angst vor Racheakten Wegeler an, die Stadt zu verlassen. Dieser hatte nämlich den Studenten aus Gründen der Typhusprophylaxe verboten, gefangene französische Soldaten zu besuchen und ihnen Almosen zu bringen. Dieses Verbot wurde falsch gedeutet, eine Pariser Zeitung beschimpfte ihn als "wütenden Feind des Volkes und der Freiheit". Wegeler hatte sich angesteckt, als er die Epidemie in einem österreichischen Lazarett in Königswinter bekämpfte. 1814 veröffentlichte er die „Kurze Anleitung den gegenwärtig herrschenden ansteckenden Typhus zu behandeln" - eine Arbeit, die einen klaren Überblick über Diagnose und Behandlung des Typhus (damals auch Spitalfieber oder Lazarettfieber) gibt. Die Schrift widmete er "mit dankbarer Rückerinnerung an die in Wien durch- 


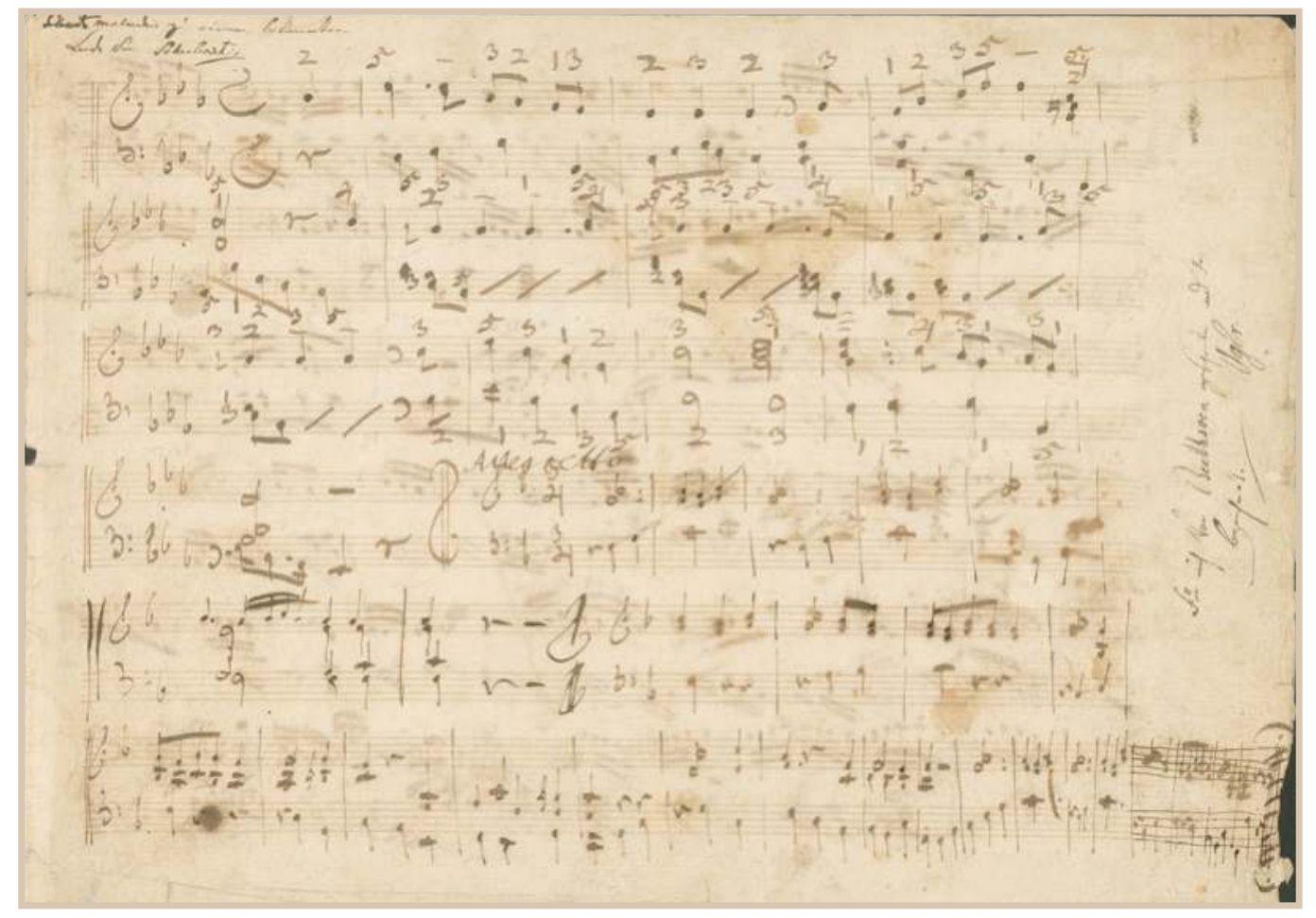

lebten Tage ${ }^{\prime 16}$ dem 1. Stabsfeldarzt Dr. Gerhard von Vering, der auch Beethoven behandelt hat. Wegeler zog also 1794 wieder nach Wien und nahm Lorenz von Breuning zum Medizinstudium mit. Hier trafen sie natürlich Beethoven wieder, der sich ja schon seit 1792 in der Kaiserstadt aufhielt. Schönstes Zeugnis ihres geselligen Lebens in Wien ist ein Brief von Lorenz an seine in Bonn verbliebene Schwester Eleonore. Das erste Blatt ist von Wegeler beschrieben und wurde später von ihm mit der Bemerkung versehen

"Als Secretair von Lenz geschrieben im Jahr 1795. Wglr."

"Mir geht es hier recht wohl. Beethoven läßt dich vielmahl grüßen. Er komponirt sehr schön, und steht hier in großem Ansehn. Er wohnt bei einem Fürsten, derihn ganz als Freund behandelt. Er hat die Tafel mit ihm, Bedienten, ein Reitpferd, u.s.w. Ich traf ihn oft bey meiner Baaße, wo er, und die übrigen, hinkömmt, und wo wir dann nie lange Weile haben. Auch bey Hun[c]zovsky, einem meiner Lehrer, kommen wir oft zusammen. ${ }^{17}$ Aber doch habe ich viel Ursache dir über meine hiesigen Freunde zu klagen, weil ich noch gar in keinem Hauße ausgeführt worden bin, wo ein nur etwas schönes Mädchen wäre." ${ }^{\prime 18}$

Allerdings gab es nicht nur Freude und Herzlichkeit, sondern in dieses Jahr fällt auch der einzige dokumentierte Streit zwischen Wegeler und Beethoven, ein Zerwürfnis der ernsteren Sorte. Der Konflikt schwelte über zwei Monate, worum es genau ging, lässt sich nicht eruieren. Jedenfalls bat Beethoven in
Abschrift des Kapliedes von Christian Friedrich Daniel Schubart. Autograph Beethovens mit Aufschrift Wegelers am rechten Seitenrand quer, 1790/91 (Beethoven-Haus Bonn, Dauerleihgabe der Julius-Wegelerschen Familienstiftung) 
einem leidenschaftlichen, im Tonfall bisweilen sogar an den Brief an die Unsterbliche Geliebte erinnernden Brief um Vergebung und Erneuerung ihrer Freundschaft: "- fest, - Ewig - unsere Freundschaft - verzeihung - vergessenheit wieder aufleben der sterbenden sinkenden Freundschaft - o wegeler verstoße sie nicht diese Hand zur aussöhnung, gib die deinige in die meine - Ach Gott. - ach nichts mehr ${ }^{\prime \prime 19}$. Interessant, dass Wegeler in seinen insgesamt zuverlässigen Notizen gerade diesen Brief nicht vollständig wiedergibt, sondern Teile unterdrückt. Im Nachhinein wollte er wohl ihre Freundschaft nicht von dieser unschönen Episode getrübt wissen und enthielt sie deshalb auch der Nachwelt vor. Ende des Jahres 1795 wählten auch Christoph und Stephan von Breuning ihren Aufenthalt in Wien, so dass sich große Teile des alten Bonner Freundeskreises dort wieder zusammenfinden konnten. Das war allerdings von kurzer Dauer, denn schon fünf Monate später verließen Christoph und Wegeler Wien in Richtung Heimat. Den empfindsamen und anhänglichen Lenz traf der Abschiedsschmerz sehr, wie man einem Brief an seine Schwester Eleonore entnehmen kann. Trost fand er, indem er sich auf ein höheres Ziel besann, das er und wohl auch der abgereiste Freund Wegeler zu erreichen strebte:

„bedenke, dass Freundes Glück gar nicht der Zweck dieses Daseins ist, denke es, dass wir da sind, um unsre Pflicht zu erfüllen, um unsrer endlosen Vollkommenheit so nahe als möglich zu treten, und dass nichts, gar nichts uns von dem festen unwandelbaren Hange abbringen darf, den uns Vernunft und Tugend mit entschlossenen Schritten zu gehen gebieten. "20

Dieser Gedanke des unbedingten Strebens und Voranschreitens, des zielgerichteten Einsatzes aller Kräfte und die Empfindung, damit einer wirklichen Pflicht Genüge zu leisten, war auch Beethoven nicht fremd. Lorenz von Breuning kehrte 1797 nach Bonn zurück. Beethoven gab ihm zwei für Eleonore komponierte kleine Stücke für Orphika (C-Dur, F-Dur) WoO $51^{21}$ mit. Es ist zu vermuten, dass Lorenz seiner Schwester ein solches kleines tragbares Hammerklavier in Leichtbauweise mitbrachte - 1795 vom Wiener Instrumentenbauer Carl Leopold Röllig neu erfunden, also absolut „up to date". Allerdings wurde die Produktion der Instrumente schon um 1840 wieder eingestellt. Lorenz starb bereits wenige Monate nach seiner Rückkehr nach Bonn. So blieb Stephan von Breuning der einzige Jugendfreund, der Beethoven in Wien bis zu seinem Tod begleitete.

Beethoven vertraute Wegelers medizinischer Kompetenz und äußerte sich ihm gegenüber erstmals und mit der Bitte um absolutes Stillschweigen über seine zunehmende Schwerhörigkeit, die ihn extrem belastete. In dieser Zeit seiner schwersten persönlichen Krise folgte dem Brief vom 29. Juni 1801 noch im selben Jahr, am 16. November, ein weiterer, wo doch sonst ihr Briefwechsel recht spärlich war. Es gibt kaum intimere Briefe Beethovens, eindringlich schilderte er die Zeichen seiner Erkrankung und ausdrücklich auch die damit verbundenen seelischen Nöte: 
"nur hat der neidische Dämon, meine schlimme Gesundheit, mir einen schlechten Stein ins Brett geworfen nemlich: mein Gehör ist seit 3 Jahren immer schwächer geworden, und das soll sich durch meinen Unterleib, der schon damals wie Du weist elend war, hier aber sich verschlimmert hat indem ich beständig mit einem Durchfall behaftet war, und mit einer dadurch außerordentlichen schwäche, ereignet haben, Frank [einer der angesehensten Ärzte in Wien] wollte meinem leib den Ton [Tonus, Spannung] wieder geben durch stärkende Medizine und mein Gehör durch Mandelöhl, aber prosit, daraus ward nichts, mein gehör ward immer schlechter, und mein Unterleib blieb immer in seiner vorigen Verfassung".

Nach einem Arztwechsel zu Gerhard von Vering, der ihm lauwarme Donaubäder verordnete "wo ich jedesmal noch ein fläschgen stärkende sachen hineingießen muste, ... Pillen für den Magen und einen Thee für's Ohr", fühlte Beethoven sich besser, aber

"meine ohren, die sausen und Brausen tag und Nacht fort; ich kann sagen, ich bringe mein Leben elend zu, seit 2 Jahren fast meide ich alle gesellschaften, weils mir nun nicht möglich ist, den Leuten zu sagen, ich bin Taub, hätte ich irgend ein anderes Fach, so giengs noch eher, aber in meinem Fach ist das ein schrecklicher Zustand"22.

Beethoven schilderte ausführlich die Behandlungen und Ergebnisse, erhoffte sich wohl einerseits den medizinischen Rat des Arztes, aber andererseits ebenso Trost und Linderung durch den ins Vertrauen gezogenen Freund. Aus dem zweiten Brief geht hervor, dass Wegeler wohl tatsächlich Ratschläge erteilt hat, nämlich Kräuterwickel für den Bauch. Beethoven war zu diesem Zeitpunkt unzufrieden mit Vering, der ihn mit "Fisikaturen" quälte, die ihn in der Bewegungsfreiheit der Arme sehr einschränkten. Vesikatorien sind blasenziehende Mittel. Beispielsweise wurde die Rinde von Seidelbast verwendet, um Entzündungen abzuleiten. Er überlegte, den Arzt zu wechseln und Wegelers Wiener Freund Johann Adam Schmidt, Medizinprofessor an der Josephsakademie, zu Rate zu ziehen.

"Er [von Vering] hat gar zu wenig sorge und Nachsicht für so eine Kranckheit ... - was hältst du von schmidt, ich wechsle zwar nicht gern, doch scheint mir W. ist zu sehr Praktiker als daß er sich viel neue Ideen durchs Lesen verschafte - S[chmidt]
Beethoven an Franz Gerhard Wegeler in Bonn, Wien, 16. November 1801. Das Datum, rechts am Rand quer von Beethoven notiert, trägt Wegeler im Zuge der Vorbereitungen der Biographischen Notizen unten auf dem Blatt mit Blaustift ein (Beethoven-Haus Bonn, Dauerleihgabe der Julius-Wegelerschen Familienstiftung)

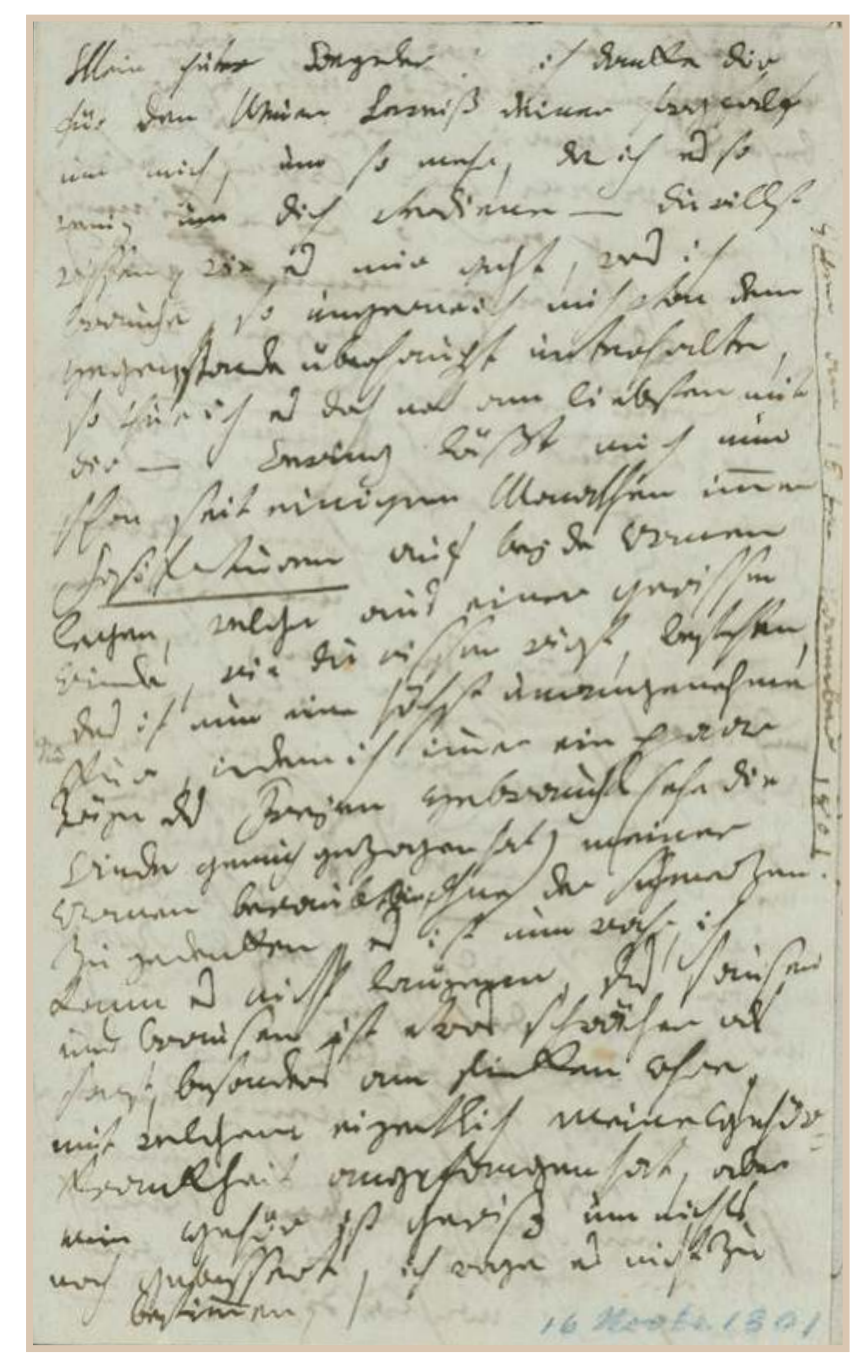


Erstausgabe des Liedes Maurerfragen (noch vor der Ausgabe mit originalem Text erschienen), Bonn, Simrock, 1806 (Beethoven-Haus Bonn)

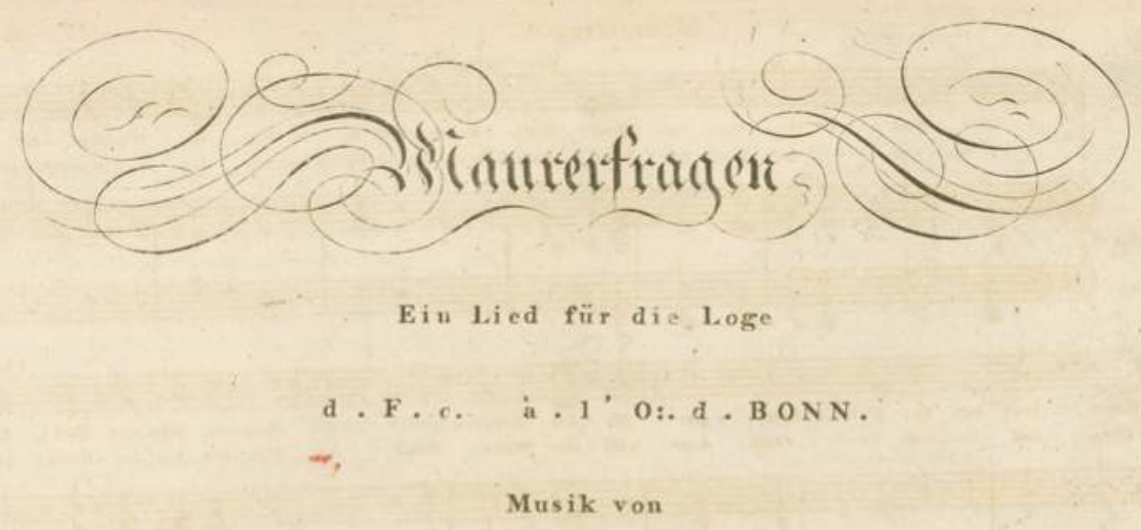

L.OUIS VAN BEETHOVEN.

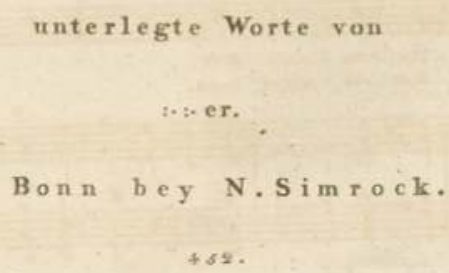

scheint mir hierin ein ganz anderer Mensch zu seyn und würde vieleicht auch nicht gar so nachläßig seyn?"23

Schmidt mache auch Behandlungsversuche mit Galvanismus (frühe Elektrotherapie). Beethoven wollte nichts unversucht lassen und war neuen Experimenten gegenüber aufgeschlossen. Dass er den Arztwechsel tatsächlich vornahm, belegt die Erwähnung Schmidts im Heiligenstädter Testament. Beethovens Gesamtverfassung hatte sich zwischenzeitlich deutlich gebessert; wie er schrieb, durch „ein liebes zauberisches Mädchen" - seine Klavierschülerin Julie Guicciardi, der er die so genannte Mondschein-Sonate op. 27 Nr. 2 widmete. Die tiefe Krise schien überwunden: „ich will dem schicksaal in den rachen greifen, ganz niederbeugen soll es mich gewiß nicht - o es ist so schön das Leben tausendmal leben". ${ }^{24}$ Zu Wegelers Doktorjubiläum 1839 ohne Verfassernennung gedruckte Verse mit der Überschrift „Beethoven's Geistesgruß an F. G. Wegeler"25 nehmen diesen Gedanken fast wörtlich auf: „O, wie ist es schön, dies Leben! Lebt' ich es doch tausendmal!"

Auch ein vermutlich von Franz Gerhard Wegeler selbst verfasstes Gedicht, das er dem langsamen Satz von Beethovens Klaviersonate op. 2 Nr. 1 unterlegte, wirkt wie ein Reflex auf Beethovens Lebenskrise. Der Text beginnt mit den Worten: "Mein Glück ist entflohen! Meine Ruhe ist dahin!" Wegeler hat die 
Musik Beethovens nicht substanziell verändert, sondern lediglich die Oberstimme des Klavierparts zusätzlich der Singstimme zugeordnet. Es entspricht also dem Typ des „Liedes am Klavier zu singen”. Wegeler ließ das Lied Die Klage 1807 bei seinem Bonner Freund Nikolaus Simrock drucken.

Wegeler arbeitete auch mehrfach Lieder Beethovens um, indem er ihnen andere Texte mit freimaurerischem Inhalt unterlegte. Sowohl in der 1806 von Mitgliedern der Bonner Lesegesellschaft (deren Vorsitz Wegeler 1806/07 innehatte) gegründeten Bonner Freimaurerloge Les Frères courageux als auch später in Koblenz wurden diese Parodien gesungen: dem Lied Maurerfragen liegt Beethovens Der freie Mann WoO 117 zugrunde, seinen neuen Text zu Beethovens Opferlied WoO 126 veröffentlichte Wegeler in den Biographischen Notizen.

Zwischenzeitlich konnte Franz Gerhard Wegeler Eleonore von Breuning heiraten, die Feier fand am 19. März 1802 statt. In der umfangreichen Sammlung der Julius-Wegelerschen-Familienstiftung hat sich ein Brief von Stephan von Breuning an seine Mutter Helene in Bonn erhalten, in dem er sie bat, der Heirat seiner Schwester, „die ungünstige Zeitumstände schon zu lange verschoben haben", nicht länger entgegenzustehen ${ }^{26}$. Wegeler konnte nach der Auflösung der Hochschule durch die französischen Machthaber einige Jahre nur als schlecht bezahlter Lehrer an einer neu eingerichteten Zentralschule unterrichten und nebenbei als Arzt praktizieren, was ihn wirtschaftlich für eine Heirat wohl nicht ausreichend absicherte. 1802 ergaben sich aber neue Perspektiven als Medizinalbeamter beim Aufbau einer staatlichen Gesundheitsfürsorge.

Erst aus dem Jahre 1810 ist der nächste Brief Beethovens an Wegeler erhalten, äußerlicher Anlass war ebenfalls ein Heiratsplan. Beethoven trug sich nämlich mit dem Gedanken, seine Schülerin Therese Malfatti zu heiraten, in die er sich verliebt hatte. Deshalb bat er am 2. Mai seinen alten Freund, ihm eine Abschrift seines Taufscheins zu schicken. Wegeler kam der Bitte auch nach. Aber Therese erwiderte Beethovens Gefühle nicht, und so zerschlugen sich die Pläne. Beethoven fragte im selben Brief auch nach dem Lied von ihm, welches in den Freimaurerlogen gesungen werde. Auch dieses Schreiben wurde im Duktus der tiefsten Vertrautheit verfasst. Nach einer Entschuldigung für das lange Schweigen ( meine Zeilen Staunen bey dir - und doch, obschon du keine schriftliche Beweise hast, bist du doch noch immer bey mir im lebhaftesten Andenken") gewährte er dem Freund einen Einblick in seinen Seelenzustand:

„Doch ich wäre glüklich, vieleicht einer der Glüklichsten Menschen, wenn nicht der Dämon in meinen Ohren seinen Aufenthalt aufgeschlagen - hätte ich nicht irgendwo gelesen, der Mensch dörfe nicht freywillig scheiden von seinem Leben, so lange er noch eine gute That verrichten kann, längst wär ich nicht mehr - und zwar durch mich selbst - o so schön ist das Leben, aber bey mir ist es für immer vergiftet ${ }^{-2}{ }^{\prime 2}$. 
Böhmisches Glas. Geschenk Beethovens für Wegeler (Beethoven-Haus Bonn, Dauerleihgabe der Julius-Wegelerschen Familienstiftung)

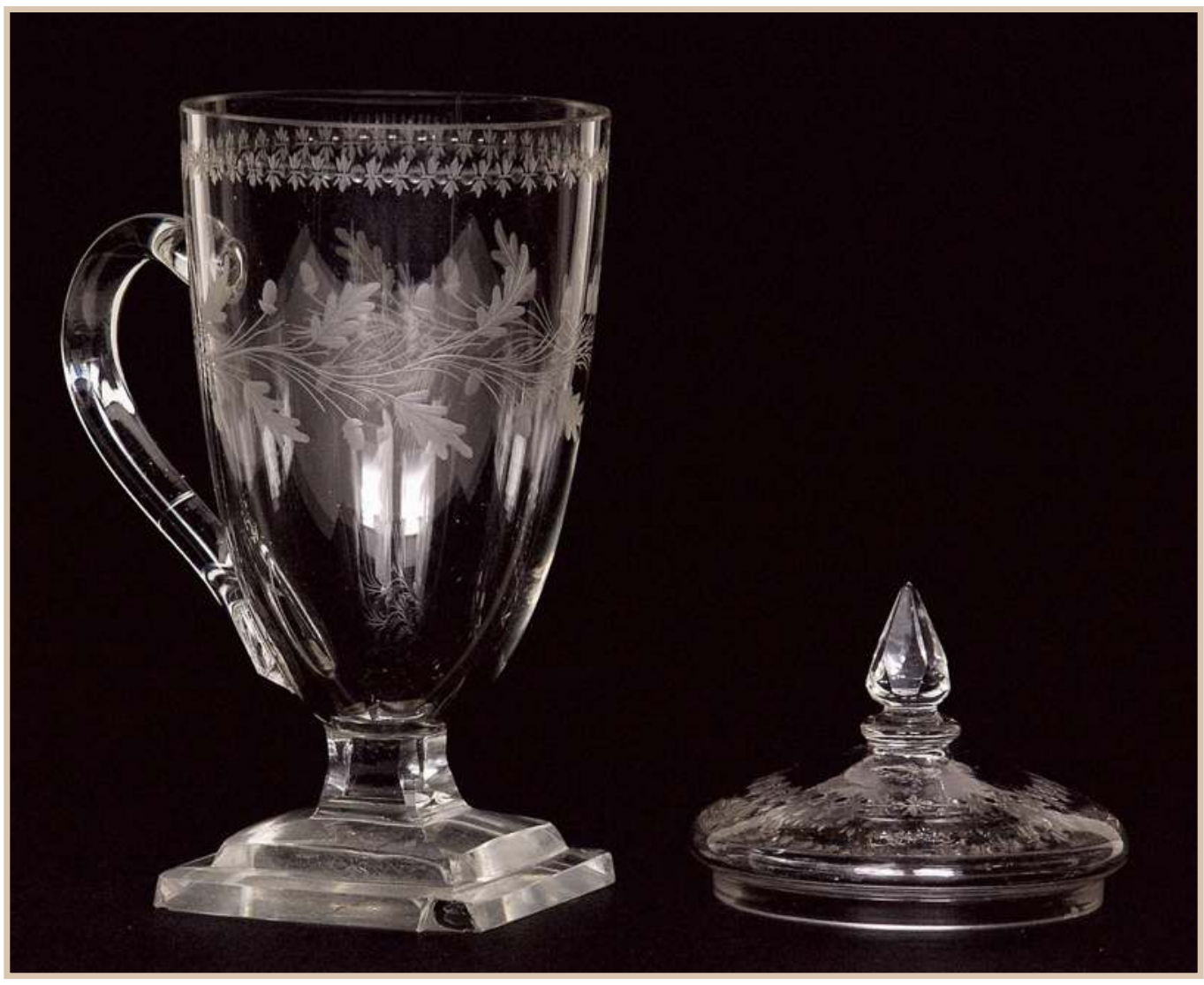

Schönste Zeugnisse der Freundschaft sind zwei Geschenke, die Beethoven 1815 seinem Bonner Jugendfreund Johann Joseph Eichhoff, der als Sachverständiger für die Rhein-Schifffahrt an Verhandlungen beim Wiener Kongress teilgenommen hatte, für Wegeler mit auf den Rückweg gab. ${ }^{28}$ Hierbei handelte es sich um ein geschliffenes Bleiglas mit Henkel und Deckel ${ }^{29}$, das Beethoven wohl bei seinen Kuraufenthalten in den böhmischen Bädern 1811 oder 1812 erworben hatte und um den gerade neu bei Artaria in Wien erschienenen Porträtstich von Blasius Höfel nach einer Zeichnung von Louis Letronne, den Beethoven mit der Widmung "Für meinen Freund / Wegeler Vien / am 27ten März 1815 /I. v. Beethoven. "30 versah (s. S. 365). Das Glas war sicher wohlüberlegt, hielt Wegeler doch als Arzt sehr viel von Trink- und Badekuren. So sorgte ermitVorschlägenzurErrichtung neuerBäderund ParksfürdieWiederherstellung von Bad Bertrich, in der südlichen Vulkaneifel gelegen, mit der einzigen Glaubersalztherme Deutschlands. Beethovens ehemaliger Geigenlehrer Franz Anton Ries und dessen Sohn Ferdinand, Wegelers enger Freund, kurten dort. Bereits 1811 hatte Wegeler den Tönissteiner Mineralbrunnen im Brohltal gepachtet und versuchte auch mit entsprechenden Veröffentlichungen die Bevölkerung vom Nutzen und Wert des Mineralwassers zu überzeugen. ${ }^{31}$ Das 


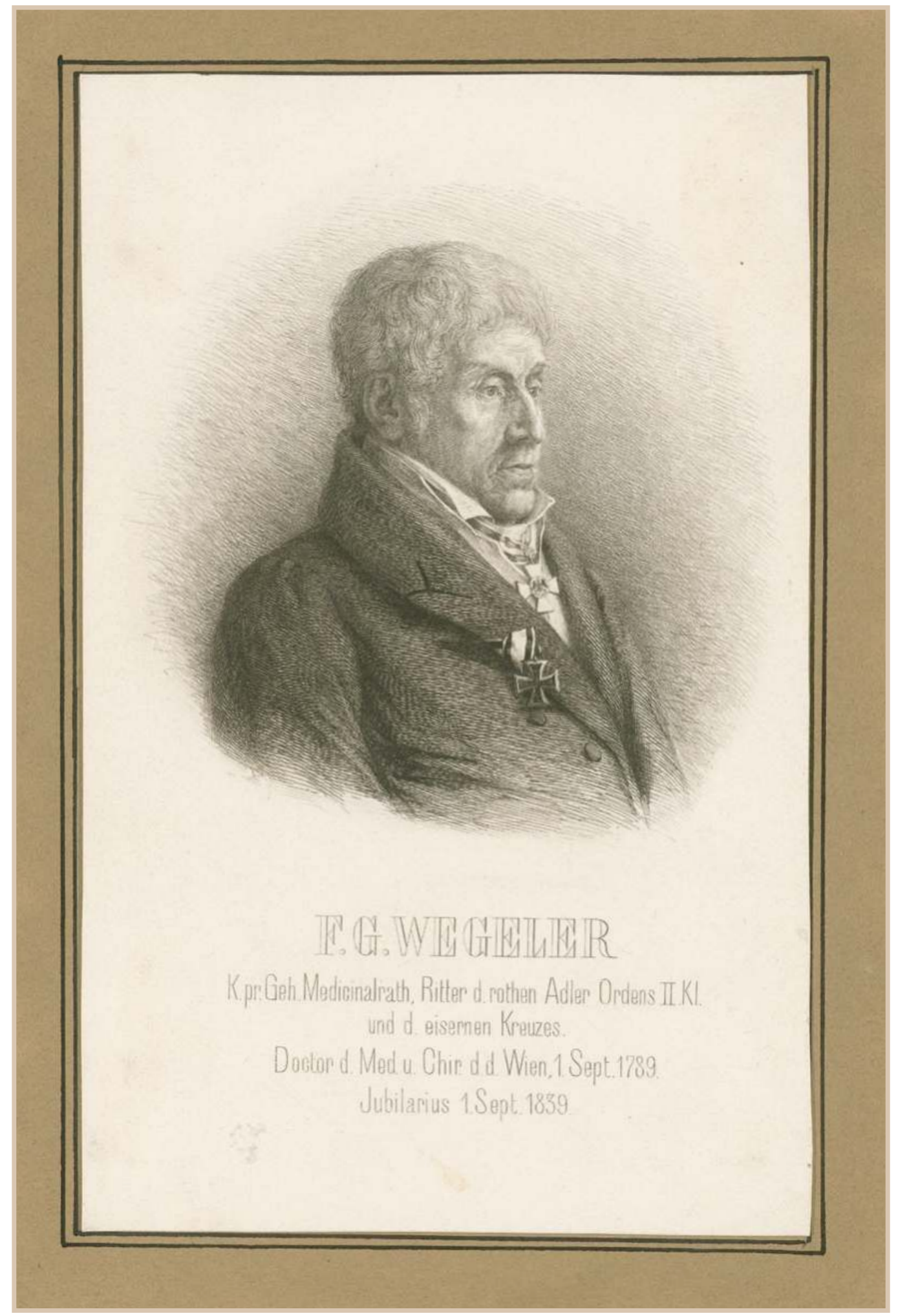

Franz Gerhard Wegeler (1765-1848). Radierung von Rudolf Carl Friedrich Ernst von Normann nach einer eigenen Zeichnung, Koblenz, 1839

(Beethoven-Haus Bonn, Dauerleihgabe der Julius-Wegelerschen Familienstiftung) 
Wasser wurde in vor Ort gebrannten Tonkrügen über die Brohl und den Rhein verschifft und preisgünstig angeboten. Der später beim Londoner Klavierbauer Broadwood angestellte Bruder von Ferdinand Ries, Peter Joseph Ries, versuchte 1819 sogar, das Wasser auch in England zu verkaufen.

Ein weiteres (Mit-)Verdienst Wegelers ist die Bekämpfung der Pocken. Er veranlasste eine möglichst flächendeckende Aufklärung und Reihenimpfungen mit dem von Edward Jenner 1796 in England eingeführten Impfstoff. Die Pocken waren nach dem Abklingen der Pestepidemien die gefährlichste Infektionskrankheit. Rund 30 Prozent der Erkrankten starben, nach Schätzungen jedes Jahr 400.000 Menschen. Für seinen Einsatz und seine Erfolge erhielt Wegeler, dessen Doktortitel von der französischen Verwaltung nicht anerkannt worden war, die Diplome Docteur en médecine und Docteur en chirurgie. Der sehr frühe Abguss von Beethovens Lebendmaske (abgenommen von Franz Klein 1812) lässt aufgrund der an der Oberfläche gut zu erkennenden Narbenbildung vermuten, dass Beethoven als Kind ebenfalls an Pocken erkrankt war.

Dies bleiben nicht die einzigen Ehrungen, die Wegeler bezeigt wurden. Er erhielt die französische Verdienstnadel und später unter preußischer Regierung das preußische Allgemeine Ehrenzeichen I. Klasse sowie das Eiserne Kreuz II. Klasse. Die höchste Auszeichnung erhielt er anlässlich seines 50-jährigen Doktorjubiläums: den Roten Adlerorden II. Klasse mit Eichenlaub, nach dem Schwarzen Adlerorden der zweithöchste preußische Orden. - Den gleichen hatte sich Beethoven als Dank für seine Widmung der 9. Sinfonie an König Friedrich Wilhelm III. erhofft. - Die wie ein Volksfest begangenen Feierlichkeiten, von denen der Coblenzer Anzeiger berichtete, zeigen, wie angesehen und beliebt der Mediziner in allen Bevölkerungsschichten war. Außer der Festschrift Analecta medica und einem silbernen Pokal wurde ihm auch eine Radierung mit seinem Porträt überreicht. ${ }^{32}$

Franz Gerhard Wegeler ist also keineswegs nur als wichtige Bezugsperson und Freund Beethovens von Bedeutung, sondern auch als hervorragender Mediziner, Lehrer und Medizinalbeamter. Er konnte zahlreiche gute und weiterführende Maßnahmen im Gesundheitsbereich einleiten und umsetzen. Aus dem Freundes- und Familienkreis um Beethoven und das Ehepaar Wegeler blieben zahlreiche Erinnerungsstücke an Beethoven und eine Vielzahl von Briefen und Stammbuchblättern sowie vier Handschriften im Familienbesitz erhalten. Zum 150. Todestag Wegelers 1998 übergab der Vorstand der JuliusWegelerschen-Familienstiftung seine einzigartige Beethoven-Sammlung als Dauerleihgabe an das Beethoven-Haus Bonn. ${ }^{33}$ Herausragende Objekte aus der Sammlung bereichern die Dauerausstellung des Museums in Beethovens Geburtshaus. 
Brief vom 28.12.1825, Beethoven-Haus Bonn (BHB), NE 55, in: SIEGHARD BRANDENBURG (Hg.), Ludwig van Beethoven. Briefwechsel Gesamtausgabe, 7 Bde, München 1996-1998, hier Bd. 6, Nr. 2100.

Brief vom 29.12.1825, BHB, NE 56, in: ebd., Nr. 2101

Brief vom 7.12.1826, BHB, Sammlung Wegeler, W 21, in: ebd., Nr. 2236.

Briefvom 1.2.1827, in: ebd., Nr. 2255

Brief vom 17.2.1827, BHB, Sammlung Wegeler, W 22, in: ebd., Nr. 2257.

BHB, Sammlung Wegeler, W 26.

Franz Gerhard Wegeler und Ferdinand Ries, Biographische Notizen über Ludwig van Beethoven, Koblenz 1838, S. XIf.

GERHARD VON BREUNING, Aus dem Schwarzspanierhaus: Erinnerungen an L. van Beethoven aus meiner Jugendzeit, Wien 1874, S. 8.

WEGELER/RIES, Biographische Notizen (wie Anm. 7), S. 10.

AnONYm (evtl. Julius Stephan WEGELER), in: Analecta medica, Staatsbibliothek zu Berlin - PreuBischer Kulturbesitz, Av 21711

Beethoven hatte sich am 14.4.1789 an der Hochschule für das Fach Philosophie immatrikuliert; s. Matrikel der Kurfürstlich Maxischen Akademie in Bonn, in: Universitätsund Landesbibliothek Bonn (ULB), S 418.

Anstellungsdekret für Wegeler, in: ULB, S 420 i

Franz Georg Wegeler, Das Buch für die Hebammen, Bonn 1800, Vorrede. Das folgende Zitat stammt aus einer späteren Auflage.

BHB, Sammlung Wegeler, W 1.

Ausschnitt aus dem Vorlesungsverzeichnis November 1788 bis September 1789: "Herr Doktor Rougemont lehrt im Winter die Anatomie und chirurgischen Operationen von 2.-3 1/2 Uhr. Es wird auch freie Uebung im Zergliedern gestattet. Im Sommer lehrt derselbe fünfmal in der Woche um die nämliche Stunde die Chirurgie. Ferner gibt es im Sommer von 7.-8. zweimal die Woche über venerische, und die übrigen Tage über Augenkrankheiten besondere Vorlesungen."

FRANZ GEORG Wegeler, Kurze Anleitung den gegenwärtig herrschenden ansteckenden Typhus zu behandeln, Koblenz 1814, Widmungsblatt.

Zum Professorenkollegium gehörte auch Beethovens späterer Arzt Johann Adam Schmidt. Johann Nepomuk Hunczovsky erwähnt ihn in einem Brief an Wegeler vom 23.7.1796, in dem er auch Grüße an Rougemont und Christoph von Breuning ausrichten ließ, in: BHB, NE 278.

Brief Ende Januar/Anfang Februar 1795, BHB, Sammlung Wegeler, W 119

Brief um 1795, BHB, Sammlung Wegeler, W 15, in: BRANDENBURG, Beethoven Briefwechsel (wie Anm. 1), hier Bd. 1, Nr. 19

Brief vom 31.5.1796, BHB, Sammlung Wegeler, W 123

Früher als Klaviersonate veröffentlicht konnte diese Klassifizierung korrigiert werden. Klaus Martin Kopitz fand in einem Brief von Wegeler an Anton Schindler vom 23.12.1827 den Hinweis, Beethoven habe zwei Stücke für Orphika für seine Frau komponiert. Vgl. Klaus Martin Kopitz, Beethoven as a Composer for the Orphica, in: The Beethoven Journal 22, 2007, H. 1, S. 25-30.

Brief vom 29.6.1801, BHB, Sammlung Wegeler, W 17, in: BRANDENBURG, Beethoven Briefwechsel (wie Anm. 1), hier Bd. 1, Nr. 65. 


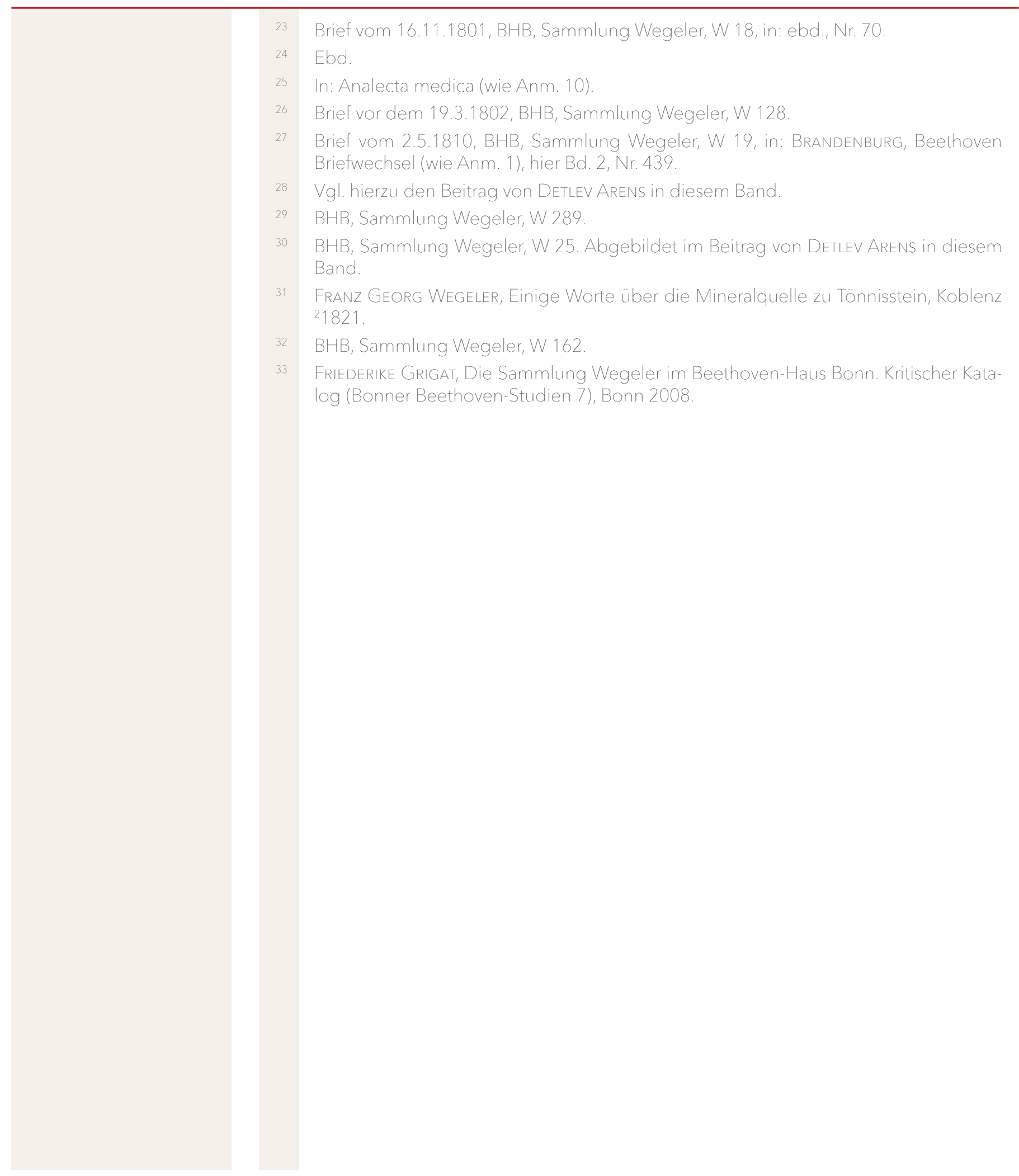

356 | Nicole Kämpken

(C) 2020 by Böhlau Verlag GmbH \& Cie. KG, Köln

https://doi.org/10.7788/9783412519704 | CC BY-NC 4.0 


\section{Einer, der im Lande blieb - \\ Johann Joseph Eichhoff (1762-1827) als \\ (Jugend-)Freund Ludwig van Beethovens}

er im 18. Jahrhundert oft leichtfertige Gebrauch des Begriffs Freund könnte gleich in der Überschrift zu Anführungszeichen verleiten. Dass Freundschaft so außerordentlich hochgehalten wurde („Wem der große Wurf gelungen, eines Freundes Freund zu sein"1), schützte schon damals nicht vor stereotyper und/oder inflationärer Verwendung.

Aber im Fall von Johann Joseph Eichhoff und Beethoven spricht doch Manches für eine vertrauensvolle Beziehung. Nur sollten sich beide lange Zeit aus den Augen verlieren: Der eine ging seinen Weg in Wien und der andere den seinen im Rheinland. Während Beethoven dort bis an die "äußersten Grenzen der Musik" ${ }^{\prime 2}$ vordringt, wird Johann Joseph Eichhoff hier zur konturenscharfen Figur eines Epochenbruchs. Und eben dieser Epochenbruch gibt den Anlass, dass sich die beiden Männer in Wien wieder begegnen und dort die Freundschaft erneuern können.

\section{Johann Joseph und Ludwig: Das familiäre Umfeld}

Ein Historiker wird die Aufzeichnungen des Bonner Bäckermeisters Gottfried Fischer nur mit ganz spitzen Fingern anfassen. Dennoch können sie als Beleg genommen werden, dass die Familien Eichhoff und Beethoven in engerem Kontakt standen. Das Kapitel Die Besucher der Beethovens verzeichnet als Erinnerungssplitter "Die alte Madam Eichhof und ihr(en) Sohn" - welchen auch immer - und gleich darauf "Herr Eichhof, früherer Beisitzer in Paris und nachher Oberkontrolleur am Rhein, mit seiner geliebten Hofsängerin".3

Möglicherweise geht die Verbindung der Familien Eichhoff/Beethoven auf Ludwigs Mutter zurück. Maria Magdalena, geborene Keverich war eine Tochter des kurtrierischen Leibkochs. Den gleichen Dienst am Bonner Hof versahen Vater (Johann August) und Sohn (Johann Joseph) Eichhoff. Deshalb könnte Maria Magdalena für die Eichhoffs ein besonderes Interesse gefasst haben. Anders als die Hofköche waren die Leib- oder Mundköche allein für die Tafel des Herrschers zuständig und hatten insofern eine herausgehobene Stellung.

Die drei Söhne von Johann August Eichhoff (1725-1782) und seiner Frau Maria Magdalena, geborene Farber (1726-1803)4, haben mehr oder weniger von sich reden gemacht. Johann Peter (1755-1825), Johann Joseph (17621827) und Lorenz (1768-1840)5 stehen unter dem Horizont der Aufklärung. Das gilt selbst für Schwester Barbara (1765-1811), die 1785 mit Bernhard 
Constantin von Schönebeck (1760-1835) einen ihrer prominenten Bonner Vertreter heiratete.

Die Quellen geben keine Auskunft darüber, ob schon der Mundkoch Johann August für eine gute Ausbildung der Söhne Sorge getragen hat. Der weitere Lebensweg von Johann Peter und Johann Joseph legt nahe, dass sie sich ihr beträchtliches Wissen großenteils im Selbststudium angeeignet haben. Für Johann Peter ist immerhin der Besuch des Jesuitengymnasiums belegt; er war schon seit 1778 ein umtriebiger Publizist im Kreis der Kölner und Bonner Aufklärer. ${ }^{7}$

Zunächst stand Johann Joseph im Schatten des älteren Bruders und sollte noch geraume Zeit den Küchendienst versehen: Johann Joseph war zunächst in die Fußstapfen seines Vaters getreten: Im Kurkölnischen Hof-Kalender auf das Jahr 1780 wird sein Name erstmals genannt, für "das Jahr Schaltjahr 1788" rückt ihn der Hofkalender an die erste Stelle der dort genannten „Mundköche, Back- und Bratmeister".

Der vorletzte Kölner Kurfürst Maximilian Friedrich von Königsegg-Rothenfels (1708-1784, Landesherr seit 1761) hatte Johann Joseph nach Paris geschickt: Offenbar sollte er sich dort mit der haute cuisine vertraut machen oder doch entsprechend weiterbilden. Die Nachricht findet sich nebenbei, aber in einem aufschlussreichen Zusammenhang: 1784 beurteilt ein "Unterthänigstes ProMemoria die Kurfürstliche Hof Musique betreffend" auch die Sängerin Eva Eichhoff - und vermerkt ihre Ehe mit dem "kurfürstl. Mundkoch". ${ }^{8}$ Darin liegt eine (weitere) bemerkenswerte Verbindung Eichhoffs zur Hofmusik, der eben auch Freund Beethoven angehörte.

1782 hatte Johann Joseph diese Eva Franziska, geborene Grau († 1822) geheiratet. Drei Söhne wurden dem Paar geboren, von denen Peter Joseph (1790-1866) als österreichischer Hofkammerpräsident der bekannteste ist. Eva Franziska Grau war etliche Jahre älter als ihr Mann und brachte den Kaufladen ihres Vaters mit in die Ehe. Für den Gatten, der sein Küchenamt wohl von Beginn an ohne Enthusiasmus versehen hatte, eröffnete sich damit die Perspektive einer wirtschaftlichen Unabhängigkeit vom Hof. Johann Josef Eichhoff ersuchte denn auch um Entlassung aus den kurfürstlichen Diensten; sie wurde ihm 1790 oder 1791 gewährt.

\section{Unter dem Horizont der Aufklärung}

Johann Peter Eichhoff darf zu den wichtigsten Vertretern der Aufklärung im Kurfürstentum gezählt werden, ${ }^{9}$ sein jüngerer Bruder wirkte weniger öffentlich. Doch auch Johann Joseph gehörte der Bonner Minervalkirche Stagira an, einem Zweig des Illuminatenordens. ${ }^{10}$

Die Bonner Universitätsbibliothek verwahrt ein handschriftliches Dokument von Johann Joseph, in dem er einen "Glaucus" scharf angreift. Dieser Glaucus ist nicht irgendeiner, sondern der Stagira-Obere Christian Gottlob Neefe 
(1749-1798). Neefe, Hoforganist und Hofkapellmeister, Lehrer und früher Förderer Ludwig van Beethovens, bekommt hier zu lesen, dass er seine Meriten als Musiker haben mag, aber zur Leitung der Geheimorganisation völlig unfähig ist. ${ }^{11}$

Noch weniger als der Illuminatenorden selbst hatte seine Bonner Zweig,"kirche" Gelegenheit sich zu entfalten; von ihrer Gründung bis zur Auflösung (1785) vergingen nur vier Jahre. Nachfolger, auch Nachfolger im Geist der Aufklärung, wird die Lesegesellschaft, und wiederum gehört Johann Joseph Eichhoff zu den Gründungsmitgliedern. ${ }^{12}$

Bei Auflösung der Stagira war Ludwig van Beethoven erst 14 Jahre alt, aber dem Kreis der späteren Lesegesellschaft stand er nahe. Und 1790 vereint ein Dokument tatsächlich seinen und Eichhoffs Namen: Beide erscheinen auf der Subskribentenliste einer Sammlung Gedichte, die der Bonner Professor Eulogius Schneider (1756-1794) verfasst hatte. ${ }^{13}$

Schneiders Band war auch von Kurfürst Maximilian Franz von Österreich (1756-1801) selbst gezeichnet worden. Falls er wirklich darin gelesen oder hat lesen lassen, wird er das Gedicht Auf die Zerstörung der Bastille ${ }^{14}$ kaum goutiert haben. Hier bekennt sich der Autor ganz offen als Anhänger der Französischen Revolution - einer, dessen Leben folgerichtig unter dem Fallbeil endete. ${ }^{15}$

Es lässt sich nicht sicher belegen, aber Vieles spricht dafür, dass die Ideale der Lese das Weltbild des jungen Beethoven mitgeprägt haben. Auch wird die Gesellschaft dazu beigetragen haben, manche Lücke seiner nur rudimentären Schulbildung zu schließen. Welche Rolle dabei der Lesegesellschafter Johann Joseph Eichhoff spielte, muss offenbleiben. Eichhoff sollte wenig später und sehr viel verbindlicher die Probe auf die Ideale machen dürfen bzw. müssen.

\section{Eichhoffs Eintrag im Stammbuch Beethovens}

Bei den schwachen Indizien lässt sich nicht im Brustton der Überzeugung behaupten, dass die Freundschaft zwischen Eichhoff und Beethoven im familiären Umfeld grundgelegt wurde. Ohne Bedenken kann sich auf den Eintrag ins Stammbuch von 1792 berufen, wer Johann Joseph Eichhoff einen Freund Beethovens nennen will, nach dessen eigener Bekundung ebendort sogar einen "ihn liebenden Freund". ${ }^{16}$

Zum Freundschaftskult des 18. Jahrhunderts gibt es so viele prominente Quellen, dass Zeugnisse aus der "zweiten Reihe” - und zu ihnen gehört dieses Stammbuch - oft vernachlässigt werden. Aber die Einträge hier sind aufschlussreich, auch wenn sie hauptsächlich Zitate bieten.

So berufen sich zwei Einträge auf Klopstock, übrigens entgegen Lessings Diktum, dass Klopstock zwar gelobt, aber nicht gelesen wird. ${ }^{17}$ Und gleich drei Einträge bedienen sich Schillers Don Carlos, aus dem Beethoven nur wenig 
später selbst zitiert, um seinerseits eine Stammbuchseite zu füllen. ${ }^{18}$ Das "Dramatische Gedicht" mit seiner antihöfischen Stoßrichtung ist das Hohe Lied der (Männer-)Freundschaft schlechthin: „Arm in Arm mit dir/ so fordr' ich mein Jahrhundert in die Schranken".

Johann Joseph Eichhoff schöpft aus einer anderen, eher entlegenen Quelle, um den Wert der Freundschaft noch kräftiger herauszustreichen. Er übernimmt (nicht ganz wortgetreu) zwei Verse eines damals 22-jährigen Dichters, des früh verstorbenen Franz Alexander von Kleist: "dass Einer nur von Millionen Weesen/ die Vorsicht dir zum Freund erlesen". ${ }^{19}$

Nach Art eines Lehrgedichts steht die erste Strophe fast ganz im Dienst diätetischer Ermahnungen, die auch für den Bereich der geistigen Nahrung volle Gültigkeit beanspruchen. ${ }^{20}$ Die Kenntnis dieser Verse hätten Eichhoffs spätere Gegner gegen ihn verwenden können. Sie versäumten selten, auf sein Mundkoch-Amt in denunziatorischer Absicht hinzuweisen.

Die in Hinsicht auf das erwähnte Stammbuch bestimmende Gemeinschaft waren offensichtlich die Gäste des Etablissements Zum Zehrgarten am Bonner Markt. Johann Josephs Eintrag findet sich in der Literatur öfter zitiert, weil die Schlussverse der Erwartung Ausdruck geben, dass der Adressat wieder nach Bonn zurückkehrt: "Dann sollst du mich (und bräch auch alles Dir)/ Und unßern trauten Krais/ Mit ofnen Armen, wahrer Liebe/ Auf deine Rückunft harren sehn!" - "Und bräch auch alles Dir", der Halbvers steht immerhin in Klammern, aber sie mindern kaum das Pathos des Versprechens, den Heimkehrer aufzufangen.

Übrigens hat Eichhoff ins Stammbuch Beethovens nicht mehr als Mundkoch, sondern als selbständiger Kaufmann geschrieben, der mit leicht gönnerhafter Attitüde den Jüngeren verabschieden konnte: "So wandre hin, du guter Junge."

\section{Eichhoff im französischen Rheinland: Vom Nationalagenten zum General-Direktor der Rheinschifffahrtsverwaltung}

Beethovens Abschied von Bonn $1792^{21}$ ist auch für seine Beziehung zu Eichhoff eine wirkliche Zäsur: Volle 22 Jahre sollte es dauern, bis sich die Beiden wiedersehen. Wahrscheinlich hatten sie während dieses langen Zeitraums keinen unmittelbaren Kontakt, und von einer "verbrieften" Freundschaft kann schon gar keine Rede sein.

Bereits 1792 drohte das Kurfürstentum Geschichte zu werden. Das geschah dann zwei Jahre später, als die Franzosen vom linken Rheinufer endgültig Besitz ergriffen. Sofort stellte sich Johann Joseph Eichhoff (wie auch sein Bruder Johann Peter) in den Dienst der Besatzer, sicher nicht aus Opportunismus, sondern aus Überzeugung, also im Glauben an die Ideale der Französischen Revolution.

Jetzt kommt Johann Joseph seine Zeit in Paris zugute, dort hatte er das Französische ziemlich vollendet beherrschen gelernt. 1795 unterzeichnet er in Bonn zahlreiche Proklamationen der Besatzer als Nationalagent. Diese Vertreter

$360 \mid$ Detlev Arens 


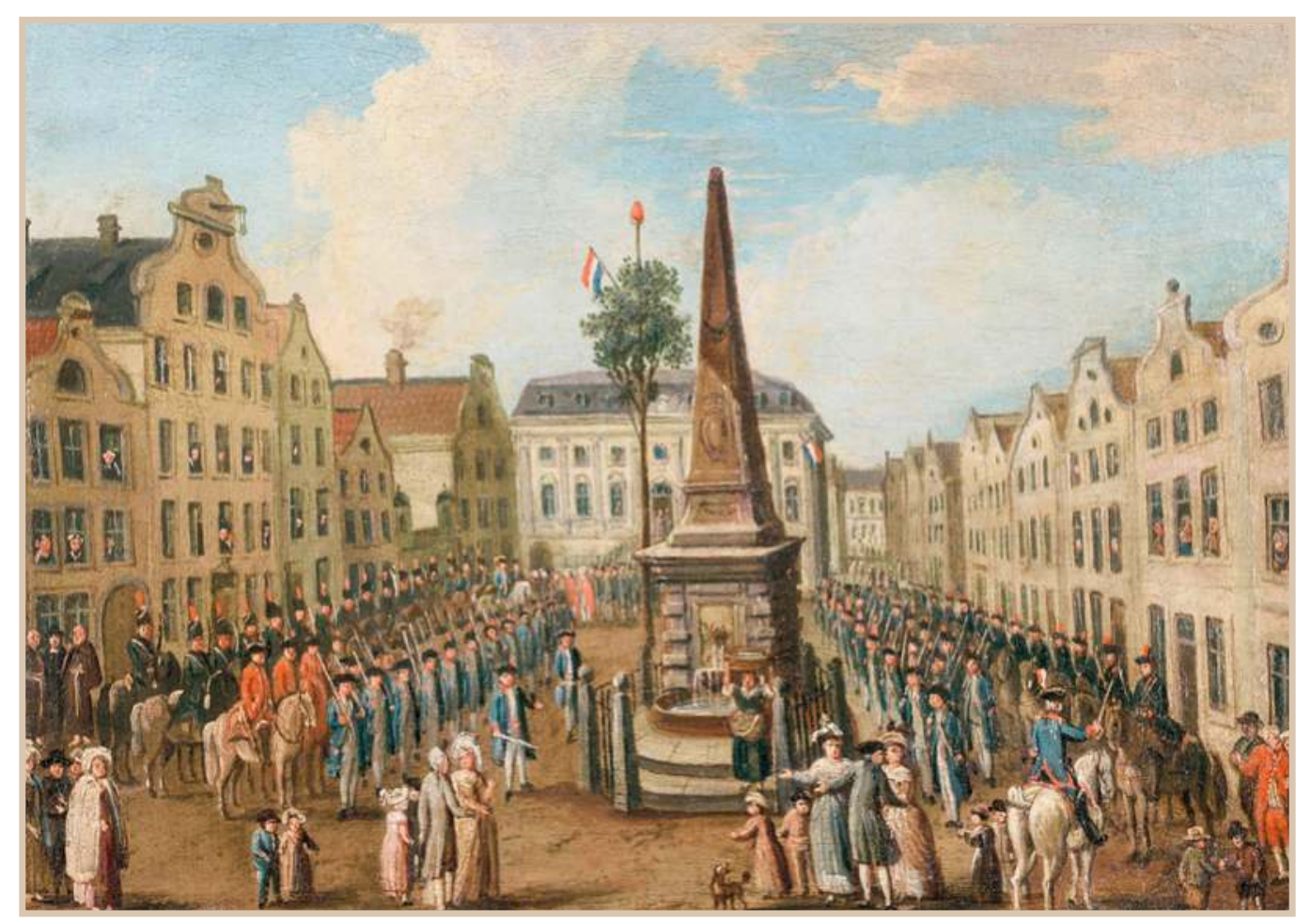

der Exekutivgewalt auf lokaler Ebene waren in Frankreich während des Terreur gefürchtete Leute. Als Garanten der revolutionären Prinzipien konnten sie ohne Weiteres an den örtlichen Entscheidungsgremien vorbei regieren.

Johann Joseph Eichhoff hat sich eher als Vermittler gesehen, und das lief im besetzten Rheinland auf einen Platz zwischen den Stühlen hinaus. Die chaotischen Verhältnisse dieser Jahre machten jeden Versuch des Ausgleichs zunichte. Schon am 3. Germinal des Jahres IV (23. März 1796) „[bat] er um Entlassung aus seiner Stelle. Dieselbe wurde bewilligt". ${ }^{22}$ Doch schon 1799 war er wieder Mitglied der Munizipialität, also der Bonner Gemeindeverwaltung, ebenfalls hielt er Kontakt zur französischen Zentralregierung.

Ein unkritischer Erfüllungsgehilfe der Besatzer war Eichhoff nicht. Davon zeugt die bemerkenswerte Antrittsrede als Maire, also als Haupt der Stadtverwaltung und insofern Oberbürgermeister. Nach seiner Ernennung Ende November 1800 wird er am 10. Januar 1801 feierlich in sein Amt eingeführt - nur einen Monat danach wurde im Frieden von Lunéville (9. Februar) das linke Rheinufer völkerrechtlich Frankreich zugeschlagen.

An diesem 10. Januar aber unternimmt er das, was heute im politischen Jargon eine "schonungslose Bestandsaufnahme" heißt. ${ }^{23}$ Immerhin, "nach dem glorreichen Tage des 18ten Brumaire" (9. November 1799), also dem Staatsstreich Napoleons, dürften die Mitbürger auf bessere Zeiten hoffen. "Diese frohe Hoffnung ... fließt aus dem eignen Munde jenes großen Mannes,
Herrichtung des Freiheitsbaumes auf dem Bonner Marktplatz. Ölgemälde von Franz Rousseau, wohl 1794 (StadtMuseum Bonn) 
Rechte Seite: Johann Joseph Eichhoff (1762-1827).

Porträt eines unbekannten Malers, nach 1802 (StadtMuseum Bonn). Vor ihm liegend sein 1802 verfasstes „Memoire sur le quatre departemens réunis" der jetzt Frankreichs, der Europas Schicksal leitet, und der noch nie ein Versprechen unerfüllt gelassen hat."24

Schon ein Jahr später folgte die nächste Rangerhöhung. Eichhoff wurde Unterpräfekt des Arrondissements (vergleichbar einem Regierungsbezirk) Bonn. Seine Mitbonner registrierten verstimmt, dass er keineswegs unempfindlich gegen die Würde der hohen Stellung war. ${ }^{25}$ Allerdings war er sie nur zwei Jahre später wieder los, angeblich, weil er im Beisein "des großen Mannes" vom Pferd fiel und/oder weil Napoleon ihn wegen seiner Vergangenheit als Mundkoch nicht für würdig erachtete, sein "großes" Frankreich zu repräsentieren. ${ }^{26}$

Eichhoff mochte vom Pferd gefallen sein, doch er fiel auf die Füße. Schon 1802 war sein „Mémoire sur les quatre départemens(!) réunis de la rive gauche du Rhin, sur le commerce et les douanes de ce fleuve" erschienen und in Paris gedruckt worden, schon hier war der Rhein als Verkehrsweg ein Hauptthema gewesen. Die ausführliche Rezension in den Göttingischen Gelehrten Anzeigen vom 25. April 1803 attestierte der Denkschrift, sie sei „mit Sachkenntnis und Freimütigkeit" geschrieben und schloss mit einem Appell an den Adressaten: „Wir hoffen und wünschen, daß viele der Ideen des Verf\{assers\} bey der nun zu errichtenden neuen Schifffahrts-Octroy genutzt werden mögen. Die Französische Regierung hat nicht leicht eine bessere Gelegenheit, die so oft gerühmten liberalen Gesinnungen zu zeigen, als hier." ${ }^{27}$

Als der Rheinschifffahrts-Octroi am 15. August 1804 den amtlichen Segen erhalten hatte, war es demnach nur folgerichtig, Johann Joseph Eichhoff als einen der vier Inspektoren zu bestellen, die ihn umsetzen und überwachen sollten. Nur ein Jahr später fungierte er als (zunächst provisorischer) Generaldirektor der Rheinschifffahrtsverwaltung mit Dienstsitz Paris.

Es war ein sehr gut dotierter Posten, aber keiner nach Art eines Frühstücksdirektors. Dass mit einem liberalisierten Warenverkehr beispielsweise der "Stapelunfug" 28 zur Disposition stand, machte die Kölner zu Eichhoffs quasi natürlichen Feinden. Und nicht nur von dieser Seite kamen immer wieder heftige Beschwerden gegen seine Amtsführung. Die unterschiedlichen Interessen der vielen Rheinanlieger standen einer frei(er)en Schifffahrt im Weg.

\section{Eichhoff im preußischen Rheinland}

Die Reizfigur Eichhoff sollte seinen Gegnern auch erhalten bleiben, als Napoleon geschlagen war und sich die Franzosen vom Rheinufer zurückgezogen hatten. In der Zeit des Übergangs, der Ungewissheit, amtierte Eichhoff weiter. Er "hatte von Paris aus der Octroiverwaltung die Weisung zugehen lassen, auf ihrem Posten zu bleiben und weiterzuarbeiten. Dieses Auftreten hat ihm die Gunst Steins [Freiherr vom Stein war Chef der Alliierten Zentralverwaltungsbehörde für die besetzten Gebiete, D.A.] eingetragen". ${ }^{29}$

Eichhoff brachte sich auch Karl August (ab 1814 Fürst) von Hardenberg in Erinnerung. Am 18. April 1814, nur sieben Tage nach dem Sturz Napoleons und 


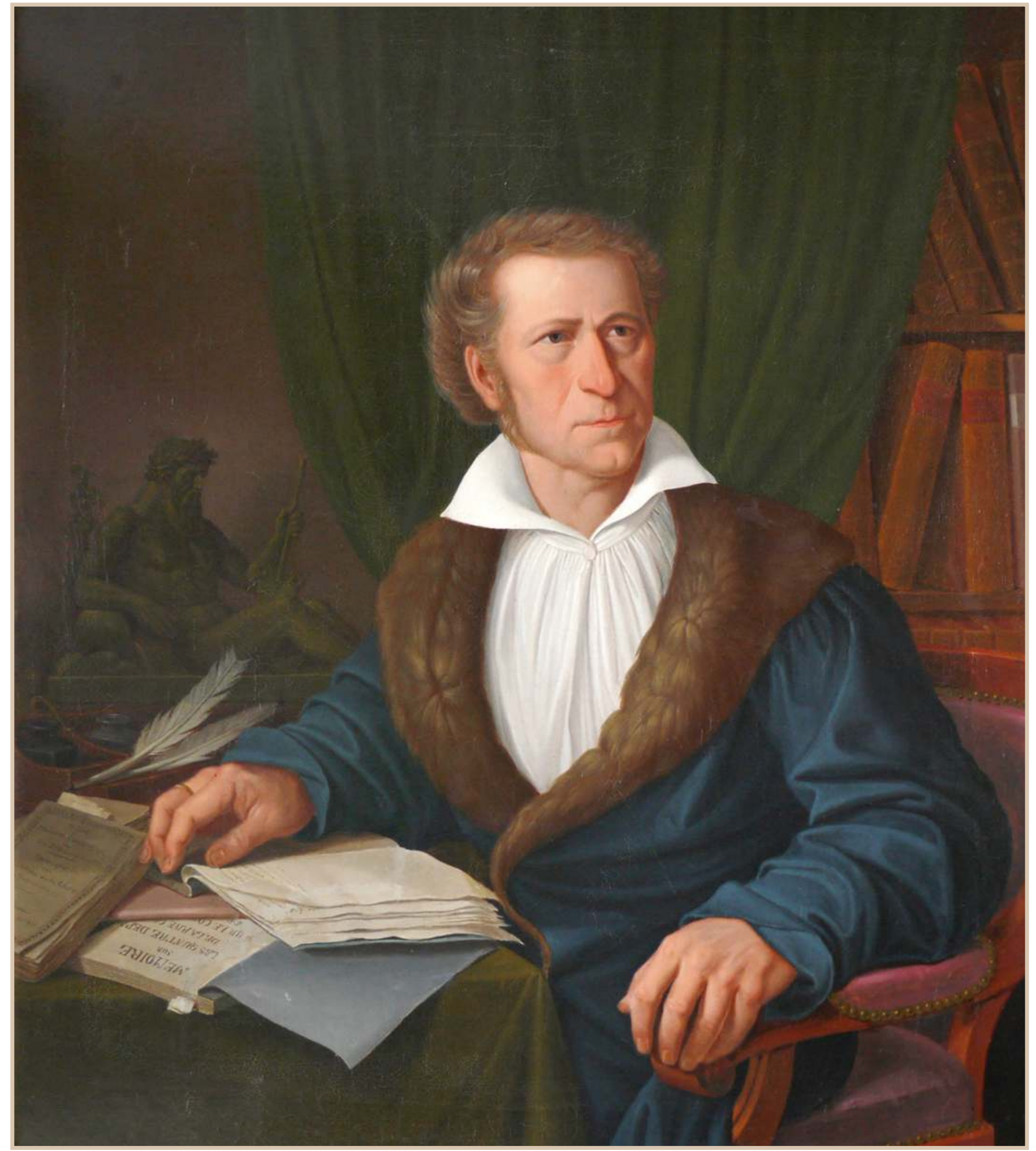

Einer, der im Lande blieb - Johann Joseph Eichhoff als (Jugend-)Freund Ludwig van Beethovens | 363

(c) 2020 by Böhlau Verlag GmbH \& Cie. KG, Köln

https://doi.org/10.7788/9783412519704 | CC BY-NC 4.0 
noch vor Abschluss des ersten Pariser Friedens, schrieb er Preußens Staatskanzler einen Brief, dem seine "ÜberlegungenzurVerwaltung derRheinschifffahrt" ("Considerations sur I' Octroi de navigation au Rhin") beilagen. ${ }^{30}$

Und noch 1814 erschien seine Topographisch-statistische Darstellung der Rheines. ${ }^{31}$ Mehrfach betont er darin die Eile, in der "das Werkchen" entstanden sei; dieser Eile sind wohl auch die vielen Korrekturen am Schluss der "Darstellung" geschuldet. So spiegeln selbst die Errata Eichhoffs Eifer, sein Gewicht in die richtigen Waagschalen zu werfen.

Dennoch: Auch diese Schrift belegt Eichhoffs souveräne Kenntnis in allen Angelegenheiten der "Handlung und Schifffahrt” auf dem Rhein. Zusätzlich kann er nun seine neun Jahre als Chef des Octroi ins Feld führen. „Da, während meiner Amtsführung, die Einrichtung getroffen war, daß die mindeste Bewegung auf dem Rheine nicht Statt haben, kein Zentner Waare von einem Orte zum andern verführt werden konnte, ohne daß mir darüber nachgewiesen würde." ${ }^{\prime \prime 2}$

Im Februar 1815 wurde er dem Schifffahrtsausschuss des Wiener Kongresses „beigezogen“, im Monat darauf beendete das Gremium mit derVerabschiedung der Rheinakte seine Arbeit. Sie legte die freie Schifffahrt auf dem Rhein bis zu dessen Mündungen fest, übernahm im Großen und Ganzen die Regelungen des Octroi, ließ aber im Einzelnen manche Fragen offen. Dieser Spielraum führte beispielsweise dazu, dass Köln und Mainz "ihr" Recht des Warenumschlags noch einige Jahre verteidigen konnten. Eichhoff aber durfte sich rühmen, dass seine Expertise hier einen angemessenen Niederschlag gefunden hatte.

Nun hatte die Rheinakte nur Rahmenrichtlinien vorgegeben, eine Centralcommission für die Rheinschiffahrt sollte "die neuen definitiven Reglements" festlegen. In Mainz ansässig, nahm sie - mit einiger Verzögerung - am 5. August 1816 ihre Arbeit auf. Auch hier erhob Eichhoff Anspruch auf eine Führungsrolle, und einmal mehr schieden sich an seiner Person die Geister. 1819 schied er aus dem Gremium aus, im gleichen Jahr erschien nochmals eine "Darstellung" von seiner Hand. ${ }^{33}$

Sie, die letzte ihrer Art, versammelt Dokumente der zähen, nicht selten obstruktiven Einigungsbemühungen für die "Freiheit des Rheins". Aber sie spricht auch pro domo und wählt dabei einen Ton, der seine Widersacher gewiss nicht für den Verfasser eingenommen hat. „Was uns persönlich betrifft, so halten wir es nicht der Mühe wert, auf eine anonyme Anschuldigung anders, als durch bloses Hinweisen auf ... unsere Berichte und Denkschriften zu antworten, und hierbei, ohne alle Bemerkung, dem unbefangenen Leser sein freies Urtheil darüber zu überlassen."34

Im Jahr seines Ausscheidens hatte er die Genugtuung, dass der Wiener Hof seinen Sachverstand auch für die Regelung der Elbschifffahrt in Anspruch nahm. ${ }^{35}$ Und selbst aus dem Gedächtnis der Nachwelt hat sich der ehemalige Generaldirektor des Octroi nicht gleich verloren. So resümiert der weiland 
preußische Generalpostmeister von Nagler (1770-1846), im aktiven Dienst stets auf der Suche nach staatsfeindlichen Umtrieben: „Dass er ein höchst ränkevoller Mann gewesen, ist außer Zweifel."36 Ganz anders urteilt Wilhelm Dorow (1790-1845), erster Leiter des Museums Rheinisch-Westphälischer Altertümer (heute LVR-LandesMuseum Bonn): „Ein, was Verstand und Formen betraf, gleich ausgezeichneter Mann."37

Bei derart konträren Einschätzungen der Person Eichhoffs gewinnt die des Schifffahrtsexperten Henry Hajnal noch an Gewicht. Er befindet aus dem Abstand eines Jahrhunderts und nur in Kenntnis der Schriftzeugnisse: „He was not only a man of great knowledge, but also an unbiassed and fair expert." ${ }^{\prime 3}$

\section{Beethoven und Eichhoff: Wiedersehen in Wien}

Beethoven hat den Wiener Kongress, also den übergeordneten Anlass für Eichhoffs Reise, als Komponist gewürdigt. ${ }^{39}$ Für Eichhoff endet die aktive Kongress-Teilnahme, als sein Ausschuss am 24. März 1815 die Schifffahrtsacte verabschiedet. Am 27. März, also drei Tage später, besucht Eichhoff Beethoven. Natürlich wäre es interessant zu wissen, wie die beiden nach so langer Zeit miteinander umgegangen sind. Doch einmal mehr schweigen die Quellen, über diesen Besuch ist kaum etwas bekannt. Das exakte Datum immerhin verdankt sich dem Wegeler-Exemplar des Höfel-Stichs, den Beethoven unter Angabe von Jahr, Monat und Tag seinem „Freund" zugeeignet hat.

Wie schon angemerkt, fehlen alle Zeugnisse direkter Kontakte aus den Jahren zwischen 1792 und 1815. Aber mittelbare muss es gegeben haben. Dafür spricht unter anderem die Widmung auf einer Komposition von Ferdinand Ries (1784-1838), Sohn von Franz Anton Ries (1755-1846), einst Beethovens älterer Kollege in der Hofkapelle. Das Titelblatt seiner Grande Sonate pour le Piano-Forte et Violon (op. 10, vor 1810 entstanden) trägt den Zusatz: „composée et dediée
Ludwig van Beethoven. Kupferstich von Blasius Höfel nach einer Zeichnung von Louis Letronne (Beethoven-Haus Bonn). Dieses Porträt brachte Eichhoff auf Bitten Beethovens nach Bonn. Es war bestimmt und gewidmet „für meinen Freund Wegeler, Vien am 27ten März 1815 L. v. Beethoven“

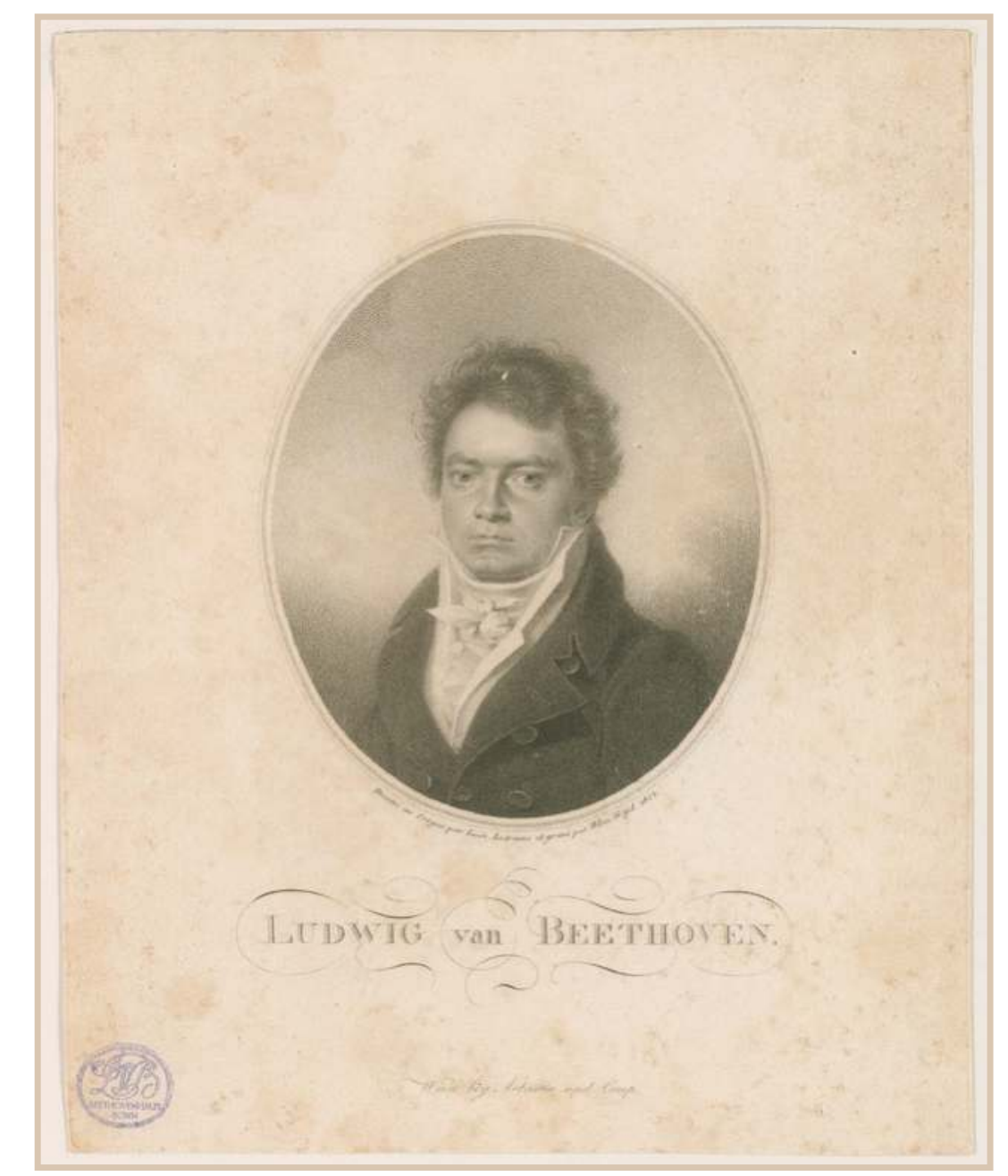


à Monsieur Eichhof, directeur Général de l'Octroi de Navigation du Rhein(!) ${ }^{\prime \prime}{ }^{40}$ Was immer den jungen Komponisten, ebenfalls Freund Beethovens und stets mit ihm in Verbindung geblieben, ${ }^{41}$ zu dieser Widmung veranlasst haben mag, der Generaldirektor Eichhoff hatte eine gesellschaftliche Stellung inne, die auch einen Werbeeffekt versprach.

$\mathrm{Ob}$ es über die Wiederbegegnung am 27. März 1815 hinaus zu weiteren Treffen zwischen Beethoven und Eichhoff kam, steht dahin. Quellen fehlen, es ist nicht einmal bekannt, wann genau Eichhoff aus Wien abreiste.

Aber am 6. Mai 1815 hat Eichhoff der Bonner Lesegesellschaft über das Wiener Wiedersehen Bericht erstattet. Zu diesem Datum vermerkt das handschriftliche Protokoll der Lese-Vorstandssitzung (unter Berufung auf Eichhoff), dass "der berühmte Tonkünstler van Beethoven unser Landsmann ein gemaltes Portrait der Gesellschaft mitteilen werde." 42 Stutzen lässt, dass dieses "unser Landsmann" nicht im fortlaufenden Text, sondern nachgetragen in der breiten Randspalte erscheint. Es wäre interessant zu wissen, was den Protokollführer Johann Heinrich Crevelt (1751-1818), auch er Mediziner und ein Jugendfreund des „Tonkünstlers", bewogen haben mag, auf die landsmannschaftliche Zugehörigkeit eigens aufmerksam zu machen. - Der Verdacht liegt nahe, dass dieser ausdrückliche Hinweis nötig war.

Bekanntlich ist das (immer nach Eichhoff) in Aussicht gestellte Porträt nie in Bonn eingetroffen. ${ }^{43}$ Doch nutzte Beethoven die Gelegenheit, über Eichhoff Verbindung zu den alten Bonner Freunden aufzunehmen. Die größte Anhänglichkeit zeigte er gegenüber dem (seit 1807 Koblenzer) Mediziner Franz Gerhard Wegeler, der 1838 zusammen mit Ferdinand Ries auch die Biographische(n) Notizen über Ludwig van Beethoven veröffentlichte.

Hier findet sich auch der Brief vom 29. September 1826 abgedruckt, in dem Beethoven nach dem Erhalt eines Kupferstichs mit seinem Porträt fragt. Wegeler erläutert in den Anmerkungen: „Unser gemeinschaftlicher Freund, der General-Director des Rheinzolls, hatte ihn mir vom Congreß mitgebracht." ${ }^{44}$ Es handelt sich dabei um einen Stich von Blasius Höfel nach einer Zeichnung von Louis Letronne(?), ein zweites Exemplar brachte Eichhoff für die Bonner Lesegesellschaft mit, sozusagen die Vorausabteilung für sein gemaltes, in Bonn nie eingegangenes Bildnis.

Nur geht auch aus dieser Niederschrift nicht hervor, was die beiden sich in Wien zu sagen hatten. Jedenfalls traf Beethoven, soweit er nostalgisch der alten Heimat und ihrem „Vater Rhein" anhing, in Eichhoff auf einen Mann, der den Strom als Verkehrs- und Handelsweg, also mit äußerster Nüchternheit zu beurteilen gewohnt war.

Nach seinem Ausscheiden aus der Zentralkommission zieht sich Eichhoff nach Kessenich (damals Bürgermeisterei Poppelsdorf) und hier auf sein Landgut zurück. In Kessenich stirbt er am 3. Dezember 1827, also im selben Jahr wie Beethoven (26. März). 
Während Beethovens Name im Jubiläumsjahr besonders machtvoll widerhallt, können mit dem Namen Eichhoff nur wenige Fachwissenschaftler etwas anfangen. Das ist bedauerlich, weil mit ihm ein Vorkämpfer für den Rhein als internationale Wasserstraße zu ehren wäre, auch wenn Vorkämpfer heißt, dass er den Weg bereiten half, aber das Ziel nicht erreicht hat.

Eichhoff im Beethoven-Jubiläumsjahr (und darüber hinaus) zu würdigen, ließe sich übrigens leicht einrichten. Sein Grab auf dem Kessenicher Alten Friedhof blieb erhalten, die urnengekrönte Rundsäule ist auch von ihrem Erscheinungsbild her ein interessantes Monument.

Und damit nicht genug, lässt sich von diesem GrabDenkmal eine Brücke zum ersten Bonner Beethoven-Denkmal schlagen. Den Kessenicher Grabstein haben laut Inschrift die drei Söhne von Johann Joseph Eichhoff "Dem Andenken der geliebten Eltern geweihet". Den jüngsten Sohn, den so erfolgreichen Peter Joseph, verzeichnet Breidensteins "Festgabe ${ }^{45}$ zur Einweihung des BeethovenDenkmals als Spender von 1000 Talern. Auf die ungewöhnliche Höhe der Summe hat damals die Allgemeine Zeitung (Augsburg und München) hingewiesen. „Unter den einzelnen ausgezeichneten Privatpersonen ... verdient eine besondere ehrenvolle Erwähnung die über alle Erwartung ansehnliche Gabe des (in Bonn gebornen) Herrn Hofkammerpräsidenten v. Eichhoff in Wien." ${ }^{46}$

„Über alle Erwartung": Nicht auszuschließen, dass der Freiherr Peter Joseph von Eichhoff so auch die Freundschaft zwischen den Vätern gewürdigt hat.

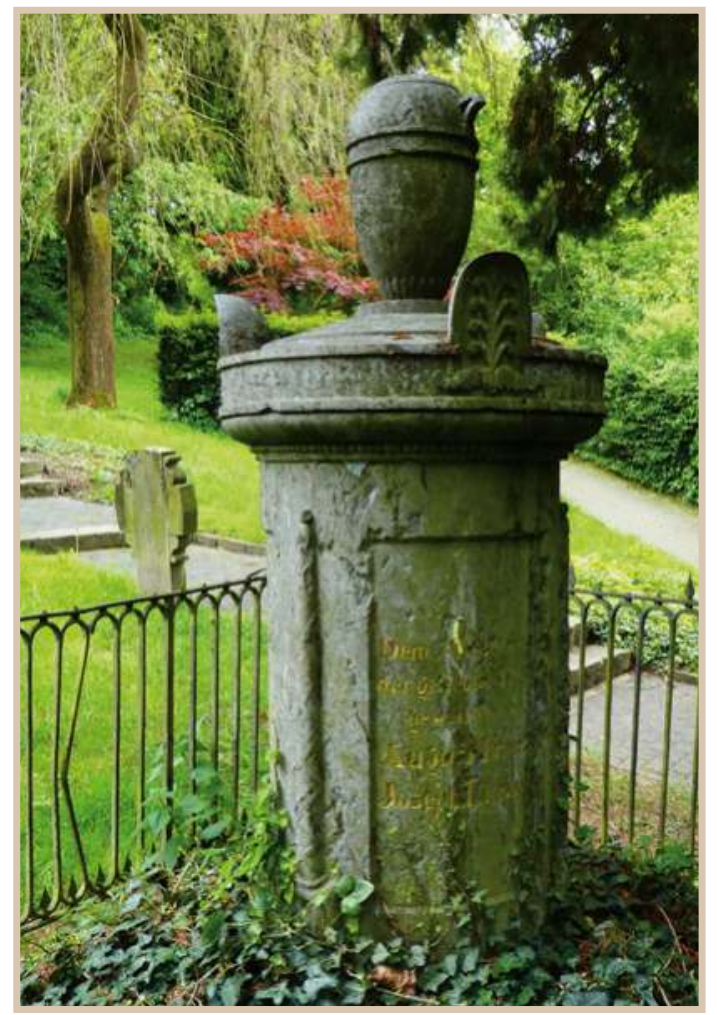

Grabmal von Johann Joseph Eichhoff und seiner EvaFranziska, geb. Grau, auf dem Alten Friedhof Kessenich (Foto: privat) 
Schönebeck war "einer der führenden Vertreter der Aufklärung im Rheinland", so CHRISTIAN SCHLÖDER, Johann Bernhard Constantin von Schönebeck. Arzt, Publizist und Autor (1760-1835), in: Internetportal Rheinische Geschichte (http://www.rheinische-geschichte.Ivr.de/Persoenlichkeiten/johann-bernhard-constantin-von-schoenebeck/DE-2086/lido/57c949333c4c63.97292842; abgerufen 9.3.2020).

Zu Johann Peter Eichhoff vgl. KARL GUTZMER, Johann Peter Eichhoff. Ein rheinischer Republikaner (1755-1825), in: EDITH ENNEN und DIETRICH HÖROLDT (Hgg.), Aus Geschichte und Volkskunde von Stadt und Raum Bonn. Festschrift Joseph Dietz (Veröffentlichungen des Stadtarchivs Bonn 10), Bonn 1973, S. 233-251; CHRISTIAN SCHLÖDER, Johann Peter Eichhoff. Journalist und Publizist (1755-1825), in: Internetportal Rheinische Geschichte (http://www.rheinische-geschichte.Ivr.de/Persoenlichkeiten/johannpeter-eichhoff-/DE-2086/lido/57c69f644b4e52.18322639, abgerufen 8.11.2019)

"Ist geheiratet mit dem Kurfürstl. Mundkoch, welcher zu Paris auf Kösten Sr. Kurfürstl. Gnad. Höchstseeln Andenkens das Kochen gelernet hat." - Offensichtlich sollte das Dossier Maximilian Franz von Österreich, den letzten Kölner Kurfürsten und großen Musikliebhaber, über das Leistungsvermögen der damaligen Hofkapelle orientieren. Zitiert nach AlEXANDER WHEELOCK THAYER, Ludwig van Beethovens Leben, nach dem Original-Manuskript deutsch bearbeitet, neu bearbeitet und ergänzt, von HERMANN DeITERS, Berlin 21901, Bd. 1, S. 175.

Nach einer Rückkehr aus Maastricht, wo er für den Deutschen Orden tätig war, in seine Geburtsstadt war Johann Peter ein rühriges Mitglied der Bonner Illuminaten, und wurde fast folgerichtig erster Präsident der Bonner Lesegesellschaft. Vgl. SCHLÖDER, Johann Peter Eichhoff (wie Anm. 7).

Illuminati sind wörtlich übersetzt "die Erleuchteten", die "Kirche" heißt nach der römischen Göttin Minerva, die in der Aufklärung als Gestaltwerdung der Vernunft das Licht der Erkenntnis verbreitet, Stagira ist der Geburtsort von Aristoteles.

[Freimaurer-Akten] (7), Beylage A, in: Universitäts- und Landesbibliothek Bonn.

Zur Bedeutung der Lese vgl. ALEXANDER WOLFSHOHL, "Lichtstrahlen der Aufklärung". Die Bonner Lese-Gesellschaft - Geistiger Nährboden für Beethoven und seine Zeitgenossen (Begleitpublikation zur Ausstellung im Beethoven-Haus Bonn), Bonn 2018.

Eulogius SCHneIDER, Gedichte, Frankfurt 1790. Vgl. hierzu den Beitrag von AleXANDER WOLFSHOHL in diesem Band.

Ebd., S. 245. - Die vorletzte Strophe lautet: "Gefallen ist des Despotismus Kette/ Beglücktes Volk! Von Deiner Hand:/ Des Fürsten Thron ward Dir zur Freiheitsstätte,/ Das Königreich zum Vaterland." - Zur Erinnerung: Der Kurfürst war der Bruder der französischen Königin Marie Antoinette von Österreich Lothringen, die mit ihrem Gatten damals schon unter Aufsicht "des Volks" im Tuilerien-Palast lebte.

Im gleichen Jahr veröffentlichte Schneider eine Elegie an den sterbenden Joseph II. und regte nach dem Tod des Kaisers die Abfassung einer Trauerkantate an. Sein Schüler Severin Anton Averdonk verfasste den Text, Komponist der Kantate WoO 87 war der damals 19-jährige Beethoven. Zu einer Aufführung kam es nicht.

Max Braubach $(H g$.$) , Die Stammbücher Beethovens und der Babette Koch, Bonn$ 21995, S. $15 f f$.

„Wer wird nicht einen Klopstock loben?/ Doch wird ihn jeder lesen? Nein/ Wir wollen weniger erhoben/ Und fleißiger gelesen sein."- Den (hohen) Ton Klopstocks schlägt im Stammbuch auch Christoph von Breuning (1773-1841) an, Bruder Stephans und Eleonores und Sohn von Helene von Breuning (1750-1838), Beethovens so genannter zweiter Mutter. 


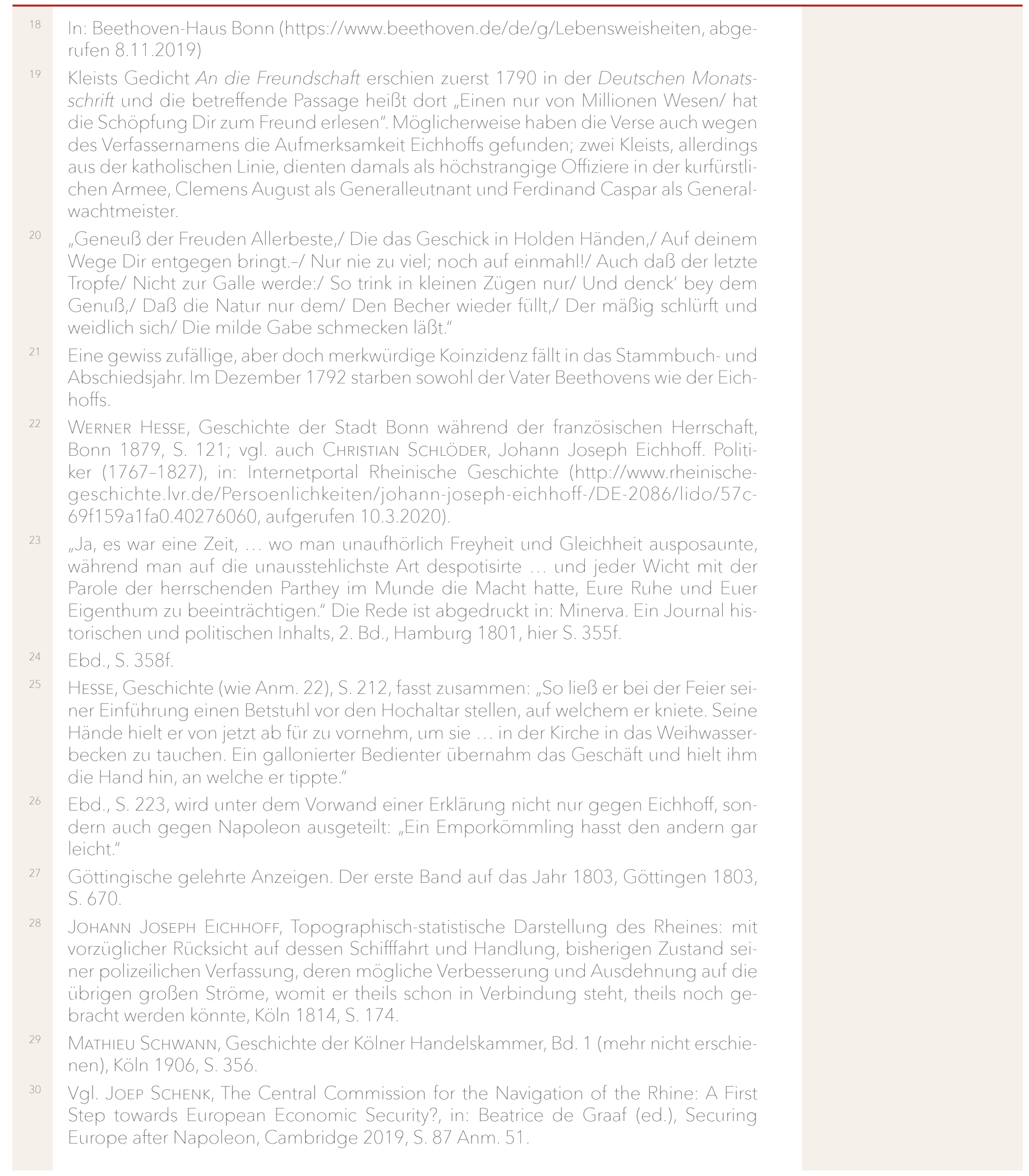

Einer, der im Lande blieb - Johann Joseph Eichhoff als (Jugend-)Freund Ludwig van Beethovens | 369 
JOHANN JOSEPH EICHHOFF, Topographisch-statistische Darstellung des Rheines: mit vorzüglicher Rücksicht auf dessen Schifffahrt und Handlung, bisherigen Zustand seiner polizeilichen Verfassung, deren mögliche Verbesserung und Ausdehnung auf die übrigen großen Ströme, womit er theils schon in Verbindung steht, theils noch gebracht werden könnte, Köln 1814

Ebd., S. VII.

JOHANN JOSEPH EICHHOFF, Pragmatisch-geschichtliche Darstellung der Verhandlungen und Beschlüsse des Congress-Committées für die Freiheit der Flüsse sowie der Berathungen der in Gefolge jener Beschlüsse in Mainz niedergesetzten Central-Kommission, Mainz 1819.

Ebd., S. VII. - In einer Fußnote zur Seite 123 fordert Eichhoff im Fall seines Rücktritts „Beibehaltung meines Ranges und voriger Emolumente [Zuwendungen neben dem Gehalt]". Laut der anonymen Schrift: Neue Organisation der Schifffahrts- und Handelsverhältnisse auf dem Rheinstrome, Basel 1822, S. 170, hat er über sein Verlangen hinaus Erfolg gehabt und auch noch sein Gehalt als Pension bezogen: „Es genießt auch derselbe wirklich, seitdem er außer Dienst-Aktivität ist ..., mit Beibehaltung seines Titels und Rangs seinen vorigen Gehalt und Emolumente."

Die Elbzölle: Aktenstücke und Nachweise 1814-1859, Leipzig 1860, S. 17. (zum Jahr 1819) - Hier zeichnet sich jene Verbindung ab, die den Aufstieg seines Sohns Peter Joseph (von) Eichhoff (1790-1866) in den Diensten der k. k. Monarchie (mit)bewirkte: Peter Joseph begann seine Karriere in der österreichischen Elbschifffahrts-Kommission.

Ernst Kelchner und Karl Mendelssohn-Bartholdy (Hgg.), Briefe des Königl. Preuß. Staatsministers, General-Postmeisters und ehemaligen Bundestags-Gesandten Karl Ferdinand Friedrich von Nagler an einen Staatsbeamten, 1. Teil, Leipzig 1869, S. 127. WILHELm Dorow, Erlebtes aus den Jahren 1813 - 1820, Erster Teil, Leipzig 1843, S. 197.

Henry Hajnal, The Danube, The Hague 1920, S. 43.

Vgl. Karin Schneider und Eva Maria Werner, Europa in Wien. Who is who beim Wiener Kongress 1814/15, Wien 2015, S. 111

Erschienen im Verlag von Nikolaus Simrock.

Vgl. hierzu den Beitrag von BARBARA Mülhens-Molderings in diesem Band.

Zitiert nach KLAUS MARTIN KOPITZ, Das Beethoven-Porträt von Ferdinand Schimon. Ein 1815 für die Bonner Lesegesellschaft entstandenes Bildnis?, in: JÜRGEN MAY (Hg.), Beiträge zu Biographie und Schaffensprozess bei Beethoven. Rainer Cadenbach zum Gedenken, Bonn 2011, S. 73-88, hier S. 77ff.

So bleibt bis heute offen, welches Bild gemeint sein könnte

Franz Gerhard Wegeler und Ferdinand Ries, Biographische Notizen über Ludwig van Beethoven, Koblenz 1838, S. 48. Zu Wegeler vgl. den Beitrag von Nicole KämPKEN in diesem Band.

HeINRICH KARL BreidensteIn, Festgabe zu der am 12. August 1845 stattfindenden Inauguration des Beethoven-Monuments, Bonn 1845, S. 10.

Allgemeine Zeitung (Ausgabe Augsburg, Außerordentliche Beilage), 2.9.1836. 


\title{
Beethoven und Graf Waldstein - Der Rittersitz Disteling zu Godesberg und die Musik zu einem Ritterballett
}

\begin{abstract}
G raf Ferdinand Ernst von Waldstein und Wartenberg (24. März 1762 26. Mai 1823) war einer der ersten und wichtigsten Förderer des jungen Beethoven in Bonn. Ihm gebührt die Ehre, zu denen zu gehören, die das Talent des jungen Musikers früh entdeckten. Waldstein war bis etwa 1794/95 "Günstling" und "Vertrauter" - so das Narrativ der älteren Geschichtsforschung - des letzten Kurfürsten von Köln, Maximilian Franz von
\end{abstract} Österreich.

Waldstein stammte aus einer bedeutenden, kunstliebenden böhmischen Familie, der durch Erbfall seit 1760 das Schloss Dux (heute: Duchcov in Tschechien) bei Teplitz (heute: Teplice) gehörte. ${ }^{1}$ Der älteste Bruder Ferdinands war Joseph Karl Emanuel von Waldstein und Wartenberg (1755-1814), eben jener Schlossherr, der es Giacomo Casanova (1725-1798) ermöglichte, als Bibliothekar auf Schloss Dux seinen Lebensabend zu verbringen. Casanova wurde 1798 auch dort beigesetzt. Im Jahr 1812 soll Ludwig van Beethoven Gast auf Schloss Dux gewesen sein und ein Konzert gegeben haben, an welches ein dort 1968 errichtetes Denkmal erinnert.

Beethoven hatte aber bereits lange vor diesem vermuteten Konzert in Schloss Dux Ferdinand Waldstein die 1803/4 komponierte sogenannte Waldsteinsonate (op. 53) gewidmet und machte auch ihn damit unsterblich. Waldstein war es, der zum Abschied Beethovens aus Bonn die berühmt gewordenen Worte in Beethovens Stammbuch schrieb: "Lieber Beethoven! Sie reisen itzt nach Wien zur Erfüllung ihrer so lange bestrittenen Wünsche. Mozart's Genius trauert noch und beweint den Tod seines Zöglings. Bey dem unerschöpflichem Hayden fand er Zuflucht, aber keine Beschäftigung; durch ihn wünscht er noch einmal mit jemanden vereinigt zu werden. Durch ununterbrochenen Fleiß erhalten Sie: Mozart's Geist aus Haydens Händen ... Bonn den 29. Oktober 1792. Ihr warer Freund Waldstein".2

Waldstein war ein quecksilbriger, eigenwilliger Geist mit dem Hang zu riskanten Aktionen und unglücklichen Finanzgeschäften, aber ein offenbar intelligenter Unterhalter, ein geschickter Verhandler, den Max Franz über Jahre

Graf Ferdinand Ernst von Waldstein und Wartenberg (1762-1823). Silhouette aus dem Stammbuch Beethovens (Österreichische Nationalbibliothek) 
sehr schätzte und förderte. ${ }^{3}$ Die Silhouette Waldsteins in Beethovens Stammbuch zeigt einen ausgeprägten Charakterkopf mit energischem Kinn und hoher Stirn. Die Worte, die er in das Stammbuch schrieb, zeugen von einem großen Kunstverstand und einer romantischen Grundhaltung. Er war es, der Beethoven die Tür in die Wiener Gesellschaft öffnete. Seine weitverzweigte hochadelige Verwandtschaft bot Beethoven die Möglichkeit, sich recht schnell in Wien zu etablieren. ${ }^{4}$

Bisher ist ein einziger Brief Beethovens bekannt, in dem er den Grafen erwähnt: „... durch eine Gelegenheit an meinen Freund den Gr[afen] Waldstein das Manuscript davon ..." Es ist ein Schreiben an den Bonner Verleger Nikolaus Simrock vom 18. Juni $1794^{5}$, das belegt, dass Beethoven und Waldstein Kontakt hielten und Beethoven das Verhältnis zum Grafen als ein freundschaftliches empfand. Beethoven schreibt nicht etwa "mein Förderer", er schreibt "mein Freund", was auf ein Verhältnis auf Augenhöhe, jedenfalls aus der Sicht Beethovens, schließen lässt. Beethoven hat offensichtlich durch den Grafen Waldstein selbst Manuskripte aus Wien nach Bonn liefern lassen und diesen wohl auch den Brief an Simrock beigelegt. So wissen wir, dass Waldstein im Sommer 1794 in Bonn weilte. Jenes Jahr 1794 war ein schicksalsschweres Jahr,

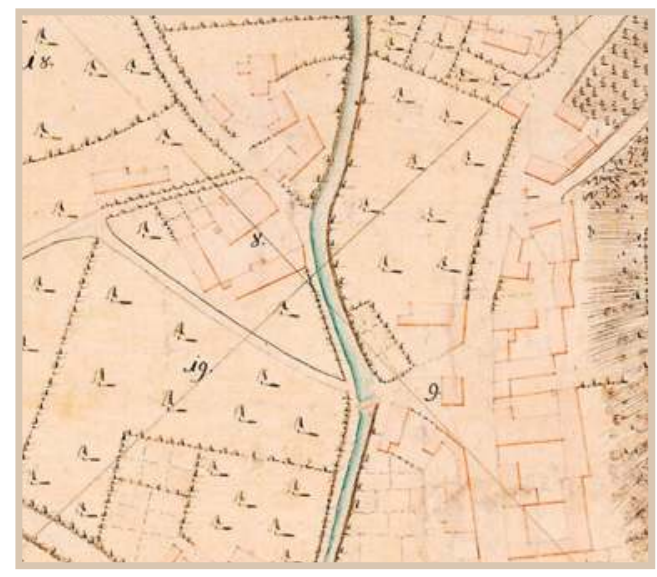
denn gegen Ende des Jahres eroberten die französischen Revolutionstruppen das Rheinland, womit faktisch das Ende des Alten Reiches für die linksrheinischen Territorien einherging.

Nur wenige Jahre vorher, etwa um 1790/91, soll Kurfürst Max Franz in Godesberg ein uraltes Anwesen, den nach einem früheren Besitzer benannten Rittersitz Di(e)steling erworben haben. ${ }^{6}$ Verkäufer waren zwei "Jungfrauen" Droste aus Bonn, Töchter des Johann Jodocus Droste, der in die Familie der Vorbesitzer Hebensturm/Hebbesturm eingeheiratet hatte. ${ }^{7}$ Jener Distelingshof lag im Bereich Schultheiß- und Villichgasse angrenzend an den - heute verrohrten - Godesberger Bach. Er hatte eine wechselvolle, bis heute im einzelnen nicht erforschte Geschichte und besaß der historischen Abfolge entsprechend noch weitere Namen, wie beispielsweise Schultheiß- oder Vinklerhof. ${ }^{8}$ Ein

Nr. 8: Rittersitz Disteling. Ausschnitt aus der Karte von Henrich Karst 1791 (Landesarchiv NRW)
Heinrich von Disteling ist nachweisbar für das 17. Jahrhundert als Lehnsmann des Gutes Odenhausen, das damals zur Ortschaft (Wachtberg-)Villip gehörte.

Dieser Kauf stand möglicherweise im Zusammenhang mit den kurfürstlichen Plänen, Godesberg zu einem modernen Gesundheits- und Badeort auszubauen. In der älteren Literatur heißt es weiter, der Kurfürst habe diesen Hof dann seinem Günstling, dem Grafen Waldstein, geschenkt, allerdings unter der Maßgabe, dass der aktuelle Pächter den Hof bis zum Ablauf des Pachtvertrags bestellen sollte. Belege dafür werden nicht genannt. Es gibt allerdings einige Ungereimtheiten, die am Wahrheitsgehalt dieser Darstellung zweifeln lassen. So galt Max Franz als außerordentlich sparsam, klug wirtschaftend und über-

372 | Pia Heckes

(C) 2020 by Böhlau Verlag GmbH \& Cie. KG, Köln

https://doi.org/10.7788/9783412519704 | CC BY-NC 4.0 


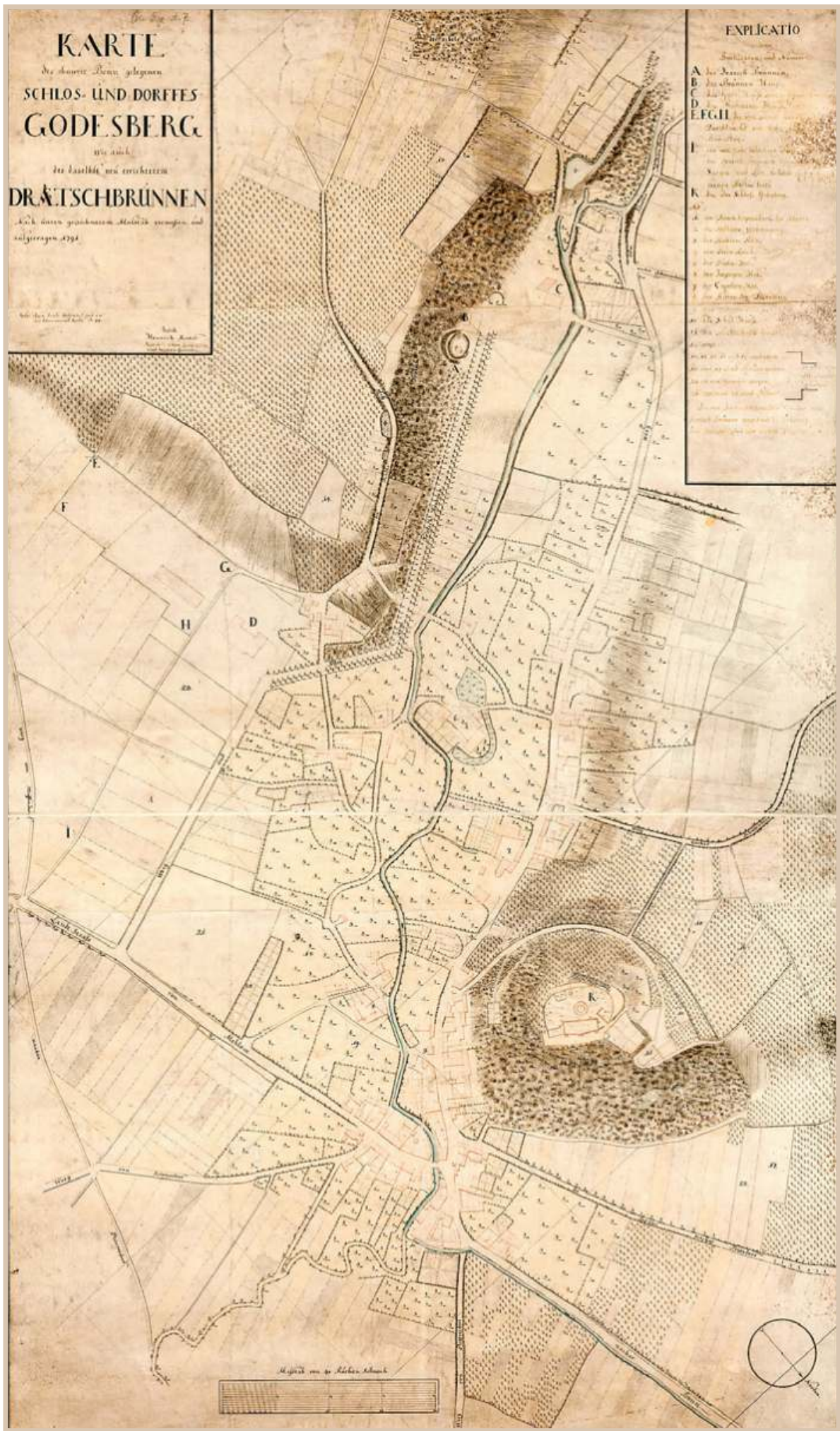

Beethoven und Graf Waldstein - Der Rittersitz Disteling zu Godesberg und die Musik zu einem Ritterballett | 373 (c) 2020 by Böhlau Verlag GmbH \& Cie. KG, Köln

https://doi.org/10.7788/9783412519704 | CC BY-NC 4.0
Plan des Dorfes Godesberg zu Beginn des Ausbaus zum Kur- und Badeort, mit ausführlicher Legende und Ausweis der zum Rittersitz Disteling gehörenden Ländereien. Henrich Karst 1791 (Landesarchiv NRW) Bearbeitet von Hans-Dieter Heckes 
Legende zur „Karte des ohnweit Bonn gelegenen Schlos- und Dorfes Godesberg" (Landesarchiv NRW)

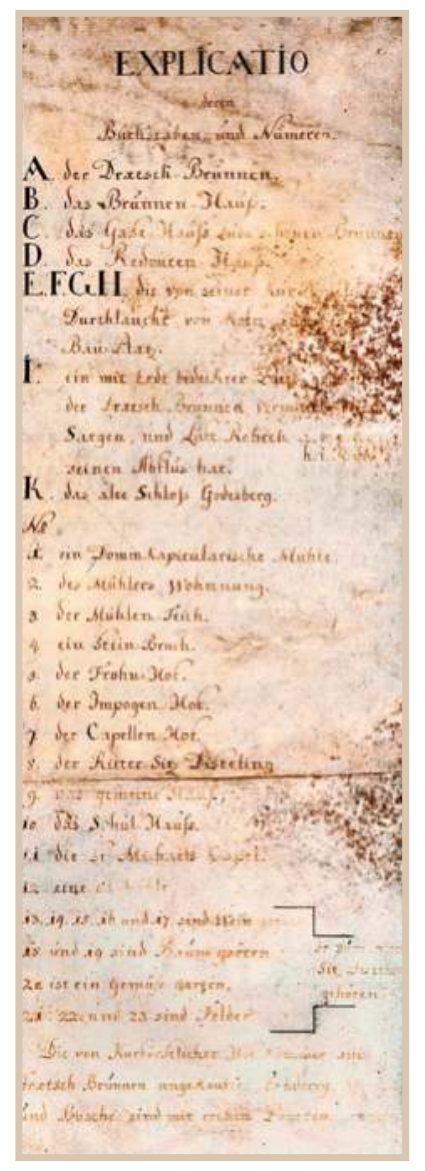

haupt nicht verschwenderisch, so dass ein solches Geschenk schon als ungewöhnlich hätte gelten müssen. Es gibt aber auch andere handfeste Gründe, warum es diese Zuwendung wohl so nicht gegeben hat.

Falls Max Franz den Distelingshof erworben hat, so hat er diese umfangreiche Liegenschaft offenbar zunächst für sich selbst erworben. Eine aufwändig gestaltete Vermesserkarte, zweifellos in kurfürstlichem Auftrag angefertigt, gibt eine sehr genaue Vorstellung von der Beschaffenheit des Dorfs zu Füßen der Godesburg gegen Ende des Alten Reiches. ${ }^{10}$ Dies ist aber nur ein Nebenaspekt: Dem Landesherrn ging es vor allem um eine genaue Aufstellung der umfangreichen Flächen, die zum Distelingshof gehörten. Hatte er doch mit Godesberg in Zukunft Großes vor; das Dorf sollte zum Mittelpunkt der höfischen Kunstund Kulturlandschaft gestaltet werden, ein Bad nach dem Vorbild der vornehmen Böhmischen Bäder, ein "Lustorte nahe bei Bonn", wie Wegeler schreibt. ${ }^{11}$ Größe $(150 \times 87 \mathrm{~cm})$ und Maßstab der Karte legen nahe, dass sie als Grundlage für zukünftige Planungen in Godesberg dienen sollte.

Bezeichnet ist der Plan folgendermaßen:

„Karte des ohnweit Bonn gelegenen Schlos- und Dorffes Godesberg wie auch des daselbst neu errichteten Draetschbrunnen. Nach unten gezeichneten Masstab vermessen und ausgefertigt 1791. Henrich Karst, Kurkölnische Leibgarde und legaler Geometer."

Als Maßstab angegeben ist „... 40 Ruthen Kölnisch.” Dass es sich um eine amtliche Auftragsarbeit handelt, geht auch aus dem auf Hinweis die Registratur hervor: "Nota. Die Karte befindet sich in der Cammeral Karte B 74."

Karst legte offensichtlich großen Wert darauf, diejenigen Grundstücke, die Teil des Distelingshofs waren, genau darzustellen. In der Legende sind sie eigens gekennzeichnet: "So zum Rittersitz Disteling gehören." Die Nummern 13 bis 23 der Karte entsprechen dem zum Hof gehörenden Grund und Boden, der die Nr. 8 - "Ritter-Sitz Disteling" - in der Liste der Bauwerke trägt: Nr. 13 bis 17 sind Weingärten, 18 und 19 sind Baumgärten, 20 ist ein Gemüsegarten, 21 bis 23 sind Felder, wobei 18 bis 21 direkt am Hof lagen und diesen besonders schön arrondierten. Die östliche Grenze dieser Stücke ist in etwa identisch mit der westlichen Seite der heutigen Moltkestraße und erstreckt sich etwa bis zur heutigen Einmündung der Löbestraße.

Nr. 23 lag gegenüber der Redoute und bildet heute die nordwestliche Ecke des Stadtparks, dort, wo sich mit dem Rosenrondell und der Probus-Säule besonders schöne Details präsentieren. 14 war ein großer Weingarten hinter der Redoute (heute Teil des Redoutenparks), 15 und 16 waren schmale Weingärten am nordwestlichen Hang des Burgberges, 17 ein Weingarten nach Friesdorf zu, nördlich des Burgberges, Nr. 22 ein Feld daneben. Aus der Reihe fällt die Nr. 13: Es handelte sich um einen sehr kleinen Wingert, der unterhalb der heutigen Petersbergstraße am Hang gegenüber dem Kloster Marienforst lag.

374 | Pia Heckes

(C) 2020 by Böhlau Verlag GmbH \& Cie. KG, Köln

https://doi.org/10.7788/9783412519704 | CC BY-NC 4.0 
Mit den günstig gelegenen, weil zusammenhängenden Grundstücken des Distelingshofes hätte der Kurfürst, wäre nicht die französische Besatzung Ende 1794 erfolgt, durchaus den Ausbau Godesbergs zu einer prachtvollen Badestadt weiter planvoll vorantreiben können.

Die Bedeutung des Hofes lag jedoch nicht nur in seinem beachtlichen Immobilienwert, sondern war auch darin begründet, dass mit dem Besitz dieses Gutes die ritterschaftliche Landtagsfähigkeit verbunden war; mit anderen Worten: Der jeweilige Eigentümer des Anwesens besaß Sitz und Stimme im Landtag Kurkölns. ${ }^{12}$ Und darum ging es möglicherweise auch beim Erwerb des Hofes.

Zurück zu Graf Waldstein: Max Franz hatte den musisch begabten Adeligen am 17. Juni 1788 in seiner Eigenschaft als Hochmeister des Deutschen Ordens höchst feierlich zum Ordensritter geschlagen, ${ }^{13}$ worauf er als zur Ballei Franken gehörig auch in den offiziellen Hofkalendern unter der Rubrik des Deutschen Ordens erscheint. ${ }^{14}$ Die entsprechende Feier war äußerst pompös, dazu kostspielig, so dass Waldstein sich bereits damals eine größere Summe Geldes, 4000 Gulden, von der Familie Breuning in Bonn geliehen hatte, um diesen festlichen Tag angemessen begehen zu können. Eine Rückzahlung des Darlehns erfolgte übrigens nicht. ${ }^{15}$

Die Schilderung der Festlichkeiten gibt einen Eindruck von dem Aufwand, der anlässlich dieser Feier getrieben wurde:

"Zu mehrer Bequemlichkeit der Zuschauer waren auf beiden Seiten für das Volk, und dem Altar gegenüber für die Dikasterien [Amtsträger der Kirche] Gerüste von Holz aufgeschlagen. Oben in der churfürstlichen Tribüne waren in der Mitte unseres Churfürsten Schwester und jene des Churfürsten von Trier, auf beiden Seiten der Churfürsten von Trier und Prinz Albert von Sachsen-Teschen; in der Nebenloge waren der Herzog von Württemberg und mehrere fremde Herrschaften. Der Zulauf von Fremden in unserer Stadt war ausserordentlich. Mittags war große Tafel von etwa 80, Abends von 150 Gedecken ..."16

Gegen Abend gab es auf dem Rhein eine eindrucksvolle Schiffsprozession mit 16 großen Yachten und etwa 50 kleinen Schiffen, die alle illuminiert waren: „Wie eine brennende Stadt schwammen die Schiffe auf dem Strome." Als ganz besonderer Höhepunkt dürfte ein Heißluftballon gegolten haben, den man zur Belustigung und Erbauung der Gäste hat aufsteigen lassen: Eine "Luftkugel

Kurfürst-Erzbischof Maximilian Franz (1754-1801). Zeitgenössisches Ölgemälde unbekannter Hand (StadtMuseum Bonn) 
wurde aufgelassen", die dann etwa zehn Stunden über den Rhein gereist sein soll. Dies war sicherlich ein Amusement, das am Rhein seinesgleichen suchte. - War doch erst fünf Jahre zuvor zum ersten Mal überhaupt ein großer Heißluftballonversuch in Frankreich durch die Brüder Montgolfier gestartet worden. Am Bonner Hof war man eben auf der Höhe der Zeit!17 - Es fällt allerdings auf, dass dieses beachtliche Ereignis in keiner weiteren Quelle Erwähnung gefunden hat.

In der Zeit von Max Franz als Hochmeister des Deutschen Ordens war die Stellung eines Ordensritters höchst exklusiv; so gab es damals im gesamten Reich doch nur etwa 100 Ritter. ${ }^{18}$ Und abgesehen vom Grafen Waldstein spiel-

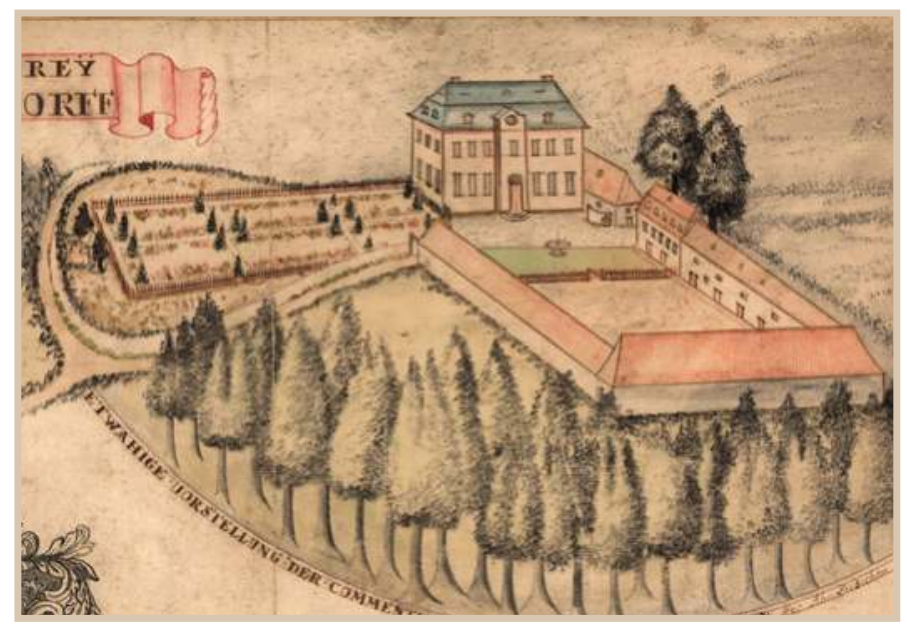

ten Ordensritter am Bonner Hof von Max Franz keine herausragende Rolle. Waldstein war mit diplomatischen Aufgaben betraut und stand Max Franz offenbar recht nahe, was sich auch darin ausdrückte, dass er bereits 1789 zum Mitglied der Staatskonferenz des Deutschen Ordens berufen worden war. ${ }^{19}$ Darüber, welche Ziele Max Franz mit dieser Förderung verband, kann man nur mutmaßen. Im Sommer 1794 kam es dann über politische Fragen zu einem nachhaltigen Zerwürfnis zwischen Max Franz und Waldstein. Am 2. Juni 1795 haben sich die Wege der beiden in Mergentheim wohl für immer getrennt. ${ }^{20}$

Der - landtagsfähige - Rittersitz Disteling in Godesberg wäre für Waldstein in mehrfacher

Deutschordenskommende Muffendorf. Titelblatt (Ausschnitt) des die Besitzungen der Kommende darstellenden Kartenwerkes, Mathias Ehmann, 1759 (Historisches Archiv der Stadt Köln)
Hinsicht eine interessante Immobilie gewesen. So lag der Hof nur unweit des im Aufbau befindlichen Kur- und Badebereichs. Dazu befand sich der Distelingshof nahe der Deutschordens-Kommende Muffendorf (fußläufig etwa eine gute halbe Stunde entfernt). Diese umfasste den größten Grundbesitz des Deutschen Ordens in der Rheinprovinz. Komtur war seit 1761 Karl Friedrich Franz Hatard Anton von Forstmeister zu Gelnhausen (1731-1814), der auch zahlreiche Hofämter in Bonn innehatte und 1792 innerhalb des Deutschen Ordens zum Landkomtur der Ballei Koblenz aufstieg. ${ }^{21}$ Die Muffendorfer Kommende hatte Max Franz nach einem Bericht des Hofrats von Mastiaux auch des öfteren als Kulisse für prachtvolle höfische Feste gedient, ${ }^{22}$ so dass sie sowohl im Orden als auch bei der höfischen Gesellschaft eine gewisse Bedeutung und Bekanntheit gehabt hat. Vielleicht hat sogar der junge Beethoven hier mit der Hofkapelle musiziert.

Waldstein hatte durchaus Ambitionen im Deutschen Orden; 1791 rechnete er damit, die Landkomturei Koblenz übertragen zu bekommen, zu der bekanntlich die Kommende Muffendorf gehörte. ${ }^{23}$ Er wurde schließlich auf eine für ihn angenehme Weise enttäuscht: 1792 übertrug man ihm die überaus begüterte

376 | Pia Heckes

(C) 2020 by Böhlau Verlag GmbH \& Cie. KG, Köln

https://doi.org/10.7788/9783412519704 | CC BY-NC 4.0 
Kommende Virnsberg in Franken, das als Kernland des Deutschen Ordens galt.

Für Waldstein wäre der Besitz des Godesberger Rittergutes Disteling, eines von 227 im Erzstift Köln, ${ }^{24}$ auch insofern von einiger Bedeutung gewesen, als mit dieser Liegenschaft, wie erwähnt, Sitz und Stimme im kurkölnischen Landtag verbunden waren. Waldstein durfte sich erhoffen, über ein solches Landtagsmandat auch an politischem Einfluss zu gewinnen, selbst wenn Max Franz vom Landtag keine allzu hohe Meinung hatte: Braubach beschrieb dessen Haltung zu den im Landtag vertretenen Ständen:

„... er erkannte ihre Rechte an, er war nicht gewillt, sie zu verkürzen, obwohl er sich manchmal über ihren Eigennutz und ihre Verständnislosigkeit gegenüber seinem guten Willen, das Land zu heben, ärgerte. Vor allem hatte er dazu in Kurköln Grund, wo es oft schwer war, sie von der Notwendigkeit von Reformen zu überzeugen und zur Bewilligung der nötigen Gelder zu veranlassen. ,Man redet viel, denkt wenig und tut nichts', so urteilte er im Februar 1785 über die Tätigkeit des Kölner Landtags." ${ }^{25}$

Wie verhielt es sich nun aber mit der angeblichen oder tatsächlichen "Schenkung" des Hofes an Graf Waldstein? Ein Schriftwechsel zwischen einer "citoyenne M. Dobeler, habitante de la ville de Bonn" und der französischen Domänenverwaltung des Departements Rhein und Mosel in Koblenz bietet interessante Aufschlüsse: Es geht dabei um eine Liegenschaft in Godesberg, die verharmlosend als "Maisonnette", an anderer Stelle als "hübsches Haus" bezeichnet wird. Dabei muss es sich allem Anschein nach um den bereits zu damaliger Zeit schon etwas in die Jahre gekommenen Distelingshof gehandelt haben. ${ }^{26}$

Bei dieser Bonner Bürgerin Dobeler handelte es sich mit an Gewissheit grenzender Wahrscheinlichkeit um eine der beiden Töchter des verstorbenen kurfürstlichen Kammerdieners und späteren Hofbüchsenspanners Franz Do(b)b(e)ler und seiner Frau Maria Gertrud Patts (Paths), die am 24. Februar 1754 in St. Remigius in Bonn geheiratet hatten: ${ }^{27}$ Maria Magdalena Antonetta, verheiratete Kal(t)berg (geb. 1759/60-1841) und Anna Maria Gertrud, verheiratete Trespagne (geb. 1764/65-1841); beide kommen als Darlehnsgeberinnen in Frage. ${ }^{28}$

Wohl ein Verwandter war der ebenfalls am Hof tätige und im musikalischen wie intellektuellen Bonn tief verwurzelte Hofkaplan Clemens Dobbeler. Seit 1788 Mitglied der Lese reiste er "niemals ohne seine Violine"29 und soll bereits 1786 auf den jungen Beethoven, "diesen schwarzgelockten Knaben, den Sohn eines Tenoristen" aufmerksam geworden sein. Ende 1792 begleitete "Abbé Dobbeler" auf Geheiß des Kurfürsten eine ebenfalls der Bonner "Musikszene" angehörende Madame Bowater zunächst nach Hamburg und dann nach England, im Gepäck die Notenhandschrift eines Beethoven-Trios, das erst später gedruckt werden sollte. Dobbeler starb 1818 in London. ${ }^{30}$

In einem Schreiben vom 6. August 1798 legt Frau Dobeler den französischen Behörden die Abschrift eines Wechsels vom 17. Juni 1794 vor, der die Unter- 
schrift des Grafen Waldstein trägt und sich auf 40 Louis d'or beläuft. Dem Schreiben ist zu entnehmen, dass Waldstein sich im Sommer 1794 in Godesberg aufgehalten hat, um seine angegriffene Gesundheit mit Hilfe des Godesberger Heilwassers zu kurieren. Zu diesem Zweck kaufte er den Hof, richtete darin ein Zimmer ein, und lieh sich das für den Erwerb nötige Geld von Frau Dobeler.

Weiter heißt es, dass Waldstein noch im Laufe des Jahres 1794, als sich die französischen Truppen dem linken Rheinufer näherten, das Rheinland verlassen habe, ohne den am Ende des Jahres 1794 fälligen Wechsel zu begleichen. - In diesen Zusammenhang gehört das Schreiben von Kurfürst Max Franz an seinen Hofmarschall Baron von Schall vom 23. Juli 1797: "Ferdinand Waldstein läßt schon über ein Jahr von sich weder dem Orden noch seinen Kreditoren etwas hören. Ich wünsche ihm viel Geld und Klugheit". ${ }^{31}$ - Dobeler schreibt weiter, dass sie unendliche vergebliche Anstrengungen unternommen habe, um zu ihrem Geld zu kommen, und nun keine andere Möglichkeit mehr sehe, als sich an die französische Verwaltung zu wenden, da diese den Distelingshof als Nationalgut eingezogen hat. Sie beantragt die Erstattung jener 40 Louis d'or, da sie sich weiterhin als Teileigentümerin sehe. Aus der vorgesehenen Liquidation des "Häuschens" dürfe ihr daher kein Nachteil entstehen.

Die Domänenkammer sieht dies anders. Da die Antragstellerin keinen Hypothekenbrief vorlegen könne, habe sie keinen Beweis erbringen können, Miteigentümerin zu sein. Daher lehnt die französische Verwaltung den Antrag ab. Auch weil Waldstein auf der Liste der Flüchtigen geführt wird, dürfe das Godesberger Gut daher als Nationalgut auf Grundlage des Gesetzes vom 1. Floréal des Jahres 3 der Republik (20. April 1795) eingezogen werden.

So kam es 1804 zur Versteigerung. Dem entsprechenden Protokoll zufolge, in dem "Graf von Waldstein" eindeutig als Vorbesitzer erscheint ${ }^{32}$ ersteigerte Anton Kürschner, der seinerzeitige Pächter, das Anwesen, bestehend aus "1 Haus mit 1 Keller und 1 Speicher 1 Scheune, 1 Kelterhaus, Ställe, 0,70 Baumgarten" am 26. April 1804 für einen Preis von 2650 Francs. Der Schätzpreis hatte übrigens bei 400 Francs gelegen.

Die umfangreichen Grundstücke, die auf der Karte von 1791 deutlich als zum Hof gehörend markiert sind, waren offenbar längst von diesem gelöst worden.

An dieser Stelle kommt eine zeitgenössische Kopie der erwähnten Karte von 1791 ins Spiel. ${ }^{33}$ Sie ist weitgehend identisch mit der vom Kurfürsten in Auftrag gegebenen Karte (Landesarchiv NRW). Allerdings sind die Abweichungen eindeutig: In der Kopie fehlen die Markierungen der Grundstücke, die zum Distelingshof gehörten. Und ausgerechnet die Stelle, an der der Distelingshof eingezeichnet ist, zeigt starke Abnutzungsspuren, so als sei häufig mit Fingern auf diese Stelle gezeigt worden. 


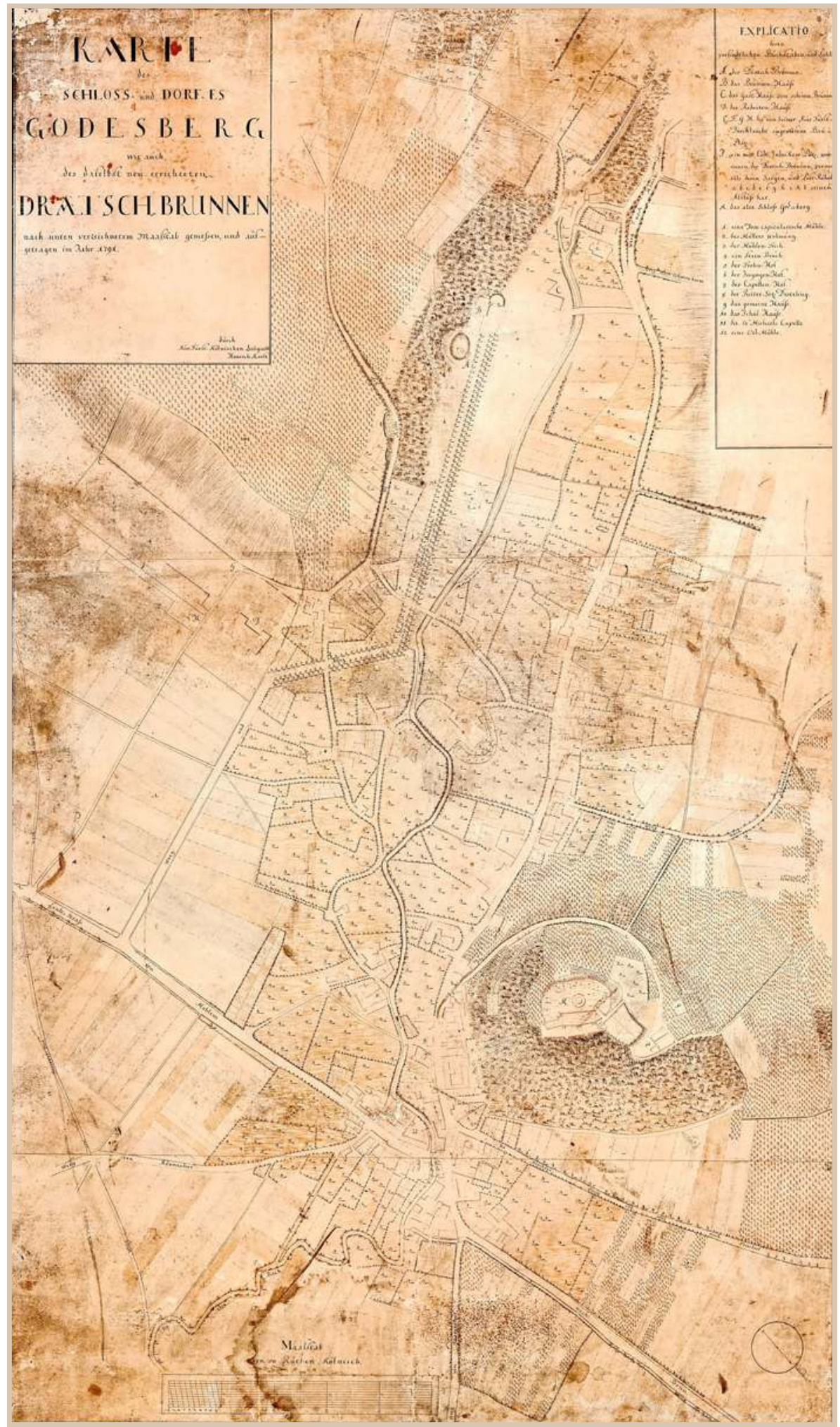

Beethoven und Graf Waldstein - Der Rittersitz Disteling zu Godesberg und die Musik zu einem Ritterballett | 379 (C) 2020 by Böhlau Verlag GmbH \& Cie. KG, Köln
Plan des Dorfes Godesberg zu Beginn des Ausbaus zum Kur- und Badeort mit knapper Legende. Henrich Karst 1791 (Stadtarchiv Bonn) Bearbeitet von Hans-Dieter Heckes 


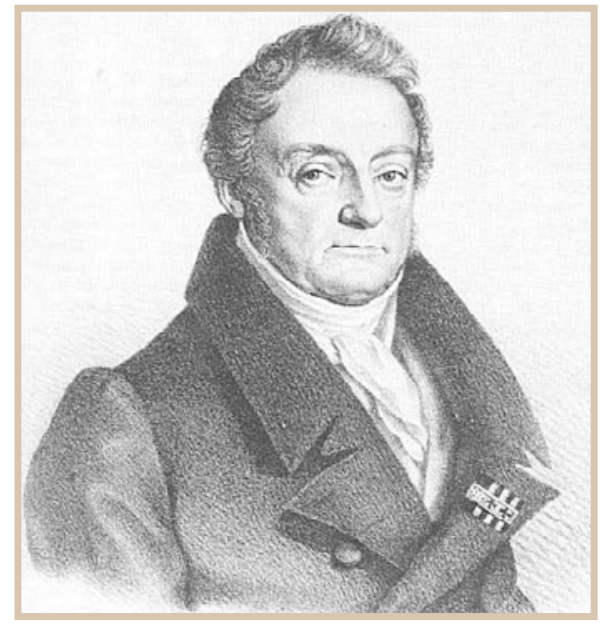

Wenn Max Franz die Grundstücke für sich selbst behalten und nur die eigentlichen Hofgebäude mit dem direkt anschließenden Land an Waldstein übertragen hat, ${ }^{34}$ spräche dies für den festen Sinn des Kurfürsten, aus Godesberg etwas Bedeutendes zu machen und die zuvor zum Distelingshof gehörenden Flächen hierfür zu verwenden. Da es wertvolle Grundstücke für die Gestaltung einer zukünftigen Nebenresidenz Godesberg waren, kann dies angenommen werden.

Welche Schlussfolgerungen lässt der Antrag der Citoyenne Dobeler nun zu? Wenn es stimmen sollte, dass Max Franz Graf Waldstein den Distelingshof um das Jahr 1791 geschenkt hat, hätte dieser 1794 kein Darlehen für den Erwerb des Anwesens benötigt.

Es wäre aber auch denkbar, dass Max Franz den Hof - ohne die von ihm für den Ausbau Godesbergs vorgesehenen Grundstücke

Graf Ferdinand Ernst von Waldstein und Wartenberg (1762-1823).

Zeitgenössische Lithografie von Antonin Machek (wikicommons)
- Waldstein zunächst überlassen und tatsächlich erst im Sommer 1794 verkauft hat, und demnach all das, was Frau Dobeler schreibt, zutreffend ist. Da sich sowohl Graf Waldstein auch als Max Franz, der Anfang Juli 1794 sein Regiment Brixen, das sein Lager im Plittersdorfer Feld aufgeschlagen hatte, visitierte, ${ }^{35} \mathrm{im}$ Sommer 1794 in Godesberg aufhielten, erscheint das Zustandekommen einer entsprechenden Vereinbarung durchaus plausibel.

Der Godesberger Rittersitz Distelingshof ging bald, nachdem die Franzosen 1805 die Gebäude versteigert hatten, unter, und seine Geschichte fiel der Vergessenheit anheim. Bereits auf der 1814 abgeschlossenen Kartierung des Rheinlands durch den Geografen Tranchot fehlen die Gebäude. Der Hof war offensichtlich bereits niedergelegt worden:

Auch Ludwig van Beethovens Beziehung zu Waldstein erfuhr just in diesem Jahr 1794 einen kleinen Höhepunkt: Sein Werk Variations à quatre mains pour le Pianoforte sur une Theme de Monsieur le Comte de Waldstein par Louis van Beethoven WoO 67 wurde in eben diesem Jahr 1794 gedruckt und damit einer größeren Öffentlichkeit bekannt gemacht. ${ }^{36}$

Im gleichen Jahr 1794 floh Waldstein, wie der Kurfürst, vor den Franzosen und setzte sich mit der Idee, ein deutsches Heer für England aufzustellen, 1796 dorthin ab. Seine Gläubiger jedenfalls hörten nie wieder etwas von ihm. Dabei klafft manche Lücke in der Erforschung seines Lebens: Nachdem er aus dem Deutschen Orden ausgetreten war (1811) und geheiratet hatte (1812), verspekulierte er das Vermögen seiner früh verstorbenen Gattin Isabella Rzewuska und starb am 26. Mai 1823 verarmt und recht elend ohne ärztliche Hilfe in Wien, wie zeitgenössische Quellen dies schildern. ${ }^{37}$

Seine Schulden beliefen sich auf 130.000 Gulden, wie Heer zu berichten weiß. Besondere, bittere Ironie des Schicksals aber war, dass laut den Memoiren der Gräfin Rosalie Rzewuska, Waldsteins älterer Bruder nur wenige Tage (am 24. Mai 1823) vor Ferdinand Ernst gestorben war, und die Kunde davon ihn

380 | Pia Heckes

(c) 2020 by Böhlau Verlag GmbH \& Cie. KG, Köln

https://doi.org/10.7788/9783412519704 | CC BY-NC 4.0 
erst am Tag seines Todes erreichte. Das reiche Erbe, das ihm so zugefallen war, konnte ihm nicht mehr von Nutzen sein. ${ }^{38}$

Beethoven und Waldstein hatten, nach allem, was wir heute wissen, zuletzt wohl keinen Kontaktmehr miteinander. 1819 beispielsweise notierte Beethoven: "Der Graf Waldstein war ja in der Nähe. Lebt er jetzt hier?"39

Bereits 1790 hatte Graf Waldstein den jungen Beethoven mit einer Musik für ein Ritterballett beauftragt, die dieser auch fertigstellte (WoO1). Das Werk wurde anlässlich eines Maskenballs im Frühjahr 1791 auch aufgeführt. Der Eintrag im digitalen Beethoven-Haus zu diesem Werk lautet:

„Am Karnevalssonntag, 6. März 1791, kam im Redoutensaal im Bonner Schloss ein ,karakteristisches Ballet in altdeutscher Tracht' durch den Bonner Adel zur Aufführung. Veranstalter des Amüsements war Graf Ferdinand von Waldstein, der im ,Theater-Kalender auf das Jahr 1792' auch als ,Erfinder desselben (...), dem Komposition des Tanzes und der Musick zur Ehre gereichen' genannt wurde. Dargestellt wurde, die Hauptneigung unserer Urväter zu Krieg, Jagd, Liebe und Zechen'". ${ }^{0}$

Erst 1838 sollte Franz Wegeler das Geheimnis um den Komponisten lüften. Er teilte mit, dass es sich um ein Frühwerk des jungen Beethoven handelte:

„... dann die Musik zu einem im Carneval von dem hohen Adel aufgeführten Ritterballet, welche jedoch bis jetzt nie gestochen wurde ... Es müssen sich darin finden ein Minnelied, ein deutsches Lied, ein Trinklied u.s.w. Diese Composition wurde lange, da Beethoven sich nicht als Verfasser genannt hatte, für das Werk des Grafen Waldstein gehalten, um so mehr, als dieser auch, in Verbindung mit dem Tanzmeister Habich aus Aachen, das Ballet organisirt hatte."41

Die erste gedruckte Ausgabe des Ritterballetts erschien als Klavierauszug 1872 bei J. Rieter-Biedermann, Leipzig und Winterthur, der Erstdruck der vollständigen Partitur 1888 in Leipzig bei Breitkopf \& Härtel.

Das Ritterballett war die erste Erfahrung, die Beethoven als damals noch sehr junger Mann mit einer dramatischen Musik machte. Ein sehr fröhliches Werk, das stilistisch noch ganz dem Barock verhaftet ist und große Heiterkeit versprüht. Von den dunklen politischen Wolken am Horizont, die das Ende des Alten Reiches ankündigten, ist nichts zu spüren.

Das Ritterballett wurde im 20. Jahrhundert mindestens zwei Mal modern interpretiert aufgeführt:

„Rudolf von Laban hat die Musik dann 1927 seinem anläßlich des Magdeburger Tänzerkongresses choreographierten, abendfüllenden ,Ritterballett' inkorporiert. Giuseppe Urbani hat sie mit zweifelhaftem Erfolg 1962 für einen Ballettabend des Theaters der Stadt Bonn wiederzubeleben versucht ...."42

Urbani traf dabei mit dem ersten Ballettabend der neu gegründeten Tanzkompagnie in Bonn auf ein vollkommen unvorbereitetes Publikum und eine ebenso hilflose Kritik, die nicht verstanden hatte, dass es sich beim Versuch 
Aufnahme von Erzherzog Karl in den Deutschen Orden durch Hochmeister Max Franz, 1801. Zeitgenössischer Kupferstich (Foto: Österreichische Nationalbibliothek)

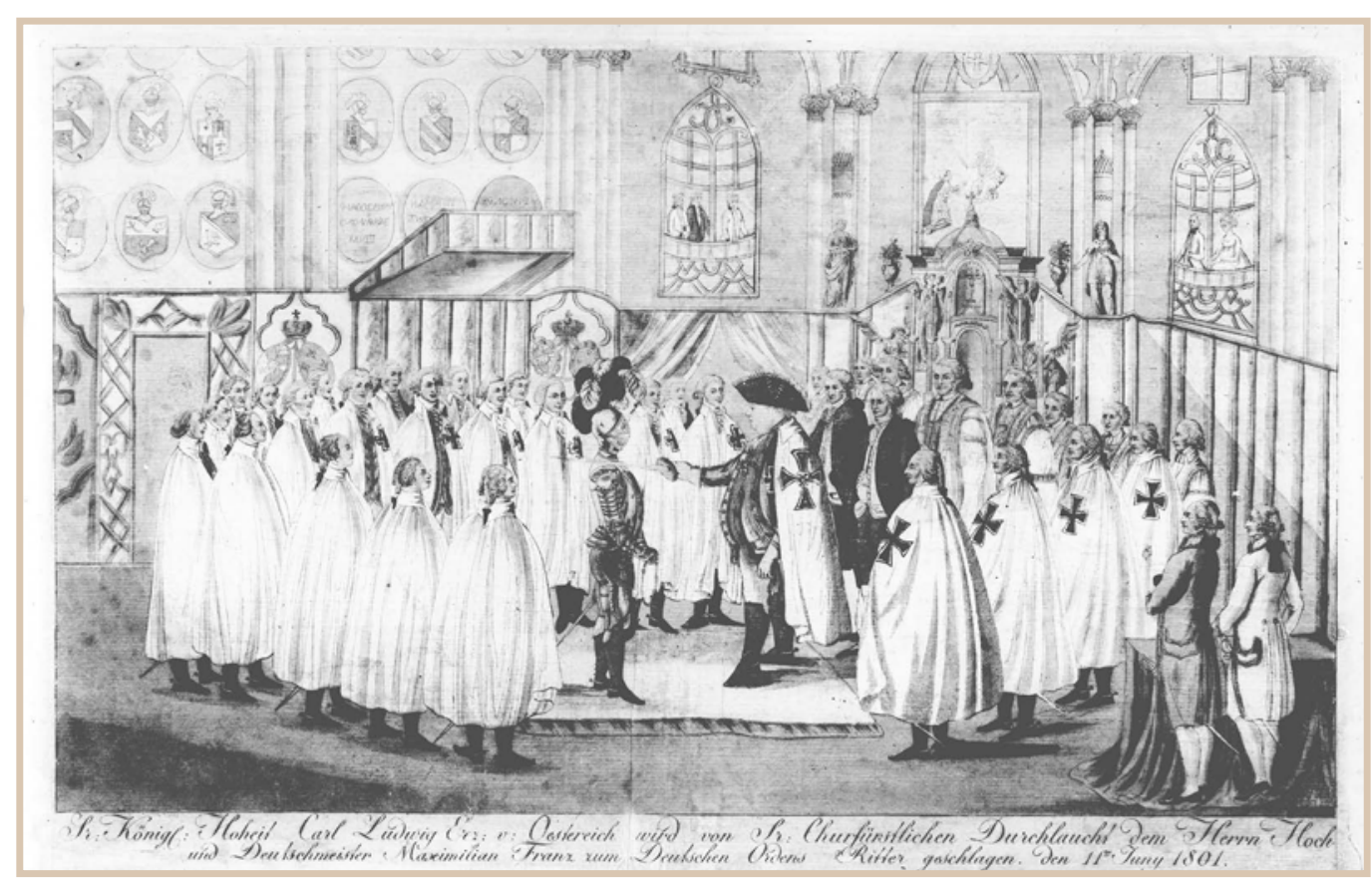

der Wiederbelebung dieses Ritterballetts um eine geniale Idee und gleichzeitig um eine Verbeugung vor der Geschichte Bonns handelte. Urbani war kunstsinnig, choreographisch absolut auf der Höhe der Zeit. In Bonn galt der frühe Beethoven damals offenkundig wenig, schrieb doch ein Kritiker gar:

„... Sonst hätte er vielleicht Beethovens ,Ritterballett', jenes unverbindliche Frühwerkchen des Bonner Junggenies für den Karneval 1791, nicht auf ursächlich raumgreifende Jagd-, Krieg- und Trinkallegorie gestellt, die dann in der Verengung nur verniedlicht wirkte." 43

Urbani selbst schreibt über das Ritterballett:

"Durch die konsequente Verwendung dieses ,Refrains' (gemeint ist der ,Deutsche Gesang') erhält die gesamte Tanzfolge den Charakter eines Rondos. So bleibt das Werk nicht fragmentarisch, wie es aus der Partitur den Anschein haben mag, sondern rundet sich zu einem vollständigen Ballett." 44 Insofern war Graf Waldstein mit seinem Ritterballett absolut auf der Höhe der Zeit. Er nutzte möglicherweise Beethovens Musik, um das höfische Bonner Publikum auf höchst elegante Weise darauf aufmerksam zu machen, dass er nicht nur als enger Vertrauter und Ritter des Deutschen Ordens das Ohr des Kurfürsten hatte, sondern voraussichtlich mit dem Erwerb des Rittersitzes in Godesberg zukünftig im Landtag - der jährlich im Bonner Kapuzinerkloster (das Kloster lag an der heutigen Ecke Belderberg/Kapuzinergasse) seine Tagungen hielt - sprechen und abstimmen durfte.

Die Idee der Ritterschaft hatte in den geistlichen Orden kontinuierlich weiterbestanden. So erschien man zu besonders feierlichen Anlässen durchaus in

382 | Pia Heckes

(C) 2020 by Böhlau Verlag GmbH \& Cie. KG, Köln

https://doi.org/10.7788/9783412519704 | CC BY-NC 4.0 
Rüstung, wie beispielsweise Erzherzog Karl von Österreich zu seiner Aufnahme in den Deutschen Orden am 11. Juni 1801 in Wien vor dem Hochmeister Max Franz, mit Helm und großartiger Helmzier aus prächtigen Federn. ${ }^{45}$

Überhaupt erlebte die Idee der Ritterschaft gegen Ende des 18. Jahrhunderts mit der beginnenden Romantik eine Wiedergeburt, eine modische Wiederbelebung, eine moralische Aufladung, die gleichsam zur Legitimation eines "guten, aufrechten" Adels diente. Vor dem Hintergrund der revolutionären Ereignisse in Frankreich kommt dem eine besondere Bedeutung zu. Waldsteins Ritterballett ist nur eine Facette dessen.

So hatte Goethe 1774 mit seinem Götz von Berlichingen seinen Durchbruch. In Berlin erfolgreich uraufgeführt, ging mit diesem Stück der Stern des jungen Klassikers im Sturm und Drang hell leuchtend auf. Man weiß, dass Beethoven Goethe "glühend" verehrte und sich mit dessen Lyrik beschäftigte. Später entstand eine Reihe musikalischer Werke nach Dichtungen Goethes. ${ }^{46}$ Auch die Handlung in Friedrich Schillers erstem großen Bühnenwerk Die Räuber wurde für die Uraufführung in Mannheim im Jahr 1782 ins Mittelalter verlegt und zu einem damals so beliebten Ritterstück umformatiert. Geschadet hat das dem stürmischen Erfolg des Stückes keineswegs.

Bleibt noch die Frage zu klären, wo das Ballett am Karnevalssonntag 1791 aufgeführt wurde. Das Bonner Schloss besaß keinen so eindeutig bezeichneten Redoutensaal.

Im Buen-Retiro-Flügel der Residenz, in Richtung des Poppelsdorfer Schlosses gelegen, befanden sich die Privatgemächer des Erzbischofs, unter anderem auch das berühmte Paradeschlafzimmer Clemens Augusts. In diesem Flügel hat sich zwar ein kleinerer Ballsaal, als Ballhaus bezeichnet, befunden, der, wie den Plänen zur Umgestaltung des Schlosses zur Universität im Jahre 1818 zu entnehmen ist ${ }^{47}$, als Buchdruckerei und als Leichenkeller verplant wurde. Der Saal hatte wegen seiner bescheideneren Ausmaße ehedem eher zu mehr privaten Zwecken, zu intimeren Festen des Hausherren Clemens August gedient und wäre nicht geeignet gewesen, einen großen Hofball anlässlich eines Karnevalssonntages aufzunehmen. Wie dieser kleine Ballsaal im Buen Retiro zur Regierungszeit von Max Franz genutzt wurde, ist nicht überliefert. Max
Die Bonner Residenz von der Hofgartenseite, nach 1777. Kupferstich nach Franz Rousseau (Stadtarchiv Bonn)

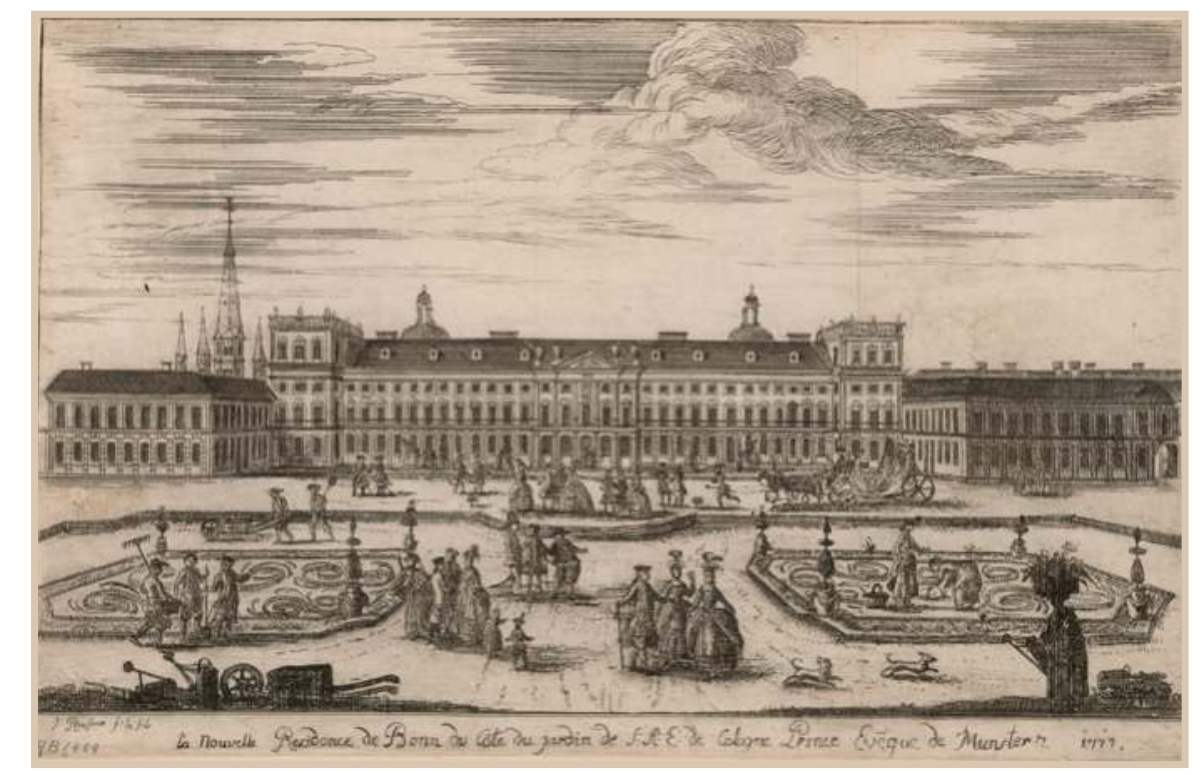


Franz bevorzugte bekanntlich das weitaus bescheidenere Wohnen im Mastiauxschen Haus am Rhein. ${ }^{48}$

Am 3. Januar 1789 war das neue Bonner Nationaltheater im Schloss eröffnet worden:

"Spiegel hatte das Komödienhaus im Galeriebau der Residenz am Koblenzer Tor zu einem Theater mit drei Rängen umbauen lassen; schon Mitte November konnte er melden, daß alle Logen vermietet seien und der Kurfürst Frau von Waldenfels neben sich und die musikalisch besonders interessierte Gräfin Wolff-Metternich gegenüber haben werde. Von hier aus schauten Hof und Bürgertum seit Beginn des so schicksalsschweren Jahres 1789 abwechselnd den Schauspielen und Opern zu, die von Truppe und Orchester geboten wurden."49

Möglicherweise war mit dem Redoutensaal dieses Theater gemeint, wo höchst anspruchsvolle Opern und Hofkonzerte aufgeführt wurden, als „das kurkölnische Hofmusikensemble zu den vorzüglichsten Europas" ${ }^{\prime 20}$ zählte. Es hat sich glücklicherweise ein Grundriss eines anonymen Baumeisters aus dem Ende des 18. Jahrhunderts erhalten, der den Theaterbau mit den eingebauten Logen im Parterre und der weiter unten erwähnten "gruftartigen Treppenanlage" vom Michaelstor hinab in den Theaterkeller zeigt. Allerdings wäre dieser Saal östlich vom Koblenzer Tor gelegen gewesen. Der eigentliche Theatersaal lag aber eindeutig westlich des Koblenzer Tors. Möglicherweise hat sich Max Franz für einen bescheidenen Umbau des Galeriebaus entschieden und dafür plädiert, den alten Theatersaal durch Einbau von Rängen und Logen zu modernisieren, was seiner bekannten Sparsamkeit entsprochen hätte. Bisher sind keine Unterlagen aus der Zeit von Max Franz zu diesem Thema bekannt geworden. Die breite Treppe in den Theatersaal hinab erfüllte aber die Repräsentationszwecke, denen das Michaels- oder Koblenzer Tor gewidmet war: der große Auftritt des Kurfürsten, der per Kutsche in den Triumphbogen vorfuhr, um dann von dort aus auch das Theater zu besuchen. ${ }^{51}$

Es könnte ebenso der Akademie-Saal aus der Zeit Clemens Augusts der Ort der Aufführung des Ritterballetts gewesen sein, der sich ebenfalls im Galeriebau des Schlosses befand und der beim großen Brand 1777 verschont geblieben war. Der Akademiesaal diente der Hofmusik und lag genau über dem Nationaltheater:

"Gerade unter dem großen Akademiesaal ist das Theater, das einem jeden Fremden, wie es sozusagen unterirdisch wie eine Gruft angebracht ist, und einen schlechten Eingang hat, auffallen muss. Logen, Dekorationen und überhaupt alles, was in einem Schauspielhause glänzen soll, ist für den Hof eines solchen erhabenen Fürsten, als Max Franz ist, zu schlecht, zu buntschäkkigt, zu kleinlicht." ${ }^{12}$

Darstellungen des Akademiesaals und des Residenztheaters nach den Umbauten durch Max Franz sind offenbar nicht überliefert. 
Von der Pracht der Räumlichkeiten zur Zeit des Kurfürsten Clemens August geben aber die bekannten Bönnschen Ballstücke von Hofmaler Franz Rousseau von 1754 eine Vorstellung, die einen Ball im damaligen Residenztheater des Bonner Schlosses zeigen. Inwiefern die Darstellung der Räumlichkeiten mit den infrage kommenden Sälen, Akademiesaal und Theatersaal, des Bonner Residenzschlosses übereinstimmt, scheint einer vertieften Untersuchung würdig, würde an dieser Stelle aber zu weit führen.

Mit Beginn der Fastenzeit 1794 jedenfalls ging die Geschichte dieses kurfürstlichen Residenztheaters zu Ende.

Die Godesberger Redoute war 1791 noch in Planung bzw. im Bau. Sie wurde erst im Frühsommer des Jahres 1792 fertiggestellt und scheidet somit als Aufführungsort definitiv aus.

Einen Redoutensaal besaß nachweislich der Englische Hof, ein vornehmes Hotel direkt gegenüber dem Hauptflügel des Bonner Schlosses, an der zum Rathaus hin gelegenen Ecke Am Hof/Fürstenstraße. ${ }^{53}$ Dies wäre dann wohl auch ein möglicher Ort der Aufführung des Ritterballetts gewesen. Allerdings ist fraglich, ob die Hofmusik dort hätte spielen dürfen und können. War doch die Musik des Ritterballetts für die Hofkapelle und die höfische Umgebung geschrieben worden.

So darf man davon ausgehen, dass das Ritterballett entweder im neuen Nationaltheater oder im darüber liegenden, einst prächtig ausgestatteten Akademiesaal des Schlosses aufgeführt worden ist. Konstantin von Schönebeck berichtet entsprechend, dass vor 1784 in diesen beiden Sälen die Redouten gegeben wurden. ${ }^{54}$

Eine allerletzte Frage kann nicht beantwortet werden: Es wäre spätestens im Sommer 1794 eine realistische Einschätzung der politischen Situation gewesen, wenn man mit einem baldigen Vorstoß der motivierten revolutionären Truppen Frankreichs bis zum Rhein gerechnet hätte, so wie man das bereits 1689 dramatisch und zerstörerisch erlebt hatte. Bereits im August 1789 hatte beispielsweise Baron von Weichs sein Bonner Palais in der Wenzelgasse verkauft, nachdem die ersten Berichte über die Französische Revolution im Bönnschen Intelligenzblatt erschienen waren. ${ }^{55}$ Kurfürst Max Franz hat die
Bonn von Süden. Kolorierte Radierung von C. Lincke, um 1780 (Stadtarchiv Bonn)

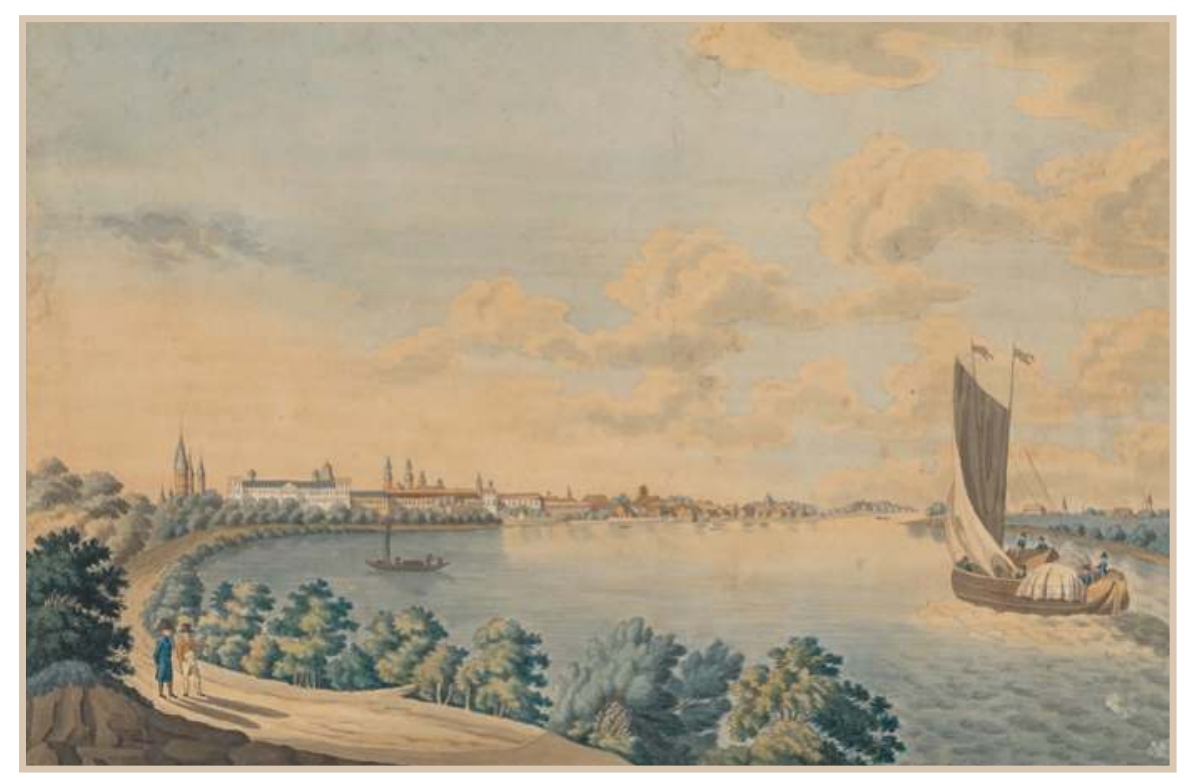


Situation wohl später zutreffend eingeschätzt, wie sein Hirtenbrief vom 30. Juli 1794 bezeugt, worin er "auf die nahe Gefahr einer Aufrichtung der französischen Blutherrschaft am Rhein ermahnte, jeder in seiner Art Hand anzulegen an die Rettung des Vaterlandes". ${ }^{56}$ Warum in dieser Situation Waldstein ein riskantes Immobiliengeschäft der oben geschilderten Art getätigt hat, bleibt ein Rätsel und gehört wohl zu den zahlreichen unglücklich verlaufenen Entscheidungen in seinem Leben.

Geblieben sind als einzige Zeugen dieser Vorgänge die großformatigen Karten von 1791 sowie Beethovens Musik für das Ritterballett.

Hierzu und zum Folgenden vgl. JANA FoJtIKova, Beethoven und Graf Waldstein, in: Ludwig van Beethoven im Herzen Europas, Prag 2000, S. 297-308, hier S. $299 f f$.

Zitiert nach dem Faksimile: MAX BRAUBACH, Die Stammbücher Beethovens und der Babette Koch, Bonn 1970, S. 19

Vgl. DeRs., Maria Theresias jüngster Sohn Max Franz, letzter Kurfürst von Köln, Wien/ München 1961, passim.

Die verwandtschaftlichen Beziehung beleuchtet sehr gründlich KONRAD KüsTER, Beethoven, Stuttgart 1994, S. $61 \mathrm{ff}$

Sieghard Brandenburg (Hg.), Ludwig van Beethoven. Briefwechsel Gesamtausgabe, 7 Bde, München 1996-1998, hier Bd. 1, Nr. 15. Zum Verleger Simrock vgl. den Beitrag von JoAnne CobB Biermann in diesem Band.

Vgl. hierzu und zum Folgenden Alfred WIEDEMANN, Geschichte Godesbergs und seiner Umgebung, Godesberg 21930, S. 512, 538f.; zur Vorgeschichte des Anwesens vgl. ebd., S. 66-70. Vgl. zum Kauf durch Max Franz und die Weitergabe an Graf Waldstein auch Chr[istian] von Stramberg, Das Rheinufer von Coblenz bis Bonn, Bd. 11 (Denkwürdiger und nützlicher Rheinischer Antiquarius ... Mittelrhein. II. Abt., II Bd. ), Coblenz 1865, S. 76

Vgl. Wiedemann, Geschichte (wie Anm. 6), S. 539 Anm. 20. Dass die beiden Damen am 2.4.1791 der Pfarrkirche in (Bonn-)Rüngsdorf 100 Taler stifteten, mag mit dem Verkauf in Zusammenhang stehen. Vgl. ebd.

Wiedemann, dem Verfasser der bis heute umfangreichsten Geschichte Bad Godesbergs war die Karte von 1791 offenbar nicht bekannt. So kam es in seiner Darstellung auch zu Verwechslungen mit anderen Godesberger Adelssitzen, wie dem weiter westlich gelegenen Fronhof oder dem Impogen- bzw. Embavenhof. Vgl. WIEDEMANN, Geschichte Godesbergs (wie Anm. 6); vgl. auch, insbesondere zu den unterschiedlichen Namen des Hofes, DIETRICH JUNG, Das Dorf Bad Godesberg im Jahr 1791, in: Godesberger Heimatblätter 19, 1981, S. 105-121, hier S. 108

Vgl. Rheinisches Archiv- und Museumsamt, Archiv Schloß Schönstein, Urkunden, Nr. 2253 (Urkunde vom 27.8.1618), nachgewiesen in archive.nrw.de.

Landesarchiv NRW, Abt. Rheinland (LAV NRW R), Karten, Nr. 2775. Ein verkleinertes Faksimile der Karte als Beilage zu JuNG, Das Dorf Bad Godesberg (wie Anm. 8)

Franz Gerhard Wegeler und Ferdinand Ries, Biographische Notizen über Ludwig van Beethoven, Koblenz 1838, S. 15 


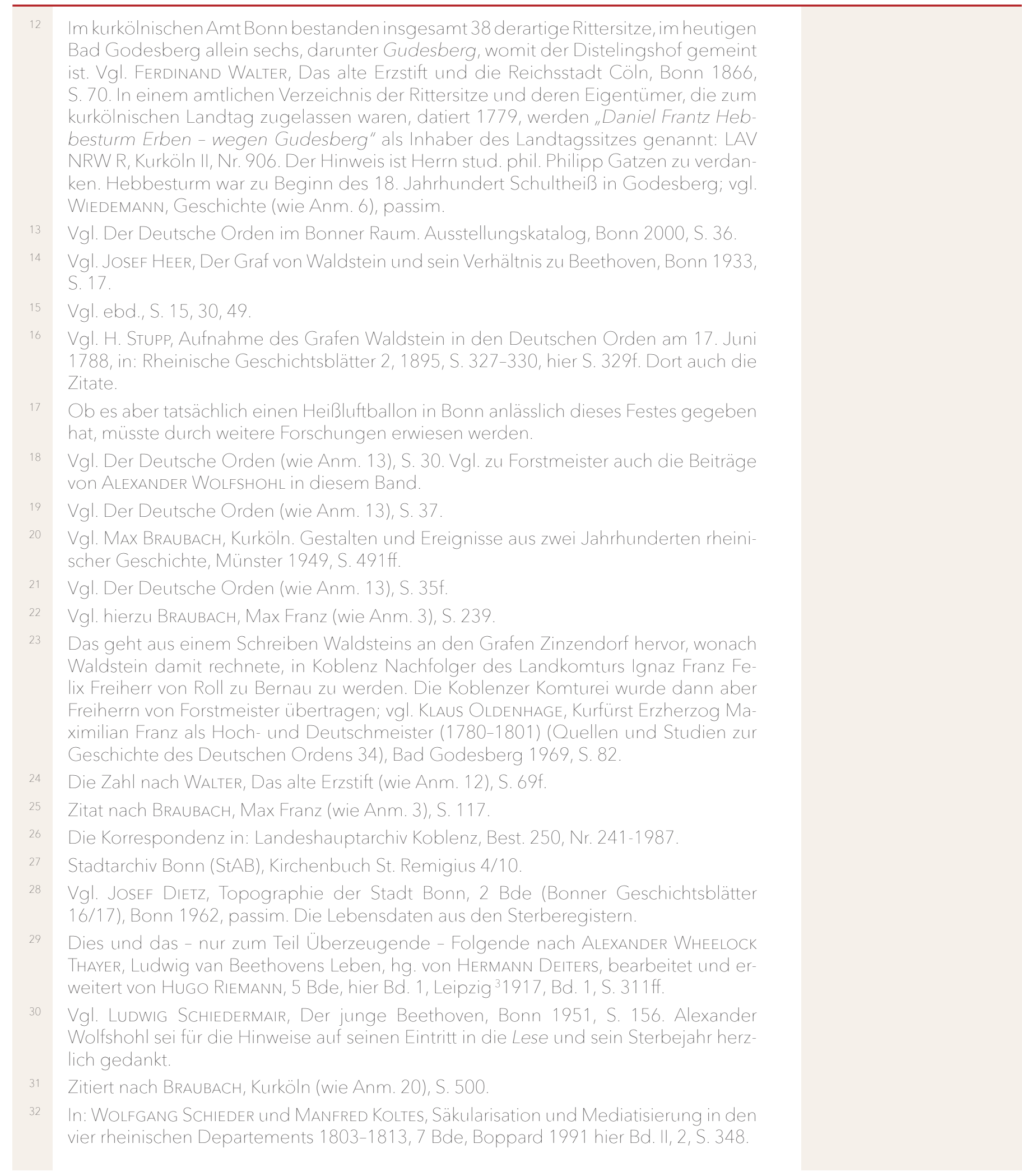


${ }_{33}$ In: StAB, SN 5 (Karten- und Plansammlung), 4799. Sie stammt aus Bad Godesberger Privatbesitz und wurde in den 1990er Jahren dem Archiv geschenkt. Für den Hinweis auf die Karte danke ich Norbert Schloßmacher, Stadtarchiv Bonn, sehr. Ob es sich um das von JuNG, Das Dorf Bad Godesberg (wie Anm. 8), S. 105, erwähnte Exemplar handelt, das "unter Glas und Rahmen" zum Bestand des während des Zweiten Weltkriegs untergegangenen Godesberger Heimatmuseums gehörte, muss ungeklärt bleiben, liegt aber nahe.

So auch WiedemAnN, Geschichte Godesberg (wie Anm. 6), S. 512: die seinerzeit nicht an Graf Waldstein übergebenen Liegenschaften habe das "Hofbauamt" übernommen.

Vgl. Braubach, Max Franz (wie Anm. 3), S. 299.

Vgl. BraubaCH, Stammbücher (wie Anm. 2), S. 159.

Vgl. hierzu HeER, Waldstein (wie Anm. 14), S. 25, 28

Vgl. ebd., S. 29.

Zitiert nach BRAUBACH, Stammbücher (wie Anm. 2), S. 159.

(https://da.beethoven.de/sixcms/detail.php?id=15106\&template=werkseite_ digitales_archiv_de\&_eid $=1502 \& \_u g=U ̈ b r i g e \% 200$ rchesterwerke\&_werkid $=164 \&$ _ mid $=$ Werke\&suchparameter $=\& \_$seite $=1$, eingesehen am 15.3.2020)

(C) 2020 by Böhlau Verlag GmbH \& Cie. KG, Köln https://doi.org/10.7788/9783412519704 | CC BY-NC 4.0 


\section{Christian Gottlob Neefe (1748-1798) und seine Bedeutung für Ludwig van Beethoven}

D ie Behauptung, dass Christian Gottlob Neefe die Musik Johann Sebastian Bachs seinem Schüler Ludwig van Beethoven in früher Jugend als kompositorisches Vorbild vermittelt und damit gewissermaßen ein Erweckungserlebnis ausgelöst habe, darf als eine der erfolgreichsten Meistererzählungen deutscher Musikgeschichtsschreibung gelten. Nur zwei Beispiele: Erwin Ratz baute seine gesamte musikalische Formenlehre ausschließlich auf Werken von Bach und Beethoven auf und begründete dies damit, dass Beethoven das Glück gehabt habe, in Neefe einen Lehrer zu finden, der ihn "mit aller Leidenschaft in die Wunderwelt Johann Sebastian Bachs einführte, und dies wurde zum entscheidenden Erlebnis für Beethoven."1 Das grundlegende Buch von Ludwig Schiedermair Der junge Beethoven enthält ein eigenes Kapitel, das Neefe würdigt, worin eine Passage die chauvinistischen Züge dieses Bildes verdeutlicht. Schiedermair schreibt, dass „zur rechten Zeit ein gütiges Geschick” dem jungen Genie Neefe als wichtigsten Lehrer beschert habe. Der Überlegung, dass der Bonner Hofkapellmeister Andrea Luchesi ${ }^{2}$ ein hochrangiger Lehrer des jungen Beethoven hätte werden können, hält er entgegen:

"Man darf es vielmehr als ein Glück bezeichnen, daß der italienische Musiker damals nicht 'Vorbild und Richtschnur' für ihn wurde und daß wohl schon der Vater und Neefe dafür sorgten, daß der Junge nicht zu sehr ins italienische Fahrwasser geriet. Gewiß wäre der junge Beethoven später auch trotz italienischer Schulung unbeirt seinen eigenen Weg gegangen, aber immerhin hätte das Vorbild Luchesis ihn für längere Zeit einer ihm innerlich fremden italienisierenden Periode zuführen können."3

Diese Passage ist 1939 in die zweite, neubearbeitete Auflage des Buches eingefügt worden und reagiert auf eine Bemerkung von Theodor Anton Henseler (1902-1964)4, Luchesi als „der einzige wirklich schöpferische Musiker seiner Umgebung" habe Beethoven maßgeblich fördern und ihm möglicherweise nachträgliche Studien (gerade auch des strengen Satzes, den er von Neefe ja offensichtlich nicht erhalten hatte und bei Johann Georg Albrechtsberger nachholen musste) in Wien ersparen können. ${ }^{5}$ In der ersten Auflage des Schiedermairschen Buches von 1925 ist sie noch nicht enthalten. ${ }^{6}$

Zwei historische Belege bilden die Basis für diese weit verbreitete, und zudem beherrschende Einschätzung:

Der erste Beleg stammt aus Carl Friedrich Cramers Magazin der Musik 1783, für das Neefe einen 20 Seiten langen Bericht über die Musik am kurfürstlichen Hof zu Bonn verfasste. ${ }^{7}$ Auf weniger als einer Seite findet sich gegen Ende die berühmte Passage über Beethoven:
Helmut Loos

\author{
Peter Andraschke \\ zum 80. Geburtstag
}


"Louis van Beethoven, Sohn des obenangeführten Tenoristen, ein Knabe von 11 Jahren, ${ }^{8}$ und von vielversprechendem Talent. Er spielt sehr fertig und mit Kraft das Clavier, liest sehr gut vom Blatt, und um alles in einem zu sagen: $\mathrm{Er}$ spielt größtentheils das wohltemperirte Clavier von Sebastian Bach, welches ihm Herr Neefe unter die Hände gegeben. Wer diese Sammlung von Präludien und Fugen durch alle Töne kennt, (welche man fast das non plus ultra nennen könnte), wird wissen, was das bedeute. Herr Neefe hat ihm auch, sofern es seine übrige Geschäfte erlaubten, einige Anleitung zum Generalbaß gegeben. Jetzt übt er ihn in der Composition, und zu seiner Ermunterung hat er 9 Variationen von ihm fürs Clavier über

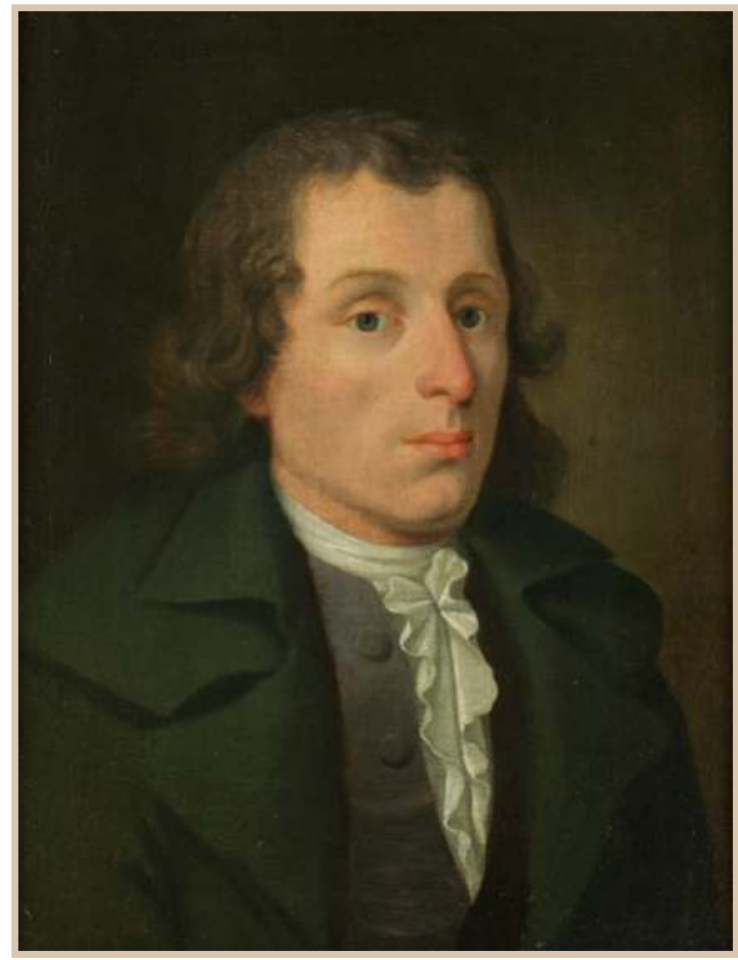
einen Marsch in Mannheim stechen lassen. Dieses junge Genie verdiente Unterstützung, daß er reisen könnte. Er würde gewiß ein zweiter Wolfgang Amadeus Mozart werden, wenn er so fortschritte, wie er angefangen." ${ }^{\prime 9}$

Seine Bedeutung für den jungen Beethoven gründet Neefe in seinem Bericht auf zwei vollkommen unbewiesene Prämissen: 1) Neefe sei „unter den Einwirkungen der strengen Leipziger Schule gebildet"10 und ein begeisterter Anhänger Johann Sebastian Bachs gewesen, der 2) in der rheinischen Residenzstadt Bonn bis dahin vollkommen unbekannt gewesen sei. Nun ist hinlänglich bekannt, dass Neefe in erster Linie Singspiele komponierte und in seinen Klavierwerken Carl Philipp Emanuel Bach zum Vorbild nahm. ${ }^{11}$ Dies bedeutete einen denkbar großen Abstand zum „alten” Bach, der allerdings über Organistenkreise hinaus im Bewusstsein informierter Musiker präsent war. Dagegen schreibt der Bonner Musikverleger Nikolaus Simrock (1751-1832) in einem Brief des Jahres 1828, dass er bereits dem neunjährigen Beethoven Präludien und Fugen von Johann Sebastian Bach überlassen habe. ${ }^{12}$ So bedenklich ein so spätes Zeugnis auch sein mag, es ver-

Christian Gottlob Neefe (1748-1798). Porträt eines unbekannten Malers, um 1780 (Beethoven-Haus Bonn) weist auf die Möglichkeit, dass der damals noch als Waldhornist im Orchester angestellte Freund Beethoven mit Johann Sebastian Bach bekannt gemacht hat und Simrocks spätere Edition des Wohltemperierten Klaviers nicht notwendigerweise von Neefe initiiert worden ist. ${ }^{13}$

Der zweite Beleg ist einer Fußnote der Berlinischen Musikalischen Zeitung von 1793 entnommen und wird als Zitat eines Beethoven-Briefes an Neefe bezeichnet:

"Ich danke Ihnen für Ihren Rath, den Sie mir sehr oft bei dem Weiterkommen in meiner göttlichen Kunst ertheilten. Werde ich einst ein grosser Mann, so haben Sie Theil daran; das wird Sie um so mehr freuen, da Sie überzeugt sein können u.s.w."

390 | Helmut Loos

(C) 2020 by Böhlau Verlag GmbH \& Cie. KG, Köln

https://doi.org/10.7788/9783412519704 | CC BY-NC 4.0 
Der Herausgeber der Zeitung, Johann Gottlieb Carl Spazier (1761-1805), hat die Fußnote in Neefes Beitrag Musikalische Nachrichten von Münster und Bonn angefügt. Spazier bedankt sich bei

"dem Hrn. Hoforganist und Musikdir. Neefe, den Deutschland längst unter seine beliebteren Komponisten zählt, für die interessanten Nachrichten, über Musik und Künstler, womit er dieses Blatt zu bereichern so gefällig hat seyn wollen, recht sehr verbunden, und nehme hier zugleich Gelegenheit, Ihn öffentlich der Hochachtung zu versichern, die ich für seine Talente und sein liebenswürdiges Herz schon lange hege."14

Am Ende des Heftes hat Spazier das Lied Das Saitenspiel aus Bilder und Träume von Herder mit Melodien von Neefe (WV 35 Nr. 14) eingerückt. ${ }^{15}$ Neefe selbst berichtet auf knapp vier Seiten ausführlich über das Musikleben am Hofe des Kurfürsten Maximilian Franz mit der Familie Romberg und anderen; neun Halbzeilen widmet er Beethoven:

"Im November vorigen Jahres reiste Ludwig van Beethoven, zweiter Hoforganist und unstreitig jetzt einer der ersten Klavierspieler, auf Kosten unsers Churfürsten (von Cölln) nach Wien zu Haydn, um sich unter dessen Leitung in der Setzkunst zu vervollkommnen. *) Haydn wollte ihn bei seiner zweiten Reise nach London mitnehmen; noch ist aber aus dieser Reise nichts geworden."

Als Anmerkung der Redaktion fügt Spazier folgende Fußnote bei:

"*) Da dieser L. v. B., mehreren Nachrichten zufolge, große Fortschritte in der Kunst machen soll und einen Theil seiner Bildung auch Hrn. Neefe in Bonn verdankt, dem er sich schriftlich dafür dankbar geäußert; so mögen, Hrn. N. Bescheidenheit mag dies erlaubt seyn lassen, einige Worte hier angeführt stehen, da sie dem Hrn. B. zur Ehre gereichen."16

Dann folgt das angebliche Beethoven-Zitat. Der Text wird in der neuen Beethoven-Briefausgabe als nicht zweifelsfrei authentisch eingeschätzt, ${ }^{17}$ denn es gibt keinen zweiten Beleg, geschweige denn ein Autograph.

Die Zweifel an Neefes Einfluss auf Beethoven, die bereits Franz Gerhard Wegeler als Zeitzeuge äußert, ${ }^{18}$ wischt Alexander Wheelock Thayer vom Tisch. ${ }^{19}$ Erst viel später erinnert Sieghard Brandenburg daran, „dass Beethoven von Neefe kaum den freiheitlichen Geist der Aufklärung aufnehmen konnte. Eher erhielt er damals eine Lektion in Personalpolitik und Hofintrige." 20 Brandenburg bezieht sich dabei vor allem auf Neefes Tätigkeit als Mitglied und 1784/85 „Princeps" des Illuminatenordens in Bonn, mit der er als Vertreter der Aufklärung in einer im Vergleich zu Leipzig eher rückständigen kurfürstlichen und fürstbischöflichen Residenzstadt erscheinen konnte. Weitere Forschungen bestätigen die Zweifel an diesem Bild. ${ }^{21}$ Bach und Beethoven ergänzt durch Brahms oder Bruckner zur Trinität deutscher Musikgeschichte erweisen sich als Meistererzählung einer nationalistischen Geschichtsfälschung, die insbesondere Beethoven zum Gott einer Kunstreligion der Moderne erhebt. ${ }^{22}$ 


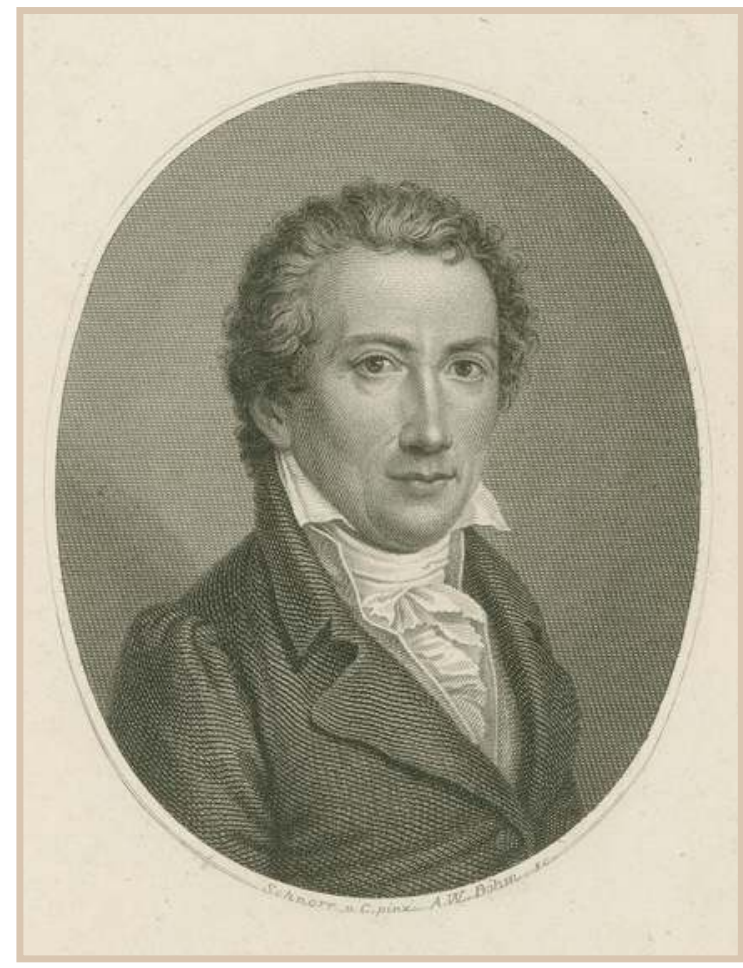

Friedrich Rochlitz (1769-1842). Kupferstich von Amadeus Wenzel Böhm nach Hans Veit Schnorr von Carolsfeld (Beethoven-Haus Bonn, Sammlung H. C. Bodmer)
So wie die Glorifizierung Beethovens mit einem romantischen Beethovenbild bereits zu seinen Lebzeiten einsetzt, soerweisen sich schonzeitgenössischeQuellenpublikationen zu Neefe als tendenziös. Kurz nach Neefes Tod veröffentlicht Friedrich Rochlitz im ersten Jahrgang seiner Allgemeinen musikalischen Zeitung "Christian Gottlob Neefens Lebenslauf von ihm selbst beschrieben". ${ }^{23}$ Er begründet dies mit dem Hinweis, dass "der als Komponist und Mensch so schätzenswerte C. G. Neefe" kürzlich gestorben sei. Seine Kompositionen zeigten zwar nicht den "Glanz des höchsten Genius", zeugten jedoch "unwidersprechlich von Talent, Kenntnis, Gefühl und Geschmack." Besonders hebt Rochlitz hervor: "Sein Charakter hatte Redlichkeit, Gefälligkeit, Offenherzigkeit und Freundschaftlichkeit zu Grundzügen; keiner seiner näheren Bekannten und Freunde hat ihn noch jetzt vergessen."24 Die Differenz, die sich hier zur Einschätzung Brandenburgs auftut, mag teilweise der Pietät eines Nachrufs zuzuschreiben sein, Rochlitz' Position wird aber von Zeitgenossen wie Christian Friedrich Daniel Schubart geteilt, der diese Rücksicht 1784/85 noch nicht nehmen musste. ${ }^{25}$ In dieser Zeit des Sturm und Drang verstärkte sich das Bedürfnis, Künstlergenies und insbesondere Komponisten zu gesellschaftlichen Leitfiguren mit moralischem Anspruch aufzubauen. Die Selbstfindung eines fortschrittlichen Bürgertums in Abgrenzung zu den alten Mächten des Adels und der Kirche setzte auf die Ideale der Aufklärung und auf moralische Bildung durch die Künste. In diesem Zusammenhang wurde insbesondere die Musik religiös überhöht, wurden ihre Schöpfer zu verehrungswürdigen Vorbildern stilisiert und scharf von alten Traditionen, insbesondere kirchlichen Bindungen abgesondert, eine Bewegung, die in erheblichem Maße von Leipzig ausging. Sie vollzog sich in vielen winzigen Schritten mit subtilen Akzentuierungen, ein Beispiel dafür ist Rochlitz Edition der Autobiographie Neefes.

\section{"Christian Gottlob Neefens Lebenslauf von ihm selbst beschrieben”}

Neefes Autobiographie ist nach Originalquellen 1924 von Walther Engelhardt ${ }^{26}$ bearbeitet und 1925 fast gleichzeitig auch von Irmgard Leux ${ }^{27}$ vollständig ediert worden. Engelhardt hat den Text 1957 nochmals publiziert und die Quellen dezidiert beschrieben. ${ }^{28}$ Es existieren zwei Überlieferungen, bezeichnet nach ihrem jeweiligen Fundort:

1) Die Handschrift Kiel ist die ältere, geschrieben von Neefes Ehefrau Susanne Maria mit dem Datum "Frankfurt, den 30. September 1782". Christian Gottlob hat die Handschrift nachträglich ergänzt, das alte Datum gestrichen und als neues hinzugefügt „Bonn. 1789”.

392 | Helmut Loos

(C) 2020 by Böhlau Verlag GmbH \& Cie. KG, Köln

https://doi.org/10.7788/9783412519704 | CC BY-NC 4.0 
2) Die Stuttgarter Handschrift ist ganz autographisch und aufgrund veränderter Schreibweise später zu datieren. Sie diente offenbar als Druckvorlage für die Veröffentlichung 1799 und enthält Korrekturen, Streichungen und Textänderungen von Friedrich Rochlitz. Tatsächlich hat Rochlitz Neefes 1782 beendeten Text um etwa ein Viertel gekürzt.

Um die Kürzungen durch Rochlitz nachzuvollziehen, eignet sich die Edition von Irmgard Leux am besten, die das Stuttgarter Manuskript ediert und die gestrichenen Worte und Passagen eigens kennzeichnet. Redaktionelle Glättung und kleinere Abweichungen interessieren hier nicht, sondern die inhaltlichen Streichungen, deren Gründe Leux als "schwer ersichtlich" bezeichnet. Meine These lautet, dass Rochlitz das religiöse Bekenntnis, das Neefe ablegt, gezielt von christlichen Elementen reinigt und es so ins Allgemeine wendet, so dass es leicht kunstreligiös gedeutet werden kann.

Hans-Josef Irmen hat glaubhaft gemacht, dass Neefe seinen Lebenslauf im Zuge seines Beitritts zum Illuminatenorden im Herbst 1781 verfasst hat, denn eine Selbstbiographie nebst "beigefügtem Karakter" gehörte zum Aufnahmeritual ebenso wie der Status eines Freimaurers im dritten Grad, also eines Freimaurermeisters. ${ }^{29}$ Wann genau Neefe Freimaurer geworden ist, lässt sich nicht ermitteln, die Gedankenwelt der "Königlichen Kunst" begleitete ihn jedoch von Jugend an. Bereits in Chemnitz war er durch den Bruder von Johann Christian Edelmann (1698-1767)30 mit der Freimaurerei in Kontakt gekommen. Heinrich Gottlob Edelmann war um 1752 Juris Practicus, also eine Art Advokat, in Chemnitz. Neefe berichtet in seinem Lebenslauf, dass er "mit eines berüchtigten plumpen Religionsspötters Edelmann Bruder" Umgang gepflegt habe: "Dieser unvorsichtige Mann, ein Advokat, gab mir unerfahrenem, schwankendem Jünglinge fast alle Lästerschriften seines Bruders in die Hände, die ich mit gierigen Zügen verschluckte und bei Gelegenheit wieder von mir gab. ${ }^{131}$ Rochlitz hat den Namen des den Freimaurern zumindest nahestehenden Religionsspötters "Edelmann Bruder" ausgelassen. In Leipzig war bereits 1741 eine der ältesten Logen in ganz Deutschland gegründet worden, 1766 aufgegangen in der Loge Minerva zu den drei Palmen, und freimaurerisches Gedankengut war in höheren Gesellschaftskreisen weit verbreitet. Aus Johann Adam Hillers (1728-1804) Freundeskreis, in den Neefe Aufnahme fand, war der Direktor der
Johann Adam Hiller (17281804). Radierung von Christian Gottlieb Geyser, 1775 (Germanisches Nationalmuseum Nürnberg)

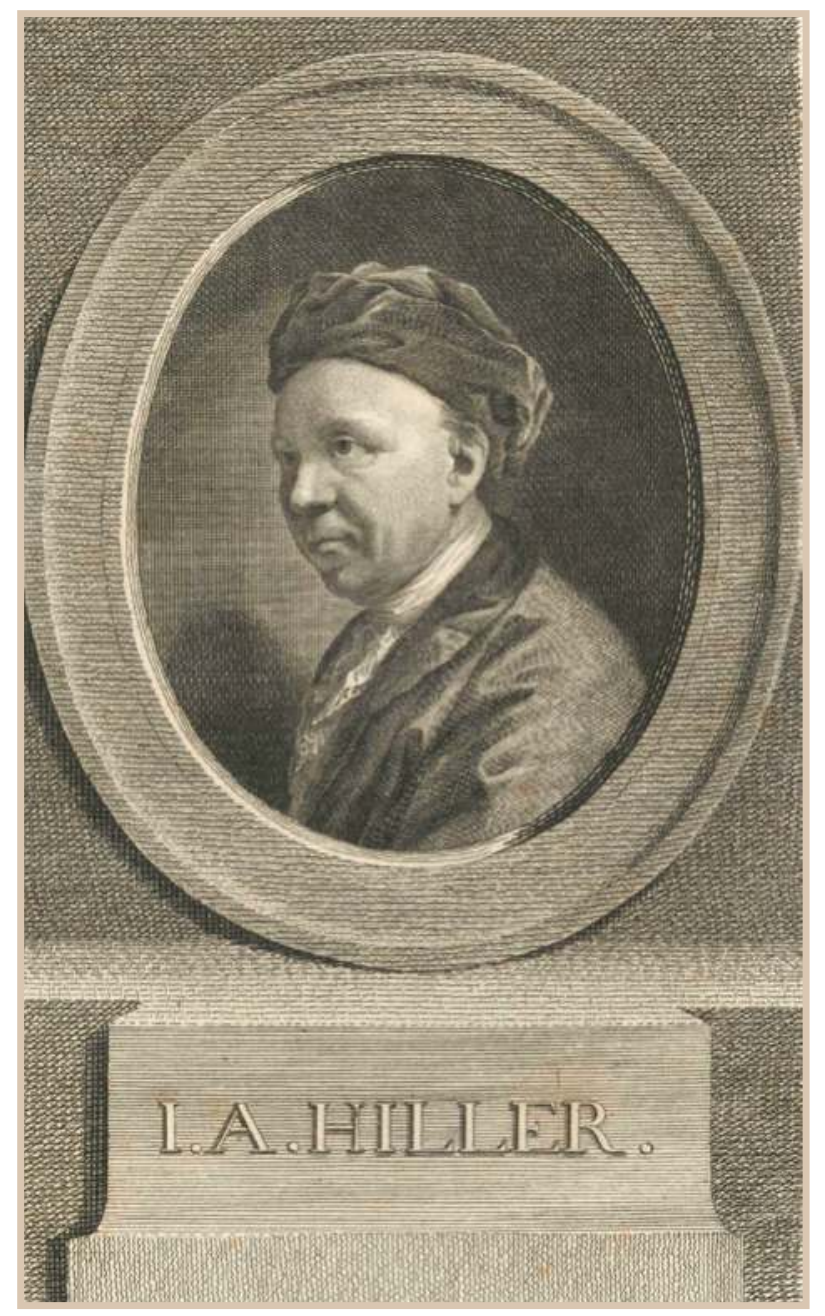


Vorderseite sowie Anschrift eines zweiseitigen Schreibens von Neefe an den in Hannover weilenden "Schauspieldirector" Gustav Friedrich Wilhelm Großmann, 20. Oktober 1787 (Beethoven-Haus Bonn, Sammlung H. C. Bodmer)

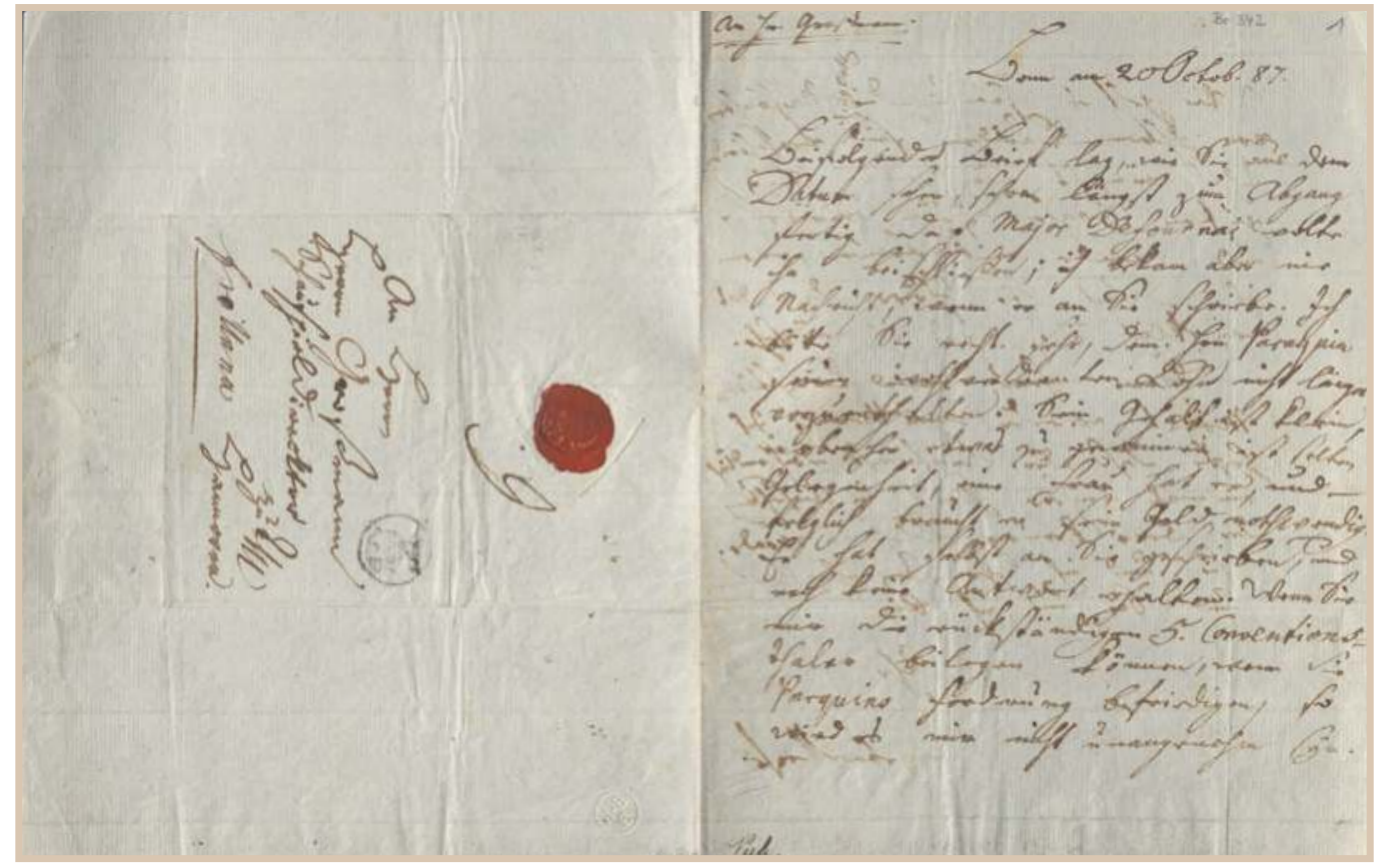

Kunstakademie und anerkannte Maler Adam Friedrich Oeser (1717-1799) Mitglied der Loge, ebenso Carl Wilhelm Müller (1728-1801)32, der literarisch ambitionierte Jurist und Freund von Christian Felix Weiße (1726-1804). In Theaterkreisen wurden die Ideen der Hamburgischen Dramaturgie (17671769) des Logenbruders Gotthold Ephraim Lessing (1729-1781) intensiv diskutiert, 33 seine Vorstellung einer moralischen Besserung der Theaterbesucher durch Furcht und Mitleid (Katharsis) fand weithin Resonanz. Wenn auch die Eignung des Singspiels dafür heftig umstritten war, so waren doch Weiße und Hiller als wichtigste Repräsentanten seiner mitteldeutschen Ausprägung in dem Diskurs ebenso aktiv wie Neefe mit seinen Freimaurerliedern von 1774. Als Kapellmeister trat Neefe 1776 der Schauspiel-Gesellschaft von Abel Seyler (1730-1800) bei, der mit Lessing in Hamburg zusammengearbeitet hatte und gerade ein neues Sommertheater in Dresden eröffnete. Bereits ein Jahr später ging die Seylersche Gesellschaft wieder auf Reisen und spielte vor allem im Rhein-Main-Gebiet (Frankfurt, Mainz, Köln, Hanau, Mannheim, Heidelberg). Einige der Schauspieler waren Freimaurer, etwa Conrad Ekhof (1720-1778), ebenso ihr (seit 1774) Theaterdirektor Gustav Friedrich Wilhelm Großmann (1746-1796). Als Seyler 1779 Konkurs anmelden musste, übernahm Großmann Neefe in seine 1778 gegründeten Kurkölnische Hofschauspielergesellschaft, mit der er an das Theater in Bonn kam. ${ }^{34}$ Es ist nicht zu übersehen, dass Neefe seine gesamte Karriere über die Geheimbünde der Freimauer und der Illuminaten befördert hat.

394 | Helmut Loos

(c) 2020 by Böhlau Verlag GmbH \& Cie. KG, Köln

https://doi.org/10.7788/9783412519704 | CC BY-NC 4.0 


\section{Rochlitz' Streichungen}

Neefe berichtet in seiner Autobiographie, dass er 1767 erstmals studienhalber nach Leipzig gereist sei, zur Zeit des Rektorats von Christian August Crusius (1715-1775), von 1750 bis 1775 ordentlicher Professor für Theologie. Neefes nähere Charakterisierung des Universitätsrektors streicht Rochlitz: „Es war ein sanfter, gutdenkender Mann, ein scharfsinniger, obgleich an sein System gebundener Philosoph und ein tätiger Christ, der aber von seinen meisten Anhängern entweder gar nicht oder falsch verstanden, und von seinen Gegner verkannt ward." ${ }^{5}$ Von insgesamt schwächlicher Konstitution beklagt Neefe seine "Hypochondrie". Er habe in seiner Jugend daran gelitten, "dieses Ungeheuer" aber besiegt. Immerhin habe er der Krankheit zu verdanken, dass sie ihn "wieder näher zur Religion" geleitet habe: "Ich trachtete also nach bessern und gründlichern Einsichten in die Religion, und (ich suchte) Gefühle für sie in meinem Herzen zu erwecken, um mit der Freudigkeit und Hoffnungen eines vernünftigen Christen sterben zu können."36 Den letzten Nebensatz ändert Rochlitz: „um mit Freudigkeit und Hoffnung sterben zu können”, vermeidet also das Bekenntnis als "vernünftiger Christ", mit dem Neefe einen zentralen Begriff der Aufklärung mit traditionellem Religionsbekenntnis verbindet. Die Bücher, die ihm geholfen hätten, charakterisiert Neefe näher:

"Die Bücher, die ich mir als Mittel zur Erreichung meines Zweckes wählte, waren folgende: Bonnets Betrachtungen überdie Natur; Moses Mendelssohns Phädon; Bonnets philosophische Beweise für das Christentum; Schröckhs christliche Kirchengeschichte; Nösselts Verteidigung der christlichen Religion; Hallers Briefe über die Offenbarung. Meine Erbauungsbücher waren: Das Neue Testament; Spaldings und Jerusalems Predigten; Gellerts Moral und geistliche Lieder. Auf solche Art ward mir die Religion (wurde mir) verehrungswürdig, und ich spürte die herrlichen Früchte derselben im Herzen und Leben." ${ }^{\prime 37}$

Rochlitz kürzt dies auf eine einfache Namenliste: "Es gelang mir, vornehmlich durch die Schriften von Bonnet, Moses Mendelssohn, Spalding, Jerusalem und Nösselt. Die Religion wurde mir verehrungswürdig, und ich spürte die herrlichen Früchte derselben im Herzen und Leben."38

Rochlitz streicht die Autoren Johann Matthias Schröckh (1733-1808) und Albrecht von Haller (1708-1777). Schröckh war 1755 an der Universität Leipzig promoviert worden und hatte sich 1756 habilitiert, bevor er 1767 als Professor der Poesie an die Universität Wittenberg ging. Seine Schrift Kirchenhistorik oder Einleitung in die christliche Kirchengeschichte erschien 1772 in Leipzig. ${ }^{39}$ Haller war ein Schweizer Universalgelehrter, weithin anerkannt als Arzt und Erforscher der menschlichen Anatomie, gleichzeitig Dichter und Literaturkritiker. In seinem Buch Briefe über die wichtigsten Wahrheiten der Offenbarung, erstmals 1772 in Bern veröffentlicht, ${ }^{40}$ erweist er sich als scharfer Kritiker des Atheismus der Aufklärung. Neefe nennt diese Literatur seine "Erbauungsbücher", 


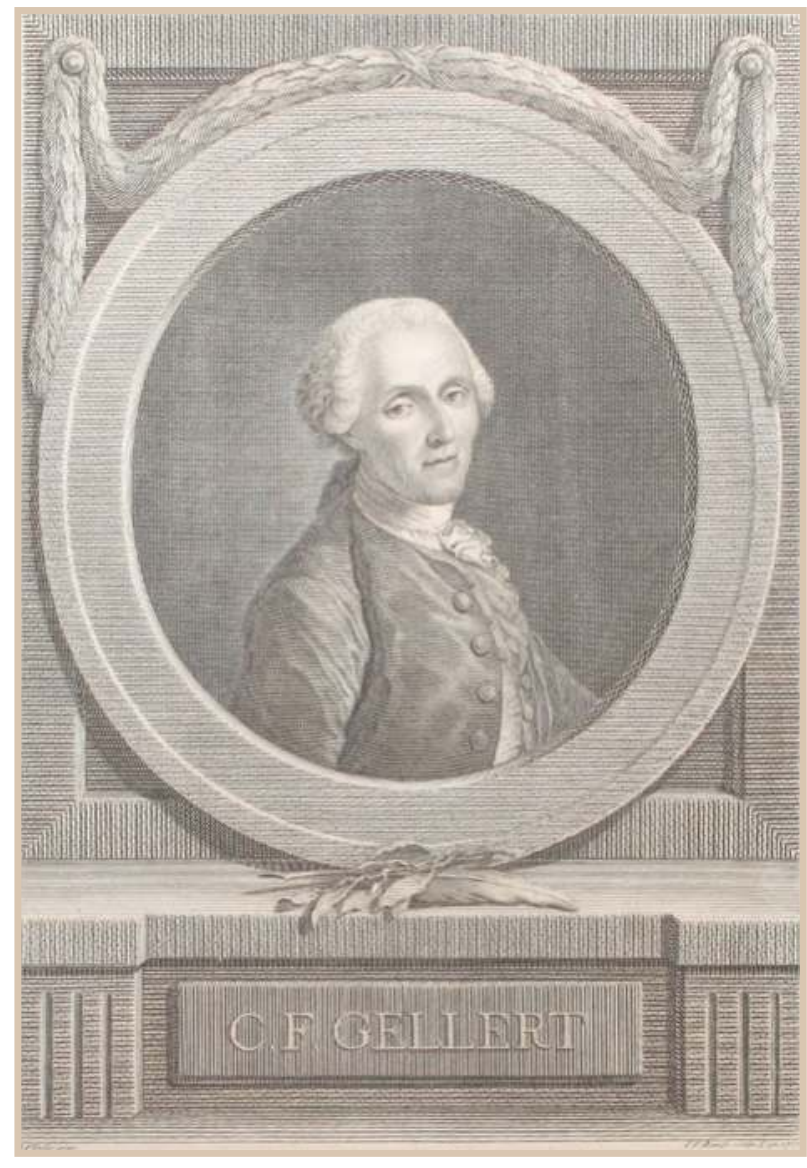

Rochlitz vermeidet diesen Begriff und erwähnt nur Johann Joachim Spalding (1714-1804), der als evangelischer Theologe im Sinne der Neologie die ethischen Werte des Christentums empirisch begründet und die kirchliche Lehre im Sinne der Aufklärung relativiert. ${ }^{41}$ Geradezu demonstrativ streicht Rochlitz das von Neefe an erster Stelle genannte Neue Testament sowie den radikalen Neologen Johann Friedrich Wilhelm Jerusalem (1709-1789), der 1753 die Sammlung einiger Predigten veröffentlicht hat. ${ }^{42} \mathrm{Zu}$ den Erbauungsbüchern zählt Neefe weiter die moralische Schrift ${ }^{43}$ und die Geistlichen Oden und Lieder von Christian Fürchtegott Gellert (1715-1769), ${ }^{44}$ dessen letzte Vorlesung über Moralphilosophie er in Leipzig noch zu hören Gelegenheit hatte und den er wie viele seiner Zeitgenossen zutiefst verehrte (er galt lange zu Unrecht abschätzig als Modephilosoph der Zeit). Rochlitz konnte seinen Namen aus Neefes Lebenslauf nicht ganz ausstreichen, aber unter den „Erbauungsbüchern" wollte er ihn offenbar nicht erwähnt sehen.

Als zweites großes Vorbild neben Gellert verehrte Neefe Johann Adam Hiller, der seine gesamte musikalische Laufbahn so entscheidend geprägt hat. Voller Dankbarkeitbringterdiesin seinerLebensbeschreibung ausführlich zum Ausdruck. Rochlitz kürzt die Passagen

Christian Fürchtegott Gellert (1715-1769). Kupferstich von Johann Friedrich Bause nach Adam Friedrich Oeser, um 1760 (Beethoven-Haus Bonn) radikal und streicht unter anderem den Satz: "Ihn [Hiller] beseelt Religion eines vernünftigen Christen." ${ }^{\text {"S }}$ So wie Rochlitz den Terminus "christlich" im gesamten Text tilgt, so unterdrückt er auch den Hinweis auf nicht deutsche Vorbilder: "Welche erstaunliche Mühe hat er [Hiller] sich gegeben, nach Art der Italiener Konservatorien in Deutschland zu errichten, wenigstens zu veranlassen, um seinem Vaterlande sowohl als Ausländern brave Sänger und überhaupt geschickte Musiker zu ziehen."46 Von den "Gelehrten, schönen Geistern und Künstlern", die Neefe bei Hiller kennengelernt hat, streicht Rochlitz aus der Liste der genannten die Namen Müller und Geyser anscheinend aus persönlicher Rücksicht, denn beide lebten noch in bzw. nahe Leipzig. Carl Wilhelm Müller war zum wiederholten Male Bürgermeister der Stadt, der Maler und Kupferstecher Christian Gottlieb Geyser (1742-1803), der Schwiegersohn von Adam Friedrich Oeser, lebte hoch angesehen auf einem Landgut in Eutritzsch. Die Namen Müller und Geyser fehlen in Rochlitz' Redaktion auch, wo Neefe die "wackern Tonkünstler" auflistet, die er neben Johann Friedrich Reichardt (1752-1814) im Hause Hillers kennengelernt hat: "Weiße, Garve, Engel, Müller, Oeser, Bause, Geyser pp". ${ }^{47}$ So rücksichtsvoll er hier wieder die Namen Müller und Geyser

396 | Helmut Loos

(C) 2020 by Böhlau Verlag GmbH \& Cie. KG, Köln

https://doi.org/10.7788/9783412519704 | CC BY-NC 4.0 
streicht, so unbedeutend erachtet Rochlitz anscheinend die von Neefe gewürdigten Damen des Leipziger Freundeskreises, Frau Zitzmann und Frau von Alvensleben, deren ausführliche und hochachtungsvolle Würdigung er ganz übergeht. ${ }^{48}$ Damit folgt Rochlitz der Konzentration auf große Männer, wie sie im 19. Jahrhundert üblich wurde, und unterdrückt die bei Neefe noch zu findende Anerkennung der Weiblichkeit, die nicht allein der Galanterie des 18. Jahrhunderts geschuldet war. Neefe dediziert Frau von Alvensleben seine Oden von Klopstock ${ }^{49}$ und spricht ihr in der Widmung ein geradezu enthusiastisches Lob für ihre Interpretation der Lieder aus. ${ }^{50}$ Friedrich Gottlieb Klopstock (1724-1803) allerdings erwähnt er in seiner Autobiographie gar nicht, mit dem er doch sogar brieflich in Kontakt stand, ${ }^{51}$ ebenso wenig Mitglieder des Göttinger Hainbundes, obwohl er doch Gedichte des Bundes und seines Umfelds häufiger vertont hat, oder Carl Friedrich Cramer (1752-1807), für dessen Magazin der Musik Neefe später nicht nur den berühmten Bericht aus Bonn geschrieben hat. $^{52}$

Wenn Neefe berichtet, dass er "am Main- und Rheinstrom" während seiner Reisen mit der Seylerschen Gesellschaft "manche wichtigen und angenehmen Bekanntschaften gemacht und einige meinem Herzen teure Freunde gewonnen"habe, so erachtet Rochlitzes nichtfürwesentlich, Neefes Namensnennungen wiederzugeben und streicht folgende Passage:

"Unter die letztern zähl' ich besonders den Herrn Baron von Knigge und Herrn Hofrat Rühl zu Frankfurt, den Herrn Amtskeller Umfenbach zu Mainz, den Herrn Kanzler Haak zu Koblenz, die Herren Hofkammerräte Bleibtreu zu Neuwied, Herrn Schmidt, Schauspieler zu Bonn bei der Großmannschen Bühne und der Herrn Hauptmann d'Antoine nebst dessen verehrungswürdiger Gattin ebenfalls zu Bonn."

Mit Ausnahme des Adolph Franz Friedrich Ludwig Freiherr Knigge (17521796), so der korrekte Name, einem führenden Illuminaten und mit der Großmannschen Theatergesellschaft in engem Kontakt, ${ }^{54}$ sind die Personen nicht leicht zu identifizieren. Für Neefes Renommee in Bonn waren die örtlichen Honoratioren sicher nützlich, aber für Rochlitz Leserschaft aus Leipziger Perspektive eher uninteressant. Beruflich verbunden war Neefe mit dem Schauspieler Schmidt ${ }^{55}$ und dem Offizier und Komponisten Ferdinand d'Antoine, beide Illuminaten der 1781 gegründeten und von 1784 bis zu ihrer Auflösung 1785 von Neefe geleiteten Minervalkirche Stagira in Bonn. Eine Kaufmannsfa-

Erste Seite eines vierseitigen Schreibens von Neefe an Klopstock, 21. Dezember 1775 (Staatsbibliothek Berlin) 
milie aus Neuwied trat 1782 nahezu geschlossen dem Illuminatenorden bei: Carl Philipp Bleibtreu (1746-1812, Ordensname Busiris), Friedrich Wilhelm Bleibtreu (*1766, Ordensname Bleibtreu), Johann Leopold Bleibtreu (*1738, Ordensname Alberoni) und Ludwig Georg Bleibtreu (1765-1835, Ordensname Johannes Taleja). ${ }^{56}$ Die Vermutung liegt nahe, dass es sich bei den anderen Honoratioren ebenfalls um Illuminaten oder geistesverwandte Freimaurer handelt, ${ }^{57}$ die Neefe als Referenz für die Aufnahme in den Orden heranzieht.

Die hier angeführten Kürzungen und die völlige Tilgung des Terminus "christlich", die Rochlitz an Neefes Lebenslauf anbringt, belegen meine These von der Reinigung seines religiösen Bekenntnisses von christlichen Elementen. Damit wird die öffentliche Wahrnehmung der Person eingreifend verändert. Inwieweit Neefes autobiographische Aussagen zutreffen mögen, inwieweit er - noch nicht lange in Bonn ansässig - mit seiner Bewerbung für den Illuminatenorden auch seine Stellung am fürsterzbischöflichen Hof zu rechtfertigen trachtet, lässt sich nicht mit Bestimmtheit sagen. Am 17. Juni 1782 war der Hoforganist Gilles van den Eeden (um 1710-1782) gestorben, dessen Nachfolge Neefe zugesichert, aber noch nicht vollzogen war. Wenn Neefe sich nun als "vernünftiger Christ" präsentiert, so nähert er sich damit Vorstellungen der katholischen Aufklärung, die sich in ihrer zweiten Phase befand. ${ }^{58}$. Über Neefes Anstellung entschied maßgeblich Caspar Anton Graf von der Heyden genannt Belderbusch (1722-1784), der allmächtige Premierminister des Kurfürst-Erzbischofs Maximilian Friedrich. ${ }^{59}$ Belderbusch hatte sich ganz im Sinne der katholischen Aufklärung erfolgreich um die Gründung der ersten Bonner Hochschule bemüht, und Neefe war - nach eigenem Bekunden - sein Protegé. ${ }^{60}$ Mit dem Singspiel brachte Neefe eine neue, deutsche musikalische Gattung an den Hof und bildete eine Alternative zu der traditionell noch fest verankerten italienischen Oper, verkörpert durch Andrea Luchesi.

Die Namen der Persönlichkeiten, die Neefe in der Autobiographie als wichtig für seine Entwicklung nennt, lassen Rückschlüsse auf seine Situation und sein Selbstverständnis zu. Als Rochlitz 1799 ihre Publikation unternimmt, kürzt er den Text nicht allein, um alles zu „unterdrücken, was dem Verstorbenen oder irgend jemand, mit dem er in Verbindung stand, im geringsten nachteilig sein könnte", wie er offen eingesteht, sondern folgt auch bewusst oder unbewusst den zeitbedingten Vorstellungen von der gesellschaftlichen Vorbildfunktion bedeutender Künstler. Wie stark Rochlitz dazu tendiert, den Komponisten eine religiöse Überhöhung zuzusprechen, erschließt sich beispielsweise aus seinem Gedicht Lebenstag des Tonkünstlers. ${ }^{61}$ Allerdings denkt Rochlitz zu dieser Zeit noch nicht an Beethoven und die Rolle Neefes als seines Lehrers. Zwar wird Beethoven im ersten Jahrgang der Allgemeinen musikalischen Zeitung unter die berühmtesten Klavierspielerinnen und Klavierspieler Wiens gezählt - dort "machen Beethoven und Wölfl das meiste Aufsehen"62 -, unter den Rezensionen seiner Werke finden sich aber noch sehr harsche Urteile. ${ }^{63}$ Neefe gehört zu 
dieser Zeit für Rochlitz zu den eigenständigen, verehrungswürdigen Komponisten, die als aufgeklärte Deutsche für die Nation besondere Bedeutung gewinnen konnten. Das passende Persönlichkeitsprofil ergibt sich aus den Vorbildern, die Rochlitz in Neefes Autobiographie stehen lässt. Die meisten hatten eine enge Verbindung zu Leipzig und seinen Spielarten der Aufklärung.

\section{Neefes autobiographisches Profil in Rochlitz' Redaktion}

Neefe würdigt am Anfang des Lebenslaufs seine Chemnitzer Lehrer, ${ }^{64}$ den Kantor Reinhard Friedrich Hoffmann, den Rektor Johann Georg Hager und seinen Konrektor Jünger sowie den Stadtorganisten Johann Friedrich Wilhelmi. Das Schulwesen in Sachsen war zu dieser Zeit noch ganz traditionell von Singen, Beten und Lesen in der Bibel geprägt, das Musikleben von Kirchenmusik, wie sie etwa Christian Gotthilf Tag (1735-1811) in Hohenstein (16 km westlich von Chemnitz) komponierte. Neefe fand Kontakt zu dem überregional anerkannten Kantor, „ein feuriger geschickter Tonkünstler, ... der itzt einer meiner liebsten Freunde ist". ${ }^{65}$ Das meiste allerdings, meint Neefe, habe er aus der Lektüre der Schriften Anleitung zum Clavierspielen von Friedrich Wilhelm Marpurg (1718-1795)66 und Versuch über die wahre Art das Clavier zu spielen von Carl Philipp Emanuel Bach gelernt. ${ }^{67}$ Damit war die Ausbildung Neefes von Musikern geprägt, die zwar Johann Sebastian Bach als alten Meister des Orgelspiels und des strengen Stils zu würdigen wussten, sich aber längst neuen Idealen zugewandt hatten. Der entsprechende, ausführliche Artikel in Hillers Lebensbeschreibungen berühmter Musikgelehrten und Tonkünstler, neuerer Zeit gibt darüber beredt Auskunft. ${ }^{68}$

Den Rektor Christian August Crusius nennt Neefe als erste Persönlichkeit der Leipziger Universität bei seinem Besuch 1767 und würdigt seine Verdienste. Er schafft sich nützliche und angenehme Bücher von Gellert, Rabener und Gessner an, "doch fand ich an den geßnerischen den meisten Geschmack”. Die Bedeutung Gellerts zu jener Zeit zumal in Leipzig kann kaum überschätzt werde. Geradezu sprichwörtlich findet sich ein Ovid-Zitat aus seiner Leipziger Antrittsvorlesung 1744 in einem Poesiealbum: "Treu sich den Künsten weyhn macht unsere Sitten mild und lehrt uns menschlich seyn".69

Die Kunst als moralische Instanz anstelle der Religion wird hier deutlich gefordert, und Klopstock, der nur wenig später in Leipzig studierte, äußert sich ganz ähnlich: „Der Vorzug der Künste vor den Wissenschaften liegt darin, daß sie geeigneter sind, die Menschen moralisch zu machen: sie erniedrigen sich und sind nicht mehr schön, wenn ihnen die moralische Schönheit fehlt."

$\mathrm{Ob}$ Neefe die beiden oben genannten Publikationen Gellerts besessen hat, ${ }^{71}$ ist nicht bekannt, zu umfangreich ist Gellerts Schaffen, zu viel von ihm veröffentlicht worden. Der zweite genannte Schriftsteller, Gottlieb Wilhelm Rabener (1714-1771), war ebenfalls Student in Leipzig und als Aufklärer durch satirische Schriften - Romane, Briefe, Gedichte und Sprichwörter - hervorgetre- 
ten. Doch besonders hoch achtet Neefe den dritten, Salomon Gessner (17301788), den Schweizer Dichter eines erotischen "Daphnis"72 und poetischer "Idyllen", 73 streckenweise religiös-moralisierenden Schwärmereien in antikisierendem Gewand. Diese Vorliebe entspricht durchaus Neefes Begeisterung für Gellert („Ewig segnet mein Herz sein Andenken!"74), den er als ersten seiner Leipziger Professoren anführt. Rochlitz kürzt ihre nähere Charakterisierung auf eine bloße Namensliste. Neefe nennt nach Gellert dessen Nachfolger Christian Gottlieb Seydlitz (1730-1808) als Professor für Logik und Metaphysik, 1777/78 Rektor der Universität Leipzig, spezifiziert seine Leistungen "in der Logik, Metaphysik, Physik und Moral ... nach crusiusischen Grundsätzen!" An der juristischen Fakultät der Universität Leipzig unterrichteten Neefe der Privatdozent Johann Gottfried Sammet (1719-1796) „in dem Natur- und Völkerrecht und justinianischen Institutionen", der ordentliche Professor Christian Heinrich Breuning (1719-1780) "in den Digesten nach dem heinecciusischen ${ }^{75} \mathrm{Kom}$ pendium" und der ordentliche Professor für Sächsisches Recht und Tractationis cursoriae Pandectarum Johann Tobias Richter (1715-1780) "nach der böhmischen und in der sächsischen Prozeßordnung". Nicht eindeutig zu identifizieren ist ein gewisser "Kleemann", möglicherweise Johann August Kleemann aus Chemnitz, der 1764 bis 1769 an der Universität eingeschrieben war und eine Arbeit über "De claudio tryphonino iuris consulto romano" (Über den römischen Rechtsgelehrten Claudius Tryphoninus) verfasst hat, was zu Neefes Angabe "Geschichte des bürgerlichen Rechtes" passen würde. ${ }^{76}$

Sicher will Neefe mit diesen Bemerkungen seine ernsten Studien und seine Kenntnisse der "Rechtsgelehrsamkeit" hervorkehren, aus demselben Grunde verweist er auf sein "Studium der Logik, Moralphilosophie und des Natur- und Völkerrechts". Entscheidend, seiner Neigung zur Musik und seinem "Gefühl vorzüglicher Fähigkeiten darzu" zu folgen, sei jedoch der Zuspruch der musikalischen und ästhetischen Freunde Johann Adam Hiller und Johann Jakob Engel (1741-1802) gewesen. Engel hat sich - nach seiner Promotion 1763 in Rostock - 1766 nochmals an der Universität Leipzig inskribiert, wandte sich dann dem Schauspiel zu und kam in Kontakt mit der Theatertruppe von Abel Seyler. Wie Neefe verkehrte er im Hause Hillers, für den er die komische Oper Die Apotheke schrieb, die letztlich dann Neefe vertonte. Engels berühmte Schrift Ueber die musikalische Malerey ist in diesem Leipziger Kreis entstanden und spiegelt seine Gedankenwelt. ${ }^{77}$

Von den Büchern, die Neefe als seiner Überwindung der Hypochondrie nützlich angibt, zählt Rochlitz die Autoren Bonnet, Moses Mendelssohn, Spalding, Jerusalem und Nösselt auf. Im Einzelnen handelt es sich um folgende Schriften: ${ }^{78}$

Charles Bonnet (1720-1793), Betrachtung über die Natur, Leipzig 1766, $31774 .{ }^{79}$ 


\section{ir \\ citte comititge}

in श口if gefeßgt

von

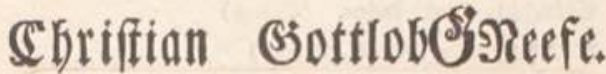

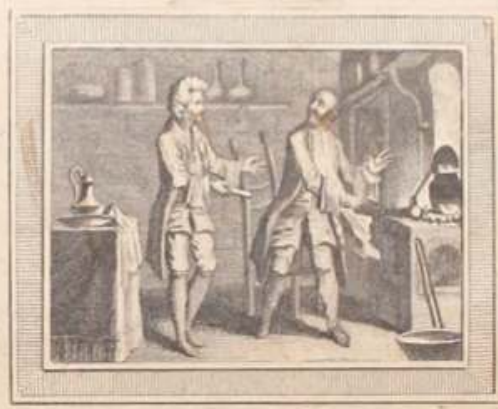

Leipzig,

bẹ) Joḩann Sriebrid) Junius. 1772.
Titelseite der von Neefe komponierten Oper (Beethoven-Haus Bonn)

Herrn Carl Bonnets, verschiedener Akademieen Mitglieds, philosophische Untersuchung der Beweise für das Christenthum. Samt desselben Ideen von der künftigen Glückseligkeit des Menschen. Aus dem Französischen übersetzt, und mit Anmerkungen herausgegeben von Johann Caspar Lavater, Zürich 1769.80

Moses Mendelssohn (1729-1786), Phädon oder über die Unsterblichkeit der Seele in drey Gesprächen, Berlin/Stettin 1767.

Johann Joachim Spalding, Predigt über die Gesinnung eines Christen bey dem herrschenden Verderben in der Welt, Berlin 1766.

Johann Joachim Spalding, Predigt über das Glück des häuslichen Lebens, Berlin u. a. 1769.81

Johann August Nösselt (1734-1807), Auszug aus der Verteidigung Wahrheit und Göttlichkeit christlicher Religion zum Gebrauch academischer Vorlesungen, Halle $1767 .{ }^{82}$

Wirklich religionskritische Schriften finden sich nicht unter dieser Lektüre Neefes, Moses Mendelssohn bildet bereits eine Ausnahme inmitten der christlichen Erbauungsliteratur. Ihm widmet Lavater als Herausgeber die Schrift Carl Bonnets Beweise für das Christenthum und fordert inn in der Widmung aus- 
drücklich dazu auf, „dieselbe öffentlich zu widerlegen, wofern Sie die wesentlichen Argumentationen, womit die Thatsachen des Christenthums unterstützt sind, nicht richtig finden: Dafern Sie aber dieselben richtig finden, zu thun, was Klugheit, Wahrheitsliebe, Redlichkeit sie thun heisse: was Sokrates gethan hätte, wenn er diese Schrift gelesen, und unwiderleglich gefunden hätte." ${ }^{83}$ Damit spielt Lavater auf eine Ode von Johann Wilhelm Ludwig Gleim (17191803) an, in der Moses Mendelssohn als der Sokrates seiner Zeit apostrophiert wird. Lavater verweist auch auf zwei weitere Favoriten Neefes: „Es geht mir bey Bonnets Schriften, wie bey Spaldings und Jerusalems. Ich empfinde, daß nichts, ohne deutlich gedacht zu seyn, hingeschrieben worden ist." 84

Ausführlich und voller Dankbarkeit würdigt Neefe seinen großen Freund und Förderer Hiller, "diesen musikalischen Gellert!"85 Die entsprechenden Passagen kürzt Rochlitz erheblich, belässt aber Neefes Hinweis, dass Hiller ihn bei ihren "Gesprächen über musikalische Dinge" auf "die besten Muster" und ihre "vorzüglichsten Schönheiten aufmerksam" gemacht habe: "Homes Grundsätze der Kritik, Sulzers Theorie u.a.m." ${ }^{\prime 86}$ Damit ist nun allerdings eine ganz andere Geisteswelt angesprochen. Henry Home Kames (1696-1782) neigt als führender schottischer Aufklärer zur Naturreligion und leitet die Grundlagen künstlerischen Schaffens von den Regungen des menschlichen Herzens ab. Seine damals populären Grundsätze der Kritik bezeichnen "die Kritik ... als eine vernunftmäßige Wissenschaft”, durch die "die schönen Künste, gleich der Moral, zu einer vernunftmäßigen Wissenschaft" werden. ${ }^{87}$ Johann Nikolaus Meinhard, der deutsche Übersetzer des Buches, charakterisiert seine Tendenz wie folgt:

"In dem Laufe dieser Untersuchungen sieht man beständig eine reizende Verbindung der Kritik, mit der Moral, des guten Geschmacks mit der Tugend; man überzeugt sich von der Wahrheit, daß eine richtige Kultur der schönen Wissenschaften das Herz bessert: eine Wahrheit die bisher sehr oft wiederholt worden, die aber noch nie so viel Licht bekommen hatte, als der eigensinnige und beredte Rousseau dem entgegengesetzten paradoxen Irrthume gegeben." 88

Parallelen zu Gellerts kunstreligiösen Thesen sind unübersehbar. Die Bedeutung des Geschmacks, dieses neu entdeckten, speziell eigenen menschlichen Vermögens für die Moralität, wie sie die schönen Künste durch das Genie zu vermitteln vermögen, betont auch Johann Georg Sulzer (1720-1779) in seiner Theorie der schönen Künste:

„Es muß jeden rechtschaffenen Philosophen schmerzen, wenn er sieht, wie die göttliche Kraft des von Geschmack geleiteten Genius so gar übel angewendet wird. Man kann nicht ohne Betrübnis sehen, was die Künste würklich sind, wenn man erkennt hat, was sie seyn könnten. ... Da ich einmal deutlich einsehe, wie genau die sittliche Bildung des Menschen, mit der Ausbreitung des guten Geschmacks zusammen hängt, so ist es mir nicht möglich mit 
Gleichgültigkeit von Dingen zu reden, die nach meiner Einsicht den Geschmack verderben, und die schönen Künste von ihrem großen Zweck abführen." 89

Sittliche Bildung durch die Künste, dies ist die wichtige neue Idee des fortschrittlichen Bürgertums, um sich von den alten Idealen der christlichen Gesellschaft als höherwertig, besser abzuheben und Führungsanspruch zu legitimieren. Die Begeisterung für die antike Vorstellung, dass das Gute und Schöne zusammenhänge (ка入окаүаӨia), geht einher mit dem Ekel vor dem Schlechten und Hässlichen, das es zu bekämpfen gelte. Implizit gilt dies gleichermaßen für den schlechteren Teil der Menschen und begründet eine Verachtung von Menschen, wie sie dem Christentum grundsätzlich fremd ist.

Der neuen Bewegung des fortschrittlichen, ja revolutionären Bürgertums gehören des Weiteren die restlichen Künstler an, die Neefe in seinem Lebenslauf nennt, allen voran Johann Friedrich Reichardt, in seiner Jugend begeisterter Anhänger der Französischen Revolution. Wichtig für das aufgeklärte Theater wurde Christian Felix Weiße, er lernte während seines Studiums in Leipzig Gellert, Lessing, Friederike Caroline Neuber (1697-1760) und Gottlieb Wilhelm Rabener kennen, er verfasste Libretti für Hiller. Weiße gehörte ebenso zu dem theaterbegeisterten Kreis um Hiller wie Johann Jakob Engel. Hier lernte Neefe auch den aufgeklärten Philosophen Christian Garve (17421798) kennen, der von 1770 bis 1772 als außerordentlicher Professor für Mathematik und Logik in Leipzig lehrte, sowie den Maler Adam Friedrich Oeser und den Kupferstecher Johann Friedrich Bause (1738-1814). Wie hoch Neefe den Umgang mit diesen Persönlichkeiten schätzte, macht seine Bemerkung deutlich, dass er angefangen habe "zu bereuen, daß ich vorher meinen Kopf mit so manchen unnützen Ideen angefüllt hatte. ${ }^{\prime \prime 90}$ Meint Neefe damit die christliche Erbauungsliteratur?

\section{Neefe als Lehrer Beethovens?}

Autobiographische Schriften werfen immer viele Fragen auf, im vorliegenden Falle etwa: Wie intensiv hat Neefe die angeführte Literatur wirklich gelesen, welche hat ihn nachhaltig beeinflusst? Wie stark war er von christlichem und aufklärerischem Gedankengut geprägt oder vertrat er eine der ausgleichenden Positionen, wie es die Bezeichnung als "vernünftiger Christ" andeutet? Fraglos waren die verschiedenen Gedanken und Ideen im Austausch mit Kollegen und Freunden immer im Gespräch, Neefe hat den Diskurs in eigenen Schriften wie seinen Dilettanterien ${ }^{91}$ reflektiert ${ }^{92}$ und beispielsweise in der Wochenzeitschrift der Bonner Illuminaten als Beiträge zur Ausbildung nützlicher Kenntnisse die Artikel "Genie" aus Rousseaus musikalischem Wörterbuch und aus Sulzers Theorie der schönen Künste nachgedruckt.93

Die Freimaurerei sah er offensichtlich nicht als ausschließenden Gegensatz zum Christentum, auch wenn sie von der katholischen Kirche unter Bann stand 


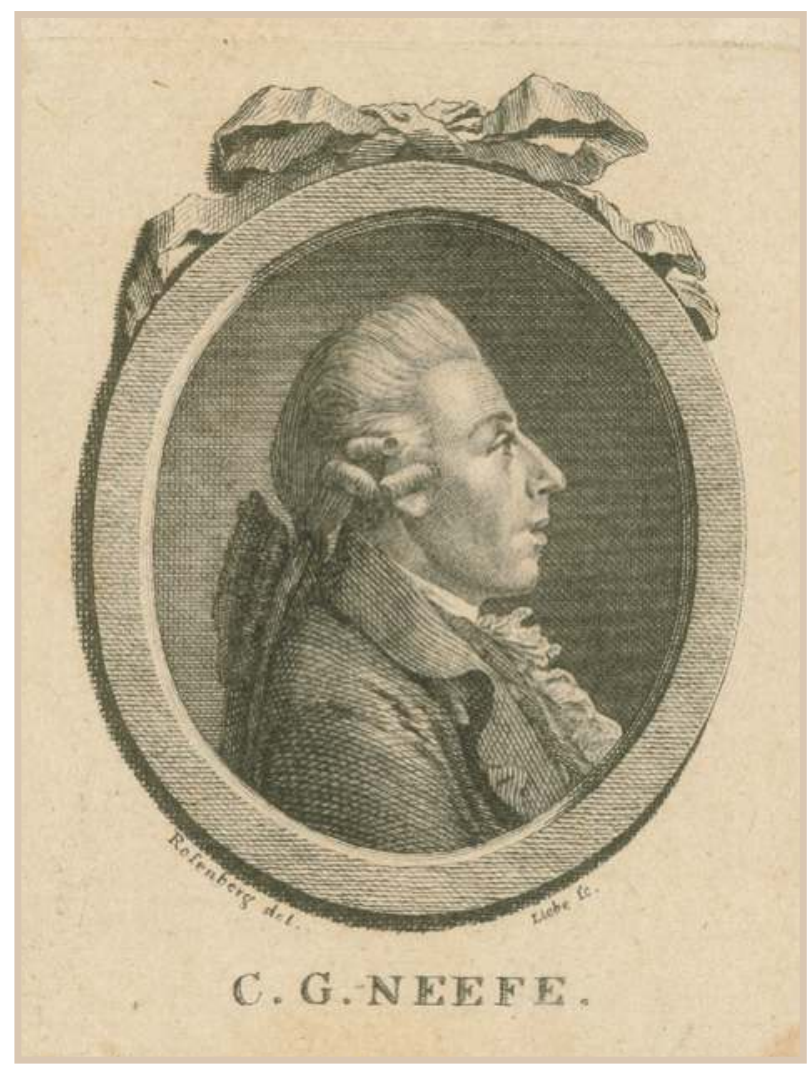

(was allerdings selbst Geistliche nicht hinderte, der "Königlichen Kunst" beizutreten). Die Vorstellung, Künstler der Zeit seien als gesellschaftliche Vorbilder unbeirrbare Überzeugungstäter gewesen, darf wohl in den Bereich des Mythos verwiesen werden; wie die meisten Menschen mussten gerade Künstler Kompromisse eingehen, sich den Gegebenheiten stellen und anpassen bis hin zum Lavieren. Neefe verstand sich in der Kunst der Intrige, wie nicht nur seine Aktivitäten im Illuminatenorden zeigen. Im Oktober 1781 trat er als "Novize" in die Bonner Minervalkirche Stagira ein und bekannte sich derart ostentativ zu den Zielen des Ordens, dass er binnen zwei Jahren ungewöhnlich schnell zum "Princeps" aufstieg. Adam Weishaupt (1748-1830) hatte im Sinne "wissenschaftlicher Wahrheit" dem Illuminatenorden das Ziel gesetzt, "dem Menschen die Bemühung um die Verbesserung und Vervollkommnung seines moralischen Charakters interessant zu machen". Als vordringliches Mittel dazu forderte er "die Recrutierung junger noch unerzogener und unausgebildeter Leute".94 Der junge Beethoven passte genau in das hier beschriebene Beuteschema, laut Neefes "Nachricht" vom 2. März 1783 in Cramers

Christian Gottlob Neefe (1748-1798).

Kupferstich von Gottlob August Liebe nach Johann Georg Rosenberg, 1780 (Beethoven-Haus Bonn)
Magazin der Musik gab er ihm "Anleitung zum Generalbaß” und Übungen zur "Composition". Beethovens Neun Variationen für Klavier über einen Marsch von Ernst Christoph Dressler WoO 63 erschienen 1782 im Musikverlag Götz in Mannheim, nach Neefes Angabe auf seine Veranlassung, einen weiteren Nachweis dafür gibt es nicht. Dass er durch Kompositionsunterricht auf die Variationen Einfluss genommen habe, ist äußerst zweifelhaft, denn im Fischhoffschen Manuskript ist vermerkt, Beethoven habe das Stück komponiert, "ohne noch Unterricht in der Composition erhalten zu haben". ${ }^{95}$ Als Neefe seinen Lebenslauf schrieb (datiert "Frankfurt, den 30. September 1782") hatte er den jungen Musiker anscheinend noch nicht im Visier, denn obwohl ihm bereits seit dem 15. Februar 1781 die Nachfolge des Hoforganisten van den Eeden zugesichert worden war, schreibt er lediglich von der "Erlaubnis, daß ich meine Stelle durch einen Vikar verwalten lassen, nach Westfalen und von da nach Frankfurt zur Michaelismesse mitreisen durfte, wo wir das vom Magistrat neuerbaute Komödienhaus einweihten. ${ }^{\prime \prime 6}$ Am 17. Juni 1782 war van den Eeden verstorben, am 20. Juni 1782 hatte Neefe die Reise angetreten.

Selbstverständlich kannte Neefe die Familie Beethoven, aber nichts deutet darauf hin, dass er mit ihr bis dahin in einen engen Kontakt getreten wäre und den aufstrebenden jungen Musiker intensiv unterrichtet hätte. ${ }^{97}$ Dass der elf-

404 | Helmut Loos

(C) 2020 by Böhlau Verlag GmbH \& Cie. KG, Köln

https://doi.org/10.7788/9783412519704 | CC BY-NC 4.0 
jährige Beethoven den Organistendienst übernehmen konnte, war vielmehr nichts Neues, zu dem er der Anleitung Neefes bedürft hätte, im Gegenteil, viel besser als der protestantische Neefe kannte sich mit Sicherheit Beethoven in der katholischen Liturgie aus. Er hatte - wie der Hofcellist Bernard Joseph Mäurer berichtet - seit etwa 1778 von Hoforganist van den Eeden Unterricht erhalten und war von ihm bereits zur Vertretung an der Orgel beim Gottesdienst herangezogen worden. ${ }^{98} 1777$ hatte der Schlossbrand auch die alte Schlosskirche im Westflügel vernichtet, so dass der Hofgottesdienst vorübergehend in der Kirche St. Ludwig des Minoritenklosters stattfinden musste. Dort war Bruder Willibald Koch als Organist tätig, dem Beethoven ebenfalls als Gehilfe beistand. ${ }^{99} 1779$ wurde die neue Schlosskirche im Ostflügel eingeweiht, wo der Hofgottesdienst nun wieder gefeiert wurde. Beethoven hatte also frühzeitig Kontakt zu beiden Organisten und half ihnen aus. Im Bonner Münster soll er 1780 von dem Organisten Zensen unterrichtet worden sein und gelegentlich gespielt haben, ebenso in seiner eigentlichen Pfarr- und Taufkirche St. Remigius auf dem Remigiusplatz. ${ }^{100}$ Es bedurfte 1782 also keineswegs einer Einweisung Beethovens in den Organistendienst, er kannte sich bereits bestens aus und erwies sich als sehr fähiger Spieler.

Dies scheint Neefe registriert zu haben, als er Ende Oktober 1782 nach Bonn zurückgekehrt war. Er besaß nun beste Berufsaussichten in der kurfürstlich-erzbischöflichen Residenzstadt und hoffte gar auf die Nachfolge Luchesis als Hofkapellmeister. In dieser Hochstimmung hat Neefe den eingangs bereits erwähnten Beitrag Nachricht von der churfürstlich-cöllnischen Hofkapelle zu Bonn und andern Tonkünstlern daselbst für Cramers Magazin der Musik verfasst, datiert auf „den 30ten März 1783", der die berühmte Passage über Beethoven enthält und pädagogisches Engagement annehmen lässt. Vermutlich initiierte Neefe auch die Edition von Beethovens drei Klaviersonaten WoO 47 mit einer ehrerbietigen Widmung an den Kurfürsten, die im Herbst 1783 im Musikverlag Rath Bossler zu Speyer publiziert wurden. Neefes Träume schienen sich endlich zu erfüllen, als Luchesi am 26. April 1783 einen längeren Urlaub antrat und Neefe seine Funktion des Kapellmeisters am Theater übernahm. Er war damit so ausgelastet, dass Beethoven den Großteil des Orgeldienstes zu bewerkstelligen hatte, ohne dafür Gehalt zu beziehen. Obwohl Beethoven bereits zuvor häufig das liturgische Orgelspiel bestritten hatte, wartete er die übliche Probezeit von einem Jahr fast ganz ab, um am 23. Februar 1784 durch die Fürsprache von Sigismund Altergraff zu Salm und Reifferscheid „eine geringe Zulage zu seinem einsweiligen Unterhalte" zu erbitten. Zur Begründung führte er seine Verdienste und Tätigkeiten an, "nach vorgegangener gnugsamen Erprüfung und gefundenen sattsamen Fähigkeit zu der Hof-Orgel, welche er bei oft überkommender Abweßenheit des Organisten Neffe bald zu der Comoedienprob, bald sonsten ohnehin öfters tractiret". ${ }^{101}$ Die Eingabe wurde abschlägig beschieden. Bemerkenswert ist die Erwähnung der Aushilfe bei der "Comoedienprob", über 
die allerdings nur wenig bekannt ist. ${ }^{102}$ Im Hoforchester, wo Franz Anton Ries (1755-1846) eine leitende Position einnahm, ${ }^{103}$ war Beethoven als Bratschist tätig und lernte ein großes Opernrepertoire kennen. ${ }^{104}$

Das Bonner Theater wurde in der Saison 1783/84 von Karoline Großmann ${ }^{105}$ geleitet, so dass Neefe sich in einem vertrauten Kreise bewegte und ein großes Ziel erreicht zu haben schien. Allein, es war von kurzer Dauer, die Ernüchterung sollte alsbald erfolgen. Am 2. Januar 1784 starb Minister Belderbusch, am 15. April 1784 Kurfürst-Erzbischof Maximilian Friedrich. Mit dem Tod des Fürsten brach traditionsgemäß die gesamte höfische Organisationsstruktur zusammen, alle Bediensteten des Hofes verloren ihre Posten, damit der neue Fürst sich seinen Hofstaat nach eigenen Vorstellungen einrichten konnte. Am 27. April 1784 traf Maximilian Franz als neuer Kurfürst, Erzbischof von Köln und Fürstbischof von Münster in seiner Residenz Bonn ein und begann mit der Neuorganisation. Gewöhnlich war dies eine Zeit voller Unsicherheit und Ränkespielen, mit denen sich die Hofangestellten in günstige Positionen für eine Wiederbeschäftigung zu bringen trachteten. Schon lange waren die dem Kurfürsten unterbreiteten Vorschläge zur Veränderung und Verbesserung der Bonner Hofkapelle bekannt, die auf eine Aufwertung der Position Beethovens zu Lasten Neefes hinausliefen. ${ }^{106}$ Es handelte sich um eine massive Intrige aus dem Umfeld der Familie Beethoven. Da der neue Kurfürst das Nationaltheater auflöste, blieb Neefe lediglich die durch Beethovens Bestallung auf die Hälfte des bisherigen Gehalts reduzierte Stelle als erster Hoforganist. ${ }^{107}$ Diese Herabsetzung veranlasste Neefe, über seine Entlassung aus dem Dienst nachzudenken. ${ }^{108}$ Großmann vertraute er an: „Beethoven wird sich am meisten freuen, und doch zweifle ich sehr, daß er jetzt vollen Nutzen davon ziehen wird. "109 Tatsächlich reichte Neefe am 5. Februar 1785 sein Abschiedsgesuch ein, von dem er sich mit einer Gehaltszulage abbringen ließ. ${ }^{110}$ Erst 1789 besserte sich die Lage, als das Theater mit Neefe als Musikdirektor wieder eröffnet wurde.

Es ist schwer vorstellbar, dass Neefe unter diesen Bedingungen sich weiterhin mit dem von einem Illuminaten geforderten pädagogischem Eifer dem jungen Beethoven zugewandt hat. Seine Witwe Susanna Maria Neefe berichtet jedenfalls 1799 in ihrer Fortsetzung von Neefes Lebensgeschichte, dass die Zeit von 1784 bis 1789 für die Familie bedrückend war, da sie den Großteil ihres Gehalts verloren hatte und Neefe sich erfolgreich um "Lectionen von vielen der ersten Häuser in Bonn" bemühen musste. Daneben kaufte er sich "einen kleinen Garten vor dem Thore" und bestellte ihn sorgfältig. ${ }^{111}$ Von Beethoven ist keine Rede mehr, er hätte seinen Unterricht kaum bezahlen können. Das 1793 Beethoven von Spazier ${ }^{112}$ unterstellte Briefzitat erscheint umso obskurer, zumal der Name Neefes weder in dem Stammbuch auftaucht, das ihm die Bonner Freunde zum Abschied 1792 überreichten, noch später von Beethoven jemals erwähnt wird. 


\section{Fazit}

Die herausgehobene Stellung, die Neefe als Lehrer Beethovens lange zugeschrieben worden ist, muss revidiert werden. Wie schon die Einschätzung Neefes als eines kirchenfeindlichen Aufklärers, wie sie Rochlitz befördert hat, bei näherer Betrachtung Zweifel aufwirft - er ließ seine in Bonn geborenen Kinder katholisch taufen -, so erscheint sein Einfluss auf den jungen Beethoven sowohl in musikalischer wie in weltanschaulicher Hinsicht als überbewertet. Aufklärerisches Gedankengut existierte in Bonn neben Neefe in ausreichendem Maße, um Beethoven damit zu konfrontieren; es seien nur die befreundeten Ordensbrüder Nikolaus Simrock und Franz Anton Ries erwähnt, im weiteren Umfeld der revolutionäre Franziskaner Eulogius Schneider (1756-1794) und die lebhaften Aktivitäten an der in Beethovens unmittelbarer Nachbarschaft angesiedelten kurfürstlichen Akademie (seit 1774, 1786 Universität). ${ }^{113}$ Auch die neue deutsche Instrumentalmusik eines Carl Philipp Emanuel Bach und eines Joseph Haydn in Bonn bekannt zu machen, war nicht Neefe vorbehalten, der sie 1784 in einer Schrift Ueber das Karakteristische oder über die Sprache der Instrumentalmusik propagiert. ${ }^{114}$ Analytisch sind dergleichen Beziehungen nicht zu beweisen, lediglich argumentativ zu postulieren, vielmehr fällt selbst bei äußerst sorgfältig ausgearbeiteten Analysen öfters eine bemerkenswert großzügige Umgangsweise mit den historischen Grundlagen auf. ${ }^{115}$

Auf der Suche nach revolutionären Spuren in Neefes musikalischem Schaffen stößt man unter seinen Liedern in dem Vademecum für Liebhaber des Gesangs und des Klaviers von 1780 auf einen Text von Gottfried August Bürger, der leicht als revolutionär gedeutet werden kann:

"Der Bauer an seinen durchlauchtigen Tyrannen.

Wer bist du, Fürst, daß ohne Scheu

Zerrollen mich dein Wagenrad,

Zerschlagen darf dein Roß?

Wer bist du, Fürst, daß in mein Fleisch

Dein Freund, dein Jagdhund, ungebleut

Darf Klau' und Rachen hau'n?

Wer bist du, daß, durch Saat und Forst,

Das Hurra deiner Jagd mich treibt,

Entatmet, wie das Wild? -

Die Saat, so deine Jagd zertritt,

Was Roß und Hund und Du verschlingst,

Das Brot, du Fürst, ist mein. 
Du Fürst hast nicht, bei Egg' und Pflug,

Hast nicht den Erntetag durchschwitzt.

Mein, mein ist Fleiß und Brot! -

Ha! du wärst Obrigkeit von Gott?

Gott spendet Segen aus; du raubst!

Du nicht von Gott, Tyrann!116

Aufgrund der letzten Strophe ist jedoch zu konstatieren, dass der Text ein christliches Selbstverständnis repräsentiert, das Jahrhunderte alt ist und die Sündhaftigkeit einer Obrigkeit anprangert, die ihrer Verantwortung vor Gott nicht gerecht wird. Dieses Bestreben um ständige Erneuerung lag auch der katholischen Aufklärung zugrunde und darf nicht als revolutionär bezeichnet werden, sondern stellt eine Revolte mit dem Ziel einer Reform dar, das christliche Weltverständnis zu verwirklichen. Möglicherweise repräsentiert die Wahl dieses Textes einen Grenzpunkt Neefes, mit dem er sich als „vernünftigen Christen" bezeichnen konnte.

Offenbar gehörte Neefe zu dem Kreis hervorragender Persönlichkeiten, die seinerzeit das musikalische und kulturelle Leben in Bonn belebten und vielfältig anregend wirkten. Mit seiner Tätigkeit als Theatermusiker, mit den Singspielen bis hin zur Oper Adelheit von Veltheim, seinen Arrangements, Klavierauszügen, Übersetzungen, Editionen, Schriften und Berichten besaß er nicht nur eine Präsenz und Ausstrahlung, die von vielen Zeitgenossen anerkannt wurde, sondern auch eine oft übersehene Nachwirkung durch Kunstlieder im Volksmund, auf die Peter Andraschke dankensweterweiter hingewiesen hat. ${ }^{117}$ Damit nahm er in der Sozialisation des jungen Beethoven einen Platz unter den vielen anderen Mitbürgern ein, die das Bonner Kulturleben prägten. Falsch ist allein die Konzentration auf Neefe und die Unterstellung einer besonderen persönlichen Beziehung zu Beethoven. Sie entspringt einem Phänomen, das in der gesamten Beethoven-Rezeption zu beobachten ist, der Vereinnahmung der historischen Persönlichkeit als gesellschaftlichem Leitbild für die eigenen, zeitbedingten Bedürfnisse. ${ }^{118}$ Die erfolgreiche Meistererzählung von Neefe als entscheidendem Vermittler der Kunst Johann Sebastian Bachs an Beethoven passt nur zu gut zu der Vorstellung einer "Hegemonie" oder "Weltherrschaft" der deutschen Musik, ${ }^{119}$ in der Neefe scheinbar die Brücke zwischen den zwei unumstrittenen Gründerfiguren schlägt. 
ERWIN RATZ, Einführung in die musikalische Formenlehre. Über Formprinzipien in den Inventionen und Fugen J. S. Bachs und ihre Bedeutung für die Kompositionstechnik Beethovens, Wien ${ }^{31973}$, S. 20. Auf Ratz stützt sich noch WILLIAM KINDERMAN, Bach und Beethoven, in: MiChaEL HeINEMANN und HANS-JOACHIM HINRICHSEN (Hgg.), Bach und die Nachwelt, 4 Bde, hier Bd. 1: 1750-1850, Laaber 1997, S. 351-377.

Vollkommen zu Recht bedauert die mangelnde Beachtung Luchesis in der Beethoven-Literatur CLAUdIA VALDER-KNeCHTGES, Die Kirchenmusik Andrea Luchesis (17411801). Studien zu Leben und Werk des letzten kurkölnischen Hofkapellmeisters, Berlin/Kassel 1983

LUDWIG SCHIEDERMAIR, Der junge Beethoven, Weimar 21939, S. 98. Zur gegenwärtigen Einschätzung siehe ULRICH KONRAD, Der "Bonner" Beethoven, in: Bonner Beethoven-Studien 12, 2016, S. 65-80. Trotzdem setzt sich der Mythos bis in jüngste Handbücher fort; siehe KNud BREYER, Kindheit, Jugend und Ausbildung, in: SIEgBERT RAMPE (Hg.), Beethovens Welt, Laaber 2019, S. 34-45, besonders S. $37 f$.

Zu Henseler vgl. RALPH FISCHER, Der Bonner Offenbachforscher und Volkskundler Theodor Anton Henseler (1902-1964). Ein Andenken anlässlich seines 50. Todestages am 11. August 2014 (Bad Emser Hefte 405), Bad Ems 2014

JuLIA RONGE, Beethovens Lehrzeit. Kompositionsstudien bei Joseph Haydn, Johann Georg Albrechtsberger und Antonio Salieri, Bonn 2011, behandelt das Thema Neefe nicht.

LUDWIG SCHIEDERMAIR, Der junge Beethoven, Leipzig 1925.

Christian Gottlob NeEFE, Nachricht von der churfürstlich-cöllnischen Hofkapelle zu Bonn und andern Tonkünstlern daselbst, in: Magazin der Musik 1, 1783, S. 377-396. Der Bericht ist datiert auf den 2.3.1783, erschienen am 30.3.1783. Der Artikel ist nicht namentlich gezeichnet, die Autorschaft Neefes ist aufgrund seiner Thematik und Neefes zahlreicher Beiträge zu Cramers Magazin der Musik sehr wahrscheinlich.

Neefe schrieb den Text demnach vor Mitte Dezember 1782. Bekanntlich war Beethoven am 17.12.1770 getauft und am gleichen Tag oder kurz zuvor geboren worden. Vgl. NoRBERT SCHLOSSMACHER, Der erste Auftritt ... Ludwig van Beethovens Taufe im Kirchenbuch von St. Remigius. Faksimile und Kommentar (Jahresgabe des Vereins Beethoven-Haus 2019), Bonn 2019.

NeEFE, Nachricht (wie Anm. 7), S. 394f. Sehr viel umfangreicher als Beethoven würdigt Neefe etwa den kurkölnischen wirklichen Hofkammerrat Johann Gottfried von Mastiaux (1726-1790). Erwar wie Neefe ein Günstling Belderbuschs und führte in Bonn ein musikalisches Haus, in dem auch Neefe seine Werke präsentieren konnte; vgl. ALEXANDER WHEELOCK THAYER, Ludwig van Beethovens Leben, nach dem Original-Manuskript deutsch bearbeitet von HeRmann Deiters, revidiert von Hugo RIEMANN, Bd. 1, Leipzig 31917, S. 97. Eine Stammtafel der Familie von Mastiaux in: EBERHARD DE CLAER, Ursprung, Name und Geschichte der Familie Schevastes zu Vilich, nebst einem Seitenblicke auf den von dem Dortmunder Gelehrten Johann Lambach im 16. Jahrhundert geführten Nebennamen Schevastes, in: Annalen des Historischen Vereins für den Niederrhein 31, 1877, S. 144-160, hier S. 160 (Stammtafel IV); zur Familiengeschichte vgl. auch NORBERT SCHLOSSMACHER, "Haydn-Kult" in Bonn. Zur Geschichte des Mastiaux'schen Hauses am Alten Zoll, in: INGRID BODSCH (Hg.), Joseph Haydn und Bonn (Ausstellungskatalog), Bonn 2001, S. 75-100.

Vgl. Thayer/Deiters/Riemann (wie Anm. 9), S. 149

Vgl. IngE Forst, Vorwort, in: ChristiAn Gottlob NeEFE, XII Klaviersonaten, hg. von WALTER THOENE, ND der Ausgabe 1773, Köln 2006, S. 7-11, insbesondere S. 9f. Neefes Widmung "An den Herrn Kapellmeister Bach in Hamburg". 
Vgl. Jürgen May, Neefe als Teilhaber an Beethovens Ruhm, in: Helmut Loos (Hg.), Christian Gottlob Neefe. Eine eigenständige Künstlerpersönlichkeit. Tagungsbericht Chemnitz 1998, Chemnitz 1999, S. 237-253, hier S. 246.

13 Siehe die Anzeige von Nikolaus Simrock im Intelligenz-Blatt Nr. V zur Allgemeinen Musikalischen Zeitung 3, 1800/1, Sp. 17f. (Februar 1801): "Da mein Exemplar vom sel. Neefe ganz berichtigt worden".

14 Berlinische Musikalische Zeitung 1, 1793, S. 149-151, hier S. 149 (38. Stück vom 19.10.1793).

15 Katja Selfert, Werkverzeichnis Christian Gottlob Neefe, in: Loos, Neefe (wie Anm. 12), S. 255-355, hier S. 307

16 Christian Gottlob Neefe, Musikal. Nachrichten aus Bonn, in: Berlinische Musikalische Zeitung 1, 1793, S. 153 [39. Stück vom 26.10.1793].

17 Ludwig van Beethoven, Brief an Christian Gottlob Neefe, aus Bonn oder Wien, zwischen Ende Oktober 1792 und 26. Oktober 1793, in: Sieghard Brandendurg (Hg.), Ludwig van Beethoven, Briefwechsel. Gesamtausgabe, 7 Bde, München 1996-1998, hier Bd. 1, Nr. 6.

18 Vgl. Franz Gerhard Wegeler und Ferdinand Ries, Biographische Notizen über Ludwig van Beethoven, Koblenz 1838, S. 11.

19 Vgl. Thayer/Deiters/Riemann (wie Anm. 9), S. 148 f

20 Sieghard Brandenburg, Beethovens politische Erfahrungen in Bonn, in: Helga LüHning und Ders., Beethoven. Zwischen Revolution und Restauration, Bonn 1989, S. 3-50, hier S. 40

21 Vgl. May, Neefe (wie Anm. 12), S. 237-253; Helmut Loos, Christian Gottlob Neefe. Das Schaffen, in: Christian Gottlob Neefe. Ein sächsischer Komponist wird Beethovens Lehrer. Katalog zur gleichnamigen Ausstellung des Schloßbergmuseums Chemnitz in Zusammenarbeit mit dem Beethoven-Haus Bonn, Chemnitz 1997, S. 59-84, hier S. 76-81; ARMIN RAAB, Christian Gottlob Neefe und das Bonner Musikleben im späten 18. Jahrhundert. Vortrag auf der Jahrestagung der Arbeitsgemeinschaft für rheinische Musikgeschichte in Aachen 1996 (Musik und Musikleben im französischen Rheinland 1792-1814), hat bereits in dem leider nicht publizierten Beitrag Neefes überragende Bedeutung für die Erziehung Beethovens massiv angezweifelt und die offensichtlichen Gegenargumente benannt. - In englischsprachiger Literatur wird das Thema wenig berücksichtigt, siehe IAN WOODFIELD, Christian Gottlob Neefe and the Bonn National Theatre, with new light on the Beethoven family, in: Music \& letters 93, 2012, 3, S. 289-315. Die kritische Sichtweise bestätigt TILMAN SKOWRONECK, Beethoven the pianist. Biographical, organological and performance-practical aspects of his years as a public performer, Göteborg 2007.

22 Vgl. Helmut Loos, E-Musik - Kunstreligion der Moderne. Beethoven und andere Götter, Kassel 2017

23 Christian Gottlob Neefens Lebenslaufvon ihm selbst beschrieben, in: Allgemeine musikalische Zeitung 1, 1798/99, Sp. 242-245, 257-261, 273-278. Als Ergänzung folgte wenig später: S[USANNE] M[ARIA] NEEFE, Neefe's Lebensgeschichte von seiner hinterlassenen Witwe fortgesetzt, in: ebd., Sp. 360-364. Eine Neuausgabe dieser Fassung erschien in: Alfred EINSTEIN (Hg.), Lebensläufe deutscher Musiker von ihnen selbst erzählt, Bd. 2: Christian Gottlob Neefe, Leipzig 1915.

24 FrIEDRICH ROChlitZ, Biographie, in: Allgemeine musikalische Zeitung 1, 1798/99, Sp. 241 


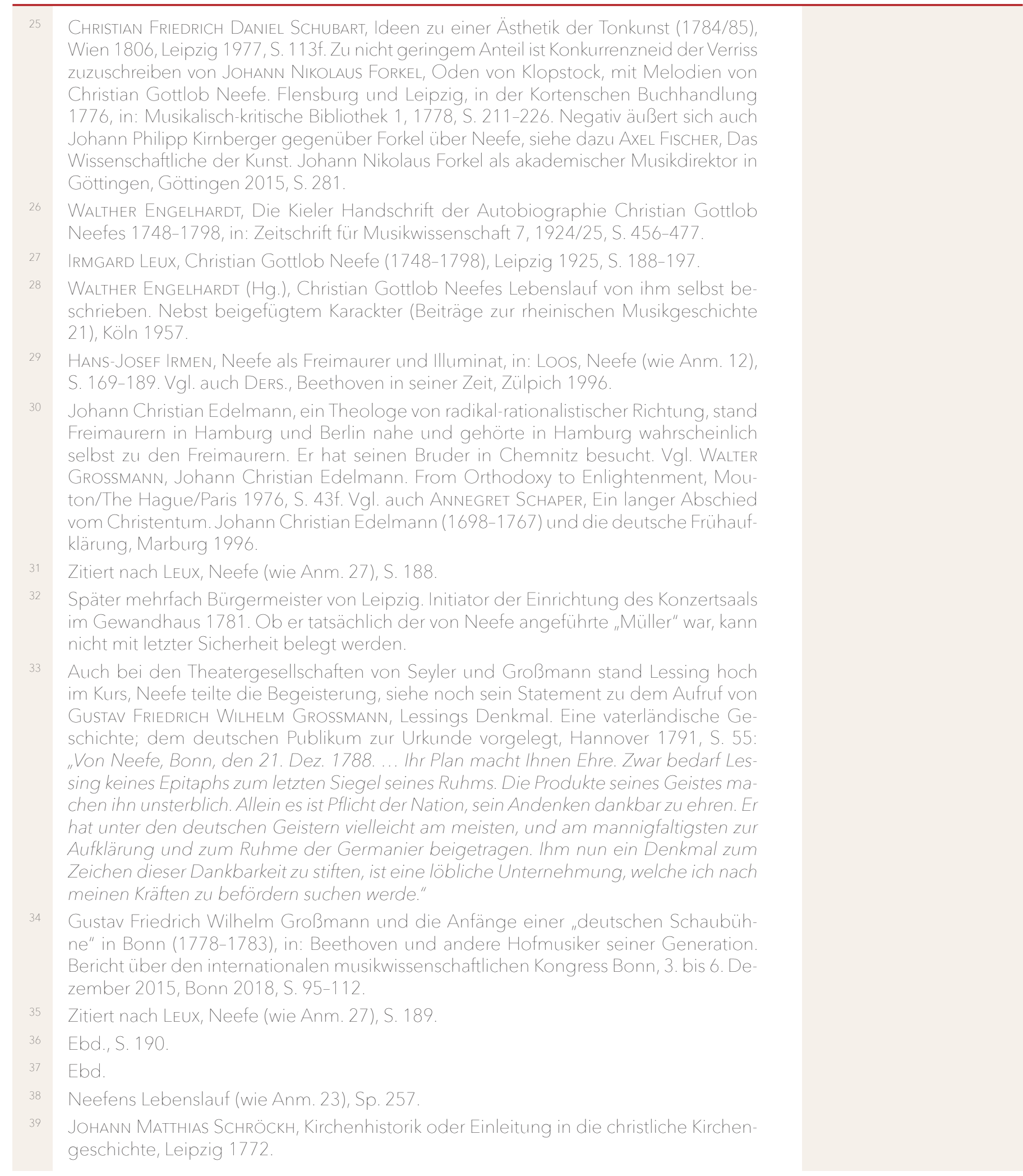

Christian Gottlob Neefe und seine Bedeutung für Ludwig van Beethoven | 411 (C) 2020 by Böhlau Verlag GmbH \& Cie. KG, Köln

https://doi.org/10.7788/9783412519704 | CC BY-NC 4.0 
AlBRECHT VON HALLER, Briefe über die wichtigsten Wahrheiten der Offenbarung, Bern 1772, Bern ${ }^{31773, ~ K a r l s r u h e ~} 1779$

JoHANN JOACHIM SPALDIng, Betrachtung über die Bestimmung des Menschen, Greifswald 1748, Greifswald 31749. Noch viele Predigten Spaldings wurden gedruckt, beispielsweise: Predigt über die Gesinnung eines Christen bey dem herrschenden Verderben in der Welt, Berlin 1766, und Predigt über das Glück des häuslichen Lebens, Berlin u. a. 1769.

Johann Friedrich Wilhelm Jerusalem, Sammlung einiger Predigten, Braunschweig 1753 .

Christian FürChtEgotT Gellert, Von der Beschaffenheit, dem Umfange und dem Nutzen der Moral. Eine Vorlesung, auf Befehl und in hoher Gegenwart Sr. Churfürstl. Durchlauchtigkeit zu Sachsen, Friedrich Augusts, den 29sten April 1765, auf der Universitäts-Bibliotheck zu Leipzig gehalten, Leipzig 1766.

DERS., Geistliche Oden und Lieder, Leipzig 1757.

BECKER, Neefe (wie Anm. 55), S. 2. Der Amtskellner Umfenbach zu Mainz ist in einer Liste der Mainzer Illuminaten verzeichnet (ebd., S. 8). Die Bonner Ordensbrüder Nikolaus Simrock und Franz Anton Ries nennt Neefe nicht, sie gehörten zu den Adressaten seines Lebenslaufs.

LEUX, Neefe (wie Anm. 27), S. 191

Ebd.

Ebd., S. 192.

Ebd.

Christian Gottlob Neefe, Oden von Klopstock, mit Melodien, Flensburg/Leipzig 1776

Vgl. Leux, Neefe (wie Anm. 27), S. 27f.

Dazu auch Christian Gottlob Neefe, Brief vom 21.12.1775 an Friedrich Gottlieb Klopstock, in: ebd., S. 28

In anderen Zusammenhängen würdigt er diese Namen, vgl. ebd.

Ebd., S. 195.

Vgl. dazu "Sind die Kerls, die Komödianten rasend?" Gustav Friedrich Wilhelm Großmann und das hannoversche Hoftheater im 18. Jahrhundert, bearb. von AXEL FISCHER und MARTIN RECTOR (Prinzenstraße, Doppelheft 7), Hannover 1996.

Vgl. Alfred BeCKer, Christian Gottlob Neefe und die Bonner Illuminaten, Bonn 1969, S. 13. Die Liste Bonner Illuminaten vom 17.6.1783 verzeichnet an erster Stelle einen "Roscius" als Meister vom Stuhl, dahinter verbirgt sich Neefes Freund, der Schauspieler Joseph Schmidt oder Schmid. An dritter Stelle folgt ein "Japhet", ein Kanoniker Schmidt oder Schmitz. Zu Josef Schmid als erstem Lokaloberen in Stagira-Bonn und anderen Bonner Illuminaten vgl. MAX BRAUBACH, Neue Funde und Beiträge zur Kulturgeschichte Kurkölns im ausgehenden 18. Jahrhundert, in: Annalen des Historischen Vereins für den Niederrhein 172, 1970, S. 155-215, hier S. $158 f$.

https://freimaurer-wiki.de/index.php/Mitglieder_des_Illuminatenordens, aufgerufen 4.11.2019

Vgl. hierzu HARM KLÜTING (Hg.), Katholische Aufklärung - Aufklärung im katholischen Deutschland, Hamburg 1993; SIEGFRIED KROSS, Beethoven und die rheinisch-katholische Aufklärung, in: DERS. (Hg.), Beethoven, Mensch seiner Zeit, Bonn 1980, S. 9-36; NIKOLAS CHONG, Aufklärung, Katholizismus und die religiöse Anschauung Beethovens, 
in: RAMPE, Beethovens Welt (wie Anm. 3), S. 88-107, hier vor allem auch Hinweise auf englischsprachige Literatur

Dass Neefe die Anwartschaft auf die Hoforganistenstelle „auf Empfehlung des dirigierenden Ministers Grafen von Belderbusch, und der Frau Gräfinn von Hatzfeld" erhalten habe, strich er selbst in der Kieler Fassung seines Lebenslaufs. Vgl. ENGELHARDT, Neefes Lebenslauf (wie Anm. 28), S. 20.

Vgl. Leux, Neefe (wie Anm. 27), S. 196.

FRIEDRICH ROCHLITZ, Lebenstag des Tonkünstlers, in: Auswahl des Besten aus Friedrich Rochlitz' sämmtlichen Schriften, Bd. 6, Züllichau 1822, S. 101-116, hier S. 103: „Doch es vernimmt mein Geist in heil'ger Bewegung / Die Ordnung ihrer himmlischen Bewegung."

Die berühmtesten Klavierspielerinnen und Klavierspieler Wiens, in: Allgemeine musikalische Zeitschrift 1, 1798/99, Sp. 323-326, hier Sp. 324

The Sonate per il Clav. o Fortepiano con un Violino, comp. e dedicate al Sigr. Antonio Salieri, dal S. Luigi van Beethoven. Op. 12, in: ebd., Sp. 570f., hier Sp. 571: "Es ist unleugbar, Herrn van Beethoven geht einen eigenen Gang: aber was ist das für ein bisarrer mühseeliger Gang! Gelehrt, gelehrt und immerfort gelehrt und keine Natur, kein Gesang! Ja, wenn man es genau nimmt, so ist auch nur gelehrte Masse da, ohne gute Methode; eine Sträubigkeit, für die man wenig Interesse fehlt; ein Suchen nach seltener Modulation, ein Ekelthun gegen gewöhnliche Verbindung, ein Anhäufen von Schwierigkeit auf Schwierigkeit, dass man alls alle Geduld und Freude dabey verliert."

Nähere Auskunft zu Personen und Situation in Chemnitz zu Neefes Zeit gibt WERNER KaDEN, Biographie Christian Gottlob Neefes, in: NEEFE, Ein sächsischer Komponist (wie Anm. 21), S, 11-57. Kaden kritisiert, dass Neefe ein zu schmeichelhaftes Bild gezeichnet habe, und deckt gravierende Mängel in Schulwesen und Kultur der Industriestadt auf.

Neefens Lebenslauf (wie Anm. 23), Sp. 243

Friedrich Wilhelm Marpurg, Anleitung zum Clavierspielen, der schönern Ausübung der heutigen Zeit gemäß, Berlin 1755.

Carl Philipp Emanuel Bach, Versuch über die wahre Art das Clavier zu spielen, Berlin 1753 .

JOHANN ADAM HILLER, Lebensbeschreibungen berühmter Musikgelehrten und Tonkünstler, neuerer Zeit, Leipzig 1784, S. 9-29.

Zitiert nach: Werner Jung, John F. ReYnolds und Bernd WiTte (Hgg.), Christian Fürchtegott Gellert, Poetologische und Moralische Abhandlungen. Autobiographisches, Berlin/New York 1994: „Von dem Einflusse der schönen Wissenschaften auf das Herz und die Sitten. Eine Rede, bey dem Antritte der Profession"; THOMAS Fuchs und STEFFEN HOFMANN (Hgg.), "In tiefer FreundsCHaft und Verbundenheit". Aus dem Stammbuchsammlung der Universitätsbibliothek Leipzig, Leipzig 2009, S. 63.

Zitiert nach Leo BALET und EBERHARD REBLING, Die Verbürgerlichung der Kunst, Literatur und Musik im 18. Jahrhundert, Dresden 1979, S. 267.

Wie Anm. 43 und 44.

SALOMON GESSNER, Daphnis, Zürich 1754.

DERS., Idyllen, Zürich 1756.

LEUX, Neefe (wie Anm. 27), S. 189.

Christian Gottlob Neefe und seine Bedeutung für Ludwig van Beethoven | 413 
Im Jahre 1745 war in Amsterdam das Compendium Institutionum Justiniani, sive elementa juris civilis von JOHANNES FRIEDRICH BöCKELMANN (1633-1681) mit einem Vorwort des Hallenser Rechtsgelehrten JOHANN GOTTLIEB HEINECCIUs (1681-1741) wieder aufgelegt worden.

GEORg ERLER (Hg.), Die jüngere Matrikel der Universität Leipzig 1559-1809, Bd. 3: Die Immatrikulationen vom Wintersemester 1709 bis zum Sommersemester 1809, Leipzig 1909, S. 198. Ebd., S. 281 findet sich der Eintrag für "Neefe ... Christ. Gottlob Chemnic. M. i 21 X. 1767." In der Disputationskartei des Universitätsarchivs Leipzig findet sich die Angabe "Kleemann, Johann August / aus Chemnitz / De claudio tryphonino iuris consulto romano / [Über Claudius Tryhoninus, dem römischen Rechtsgelehrten.] / 19.10.1768 - iur. utr. b. 3.4.1769 / Phil. Fac., B 122, B 122, Bd. 47, Nr. 13." Für die freundliche Auskunft danke ich der Archivarin P. Hesse.

JOHANN JAKOB ENGEL, Ueber die musikalische Malerey, Berlin 1780.

Fast alle von Neefe genannten Bücher sind in zahlreichen Auflagen erschienen; welche ihm jeweils vorlag, ist nicht genauer zu bestimmen.

Leipzig 1766, S. 513: „Es würde aber diese Betrachtung sehr unfruchtbar seyn, wenn sie uns nicht zu dem Urheber der Natur leitete. Diesen anbetungswürdigen Schöpfer muß man in der unermeßlichen Kette der mancherley Naturwerke unaufhörlich suchen; allwo seine Macht und Weisheit mit so viel Wahrheit und Glanze abgebildet sind."

JohAnn CASPAR LAVATER, Vorrede des Uebersetzers, in: Herrn Carl Bonnets, verschiedener Akademieen Mitglieds, philosophische Untersuchung der Beweise für das Christenthum. Samt desselben Ideen von der künftigen Glückseligkeit des Menschen. Aus dem Französischen übersetzt, und mit Anmerkungen herausgegeben von JOHANN CASPAR LAVATER, Zürich 1769, S. IV: „Ich habe bey dem Durchlesen dieses fürtrefflichen Werkes tausendmal gewünscht, daß alle Menschen in der Welt die Wahrheit und Bündigkeit der Beweise für das Christenthum, die ich in demselben antraf, in demjenigen Licht einsehen mögen, in welchem sie mir einleuchten."

Dies sind nur zwei Beispiele der zahlreich gedruckten Predigten Spaldings. Welche genau Neefe vorlagen, ist nicht bekannt. Vgl. auch JOHANN JOACHIM SPALDING, Betrachtung über die Bestimmung des Menschen, Greifswald 1748, ${ }^{3} 1749$.

Vorrede, ohne Seitenzahl: „Als ich anfing die Vertheidigung der Wahrheit und Göttlichkeit der christlichen Religion aufzusetzen, war meine Absicht, ein klein Buch zu entwerfen, das bey meinen academischen Vorlesungen über diese Sache zum Grunde gelegt werden köne. ... ich habe in demselben, wie ich denke, keinen Hauptpunkt oder Beweis vorbey gelassen, und so gar von denen Untersuchungen, die durch Einwürfe einzelner Feinde der christlichen Religion veranlasset worden waren, das, was das wesentlichste war und zur eigentlichen Sache gehörte, kürzlich mit berühret." Johann Caspar Lavater, Widmung, in: Herrn Carl Bonnets (wie Anm. 81), ohne Seitenzahl. LAVATER, Vorrede (wie Anm. 80), S. VI.

LEUX, Neefe (wie Anm. 27), S. 191

Ebd., S. 192

HEINRICH HOME, Grundsätze der Kritik. Aus den Englischen übersetzt von Joh. Nikolaus Meinhard, Leipzig 1772, hier zitiert nach der vierten Englischen verbesserten Ausgabe, Frankfurt/Leipzig 1775, S. 9. S. 543f.: Wenn auch "kein Talent so oft gemisbraucht wird, als die Vernunft", so dürfe sie nicht verunglimpft werden, weil sonst nicht einzusehen wäre, "welche Regel uns davon abhalten würde, schimmernde Kleinigkeiten für 
wichtige Dinge, den Schein für die Sache, und Aberglauben oder Schwärmerei für wahre Religion anzunehmen."

Vorbericht des Uebersetzers, in: Ebd

JohAnN GEORg Sulzer, Theorie der schönen Künste, Erster Theil von A bis J, Leipzig 1773, S. V, X

LeuX, Neefe (wie Anm. 27), S. 192.

Christian Gottlob Neefe, Dilettanterien, [Bonn] 1785

Rainer Cadenbach, Neefe als Literat, in: Loos, Neefe (wie Anm. 12), S. 151-168.

Beiträge zur Ausbildung nützlicher Kenntnisse 1, 21. Stück vom 30.8.1784, S. 169-176; 22. Stück vom 6.9.1784, S. 177-183.

Zitiert nach IRMEN, Neefe (wie Anm. 29), S. $170 f$

Thayer/Deiters/Riemann (wie Anm. 9), Bd. 1, S. 155. Das Manuskript des Wiener Pianisten Joseph Fischhof (1804-1857) enthält Quellenabschriften für eine Beethoven-Biographie, die nicht zustande kam.

LEUX, Neefe (wie Anm. 27), S. 197

SKOWRONECK, Beethoven (wie Anm. 21), S. 67-73, arbeitet die Zeiten heraus, zu denen ein Unterricht überhaupt hätte stattfinden können.

Vgl. Thayer/Deiters/Riemann (wie Anm. 9), Bd. 1, S. 137. Zu Beethovens Lehrern van den Eeden, Pfeiffer und Rovantini siehe auch SkOwronECK, Beethoven (wie Anm. 21), S. 46-52.

Siehe auch THEOdOR FrimmeL, Beethoven-Handbuch, Bd. 1, Leipzig 1926, S. 438f., mit Verweis auf Gottfried Fischers Bericht über Beethovens Bonner Jugendzeit.

ThaYer/Deiters/Riemann (wie Anm. 9), Bd. 1, S. 139f. Vgl. auch Schiedermair, Der junge Beethoven (wie Anm. 6), S. 135f., DerS., Der junge Beethoven (wie Anm. 3), S. $77 f$. Die Kirche wurde 1806 oder 1807 wegen Baufälligkeit niedergelegt. Nachdem das Minoritenkloster 1803 im Zuge der Säkularisierung aufgelöst worden war, wurde die bisherige Klosterkirche 1806 zur neuen Pfarrkirche St. Remigius. Vgl. hierzu den ausführlichen Beitrag von GISBERT KNOPP in diesem Band

Zitiert nach ThaYer/Deiters/RIemAnn (wie Anm. 9), Bd. 1, S. 165.

Ebd., S. 158, ohne weiteren Nachweis: „So mit Geschäften überhäuft, konnte Neefe nicht länger die Theaterproben am Klavier leiten, und Ludwig, jetzt 12 Jahre alt, wurde auch Cembalist im Orchester." Vgl. auch ebd., S. 86, 145

Nach dem Bericht von Carl Ludwig Junker; vgl. JoHn DAVID WILSON, Das Bonner Opernleben zur Zeit des jungen Beethoven. Katalog zur Sonderausstellung im Beethoven-Haus Bonn 22. Oktober 2015 - 2. März 2016 (Veröffentlichungen des Beethoven Hauses, Ausstellungskataloge 24), Bonn 2015, S. 19

Vgl. Elisabeth Reisinger, Juliane Riepe und John D. Wilson, The Operatic Library of Elector Maximilian Franz. Reconstruction, catalogue, contexts, Bonn 2018.

Sie verstarb wenig später, und Neefe veröffentlichte einen besonderen Nachruf: Karoline Großmann. Eine biographische Skizze herausgegeben von C. G. NEEFE, Göttingen 1784

Vgl. Thayer/Deiters/Riemann (wie Anm. 9), Bd. 1, S. 189-199.

Neefe verdiente zunächst nur 200 Florin, Beethoven 150 Florin; vgl. ebd., S. 198.

Neefes ganze Verbitterung spricht aus einem Brief vom 23.7.1784 an Gustav Friedrich Wilhelm Großmann, in: LEUX, Neefe (wie Anm. 27), S. $88 f$. 
109 Christian Gottlob Neefe, Brief vom 19.1.1785 an Gustav Friedrich Wilhelm Großmann, zitiert ebol., S. 90.

Vgl. Leux, Neefe (wie Anm. 27), S. 90.

S[USANNE] M[ARIA] NeEFE, Neefe's Lebensgeschichte von seiner hinterlassenen Witwe fortgesetzt, in: Allgemeine musikalische Zeitung 1,1798/99, Sp. 360-364.

Wie Anm. 14

Vgl. zuletzt ALEXANDER WOLFSHOHL, "Lichtstrahlen der Aufklärung". Die Bonner Lese-Gesellschaft - Geistiger Nährboden für Beethoven und seine Zeitgenossen (Begleitpublikationen zu Ausstellungen des Beethoven-Hauses 27), Bonn 2018

IN: Beiträge zur Ausbreitung musikalischer Kenntnisse. Viertes Stück. Bonn den 3ten May 1784, S. 33-37.

115 Vgl. Hans-JoACHIM HInRICHSEN, "Er ist der Vater, wir sind die Bub'n". Carl Philipp Emanuel Bach und Beethovens Bonner Kurfürstensonaten, in: ToBIAS JANZ (Hg.), C. P. E. Bach und Hamburg. Generationenfolgen in der Musik (Studien und Materialien zur Musikwissenschaft 97), Hildesheim u. a. 2017, S. 65-84, hier S. 67: Beethoven sei „spätestens seit 1779 Schüler Christian Gottlob Neefes" gewesen. Vgl. auch JoEL LESTER, What Beethoven might have learned from J. S. Bach, in: Bonner Beethoven-Studien 11, 2014, S. 111-132. Eine ausgewogene Darstellung ohne Neefes fragwürdige Ausnahmestellung gibt HaNS-JOACHIM HINRICHSEN, Ludwig van Beethoven. Musik für eine neue Zeit, Kassel 2019.

GotTfried August Bürger, Der Bauer an seinen durchlauchtigen Tyrannen (1773), in: Christian GotTlob Neefe, 21 Lieder in Vademecum für Liebhaber des Gesangs und des Klaviers, Nr. 16, Leipzig 1780.

Peter AndraschKe, Neefes Volkstümlichkeit, in: Loos, Neefe (wie Anm. 12), S. 129-149.

Noch jüngst greift JOACHIM GERHARDT, Protestantische Spuren im Leben von Ludwig van Beethoven. Evangelisch geprägt und im Glauben gestärkt, in: DERS. und ECKART Wüster (Hgg.), Evangelisch in Bonn. Ein Lese- und Bilderbuch mit einer beigelegten Karte aller evangelischen Kirchen im Großraum Bonn, Rheinbach 2016, S. 181-188, allzu willig die Märvom bestimmenden Einfluss Neefes auf Beethovens gesamtes Leben und Schaffen auf (besonders S. 181ff. und 186: „Die bei Neefe gelegten Grundlagen trugen Früchte.").

119 Helmut LoOs, Probleme der Musikgeschichtsschreibung zwischen Ost- und Westeuropa, in: Klaus Wolfgang Niemöller und Helmut Loos (Hgg.), Die Musik der Deutschen und ihrer Nachbarn im Osten. Ostseeraum - Schlesien - Böhmen/Mähren - Donauraum. [Tagung] vom 23. bis 26. September 1992 in Köln, Bonn 1994, S. 1-17. 
$\mathbf{N}$ ikolaus Simrock (1751-1832), der Gründer des später weltweit agierenden Musikverlags, war eine Person, die Beethoven seit Kindertagen kannte. Zunächst als angesehener Kollege von Beethovens Vater in der Bonner Hofkapelle bekannt, fungierte er ab spätestens 1783 als Kollege des jungen Ludwig selbst, und schließlich, nach Beethovens Umsiedlung 1792 nach Wien, war Simrock einer seiner Verleger. Im kleinen Bonn und in der noch kleineren Hofwelt dort sah man sich oft. Nachdem Beethoven nach Wien gezogen war, sind sie sich nie wieder persönlich begegnet, sie blieben jedoch viele Jahre in brieflichem Kontakt. Es sollte eine wechselvolle Beziehung werden, in der Simrock - trotz teilweiser Unstimmigkeiten bis hin zum Zerwürfnis zwischen den Parteien - lange Zeit als wichtiges emotionales Verbindungsglied für den "Wiener" Beethoven zur "verlorenen" rheinischen Heimat diente.

Simrock wurde 1751 in Mainz in die Familie eines niederen Offiziers in etwas bedrängten Verhältnissen hineingeboren; er ließ sich in jungen Jahren zum Waldhornisten ausbilden und begab sich dann 15-jährig als Militärmusiker

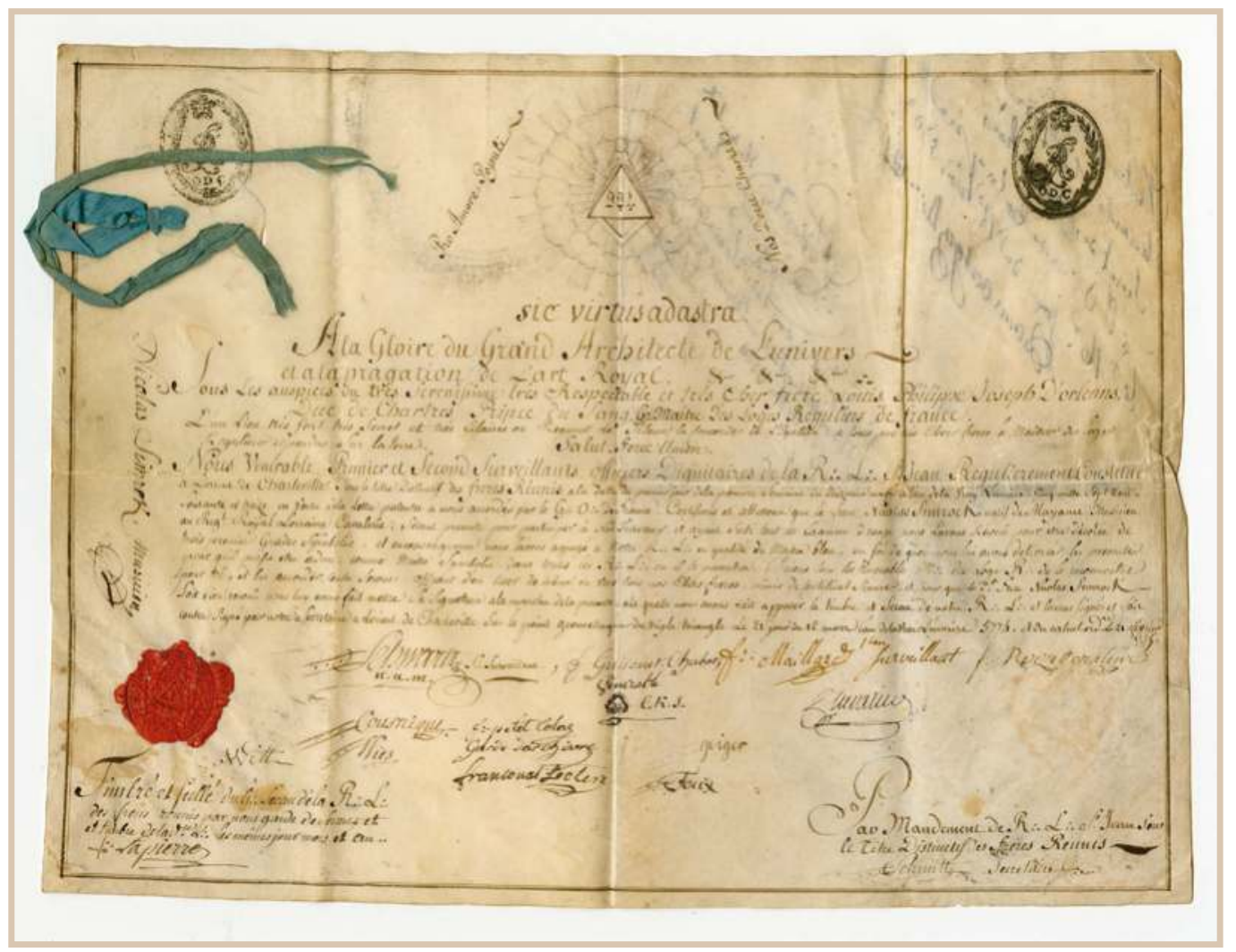

Beethoven und Simrock | 417 (C) 2020 by Böhlau Verlag GmbH \& Cie. KG, Köln https://doi.org/10.7788/9783412519704 | CC BY-NC 4.0
Freimaurerpatent für Nikolaus Simrock, Charleville 21. Februar 1775 (Stadtarchiv Bonn) 
Nikolaus Simrock (17511832). Zeitgenössische Lithografie (Stadtarchiv Bonn)

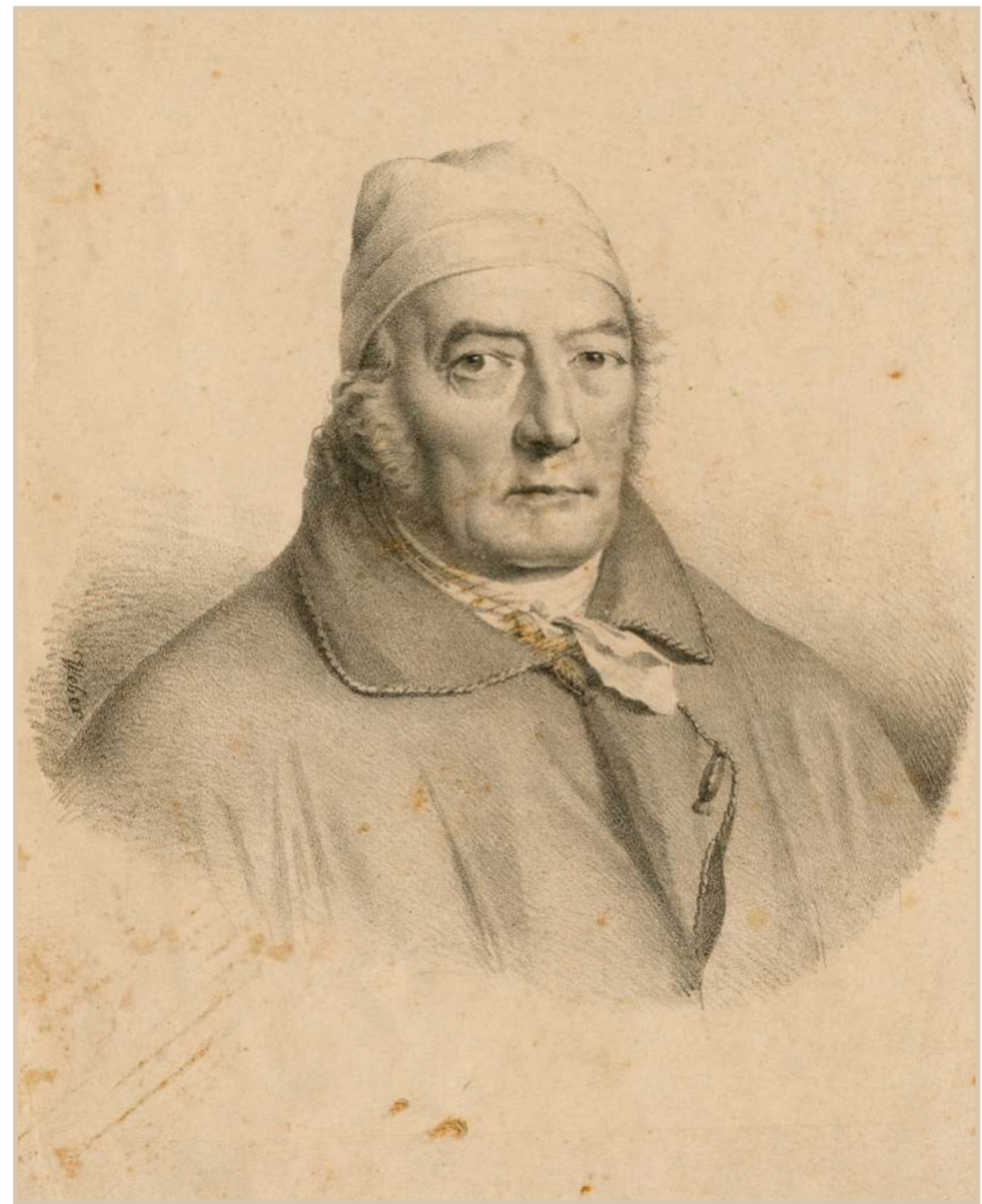

nach Frankreich in die Régiment Royal Lorraine Cavallerie. Vielleicht wurde er dort im vorrevolutionären Frankreich mit aufklärerischem Gedankengut „infiziert", auf jeden Fall ist aus dieser Zeit das erste Dokument zu seiner Beschäftigung mit solchen Ideen erhalten: sein Freimaurer-Patent, das seine Erhebung am 21. Februar 1775 zum Meister in der Loge Les Frères réunis von Charleville beurkundete. ${ }^{1}$ 
Die Ideen der Aufklärung ließen Simrock nie wieder los: er agierte den Rest seines Lebens (mit wenigen erzwungenen Pausen) als führendes Mitglied diverser aufklärerischer Organisationen.

Nach neun Jahren in Frankreich tauschte Simrock dann im März 1775, 23-jährig, die Stelle beim lothringischen Militär für das zunächst etwas ruhigere Leben eines Hofmusikers in der Kapelle des damaligen Kurfürsten von Köln, Maximilian Friedrich von Königsegg-Rothenfels. 1780 heiratete er die Mainzerin Ottilie Blaschek (1756-1829), 13 Kinder wurden nach und nach geboren (in den ersten sechs Jahren eine Geburt pro Jahr). Er war ein geschätztes Mitglied der Hofkapelle, die Arbeit als Hofmusiker war jedoch nicht immer eine Vollzeitbeschäftigung, und wie viele Kollegen konnte Simrock Nebengeschäften nachgehen. Fast alle Musiker haben Unterricht erteilt und mit Noten, Instrumenten oder anderem gehandelt; Beethovens Großvater - auch er Ludwig van Beethoven genannt (1712-1773) -, Bassist in der Bonner Hofkapelle und später Kapellmeister, war mit Weinhandel wohlhabend geworden. Simrock betrieb seine Geschäfte in größerem Stil als die meisten Kollegen: Inserate ab 1785 im Bönnischen Intelligenzblatt zeigen eine breite Warenpalette an: Bücher, Stiche, Tapeten, Papiere aller Art, Schreibwaren, Musikinstrumente, Stoffe, Wein und Modeartikel. Sein Erfolg wuchs; interessanterweise behielt Simrock diese Warenvielfalt bei, auch nachdem sein Musikverlag international agierte.

\section{Der Verlag}

Simrocks Geschäft mit Noten machte zunächst nur eine Sparte unter vielen aus; wann er mit dem Notenhandel anfing, ist nicht ganz klar. Spätestens 1783 wurde Simrock lokaler Kommissionär für einige der frühen Musikverleger wie die Wiener Firma Artaria. Im Jahre 1784 gewährte ihm der neue Kurfürst, Maximilian Franz von Österreich, 40 Taler im Jahr zur Beschaffung von Notenmaterialien, ${ }^{2}$ vermutlich mindestens zum Teil für das neue Ensemble aus Bläserpaaren (oft zwei Hörner, zwei Oboen, zwei Fagotte, und zwei Klarinetten), die Harmonie genannt, ein Ensemble, das im Wien des Kaisers Joseph II., des ältesten Bruders von Max Franz, seit kurzem große Mode war. Simrock spielte Horn in der Bonner Harmonie und war wahrscheinlich ihr Leiter. Vielleicht schon 1779, aber mit Sicherheit seit 1788 lieferte Simrock Notenmaterial an die Opernbühnen der Höfe in seiner Heimatstadt Mainz und in Mannheim. ${ }^{3}$ Diese Opernwerke waren nicht gedruckt, sondern in Simrocks Kopisterei handschriftlich gefertigt. Einen Eindruck vom Umfang des Geschäfts alleine in der Sparte Opern/Operetten gibt ein "Verzeichniss der Operetten, welche, in Partitur oder mit ausgeschriebenen Sing- und Instrumentstimmen, bei Hofmusikus SIMMROCK in BONN zum billigsten Preise zu haben sind", vermutlich aus dem Jahre 1794. Die Liste zeigt 89 Opern bzw. Operetten, zusätzlich sind 18 davon als Klavierauszüge und 28 arrangiert für achtstimmige Harmonie zu 
haben. ${ }^{4}$ Brandenburg bemerkt, dass Simrock die bemerkenswerte Anzahl von mindestens fünf Kopisten beschäftigte, die nicht auch für den Hof tätig waren, ein weiterer Beweis für den Umfang seines Kopistengeschäfts. ${ }^{5}$

Simrocks erster Notenstich folgte 1793, ein Klavierauszug von Mozarts Zauberflöte, dem Kurfürsten Maximilian Franz in einem ausführlichen Text gewidmet. Für die Bearbeitung griff er auf einen Kollegen zurück , Fridrich [sic] Eunike / Churfürstl: Cölnischen Hof- und Opern Saenger"; für andere frühe Arrangements nahm er den Bonner Hoforganisten Christian Gottlob Neefe, einen Lehrer Beethovens. Der Stich dieser ersten Edition war außer Haus gegeben worden, aber ab dem vierten Druckwerk wurden alle Ausgaben bei Simrock gestochen, vermutlich zunächst von ihm selbst. Der dritte Druck überhaupt war schon ein Werk Beethovens, seine 13 Variationen für Klavier WoO 66 über die Ariette Es war einmal ein alter Mann aus der populären komischen Oper Das rothe Käppchen von Karl Ditters von Dittersdorf. Die Ausgabe war erst nach Beethovens Weggang nach Wien erschienen; es gibt keine Dokumentation, dass Simrock eine Rückfrage beim Komponisten gehalten oder ein Honorar dafür gezahlt hätte. Sieghard Brandenburg zweifelt auch daran, dass Simrock mit diesen ersten gedruckten Noten beabsichtigte, einen Verlag zu gründen, aber das Notengeschäft entwickelte sich zunehmend und die Erfolge waren nicht zu übersehen.

\section{Exkurs: Musikverlegen zur Zeit Beethovens}

Zu Beethovens Lebzeiten waren die Gepflogenheiten um das Verlegen musikalischer Werke anders als heute. ${ }^{6}$ Ein musikalisches Werk war eine "Ware" wie jedes andere Objekt - ein Konzept vom "geistigen Eigentum" lag noch in weiter Ferne. Der Komponist trug sein Werk zum Markte, und - wenn er erfolgreich war - hat er es für eine gewisse Summe an einen Verleger verkauft, der damit der "Originalverleger" wurde. Damit endete jede Kontrolle des Komponisten über sein Werk. Der Originalverleger besaß sämtliche Rechte als nun rechtmäBiger Besitzer, so auch das Recht auf beliebige Bearbeitung.

Verleger und Komponisten waren mit einem großen gemeinsamen Problem konfrontiert: Ein wirksames internationales Copyright existierte zu der Zeit noch nicht. Für den Verleger bedeutete diese Situation, dass er vor Nachdruckern ungeschützt war. Der Originalverleger zahlte dem Komponisten ein Honorar, der Nachdrucker nicht; dieser konnte das Werk sofort nachstechen und zu einem geringeren Preis anbieten, dabei ging dem Originalverleger seine Investition verlustig. Abmachungen innerhalb des eigenen Rechtsraumes boten im eigenen Lande einigermaßen Schutz, aber nur dort. Alle Verleger haben Werke, die im Ausland gedruckt wurden, völlig legal nachgedruckt, manche in größerem Maße als andere. Simrock war für die Menge seiner Nachdrucke - und seine Schnelligkeit in der Produktion - bekannt, gefürchtet und teilweise als „Pirat" geächtet. - Es scheint, als ob Simrock sich der Probleme 
des Originalverlegers dadurch weitgehend entziehen wollte, dass er fast immer der Nachdrucker war, und nicht der Originalverleger.

Diese rechtliche Situation machte die Verhandlungen zwischen Komponisten und Verleger delikat. Der Komponist war darauf angewiesen, verlegt zu werden, vor allem einer ohne feste Anstellung wie Beethoven, der von seinen Kompositionen mindestens zum Teil zu leben versuchte. Der Verleger musste einen Preis aushandeln, der für ihn wirtschaftlich vertretbar war, um sich ökonomisch möglichst wenig zu exponieren, ohne einem begehrten Autor das Geschäft zu vergraulen. Die beiden Partner sahen die Gefahr des Nachdruckens unterschiedlich: Obwohl ein Nachdrucker kein Honorar an den Komponisten zahlte, konnte ein schöner Raubdruck doch helfen, das Renommee eines Komponisten zu vergrößern, sein Werk zu verbreiten, und seine Position bei späteren Verhandlungen mit Verlegern zu stärken. Dieser Gedankengang kann uns helfen, Beethovens oft stille Hinnahme der vielen Nachdrucke Simrocks zu erklären.

\section{Simrocks Verlagsprogramm}

Simrock scheint recht schnell auf ein erfolgreiches Modell für sein Verlagsprogramm gekommen zu sein, wie eine Durchsicht seiner frühen Kataloge von Druckwerken zeigt. Gut absetzbare Werke waren sein Ziel, vielfach Hausmusik. Klaviermusik spielte eine entsprechend große Rolle: einfache bis mittelschwere Variationszyklen (etwa zwischen 1793 und ca. 1812 erschienen 16 Variationswerke Beethovens bei Simrock als Einzelausgaben); Bearbeitungen für Klavier zwei- und vierhändig ; "Romancen und Lieder"; auch Werke mit flexibler Besetzung waren begehrt: von Beethoven etwa Sechs leichte Variationen über ein Schweizer Lied für Klavier oder Harfe WoO 64, noch in seiner Bonner Zeit komponiert und von Simrock 1798 gedruckt; auch op. $81 \mathrm{~b}$ (das Sextett für Streicher und zwei Hörner) hat den ehemaligen Waldhornisten gelockt: Dieses Werk aus den frühen Wiener Jahren Beethovens hat Simrock 1810 verlegt und gleich in weiteren Bearbeitungen für Streichquintett und Klaviertrio angeboten. Werke, die sich gut verkauften, wurden in zahlreichen Auflagen und späteren Ausgaben gedruckt. Neben Hausmusik bot Simrock noch viele Harmonie-Arrangements von aktuellen Opern-Hits an. Oft, vor allem bei den Frühwerken, ist unklar, wie Simrock an seine Vorlagen kam, aber seine Drucke waren schön, korrekt und schnell produziert. Auch seine ärgsten Feinde mussten dies zugeben.

\section{Simrock als Originalverleger Beethovens}

Die Liste der Originalausgaben von Werken Beethovens, das heißt derjenigen Werke, wofür Simrock Beethoven ein Honorar bezahlt hat und damit Besitzer aller Rechte wurde, erstaunt. Zunächst wundert überhaupt die kleine Zahl von Originalausgaben, und danach vielleicht noch mehr der allgemeine Mangel an 


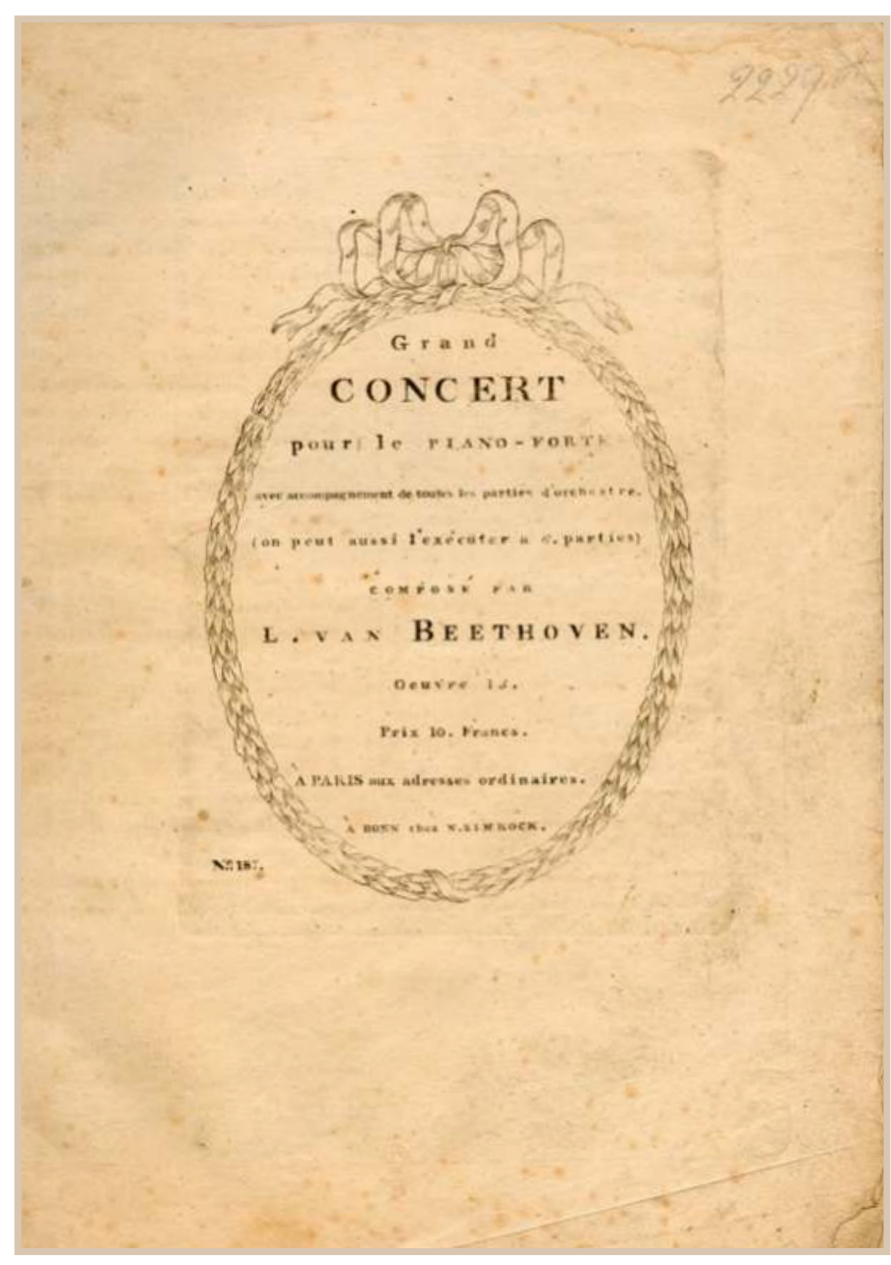

"bedeutenden" Werken. Von den berühmten und besonders gewichtigen Werken sind es nur zwei: die sogenannte Kreutzer-Sonate für Violine und Klavier op. 47 und die beiden Sonaten op. 102 für Violoncello mit Klavier. In beiden Fällen gibt es Anlass zu vermuten, dass Nikolaus Simrock sie wahrscheinlich nie gekauft hätte, wenn er die Stücke vorher gekannt hätte. ${ }^{8}$ Andere Verleger zunehmend ab etwa 1803 - buhlten darum, Beethovens Werke zu drucken; es bedeutete für viele offenbar ein Prestigegewinn, sich als Beethoven-Verleger rühmen zu können. Der Verleger Carl Friedrich Peters etwa wagte sich zögernd mit einem schmeichelnden Brief vom 18. Mai 1822 an Beethoven und schrieb, „... seit meinem Etablissement war es mein Wunsch auch mit Ihnen in Verbindung zu kommen ...".9 Er zählt etliche Gattungen auf, die er gerne von Beethoven verlegen würde und schließt mit der Aussage, "Was Sie mir senden würde mir willkommen sein, denn ich suche Ihre Verbindung nicht aus Eigennütz sondern aus Ehre." Nicht so Simrock. Sein Geschäftsgehabe war nüchtern, völlig unsentimental und vollständig auf seinen anvisierten Markt abgestellt. Er verstand seine Kundschaft als Amateure, die niemals eine Kreutzer-Sonate in Angriff würden nehmen könnten.

Titelblatt des Simrockschen Drucks von Beethovens Klavierkonzert op. 15, 1802 (Stadtarchiv Bonn)
Simrock gilt als Originalverleger von WoO 67, die Variationen zu vier Händen (Waldstein-Variationen); allerdings ist es ungewiss, wie Simrock an das Werk gekommen ist. Diese Ausgabe ist Gegenstand von Beethovens ersten erhaltenen Brief an Simrock, noch in der alten Schreibweise "Simmrock" geschrieben. ${ }^{10}$ Beethoven, der sich in den ersten eineinhalb Jahren in Wien schon als Virtuose durchgesetzt hatte, wollte noch mehr: als Komponist anerkannt werden. Sein erster wichtiger Wiener Mäzen, Prinz Karl Lichnowsky hatte mit Beethoven geplant, das Erscheinen seines gewichtigen Opus 1, die drei Klaviertrios, regelrecht zu inszenieren, ${ }^{11}$ doch jetzt drohte, dass Simrock kurz davor mit Beethovens Waldstein-Variationen das große "Debut" Beethovens vereiteln könnte. Beethoven schreibt Simrock: Sein Bruder Kaspar Karl habe ihm gesagt, dass Simrock die Variationen zu vier Händen WoO 67 schon gestochen habe, oder doch stechen würde, "das anfragen deswegen bey mir, dünkt mich wäre doch wohl der Mühe werth gewesen". Was wäre gewesen, schreibt er, wenn er sie schon Artaria verkauft hätte? Aber

422 | Joanna Cobb Biermann

(c) 2020 by Böhlau Verlag GmbH \& Cie. KG, Köln

https://doi.org/10.7788/9783412519704 | CC BY-NC 4.0 
"das einzige, was ich mir ausbitte ist, daß sie jetzt den Stich damit aufgeben, und mir nur schreiben, ob sie sie schon wircklich angefangen haben, ist das, so schicke ich ihnen von hier durch eine Gelegenheit an meinen Freund den Gr[afen] waldstein das Manuscript davon, wonach sie sie denn stechen können, weil darin verschiedenes verbessert ist, und ich doch wenigstens wünsche meine Sachen in ihrer möglichen Vollkommenheit erscheinen zu sehen ...".

Weiter beschwert sich Beethoven, dass Simrock ihm von einem anderen Variationszyklus (WoO 66, 13 Variationen über Es war einmal ein alter Mann, der im Herbst 1793 bei Simrock erschienen war) nur ein einziges Exemplar geschickt habe, und vermerkt zugleich, dass ", artaria für die anderen [WoO 40, 12 Variationen über Se vuol ballare aus Mozarts Le nozze di Figaro] ein gutes Honorarium und 12 Exemplare gab." Sofort danach schaut Beethoven jedoch in die Zukunft: "schreiben sie mir, ob sie etwas anders von mir wollen, und was?" Abschließend dann: "leben sie wohl und grüßen sie mir den Ries." Beethoven erkundigte sich häufig bei seinen Bonner Korrespondenten nach Franz Anton Ries. ${ }^{12}$

\section{Simrock als Beethoven-Verleger I}

Von Wien aus bot Beethoven Simrock immer wieder Werke an. Der Verleger winkte fast immer ab, druckte aber die fremden Originalausgaben schnell nach. Nach dem Einmarsch der revolutionären Armee Frankreichs 1794 in Bonn und die Eingliederung des linksrheinischen Bonn in das Département du Rhin et Moselle 1797 wurde Simrock französischer Citoyen. Diese Lage lernte er zu seinem Vorteil gegenüber den Wiener und Leipziger Verlegern auszunutzen. Und etwa spätestens ab 1809 bis zum Ende der französischen Zeit 1815 betrieb Simrock auch ein "Commissions-Lager zu Beul", eine Art Vertriebsfirma in Beuel, einer Gemeinde im Rechtsrheinischen, Bonn gegenüber, womit er sich auch ein Standbein in "Deutschland" schuf. ${ }^{13}$

Einmal nutzte Beethoven Simrocks Schnelligkeit als Nachdrucker jedoch zu seinem Vorteil. Der Zürcher Verleger Hans Georg Nägeli hatte sich 1802 an Beethoven gewandt, und bat ihn um Sonaten für sein Klavier-Periodikum Répertoire des Clavecinistes. Beethoven sagte zu und schickte ihm die Sonaten, die wir jetzt als op. 31 kennen. Ferdinand Ries, zur Zeit Schüler bei Beethoven, berichtet über die Ankunft der Belegexemplare der ersten beiden Sonaten von op. 31 im Mai 1803. Beethoven war beim Schreiben:

„'Spielen Sie die Sonaten einmal durch,' sagte er zu mir, wobei er am Schreibpulte sitzen blieb. Es waren ungemein viele Fehler darin, wodurch Beethoven schon sehr ungeduldig wurde. Am Ende des ersten Allegro's, in der Sonate in G dur, hatte aber Nägeli [nach T. 298] sogar vier Takte hinein componirt ... Als ich diese spielte, sprang Beethoven wüthend auf, kam herbei gerannt und stieß mich halb vom Clavier, schreiend: Wo steht das, zum Teufel?' - Sein Erstaunen und seinen Zorn kann man sich kaum denken, als 
er es so gedruckt sah. Ich erhielt den Auftrag, ein Verzeichnis aller Fehler zu machen und die Sonaten auf der Stelle an Simrock in Bonn zu schicken, der sie nachstechen und zusetzen sollte: Edition très correcte". ${ }^{14}$

Ries schrieb ein Fehlerverzeichnis mit mehr als 80 Fehlern in den beiden Sonaten und sandte sie am 29. Juni nach Bonn; Simrocks korrigierte Ausgabe konnte schon Ende August im Reichsanzeiger angezeigt werden.

\section{Exkurs: Simrock als Bonner Aufklärer}

Neben seinen Aufgaben als Musiker, Geschäftsmann und Pater familias fungierte Simrock als einer der ersten Aufklärer in Bonn, neben u.a. Christian Gottlob Neefe und Franz Anton Ries, allesamt Hofmusiker. Dass Simrock schon in jungen Jahren 1775 Freimaurermeister in Frankreich wurde, belegt das erwähnte Patent. Als er nach Bonn zog, gab es keine Maurer-Bruderschaft für ihn dort; eine Loge der strikten Observanz existierte zwar noch, aber nur Adlige waren zugelassen. Sein Interesse an aufklärerischen Ideen und Organisationen erlosch aber keinesfalls. Als sich eine Gruppe der geheimen Organisation der Illuminaten 1781 in Bonn formierte, die sich die Minervalkirche von Stagira nannte, war Simrock bereits 1782 dabei. Diese Organisation ist erst 1776 in Ingolstadt von Adam Weishaupt, einem jungen Professor der Philosophie und des Kirchenrechts, gegründet worden, in der Absicht, seinen Studenten Zugang zu aufklärerischer Literatur und ihrem Gedankengut zu ermöglichen. Die Gruppe erlebte einen starken Zuwachs ab 1780, als Adolph Freiherr von Knigge - ein Mann von niederem Adel und aufgeklärter Verfechter radikaler republikanischer Ideen - in die Organisation einstieg und alles neugestaltete. Über die Ziele des Illuminaten-Ordens herrscht nach wie vor Unstimmigkeit: Alles vom Männerklub mit angehängtem Lesezirkel bis hin zu revolutionärer Zelle, die die bestehende gesellschaftliche und politische Ordnung beenden wollte, wird behauptet. Es scheint, als ob Unklarheit - auch Unwissenheit - über die Endziele auch damals innerhalb der Organisation selbst herrschte, wie Knigge 1781 selbst schrieb. Er nannte jedoch die gemeinsamen Ideen, die sämtliche Mitglieder teilten: „Allgemeine Aufklärung zu befördern; sich unter einander zu schützen, beyzustehn, und im bürgerlichen Leben jedes Mitglied nach Verdienst und Fähigkeit emporzuheben". ${ }^{15}$ Aber Knigge und einige weitere Mitglieder hatten weiterführende und radikalere Ziele: Die Vorstellung war, dass durch rigorose Selbstbildung - intellektuelle sowie moralische - eine Klasse Männer sich herausbilden würde, die in der Lage sein würde, die korrupte europäische Gesellschaft zu transformieren und die Monarchie und eventuell den ganzen Staat überflüssig zu machen. In Bonn stieg Simrock bald in die Führungsriege als "Ceremonien-Meister" oder "Censor" auf, später fungierte er als Schatzmeister oder "Quästor", wie ein Dokument im Bonner Stadtarchiv belegt. ${ }^{16}$ Simrock scheint dem radikaleren Flügel angehört zu haben. ${ }^{17}$ 
Die vermuteten umstürzlerischen Absichten der Illuminaten führten zur Unterdrückung des Ordens durch die Obrigkeit in Bayern. Der regionale Führer des Ordens in Neuwied, Johann Martin Graf zu Stolberg-Roßla, verordnete die Auflösung aller lokalen Gruppen; die Bonner Illuminaten folgten seinem Dekret im Juli 1785. Somit endete ihr Wirken dort. Doch zwei Jahre danach wurde eine neue, offenere Organisation mit aufklärerischen Zielen in Bonn gegründet, die Lesegesellschaft, die sich der Selbstbildung, Selbstverbesserung und dem freundlichen Umgang gleichgesinnter Männer verschrieben hatte. Politische Diskussionen waren allerdings hier expressis verbis verboten. Simrock, sowie sämtliche ehemalige Bonner Illuminaten waren Gründungsmitglieder. Und nachdem Bonn „französisch" geworden war, gab es eine erneute Gründung 1805 einer Freimaurerloge, Les Frères courageux. Simrock war wieder Gründungsmitglied.

Ob Simrock - und Beethovens Lehrer und ältere Kollegen in der Hofkapelle, Neefe und Ries - den jungen Beethoven mit ihren aufklärerischen Vorstellungen beeinflusst haben? Das kann nicht mit Gewissheit gesagt werden, aber Beethoven war Zeit seines Lebens von „aufgeklärten" Männern umgeben. Er arbeitete in der Bonner Hofkapelle neben diesen drei Kollegen, als der Illuminaten-Orden aktiv war und als seine Auflösung 1785 angeordnet wurde. Wegen seines Alters durfte Beethoven der Lesegesellschaft nicht beitreten, aber er verkehrte im Bonner Zehrgarten mit vielen Männern, die LeseMitglieder und sonst in aufgeklärten Gesellschaften involviert waren. Ein Brief Beethovens an Simrock vom 2. August 1794 zeigt deutlich, dass Beethoven sich über Simrocks politische Ansichten im Klaren war; dessen Einstellung lehnte er hier nicht $a b .{ }^{18}$

Der Brief ist ein faszinierendes Zeugnis - man meint, er sei fast im Bewusstseinsstrom hingeschrieben - und besteht aus launigen ironischen Bemerkungen, normaler geschäftlicher Korrespondenz, privatem Austausch und ernstem Bericht über die aktuelle politische Situation. Er verdient hier eine ausführlichere Behandlung: Der Ton ist vertraut. Zunächst entschuldigt sich Beethoven dafür, dass er die Korrekturfahnen für Simrocks Stich von den WaldsteinVariationen so lange zurückgehalten habe - es handelte sich um diejenigen Variationen, die Beethoven zu der Zeit überhaupt nicht gedruckt haben wollte, wie wir in dem oben zitierten Brief sahen ${ }^{19}$ - und schreibt süffisant, dass Simrock jetzt sicher die Fehler selbst finden würde! ${ }^{20}$ Weiter gratuliert Beethoven Simrock ob seines schönen Stichs, aber mit einem kleinen Seitenhieb: „übrigens muß ich ihnen Glück wünschen in Ansehung ihres Stichs, der schön, Deutlich, und LesBar ist, wahrhaftig, wenn sie so fortfahren, so werden sie noch das Oberhaupt im stechen werden, versteht sich im Notenstechen." Es folgt dann ein Hinweis auf die sozial-politische Situation, wieder leicht ironisch ausgedrückt: „ich versprach ihnen im vorigen Brief ${ }^{21}$ etwas von mir zu schicken, und sie legten das als Cavalier Sprache aus, woher hab ich den[n] diese predi- 


\section{IIphabetifdes}

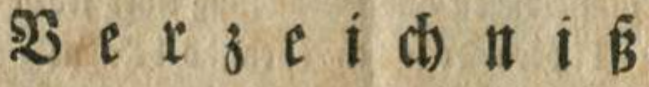

Der in Der Rurfurftlidien Sefidenjftadt Sonn wofnenden. Sreiheitbidh warmer Baterlano $8=2$ etráther, uno Stif:

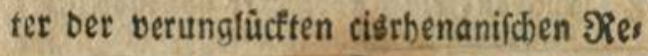
publit, Die feit bem Einmarfob ber frán, fifchen Stupden Die friediche - ifrem gurfien und Waterlano getreu gebliebene Difberoobner ourd) alletlei Rift, Beftug uno glánjende Derfvectungen su ber füfren, und auf ibren (d)ảndicben Эfab zu lenten fich bemuibten, uno da ibre ver= abrdjeutungstwuttoigen sunftgriffe an oek unmandelbaren Treue und felfenfeften Stanbhaftigfeit Der biederen $\mathfrak{\text { Jurget }}$

kat verdient? - Pfui, wer würde in unsern demokratischen Zeiten noch so eine Sprache annehmen ..." Weiter erwähnt Beethoven die aktuelle politische Situation in Wien. Einen Monat früher, im Juli 1794 planten angeblich revolutionäre Wiener Jakobiner um Franz Hebenstreit eine Revolution, in welcher der Kaiser getötet und zahlreiche Aristokraten verhaftet werden sollten, wie Spitzel behaupteten. Erst eine Woche vor Beethovens Brief an Simrock wurden in der Nacht vom 23. zum 24. Juli 1794 Hebenstreit und andere Aufständische verhaftet. ${ }^{22}$ Beethoven schreibt, "hier hat man verschiedene Leute von Bedeutung eingezogen, man sagt, es hätte eine Revolution ausbrechen sollen". Anschließend gibt Beethoven seiner berühmten Einschätzung des Wiener revolutionären Geistes lakonisch Ausdruck: "aber ich glaube, so lange der österreicher noch Braun's Bier und würstel hat, revoltirt er nicht." Zur aktuellen Lage schreibt er weiter, "Es heißt, die Thöre zu den vorstädten sollen nachts um 10 uhr gesperrt werden. Die Soldaten haben scharf geladen. man darf nicht zu laut sprechen hier, sonst giebt die Polizei einem quartier."

Wieder von dem Ernst der Lage abweichend schreibt Beethoven launig, "sind ihre Töchter schon groß, erziehen sie mir eine zur Braut ..." - zu diesem Zeitpunkt war Simrock Vater von sechs Töchtern. Plötzlich wieder ernster werdend, schreibt Beethoven

Schmähschrift von 1799; zu den angeblichen Vaterlandsverrätern gehörte auch Nikolaus Simrock (Stadtarchiv Bonn) bezüglich der Bonner politischen Lage: „sie müssen doch auch jetzt in Angst leben." Anschließend erkundigt er sich wieder nach Franz Anton Ries und fragt schließlich: "haben sie schon meine Partie aufgeführt[?]", vermutlich das Oktett op. 103, ein Werk für Harmoniemusik, das wohl handschriftlich in Bonn verfügbar war. Es gehörte zu den Werken („eine achtstimmige Parthie"), die Haydn dem Kurfürsten Max Franz Ende November 1793 sandte, um Beethovens Fortschritte unter seiner Leitung in Wien zu belegen..$^{23}$

Es war nicht allein Beethoven, der von Simrocks freiheitlichen republikanischen Ansichten wusste, sondern sie waren in Bonn wohl allgemein bekannt. 1799 wurde ein bemerkenswertes Dokument in Bonn gedruckt, eine Schmähschrift mit dem langen Titel "Freiheitsschwärmer, Vaterlands-Verräther, und Stifter der verunglückten cisrhenanischen Republik, die seit dem Einmarsch der fränkischen Truppen die friedlich - ihrem Fürsten und Vaterlandsgetreu gebliebene Mitbewohner durch allerlei List, Betrug und glänzende Ver-

426 | Joanna Cobb Biermann

(c) 2020 by Böhlau Verlag GmbH \& Cie. KG, Köln

https://doi.org/10.7788/9783412519704 | CC BY-NC 4.0 
sprechungen zu verführen ... sich bemühten. ${ }^{24}$ Darin waren sowohl Simrock als auch Franz Anton Ries aufgeführt. Die Schrift ist zu einem späteren Zeitpunkt "überarbeitet" worden, indem ein Unbekannter einige Namen mit schwarzer Tinte (fast) unkenntlich gemacht hat, und sie als diejenigen bezeichnete, "die klüger geworden sind". Weder Simrock noch Ries gehörten zu diesen "Umgefallenen", aber sie sind auch nicht in einem anderen Dokument unter den Radikalen genannt, die am 22. September 1797 eine Republik nach dem revolutionären französischen Modell in dem linksrheinischen Gebiete ausgerufen hatten. ${ }^{25}$

\section{Simrock als Beethoven-Verleger II}

Verhandlungen zwischen Beethoven und Simrock verliefen sich über die Jahre. Simrock kaufte selten Werke Beethovens, wie schon erwähnt, druckte jedoch großzügig nach und richtete viele Bearbeitungen ein, ohne um Erlaubnis zu bitten. Interessant mit Bezug auf Simrocks aufklärerische Tätigkeiten sind seine zwei Arrangements von Liedern Beethovens für Zwecke freimaurischer Zeremonien. Simrock schuf sie für die in Bonn 1805 neugegründete Loge (aber durch ihre Drucklegung machte er sie für andere Logen zugänglich). Es handelt sich um Beethovens Der freie Mann WoO 117, ein Lied für einstimmigen Chor, eine (Solo-) Stimme und Klavier, sowie um das Opferlied WoO 126 für Singstimme und Klavier.

Eine erste Version des Liedes Der freie Mann entstand 1792 noch in Bonn, die zweite verfasste Beethoven Ende 1794 oder Anfang 1795 in Wien. Es war diese zweite Fassung, die Simrock 1805 mit dem Titel Maurerfragen und mit einem neuen Text von Beethovens Jugendfreund (und Simrocks Logenbruder) Franz Gerhard Wegeler versah. Die Bearbeitung war für die Befragung eines neuen Mitglieds bei der Aufnahmezeremonie geeignet: „[Chor:] Was ist des Maurer Ziel? [eine Stimme:] Stets edler sich zu heben, / Das höchste zu erstreben / Frei von des Zufalls Spiel, / Das ist des Maurers Ziel [...]."26 Diese Simrocksche Fassung war der neuen Freimaurerloge in Bonn, den Frères courageux à l'Orient de Bonn, gewidmet (als: „Ein Lied für die Loge / d. F. c. à. I'O:. d. BONN.").

Beethovens Opferlied mit Text von Friedrich von Matthisson (1761-1831) entstand Ende 1794/Anfang 1795, blieb aber zunächst bis zur Überarbeitung 1798 in unvollendeter Form. Von Simrocks Version, wieder mit Text von Beethovens Freund Wegeler, wusste Beethoven offenbar nichts, wie aus einem Brief von Beethoven an Wegeler vom 2. Mai 1810 hervorgeht: "man sagt mir, daß Du in euren Freymaurerlogen ein lied von mir singst, vermuthlich in $E$ dur, und was ich selbst nicht habe." ${ }^{27}$ Beethoven hatte gut geraten: Das Lied steht tatsächlich in E-dur; Wegelers zweistrophiger Neutext ist überschrieben "Bei der Aufnahme eines Maurers" und der Text fängt mit den Worten an: "Das Werk beginnet! Heil'ge Glut / Erhebe froh des Neulings Muth / ..."28 


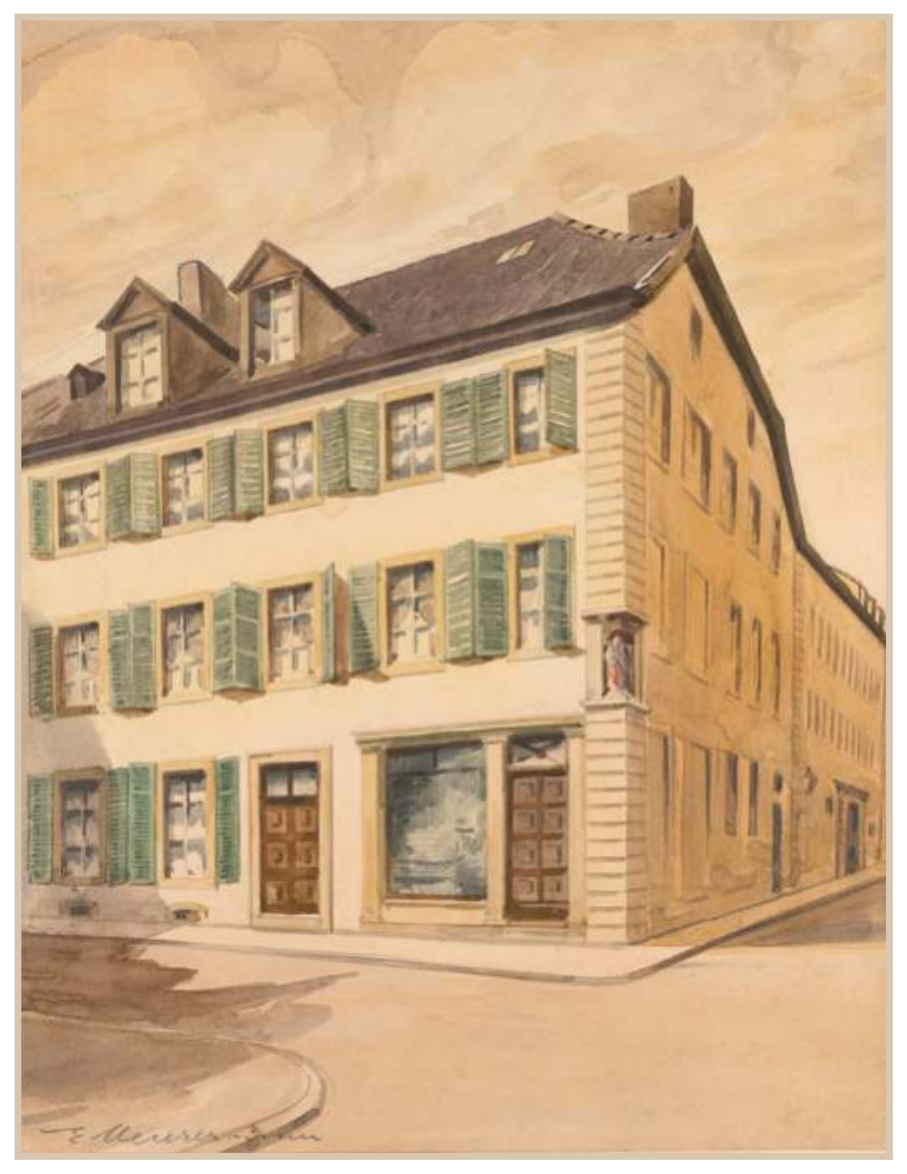

\section{Das Debakel:}

\section{Die Verhandlungen um die Missa solemnis}

Die jahrelangen Verhandlungen um Beethovens Missa solemnis markierten schließlich den Tiefund Endpunkt der langen Beziehung zwischen Beethoven und Simrock. Die Messe, Beethovens letztes und größtes Werk geistlicher Musik, war für die Inthronisation am 9. März 1820 seines Schülers und treuesten Mäzens seit etwa 1812, Erzherzog Rudolph, als Erzbischof von Olmütz in Mähren bestimmt. Doch der Termin und dann noch weitere zwei Jahre verstrichen, so dass Beethoven dem Erzherzog eine Abschrift der Messe erst am 19. März 1823 überreichen konnte.

Der Weg zur Publikation war ähnlich steinig und langwierig. Der umfangreiche Briefwechsel zwischen Beethoven und Simrock, obzwar unvollständig, erlaubt einen Einblick in den Prozess und auch in die Persönlichkeiten; beide Männer zeigten sich dabei in keinem vorteilhaften Licht.

Am 10. Februar 1820 bot Beethoven den Simrocks (Sohn Peter Joseph und Vater Nikolaus) anscheinend als erste Verleger die Messe $a^{29}$, aber doch lange bevor das Werk annähernd fertig war - erst Kyrie und Gloria waren vollendet zum

Das vormalige Verlagshaus Simrock, Bonngasse 35 (Ecke Maargasse). Aquarell von Ernst Meurer, um 1930 (Stadtarchiv Bonn)
Zeitpunkt seines Briefes (es war kein einmaliges Verfahren bei Beethoven, unfertige Werke als vollendet darzustellen). Das vorgesehene Aufführungsdatum stand bevor und Beethoven wünschte sich sicherlich, dass die Komposition weiter fortgeschritten wäre, als sie in Wirklichkeit war. Auch fühlte er sich zu der Zeit unter finanziellen Zwängen: Er hatte Schulden und brauchte Geld; er wollte die acht Bankaktien, die er als Erbe für seinen Neffen Karl vorgesehen hatte, nicht antasten.

Beethoven verlangte 125 Louisdors für die Messe. - Wichtig für das Verständnis des Verlaufs der weiteren Verhandlungen ist die Tatsache, dass Beethoven sofort und dann wiederholt seinen Hoffnungen Ausdruck gab, dass Simrock auf den Plan einer Gesamtausgabe seiner Werke eingehen würde. ${ }^{30}$ Anscheinend machte Vater Nikolaus Simrock in einem verlorengegangenen Brief ein Gegenangebot von 100 Louisdors, also 20 Prozent weniger an Wert als die Summe, die Beethoven gefordert hatte. Am 18. März willigte Beethoven trotzdem ein: "Was die Meße betrifft, so habe [ich] es Reiflich überlegt, u. könnte ihnen selbe wohl für das mir von ihnen angebotene Honor. von 100 louisdor geben ...." ${ }^{31}$ 
Ende April meinte Beethoven Simrock gegenüber, dass die Messe im Mai oder Juni abgeliefert werden könnte und bat ihn, das Honorar seinem Gewährsmann und Freund in Frankfurt/Main, Franz Brentano, zu schicken, der auch die Partitur entgegennehmen würde. Im Juli des Jahres fing eine neue Auseinandersetzung um das Honorar an und zwar um die verabredete Münze für die Bezahlung. In dem erhaltenen Briefwechsel war die Rede bislang nur von Louisdors, ohne eine nähere Bezeichnung, ${ }^{32}$ aber zu der Zeit waren viererlei unterschiedliche Louisdors im Umlauf. In einem Schreiben vom 23. Juli33 reagierte Beethoven auf Simrocks Behauptung in dessen Brief vom 10. Juli, ${ }^{34}$ dass er die sogenannten "leichten" Louisdors gemeint habe; Beethoven erwiderte, dass er die "schweren" Schild-Louisdors bei der Berechnung zu Grunde gelegt habe (Simrocks leichte Louisdors wären 31 Prozent weniger wert als Beethovens Schild-Louisdors). Beethoven meinte weiter, "ich habe Ihnen bey diesem Preis sehr viel nachgelassen was ich nicht leicht bey einem andern Verleger thun würde \& wobei ich wirklich unsrer alten freundschaftl. Verhältniße eingedenk war".

Was war hier geschehen? War es einfach eine unklare Absprache? Oder wollte Simrock den Preis noch weiter drücken? Versuchte Beethoven, etwas von seinem nachgelassenen Preis durch eine höherwertige Münze auszugleichen? Wollte er sicherheitshalber Kursschwankungen und Inflation gegensteuern? Es ist aus der Quellenlage nicht zu entscheiden. Beethoven war in jedem Falle in solchen Berechnungen unbeholfen und musste oft Kundigere zu Rate ziehen. In diesem Fall war es sein Freund Franz Oliva, der in einem Konversationsheft schrieb, "der alte gut Freund wollte Sie bey der vorgeschlagenen Berechnung um einige Hundert Gulden prellen." ${ }^{\prime 35}$ Oliva verfasste einen Brief an Simrock, der eine detaillierte Erklärung seiner Berechnung des Honorars mit genauer Festlegung des Wertes der zugrunde gelegten Münzen enthielt, den Beethoven - der keinesfalls in der Lage gewesen wäre, eine solche komplizierte Rechnung aufzustellen - einfach unterschrieb. ${ }^{36}$ Simrock, der unsentimentale, konsequente Geschäftsmann, blieb hart. Beethoven war irgendwie nicht in der Lage, das Geschäft einfach abzubrechen. Seine weiteren Briefe zeugen von einer emotionalen Abwärtsspirale; Beethoven machte teils verzweifelte Versuche, an Simrocks Gefühle zu appellieren: Beethoven erinnerte den Verleger wiederholt an Gefälligkeiten, die er ihm über die Jahre erwiesen hatte, und an die gemeinsame rheinische Heimat, und führte sogar seine toten Eltern auf: „ich hege die Hoffnung Vielleicht künftiges Jahr [1821] meinen vaterländischen Boden betreten zu können, u. die Gräber meiner Eltern zu besuchen". ${ }^{37}$ Verzweifelt klingt der Anfang dieses Briefs, in dem er "Mein lieber Alt Papa" schreibt, eine Anrede, die sein ehemaliger Schüler Ferdinand Ries teilweise in Briefen an Simrock benutzte, bei Ries Ausdruck einer wirklich engen, lebenslangen familiären Beziehung. Bei allem Renommee war Beethoven Simrock im Verhandeln nicht gewachsen; Simrock ließ sich nicht 
erweichen, Beethoven willigte schließlich ein und Simrock schickte das Geld für die noch lange nicht fertige Missa solemnis nach Frankfurt.

Beethovens stetes Unbehagen über das ganze "Schachern", wie er es nannte, kam zum Ausdruck in einem berühmten Brief an Simrock, den Beethoven am 28. November 1820 schrieb, nachdem Simrock ihn - abermals? - übervorteilt hatte. Während der Verhandlungen führte der Verleger als Argument für die Höhe seines Honorarangebots seine Bedenken an wegen der Absetzbarkeit einer Messe im protestantischen Norddeutschland. Beethoven konterte, dass seine Messe in C-dur op. 86, die 1812 bei den Leipziger Verlegern Breitkopf \& Härtel mit einer zusätzlichen angepassten deutschen Textübersetzung erschienen war, sich gut verkaufe und bot Simrock eine solche für die Missa solemnis an. Der Verleger sagte sofort zu, ohne über die Bezahlung ein Wort zu verlieren. Beethoven schien gar nicht in der Lage zu sein, ihm die zusätzlichen Kosten einfach in Rechnung zu stellen. Wieder erwähnt er seine Hoffnung auf eine Gesamtausgabe ${ }^{38}$ :

"Die übersetzung kostet mich wenigstens $50 \mathrm{fl}$. W[iener] W[ährung], ich hoffe wenigstens, daß sie diese noch zu legen werden - $u$. So requiescant in pace - ich schreibe lieber 10000 Noten als einen Buchstaben, besonders wenn es sich um das so $u$. nicht so nehmen handelt, ich hoffe dafür umso mehr von ihnen begünstigt zu werden, in der Herausgabe meiner Sämtlich. Werke..."

Er verstehe nichts von kaufmännischen Dingen, wisse aber, dass er mindestens 100 Florin bei Simrocks Kalkulation verliere.

Simrock ließ sich durch solche Appelle nicht erweichen, Beethoven fühlte sich in der Situation machtlos, wie er seinem Freund und in dieser Verhandlung Mittelsmann Franz Brentano in Frankfurt am gleichen Tag schrieb: „meine Lage ist dermalen Hart u. bedrängt, dies darf man nun einen Verleger am wenigstens schreiben."39 Doch gerade jetzt, nachdem er Simrock die Missa erneut fest zugesprochen hatte, fing Beethoven an, im Geheimen mit anderen Verlegern darüber zu verhandeln! Es waren letztendlich insgesamt acht: Adolph Martin Schlesinger in Berlin (1821), Steiner und Artaria in Wien und Peters in Leipzig (1822), Anton Diabelli in Wien, Maurice Schlesinger in Paris sowie Probst in Leipzig und Schott in Mainz (1824). Dreien davon hat er die Messe sogar fest zugesagt! Hiermit hat er sich viel Ärger eingehandelt, Feinde gemacht, und einen Ruf in der Nachwelt als gerissener und unehrlicher Verhandlungspartner eingehandelt. Auch gegenüber seinem Freund Brentano war Beethoven unehrlich: 1821 überzeugte er Brentano, ihm die volle Summe, die Simrock bei ihm hinterlegt hatte, aus der eigenen Tasche zu leihen. Am 13. September 1822 machte Beethoven einen letzten Versuch, ein höheres Honorar von Simrock zu bekommen. Er berichtete, dass er von anderen für die Messe mehr angeboten bekommen hatte: ${ }^{40}$ 
„Das Geringste, was mir bisher von wenigstens vier Verlegern für die Messe angetragen worden, ist $1000 \mathrm{fl}$. in C[onventions] M[ünze]. im zwanziger Fuß, o/ den Gulden zu 3 Zwanziger Österreichischer C.M. gerechnet. ${ }^{41}$ So leid es mir thut, wenn wir uns gerade bey diesem Werke deßwegen trennen müßen, so weiß ich doch, daß Ihre Biederherzigkeit nicht zugeben würde, daß ich bey diesem Werke, welches vielleicht das größte ist, was ich geschrieben, einen Verlust erleide. ... Ich hoffe, mein lieber Simrock, den ich ohnehin für den reichsten von allen diesen Verlegern halte, wird seinen alten Freund nicht um ein paar hundert Gulden willen weiter ziehen lassen".

Doch Simrock tat es. Erbost brach er den Kontakt zu Beethoven ab. ${ }^{42}$ Die viereinhalb verbliebenen Jahre bis zu Beethovens Tod waren anscheinend nicht genug, um Simrocks Groll zu legen: Am 28. März, zwei Tage nach Beethovens Tod, schrieb die gemeinsame Freundin Nannette Streicher von der Wiener Klavierbauer-Firma die traurige Nachricht an Simrock. ${ }^{43}$ Doch anscheinend behielt er sie für sich; erst zwei Monate später erfuhr die Bonner Bevölkerung vom Ableben des berühmtesten Sohnes der Stadt. ${ }^{44}$ Beethovens unlautere Handlungen um die Herausgabe der Missa solemnis - die Geheimnistuerei, die Unehrlichkeiten - zeigen ihn in keinem vorteilhaften Licht. Tendenzen, die schon länger vorhanden waren, sind hier ins Extreme getrieben. Der alternde Komponist, schon immer ein hochkomplizierter Mensch, zeigte sich mit zunehmendem Alter und fortschreitender Taubheit immer ängstlicher, misstrauischer (und unaufrichtiger) seiner Umwelt gegenüber. Was die Verhandlungen um die Messe angeht, wird immer wieder behauptet, dass Beethoven die vielen Verleger gegeneinander ausspielte, um einen Höchstpreis zu erzielen. Dies entspricht der Wahrheit nicht genau: Das Honorar, das Beethoven für seine große Messe verlangte, blieb erstaunlich konstant, bei etwa 1000 Florin Konventions-Münze. Allerdings war es ihm doch bei den Verhandlungen mit dem endgültigen Originalverleger Schott in Mainz gelungen, mehrere Werke zu vorteilhaften Bedingungen gleichzeitig abzusetzen. ${ }^{45}$

Beethoven starb kurz vor dem Erscheinen der Missa solemnis. Simrock, 19 Jahre älter, sollte ihn noch fünf Jahre überleben. Simrocks eisernes Geschäftsgebaren war von großem Erfolg gekrönt. Er starb am 12. Juni 1832 in Bonn, 82-jährig, inmitten seiner großen Familie, als reicher und einflussreicher Mann.

Überliefert in: Stadtarchiv Bonn (StAB), SN 156/183 (Nachlass Karl Simrock)

Vgl. Sieghard Brandenburg, Die Gründungsjahre des Verlags N. Simrock in Bonn, in: Bonner Geschichtsblätter 29, 1977, S. 28-36, hier S. 28, der dies als Privileg bewertete. HUBERT UNVERRICHT, Beziehungen zwischen der Bonner und der Mainzer Hofkapelle zu Amtszeit Righinis, in Bonner Geschichtsblätter 29, 1977, S. 20-27, hier S. 23-25. 
Eingebunden in Simrocks Zauberflöten-Klavierauszug, in: Beethoven-Haus Bonn, D-BNba Geyr 7

Vgl. hierzu und zum Folgenden BrandenBurG, Gründungsjahre (wie Anm. 2), S. 30

Für weitere Details siehe JoAnNA COBB BIERMANN, Beethoven und seine Verleger, in: SiegBeRT RAmpe (Hg.), Beethovens Welt (Das Beethoven-Handbuch 5), Laaber 2019, S. 306-323.

Andere Variationswerke hat Simrock auch später gedruckt, etwa Beethovens op. 107, Variationen über (10) Volkslieder für Klavier und Flöte oder Violine ad libitum, komponiert 1818/19, und in Englischer Originalausgabe 1819, dann bei Simrock in seiner deutschen Originalausgabe im August/September 1820 erschienen. Alle Angaben über Erscheinungsdaten in diesem Aufsatz stammen aus dem neuen Werkverzeichnis: Kurt Dorfmüller, NORBert Gertsch und Julia Ronge (Bearbb.), Ludwig van Beethoven. Thematisch-bibliographisches Werkverzeichnis, 2 Bde, München 2014

Simrocks Sohn Peter Joseph hat op. 102 zusammen mit zwei Liedern WoO 140 und WoO 145 anlässlich eines Besuchs bei Beethoven in Wien im September 1816 gekauft. Die Kreutzer-Sonate op. 47 hat Simrock ungesehen gekauft und die Herausgabe so sehr hinausgezögert, dass Beethoven ihm den berühmten Brief vom 4.10.1804 schrieb und etwas ausfällig fragte, "wo stekt dieser langsame Teufel - der die Sonate heraus treiben soll - sie sind sonst der geschwinde Teufel, sind dafür bekannt, daß sie, wie Faust ehmals mit dem schwarzen im Bunde Stehen, und sind dafür eben so geliebt von ihren Kameraden ...", letzteres ein Hinweis auf Simrocks Ruf unter Verlegern als "Pirat". Sieghard Brandenburg (Hg.), Ludwig van Beethoven. Briefwechsel Gesamtausgabe, 7 Bde, München 1996-1998, hier Bd. 1, Nr. 193.

BRANDENBURG, Beethoven Briefwechsel (wie Anm. 8), hier Bd. 4, Nr. 1465.

10 Ebd., Bd. 1, Brief 15, Wien, 18.6.1794

11 Vgl. Dorfmüller/Gertsch/Ronge, Werkverzeichnis (wie Anm. 7), Bd. 1, S. 3. Der Vertrag zwischen Beethoven und Artaria befindet sich jetzt im Beethoven-Haus Bonn, D-BNba Geyr 7., D-BNba, Slg. H. C. Bodmer, HCB Br 280, ein Faksimile davon ist Online im Digitalen Beethoven-Haus zu sehen

12 Franz Anton Ries (1755-1846), Konzertmeister der Hofkapelle, Geigenlehrer Beethovens, den Ludwig van Beethoven in dankbarer Erinnerung hielt, weil er der Familie nach dem Tode der Mutter 1778 und folgenden Dienstunfähigkeit des Vaters beistand. Vater von Ferdinand Ries (1784-1838), Klavier- und Kompositionsschüler von Beethoven in Wien. Vgl. hierzu den Beitrag von BARBARA Mülhens-Molderings in diesem Band.

Siehe DorfmüLler/Gertsch/ROnge, Werkverzeichnis (wie Anm. 7), Bd. 2, S. 777.

Franz Gerhard Wegeler und Ferdinand Ries, Biographische Notizen über Ludwig van Beethoven, Bonn 1838, S. 88 f.

15 Adolph FreIHERR vON KNIGgE, Philo's endliche Erklärung und Antwort, auf verschieden Anforderungen und Fragen, die an ihn ergangen, seine Verbindung mit dem Orden der Illuminaten betreffend, Hannover 1788, zitiert nach W. DANIEL WILSON, Geheimräte gegen Geheimbünde. Ein unbekanntes Kapitel der klassisch-romantischen Geschichte Weimars, Stuttgart 1991, S. 26.

16 StAB, SN 1/334 (Sammlung Bonn)

17 Vgl. JoAnna Cobb Biermann, Nikolaus Simrock: Verleger, in: INGRID BOdSCH (Hg.), Das Haus Simrock. Beiträge zur Geschichte einer kulturtragenden Familie des Rheinlands, Bonn 2003, S. 43-45. 


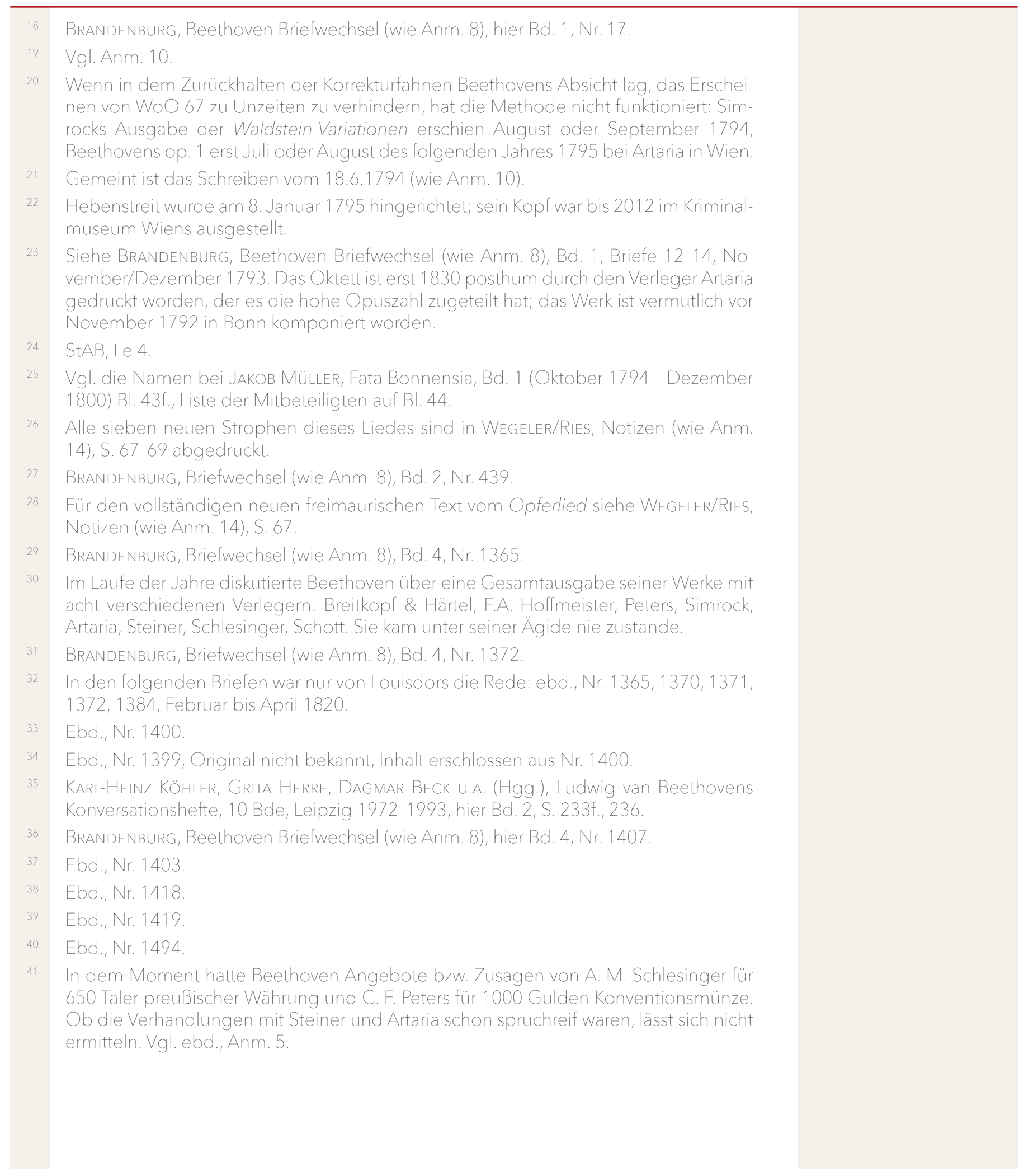




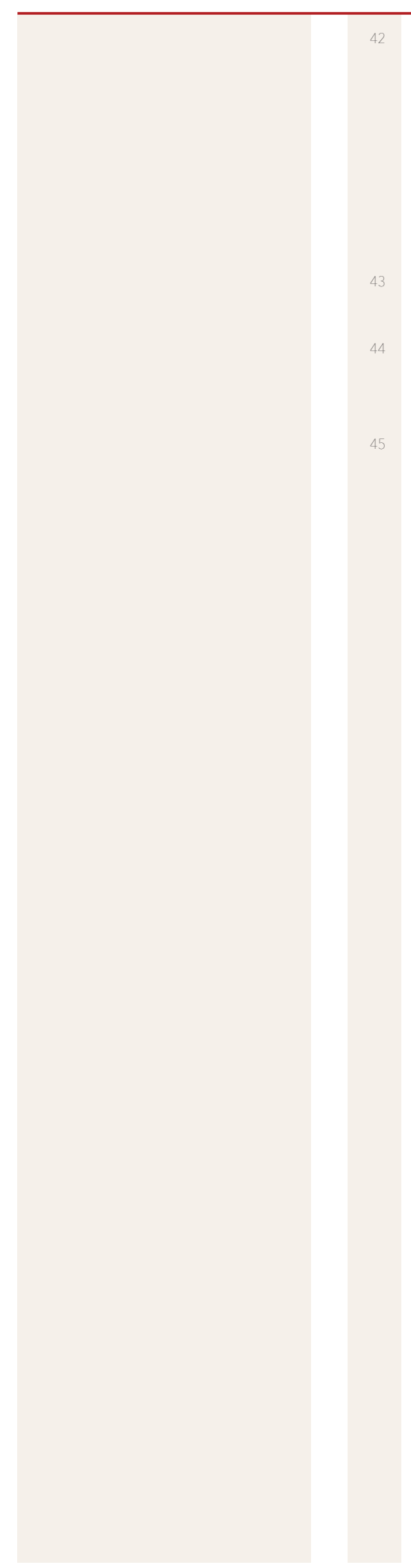

Als Brentano von Beethovens Vertragsbruch erfuhr, verlangte er, dass Beethoven seine Pflichten Simrock gegenüber erfüllen, oder ihm (Brentano) die volle Summe wieder zurückzahlen sollte. Beethoven zahlte sie ihm anscheinend in zwei Raten zurück, die erste im März 1823 (vgl. Brandendurg, Beethoven Briefwechsel [wie Anm. 8], hier Bd. 5, Nr. 1608, Wien 10.3.1823). Am 1. August 1824 wies Beethoven von Baden aus seinen Rechtsanwalt an, die restliche Schuld aus der im September anvisierten Zahlung von Schott für die Missa solemnis und andere Werke abzugleichen (vgl. ebd., Nr. 1855)

Vgl. TheOdor Anton Henseler, Das musikalische Bonn im 19. Jahrhundert (Bonner Geschichtsblätter 13), Bonn 1959, S. 95.

Sie wurde in der Zeitschrift Caecilia 6, Intelligenzblatt 24, S. 27-29 publiziert. Diese Zeitschrift wurde vom Schott-Verlag in Mainz (der Verlag wurde damals B. Schotts Söhne genannt) von 1824 bis 1839 herausgegeben.

Vgl. Biermann, Beethoven und seine Verleger (wie Anm. 6), S. 320. 


\section{Beethovens erste Reise nach Wien $1786 / 87^{1}$}

Dieter Haberl

S chon weit vor der Einführung eines offiziellen Reiseverkehrs per Postkutsche zogen Musiker, Sänger, Spielleute und Schauspieler zu Fuß, zu Pferde oder mit Zugtier und Wagen von Ort zu Ort. Der Drang, stets Neues, noch nicht Gehörtes, auch Bekanntes abgewandelt oder schon Gekanntes in anderer Form und Darbietung zu erleben, ist wohl eine Grundbefindlichkeit des menschlichen Musik-Erlebens. Das Reisen wurde dadurch früh zu einem festen Bestandteil des Musikerlebens.

Bereits das Zeitalter der Renaissance kannte ein ausgesprochen internationales Musikleben in Europa. Im 18. Jahrhundert reisten die hervorragendsten Musiker - und auch die, die noch berühmt werden wollten - zu den wichtigsten Zentren der Musik (wie z. B. Wien, Rom, Venedig oder Paris). Von Wolfgang Amadé Mozart (1756-1791) wissen wir recht genau, wie viel Zeit seines Lebens er in der Postkutsche zubrachte und welch beachtliche Strecken er von Kindesbeinen an in Mitteleuropa zurücklegte. Wer als Musiker erfolgreich und berühmt werden wollte, der musste sich an vielen Orten hören lassen, der sollte früh Kontakte zu adligen Protektoren und Mäzenen pflegen, der durfte Briefe schreiben und bemüht sein, Unterricht von den angesehensten Lehrern zu erhalten - denken wir an Mozarts Aufenthalt bei Padre Martini in Bologna. ${ }^{2}$ Eine exponierte und entsprechend dotierte Anstellung - als Kapellmeister, Hofkomponist oder Konzertmeister - konnte nur erlangen, wer diese Voraussetzungen möglichst vollständig erfüllte. Über die Qualifikation eines Musikers oder Sängers entschieden bei weitem nicht nur seine instrumentalen oder stimmlichen Fähigkeiten, die ja ohnehin Grundvoraussetzung für die Wahl des Musikerberufs waren, sondern auch die Fähigkeit der Integration in das im 18. Jahrhundert noch größtenteils vom Adel geprägte Musikleben. In dieser höfischen Musikkultur war der adlige Stand des Dienstherrn ebenso wichtig wie der künstlerische Rang und Name des Lehrmeisters; die Bedeutung des Lehrers wiederum war fast ebenso wichtig wie das eigene Talent und Können.

Hatte ein Musiker dann dank seiner vielfachen Bemühungen eine entsprechende Anstellung erreicht, dann musste er neben seinen stationären Pflichten bei Hofe (Hofmusik, Konzerte, Kompositionen, Widmungen etc.) auch wieder Reisen unternehmen und sich bei anderen Höfen hören lassen - natürlich immer in Verbindung mit dem Namen seines Brotherrn. Eine musikalische Karriere war in nicht unerheblichem Maß von der Gunst eines Potentaten abhängig. Dieser finanzierte häufig bereits teilweise die Ausbildung eines heranwachsenden Musikers, sandte ihn im fortgeschrittenen Stadium der Ausbildung zu besonders geschätzten Lehrmeistern, empfahl seinen Zögling 
Schattenriss des jungen Ludwig van Beethoven

(ca. 1786),

erstmals veröffentlicht in:

FRANZ GERHARD WEGELER UNd FERDINAND RIES, Biographische Notizen über Ludwig van Beethoven, Koblenz 1838 für mögliche Auftritte und Vorspiele bei anderen Adelshäusern, deckte die Reisekosten und finanzierte je nach Vermögen auch längere Kunstreisen.

Im Folgenden soll dargestellt werden, wie sich die genannten Faktoren beim jungen Ludwig van Beethoven verhielten. Zunächst seien kurz das familiäre und höfische Umfeld in Bonn, seine Lehrer, Dienstherren, Gönner und Freunde vorgestellt und anschließend seine erste große Reise, seine Reiseroute, Reisedaten und Reisebegleitungen untersucht. Neu erschlossene Quellen in Archiven und Bibliotheken und deren genaue Auswertung ermöglichen auch noch nach mehr als 200 Jahren die teilweise Rekonstruktion von Beethovens erster Reise nach Wien und diese neu gewonnenen Daten geben Anlass zu weiteren Fragestellungen, deren Untersuchung uns im zweiten Teil des Artikels beschäftigen wird.

Wolfgang Amadeus Mozart war in seinem kurzen Leben von 35 Jahren, zehn Monaten und neun Tagen 3720 Tage auf Reisen, das sind zehn Jahre, zwei Monate und acht Tage; rechnet man die allerfrüheste Kindheit ab, dann ist Mozart rund ein Drittel seines Lebens auf Achse gewesen. ${ }^{3}$ Und Mozart war von der Notwendigkeit des Reisens überzeugt. Er schrieb im September 1778 in einem Brief an seinen Vater aus Paris: "ich versichere sie, ohne reisen | wenigstens leüte von künsten und wissenschaften | ist man wohl ein armseeliges geschöpf!" Und im gleichen Brief weiter ausführend: "ein Mensch von mittelmässigen Talent bleibt immer mittelmäßig, mag er reisen oder nicht - aber ein Mensch von superieuren Talent | welches ich mir selbst, ohne gottlos zu seyn, nicht absprechen kann | wird - schlecht, wenn er immer in den nemlichen ort bleibt."

Natürlich verhält es sich mit der Reisefreudigkeit Beethovens beileibe nicht so wie mit der Mozarts. Auch wenn Beethoven Mozart mit seiner Lebenszeit von 57 Jahren bei weitem übertrifft, ist er doch nicht annähernd so viel wie Mozart unterwegs gewesen. Die Beethoven-Forschung kann - im Gegensatz zur Mozart-Forschung - noch keine exakten Chronologien der Beethovenschen Reisen anbieten, umso gerechtfertigter erscheint eine genauere Untersuchung vor allem der ersten größeren Reise Beethovens, da sie zum einen einen zeitlich wesentlich längeren Raum einnahm als bisher vermutet und zum anderen auf die Beethovensche Entwicklung wohl von weit größerem Einfluss war als bisher angenommen. Gerade weil Beethoven kurz nach seinem 16. Geburtstag zu dieser ersten eigenständigen Reise aufbrach, darf ihr Stellenwert in seinem jungen Leben nicht unterschätzt werden. 
Dass er sich auch in seinem späteren Leben noch ausdrücklich an zwei Persönlichkeiten erinnerte, deren Bekanntschaft er nur auf dieser ersten Wienreise gemacht haben konnte, nämlich an W. A. Mozart und an Kaiser Joseph II. (1741-1790)5 - beide waren bei seinem zweiten Eintreffen in Wien im Jahr 1792 bereits verstorben -, zeigt, dass er Kontakt zu den ersten Wiener Kreisen hatte, sowohl in gesellschaftlicher wie in musikalischer Hinsicht. Das bedurfte hoher Empfehlungen und starker Protektoren. Angemerkt sei an dieser Stelle nur, dass Beethovens Bonner Dienstherr, Kurfürst Maximilian Franz (17561801), der jüngste Bruder des regierenden Habsburger Kaisers Joseph II., zugleich ab 1780 Hochmeister des Deutschen Ordens sowie ab 1785 Fürsterzbischof von Köln und Bischof von Münster war. Diese Kontakte dürften es gewesen sein, die dem jungen Talent aus Bonn, in Wien noch gänzlich unbekannt, etliche Türen in den Wiener Adelskreisen öffneten und ihn in die Salons der bekannten kunstliebenden Aristokratenfamilien in Wien einführten. Ohne Zweifel war der junge Beethoven um Kontakte zu diesen Kreisen bemüht, denn es war ihm, sicher nicht zuletzt aus der Familiengeschichte seines Großvaters wie auch seines Vaters ${ }^{6}$, bewusst, dass künstlerischer Erfolg, sei es interpretatorischer oder auch kompositorischer, nur auf dem Weg über die adligen Gönner zu erreichen war.

\section{Beethovens Umfeld in Bonn}

Der Großvater Ludwig (auch Louis) van Beethoven (1712-1773) besaß eine gut ausgebildete Bassstimme und trat nach Anstellungen in Belgien im Jahr 1733 in den Dienst der kurfürstlichen Hofkapelle in Bonn. Bis zum Jahr 1761 stieg er dort - für einen Sänger durchaus ungewöhnlich - vom Bassisten bis zum Kapellmeister auf. Sein einziger Sohn Johann (ca. 1740-1792), der Vater des Komponisten Beethoven, trat bereits 1752 als zwölfjähriger Knabensopran in den Dienst des Kurfürsten und setzte seine Laufbahn in der Hofkapelle später als Tenorist fort. Sein nicht allzu reichliches Einkommen besserte er sich mit der Erteilung von Klavier-, Violin- und Gesangsstunden etwas auf. Im November 1767 heiratete er Maria Magdalena (1746-1787), die gerade verwitwete Tochter des kurfürstlich-trierischenen Hof- „Küchenmeisters" Heinrich Keverich. Das erste Kind aus dieser Verbindung, getauft am 2. April 1769 auf den Namen Ludwig Maria, lebte nur sechs Tage. Das zweite Kind wurde am 17. Dezember 1770 ebenfalls auf den Namen des Großvaters Ludwig getauft, dieser ist der spätere Komponist. Fünf weitere Kinder wurden dem Ehepaar geboren, von denen aber nur die Söhne Kaspar Anton Karl (*1774) und Nikolaus Johann (*1776) das Erwachsenenalter erreichen sollten.

Bereits als Achtjähriger trat Ludwig am 26. März 1778 zusammen mit einer Musikschülerin ${ }^{7}$ seines Vaters in einem öffentlichen Konzert auf. Der Ankündigung zufolge spielte er im Rahmen dieses ersten öffentlichen Auftritts unter der falschen Altersangabe von sechs Jahren verschiedene Klavierkonzerte 
und Klaviertrios. ${ }^{8}$ Wenig später wurde Ludwig Schüler des alten Bonner Hoforganisten Heinrich van den Eeden (ca. 1710-1782) ${ }^{9}$ sowie weiterer lokal angestellter Musiker. Mit dem Eintreffen Christian Gottlob Neefes (1748-1798) im Jahr 1779 in Bonn eröffneten sich neue Möglichkeiten für die musikalische Ausbildung Beethovens. Zwar ist unklar, wann genau Beethovens Unterricht bei Neefe begann, doch als im Februar 1781 Neefe den Posten als Hoforganist in Bonn erhielt, wurde der junge Ludwig schon sein Gehilfe. Und als Neefe im Juni 1782 Bonn für kurze Zeit verließ, fungierte der junge elfeinhalbjährige Hilfsorganist Beethoven bereits als seine Vertretung. ${ }^{10}$ Im März 1783 erschien - sicher auf Neefes Vermittlung hin - die erste gedruckte Notiz über den jungen Ludwig van Beethoven in Cramers Magazin der Musik. ${ }^{11}$ Um den WunderkindAspekt zu unterstreichen, wurde dort das Alter des Komponisten mit elf Jahren angegeben und - für unsere weiteren Überlegungen ebenso wichtig - die Notwendigkeit einer finanziellen Unterstützung für zukünftige Reisen angesprochen und die Hoffnung geäußert, dass er ein zweiter W. A. Mozart werden könnte.

\section{CARL FRIEDRICH CRAMER, Magazin der Musik,}

1. Jg., Hamburg 1783

(Bayerische Staatsbibliothek München)

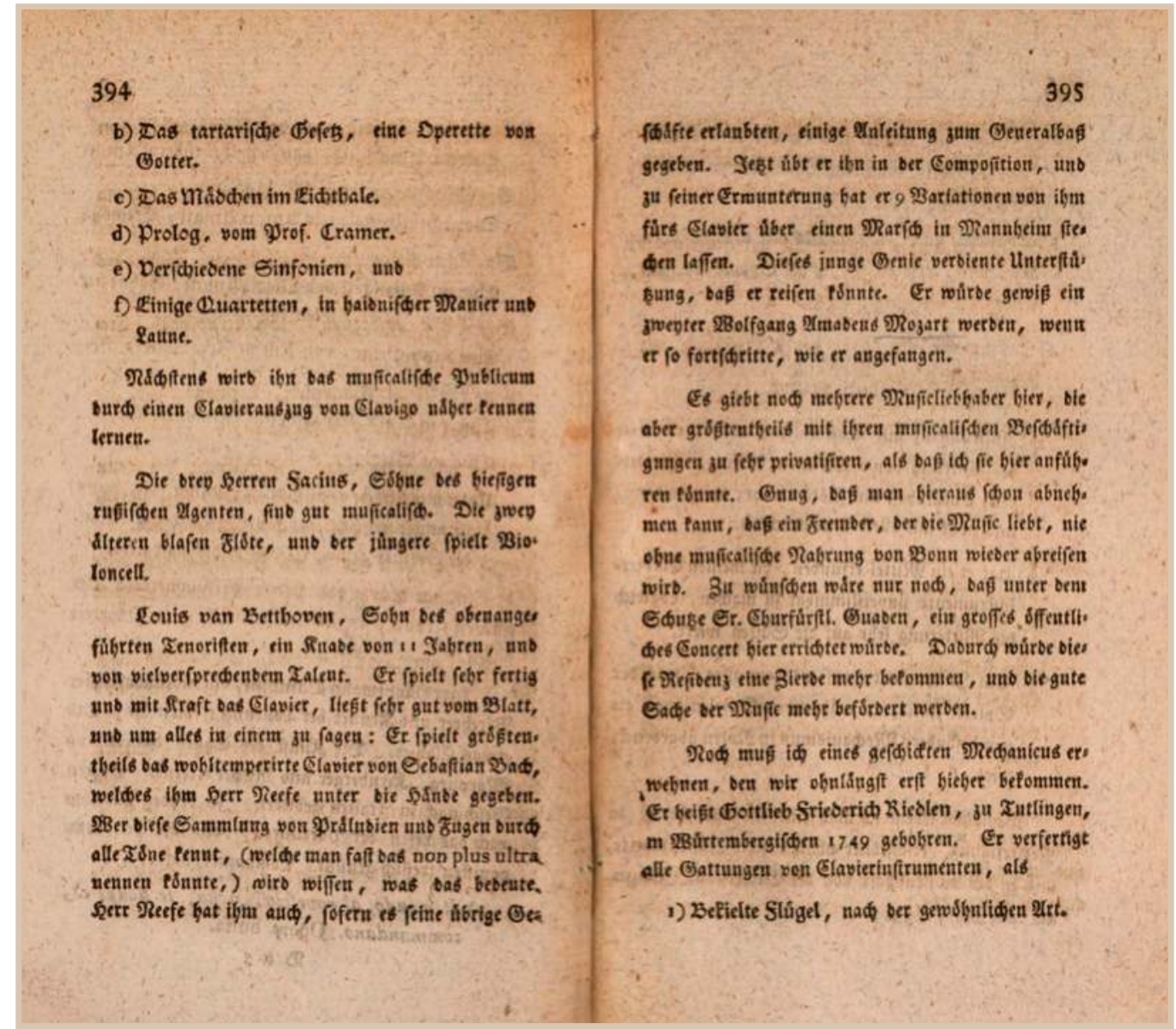

438 | Dieter Haberl

(C) 2020 by Böhlau Verlag GmbH \& Cie. KG, Köln

https://doi.org/10.7788/9783412519704 | CC BY-NC 4.0 
Im Herbst 1783 erschienen dann die drei dem Kurfürsten Maximilian Friedrich (1708-1784) gewidmeten Klaviersonaten Beethovens, die sogenannten Kurfürstensonaten WoO 47 im Druck. Leider verstarb der Widmungsträger, noch bevor er ein offizielles Salär für den jungen Beethoven als zweiten Hoforganisten festgelegt hatte.

Der neue Kurfürst Maximilian Franz legte 1784 Beethovens Bezüge für die Dienste als Hoforganist auf 150 Gulden jährlich fest. ${ }^{12}$ Beethovens Lehrer Neefe setzte sich wohl in den folgenden Jahren weiter dafür ein, dem jungen Genius die Möglichkeit zum Reisen zu geben, denn außer einer Reise zusammen mit der Mutter im Jahr 1781 nach Rotterdam war sein Schüler offensichtlich über das Bonner Umland noch kaum hinausgekommen. Der Plan, dass Beethoven Wien und das ihm zugedachte Vorbild Mozart besuchen sollte, begann zu reifen, bis er im Jahr 1786/87 endlich in die Tat umgesetzt wurde.

Beethovens stärkstes künstlerisches Mittel in diesen Jahren waren nicht seine eigenen Kompositionen, es waren die aus dem Stegreif gespielten Improvisationen, oft über ein ad hoc gestelltes oder ein selbstgewähltes Thema. Schon der junge Beethoven muss hier eine Fähigkeit besessen haben, die über das freie Phantasieren weit hinausging: Er soll sowohl formal durchdachte Sonatensätze sowie Finalrondos erfunden, Variationsformen über ein ausgewähltes Thema improvisiert oder auch mehrere musikalische Gedanken aneinandergereiht verarbeitet haben. ${ }^{13}$ Der Einsatz dieser ihm als fähigen Organisten und Klavierspieler verfügbaren Improvisations-Mittel dürfte vor allem in den musikalisch gebildeteren Wiener Adelshäusern zum Beispiel des Baron Gottfried van Swieten (1733-1803) oder des Fürsten Karl Lichnowsky (1761-1814) nicht ohne Wirkung geblieben sein. Beethoven war in diesen jungen Jahren ein genialer Improvisator, der es verstand, das Publikum in seinen Bann zu ziehen. Die Anzahl seiner niedergeschriebenen Kompositionen hingegen war zu dieser Zeit, verglichen mit dem Fuvre des sechzehnjährigen Mozart, noch eher gering bemessen.

\section{Beethovens erste Reise nach Wien - die bisherige Forschung}

Wegen des Fehlens einschlägiger Dokumente blieb der Beethoven-Forschung bis heute Vieles über die genauen Daten der Reise unklar, ja sogar Zweck und Ziel der Reise sind teils umstritten. ${ }^{14}$ Gesichert ist bisher nur das Ende der Reise durch den aus einem Brief Beethovens abzuleitenden Terminus ante quem: Da Beethoven bei seiner Rückkehr nach Bonn seine tuberkulosekranke Mutter noch lebend vorfand, muss er spätestens Mitte Juli 1787 wieder nach Bonn heimgekehrt sein, da seine Mutter am 17. Juli 1787 verstorben ist. In diesem Schreiben nach Augsburg - dem ersten erhaltenen eigenhändigen BeethovenBrief überhaupt - gibt Ludwig dem Freiherrn Joseph von Schaden (1754-1814) Kunde davon, was sich seit seiner Abreise aus Augsburg ereignet hat: 
"ich muß ihnen bekennen: dass seitdem ich von augspurg hinweg bin, meine freude und mit ihr meine gesundheit begann aufzu hören; je näher ich meiner vaterstadt kam, je mehr briefe erhielte ich von meinem vater, geschwinder zu reisen als gewöhnlich, da meine mutter nicht in günstigen gesundheitsumständen wär; ich eilte also, so sehr ich vermochte, da ich doch selbst unpäßlich wurde: das verlangen meine kranke mutter noch einmal sehen zu können, setzte alle hinderniße bei mir hinweg, und half mir die gröste beschwerniße überwinden. ich traf meine mutter noch an, aber in den elendesten gesundheitsumständen; sie hatte die schwindsucht und starb endlich ungefähr vor sieben wochen, nach vielen überstandenen schmerzen und leiden". ${ }^{15}$

Wegen des Fehlens weiterer Belege für die Reise wurden über deren Verlauf verschiedene Hypothesen entwickelt und tradiert. Die erste datierte Erwähnung in der Beethoven-Literatur findet sich in der 1840 von Anton Felix Schindler (1796-1864) verfassten Biographie von Ludwig van Beethoven. Dort heißt es: "Mozart, der Urquell alles Lichtes im Reiche der Tonkunst, den Beethoven bereits bei seiner im Winter von 1786 auf 1787 statt gefundenen ersten Anwesenheit in Wien kennen lernte, der, als er Beethoven über ein ihm aufgegebenes Thema phantasiren liess, zu den Anwesenden sagte: ,dieser Jüngling wird noch viel in der Welt von sich reden machen'."16 Christian Wilhelm von Lenz (1808-1883) wiederholte diese Nachricht im Jahr 1852; er schrieb über die fragliche Reise: „Man war im Winter von 1786 auf 1787. Als Mozart mit dem sechzehnjährigen Klavierspieler aus Bonn zusammentraf ...."17 Auch der MozartBiograph Otto Jahn (1813-1869) übernahm diese Datierung, leider verkürzt, im 1858 erschienenen dritten Band seiner Mozart-Biographie: „Beethoven der als vielversprechender Jüngling im Winter 1786 nach Wien kam, aber nach kurzem Aufenthalt wieder nach Hause reisen mußte, wurde zu Mozart geführt und spielte ihm auf seine Aufforderung etwas vor ...." ${ }^{\prime 18}$ Schindler selbst modifizierte dann in der 1860 erschienenen Neuauflage seiner Beethoven-Biographie seine ursprüngliche Angabe mit Hinblick auf die bereits 1838 erschienenen Biographischen Notizen über Ludwig van Beethoven von Franz Gerhard Wegeler und Ferdinand Ries in: „Über den kurzen Besuch, den Beethoven zur Frühlingszeit 1787 der Kaiserstadt gemacht, schweigt Wegeler ganz, aber auch der Verfasser [Anton Schindler] weiß nur wenig darüber zu sagen. ${ }^{19}$ Schindler hatte durch den Widerspruch in seinen zwei Aussagen die eigene Glaubwürdigkeit erschüttert. Dies trug nicht wenig zur Verwirrung bei, denn nunmehr existierten neben der ursprünglichen Datierung "Winter von 1786 auf 1787" bereits zwei weitere, nämlich "Winter 1786" und "Frühlingszeit 1787".

Ein wichtiger Zeuge in diesem Zusammenhang ist der Arzt Dr. Moritz Gerhard von Breuning (1813-1892), ein Sohn von Beethovens Jugendfreund Stephan von Breuning (1774-1827). Er unterstützt in seinen Erinnerungen aus dem Schwarzspanierhause, die er 1874 herausgab, nämlich die ursprüngliche 
Datierung der ersten Wienreise: „... Beethoven war im Winter 1786 auf 87 in Wien angekommen, und hatte bald allenthalben offene Arme, zumal zuvorkommendste Aufnahme bei den allbekannten kunstliebenden aristokratischen Familien jener Wiener Zeit gefunden." 20

Was war nun in der Beethoven-Forschung des 20. Jahrhunderts passiert, dass der erste Wiener Aufenthalt Beethovens vom Winter 1786/87 auf etwa zwei Wochen im April 1787 verkürzt werden konnte? ${ }^{21}$ Alexander Wheelock Thayer (1817-1897) hatte in dem 1866 in der Übersetzung von Hermann Deiters (1833-1907) erschienenen ersten Band seiner Beethoven-Biographie die Vermutung geäußert, dass Beethoven als Hoforganist in Bonn durch die Musikaufführungen in der Karwoche festgehalten gewesen sei, deshalb erst nach Ostern (Ostermontag: 9. April 1787) Urlaub für die Reise bekommen habe und daher erst im Mai 1787 Wien habe erreichen können. ${ }^{22}$ Sowohl Hermann Deiters in der 1901 neu bearbeiteten und ergänzten Fassung dieses Bandes als auch Hugo Riemann (1849-1919) in einer Fußnote zur 1917 erschienen dritten Auflage der Thayerschen Beethoven-Biographie haben Zweifel an dieser Hypothese angemeldet. ${ }^{23}$ Auch Theodor Frimmel (1853-1928) hatte 1926 auf die Fragwürdigkeit dieses Ansatzes hingewiesen und ergänzend bemerkt, dass sich, trotz der Datierungshypothese für die Abreise, "ohne Kenntnis der Reiseart und des Tempos" nicht bestimmen lässt, wann Beethoven in Wien eingetroffen ist. ${ }^{24}$

Neue, scheinbar unterstützende Argumente, erhielt die Hypothese des späten Reiseaufbruchs durch einen zum 100. Todestag Beethovens erschienenen Beitrag von Eduard Panzerbieter (1868-1941). ${ }^{25}$ Panzerbieter hatte in den im Wochenblatt der Münchner Zeitung veröffentlichten „Fremdenzetteln" zweimal den Namen Beethovens nachgewiesen und konnte damit dessen Aufenthalt in München für den 1. April und den 25. April des Jahres 1787 belegen. Panzerbieter nahm an, dass Beethoven über München nach Wien gereist sei und dass die erste Übernachtung in München auf der Hinreise nach Wien und die zweite Übernachtung auf der Heimreise nach Bonn getätigt wurde. Das war ein Fehlschluss mit weitreichenden Folgen. Die Fremdenzettel in der Münchner Zeitung geben nämlich keine Richtung an, aus der Reisende kommen oder in die sie fahren, sondern nennen nur den Namen der Übernachtungs-Gaststätte. Außerdem übersah Panzerbieter das gleichzeitige Eintreffen eines weiteren Musikers in München, der ein wichtiges Indiz für Beethovens Reiseroute darstellt.

Zur Unterstützung seiner Argumentation rechnete Panzerbieter für die Wegstrecke von Bonn nach München (ca. 500 km) mit der Postkutsche etwa 12 Tage, da er die Abreise "spätestens um den 20. März herum" datierte und das Eintreffen in München für den 1. April feststand. ${ }^{26}$ Die Weiterreise von München nach Wien (ca. 400 km) hätte dann - Panzerbieters Rechnung zufolge - in quasi doppelter Geschwindigkeit erfolgen müssen, denn für die Hin- und Rückreise 
Regensburgisches Diarium,

26. Jg., Nr. I vom

2. Januar 1787, Titelblatt

(Staatliche Bibliothek Regensburg)
München-Wien sowie den Aufenthalt in Wien stand lediglich die Spanne zwischen 1. und 25. April zur Verfügung. Panzerbieter teilte dafür den Zeitraum der zur Verfügung stehenden 24 Tage in 5 Tage Hinreise, 14 Tage Aufenthalt und 5 Tage Rückreise auf. Schon die Unstimmigkeiten bei den Reisegeschwindigkeiten lassen den Zeitplan fragwürdig erscheinen.

Trotzdem setzte sich die Darstellung Panzerbieters in der Folgezeit als die in der Beethoven-Forschung anerkannte durch und verdrängte allmählich die aus dem 19. Jahrhundert stammende Nachricht von der im Winter 1786/87 begonnenen ersten Wien-Reise. Sie fand Eingang in spätere Lexikon-Artikel ${ }^{27}$, Beethoven-Biographien ${ }^{28}$ und -Handbücher ${ }^{29}$ und wurde ohne kritisches Hinterfragen auch in die Mozart-Forschung kolportiert. ${ }^{30}$

Schließlich wurde durch die Kürze des von Panzerbieter veranschlagten Wien-Aufenthaltes das Vorspiel bei Mozart sowie ein möglicher Unterricht bei diesem in Zweifel gezogen; Klaus Kropfinger (1930-2016) sprach der ersten Wien-Reise sogar jegliche Bedeutung ab: „Gemessen an den Erwartungen, die man daran geknüpft hatte - und die bezeugte Enttäuschung des Kurfürsten ... spricht für sich -, hatte diese Reise praktisch nicht stattgefunden." ${ }^{\prime 31}$

Eine neu erschlossene Quelle, das Regensburgische Diarium, kann nun helfen aufzuklären, wie es sich mit Beethovens erster Reise wirklich verhielt. Sie zeigt nämlich die Daten der oben angeführten Münchner Zeitung in neuem Licht.

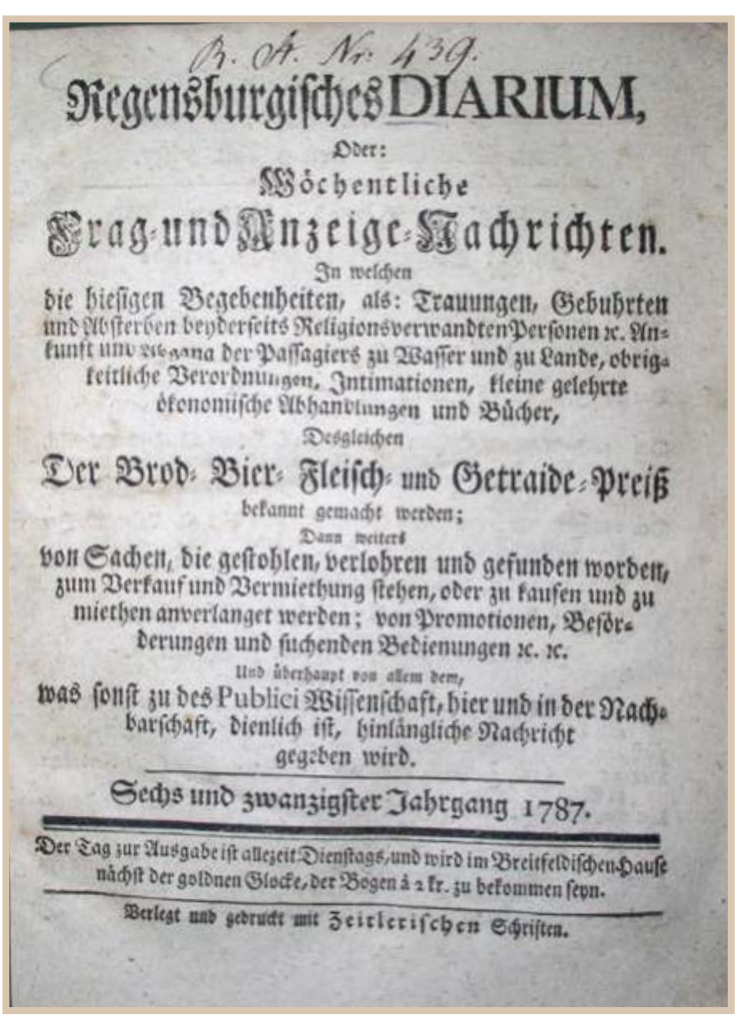

\section{Exkurs I: Das Regensburgische Diarium}

Das sogenannte Regensburgische Diarium, Oder: Wöchentliche Frag- und Anzeige-Nachrichten erschien unter mehrfach wechselnden Titelfassungen in den Jahren zwischen 1760 und 1810 regelmäßig als wöchentliches Intelligenzblatt in Regensburg. Als wichtige Primärquelle für die zweite Hälfte des 18. Jahrhunderts enthält es neben allgemeinen Nachrichten eine Fülle musikhistorisch wichtiger Namen, Daten und Fakten, die aufgrund des streng chronologischen Erscheinens des Periodikums einen hohen Quellenwert besitzen. Regensburg war während dieser Zeit, bedingt durch das Zusammentreffen wichtiger Nord-Süd- und Ost-West-Reiserouten, den Sitz des Immerwährenden Reichstages mit seinen Gesandtschaften und die glänzende Hofhaltung des fürstlichen Hauses Thurn und Taxis im Prinzipalkommissariat, sowohl Aufenthaltsort international bekannter Musiker sowie fester Kontakt-, Informations- und Drehpunkt auf vielen Musikerreisen. Auf seine mögliche Bedeutung für die Beethoven-Forschung hatte Max Unger (1883-1959) bereits 1936 nachdrücklich hingewiesen. ${ }^{32}$ 
Das Regensburgische Diarium druckte in seinen wöchentlichen Ausgaben jeweils Listen mit den eintreffenden und abreisenden Gästen der Reichsstadt ab. Genauestens verzeichnet es auch das Eintreffen und die Abreise der Musiker, nennt Herkunfts- sowie Zielort der Durchreisenden und gibt Auskunft über ihre Dienstverhältnisse und jeweiligen Dienstherren. Regensburg ist daher ein idealer Beobachtungsstandpunkt, um die Reisebewegungen der Musiker und damit die Kontakte zwischen dem böhmisch-schlesischen, dem österreich-ungarischen, dem franko-flämischen und dem norddeutsch-skandinavischen Kulturraum in der zweiten Hälfte des 18. Jahrhunderts zu registrieren. Die Buchhändler veröffentlichten im Diarium Anzeigen mit den neuesten bei ihnen erhältlichen Musikdrucken; Opern- und Konzertaufführungen wurden durch Programmvoranzeigen dokumentiert, und personelleVeränderungen in der Thurn und Taxisschen Hofkapelle wurden ebenso angezeigt wie Personalia bei den Stadt- und Kirchenmusikern. Von der Musikwissenschaft wurde dieses unerschlossene Periodikum bislang als Quelle noch kaum beachtet. Dieses Desiderat der Forschung resultiert einerseits aus der schweren Zugänglichkeit der Quelle (sie ist in keiner Bibliothek vollständig vorhanden), andererseits aus ihrer schweren Benutzbarkeit (von den gut 400 Seiten eines Jahrgangs betreffen in jeder Nummer oft nur einige Zeilen das Musikleben) und aus der fehlenden Erschließung (es existierten keine Register zu dieser Quelle). ${ }^{33}$

Drei Beispiele für Reiseangaben aus dem Regensburgischen Diarium seien hier kurz angeführt:

1) Im Jahr 1764 für Christoph Willibald Gluck: Auf der Rückreise von den Krönungsfeierlichkeiten in Frankfurt am Main fuhr der kaiserliche Kapellmeister Gluck am 13. April 1764 „per Calesch” in Regensburg ein und übernachtete im Gasth of Zum Weißen Lamm. Am folgenden Tag wurde er wahrscheinlich Augen- und Ohrenzeuge der Huldigung der Reichshauptstadt Regensburg an den frisch gekrönten Monarchen, der per Schiff auf der Donau an der Reichsstadt vorüberfuhr. Gluck verließ am 14. April 1764 Regensburg durch das Ostentor auf dem Landweg in Richtung Wien. ${ }^{34}$

2) Im Jahr 1790 für Wolfgang Amadé Mozart: Am 25. September 1790 reiste „Per Posta, Herr Mozart, Kön[iglich] Ung[arischer] Kapellmeister, s[elb] 2." zum Ostentor - also aus der Wiener Richtung kommend - in Begleitung eines Dieners nach Regensburg ein und übernachtete im Gasthof Zum Weißen Lamm. ${ }^{35}$

3) Knapp vier Jahre später, am 22. Januar 1794, kam Joseph Haydn, der sich auf der zweiten Reise nach London befand, mit dem Postwagen zum Ostentor nach Regensburg herein, übernachtete ebenfalls im Weißen Lamm und verließ die Stadt am folgenden Tag über die Steinerne Brücke: „Tit. Herr von Heyde, fürstl[ich] esterhazyscher Kapellmeister ...."36 
\%) (II) के

In oer Obern Erabes Part 3 u Gt. Rupredot, Ectrattete: 38 शaar. Betauffete: 155 . Bearabenc: 245 .

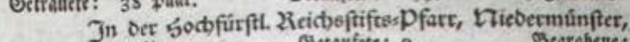

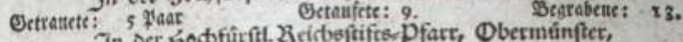

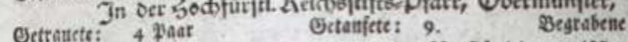
2lus oer కodblobl. Eongregation bee Vertúnbigung Marif, - _ - - _eflorbelk: $2 z$. ź

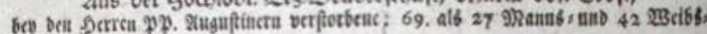
perfonthi.

2 ungelommene uno abgegangene Serrfdaften unop a fiagiers. zur freincenen $23 \mathrm{ruck}$ berein:

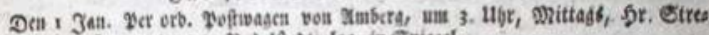
bel, zroumetter von Stubciftabt, log. in Eviegel.

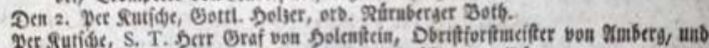

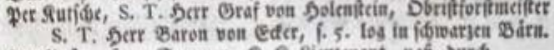

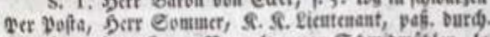

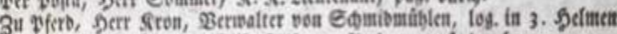

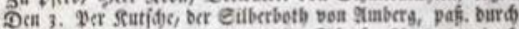

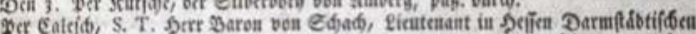

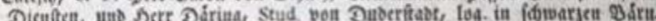

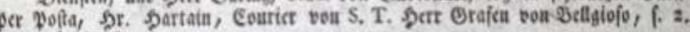

Yer yoffa mit a 3 .

pap. Burdi.

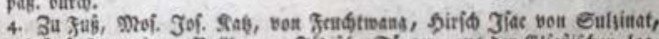

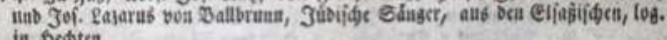
in sotten.

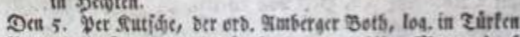

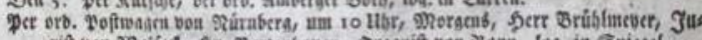

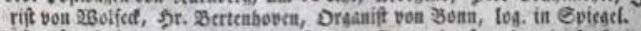

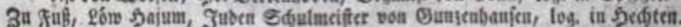

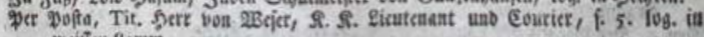
weificn Qantu.

Dett 7. Per Ealéi

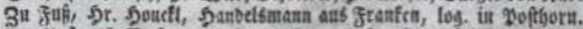

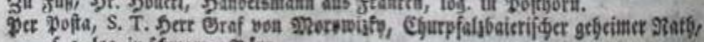

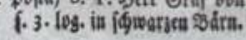

\section{Beethovens erste Reise nach Wien im Spiegel der neuen Quellenlage}

Mit Hilfe des Regensburgischen Diariums kann nun aufgezeigt werden, in welchem Zeitintervall Beethovens Reise wirklich anzusiedeln ist. Zunächst die belegbaren Daten und Fakten in chronologischer Folge:

Beethoven ist bereits am Freitag, den 5. Januar 1787, um 10 Uhr vormittags, mit der Postkutsche von Nürnberg kommend in Regensburg eingefahren. Damit ist zugleich zwingend erwiesen, dass er zu seiner ersten Reise nach Wien noch Ende des Jahres 1786 aufgebrochen sein muss, denn die Distanz Bonn-Regensburg (minimal 311/2 Posten entspricht 126 Poststunden, ca. $500 \mathrm{~km}$ ) war 1787 mit normaler Postkutsche in 41/2 Tagen nicht zu bewältigen. ${ }^{37} \mathrm{Im}$ Originaleintrag des Regensburgischen Diariums heißt es in der am 9. Januar 1787 ausgegebenen Nummer II dieses Jahres unter der Rubrik "Zur steinernen Bruck herein": [5. Januar] „Per ord[inari] Postwagen von Nürnberg, um 10 Uhr, Morgens, Herr Brühlmeyer, Jurist von Wolfeck, H[er] r Bertenhoven, Organist von Bonn, log[iert] in Spiegel". ${ }^{38}$ An der verdruckten Schreibweise "Bertenhoven" würde man Ludwig van Beethoven nicht zweifelsfrei erkennen können, doch der Zusatz der Funktion „Organist" und

Regensburgisches Diarium, 26. Jg., Nr. II vom 9. Januar 1787 (Staatliche Bibliothek Regensburg) die Ortsangabe "von Bonn" machen auch hier die Person eindeutig identifizierbar. Auch eingehende Recherchen unter den Bonner Musikern im letzten Viertel des 18. Jahrhunderts konnten weder einen Organisten namens "Bertenhoven" noch überhaupt die gedruckte Namensform zu Tage fördern. Ludwig van Beethoven hingegen war spätestens ab 1785 zusammen mit seinem Lehrer Christian Gottlob Neefe offiziell als Hoforganist in Bonn angestellt worden und versah mit Neefe abwechselnd den dortigen Dienst. ${ }^{39}$ In einer Besoldungsliste der Bonner Hofkapelle vom 25. Juni 1784, werden unter der Bezeichnung "Organisten" bereits "Neefe" und "Bethoven [sic] Sohn" mit einem jährlichen Gehalt aufgeführt. ${ }^{40}$ Auch den bereits erwähnten Brief vom 15. September 1787 an Freiherrn Joseph von Schaden unterschrieb Beethoven mit: „I. v. beethowen. / kurf[ürstlich]-kölnischer hoforganist. "“11

Die im Regensburgischen Diarium beigedruckte Angabe "log[iert] in Spiegel" bezieht sich auf die Auswahl des Übernachtungsquartiers. Beethoven wohnte in der Gaststätte Im Goldenen Spiegel in der Spiegelgasse Haus-Nr. 4 (nach alter Zählung C 98). ${ }^{42}$ - Seit mindestens 1667 wurde in diesem Haus mit seinen im Kern romanischen Mauern und dem vorgeblendeten gotischen Erker eine Gaststätte betrieben, die bis um 1860 bestand..$^{43}$

444 | Dieter Haberl

(C) 2020 by Böhlau Verlag GmbH \& Cie. KG, Köln

https://doi.org/10.7788/9783412519704 | CC BY-NC 4.0 
Am Palmsonntag, den 1. April 1787, ist - wie Panzerbieter bereits nachwies - Beethovens Übernachtung in München dokumentiert. Der Eintrag in der Münchner Zeitung lautet: "4) Bei H[er]rn Albert, Weingastgeber zum schwarzen Adler in der Kaufingergasse / Den 1. April. Herr Peethofen, Musikus von Bonn bei Kölln. Herr Dürelli, Musikus von Regensburg. Herr von Schaden, mit dessen Frau, von Wallerstein, mit 1 Bed[ienten]. Herr Doktor Paul von Wallerstein, H. Mayer, Verwalter von Tit[ulierten] H[errn] Grafen v[on] Lamberg, von Dandern [Tandern]." ${ }^{\prime 4}$ Beim musikliebenden Weinwirt Franz Joseph Albert († 1789) bzw. dessen Sohn Carl Franz Xaver im Gasthof Zum Schwarzen Adler übernachtete während seiner München-Aufenthalte im Jahr 1777 und 1790 auch W. A. Mozart. ${ }^{45}$

In derselben Ausgabe dieser Zeitung - jedoch von Panzerbieter übergangen - finden sich wenige Zeilen vorher als Gäste angezeigt: „2) Bei H[er]rn Streicher, Weingastgeber zum goldenen Kreuz in der Kaufingergasse. Den 1 April. Herr Willmann, Musikdirektor bei S[eine]r Exz[ellenz] Herrn Grafen von Palfy von Wien mit 3 Kons[orten]. Herr Plankenberger von Wien." Den genannten Musikdirektor des Grafen Pállfy, Johann Ignaz Willmann (1739-1815), kannte Beethoven seit seiner Bonner Kindheit, denn Willmann war ab 10. April 1767 als Violinist in der Bonner Hofkapelle angestellt und mit der Familie Beethoven befreundet. ${ }^{46}$ Die Familie Willmann hatte das "Fischer'sche Hinterhaus, Giergasse 950" angemietet und wohnte in direkter Nachbarschaft zur Familie Beethoven (Rheingasse 934). ${ }^{47}$

- Johann Ignaz Willmann unternahm ab 1774 mehrfach Konzertreisen und wurde am 21. August 1777 Mitglied der Wiener Tonkünstlersozietät. Am 16. März 1784 konzertierten seine drei minderjährigen Wunderkinder Magdalena (12 Jahre, Gesang), Walburga (14 Jahre, Klavier) und Maximilian (16 Jahre, Violoncello) erstmals in einem Akademiekonzert in Wien. ${ }^{48}$ Am 29. April 1786 verließ Willmann zusammen mit Wenzel Müller (1767-1835) die Stadt Brünn und kehrte wieder nach Wien zurück, ${ }^{49}$ wo seine drei Wunderkinder erneut bei einer Akademie am 7. März 1787 im Kärntnertor-Theater auftraten (vgl. Exkurs II). Am 15. Mai 1787 war er schließlich in Mainz nachweisbar. ${ }^{50}$ -

Überdenkt man den Nachweis der gleichzeitigen Anwesenheit Beethovens und Willmanns in München genauer, so reihen sich folgende Indizien aneinander: Da an Sonntagen, morgens um 10 Uhr, der Ordinari-Postwagen, also die regelmäßig (einmal pro Woche) verkehrende Postkutsche, von Wien nach München zurückkehrte, ${ }^{51}$ für Beethoven und für Johann Ignaz Willmann das zeitgleiche Eintreffen in München am Sonntag, den 1. April 1787, feststeht, beide - wie oben belegt - in Gasthäusern in der Kaufingergasse Quartier nahmen und für Musikdirektor Willmann eine Weiterreise in Süd-Nord-Richtung nach Mainz belegt werden kann ${ }^{52}$, ist mit hoher Wahrscheinlichkeit anzunehmen, dass Beethoven und Willmann gemeinsam mit derselben Postkutsche aus Wien in München eintrafen. Panzerbieter hatte bei seiner Quellen- 
interpretation die Angabe des Dienstverhältnisses "Musikus von Bonn bei Kölln" für den unmittelbaren Ausgangspunkt einer Reise Bonn-München gehalten und daher fest angenommen, Beethoven müsse aus Bonn gekommen sein. ${ }^{53}$ Die Reisestrecke mit der normalen Postkutsche („ordinari Post") von Wien nach München betrug je nach Routenwahl 28 bis 2911/2 Posten, das entspricht 112 bis 118 Poststunden. ${ }^{54}$ Die Abreise von Wien nach München muss daher spätestens am 28. März 1787 erfolgt sein. Die fünftägige Dauer für eine Reise München-Wien wird auch durch einen Brief Wolfgang Amadé Mozarts bezeugt; dieser reiste am 12. März 1781 mit der Postkutsche von München ab und erreichte auf der Route Altötting-Braunau-Linz am 16. März 1781 vormittags 9 Uhr Wien. ${ }^{55}$

Im Regensburgischen Diarium begegnen wir knapp fünf Monate nach dem ersten Eintrag Anfang Januar 1787 abermals Herrn Beethoven. In der am 1. Mai 1787 ausgegebenen Nummer wurde unter der Rubrik "Zum Weyh St. Peter-Thor hinaus" gedruckt: [24. April] „Per Münchner Postwagen, um 11 Uhr, Vormittags, H[er]r Bethhoffen, H[er]r Siegmund, Passagiers. "'56 Dass es sich bei dem ohne Vornamen, Funktion oder Ortsangabe Genannten ganz sicher um Ludwig van Beethoven handelt, beweist die Münchner Zeitung, in der das Eintreffen in München dokumentiert ist. Dort heißt es in dem am 2. Mai 1787 ausgegebenen Wochen-Blat unter der Rubrik "Anzeige der hier angekommenen Fremden": "Bei H[er]rn Albert, Weingastgeber zum schwarzen Adler in der Kaufingergasse: Den 25. April: Herr Peethoven, Kurköllnischer Kammervirtuos von Bonn." ${ }^{157}$ Den Ehrentitel eines „Kammervirtuosen" hatte der 16-jährige Beethoven zwar nominell nicht inne, doch die Namensform "Peethoven”, das Dienstverhältnis "kurköllnisch" und die Ortsangabe „von Bonn" sind hinreichende Indizien zu seiner Identifizierung.

Nur sieben Monate früher hatte Johann Wolfgang von Goethe (1749-1832) im Rahmen seiner Italienischen Reise die gleiche Postkutschenfahrt von Regensburg nach München unternommen und übernachtete ebenfalls im Gasthof Zum Schwarzen Adler. ${ }^{58}$ Goethe berichtete darüber recht genau unter dem Eintrag "München, den 6. September [1786]": "Den fünften September halb ein Uhr Mittag reiste ich von Regensburg ab. Bei Abach [Bad Abbach] ist eine schöne Gegend, wo die Donau sich an Kalkfelsen bricht, bis gegen Saale [Saal a. d. Donau] ... Um sechs Uhr morgens war ich in München."59 Der "Extra”Postwagen Goethes benötigte also 171/2 Stunden für die Strecke, die zunächst am Fluss entlang bis Neustadt an der Donau führte und dann nach Süden in Richtung Geisenfeld und Pfaffenhofen an der IIm abbog. Die Nacht über wurde - von den Pferdewechseln an den "Posten" abgesehen - durchgefahren. Die Poststrecke muss in gutem Zustand gewesen sein, denn auf der $81 \frac{1}{2}$ Posten (ca. 130 km) langen Route wurde, vermutlich dank entsprechender Pferdeanzahl im Vorspann des Extrapostwagens die für damalige Verhältnisse überdurchschnittliche Geschwindigkeit von 7,4 km/h erreicht. ${ }^{60}$ 


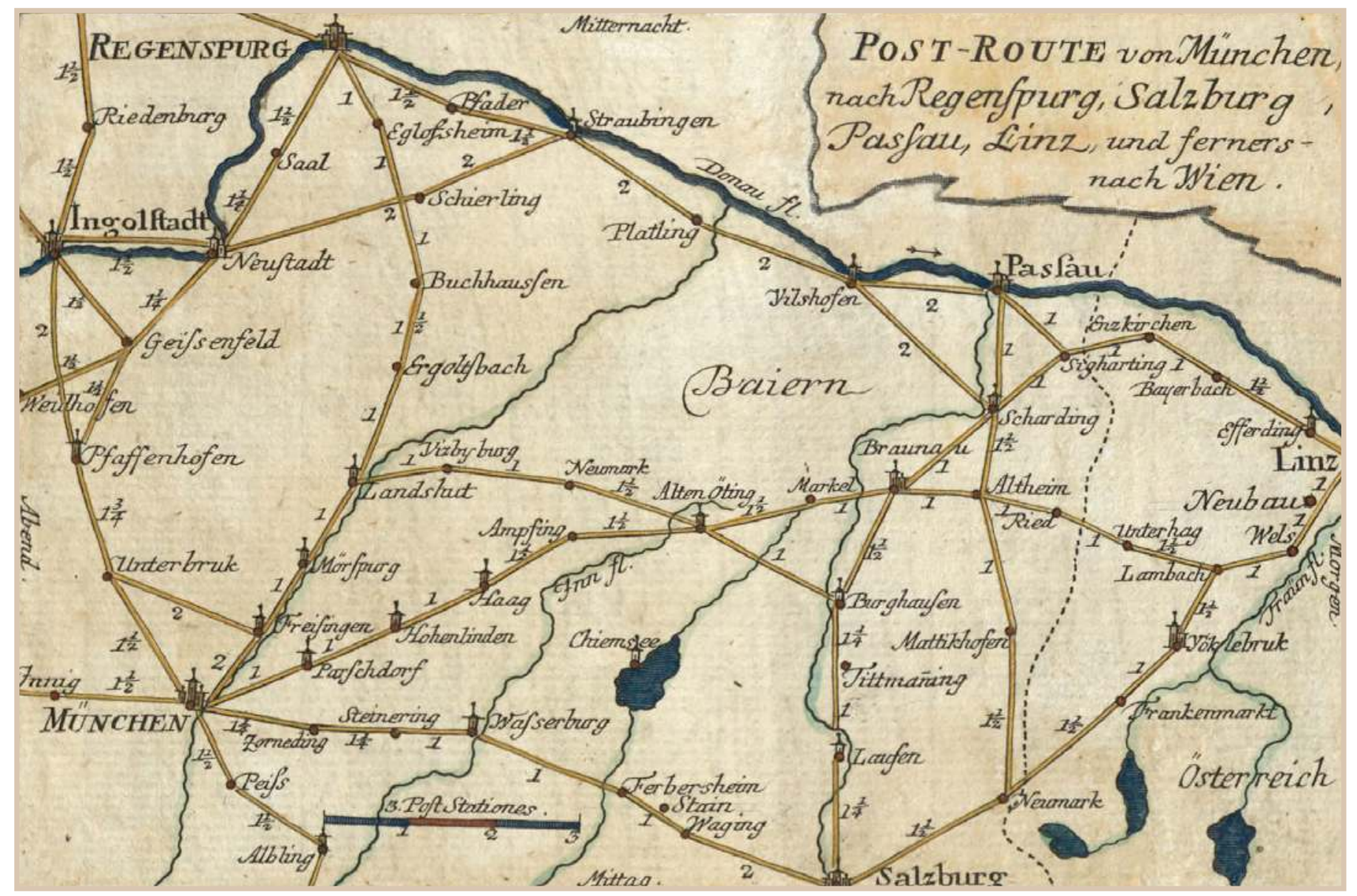

Es ist davon auszugehen, dass Beethovens Fahrt von Regensburg nach München ganz ähnlich verlief. Er verließ, wie schon erwähnt, am Dienstag, den 24. April 1787, um 11 Uhr mittags, die Stadt Regensburg und dürfte nach durchfahrener Nacht am Nachmittag oder Abend des 25. April in München eingetroffen sein. Der Reise Atlas von Bajern aus dem Jahr 1796 nennt als Fahrzeit der regulären Postkutsche Regensburg-München je nach Routenwahl zwischen 293/4 und 35 Stunden. ${ }^{61}$ Demnach wäre Beethoven am Nachmittag oder Abend des 25. April 1787 in München angekommen.

Aufgrund der unter der Rubrik "Ankommende Herrschaften und Reisende. / Zum weißen Lamm" im Augsburgischen Intelligenzblatt gedruckten Ankunftsnotiz: "Den 26sten [April] ... H[er]r von Beethaden, Musikus von Wien" wissen wir, dass Ludwig van Beethoven schon am nächsten Tag, Donnerstag, den 26. April, in Augsburg eintraf. ${ }^{62}$ Auch im Augsburgischen Intelligenzblatt wurde Beethovens Name korrumpiert wiedergegeben. Beethoven hat sich also nur eine Nacht in München aufgehalten und fuhr schon am folgenden Tag in das 41/4 Posten (ca. 63 km) entfernt liegende Augsburg weiter. Die Fahrzeit

Postkarte mit Routen der fahrenden Post, Teilblatt IV (Südbayern / Oberösterreich), 2. Hälfte 18. Jh., Original 13,5 x 20,5 cm (Privatbesitz) 
Beethoven-Namensformen 1787

05.01.1787 Regensburg Hr. Bertenhoven, Organist von Bont

Şr. Bertenl)uven, Sryanift von B̧unt

01.04.1787 Munchien Herr Peethofen, Musikus von Bonn bei Kölln.

\section{Sperr}

Peetboren. Mrujifus oon Bonn bci Gidln.

24.04 .1787 Regensburg Hr. Bethhoffen

\section{S. Bethloffien}

25.04.1787 Munchen Herr Peethowen, Kurköllnischer Kammervirtuos von Bonn.

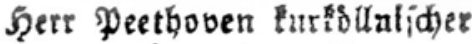 Sammerbirtude von Bonn.}

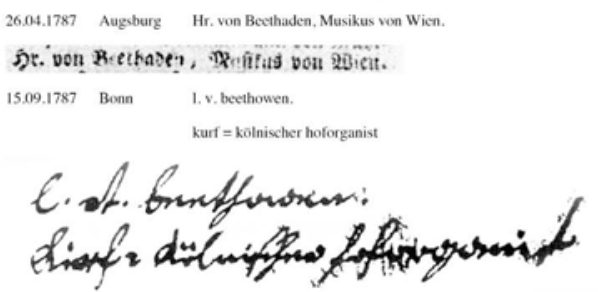

der regulären Postkutsche dorthin wäre mit 17 Stunden anzusetzen. ${ }^{63}$ Da jedoch am Donnerstag von München keine Postwagen abgingen, ${ }^{64}$ muss Beethoven eine andere "Mitfahrgelegenheit" nach Augsburg genutzthaben.Ausdrücklich erwähnt Beethoven seinen dortigen Besuch auch im schon zitierten Brief an den Freiherrn von Schaden. Mit Rückblick auf seinen damaligen Engpass in der Reisekasse schrieb er: "die außerordentliche güte und freundschaft, die sie hatten mir in augsburg drey k[a]r[o]lin [Carolin d'or] zu leihen, muß ich sie bitten noch einige nachsicht mit mir zu haben; meine reise hat mich viel gekostet ..." ${ }^{\prime 65}$ Der Fürstlich OettingenWallersteinsche Hofrat Freiherr von Schaden scheint auf dieser Reise Beethovens eine nicht unerhebliche Rolle gespielt zu haben, denn - wie bereits berichtet - am 1. April 1787 sind "Herr Peethofen, Musikus von Bonn bei Kölln; Herr Dürelli, Musikus von Regensburg; Herr von Schaden, mit dessen Frau, von Wallerstein ..."66 in München eingetroffen und haben zusammen im Gasthaus Zum Schwarzen Adler übernachtet. Beethoven hat also Freiherrn von Schaden auf seiner Reise mindestens zweimal, nämlich spätestens am 1. April in München sowie ab dem 26. April in Augsburg,

Gedruckte Namensformen des Regensburgischen Diariums, des Wochenblatts der Münchner Zeitung und des Augsburgischen Intelligenz-Blattes im Vergleich mit Beethovens eigenhändiger Unterschrift im Brief vom 15. September 1787 an Freiherrn von Schaden (Faksimile in: LUDWIG SCHIEDERMAIR, Der junge Beethoven, Bonn ${ }^{3}$ 1951, S. 128f.) getroffen. Vor allem die erwähnte Ehefrau des Barons von Schaden, Nanette von Schaden, geborene von Stadler (1763-1834), dürfte an Beethoven musikalisches Interesse gefunden haben; sie war als Schülerin Ignaz von Beeckes und Antonio Rossettis eine ausgezeichnete Pianistin, besaß eine ausgebildete Singstimme und komponierte auch selbst. ${ }^{67}$ Der genannte "Herr Dürelli, Musikus von Regensburg" war niemand anderer als der am Thurn und Taxisschen Hofe in Regensburg angestellte italienische Tenor Giuseppe Durelli, der bei der zweiten Periode der italienischen Oper im Regensburger Theater (1784/1786) das sogenannte "Ernste Fach" vertrat und 1788 am Münchner Hoftheater sang. ${ }^{68} \mathrm{Er}$ war nach der im Sommer 1786 vom Fürsten von Thurn und Taxis beschlossenen Abschaffung der italienischen Oper aus Regensburg abgereist ${ }^{69}$ und traf - vermutlich auf der Suche nach einem neuen Engagement - Anfang April 1787 mit Beethoven und dem Ehepaar von Schaden in München zusammen. Er ist höchstwahrscheinlich identisch mit demjenigen italienischen Tenor namens „Anton Dorelli“ [sic], der laut Felix Joseph Lipowsky (1764-1842) im Jahr 1788 als Hofsänger in kurbayerische Dienste trat. ${ }^{70}$ Sein vollständiger Name könnte Giuseppe Antonio Durelli gelautet haben.

Der junge Ludwig van Beethoven hatte also bereits auf seiner ersten Reise nach Wien Kontakte zu Angestellten der beiden musikalisch wichtigen Fürstenhöfe in Schwaben, zu Thurn und Taxis in Regensburg sowie zu Oettingen-Wallerstein, geknüpft. Die Hofkapellen der beiden Fürstenhäuser

448 | Dieter Haberl

(C) 2020 by Böhlau Verlag GmbH \& Cie. KG, Köln

https://doi.org/10.7788/9783412519704 | CC BY-NC 4.0 
zählten gerade im letzten Drittel des 18. Jahrhunderts zu den renommiertesten Klangkörpern im süddeutschen Raum. ${ }^{71}$ Ihnen gehörte eine Reihe bekannter Musiker an, die fast alle auch kompositorisch tätig waren. Stellvertretend seien hier nur Ignaz von Beecke (1733-1803), Antonio Rosetti (ca. 1750-1792), Franz Xaver Pokorny (1729-1794), Theodor von Schacht (1748-1823), Joseph Touchemoulin (1727-1801), Joseph Reicha (1752-1795) oder Joseph Riepel (1709-1782)genannt. Die beiden erhaltenen umfangreichen Musiksammlungen der Fürstenhäuser Oettingen-Wallerstein und Thurn und Taxis geben ein eindrucksvolles Zeugnis von dem an den beiden Höfen gepflegten Musikleben ab. ${ }^{72}$ - Wie eng die Beziehungen zwischen den beiden Fürstenhöfen waren, zeigt sowohl die Vermählung von Fürst Kraft Ernst zu Oettingen-Wallerstein (1748-1802) mit Maria Theresia Carolina (1757-1776), der ältesten Tochter des Fürsten Karl Anselm von Thurn und Taxis (1733-1805), im Jahr 1775 sowie die ausgedehnten Besuche des Fürsten von Oettingen-Wallerstein beim Fürsten von Thurn und Taxis in Regensburg und dessen Gegenbesuche. ${ }^{73}$ - Diese besten Beziehungen zwischen Regensburg und Oettingen-Wallerstein dürften auch dem jungen Beethoven nicht unbekannt gewesen sein, denn seit 1785 war er mit dem Bonner Hofmusiker Joseph Reicha (1752-1795) befreundet. Der Cellist Joseph Reicha war 1770 aus Böhmen kommend in Regensburg eingetroffen und aller Wahrscheinlichkeit nach zunächst als Musiker in Regensburg angestellt. ${ }^{74}$ Im Jahr 1774 wurde er erster Cellist der fürstlichen Hofkapelle in Wallerstein, und im April 1785 wechselte er als Solocellist und Direktor der Instrumentalmusik an den kurfürstlichen Hof nach Bonn. ${ }^{75}$ Sein Neffe Anton Reicha (1770-1836), den er von Wallerstein nach Bonn mitbrachte, wurde ein enger Freund Beethovens.

\section{Exkurs II: Die Familie Willmann und ihre Kontakte zu W. A. Mozart}

AufBeethovens Reisebegleiter bei seiner Rückreise aus Wien, den Musikdirektor Johann Ignaz Willmann und seine Wunderkinder, soll hier noch gesondert eingegangen werden, einerseits weil die Mitglieder der Familie Willmann in der bisherigen Forschungsliteratur öfter miteinander verwechselt wurden, andererseits weil ihrem Mozart-Kontakt eine wichtige Schlüsselfunktion zukommt. Bereits Karl Maria Pisarowitz (1901-1979) hatte vermutet, dass dieser "der Urheber von L. van Beethovens Schülerreise zu Mozart gewesen" sei. ${ }^{76}$ Obwohl Pisarowitz damals noch nicht den Nachweis für das gemeinsame Eintreffen Beethovens und Willmanns am 1. April 1787 in München kannte, hatte er aus seiner detaillierten Kenntnis der Willmannschen Familiengeschichte diese Hypothese ableiten - wenn auch noch nicht beweiskräftig unterstützen - können. Er wusste, dass sowohl eine Tochter von Willmanns Dienstherrn, dem Grafen Johann Pálffy-Erdöd, sowie die älteste Tochter des Musikdirektors selbst Klavierschülerinnen bei W. A. Mozart in Wien gewesen waren. ${ }^{77}$ Betrachten wir die beiden Mozart-Schülerinnen getrennt: 
Komtesse Josepha Gabriela Pálffy (*1765) war eine Tochter aus der Ehe zwischen Maria Gabriela Gräfin Colloredo, einer Schwester des Salzburger Erzbischofs Hieronymus Colloredo-Waldsee (1732-1812), und dem besagten Grafen Johann Leopold (János Lipót) Graf von Pálffy-Erdöd (1728-1791). ${ }^{78}$ W. A. Mozart berichtet über diese Schülerin an seinen Vater Leopold in einem Brief vom 4. Januar 1783 aus Wien: "Heute habe ich die ältere Comteße Balfi zur schüllerin bekommen, das ist, die tochter <des erzbischofs seiner Schwester> aber ich bitte es noch bey sich zu behalten, indemm ich nicht gewiss wissen kann, ob mann es gerne wissen lässt." ${ }^{179}$ Die damals 18-jährige Komtesse Pálffy-Erdöd war eine jener adligen Töchter, die Mozart wohl weniger aus musikalischem sondern vielmehr aus finanziellem Interesse zu unterrichten pflegte. Am 9. Januar 1784 gab Mozart beim Grafen Pállfy-Erdöd eine musikalische Akademie. ${ }^{80}$

Auch dem Musikdirektor Willmann war es gelungen - möglicherweise durch die Vermittlung seines Dienstherrn - seine eigene hochbegabte Tochter als Klavierschülerin Mozarts unterzubringen. Maximiliana Valentina Walburga Willmann (1769-1835, ab 1797 verheiratet mit Franz Xaver Huber (1755-1814), dem Textdichter von Beethovens Oratorium Christus am Ölberg, - war die ältere der beiden Töchter Willmanns aus erster Ehe. ${ }^{81}$ Sie debütierte schon als 14-Jährige zusammen mit ihren beiden Geschwistern Magdalena (1771-1801) und Max (1767-1813) als Wunderkind im Wiener Konzertprogramm des Jahres 1784.

Ausführliche Informationen zu dieser Mozart-Schülerin verdanken wir Ernst Ludwig Gerbers Neuem historisch-biographischen Lexikon der Tonkünstler:

„Willmann (Dem[oiselle]) die ältere, eine wohlgeratene Schülerin von Mozart im Klavierspielen, stand im J[ahr] 1791 noch in Churf[ürstlich] Cölnischen Diensten zu Bonn, wo sie in den Hofmusiken zuweilen spielte und dabey Unterricht im Klavierspielen gab. ... Wo sie gegenwärtig lebt, ist nicht bekannt. Erst zu Ende des 1801sten Jahres erfuhr man wieder von Leipzig, daß sie sich daselbst, als verheyratete Huber, mit einem von ihr gesetzten Konzerte fürs Fortepiano öffentlich hatte hören lassen, wobey Komposition und Spiel gerühmt wurden. Ganz besondere Kunstfertigkeit soll sie damals in Privatgesellschaften gezeigt haben." ${ }^{\text {"2 }}$

Wann genau Mozart sie als Schülerin annahm, ist nicht bekannt, ${ }^{83}$ doch muss es vor März 1787 gewesen sein, da sie am 7. März dieses Jahres bei einer Akademie im Kärntnertor-Theater das Klavierkonzert in C-Dur, KV 503, von W. A. Mozart zur öffentlichen Aufführung brachte, ${ }^{84}$ für Otto Erich Deutsch (1883-1967) ist das ein hinreichend zuverlässiges Zeichen für ihre Schülerschaft bei Mozart. ${ }^{85}$ O. E. Deutsch verwechselte allerdings den Vornamen der jungen Pianistin und schrieb Marianne anstatt Walburga, was auch zu "Marie" Willmann korrumpiert wurde. ${ }^{86}$ Den jungen Beethoven dürfen wir übrigens als Zuhörer dieses Klavierkonzertes im Kärntnertor-Theater vermuten, denn er wird - selbst in Wien anwesend (vgl. unten) - wohl kaum das öffentliche Konzert der jungen Bonner Mozart-Schülerin versäumt haben. ${ }^{87}$ 
Die jüngere der beiden Schwestern, Johanna Magdalena Willmann (17711801, ab 1796 verheiratet mit Antonio Galvani, einem Triester Kaufmann Trauzeuge war u. a. der Mozart-Schüler Franz Xaver Süßmayr) - wurde von Vincenzo Righini (1756-1812) zwischen ca. 1780 und 1786 in Wien zur Sängerin ausgebildet und bestach vor allem durch einen außergewöhnlich großen Stimmumfang in der Tiefe. Sie debütierte am 3. Dezember 1786 in Ignaz Umlaufs (1746-1796) Oper Der Ring der Liebe, oder Zemirens und Azors Ehestand im Wiener Kärntnertor-Theater. ${ }^{88}$ Wahrscheinlich komponierte Beethoven für sie 1791/92 in Bonn die Szene und Arie Primo amore, piacer del ciel (ursprünglicher deutscher Text Erste Liebe, Himmelslust) WoO 92, die mehrere besonders tiefe Passagen aufweist. ${ }^{89}$ Teilweise wurde sie mit J. I. Willmanns zweiter Gattin, Anna Maria Antonetta de Tribolet (1768-1813, ab 1793 verheiratete Willmann), also mit ihrer Stiefmutter, verwechselt, die ab 1795 ebenfalls als erfolgreiche Sängerin in Wien auftrat. Gerber schreibt:

„Willmann (Dem[oiselle]) der Vorhergehenden jüngere Schwester, ums J[ahr] 1798 erste Sängerin am Schikanederschen Theater zu Wien, geb[oren] zu Forchtenberg im Hohenlohischen ums J[ahr] 1775 [recte: Bonn, am 13. September 1771], gehört zu den berühmtesten deutschen Sängerinnen, gerühmt wegen ihrer wundervollen tiefen und dabey ungemein angenehmen Stimme, wegen ihrer Kunstfertigkeit und ihres Geschmacks im Vortrage und wegen ihrer vortrefflichen Aktion, so daß an dieser Künstlerin nichts zu wünschen übrig bleibt. Ihre erste Bildung hat sie wahrscheinlich der 1790 so herrlich blühenden Kapelle des Churfürsten von Cöln zu Bonn zu danken, wo sie als Mitglied derselben, aufgemuntert von diesem so liebenswürdigen Gönner und Kenner der Künste, Jahre lang unter den Rombergen, Beethoven und Neefen, täglich lebte und webte, bis der Krieg auch diesen angenehmen Musensitz zerstörte. Sie machte darauf 1792, in Gesellschaft ihres Vaters und ihrer Schwester, eine Reise an die vornehmsten Höfe im Reiche, wo sie allenthalben mit besonderer Auszeichnung aufgenommen wurde ..."90

Der ältere Bruder Maximilian Friedrich Ludwig Willmann (1767-1813), das Patenkind von Beethovens Großvater, war ein frühreifer Violoncello-Virtuose, über dessen Ausbildung bislang noch nichts bekannt ist. Er wurde um 1789 Violoncellist in der kurfürstlichen Hofkapelle in Bonn und wechselte ca. 1794 an den Thurn und Taxisschen Hof nach Regensburg. Ab 1798 war er Solocellist im Schikanederschen Theater an der Wien. ${ }^{91}$

Gegen Ende März 1787 reiste Vater Willmann über München und Mainz zurück nach Bonn zu seiner Frau Maria Elisabeth († 1789) und den beiden Söhnen Franz (1765-1789) und Karl (1773-1811), die in Bonn verblieben waren. ${ }^{92}$ Der bereits zitierte Eintrag im Wochenblatt der Münchner Zeitung "Herr Willmann, Musikdirektor bei S[eine]r Exz[ellenz] Herrn Grafen von Palfy von Wien mit 3 Kons[orten]" - dürfte ein Hinweis darauf sein, dass Willmann in Begleitung seiner drei Wunderkinder Walburga, Magdalena und Max reiste. 
Der Musikdirektor Willmann war also im direkten Bonner Umfeld der Familie Beethoven derjenige, der über die besten Kontakte zu W. A. Mozart in Wien verfügte. Es erscheint daher sehr naheliegend, dass der 16-jährige Ludwig van Beethoven zu dem mutmaßlich bereits ab April 1786 in Wien weilenden Johann Ignaz Willmann reiste, um auf diesem Weg Kontakt zu W. A. Mozart zu finden und so Unterricht von ihm zu erhalten. Der nun vorliegende Beleg für das gemeinsame Eintreffen Willmanns und Beethovens in München auf der Rückreise von Wien, erhärtet die Hypothese von Pisarowitz aus dem Jahr 1968.

\section{Beethovens erste Reise nach Wien - Rekonstruktion ihres Verlaufs}

Die Abreise aus Bonn muss, wie bereits oben angeführt, spätestens Ende 1786 erfolgt sein, denn die Länge der Postroute von Bonn nach Regensburg beträgt 311/2 Posten, das entspricht 126 Poststunden. Um am 5. Januar 1787 um 10 Uhr Vormittag in Regensburg eintreffen zu können, musste Beethoven also spätestens am Silvestertag des Jahres 1786 Bonn verlassen haben. Sollte er Reiseunterbrechungen vorgenommen oder Abstecher von der direkten Postroute gemacht haben, so müsste die Datierung der Abreise aus Bonn entsprechend vorverlegt werden. Die normale Reiseroute von Bonn nach Wien, wie sie auch auf einer zeitgenössischen belgischen Landkarte von 1789 beigedruckt ist, führte über Frankfurt am Main, Würzburg, Nürnberg nach Regensburg und weiter über Passau, Linz nach Wien.

Das Eintreffen in Regensburg steht für Freitag, den 5. Januar 1787, fest. Dass es sich um den Vortag des Festes Epiphanie (Fest der Erscheinung des Herrn bzw. der Heiligen Drei Könige) handelt, kann sich zufällig im Ablauf der Reise so ergeben haben. Sollte eine nicht auszuschließende Reiseplanung stattgefunden haben, so wäre der Zeitpunkt kirchenmusikalisch gesehen günstig gewählt. Der junge katholische Organist aus Bonn hätte am Dreikönigstag und dem daran anschließenden Sonntag (7. Januar) ausgiebig Gelegenheit gehabt, musikalisch feierlich gestaltete Gottesdienste in der alten Reichsstadt zu erleben (z. B. im Dom St. Peter, im Kollegiatstift Unserer Lieben Frau zur Alten Kapelle oder im Benediktinerstift St. Emmeram) und die verschiedenen Organisten und Orgelwerke der Regensburger Kirchen zu hören. Ob Beethoven diese Möglichkeiten nutzte oder eventuell sogar einige Tage in Regensburg verweilte, um nähere Kontakte zu Mitgliedern der Thurn und Taxisschen Hofkapelle aufzunehmen, muss offen bleiben. Früheste Gelegenheit mit dem Postwagen die Reise nach Wien fortzusetzen, bot sich für ihn erst am Dienstag, den 9. Januar, denn der sogenannte Wiener-Cours fuhr in Regensburg jeweils wöchentlich, Dienstag um 12 Uhr ab. ${ }^{93}$ Beethoven hätte somit Gelegenheit zu einem fünftägigen Regensburg-Aufenthalt gehabt. Die Möglichkeit, dass Beethoven schon früher in einer privaten Kutsche als Mitfahrer nach Wien weitergereist sein könnte, muss aber ebenfalls in Betracht gezogen werden. Die 


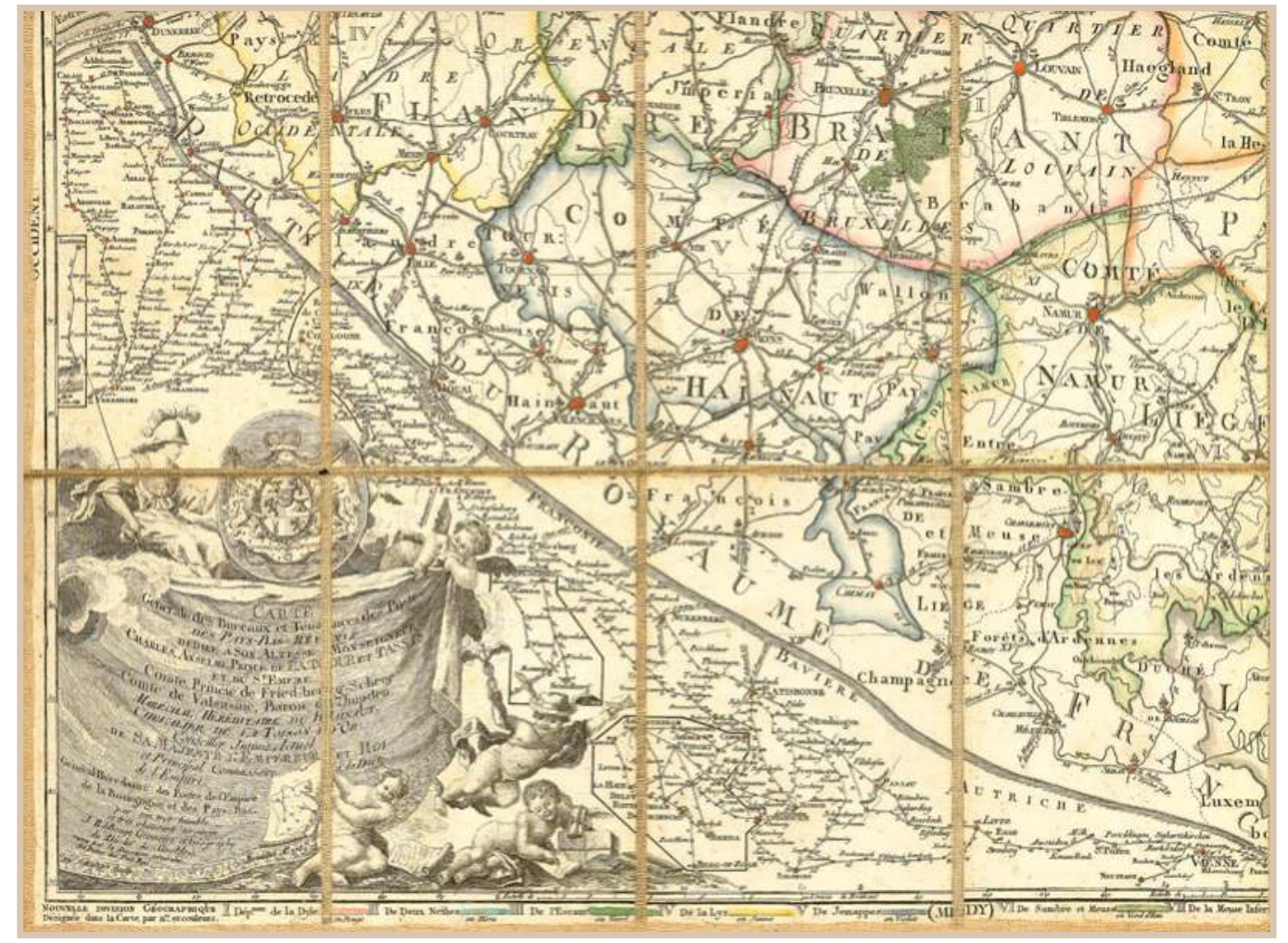

Personenschifffahrt auf der Donau in Richtung Wien ruhte zur Winterszeit und kann als Reisemittel ausgeschlossen werden.

Sollte Beethoven, wie bei seiner Einfahrt per Ordinari-Postkutsche am 5. Januar 1787 geschehen, Regensburg auch wieder mit der planmäßig verkehrenden Postkutsche verlassen haben, so wäre er frühestens am Sonntag, den 14. Januar 1787, in Wien eingetroffen. Das ergibt sich aus der Beschreibung, die der Wiener-Cours 1796 aufweist: „Eodem [Dienstags] 12 U[hr] Mittags. / Ueber Straubing, Plattling, Vilshofen, Passau, kommen allda an Mittwochs Mittags, gehen von da nach einer Stunde auf Linz, kommen allda Donnerstags Nachm[ittag], von da weiters nach Wien, und kommen allda Sonntags frühe an ..."94 Gönnte sich der Reisende keine längeren Erholungspausen, dann konnte er in quasi „ununterbrochener Fahrt" von Regensburg aus binnen sechs Tagen mit derPostkutsche Wien erreichen. Wieein Vergleich der Streckenführung für die Jahre 1764, 1787, 1789 und 1796 zeigt, hatte sich die Route RegensburgWien in mehr als drei Jahrzehnten nicht verändert. Auch ein Vergleich zwischen den Regensburger Abfahrtsterminen im Reise Atlas von 1796 und den Angaben des Regensburgischen Diariums für das Jahr 1787 ergibt, dass diese fast gleich geblieben waren. Die Abfahrt des Wiener Postwagens "Zum Ostentor hinaus" ist 1787 jeweils dienstags zwischen 12 Uhr Mittag und 2 Uhr Nachmittag genannt. ${ }^{95}$
Carte Générale des Bureaux et Ténances des Postes des Pay-Bas-Réunis - dédiée à son Altesse Monseigneur Charles Anselme, Prince de la Tour et Tassis, Brüssel 1789. Papier auf Leinwand, Original 49,5 x 66,5 cm (Ausschnitt) (Privatbesitz) 


\begin{tabular}{|c|c|c|c|c|c|c|c|}
\hline Dezember 1786 & Januar 1787 & Februar 1787 & März 1787 & April 1787 & Mai 1787 & Juni 1787 & Juli 1787 \\
\hline Fr 01.12. & Mo 01.01. Neujahr & $\overline{\text { Do } 01.02 .}$ & $\overline{\text { Do 01.03. }}$ & So 01.04. München & $\overline{\text { Di } 01.05 .}$ & $\overline{\text { Fr } 01.06 .}$ & $\overline{\text { So } 01.07}$ \\
\hline Sa 02.12 & Di 02.01 & Fr 02.02. & Fr 02.03. & Mo 02.04 & Mi 02.05 & Sa 02.06 & Mo 02.07 . \\
\hline So 03.12 . & Mi 03.01. & Sa 03.02 . & Sa 03.03 . & Di 03.04 . & Do 03.05. & So 03.06 . & Di 03.07. \\
\hline Mo 04.12. & Do 04.01. & So 04.02 . & So 04.03 . & Mi 04.04 & Fr 04.05. & Mo 04.06. & Mi 04.07. \\
\hline Di 05.12 . & Fr 05.01. Regensburg & Mo 05.02 . & Mo 05.03 . & Do 05.04 & Sa 05.05 . & Di 05.06. & Do 05.07. \\
\hline Mi 06.12. & Sa 06.01 & Di 06.02 . & Di 06.03 . & Fr 06.04. Karfreitag & So 06.05 . & Mi 06.06. & Fr 06.07 \\
\hline Do 07.12. & So 07.01 . & Mi 07.02. & Mi 07.03. & Sa 07.04. Karsamstag & Mo 07.05. & Do 07.06. & Sa 07.07. \\
\hline Fr 08.12. & Mo 08.01. & Do 08.02. & Do 08.03. & So 08.04 . Ostersonntag & Di 08.05 & Fr 08.06. & So 08.07 . \\
\hline Sa 09.12 . & Di 09.01. & Fr 09.02. & Fr 09.03 & Mo 09.04. Ostermontag & Mi 09.05. & Sa 09.06 . & Mo 09.07. \\
\hline So 10.12 . & Mi 10.01 & Sa 10.02 . & Sa 10.03 & Di 10.04 & Do 10.05 & So 10.06 . & Di 10.07 \\
\hline Mo 11.12 . & Do 11.01 . & So 11.02 . & So 11.03 . & Mi 11.04 & Fr 11.05 & Mo 11.06 & Mi 11.07 \\
\hline Di 12.12 . & Fr 12.01 & Mo 12.02 . & Mo 12.03 & Do 12.04 & Sa 12.05 & Di 12.06. & Do 12.07 . \\
\hline Mi 13.12 . & Sa 13.01 & Di 13.02 . & Di 13.03. & Fr 13.04 & So 13.05 . & Mi 13.06 & Fr 13.07. \\
\hline Do 14.12 . & So 14.01 . & Mi 14.02 . & Mi 14.03 & Sa 14.04 & Mo 14.05 . & Do 14.06 . & Sa 14.07 \\
\hline Fr 15.12. & Mo 15.01 . & Do 15.02 . & Do 15.03 . & So 15.04 . & Di 15.05 . & Fr 15.06. & So 15.07 . \\
\hline Sa 16.12 . & Di 16.01 . & Fr 16.02. & Fr 16.03 & Mo 16.04 & Mi 16.05 & Sa 16.06 & Mo 16.07 \\
\hline So 17.12 . & Mi 17.01 & Sa 17.02 . & Sa 17.03 . & Di 17.04 & Do 17.05 . & So 17.06 . & Di 17.07. Tod der Mutter \\
\hline Mo 18.12 . & Do 18.01 & So 18.02 & So 18.03 . & Mi 18.04 . & Fr 18.05 . & Mo 18.06 . & Mi 18.07 \\
\hline Di 19.12 . & Fr 19.01 & Mo 19.02. Rosenmontag & Mo 19.03 . & Do 19.04 & Sa 19.05 & Di 19.06. & Do 19.07 . \\
\hline Mi 20.12 & Sa 20.01 . & Di 20.02 . Fastnacht & Di 20.03 . & Fr 20.04 & So 20.05 . & Mi 20.06 & Fr 20.07 \\
\hline Do 21.12. & So 21.01 . & Mi 21.02. Aschermittwoch & Mi 21.03 & Sa 21.04 & Mo 21.05. & Do 21.06 & Sa 21.07 \\
\hline Fr 22.12 & Mo 22.01 . & Do 22.02 & Do 22.03 . & So 22.04 . & Di 22.05 . & Fr 22.06. & So 22.07 . \\
\hline Sa 23.12 & Di 23.01 . & Fr 23.02. & Fr 23.03. & Mo 23.04 & Mi 23.05. & Sa 23.06 . & Mo 23.07 . \\
\hline So 24.12 . Heiligabend & Mi 24.01 & Sa 24.02 . & Sa 24.03 & Di 24.04. Regensburg & Do 24.05 . & So 24.06 . & Di 24.07. \\
\hline Mo 25.12. Weihnachten & Do 25.01 . & So 25.02 . & So 25.03 . & Mi 25.04. München & Fr 25.05 & Mo 25.06 . & Mi 25.07 \\
\hline Di 26.12 & Fr 26.01 & Mo 26.02 . & Mo 26.03 . & Do 26.04. Augsburg & Sa 26.05 & Di 26.06 & Do 26.07 . \\
\hline Mi 27.12 & Sa 27.01 . & Di 27.02 . & Di 27.03 & Fr 27.04 & So 27.05 . Pfingsten & Mi 27.06 & Fr 27.07. \\
\hline Do 28.12 . & So 28.01 . & Mi 28.02 & Mi 28.03 & Sa 28.04 & Mo 28.05 & Do 28.06 . & Sa 28.07 \\
\hline Fr 29.12 & Mo 29.01 . & & Do 29.03 . & So 29.04 . & Di 29.05. & Fr 29.06. & So 29.07 . \\
\hline Sa 30.12 & Di 30.01. & & Fr 30.03 & Mo 30.04 & Mi 30.05 & Sa 30.06 & Mo 30.07 . \\
\hline So 31.12 . Silvester & Mi 31.01. & & Sa 31.03 . & & Do 31.05 . & & Di 31.07. \\
\hline
\end{tabular}

Kalender Dezember 1786-Juli 1787 mit nachweisbaren Reisedaten
Für Beethovens Aufenthalt in Wien sind bislang keine archivalischen Quellen gefunden worden. Überliefert sind lediglich die Berichte und Anekdoten verschiedener Zeitgenossen, die aber erst in großem zeitlichen Abstand zur ersten Wien-Reise, und zwar erst nach Beethovens Tod aufgezeichnet wurden. ${ }^{96}$ Außer Zweifel steht, dass Beethoven in Wien gewesen ist, denn der Eintrag im Augsburgischen Intelligenz-Blatt zum 26. April 1787 nennt ihn, im Gegensatz zu allen übrigen Zeitungsnachweisen, die sein Dienstverhältnis angeben, ausdrücklich als einen "Musikus von Wien".97 Diesen Wiener Aufenthalt kann man nun mit einer Datierungshypothese umreißen: Da durch das Eintreffen in Regensburg (5. Januar 1787) und in München (1. April 1787) sowie durch die beschriebenen Reiserouten und-geschwindigkeiten der Postkutschen Erkenntnisse über ein frühestmögliches Eintreffen und eine spätestmögliche Abreise aus Wien gewonnen werden können, lässt sich die maximale Länge des WienAufenthaltes bestimmen. Beethoven kann mit der Postkutsche frühestens am 14. Januar 1787 (mit einer eher aufgebrochenen oder schneller fahrenden Privatkutsche eventuell schon um den 12. Januar) in Wien eingetroffen sein und muss Wien spätestens am 28. März 1787 wieder verlassen haben, um am 1. April in München anzukommen: Daraus ergibt sich eine maximale Aufenthaltsdauer von 101/2 Wochen. Mögliche Abweichungen von der Hauptreiseroute oder Zwischenaufenthalte auf den Strecken Regensburg-Wien bzw. Wien-München würden natürlich eine Verkürzung des Wiener Aufenthalts bedeuten.

454 | Dieter Haberl

(C) 2020 by Böhlau Verlag GmbH \& Cie. KG, Köln

https://doi.org/10.7788/9783412519704 | CC BY-NC 4.0 
Dass Beethoven nach seinem Eintreffen in München am 1. April noch einmal zurück nach Wien gereist sein könnte, wäre zwar theoretisch möglich, ist aber vor dem Hintergrund seiner finanziellen Situation sehr unwahrscheinlich. Plausibler hingegen erscheint, dass die Ankunft in München am Palmsonntag (1. April) eventuell im Zusammenhang mit kirchenmusikalischen Aufführungen im Rahmen der Kar- und Osterwoche stehen könnte. Einerseits ist möglich, dass Beethoven die Karwoche und die Osterfeiertage in München verbrachte und eventuell zusammen mit seinen Reisebegleitern, dem Ehepaar von Schaden und Musikdirektor Willmann, die Akademiekonzerte und Opernaufführungen in der Woche ab dem Ostermontag (9. April) besuchte. Andererseits bedeutet der Nachweis einer Abfahrt per Postkutsche am 24. April 1787 von Regensburg nach München, dass zwingend vor diesem Termin, also in der Zeit zwischen dem 2. und dem 22. April, ein Ortswechsel von München nach Regensburg stattgefunden haben muss, der nicht in den Diarien vermerkt ist. Dieser zweite Besuch Beethovens in Regensburg - bereits auf der Hinreise nach Wien war er am 5. Januar hier eingetroffen - darf auch im Zusammenhang mit Beziehungen zu Mitgliedern der Thurn und Taxisschen Hofkapelle gesehen werden. Diese können auf mehreren Wurzeln basieren: Zunächst muss der Sänger Durelli genannt werden, der zusammen mit Beethoven in der Nacht vom 1. zum 2. April im Gasthaus Zum Schwarzen Adler in München übernachtet hat. Ebenso kann der französische Violinist und Komponist Joseph Touchemoulin erwähnt werden, der direkter Amtsvorgänger von Beethovens Großvater als Kapellmeister der Bonner Hofkapelle gewesen ist und seither am Thurn und Taxisschen Hof in Regensburg angestellt war. Auch der Musikdirektor Johann Ignaz Willmann, der zusammen mit Beethoven am 1. April in München eintraf, dürfte gute Kontakte zum Haus Thurn und Taxis gepflegt haben, denn bereits 1767 besuchte er als kurkölnischer Konzertmeister die Stadt und sicher auch den Hof in Regensburg ${ }^{98}$, und von etwa 1794 bis zum Jahr 1798 hatte sein Sohn Max Willmann (1767-1813) die Stelle eines Violoncellisten in der Regensburger Hofkapelle inne. ${ }^{99}$

Ein weiterer möglicher Anreiz für Beethoven, ein zweites Mal nach Regensburg zu reisen, könnte eine wirklich außergewöhnliche musikalische Aufführung am Karsamstag, den 7. April, gewesen sein. An diesem Tag um 18 Uhr ist nämlich, wie neue Forschungen zeigten, in der Augustinerkirche in Regensburg von der fürstlich Thurn und Taxisschen Hofmusik die Instrumentalfassung der Sieben letzten Worte unseres Erlösers am Kreuze von Joseph Haydn erstmals in Regensburg, ja zum dritten oder vierten Mal seit der Uraufführung überhaupt, aufgeführt worden. Der Komponist selbst hatte die als Karfreitagsmusik für Cádiz in Spanien bestellte Komposition am 26. März 1787 im Palais Auersperg in Wien dirigiert und man darf - solange keine früheren Aufführungen nachweisbar sind - annehmen, dass es sich dabei um die Uraufführung des Werkes handelte. Nur wenige Tage später, am 30. März 1787, erklangen dann die 
Sieben letzten Worte in Bonn unter der Leitung des Beethoven-Freundes Joseph Reicha. ${ }^{100}$ - Ob die für die Karfreitagsandacht am 6. April 1787 in der Santa Cueva in Cádiz angenommene Aufführung tatsächlich stattfand, konnte noch nicht geklärt werden. ${ }^{101}$ - Die Regensburger Aufführung am 7. April 1787 ist hingegen durch zwei Aufführungshinweise im Regensburgischen Diarium hinreichend belegt. ${ }^{102}$

Es ist möglich, dass Beethoven die Wiener Aufführung vom 26. März 1787 kurz vor seiner Abreise noch miterlebt hat, zumindest dürfte er jedoch von der dort geplanten Aufführung der neuesten Haydnschen Musik Kenntnis erlangt haben. Durch briefliche Kontakte nach Bonn - diese bestanden zumindest zu seinem Vater Johann ${ }^{103}$ - konnte er von der dortigen Aufführung unter Joseph Reicha Kunde erhalten haben. Auch Durelli konnte ihm am 1. April in München eventuell von der bevorstehenden Aufführung der fürstlichen Hofkapelle am 7. April 1787 in Regensburg berichtete haben. Hier sind zukünftige Untersuchungen gefordert, weitere belegbare Daten zu liefern. Beim derzeitigen Stand der Forschung kann weder die Länge des Aufenthaltes in München ab dem 1. April 1787 noch die Dauer des zweiten Regensburger Aufenthalts vor dem 24. April 1787 genauer angegeben werden.

Bei seiner Abreise aus Regensburg am 24. April scheint es Beethoven eilig gehabt zu haben, denn er gönnte sich in München (25. April) nur eine Übernachtung und reiste am folgenden Tag sofort nach Augsburg weiter. Es kann aber nicht der Gedanke einer schnellen Heimreise nach Bonn gewesen sein, der ihn nach Augsburg fahren ließ, denn von Regensburg aus wäre die Reise via Nürnberg-Würzburg-Frankfurt nach Bonn auf direkterem Wege möglich gewesen. Es muss andere Gründe gegeben haben, die Beethoven einen Umweg über Augsburg machen ließen. Neben dem bereits mehrfach erwähnten Baron von Schaden, der "ums Jahr 1788" zusammen mit seiner Frau Nanette in Wallerstein lebte ${ }^{104}$ und bei seinen Besuchen in der Stadt Augsburg - er war ab 1786 auch Augsburger Ratskonsulent ${ }^{105}$ - regelmäßig im Gasthaus Zum weißen Lamm übernachtete ${ }^{106}$, kommt als weitere Augsburger Kontaktperson der bekannte Klavier- und Orgelbauer Johann Andreas Stein (17281792) in Frage. Zunächst als Orgelbauer tätig, hatte sich Stein ab 1755 zunehmend mit dem Bau von Klavieren beschäftigt, konstruierte einen neuen Auslösemechanismus, die sogenannte Deutsche oder auch Wiener Mechanik, die von W. A. Mozart besonders geschätzt wurde. ${ }^{107}$ Auch das schon in anderem Zusammenhang zitierte anonyme Schreiben aus Bonn vom 8. April 1787 bezeugt die mehrfache Präsenz Steinischer Klaviere in Bonn: „Das Clavier wird vorzüglich geliebt; wir haben hier mehrere Steinische Hammerclaviere von Augsburg, und andere denen entsprechende Instrumente". ${ }^{108}$ Es war also für Beethoven durchaus naheliegend, dem von W. A. Mozart und den Bonner Musikern gleichermaßen geschätzten Augsburger Instrumentenbauer auf der Rückreise einen Besuch abzustatten. Außerdem ist auch von Beethoven über- 
liefert, dass er es bereits in Bonn gewohnt war, " "nur auf einem Steinischen zu spielen". 109 Die Tochter des Augsburger Klavierbauers Stein, Anna Maria, genannt Nanette (17691833), erinnerte sich noch im Jahr 1824, als sie zusammen mit ihrem Ehemann Johann Andreas Streicher (1761-1833) Beethoven in Wien traf, an den Besuch Beethovens in der Werkstatt ihres Vaters in Augsburg im Jahr 1787. ${ }^{110}$

Aber auch musikalische Aufführungen könnten für Beethovens AugsburgBesuch mitverantwortlich sein. Auffällig zahlreich sind im Augsburgischen Intelligenz-Blatt im Umkreis von Beethovens Eintreffen nämlich die Einträge von Musikern, Sängern und musikkundigen Zuhörern. Diese Ansammlung von Ausführen den und Publikum könnte auf eine größere musikalischeVeranstaltung Ende April oder Anfang Mai in Augsburg hindeuten. Unter den prominenten Gästen finden sich "H[err] Ape, Hofschauspiel Director von Durlach", "H[er]r Baron v[on] Welden von Laubheim, Hochfürstl[ich] Thurn- und Taxischer Regierungspräsident mit Suite kommt von Regensburg" ",H[er]r Musik-Directeur Hueber von Kaufbeuren nebst Frau und Gesellschaft", "Frau Gräfin von Fugger", "HerrWeisgerbermit drey Cons[orten] Virtuosen [d.h. Sängern] von Regensburg", "Sign[o]r Balestrini [Solooboist] aus Regensburg", "H[er]r Verandeny Musikus von München", "H[er]r Jäger Musik Director von Anspach mit H[er]rn Sohn", "H[er]r Hofkammerrath Kramer von Wallerstein", "S[ein]e Exc[ellenz] H[er]r Baron v[on] Lehrbach K. K. Minister an churpfalzbairischen Hof und schwäbischen Kreis mit Suite" sowie "H[er]r Graf Fugger von Diettenheim nebst Frau Gräfin. und Dienerschaft". 111 Sicherlich ist bei dieser illustren Zusammenkunft Musik erklungen und wahrscheinlich hat Beethoven selbst sich auch auf einem Steinischen Flügel hören lassen. Hier sind wiederum zukünftige Forschungen in Augsburg gefordert, weitere Belege für das musikalische Programm dieses Zeitraums zu suchen, denn es ist anzunehmen, dass sich Beethoven für mehrere Tage in Augsburg aufgehalten hat. Diese Annahme wird auch durch den Hinweis auf ein Orgelkonzert und mehrmaliges Phantasieren auf Steinischen Klavieren unterstützt, der sich, basierend auf einer Aussage von Nanette Streicher, im Reisetagebuch von Dr. med. Karl Bursy (1791-1870) unter dem Eintrag vom 24. Juni 1816 erhalten hat. ${ }^{112}$

Über den Verlauf von Beethovens Reiseroute von Augsburg nach Bonn ist bisher nichts bekannt. Die kürzest mögliche Postkutschenstrecke wäre über Frankfurt am Main verlaufen. Die Fahrt von Augsburg nach Frankfurt dauerte 68 Poststunden, wobei man drei Nächte im Wagen zubringen musste ${ }^{113}$; für die Strecke Frankfurt am Main bis Bonn sind abermals 42 Stunden zu veranschlagen. Daraus folgt, dass Beethoven selbst bei einem nur kurzen Augsburg-

Inschrift am ehemaligen Wohnhaus von Johann Andreas Stein in Augsburg, Ulrichsplatz Nr. 10 (Foto: Dieter Haberl) 
Aufenthalt und keinen weiteren Fahrtunterbrechungen Bonn frühestens am fünften Tag nach der Augsburger Abreise, also erst im Monat Mai hat erreichen können.

\section{Zusammenfassung und Ausblick}

Beethovens erste Reise nach Wien hat bereits Ende 1786 begonnen und bis mindestens in den Mai 1787 gedauert; sie war daher sicher mit einer mehr als viermonatigen Abwesenheit von Bonn (minimal 121 Tage) verbunden. Aus den durch die Zeitungseinträge (im Regensburgischen Diarium, im Wochenblatt der Münchner Zeitung und im Augsburgischen Intelligenz-Blatt) gewonnenen Rahmendaten der Reise kann die Reiseroute über Regensburg (5. Januar 1787), eine Ankunft in Wien im Januar 1787 und die Abreise aus Wien im März 1787 abgeleitet werden. Die neue Chronologie legt die Vermutung nahe, dass der Wien-Aufenthalt des Jahres 1787 für Beethoven fruchtbarer war, als man bisher glaubte. ${ }^{114}$

Setzen wir die Wiener Anwesenheiten Beethovens und Mozarts in zeitliche Relation: Mozart war am 8. Januar 1787 nach Prag abgereist und um den 12. Februar nach Wien zurückgekehrt. ${ }^{115}$ Beethoven und Mozart hatten also von Mitte Februar bis maximal Ende März sechs Wochen lang Gelegenheit zum persönlichen Kontakt in Wien. Die bisherige Hypothese vom 14-tägigen WienAufenthalt Beethovens im April 1787 wurde durch die vorangegangenen Ausführungen hinreichend entkräftet.

Die Rückreise erfolgte zunächst nach München (1. April 1787), woran sich, als Abstecher von der gewählten Rückreiseroute, ein zweiter Aufenthalt in Regensburg anschloss. Dieser endete am 24. April 1787 mit der Abreise via München nach Augsburg, wo Beethoven am 26. April 1787 eintraf. Da die schnellere Rückreisemöglichkeit nach Bonn von Regensburg aus bestanden hätte, ist ein wichtiger Grund für den „Umweg” Augsburg anzunehmen. Die Nachricht vom aussichtslosen Gesundheitszustand seiner Mutter kann Beethoven also nicht schon in Wien erhalten haben, sonst hätte er die zweimalige Passage München-Regensburg, Regensburg-München nicht in sein Rückreiseprogramm aufgenommen. Da Beethoven zwischen Mai und Mitte Juli in Bonn eingetroffen sein muss (er traf seine Mutter noch lebend), könnten sich an den Augsburger Aufenthalt ein derzeit noch nicht belegbarer Besuch in Wallerstein sowie andere bisher unbekannte Reisestationen auf dem Heimweg nach Bonn, möglicherweise in Begleitung der Musikerfamilie Willmann, angeschlossen haben.

Die vieldiskutierte Schülerreise Beethovens zu Mozart nach Wien konnte durch die neu erschlossenen Quellen zwar nicht unmittelbar dokumentarisch belegt werden, doch konnte durch die Richtigstellung der Rahmendaten der Reise der Zeitraum, in dem ein persönlicher Kontakt zwischen Mozart und Beethoven bestanden haben kann, wesentlich ausgeweitet werden. Zukünftige 
Forschungen werden im neu erschlossenen Zeitraum Dezember 1786 bis Mai/ Juli 1787 nach weiteren Belegen für Ludwig van Beethovens Anwesenheit außerhalb Bonns Ausschau halten.

Dieser Beitrag basiert in wesentlichen Teilen auf einem Vortrag, den der Verfasser am 8.5.2006 an der Universität Augsburg gehalten hat; veröffentlicht in: Neues Musikwissenschaftliches Jahrbuch 14, 2006, S. 215-255. Die hier vorliegende Fassung wurde auf den aktuellen Forschungsstand gebracht, neue Forschungsergebnisse eingearbeitet und neuere Forschungsliteratur ergänzt.

Vgl. Rudolph Angermüller, Mozarts Reisen in Italien, Bad Honnef 1994, S. 64-69, 147-152.

Vgl. Salzburger Mozart-Lexikon, hg. vom Land Salzburg und der Internationalen Salzburg Association unter der Leitung von GERHARD AMMERER und RUDOLPH ANGERMÜLLER, Bad Honnef 2005, S. VIII.

ULRICH KONRAD, Mozart: Briefe und Aufzeichnungen. Gesamtausgabe. Erweiterte Ausgabe mit einer Einführung und Ergänzungen, 8 Bde, Kassel u.a. 2005, hier Bd. 2, S. 473.

Vgl. Anton SCHIndLeR, Biographie von Ludwig van Beethoven, Münster ${ }^{31860,}$, Nachdruck in: Reclams Universal-Bibliothek 496, Leipzig 41988, S. 60

Ohne die besondere Gunst des neuen Kurfürsten Maximilian Friedrich hätte der Großvater Ludwig van Beethovens 1761 wohl nicht die Nachfolge des Bonner Kapellmeisters Joseph Touchemoulin erhalten. Der Kurfürst reduzierte nach seinem Regierungsantritt (1761) zunächst schrittweise das Salär des jungen Touchemoulin bis dieser frei resignierte und ernannte schließlich am 16.7.1761 Beethovens Großvater, Louis van Beethoven (1712-1773), zum Kapellmeister. Vgl. JeAN HARDEN, Touchemoulin, in: The New Grove Dictionary of Music and Musicians (NGroveD) 19, London 1980, S. 92, sowie 22001, S. 651. Touchemoulin ging anschließend als Konzertmeister an den Thurn und Taxisschen Hof nach Regensburg

Es handelte sich um die damals 18-jährige Hofaltistin Johanna Helene Averdonc (1760-1789). Vgl. THEOdor FrImmEL, Beethoven-Handbuch, 2 Bde, Leipzig 1926, hier Bd. I, S. 26

Vgl. H. C. RobBins LANDON, Ludwig van Beethoven. Leben und Werk in Zeugnissen der Zeit, Stuttgart 1994, S. 26

Vgl. FrIMmel, Beethoven-Handbuch 1 (wie Anm. 7), S. $118 f$.

Vgl. Wolfgang AleXander Thomas-San-Galli, Ludwig van Beethoven, München 1921 , S. 36; Walther Engelhardt (Hg.), Christian Gottlob Neefens Lebenslauf von ihm selbst beschrieben. Nebst beigefügtem Karakter 1789 (Beiträge zur Rheinischen Musikgeschichte 21), Köln 1957, S. 22

Vgl. Carl Friedrich Cramer, Magazin der Musik, Hamburg 1783, S. $394 f$

Vgl. AleXander Wheelock Thayer, Ludwig van Beethoven's Leben, nach dem Original-Manuscript deutsch bearbeitet von HeRMANn DeITERS, 3 Bde, Berlin 1866, 1872, 1879, hier Bd. 1, S. 155.

Vgl. FrIEDRICH KERST, Die Erinnerungen an Beethoven gesammelt und herausgegeben, 2 Bde, Stuttgart 1913, hier Bd. 1, S. 60 
and in the spring of 1787 Beethoven visited Vienna. In absence of documents much remains uncertain about the precise aims of the journey and the extent to which they were realized; but there seems little doubt that he met Mozart and perhaps had a few lessons from him. It seems equally clear that he did not remain in Vienna for longer than about two weeks." JOSEPH KERMAN und ALAN TYSON (with SCOTT G. BURNHAM), Beethoven, Ludwig van, § 2 Youth, in: NGroveD 3, London u. a. ${ }^{22} 2001$, S. 74

15 Sieghard Brandenburg, Ludwig van Beethoven Briefwechsel. Gesamtausgabe, 7 Bde, München 1996-1998, hier Bd. 1, Nr. 3

ANTON SCHINDLER, Biographie von Ludwig van Beethoven, Münster 1840, S. 24

Wilhelm von Lenz, Beethoven et ses trois Styles, St. Petersburg 1852, S. 134; Ders., Beethoven, eine Kunststudie, I. Das Leben, Kassel 1855, S. 15; Ders., dasselbe, Neudruck mit Ergänzungen und Erläuterungen von ALfRED CHRISTIAN KALISCHER, Berlin/ Leipzig 1908, S. $28 f$

OTtO JaHN, W. A. Mozart, 4 Bde, Leipzig 1856-1859, hier Bd. 3, 1858, S. 306

SCHINDLER, Beethoven, 1860 (wie Anm.5), S. 60. Er bezieht sich auf Franz GERHARD Wegeler und Ferdinand Ries, Biographische Notizen über Ludwig van Beethoven, Koblenz 1838

GerHARD VON Breuning, Aus dem Schwarzspanierhause, Wien 1874, S. 30

KLaUs Kropfinger, Beethoven, in: Die Musik in Geschichte und Gegenwart (MGG), Personenteil, Bd. 2, Kassel 21999, S. 743. Kropfinger setzt nach dem Mozart-Kontakt Beethovens ein "[?]", übernimmt aber die von Eduard Panzerbieter abgeleitete Zeitspanne "7.-25. April" für die Gesamtdauer des Wien-Aufenthalts im Jahr 1787; vgl. EdUARD PANZERBIETER, Beethovens erste Reise nach Wien im Jahre 1787, in: Zeitschrift für Musikwissenschaft 10, Oktober 1927 - September 1928, S. 153-161 (Reprint Breitkopf \& Härtel Wiesbaden 1971). Vgl. auch KERMAN/TYSON, Beethoven (wie Anm. 14), S. 74: „... did not remain in Vienna for longer than about two weeks."

AleXANDER WheElock THAYER, Ludwig van Beethovens Leben, nach dem Original-Manuskript deutsch bearbeitet, neu bearbeitet und ergänzt, von HERMANN DEITERS, Berlin 21901, Bd. 1, S. 196 Anm. 2; DeRs., Ludwig van Beethovens Leben, nach dem Original-Manuskript deutsch bearbeitet von HeRMANn DeITERS, hg. von Hugo RIEMANN (Thayer/Deiters/Riemann), 5 Bde, Leipzig 31907-1917, hier Bd. 1, Leipzig 1917 (Reprint Hildesheim 1970 und 2001), S. 213 Anm. 1.

FRIMMEL, Beethoven-Handbuch 1 (wie Anm. 7), S. 431

Vgl. PANZERBIETER, erste Reise (wie Anm. 21)

Ebd., S. 154

Joseph SCHMIdT-Görg, Beethoven, in: MGG 1, 1949, Sp. 1509-1565, hier Sp. 1515.

WALter RieZler, Beethoven, Zürich 1936, 101971, S. 22f.; LUDWIg SCHIEDermair, Der junge Beethoven, Bonn 31951, S. 119-123; DERS., dasselbe, neu bearbeitet von LUDWig-Ferdinand SChiedermaiR, Wilhelmshafen 1970, S. 77-79; Stephan Ley (Hg.), Biographie von Ludwig van Beethoven, verfaßt von Anton Schindler. In verkürzter Form mit berichtigenden Anmerkungen, Bonn 1949, S. 469; MAYNARD SOLOMON, Beethoven. Biographie, München 1979, S. 47; Donald W. MACArdLE (Hg.), Beethoven as I knew him, Mineola/New York 1996, S. 82 Anm. 27

29 Barry CoOper, The Beethoven Compendium. A Guide to Beethoven's Life and Music, London 1991, First paperback edition with corrections 1996, S. 13; DERS., Das Beethoven-Kompendium. Sein Leben - seine Musik, München 1992, S. 13 


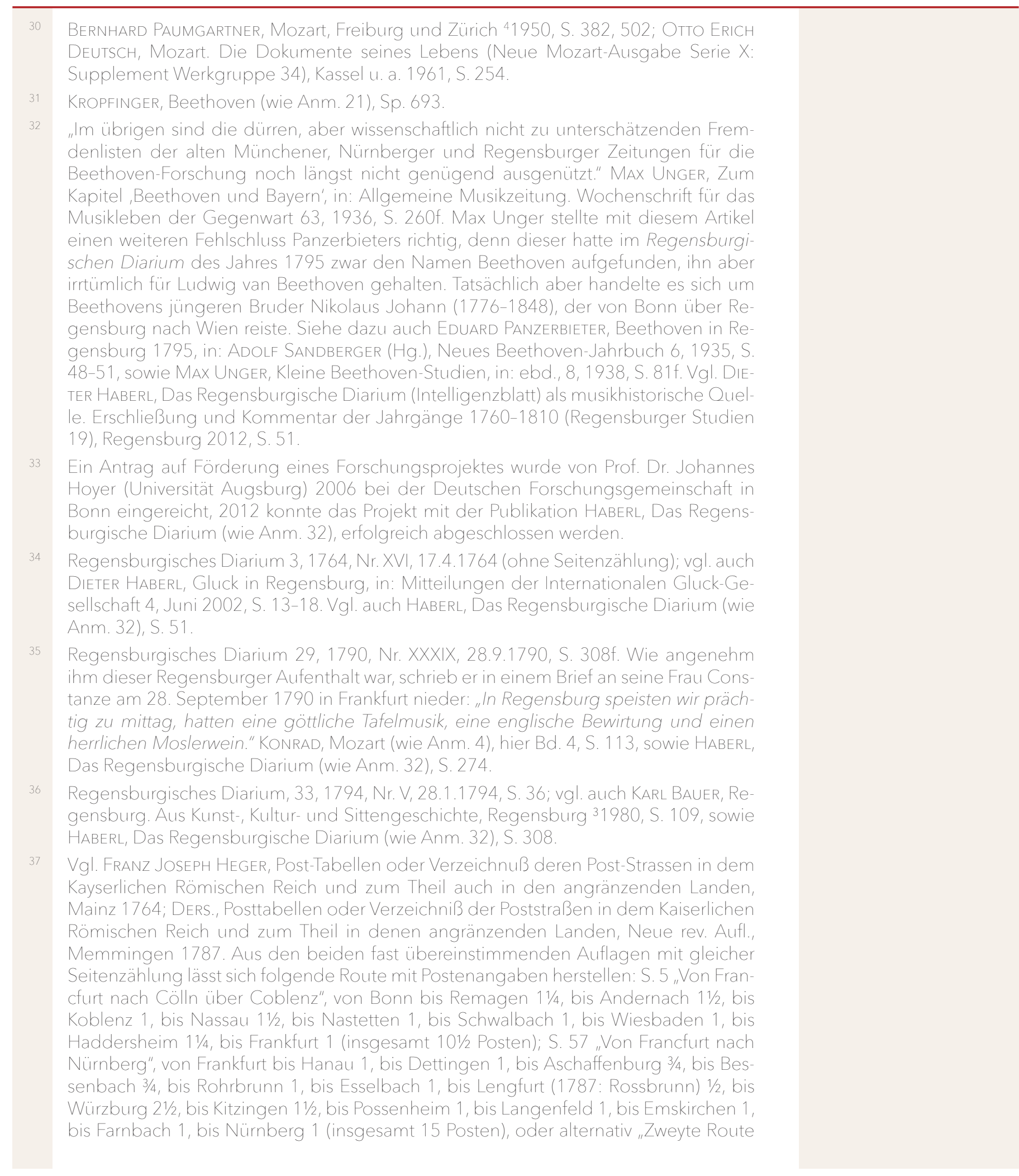

Beethovens erste Reise nach Wien 1786/87 | 461 (c) 2020 by Böhlau Verlag GmbH \& Cie. KG, Köln https://doi.org/10.7788/9783412519704 | CC BY-NC 4.0 
über Miltenberg und Anspach", von Frankfurt bis Aschaffenburg 23/4, bis Obernburg 1, bis Miltenberg 1, bis Hundheim 1, bis Bischoffsheim 1, bis Würzburg 11/2, bis Ochsenfurt 1, bis Uffenheim 11/2, bis Obernzenn 11/4, bis Anspach 11/4, bis Kloster Heilsbronn 1, bis Nürnberg 11/2 (insgesamt 153/4 Posten); S. 62 "[Von Nürnberg] nach Regensburg", von Nürnberg bis Amberg 41/2, bis Schwandorff 11/2, bis Pirckensee 11/4, bis Regensburg 11/4/4 (insgesamt 8 1/2 Posten), oder alternativ „Zweyte Route”, Nürnberg bis Feucht 1, bis Postbaur 1, bis Teiningen 1, bis Parsberg 1, bis Labor 1 bis Regensburg 1 (insgesamt 6 Posten); insgesamt Bonn-Regensburg 311/2 bzw. alternativ 343/4 Posten. 1 Posten (Poststation) entspricht 4 Poststunden. 1 Poststunde entspricht $1 / 2$ Meile $=12703$ $F u ß=3707,5 \mathrm{~m}$. Selbst die Briefbeförderung ist für das Jahr 1802 auf der Strecke Bonn-Regensburg mit fünf Tagen angegeben, vgl. Wegweiser in der Kaiserl. Freyen Reichsstadt Regensburg und ihrer Gegend, Regensburg 1802, S. 63

Regensburgisches Diarium 26, 1787, Nr. II, 9.1.1787, S. 11. Vgl. auch HABERL, Das Regensburgische Diarium (wie Anm. 32), S. 239

Vgl. Wegeler/Ries, Biographische Notizen (wie Anm. 19), S. 11 f.

Vgl. Thayer/Deiters/Riemann (wie Anm. 23), hier Bd. 1, S. 197-199.

SCHIEDERMAIR, Der junge Beethoven (wie Anm. 28), S. 125; zwischen S. 128 und 129 findet sich der Brief auch als Faksimile abgedruckt.

Die beiden Nummerierungen finden sich auf dem heute noch am Gebäude angebrachten älteren Hausnummernschild, das die moderne Hausnummernzählung mit Straßenname (Spiegelgasse 4) und die alte Zählung nach der Litera-Benennung mit Wachtzugehörigkeit (Lit. C [Wildwercherwacht] 98) angibt.

Vgl. BAUER, Regensburg (wie Anm. 36), S. 191. Vgl. Wegweiser (wie Anm. 37), S. 51 f., § 40: "Gastgeber und Weinwirthe / ... / Der goldene Spiegel"

Kurfürstlich gnädigst privileg. Münchner Zeitung, verlegt von JOSEPH LUDWIG EDLEN VON DROu In, jeweils mittwochs als Teil dieser Zeitung "Wochen Blat" [sic] mit "Anzeige der hier angekommenen Fremden": Nr. XIV, 4.4.1787 (ohne Seitenzählung).

Vgl. Robert MünSTER, „ich würde München gewis Ehre machen": Mozart und der Kurfürstliche Hof zu München, Weißenhorn 2002, S. 62, 66, 68, 82, 134, 136; ein Porträt des Mozart-Freundes, den die Münchner den "gelehrten Wirt" nannten, ebd. S. 61. Vgl. Thayer/Deiters/Riemann (wie Anm. 23), hier Bd. 1, S. 52, 59, 243 und 462; vgl. Inge Forst und GÜnther MASSEnkEIL, Bonn, in: MGG, Sachteil 2, Kassel u. a. 1995, Sp. 59.

47 Thayer, Beethoven's Leben (wie Anm. 12), hier Bd. 1, Anhang VII, S. 348

Wiener Zeitung Nr. 23, 20.3.1784, Anhang zur Wiener-Zeitung Nr. 23. 1784, S. $585 f$. "Nationalhoftheater. ... - Die am 16. [März 1784] gehaltene musikalische Akademie gab Herrr [sic] Willmann zum Vortheil seiner Kinder, und der M[ademoise]lle Ringbauer. Die jüngere Mlle. Willmann sang, die ältere spielte auf den Forte piano, und ihr Bruder auf dem Violoncello. Mlle. Ring bauer, in einem Altervon 12 Jahren ließ sich auf der Violine hören." Zu Ringbauer vgl. ERnSt LUdWIG GeRBER, Historisch-Biographisches Lexicon der Tonkünstler, Leipzig 1790-1792, II. Teil, Sp. 293.

49 ROBert HaAs, Wenzel Müller, in: Mozart-Jahrbuch 1953, hg. von der Internationalen Stiftung Mozarteum, Salzburg 1954, S. 81-84, hier S. 81

Vgl. Karl Maria Pisarowitz, Willmann, in: MGG 14, Kassel 1968, Sp. 692-694.

Vgl. Adrian von RiedL, Reise Atlas von Bajern, München 1796, Erste Lieferung, Beylage Nro. II [S. 23]: „Nach München zurück kommt der Postwagen am Sonntage Morgens um 10 Uhr aus Ungarn und Steuermarkt, von Wien, Linz, St. Pölten, Braunau, Ried, Altenötting und Haag, wohin er am Mondtage abgegangen war". 


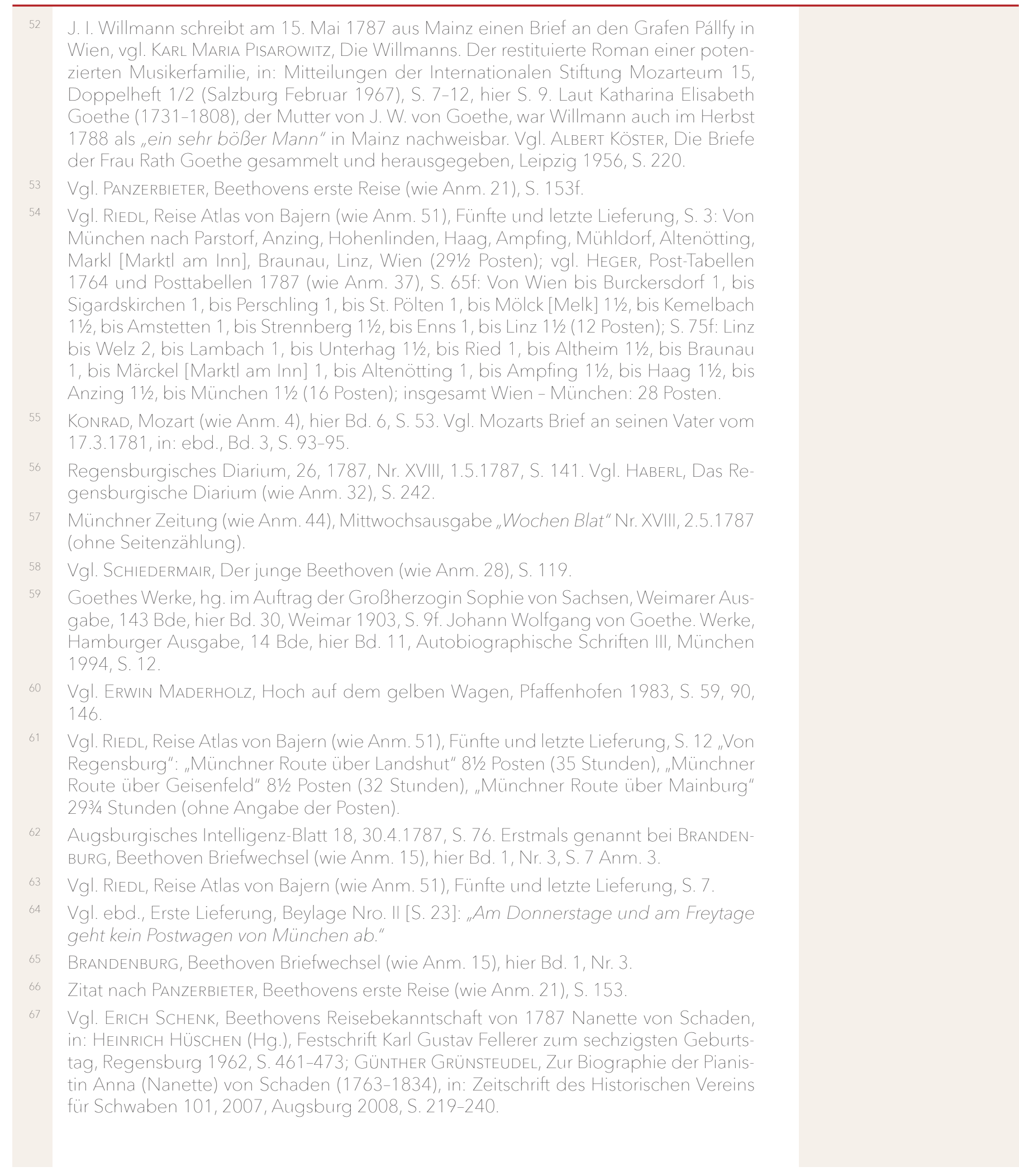

Beethovens erste Reise nach Wien 1786/87 | 463 
Vgl. SIGFRID FÄRBER, Das Regensburger Fürstlich Thurn und Taxissche Hoftheater und seine Oper 1760-1786 (Mit einem Opernkatalog der Fürstlich Thurn und Taxisschen Hofbibliothek), in: Verhandlungen des Historischen Vereins von Oberpfalz und Regensburg 86, 1936, S. 3-154, hier S. 101, 116; ChristOPH MeIXNER, Musiktheater in Regensburg im Zeitalter des Immerwährenden Reichstages (Musik und Theater 3), Sinzig 2008, S. 302.

Ein Brief von Matheus Patin an Hofmarschall Baron de Westerholt, datiert Regensburg 17.8.1786, nennt Durelli als bereits abgereist; Fürst Thurn und Taxis Hofbibliothek und Zentralarchiv Regensburg, Haus- und Familiensachen, Sign. 2442, Nr. 96.

Vgl. Felix Joseph LIPOWsky, Baierisches Musik-Lexikon, München 1811, S. 70. Reprint Hildesheim u. a. 1982. Vgl. hierzu GERBER, Lexicon (wie Anm. 48), hier Teil 1, Sp. 350.

Vgl. Ludwig SchiedermaIR, Die Blütezeit der Öttingen-Wallerstein'schen Hofkapelle. Ein Beitrag zur Geschichte der deutschen Adelskapellen, in: MAX SEIFFERT (Hg.), Sammelbände der Internationalen Musikgesellschaft 9, Leipzig 1907-1908, S. 83-130. Reprint Hildesheim und New York 1971; JOHANNES HOYER, Beziehungen der Oettingen-Wallersteinschen Hofkapelle im späten 18. Jahrhundert zum Memminger Collegium musicum - eine Dokumentation, in: Rosetti-Forum 5, 2004, S. 1-160; GERTRAUT HABERKAMP, Die Musik am Hofe der Fürsten von Thurn und Taxis im 18. Jahrhundert, in: Reichsstadt und Immerwährender Reichstag (1663-1806). 250 Jahre Haus Thurn und Taxis in Regensburg (Thurn und Taxis-Studien, hrsg. v. Fürst Thurn und Taxis Zentralarchiv und Hofbibliothek 20), Kallmünz 2001, S. 139-154.

Vgl. GeRTRAUT HABERKAMP, Thematischer Katalog der Musikhandschriften der Fürstlich Oettingen-Wallerstein'schen Bibliothek Schloß Harburg. Mit einer Geschichte des Musikalienbestandes von VOLKER VON VOLCKAMER (Kataloge Bayerischer Musiksammlungen 3), München 1976; DIES., Thematischer Katalog der Musikhandschriften der Fürst Thurn und Taxis Hofbibliothek in Regensburg. Mit einer Geschichte des Musikalienbestandes von HUgo AngeRER (Kataloge Bayerischer Musiksammlungen 6), München 1981

Vgl. Günther GrünSTEUdel, Der Geiger Anton Janitsch (um 1752-1812). Stationen einer Karriere, in: Rosetti-Forum 4, 2003, S. 15-30, Anm. 29. Ein Nachweis eines Oettingen-Wallerstein-Besuches in Regensburg z. B.: Regensburgisches Diarium 26, 1787, Nr. V, 30.1.1787, S. 37: "Zum Jakoberthor herein: Den 22. Jan. Per Posta, Sr. Hochfürstl. Durchl. Fürst von Oettingen, s. 2. log[iert] bey Sr. Hochfürstl. Durchl. Fürst von Taxis".

Regensburgisches Diarium 9, 1770, Nr. XXXV, 28.8.1770 (ohne Seitenzählung): "Zur steinernen Brucke herein: / [24. August] Zu Fuß, Joh. König, und Joseph Reicha, 2 Musicanten aus Böhmen, log. in der blauen Lilie". Vgl. HABERL, Das Regensburgische Diarium (wie Anm. 32), S. 91

Vgl. SCHIEDERMAIR, Der junge Beethoven (wie Anm. 28), S. $39 f$.

PisArowitz, Willmann (wie Anm. 50), Sp. 692. Zu Pisarowitz vgl. ECKHARd JIRGEns, Pisarowitz, in: Lexikon zur Deutschen Musikkultur Böhmen, Mähren, Sudetenschlesien, hg. v. Sudetendeutschen Musikinstitut, 2 Bde, München 2000, hier Bd. 2, Sp. 2062-2064; Bibliographie Pisarowitz, Karl Maria, in: HeINRICH SIMBRIGER, Werkkatalog zeitgenössischer Komponisten aus den deutschen Ostgebieten, 5. Ergänzungsband, Esslingen 1974, S. 212-215

Für die freundlichst gewährte Einsicht in den Nachlass Pisarowitz im Stadtarchiv Mindelheim sei Herrn Stadtarchivar Dr. Andreas Steigerwald herzlich gedankt.

78 Gernot Gruber und Joachim Brügge (Hgg.), Das Mozart-Lexikon, Laaber 2005, S. 559 


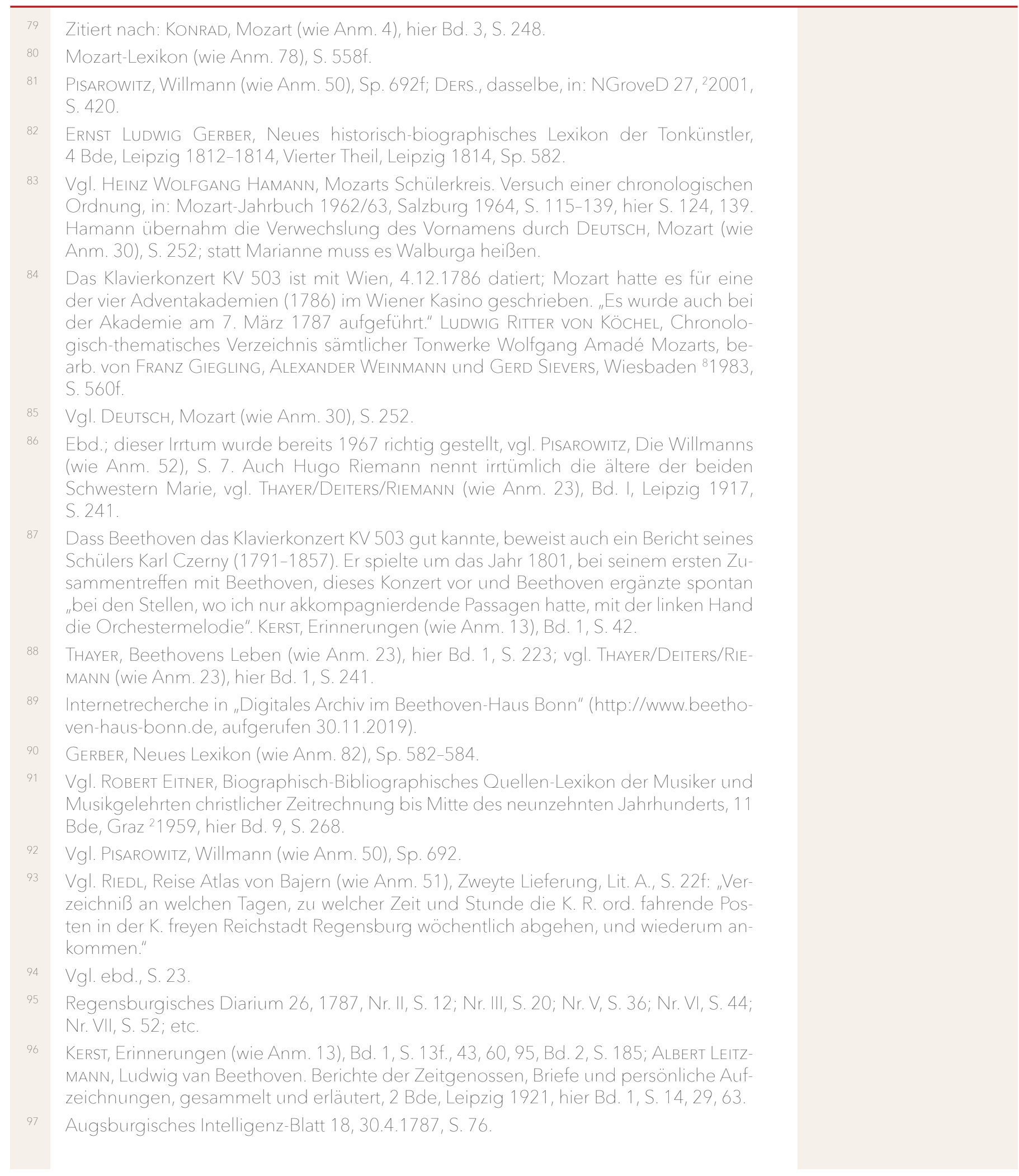

Beethovens erste Reise nach Wien 1786/87 | 465 
Regensburgisches Diarium 6, 1767, Nr. XLV, 10.11.1767: "Zur steinernen Brucke herein: Den 6. [November] Per ord[inari] Postwagen von Nürnberg, Herr Willmann, Churcöllnischer Concertmeister, s[elb] 2." Vgl. HABERL, Das Regensburgische Diarium (wie Anm. 32), S. 73

Karl Maria Pisarowitz, Willmann in: NGroveD 20, 1980, S. 441f.; NGroveD 27, 22001, S. $419 f$

Eine Besprechung der Aufführung erschien in einem anonymen Brief aus Bonn vom 8.4.1787, in: Carl Friedrich Cramer, Magazin der Musik, Hamburg 1787, S. 1385.

Vgl. Dieter HABERL, "Diese Pause wurde von der Musik ausgefüllt" - Joseph Haydns Instrumentalfassung der "Sieben letzten Worte unseres Erlösers am Kreuze", in: Die sieben letzten Worte Jesu in der Musik. Handschriften und Drucke aus der Bischöflichen Zentralbibliothek Regensburg. Katalog zur Ausstellung in der Bischöflichen Zentralbibliothek Regensburg, 6. April bis 23. Mai 2001 (Bischöfliches Zentralarchiv und Bischöfliche Zentralbibliothek, Kataloge und Schriften 17), Regensburg 2001, S. 57-63

Regensburgisches Diarium 26, 1787, Nr. XIII, 27.3.1787, S. 101, sowie Nr. XIV, 3.3. [recte: 3.4.] 1787, S. 109f. Vgl. HABERL, Das Regensburgische Diarium (wie Anm. 32), S. 241.

Vgl. Brandendurg, Beethoven Briefwechsel (wie Anm. 15), hier Bd. 1, Nr. 3,S. 7 Anm. 4.

Gerber, Lexikon (wie Anm. 82), Sp. 37; ScHENK, Beethovens Reisebekanntschaft (wie Anm. 67), S. 469.

MARTIN STAEHELIN, Beethovens Brief an den Freiherrn von Schaden von 1787 (Jahresgabe des Vereins Beethoven-Haus 1), Bonn 1982, S. $9 f$.

Augsburgisches Intelligenz-Blatt 76, 4.12.1786, S. 200; 2, 8.1.1787, S. 12; 9, 26.2.1787, S. 40 .

Josef Mancal, Stein, Johann Andreas, in: Wolfram Baer u. a. (Hgg.), Augsburger Stadtlexikon. Geschichte, Gesellschaft, Kultur, Recht, Wirtschaft, Augsburg 1985, S. 363 .

Wie Anm. 100, S. 1386

Thayer/Deiters/Riemann (wie Anm. 23), hier Bd. I, Leipzig 1917, S. 272

Ebd., S. 216; vgl. Ludwig van Beethovens Konversationshefte, hg. im Auftrag der Deutschen Staatsbibliothek Berlin v. KARL-HeInz KöHLER und GrITA Herre, 11 Bde, Leipzig 1972-2001, hier Bd. 6, Hefte 61-76, Leipzig 1974, S. 321: Eintrag von der Hand des Neffen Karl vom September 1824, Heft 74, f. 13r-13v "Fr[au] v. Streicher sagt, es | freut sie, daß du mit | 14 Jahren die Instrumen- | ten ihres Vaters, und | jetzt die ihres | Sohnes siehst."

111 Augsburgisches Intelligenz-Blatt 18, 30.4.1787, S. 76; 19 vom 7.5.1787, S. 80.

"Sie [Nanette Streicher, geborene Stein] hat in Augsburg Beethoven zuerst kennen gelernt, wie er als zwölfjähriger [recte: 16-jähriger] Knabe ein Konzert auf der Orgel gegeben und öfters auf den Instrumenten ihres Vaters so herrlich phantasiert habe." Otto Clemen, Andreas Streicher in Wien, in: Adolf Sandberger (Hg.), Neues Beethoven-Jahrbuch 4, 1930, S. 107-117, hier S. 111

113 Maderholz, Hoch auf dem gelben Wagen (wie Anm. 60), S. 57.

114 So beispielsweise Jan CAEYERS, Beethoven. Een Biografie, Amsterdam 2009; DeRS., Beethoven. Der einsame Revolutionär. Eine Biographie, neu bearb. Aufl., München 2012, S. $85 f$.

115 Deutsch, Mozart (wie Anm. 30), S. 251 


\section{Beethovens Reise nach Mergentheim 1791 - Nahaufnahme einer bekannten Unternehmung}

Julia Ronge

Lewis Lockwood

zum 90. Geburtstag

1

791 berief der Hoch- und Deutschmeister Maximilian Franz, Kurfürst von Köln, in der Zentrale des Deutschen Ordens in Mergentheim ein Großkapitel ein, das erste Generalkapitel seit 1780. Die Folgen der Französischen Revolution machten sich durch Gebietsverluste in Elsass und Lothringen sowie durch Flüchtlinge aus Frankreich und drohende kriegerische Auseinandersetzungen auch für den Deutschen Orden bemerkbar. Daraus resultierende dringende Fragen mussten in großer Runde besprochen und geklärt werden. Zudem hatte Max Franz ein Interesse daran, die Verschmelzung der Ballei, also der Ordensprovinz Franken, mit der dem Hochmeister unmittelbar unterstellten Kommende Mergentheim, dem so genannten Meistertum, weiterzuführen, da dies seine Macht stärkte. Wichtige, den gesamten Deutschen Orden betreffende Beschlüsse wurden grundsätzlich vom Generalkapitel gefasst, an dem alle Landkomture der einzelnen Balleien mit ihren Ratsgebietigern (Beratern des Komturs) teilnahmen. Das Generalkapitel war das oberste Gremium des Deutschen Ordens, der Hochmeister hatte dort dieselbe Stimme wie alle anderen.

Um in der Provinz in jeder Hinsicht ausreichend versorgt zu sein, nahm der Kurfürst aus Bonn Teile seines Hofstaats nach Mergentheim mit, darunter auch eine Auswahl von Mitgliedern seiner Hofkapelle, unter ihnen Ludwig van Beethoven. Max Franz ließ sich immer wieder von seinen Musikern begleiten; auch zu Orten, die, wie Münster, eine eigene Dommusik besaßen, nahm er seine Kapelle mit ${ }^{1}$ und selbst wenn er den Sommer in Augustusburg in Brühl verbrachte, mussten Mitglieder der Kapelle, zumindest die Harmoniemusik, also die Bläser, dorthin umziehen. ${ }^{2}$

Die Erlebnisse Beethovens in Mergentheim bzw. auf der Reise dorthin werden anekdotisch von Franz Gerhard Wegeler festgehalten, der sie 1838 in seinen zusammen mit Ferdinand Ries in Koblenz veröffentlichten Biographische[n] Notizen über Ludwig van Beethoven veröffentlichte. Wegelers Quelle stammte vermutlich aus erster Hand, von befreundeten Hofmusikern, die ebenfalls an der Reise teilgenommen hatten; in Frage kommen am ehesten Franz Ries und Nikolaus Simrock.

Erstmals wird die Mergentheim-Reise von Wegeler in Zusammenhang mit der Haydn als Arbeitsprobe vorgelegten Kantate ${ }^{3}$ genannt:

„Später sollte diese Cantate in Mergentheim aufgeführt werden, aber mehrere Stellen waren für die Blas-Instrumente so schwierig, daß einige Musiker erklärten, solche nicht spielen zu können, und so ward auf die Aufführung verzichtet." 
Die zweite Erwähnung betrifft Beethovens berühmtes Zusammentreffen mit Johann Franz Xaver Sterkel in Aschaffenburg:

„Diese Variationen [Righini-Variationen WoO 65] gaben zu folgendem besonderen Vorfall Veranlassung. Beethoven, der bis dahin noch keinen großen, ausgezeichneten Klavierspieler gehört hatte, kannte nicht die feinen Nuancierungen in der Behandlung des Instruments; sein Spiel war rauh und hart. Da kam er auf einer Reise von Bonn nach Mergentheim, der Residenz des Kurfürsten in seiner Eigenschaft als Deutschmeister, mit dem Orchester nach Aschaffenburg, wo er durch Ries, Simrock und die beiden Romberg zu Sterkel gebracht wurde, welcher, dem Gesuch Aller willfahrend, sich zum Spielen hinsetzte. Sterkel spielte sehr leicht, höchst gefällig, und, wie Vater Ries sich ausdrückt, etwas damenartig. Beethoven stand in der gespanntesten Aufmerksamkeit neben ihm. Nun sollte auch er spielen, that dieses jedoch erst dann, als Sterkel ihm zu verstehen gab, er zweifle, daß selbst der Compositeur obiger Variationen sie fertig spielen könne. Jetzt spielte Beethoven nicht nur Variationen, so viel er sich deren erinnerte, (Sterkel konnte sie nicht auffinden,) sondern gleich noch eine Anzahl anderer, nicht weniger schwierigen und dies, zur größten Ueberraschung der Zuhörer, vollkommen und durchaus in der nämlichen gefälligen Manier, die ihm an Sterkel aufgefallen war. So leicht ward es ihm, seine Spielart nach der eines andern einzurichten." 5

Sterkel war kurmainzischer Hofkapellmeister und in dieser Funktion Nachfolger von Vincenzo Righini. Aschaffenburg war eine der Hauptresidenzen des Kurfürst-Erzbischofs von Mainz. Beethovens Righini-Variationen waren im August 1791 im Mainzer Verlag Schott erschienen.

Schließlich berichtet Wegeler noch von der Aufgabenverteilung auf der Reise:

„Diese Reise übrigens, welche das ganze Orchester in zwei Jachten den Rhein und Main hinauf in der schönsten Jahreszeit machte, war für Beethoven eine fruchtbare Quelle der schönsten Bilder in der Erinnerung geworden. Bei den Rollen, welche der zum großen König erwählte Sänger und bekannte Komiker Lux austheilte, wurden Beethoven und Bernhard Romberg zu Küchenjungen ernannt und als solche in Dienst gesetzt. Das Diplom seiner weiteren Beförderung, welches Beethoven erhielt, datirt: auf der Höhe von Rüdesheim, wird man wohl noch in seiner Verlassenschaft gefunden haben; wenigstens habe ich es noch im Jahr 1796 bei ihm in bestem Verwahrsam gesehen. Ein Großes, im Deckel einer Schachtel in Pech abgedrucktes Siegel, durch einige aufgetrennte Fäden eines Schiffseils befestigt, gab diesem Diplom ein gar ehrenfestes Ansehen." ${ }^{16}$ 


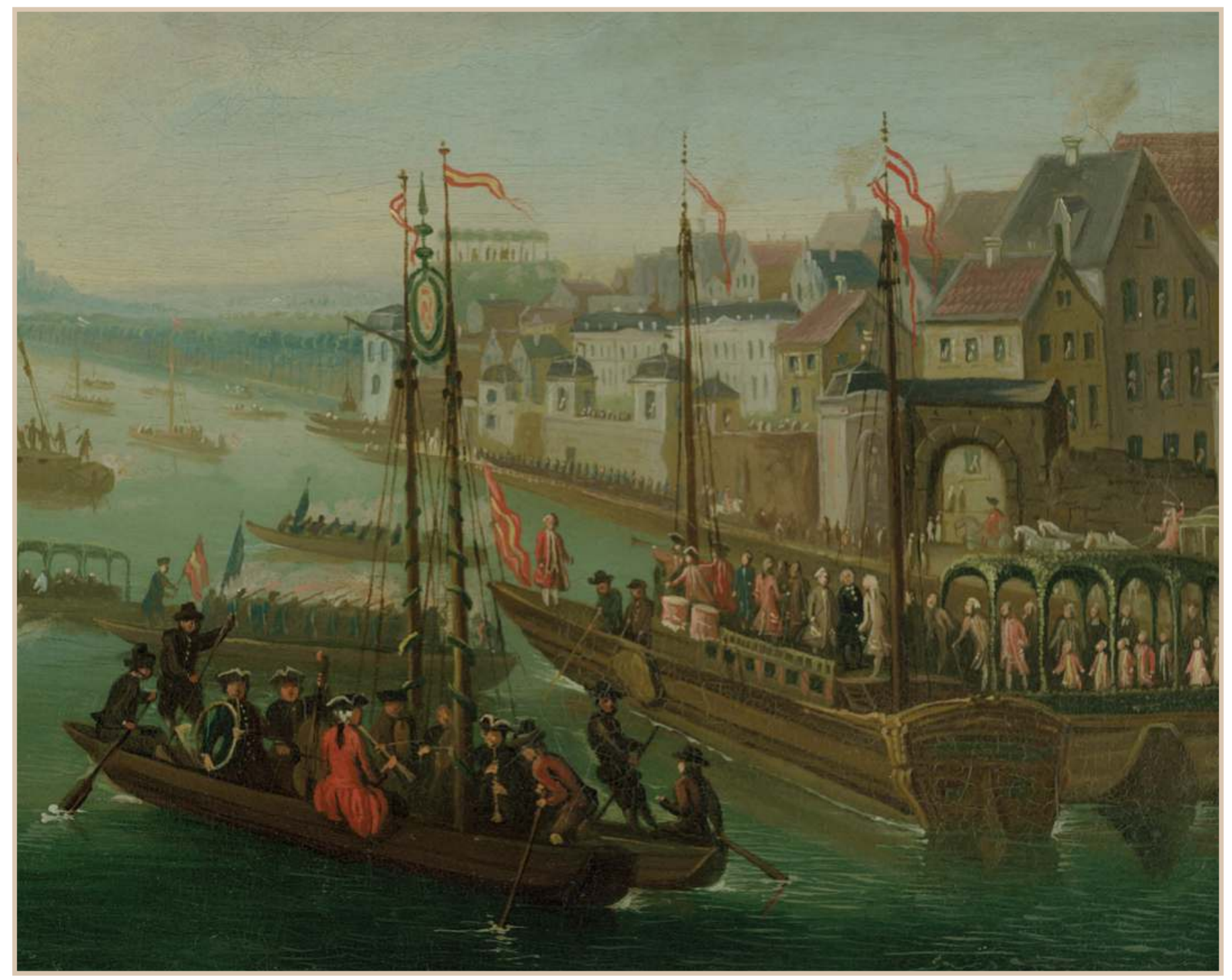

Das von Wegeler erwähnte Jux-Diplom ist entgegen seiner Hoffnung nicht erhalten geblieben. Über den Aufenthalt vor Ort in Mergentheim berichtet er nichts, sieht man davon ab, dass Beethovens Kantate entgegen der ursprünglichen Planung nicht aufgeführt werden konnte. Ferdinand Ries lässt Beethovens Mergentheim-Reise gänzlich unerwähnt, obwohl sein Vater ebenfalls daran beteiligt war und möglicherweise zu Hause davon berichtet hat.

Das einzige zeitgenössische Zeugnis eines Konzerts am Hof in Mergentheim sowie eines Auftritts des jungen Ludwig van Beethoven überliefert der Döttinger Pfarrer, Komponist, Musik- und Kunstschriftsteller Carl Ludwig Junker (1748-1797), ${ }^{7}$ der mit den Reichsfürsten von Hohenlohe für zwei Tage ${ }^{8}$ beim Generalkapitel weilte, wovon später noch die Rede sein wird.

Musiker der Bonner Hofkapelle bei der Ankunft von Erzherzog Maximilian Franz als Koadjutor des Kurfürsten Max Friedrich am 3. Oktober 1780. Ölgemälde von Franz oder Jakob Rousseau (Ausschnitt) (Beethoven-Haus Bonn) 
Die Reise wurde von der Verwaltung in Bonn minutiös geplant und ausführliche Listen des mitreisenden Personals angelegt. ${ }^{9}$ Dazu gehörten neben den Ordensrittern und Angehörigen des Staatsrats und der Ordenskanzlei mehrere Kammerportiers, Kammer- und Hoflakaien, Läufer, Stall- und Reitknechte sowie zahlreiches Küchenpersonal, darunter neun Hofköche, mehrere Lehrköche und Beiköche, aber auch Konditoren, Kesselreiber, Silberdiener und Tafeldecker und natürlich die Hofmusiker. Die Listen in den Kapitelsakten weisen 24 Musiker und einen Kalkanten, der den Blasebalg der Orgel tritt, aus:

$\begin{aligned} \text { "Musici } & \text { Demois. [Magdalena] Willmann nebst } \\ & \text { Schwester [Walburga] und Vater [Johann Ignaz Willmann] } \\ & \text { Louis Simonetti } \\ & \text { [Franz Anton] Ries } \\ & \text { Andreas Romberg } \\ & \text { [Friedrich] Müller } \\ & \text { Mendel } \\ & \text { [Johann] Spizeter } \\ & \text { [Joseph] Lux } \\ & \text { [Ludwig van] Beethoven } \\ & \text { [Bernhard] Romberg der Violoncellist } \\ & \text { [Sebastian] Pfau } \\ & \text { [Johann] Goldberg } \\ & \text { und die 8 Harmonische Instru- } \\ & \text { menten nebst } \\ & \text { dem Calcanten } \\ & \text { die Trompeter }\end{aligned}$

[Philipp] Göpfert

[Michael] Baltus"10

Im Deutschordens-Zentralarchiv in Wien wird eine Quartierliste für den Aufenthalt in Mergentheim aufbewahrt, die präziser gefasst ist und gegenüber den Planungsakten mehr Namen enthält. ${ }^{11}$ In dieser Quartierliste sind 26 Musiker, eine Schauspielerin und ein Kalkant aufgezählt, wobei die Holzbläser nicht kumulativ sondern einzeln genannt werden:

Magdalena und Walburga Willmann sowie deren Vater Johann Ignaz Willmann (wobei nur Magdalena Willmann Mitglied der Hofkapelle war, ${ }^{12}$ ihr Vater und ihre Schwester scheinen zusätzlich engagiert worden zu sein), eine nicht identifizierbare Schauspielerin aus Prag ("die Prager actrice"), Ludwig Simonetti, Franz Anton Ries, Ludwig van Beethoven, Christoph Brandt, Johann Spizeter, Friedrich Müller, Georg Liebisch, Johann Goldberg, Sebastian Pfau, Mendel (Vorname unbekannt), Joseph Lux, Thomas Pokhorny, Joseph und Georg Welsch, Nikolaus Simrock, Andreas Bamberger, Joseph Pachmeyer, Theodor Zilleken, Michael Meuser, Andreas und Bernhard Romberg, Philipp Göpfert, Michael Baltus und der Hofkalkant Michael Funk. 


\section{Heriona! quít}

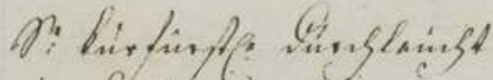

$$
\begin{aligned}
& \text { ti) dinglowionerthuse } \\
& \text { in Ralgonabiedingar } \\
& 12 \text { atsinni hithar }
\end{aligned}
$$

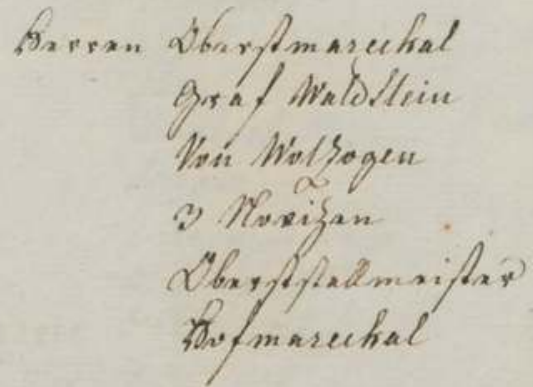

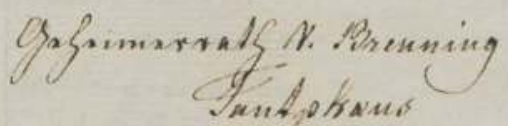

Mutpotrans

Wreos?

glosel

inibehisusesnes tocses

nomman." Eses

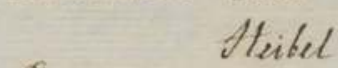
Dammaspondiero Derberger
Atemmer

ethrisiei demois Willmann nabf?

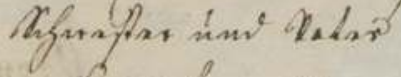

diniv Simanelle

tie.

Andiear lonbers

ellulles.

ethusel

piseter

Besethonem

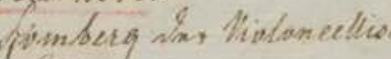
Cifid
Liste des nach Mergentheim gereisten kurfürstlichen Personals, darunter Ludwig van Beethoven (Landesarchiv BadenWürttemberg, Staatsarchiv Ludwigsburg) 
Das aus diesen Musikern gebildete Ensemble setzt sich folgendermaßen zusammen, wobei einige Musiker (Beethoven, Brandt, Müller, Pachmeyer, Pfau, Pokhorny, Lux und Spizeter) verschiedene Instrumente beherrschten und deshalb mehrfach auftauchen:

9 Violinen (Ries, Brandt, Goldberg, Müller, Andreas Romberg, Spizeter, Willmann, Pfau, Pokhorny)

2 Violen (Beethoven, Lux)

1 Violoncello (Bernhard Romberg)

1 Kontrabass (Pokhorny)

1 Flöte (Pfau)

3 Oboen (Liebisch, Pachmeyer, Joseph Welsch)

2 Klarinetten (Meuser, Pachmeyer)

2 Fagotte (Georg Welsch, Zilleken)

2 Hörner (Simrock, Bamberger)

2 Trompeten (Göpfert, Baltus)

Orgel bzw. Continuo (Beethoven)

1 Sopran (Magdalena Willmann)

3 Tenöre (Simonetti, Mendel, Brandt)

3 Bässe (Müller, Lux, Spizeter)

Entfernt man die doppelten Nennungen und teilt die Musiker in eine brauchbare Besetzung auf, so sah das Orchester vermutlich folgendermaßen aus:

3 Violinen I

3 Violinen II

1 Viola

1 Violoncello

1 Kontrabass

1 Fagott als Teil der Bassgruppe

1 Flöte

2 Oboen

2 Klarinetten

1 Fagott

2 Hörner

2 Trompeten

1 Tasteninstrument als Continuo

Das entspricht in etwa der üblichen Besetzung fürstlicher Kapellen mit geringen Abstrichen bei der Anzahl der Violinen. Da weder Neefe noch Reicha mitgefahren waren, oblag Franz Anton Ries die Leitung der Kapelle.

Nicht weiter überraschend hatte der Hof offenbar die fähigsten Musiker für diese Reise ausgewählt. Die älteren unter ihnen tauchen bereits 1783 in Neefes Nachricht von der churfürstlich-cöllnischen Hofcapelle zu Bonn und andern Tonkünstlern daselbst auf: Brandt wird dort als "guter Sologeiger" charakterisiert, Ries "spielt fertig und angenehm", Goldberg ist "ein junger viel verspre- 
chender Violinspieler", Pfau besitzt "einen angenehmen Ton und Fertigkeit", Meuser ist auf der Klarinette "besonders gut", Simrock und Bamberger spielen "Sehr brav". ${ }^{13}$ Joseph Gregor Lang hebt 1790 in seiner Reise auf dem Rhein die herausragendsten Sänger und Schauspieler der Bonner Bühne hervor: "Die beiden Demoisellen Keilholz sind die besten Aktrizen, Willmann, eine gute Sängerin, und Steiger, Müller, Lux und Spizeter sind schon als brave Akteurs bekannt." ${ }^{14}$ Mit Ausnahme von Steiger waren die genannten Darsteller alle Teil der nach Mergentheim reisenden Truppe.

Magdalena Willmann und Ludwig Simonetti waren gefeierte Solisten, die nach der Reise ein Extratrinkgeld von jeweils 100 Talern erhielten, während die restlichen Musiker sich 1000 Taler Pauschaltrinkgeld teilen mussten, also jeder 40 Taler bekam. Die Anzahl der Sänger war stark begrenzt und hätte für eine größer besetzte Aufführung nicht ausgereicht. So findet sich keine Altstimme unter den mitgereisten Bonner Musikern, und auch der Sopran ist mit Magdalena Willman nur einfach besetzt. Es ist daher unklar, wie Chöre in den Opern verwirklicht wurden, ob solistisch besetzt als Ensemble oder mit Verstärkung durch die zusätzlich zu den mitgebrachten Bonner Musikern engagierte Theatergesellschaft von Franz Friedrich Häußler aus Nürnberg. Walburga Willmann war als Pianistin eine Schülerin Mozarts, sie trat offenbar an Konzertabenden in Mergentheim auf. Dass man Walburga Willmann eigens für Mergentheim engagiert hatte, legt außerdem nahe, dass Beethoven für solistische Auftritte am Klavier nicht in Betracht gezogen wurde.

Das Gros der Reisenden wurde von Bonn aus auf Schiffen den Rhein hinauf befördert, wobei die Akten sogar die Namen der Schiffer und die Größe ihrer Boote festhalten. Nur wenige Angestellte nahmen den Landweg. Dazu gehörten diverse Köche und Konditoren ebenso wie mehrere Kutscher und Pferdeknechte sowie ein Hufschmied. Während die Kutscher zum Teil auch die Kutschen nach Mergentheim brachten, ist nicht ganz klar, warum die Küchenchefs nicht mit dem restlichen Personal fuhren.

Auch der Kurfürst mit seinem engsten Gefolge (den Deutsch-Ordens-Rittern und Novizen, dem Kanzleidirektor Georg Joseph von Breuning, einem KabinettSekretär, seinem Leibarzt, seinem Kammerdiener sowie einem Lakaien und zwei Läufern) reiste über Land, offiziell weil er zunächst zum Landtag nach Arnsberg musste, der ab dem 10. August tagte und üblicherweise ca. drei Wochen dauerte. Einem Schreiben des kaiserlichen Gesandtschaftssekretärs Gottfried von Kornrumpf an den Reichsvizekanzler Franz de Paula Gundaker von ColloredoMannsfeld zufolge war der Landtag aber nur vorgeschoben. Im Sommer 1791 spitzte sich die Lage in Frankreich zu, immer mehr französische Immigranten kamen an den Rhein, besonders nach Koblenz, wo in Ehrenbreitstein der Trierer Erzbischof und Kurfürst Clemens Wenzeslaus von Sachsen residierte, der ein Onkel Ludwigs XVI. war. Max Franz hatte den französischen Emigranten den Aufenthalt in seinem Kurfürstentum verwehrt, während beispielsweise die Stadt 
Köln ihnen Aufenthaltsrecht gewährte. Die drei geistlichen Kurfürsten von Trier, Mainz und Köln sahen sich durch die Situation in Frankreich wegen ihrer territorialen Nähe besonders bedroht, Mainz und Trier hatten zudem Schwierigkeiten im Elsass, weil sie dort Güter und Gerechtsame besaßen. Die in Koblenz ansässigen französischen adeligen Emigranten drängten zudem auf einen Krieg gegen Frankreich. Maximilian Franz lehnte den Gedanken eines Reichskrieges gegen das revolutionäre Frankreich ab, weil er einen solchen als Einmischung in die inneren Angelegenheiten eines anderen Landes betrachtete. Außerdem fürchtete er, den Franzosen einen Anlass zu geben, bis an den Rhein vorzurücken und die linksrheinischen Gebiete in Besitz zu nehmen. ${ }^{15}$ Er verfolgte für Kurköln eine Politik des Abwartens und der Neutralität und sah sich durch seine beiden geistlich-kurfürstlichen Kollegen zunehmend bedrängt, die ihn nicht nur zu einer offensiveren Politik, sondern wohl auch wegen seiner dynastischen Beziehungen zum Kaiser zu einer Fürsprache in Wien bewegen wollten. Max Franz versuchte dagegen, seinen kaiserlichen Bruder von jeder Form der militärischen Intervention zugunsten der französischen Monarchie abzubringen. Wäre Max Franz zusammen mit seinem Hofstaat zu Schiff auf dem Rhein Richtung Mergentheim gereist, so hätte er die Herrschaftsgebiete der beiden anderen geistlichen Kurfürsten durchquert und wäre in beiden Fällen an einem Höflichkeitsbesuch in den Residenzen Ehrenbreitstein und Aschaffenburg nicht vorbei gekommen. Auch die Angehörigen des französischen Königshauses hätte er empfangen müssen. Kornrumpf meldete nach einem Besuch bei Max Franz vom 25. August 1791 nach Wien:

"I[hre] K[ur]f[ürstliche] D[urchlaucht] äußerte weiter, daß sie seit des Kaisers Aufenthalt zu Mailand auf die ihnen mitzuteilen versprochene Allerhöchste Gesinnungen über diesen Gegenstand bei Ankunft mehrerer Kuriere vergeblich gehofft hätten, und daß sie bei der Unentschlossenheit und dem verschiedenen Interesse der größeren Höfe noch kein Auskunftsmittel sähen, wie die Umstände in Frankreich in Absicht auf das Reich und die königliche Familie abgeändert werden könnten, immaßen der drei geistlichen Kurhöfe Willfährigkeit von geringem Erfolg sein dürfte, wiewohl sie für ihre Person aufrichtig bereit wären, mit Rat und Tat beizuwirken. Bei dieser Lage der Sachen könnten I[hre] D[urchlaucht] die längst vorgehabte Reise nach Mergentheim nicht weiter hinausschieben und gedächten daher, um einer Zusammenkunft mit dem Herrn Kurfürsten von Mainz und Trier auszuweichen und um auch nicht die französischen Prinzen zu Koblenz zu sehen, den Weg über Arnsberg unter dem Vorwand des dortigen Landtages zu nehmen und von da ihre Reise über Fuld[!] nach Mergentheim fortzusetzen. Die fernere Absicht I[hrer] K[ur]f[ürstlichen] $D$ [urchlaucht] wäre, im Spätjahr sich nach Wien zu erheben und den größten Teil des Winters daselbst zuzubringen, vorausgesetzt, daß es 
nicht etwa zu einem Feldzug gegen Frankreich käme, in welchem Fall Höchstsie wieder nach Bonn zurückkehren würden.."16

Die Anwesenheit des Kurfürsten beim westfälischen Landtag war nicht verpflichtend, Max Franz hätte ohne weiteres darauf verzichten können. ${ }^{17}$ Doch er wollte um jeden Preis ein Zusammentreffen mit den französischen Aristokraten in Koblenz sowie mit den Kurfürsten von Trier und Mainz vermeiden - der Landtag in Arnsberg bot ihm da eine willkommene Ausrede.

Die Verschiffung auf dem Rhein sollte am 25. August und den Folgetagen statthaben und umfasste fünf Jachten und zwei Bagageschiffe. Die Musiker wurden zusammen mit dem Kabinettssekretär Wreden, dem Deutschordenssekretär und mehreren Kammerdienern auf zwei verschiedene Schiffe aufgeteilt. Die Schiffe fuhren rhein- und mainaufwärts bis Miltenberg. Dort wurden die Reisenden durch von Mergentheim kommende Kutschen abgeholt und fuhren landeinwärts über die Stationen Hundheim (heute ein Ortsteil von Külsheim) und Bischofsheim (heute Tauberbischofsheim) ans endgültige Ziel. Dabei wurden am 1. September zuerst die Suite, also die Höherrangigen, befördert, das Personal verblieb zunächst in Miltenberg. Die Kutschen kamen am 4. September zurück, um nun auch das übrige Gefolge abzuholen.

Die auf dem Landweg Reisenden - darunter der kurkölnische Kämmerer und Erb-Hofmeister Anton Graf von Belderbusch und Ferdinand Graf Waldstein, des Deutschen Ordens Geheimer Konferenzrat - waren schneller unterwegs. Über die Landreise sind wir gut unterrichtet, weil die Stationen und notwendigen Ausgaben für Post, Tränke, Barriere, Schmier, ${ }^{18}$ Überfahrten und Trinkgelder sowie gegebenenfalls Essen, Übernachtungen und Mietlakaien im Gegensatz zu den Schiffsreisenden in den Akten minutiös festgehalten wurden. Ihr Weg führte sie von Bonn über die Stationen Remagen, Andernach, Koblenz, Nassau, Nastetten, Bad Schwalbach, Wiesbaden, Mainz, Hattersheim am Main, Frankfurt am Main, Seligenstadt, Aschaffenburg, Obernburg am Main, Miltenberg, Hundheim und Tauberbischofsheim nach Mergentheim und dauerte vier Tage. Die zahlreichen Posten und Pferdewechsel lassen diese Reise sehr aufwändig erscheinen, sie ging aber vergleichsweise schnell voran.

Da die Schiffe rheinaufwärts getreidelt werden mussten, dauerte die Beförderung zu Wasser dagegen deutlich länger. Wenn die Schiffe wie geplant ab dem 25. August in Bonn aufgebrochen sind und die Strecke bis Miltenberg bis zum 3. September bewältigt haben, so waren die Reisenden maximal zehn Tage unterwegs, auf jeden Fall aber mindestens doppelt so lange wie zu Land. Über die einzelnen Stationen der Beförderung auf dem Rhein ist in den Akten nichts überliefert. Da alle Boote mit Zimmern ausgestattet waren, wurde wohl auch auf dem Boot übernachtet und gegessen, so dass dafür keine Kosten anfielen und auch nicht bilanziert wurden. Eine solche Beförderung flussaufwärts schilderte Lady Mary Coke in ihrem Tagebuch. Sie war 1767 von Bonn Richtung Mainz gefahren. Die Jacht war offenbar der der Bonner Musiker ähnlich: 
"They are very pretty Vessels, consisting of three rooms, \& a very fine deck railed round, where it is very agreeable sitting or walking when the weather is not too hot.... My good friends furnished the Yacht with everything I cou'd want - Bed, table, Chairs, plates, glasses, \& all kinds of provisions for my Voyage, \& six bottles of wine."19

Lady Coke schildert auch das Prozedere der Treidelfahrt. Die Jacht machte abends um $10 \mathrm{Uhr}$ am Ufer fest und fuhr in der Morgenfrühe um 4 Uhr weiter. Zweimal am Tag wurde angelegt, um die Treidelpferde zu wechseln. ${ }^{20}$ Die Gesamtkosten für die Bootsfahrt waren wegen der Pferdewechsel und der zusätzlichen Kosten für die Pferdeführer vergleichsweise hoch. Lang beschreibt den Vorgang für eine Fahrt von Köln nach Mainz folgendermaßen:

"Die Beschwerden der Zölle und die der Pferde, welche den zu Berg gehenden Schiffen vorgespannet werden, erschweren die Fracht um ein merkliches. Der gewöhnliche Preis eines solchen Pferdes von Kölln bis Mainz kömmt an 9 bis 12 Reichsthaler: aber hoher Futterpreis und Hindernisse wegen der Feldarbeit, bringen ihn auch wohl zuweilen bis auf 16 oder 18 Reichsthaler; und dabei muss der Schiffer noch Pferde und die sogenannten Halfterknechte, deren ein jeder drei Pferde zu besorgen hat, auf der ganzen Reise in Kost und Fourage frei halten. - Die Fahrt der Thalschiffe ist eben so geschwind, als die Fahrt der Bergschiffe langsam ist. Ein belastetes Schiff hat zu einer Fahrt von Kölln bis Mainz, nach Beschaffenheit der Witterung und der Höhe des Wassers, 9-15, auch wohl 18 Tage nöthig, und allzuwildes Wasser, oder Stürme, zwingen es auch wohl zuweilen, 12 bis 14 Tage Halt zu machen: dahingegen ein zu Thal gehendes Schiff von Mainz bis Kölln eine Strekke von 36 Stunden, im Sommer, ohngeachtet der Aufhaltungen, die ihm jeder Zoll verursachet, die Reise in dreien Tagen abmachen kann." ${ }^{21}$

Offenbar war das Wetter Ende August 1791 günstig, denn die Reisenden waren zu Wasser wohl nur die Mindestanzahl von Tagen unterwegs und wurden weder durch den Fluss noch andere Umwelteinflüsse behindert. Sollten die in den Planungsakten festgehaltenen Daten stimmen, dann wären die Hofmusiker am 4. September in Miltenberg abgeholt und noch am selben Tag nach Mergentheim gebracht worden.

Die höheren, auf dem Landwege reisenden Herren, die nicht mit dem Kurfürsten über Arnsberg gefahren waren, waren den Akten zufolge

"den 1 ten 7 bris von Bonn abgereißt, speißeten des Mittags bei S[einer] K[urfürstlichen] D[urc][lauch]t von Trier zu Coblenz, und sezten nach der Tafel ihre Reiße fort bis Naß, und folgenden Tags bis Mainz, den $3^{\text {ten }}$ bis Aschaffenburg, wie sie bei S[einer]r kurfürstl[ichen] Gnaden speisten, und den $4^{\ddagger}$ ihre Reiße bis Mergentheim fortsezten, und abends gegen 8 Uhren ... anlangten". ${ }^{22}$ 
Der Kurfürst, der von Arnsberg über Fulda gereist war, hatte noch anderthalb Tage beim Fürstbischof von Würzburg, Franz Ludwig von Erthal, Station gemacht, kam am 5. September um 9 Uhr abends von Würzburg aus in Mergentheim an und wurde "von samtlich albereits anwesend gewesenen hohen Ordens Rittern in ihren weißen Mändlen am Wagen empfangen". ${ }^{23}$ Die Räte, Geistlichen und anwesenden Militärs durften ihr "bewillkommnungs Kompliment" erst am nächsten Tag gegen Mittag ablegen.

Das Gros der Akten zum Großkapitel im Staatsarchiv Ludwigsburg beinhaltet die Mitschrift des Kapitels in halbbrüchig beschriebenen Doppelblättern. Es handelt sich dabei nicht um das offizielle Kapitelsprotokoll (dieses befindet sich im Deutschordens-Zentralarchiv in Wien), sondern um ein für den erkrankten Landkomtur der Ballei Koblenz, Ignaz Felix von Roll, angefertigtes Journal. Von Roll hatte seinen Koadjutor Karl Franz Friedrich von Forstmeister bevollmächtigt und an seiner Statt nach Mergentheim beordert. Ob Forstmeister selbst Protokoll führte oder doch eher von ihm bestellte Schreiber (die Mitschrift zeigt mehrere Hände, in einem ebenfalls überlieferten Briefentwurf ist von einem Sekretär Hartig die Rede ${ }^{24}$ ), ist unklar. Einzelne Vermerke belegen, dass samstags ${ }^{25}$ die neuesten Teile des Diariums nach Koblenz geschickt wurden, so dass von Roll regelmäßig über den Fortgang des Kapitels unterrichtet wurde.

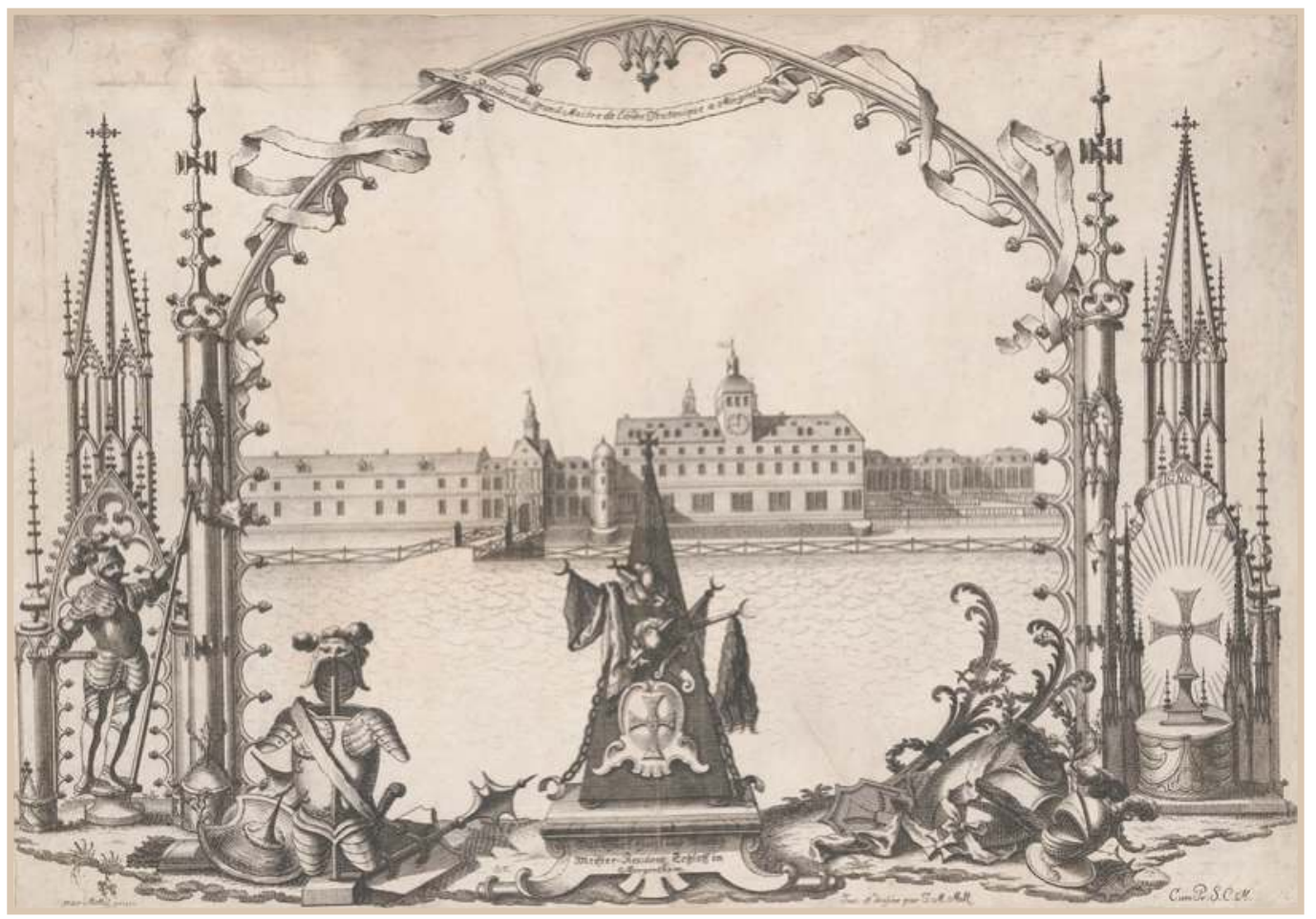

Schloss Mergentheim, Sitz des Hochmeisters des Deutschen Ordens. Kupferstich von Nikolaus Mettely nach Johann Martin Metz, um 1760 (Stadtarchiv Bonn) 
Das Generalkapitel wurde am Sonntag, den 18. September, durch ein feierliches Hochamt eröffnet und sollte bis Donnerstag, den 20. Oktober, andauern. Jeweils an vier Tagen in der Woche, nämlich Montag, Mittwoch, Freitag und Samstag, tagte das Kapitel, während an den verbleibenden Wochentagen Dienstag und Donnerstag die Ordenskonferenz abgehalten wurde. Der Tagesablauf in Mergentheim war streng geregelt. Max Franz hatte bereits Ende Juni in einem Schreiben an seinen Stellvertreter im Meistertum, Christian Graf zu Erbach-Schönberg, das Programm detailliert angeordnet:

"Des Morgens 8 Uhr Audienzen, um 9 Uhr die feierliche Messe in der Hofkapelle, sodann die Kapitels Session, oder sonstige Geschäfften, um 1 würde zu Mittag gespeiset in der Salla Terrena, nach Tische von 3 biß 5 würde gespielt, oder nach Umständen spatzieret[;] um 5 Uhr oder $1 / 26$ in der Woche 4 mahl Comödie, einmahl Bal in der Salla terrena und einen Tag großes und einen Tag kleines Concert, um 1/2 9 Uhr wäre das Souper, und hiemit des Tages Arbeit vollendet. "26

Auch eine Tischordnung wurde festgelegt:

"samtliche hohen Ordens Mitglieder speißen alle Mittag und Abends bei Hof, die HH. Ballei Sindici aber werden die Hälfte einen, und die anderen Helfte den anderen Tag zur Marschalls Tafel gebeten, an welcher der hohe Ordens Ritter von Rabenai, welcher dermahlen dahier als HofMarschall unter der Leitung des hohen Ordens Ministern angestellet ist, und alles zu besorgen hat, die honeurs macht.

Die Tafeln sind

1. die kurfürstl. Tafel à 60 Personen

2. die Marschals Tafel zu 40 Personen

3. die Kammer Tafel à 30 Personen

4. Officianten Tafel à 40 Personen

5. Laihen und Kellerdiener Tafel à 30 Personen." ${ }^{27}$

Über die Speisenabfolge findet sich nichts in den Akten oder Protokollen. Anhaltspunkte über die Tafel des Hoch- und Deutschmeisters liefert aber der geborene Bonner und kurkölnische Beamte Peter Joseph Boosfeld, der im März 1784 in Mergentheim weilte und seine Eindrücke in einem Brief an seinen Freund, den späteren kurkölnischen Geheimrat Johann Tillmann von Pelzer wiedergibt:

„Unsere Tafel wird in Silber mit zwölf Schüsseln bedient. Die Speisen sind gut, überhaupt sind die Wiener so gewohnt, daß man mit ihnen wohl fürlieb nehmen kann. ... Die Tafel von Ihrer Königlichen Hoheit besteht täglich in etwa zehn Couverts." ${ }^{\text {28 }}$

In den Listen, in denen das für Mergentheim abgestellte Personal verzeichnet ist, finden sich auch Aufstellungen, welche Bedienten an den Tafeln vorlegen mussten. ${ }^{29}$ Dazu gehörten nicht nur professionell dafür ausgebildete Diener und Hoflakaien wie der Silberdiener Hellinger, der auch für das 


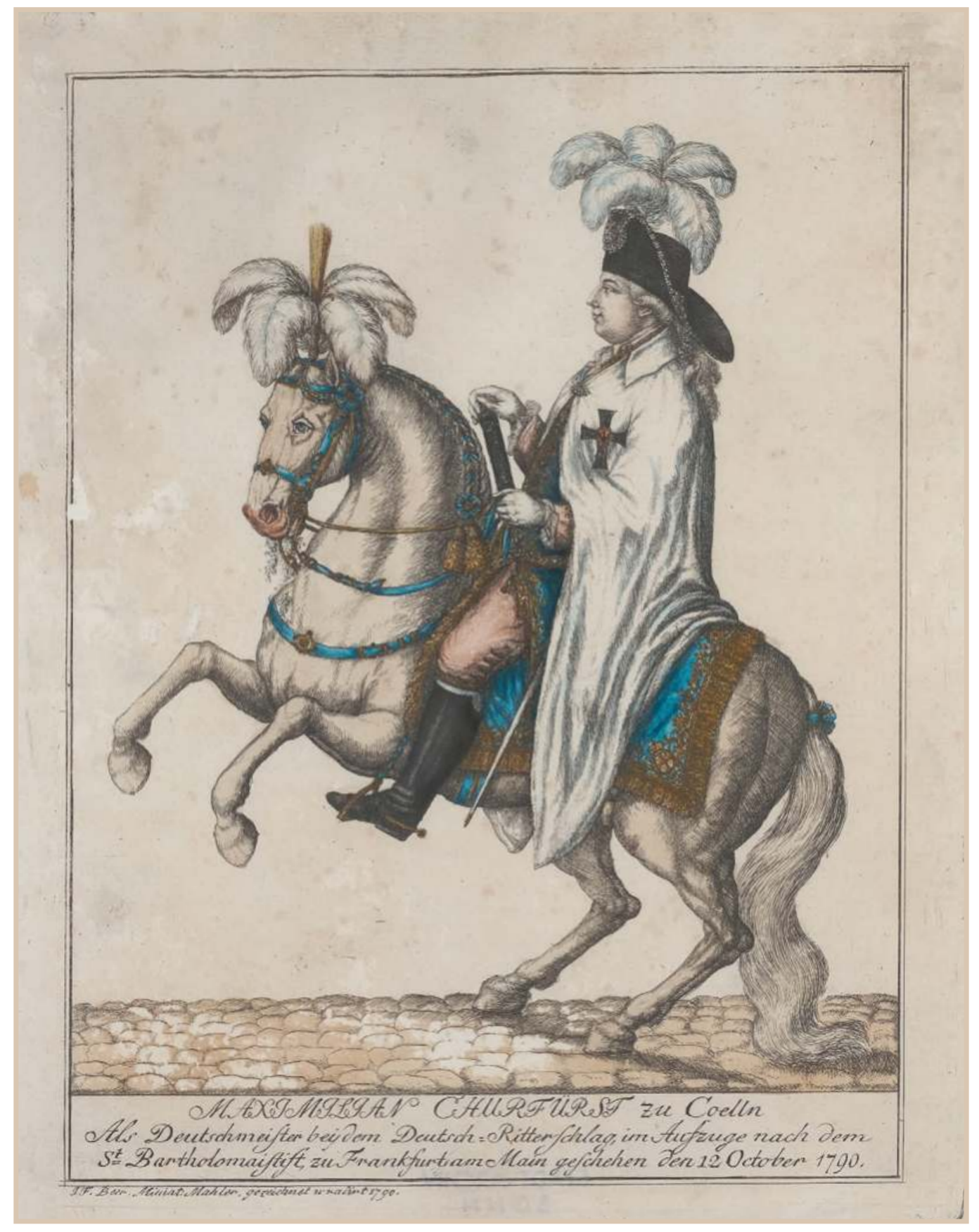

Servieren von Desserts vorgesehen war, und der Tafeldecker Schweinheim oder der Kammerportier Auberger, der den Wein präsentieren musste. Neben Gardereitern und Jägern, waren auch explizit "6 Hofmusici" für die kurfürstliche Tafel und "2 Musici" zum Tischdienst an der Marschallstafel eingeteilt. Da die Hofgesellschaft über sechs Wochen in Mergentheim weilte, zwei offizielle
Kurfürst Maximilian Franz (1759-1801) im Ornat des Hochmeisters des Deutschen Ordens. Kolorierte Radierung von Johann Friedrich Beer, 1790 (Stadtarchiv Bonn) 
Essen am Tag stattfanden - mittags und abends - und der Dienst sicher turnusmäßig wechselte, Beethoven zudem zu den jüngeren Musikern gehörte, die eher unliebsame Dienste übernehmen mussten als die Altgedienten, und die Holzbläser weitgehend ausfielen, weil sie für die Tafelmusik zuständig waren, ${ }^{30}$ wird er gewiss regelmäßig zum Servieren an den herrschaftlichen Tafeln herangezogen worden sein.

Der Hoch- und Deutschmeister Max Franz weilte regelmäßig in seinem Meistertum Mergentheim und wusste, dass der Ort für angemessene Abendunterhaltungen zu klein und zu provinziell war - Mergentheim zählte damals ca. 2800 Einwohner. Um gähnender Langeweile vorzubeugen und die Atmosphäre des Kapitels nicht zu stark zu belasten, hatte er deshalb seine Bonner Hofmusiker mitgebracht, die für Zerstreuung sorgen sollten. In dem bereits erwähnten Schreiben an seinen Statthalter Christian Graf zu ErbachSchönberg führt Max Franz seine Beweggründe näher aus:

"Da nun um diese Zeit die Abende schon lang werden, und die Gegend von Mergentheim wenig Vergnügungen darbietet, so wäre Ich gesonnen nebst den blasenden Instrumenten, so bei Tische spielen und aufwarten müßen, ein Dutzend aus meinem Orchester mitzunehmen, um sowohl einige Musik Concerte zu haben, als auch vielleicht Comödie zu spielen. Mein erster Gedanke war, meine hiesige Schauspieler mit hinauf zu bringen, welches lch aber bei näherer Erwägung ganz unthunlich und viel zu kostspielig befunden habe. Ich habe Mich daher entschlossen ein oder andern herumziehende Trupp für diese kurze Zeit dahin zu berufen, welche zugleich für decoration, Garderobe u. d. gl. gegen ein Accord mäßiges fragen. wirklich hat sich schon eine gewisse Passauische Gesellschaft die dermahlen in den Bädern zwischen Koblenz und Mainz spielt, und eine andere Gesellschaft aus Erlangen und Nürnberg gemeldet. Erstere verlangt wochentlich nur 10 Carolinen und das Orchester frei, welches Mir zimlich mäßig scheint". ${ }^{31}$

Die Hofkapelle mitzunehmen, war bereits vergleichsweise kostspielig. Musik hatte für Max Franz aber einen hohen Stellenwert, weshalb er sich diese Ausgabe leistete. Die Theatertruppe benötigte man zur Abwechslung, sie durfte aber nicht so teuer sein. Schließlich wurde, wie erwähnt, für die Dauer des Kapitels die Häußlersche Theatertruppe aus Nürnberg engagiert (die "andere Gesellschaft"), die mit den Hofmusikern an den Abenden alternierten, aber auch mit diesen gemeinsame Produktionen auf die Bühne brachten. Der Gothaer Theaterkalender auf das Jahr 1792 hält bezüglich der Häußlerschen Gesellschaft fest, sie gebe "die auserlesensten Stücke und die größten Opern." ${ }^{\prime 32}$

Auch die Abendunterhaltungen wurden im Vorhinein festgelegt. Max Franz hatte Erbach mitgeteilt, er erwarte "4 mah/ Comödie, einmahl Bal ... und einen 
Tag großes und einen Tag kleines Concert". ${ }^{33}$ Die endgültige Feinplanung findet sich wieder im Diarium für von Roll:

"So viel nur die Veränderungen und lustbarkeiten wehrend des Groskapitels betrifft, so sind solche folgender Gestalten angeordnet Sonntags Comedie Monntags Ball

Dienstags Operette

Mittwochs großes Concert

Donnerstags Comedie

Freitag accademie samstags Operette

und sollen vom 11 $1^{\text {th }}$ dießes [September] seinen Anfang nehmen, und 6 Wochen lang continuiret werden. ${ }^{\prime 34}$

Mit anderen Worten: Sonntags und donnerstags gab es eine Theateraufführung durch die Häußlersche Truppe, dienstags und samstags eine Opern- oder Singspielproduktion, bei der die Hofmusik gegebenenfalls von Sängern und Schauspielern aus der Häußlertruppe unterstützt wurde. Montags spielten die Bonner Musiker zum Tanz auf, mittwochs und freitags gab es Konzert, wobei am Freitag Kammermusik zum Besten gegeben wurde. Freitags konnte deshalb nur ein kleineres Musikprogramm gegeben werden, weil am Sterbetag Christi ein Ball oder eine Musiktheateraufführung die Würde dieses Wochentages verletzt hätte. ${ }^{35}$ Das höfische Abendprogramm wurde offenbar immer geregelt festgelegt, denn einen ähnlichen Wochenplan hat es auch bei dem Aufenthalt von Max Franz in Münster im ersten Quartal 1793 gegeben, wie Neefe berichtet:

"Wöchentlich wurden drei theatralische Vorstellungen gegeben, unter denen jedoch die Opern am häufigsten besucht wurden. Donnerstags war groß Konzert im Theater, und jede Woche einmal Ball." ${ }^{136}$

Auch den Ort der Darbietungen hat Max Franz festgelegt: Für Theater- und Opernaufführungen schlägt er als schicklichsten Platz "die damals noch unbesetzte Orangerie im Schloß-Garten", "desto mehr als Thymm ehemals auch dort gespielt hat, und es keine Logen bedarf." ${ }^{\prime 37}$ Leider ist die Orangerie des Schlosses nicht mehr erhalten, so dass man weder über Größe noch genaue Beschaffenheit etwas weiß. Der Kölner Kurfürst und Hochmeister des Deutschen Ordens Clemens August von Wittelsbach hatte für Opernaufführungen noch Zelte im Äußeren Schlosshof errichten lassen. Für die Zeit von Max Franz ist dazu allerdings nichts bekannt. ${ }^{38}$

Der Ball sollte in der Sala terrena stattfinden, ${ }^{39}$ einem 1739 bis 1745 errichteten freistehenden Rokoko-Gartenfesthaus im Park südlich des Schlosses, das 1823 wieder abgerissen wurde. Für die Konzerte wird kein gesonderter Raum festgelegt, vielleicht erklangen sie im zwischen 1780 und 1782 eingebauten Kapitelsaal, in dem auch heute noch Konzerte stattfinden ${ }^{40}$ oder ebenfalls in 
der Sala terrena. In Frage kämen zumindest für das Kammerkonzert auch die Privatgemächer von Max Franz.

Die Vergnügungen waren offenbar auch für Mergentheimer Bürger zugänglich, erforderten aber ein Eintrittsgeld. Zumindest hat Christian Friedrich Karl Fürst zu Hohenlohe-Kirchberg, der Max Franz während des Kapitels anlässlich dessen Namenstages am 12. Oktober einen Höflichkeitsbesuch in Mergentheim abstattete und dort eine Opernaufführung besuchte, ausweislich seiner Rechnungsbücher zwei Gulden für zwei Personen Eintritt gezahlt. ${ }^{41}$

Die Harmoniemusik des Bonner Orchesters war außerdem für die Tafelmusik verantwortlich, wie wir dem Bericht Carl Ludwig Junkers entnehmen können, der wie erwähnt zusammen mit Christian Friedrich Karl zu Hohenlohe-Kirchberg im Oktober in Mergentheim weilte:

"Gleich am ersten Tage hörte ich Tafelmusik, die, so lange der Kurfürst in Mergentheim sich aufhält, alle Tage spielt. Sie ist besezt mit 2 Oboen, 2 Klarinetten, 2 Fagotten, 2 Hörner. Man kann diese 8 Spieler mit Recht Meister in ihrer Kunst nennen. Selten wird man eine Musik von der Art finden, die so gut zusammenstimmt, so gut sich versteht, und besonders im Tragen desTons einen so hohen Gradvon Wahrheitund Vollkommenheit erreicht hätte, als diese. Auch dadurch schien sie sich mir von ähnlichen Tafelmusiken zu unterscheiden, daß sie auch größere Stüke vorträgt; wie sie denn damals die Ouverture zu M. Don Juan spielte."42

Die von Junker in den höchsten Tönen gerühmten Holzbläser waren wohl Georg Liebisch und Joseph Welsch an der Oboe, Michael Meuser und Joseph Pachmeyer an der Klarinette, Georg Welsch und Theodor Zilleken am Fagott sowie Nikolaus Simrock und Andreas Bamberger am Horn. Junkers überschwängliches Lob hebt die Qualität dieser Harmoniemusik hervor, und relativiert damit die oben zitierte Behauptung Wegelers, Beethovens Kantate habe in Mergentheim nicht gespielt werden können, weil sie für die Bläser zu schwer gewesen sei. Möglicherweise hatte Beethoven diese Kapellkollegen im Sinn, als er 1792 und 1793 die Parthia in Es-Dur op. 103 und das Rondo in Es-Dur WoO 25 für dieselbe Besetzung komponierte.

Über das während des Großkapitels dargebotene Unterhaltungsprogramm und die musikalisch aufwändigeren Liturgien gibt das Diarium nur spärlich Auskunft. Demzufolge wurde am 14. September, im liturgischen Kalender das Fest Kreuzerhöhung, das Titelfest des Deutschen Ordens "mit aller Solemnität gefeiert". ${ }^{43}$ Von Montag, 3. Oktober, an wurden "Solemne Exequien" für den verstorbenen Deutschordensritter, Großkapitular, Ratsgebietiger und Komtur der Ballei Koblenz Graf Ignaz von Wurmbrand gehalten. ${ }^{44}$ Worin genau die jeweilige Solemnität bestand und welche Auswirkungen das auf die Musik während der Liturgien hatte, ist unklar. ${ }^{45}$ Am Mittwoch, 28. September, kam gegen Mittag der Fürstbischof von Würzburg zu einem Besuch vorbei. Er wurde "beim Aussteigen von samtlichen hohen Ordens Rittern am Wagen, von S . K. Dht aber 
oben an der Stiege empfangen, nachmittags ware großes Concert, und Soupé, nach welchem ihro fürstl. Gnaden bei hiesigem H. Stadtpfarrer übernachteten, und am folgenden Morgen um 8 uhren nach Würzburg zurückkehrten". ${ }^{46} \mathrm{Am}$ Mittwoch, 5. Oktober, gab es für die Ritter, die nicht in das Kapitel eingebunden waren (nicht alle in Mergentheim Anwesenden durften an den Sitzungen teilnehmen), eine organisierte Jagd. ${ }^{47}$ Am 8. Oktober machte man nachmittags eine Spazierfahrt zum rund fünf Kilometer entfernten Schloss Neuhaus, einem Deutschordensamt. ${ }^{48} \mathrm{Am} 12$. Oktober feierte der Kölner Kurfürst und Hoch- und Deutschmeister Maximilian Franz seinen Namenstag. Aus diesem Anlass waren viele zusätzliche Gäste angereist. Das Diarium vermerkt dazu:

"Mittwoch den $12^{\text {tn }}$ ware große Galla wegen dem höchsten Namenstag S[eine]r K[urfürstlichen] D[urc]h[lauch]t, des Mittags speißeten an 3 Tafeln 128 Personen, und des Abends ware großes Concert, und Soupé, womit sich das Festin beschloßen, doch ist nicht unbemerkt zu laßen, daß des Morgens S[eine]r K[urfürstlichen] D[urc]h[lauch]t die höchste Gnade hatten, dem H[errn] Ordens Minister H[errn] von Forstmeister 1/000 [1000] Dukaten, um solche unter die Hofdienerschaft zu vertheilen, zuzustellen." 49

Die Akten halten keine weiteren Informationen über das Rahmenprogramm des Kapitels bereit. Mehr Ertrag bietet das Tagebuch ${ }^{50}$ des Deutschordensritters Johann Karl ${ }^{51}$ Christian Heinrich Graf von Zinzendorf und Pottendorf, der den Landkomtur der Ballei Österreich, Aloys Graf von Harrach, auf dem Kapitel vertrat und vom 16. September bis 20. Oktober in Mergentheim weilte. Der aus pietistischer Familie stammende Karl von Zinzendorf war 1764 zum Katholizismus übergetreten. 1765 begann er das Noviziat beim Deutschen Orden und wurde am 16. September 1770 in Mergentheim zum Ritter geschlagen. Im Sommer 1788 hatte er Bonn und Brühl besucht und sich am 6. August in das Gästebuch der Bonner Lesegesellschaft eingetragen. ${ }^{52}$ Zinzendorf war ein notorischer Tagebuchschreiber und hielt detailliert seinen Tagesablauf fest. Da er sich für Musik im allgemeinen, besonders aber für Theater und Oper interessierte, sind seine Tagebücher ein Fundus für die Musik- und Theatergeschichte seiner Zeit. Dass Zinzendorf zum Großkapitel nach Mergentheim reiste, ist im Hinblick auf das dort gebotene Abendprogramm ein wahrer Glücksfall,
Karl von Zinzendorf (17391813), Kupferstich (Österreichische Nationalbibliothek)

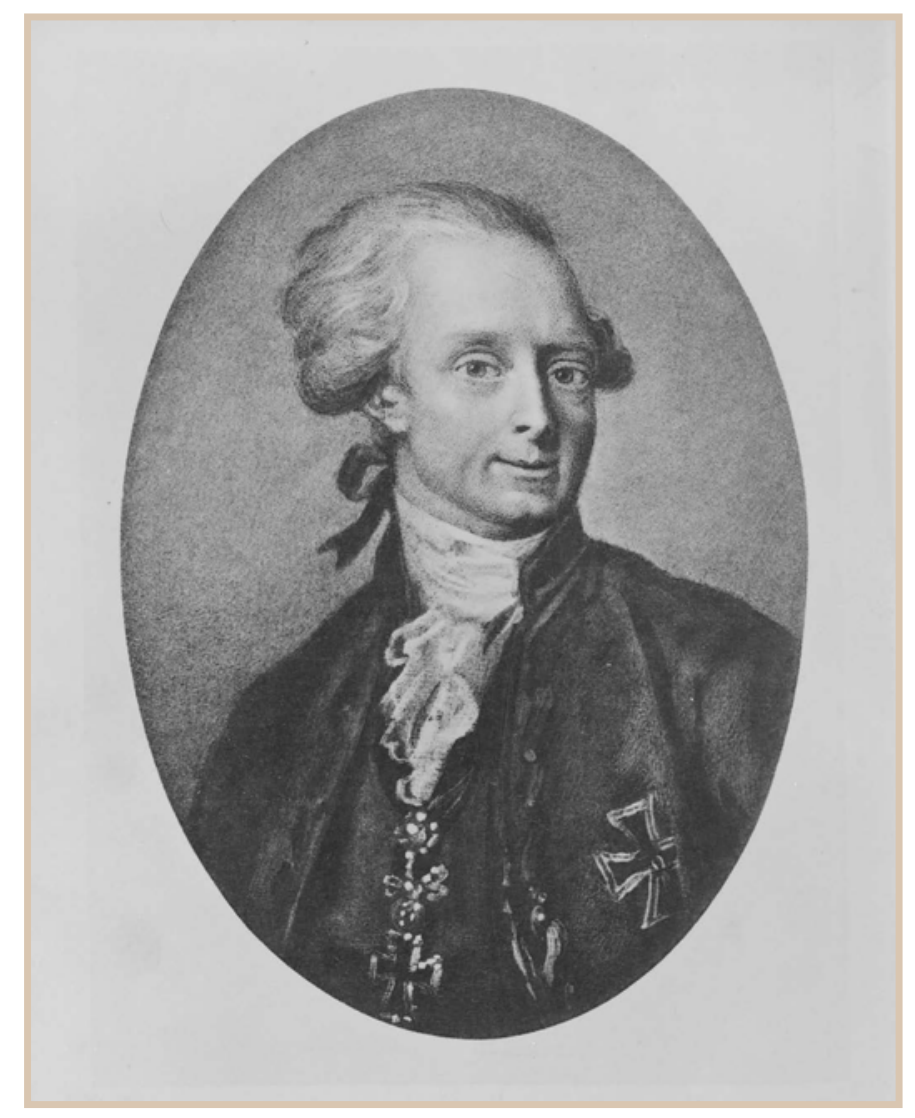


denn mit seiner Hilfe lässt sich nachzeichnen, welches Repertoire die Bonner Hofkapelle zum Besten gab. Zudem kritisierte Zinzendorf mit spitzer Feder Darsteller und Sänger der von ihm besuchten Produktionen, so dass in Grenzen auch eine qualitative Einschätzung möglich ist.

Zinzendorfs Tagebuch erwähnt fast alle Darbietungen, nur wenige Termine, vor allem die Anfangstage, bleiben unbesetzt. In der bereits oben erwähnten Aufstellung der Lustbarkeiten wurde festgelegt, dass diese am Sonntag, 11. September, beginnen sollten. Da Zinzendorf erst am 16. September in Mergentheim eintraf, bleiben die ersten fünf Abende und ihre Gestaltung bis auf weiteres unbekannt. Auch über den Abend seiner Ankunft berichtet er nichts Musikalisches, allerdings wurde Freitag Kammermusik gegeben, die Zinzendorf nie en detail beschreibt. Am Freitag, 23. September, scheint es kein Programm gegeben zu haben, Zinzendorf spielt daher Whist mit den Landkomturen der Balleien Elsass und Aldenbiesen sowie dem Oberstmarschall und verbringt anschließend den Abend mit dem Landkomtur von Sachsen. Der Kurfürst war am Nachmittag dieses Tages nach Würzburg gefahren, um dort seinen Neffen und späteren Koadjutor Erzherzog Karl abzuholen, der ihn beim Großkapitel besuchte und bis Sonntag, 25. September, blieb, und kehrte erst am nächsten Morgen zurück. Vermutlich fiel das musikalische Abendprogramm wegen der Abwesenheit des Hoch- und Deutschmeisters aus. Für den 7. Oktober führt Zinzendorf keine Veranstaltung und auch keine andere Beschäftigung an, da es aber ein Freitag war, wird wohl wieder ein Kammermusikabend gewesen sein. Am Samstag, 15. Oktober, dürfte es eine Theatervorstellung gegeben haben, das Stück bleibt allerdings unerwähnt, da Zinzendorf melancholisch war und lieber in sein Quartier zurückkehrte. ${ }^{53}$

Zinzendorf erwähnt auch außermusikalische Lustbarkeiten zusätzlich zu denen, die bereits im Diarium für Roll aufgeführt sind. Am Montag, 26. September, begab sich die ganze Gesellschaft mit Kutschen und auf Pferden nach Königshofen, ${ }^{54}$ einer Kleinstadt, die zu den Besitzungen des Kurfürsten von Mainz gehörte, wo ein Jahrmarkt stattfand. „L'Electeur joua a la Lotterie, gagna un gilet de toile imprimée et un mouchoir, et fit gagner au petit Handel une pendule. II s'arreta trop longtems a ces boutiques picantes", ${ }^{55}$ mokiert sich Zinzendorf. Kurz vor Abschluss des Kapitels, am 19. Oktober, wurde noch eine weitere Jagd veranstaltet, an der auch der Kurfürst teilnahm. Dabei zeigte er sich den Beobachtungen Zinzendorfs zufolge einer jungen Dame gegenüber freundlich, womit er eine andere eifersüchtig machte: "L'Electeur polissime avec la petite Christine Adelsheim, lui enleve son soulier, Antonie Engelhard la fille d'un Chancelliste un peu plus grande en est jalouse. Celleci est tous les jours spectatrice de notre diner, et l'Electeur lui envoye des confitures. ${ }^{\prime 56}$

Zum Programm der Konzerte und Kammermusikabende äußert sich Zinzendorf meist nicht, man erfährt lediglich von seiner Anwesenheit und in der Regel auch 
von den Gesprächspartnern, mit denen er sich während der Musikdarbietung unterhalten hat, sowie von den Gesprächsthemen. Absolute Musik war für ihn keiner weiteren Erwähnung wert. Lediglich am Freitag, 30. September, streift er knapp die ihn sehr langweilende Kammermusik mit Gesang, in der Walburga Willmann auf dem Cembalo ihre Schwester Magdalena und den Tenor Ludwig Simonetti begleitete: "Les deux sœurs Willmann, l'une joua du clavecin, l'autre chanta ainsi que l'Italien Simonetti, D'ailleurs beaucoup d'ennuie. ${ }^{157}$ Auch am Freitag, 14. Oktober, gab es Gesangsdarbietungen, die er kurz erwähnt. Die Sängerin Baumwahl habe "beaucoup de voix sans savoir la manier et se destine a etre religieuse", dagegen habe Simonetti "des baccheroles charmantes" zu Gehör gebracht. ${ }^{58}$ Mehr scheint ihn an diesem Abend die Klagen des Kurfürsten über hässliche und wenig gebildete Frauen interessiert zu haben. "L'Electeur se plaignait de ce que nous avions aussi souvent ${ }^{59}$ de femmes laides. II dit qu'a Bonn les femmes n'aprennent ni musique ni dessein, mais bien de monter a cheval a califourchon. On est trop pauvre pour leur donner des maitres." 60

Die einzige ausführliche Beschreibung eines Konzerts bei Hofe liefert uns wieder Carl Ludwig Junker, der nähere Auskunft über das Namenstagskonzert gibt. Am Morgen des 12. Oktober um $10 \mathrm{Uhr}$ war Probe in der Wohnung des Kapellmeisters Franz Ries, der zusammen mit Simonetti beim Kaufmann Nikolaus Martin untergebracht war. Das Konzert selbst fand um 18 Uhr vor dem Abendessen statt. Wegen der vielen angereisten Festgäste gab es im Saal nicht mehr viel Platz und es war heiß. „Den armen Spielern wurde im Konzert so sehr zugesezt, sie wurden von der Menge der Zuhörer so gepreßt, so eingeschlossen, daß sie kaum spielen konnten, und daß ihnen der helle Schweiß über das Gesicht lief; aber sie ertrugen dies alles ruhig und gelassen, man sah keine unzufriedene Mine an ihnen",61 bezeugt Carl Ludwig Junker die Aufführungssituation. Junker beschreibt auch das Programm und die Qualität der Ausführung:

"Die Eröfnung geschah durch eine Sinfonie von Mozart, hierauf kam eine Arie mit einem Rezitativ, die Simonetti sang; denn ein Violonzellkonzert, gespielt von Hrn. Romberger. Nun folgte eine Sinfonie von Pleyel, Aria von Simonetti gesungen, von Regini62 gesezt. Ein Doppelkonzert für eine Violine und ein Violonzell, von den beiden Hrn. Rombergers fürgetragen. Den Beschluß machte die Sinfonie von Hr. Winneberger ${ }^{63}$, die sehr viele brilliante Stellen hatte. ${ }^{64}$ Hier gielt mein oben schon gefälltes Urtheil wieder vollkommen; die Aufführung konnte durchaus nicht pünktlicher seyn, als sie war. Eine solche genaue Beobachtung des Piano, des Forte, des Rinforzando, eine solche Schwellung, und allmählige Anwachsung des Tons, und dann wieder ein Sinkenlassen desselben, von der höchsten Stärke bis zum leisesten Laut, - - dies hörte man ehemals nur in Mannheim. Besonders wird man nicht leicht ein Orchester finden, wo die Violinen und Bässe so durch- 
aus gut besezt sind, als sie es hier waren. Selbst Hr. Winneberger war vollkommen dieser Meinung, wenn er diese Musik mit der gleichfalls sehr guten Musik in Wallerstein verglich." 65

Aus heutiger Sicht erstaunt, dass Beethoven nicht als Solist in Erscheinung trat. Die aus Bonn mitgereisten Stars waren jedoch, wie bereits genannt, der Tenor Simonetti sowie unter den Instrumentalisten die beiden Cousins Andreas und Bernhard Romberg. Für solistische Klavierdarbietungen hatte man mit Walburga Willmann, wie erwähnt, eine Mozart-Schülerin engagiert, obwohl in Bonn vornehmlich Beethoven für die Klavierkonzerte zuständig war: "Klavierkonzerte spielt Hr. Ludwig van Bethoven, und Hr. Neefe akkompagnirt bei Hofe, im Theater und in Konzerten. Demoisell Willmann, eine gute Mozartische Schülerin im Klavier, spielt zuweilen im Konzert, und giebt Unterricht im Klavierspielen."66 Junker vermutete in seinem Bericht, das Instrument habe vielleicht nicht Beethovens Wünschen entsprochen; "es war ein spathischer Flügel, und er ist in Bonn gewohnt, nur auf einem Steinischen zu spielen." ${ }^{67}$ Allerdings wäre Beethoven wahrscheinlich nicht gefragt worden, ob ihm das Instrument genehm sei, und er hätte sich sicher nicht dem Willen des Kurfürsten entzogen, wenn dieser ihn hätte konzertieren hören wollen. Die Wahrheit wird, wie angesprochen, wohl sehr viel prosaischer sein: Beethoven fungierte beim Großkapitel 1791 als einfacher Tuttist, der entweder Bratsche im Orchester oder Continuo auf einem Tasteninstrument spielte und wohl auch bei den Gottesdiensten den Orgeldienst zu versehen hatte (immerhin hatte man ja eigens aus Bonn einen Kalkanten mitgebracht).

Neben den Konzerten lässt Karl von Zinzendorf in seinem Tagebuch auch die montäglichen Bälle weitgehend unerwähnt. Sie finden statt, und er war wohl auch dort, aber weder Musik noch Gesellschaft werden näher beschrieben. Am Montag, 3. Oktober, war Zinzendorf überrascht, bei Hofe Kammermusik vorzufinden. Vermutlich fiel der Ball wegen der bereits erwähnten Trauerfeierlichkeiten für Graf Wurmbrand aus. Auch am Montag, 17. Oktober, kurz vor Beendigung des Kapitels, wurde der Ball durch Kammermusik ersetzt, die Zinzendorf aber ebenso wenig näher würdigt. Bälle der Mergentheimer Hofhaltung unter Anwesenheit des Hoch- und Deutschmeisters schildert allerdings der bereits erwähnte kurkölnische Beamte Peter Joseph Boosfeld 1784:

„Das Gerücht, als ob er [Max Franz] ein Devotant und Freudenscheu oder Weiberscheu sei, ist wohl falsch. ... Sieben Bälle hat er gegeben und ist auf allen selbst zugegen gewesen, hat Alle animirt, auch bis ein, zwei Uhr sich aufgehalten. Selbst die Exercitienbälle, welche in der Wohnung des Statthalters auf dem Schloß gegeben werden, hat er jedesmal besucht und ermuntert. Noch besonders hat er auch für die hiesige Bürgerschaft Bälle gegeben, welches Alles das ihm nachgesagte, devote Wesen nicht beweist." 68 
Der Kurfürst tanzte offenbar gerne, andernfalls hätte es gewiss auch nicht regelmäßig Bälle im Abendprogramm gegeben. Nicht nur bei den Bällen waren bei den Abendveranstaltungen auch regelmäßig Frauen anwesend, weibliche Familienmitglieder der Kapitelsteilnehmer, der angereisten Gäste oder des Mergentheimer Bürgertums. Darauf lassen Bemerkungen bei Zinzendorf schließen, der einige der Damen erwähnt und zum Teil auch süffisant beschreibt. Auch in Bonn waren Frauen stets bei Veranstaltungen bei Hofe zugelassen, und selbst wenn der Kurfürst im Sommer in Augustusburg in Brühl weilte, hatten Besucher und auch weibliche Gäste zu den Abendessen und Veranstaltungen nach vorheriger Anmeldung Zutritt. ${ }^{69}$

Noch mehr als Tanzen liebte der Kurfürst die darstellende Kunst, die auch zu den Kerninteressen Zinzendorfs gehörte, weshalb er glücklicherweise darüber genauer Auskunft gab. Gemäß der regulierten Abfolge der Unterhaltungen gab es Sonntag und Donnerstag "Comedie", also Theateraufführungen, Dienstag und Samstag dagegen "Operette”, also Singspiele und komische Opern. Die Aufführungen begannen wohl in der Regel wie auch die Konzerte um 18 Uhr.

Die Übersicht der von Zinzendorf besuchten Veranstaltungen (s. Anhang) macht deutlich, dass man Lustspiele und leichte Unterhaltung bevorzugte. Schon Lang hatte kritisiert: "Noch ist man etwas eigensinnig in der Auswahl der guten Stükke, und verstümmelte Operetten verdrängen oft die besten vaterländischen Schauspiele."70 Die wenigen vergleichsweise ernsten Stücke im Mergentheimer Programm gehören allesamt dem Sprechtheater an. Die Darbietungen waren in Bonn bereits längere Zeit im Repertoire, wie ein Abgleich mit den Gothaer Theaterkalendern zeigt. ${ }^{71}$ Sie entsprachen dem Zeitgeschmack und waren Publikumsmagneten auch an anderen Bühnen.

Auffallend ist, dass Zinzendorf eher die Bonner Musiker positiv hervorhebt. Sie scheinen musikalisch qualitativ besser gewesen zu sein als die Nürnberger, was angesichts der Spezialisierung - die Bonner waren in erster Linie Musiker, die Nürnberger Schauspieler - nicht überraschend ist. Aus dem oben zitierten Brief von Max Franz wissen wir, dass er bewusst bei der Theatertruppe gespart hat - möglicherweise machte sich das auch in der Qualität der schauspielerischen Leistung bemerkbar. Zinzendorfs Beschreibungen sind sehr knapp und mitunter mokant. Zu Beginn seines Aufenthaltes ist er noch milde gestimmt, vielleicht waren die Aufführungen aber auch tatsächlich gut. Je länger er in Mergentheim bleibt, umso ungehaltener wird er, denn die Kleinstadt bietet ihm, der das Kulturleben Wiens gewohnt war, nicht genug Abwechslung und auch nicht auf dem von ihm gewohnten Niveau. Am Samstag, 17. September, betont er, die Oper La cosa rara sei durch "une troupe allemande de Nuremberg" aufgeführt worden, die das Stück gut dargeboten habe, "bien executée". ${ }^{72}$ Im Barbier von Sevilla am Dienstag, 20. September, übernahmen offenbar die Bonner die Hauptpartien: "C'etaient des gens au service du Monseigneur, un nommé Luchs, la Dem쓰 Willmann, qui executerent cette piece 
a merveille." ${ }^{173} \mathrm{Am}$ Sonntag, 25. September, bemängelt er das lustlose Spiel der Schauspielerin Spiri aus der Häußlerschen Truppe - "La Spiri joua a contrecoeur" -, obgleich er das Stück an sich für "amusant" hält. ${ }^{74}$ In der Schönen Schusterin spottet Zinzendorf über Magdalena Willmann, die weniger durch ihren Gesang als mit ihrem Kostüm glänzte. ${ }^{75}$ Der Theater-Kalender auf das Jahr 1792 hatte sich über die Bonner Aufführung der Schönen Schusterin, bei der ausschließlich Sänger eingesetzt worden waren, die auch nach Mergentheim mitgefahren sind, noch lobend geäußert: „In der Operette aber verdienen Herr Brand als Baron von Vicourt, Hr. Müller als Michel, Hr. Lux als Meister Sock, und Demois. Willmann als Frau Lehne allen Beifall." ${ }^{176}$

Am Sonntag, 2. Oktober, lobt Zinzendorf den Prinzipal Franz Häußler, der seine Rolle "a merveille" dargeboten habe. ${ }^{77}$ Am Dienstag, 4. Oktober, kritisiert er reichlich ungnädig die Schauspielerin Opiz, die wie eine Katze singe, dafür aber wenigsten hübsch sei. ${ }^{78}$ An der Gemeinschaftsproduktion von Menschenhaß und Reue am 6. Oktober lässt Zinzendorf kein gutes Haar: In seinen Augen deklamierten die Darsteller nicht richtig oder sie spielten schlecht oder waren schlecht gekleidet. ${ }^{79}$ Bei den Bonner Aufführungen in den Jahren 1789 bis 1791 hatte das Stück noch gefallen, aber möglicherweise war Zinzendorf aus Wien Besseres gewohnt oder die Mischung der beiden Ensembles war nicht erfolgreich. Mozarts Entführung aus dem Serail am 8. Oktober hält Zinzendorf schlicht für "mal chanté". ${ }^{80}$ Am Sonntag, 9. Oktober, lobt er die Leistungen eines männlichen Darstellers in Die Frauenzimmer-Laune. Offenbar wollte er den Namen noch nachtragen, denn er ließ an der entsprechenden Stelle im Tagebuch eine Lücke, die aber nicht gefüllt wurde.

Besonders zufrieden ist Zinzendorf mit der Bonner Hofkapelle, die am Vorabend zum Namenstag des Kurfürsten, am Dienstag 11. Oktober, den König Theodor von Paisiello zum Besten gab: "fut rendu en allemand ausi bien que possible par la troupe del'Electeur, la musique alla a merveille"..$^{81}$ Schon der Gothaer Theater-Kalender auf das Jahr 1792 hatte die Bonner Aufführung von Ende 1790 gelobt, die offenbar mit denselben Darstellern wie den nach Mergentheim gereisten dargeboten worden war: „Hr. Müller spielte den König mit Anstand. Herr Lux belustigte als Gastwirth, und Demoiselle Willmann zeichnete sich durch ihren Gesang in der Rolle der Lisette aus." ${ }^{82}$ Eine ausführlichere Rezension der Mergentheimer Aufführung findet sich wieder bei Junker:

"Bald nach der Tafelmusik gieng das Schauspiel an. Es war König Theodor, mit Musik von Paisiello. Die Rolle Theodors spielte Hr. Nüdler [recte: Müller?], besonders stark in tragischen Scenen, zugleich gut in der Aktion. Den Achmet stellte Hr. Spizeter vor, ein guter Baßist, nur zu wenig handelnd, und nicht immer mit Wahrheit; kurz, zu kalt. Der Gastwirth war Hr. Lux, ein sehr guter Baßsänger, und der beste Akteur, ganz geschaffen fürs Komische. Die Rolle der Lisette wurde durch Demoiselle Willmann vorgestellt. ... Sie singt mit sehr viel Geschmak, hat 
vortreflichen Ausdruk, und eine rasche, hinreissende Aktion. Auch Hr. Mändel im Sandrino war ein sehr guter, gefälliger Sänger. Das Orchester war vortreflich besezt; besonders gut wurde das Piano und Forte, und das Crescendo in obacht genommen. Hr. Ries, dieser vortrefliche Partiturleser, dieser große Spieler vom Blatt weg, dirgirte mit der Violine. Er ist ein Mann, der an der Seite eines Cannabichs steht, und durch seinen kräftigen, sichern Bogenstrich allen Geist und Leben giebt....

Die Oper selbst hat so viel Licht und blühendes Kolorit, daß sie auf das erstemal einen starken Eindruk macht, und mit sich fortreißt, aber bei öftern Vorstellungen, glaube ich, ist die Komposition für einen deutschen Magen wohl - zu italienisch.

Auf mich wirkte am meisten die Arie, wo der unglükliche König seinen fürchterlichen Traum erzählt. Hier hat der Komponist einigemal mit ausserordentlichem Glük gemalt, ohne ins Läppische zu fallen, und durch die Blasinstrumente eine vortrefliche Schattirung in sein Gemälde gebracht. Ich glaube, es ist im ganzen Stük keine Arie, die so viel große, fürspringende Stellen hat, so tief eingreifend ist, als diese Arie. Ausserdem schien mirs, als ob der Komponist zu viel wiederhole, seinen Gedanken oft zu sehr in langweilige Länge ausdehne, also nicht immer den glüklichen Zielpunkt treffe. Auch waren in den Chören die begleitenden Stimmen zu überladen gesezt."

Der König Theodor scheint ausschließlich von der Bonner Hofkapelle produziert worden zu sein, möglicherweise sogar auf Wunsch des Kurfürsten, der sicher in Anwesenheit seiner Namenstagsgäste kein Risiko eingehen und nur beste Qualität bieten wollte. Von Zinzendorf erfahren wir außerdem, dass wegen des Festes während der Aufführung das Theater gegen den Wunsch des Kurfürsten illuminiert wurde, Zinzendorf zufolge zum Nachteil für das Stück. ${ }^{84}$ Auch ein Prolog zu Ehren des Kurfürsten hätte vorgetragen werden sollen, den Max Franz in seiner Bescheidenheit aber untersagte, ebenso wie das Tragen der Galauniform.

Die Jäger von Iffland am Donnerstag, 13. Oktober, war wieder eine Gemeinschaftsproduktion, und diese kommen bei Zinzendorf immer schlechter weg als Aufführungen, die von den Bonner Hofmusikern alleine verantwortet wurden. So kritisiert Zinzendorf auch die Leistungen der Frau Häußler, die ihre Rolle "completement manqué", total verfehlt habe. Müller "de la troupe de I'Electeur" dagegen habe seinen Part gut gespielt. ${ }^{85}$ Die letzte Erwähnung erfahren zwei Schauspielerinnen im Listigen Bauernmädchen am 18. Oktober, die gut gespielt haben. ${ }^{86}$

Bisweilen äußert sich Zinzendorf auch nur über die Qualität des Stückes, nicht über seine Aufführung oder Inszenierung. So notiert er am 22. September, Kaspar der Thorringer sei ein "Singuliére piéce". ${ }^{87}$ Die Tempelritter am 29. September hält er für ein „piéce incroyable" ${ }^{\prime 88}$, was keinesfalls als positives Urteil 
gewertet werden kann, und kritisiert vor allem die völlig ahistorische Schilderung. Als Ordensritter ist er empört über die politische Haltung, die den Tempelrittern angedichtet wird: "On voit clairement que le jeune auteur qui a cousu ensemble ce drâme infame, etoit rempli de l'idée que les templiers etoient des francs maçons. ${ }^{189}$ Zudem ärgert ihn die Kostümwahl, die den bekannten Uniformen der Templer in ihrer Farbgebung nicht entsprach und lächerlich wirkte..$^{90}$ An der Frauenzimmer-Laune am 9. Oktober findet Zinzendorf nur wenig Außergewöhnliches ${ }^{91}$ und den Argwöhnischen Liebhaber am 16. Oktober hält er schlicht für ein ziemlich dummes Stück, "une assez sotte piéce".92

Zinzendorfs in Mergentheim vorherrschende Stimmungslage war Langeweile, die er seinem Tagebuch in regelmäßigen Abständen anvertraut. „Je fus m'ennuyer a ce long opera" ist die einzige Erklärung, die er für das DittersdorfSingspiel Doktor und Apotheker am 24. September übrig hat. Auch den Bettelstudent am Samstag, 1. Oktober, findet er stumpfsinnig und zieht Parallelen zum Alltag in Mergentheim: "l'opera der Bettel Student m'ennuya comme toute cette vie de Mergentheim m'ennuye a perir". ${ }^{\prime 3}$ Am Dienstag, 4. Oktober, gibt er vor, vor Eintönigkeit eingeschlafen zu sein, obwohl er doch, wie erwähnt, festhält, eine der Sängerinnen habe wie eine Katze gesungen. Am Montag, 17. Oktober, fragt Zinzendorf beim Kurfürsten nach, ob er schon abreisen dürfe, wird von diesem aber auf Donnerstag, wenn alle Beschlüsse des Großkapitels niedergelegt und unterschrieben sind, vertröstet.

Der Kapitelsrezess wird am Donnerstag, 20. Oktober, durch den Kanzleidirektor Georg Joseph von Breuning verlesen und auf drei Exemplaren, darunter eines aus Pergament, unterschrieben; die Unterschriftsprozedur dauert über eine Stunde: zuerst der Kurfürst, dann elf Großkomture und sieben Ratsgebietigern, also insgesamt 19 Unterschriften. Zinzendorf kann danach nicht schnell genug aus Mergentheim fortkommen und verlässt noch am selben Abend die Stadt - "tres content d'en etre dehors".94

Der Kölner Kurfürst blieb noch bis 2. November in Mergentheim, um von dort nach Wien weiterzureisen, wo er am Morgen des 6. November ankam. ${ }^{95}$ Spätestens nach der Abreise des Kurfürsten werden auch seine Musiker die Heimreise nach Bonn angetreten haben. Allerdings geben die Akten darüber im Gegensatz zur Hinreise keine Auskunft, so dass wir nur vermuten können, dass die Hofkapelle spätestens gegen Ende der ersten Novemberwoche wieder zu Hause war. Der Gothaer Theaterkalender auf das Jahr 1793 berichtet erst ab 28. Dezember 1791 wieder vom Bonner Spielbetrieb, ${ }^{96}$ zuvor scheinen die Musiker noch eine wohlverdiente Pause genossen zu haben. 


\section{Anhang}

Die von Karl von Zinzendorf beim Generalkapitel des Deutschen Ordens in Mergentheim im Herbst 1791 besuchten Aufführungen:

Samstag Una cosa rara, Dramma gioco- Vicente Martín y Soler (Musik), 17.09. so in due atti (UA Wien 1786) Lorenzo da Ponte (Text)

Sonntag Der Diener zweier Herren Carlo Goldoni, deutsch 18.09 . (Il servitore di due padroni), Lustspiel in drei Aufzügen (UA Mailand 1746)

Dienstag 20.09 .

Donnerstag Kaspar der Thorringer, 22.09.

Samstag 24.09 .

Sonntag 25.09.

Dienstag 27.09. Schauspiel in fünf Aufzügen (1785)

Der Barbier von Sevilla (II barbiere di Siviglia), Singspiel in vier Aufzügen (UA St. Petersburg 1782, deutsche Fassung von Großmann 1776)

Doktor und Apotheker Komisches Singspiel in zwei Aufzügen (UA Wien 1786)

Irrtum auf allen Ecken (She stoops to conquer), Lustspiel in fünf Aufzügen (UA London 1773, deutsche Fassung von Schröder 1784)

\section{Die schöne Schusterin} ou le soulier moredoré (oder Die pucefarbenen Schuhe), Komisches Singspiel in zwei Aufzügen (UA Wien 1779)
Giovanni Paisiello (Musik), Pierre Augustin Caron de Beaumarchais (Text), deutsch von Gustav Friedrich Wilhelm Großmann

Joseph August Graf von Törring

Carl Ditters von Dittersdorf (Musik), Johann Gottlieb Stephanie d. J. (Text)

Oliver Goldsmith, deutsch von Friedrich Ludwig Schröder
Ignaz Umlauf (Musik), Johann Gottlieb Stephanie d. J. nach einer Vorlage von Baligand de Serrières (Text)

Donnerstag Die Tempelherren, Trauerspiel Johann Nepomuk Ritter von 29.09. in fünf Aufzügen (Graz 1788) Kalchberg 
Samstag

01.10.
Die beiden Billets

(Les deux billets), Lustspiel in einem Aufzug (Leipzig 1790)

Der Bettelstudent, Komische Oper in zwei Aufzügen (UA Wien 1785)

Sonntag So zieht man dem Betrüger 02.10 .

Dienstag 04.10. die Larve ab, Lustspiel in fünf Aufzügen (1787)

Der Jurist und der Bauer, Lustspiel in zwei Aufzügen (UA Wien 1773)

Die Kolonie (La colonie), Singspiel in zwei Aufzügen (UA Paris 1775)

Donnerstag Menschenhaß und Reue, 06.10. Schauspiel in fünf Aufzügen (UA Reval 1788)

Samstag Die Entführung aus dem 08.10. Serail, Singspiel in drei Aufzügen (UA Wien 1782)

Sonntag 09.10.

Dienstag 11.10.
Die Frauenzimmer-Laune oder: Sagten Sie was?, Lustspiel in drei Aufzügen (1786)

König Theodor in Venedig (Il re Teodoro a Venezia), Singspiel in zwei Aufzügen (UA Wien 1784)
Jean-Pierre Claris de Florian, deutsch von Christian Leberecht Heyne (alias Anton Wall)

Peter von Winter (Musik), Paul Weidmann (Text)

Alois-Friedrich Graf von Brühl

Johann Rautenstrauch

Antonio Maria Gasparo Sacchini (Musik), NicolasEtienne Framéry (Text)

August von Kotzebue

Wolfgang Amadé Mozart (Musik, KV 384), Christoph Friedrich Bretzner, Johann Gottlieb Stephanie d. J. (Text)

Heinrich Christian Pleißner
Giovanni Paisiello (Musik), Giovanni Battista Casti (Text), deutsch von Christian August Vulpius


Donnerstag Die Jäger, ein ländliches

13.10. Sittengemälde in fünf Aufzügen (Berlin 1785)

Sonntag 16.10 .

Der argwöhnische Liebhaber, Lustspiel in fünf Akten

(Leipzig 1783)

Dienstag

18.10 .
Das listige Bauernmädchen (La contadina astuta), Intermezzo in zwei Teilen (UA Neapel 1734)
August Wilhelm Iffland

\section{Christoph Friedrich Bretzner}

\author{
Giovanni Battista Pergolesi \\ (Musik), Tommaso Mariani \\ (Text)
}

Siehe auch Christian GOTTlob NeEFE, Musikal. Nachrichten von Münster und Bonn, in: Berlinische musikalische Zeitung 38, 19.10.1793, S. 149, der von einer Reise des Kurfürsten nach Münster im Dezember 1792 berichtet.

Vgl. die entsprechenden Quartierslisten in Landesarchiv Nordrhein-Westfalen, Abt. Rheinland (LAV NRW R), Kurköln II, 402, BI. 15r, 16r, 26r, 30r, 70r.

In der Regel findet sich an dieser Stelle ein Verweis darauf, dass es sich entweder um die Kantate auf den Tod Kaiser Josephs II. WoO 87 oder um die Kantate auf die Erhebung Leopolds II. zur Kaiserwürde WoO 88 handelt. Angesichts der Tatsache, dass die Bonner Hofkapelle in erster Linie unterhalten sollte, scheint es mir nahezu ausgeschlossen, dass zu diesem Zweck die Trauerkantate vorgesehen war. Es wird sich wohl eher um WoO 88 gehandelt haben

FRANZ GERHARD WEGELER und FERDINAND RIES, Biographische Notizen über Ludwig van Beethoven, Koblenz 1838, S. 16.

Ebd., S. 17

Ebd., S. $17 f$.

Carl Ludwig Junker, Noch etwas vom Kurköllnischen Orchester, in: Musikalische Korrespondenz der teutschen Filarmonischen Gesellschaft 47, 23.11.1791, Sp. 373-376, und 48, 30.11.1791, Sp. 379-382

Am 11. und 12.10.1791

Wenn nicht anders angegeben, folgt die Darstellung den im Landesarchiv Baden-Württemberg, Staatsarchiv Ludwigsburg (LA BaWü, StALu), unter B 323 Bü 204 aufbewahrten Akten zum Kapitel zu Mergentheim. Stark zusammenfassend wurden sie bereits ausgewertet von: AdOLF SANDBERGER, Zur Reise nach Mergentheim und Aschaffenburg, in: Ausgewählte Aufsätze zur Musikgeschichte 2 (Forschungen, Studien und Kritiken zu Beethoven und zur Beethovenliteratur), München 1924, S. 131-134. Die Akten sind weder foliiert noch paginiert, was den genauen Nachweis des Zitats erschwert. B 323 Bü 204 ist vollständig digitalisiert und auffindbar unter https://www2. landesarchiv-bw. de/ofs21/olf/startbild.php?bestand=17175 (26.6.2019). Um den Zitatnachweis nachvollziehbarer zu machen, wird deshalb im Folgenden die Bildnummer des Digitalisates angegeben. Ich danke Dr. Peter Müller vom Landesarchiv Baden-Württemberg, Staatsarchiv Ludwigsburg, für die Hilfe bei Auffindung und Bereitstellung der Akten. 


\section{LA BaWü, StALu B323 Bu204, Bild 14.}

Deutschordens-Zentralarchiv Wien (DOZA), GK 1791 DOZA 750 GK002.

12 Ernst Ludwig Gerber vermerkt in seinem Neuen historisch-biographischen Lexikon der Tonkünstler, Leipzig 1812-1814, Bd. 4, Sp. 582, die ältere Demoiselle Willmann, „eine wohlgeratene Schülerin von Mozart im Klavierspielen, stand im J. 1791 noch in Churf. Cölnischen Diensten zu Bonn, wo sie in den Hofmusiken zuweilen spielte und dabey Unterricht im Klavierspielen gab." In den Hofkalendern wird [Maximiliana Valentina] Walburga Willmann allerdings im Gegensatz zu ihrer Schwester [Johanna] Magdalena nicht genannt. Wal burga Willmann heiratete 1797 Franz Xaver Huber, den Textdichter von Beethovens Oratorium Christus am Ölberge op. 87

[Christian Gottlob Neefe], den 30sten März 1783. Nachricht von der churfürstlich-cöllnischen Hofcapelle zu Bonn und andern Tonkünstlern daselbst, in: CARL FRIEDRICH CRAMER, Magazin der Musik 1, 1783, S. 377-396, hier S. $384 f$.

Joseph GREgor LANG, Reise auf dem Rhein. Theil II: Reise auf dem Rhein von Andernach bis Düsseldorf, Koblenz 1790, S. $206 f$.

Vgl. EduARd Hegel, Das Erzbistum Köln zwischen Barock und Aufklärung vom Pfälzischen Krieg bis zum Ende der französischen Zeit 1688-1814 (Geschichte des Erzbistums Köln 4), Köln 1979, S. 72, 480

Der kaiserliche Gesandtschaftssekretär Gottfried von Kornrumpf an den Reichsvizekanzler Franz de Paula von Colloredo Koblenz, 28.8.1791, zitiert nach JOSEPH HANSEN (Hg.), Quellen zur Geschichte des Rheinlandes im Zeitalter der Französischen RevoIution 1780-1801, ND der Ausgabe Bonn 1931, bearb. von STEPHAN LAUX, Düsseldorf 2003 (Publikationen der Gesellschaft für rheinische Geschichtskunde XLII), S. 945f., hier S. 946.

Vgl. Aloys MeIster, Das Herzogtum Westfalen in der letzten Zeit der kurkölnischen Herrschaft, in: Westfälische Zeitschrift 64, 1906, S. 96-136, besonders S. 111

Auf jeder Poststation wurden die Achsen neu geschmiert, damit sich die Räder nicht festfraßen.

The Letters and Journals of Lady Mary Coke. Volume second 1767-1768, Bath 1970, S. 82.

"The Yacht anchor'd at ten O'clock at night, when I went to shore to take a little walk, but return'd at eleven, \& went to Bed. They always stay till four O'clock in the morning, \& then proceed on the Voyage; they likewise cast Anchor twice in the day to bate the Horses, at which times I usually went on Shore to look about me." Ebd., S. 83.

LANG, Reise (wie Anm. 14), S. $256 f$.

LA BaWü, StALu B323 Bu204, Bild 29 und 30

Ebd., Bild 30.

Ebd., Bild 115

Siehe dazu den Briefentwurf an von Roll, ebd., Bild 117

Max Franz an Christian Graf zu Erbach-Schönberg, Wien, 29.6.1791, in: DOZA, Militaria $18 / 5$, S. 5

LA BaWü, StALu B323 Bu204, Bild 30 und 31

Zitiert nach: HeRRMANN HüFfER, Bericht über eine Reise nach Mergentheim, in: Annalen des Historischen Vereins für den Niederrhein 13/14, 1863, S. 110-117, hier S. 114. 


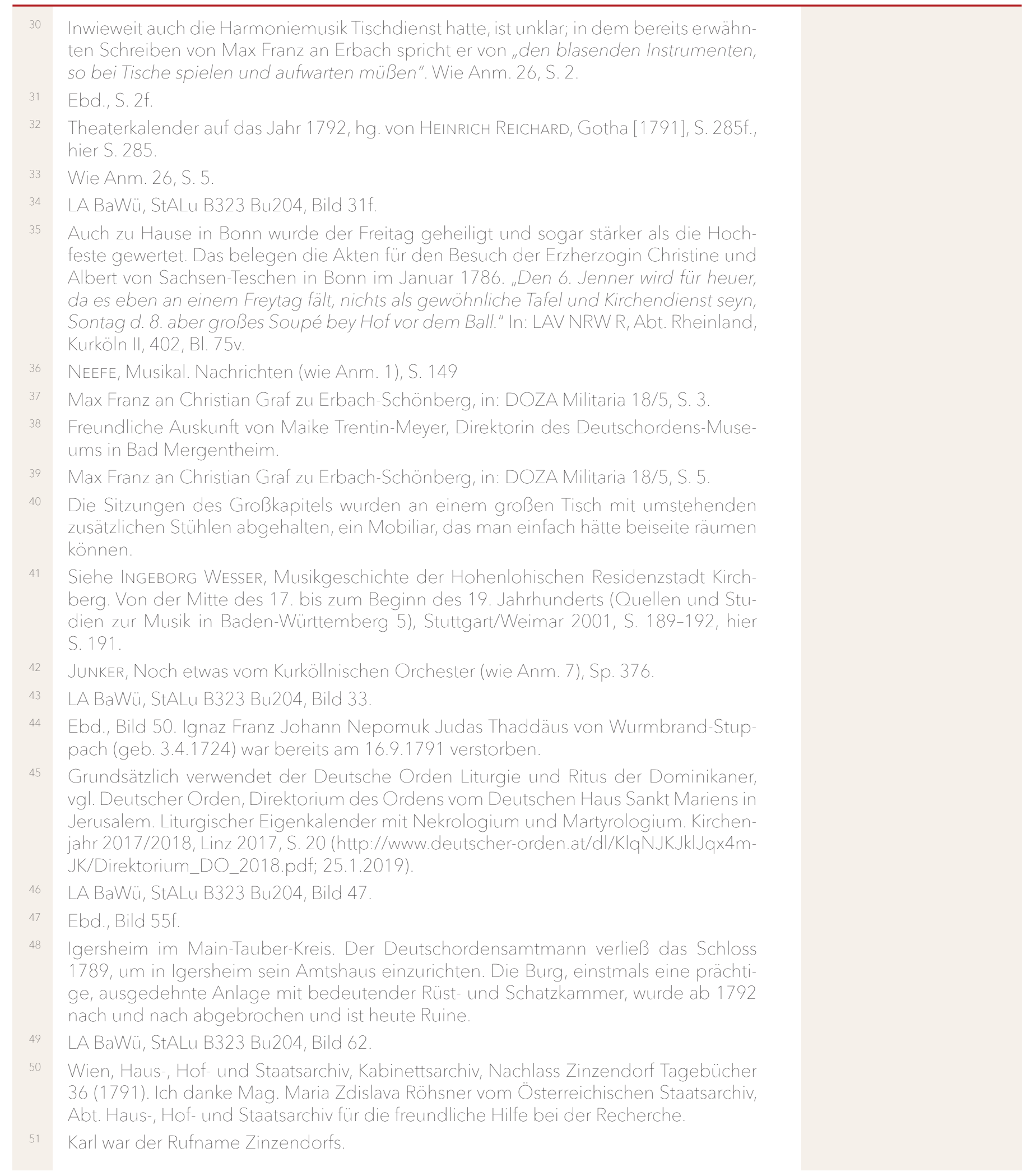

Beethovens Reise nach Mergentheim 1791 - Nahaufnahme einer bekannten Unternehmung | 495 
Derzeit als Depositum im Beethoven-Haus.

Zinzendorf Tagebücher (wie Anm. 50), BI. 244v.

Ca. 10 km von Mergentheim, heute Teil der Stadt Lauda-Königshofen.

Zinzendorf Tagebücher (wie Anm. 50), BI. 220v.

Ebd., Bl. 249v-250r.

Ebd., Bl. 226r.

Ebd., Bl. 243v.

Die Lesart "aussi souvent" ist unsicher.

Zinzendorf Tagebücher (wie Anm. 50), Bl. 243v

JUNKER, Noch etwas vom Kurköllnischen Orchester (wie Anm. 7), Sp. 381

Vincenzo Righini (1756-1812).

Paul Anton Wineberger (1758-1821), gebürtig aus Mergentheim, ab 1778 in Mannheim Seminarlehrer und Organist der Großen Hofkirche, ab 1780 Cellist in der Hofkapelle des Fürsten von Oettingen-Wallerstein, ab 1785 dort Konzertmeister. In dem Verzeichnis, das in Bonn von Max Franz' Musikaliensammlung angelegt wurde und das sich heute in Modena befindet (Modena, Biblioteca Estense Universitaria, Catalogo storico, E.40.4.9-10 [Cat. 53/I-II]), sind sechs verschiedene Wineberger-Sinfonien aufgeführt (B-, F-, C-, D-, G- und D-Dur), erstaunlicherweise gibt es zumindest dem Incipit nach keine Überschneidung zu den im von GERTRAUD HABERKAMP erstellten Thematischen Katalog der Musikhandschriften der Fürstlich Oettingen-Wallerstein'schen Bibliothek Schloß Harburg (Kataloge Bayerischer Musiksammlungen), München 1976, aufgelisteten Sinfonien.

Im vorangegangen Absatz, in dem er die Probe für das Konzert schildert, hatte Junker Winebergers Sinfonie als "gewiß nicht leicht" qualifiziert, "weil besonders die Blasinstrumente einige konzertirende Solos hatten". JUNKER, Noch etwas vom Kurköllnischen Orchester (wie Anm. 7), Sp. 376

Ebd.

Kurfürstliche Kabinets-, Kapell- und Hofmusik. 1791., in: Musikalische Korrespondenz der teutschen filarmonischen Gesellschaft 28, 13.7.1791, Sp. 220-222, hier Sp. 222 JUNKER, Noch etwas vom Kurköllnischen Orchester (wie Anm. 7), Sp. 380 HüFFER, Bericht über eine Reise (wie Anm. 28), S. $115 f$

"für die wohnende Noblesse ist täglich Mittags und Abends Tafel a table ronde von 12 bis 16 couverts. Sontags und Mitwochs aber werden Kavaliers und Damen von Bonn und Köln zur mitags Tafel geladen, folglich die Tafel auf 24 bis 30 komme" (1786), in: LAV NRW R, Abt. Rheinland, Kurköln II, 402, BI. 25r. LANG, Reise (wie Anm. 14), S. 207

So führt der Theaterkalender auf das Jahr 1791 für die Saison vom 3.1. bis 20.5.1789 Die beiden Billets und Die Entführung aus dem Serail ("gefiel sehr") auf. Für die Wintersaison vom 13.10.1789 bis 23.2.1790 nennt der Theaterkalender Die Jäger ("gefiel"), Der Barbier von Sevilla ("gefiel"), Die schöne Schusterin, Die beiden Billets ("gefiel"), Menschenhaß und Reue ("gefiel sehr"), Das listige Bauernmädchen ("ward ebenfalls viel gelacht") sowie Der Apotheker und Doktor ("gefiel"), siehe Theaterkalender auf das Jahr 1791, Gotha [1790], S. 199f. Der Theater-Kalender auf das Jahr 1792 ist in seiner Darstellung ausführlicher. In der Saison 1790/91 wurde in Bonn König Theodor in Venedig gegeben. Außerdem Der Barbier von Sevilla ( sehr"), Die schöne Schusterin ("In der Operette aber verdienen Herr Brand als Baron 
von Vicourt, Hr. Müller als Michel, Hr. Lux als Meister Sock, und Demois. Willmann als Frau Lehne allen Beifall."), Menschenhaß und Reue ("gefiel, aber nicht jedermann so, wie vorm Jahre"), Der Jurist und der Bauer, siehe Auszug eines Briefs aus Bonn, in: Theater-Kalender auf das Jahr 1792, Gotha [1791], S. 336-340.

Zinzendorf Tagebücher (wie Anm. 50), BI. 209v.

Ebd., BI. $211 \mathrm{v}$

Ebd., BI. 219v

"la Willmann ne brille point par le chant mais bien par son joli habit"; ebd., BI. 221 r.

Auszug eines Briefs aus Bonn, in: Theater-Kalender auf das Jahr 1792, Gotha [1791], S. 336-340, hier S. 337

Zinzendorf Tagebücher (wie Anm. 50), BI. 228r.

"Me Grethe la fille d'Opiz chanta comme un chat, avec une assez jolie figure"; ebd., BI. $231 r$.

"le rôle du major joué par M. Mueller qui a la pron[on]ciation hambourgeoise, Lotte Me Ambs joua mal, Bittermann M. Lux etoit mal vetu. Me Muller representée par Me Häusler fort mal.", ebd., BI. 233r.

Ebd., Bl. $235 \mathrm{v}$

Ebd., BI. 240r.

Auszug eines Briefs aus Bonn (wie Anm. 76), S. 336.

JUNKER, Noch etwas vom Kurköllnischen Orchester (wie Anm. 7), Sp. 374f. Da nicht viele Sänger mitgereist waren, waren die Chöre vielleicht nur solistisch besetzt, weshalb das Orchester Junker klanglich zu stark erschien.

Zinzendorf Tagebücher (wie Anm. 50), Bl. 240r.

Ebd., BI. $241 \mathrm{v}$.

"la contadine scaltra ou la caltellini jouaint bien"; ebd., Bl. 248v.

Ebd., Bl. $215 \mathrm{v}$

Ebd., BI. 224r.

Ebd.

"Aulieu de manteaux bleues avec des croix rouges, on a donné aux Chevaliers des manteaux noirs avec des croix blanches, a Jaques de Molay, a Guy d'Auvergne un habillement ridicule." Ebd., BI. 224v.

„peu qui n'a pas le sens commun", ebd., Bl. 236r.

Ebd., BI. 245v

Ebd., BI. 227r.

Ebd., BI. 250v

Wiener Zeitung Nr. 90, 9.11.1791, S. 2864: „An eben diesem Tage [Sonntags den 6. d. M.] des Morgens sind Se. K. H. der Erzherzog Maximilian, Kurfürst zu Kölln, hier eingetroffen." Der Kurfürst blieb bis 18.12. in Wien; vgl. ebd., Nr. 102, 21.12.1791, S. 3249.

Theater-Kalender auf das Jahr 1793, hg. von HEINRICH REICHARD, Gotha [1792], S. 125. 


\section{Ludwig van Beethoven, Joseph Haydn und (Bad) Godesberg}

ediglich zwei Begebenheiten haben sich überliefert, die eine Anwesenheit

Ludwig van Beethovens in Godesberg, seit 1926 Bad Godesberg und seit 1969 ein Stadtbezirk Bonns, plausibel erscheinen lassen. Tatsächlich jedoch ist ein weit häufigerer, nicht zuletzt mit seiner Berufstätigkeit in Verbindung stehender Aufenthalt Beethovens in Godesberg mehr als nur wahrscheinlich. Auch gibt es Indizien dafür, dass der junge Beethoven eine besondere Affinität zu diesem Ort gehabt hat.

Godesberg war zu Beethovens Bonner Jahren ein sehr kleines Dorf, nicht einmal Pfarrort, wenige Kilometer südlich der kurkölnischen Residenzstadt Bonn gelegen, wegen der reizvollen Landschaft ein durchaus gern besuchtes Ausflugsziel. Der Ort zählte um das Jahr 1790 lediglich 350 erwachsene Einwohner, dazu 103 Kinder. ${ }^{1}$ Die wenigen Häuser schmiegten sich mehrheitlich an den Fuß des Godesbergs, der bis heute von der Ruine der 1583 zerstörten landesherrlichen Burg, der Godesburg, bekrönt wird. Es bestanden mehrere größere, zum Teil in geistlichem Besitz befindliche Anwesen, einige Mühlen, drei Kapellen, darunter die von Eremiten betreute, für die Liturgie des hochadligen Michaelsordens und der gleichnamigen Bruderschaft genutzte Michaelskapelle am Burgberg sowie - etwas außerhalb in südwestlicher Richtung - das Birgittenkloster Marienforst. ${ }^{2}$

Am Rand dieses Dorfes hatte Kurfürst und Erzbischof Maximilian Franz (1756-1801, Regierungszeit seit 1784) ab 1790 bei einer Heilwasser liefernden Mineralquelle - und damit ganz der Mode seiner Zeit folgend - eine Art Spa entstehen lassen, das sich in kürzester Zeit in seiner Kombination aus Gesundheits-, Freizeit- und Kulturstandort zu einem gesellschaftlichen Nebenzentrum des kölnischen Kurstaates entwickelte.

Diese Mineralquelle, die so genannte Draitschquelle, bildete Kern und Ursprung dieser landesherrlichen Initiative. Möglicherweise schon in römischer Zeit als Heilquelle identifiziert ${ }^{3}$, wurde der Brunnen anschließend allenfalls von der ortsansässigen Bevölkerung genutzt; auch von seiner Rolle als Viehtränke ist die Rede. ${ }^{4}$ Bereits Kurfürst Clemens August (Regierungszeit 1723-1761) hatte um 1750 Expertisen hinsichtlich der Qualität des Wassers in Auftrag gegeben, deren unbefriedigendes Ergebnis ihn jedoch von weiteren Plänen für Godesberg Abstand nehmen ließ. Erst sein Nachnachfolger, Max Franz, griff das Projekt wieder auf, nachdem er von seinem Leibarzt Martin von Ney auf die heilende Wirkung des Godesberger Wassers aufmerksam gemacht worden war. Der in Bonn praktizierende Arzt und spätere Professor der Chemie Ferdinand Wurzer (1765-1844) unternahm eine genaue wissenschaftliche 
Der "Gesundheitsbrun" in Godesberg. Kupferstich von Johann Ziegler nach Lorenz Janscha, 1792 (Stadtarchiv Bonn). Im Hintergrund die Ruine der Godesburg

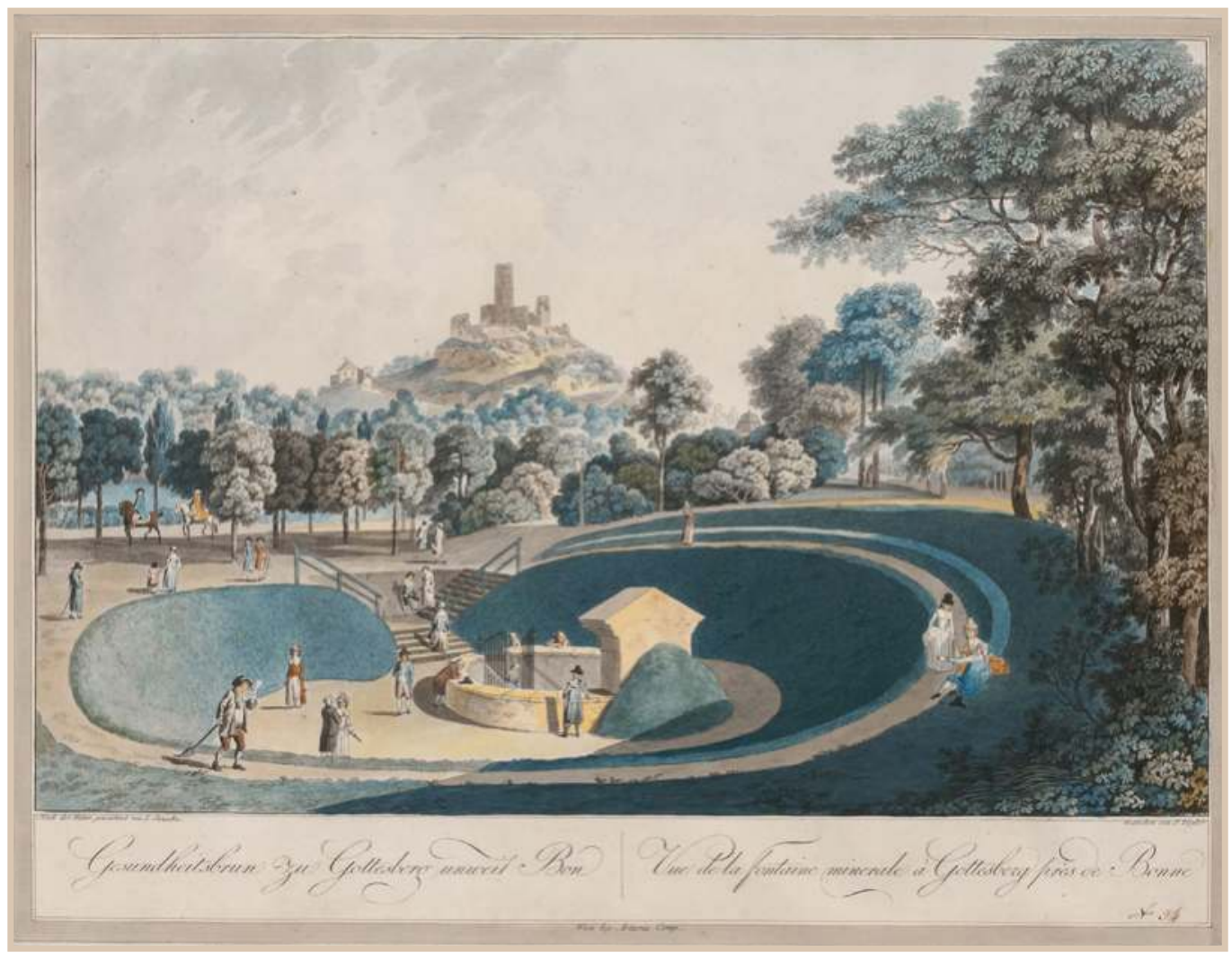

Analyse der Draitschquelle und kam zu dem höheren Orts wohl auch erhofften Resultat, dass das Wasser für nahezu jede bekannte Krankheit eine heilende, mindestens aber eine lindernde Wirkung entfalte. ${ }^{5}$

Diese Ergebnisse bestärkten Kurfürst Max Franz in seinem offenbar schon länger gehegten Wunsch, Godesberg zu einem Bade- und Kurort auszubauen. Eine ganze Reihe von Infrastrukturmaßnahmen wurde angeordnet und durchgeführt, wie die Verlegung des in unmittelbarere Nähe zur Quelle vorbeiflieBenden Baches, eine neue Fassung der Quelle, der Bau eines Brunnenhauses und die Anstellung eines Brunnenmeisters, der Erwerb und die Erschließung des angrenzenden Waldstücks, die Anlage von Spazierwegen, der Bau eines Gasthauses (Zum schönen Brunnen) und die Anlage der bis heute bestehenden Brunnenallee als Verbindung zwischen der Mineralquelle einerseits und dem nur wenige Gehminuten entfernten Zentrum des geplanten Kurbetriebs. Hierbei handelte es sich um insgesamt drei Baukörper, zunächst sechs repräsentative so genannte Logierhäuser, die von finanzkräftigen, vom Kurfürsten obendrein mit Vergünstigungen bedachten Investoren zwischen 1791 und 1793 errichtet wurden und zur Unterbringung der Kurgäste bestimmt waren. Das kleinste dieser Häuser ließ übrigens der Bonner Hofmusiker und Geigenlehrer Beethovens Franz Anton Ries (1755-1846) errichten. An diese 


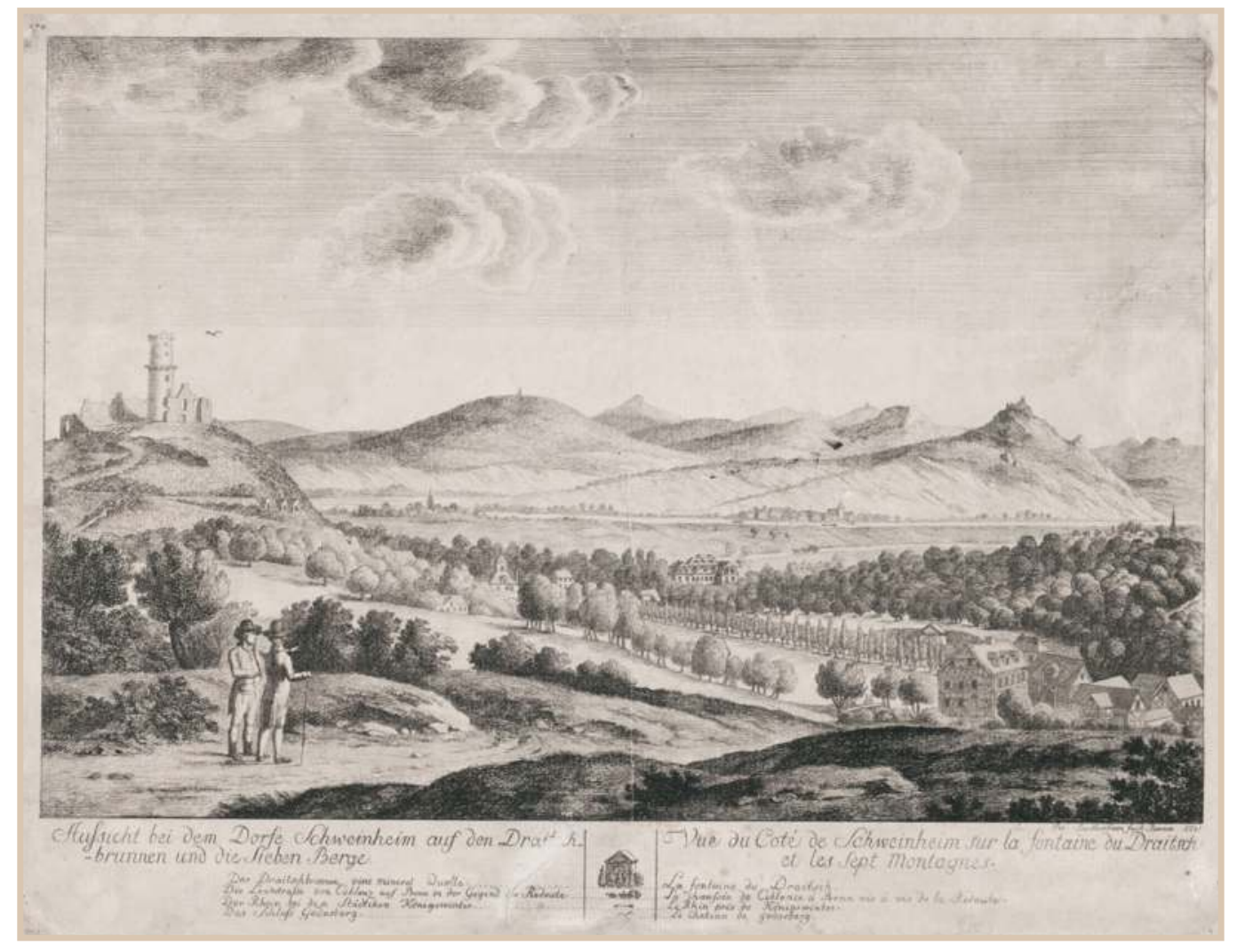

Häuserzeile schloss sich ein kleiner Theaterbau (Haus an der Redoute) und als Herzstück des Gesamtkomplexes die frühklassizistische Redoute an, gedacht als Ball-, Tanz-, Spiel- und Konzertsaal. ${ }^{6}$

Pfingstmontag 1790, noch keines der genannten Bauprojekte war realisiert worden, eröffnete der von seinen Plänen offenbar regelrecht beseelte Landesherr die erste Badesaison in Godesberg. Die konkrete Umsetzung seines Vorhabens, die Aufsicht über den Brunnen und den gesamten Kurbetrieb aber auch deren Nutznießung übertrug er einer Art Aktiengesellschaft, der so genannten Admodiationsgesellschaft, die sich vornehmlich aus Mitarbeitern des Hofes zusammensetzte. Max Franz verpflichtete sie insbesondere , noch im laufenden Jahre mit der Erbauung der an dem ihr überlassenen Godesberger Brunnen noethigen Spiel- und Tanzsaelen nach den Uns vorgelegten Rissen den Anfang zu machen, und es dergestalt einzurichten, daß die Saele im Jahre 1791 fertig werden."

Die Arbeiten zogen sich hin, und erst mit der feierlichen Eröffnung der dritten Saison, an Pfingsten 1792, konnte die Redoute ihren Betrieb aufnehmen. Auch in den beiden Folgejahren wurde der Kur- und Kulturbetrieb in Godesberg jeweils am Pfingstfest eröffnet und dauerte bis in den Spätsommer respektive den frühen Herbst.
Blick von der Schweinheimer Höhe auf das im Entstehen begriffene Kurviertel in Godesberg. Kupferstich von Peter Beckenkamp, 1792 (Stadtarchiv Bonn). In der Bildmitte die Rückansicht der Redoute, von dort die frisch bepflanzte Brunnenallee zum Draitschbrunnen 
Eine Reihe zeitgenössischer Berichte hat sich erhalten, die einen nachhaltigen Eindruck vom Leben und Treiben in und bei der Redoute jener Jahre vermitteln. Am anschaulichsten leisten dies die 1793 anonym erschienenen Briefe eines Reisenden an seinen Freund Ueber den Aufenthalt beim Godesberger Gesundbrunnen, die neben den amtlichen Schriftstücken zweifellos wichtigste Quelle zum Godesberger Kur- und Badebetrieb jener Jahre. Mit großer Gewissheit handelte es sich beim Autor um den Würzburger Mediziner und Chemiker Prof. Dr. Johann Georg Pickel (1751-1838). ${ }^{8}$

Mit der Gastronomie in Godesberg zeigte sich der "Reisende" durchaus zufrieden: Zur "Nachtstafel", so berichtet er, brachte man

„mich in einen geräumigen schönen Speissaal. Ich fand gute Tischgesellschaft; eine wohlbesezte Tafel, wohl appretirte Speisen und guten Wein, und an diesen hielt ich mich für heute, denn, so gesund auch das Godesberger Wasser seyn mag, wolt ichs doch nicht gleich am ersten Abend mit meinem Wirth verderben und nach Wasser fragen, weil ich wohl denken konte: der Mann habe sich um Wasser zu verzapfen nicht hier etablirt."

Auch die täglichen "Lustbarkeiten”, nämlich "Spiel, Ball, Concert oder Komedie”, fanden sein Wohlwollen, zumal "sie auch einer großen Stadt Ehre machen könten". Die Theateraufführungen, in der Regel drei pro Woche, wurden in dem für den großen Publikumsandrang als zu eng beschriebenen

Redoute, Theater und Logierhäuser (von rechts) in Godesberg. Kupferstich von Johann Ziegler nach Lorenz Janscha, 1792 - jüngerer Druck (Stadtarchiv Bonn)

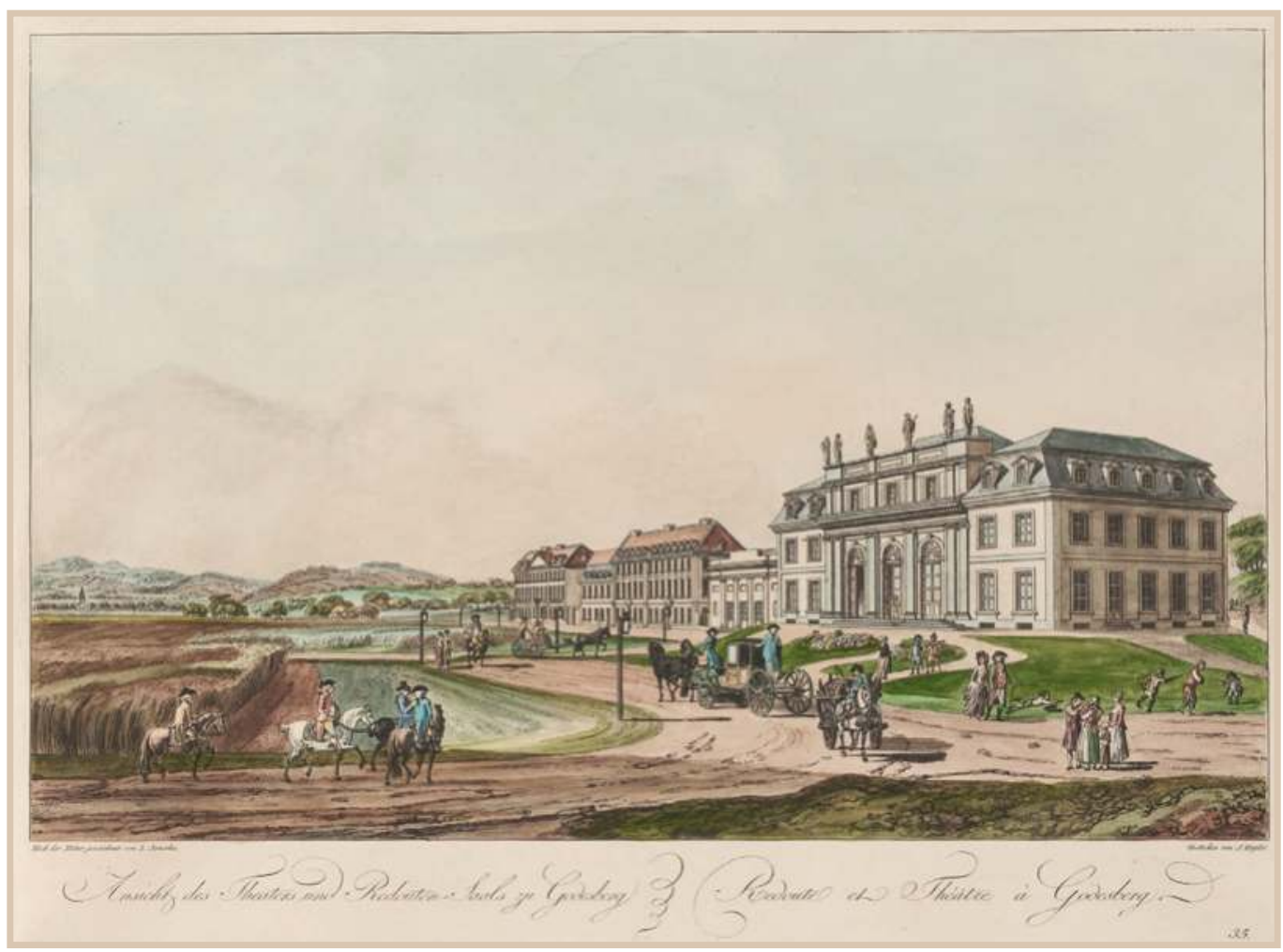

502 | Norbert Schloßmacher

(C) 2020 by Böhlau Verlag GmbH \& Cie. KG, Köln

https://doi.org/10.7788/9783412519704 | CC BY-NC 4.0 


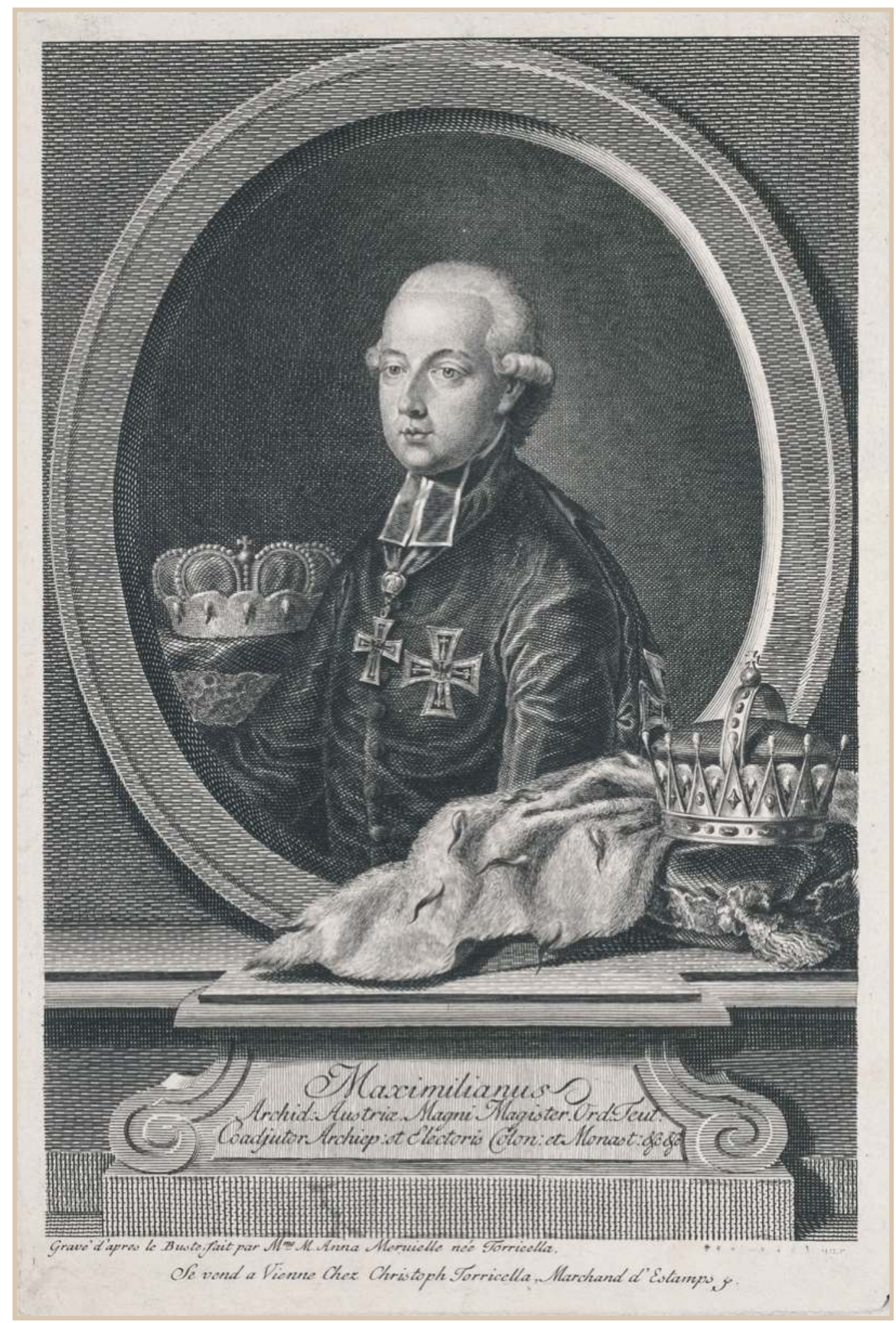

Kurfürst und Erzbischof

Maximilian Franz von

Österreich (1756-1801).

Kupferstich nach einer Büste von M. Anna Merville, geb.

Torricella, um 1790

(Stadtarchiv Bonn) 
Theaterbau unmittelbar neben der Redoute aufgeführt, und zwar „von der Bönnischen Hof-Schauspieler-Gesellschaft und der dortigen Hofmusik ... Kein Zweifel also: daß sie gut sind." Die Konzerte, ebenfalls von der Bonner Hofkapelle gespielt, fanden jeweils Dienstagabend in der Redoute statt, wo auch regelmäßig Glücksspiele und Bälle veranstaltet wurden. Ein regelmäßiger Kutschendienst sorgte für den Personentransfer von und nach Bonn, sonnund feiertags brachte eine Rhein-Jacht Tanz- und Amüsierwillige unter Begleitung von "Janitscharen-Musik ... zu den Godesberger Vergnügungen". Diese Musik geht zurück auf osmanische Militärmusik, und fand Eingang in die Wiener Klassik. Auch Beethoven komponierte einen türkischen Marsch op. 113 Nr. 4 sowie Variationen für Klavier op. 76 hierzu.

Ein weiterer, den Kur- und Kulturbetrieb im damaligen Godesberg beschreibender Reisebericht stammt aus der Feder der englischen Schriftstellerin Ann Radcliffe (1764-1823), die gleichsam als eine Art Vorbotin der spätestens zwei Jahrzehnte später von den britischen Inseln her einsetzenden Reisewelle erscheint. ${ }^{10}$ Die eher als Autorin von Schauer- und Schreckensromanen in der Tradition der gothic novels bekannte Literatin schildert die Situation in Godesberg im Juni 1794 zu einem Zeitpunkt, als die Vorposten der Französischen Revolution schon weit im Westen des Heiligen Römischen Reiches Deutscher Nation standen und die Lieblingsschwester des Kölner Kurfürsten, die französische Königin Marie Antoinette bereits unter der Guillotine zu Tode gekommen war. Überwältigt zeigt sie sich von der landschaftlichen Schönheit der Gegend um Godesberg und nimmt damit spätere Beschreibungen der Rheinromantik gleichsam vorweg. Auch erwähnt sie die zahlreichen musikalischen Darbietungen, namentlich spricht sie von den „Feinheiten Mozartscher Musik, die weiterhin von einem ausgezeichneten Orchester vorgetragen wurde, und die vom Kurfürsten weiterhin veranstalteten Bälle, zu denen er häufig selbst erscheine und zwar „mit der Gelassenheit und Schlichtheit eines privaten Gentleman"11.

Tatsächlich hatte sich Godesberg in kürzester Zeit zu einer Art Nebenresidenz zu Bonn entwickelte. Insbesondere in der Sommersaison kam es in Godesberg zu einem Stelldichein höfischer und adeliger Kreise. ${ }^{12}$

Kurfürst Max Franz hielt sich immer häufiger in Godesberg auf, möglicherweise auch auf dem Rittersitz Disteling, den der Kurfürst 1791 - angeblich - gekauft und ihn seinem engen Vertrauten, dem aus Wien stammenden Graf Ferdinand von Waldstein (1762-1823) überlassen hatte. ${ }^{13}$ Der Deutschordensritter Waldstein war "Liebling und beständiger Gefährte des jungen Kurfürsten", bedeutender Gönner Beethovens und offenbar "der erste, der den Namen des jungen Komponisten mit Mozart und Haydn in Verbindung brachte." ${ }^{14}$ Berühmt geworden ist sein Eintrag in Beethovens Stammbuch anlässlich dessen Reise nach Wien: Waldstein wünschte dem jungen Musiker unter dem 29. Oktober 1792 nichts weniger als "Mozart's Geist aus Haydens Händen". ${ }^{15}$ In dem am kur- 
kölnischen Hofe akkreditierten britischen Gesandten Ralph Heathcotte haben wir für die Vorliebe des Kurfürsten hinsichtlich seiner Gründung einen verlässlichen Zeugen; im Juni 1793 berichtet er ins Londoner Außenministerium:

„Seit Anfang dieses Monats verbringt der Kurfürst von Köln einen großen Teil seiner Zeit in Godesberg ... Es ist nicht unwahrscheinlich, daß er [der Ort Godesberg] in ein paar Jahren, wenn alles bis zu dem Grad von Vollkommenheit gediehen ist, den das bisherige Arrangement vermuten läßt, von Ausländern sehr aufgesucht werden wird."16

Vor allem war es eben der in Godesberg herrschende "Charme der Musik"17, der ganz wesentlich zum Ruhm des Ortes in jenen1790er Jahren beigetragen hat. Und Teil dieses Musiklebens war Ludwig van Beethoven, der - ohne dass dies im Einzelnen überliefert ist - bis zu seinem zweiten Aufbruch nach Wien im November 1792 als Mitglied der Hofkapelle zweifellos häufig in der Godesberger Redoute konzertierte, während der "Saison" bekanntlich jeden Dienstag. Welche Musik den Kurgästen dabei gespielt wurde, ist im Einzelnen nicht überliefert. An der wohl bedeutendsten Inszenierung in Godesberg, der im Juni 1793 in der Redoute unter Leitung von Franz Anton Ries aufgeführten Zauberflöte, war Beethoven natürlich nicht mehr beteiligt. Diese Darbietung zählte zu den Höhepunkten des Godesberger Musiklebens jener Jahre, eine Aufführung, "zu der Fremde von weit und breit herbeiströmten."18

Abgesehen von seinen Auftritten mit der Hofkapelle in Godesberg, gibt es wenigstens für zwei weitere Aufenthalte Beethovens im Kurort Godesberg überzeugende Belege: eine Inszenierung von großer musikgeschichtlicher Bedeutung der eine, der andere eine eher zufällige, fast beiläufige Begebenheit. Gemeint sind zum einen die Begegnung Beethovens mit Joseph Haydn (17321809) im Juli $1792^{19}$ und zum anderen ein Spaziergang des jungen Musikers mit Freunden zwei Jahre zuvor im Sommer 1790 von der Draitschquelle nach Marienforst mit einem anschließenden Orgelspiel in der dortigen Klosterkirche.

Gewährsmann für das Treffen mit Haydn ist der aus Bonn stammende Arzt Franz Gerhard Wegeler (1765-1848), einer der ältesten und vertrautesten Freunde Beethovens. Wegeler lehrte an der kurfürstlichen Universität als Medizinprofessor, heiratete die Jugendfreundin Beethovens, Eleonore von Breuning (1771-1841), und lebte und praktizierte ab 1807 in Koblenz. ${ }^{20}$ Gemeinsam mit einem weiteren Beethoven-Freund und Wiener Schüler, dem Pianisten und Komponisten Ferdinand Ries (1784-1838), gab Wegeler die 1838 erschienenen Biographischen Notizen über Ludwig van Beethoven heraus, der ersten Beethoven-Biographie überhaupt, die zu den frühesten und wichtigsten Quellen der Beethovenforschung zählt. Zugedacht war das Werk dem Vater eines der beiden Herausgeber, Franz Anton Ries, „Beethoven's erstem Beschützer", wie es in der Widmung heißt.

Über die so häufig thematisierte Begegnung Beethovens mit Haydn in Godesberg heißt es dort: 
Joseph Haydn (1732-1809). Lithografie aus Meyers Conversationslexikon, um 1850 (Stadtarchiv Bonn)

Johann Peter Salomon (1745-1815). Lithografie nach einer Zeichnung von F. Ingenmey, 1852 (Stadtarchiv Bonn)
"Als Haydn zuerst aus England zurückkam, ward ihm vom Kurfürstlichen Orchester ein Frühstück in Godesberg, einem Lustorte nahe bei Bonn, gegeben. Bei dieser Veranlassung legte ihm Beethoven eine Cantate vor, welche von Haydn besonders beachtet und ihr Verfasser zu fortdauerndem Studium aufgemuntert wurde."21

Dem Besuch vom Sommer 1792 war eine erste Visite im Dezember 1790 vorausgegangen. Haydn befand sich mit dem aus Bonn stammenden, aber bereits seit geraumer Zeit in England tätigen Musiker und Komponisten Johann Peter Salomon (1745-1815) auf dem Weg nach London. Salomon hatte inn nach dem Tod des Fürsten Esterhazy, in dessen Diensten Haydn lange gestanden hatte, engagiert. ${ }^{22}$ Am Samstag, den 25. Dezember, war die kleine Reisegesellschaft in Bonn eingetroffen.

Von wem die Einladung zu diesem ersten Besuch ausgegangen war, ob es überhaupt eine offizielle Einladung gegeben hat, ist nicht belegt. Man kann aber davon ausgehen, dass Salomon, der Familie und immer noch gute Freunde in Bonn hatte, diese Einkehr vorgeschlagen hat; ferner dass Kurfürst Max Franz, der Haydn in hohen Ehren hielt und seine Werke sammelte, diesen neben Mozart berühmtesten Musiker des damaligen Europa nicht einfach an Bonn hätte vorbeiziehen lassen. Und in der Tat spielte der Kurfürst bei diesem Besuch Haydns in Bonn eine prominente Rolle. Gemeinsam besuchten sie am zweiten Weihnachtstag in der Schlosskirche die vom damaligen Hofkapellmeister Andrea Luchesi (1741-1801, in dieser Funktion seit 1774) geleitete Aufführung einer Haydn-Messe. Im Anschluss ließ es sich Max Franz nicht nehmen, dem berühmten Gast seine Hofmusiker persönlich vorzustellen, darunter natürlich auch den jungen Beethoven. Bereits am Vortag, dem Tag der Ankunft in Bonn, hatte Franz Anton Ries Haydn als Gast in die drei Jahre zuvor gegründete Lesegesellschaft eingeführt. ${ }^{23}$

506 | Norbert Schloßmacher

(c) 2020 by Böhlau Verlag GmbH \& Cie. KG, Köln

https://doi.org/10.7788/9783412519704 | CC BY-NC 4.0 
Haydns Besuch in Bonn war nur von kurzer Dauer; am 31. Dezember war seine Reisegruppe bereits in Calais, am 2. Januar 1771 erreichte sie London. Haydn verbrachte in England äußerst erfolgreiche Monate, ehe er sich im Juni 1792 wieder auf den Heimweg nach Wien machte. ${ }^{24}$

Bevor er spätestens am 13. Juli 1792 zur am folgenden Tag stattfinden Krönung Kaiser Franz II. in Frankfurt eintraf, hat Haydn erneut Station am Rhein gemacht, dieses Mal, wie Wegeler in seinem Bericht andeutet, in Godesberg und auf Einladung des Hoforchesters. Haydn war dieses Mal allein. Salomon bedauerte seinerzeit in einem Brief an seinen Bonner Schwager Cornelius Michael Geiger wegen dringender Geschäfte in London nicht mit von der Partie sein zu können und avisierte einen mündlichen Bericht:

"Ich kann so gerne ich auch wollte, den lieben Papa Haydn nicht zu Ihnen begleiten, die Angelegenheiten meiner Unternehmungen erheischen unumgänglich meine Gegenwart in England ... Mr Haydn wird Ihnen mündlich die Umstände besser zergliedern." 25

In Godesberg also kam es zu der so bedeutsamen Begegnung zwischen Haydn und Beethoven. Bei der Kantate, die Beethoven - folgt man Wegeler dem berühmten Haydn bei dieser Gelegenheit vorlegte, handelte es sich - wie Julia Ronge ${ }^{26}$ verbindlich feststellte - um eine der so genannten Kaiserkantaten, entweder um das Stück Auf den Tod Josephs des Zweiten WoO 87 oder um gleichsam das Anschlusswerk - Auf die Erhebung Leopolds des Zweiten zur Kaiserwürde WoO 88, die beide 1790 entstanden sein müssen. Es waren die bis dato anspruchvollsten Arbeiten des jungen Genies. Die erste Kantate dürfte eine Auftragsarbeit der Bonner Lese gewesen sein für eine geplante - letztlich aber nicht stattgefundene - Trauerfeier für Joseph II., den Bruder des Kurfürsten. Die Texte zu beiden Kantaten stammen von Severin Anton Averdonk (1768-1817), einem späteren Geistlichen und seinerzeitigen Schüler von Eulogius Schneider (1756-1794), was die Nähe zur Lese untereicht.

Die Haydn-, mehr noch die Beethoven-Forschung hat sich immer wieder mit der Begegnung dieser beiden Großen der Musikgeschichte beschäftigt. Es gab viele Einwände, Wegelers Bericht wurde immer wieder aus den verschiedensten Gründen und mit den unterschiedlichsten Argumenten in Zweifel gezogen. ${ }^{27}$ Der genaue Verlauf dieser Debatte muss uns hier nicht beschäftigen. ${ }^{28}$ Inzwischen neigt die Forschung dazu, dem Bericht Wegelers zu folgen, ${ }^{29}$ der sicherlich auch gestützt wird durch die indirekte Autorität von Ferdinand Ries und seinem Vater Franz Anton Ries, die sich 1792 in Godesberg, sozusagen vor Ort, niedergelassen hatten. ${ }^{30} \mathrm{Im}$ Übrigen wurde die persönliche Begegnung von Haydn und Beethoven am Rhein und die Überreichung der Komposition nie infrage gestellt, mag sich das Ganze nun 1790 in Bonn oder 1792 in Godesberg zugetragen haben. Jedenfalls gewann Haydn einen derart positiven Eindruck von seinem jungen Kollegen, dass er ihn auf Empfehlung von Kurfürst Max Franz in Wien als Schüler angenommen hat. Diese Begegnung 
wurde zum Auslöser für Beethovens (zweite) Reise nach Wien im November 1792, die er als Stipendiat des Kurfürsten antrat und von der er (im Gegensatz zur ersten) nie mehr in seine Geburtsstadt zurückkehrte.

Übrigens gerieten die beiden Kompositionen in Vergessenheit, auch Beethoven kümmerte sich nicht weiter um sie. Erst 1884 wurden Partiturabschriften bei einer Auktion angeboten und von Johannes Brahms als Werke Beethovens identifiziert. ${ }^{31}$

Haydn scheint zum Zeitpunkt seiner Stippvisite in Godesberg übrigens davon ausgegangen zu sein, in absehbarer Zeit wieder zu Salomon nach London zurückzukehren. Auch war er offensichtlich gewillt, seinen zukünftigen Schüler dorthin mitzunehmen, wie auch der meist gut unterrichtete Christian Gottlob Neefe, Beethovens Lehrer und Kollege, zu berichten wusste.. ${ }^{32}$ Vielleicht war Beethoven sogar schon in diese Planungen eingeweiht. Insbesondere der Eintrag seines Freundes Christoph von Breuning (1773-1841) in das zu Beethovens Abschied von Bonn Ende Oktober/Anfang November 1792 angelegte Stammbuch erlaubt diesen Schluss. Darin schreibt Breuning: „... sieh! Es winket, o freund, lange Dir Albion, sieh! Den schattigen Hain, den es dem Sänger beut, eile denn ungesäumet über die flutende See, wo ein schönerer Hain beut seine Schatten Dir, und so freundlich die Hand reichet ein Barde dar, der von unsren Gefilden floh' auch in Albions Schutz ..." 33 Der Hinweis auf Albion, dem aus dem Keltischen stammenden, fast ausschließlich poetisch gebrauchten Namen für Britannien und auf den Barden, bei dem es sich nur Johann Peter Salomon handeln kann, legen in der Tat nahe, dass Beethoven und damit auch seinem Umfeld die England betreffenden Pläne Haydns bekannt waren, Pläne, die Haydn auch erst im Sommer 1792 geäußert haben kann.

Es kann nicht verwundern, dass die Begegnung der beiden Musiker auch die Fantasie von Schriftstellern angeregt hat; das Potential, das in diesem "Jahrhundert-Treffen" steckte, konnte nicht unbeachtet bleiben. Es fällt jedoch auf, dass die literarische Auseinandersetzung weniger das eigentliche Geschehen im Blick hatte als vielmehr ein Konterfei der Autoren und ihrer jeweiligen Epoche präsentierte. Man kann dies sowohl in der Darstellung beobachten, die der spät(rhein)romantische Autor, der Arzt Wolfgang Müller von Königswinter (1816-1873) in seiner 1861 erschienenen Erzählung Furioso. Aus Beethovens Jugend gegeben hat, wie auch in der viel später verfassten (1952) Novelle Das Godesberger Frühstück des rheinischen Journalisten und Literaten Heinz Magka (1904-1960).

Bei Müller heißt es:

„Als die drei Ankömmlinge (gemeint waren Franz Anton Ries, Graf Waldstein und der junge Beethoven) den Saal der Redoute betraten, fanden sie dort bereits die ganze Kapelle versammelt, auf dem gedeckten Tische aber war ein trefflicher Imbiß bereitet, der aus kalten Speisen und feinen Weinen bestand. Dabei erblickte man rings im Saale kurfürstliche Bedienten zum 
Serviren bereit. Daß es sich hier um eine Gasterei handeln sollte, machte Beethoven noch verdrießlicher [Er war von Ries und Waldstein zur Fahrt nach Godesberg überredet worden, ohne zu wissen, was ihn dort erwartete, N. Schl.]. Er wünschte sich jetzt zweifach und dreifach in seine häusliche Einsamkeit zurück. Als man sich zu Tische setzte, hatte er sich kaum umgesehen, wer zugegen sei, und noch viel weniger gefragt, was denn dieses improvisirte Fest bedeuten solle.

Wie erstaunt aber war er, als der Graf Waldstein nach einiger Zeit an sein Glas klingelte, sich erhob und das Wort nahm, indem er auseinandersetzte, daß der Kurfürst diese Mahlzeit angeordnet und die Mitglieder der Kapelle eingeladen habe, um einen Gast zu feiern, der eben von London anlangend, wo er den höchsten Ruhm erworben, nach seiner jetzigen Heimat Wien zurückkehre, und der gegenwärtig als der gefeiertste Meister im Reiche der Tonkunst gepriesen werden, und daß jener Gast niemand anderes sei, als der in diesem Kreise weilende treffliche, liebenswürdige, große Joseph Haydn.

Wenn alle Anwesenden die Gläser erhoben, dann lautes Hoch anstimmten, sah Beethoven mit einem Gefühl freudigen Erstaunens auf und erblickte, sich gerade gegenüber an Waldsteins' in der Mitte des Tisches, ein kleines graues Männchen mit einem überaus freundlichen und wohlwollenden Gesichte und äußerst muntern und lebendigen Augen, in dessen ganzem Wesen sich wohlwollend, Scherz, Schelmerei und Kindlichkeit paarten. Die trüben Gedanken des jungen Musikers machten nun doch, wie schwer sie ihm auch das Herz belasteten, einer freundlichen Stimmung Platz, und Waldstein fand auch bald Gelegenheit, den ältern Meister mit dem jüngern bekannt zu machen und beide in ein vertrautes Gespräch zu verwickeln.

Als die Mahlzeit aufgehoben wurde, hatten sich Haydn und Beethoven durch eine lange Unterhaltung über die Kunst, welche beider Ziel und Ende war, befreundet und der junge Meister zeigte sich sofort bereit, sein Klavierspiel auf einem im Nebenzimmer stehenden Flügel hören zu lassen. In der Tath entwickelte er auch diesmal wieder eine Kraft und Fülle von phantastischen Gedanken, daß der alte Musiker in die lebhaftesten Lobsprüche ausbrach.

Gott sei gedankt, rief Haydn, die Kunst ist ewig. Gluck, der herrliche Meister, ist tot, Mozart, der Liebling der Götter, ging den Weg alles Fleisches. Ich bin ein alter Mann, dessen Tage sich zu Ende neigen. Aber es ist ein neues Genie aufgestanden, daß[sic!] uns, wenn es will, alle in den Schatten stellen wird. Und dann umarmte und küßte er den jungen Mann.

Beethoven konnte tief gerührt, wie er war, nicht antworten.

Als das Fest spät am Abend zu Ende ging und Haydn, der schon in der Frühe des anderen Tages abreisen wollte, Abschied von dem jungen Meister nahm, sprach er: Kommen Sie zu uns nach Wien! Wenn ich Ihnen noch mit meinen alten Kräften nützen kann, so stehe ich herzlich gern zu Dienst. Musik kann ich Sie nicht lehren, denn Sie haben die Musik. Aber im Betreff der Form bin 
Der Brunnen der Draitschquelle in Bad Godesberg, Kupferstich von F. X. Schütz nach einer Vorlage von Rousseau, 1790 (Stadtarchiv Bonn). Im Hintergrund die Ruine der Godesburg, links das Gasthaus Zum schönen Brunnen

ich doch imstande, Ihnen nützliche Anweisung zu erteilen. Wir bedürfen nach den großen Verlusten, die wir erlitten haben, und wenn ich selbst einst scheide, neue und frische Kräfte. Also auf Wiedersehen in Wien!" 34

Wolfgang Müller von Königswinter taucht die Ereignisse - weitgehend unbekümmert hinsichtlich der historischen Fakten - in ein erzählerisches Klima, das ganz vom Glück jener Prophezeiung getragen und beherrscht wird, die Graf Waldstein 1792 in das Stammbuch Beethovens geschrieben hat: Beethoven, der den Genius Mozarts und Haydns aufnimmt und in die Zukunft hineinträgt. Überflüssig zu sagen, dass dem guten Papa Haydn derlei Prophezeiung nicht eingefallen wäre, zumal ja damals auch in keiner Weise abzusehen war, dass sich die Musikgeschichte in der Tat in diese Richtung entwickeln würde. Dabei ist es sicherlich so, dass er mit seiner Schilderung des so scheuen, fast begriffsstutzigen Beethoven genauso weit von der Wahrheit entfernt war wie mit der von Haydns Vertrauensseligkeit.

Heinz Magka interessierte vorrangig die Liebesbeziehung - eine "verschwiegene Episode" - zwischen Ludwig van Beethoven und Eleonore von Breuning. Innerhalb dieses Stücks, das schwülstig-sentimental abgehandelt wird, ist die Begegnung der beiden Musiker nur eine Episode; unangenehm stößt einer heutigen Lektüre das übertriebene Pathos und der deutschtümelnde Ton auf. Ein knapper Textauszug mag genügen. Ludwig hat gerade von Neefe erfahren, dass der große Haydn ihn in Godesberg treffen will:

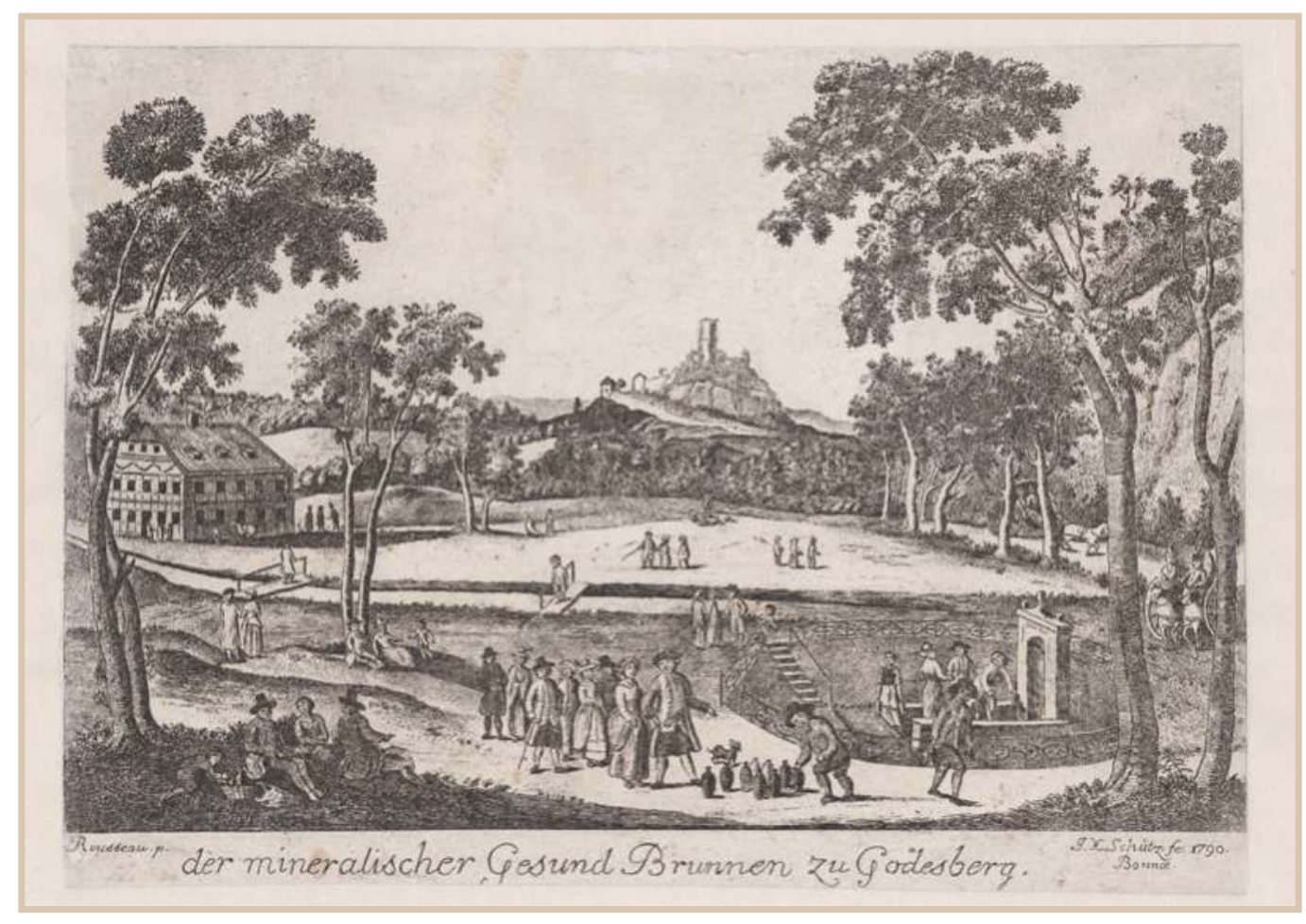

510 | Norbert Schloßmacher

(c) 2020 by Böhlau Verlag GmbH \& Cie. KG, Köln

https://doi.org/10.7788/9783412519704 | CC BY-NC 4.0 


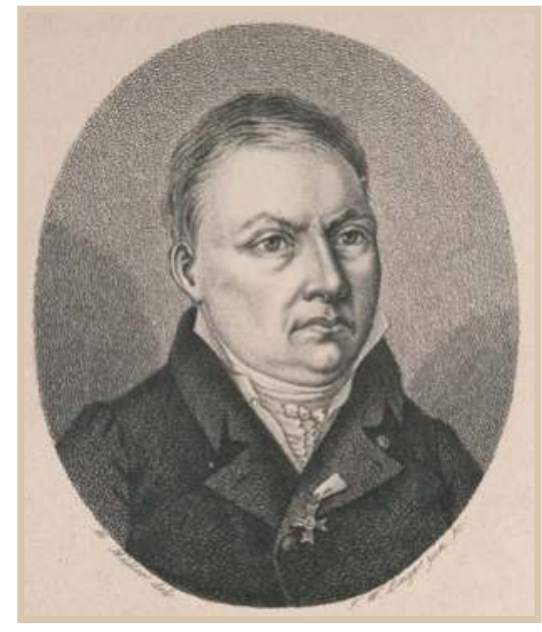

"Ludwig van Beethoven fährt nach Godesberg. Noch ahnt er nicht, daß sich dort, in jenem kleinen Lustorte, nahe der kurfürstlichen Residenzstadt Bonn, der Vorhang öffnen soll zum Beginn der gewaltigsten Sinfonie eines Lebens im Reiche der Töne. Noch ahnt er es nicht, daß dort die Würfel fallen sollen zum Auftakt eines Spiels, das brausend eine Welt erfüllen soll und das durch Leid und Qual hindurch im trutzig-harten Dennoch zum Finale führen soll!" 35

Das Treffen von Beethoven und Haydn fand im vergangenen Jahrhundert auch eine bildnerische Würdigung. Im Park hinter der Redoute in Bad Godesberg, übrigens das einzige nennenswerte Bauwerk, das Maximilian Franz während seiner zehnjährigen Regierungszeit am Rhein hat errichten lassen, findet sich an eher verstecktem Ort eine von dem ungarischen Bildhauer Franz Rotter geschaffene und am 22. Oktober 1963 aufgestellte steinerne Stele mit einer bronzenen Büste Ludwig van Beethovens. Sie trägt die Inschrift: Zum Gedenken an Ludwig van Beethovens Begegnung mit Joseph Haydn im Juli 1792.36

Die zweite Begebenheit ist überliefert durch den eingangs erwähnten Chemiker Ferdinand Wurzer, der das erste und zugleich bahnbrechende Gutachten über das Godesberger Heilwasser verfasst hatte. Wurzer, fünf Jahre älter als Beethoven, seit 1791 Mitglied der Bonner Lese und seit 1793 Professor an der Bonner Universität, von 1805 an in Marburg lehrend, korrespondierte mit dem Herausgeber des Rheinischen Antiquarius über die seinerzeit strittige Frage nach Beethovens Geburtshaus. ${ }^{37}$ Das Datum des Schriftwechsels ist bedauerlicherweise nicht überliefert, er dürfte aber in den 1830 er Jahren stattgefunden haben. Wurzer, der nach eigenen Angaben "die Beethovensche Familie wohl gekant" habe, fügte seinen Ausführungen zum familiären Umfeld der Beethovens "eine Anekdote" an, "die zu meinen angenehmen Reminiscenzen gehört."In diesem Zusammenhang nennt er Beethoven einen "ausgezeichneten und liebenswürdigen Mann, den ich sehr wohl gekant habe." Wurzer berichtet:

„Im Sommer des Jahres 1790 oder 1791 war ich eines Tages in Geschäften am Godesberger Brunnen. Nach Tisch kommt Beethoven mit einigen jungen Männern auch dahin. Ich erzählte ihm, daß die Kirche zu Marienforst (Kloster hinter Godesberg im Busche) reparirt und aufgeputzt worden, und dies sei auch der Fall mit der dasigen Orgel, die entweder ganz neu oder doch sehr vervollkommnet worden sei. Die Gesellschaft bat ihn, ihr die Freude zu machen und auf derselben zu spielen. Seine große Gutmüthigkeit gewährte bald unse-
Ferdinand Wurzer

(1765-1844).

Stahlstich von F. W. Linger nach einer Vorlage von M. Müller, um 1820 (Stadtarchiv Bonn) 
Das Kloster Marienforst in südwestlicher Richtung. Kupferstich von Charles Dupuis, um 1790

(Stadtarchiv Bonn).

In der Bildmitte die zweischiffige Klosterkirche

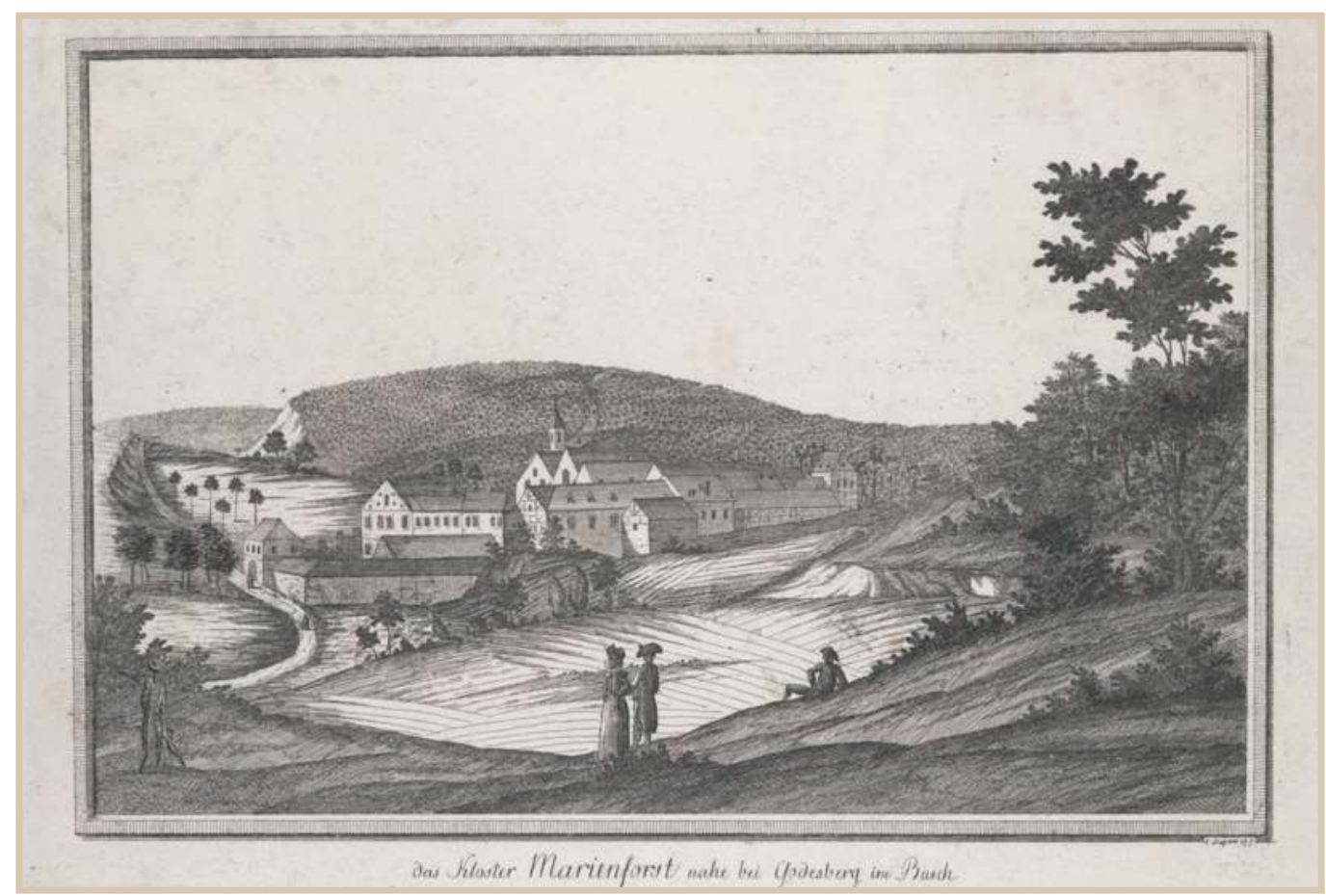

re Bitte. Die Kirche war geschlossen; aber der Prior war sehr gefällig und ließ uns dieselbe öffnen. Beethoven fing nun an, Themata, die ihm die Gesellschaft angab, zu variiren, so daß wir wahrhaft davon ergriffen wurden; aber was weit mehr war und den neuen Orpheus verkündigte: gemeine Arbeitsleute, die unten in der Kirche das durch das Bauen Beschmutzte rein machten, wurden lebhaft davon afficirt, legten vor und nach ihre Werkzeuge hin und hörten mit Staunen und sichtbarem Wohlgefallen zu. SIT EI TERRA LEVIS!"

Dass Wurzer, auf dessen Expertise letztlich der Ausbau Godesbergs zum Heilbad zurückging, sich häufig am Quellort aufgehalten hat, liegt auf der Hand. Warum sollten Beethoven und seine Freunde nicht einen Ausflug nach Godesberg gemacht haben? Der etwas mehr als ein Kilometer lange Weg vom Brunnen zum Birgittenkloster Marienforst ${ }^{38}$ wurde in jenen Jahren zur Erbauung der Kurgäste zur Marienforster Promenade ausgebaut. Bauarbeiten an der zweischiffigen Klosterkirche sind für 1790 nachzuweisen ${ }^{39}$, und die kleine, mit sieben Registern ausgestattete Orgel war durchaus brauchbar, wurde sie doch nach dem Abriss der Klosterkirche 1806 an die Pfarrkirche in Sinzig abgegeben, wo sie noch Jahrzehnte ihren Dienst tat. ${ }^{40}$ Dass Prior Johannes (Geburtsname Christian) Hohenschurz das Orgelspiel erlaubte, ist genauso wahrscheinlich wie Beethovens spontane Improvisationen. Und dass die Handwerker ihre Arbeit ob der hohen Spielkunst ehrfurchtsvoll niederlegten, beweist Beethovens Genialität - der neue Orpheus - auch dem größten Skeptiker. Die Geschichte kann also durchaus als glaubhaft gelten und als 
Puzzleteil in Beethovens Lebensbild eingepasst werden.

Überhaupt scheint Godesberg für Beethoven eine gewisse Vertrautheit besessen zu haben. Es ist davon auszugehen, dass er über seine musikalischen Verpflichtungen hinaus den landschaftlich reizvollen Ort geschätzt und wiederholt aufgesucht hat und angenehme Erinnerungen mit ihm verband. Gehörte die Godesburg doch, ausweislich eines Briefes Wegelers an Beethoven, zu denjenigen "Haken" aus der Jugendzeit, "an welche Du manche Idee froh anknüpfen kannst". ${ }^{41}$

Vergessen hatte Beethoven das reizvolle Godesberg jedenfalls auch nach Jahrzehnten nicht. 1825, zwei Jahre vor seinem Tod, wäre es fast doch noch zu einer weiteren Begegnung mit Godesberg gegeben: Sein Freund und Schüler Ferdinand Ries hatte ihn eingeladen, ihn in Godesberg, "einer der schönsten Gegenden des Rheins", wohin er mit seiner Familie nach seiner Rückkehr aus England gezogen war, zu besuchen und auch noch einmal eine längere Zeit am Rhein zu wohnen. ${ }^{42}$

Dazu ist es bekanntlich nicht gekommen.

Godesberg, das unter Kurfürst Max Franz für ein paar Jahre als eine Art Nebenresidenz diente und sich vorübergehend, insbesondere aufgrund des dort herrschenden Charme der Musik, zu einem kulturellen Zentrum entpuppte, ist aus Beethovens Lebensbild nicht wegzudenken.

Stadtarchiv Bonn (StAB), Nachlass Spiegel (Bonner Teil) 58; das nicht betitelte Konvolut enthält ein nach Dekanaten gegliedertes Verzeichnis sämtlicher Pfarrorte des Erzstifts Köln mit Angaben zum Stand des Volksschulwesens. Hinzu kommen Angaben zum Bevölkerungsstand in den einzelnen Dörfern. Die Verzeichnisse scheinen um 1790 im Zusammenhang mit den Bemühungen um eine Reform des Schulwesens entstanden zu sein.

Zur Topografie Godesbergs am Ende des Ancien régime vgl. DIETRICH JUNG, Das Dorf Godesberg im Jahre 1791, in: Godesberger Heimatblätter 19, 1981, S.105-121.

Ein in der Godesburg im Mittelalter verbauter römischer Weihestein des ausgehenden 2. Jahrhunderts für die Fortunae Salutares, Aesculapius und Hygia wurde als - nur bedingt überzeugendes - Argument genommen, um die Nutzung der Mineralquelle bereits zur Römerzeit nachzuweisen. Vgl. HEINz GüNTER HORn (Hg.), Die Römer in Nordrhein-Westfalen, Stuttgart 1987, S. 383.

Zur Geschichte der Quelle vgl. NORBERT SChLOSSMACHER, „... prickelnd, wie Champagner". Zur Geschichte des Bad Godesberger Wassers, in: Godesberger Heimatblätter 41, 2003, S. 54-88

Vgl. FERDInAnd Wurzer, Physikalisch-chemische Beschreibung der Mineralquelle zu Godesberg bey Bonn, Bonn 1790. Auszüge dieser Analyse erschienen im Mai 1790 auch im "aufgeklärten" und viel gelesenen Bönnischen Intelligenzblatt. Vgl. GEORG SCHWEDT, Ferdinand Wurzer und die Gründung des Godesberger Gesundbrunnens, Bonn 2015. Zu Wurzer zuletzt NORBERT FlöRKEN (Hg.), Ferdinand Wurzer. Bonner Chemie-Pionier. Schriften 1788-1844 (Bonner Gelehrte 2), Bonn 2020. 
Vgl. die bau- und kunstgeschichtliche Bewertung des Komplexes von WILFRIED HANSMANN, Die Bau- und Kunstgeschichte, in: DIETRICH HöROLDT (Hg.), Bonn als kurkölnische Haupt- und Residenzstadt (Geschichte der Stadt Bonn 3), Bonn 1989, S. 351 448, hier S. 441-448

Kurfürstliches Privileg für die Admodiationsgesellschaft vom 7.7.1790, zitiert nach Alfred Wiedemann, Geschichte Godesbergs und seiner Umgebung, Bad Godesberg 21930, S. $515 f$

Vgl. die kommentierte Edition: HANS KLEINPASS, in: Godesberger Heimatblätter 16, 1978, S. 11-51. Pickel fertigte ebenfalls eine Analyse des Godesberger Mineralwasser an, die in besagten Briefen abgedruckt ist. Der Verein für Heimatpflege und Heimatgeschichte Bad Godesberg gab 1978 auch ein Faksimile dieser Schrift heraus. Die folgenden Zitate sind dieser Vorlage entnommen.

Wiedemann, Geschichte Godesbergs (wie Anm. 7), S. 525.

Zu britischen Rheinreisenden in Bonn vgl.: NORBERT SCHLOSSMACHER, "It is difficult to imagine a more agreeable spot than this for a residence..." Briten in Bonn bis zur Mitte des 19. Jahrhunderts. Eine Skizze, in: Bonner Geschichtsblätter 47/48, 1998, S. 273-301.

ANN RADCLIFFE, A Journey made in the Summer of 1794 through Holland and the Western Frontier of Germany with a Return down the Rhine, London 1795. Hier zitiert nach KARL HEINZ STADER, Bonn und der Rhein in der englischen Reiseliteratur, in: EDITH ENNEN und DIETRICH HÖROLDT (Hgg.), Aus Geschichte und Volkskunde von Stadt und Raum Bonn. Festschrift Josef Dietz (Veröffentlichungen des Stadtarchivs Bonn 10), Bonn 1973, S. 117-153, hier S. 128

Vgl. SCHLOSSMACHER, prickelnd, wie Champagner (wie Anm. 4), S. $64 f$.

Zum Rittergut Disteling, mit dessen Besitz ein Landtagsmandat verbunden war, seiner äußerst verworrenen Geschichte und der Rolle des Grafen Waldstein vgl. den Beitrag von PIA HECKES in diesem Band.

MAYNARD SOLOMON, Beethoven, München 1977, S. 55

Max BraubaCh (Hg.), Die Stammbücher Beethovens und der Babette Koch. In Faksimile mit Einleitung und Erläuterungen, Bonn 1970, S. 19.

Zitiert nach ALBERT SCHULTE, Das Bad zu Godesberg im Urteil eines bei Kurköln akkreditierten englischen Diplomaten, in: Godesberger Heimatblätter 1, 1963, S. 26-30, hier S. 29. Dort auch der englische Text des Schreibens vom 13.6.1793.

So Ann RADCLIFFE 1794, zitiert nach STADER, Bonn (wie Anm. 11).

18 Ludwig SchiedermaIR, Der junge Beethoven, Wilhelmshaven 1970, S. 71; vgl. auch Claudia Valder-Knechtges, Die Musikgeschichte, in: Höroldt, Bonn 3 (wie Anm. 6), S. 449-514, hier S. 503

19 Vgl. zu dieser Begegnung Norbert Schlossmacher, Die Redoute in Godesberg, in: INGRID BODSCH (Hg.), Joseph Haydn und Bonn (Katalog zur Ausstellung), Bonn 2001, S. 100-114.

20 Zu Wegeler u.a.: Berthold Prössler, Franz Gerhard Wegeler: ein rheinischer Arzt, Univ.-Professor, Medizinal-Beamter und Freund Beethovens (Jahresgabe des Vereins Beethoven-Haus 17), Bonn 2000. Der Beitrag erschien zuerst in: Koblenzer Beiträge zur Geschichte und Kultur 7, 1998. Zuletzt: NORBERT FlörkEN (Hg.), Franz Gerhard Wegeler. Ein Freund Beethovens. Reden und Schriften 1786-1845, Bonn 2020, sowie den Beitrag von Nicole KÄMPKEN in diesem Band. 
Franz Gerhard Wegeler und Ferdinand Ries, Biographische Notizen über Ludwig van Beethoven, Koblenz 1838, S.15f.

Vgl. hierzu Howard Chandler Robiins Landon, Johann Peter Salomon - „Er brachte Haydn nach England", in: BodsCH, Haydn (wie Anm. 19), S. 130-141.

Zum Ablauf des Haydn-Besuchs in Bonn vgl. INGRID BODSCH, Das kulturelle Leben in Bonn unter dem letzten Kölner Kurfürsten Maximilian Franz von Österreich (1780/841794), in: DIES., Haydn (wie Anm. 19), S. 61-73, hier S. 61 f.

Zu Haydns Zeit in England vgl. Howard CHANDLER RobBIns LANDON, Haydn in England 1791-1795, London 1985, sowie DerS., Haydn und England, in: BodsCH, Haydn (wie Anm. 19), S. 143-149

Schreiben vom 28.6.1792, in: Beethoven-Haus Bonn, NE 166.

Vgl. JuLIA RONGE, Beethovens Lehrzeit. Kompositionsstudien bei Joseph Haydn, Johann Georg Albrechtsberger und Antonio Salieri (Schriften zur Beethoven-Forschung 20), Bonn 2011, S. 31. Vgl. zu beiden Kantaten und ihrem Entstehungszusammenhang außerdem Jürgen MAINKA, Beethovens Bonner Kantaten, in: HEINZ ALFRED BROCKHAUS und KonRAD Niemann (Hgg.), Bericht über den internationalen Beethoven-Kongress 10.-12. Dezember 1970 in Berlin, Berlin 1971, S. 315-326.

Vgl. Schiedermair, Beethoven (wie Anm. 18), S. $211 \mathrm{f}$.

Eine Zusammenfassung der älteren Diskussion bei WIEDEMANN, Geschichte Godesbergs (wie Anm. 7), S. 520-522, sowie zuletzt bei SCHLOSSMACHER, Redoute (wie Anm. 19). S. $102 f$.

Stellvertretend für die zahlreichen jüngeren Beethoven-Biografien vgl. JAN CAEYERS, Beethoven. Der einsame Revolutionär. Eine Biographie, München ${ }^{32} 2015$, S. 109, sowie JAN SWAFFORD, Beethoven. Anguish and Triumph, London 2014, S. 122-124, 967 Anm. 23. Vgl. auch Armin RaAB, Haydn, (Franz) Joseph, in: Heinz von Loesch und Claus RAAB, Das Beethoven-Lexikon, Laaber 2008, S. 314-318, hier S. $314 f$.

Franz Anton Ries hatte 1791 eines der sechs der Redoute benachbarten Logierhäuser an der Kurfürstenallee erworben. 1824 war auch sein Sohn Ferdinand mit seiner Familie für einige Jahre dorthin gezogen. Vgl. HANS KLEINPASS, Die Straßennamen der Gemarkung Rüngsdorf, Teil 4 (Riesstraße), in: Godesberger Heimatblätter 11, 1973, S. 115-124, hier S.116ff., sowie den Beitrag von BARBARA MüLhenS-MOLDERUnGs in diesem Band.

Vgl. u. a. Solomon, Beethoven (wie Anm. 14), S. 69ff., gestützt auf ältere Forschungen. So Christian Gottlob NeEFE, Musikal. Nachrichten aus Bonn, in: Berlinische musikalische Zeitung I, 1793, S. 153 (39. Stück vom 26.10.1793). Neefe erwähnt in diesem Zusammenhang auch, dass Haydn noch nicht wieder nach London aufgebrochen sei. - Dies geschah bekanntlich erst 1794/95. - Vgl. in diesem Zusammenhang LANDON, Haydn in England (wie Anm. 23), S.192ff.

Zitiert nach BRAUBACH, Stammbücher (wie Anm. 15), S. 27. Ebd., S. 134f., auch eine Kurzbiografie Breunings.

Wolfgang Müller von Königswinter, Furioso. Aus Beethoven's Jugend, in: Ders., Erzählungen eines rheinischen Chronisten, 2 Bde, Leipzig 1860/61, hier Bd. 2, S. 103-327, Zitat S. 292-295. Wolfgang Müller (1816-1873), Arzt in Düsseldorf und Köln, stand dem Bonner Maikäfer-Bund um Johanna und Gottfried Kinkel, Karl Simrock, Ferdinand Freiligrath nahe und besaß Kontakte mit anderen Literaten, darunter Heinrich Heine und Georg Herwegh. Vgl. das Lebensbild von PIA HECKES (http://www.rheinische-geschichte.Ivr.de/Persoenlichkeiten/wolfgang-mueller-von-koenigswinter/DE2086/lido/57c9516754ab31.17301722, aufgerufen 16.2.2020). 
35 Heinz Magka, Das Godesberger Frühstück, Bad Godesberg 1952, der Textauszug S. 101. Ein knappes Lebensbild dieses rheinischen Journalisten, Karnevalisten und Literaten bietet INGRID SCHAMPEL, Das unvergessene "Godesberger Frühstück" und sein Dichter Heinz Magka, in: Godesberger Heimatblätter 37, 2000, S. 178-182

Zu diesem Denkmal und seiner Geschichte vgl. Hans KLEINPASS, Die Straßennamen der Gemarkung Rüngsdorf, Teil 2 (Haydnstraße), in: Godesberger Heimatblätter 9, 1971, S. 64-77, hier S. 65.

37 Das hier interessierende Schreiben in: CHR\{ISTIAN\} VON STRAMBERG, Das Rheinufer von Coblenz bis Bonn. Historisch und topographisch dargestellt, 14 Bde (Denkwürdiger und nützlicher Rheinischer Antiquarius, welcher die wichtigsten und angenehmsten geographischen, historischen und politischen Merkwürdigkeiten des ganzen Rheinstroms, von seinem Ausflusse in das Meer bis zu seinem Ursprunge darstellt. Von einem Darsteller in historischen Dingen. Mittelrhein. Der III. Abtheilung 14. Band), Koblenz 1869, S. 124-126. Hieraus auch die folgenden Zitate.

38 Das 1228 erstmals erwähnte Kloster (wohl Augustinerinnen) wurde 1450 vom Birgittenorden übernommen. Birgittenklöster besaßen einen Frauen- und einen Männerkonvent unter Gesamtleitung einer Äbtissin. Vgl. ElKE STRANG, Das Kloster Marienforst bei Bad Godesberg von seiner Gründung im 13. Jahrhundert bis zur Auflösung 1802 (Veröffentlichungen des Stadtarchivs Bonn 56), Bonn 1995.

39 Im Zusammenhang mit der Aufnahme eines Darlehns durch die Klosterleitung im Jahre 1795 ist die Rede von dem "im Jahre 1790 notwendig unternommene(n) Kirchenbau"; zitiert nach WiedemAnN, Geschichte Godesbergs (wie Anm. 7), S. 329

$40 \quad 1880$ kam die Orgel an die Kirche in Sinzig-Koisdorf, 1931 wurde das Instrument aufgegeben. Vgl. BASTIAN SteIngIeSSER, Bonn-Bad Godesberg - Marienforst, in: MANFred Groten u.a. (Hgg.), Nordrheinisches Klosterbuch. Lexikon der Stifte und Klöster bis 1815, Teil 1, Siegburg 2009, S. 400-409, hier S. 407

41 Schreiben vom 28.12.1825, in: SIEGHARD BRANDENBURG (Hg.), Ludwig van Beethoven. Briefwechsel Gesamtausgabe, 7 Bde, München 1996-1998, hier Bd. 6, Nr. 2100 . Die übrigen Haken waren übrigens Bonn, der Kreuzberg und die Baumschule. Das Schreiben ist voller Melancholie und Reminiszenzen an die gemeinsame Jugendzeit: "Ist der Mensch, und wenn er so hoch steht, wie du, doch nur einmal in seinem Leben glücklich, nämlich in seiner Jugend."

42 Wegeler/Ries, Notizen (wie Anm. 21), S. 163 


\section{Die Rezeption der Nachricht von Beethovens Tod in Bonn}

D

er Einmarsch der französischen Revolutionstruppen 1794 in Bonn stürzte die Stadt in schmerzhafte Veränderung, beendete "die glanzvolle Geschichtsperiode, in der Bonn zur schönsten Barockresidenz am Rhein aufgestiegen war und seine lebensfrohe, musikbegeisterte Bürgerschaft sowohl in der Lese- und Erholungsgesellschaft Zugang zu den modernen Ideen der Aufklärung fand als auch über eine zu großen Hoffnungen berechtigende Universität verfügte."1

Nicht nur zahlreiche wohlhabende Bürger verließen Bonn. Beamte, die blieben, hatten mit Unsicherheiten zu kämpfen; Häuser und Ladenlokale standen leer, die Zahl der Armen und Arbeitslosen stieg. Um 1800 wirkte Bonn verlassen und still. Das kulturelle Leben ging stark zurück und 1798 erfolgte das formelle Ende der Universität. ${ }^{2}$ Mit Gründung der Evangelischen Gemeinde im Jahr 1816 setzte eine positive Entwicklung durch Zuzug ein. ${ }^{3}$ Die Einrichtung der Universität 1818 stellt dann einen Meilenstein in der Geschichte und Entwicklung der Stadt Bonn dar, „weil die Hochschule auf die Dauer vollgültigen Ersatz für die verloren gegangene Residenz- und Hauptstadteigenschaft gewährte." ${ }^{4}$ Schon nachdem die Franzosen Bonn verlassen hatten, verfolgten die Stadt, ihr Rat und ihr Oberbürgermeister konsequent den Plan, die preußische Rheinuniversität in Bonn anzusiedeln. Die Offenheit gegenüber einer katholischen und evangelischen Fakultät war dabei hilfreich. ${ }^{5}$ Auch in wirtschaftlicher Hinsicht war die Universität in der Bedeutung für Bonn nicht zu unterschätzen. Bereits im Jahr 1825 konnte die Einwohnerzahl von 1790 übertroffen werden. Wirtschaftlich relevant, zuträglich für Handel und Verkehr war das ebenfalls seit 1818 in Bonn ansässige Oberbergamt. ${ }^{6}$ Zwischen 1825 und 1828 war erneut ein Anstieg der Bevölkerung zu verzeichnen. Ursächlich hierfür scheint die positive Entwicklung der Universität - ca. 1.000 Studenten waren eingeschrieben - sowie eine Krise im landwirtschaftlichen Sektor, die der Stadt Bonn zahlreiche neue Einwohner verschaffte. ${ }^{7}$ Die Bonner Studentenverbindungen wurden gegründet: so 1820 die Corps Rhenania und Guestphalia, 1821 das Corps Borussia. Seit 1818 befand sich die Antikensammlung im Aufbau; 1824 wurde die Anatomie erbaut. ${ }^{8}$ Die Universität bereicherte auch das kulturelle und geistige Leben Bonns. Bedeutende Wissenschaftler und Mitglieder der Bonner Gesellschaft waren August Wilhelm von Schlegel (1829 Mitglied des Stadtrates), Barthold Georg Niebuhr(1831 Mitglied des Stadtrates), Johannes Müller und Friedrich Wilhelm August Argelander. 1825 kam es zur Gründung des Vereins zur Erweiterung und Verschönerung der Stadt Bonn; die Leitung übernahm Schlegel. Im gleichen Jahr fand erstmals an Rosenmontag 
Heinrich Karl Breidenstein (1796-1876). Nach einem Medaillonrelief, Fotografie (Stadtarchiv Bonn)

ein bürgerlicher Fastnachtszug in Bonn statt. Sodann erfolgte 1826 die Gründung der Bönnschen Karnevalsgesellschaft (ab 1882 Große Bonner KarnevalsGesellschaft). ${ }^{9}$

Bürgerschaftliches Engagement konnte vor allem im Musikleben der Stadt beobachtet werden: „Das wichtigste Ereignis der Epoche, das erste Beethovenfest zur Enthüllung des Denkmals auf dem Münsterplatz 1845 in Anwesenheit der Monarchen von Preußen und England sowie unter Beteiligung international angesehener Künstler, ist ausschließlich bürgerschaftlicher Initiative zu verdanken."10 Doch hierzu später mehr.

Im literarischen Leben spielten Gottfried und Johanna Kinkel und ihr Maikäferbund eine bedeutende Rolle, die Lese war die "führende gesellige Vereinigung", wobei der Bildungsanspruch hinter das Gesellige zurücktrat; und auch im Haus von Sibylle Mertens-Schaaffhausen verkehrte ein ebenfalls führender und aufgeschlossener Zirkel vor allem von Altertumskundlern und Künstlern. ${ }^{11}$

Die Verwaltung der Stadt war noch bis zur Mitte des 19. Jahrhunderts von der französischen Munizipalverwaltung beeinflusst, es handelte sich dabei weniger um eine Selbstver-

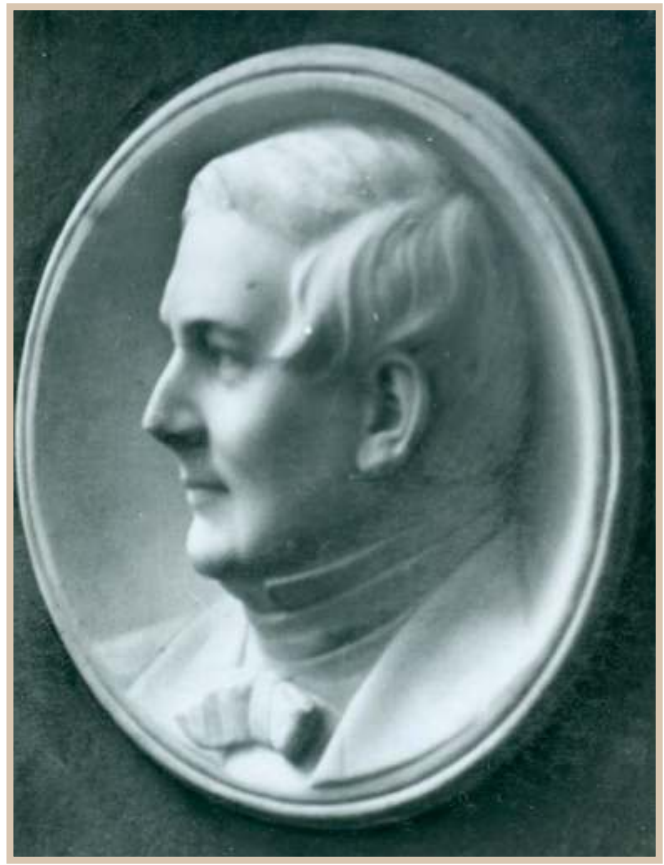
waltung als vielmehr um eine staatliche Auftragsverwaltung. ${ }^{12}$ In Folge der Schuldenlast suchte man - wie auch in anderen Städten - die Verwaltungs- und Personalkosten niedrig zu halten. ${ }^{13}$ Darüber hinaus dominierte die Vorstellung einer eher schlanken Verwaltung, man tendierte dahin, Aufgaben und Projekte, mit denen ein Gewinn erwirtschaftet werden konnte, an Bürger zu delegieren. ${ }^{14}$ In der städtischen Haushaltsführung war lediglich ein Hauptetat vorgesehen sowie ein Etat für Volksschulen. ${ }^{15}$ So existierte auch keine eigene Bauverwaltung mit Arbeitern oder technischem Personal. Für Tätigkeiten in diesem Bereich wurde gerne das Personal der Universität herangezogen, und - sofern erforderlich - private Firmen beauftragt. ${ }^{16}$ Und derart verhielt es sich auch im kulturellen Bereich, erst im Jahr 1859 wurde eine eigene Stelle für einen Musikdirektor geschaffen. ${ }^{17}$

Die Bonner Musikszene hatte von der Residenzfunktion der Stadt profitiert. Kurfürst Max Franz von Österreich (1784-1801) nahm sich das Musikleben Wiens mit Haydn und Mozart zum Vorbild, viele Mozart-Opern wurden aufge- 
führt. Beethoven - seit 1782 Organist und Bratschist der kurfürstlichen Kapelle - konnte hier zahlreiche Eindrücke der aktuellen, zeitgenössischen Musik sammeln. Parallel gab es in Bonn aufgeklärte Geister wie den Komponisten Christian Gottlob Neefe und seinen Kreis, die Beethoven ebenfalls in seiner Entwicklung beeinflussten und voranbrachten. ${ }^{18}$ Beethovens Umfeld, seine musikalische Herkunft, veränderte sich mit dem Einmarsch der Franzosen. Konstanten blieben lediglich der Musikverlag von Nikolaus Simrock sowie das Wirken von Vater und Sohn Ries. Franz Ries (1755-1846), letzter kurfürstlicher Konzertmeister der Hofkapelle, veranstaltete mit der Konzertgesellschaft öffentliche Konzertabende mit zurückgebliebenen Musikern der Hofkapelle. 1806 leiteten Franz Ries und sein Sohn Ferdinand Konzerte, bei denen Werke Beethovens gespielt wurden. Auch in den 1820er Jahren wurden Stücke Beethovens in Bonn aufgeführt. Musik spielte im Leben der Bonner eine wichtige Rolle; seit 1821 gab es zwei "musikalische Verleihinstitute". Bekannte Musiklehrer in Bonn waren Joseph Simrock, Sohn von Nikolaus Simrock, Franz Josef Mompour, Inhaber einer Musikalienhandlung, und Heinrich Carl Breidenstein. ${ }^{19}$ Ein modernes Musikleben war im Rheinland noch nicht etabliert. Die Entwicklung eines solchen ist "der Tatkraft des aufstrebenden Bürgertums" zu verdanken. "Liebhabervereine unter Leitung befähigter Musikfreunde [waren] lange Zeit das charakteristische Rückgrat der öffentlichen Musikpflege im Rheinland. Wann sich die Ablösung der Dilettanten durch Berufsmusiker vollzog, das hing ganz von den örtlichen und persönlichen Umständen ab. In Bonn war der Prozeß von besonders langer Dauer und verwickelt." ${ }^{\prime 20}$

Langsam also belebten private Initiativen die Bonner Musikszene. Die verschiedenen Kreise rivalisierten jedoch in Teilen untereinander, wirkten nicht zusammen; ein zentrales Konzerthaus gab es nicht. Heinrich Karl Breidenstein, seit 1822 Musikdirektor und seit 1826 außerordentlicher Professor der Universität - er besetzte den ersten musikwissenschaftlichen Lehrstuhl der neuzeitlichen Universitätsgeschichte -, brachte das Bonner Musikleben ein Stück voran. Er gründete den Singverein und hatte es sich zur Aufgabe gemacht, die Musik Beethovens den Bonnern näherzubringen, auch wenn die musikalischen, professionellen Voraussetzungen in Bonn nicht gegeben waren. So führte er dessen Werke am 21. März 1824 im Rahmen eines Konzertes zu Gunsten der Armen auf, die Winterkonzerte 1826/27 wiesen in ihrem Programm die 2. und die 8. Sinfonie sowie die Ouvertüre aus Fidelio auf. Anlässlich des Tauftages am 17. Dezember 1826 führte Breidenstein die 4. Sinfonie zum ersten Mal in Bonn auf. Es handelt sich hierbei um das erste Konzert, das einen unmittelbaren Bezug zu Beethoven hat. Das nächste Konzert dieser Art sollte die Totenfeier für den Komponisten am 13. Juli 1827 sein.

Die Erstaufführungen von Beethovens Sinfonien fanden in Bonn spät statt. Insgesamt gesehen kann das Programm der Bonner Konzerte allgemein als 
"konventionell" bezeichnet werden, es bot wenig Neues im Vergleich zu anderen Städten. ${ }^{21}$ Als Chorleiter und Komponisten haben sich neben Breidenstein auch Friedrich Heimsoeth, Anton Mohr, Peter Grabeler und Johanna Kinkel hervorgetan. ${ }^{22}$ Das Bonner Musikleben war von Uneinigkeit geprägt. Von Breidensteins Singverein spaltete sich ein Teil der studentischen Mitglieder ab und gründete den Bonner Musikverein. Zudem bestand eine Rivalität der Universitätsprofessoren Breidenstein - Anhänger der Musik von Berlioz, Liszt und Wagner - und Friedrich Heimsoeth. Letzterer vertrat eine konservative Richtung. Heimsoeth tat sich im Zuge der Gründung des Städtischen Gesangvereins hervor und spielte in der zweiten Hälfte des 19. Jahrhundert eine bedeutende Rolle im Konzertleben der Stadt. Breidensteins Position war als Lehrstuhlinhaber für Musikwissenschaft nicht weniger wichtig. Er ist zudem der Initiator des ersten Beethovenfestes von 1845, in dessen Rahmen erstmals die Missa solemnis und die 9. Sinfonie in der Geburtsstadt Beethovens aufgeführt wurden. 1834 suchte man die Kräfte zu bündeln, es schlossen sich mehrere musikalische Vereine, der Singverein Breidensteins, der Verein der Bürger und Studierenden und die Konzertgesellschaft zusammen und gliederten sich als Musikverein der Lese- und Erholungsgesellschaft der Lese an. Doch die Vereinigung sollte scheitern. ${ }^{23}$ Am 13. Januar 1839 starb Ferdinand Ries; das vielfältige Musikleben Bonns vereinigte sich zu einer großen Trauerfeier. Mozarts Requiem wurde unter Leitung von Friedrich Heimsoeth gespielt. Dies war ein so großer Erfolg, dass Heimsoeth und auch Breidenstein weitere Konzerte gaben, „und dies alles wirkte so belebend auf den Sinn für Chormusik und ein Musikleben größeren Stils ein, daß die folgenden 10 Jahre geradezu eine Glanzzeit des öffentlichen Musiklebens Bonns wurden." Anfang der 1840 er Jahre fanden zahlreiche musikalische Veranstaltungen in Bonn statt. 1843 gründete Breidenstein den Orchesterverein bestehend aus Berufsmusikern, Laien und Zuhörern. Breidenstein bereitete so das Musikleben Bonns auf das anstehende Beethovenfest 1845 vor. ${ }^{24} 1859$ erfolgte mit der Berufung eines städtischen Musikdirektors der erste Schritt hin zu einem Musikbetrieb, der auch öffentlich finanziert wurde. ${ }^{25}$

\section{Schlechte Nachrichten erreichen Bonn}

Am 26. März 1827 verstarb Beethoven in Wien. Nach längerer Krankheit war dies keine Überraschung für das Umfeld seiner Wahlheimat. Am 21. Februar hatte die Allgemeine musikalische Zeitung zuletzt von seinem Gesundheitszustand berichtet. Nach einigen Informationen zu Krankheit und Therapie meldete die Zeitung: "Nach seiner Genesung will er ungesäumt die von Bernard gedichtete religiöse Cantate zu componiren beginnen. Der Himmel gebe diesem Vorsatze Gedeihen! Doch das Schwellen des Unterleibes macht seinen Freunden - und wer zählte wohl nicht zu diesen? - nur allzusehr für das theure Leben bange. ${ }^{\prime 26}$ Am 26. März verstarb der Komponist, am 28. desselben 


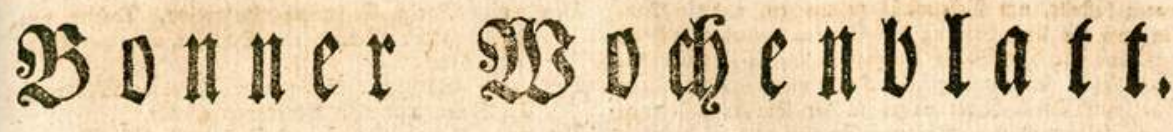 \\ $N^{10} 45$. \\ Conntag Den $3 \stackrel{\text { en }}{-}$ รันni 1827.}

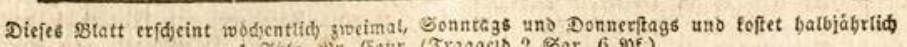

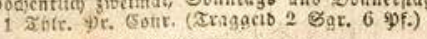

Befanntmad)ung

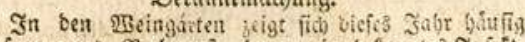

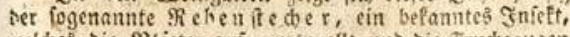

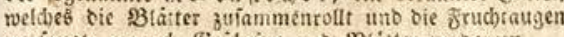
autfaugt, wonad) (seideine unt sblitter verborrent.

Die EBeingartsbefilker werben Daber auf bie Yiad)= theile jener ichatididen Salette aufmerffam gemacht unb veranlast, burch Zcuileien oerielben unb 3erftoren ber

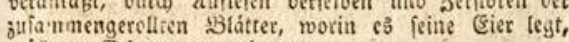
gróserm Edbazent vorzubeugen.

23 on n, Den 2. Šmi 1827 .

Der Dber:Bürgermeifter, is i nó ed.

Beithoven ร Iootenfeier.

Den grosiften Bertuft, rechent bie mufitatide

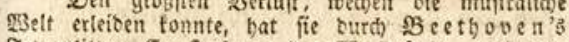

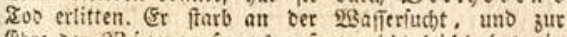
(E)re Der 23 icner fon es gefagt, nid)t leicht ljat ein Evotesfall to auberorbentlicte uno allgemeine 2 Betrubs nis hersorgebracht als biefer. 2fles vereinigte fich um ten grofen Ionoidter auf cine witroige 2rt zu (5rabe 8il beftatten. Sech) junge Sánger trugen feinen Sarg, reghs Stapeffmeitter bielten oie Enben oes Eeidentuches, Eedjeth Ë́nger trugen sin von ibm componirtes Ion:

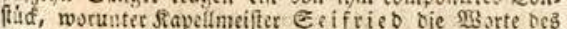
Miserere geiest hatte, von (Srillyary er verfagite eine berrlide Pebe auf ben $B$ erblichenen, weidse $2 \mathrm{n}$ :

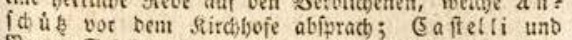
Baron 5 d ledita biósteten Ricber, weldee beim Reiz. a) rnjeghingnifie autgetbeilt rutrben; bie bedeutenbeten Wrreter aiter stinfte umgaben mit Fadetn ben Sarg; Wrofefjoren uno Dilettanten, Staatรืmánner uno Stủnis lit folgten ber geide uno eine Menf́chenmenge von meje als 20,000 verfammelte fid) auf ben plátzen,

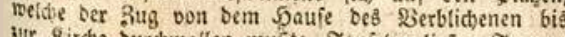

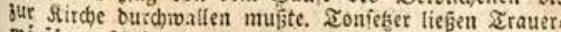
máriabe eribeinen; bic erften Dontüntter vereinigten fic gut Xuifúthrung ber Eeelenmeficu, welche für ben 2ietifurbenen in verichiebenen Sitchen gebalten wurben.

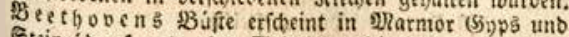
Steinabbrud uno eine gribaitle wirb auf bea grefen Surterbenen geprägt. 2Rebrere plane fino bereirs ent: worfeil, zur Deranftaltung von Eonzerten unt zur

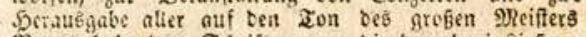

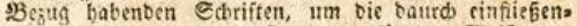
Den Summen zи einem Dentmale für ben शreifter vertventen. Sie feben wobl aub bem allen, wie 233 ien feine groß̉en श̊ánner ést.

Ein stronleudoter einjig in feiner 2 rt.

Steine Ration bat to viele Eonberlinge aufjumeir fen, wie bie englifde, unb biefe zeigt fich nid)t allein in ibrem feben, ionbirn auch in oer Sterbifunde, bas von jette on bie viefen fonberkace Ieftamente, nods mets aber oie nutbe als irgenbwo vortommenten Seitffmorbe Die oft unter gropes 2 (uffecten erregenben umftanoen verúbt twetben.

Eorb Malcroft geborte zu ben Sonberlingen; or war

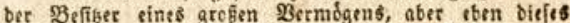

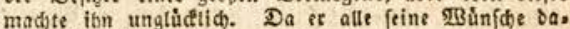
burd) befriebigen tonte, fo batte et die greuben bit IBeit, bie eblen uno uneblen, in foder Ueberfutle genof= fen, baß er, burch Ueberfáttigung batan, einen Moiber: willen gegen fie empfant. Die Folge bavon war sin

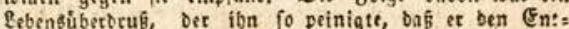

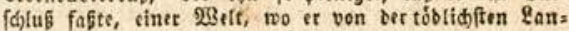
gemeite gemartert wurbe, freimillig it ent fagen, und feinem freubelofen Reben sin Biel ju feşen.

Er orbnete ju biefem Xustritt aus ber Befeurdaft Der Eebenben alles mit einse sidite unb \$iuhe an, baß Pines feiner Umgetung unb SBefannten - benn freunbe im coterr: Sinne bes Borts batte ber Eord nidht baven nidit bie minbefte 2flynung baben fonnte; vielmebs Da bice Znorbnungen ibm eine neue Befdáftigung $\mathrm{ga}$.

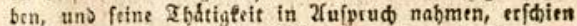
is minber mitrrift unb úbelgetaunt, wis ef fid fihen fe minoer mert lenger 3eit gervóbntide gejeigt batte.

Det Tag, icinen Borfas autjufúbren was einges trofien. Er batte baju alle feine Befannte ju einem Diner einlaben taffen. Zutes war auf bas sobffitiofite und (5) innendfte eingeribtet. Gein Shaushofmeiftet hatte ben Befotel erbalten, es an nidis mangsin ju laffer. Die Bsafte fitlten fidh ein. Der forb empfing mit uno gemóbnitdyer Speiterteit; wat gegen Jeben juberkommen. bes, wie es fonft feine $\gamma_{\text {rtt }}$ mar. Ein Ebor Sautbofften
Bericht über das Begräbnis in Wien. Bonner Wochenblatt, 3. Juni 1827

(Stadtarchiv Bonn)

Monats, in der nächsten Ausgabe, brachte die Allgemeine musikalische Zeitung einen ausführlichen Nachruf auf Beethoven. ${ }^{27}$

In diesen Tagen ahnte man in Bonn nichts vom Ableben Beethovens. Erst Anfang Juni 1827, als das Bonner Wochenblatt am 3. des Monats einen Wiener Artikel über das aufwendig gestaltete Begräbnis, an dem am 29. März 20.000 
Schreiben Tobias Haslinger, Wien, an Nikolaus Simrock, Bonn, vom 27. März 1827

(Beethoven-Haus Bonn, Sammlung H. C. Bodmer)
Menschen teilgenommen haben sollen und der Schriftsteller Franz Grillparzer die Grabrede hielt, abdruckte, wurde der Tod einem größeren Kreis in Bonn bekannt. ${ }^{28}$ Es ist jedoch davon auszugehen, dass Bekannte und Freunde schon früher vom Tod Beethovens erfahren hatten. Franz Gerhard Wegeler, seit 1807 in Koblenz, ist sehr wahrscheinlich durch seinen Schwager Stephan von Breuning, wie Wegeler ein Jugendfreund Beethovens und seit 1826 Mitvormund für dessen Neffen Karl, unterrichtet worden. ${ }^{29}$

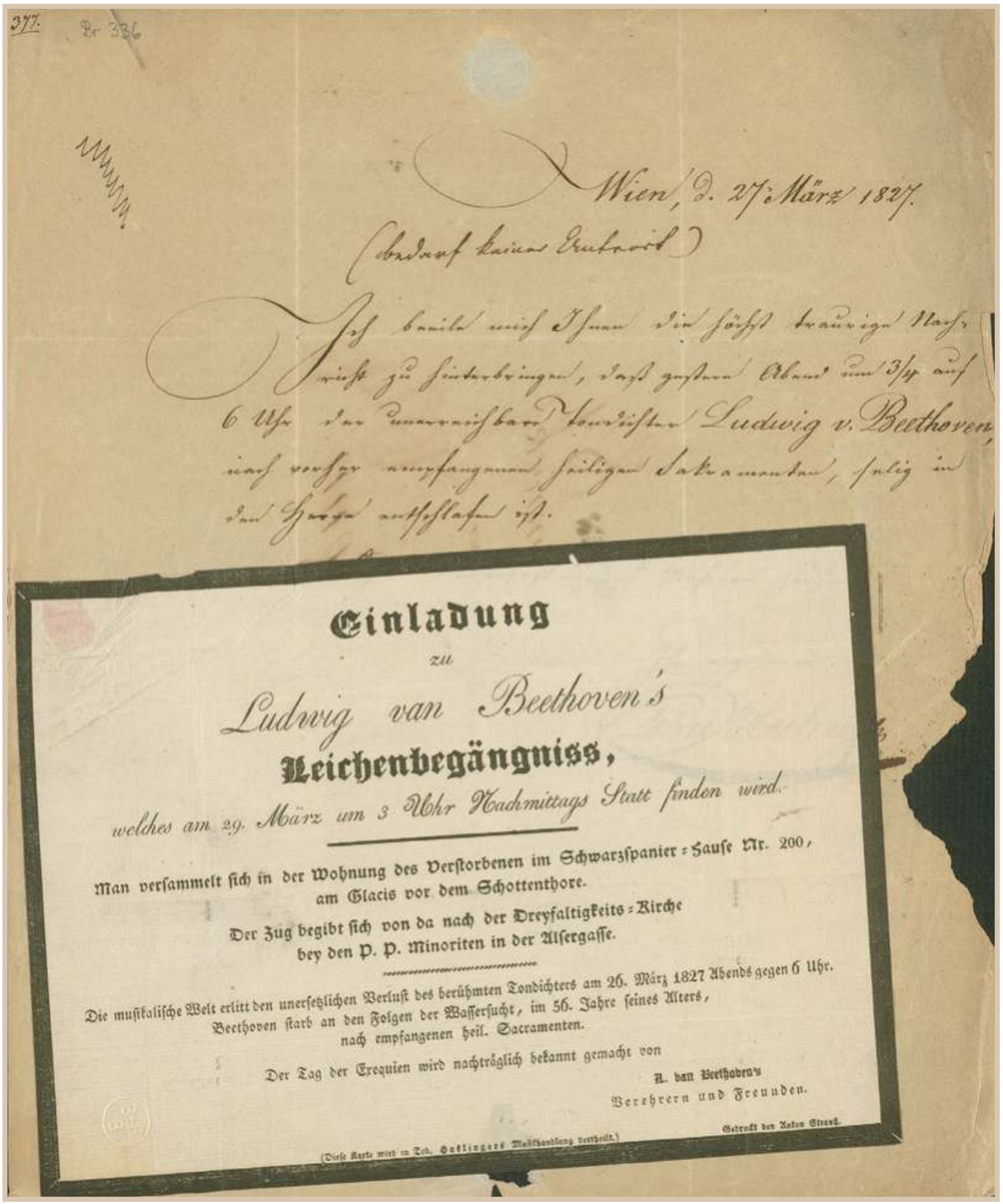

522 | Yvonne Leiverkus

(c) 2020 by Böhlau Verlag GmbH \& Cie. KG, Köln

https://doi.org/10.7788/9783412519704 | CC BY-NC 4.0 
Ein weiterer Bonner erfuhr schon deutlich früher als die übrigen Bonner vom Tod Beethovens: Nikolaus Simrock, der Bonner Musikverleger. Bei Simrock handelt es sich um einen alten Weggefährten Beethovens, um denjenigen kurfürstlichen "Hofmusiker, der aus der Franzosenzeit am glänzendsten hervorging, als solventer Geschäftsmann, mit dem doppelten Ruhme des Begründers eines weltbekannten Musikverlages und des fast einzigen Bindegliedes zwischen dem großen Beethoven in Wien und der kleinen Vaterstadt Bonn, das war der ehemalige Waldhornist Nikolaus Simrock."30 Nikolaus Simrock (17511832) war seit 1775 in Bonn ansässig und wirkte als zweiter Waldhornist in der kurfürstlichen Kapelle. Wie viele seiner Kollegen verdiente sich Simrock neben seiner Tätigkeit in der Hofkapelle durch das Erteilen von Musikunterricht sowie durch den Handel mit Instrumenten und Musikalien einiges dazu. Unter den Kollegen nahm Simrock den Nebenerwerb betreffend eine besondere Stellung ein, denn er betrieb diesen in größerem Maße und mit der ausdrücklichen Erlaubnis des Kurfürsten. ${ }^{31} 1775$ wurde Simrock auch Mitglied der Hofkapelle, zu diesem Zeitpunkt war Beethovens Vater Tenorist und Ludwig fünf Jahre alt. Im Jahr 1783 wurde der 12-jährige Ludwig als zweiter Organist, Bratschist und Begleiter auf dem Cembalo Kollege des 19 Jahre älteren Simrock. Es gibt nur wenige Quellen, die Aufschluss über das Verhältnis der beiden zueinander geben. In seinen Erinnerungen an die Reise der Hofkapelle nach Mergentheim 1791 zeigte sich Simrock vom Spiel Beethovens beeindruckt. Briefe informieren zwar über die geschäftliche, berufliche Beziehung der beiden - jedoch nicht über die persönliche. Es wird in Frage gestellt, ob es überhaupt eine gab. ${ }^{32}$ In seiner Anfangszeit betrieb der Verlag Simrock Ende des 18. Jahrhunderts Kommissionshandel und konzentrierte sich dabei auch zunächst auf Bonn, die kurkölnische Residenzstadt. Der Betrieb konnte sich trotz grundlegender politischer Veränderungen in Bonn ab 1794 zu einem gut vernetzten und international agierenden Musikverlag entwickeln. Erste Druckwerke des Musikverlages stammten von den Bonner Komponisten Neefe und Beethoven. Geschäftliche Kontakte bestanden darüber hinaus u. a. in den Anfangsjahren zu Anton Reicha, dann auch zu Ludwig Spohr, Carl Maria von Weber, Felix Mendelssohn Bartholdy und Johannes Brahms. Simrock konnte sein Programm über die Jahre stetig erweitern, im Angebot waren alle Werke bekannter und beliebter Komponisten. Simrock brachte fast alle Werke Beethovens - in der Regel - als Nachdruck heraus. ${ }^{33}$ So trug er zum Bekanntwerden von Beethovens Musik maßgeblich bei. 1792 brach Beethoven nach Wien auf, bis dahin umfasste sein Werk ca. 50 Stücke. Keines davon war bis dahin im Verlag Simrock erschienen, da der Verlag erst ab 1793 arbeitete. So ergab sich die verlegerische Beziehung mit dem Komponisten erst nach dem Weggang Beethovens. 13 Werke Beethovens erschienen bei Simrock als Erstausgaben. ${ }^{34}$ Simrock strebte an, "größer besetzte Werke" Beethovens herauszubringen, so auch die C-Dur-Messe op. 86 oder die Missa solemnis op. 123. Aus dieser 
Zusammenarbeit ergab sich ein Konflikt zwischen dem profitorientorientierten und konsequenten Verleger und einem im Umgang schwierigen Komponisten, der unter seinem fortschreitenden Gehörverlust litt und seinen Mitmenschen verstärkt mit Misstrauen gegenübertrat. Bis 1824 verhandelte Beethoven mit sieben Verlegern über die Missa solemnis, drei Verleger erhielten sogar eine feste Zusage. Überdies hatte Simrock in der Zwischenzeit Beethoven bereits ein Honorar gezahlt, mit dem dieser sehr unzufrieden war. Durch sein ungeschicktes Verhandeln und Geschäftsgebaren machte sich Beethoven unbeliebt. Das Zerwürfnis der beiden führte zum Ende ihrer Geschäftsbeziehung. ${ }^{35}$

Bereits am 27. März, am Tag nach dem Tod, wandte sich Tobias Haslinger, der Wiener Musikverleger, an Simrock und teilte diesem per Brief mit: "Ich beeile mich Ihnen die höchsttraurige Nachricht zu hinterbringen, daß gestern Abend um 3/4 auf 6 Uhr der unerreichbare Tondichter Ludwig van Beethoven, nach vorher empfangenen heiligen Sakramenten, selig in den Herrn entschlafen ist."136

Bereits sechs Wochen zuvor, am 14. Februar 1827, hatte sich Andreas Streicher von der Wiener Klavierbaufirma Nannette Streicher geb. Stein und Sohn, Ehemann der Firmeninhaberin Nannette Streicher, an den Kunst- und Musikverlag Simrock in Köln gewandt. - 1812 hatte Peter Joseph Simrock, ein Sohn von Nikolaus Simrock, eine dortige Niederlassung gegründet. - In diesem Brief berichtete Andreas Streicher eingehend vom schlechten Gesundheitszustand Beethovens, von dessen Wassersucht sowie der Erhärtung der Leber. Er drückte seine Hoffnungslosigkeit bezüglich einer Genesung aus. ${ }^{37}$ Somit war Simrock wahrscheinlich schon sehr früh darüber informiert, dass Beethoven im Frühjahr 1827 im Sterben lag. ${ }^{38}$

Am 9. Mai 1827 wurde seitens der Firma Streicher ein Schreiben an den Kunst- und Musikverleger Peter Joseph Simrock in Köln verfasst; darin wurde dieser auf den Verkauf von Beethovens musikalischem Nachlass aufmerksam gemacht, bei Interesse solle man sich zurückzumelden. ${ }^{39}$ Offensichtlich haben weder Simrock noch andere in Bonn, die früher vom Tod erfahren hatten, diese Information in der Stadt mit einem weiteren Kreis geteilt, noch hat jemand etwas für das ehrende Andenken getan. ${ }^{40}$ Wie erwähnt, erst das Bonner Wochenblatt mit seiner Ausgabe vom 3. Juni 1827 machte den Tod Beethovens den Bonnern bekannt. Danach entwickelte sich in der Musikszene der Stadt eine Initiative für eine Gedenkveranstaltung.

\section{Totenfeier für Beethoven in Bonn}

Breidenstein, der Musiklehrer der Universität, war, als der Tod Beethovens in Bonn allgemein bekannt wurde, nicht in der Stadt. Kurz zuvor hatte er sich, von seinen Diensten an der Universität beurlaubt, zu einem Forschungsaufenthalt nach Berlin aufgemacht. Noch im Dezember 1826 hatte er Beethoven zu dessen Geburtstag eines seiner Winterkonzerte mit der Bonner Erstaufführung der 4. Sinfonie des Komponisten gewidmet und in einer ausführlichen Vorbe- 
sprechung im Bonner Wochenblatt seine große Wertschätzung für diesen Komponisten der modernen Instrumentalmusik ausgedrückt. ${ }^{41}$ Hätte sich Breidenstein zu diesem Zeitpunkt in Bonn aufgehalten, so wäre sicherlich mitseinem Engagementzu rechnen gewesen.

Am 12. Juli 1827 luden der Musikalische Zirkel und die Junggesellen-Bruderschaft Mariae Reinigung über eine Anzeige im Bonner Wochenblatt "Freunde, Bekannte und Verehrer" des Verstorbenen für den folgenden Tag, um 10 Uhr, in die "Jesuitenkirche" ein, um ein Seelenamt für Beethoven zu feiern. Das Requiem von Mozart sollte in diesem Rahmen zur Aufführung gebracht werden. ${ }^{42}$ Veranstalter, Organisatoren bzw. Darbietende waren zum einen die JunggesellenBruderschaft Mariae Reinigung, im Jahr 1738 durch die Jesuiten für junge Handwerker und Künstler gegründet und im geistlichen Musikleben der Stadt Bonn aktiv, ${ }^{43}$ und zum anderen der Musikalische Zirkel, eine Gesell-

schaft musikinteressierter Bürger und vornehmlich Laien, die seit 1818/19 existierte. ${ }^{44}$ Peter Grabeler, als Komponist von Kirchen- aber auch von Karnevalsmusik bekannt, war an der Gründung des "Zirkels" beteiligt und dirigierte während der Gedenkveranstaltung. ${ }^{45}$

Veranstaltungsort war die Kirche der Junggesellen-Bruderschaft, die vormalige Jesuitenkirche in der Bonngasse - in der Nachbarschaft zu Beethovens Geburtshaus. ${ }^{46}$ In dieser Kirche hielt die Sodalität ihre kirchenmusikalischen Gottesdienste ab und hier ließ sie auch schon die Seelenämter für Pius VI. 1799 und Max Franz 1801 stattfinden. Für das Traueramt im Gedenken an den ehemaligen Landesherrn hatte man allerdings das "ganze Orchester von Cöln ... kommen lassen". Die Leitung oblag damals dem Kölner Domkapellmeister Mayer. In der Gestaltung der Gedenkfeier versuchte man, dem Sohn der Stadt gerecht zu werden und ihm ebenso aufwendig die Ehre zu erweisen wie zuvor dem Papst und dem ehemaligen Kurfürsten. ${ }^{47}$ Angesichts der Bonner Musikszene im Jahre 1827 war die Durchführung einer solchen Veranstaltung mit einigen Anstrengungen verbunden. Beethoven selbst hatte kein Requiem komponiert. In Bonn wählte man wie bei den Wiener Seelenämtern eine der bedeutendsten Requiemvertonungen aus der Zeit: das Requiem Mozarts (KV 626). Dieses Werk hatte sich mittlerweile als Standard etabliert. So wurde es auch im Zuge des Abschieds von Joseph Haydn 1809 gespielt. Zudem hatte sich Beethoven eingehend mit diesem Werk auseinandergesetzt, hatte einen starken Bezug dazu und bewunderte es. ${ }^{48}$

Peter Grabeler konnte seine Position im Bonner Musikleben in der Abwesenheit von Breidenstein weiter festigen. Nach der Gedenkfeier für Beethoven
Einladung zur Totenfeier in der früheren Jesuitenkirche (Ausschnitt). Bonner

Wochenblatt, 12. Juli 1827

(Stadtarchiv Bonn) 
Gymnasialkirche, vormalige Jesuitenkirche in der Bonngasse. Stahlstich von Ernst Grünewald nach Bernhard Hundeshagen, um 1830 (Stadtarchiv Bonn)

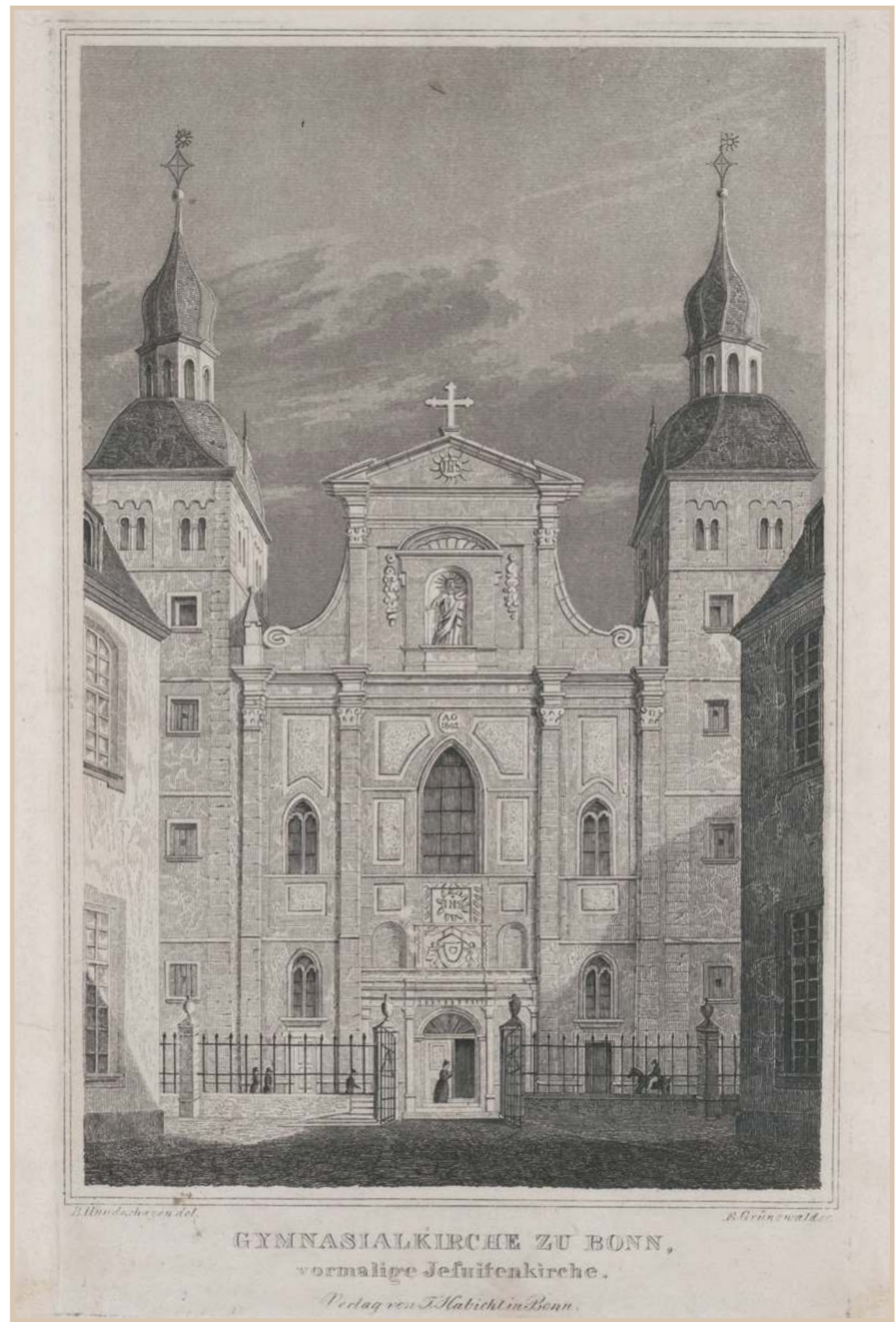

526 | Yvonne Leiverkus

(C) 2020 by Böhlau Verlag GmbH \& Cie. KG, Köln

https://doi.org/10.7788/9783412519704 | CC BY-NC 4.0 
gründete sich der Kirchenmusikverein in Bonn; gemeinsam mit Grabeler nahm man sich der C-Dur-Messe von Beethoven an und brachte diese am 2. Februar 1828 zum Titularfest der Junggesellen-Bruderschaft, wiederum in der "Jesuitenkirche", zur Aufführung. ${ }^{49}$

\section{Ein Denkmal als ehrendes Andenken}

Beethoven wurde und sollte auch nicht in den folgenden Jahren in Bonn vergessen werden. ${ }^{50}$ In Bonn war man davon überzeugt, dass ein Denkmal dem großen Sohn der Stadt und seinem musikalischen Werk ein angemessenes Andenken bereiten würde.

In Deutschland wurden gegen Ende des 18. Jahrhunderts Denkmäler für Dichter und andere ehrwürdige Männer in Parkanlagen - privat und öffentlich - errichtet. In England geschah dies bereits etwas früher, in der ersten Hälfte des 18. Jahrhunderts. Das Denkmal hatte dabei nicht nur den Zweck des Erinnerns und des Ehrens, sondern sollte ebenso auf den Betrachter einwirken: „aufklärerisches Ideengut von der Erziehbarkeit des Menschen" wird hier feststellbar. Die Zahl der Denkmäler im öffentlichen aber auch privaten Raum stieg im Lauf des 19. Jahrhunderts stark an. ${ }^{51}$ Nach 1835 entstanden an zentralen und öffentlichen Plätzen nach und nach Standbilder dieser Art - so für Justus Möser 1836 in Osnabrück, für Johannes Gutenberg 1837 in Mainz, 1839 für Friedrich Schiller in Stuttgart oder für Albrecht Dürer 1840 in Nürnberg jedoch alle außerhalb von Preußen. "Auf preußischem Territorium sollte Hähnels Beethoven-Denkmal das erste sein, das einem ,Großen des Geistes' nach dem Luther-Denkmal von 1821 auf einem öffentlichen Platz errichtet wurde; als bürgerlicher Zeitgenosse und Zivilist stand Beethoven sogar im Preußen der Jahrhundertmitte allein auf seinem Sockel." 52

So gehört das Projekt zur Aufstellung eines Denkmals für Beethoven in seiner Geburtsstadt zu den frühen Unternehmungen dieser Art. Die Idee für ein Denkmal in Bonn ist erstmals für das Jahr 1832 dokumentiert. Am 5. Juli 1832 erschien ein Artikel im Bonner Wochenblatt, in dem darauf hingewiesen wurde, dass

„bedeutende Männer des deutschen Vaterlandes ... öffentliche Denkmale ihres Namens und ihrer Verdienste erhalten. ... Auch in unseren Mauern ist, wie bekannt, ein Mann geboren, unsterblichen Andenkens. Zwar hat er sich selbst ein Denkmal gesetzt in den Herzen aller fühlenden Deutschen, sollte es aber nicht passend sein, daß auch er in seiner Vaterstadt, in der er ja auch einen Teil deiner Bildung erhielt, ein öffentlich ehrendes Denkmal erhalten, seinen speciellen Landsleuten, so wie den Deutschen anderer Provinzen zur Freude und Nacheiferung." ${ }^{\prime 5}$

Heinrich Karl Breidenstein, der Musikdirektor der Bonner Universität und spätere Präsident des Denkmalkomitees, gab zwar rückblickend an, bereits 1828 die Idee für ein Denkmal gehabt zu haben. ${ }^{54}$ Dies ist jedoch nicht beleg- 
bar, so dass man sagen kann, dass nicht der Tod Beethovens im Jahr 1827 unmittelbar zu der Initiative zur Errichtung eines Denkmals geführt hatte.

Obwohl Beethoven Bonn schon 1792 verlassen hatte, war er in seiner Heimatstadt trotzdem präsent. ${ }^{55}$ Bereits im Jahr 1808 - noch zu Lebzeiten Beethovens - stellten der Kanonikus Franz Pick und der Maire Belderbusch Überlegungen an, die Martinskirche als "Pantheon verdienter Bonner Bürger" herzurichten. Auch Beethoven sollte im Falle einer Umsetzung geehrt werden. ${ }^{56}$

Im Juni 1835 schlossen sich Bonner Musikfreunde und Honoratioren zum Bonner Verein für Beethovens Monument zusammen. Dem engeren Kreis dieses Vereins, dem Komitee, gehörten u. a. August Wilhelm von Schlegel, Heinrich Karl Breidenstein und Johann Jakob Noeggerath an. ${ }^{57}$ Am 17. Dezember 1835, dem 65. Tauftag Beethovens, startete das Komitee den "Aufruf an die Verehrer Beethovens", an Persönlichkeiten aus dem Musik- und Theaterleben, an Musikfreunde, an Musikvereine, der zu Spenden animieren sollte. Unter seinem Präsidenten Schlegel stellte der Verein folgendes fest:

"Zu allen Zeiten hat man es für eine heilige Pflicht gehalten, grosse Männer durch die Errichtung würdiger und lange dauernder Denkmale zu ehren, und so den Dank und die Bewunderung ihrer Zeitgenossen auch auf die nachkommenden Geschlechter zu vererben. ... Eine so äußerst seltene, wohlthätige und weithin wirkende Erscheinung verdient es, auf eine seltene und außerordentliche Weise gefeiert zu werden, nämlich durch ein plastisches, möglichst großartiges Monument." ${ }^{158}$

Dem Aufruf ist zu entnehmen, dass der Verein demnach in der Darstellung die individuelle Erscheinung Beethovens für das Denkmal anstrebte. Die Formulierung großartig deutet auf ein Standbild der gesamten Person hin. Die Vorstellung von einem Denkmal in dieser Art war für das Jahr 1835 etwas Besonderes, denn die figürliche Darstellung setzte erst danach verstärkt ein. ${ }^{59}$ Im Aufruf wurde lediglich die Stadt Bonn als Aufstellungsort festgelegt; konkreter ging der Verein nicht darauf ein. Für Bonn spreche, dass sie die Geburtsstadt sei, eine vorteilhafte Lage und viele auswärtige Besucher zu verzeichnen habe. Die Frage des genauen Aufstellungsortes in der Stadt war keine einfache. Im Jahr 1835 gab es in Preußen lediglich ein entsprechendes Denkmal auf einem öffentlichen Platz: das Luther-Denkmal auf dem Wittenberger Marktplatz. Diesen Standort hatte Friedrich Wilhelm III. ausnahmsweise gewählt, um das Verdienst Luthers um die Reformation zu würdigen. ${ }^{60}$ In der Lage Denkmäler zu errichten waren diejenigen, die über das Recht und die Mittel verfügten, die Obrigkeit, der Souverän. Dieses von Bürgern getragene Projekt zur Errichtung des Denkmals trug zur bürgerlichen und auch städtischen Profilierung und Selbstvergewisserung bei. ${ }^{61}$

Die Art der Ehrung wurde über Bonn hinaus diskutiert, Robert Schumann beteiligte sich, ebenso Wilhelm Speyer, Hofkapellmeister und General- 
musikdirektor in Kassel, der der Ansicht war, dass ein herkömmliches Denkmal dem Wesen und der Bedeutung Beethovens nicht gerecht würde, er schlug ein Denkmal auf dem Siebengebirge vor. Die Umsetzung eines solchen Vorhabens sprengte jedoch den Rahmen der Möglichkeiten des Vereins. ${ }^{62}$ Als Präsident des Vereins und im Bereich der künstlerischen Ausgestaltung eines solchen Projektes durchaus fachkundig nahm sich Schlegel den weiteren Fragen der Umsetzung, der Auswahl eines entwerfenden Bildhauers sowie der Bestimmung eines Standortes in der Stadt an. Schlegel hatte die Idee, dass die Bildhauer Friedrich Tieck, Christian Daniel Rauch und der Baumeister Karl Friedrich Schinkel, alle Vertreter der Berliner Bildhauerschule, sich gemeinsam der Sache annehmen und Vorschläge machen sollten. Ein Bildhauer aus der Region, dem Rheinland kam in den Überlegungen Schlegels nicht vor. Die Ausführung sah Schlegel bei Tieck; im Sommer 1836 nahm er Kontakt auf. Was den Standort des Denkmals anbelangte - Schlegel favorisierte den Münsterplatz -, zweifelte Schinkel daran, dass der preußische König einen öffentlichen Platz genehmigen würde. Daher war sein Vorschlag der Kreuzgang des Münsters, mit dem sich auch Schlegel anfreunden konnte. ${ }^{63}$ Aufgrund der Tatsache, dass das Zusammentragen der notwendigen finanziellen Mittel schleppend verlief - 1837, also zwei Jahre nach dem ersten Aufruf des Vereins, war erst etwa die Hälfte der benötigten Summe zusammengekommen ${ }^{64}$ - und weil darüber hinaus 1838 immer noch keine königliche Genehmigung vorhanden oder der Standort des Denkmals geklärt war, verlor das Projekt an Dynamik. Das Bonner Wochenblatt hält am 9. Februar 1838 fest: „Beethovens Monument, einst die Unterhaltung des Tages, scheint nunmehr ganz zu ruhen." 65 So gab Schlegel das Amt des Präsidenten des Denkmalkomitees an Breidenstein weiter. ${ }^{66}$

Der zweite Spendenaufruf Ende 1838 war erfolgreicher. Franz Liszt, ein Bewunderer des Werks Beethovens, dessen Bedeutung er für Musiker "ähnlich der Wolken- und Feuersäule, die die Israeliten durch die Wüste führte", beschrieb, sicherte durch seine Beteiligung die Finanzierung. ${ }^{67}$ Das Komitee einigte sich mit Liszt: Der Komponist spendete den für das Denkmal fehlenden Betrag, der Auswahl des ausführenden Künstlers sollte ein Wettbewerb vorangestellt werden, dem auch der preußische König positiv gegenüberstand. Im Oktober 1840 erfolgte dann die "Aufforderung an die plastischen Künstler zur Einsendung von Skizzen und Modellen zu Beethovens Denkmal". ${ }^{68}$ Unterdessen war erneut der Standort Gegenstand der Diskussionen. Friedrich Wilhelm III. erachtete den Münsterplatz als ungeeignet. Weitere Standorte wurden öffentlich im Bonner Wochenblatt und auch in der Kölnischen Zeitung diskutiert: u.a. der Hofgarten, der Stiftsplatz, der Wilhelmsplatz, der Römerplatz (heute Remigiusplatz), der Vierecksplatz und der Marktplatz. Letztendlich war man sich darüber einig, dass der Münsterplatz, der Hofgarten oder der Stiftsplatz in Frage kamen. ${ }^{69}$ Die Generalversammlung kam zu dem Schluss, dass der Münsterplatz der angemessenste Standort sei, denn er war zentral gelegen 
und viel besucht, bot "herrliche Hintergründe": Bäume, die Münsterkirche als Hauptkirche Bonns, das Fürstenbergische Palais, darüber hinaus befand sich dort die Post, hier war die Station der Schnellwagen, wo Reisende ankamen. ${ }^{70}$ Zur Sicherheit gab man in der erneuten Anfrage der königlichen Genehmigung noch den Platz vor dem Koblenzer Tor an. Am 10. Mai 1843 genehmigte Friedrich Wilhelm IV. letztendlich den Münsterplatz als Standort. ${ }^{71}$

Bei der Auswahl des Siegerentwurfs ließ sich das Denkmalkomitee von sachkundigen Beratern unterstützen: so von Wilhelm von Schadow, Carl Ferdinand Sohn, Theodor Hildebrandt, Friedrich Gottlieb Welcker, Johann Claudius von Lassaulx und Matthias Joseph de Noël. Gottfried Kinkel stellte fest, dass sich kein Künstler der ersten Reihe an dem Wettbewerb beteiligt habe: Ernst Julius Hähnel, Gustav Hermann Bläser, Johann Friedrich Drake, Hermann Knaur, Hermann Rudolf Heidel, Eduard Schmidt von der Launitz, Emil Cauer d. Ä. Nach seinem Dafürhalten war dies auf den Umstand zurückzuführen, dass zum Zeitpunkt der Ausschreibung des Wettbewerbs die Zusammensetzung der ausschlaggebenden Jury nicht bekannt war. ${ }^{72}$ Gewinner des Wettbewerbs waren Hähnel und Bläser, die auch Kinkel favorisierte. Die Höhe der Kostenvoranschläge machten eine Beauftragung jedoch unrealistisch. ${ }^{73}$ Letztendlich erklärte sich Hähnel 1842 bereit - in der Zwischenzeit sollte der Münchner Bildhauer Schwanthaler mit der Ausführung beauftragt werden das Denkmal zu der vom Denkmalkomitee veranschlagten Summe zu schaffen. ${ }^{74}$ Die Teilnehmer des Wettbewerbs vertraten die bedeutendsten Bildhauerschulen in Deutschland: Bläser, Cauer und Drake waren Schüler von Rauch in Berlin, Heidel lernte bei Schwanthaler in München, der RietschelSchüler Knaur und Hähnel kamen aus Dresden sowie Launitz als Schüler Thorvaldsens in Rom. Schaal widerspricht dem Urteil Kinkels über die Bedeutung der Wettbewerber und bescheinigt diesen herausragende Plätze in der Bildhauerei. Insbesondere Drake und Bläser hebt sie in deren Stellung in der Berliner Bildhauerschule hervor, ebenso wie Hähnel als Mitbegründer der Dresdner Bildhauerschule. ${ }^{75}$ Der Grund dafür, dass nicht Schadow, Thorvaldsen, Rietschel oder Schwanthaler Interesse am Wettbewerb zeigten, ist vielmehr in der mangelnden Bedeutung Bonns zu sehen, der Stadt, die 1814 mit der Rheinprovinz an Preußen übergegangen war. Ein Denkmalprojekt in dieser Stadt war eben weniger prestigeträchtig als jenes in Wittenberg (Luther-Denkmal von Schadow 1821) oder Frankfurt am Main (GoetheDenkmal vom Schwanthaler 1844). ${ }^{76}$

Am 23. Februar 1842 erfolgt die Vertragsunterzeichnung mit Hähnel in den Räumen der Bonner Lese- und Erholungsgesellschaft. Die Ausführung sollte der Nürnberger Bildhauer und Erzgießer Jacob Daniel Burgschmiet übernehmen. Kritik an der Wahl Hähnels und der Nichtberücksichtigung des Rheinländers Bläser prallte an den Bonner Akteuren ab. ${ }^{77}$ Aus Bonner Sicht kann die Vertragsgestaltung als äußerst vorteilhaft bezeichnet werden: 
„Der Kontrakt war besiegelt, und Hähnel hatte sich den Auftrag für ein erstes freiplastisches Denkmal erkämpft. Einige Bedingungen, in die er sich fügen mußte, erscheinen aus heutiger Sicht überzogen, denn außer der Anfertigung der Gußmodelle für Statue und Reliefs hatte er auch noch für den steinernen Sockel und das Fundament zu sorgen, den Guß nebst Ziselieren und Polieren zu planen, den Transport zu organisieren und dessen Risiko zu tragen, die Aufstellung der Gußteile in Bonn vornehmen zu lassen, alle Reisen für sich und die Handwerker zu finanzieren und zwischenzeitlich noch drei Gutachten über die Qualität seiner Arbeit zu bestehen."78

Bei der Verhandlung über die Modalitäten und den Zeitplan der Ausführung wurde Hähnel vom Komitee und von Breidenstein unter Druck gesetzt, die Bonner Vorgaben zu akzeptieren. Ursprünglich sollte die Enthüllung im August 1843 stattfinden. ${ }^{79}$

In Bonn wartete man ungeduldig auf die sich verzögernde Fertigstellung des Denkmals. Ursächlich für die Verzögerungen waren letztendlich die unrealistischen Vertragsbedingungen, der Zeitplan, die Kostenschätzung, die das Denkmalkomitee Hähnel auferlegt hatte, der wiederum unbedingt diesen Auftrag ausführen wollte, um sich als Künstler zu etablieren. ${ }^{80}$

Am 10. Juli 1845 konnte die Grundsteinlegung stattfinden: Eine Bleikassette mit Partituren der Missa solemnis und der 9. Sinfonie wurde im Fundament deponiert - auf Initiative des Musikverlages Schott aus Mainz und im Beisein des Komitees. ${ }^{81}$

Der Transport der Beethovenstatue, der Reliefs und des Postamentes per Schiff durch den "Ludwigskanal nach Bamberg und den Main und Rhein glich einem Triumphzug. In Bamberg, Schweinfurt und allen größeren Städten flußabwärts wurde das Schiff mit Böllerschüssen, Flaggenschmuck und Chorliedern gegrüßt." ${ }^{22}$ Breidenstein hielt die Ankunft des Schiffes am 23. Juli in Bonn in seiner Festgabe fest. Es

„wurde auf das Feierlichste empfangen. Ein Theil des Festkomités war ihm bis Königswinter entgegen gefahren, und brachte es gegen Abend auf einem mit bunten Flaggen und grünen Zweigen geschmückten Schiffe, begleitet von mehreren mit Sänger- und Musikchören gefüllten Nachen, unter anhaltenden Geschützessalven an das Ufer von Bonn. Hier wurde es auf einem mit Guirlanden und Kränzen gezierten Wagen geladen und, nachdem ich einige Worte zur Begrüssung desselben gesprochen, in Begleitung eines ausgedehnten, aus Bürgern und Studirenden gebildeten Fackelzuges, bei festlicher Beleuchtung der Stadt an den Ort ihrer Bestimmung gebracht.".83

Am 11. August sollte nun das Denkmal im Rahmen eines drei Tage andauernden Musikfestes enthüllt und eingeweiht werden. Da sich Friedrich Wilhelm IV. entschied, mit seinen Gästen, Königin Viktoria von Großbritannien und 
Künstlerkonzert in der Festhalle am 13. August 1845. Holzstich (Stadtarchiv Bonn)

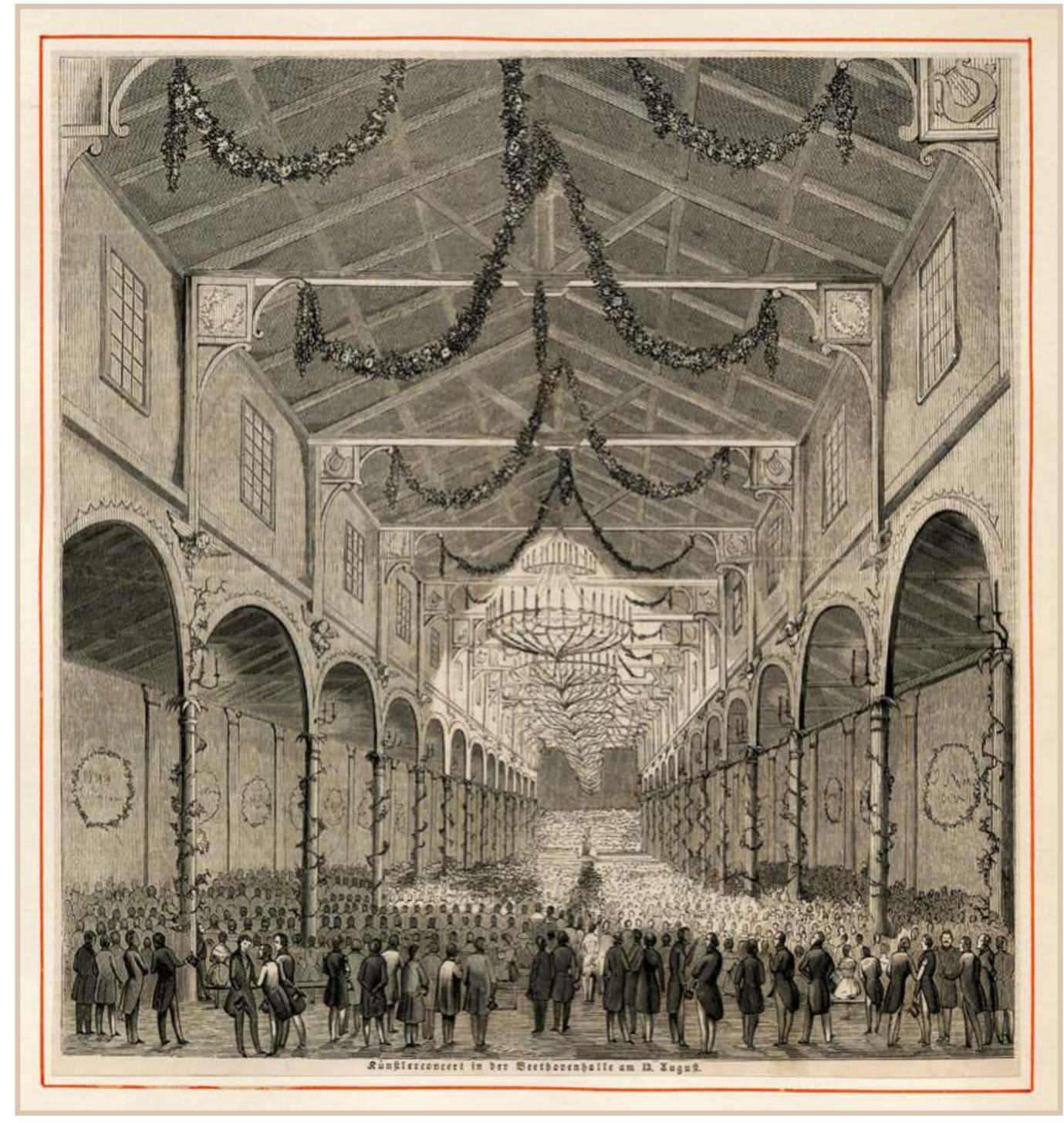

Prinzgemahl Albert, an der Einweihung teilzunehmen, wurde der Termin auf den 12. August gelegt. ${ }^{84}$ Seit Juni bestand ein eigenes Festkomitee, überwiegend mit den Mitgliedern des Denkmalkomitees besetzt, dessen Aufgabe die Organisation war. Franz Liszt besorgte die musikalische Planung ${ }^{85}$ und veranlasste in Ermangelung einer entsprechenden Konzerthalle den Bau einer neuen Halle auf seine Kosten. ${ }^{86}$ Ursprünglich hatten die Organisatoren die akademische Reitbahn - damals von der Universitätsbibliothek genutzt - mit eigens gebauten Tribünen, Logen, Podien und Bänken und dann auch die Militärreitbahn als Konzertlokal vorgesehen. Liszt zweifelte jedoch daran, dass die Reitbahn aufgrund akustischer und auch optischer Mängel der geeignete Veranstaltungsort wäre. ${ }^{87}$ Er setzte den Bau einer dem Anlass und dem Werk

532 | Yvonne Leiverkus

(c) 2020 by Böhlau Verlag GmbH \& Cie. KG, Köln

https://doi.org/10.7788/9783412519704 | CC BY-NC 4.0 


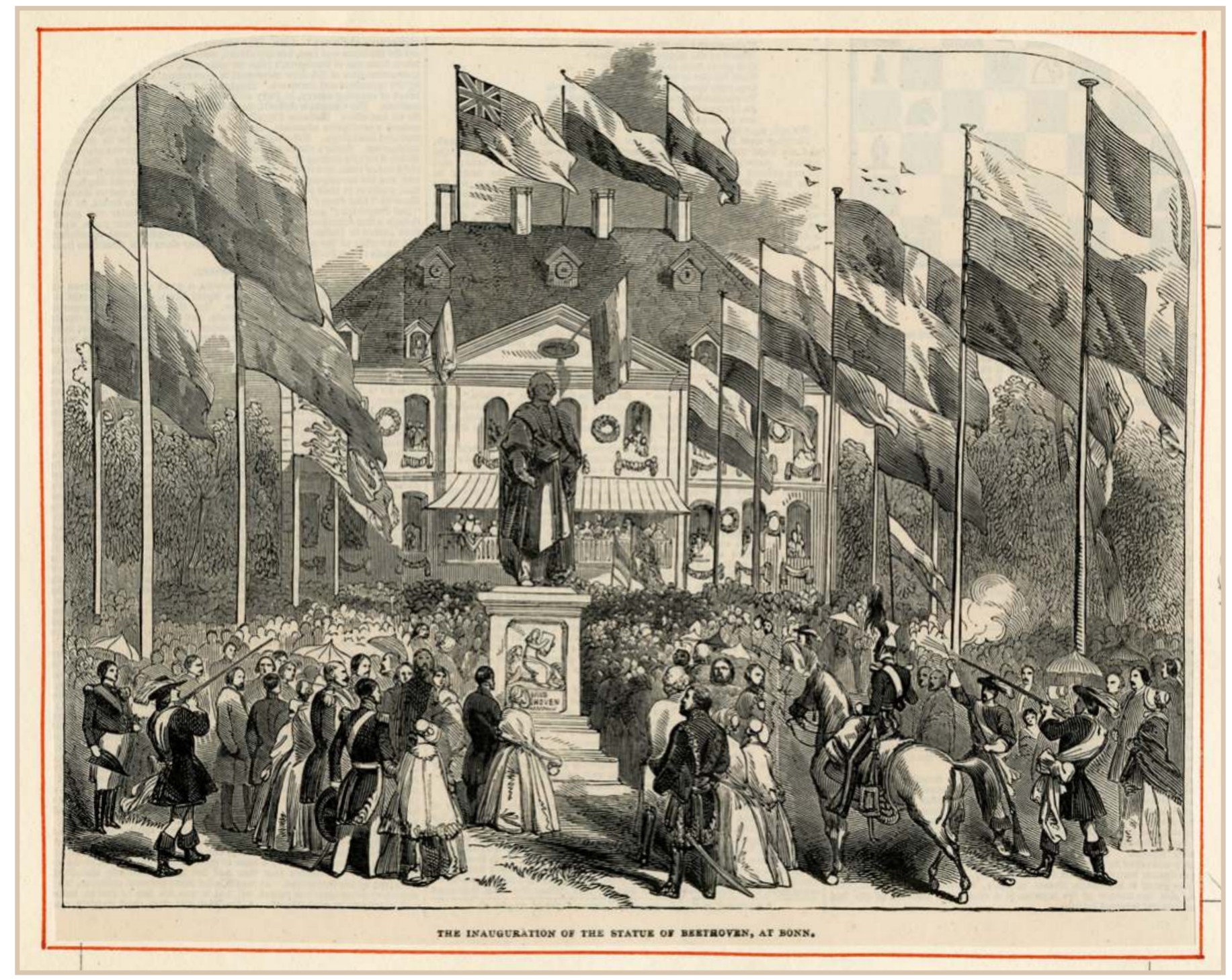

Beethovens angemessenen Halle durch. So erhielt der Kölner Dombaumeister Ernst Friedrich Zwirner den Auftrag für einen Neubau. Zwei Wochen blieben für die Errichtung eines Konzerthauses mit ausreichend Platz für den Festspielchor und das -orchester sowie für 2000 Besucher. ${ }^{88}$ Baubeginn war der 27. Juli 1845, Standort der Halle der Räss'sche Garten neben dem Franziskanerkloster in unmittelbarer Nähe zur Universitätsbibliothek. 14 Bonner Handwerkermeister und 95 Schreiner, Zimmerleute und Dekorateure machten sich ans Werk. Das Projekt gelang. Bereits zwölf Tage nach Baubeginn konnten die letzten Proben vor den Feierlichkeiten stattfinden. ${ }^{89}$ Die Beethovenhalle des Jahres 1845 wurde vollständig aus Holz gebaut. Sie hatte die Form einer Basilika und bestand aus einer Haupthalle, zwei Nebenhallen sowie Restau-
Enthüllung des Beethovendenkmals auf dem Münsterplatz 12. August 1845. Holzstich (Stadtarchiv Bonn) 
rations- und andere -säle. Aufgemalte Friese, efeuumrankte Säulen und Kapitellschmuck waren ihr Dekor. An den Wänden der Seitenhallen waren die Namen der Hauptwerke Beethovens eingefasst in Laubkränze angebracht. Der Name des Komponisten selbst erschien umgeben von zwei Genien in einem Palmenkranz. ${ }^{90}$ Nicht nur Franz Liszt, auch weitere große Persönlichkeiten der internationalen Musikwelt kamen nach Bonn, um an der feierlichen Enthüllung teilzunehmen, unter ihnen Giacomo Meyerbeer, Ignaz Moscheles, Friedrich Burgmüller, George Smart und Hector Berlioz. ${ }^{91}$

Das preußische Königspaar, Friedrich Wilhelm IV. und Elisabeth, sowie die englische Königin Viktoria und Prinzgemahl Albert wohnten der Enthüllung bei. ${ }^{92}$ Ein großes Ereignis für die Stadt Bonn, bei dem die Bonner nicht nur Zuschauer waren, sondern auch die Feierlichkeiten für sich zu nutzen wussten: Das Verlagshaus Simrock brachte eine neue Ausgabe mit Werken für Klavier von Beethoven heraus. Besucher konnten den Bücher- und Musikalienschrank des Komponisten im Haus der Rheingasse Nr. 934 (heute 24) - hier lebte Beethoven einige Jahre als Kind und Jugendlicher - bewundern oder Beethovens erstes Klavier gegen die Zahlung eines Silbergroschen in Augenschein nehmen. ${ }^{93}$ Gegenüber dem Geburtshaus wurden BeethovenZigarren zum Verkauf angeboten. Ein Anzugstoff mit Streifen und Punkten, die an Notenlinien und Noten erinnerten, konnte ebenfalls erworben werden. ${ }^{94}$ Das musikalische Programm des Festes wurde von Werken Beethovens bestimmt. Es stellte Musik vor, die die meisten Bonner noch nie gehört hatten. So wurden unter Leitung von Ludwig Spohr am 10. August die Missa solemnis und die 9. Sinfonie gegeben, am 12. August leitete Breidenstein in der Münsterkirche die Aufführung der Messe in C-Dur während des Hochamtes, am selben Tag abends fand ein weiteres großes Konzert mit Werken Beethovens unter der Leitung Liszts statt. Am Tag nach der Enthüllung gaben die anwesenden Künstler ein Konzert, das mit Beethovens Egmont-Ouvertüre endete. ${ }^{95}$ Trotz ihrer hochgelobten Akustik wurde diese erste Bonner Beethovenhalle bereits nach zwei Monaten wieder abgerissen; von dem Holzbau ging eine zu große Brandgefahr aus. ${ }^{96}$

Das Denkmal, Beethoven als überlebensgroße Figur, sowie die Reliefs des Postamentes kamen bei den Zeitgenossen gut an. Die Figur befindet sich im Schrittstand. Breidenstein verstand dies als Darstellung der fortschrittlichen Haltung Beethovens. Hähnel mochte dieser Interpretation nicht zustimmen. Die Reliefs, die allegorischen Darstellungen der geistlichen, der dramatischen Musik, der Sinfonie und der Fantasie, hielten die Facetten von Beethovens Musik fest und würdigten diese. Hähnel schuf die Figur als

„majestätische, ehrfurchtgebietende Erscheinung. Nicht das 22jährige Bonner Wunderkind, das nach Wien auswandert, nicht der melancholisch sinnende jugendliche Beethoven des Wiener Denkmals, der zeusgleiche Heros Klingers oder der Titan Peter Breuers, sondern der sich seiner 
Berühmtheit bewußte Meister in seinen letzten Lebensjahren tritt würdevoll vor uns." ${ }^{\prime 97}$

Insgesamt kann das Ereignis, die Aufstellung des Denkmals und das erste Beethovenfest, als Erfolg gewertet werden. Dies wurde auch allgemein anerkannt. Jedoch musste das Komitee und vor allem der Präsident des Vereins auch Kritik hinnehmen: Unerfahrenheit, mangelnde musikalische Kenntnis lauten die Vorwürfe. Darüber hinaus wurde eine Überforderung angesichts der Bedeutung und des Umfanges der Festlichkeiten festgestellt, Gäste wie Künstler wurden nicht wertschätzend und angemessen behandelt. Mangelnde Großzügigkeit, Kleinkariertheit waren nicht nur während des Festes von Teilnehmern bemerkt worden. Es fehlte auch an Wertschätzung im Verhalten des Komitees gegenüber Hähnel, Burgschmiet und Liszt, die gut gearbeitet hatten, sich zum Teil über die Maßen finanziell eingesetzt hatten, dafür jedoch keinen angemessenen Dank erhielten bzw. das ihnen noch zustehende Geld einfordern mussten. ${ }^{98}$ Hähnel mied in der Zukunft Bonn, "um nur seinen Beethoven nicht wiedersehen zu müssen." 99 Eine Ehrenbürgerschaft wie für Schwanthaler in Salzburg als Dank für das Mozart-Denkmal war in Bonn nicht vorgesehen. Die Stadt Bonn machte jedoch Liszt in Anerkennung seiner groBen Verdienste ein Grundstück in der Stadt zum Geschenk - wohl in der Hoffnung er würde sich in Bonn niederlassen. Eine Straße sollte zudem nach ihm benannt werden; dies lehnte Liszt ab. Den künstlerischen Leiter des ersten Beethovenfestes band man dann auch nicht mehr in die Ausführung des zweiten Beethovenfestes zum 100. Geburtstag Beethovens ein. ${ }^{100}$

In der Betrachtung der Reaktion auf den Tod Beethovens in Bonn bleibt die Frage offen, warum die Nachricht erst Anfang Juni in Bonn über die Presse Verbreitung fand. Zumindest Simrock war wohl informiert, unternommen hat er allerdings wohl nichts, so dass man von einer verzögerten Reaktion sprechen kann. Die im Bonner Stadtarchiv überlieferten Quellen erwecken nicht den Eindruck, dass sich die Bonner Stadtgesellschaft im besonderen Maße mit dem Tod des großen Sohnes der Stadt beschäftigte. In Tagebüchern und Briefen der zum Teil umfänglichen Nachlässe findet man jedenfalls keine Hinweise: so weder in der Korrespondenz des Nikolaus Simrock mit seinen Söhnen Peter Joseph und Karl, noch in Zeugnissen von Gottfried und Johanna Kinkel, ebenso wenig in den Unterlagen der Familien Hauptmann, Kaufmann, Bleibtreu, Pfingsten und Brandis. Gleiches gilt für die reiche Überlieferung der Briefe Ernst Moritz Arndts. Auch die Unterlagen der Lese- und Erholungsgesellschaft oder die überlieferten städtischen Quellen helfen hier nicht weiter. ${ }^{101}$ Als ein breiter Kreis in Bonn Bescheid wusste, reagierten maßgebliche Vertreter des bürgerlichen Bonner Musiklebens.

Wenngleich die Gedenkfeier nach Bekanntwerden des Todes in Bonn bescheiden im Vergleich zum Wiener Begräbnis ${ }^{102}$ oder anderen Gedenkveranstaltungen ausfiel, so hat man doch in Bonn die zur Verfügung stehenden 
Kapazitäten und Mittel ausgeschöpft. Die Reaktion in Bonn auf den Tod Beethovens, das Denkmal, das man ihm Jahre später setzte samt begleitendem Fest zeugt von der Gewissheit um die Bedeutung des Sohnes der Stadt, von dem Anspruch dieser zu genügen. Dabei übertraf man in Bonn die Erwartungen - auch die eigenen - und wuchs in der mittelgroßen Stadt der rheinischen Provinz Preußens über sich hinaus. In seinem Artikel im Bonner Wochenblatt aus dem Jahr 1832 appellierte Andreas Dederich an die Bonner Bürger sich zu engagieren. 1845 wurde dieses überragende Engagement sichtbar. Das Beethoven-Fest wurde "trotz aller Querelen zu einem Pilgerziel der Beethoven-Verehrer, ja geradezu zu einer Art ,Woodstock' des Vormärz." Keine andere Veranstaltung zu Ehren und zum Gedenken an Beethoven nach den Begräbnisfeierlichkeiten in Wien hatte die Qualität und Bedeutung des ersten Bonner Beethoven-Festes. ${ }^{103}$

Es bleibt offensichtlich, dass

„diese großartige Huldigung Beethovens in seiner Geburtsstadt nicht nur einen lokalen oder nationalen, sondern internationalen Charakter trug, daß sie auf dieser Grundlage zum erstenmal vor der Weltöffentlichkeit Beethovens überragende Bedeutung sichtbar machte, .... Gewiß ist auch, daß die Beethovenfeier von 1845 das bedeutendste musikalische Ereignis ist, das je in Bonn stattgefunden hat. Es wurde von keinem späteren überboten und hat Bonns Rang, Anspruch und Verpflichtung als Musikstadt ... für alle Zukunft unwiderruflich festgelegt." ${ }^{104}$

Doch dem Erfolg des Jahres 1845 folgten zunächst keine weiteren von Dauer geprägten Initiativen. Am 3. August 1845 warben „Bonner Musikfreunde” in der Kölnischen Zeitung für die Gründung einer Beethoven-Stiftung und für den Erwerb des Nachlasses des Komponisten. ${ }^{105}$ Doch erst 1889 erfolgte die Gründung des Vereins Beethoven-Haus, der mit dem Aufbau einer Sammlung zu Beethoven begann und das Geburtshaus vor dem Abriss bewahrte.

\footnotetext{
DieTRICH HÖROLDT, Bonn 1794-1989. Ein Resümee, in: DERS. (Hg.), Von einer französischen Bezirksstadt zur Bundeshauptstadt 1794-1989 (Geschichte der Stadt Bonn 4), Bonn 1989, S. 745-758, hier S. 747

Vgl. ebd. Vgl. für die Entwicklung der folgenden Jahre: DIETRICH HÖROLDT, Bonn im Vormärz und in der Revolution, in: DERS. (Hg.), Bezirksstadt (wie Anm. 1), S. 73-186. Vgl. HöroldT, Resümee (wie Anm. 1), S. 748.

Ebd., S. 749 .

Vgl. Karl Gutzmer, Chronik der Stadt Bonn, Dortmund, S. 100; Josef Kolvenbach, Bonn 1814-1848. Verwaltung, Verfassung und Verhältnis zum preußischen Staat, in: Bonner Geschichtsblätter 8, 1954, S. 5-91, hier S. 33f.

Vgl. Höroldt, Resümee (wie Anm. 1), S. 749.
} 
Vgl. DiETRICH HÖROLDT, Sozialstruktur der Stadt Bonn vom ausgehenden 18. bis in die Mitte des 19. Jahrhunderts, in: Edith Ennen und Dietrich HÖROldT (Hgg.), Aus Geschichte und Volkskunde von Stadt und Raum Bonn. Festschrift Josef Dietz zum 80. Geburtstag am 8. April 1973 (Veröffentlichungen des Stadtarchivs Bonn 10), Bonn 1973, S. 282-331, hier S. 290. Um 1790 sah die berufliche Zugehörigkeit der Bonner folgendermaßen aus: Die Hälfte war im gewerblichen Bereich tätig, bei einem Drittel handelte es sich um Dienstboten, ein Fünftel war im „Öffentlichen Dienst” oder freiberuflich zu verorten, im landwirtschaftlichen Bereich waren es gut drei Prozent. Im Jahr 1828 (1825) lag die Einwohnerzahl bei 11.526, davon 52 Professoren (Sackkalender 1825), 49 Lehrer (Stadtarchiv Bonn [StAB], Pr 356), "Öffentlicher Dienst"/Freiberufler 95 (1825), Gewerbe, Industrie, Handwerk, Handel und Verkehr 1.411 (1825) und 1.633 (1828), Dienstboten 811 (1825) und 1.228 (1828). Vgl. Ebd., S. 284 und Anm. 8. Vgl. Gutzmer, Chronik (wie Anm. 5), S. 102

1828 verbot König Friedrich Wilhelm III. Karnevalsfeiern; 1842 wurde das Verbot durch Friedrich Wilhelm IV. aufgehoben. Vgl. GutzMER, Chronik (wie Anm. 5), S. 102.

HöroldT, Resümee (wie Anm. 1), S. 749

DerS., Bonn im Vormärz (wie Anm. 2), S. 177; DerS., Resümee (wie Anm. 1), S. 750.

GeBHARD AdERS, Bonner Stadtverwaltung 1814-1914, in: ENnEN/HÖROLDT, Aus Geschichte (wie Anm. 7), S. 380-417, hier S. 380; KolvenBACH, Bonn 1814-1848 (wie Anm. 5), S. 5-91.

ADERS, Bonner Stadtverwaltung (wie Anm. 12), S. 381; HöROLDT, Bonn im Vormärz (wie Anm. 2), S. 89-92.

Vgl. Aders, Bonner Stadtverwaltung (wie Anm. 12), S. 382

Vgl. ebd., S. 389

Vgl. ebd., S. 393

Vgl. ebd., S. 385

Vgl. zum Musikleben in Bonn zur Zeit der Herrschaft des Kurfürsten Max Franz: Max BRAUBACH, Kurköln. Gestalten und Ereignisse aus zwei Jahrhunderten rheinischer Geschichte, Münster 1949, S. 453-485; LUDWIG SCHIEDERMAIR, Der junge Beethoven, Leipzig 1925, S. 38-90; CLaudia VAlDER-KNeChtges, Die Musikgeschichte, in: Dietrich HÖROLDT (Hg.), Bonn als kurkölnische Haupt- und Residenzstadt 1597-1794 (Geschichte der Stadt Bonn 3), Bonn 1989, S. 449-514.

Vgl. Michael Ladenburger, Musik zu Beethovens Begräbnis. Musik zu seinem Gedenken, in: Ders. und Silke Bettermann (Hgg.), Drei Begräbnisse und ein Todesfall. Beethovens Ende und die Erinnerungskultur seiner Zeit (Veröffentlichungen des Beethoven-Hauses, Ausstellungskataloge, 12), Bonn 2002, S. 69-80, hier S. 77; MICHAEL LADENBURGER, Als das "neue Bonn" sich bewährte oder: Das Musikfest zwischen den Fronten. Das Beethoven-Fest 1845 im Kontext der Bonner Musikgeschichte, in: INGRID BoDsCH (Hg.), Monument für Beethoven. Zur Geschichte des Beethoven-Denkmals (1845) und der frühen Beethoven-Rezeption in Bonn. Katalog zur Ausstellung des Stadtmuseums Bonn und des Beethoven-Hauses, Bonn 1995, S. 135-155, hier S. 135; Carl Steven, Heinrich Carl Breidenstein. Ein Stück aus der rheinischen Musikgeschichte des 19. Jahrhunderts, Köln 1924, S. 25-27; THEOdOR ANTON HENSELER, Das musikalische Bonn im 19. Jahrhundert (Bonner Geschichtsblätter 13), Bonn 1959, S. 47-53.

SteVEn, Breidenstein (wie Anm. 19), S. 27 f. 
22 Der Singverein wurde erstmals im Bonner Wochenblatt, 15.1.1824, erwähnt, bestand aber schon vorher; vgl. HENSELER, Das musikalische Bonn (wie Anm. 19), S. 79, 84; Steven, Breidenstein (wie Anm. 19), S. 28f:; GutzMer, Chronik (wie Anm. 5), S. 107; HÖROLDT, Bonn im Vormärz (wie Anm. 2), S.170-173; EdITH ENNEN, ARnOLd E. MAURER und ClaudiA VALDER-KNECHTGES, Bonn unter französischer Herrschaft (1794-1814), in: HÖROLDT (Hg.), Bezirksstadt (wie Anm. 1), S. 9-71, hier S. 64-70. Vgl. darüber hinaus zur Musikgeschichte in der ersten Hälfte des 19. Jahrhunderts MARION LIENIG, Bürgerliche Musikkultur in Bonn. Das, Album' des Andreas Velten - eine Quelle zur Bonner Musikgeschichte aus dem 19. Jahrhundert (Veröffentlichungen des Stadtarchivs Bonn 55), Bonn 1995

Vgl. Steven, Breidenstein (wie Anm. 19), S. 29; Henseler, Das musikalische Bonn (wie Anm. 19), S. 57

StEVEn, Breidenstein (wie Anm. 19), S. 35f.; HENSELER, Das musikalische Bonn (wie Anm. 19), S. 124f., 132-134

Gutzmer, Chronik (wie Anm. 5), S. 107

Allgemeine musikalische Zeitung vom 21.2.1827 (https://opacplus.bsb-muenchen. deNta2/bsb10527977/bsb:4114449?page=3, 25.2.2020).Vgl. auch HENSELER, Das musikalische Bonn (wie Anm. 19), S. $94 f$.

Allgemeine musikalische Zeitung vom 28.3.1827 (https://opacplus.bsb-muenchen. deNta2/bsb10527977/bsb:4114449?page=3, 25.2.2020)

Vgl. auch HENSELER, Das musikalische Bonn (wie Anm. 19), S. 95f. Zum Wiener Begräbnis vgl. LAdenburger, Musik zu Beethovens Begräbnis (wie Anm. 19), S. 69-72. Vgl. auch ALEXANDER WHEELOCK THAYER, Ludwig van Beethovens Leben, hg. von HERMANN DEITERS, bearbeitet und erweitert von HUGO RIEMANN, 5 Bde, hier Bd. 1, Leipzig 1908, S. 494-497

Vgl. LAdEnBurger, Musik zu Beethovens Begräbnis (wie Anm. 19), S. 77

HENSEler, Das musikalische Bonn (wie Anm. 19), S. 36 und Anm. 32. Vgl. zur Familie Simrock und den Verlag: WALther OtTENDORF-SimRock, Das Haus Simrock. Ein Beitrag zur Geschichte der kulturtragenden Familien des Rheinlandes. Von der Herausgeberin revidierte Fassung der 2. Auflage von 1954, in: INGRID BODSCH (Hg. und Bearb.), Das Haus Simrock, Beiträge zur Geschichte einer kulturtragenden Familie des Rheinlandes, Bonn 2003, S. 109-218; Walther OtTEndORf-SimRock, Die Musikverleger Simrock aus Bonn, in: KARL GUSTAV FELLERER ( $H$ g.), Rheinische Musiker (Beiträge zur Rheinischen Musikgeschichte 43), Köln 1960, S. 237-248; ERICH H. MüLLER, Beethoven und Simrock, in: DERS. (Hg.), Simrock Jahrbuch II, Berlin 1929, S. 10-62; NORBERT M. BORENGÄSSER, Die Simrocks in Bonn, 3 Tle, in: Die Laterne 2/2006, S. 39-44, 3/2006, S. 66-73, 4/2006, S. 109-111

JoAnna Cobb Biermann, Nikolaus Simrock - Verleger, in: Bodsch, Haus Simrock (wie Anm. 30), S. 11-56, hier S. 12f.; SIEGFrIED BrAndENBURG, Die Gründungsjahre des Verlags N. Simrock in Bonn, in: Bonner Geschichtsblätter 29, 1977, S. 28-36, hier S. 28; BORENGÄSSER, Die Simrocks (wie Anm. 30), S. 40; OTTO BıBA, Die Simrocks - Verleger für Beethoven wie für Brahms, in: BodsCH, Haus Simrock (wie Anm. 30), S. 57-68, hier S. 61 CobB Biermann, Simrock (wie Anm. 31), S. 27f. Vgl. hierzu auch den Beitrag von JoAnna CobB BIERMAnN in diesem Band

Brandenburg, Gründungsjahre (wie Anm. 31), S. 28; Cobb Biermann, Simrock (wie Anm. 31), S. 14, 24

Cobb BiermanN, Simrock (wie Anm. 31), S. 28-35; BrAndenburg, Gründungsjahre (wie Anm. 31), S. 41-43; BORENGÄSSER, Die Simrocks (wie Anm. 30), S. 41

\section{8 | Yvonne Leiverkus}

(C) 2020 by Böhlau Verlag GmbH \& Cie. KG, Köln

https://doi.org/10.7788/9783412519704 | CC BY-NC 4.0 
Müller, Beethoven und Simrock (wie Anm. 30), S. 61f.; CobB Biermann, Simrock (wie Anm. 31), S. 38-42; JAN CAEYERS, Beethoven. Der einsame Revolutionär. Eine Biographie, München ${ }^{4} 2017$, S. 626-628. Vgl.

Schreiben Tobias Haslinger, Wien, an Nikolaus Simrock in Bonn, 27.3.1827, mit Einladung zur Beisetzung (Beethoven-Haus Bonn [BHB], HCB Br 336); LADENBURGER, Musik zu Beethovens Begräbnis (wie Anm. 19), S. 77, 91

Schreiben Andreas Streicher an den Kunst- und Musikverlag Simrock in Köln, 14.2.1827 (Deutsches Literaturarchiv Marbach, Mediennummer HS009189326); freundlicher Hinweis von Herrn Dr. Michael Ladenburger.

Henselerführt aus, Simrock habe aus einem Brief der Nannette Streichervom 28.3.1827 vom Tod Beethovens erfahren. Als Quelle für diesen Brief führt er Versteigerungskataloge des Antiquariates Leo Liepmanssohn in Berlin an. In diesen Katalogen werden jedoch keine konkreten Adressaten angegeben; es erfolgt lediglich der Hinweis, dass es sich um Nachrichten an „befreundete Firmen” handelt. Dass der Brief vom 28.3.1827 an die Firma Simrock ging, kann nicht verifiziert werden. Am 28.3.1827 ging allerdings ein Brief von Johann Baptist Streicher an Johann Andreas Stumpff, Klavierbauer in London, hinaus. Streichers haben wohl verschiedene geschäftliche Kontakte über das Ableben Beethovens informiert. Es kann sein, dass es auch einen Brief an Simrock, Vater oder Sohn, gegeben hat. Im Falle des Briefes vom 9.5.1827 bestätigt sich der Empfänger Simrock, jedoch nicht Nikolaus Simrock, wie Henseler vermutet, sondern Peter Joseph Simrock in Köln. Die Zitate, die Henseler anführt, stimmen mit den Zitaten in den Katalogen überein; vgl. HENSELER, Das musikalische Bonn (wie Anm. 19), S. 95; LeO LiePMAnNsSOHn (Hg.), Autographen von Musikern, Schriftstellern, Gelehrten, Naturforschern, bildenden Künstlern und historischen Persönlichkeiten, Katalog Nr. 50, Berlin 1930, S. 6 Nr. 26 (Brief vom 28.3.1827) und S. 6 Nr. 25 (Brief vom 9.5.1827).

Schreiben Firma Nannette Streicher geb. Stein und Sohn an den Kunst- und Musikverleger Peter Joseph Simrock Köln, 9.5.1827 (BHB, HCB Br 385). Der Brief stammt von der Hand Andreas Streichers (freundlicher Hinweis von Dr. Michael Ladenburger). Henseler erweckt in seiner Darstellung den Eindruck, der Brief vom 9.5.1827 sei an Nikolaus Simrock gegangen; vgl. Henseler, Das musikalische Bonn (wie Anm. 19), S. 95

Vgl. auch CobB BIERMAnN, Simrock (wie Anm. 31), S. 42, die sich jedoch auf Henseler und den Brief von Nannette Streicher vom 28.3.1827 bezieht, HENSELER, Das musikalische Bonn (wie Anm. 19), S. 95.

Bonner Wochenblatt, 17.12.1826; vgl. Henseler, Das musikalische Bonn (wie Anm. 19), S. 87-89.

Einladungskarte von Bonner Musikfreunden und der Junggesellen-Bruderschaft zur Totenfeier am 13.7.1827, Einblattdruck, Bonn, 12.7.1827 (BHB, Faksimile).

Vgl. zur Bruderschaft: FELIX HAUPTMANN, Die Junggesellen-Sodalität unter dem Titel Mariä-Reinigung. Zur Feier ihres 150jährigen Jubiläums aus dem Archive der Sodalität zusammengestellt, in: Aus kurfürstlicher Zeit. Sammelband. Jüngere Zeit. 8 Beiträge zur Geschichte von Bonn und Umgegend von verschiedenen Autoren, Bonn [1888], S. 57114, S. 72f. Am 21.5.1843 feierte die Junggesellen-Bruderschaft verspätet ihre 100-Jahrfeier. Henseler, Das musikalische Bonn (wie Anm. 19), S. 58; VAlDER-KNECHTGES, Bonn unter französischer Herrschaft (wie Anm. 22), S. 67f. Weitergehende Informationen zur Bruderschaft befinden sich gegebenenfalls im Historischen Archiv des Erzbistums Köln (Bestand Bonn - GVA Überhaupt I 003: Junggesellen-Bruderschaft unter dem Titel Mariae Reinigung (1821-1921)); aufgrund der Schließung des Archivs bedingt durch die "Corona-Krise" waren ein Besuch und eine Beauskunftung nicht möglich.

Die Rezeption der Nachricht von Beethovens Tod in Bonn | 539 
Der Musikalische Zirkel ist der zweite Verein dieser Art in Bonn neben dem Musikalischen Verein, welcher seit 1818/19 Spuren hinterließ. Beide Vereine bestritten Konzerte in Bonn. Am 8.2.1829 fand das 11. Stiftungsfest des Zirkels statt. Weiter ist der Verein für 1826 fassbar, als am 16.2.1826 ein Konzert zugunsten der Armen der Stadt stattfand. Im Bonner Wochenblatt erhielt der Zirkel für sein Konzert anlässlich des Geburtstages Beethovens am 20.1.1830 - das Konzert fand verspätet statt - eine wenig schmeichelhafte Kritik. Vgl. Ladenburger, Als das "neue Bonn” (wie Anm. 19), S. 138; Henseler, Das musikalische Bonn (wie Anm. 19), S. 47-53, 93f.; Steven, Breidenstein (wie Anm. 19), S. 25-27.

LAdenburger, Musik zu Beethovens Begräbnis (wie Anm. 19), S. 77. Zu Grabeler vgl. auch StAB, SN 94/336: Aufruf zur Sammlung Material über Peter Grabeler; HENSELER, Das musikalische Bonn (wie Anm. 19), S. 90-102

Erst um 1840 gelang es Franz Gerhard Wegeler und Karl Moritz Kneisel, das Geburtshaus in der Bonngasse zu bestimmen. Vgl. SiLKe BetTermanN und MiChaEL LADENBURGER, Vierzehn Beethoven-Häuser in alten Ansichten, in: SILKE BETTERMANN, WALTER Brauneis und Michael LADENBURger (Hgg.), Von der Bonngasse zum Schwarzspanierhaus. Beethoven-Häuser in alten Ansichten (Veröffentlichungen des Beethoven-Hauses, Ausstellungskataloge, 10), S. 35-85, S. 35; NORBERT SCHLOSSMACHER, Der erste Auftritt... Ludwig van Beethovens Taufe im Kirchenbuch von St. Remigius. Faksimile und Kommentar (Veröffentlichungen des Beethoven-Hauses Bonn, Jahresgaben des Vereins Beethoven-Haus 35), Bonn 2019, S. 1

Vgl. HauptMAnN, Die Junggesellen-Sodalität (wie Anm. 43), S. 52f.; VALDER-KNECHTGES, Bonn unter französischer Herrschaft (wie Anm. 22), S. 68.

Weitere Seelenämter bzw. Gedenkkonzerte gab es in Graz, Magdeburg, Leipzig, Berlin und Zürich; vgl. LADENBURGER, Musik zu Beethovens Begräbnis (wie Anm. 19), S. 69, 74-76. In Wien war der Aufwand bezüglich der musikalischen Ausgestaltung des Begräbnisses groß; für diesen Anlass wurden Kompositionen von Beethoven bearbeitet. Bonner Wochenblatt, 7.2.1828; STEVEN, Breidenstein (wie Anm. 19), S. 29; HeNSELER, Das musikalische Bonn (wie Anm. 19), S. 56, $95 f$

Z. B. Bonner Wochenblatt, 26.3.1829: Erinnerung an Beethoven zu dessen Todestag (Auszug aus der Allgemeinen Wiener Theaterzeitung, 25.3.1829).

51 JUTTA SCHUCHARD, Teueres Andenken - Beethoven und die Erinnerungskultur seiner Zeit, in: LADENBurger/BetTermann, Drei Begräbnisse (wie Anm. 19), S. 191-200, hier S. 191. Vgl. auch INGRID BODSCH, Monument für Beethoven. Die Künstlerstandbilder des bürgerlichen Zeitalters als Sinnstifter nationaler Identität?, in: Dies. (Hg.), Monument für Beethoven. Zur Geschichte des Beethoven-Denkmals (1845) und der frühen Beethoven-Rezeption in Bonn. Katalog zur Ausstellung des Stadtmuseums Bonn und des Beethoven-Hauses, Bonn 1995, S. 157-178.

52 HORST HallensleBen, Das Bonner Beethoven-Denkmal als frühes „bürgerliches Standbild", in: BodsCH, Monument für Beethoven (wie Anm. 51), S. 29-38, hier S. 36. Zum Denkmal vgl. auch JohANN Adolf SCHMOLL GEN. EINSENWERTH, Zur Geschichte des Beethovendenkmals, in: Saarbrücker Studien zur Musikwissenschaft 1, Kassel 1966, S. 242-277; WILLI KAHL, Zur Geschichte des Beethovendenkmals, in: Beethoven-Jahrbuch. N. F. Reihe 2, Bonn 1953/54, S. 63-79

53 Bei dem Autor handelt es sich wahrscheinlich um den Gymnasiallehrer Andreas Dederich. Vgl. hierzu HENSELER, Das musikalische Bonn (wie Anm. 19), S. 165, und SUSANN SCHAAL, Das Beethovendenkmal von Ernst Julius Hähnel in Bonn, in: BoDsCH, Monument für Beethoven (wie Anm. 51), S. 39-128, hier S. 101 und Anm. 14. 


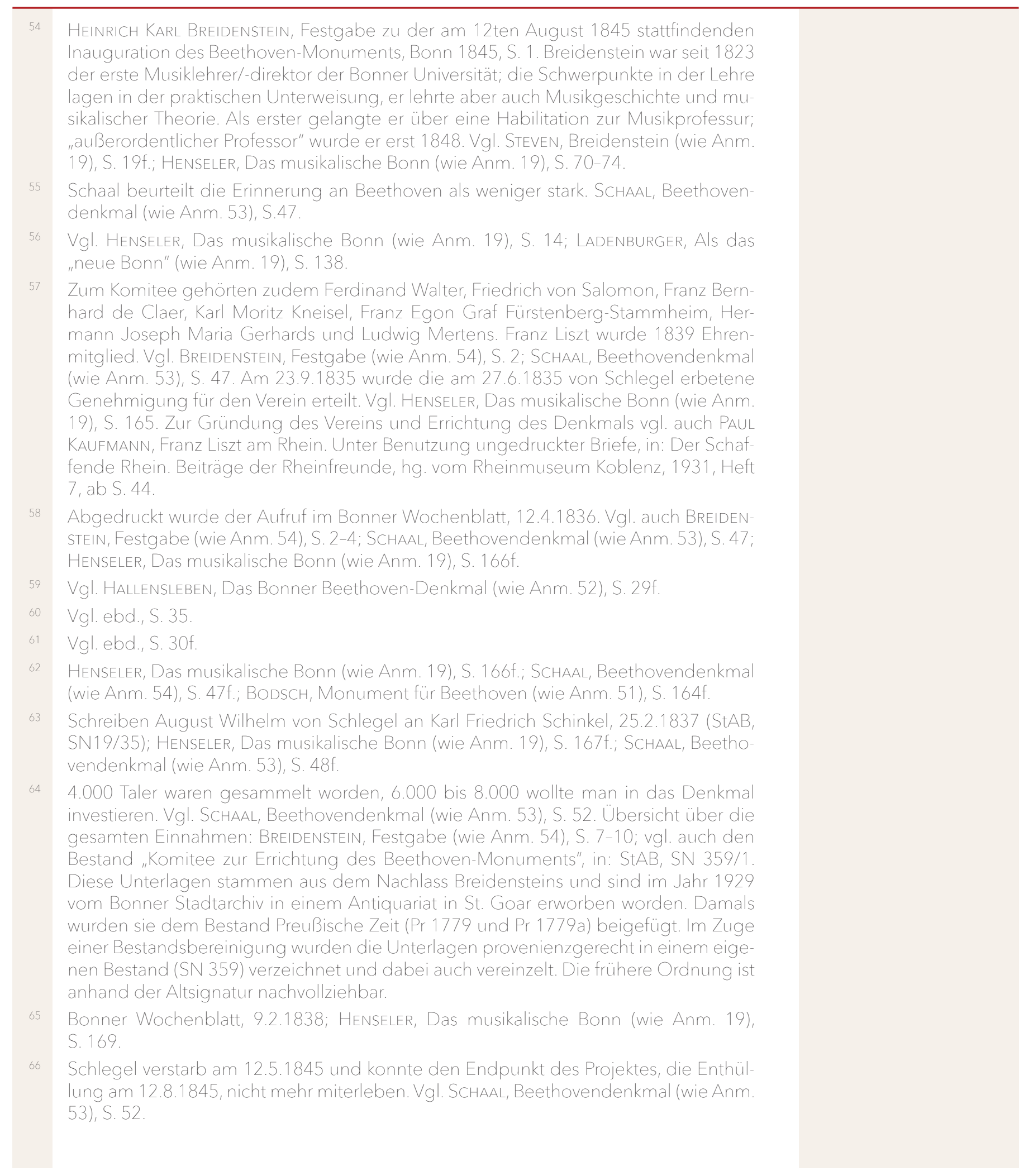

Die Rezeption der Nachricht von Beethovens Tod in Bonn | 541 (c) 2020 by Böhlau Verlag $\mathrm{GmbH}$ \& Cie. KG, Köln https://doi.org/10.7788/9783412519704 | CC BY-NC 4.0 
Informationen über den zweiten Aufruf befinden sich bei BREIDENSTEIN, Festgabe (wie Anm. 54), S. 6-10 (Übersicht der eingegangenen Spenden). Das Bonner Wochenblatt überliefert diesen nicht. HensELER, Das musikalische Bonn (wie Anm. 19), S. 169-172; SCHAAL, Beethovendenkmal (wie Anm. 53), S. 50-52, 103 mit Anm. 28, 30. Zitat nach Robert StockHAmmer, Franz Liszt. Im Triumphzug durch Europa, Wien 1986, S. 146. BREIDENSTEIN, Festgabe (wie Anm. 54), S. 10f.; SCHAAL, Beethovendenkmal (wie Anm. 53), S. 53; GISBERT KNOPP, Das erste Bonner Beethovenfest 1845 nach dem illustrierten Bericht von Anton Schindler und die Errichtung der ersten Beethovenhalle unter der Leitung des Kölner Dombaumeisters Ernst Friedrich Zwirner, in: Bonner Geschichtsblätter 62/63, 2013, hier S. 343-370, S. 345f Kölnische Zeitung, 28.8.1840, 3.9.1840, und Bonner Wochenblatt, 8.8.1841. Zur Diskussion vgl. SCHAAL, Beethovendenkmal (wie Anm. 53), S. 53-57.

Kölnische Zeitung, 3.9.1840; SCHAAL, Beethovendenkmal (wie Anm. 53), S. 52-56; SUSANN SCHAAL, Zur Entstehungsgeschichte des Denkmals, in: BODSCH, Monument (wie Anm. 51), S. 129-133, S. 130; MARGOT EILERS, Ein Gang durch die Bonner Postgeschichte: 100 Jahre Postamt Bonn Münsterplatz 1877-1977, Bonn 1977

Vgl. BREIDENSTEIN, Festgabe zur Inauguration (wie Anm. 55), S. 14; SCHAAL, Beethovendenkmal (wie Anm. 53), S. 57, 85, 132

Augsburger Allgemeine Zeitung, Beilage 233, 21.8.1845; HENSELER, Das musikalische Bonn (wie Anm. 19), S. 173; SCHAAL, Beethovendenkmal (wie Anm. 53), S. 57, 105 und Anm. 56. Zu den Wettbewerbsentwürfen val. ebd., S. 59-68. Darunter auch der Entwurf des in Bonn geborenen Hermann Rudolf Heidel, dem Gottfried Kinkel mehr Erfolg gegönnt hätte; vgl. ebd. S. 63-65.

Henseler, Das musikalische Bonn (wie Anm. 19), S. 173; ScHAAL, Beethovendenkmal (wie Anm. 53), S. 57-61, 70.

BREIDENSTEIN, Festgabe (wie Anm. 54), S. 12f.; SCHAAL, Zur Entstehungsgeschichte (wie Anm. 70), S. 130

Vgl. ScHAAL, Beethovendenkmal (wie Anm. 53), S. 69

Vgl. ebd., S. 70 .

Vgl. ebd., S. 73; SCHAAL, Zur Entstehungsgeschichte (wie Anm. 70), S. 133. Vgl. auch BREIDENSTEIN, Festgabe (wie Anm. 54), S. 12f. Zu den Verhandlungen vgl. die Korrespondenz mit Hähnel, in: StAB, SN 359/12

SCHAAL, Beethovendenkmal (wie Anm. 53), S. 72 und Anm. 119.

Schreiben Hähnels an Breidenstein, 21.5.1844, in: StAB, SN 359/12; SCHAAL, Beethovendenkmal (wie Anm. 53), S. 39, 93

Vgl. Henseler, Das musikalische Bonn (wie Anm. 19), S. 172-177; SCHAAL, Beethovendenkmal (wie Anm. 53), S. 115f. und Anm. 187. Zum Fortgang der Fertigstellung vgl. ebd., S. 73-94. Zu Verzögerung kam es auch, da Hähnel an seinem ursprünglichen Entwurf Änderungen durchsetzen wollte, die jedoch in Bonn auf Ablehnung stießen und daher nicht umgesetzt werden durften; vgl. ebd. S. 80-82.

81 Der Mainzer Verlag Schott verlegte die beiden großen Werke Beethovens; vgl. SCHAAL, Beethovendenkmal (wie Anm. 53), S. 95; DIES., Zur Entstehungsgeschichte (wie Anm. 70), S. 133; HeINRICH KARL BREIDENSTEIN, Zur Jahresfeier der Inauguration des Beethoven-Monuments. Eine actenmäßige Darstellung dieses Ereignisses der Wahrheit zur Ehre und den Festgenossen zur Erinnerung, Bonn 1846, S. 4.

82 Henseler, Das musikalische Bonn (wie Anm. 19), S. 203f., SCHAAL, Beethovendenkmal (wie Anm. 54), S. 96; Zitat: Bonner General-Anzeiger, 21.12.1949.

\section{2 | Yvonne Leiverkus}

(C) 2020 by Böhlau Verlag GmbH \& Cie. KG, Köln

https://doi.org/10.7788/9783412519704 | CC BY-NC 4.0 


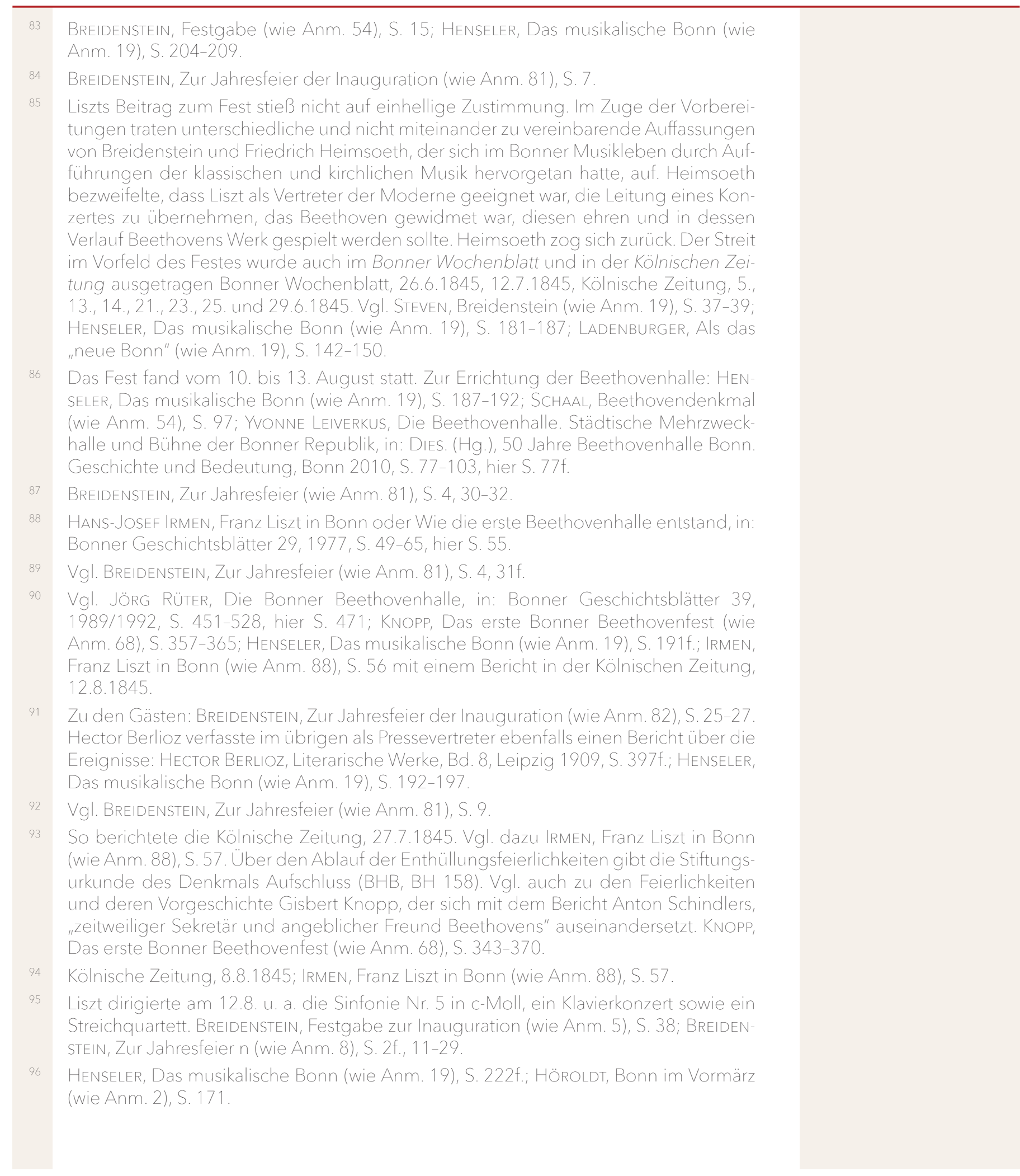

Die Rezeption der Nachricht von Beethovens Tod in Bonn | 543 
97 SchAAL, Beethovendenkmal (wie Anm. 53), S. 45. Das Wiener Beethovendenkmal stammt von Caspar Zumbusch, 1880; Max Klingers Statue, 1902, befindet sich im Gewandhaus in Leipzig; das Beethovendenkmal von Peter Breuer, 1926/27, in der Bonner Rheinaue. SCHAAL, Beethovendenkmal (wie Anm. 53), S. 39-45, S. 101 und Anm. 8.

Vgl. Henseler, Das musikalische Bonn (wie Anm. 19), S. 195f., 216-219; SCHAAL, Beethovendenkmal (wie Anm. 53), S. 115f. und Anm. 186. Vgl. auch zu den Vorwürfen: BREIDENSTEIN, Zur Jahresfeier (wie Anm. 81), S. 37-39; StEVEn, Breidenstein (wie Anm. 19), S. $40 f$

EMIL NAUMAnN, Nachklänge. Eine Sammlung von Vorträgen und Gedenkblättern aus dem Musik-, Kunst- und Geistesleben unserer Tage, Berlin 1872, S. 231; SCHAAL, Beethovendenkmal (wie Anm. 5), S. 115 und Anm. 186.

StockHAMmer, Franz Liszt (wie Anm. 6), S. 112f.; SchAAL, Beethovendenkmal (wie Anm. 53), S. 115 und Anm. 186.

101 Vgl. StAB, SN 156 (Nachlass Karl Simrock); StAB, SN 75 (Nachlass Hauptmann); StAB, SN 94 (Familie Kaufmann), StAB, SN 267 (Schmidt-Bleibtreu), StAB, SN 40 (Brandis), StAB, SN 98 (Gottfried und Johanna Kinkel), StAB, SN 109 (Lese- und Erholungsgesellschaft). Zu Arndt: StAB, SN 25 (Sammlung Arndt), sowie AlBRECHT DüHR (Hg.), Ernst Moritz Arndt. Briefe, 3 Bde, Darmstadt 1972-1975; HANS-JOACHIM HACKER, DIETRICH HÖROldT, Felicitas KNoppKE und Dieter Körschner (Hgg.), Ernst Moritz Arndt. Unveröffentlichte Briefe aus den Stadtarchiven Bonn und Stralsund (Veröffentlichungen des Stadtarchivs Bonn 34), Bonn 1995.

Das Begräbnis Beethovens wurde, auch verglichen mit denen anderer großer Komponisten wie Mozart, Haydn, Salieri oder Schubert, deutlich aufwendiger gestaltet. Auch nahm die Bevölkerung großen Anteil, waren z. B. Schulen geschlossen. Die Ausgestaltung des Begräbnisses - auch als gesellschaftliches Ereignis - wurde für spätere Begräbnisfeiern beispielhaft. Vgl. LADENBURGER, Musik zu Beethovens Begräbnis (wie Anm. 19), S. 89

LAdenburger, Als das "neue Bonn" (wie Anm. 19), S. 138, 150

HENSELER, Das musikalische Bonn (wie Anm. 19), S. 164

Kölnische Zeitung, 3.8.1845. 


\section{Personenregister}

Nicht berücksichtigt wurden Ludwig van Beethoven d. J. sowie die Autor*innen von Sekundärliteratur.

\section{A}

Adelsheim, Christine 484

Adlung, Jacob 157, 159

Afsprung, Johann Michael 96

Aix, Francois-Joseph d' 154, 156, 163

Albert, Carl Franz Xaver 445

Albert, Franz Joseph $445 f$.

Albert, Prinzgemahl 532, 534

Albrechtsberger, Johann Georg 315, 320, 389

Aleff, Stud. 154

Alembert, Jean Baptist de Rond d' 92

Ali, Hof-Fourier 269

Altstätten, Bertram Maria (Apollinar) 153, 221, 223

Alvard 53

Alvensleben, Frau von 397

Amati, Antonio 170

Amati, Girolamo 170

Amati, Nicolo 170

Amecke, Stud. 154

Amenda, Carl Friedrich 289, 292-295, 298

Anckenbrand, Hofbäcker 302

Andlau, Gerard Carl Friedrich von 103, 199

Andlau, Johann Baptist Freiherr von 102, 139, 149

Andre, Musikverleger 179

Angelbis 154

Anna Amalia, Herzogin in Weimar 264

Anna Amalia, Prinzessin von Preußen 264

Anschel, Salomon 126, 221

Anschel, Stud. 151

Antoine, Ferdinand d' 128, 164f., 218, 238, 240, 397

Antoine, Josepha Antonetta d' 204

Antoine, Katharina d' 128

Ape, Schauspieldirektor 457

Apel, Achatius 123, 133, 135

Apollinar, s. Altstätten

Apponyi, Anton Georg Graf 159

Aquin, Thomas von 92

Archenholz, Johann Wilhem 115, 143

Argelander, Friedrich Wilhelm August 517

Argens, Jean-Baptiste Marquis d' 92

Arnds, Hofrat 154

Arndt, Ernst Moritz 535, 544

Artaria, Verleger 352, 419, 422f., 430, $432 f$.

Asbach, Backmeister 20

Auberger, Kammerportier 479

Audebert, Jean Baptiste 112
Averdonk, Johanna Helene 261, 459

Averdonk, Severin Anton 132, 154, 261, 366, 507

Ayrton, William 332

\section{B}

Bacchiochi, Herr 154

Bach, Carl Philipp Emanuel 172f., 198, 209, 390, 399, 407, 409

Bach, Johann Christian 270

Bach, Johann Sebastian 180, 270, 389-391, 399, 408

Bachem, Hofkommissarius 150

Backof, Carl 19

Baedeker, Karl 331

Balestrini, Oboist 457

Ball (auch: Boll, Pall, Poll), Maria Josepha,

verh. van Beethoven 11, 25, 27, 41, 50, 195f., 211

Baltus, Michael 470, 472

Bamberger, Andreas 230, 246, 470, 472f., 482

Baruch, Simon 115, 143, 154

Basch, Bürgermeister 154

Battaglia, Antonio 201

Bauch, Heribert, Pfr. St. Remigius 57, $68 f$.

Baudissin, Wolf Heinrich von 56

Bauer, Carl Ludwig, Hofrat 178f., 207

Bauer, Peter Carl 204

Baum, Cunibert Joseph 52

Baum, Gertrud 40, 44, 46

Baum, Johann 44, 52

Baumwahl, Sängerin 485

Bause, Tonkünstler 396

Bause, Johann Friedrich 396, 403

Beaumarchais, Pierre Augustin Caron de 92, 491

Bebenburg, Freiherr Friedrich Karl Karg von 161

Beckenkamp, Benedikt 28

Beckenkamp, Johann Peter 145, 230, 501

Beckenkamp, Veronika, geb. Krämer 230

Becker, Gebr. 110

Becker, Prof. 154, 240

Becker, Anselm OSB 114, 239

Becker, Clemens 117

Beecke, Ignaz von 448f.

Beer, Johann Friedrich 479

Beethoven, Anna Maria Franziska van 22, 31

Beethoven, Franz Georg van 31

Beethoven, Johann van 11f., 14-16, 18-25, 27-32, 39-42, 44, $46,164,167 f ., 204,303,306,369,389,417,432,437,440$, 456, 523

Beethoven, Karl van 42, 90, 522

Beethoven, Kaspar Anton Karl van 22f., 31, 42, 51, 422, 437 
Beethoven, Kornelius van 40

Beethoven, Ludwig (Louis) van (d. Ä.) 11-13, 15, 27, 39-41, 44, 46, 52, 59, 203f., 301f., 332, 417, 419, 437, 451, 455, 459

Beethoven, Ludwig Maria van 31, 46

Beethoven, Maria Margarete Josepha van 22, 31

Beethoven, Maria Magdalena van, geb. Keverich, verw. Leym 11-16, 18-24, 26-33, 40-42, 44-46, 302, 306, 308, 326, 337, 345, 357, 437, 439f., 458

Beethoven, Maria Bernhardine Ludovica van 24

Beethoven, Maria Louise van, geb. Stuyckers 40

Beethoven, Markus Joseph van 24

Beethoven, Michael van 40

Beethoven, Nikolaus Johann van 22f., 31, 42, 437, 461

Beißel, Reiner 38f.

Belderbusch, Anna Barabara von, s. Koch

Belderbusch, Anna Maria Gräfin von, geb. Freiin von

Wambolt von Umstadt 90, 99, 104, 139, 149, 164f., 257

Belderbusch, Anton Maria Karl Reichsgraf von, Maire 63, 90, 99, 111, 132, 164, 283, 287, 318, 381, 475, 528

Belderbusch, Caspar Anton Reichsgraf von der Heyden gen., Premierminister 16, 19, 21f., 51, 90, 108, 150, 156, 164, 203, 214f., 218, 224, 230, 237, 398, 406, 409, 413,

Belderbusch, Karl Leopold Reichsgraf von 90, 114, 137, 224, 235, 237

Belzer, Frau von, s. Peltzer

Belseroski, Joseph Clemens 27

Benfeld 121

Benyowski, Maurice-Auguste Comte de 92

Berghes, de, Referendar 154

Berlioz, Hector 534, 543

Bernard, Dichter 520

Berschitz, Martin 186

Bersword, von, Geh. Rat 154

Bertòla, Abbate 121

Best, Arzt (Köln) 151

Bethmann-Unzelmann, Friederike, s. Flittner

Beyer, Johanna Elisabeth, s. Ries

Biegeleben, Engelbert 154

Bieler, Vitus 57

Bitter, Herr 150

Blankenheim, Comtesse de 149

Bläser, Gustav Hermann 530

Bleibtreu, Carl Philipp, Hofkammerrat (Neuwied) $397 f$.

Bleibtreu, Familie 515, 544

Bleibtreu, Friedrich Wilhelm 398

Bleibtreu, Johann Leopold 398

Bleibtreu, Ludwig Georg 398

Blum, von, Rat 154

Blumauer, Johann Aloys 95, 117

Boccerini, Luigi 247, 264

Bocholtz-Asseburg, Felicitas von, geb. Wolff-Metternich zur Gracht 167
Bocholtz-Asseburg, Hermann Werner Freiherr von 167 Bocholtz, Friedrich Wilhelm Graf von 167

Böhm, Wenzel 392

Boenen zu Berge, Familie 293

Boenen zu Berge, Ludolf Friedrich Adolf,

s. Westerholt-Gysenberg

Boeselager, Fräul. von 149

Bohnenberger, Gottlieb Christoph 187

Boileau-Despréaux, Nicolas 92

Boll, Maria Josepha, s. Ball

Bonnet, Charles 395, 400-402

Bonneval, Claude Alexandre Comte de 91

Boosey, Verleger 324

Boosfeld, Peter Joseph 110, 154, 478, 486

Borlatti, Oberkellner (Lechenich) 153

Bornheim, Frau von 99, 149

Bornheim, Fräul. von 99, 149

Boßler, Heinrich Philipp 180, 185, 405

Bourscheid zu Burgbroel, Max Freiherr von 100

Bourscheid, Hofrat 281

Bourscheidt $149 f$.

Bourscheidt, Anton, Futterknecht 100

Bourscheidt, Ferdinand Freiherr von 100, 139, 231

Bourscheidt, Karl Joseph Maria von 100, 102, 139

Boutmy, Sekretär 156

Bowater, Frances 103, 139, 149, 377

Bowater, John Esq. 103, 139, 149

Brahms, Johannes 391, 508, 523

Brand, Sänger 488, 496

Brander, Georg Friedrich 186

Brandis, Familie 515, 544

Brandt, Christina Sophia Henriette, geb. Hartmann $174 f$.

Brandt, Christoph 175, 470, 472

Brant, Sebastian 136

Braumann, von, Stud. 154

Breidenstein, Heinrich Karl 367, 518-520, 525, 527-529, 531, 534, 541-543

Breitkopf \& Härtel, Verleger 381, 430, 433

Brentano, Franz 429f., 434

Brentano, Madame 324

Bretzner, Christoph Friedrich $492 \mathrm{f}$.

Breuer, Hofkammerrath 150

Breuer, Peter 534, 544

Breughel, Jan 172

Breuning, Christian Heinrich 400

Breuning, Christoph von 107-109, 130f., 230, 237, $281 \mathrm{f}$. 288f., 291f., 342, 348, 355, 368, 505, 508, 515

Breuning, Eleonore von, verh. Wegeler 107-111, 158, 164, $168,277,279,281 \mathrm{f} ., 286,288,290,297-299,317,326,339$, $342,344,351,505,510$

Breuning, Emanuel Joseph von, Hofrat 164f., 172, 204, 279, 299 
Breuning, Familie 107-110, 230, 277, 280, 287, 290, 292, 342, 375

Breuning, Franz Jakob von 139

Breuning, Georg Joseph von, Geh. Rat 100, 110, 139, 152f., 473, 490

Breuning, Helene, geb. Kerich 107, 109, 279, 285f., 293, $342,344,351,368$

Breuning, von Herr 154

Breuning, Johann Lorenz von, Kanoniker 100, 107, 109f., 130, 153f., 299, 342

Breuning, Lorenz (Lenz) von 107, 109, 158, 287, 290f., 292 f. 295, 299, 347f

Breuning, Moritz Gerhard von 342, 440

Breuning, Stephan von 46, 107, 109, 130f., 230, 283, $289 f$. 294f., 307, 315, 342, 348, 351, 440, 522

Breuning, Stud. 154

Brigaß..., Frau 149

Broadwood, Thomas 158, 176, 354

Broggia, Johann Baptist 163, 204

Browne, Graf 313f., 335

Bruchausen, Anton 94

Bruckner, Anton 391

Brühl, Alois-Friedrich Graf von 492

Brühlmeyer, Jurist 444

Brunsvik, Familie 335

Bücken, Josef, Pfr. St. Remigius 67

Bülow, Hans von 159

Bürger, Gottfried August 106, 294, 407

Burgmüller, Friedrich 534

Burke, Edmund 95

Burmann, Adolf Sigismund, Kanoniker 56

Burmann, Maximilian Heinrich, Titularbf. Trier 76

Burmann, Peter von, Geheimrat 76

Bursy, Karl 457

\section{C}

Caesarius von Heisterbach 53

Calkum gen. Lohausen, Franz Joseph Freiherr von 101

Cambini, Giuseppe Maria 247, 264

Camões, Luis de 92

Campe, Joachim Heinrich 110, 121

Cannabich, Karl 309, 313, 489

Cantillon, Richard 93

Caramé, Stud. 154

Carl Eugen Herzog von Württemberg 346, 375

Carus, Friedrich August 148

Casanova 371

Cassel, Simon Meyer 147

Casti, Giovanni Battista 492

Cauer, Emil d, Ä. 530

Chigi, Fabio Kardinal 71

Chlodwig 35, 61, 70f., 87

Chopin, Frédéric 322
Christ, Stud. 154

Cicero 94, 105

Claer, Franz Bernhard de 541

Claudius, Matthias 106, 132

Clemens August, Kf.-Ebf. von Köln 16, 40, 42, 58, 68, 115, 119f., 140, 161-163, 172, 204, 207, 233, 250, 301, 369, 383-385, 481, 499

Clemens Wenzeslaus, Kf.-Erbf. von Trier 28, 375, 473

Clemens XIV., Papst 36

Clementi \& Co, Verleger 324

Coels, Frau von 154

Coke, Mary $475 f$.

Collen, Johann von, Glockengießer 62

Colloredo, Maria Gabriela Gräfin von 450

Colloredo-Mannsfeld, Franz de Paula Gundaker von 473, 494

Colloredo von Waldsee und Mels, Hieronymus Franz de

Paula Josef Graf, Ebf. von Salzburg 251, 260, 450

Comenius, Johann Amos 114

Corneille, Pierre 92, 136

Corneli, Stud. 154

Corty, Stud. 154

Couchet, Petrus Johannes 171, 206

Courtin, Johann u. Anna Maria, geb. Lohe 44, 52

Cramer, Illuminat 240

Cramer, Frau von 165, 167

Cramer von Clauspruch, Friedrich Joseph Anton 167

Cramer von Clauspruch, Johann Arnold Heinrich, Ass.

Reichskammergericht 154, 167

Cramer von Clauspruch, Peter Josef Xaver Johannes

Nepomuk, Geistl. Rat 154, 167

Cramer von Clauspruch, Therese (Norf) 155

Cramer von Clauspruch Josepha Maria Ursula, s. Gebler

Cramer, Carl Friedrich 185, 252, 267, 321, 389, 397, 404f., 409,438

Cramer, Franz Heinrich OSB 239

Creed, Mr. 184

Cremer, Stud. 154

Cressener, George 128

Cressener, Henriette $128 f$.

Crevelt, Johann Heinrich 111f., 129, 142, 151-154, 215,

226f., 230, 232, 237, 280-284, 287, 296f., 340

Cronegk, Johann Friedrich Freiherr von 94, 105, 117

Crusius, Christian August 395, $399 f$.

Custin, General 282

Czerny, Karl 465

D

Daes, Freifrau von 163

Daniels, Heinrich Gottfried Wilhelm 152, 154, 221, $239 f$.

Dante 134

Dardenne, Schauspieler 154

Daubach, Anna Margaretha 14 
Davidszoon de Heem, Anna, geb. Ruckers 172

Davidszoon de Heem, Johann 172

Davis, James 182

Deckher, Stud. 154

Dederich, Andreas 536, 540

Defournay, Offizier 154

Degenhart, Johann Martin 230, 280, 282

Deiters, Hermann 441

Dejean, Anton 171

Dejean, Ferdinand 168, 171, 207

Delwich, von, Fähnrich 149

Dereser, Thaddäus Anton OCD 112, 143, 230, 239f., 281

D(i)ericks, Registrator 150, 152

Deuren, Fräul. von, Kanonisse (Vilich) 152

Diabelli, Anton 325, 430

Diderot, Denis 92

Dies, Albert Christoph 169, 252

Diodor 94, 105

Disteling, Heinrich von 372

Ditters von Dittersdorf, Carl 420, $490 f$.

Dob(b)eler, Anna Maria Gertrud,

verh. Trespagne 377f. 380

Dob(b)eler, Clemens, Hofkaplan 203, 377

Dob(b)eler, Franz 203, 377

Dob(b)eler, Maria Magdalena Antonetta, verh. Kal(t)berg 377f., 380

Dob(b)eler, Maria Gertrud, geb. Patts (Paths) 377

Dörfeld, Johann Ludwig 128f., 150, 230, 280, 287, 298

Dörfeld, Susanne Maria, geb. Struve,

verw. Kaufmann 150, 287, 298

Dohnal, Joseph 158

Dorow, Wilhelm 365

Drake, Johann Friedrich 530

Dreesen, Paul, Kanoniker 150-152, 154

Dressler, Catharina Elisabeth, geb. Renner 206

Dressler, Ernst Christoph 167, 175, 206, 404

Drewer, Anna Maria, s. Ries

Drewer, Ferdinand, Violinist 303-305, 310, 315, 336,

Drewer, Franz 315

Drewer (Treves), Laurent 332

Droste, Jungfrauen 372, 386

Droste, Johann Jodocus 372

Droste zu Vischering, Adolf Heidenreich 99

Dürck, Friedrich 342f.

Dürer, Albrecht 527

Dumont, Hofrat 153

Dupuis, Charles 284, 512

Durelli, Giuseppe Antonio 445, 448, $455 f ., 464$

Dussek, Familie 304

\section{E}

Ebbinghaus, Gustav 16

Ebhard, Hofrat 154
Edelmann, Heinrich Gottlob 393

Edelmann, Johann Christian 393, 411

Eeden, Gilles van den 161, 398, 404f., 415, 438

Eggers, Freiherr von 125

Ehemant, Joseph 329

Ehmann, Mathias 376

Eichhoff, Barbara, s. Schönebeck

Eichhoff, Eva Franziska, geb. Grau 358

Eichhoff, Johann August 357

Eichhoff, Johann Joseph, Bürgermeister, Rheindirektor 115, 129f., 132, 151, 219, 223, 230, 237f., 240, 282-284, 352, 357-367, 369f.

Eichhoff, Johann Peter, Publizist 113, 115, 121, 129, 132, 150f., 153, 219, 222f., 225-227, 236, 238, 240, 280, 357f., $367 f$.

Eichhoff, Lorenz 357, 367

Eichhoff, Maria Magdalena, geb. Farber 357, 367

Eichhoff, Peter Joseph Freiherr von, österr.

Hofkammerpräsident 235, 370

Eigelmayer, Adelheid, s. Ries

Eigelmayer, Friedrich Joseph 163, $305 f$.

Eigelmayer, N. (Vater), Knabentafeldecker $305 f$.

Eilender, Peter Joseph 111, 230, 237, $282 f$.

Ekhof, Conrad 394

Elckens, Ferdinand, Pfr. St. Remigius 62, 69, 87

Elisabeth Ludovica von Bayern 534

Elverfeldt gen. Beverförde-Werries, Baron Friedrich Clemens von 293

Elverfeldt gen. Beverförde-Werries, Maria Anna Wilhelmine, s. Westerholt-Gysenberg

Engel, Johann Jakob 396, 400

Engelhard, Antonie 484

Engelhardt, Walther 392

Epée, Abbé de l' 121

Erbach-Schönberg, Graf Christian zu 478, 480, $494 f$.

Erdmann, Johann Andreas 187

Ernst von Bayern, Kf.-Ebf. von Köln 55

Erthal, Franz Ludwig von, Bf. von Würzburg 218, 477

Erthal, Friedrich Karl Josef von, Kf.-Ebf. von Mainz 218

Erthal, Lothar Franz Michael Freiherr von und zu 218, 238, 240

Eschbaum, Ernst 101

Eschbaum, Stud./Kandidat 128, 149

Eschbaum, Kaufmann 102

Eschborn, Benedict 335

Esenwein, Georg Daniel, Pfr. 186

Esenwein, Sibylla Juliana, s. Riedler

Esper, Dachdecker 60

Esser, Reiner Josef 119, 121, 133, 144, 154, 269

Esterhazy, Fürst Franz von 246, 506

Eunike, Friedrich, Sänger 420 


\section{$\mathbf{F}$}

Fabritius, Laurentius, Pfr. St. Remigius 69

Falkenstein, Johann Heinrich 111, 142

Farber, Johann Peter 357, 367

Feddersen, Jakob Friedrich 106

Feder, Johann Heinrich Georg 133-136, 147, 220, 234

Feller, Franz-Xaver von SJ 96

Ferdinand von Österreich 282

Ferdinand, Kf.-Ebf von Köln 74, 88

Ferro, Pascal Joseph 96, 118

Feu(s)ser, Therese 150, 154

Fiala, Mme. 103

Fickermann, Stud. 154

Fielding, Henry 94

Fischenich, Bartholomäus 230-232, 237, 280f., 287, 296

Fischer, Cäcilie 26, 29

Fischer, Gottfried 11f., 16, 19, 23f., 26-32, 90

Fischer, Familie 16-18, 20, 30

Fischer, Johann Theodor 11f., 27

Fischer, Maria Susanne Katharina, geb. Rheindorf 27

Fleischer, Johann Christoph 159, 203

Fleury, Abbé 91

Flittner, Friederike, verh. Bethmann-Unzelmann 97, 108, $138,140,222,235$

Floret, Engelbert 230, 281

Florian, Jean-Pierre Claris de 492

Fontaine, Jean de la 92f., 105

Forlivesi, Hofkaplan 150

Forster, Georg 96, 124

Forstmeister zu Gelnhausen, Freiherr Karl Franz Friedrich Hastard Anton OT 90-98, 100, 102-105, 108, 115, $117 \mathrm{f}$., 128f., 138, 140, 150, 154, 156, 216f., 234, 240, 276, 387, 477,483

Forstmeister, Karl von 102

Forstmeister, Karolina Freifrau von, geb. Freiin von Steinen zu Scherfffen 102, 149

Frangipani, Ottavio Mirto, Nuntius 49

Frank, Arzt (Wien) 349

Franz II., Kaiser 97, 507

Freiligrath, Ferdinand 515

Freusberg, Pfr. St. Martin 154

Frey, A. 269

Frickel, Mathias 17, 214, 278

Friederici, Christian Ernst u. Gottfried Christian 170, 172175, 194f., 199

Friedrich II., König von Preußen 91, 46, 143, 178

Friedrich III., Kurfürst 56

Friedrich von Dänemark 209

Friedrich Wilhelm III., König von Preußen 114, 323, 354, 528f., 537

Friedrich Wilhelm IV., König von Preußen 312, 530f., 534, 537

Frimmel, Theodor 441
Frings, Gerard, Hofkaplan 100, $149 f$.

Fromaget, Nicolas 93

Fuchs, Wwe. 302

Fucks, Dorotheus, Laienbruder 70

Füger, Gottlieb Christian 164, 204

Füger, Heinrich 204

Fürstenberg, Wilhelm Egon von, kurköln. Minister 56

Fürstenberg-Stammheim, Franz Egon Graf 541

Fugger von Diettenheim, Graf u. Gräfin 457

Funk, Michael 470

\section{G}

Gabler, Joseph 179

Galvani, Antonio 451

Garve, Christian 396, 403

Gebler, Karl und Josepha Maria Ursula von, geb. Cramer von Clauspruch 167

Gehra, Johann Ludwig 127

Geib, Johann Lorenz (John) 209

Geiger, Cornelius Michael 507

Geisler, Adam Friedrich 107

Geisler, Adjut. 154

Geisselbrunn, Jeremias 72

Geldern, Friderike von, geb. von Steinen zu Scherffen 102

Geldern, Graf von 102

Gellert, Christian Fürchtegott 106, 110, 120, 127, 132, 395f., 399f., $402 f$.

Genlis, Madame de 93

Gerber, Ernst Ludwig 158, 302, 450f., 494

Gerbert 53

Gerhard, Pleban St. Martin 55

Gerhards, Hermann Joseph Maria 541

Gerold, Bernhard Franz Josef von 150, 152, 218, 222, 237f., 240

Gerolt, R. J. 63

Gessner, Salomon 106, 112, 120, 399f.

Geyser, Christian Gottlieb 393, 396

Gibbon, Edward 93

Gielsdorf, Lambert u. Mechthild von 54

Ginetti, Peter Wilhelm Joseph de 114, 120, 144, 221, $239 f$.

Glaeßmecher, Laurens, Glaser 64

Gleim, Johann Wilhelm Ludwig 106, 402

Gluck, Christoph Willibald 443, 509

Goebel, Familie 205

Goebel, Ferdinand 168, 177, 205

Goebel, Franz 168, 170, 176f., 179, $206 f$.

Goebel, Lise 168, 179

Goebel, Marianne 168, 179

Göpfert, Philipp 470, 472

Goethe, Johann Caspar 173

Goethe, Johann Wolfgang von 94, 106, 117, 120, 125, 132, 383,446

Goethe, Katharina Elisabeth 107, 151, 463 
Goldberg, Johann 470, 472

Goldoni, Carlo 491

Goldsmith, Oliver 491

Gompertz, Goldina, geb. Kauffmann 301

Gottsched, Johann Christoph 114, 120, 222

Gottwaldt, Joseph Karl 25

Grabeler, Peter 520, 525, 527, 540

Grabler, Sigismund 101, 149

Graf, Conrad 197

Graf, Stud. 154

Graf(f), Herr 149

Greiner, Johann Carl 185, 209

Greth, Carl von $293 f$.

Greth, Johanna (Jeanette) von, geb. von Ho(h)nrath 277, $293 f$.

Griesinger, August 169

Grillparzer, Franz 367, 522

Grimm, Anton, Dachdecker 59

Großmann, Gustav Friedrich Wilhelm 97, 103-108, 110, 138, $140,151,175,215,218,238,240,242,245,247,258,268$, 394, 397, 406, 411, 415f., 491

Großmann, Karoline 103-105, 107, 138, 140, 406, 415

Grözinger, Verleger 145

Gruben, Constantin von 132, 168, 230

Gruben, von, Stud. 154

Gruben, Walburga von 165, 168

Grünewald, Ernst 526

Guarneri, Andrea 170

Gudenau, Baron von, s. Vorst

Guicciardi, Julie 350

Guisez, Hofratssekretär 150

Gunsberg, von, Hofkammerrat 150, 152

Gunzenhausen, Heymann Loeb 155

Gunzenhausen, Meyer Heymann 115, 143, 155

Gutenberg, Johannes 527

Guttenberg, Fräul. von 149

Gymnich, Clemens August Freiherr von und zu, kurmainz.

Rat, kurköln. Kammerherr 156

Gymnich, Karl Otto Freiherr von und zu, geh. Konferenzrat 101, 150, 216, 239f.

Gymnich, Johanna von, Stiftsdame (Neuss) 151

Gymnich, Thesese von, Stiftsdame (Neuss) 151

Gyrowetz, Adalbert 270

\section{H}

Haak, Kanzler (Koblenz) 397

Haan, Simplicianus OESA 113

Hadebald, Ebf. von Köln 53f.

Hähnel, Ernst Julius 527, 530f., 534f., 542

Hagedorn, Friedrich von 110

Hagen, Johann, Bäcker 65

Hager, Johann Georg 399

Halem, Anton von 132
Haller, Albrecht von 120, 395

Hanf, Ferdinand 115

Hardenberg, Karl August Fürst von 362

Harold, Edmund von 106

Harrach, Graf Aloys von 483

Hartknoch, Verleger (Riga) 179

Harttrodt, S. C. 148

Haslinger, Tobias 46, 522, 524, 539

Hasslinger, J.A. 121

Hatzfeld, August Clemens Ludwig Maria, Domherr (Eichstätt) 165

Hatzfeld, Clemens August Johann Nepomuk Graf,

Generalleutnant 104, 132, 165, 167, 203, 413

Hatzfeld, Maria Anna Hortensia von, geb. Gräfin von Zierotin $104,132,154,164 f$.

Hauptmann, Familie 515, 544

Hauser, Prof. 152

Häußler, Franz Friedrich 473, 480f., 488

Häußler, Frau 489

Haydn, Joseph 157, 168-170, 210, 227, 247, 251-254, 264, 270f., 317, 391, 426, 443, 455f., 467, 499, 504-511, 515, $518,525,544$

Heathcot(t)e, Antoinette, geb. Wolter 99, 149

Heathcot(t)e, Ralph 287, 505

Heathcot(t)e, Rudolph 99

Hebbesturm (Hebensturm), Daniel Franz 372, 387

Hebenstreit, Franz 426, 433

Hebenstreit, Pantaleon 201

Heckel, Franz Leopold Edler von 100, 149f., 230, $280 f$.

Hedderich, Philipp Franz Anton OFMConv 112, 114, 117, 143, 152, 219f., $239 f$.

Hegel, Simon, Hoflaquai 149

Heidel, Hermann Rudolf 530, 542

Heimsoeth, Friedrich 520, 543

Heine, Heinrich 515

Heinen, Wilhelm Joseph $111 \mathrm{f}$.

Heinse, Wilhelm 95

Heller, Ferdinand, Hofsänger 129, 150, 154(?), 303

Heller, Gaudenz, Hofviolinist 129, 150, 154(?), 230

Hellinger, Silberdiener 478

Hendel, Johann Christian 107

Henri, Hoftapezierer 150

Henseler, Theodor Anton 389, $539 f$.

Herder, Johann Gottfried 110f., 120, 125, 132, 135, 298, 391

Hermann, Dekan 55

Hermes, Johann Timotheus 95

Herter, M. 62

Herwegh, Georg 515

Hetzler, Illuminat (Frankfurt/M.) 95

Heuser, Stud. 154

Heyne, Christian Leberecht 492

Hildebrandt, Theodor 530 
Hiller, Johann Adam 158, 393f., 396, 399f., $402 f$.

Hirschmann, Herr 154

Hittorf, Hofapotheker 156

Höcker, Hofkammerrat 150

Höfel, Blasius 352, 356, 366

Hölty, Ludwig 132

Höpp, Madame, geb. Mainone (Leipzig) 155

Hörster, Hofrat 156

Hoffmann, Leopold 270

Hoffmann, Reinhard Friedrich, Kantor (Chemnitz) 399

Hoffmeister, Franz Anton, Verleger 270, 433

Hofmeister, Herr 103, 149

Hogenberg, Franz 78

Hohenlohe, Fürsten, Domherren (Köln) 99, 138

Hohenlohe-Bartenstein, Fürstin Franziska, s. Salm

Hohenlohe-Bartenstein, Fürst Joseph von, Domherr (Köln u.

Straßburg) 216, 240

Hohenlohe-Kirchberg, Fürst Christian Friedrich Karl 469,

482

Hohenschurz, Herr 154

Hohenschurz, Christian (Ordensname: Johannes) OSBir 512

Hohenzollern, Fürstin 99

Hohenzollern, Graf von, Obristhofmeister 58, 99

Hohlfeld, Johann 184f., 209

Ho(h)nrath, s. Greth

Holnstein, Graf von 139

Homberg, Pfr. Dietkirchen 154

Hornemann, Christian 299, 315

Horst, Anna, s. Ries

Horst, Goswin 307, 333

Hoynck, Franz Rudolf, Pfr. St. Remigius 69

Huber, Franz Xaver 450, 494

Hueber, Musikdirektor (Kaufbeuren) 457

Hünten, Herr 149

Hüpsch, Freiherr von 153

Humboldt, Alexander von 96

Humboldt, Wilhelm von 122, 134

Hume, David 95, 118

Hun(c)zovsky, Johann Nepomuk 347, 355

Hundeshagen, Bernhard 526

Hupp, Maler 154

Hupperich, Anna Maria 48

Hupperich, Familie 52

Hupperich, Gertrud, geb. Bintz 48

Hupperich, Jakob 48

Hupperich, Johannes 48

\section{I}

Iffland, August Wilhelm 489, 493

Ignaz XIII., Papst 57

Ingenmey, F. 506

Isaac, Andreas, Hofkammerrat 188f., 191

Isbach, Peter, Pfr. St. Remigius 43, 52, 69
Isenstein-Birstein, Fürst von 283

J

Jacobi, Friedrich Heinrich 106

Jacquemin, Carl Graf von 139

Jacquemin, Familie 103, 133

Jacquemin, Heinrich Ludwig Freiherr von 139

Jacquemin, Herr 149

Jacquemin, Sophie de, verh. von Andlau 103

Jäger, Sohn 457

Jäger, Vater, Musikdirektor (Ansbach) 457

Jäger, Vitus 113

Jagenberg, Walter 28

Jahn, Otto 440

Janscha, Lorenz 13, 309f., 500, 502

Jaques, Bürger 152

Jenger, Georg (Gereon) Friedrich 26, 28

Jenner, Edward 354

Jérôme, König von Westphalen 287

Jerusalem, Johann Friedrich Wilhelm 395f., 400, 402

Joassin, Marianne, Demoiselle 154

Jochmaring, Romuald Anton 230

Jörres, Glasmaler 74

Jolyot de Crebillons, Claude Prosper 92

Jordaens, Jacob 172

Jordaneus, Johann, Pfr. St. Remigius 69

Joseph Clemens, Kf.-Ebf. von Köln 57, 69, 144, 256

Joseph II., Kaiser 96, 188, 224, 250, 253, 345, 419, 437, 507

Jungen, Stud. 154

Jünger, Konrektor (Chemnitz) 399

Junker, Carl Ludwig 157, 245, 415, 482, 485f., 488, $496 f$.

Justi, Johann Heinrich Gottlob von 117

$\mathbf{K}$

Kaiff, geistl. Rat 150

Kaipf, Knabenhofmeister 154

Kalchberg, Johann Nepomuk Ritter von 491

Kalkbrenner, Musiker 321

Kalt, Hofkammerrat 154

Kaltenauer, Postmeister 152

Kames, Henry Home 402

Kanitz, Friedrich Ludwig von 120

Karl August Herzog von Pfalz-Zweibrücken 286

Karl von Österreich, Erzherzog OT $382 \mathrm{f}$.

Karst, Henrich, Geometer 372-374, 379

Katharina II., Zarin 178

Kauffmann, Goldina, verh. Gompert 101, 149

Kauf(f)mann, Moyses 101, 149

Kauf(f)mann, Salomon 101, 149

Kauffmann, Sussmann 101, 149

Kauffmann 149

Kaufmann, Familie 515, 535, 544

Kaufmann, Hofk. 154 
Kaufmann, H. J. 149

Kaufmann, Jud 149

Kaufmann, Matthias Josef 150

Kauhlen, Franz Wilhelm 103, 150, 154, $239 f ., 345$

Keilholz, Christine und Dorothea 129, 154, 473

Kelsinger, Maria Josepha Ernestine, s. Laym

Kem(mer)ling, Caspar, Pfr. St. Remigius 59, 69

Kempen, Melchior 28

Kemper, Peter 187, 193-195, 201

Kerich, Helene, s. Breuning

Kerich, Joseph Abraham $108 f$.

Kerp, Mr. le Conseiller 149

Kettels, Abbé 154

Ketterlinus, Christian Wilhelm 127

Khevenhüller-Metsch, Johann Josef 257

Keverberg zu Aldengoor, Herr 150

Keverberg, Karl Ludwig Freiherr von 129f., 152, 230, 281

Keverich, Anna Clara, geb. Westorff $13 f$.

Keverich, Johann Heinrich 13, 25f., 41, 51, 437

Keverich, Maria Magdalena, s. Beethoven

Kindermann, Ferdinand 118

Kinkel, Gottfried 515, 518, 530, 535, 542, 544

Kinkel, Johanna 515, 518, 520, 535, 544

Kinsky, Fürst von 315

Kints, Kand. 150

Kircher 149

Kirchrath, Vikar 149

Kleemann, Johann August 400, 414

Klein, Franz 354

Klein, Karl Theodor, Kand. (Rheinbach) 152

Klein, Stud. 154

Kleine, Johann Christian 208

Kleinheinz, Franz Xaver 335

Kleist, Clemens August Freiherr von 216, 240

Kleist, Ewald von 94, 105

Kleist, Franz Alexander von 360

Kleist, Heinrich von 369

Klemmer, Anna Maria, s. Koch

Klemmer, Jakob 129, 231, 280, $283 f$.

Klinckerfuß, Orgelbauer (Stuttgart) 206

Klinger, Friedrich Maximilian 106

Klinger, Max 534, 544

Klöckner, Johann Heinrich Joseph, Pfr. St. Remigius 69

Klopstock, Friedrich Gottlieb 95, 105, 120, 132, 283, 299,

359, 368, 397, 399, 412

Knaur, Hermann 530

Kneisel, Carl Moritz 226, 540f

Knigge, Adolph Franz Friedrich Ludwig Freiherr von $217 \mathrm{f}$., 231, 397, 424

Koch, Anna Maria (Witwe), geb. Klemmer 111, 123, 129,

150, 280-282, 287, 296

Koch, Barbara (Babette), verh. Belderbusch 108, 111, 131,

154, 164, 168, 205, 235, 281f., 284, 286-288, 292, $296 f$.
Koch, Familie 283f., 287, $296 f$.

Koch, Marianne 282, 297

Koch, Matthias 131, 150, 230, 282-284, 291

Koch, Michael 280

Koch, Stud. 154

Koch, Willibald OFM 190, 405

König, Ludwig 70, 201

Königsegg-Erps, Gräfin, s. Zierotin

Königsegg-Aulendorf, Graf Meinrad von, Domherr (Köln) 216f., 245

Königsegg-Rothenfels, Graf Ernst von, Domherr (Köln)

$216 f ., 240$

Könneke, Jakob 202

Kohlbrenner, Franz Seraph 250

Kolter, Stud. 154

Kornrumpf, Gottfried von 473f., 494

Kotzebue, August von 492

Kozeluch, Leopold Anton 176

Kracht, Stud. 154

Kramer, Hofkammerrat (Wallerstein) 457

Kraus, Joseph Martin 270

Krug, Dorothea 159

Krummans, Stud. 154

Kruse, Stud. 154

Kügelgen 203

Kügelgen, Gerhard 230, 281

Kügelgen, Karl Ferdinand 129f., 133, 154, 230, 281

Kühlwetter, Hubert 333

Kummer, Assessor 30

Kürschner, Anton 378

\section{$\mathbf{L}$}

Laban, Rudolf von 381

Lachaussée, Stud. 154

Lamberg, Graf von 445

Lang, Johann Georg, Komponist 179

Lang, Joseph Gregor 122, 473

Langenbucher, Jakob 186

La Roche, Sophie von 95, $105 f$.

Lassaulx, Johann Claudius von 530

Lauf(f)er 149

Lavater, Johann Caspar 107-109, $401 \mathrm{f}$.

Laym (Leym), Johann 14, 26, 41

Laym, Johann Franz Ludwig 26

Laym, Johann Peter Anton 14, 31

Laym, Johann Philipp 26

Laym, Maria Friederike 26

Laym, Maria Josepha Ernestine, geb. Kelsinger 26

Leerodt, Freiherr Joseph von 216f., 234, 240

Legros, Martin 58

Lehmann, Leo 321

Lehrbach, Baron von 457

Leizel, Balthasar Friedrich 227 
Lenné, Peter Joseph 314, 335

Lenz, Christian Wilhelm von 440

Leopold II., Kaiser 97, 101f., 127, 132, 156, 175, 254, 347

Leroth, Freifr. von, Kanonisse 154

Leschen, Wilhelm 197

Lessing, Gotthold Ephraim 94f., 105, 136, 359, 394, 403, 411

Letronne, Louis 352, $365 f$.

Leydahler, Vitus 57

Leym, s. Laym

Liebe, Gottlob August 404

Li(e)bisch, Georg, Oboist 230, 246, 470, 472, 482

Lichnowsky, Karl Fürst von 422, 439

Lichtenstein, Gräfin von 149

Liepmanssohn, Leo 539

Lincke, C. 385

Linger, F. W. 511

Linguet, Simon Nicolas Henri 96, 124

Lipowsky, Felix Joseph 448

Liszt, Franz 520, 529, 532, 534, 536, 541, 543

Lith, Johann Wilhelm von der 117

Llotard, Jean-Etienne 243

Lobkowitz, Fürst 316

Löhneisen 117

Löltgen, Garnisonspfr., Hofkammerrat 150, 154

Lohbauer, Philipp Gottfried 127

Lomberg, Joseph Vitalian 113f., 150

Louis Philippe, König von Frankreich 328

Luchesi, Andrea 195, 204, 242, 250, 252, 265f., 389, 398, 405, 409, 506

Luchesi, Josepha Antonetta, s. d'Antoine 204

Luchesi, M. Jakob Ferdinand 204

Luchesi, Maximilian Friedrich 204

Luchet, Jean-Pierre-Louis de 93

Ludolf, Pleban St. Remigius 55

Ludwig XIV., König von Frankreich 56

Ludwig XVI., König von Frankreich 56

Lützerath (Lützelrode), Johann Friedrich Freiherr von 154, 165

Lützerath, Frau von 165

Luther, Martin 220, 528

Lux, Joseph, Schauspieler 154, 230, 273, 468, 470, 472f., 487.f, 497

\section{M}

Machek, Antonin 380

Mäurer, Bernard Joseph 405

Magka, Heinz 508, 510

Mainone, Karl 155

Maintenon, Madame de 92

Malchus, Carl August 231, 281f., 285-288

Malfatti, Therese 48, 351

Managetta, Johann Wilhelm Ritter von Lerchenau 118
Maria Thersesia von Österreich 256

Mariani, Tommaso 493

Marie Antoinette, Königin von Frankreich 368, 504

Marius, Jean 181

Marivaux, Schriftsteller 125

Marpurg, Friedrich Wilhelm 399

Martens, Frédéric 329

Martin, HI. 35

Martin, Nikolaus, Kaufmann 485

Martin, Stud. 154

Martini, Padre (Bologna) 435

Marx, Lion 101, 149

Marx, Marx Jakob 101

Mastiaux, Amalie von 110, 150, 155, 165, 167, 169, 177

Mastiaux, Caspar Anton von, Domherr 110, 134, 153, 165, 228, 230, 253

Mastiaux, Caspar Anton Joseph von 110, 153, 165

Mastiaux, Familie 409

Mastiaux, Johann Gottfried von, Hofkammerrat 110, 142, 152f., 157, 165, 168-170, 176-179, 187f., 195, 205f., 252f., 376

Mastiaux, Max Joseph von, Kanoniker 110, 129f., 150f., 153, 165,177

Matthisson, Friedrich von 427

Mattioli, Cajetan/Gaetano 195, 267, 303

Maximilian Franz von Österreich, Kf.-Ebf. von Köln 22f., 94, 96, 98, 102, 115-120, 122f., 128f., 133, 138f., 168f., 188, 192f., 195, 205, 213, 218, 220, 224f., 229, 235, 241-250, 252-260, 263-267, 269f., 281f., 297, 302f., 307, 309, 334, 344f., 359, 368, 371f., 374-380, 382-386, 391, 406, 419f., $426,437,439,467,469,473-475,478-483,486 f ., 489,494-$ 501, 503f., 506f., 511, 513, 518, 525, 537

Maximilian Friedrich von Königsegg-Rot(h)enfels, Kf.-Ebf. von Köln 39, 41f., 59, 97, 99, 108, 115f., 119, 162, 165, $188,192,199,204,207,210,213,216,218-220,224,233$, $241-243,247,249 f ., 259,267,269,302,344,346,358,398$ 406, 419, 439, 459, 469

Maximilian Heinrich, Kf.-Ebf. von Köln 65, 70f., 76

Mayer, Domkapellmeister 525

Mayer, H. 445

Meder, Johann Franz 102, 149

Meder, Johann Leopold, Rentmeister 102, 149

Meiners, Christoph 134

Meinhard, Nikolaus 402

Meißner, August Gottlieb 95, 105

Melon, Jean-Francois de 118

Memering, Friedrich, Kand. 152

Memering, Stud. 154

Mendel, Musiker 470, 472

Mendelssohn, Abraham 144

Mendelssohn, Fanny 144

Mendelssohn, Leah 144

Mendelssohn, Moses 106, 122, 395, 400-402 
Mendelssohn-Bartholdy, Felix 144, 322, 523

Menn, Johann Georg 119, 144

Mer(c)kenich, Johann Peter 142, 152, 154

Merian, Matthäus 79

Merlin, Jean-Joseph 181, $183 f$.

Mertens-Schaaffhausen, Sibylle von 518

Mertens, Lizentiat 154

Mertens, Ludwig 541

Merville, M. Anna, geb. Torricella 503

Metastasio, Pietro 92

Mettely, Nikolaus 477

Metternich, Cornelius, Pfr. St. Remigius 67

Metternich, Franz Georg Graf von 97, 99

Metternich, Hofrat (Köln) 156

Metz, Martin 477

Meunier, Vikar 154

Meurer, Ernst 428

Meuser, Michael 246, 470, 472f., 482

Meyer, Stiftsdechant 150

Meyerbeer, Giacomo 328, 534

Michelis, Fr. 20

Mieg, Johann Friedrich 96

Mirman, von, Leutnant 196, 205

Mirman, von, Kämmerer 205

Mittelmeyer, Anton Ferdinand 99, 149

Mizler, Lorenz Christoph 180

Möser, Justus 527

Mohr, Anton 520

Molière, Jean Baptiste Poquelin 92, 136

Mompour, Franz Josef 519

Monceau, Henri Louis Duhamel de 118

Montesquieu, Charles-Louis de 93, 115

Moscheles, Ignaz 534

Moser, Friedrich Carl von 96

Moser, Johann Jacob 186, 209

Moutier, du 179

Mozart, Constanze 245, 258

Mozart Leopold 173

Mozart, Wolfgang Amadeus 165f., 177, 206, 260, 268, 270,

297, 303, 371, 390, 420, 423, 435-440, 442f., 445f., 449-

$452,456,458,460,465,473,485 f ., 488,492,494,504$,

506, 509f., 518, 520, 525, 535, 544

Müller, Adolph 319

Müller, Carl Wilhelm, Jurist (Leipzig) 394, 396, 411

Müller, Friedrich, Sänger 230, 470, $472 f$.

Müller, Gertrud, s. Baum

Müller, Hofk(ammerrat) 150, 154

Müller, Jacob, Beig. 59

Müller, Johannes 517

Müller, Kand. 152

Müller, M., Zeichner/Maler 511

Müller, Matthäus, Instrumentenbauer (Wien) 182

Müller, Schauspieler 473, 488f., 497
Müller, Wenzel 445

Müller, Wilhelm Christian, Musikschriftsteller (Bremen) 319, 335

Müller (von Königswinter), Wolfgang 508, 510, 515

Münchs, Anna Maria 48

Musäus, Johann Carl August 94

\section{$\mathbf{N}$}

Nachtsheim, Stud. 154

Nägeli, Hans Georg 423

Nagler, von, Generalpostmeister 365

Napoleon Bonaparte 63, 88, 287, 316, 320, $361 f ., 369$

Necker, Jacques 93, $117 f$.

Neeb, Johannes 114

Neefe, Christian Gottlob 95, 100, 108f., 126-129, 132, 150f., 154, 157f., 164-168, 170f., 174-176, 179-181, 183-187, 195, $198,201,204,206,215,218,222 f ., 229 f ., 235,238,240$, 244-246, 251, 253, 256-258, 263, 265, 267-269, 307, 312, 358f., 389-416, 420, 424f., 438f., 444, 451, 472, 481, 486, $508,510,515,519,523$

Neefe, Susanna Maria, geb. Zinck 128, 174, 392, 406

Neesen, Joseph 110, 141

Neesen, Kurf.-pfalzbayr. Rat 150

Nesselrode-Reichenstein, Graf, Hofkammerpräsident 104, $154,236,239$

Nesselrode-Reichenstein, Gräfin 104

Nettekoven, Oberkelllner 154

Neuber, Friedrike Caroline 403

Ney, Martin von 345, 499

Nicola, Geigenbauer 170

Niebuhr, Barthold Georg 517

Noeggerath, Johann Jakob 528

Noel, Matthias Joseph de 536

Nösselt, Johann August 395, $400 f$.

Nonn, Carl 21

Noot, Hendrik van der 93

Normann, Rudolf Carl Friedrich Ernst von 353

Nüdel, Stud. 154

\section{O}

Oberthür, Bonifaz Anton 112-114, 124, 141, 143, 150, 154, 224f., 232, $239 f$.

Odenkirchen, Clement 333

Oeppen, Johann Laurenz 102

Oeser, Adam Friedrich 394, 396, 403

Oettingen-Wallerstein, Fürst Kraft Ernst zu 449, 496

Oettingen-Wallerstein, Fürstin Maria Theresia Carolina von, s. Thurn und Taxis

Oliva, Franz 429

Oppenheim, Salomon Herz 115, 143

Opiz, Schauspielerin 488, 497

Opiz, Grethe 497

Ordonez, Karl von/Carlos d' 247, 264, 270 
Orsbach, Alexander von 64

$\mathbf{P}$

Pachmayer, Joseph 246, 470, 472, 282

Paisiello, Giovanni 488, $491 f$.

Pálffy-Erdöd, Johann Leopold Graf von 304, $449 f$.

Pálffy, Gräfin Josepha Gabriela 304

Pall, Maria Josepha, s. Ball

Pannensmit, Peter 78

Pape, Gewerbeoberlehrer 74

Paraquin, Johann Baptist 230

Pasztory, Anna von 297

Patin, Matheus 464

Paulinus, P. OFMCap 233

Peltzer, Johann Jakob Tillmann (von) 110, 142, 165, 230

Peltzer (Belzer), Theresia Barbara $164 \mathrm{f}$.

Peretti, Zinngießer 30

Pergolesi, Giovanni Battista 493

Perner, Andreas 230

Pesch, P. Lucianus OFMCap 233

Pesselier, Charles Etienne 118

Peters, Carl Friedrich 422, 430, 433

Pfau, Sebastian 165, 230, 244f., 470, $472 f$.

Pfeffel 132

Pfeifer, Stud. 155

Pfeifer, Tobias Friedrich 20

Pfingsten, Familie 515, 544

Philipp Wilhelm von der Pfalz 87

Philippart, Clemens August Josef 215

Picart, B. 18

Pick, Franz, Kanonikus 63, 318, 514, 528

Pick, Stud. 155

Pickel, Johann Georg 502, 514

Pisarowitz, Karl Maria 449, 452, 464

Pius VI., Papst 220, 525

Plankenberger, Herr (Wien) 445

Pleißner, Heinrich Christian 492

Plenck, Joseph Jakob von 348

Pleyel, Ignaz 270, 485

Plinius 94

Pock, Joshua $181 \mathrm{f}$.

Pohlmann, Johannes 211

Pok(h)orny, Thomas 230, 470, 472

Pokorny, Xaver 449

Poll, Conrad 95f., 211

Poll, Maria Josepha, s. Ball

Polzer, Wenzel Hermann 230, 280

Ponte, Lorenzo da 491

Pouget, Francois-Aimé 91

Probst, Verleger (Leipzig) 430

Püttner, Johann Stephan 117

Pulte, Kand. 152

Putz, Lambert, Pfr. St. Remigius 66, 69
$\mathbf{R}$

Rabenai, Ritter von OT 478

Rabener, Gottlieb Wilhelm 106, 110, 120, 399, 403

Racine, Jean Baptiste 92, 136

Radcliffe, Ann 504

Radermacher, Kanonikus 285

Radius, Albertin, Pfr. St. Remigius 69

Radoux, Wilhelm Amelius 41, 305

Ramler, Karl Wilhelm 106, 120

Rasche, F. L. L., Gerichtsschreiber 195

Ratz, Erwin 389, 409

Rauch, Christian Daniel 529f.

Rautenstrauch, Johann 492

Rebele, Andreas 202

Rederscheidt, Anna Catharina 70, 87

Reginar 53

Reicha, Anton, Hofmusiker 129, 133, 155, 262, 268f., 272, $281,297,449,523$

Reicha, Joseph, Direktor der Instrumentalmusik 100, 108 , $126,139,155,179,211,230,259,265-269,303,307,309$, $449,456,464,472$

Reichardt, Johann Friedrich 179, 258, 396, 403

Reichersberg, Freiherr von 152

Reinermann, Lambert, Pfr. St. Remigius 74

Remigius, Bf. (Reims) 35

Reumont, Stud. 155

Reuschel, Tobias Christoph 206

Rheindorf, Christian 29

Rheindorf, Maria Agnes 29

Rheindorf, Maria Susanne Katharina, s. Fischer

Ribini, Johann Daniel 297

Richter 325

Richter, Johann Heinrich, Maler 340

Richter, Johann Jakob 230, 282, 285, 297

Richter, Johann Tobias 400

Richter, Rudolf 159, 203

Riedlen, Andreas, Schreiner 186

Riedlen, Friederike Luise 186

Riedlen, Johann Heinrich, Pfr. 186

Riedlen, Juliana Charlotte 186

Riedlen, Sibylla Juliana, geb. Esenwein 186

Riedler (Riedlen), Gottlieb Friedrich, Orgelbauer 157, 159,

175-177, 179f., 183-188, 190, 192-197, 201, 209-211

Riegel, Lehrer 155

Riemann, Hugo 441, 465

Riepel, Joseph 449

Ries, Adelheid, verh. Eigelmayer 302, 305-307

Ries, Anna, geb. Horst 307f.

Ries, Anna Maria, verh. Drewer 303-305, 310, 315, 336

Ries, Familie 301-305, 308, 311, 314, 317, 319, 321, 328,

$332,338,515$ 
Ries, Ferdinand 24, 30, 283f., 295, 307, 311-331, 335f., 338 342, 365f., 423f., 429, 432, 440, 467, 469, 505, 507, 513, 515, 519f.

Ries, Franz Anton 22, 30, 129, 132, 150, 165, 175f., 204, 218, 230, 237f., 240, 244f., 253f., 265, 302-305, 307-313, 318, 325, 331f., 338, 352, 365, 406f., 412, 423, 425-427, 432, 467f., 470, 472, 485, 489, 500, 505-509, 515, 519

Ries, Harriet, geb. Mangeon 323f., 328, 338

Ries, Johann 301f., 303-305, 308

Ries, Johanna Elisabeth, geb. Beyer 308

Ries, Joseph Franz 315, 326, $338 f$.

Ries, Peter Joseph 354

Rieter-Biedermann, J., Verleger 381

Rietschel 530

Righini, Vincenzo 166, 451, 468, 485, 496

Ringlin, Georg 82

Ringbauer, Mlle. 462

Riva, Antonio 80

Rochlitz, Friedrich 392f., 395-400, 402, 407

Röllig, Carl Leopold 158, 202, 348

Röser, Maximilian Justin Anton 100

Roll zu Bernau, Ignaz Franz Felix Freiherr von OT 387, 477, 481, 494

Rolshausen, Freiherr von, Hofrat 150, 155

Romanzow, Graf von 156

Romberg, Andreas, Violinist 151(?), 244f., 257, 268, 271, 273, 281, 291, 297, 299, 309, 391, 451, 468, 470, 472, $485 f$. Romberg, Bernhard, Cellist 151(?), 244f., 257, 268, 281, 291, 293f., 297, 299, 309, 312, 320, 391, 451, 468, 470, 472, $485 f$.

Roque, de la, Kand. 152

Rordorf, Caspar 34

Rosenberg, Georg 404

Rosetti, Antonio 449

Roth 155

Rotter, Franz 511

Rougemont, Joseph Claudius de 112, 114, 120, 125, 142, 155, 221f., 239f., 357

Rousseau, Jacob, Maler und Radierer 82f., 103, 469, 510(?)

Rousseau, Jean Jacques 92-94, 106, $402 f$.

Rousseau, Franz, Maler und Radierer 227, 241f., 248, 284, 301, 306, 361, 383, 385, 469, 510(?)

Rousselois, Marie Wilhelmine 268

Rovantini, Franz Georg 20, 168, 415,

Rovantini, Johann Konrad 14, 41, 51

Rovantini, Maria Magdalena 20, 29

Rubens, Peter Paul 172

Ruckers I, Andreas 164, 170-173, 206

Ruckers II, Andreas 171

Ruckers, Anna, s. Davidszoon de Heem

Ruckers, Hans 171

Ruckers, Johannes 171

Rudolph, Erzherzog 316, 323, 428
Rühl, Hofrat (Frankfurt/M) 397

Ruprecht, Ebf. von Köln 54

Russel, William 95

Rzewuska, Gräfinnen Isabella und Rosalie 380

\section{S}

Sacchini, Antonio Maria Gasparo 492

Sachs, Magdalena Sophie 206

Sachsen, Maria Kunigunde von, Äbtissin 375

Sachsen-Teschen, Erzherzog Albert (Albrecht) von 103, 154, $257,375,495$

Sachsen-Teschen, Erzherzogin Marie Christine, geb.

Erzherzogin von Österreich 102f., 375, 495

Salieri, Antonio 544

Salm, Eleonora Maria Gräfin von, geb. von Waldburg-Zeil 139

Salm, Franziska Gräfin von, geb. Hohenlohe-Bartenstein 99, 139,149

Salm, Graf u. Gräfin 104

Salm-Reifferscheid-Dyck, Franz Altgraf von 99, 139

Salm-Reifferscheid-Dyck, Sigismund Altgraf von 11, 22, 25, 99, 139, 405

Salm-Salm, Prinz Emanuel von 216f., 240

Salomon, Friedrich von 541

Salomon, Johann Peter 163, 205, 252, 304, 318, 321, 325,

506-508

Salomon, Philipp 27

Samme, Johann Gottfried 400

Sandfort, Hermann 35-37, 49, 57, 81, 84, 88, 150, 155

Sattler, Johann Tobias 96

Satzenhoven, Caroline von, Äbtissin 90, 163, 203

Saur, Jean André $318 f$.

Schaaf, Carl 40

Schacht, Theodor von 449

Schaden, Nanette (Anna) von, geb. von Stadler 448, 455f., 463

Schaden, Joseph von 30, 333, 439, 444f., 448, $455 f$.

Schadow, Wilhelm von 530

Schäfer, Stud. 155

Schall, Reichsfreiin von 128

Schall zu Bell, Clemens August Freiherr von d. Ä. 151f., 155, 164f., 218, 222f., 227, 238, 240

Schall zu Bell, Clemens August Freiherr von d.J. 150, 155, 218, 238, 240, 378

Schallmeyer, Prof. 152

Scheben, Sebastian OSB 155, 162, $239 f$.

Scheidler, Ferdinand August 114, 136, 155

Schenk von Nideggen, Martin 56, 78

Scheufele, Leo 80

Schevastes, Familie 409

Schevastes, Herr 151

Schiller, Charlotte 296 
Schiller, Friedrich von 105, 111, 125, 132, 215, 282f., 291, 296, 336, 359, 383, 527

Schindler, Anton 202, 330, 342, 355, 440

Schinkel, Karl Friedrich 529, 541

Schlegel, August Wilhelm von 328f., 517, 528f., 541

Schlegel, Johann Adolf 120

Schlesinger, Adolph Martin, Verleger (Berlin) 322, 430, 433(?),

Schlesinger, Maurice, Verleger (Paris) 331, 430 433(?)

Schlesinger, Nathan Horwitz 115, 131, 155

Schmid, Josef 412

Schmidt 210

Schmidt, Fähnrich 149

Schmidt, Johann Adam, Arzt (Wien) 349f., 355

Schmidt, Joseph, Schauspieler 151, 238, 240, 397, 412

Schmidt, Klamer 132

Schmidt, Stabsfourier 151

Schmidt von der Launitz, Eduard 530

Schmitz, Herr 149

Schmitz, Joseph, Kanoniker 101, 151, 155, 238, 240, 412

Schmitz, Stud. 155

Schneider, Eulogius OFM 111, 113f., 127, 131f., 142f., 146, $151,154,285,359,368,407,507$

Schnitzler, Hofkaplan 155

Schnorr von Carolsfeld, Veit 392

Schönebeck, Barbara, geb. Eichhoff $357 f$.

Schönebeck, Johann Bernhard Constantin von 123f., 127, $151,153,223,358,368,385$

Schöneberg, Prediger (Oberkassel) 153

Schorlemmer, Frau von 99, 149

Schorlemmer, Friedrich Wilhelm Freiherr von 99

Schott, Verleger (Mainz) 180, 277, 341, 430f., 433f., 468, 531,542

Schreiber, Aloys Wilhelm 131

Schröckh, Johann Martin 395

Schröder, Friedrich Ludwig 491

Schroeter, Christoph Gottfried $179 f$.

Schubart, Christian Friedrich Daniel 127, 132, 346f., 392, 411

Schubert, Franz 322, 544

Schuchardt, Johann Ernst 206

Schücking, Clemens August, Sekretär 225f., 228, 236, $238 f$. Schüren, Elias Peter Joseph van der OFMConv 123, 133, 135f., 220, $239 f$.

Schütz, F. X. 510

Schugt, Stud. 155

Schulin, Johann Philipp 127, 156

Schulten, C. A. 192

Schumann, Robert 328, 528

Schuster, Dr. 337f.

Schwanthaler, Ludwig 530, 535

Schweinheim, Tafeldecker 479

Schwenck, Pfr. St. Remigius 69
Schwickert, Verleger (Leipzig) 179, 198, 211

Seida, von, Stud. 155

Seiferheld, Georg Heinrich 211

Seinsheim, Graf von 58

Senden, von 149

Senft, Peter 206

Serrières, Baligand de 491

Seydlitz, Christian Gottlieb 400

Seyfried, Iganz Ritter von 200

Seyler, Abel 174, 394, 397, 400, 411

Shakespeare, William 95

Siegmund, Herr 446

Silbermann, Gottfried 172, 201

Simon, Baruch 115

Simonetti, Louis/Ludwig/Luigi, Sänger 244f., 258, 470, $472 f$. $485 f$.

Simrock, Dora 317

Simrock, Henri 318

Simrock, Joseph 519

Simrock, Karl 515

Simrock, Nikolaus 46, 129, 132, 151, 155, 165f., 175, 180, $196,204,207,218,230,237 f ., 240,246,253 f ., 265,307$, 309f., 316-318, 323, 336f., 350f., 370, 372, 386, 390, 407, $410,412,417-434,467 f$., 470, 472f., 482, 515, 519, 522$524,534 f ., 539$

Simrock, Ottilie, geb. Blaschek 419

Simrock, Peter Joseph 317, 428, 432, 524, 539

Smart, George 534

Sohn, Carl Ferdinand 530

Soler, Vicente Martin y 491

Späner, Kand. 152

Spalding, Johann Joachim 395f., $400 f$.

Spath, Franz Jacob 159, 161 f., 198

Spazier, Johann Gottlieb Carl 391

Spee, Graf von, Obristkuchenmeister 155

Speyer, Wilhelm, Hofkapellmeister (Kassel) 528

Spiegel zum Di(e)senberg, Freiherr Ferdinand August,

Domherr (Münster und Osnabrück) 156

Spiegel zum D(i)esenberg, Freiherr Friedrich Ernst von OT

156

Spiegel zum D(i)esenberg und Canstein, Freiherr Franz

Wilhelm von 97f., 104, 112, 119, 121f., 126, 133f., 155f.,

215-218, 224f., 231-234, 236, 238-240, 253, 265, 296f., 384

Spillberg, Johann, Maler 61, 71f., 87

Spiri, Schauspielerin 480

Spittler, Ludwig Timotheus von 124, 134

Spitz, Andreas OSB 114, 220, 235, $239 f$.

Spizeter, Johann, Musiker 470, $472 \mathrm{f}$.

Spohr, Ludwig 523, 534

St. Germain, Comte de 91

St. Vanne 149

Stachelscheidt, Stud. 155

Stahl, Hofk. und Baumstr. 155 
Stainer, Jacob 170

Stamitz, Anton 247, 264

Stamitz, Carl 247, 264

Stark, Ferdinand 151

Stark, Quirin, Offermann 65

Starz, Herr 151

Steiger, Anton, Schauspieler 100, 149, 155, 230, 257, 259, 269,473

Stein, Anna Maria (Nan(n)ette) 166, 176, 196, 203f., 431, 457, 466, 524, 539

Stein, Frl. von 149

Stein, Fritz von 107

Stein, Johann Andreas, Klavierbauer 165f., 181, 183, 186, 197f., 207f., 456f., 466

Stein, Matthäus Andreas, Klavierbauer 197, 207

Stein, Freiherr vom 362

Steinen, Baron von (B. de) 102, 149

Steinen, Baronne von (Baronne de) 102, 149

Steinen, Frl. von 102, 149

Steinen, von 149

Steinen, Mme. de 149

Steinen zu Scherffen, Augusta Clementine Freifrau von,

s. Weichs

Steinen zu Scherffen, Friderike Freifrau von, s. Geldern

Steiner, Verleger 430, 433

Steinhausen, Heinrich, Apotheker 63

Steinmann, Vizesatrap 58

Steinmüller, Johannes 29

Steinway \& Sons 158

Stempel, Gerardus 79

Stephanie, Johann Gottlieb d.J. $491 \mathrm{f}$.

Sterkel, Johann Franz Xaver, Abbé 270, 309, 468

Sterne, Laurence 94, 105, 120, 140

Stieler, Ferdinand von, Offizier 101, 149, 151, 155

Stieler, Joseph Karl, Maler $342 f$.

Stolberg-Roßla, Johann Martin Graf zu 425

Storck, Abraham $79 f$.

Stradivari, Antonio 170

Streicher, Johann Andreas 159, 197, 294, 298, 457, 524, 539

Streicher, Johann Baptist 539

Streicher, Nannette, s. Stein

Streicher, Wirt (Regensburg) 445

Strobelius, Ferdinand, Pfr. St. Remigius 69

Struve, Anton Sebastian, russ. Agent 287

Struve, Burkhard Gotthelf 117

Struve, Heinrich von 230, 232, 237, 282, 287, 298

Struve, Susanne Maria, s. Dörfeld

Stumpff, Andreas 539

Stupp, Reiner 114

Süßmayr, Franz Xaver 451

Sulzer, Johann Georg 184, $402 f$.

Sussmann, Joseph Löw 131, 148, 155
Swanan, Joachim, Klavierbauer 208

Swieten, Baron Gottfried van 439

Sylvester, Br. OCarm 57

$\mathbf{T}$

Tag, Christian Gotthilf 399

Tandern/Dandern, von 445

Taskin, Pascal 171, 173, 206

Tasso, Torquato 93, 105

Tautphäus, von, Geheimsekretär u. Frau (Mergentheim) 155

Tetens, Nikolaus 122, 134, 147

Thaddäus, Prof. 155

Theile, Kammerdiener 155

Thenn, Johann Christoph 186

Thönessen, Stud. 186

Thorvaldsen 530

Thümmel, Moritz August von 120

Thürheim, Joseph Gundacker Graf 202

Thurn und Taxis, Franziska Gräfin von, geb. von Zierotin 166, 234

Thurn und Taxis, Fürst Karl Anselm von 448f., 464

Thurn und Taxis, Maria Theresia Carolina von, verh.

Oettingen-Wallerstein 449

Thurn und Taxis, Maximilian Karl Heinrich Joseph Graf 166f., 234, 240

Tieck, Friedrich 529

Tieffenbrunn, Otto Joachim 199

Töring, Stud. 155

Törring, Joseph August Graf von 491

Tossetti, Hofkammerrat 151

Touchemoulin, Joseph 449, 455, 459

Treves (Drewer), Laurent 332

Tribolet, s. Willmann

Tripps, de 149

Trost, Heinrich Gottfried 172

Trotti, von, Obristleutnant 151

Tryphonius, Claudius 400

Türk, Daniel Gottlob 158

Tussy, Franz 163, 238, 240

U

Ugarte, Graf Johann Wenzel 246

Umfenbach, Amtskellner (Mainz) 397, 412

Umlauf, Ignaz 451, 491

Unger, Johann Friedrich 184

Unger, Max 442, 461

Urbach, Stud. 155

Urbani, Giuseppe $381 \mathrm{f}$.

\section{V}

Vanhal, Johann Baptist 179f., 247, 264

Velten, Andreas Anton, Kreisphysikus 38

Velten, Anton Joseph 101, 149 
Velten, Johann Friedrich Marian 139, 222f., 229, 236, $239 f$. 281

Verandeny 487

Vering, Gerhard von 347, 349

Viktoria, Königin von England 531, 534

Villars, Claude-Louis-Hector de 91

Vinci, Leonardo da 185

Vogel, Hofkammerrat 156, 297

Vogler, Georg Joseph, Abbé 197, 211

Vohs, Schauspieler 155

Vola, Postsekretär 149

Voltaire, Francois Marie Arouet de 92f., 105, 125, 136

Vorst-Lombeck-Gudenau, Familie 104, 205

Vorst Freiherr zu Lombeck-Gudenau Burggraf von

Drachenfels, August von der 168

Vorst Freiherr zu Lombeck-Gudenau 165, 168

Vulpius, Christian August 492

\section{W}

Wacker, Stallmeister 155

Wagner, B. C. 60

Wagner, Richard 520

Waldburg-Zeil, Eleonora Maria Gräfin von, s. Salm

Waldbott, Freiherr Johann Otto, Herr zu Gudenau 65

Waldbott-Bassenheim, Clemens August von 99

Waldbott-Bassenheim, Franz Karl von 99

Waldbott-Bassenheim, Max Friedrich von 99

Waldburg, Gebhard Truchsess von, Kf.-Ebf. von Köln 55

Waldburg, Karl Truchsess von 56

Waldenfels, Frau von 165, 384

Waldenfels, Freiherr von, Domherr (Trier und Würzburg) 155

Waldenfels, Johann Christian Freiherr von, Staatsminister 99, 104, 149

Walderdorff, Johann Philipp von, Ebf. von Trier 13, 15, 27

Waldstein und Wartenberg, Graf Ferdinand Ernst von 155

$167,230,253,261,280,282,371 f ., 375-378,380-383,386-$

$388,423,475,504,508-510,514$

Waldstein und Wartenberg, Graf Joseph Karl Emanuel von 371

Wallerstein, Paul von 445

Wallraf, Ferdinand Franz 142, 153, 318, 336

Walpole, Horace 93

Walter, Anton, Klavierbauer 211

Walter, Ferdinand 541

Wambolt, Maria Augusta von 164

Wambolt von Umstadt, Anna Maria Freiin, s. Belderbusch

Warsberg, Freiherr von Domherr (Trier) $154 \mathrm{f}$.

Weber, Carl Maria von 175

Weber, Caroline von, geb. Brandt 175

Weber, Stud. 155

Wegeler, Eleonore, s. Breuning
Wegeler, Franz Gerhard 21, 23f., 31, 46, 109, 112, 120, 123, $141,169,194,202,210,221,231,253,277-279,281,283-$ 285, 287-289, 307, 311-313, 317, 326, 330f., 337, 339-342, 344-355, 365f., 370, 374, 381, 391, 427, 440, 467-469, 487, $505-507,513,522,540$

Weichs, Augusta Clementine Freifrau von, geb. von Steinen zu Scherffen 102

Weichs, Caroline von 165, 167

Weichs, Franz Salentin von Domherr (Osnabrück, Paderborn) 100, 129, 149, 151, 155

Weichs zu Rösberg, Clemens August Freiherr von,

Obristjägermeister 99f., 102, 129, 149, 167, 203, 385

Weichs zur Wenne, Maximilian Freiherr von, Kammerknabe 230

Weidmann, Paul 492

Weinreis, Johann 220-223

Weis, Stud. 155

Weisgerber, Herr 457

Weishaupt, Adam 125, 217, 229, 234, 404, 424

Weiße, Christian Felix 106, 120, 394, 396, 403

Welcker, Friedrich Gottlieb 530

Welden von Laubheim, Baron von 457

Welsch, Georg 246, 470, 472, 482

Welsch, Joseph 230, 246, 472, 482

Weltman, Amries 179

Werner, Friedrich Bernhard 82

Werner, Johann Ludwig von 114, 155

Wessel, Stud. 155

Westerburg, Reinhard von, Propst 55

Westerburg, Siegfried von, Ebf. von Köln 55

Westerholt-Gysenberg, Ludolf Friedrich Adolf Freiherr von

Oberstallmeister, geb. Boenen zu Berge 156, 464

Westerholt-Gysenberg, Maria Anna Wilhelmine von und zu, verh. Elverfeldt gen. Beverförde-Werries $293 \mathrm{f}$.

Westerholt-Gysenberg, Wilhelmine Friederike Franziska

Anna Freiin von und zu 277

Westorff, Anna Clara, s. Keverich

Westphalen zu Fürstenberg, Clemens August Reichsgraf von 104, 282, $285 f$.

Westphalen, Söhne 285

Wezel, Johann Carl 94, 105

Widnmann, Joseph von 126

Wiedenbrück, Ferdinand Freiherr von, OT 102, 149

Wieland, Christoph Martin 95, 106, 112, 117, 120, 125, 132, 137

Wilhelmi, Johann Friedrich 399

Wilich, Johann, Pfr. St. Remigius 69

Willem V., Prinz von Oranien 21, 201

Willemer, Johann Jakob 151

Willer, Wilhelm 106, 140

Willich/Willig, Justus Martin 101, 149, 151, 155

Willmann, Anna Maria Antonetta de, geb. Tribolet 451

Willmann, Elisabeth 451 
Willmann, Familie 445, 449, 458

Willmann, Franz 451

Willmann, Johann Ignaz 445, 449-452, 455, 462f., 466, 470, 472

Willmann, Johanna Magdalena, verh. Galvani 272f., 450f., 462, 470, 472f., 485, 487f., 494, 497

Willmann, Maximilian Friedrich Ludwig 230, 450f., 455, 462

Willmann, Maximiliana Valentina Walburga, verh. Huber 449-451, 462, 470, 473, 485f., 494

Windeck, Amtmann (Bornheim) 151

Windeck, Carl, Hofratsprokurator 101, 149, 151, 155

Windeck, Johann Martin Joseph, Bürgermeister 46

Win(n)eberger, Paul Anton 495f.

Winter, Peter von 492

Wizenmann, Thomas 106

Wolff, Christian Freiherr von 114, 118

Wolff, Moyses Abraham, Leibarzt 103, 115, 143, 149, 163

Wolff, Wolff Jacob 126, 140

Wolff-Metternich, Adolf Baron von 64

Wolff-Metternich, Antonette Gräfin, geb. von Asseburg 99, 128, 150f., 384(?)

Wolff-Metternich, August Wilhelm von, Dompropst (Münster) 205

Wolff-Metternich, Felicitas Gräfin 149-151, 165, 167, 384(?)

Wolff-Metternich, Max von $150 f$.

Wolff-Metternich zur Gracht, Johann Ignaz Graf 99, 104, 150f., 154, 167, 188

Wolfgang Wilhelm, Herzog 71, 87

Wolter, Hofrat 149

Wolzogen, Karl Freiherr von OT 102, 128, 149, 151

Worms, Stud. 155

Wrede, Engelbert Freiherr von, Domherr (Hildesheim und Münster) 108, 151f., $155 f$.

Wrede(n), Karl Josef, Kanoniker, Hofrat, design. Bischof 152, $157,230,281,475$

Wulf, Proc. 155

Wurmbrand-Stuppach, Ignaz Franz Johann Nepomuk Judas Thaddäus von 482,486, 495

Wurzer, Ferdinand 499, 511-513

Wurzer, Joseph 119, 135

Wynmar, Glasmacher 54

$\mathbf{Y}$

Young 117

\section{$\mathbf{Z}$}

Zartmann, Christoph 101, 149

Zeller, Simon 345

Zensen, Organist 405

Zeyhen, Prof. 151

Ziegler, Johann 13, 309f., 500, 502

Zierotin, Franziska, s. Thurn und Taxis

Zierotin, Graf Johann Karl von 165
Zierotin, Gräfin von, geb. Gräfin von Königsegg-Erps 165 Zierotin, Gräfin Maria Anna Hortensia von, s. Hatzfeld Zilecken/Zilleken, Theodor 246, 470, 472, 483

Zinzendorf, Graf Johann Karl Christian Heinrich von 387, 483f., 486-491, 495

Zitzmann, Frau 397

Zmeskall, Nikolaus 211, 298

Zulehner, Johann Anton 114

Zumbusch, Caspar 544

Zwirner, Ernst Friedrich 533 